照 





AN

INTRODUCTION

To

E N T O M O L O G Y. 



\section{AN \\ INTRODUCTION}

TO

\section{E N T 0 M 0 L 0 G $Y$; \\ OR,}

Élenrents

OF THE

NATURAL HISTORY OF INSECTS:

COMPRISING AN ACCOONT OF

NOXIOUS AND USEFUL INSECTS,

of TIEIR METAMoRPHoses, FOOD, STRATAgEMS, HABITATIONS, SOCIETILS, MOTIOAS, NOISES, HYBERNATION, INSTINCT,

ETC. ETC.

BY

WILLIAM KIRBY, M.A. F.R.S. F.L.S.

íctor of barhair;

AND

WILLIAM SPENCE, EsQ, F.R.S. F.L.S.

\section{Sicbontly (üDition}

(FLEVENTH THOUSAṆD)

WITI A. APPENDIX RELATIVE TO TIL ORIGIN AND PROORESS OF THE WORK.

\section{LONDON}

LONGMAN, GREEN, LONGMAN, AND ROBERTS 



\section{ADVERTISEMENT}

To

\section{THIS SEVENTH EDITION.}

This work is now published at one sixth of the price of the Sixth Edition, so as to bring it within reach of all desirous of becoming acquainted with the Natural History of Insects, and thus carrying out more effectually the object of the Authors - that of introducing others to a branch of - scicnce which they had found so delightful.

Though compressed by a smaller type into One Volume, it contains every line of the Sixth Edition, which includes much new matter not in the five preceding editions; and, to render the work more complete, the account of its origin and progress, furnished by Mr. Spence to the "Life" of Mr. Kinbr by Mr. Freeman, is, with his permission, given as an Appendix.

W.S.

London, April, 1856. 



\section{ADVERTISENENT'}

To

\section{THE SIXTH EDITION.}

When the present work was originally published, the Authors had no expectation that the demand for it would be so extensive and permanent as it has proved; and they need not say how gratifying this unlooked-for result has been to their feelings, as realising their earnest hope of assisting to remove the prejudices against the study of Entomology, which existed in full force thirty years ago when they took up the subject, but which have now happily disappeared.

Though, however, a regular annual demand for a certain number of copies has always continued up to the present time, so as to have exhausted the last edition, the publishers have suggested that the future sale of the work, and its main object - that of extending the knowledge of insects-would be much forwarded, if the first two volumes, treating of their manners and economy, were published separately, so as to obviate the necessity to those who do not care to pursue the study farther, of being burdened with the heary cost of two additional volumes of matter, chicfly technical, in which they feel no interest. 
It is in compliance with this suggestion that these volumes now appear as a distinct work, and (though greatly enlarged by new matter) at a considerable reduction of price; but at the same time it is hoped that a new edition of the two remaining volumes will follow at a future period, when they will be also given as a distinct work, comprising the anatomy, physiology, orismology, Src. of the science. 


\section{PREFACE}

To

\section{THE FIRST EDITION, 1815.}

ONe principal cause of the little attention paid to Entomology in this country has doubtless been the ridicule so often thrown upon the science. The botanist, sheltered now by the sanction of fashion, as formerly by the prescriptive union of his study with medicine, may dedicate his hours to mosses and lichens without reproach; but in the minds of most men, the learned as well as the vulgar, the idea of the trifling nature of his pursuit is so strongly associated with that of the diminutive size of its objects, that an Entomologist is synonymous with every thing futile and childish. Now, when so many other roads to fame and distinction are open, when a man has merely to avow himself a botanist, a mineralogist, or a chemist, a student of classical literature, or of political economy, to insure attention and respect, there are evidently no great attractions to lead him to a science which; in nine companies out of ten with which he may associate, promises to signalise him only as an object of pity or contempt. Even if he have no other aim than self-gratification, yet "the sternest stoic of us all wishes at least for some one to enter into his views and feelings, and confirm him in the opinion which he entertains of himself:" but how can he look for sympathy in a pursuit unknown to the world, except as indicative of littleness of mind?

Yet such are the genuine charms of this branch of the study of nature, that here as well as on the Continent, where, from being 
equally slighted, Entomology now divides the empire with her sister Botany, this obstacle would not have been sufficient to deter numbers from the study, had not another more powerful impediment existed,- the want of a popular and comprehensive Introduction to the science. While elementary books on Botany have been multiplied amongst us without end and in every shape, Curtis's translation of the Fundamenta Entomologice, published in 1772, Yeats's Institutions of Entomology, which appeared the year after, and Barbut's Genera Insectorum, which came out in 1781, - the two former in too unattractive, and the latter in too expensive a form for general readers, - are the only works professedly devoted to this object which the English language can boast.

Convinced that this was the chief obstacle to the spread of Entomology in Britain, the authors of the present work resolved to do what was in their power to remove it, and to introduce their countrymen to a mine of pleasure, new, boundless, and inexhaustible, and which, to judge from their own experience,-formed in no contracted field of comparison,-they can recommend as possessing advantages and attractions equal to those held forth by most other branches of human learning.

The next question was, in what way they should attempt to accomplish this intention. If they had contented themselves with the first suggestion that presented itself, and merely given a trans.lation of one of the many Introductions to Entomology extant in Latin, German, and French, adding only a few obvious improvements, their task would have been very unsy; but the slightest examination showed that, in thus proceeding, they would have stopped far short of the goal which they were desirous of reaching. In the technical department of the science they found much confusion, and numerous errors and imperfections; the same name sometimes applied to parts anatomically quite different, and different names to parts essentially the same, while others of primary importance were without any name at all. And with reference to the anatomy and physiology of insects, they could nowhere mect with a full and accurate generalisation of the various facts connected with these subjects, scattered here and there in the pages of the authors who have studied them.

They therefore resolved to begin, in some measure, de novo, to 
institute a rigorous revision of the terms employed, making such additions and improvements as might seem to be called for; and to attempt a more complete and collected account of the existing discoveries respecting the anatomical and physiological departments of the science than has yet been given to the world; -and to these two points their plan at the outset was limited.

It soon, however, occurred to them, that it would be of little use to write a book which no one.would peruse; and that, in the present age of love for light reading, there could not be much hope of leading students to the dry abstractions of the science, unless they were conducted through the attractive portal of the economy and natural history of its objects. To this department, therefore, they resolved to devote the first and most considerable portion of their intended work, bringing into one point of view, under distinct heads, the most interesting discoveries of Reaumur, De Geer, Bonnet, Lyonet, the Hubers, \&cc, as well as their own individual observations, relative to the noxious and beneficial properties of insects, their affection for their young, their food, and modes of obtaining it, their habitations, societies, \&c. \&c.; and they were the more induced to adopt this plan from the consideration that, though many of the most striking of these facts have been before presented to the English reader, a great proportion are unknown to him; and that no similar generalisation (if a slight attempt towards it in Smellie's Philosophy of Natural History, and a confessedly imperfect one in Latreille's Histoire N'aturelle des Crustacés et des Insectes be excepted) has ever been attempted in any language. Thus the entire work would be strictly on the plan of the Philosophia Entomologica of Fabricius, only giving a much greater extent to the Economia and Usus, and adverting to these in the first place instead of in the last.

The epistolary form was adopted, not certainly from any idea of their style being particularly suited to a mode of writing so difficult to keep from running into incongruities, but simply becauso this form admitted of digressions and allusions called for in a popular work, but which might have seemed misplaced In a stricter kind of composition; - because it is better suited to convey those practical directions which in some branches of the pursuit the student requires; - and, lastly, because by this form the objection 
against speaking of the manners and economy of insects before entering upon the definition of them, and explaining the terms of the science,- a retrograde course, which they have chosen from their desire to present the most alluring side of the science first, is, in great measure, if not wholly obviated.

Such is the plan which the Authors chalked out for themselves; a plan which in the execution they have found so much more extensive than they calculated upon, that, could they have foreseen the piles of volumes through which it has entailed upon them the labour of wading, often to glean scarcely more than a single fact, the numerous anatomical and technological investigations which it has called for, and the long correspondence, almost as bulky as the entire work, unavoidably rendered necessary by the distant residence of the parties, they would have shrunk from an undertaking of which the profit, if by great chance there should be any, could not be expected to repay even the cost of books required in it, and from which any fame must necessarily be confined to a very limited circle. But having entered upon it, they have perserered : and if they succeed in their grand aim, that of making converts amongst their countrymen to a study equally calculated for promoting the glory of God and the delight and profit of man, they will not deem the labour of the leisure hours of six years ill bestowed.

And liere it may be proper to observe, that one of their first and favourite objects has been to direct the attention of their readers "from nature up to nature's God." For, when they reflected upon the fatal use which has too often been made of Natural History, and that from the very works and wonders of God some philosophists, by an unaccountable perversion of intellect, have attempted to derive arguments either against $\mathrm{His}$ being and providence, or against the religion revealed in the Holy Scriptures, they conceived they might render some service to the most important interests of mankind, by showing how every department of the science they recommend illustrates the great truths of religion, and proves that the doctrines of the Word of God, instead of being contradicted, are triumphantly confirmed by His H'orks.

"To see all things in God," has been accounted one of the peculiar privileges of a future state; and in this present life, "to sce God in 
all things," in the mirror of the creation to belsold and adore the reflected glory of the Creator, is no mean attainment; and it possesses this advantage, that thus we sanctify our pursuits, and, instead of loving the creatures for themselves, are led by the survey of them and their instincts to the love of Him who made and endowed them.

Of their performance of the first part of their plan, in which there is the least room for originality, it is only necessary for the Author's to say, that they have done their best to make it as comprehensive, as interesting, and as useful as possible: but it is requisite to enter somewhat more fully into what has been attempted in the anatomical, physiological, and technical parts of the work.

As far as respects the general physiology and internal anatomy of insects, they have done little more than bring together and combine the observations of the naturalists who have attended to these branches of the science; but the external anatomy they have examined for themselves through the whole class, and, they trust, not without some new light being thrown upon the subject; particularly by pointing out and giving names to many parts never before noticed.

In the Terminology, or what, to avoid the barbarism of a word compounded of Latin and Greek, they would beg to call the Orismology of the science, they lave endeavoured to introduce throughout a greater degree of precision and concinnity, dividing it into general and partial Orismology; under the former head, defining such terms as relate to Substance, Resistance, Density, Proportion, Figure, Form, Superficies (under which are introduced Sculpture, Clothing, Colour, \&c.), Margin, Termination, Incision, Ramification, Division, Direction, Situation, Connection, Arms, \&rc.; and under the latter, those that relate to the body and its parts and members, considered in its great subdivisions of Head, Trumk, and Abdomen. In short, they may rest their claim of at least aining at considerable improvement in this department upon the great number of new terms, and alterations of old ones, which they have introduced,-in external Anatomy alone falling little short of 150. If it should be thought by any one that they have made too many changes, they would remind him of the advice of Bergman to Mor- 
veau, when reforming the nomenclature of Chemistry, the soundness of which Dugald Stewart has recognised : - "Ne faites grace à aucune dénomination impropre. Ceux qui savent déjà, entendront toujours; ceux qui ne savent pas encore, entendront plutôt."

Throughout the whole publication, wherever any fact of importance not depending on their own authority is mentioned, a reference to the source whence it has been derived is generally given; so that, if the work should have no other value, it will possess that of saving much trouble to future inquirers, by serving as an index to direct them in their researches.

The Authors are perfectly sensible that, notwithstanding all their care and pains, many imperfections will unavoidably remain in their work. There is no science to which the adage, Dies diem docet, is more strikingly applicable than to Natural History. New discoveries are daily made, and will be made, it is probable, to the end of time; so that whoever flatters himself that he can produce a perfect work in this department, will be miserably disappointed. The utmost that can reasonably be expected from naturalists, is to keep pace with the progress of knowledge; and this the authors have used their best diligence to accomplish. Every new year since they took the subject in hand, up to the very time when the first sheets were sent to the press, numerous corrections and alterations have suggested themselves; and thus they are persuaded it would be were they to double the period of delay prescribed by Horace. But Poetry and Natural History are on a different footing; and though an author can plead little excuse for giving his verses to the world while he sees it possible to polish them to higher excellence, the naturalist, if he wishes to promote the extension of his science, must be content to submit his performances to the public disfigured by numerous imperfections.

In the introductory letter several of the advantages to be derived from the study of Entomology are pointed out; but there is one which, though it could not well have been insisted upon in that place, is too important to be passed over without notice,-its value in the education of youth.

All modern writers on this momentous subject unite in recommending in this view Natural History; and if "the quality of accurate discrimination, the ready perception of resemblances 
amongst diversities, and still more, the quick and accurate perception of diversity in the midst of resemblances, constitutes one of the most important operations of the understanding ; if it be indeed the foundation of clear ideas, and the acquisition of whatever can be truly called knowledge depends most materially on the possession of it;" if " the best logic be that which teaches us to suspend our judgments;" and "the art of seeing, so useful, so universal, and yet so uncommon, be one of the most valuable a man can possess," there can be no doubt of the judiciousness of their advice. Now of all the branches of Natural History, Entomology is unquestionably the best fitted for thus disciplining the mind of youth; and simply from these circumstances, that its objects have life, are gifted with surprising instincts admirably calculated to attract youthful attention, and are to be met with every where. It is not meant to undervalue the good effects of the study of Botany or Mineralogy ; but it is self-evident that nothing inanimate can excite such interest in the mind of a young person as beings endowed with vitality, exercising tleir powers and faculties in so singular a way; which, as Reaumur observes, are not only alive themselves, but confer animation upon the leaves, fruits, and flowers that they inhabit, which every walk offers to view, and on which new obserrations may be made without end.

Besides these advantages, no study affords a fairer opportunity of leading the young mind by a natural and pleasing path to the great truths of Religion, and of inpressing it with the most lively ideas of the power, wisdom, and goodness of the Creator.

Not that it is recommended to make children collectors of insects; nor that young people, to the neglect of more important duties and pursuits, should generally become professed Entomologists; but, if the former be familiarised with their names, manners, and economy, and the latter initiated into their classification, it will be an excellent method of strengthening their habits of observation, attention, and memory, equal perhaps, in this respect, to any other mental exercise; and then, like Major Gyllenlal, who studied Entomology under 'Thunberg about 1770, and, after an interval of twenty years devoted to the service of his country, resumed lis favourite pursuit with all the ardour of youth, and is at this time giving to the world a description of the insects of Sweden, 
invaluable for its accuracy and completeness, they would be provided in their old age with an object capable not merely of keeping off that tadium vite so often inseparable from the relinquishment of active life, but of supplying an unfailing fund of innocent amusement, an incentive to exercise, and, consequently, no mean degree of health and enjoyment.

Some, who, with an ingenious author*, regard as superfluous all pains to show the utility of Natural History in reference to the common purposes of life, asking, "if it be not enough to open a source of copious and cheap amusement, which tends to harmonise the mind, and elevate it to worthy conceptions of nature and its Author? - if a greater blessing to a man can be offered than happiness at an easy rate, unalloyed by any debasing mixture?" may think the earnestness displayed on this head, and the length which Las been gone in refuting objections, needless. But Entomology is so peculiarly circumstanced, that, without removing these obstacles, there could be no hope of winning votaries to the pursuit. Pliny felt the necessity of following this course in the outset of his book which treats on insects; and a similar one has been originally called for in introducing the study even to those countries where the science is now most honoured. In France, Reaumur, in each of the successive volumes of his immortal work, found it essential to seize every opportunity of showing that the study of insects is not a frivolous amusement, nor devoid of utility, as his countrymen conceived it; and in Germany, Sulzer had to traverse the same road, telling us, in proof of the necessity of this procedure, that on showing lis works on insects wïth their plates to two very sensible men, one commended him for employing his leisure hours in preparing prints that would amuse children and keep them out of mischief, and the other admitted that they might furnish very pretty patterns for ladies' aprons! And though in this country things are not now quite so bad as they were when Lady Glanville's will was attempted to be set aside on the ground of lunacy, evinced by no other act than her fondness for collecting insects; and Ray had to appear at Exeter on the trial as a witness of her sanity $\dagger$; yet nothing less than line upon line can be expected to eradicate the deep-rooted preju- 
dices which prevail on this subject. "Old impressions," as Reaumur has well observed, "are with difficulty effaced. They are weakened, they appear nnjust eren to those who feel them, at the moment they are attacked by arguments which are unanswerable; but the next instant the proofs are forgotten, and the perverse association resumes its empire."

The Authors do not know that any curiosity will be excited to ascertain what share has been contributed to the work by each of them; but if there should, it is a curiosity they must be excused from gratifying. United in the bonds of a friendship, which, though they have to thank Entomology for giving birth to it, is founded upon a more solid basis than mere community of scientific pursuits, they wish that, whether blame or praise is the fate of their labours, it may be jointly awarded. All that they think neeessary to state is, that the composition of each of the different departments of the work has been, as nearly as possible, divided between them; that though the letter, or series of letters, on any particular subject, has been usually undertaken by one, some of the facts and illustrations have generally been supplied by the other, and there are a few to which they have jointly contributed; and that throughout, the facts for which no other authority is quoted, are to be considered as resting upon that of one or other of the authors, but not always of him, who, from local allusions, may be conceived the writer of the letter in which they are introduced, as the matter furnished by each to the letters of the other must necessarily be given in the person of the supposed writer.

In acknowledging their obligations to their friends, the first place is due to Simon Wilkin, Esq. of Costessey near Norwich, to whose liberality they are indebted for the plates which illustrate and adorn the work, which have been drawn and engraved at his expense by Mr. JoHn Curtis, whose intimate acquaintance with the subject has enabled him to give to the figures an accuracy which they could not have received from one less conversant with the science.*

* This refers to the year 1815, when the first volume of this work was pullished. In the twenty-seven years since elapsed, Mr. Curtis's Entomological labours, and especially his British Entomology in sixteen volumes, equally admirable for its scientific and artistical excellence, have descrvedly gained him a very high reputation wherever the science is cultivated. (1842.) 
To Alexander Macleay, Esq. they are under particular obligations for the warm interest he has all along taken in the work, the judicious advice he has on many occasions given, the free access in which he has indulged the authors to his unrivalled cabinet and well-stored library, and the numerous other attentions and accommodations by which he has materially assisted them in its progress.

'To the other friends who have kindly aided them in this undertaking in any way, they beg here to offer their best thanks. 


\section{CONTENTS.}

LETTER I.

INTRODUCTORY

\section{LETTER II.}

ObJections answered

That Entomology is a trifling pursuit

That Entomologists confine themselves chiefly to nomenclature That it leads to cruelty

\section{LETTER III.}

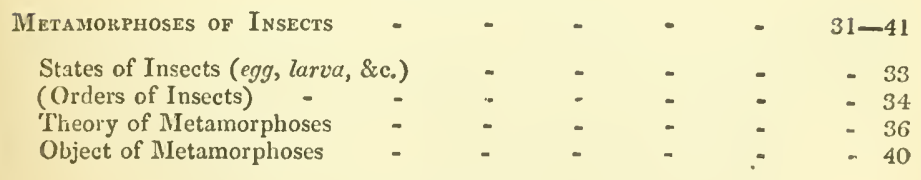

\section{LETTER IV.}

Direct Injuries caused by Insects (Afrecting Man Personalix) 42-7i

1. Insects which make man their food Pediculus humanus, \&c. -

Acari -

Larve :

Fleas -

Chigoes

Harvest bugs, Ticks, \&c.

Bed Bugs, \&ce.

Insects giving an electrical shock

Horse Flies, \&c.

Mosquitoes, \&:c. -

2. Insects which attach mun from revenge n" ferts

Bees, Wasps, \&c.
$43-63$

- 43

- 46

- 51

- 52

- 53

- 54

- 55

- 56

\begin{tabular}{l}
-57 \\
\hline
\end{tabular}

- 58

$68-67$

- 63 
2. Insects which attack man from revenge or fear - continued.

Ants

Scorpions

Centipedes, Tarantula, Sc.

- 64

- 65

- 66

3. Insects simply annoying to man

Thrips, Simulium, \&ic.

House Fly

Hairy Caterpillars, \&c. -

4. Insects producing internol discases

Beetles

Caterpillars

Gad-flies, \&c.

Bees collecting poisonous honey

LETTER V.

Indirect Injuries caused by INSECTS

$78-89$

1. Injuries to our living animal property

To the Horse

$\mathrm{Ox}$

Sheep

Deer

Dog

Hive Bee, \&c.

$78-89$

- 78

- 80

- 84

$-85$

- 87

- 88

LETTER VI.

INDIRect InJuries - continued -

$90-124$

2. Injuries to our living vegetable property

- 90

To Field Crops

Wheat

Wheat, \&c., in granarics

Rye, Barley

Indian Corn, \&c.

Peas, Beaus, \&ic.

Clover Seed

Pastures and IIIeadows

Crops generally

Hops -

Sugar

Cotton, Tobacco, and Coffec

Carrots

Potatoes

Turnips

Beet -

Garden Crops -

Kitchen Garden

Radishes, Lettuees, \&c.

Cabbages, Cauliflowers, \&c.

Peas, Beans, Carrots, \&c.

$$
\begin{array}{r}
90-105 \\
-\quad 90 \\
-\quad 93 \\
-194 \\
-\quad 95 \\
-\quad 95 \\
-197 \\
-\quad 97 \\
-199 \\
-100 \\
-101 \\
-102 \\
-102 \\
-103 \\
-103 \\
-105 \\
105-117 \\
105-109 \\
-105 \\
-105 \\
-106
\end{array}
$$


2. Injuries to our living vegetable property - contınued.

Page

To Flower Garden - - _ _ -

Stove and Greenhouse - $\quad$ -

Orchard and Fruitery - _ _ _

Raspberries - - - - -

Gooseberries and Currants - $\quad-$

Cherries - $\quad-\quad$ - $\quad$ -

Plums

Pears

Apples

Peaches and Nectarines

Olives

Chestnuts and Dates

Pomegranates and Oranges

Grapes

Fruit trees generally -

Plantations and Groves

By Beetles

Aphides (honey-dew)

Insects attacking the interior of trees

Insects attacking their bark and alburnum

108

- 109

$109-116$

- 109

$-110$

- 110

- 111

- 111

$-111$

- 113

- 114

- 114

- 114

$-115$

$-116$

$-117$

$-117$

$-117$

$-119$

- 120

- 121

LETTER VII.

Indirect Injuries - continued -

The ravages of Locusts

- $125-131$

\section{LETTER VIII.}

INDIRECT INJURIES - concluded

- 132-143

3. Injuries to our dead property, whether animal or vegetuble

- $132-143$

To our Food -
$\begin{aligned} & \text { Drugs - } \\ & \text { Clothes - }\end{aligned}$
Houses and Furniture
Timber -
Books, Pictures, \&e.
Dead Stock generally

$-132$

- 135

- 135

- 136

- 137

$-138$

$-139$

\section{LETTER IX.}

Indrect Benefts derived from Insects

- $144-170$

By maintaining a due balance between vegetable and animal productions removing nuisances and deformities destroying noxious Insects serving as food for other animals promoting the fertilisation of plants - 
LETTER X.

Direct Benefits derived from Insects

$171-191$

As serving for the food of man

As affording Medicines

Dyes -
Wax
Honey -
Silk -

LETTER XI.

Affection of Insects for theIR Young

- $192-215$

1. Insects which pcrish before their young eome into existence Butterflies

Iehneumons

Sand Wasps, \&c. -

Wild Bees

Beetles

2. Insects which attend their young when hatched -

Mason Wasp

Saw Fly

Wood-boring Beetle

Field Bug

Earwigs -

Spiders -

Ants

Wasps

Bees

Humble Bees

Termites -

$\begin{array}{rrr}\text { - } & - & - \\ - & - & - \\ - & - & - \\ - & - & -\end{array}$

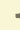

$$
\begin{aligned}
& 192-201 \\
&- 192 \\
&- 193 \\
&- 195 \\
&- 197 \\
&- 198 \\
& 202-215 \\
&--202 \\
&- 202 \\
&- 203 \\
&- 203 \\
&- 209 \\
&- 204 \\
&- 206 \\
&- 210 \\
&-212 \\
&-213 \\
&-214
\end{aligned}
$$

\section{LETTER XII.}

Food of Insects

Insects which feed on vegetables animals -

Time of feeding

both vegetables and animals

Instruments of nutrition

Proportion of food consumed

Power of abstinence

\section{LETTER XII.}

Foop of INSECTS - continued

$$
\begin{array}{rr}
- & 227-244 \\
- & 227-244 \\
- & -227 \\
-\quad & -229 \\
- & -231
\end{array}
$$$$
\text { Threads of Spiders }
$$$$
\text { Webs of House Spiders, \&c. }
$$$$
\text { Nets of Geometric Spiders }
$$ 
Stratagems employed in procuring food-continued.

Page

Renewal of Geometric nets

Other Spiders' webs

Spiders which do not form webs or nets

Diring Spider

Ant Lion

Leptis Vermileo -

\section{LETTER XIV.}

Habitations of Insects

1. Of solitary insects forming them for their young

$245-267$

$245-257$

Clothier Bees

Carpenter Bees

Mason Bees

Upholsterer Bees

-Leaf-cutting Bees

Mason Wasp

Leaf-rolling Weevils

Gall Flies
$-236$

- 238

- 239

- 240

$-242$

- 244

2. Of solitary insects forming them for their own use

In the interior of leaves

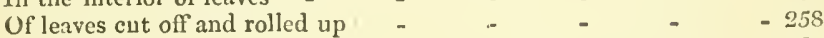

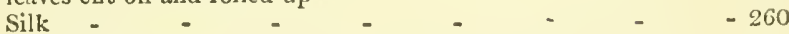

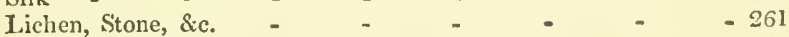

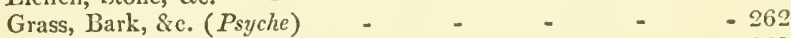

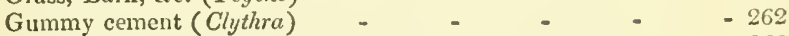

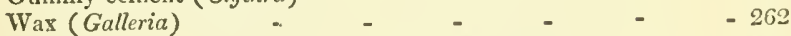

Wool or Hair (Caterpillars of Clothes-Moths) - $\quad$ - 263

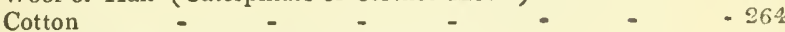

Grass, Rushes, Sand, \&c. (Caddis-worms) - _ - $\quad$ - 264

Earth and Silk with a trap door (Spiders) _ _ _ $\quad-265$

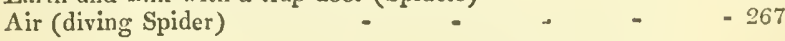

\section{LETTER XV.}

Habitations of INSECTS - continued

3. Of insects living in society

$268-289$

Caterpillars

Ants

Hive Bees

Humble Bees

Wasps

Termites 
Societies of Insects.

1. Imperfect societies

Associations for company of males for emigrating of Caterpillars Aphides Lady-birds Turnip Saw-flics Dragon-flies Frog-hoppers Beetles Butterfiles Field Bugs Locusts for mutual assistance Ateuchus pilularius Caterpillars

$290-303$
-291
-292
-293
-293
-294
-295
-295
-295
-296
-296
-296
-297
-298
-300
-300
-301

\section{LETTER XVII.}

Societies of Insects-continued

2. Perfect societies (White Ants and Ants)

White Ants.

Individuals composing the society

Establishment of colonies

Building and repairing habitations

Collecting food

Defence of habitations

Termes lucifugus

Ants.

Storing up food

(Gould's "English Ants")

- 313

Individuals composing the society - $\quad-\quad$ - $\quad-\quad$ - 316

Formation of new societies - Winged Ants - $\quad-\quad-317$

Langriage

Affections and aversions

Formic acid

Wars

Slave-making

Milch Cattle - Aphides, \&c.

Emigrations

Working all night

Roads and track-ways

Strength and perseverance

Bridge-making

Repose and sleep

Sports and games

- 321

- 324

$-325$

- 326

- 328

- 335

- 338

- 342

- 343

- 344

- 345

- 345

- 346 
LETTER XVIII.

l'age

Perfect Societies of Insects - continued

$348-355$

Wasps. - Humble Bees

Wasps.

Individuals composing the society

Labours of workers

Storing up honey

Sentinels

Humble Bees

Individuals composing the society

Employment of females

Small females

Parasitic Humble Bees

Temper and disposition

$-348$

$-350$

$-350$

$-350$

LETTER XIX.

Perfect Societies of Insects - continued

$356-379$

Hive Bee

Individuals composing the society

Education of a new Queen

Larvæ and pupæ

Queen Bee

Combats of Queens

First swarm conducted by the old Queen

Treatment of young Queens

Devotion to the Queen

Loss of a Queen

Fecundation of the Queen

Oviposition by the Queen

Swarming

LETTER XX.

Perfect Societies of Insects - concluded

$380-403$

Hive Bee

Drones

Workers

Distance of excursions

collecting nectar pollen .

Scouts

Fopulation of a live

Transportation of hives

Ventilation

$$
\begin{array}{r}
356-379 \\
-357 \\
-360 \\
-365 \\
-366 \\
-367 \\
-368 \\
-369 \\
-370 \\
-371 \\
-373 \\
-374 \\
-375
\end{array}
$$
propolis - 
Sive Bee-contiuued.

Cleanliness -

Language -

Anger

Wars

Enemies

Accidents

Temperature of the bive

Instincts not mere sensations

\section{LETTER XXI.}

Mgans by which INSECTS DEFend theJiselves

- 394

- 394

- 395

- 397

- 399

- 400

- 401

$-402$

1. Passive.

By imitating various substances, objects, and colours their brilliant colours

frightful aspect, horns, \&c.

spines, hairs, \&c.

hardness and toughness

involuntary offensive secretions -

power of vitality

extraordinary multiplication

$+$

$404-430$

2. Active.

By rolling themselves into a ball -

simulating death

assuming various attitudes

motions to alarm or escape their enemies

noises

disgusting and powerful scents

scent-organs -

explosive discharges

emission of repulsive fluids

their weapons of defence

concealing themselves

feeding only by night
especial modes of defence

feeding only by night
especial modes of defence

-
-
-
-
-

$-404$

- 407

$-407$

$-408$

- 409

- 409

$-409$

$-411$

\section{LETTER XXII.}

Motions of Insects.

Larva and Pupa.

1. Of Larve.

Destitute of proper legs Provided with proper legs Residing in water 
Motrons of Insects - continued.

\section{Imago}

1 While in repose

2. While in action.
Walking
Running
Jumping
Climbing
Flying without wings (Spiders) with wings Beetles

Earwigs

Stylops, \&:c.

Grasshoppers, \&cc.

Field Bugss, \&c.

May-flies, \&cc.

Butterflies and Moths

Bees, Wasps, \&c.

Flies, \&c.

Swimming

Walking in or on water

Burrowing

Hovering

Gyrations

Dancing

LETTER XXIV.

NoIses producen by INSECTS

While in motion

While feeding, \&c. - $\quad$ - $\quad$ -

In cailing, commanding, or giving an alarm -

As expressive of fear, anger, sorrow, love, \&c. -

By Beetles

Field Bugs -

Moths

Bees, \&c.

Grasshopper tribe

Crickets

Locusts, \&c. -

Cicadæ, \&c. -

LETTER XXV. 
Luninous Insects-continued.

Other Luminous Beetles

Lantern-flies

Other Luminous insects

Source of their luminous property

Its remote cause

Its use

\section{LETTER XXVI.}

Hybernation of Insects

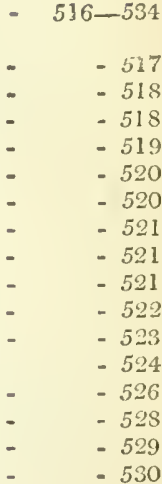

In the egg state

pupa state

larva state

perfect state -

Time of bybernation -

Site of Hybernacula

Solitary and social hybernation

Hybernation in several states -

Torpidity produced by cold -

Variations of torpidity

Some inseets never torpid

State of the Hive Bee in winter

Power of resisting cold by insects in different states

Cause of this power

Resumption of activity

Cause of hybernation

\section{LETTER XXVII.}

\section{INSTINCT OF INSECTS}

Nature of instinct

Definition of instinet

Exquisiteness of the instincts of Insects

Variations of instinet -

Variations of instinct in the IIive Bec

These variations not the result of reason

Number of instincts in Insects

Estraordinary development of instinct in Insects

Reason in Insects

Insects gain knowledge from experience receive and communicate information are endowed with memory 


\section{INTRODUCTION}

\section{ro \\ E N T O M O L O G Y.}

Dear Sir,

LETTER I.

I CANNoT wonder that an active mind like yours should experience no small degree of tedium in a situation so far removed, as you represent your new residence to be, from the "busy hum of men." Nothing certainly can compensate for the want of agreeable society; but since your case, in this respect, admits of no rencdy but patience, I am glad you are desirous of turning your attention to some pursuit, which may amuse you in the intervals of severer study, and in part supply the void of which you complain. I am not a little flattered that you wish to be informed which class in the three kingdoms of nature is, in my opinion, most likely to answer your purpose; at the same time intimating that you feel inclined to give the preference to Entomology, provided some objections can be satisfactorily obviated, which you have been accustomed to regard as urged with a considerable semblance of reason against the cultivation of that science.

Mankind in general, not excepting even philosophers, are prone to mignify, often beyond its just merit, the science or pursuit to which they have addicted themselves, and to depreciate any that seems to stand in competition with their favourite: like the redoubted champions of romance, each thinks himself bound to take the field against every one that will not subscribe to the peerless beauty and accomplishments of his own Dulcinea. In such conflict for pre-cminence I know no science that, in this country, lras eome off worse than Entomology : her champions hitherto have been so few, and their efforts so unavailing, that all her rival sisters have been exalted above her; and I believe there is scarcely any branch of Natural History that has had fewer British admirers. While Botany boasts of her hosts, she, though not her inferior either in beauty, symmetry, or grace, has received the homage of a very slender train indeed. Since therefore the merits of Entomology have been so little acknowledged, you will not decm it invidious if I advocate the cause of this distressed damsel, and endeavour to effect her restoration to her just rights, privileges, and rank.

Things that are universally obvious and easy of examination, as they are the first that fall under our notice, so are they also most commonly: 
those which we first feel an inclination to study; while, on the contrary, things that must be sought for in order to be seen, and which when songht for avoid the approach and inquiring eye of man, are often the last to which he directs his attention. The vegetable kingdom stands in the former predicament. Flora, with a liberal hand, has scattered around us her charming productions; they everywhere meet and allure us, enchanting us by their beauty, regaling us by their fragrance, and interesting us as much by their subservience to our luxuries and comfort, as to the necessary support and well-being of our life. Beasts, birds, and fishes, also, in some one or other of these respects, attract our notice ; but insects, unfortunate insects, are so far from attracting us, that we are accustomed to abhor them from our childhood. The first knowledge that we get of them is as tormentors; they are usually pointed out to us by those about us, as ugly, filthy, and noxious creatures; and the whole insect world, butterflies perhaps and some few others excepted, are devoted by onc universal ban to proscription and execration, as fit only to be trodden under our feet and crushed; so that often, before we can persuade ourselves to study them, we have to remove from our minds prejulices deeply rooted and of long standing.

Another principal reason which has contributed to keep Entomology in the background arises from the diminutive size of the objects of which it treats. Being amongst the most minute of nature's productions, they do not so readily catch the eye of the obscrver ; and when they do, mankind in general are so apt to estimate the worth and importance of things hy their bulk, that because we usually measure them by the duodecimals of an inch instead of by the foot or by the yard, insects are deemed too insignificant parts of the creation, and of too little consequence to its general weifare, to render them worthy of any serious attention or study. What small foundation there is for such prejudices and misconceptions, I shall endeavour to show in the course of our future correspondence ; my object now, as the champion and advocate of Entomology, is to point out to you her comparative advantages, and to remove the veil which has !hitherto concealed those attractions, and that grace and beauty, which entitle her to equal admiration at least with her sister branches of Natural History.

In estimating the comparative value of the study of any department in this branch' of science, we ought to contrast it with other's, as to the rank its objects hold in the scale of being; the amusement and instruction which the student may derive from it; and its utility to society at large. With respect to public utility, the study of each of the three kingdoms may perhaps be allowed to stand upon nearly an equal footing; I shall not, therefore, enter upon that subject till I come to consider the question C'ii bono? and to point out the uses of Entomology, but confine myself now to the two first of these circumstances.

As to rank, I must claim for the entomologist some degree of precedence before the mineralogist and the botanist. The mineral kingdom, whose objects are neither organised nor sentient, stands certainly at the foot of the scale. Next above this is the vegetable, whose lovely tribes, thongh not endued with sensation, are organised. In the last and highest place ranks the animal world, consisting of beings that are both organised and sentient. To this scale of precedence, the great modern luminary of Natural History, notwithstanding that Botany was always his favourite 
pursuit, lias given his sanction, acknowledging in the preface to his Fauna Suecica, that although the veretable kingdom is nobler than the mineral, yet the animal is more excellent than the vegetable. Now it is an indisputable axiom, I should think, that the more exalted the ohject the more excellent the study. By this observation, however, I would by no means be thought to depreciate or discountenance the study either of plants or minerals. All the works of our Creator are great, and worthy of our attention and investigation, the lowest in the seale as well as the highest. the most minute and feeble as well as those that exeed in magnitude anil might. Nor ought those whose inclination or genius leads them to one department, to say to those who prefer another - "we have no need of you"-for each in his place, by diffusing the knowledge of his works, and adding to the stock of previous discoveries, contributes to promote the glory of the Great Architect of the universe and the good of his creatures.

It is not my wish to claim for my favourite science more than of right belongs to her ; therefore, when the question is concerning rank, I must concele to the higher orders of animals, I mean Fishes, Amphibia, Birds, and Quadrupeds, their due priority and precedence. ${ }^{1}$ I shall only observe here, that there may exist circumstances which countervail rank, and tend to render the study of a lower order of beings more desirable than that of a higher: when, for instance, the objects of the higher study are not to be come at or preserved without great difficulty and expense; when they are few in number; or, when they are already woli ascertained and known: circumstances which attach to the study of those animals that precede insects, while they do not attach to the study of insects themselves.

With regard to the amusement and instruction of the student, much doubtless may be derived from any one of the sciences alluded to ; but Entomology certainly is not behind any of her sisters in these respects; and if you are fond of novelty, and anxious to make new discoveries, she will open to you a more ample field for these than either Botany or the higher branches of Zoology.

A new vertebrate animal or plant is seldom to be met with even by those who have leisure and opportunity for extensive researches; but if you collect irsects, you will find, however limited the manor upon which you can pursue your game, that your efforts are often rewarded by the capture of some nondeseript or rarity at present not possessed by other entomologists, for I have seldom seen a cabinet so nieagre as not to possess some unique specinen. Nay, though you may have searched every spot in your neighbourhood this year, turned over every stone, shaken every bush or tree, and fished every pool, you will not have exhausted its insect pro. ductions. Do the same another year and another, and new treasures will still continue to enrich your cabinet. If you leave your own vicinity for an entomological excursion, your prospects of success are still further increased; and even if confined in bad weather to your inn, the windows of your apartment, as I have often experienced, will adk to your stock. If a sudden shower obliges you at any tinie to seek shelter under a tree, your attention will be attracted, and the tedium of your station relieved, where

1 If, however, rank were to be estimated by number of species or individuals of a species, the pre-eminence coultl be claimed by insects, which, from the calculations made by various entomologists, probably amount to 400,000 or even more, perfectly distinet from each other; while for all the other classes of animals together, 30,000 species would be a high estimate. 
the botanist could not hope to find even a new lichen or moss, by the appearance of several insects, driven there perhaps by the same cause as yourself, that you have not observed before. But should you, as I trust you will, feel a desire to attend to the manners and economy of insects, and become ambitions of making discoveries in this part of entomological science, I can assure you, from long experience, that you will here find an inexhaustible fund of novelty. For more than twenty years my attention has been directed to them, and during most of iny summer walks my eyes have been employed in observing their ways; yet I can say with truth, that so far from having exhausted the subject, within the last six months I have witnessed more interesting facts respecting their history than in namy preceding years. To follow only the insects that frequent your own garden, from their first to their last state, and to trace all their proceedings, would supply an interesting amusement for the remainder of your life, and at its close you would leave much to be done by your successor; for where we know thoroughly the history of one insect, there are hundreds concerning which we have ascertained little besides the bare fact of their existence.

But numerous other sources of pleasure and information will open themselves to you, not inferior to what any other science can furnish, when you enter more deeply into the study. Insects, indeed, appear to have been nature's favourite productions, in which, to manifest her power and skill, she has combined and concentrated almost all that is either beantiful and graceful, interesting and alluring, or curious and singular, in every other class and order of her children. To these, her valued miniatures, she has given the most delicate touch and highest finish of her pencil. Numbers she has armed with glittering mail, which reflects a lustre like that of burnished metals ${ }^{1}$; in others she lights up the dazzling radiance of polished gems. ${ }^{2}$ Sonse she has decked with what looks like liquid drops, or plates of gold and silver ${ }^{3}$; or with scales or pile, which mimic the colour and emit the ray of the same precious metals. ${ }^{4}$ Some exhibit a rude exterior, like stones in their native state ${ }^{5}$, while others represent their smooth and shining face after they have been submitted to the tool of the polisher: others, again, like so many pigmy Atlases bearing on thei: backs a microcosm, by the rugged and various elevations and depressions of their tulserculated crust, present to the eye of the beholder no unapt imitation of the unequal surface of the earth, now horrid with mis-shapen rocks, ridges, and precipices - now swelling into hills and mountains, and now sinking into valleys, glens, and caves ${ }^{6}$; while not a few are covered with branching spines, which funcy may form into a forest of trees. ${ }^{7}$

What numbers vie with the charming offspring of Flora in various beauties! some in the delicacy and variety of their colours, colours not like

1 The genera Eumolpus, Lamprima, Rynchites.

2 Cryptorhynchus corruscans. Germar (Insect. Spec. Nov. j. 216.) regards this insect is synonymous with Illiger's Eurhinus cupratus, the description of which I liad not seen when the Century of Insects (Linn. T'rans, xii.) was written, nor an 1 able now to speak decisively on the subject.-K.

3 Lrycina Cupido, Argynnis Passiflora, Lathonia, \&c.

4 P'epsis fuscipennis, argentata, \&c.

5 The species of the genus Trox.

6 Many of the Scarabcida, Dynastide, \&c.

7 Many caterpillars of Butterflies (Merian, Surinam, t. xxii. xxr. \&c.) and of Sauflies (Réaum, v. t. sii. f. 7, 8-14.). 
those of flowers evanescent and fugitive, but fixed and durable, surviving their subject, and adorning it as much after death as they did when it was alive ; others, again, in the veining and texture of their wings; and others in the rich cottony down that clothes them. To such perfection, indeed, has nature in them curried her mimetic art, that you would declare, upon beholding some insects, that they had robbed the trees of their leaves to form for themselves artificial wings, so exactly do they resemble them in their form, substance, and vascular structure; some representing green leaves, and others those that are dry and withered. ${ }^{1}$ Nay, sometimes this mimicry is so exquisite, that you would mistake the whole insect for a portion of the branching spray of a tree. ${ }^{2}$ No mean beanty in some plants arises from the fluting and punctuation of their stems and leaves, and a similar ornament conspicuously distinguishes numerous insects, which also imitate with multiform variety, as may particularly be seen in the caterpillars of many species of certain tribes of butterflies (Nymphalide), the spines and prickles which are given as a Noli me tangere armour to scver:!l vegetable productions.

In fishes the lucid scales, of varied hue, that cover and defend them, are universally admired, and esteemed their peculiar ornament; but place il butterfly's wing under a microscope, that avenue to unseen glories in new worlds, and you will discover that nature has endowed the rost numerous of the insect tribes with the same privilege, multiplying in them the forms ${ }^{3}$, and diversifying the colouring of this kind of clothing beyond all parallel. The rich and velvet tints of the plumige of birds are not superior to what the curious observer may discover in a variety of Lepidoplera, and those many-coloured eyes which deck so gloriously the peacock's tail are imitated with snccess by one of our most common butterflies. ${ }^{4}$ Feathers are thought to be peculiar to birds; but insects often imitate them in their antennæ ${ }^{5}$, wings ${ }^{6}$, and even sometimes in the covering of their bodies ${ }^{7}$ We admire with reason the coats of quadrupeds, whether their skins be covered with pile, or wool, or fur ; yet are not perhaps aware that a vast variety of insects are clothed with all these kinds of hair, but infinitely finer and more silky in texture, more brilliant and delicate in colour, and more variously shaded than what any other animals can pretend to.

In variegation, insects certainly exceed every other class of animated beings. Nature, in her sportive mood, when painting them, sometimes imitutes the clouds of heaven; at others, the meandering course of the rivers of the earth, or the undulations of their waters : many are veined like beautiful marbles; others have the semblance of a robe of the finest net-work thrown over them; some she blazons with heraldic insignia, giving them to bear in fields sable - azure - vert - gules - argent and or, fesses - bars - bends - crosses - crescents - stars, and even animals. ${ }^{8}$ On many, taking her rule and compasses, she draws with precision mathematical figures; points, lines, angles, triangles ${ }^{9}$, squares, and circles. On

1 Various species of the families Gryllide and Mantida.

2 Many species of Phasmida.

3 De Geer, I. t. 3. f, 1-34. \&c. Audouin, Hist. Pyr. de la Vigne, PI. 3.

4 Vanessa Io.

5 Culex, Chironomus, and other Timelida.

6 Pierophorus.

7 Ilicirs of many of the Apida. Mon. Ap. Aug. I. t. 10. *Ad. 1. f. 1.6.

8 Plinus imperialis $\mathrm{L}$.

9 'Trichius (Archimedius K.) delta P. 
others she pourtrays, with mystic hand, what seem like hieroglyphic symbols, or inscribes them with the characters and letters of varions languages, often very correctly formed ${ }^{1}$; and what is more extraordinary, she has registered in other's figures which correspond with several dates of the Christian era. ${ }^{2}$

Nor has nature been lavish only in the apparel and ornament of these privileged tribes; in other respects she has been equally unsparing of her favours. To some she has given fins like those of fish, or a beak resembling that of birds ${ }^{3}$; to others horns, nearly the counterparts of those of various quadrupeds. The bull ${ }^{4}$, the $\operatorname{stag}^{5}$, the rhinoceros ${ }^{6}$, and even the hitherto vainly sought for unicorn ${ }^{7}$, have in this respect many representatives amongst insects. One is armed with tusks not unlike those of the elephant ${ }^{8}$; another is bristled with spines, as the porcupine and hedgehog with quills ${ }^{9}$; a third is an armadillo in miniature; the disproportioned hind legs of the kangareo gives a most grotesque appearance to a fourth ${ }^{10}$; and the threatening head of the snake is found in a fifth. ${ }^{11}$ It would, however, be endless to produce all the instances which occur of such imitations; and I shall only remark that, generally speaking, these arms and instrunients in structure and finishing far exceed those which they resemble.

But further, insects not only mimic, in a manner infinitely various everything in nature, they may also with very little violence he regarded as symbolical of beings out of and above nature. The butterfly, adorned with every beanty and every grace, horne by radiant wings through the fields of ether, and extracting nectar from every flower, gives us some idca of the blessed inhabitants of liappier worlds, of angels, and of the spirits of the just arrived at their state of perfection. Again, other insects seem emblenkitical of a different class of unearthly beings; when we behold some tremendous for the numerous horns and spines projecting in horrid array from their head or shoulders; - others for their threatening jaws of fearful length, and armed with cruel fangs: when we survey the clismal hue and denoniac air that distinguish others, the dens of darkness in which they live, the impurity of their food, their prediatory habits and cruelty, the nets which they spread, and the pits which they sink to entrap the unwary, we can scarcely help regarding them as aptly symbolising evil demons, the enemies of man, or of impure spirits, for their vices and crimes driven from the regions of light into darkness and punishment. ${ }^{12}$

1 Acrocinus longimanus F., Tranessa C. allum, Acronycta $\psi$, Plusia $\gamma$.

2 On the underside of the primary wings near the margin in Argynnis Aglaia, Lnthonia, Selene, \&c.

3 Finpis, Asilus.

4 Onthophagus Taurus Curtis, Brit. Ent. t. 52.

5 Lucanus Cervus.

6 Oryctes.

7 Iy ynastcs ITercules.

8 Andrena spinigera. Melitta, ** c. K. and especially Dicronocephalus Hardwickii and Cyphonoccphalus smaragdulus Westw., Arc. Enit. F'l.33. fig. 2.

9 Hispa.

10 Scarabans macropus, Francillon. Now ascertained, by the discovery of numerous speçimens by the French collectors, to be the male of a species of the genus Chrysina K. MIr. W. S. MacLeay informs us that he gave the manuscript name of Eusceles to the group to which it belongs.

11 Raphidia ophiopsis.

12 This idea seems to have been present to the mind of Linné and Fabricius. when they gave to insects such uames as Beelzebub, Bulial, Titan, Trphor, Nimrod, Geyor, and the like. 
The sight indeed of a well-stored cabinet of inseets will bring before every beholder not conversant with them, forms in endless variety, which before he would not have thought it possible could exist in nature, resembling nothing that the other departnents of the animal kingdom exhibit, and exeecding even the wildest fictions of the most fertile imagination. Besides prototypes of beauty and symmetry, there in miniature he will be amused to survey (for the most horrible creatures, when ileprived of the power of injury, become sources of interest and objects of curiosity), to use the words of our great poet,

\section{all prodigious things,}

Abominable, unutterable, and worse
Than fables yet have feign't, or fear conceiv'd,
Gorgons, and Hydras, and Chimæras dire.

But the pleasures of a student of the science to which I am desirous of introchcing you, are far from being confined to such as result from an examination of the exterior form and decorations of insects; for could these, endless as they seem, be exhausted, or, wonderful as they are, lose their interest, yet new sources, exuberant in amusement and instruction, may be opened, which will furnish an almost infinite fund for his curiosity to draw upon. The striking peeuliarity and variety of structure which they exhibit in their instruments of nutrition, motion, and oviposition; in their organs of sensation, generation, and the great fountains of vitality,indeed their whole system, anatomically considered, will open a world of wonders to you with which you will not soon be satiated, and during your survey of which you will at every step feel disposed to exclaim with the Roman naturalist_-" In these beings so minute, and as it were such nonentities, what wisclom is displayed, what power, what unfathomable perfection?" 1 But eren this will not bring you to the end of your pleasures : you must leave the dead to visit the living; you must behold insects when full of life and activity, engaged in their several employments, practising their various arts, pursuing their amours, aud preparing habitations for their progeny: you must notice the laying and kind of their eggs; their wonderful netamorphoses; their instinets, whether they be solitary or gregarious ; and the other miracles of their bistory - all of which will open to you a rieher mine of amusement and instruetion, I speak it without hesitation, than any other department of Natural History ean furnish. A minute enumeration of these particulars wonld be here misplaced, and only forestall what will be detailed more at large hereafter; but a rapicl glance at a very few of the most remarkable of them may serve as a stimulus to exeite your curiosity, and induce yon to enter with greater eagerness into the wide field to which I shall conduct you.

The lord of the ereation plumes himself upon his powers of invention, and is proud to enumerate the various useful arts and maehines to which they have given birth, not aware that "He who teacheth man linowledge" has instructed these despised insects to anticipate him in many of them. The builders of Babel doubtless thought their invention of turning earth into artifieial stone a very happy discovery ${ }^{2}$; yet a little bee ${ }^{3}$ had practised this art, using indeed a different process, on a small scale, and the white ants on a large one, ever since the world began. Man thinks that

1 Plin. Hist. Nat. I. 11. c. 2.

2 Gen. xi. 3

3 Megachile muraria. 
he stands unrivalled as an architect, and that his buildings' are without a paralle! among the works of the inferior orders of animals. He wonld be of a different opinion did he attend to the history of insects: he would find that many of them have been architects from time immemorial; that they have had their houses divided into various apartments, and containing staircases, gigantic arches, domes, colonnades, and the like; nay, that even tunnels are excavated by them so immense, compared with their own size, as to be twelve times bigger than that of Sir M. I. Brunel nnder the Thames. ${ }^{1}$ The modern fine lady, who prides herself on the lustre and beauty of the scarlet hangings which adorn the stately walls of her drawingroom, or the carpets that cover its floor, fancying that nothing so rich and splendid was ever seen before, and pitying her vulgar ancestors, who were doomed to unsightly white-wash and rushes, is ignorant all the while, that before she or her ancestors were in existence, and even before the boasted Tyrian dye was discovered, a little insect lad known how to hang the walls of its cell with tapestry of a scarlet more brilliant than any lier rooms can exhibit ${ }^{2}$, and that others daily weave silken carpets, both in tissue ancl texture infinitely superior to those she so much admires. No female ornament is more prized and costly than lace, the invention and fabrication of which seems the exclusive claim of the softer sex. But cven here they have been anticipated by these little industrious creatures, who often defend their helpless chrysalis by a most singular covering, and as beautiful as singular, of lace. ${ }^{3}$ Other arts have been equally forestalled by these creatures. What vast importance is attached to the invention of paper! For nearly six thousand years one of our commonest insects has known how to make and apply it to its purposes ${ }^{4}$; and even pasteboard, superior in substance and polish to any we can produce, is manufactured by another. ${ }^{5}$ We imagine that nothing short of human intellect can be equal to the construction of a diving-bell or an air-pump - yet a spider is in the daily habit of using the one, and, what is more, one exactly similar in principle to onrs, but more ingeniously contrived; by nucans of which she resides unwetted in the boson of the water, and procures the necessary supplies of air by a much more simple process than our alternating buckets ${ }^{6}$ - and the caterpillar of a little moth knows how to imitate the other, producing a vacuum, when neccssary for its purposes, without any piston beside its own body. ${ }^{7}$ If we think with wonder of the populous cities which have employed the united labours of man for many ages to bring them to their full extent, what shall we say to the white ants, which require only a few months to build a metropolis capable of containing an infinitely greater number of inhabitants than even imperial Nineveh, Babylon, Rome, or Pekin, in all their glory?

That insects should thus have forestalled us in our inventions ought to urge us to pay a closer attention to them and their ways than we have hitherto done, since it is not at all improbable that the result would be inany useful hints for the improvement of our arts and manufactures, and

1 The white ants.

2 Megachile Papaveris.

3 The late ingenious Mr. Paul, of Harlston in Norfolk, under the bark of a tree discovered a considerable portion of a fabric of this kind, which from its amplitude must have been destined for some other purpose.

tThe common wasp.

- Argyroneta aquatica.

5 Chartergus nidulans.

7 Tinea serratella L. 
perhaps for some beneficial discoveries. The painter might thus probably be furnished with more brilliant pigments, the dyer witl more delicate tints, and the artizan with a new and improved set of tools. In this last respect insects deserve particular notice. All their operations are performed with admirable precision and dexterity; and though they do not usually vary the mode, yet that mode is always the best that can be conceived for attaining the end in view. The instruments also with which they are provided are no less wonderful and various than the operations themselves. They have their saws, and files, and augurs, and gimlets, and knives, and lancets, and scissors, and forceps, with many other similar implements; several of which act in more than one capacity, and with a complex and alternate motion to which we have not yet attained in the use of our tools. Nor is the fact so extraordinary as it may seem at first, since "He who is wise in heart and wonderful in working" is the inventor and fabricator of the apparatus of insects ; which may be considered as a set of miniature patterns drawn for our use by a Divine hand. I shall hereafter give you it more detailed account of some of the most striking of these instruments ; and if you study insects in this view, you will be well repaid for all the labour and attention you bestow upon them.

But a more important species of instruction than any hitherto enumerated may be derived from entomological pur'suits. If we attend to the history and manners of insects, they will furnish us with many useful lessons in Ethics, and from them we may learn to improve ourselves in various virtues. We have indeed the inspired authority of the wisest of mankind for studying them in this view, since he himself wrote a treatise upon them, and sends his sluggard to one for a lesson of wistom. ${ }^{1}$ And if we value diligence and indefatigable industry, judgment, prudence, and foresight, economy, and frugality ; if we look upon modesty and diffidence as female ornaments; if we revere parental affection; of all these, and many more virtues, insects in their various instincts exhibit several striking examples, as you will sec in the course of our correspondence.

With respect to religious instruction insects are far from unprofitable; indeed in this view Entomology seems to possess peculiar advantages above every other branch of Natural History. In the larger animals, though we admire the consummate art and wisdom manifested in their structure, and adore that Almighty power and goodness, which by a wonderful machinery, kept in motion by the constant action and re-action of the great positive and negative powers of nature, maintains in full force the circulations necessary to life, perception, and enjoyment; yet as there seems no disproportion between the objects and the different operations that are going on in them, and we see that they afford sufficient space for the play of their systems, we do not experience the same sensations of wonder and astonishment that strike us when we behold similar operations carried on without interruption in animals scarcely visible to the naked eye. That creatures, which in the scale of being are next to nonentities, should be elaborated with so much art and contrivance, have such a number of parts both internal and external, all so highly finished and each so nicely calculated to answer its end ; that they should include in this evanescent form such a rariety of organs of perception and instruments of motion, exceeding in number and peculiarity of structure those of other animals; that their nervous and

11 Kings, iv. 33. Prov, vi. 6-8. 
respiratory systems should be so complex, their secretory and digestive vessels so various and singular, their parts of generation so clearly developed, and that these minims of nature should be endowed with instincts in many cases superior to all our boasted powers of intellect - truly these wonders and miracles declare to every one who attends to the subject, "The hand that made us is divine." We are the work of a Being infinite in power, in wisdom, and in goodness.

But no religious doctrine is more strongly established by the history of insects than that of a superiutending Providisces. That of the innumerable speeies of these beings, many of them beyond conception fragile and exposed to dangers and enemies without end, no link should be lost from the chain, but all be maintained in those relative proportions necessary for the general good of the system; that if one species for a while preponderate, and instead of preserving seem to destroy, yet counter-ehecks should at the same time be provided to reduce it within its due limits; and further, that the operations of insects should be so directed and overruled as to effect the purposes for which they were created, and never exceed their commission : nothing can furnish a stronger proof than this, that an unseen hand holds the reins, now permitting one to prevail, and now another, as shall best promote certain wise ends; and saying to each, "Hitherto shalt thou eome and no further."

So complex is this mundane system, and so incessant the conflict between its component parts, an observation which holds good particularly with regard to insects, that if, instead of being under such control, it were left to the agency of blind chance, the whole must inevitably soon be deranged and go to ruin. Insects, in truth, are a book in which whoever reads under proper impressions cannot avoid looking from the effect to the Cause, and acknowledging his eternal power and godhead thus wonderfully displayed and irrefiagably demonstrited: and whoever beholds these works with the eyes of the body must be blind indeed if he camnot, and perverse indeed if he will not, with the eye of the soul, behold in all his glory the Almighty Workman, and feel disposed, with every power of his nature, to praise and magnify

Him first, Him last, Him midst, Him without end.

And now having led you to the vestibule of an august temple, which in its inmost sanctuary exhibits enshrined in glory the symbols of the Divine Presence, I should invite you to enter and give a tongue to the Hallelujahs, which every ereature in its place, by working his will with all its faculties, pours forth to his great Creator : but I must first endeavour to remove, as I trust I shall effectually, those objections to the study of these interesting beings which $I$ alluded to in the outset of this letter, and this shall be the aim of my next address. 


\section{LETTER II.}

\section{OBJECTIONS ANSWERED.}

Is my last I gave you a general view of the science of Entomology, and endeavoured to prove to yon that it possesses attractions and beauty sufficient to reward any student who may profess himself its votary. I am now to consider it in a less alluring light, as a pursuit attended by no small degree of obloquy, in consequence of eertain objections thought to be urged with great force against it. To obviate these, and remove every scruple from your mind, shall be the business of the present letter.

Two principal oljections are usually alleged with great confidence against the study and pursuit of insects. By some they are derided as trifling and unimportant, and deemed an egregious waste of time and talents; by others they are reprobated as unfeeling and eruel, and as tending to harden the heart.

I. I shall begin with the first of these objections - that the entomologist is a mere triffer. As for the silly outcry and abuse of the ignorant vulgar, who are always ready to laugl at what they do not understand, and because insects are minute objeets conelude that the study of them must be a elildish pursuit, I shall not waste words upon what I so cordially despise. Bnt since even learned men and philosophers, from at partial and prejucticed view of the subject, having recourse to this common-place logie, are sumetimes disposed to regard all inquiry into these minutice of nature as useless and idle, and the wark of a little mind; to remove such prejudice and miseonceptions I shall now dilate somewhat upon the subject of 'iu bono?

When we see many wise and learned men pay attention to any particular department of science, we may naturally eonclude that it is on account of some profit and instruction which they foresee may be derived from it; and therefore in defending Entomology I shall first have recourse to the argumentum ad verecundiam, and mention the great names that have cultivated or recommended it.

We may begin the list with the first man that ever lived upon the earth, for we are told that he gave a name to every living creature , amongst which insects must be included; and to give an appropriate name to an olject necessarily requires some knowledge of its distinguishing properties. Indeed one of the principal pleastires and cmployments of the paradisiacal state was probably the stuly of the various works of ereation. ${ }^{2}$ Before the Fall the book of mature was the Bible of man, in which he could read the perfeetions and attributes of the invisible Godhead ${ }^{3}$, and in it, as in a mirror, behold an image of the things of the spiritual world. Moses also appears to have been eonversant with our little animals, and to have studied them with some attention. This he has shown, not only by being aware of the distinctions which separate the varions tribes of grasshoppers, erickets, \&e. (Gryllus, L.) into different

1 Gen. ii. 19.

2 Linn. Fn. Suec. Prxf.

3 Rom. i. 19, 20. 
genera ${ }^{1}$, but also by noticing the different direction of the two anterior from the four posterior legs of insects; for, as he speaks of them as going upon four legs ${ }^{2}$, it is evident that he considesed the two anterior as arms. Solomon, the wisest of mankind, made Natural History a peculiar object of study, and left treatises behind him upon its various branches, in which creeping itings or inseets were $110 \mathrm{t}$ overlooked ${ }^{3}$; and a wiser than Solomon diren'ts our attention to natural productions, when he bids us consider the lilies of the field ${ }^{4}$, teaching us that they are more worthy of our notice than the most glorious works of man : he also not obseurely intimates that insects are symbolieal beings, when he speaks of seorpions as synonymous with evil spirits ${ }^{5}$; thus giving into our hands a clue for a more profitable mode of studying them, as furnishing moral and spiritual instruction.

If to these seriptural anthorities we add those of uninspired writers, ancient and modern, the names of many worthies, celebrated both for wisdom and virtue, may be produced. Aristotle among the Greeks, and Pliny the elder among the Romans, may be denominated the fathers of Natural History, as well as the greatest philosophers of their day; yet both these made insects a principal olject of their attention : and in more recent times, if we look abroad, what names greater than those of Redi, Malpighi, Vallisnieri, Swammerdam, Leeuwenhoek, Reaumur, Linné, De Geer, Bonnet, and the Hubers? and at home, what philosophers have done more honour to their country and to human nature than Ray, Willoughby, Lister, and Derham? Yet all these made the study of insects one of their most favourite pursuits; and, as if to prove that this study is not incompatible with the highest flights of genius, we can add to the list the name of one of the most sublime of our poets, Gray, who was very zealously devoted to Entomology ; as were the celebrated modern artists, Fuseli and Stothard, and that prodigy of talent, our Dr. Thomas Young, one of whose first essays was upon the habits of spiders, and above all, the inmortal Cuvier, who began his career in this science, and retained for it to the last a strong predilection. ${ }^{6}$ As far, therefore, as names have

1 Levit. xi. 21,22. Lichtenstein in Linn. Trans. iv. 51, 52,

2 Levit. xi. 20. conf. Bochart, IIierozoic. ii. 1. 4. c. 9. 497, 498.

31 Kings, iv. 33.

4 Luke, xii. 27.

5 Ibid. x. 19, 20.

6 Several manuscript volumes of Cuvier's descriptions of insects, and beantifully accurate figures by lis own pen, begun to be written and drawn when he was but seventeen years of age, and continued for five or six years following, still exist (fac-siniles of some of which have recently been published in Silbermann's Revue Entomologique); and it was, as he himself avowed, the marvels which he discovered in the organisation of insects which elevated his genius to the still higher conceptions which made him the first naturalist of the age. In acknowlenging the honour which the Entomological Society of France had conferred on him, in electing him an honorary member, he thus expressed himself in his letter, dated, alas! but a fortnight before his death. "I should have been more worthy of the honour formerly, when in ny yonth this fine science occupied all my leisure moments, but if other branches of natural history have not permitted me to give myself up to it with the same ardonr, I do not the less feel always the greatest interest in it." "If," said he one day to his friend, Professor Audouin, "I had not studied insects when I was at college from taste, I should, at a later period, from reason and necessity." For he was convinced that the habit of devoting the entire attention to the examination of minute details, and the experience of the danger of falling into error the moment this habit is deviated from, are most useful preliminaries to the study of the higher animals, and to enable us to derive from it its most valuable fruits. "Are you an entomologist?" he asked, one day in M. Audouin's presence, a young man who had ventured to speak to him of some remarkable peculiarity which he fancied he had discovered in dissectiug a human subject. "No," replied the medical student. 
weight, the above enumeration seems sufficient to sheiter the votaries of this pleasing science from the charge of folly.

But we do not wish to rest our defence upon authorities alone; let the voice of reason be heard, and our justification will be complete. The entomologist, or, to speak more generally, the naturalist (for on this question of Cui bono? every student in all departments of Natural History is concerned), if the following considerations be allowed their due weight, may claim a much higher station amongst the learned than has hitherto been conceded to him.

There are two principal avenues to knowledge - the study of words and the study of things. Skill in the learned languages being often necessary to enable us to acquire knowledge in the former way, is usually considered as knowledge itself; so that no one asks Cui bono? when a person devotes himself to the study of verbal criticism, and employs his time in correcting the errors that have crept into the text of an ancient writer. Indeed it must be owned, though perhaps too much stress is sometimes laid upon it, that this is very useful to enable us to ascertain his true meaning. But after all, words are but the arbitrary signs of ideas, and have no value independent of those ideas, further than what arises from congruity and narmony, the mind being dissatisfied when an idea is expressed by inadequate words, and the ear offended when their collocation is inharmonious. To account the mere knowledge of words. therefore, as wisdom, is to mistake the cask for the wine, and the casket for the gem. I say all this because knowledge of words is often extolled beyond its just merits, and put for all wisdom; while knowledge of things, especially of the productions of nature, is derided as if it were mere folly. We should recollect that God hath condescended to instruct us by both these ways, and therefore neither of them should be depreciated. He hath set before us his word and his world. The former is the great avenue to truth and knowledge by the study of words, and, as being the immediate and authoritative revelation of his will, is entitled to our principal attention; the latter leads us to the sane conclusions, though less directly, by the study of things, which stands next in rank to that of God's word, and before that of any work of man. And whether we direct our eyes to the planets rolling in their orbits, and endcavour to trace the laws by which they are guided through the vast of space, whether we analyse those powers and agents by which all the operations of nature are performed, or whether we consider the various productions of this our globe, from the mighty cedar to the microscopic mucor - from the giant elephant to the invisible mite, still we are studying the works and wonders of our God. The book, to whatever page we turn, is written by the finger of Him who created us; and in it, provided our minds be rightly disposed, we may read his eternal verities. And the more accurate and enlarged our knowledge of his works, the better shall we be able to understand his word; and the more

"Well then," rejoined Cuvier, "I advise you to dissect an insect. I leave the species to your own choice: it may be the largest you can find; and having done this, review your supposed discovery, and if you still think it exact, I will take your word for it." The young man, a friend of MI. Audouin, submitted with a good grace to this test, and having acquired more dexterity and more caution, came shortly to thank Cuvier for his advice, and to confess his former mistake. "You see," said the latter, smiling, "that my touchstone was not bad." (Audouin-Notice sur George Cuvier. Ann. Soc. Ent. de France, i. 317.) 
practised we are in his word, the more readily shall we discern his truth in his works; for, proceeding from the sane great Author, they must, when rightly interpreted, mutually explain and illustrate each other.

Who then shall dare maintain, unless he has the hardihood to deny that God created them, that the study of insects and their ways is trifing or unprofitable? Were they not arrayed in all their beauty, and surrounded with all their wonders, and made so instrumental (as I shall hereafter prove them to be) to our welfare, that we might glorify and praise him for them? Why were insects made attractive, if not, as Ray well expresses it, that they might ornament the universe and be delightful objects of contemplation to man ? ${ }^{1}$ And is it not clear, as Dr. Paley has observed, that the production of beauty was as much in the Creator's mind in painting a butterfly or in studding a beetle, as in giving symmetry to the human frame, or graceful curves to its muscular coreriug ? ${ }^{2}$ And shall we think it beneath us to study what he hath not thought it beneath him to adorn and place on this great theatre of creation? Nay, shall we extol those to the skies who bring together at a vast expense the most valuable specimens of the arts, the paintings and statues of Italy and Greece, all of which, however beautiful as works of man, fall short of perfection; and deride and upbraid those who collect, for the purpose of admiring their beauty, the finshed and perfect chefs-d'œurre of a Divine artist? May we gaze with rapture unblamed upon an Apollo of Belvedere, or Venus de Medicis, or upon the exquisite paintings of a Raphael or a Titian, and yet when we behold with ecstasy sculptures that are produced by the chisel of the Almighty, and the inimitable tints laid on by his pencil, because an insect is the subject, be exposed to jeers and ridicule?

But there is another reason, which in the present age renders the study of Natural History an object of importance to every well-wisher to the cause of religion, who is desirous of exerting his faculties in its defence. For as enthusiasm and false religion have endeavoured to maintain their ground by a perversion of the text of Scripture, so also the patrons of infidelity and atheism have laboured hard to establish their impiety by a perversion of the text of nature. To refute the first of these adversaries of truth and sound religion, it is necessary to be well acquainted with the word of God; to refute the second, requires an intimate knowledge of his works; and no department can furnish him with more powerful arguments of every kind than the world of insects - every one of which cries out in an audible voice, There is a (rod - he is Almighty, all-wise, all-good - his watchful providence is ever, and every where, at work for the preservation of all things.

But since mankind in general are too apt to look chicfly at this world, and to regard things as important or otherwise in proportion as they are connected with sublunary interests, and promote our present welfare, I shall proceed further to prove that the study of insects may be productive

1 "Quxri fortasse a nonnullis potest, Quis Papilionum usus sit? Respondeo, Ad ornatum Universi, et at hominibus spectaculo sint: ad rura illustranda velut tot bractex inservientes. Quis enim eximiam earum pulchritndinem et rarietatem contemplans mira voluptate non afficiatur? Quis tot colorum et schematum elegantias naturx ipsius ingenio excogitatas et artifici penicillo depictas curiosis oculis intuens, divinie artis vestigia eis impressa non agroscat et mirefur?" Riai. Hist. Ins. 109.

2 Nat. Theol. 213. 
of considerable utility, even in this view, and may be regarded in some sort as a necessary or at least a very useful concomitant of many arts and sciences.

The importance of insects to us both as sources of good or evil, I shall endeavour to prove at large hereafter; but for the present, taking this for granted, it necessarily follows that the study of them must also be important. For when we suffer from them, if we do not know the cause, how are we to apply a remcly that may diminish or prevent their ravages? Ignorance in this respect often occasions us to mistake our enemies for our friends, and our triends for our enemies ; so that when we think to do good we only do harm, destroying the innocent and letting the guilty escape. Many such instances have occurred. You know the orangecoloured fly of the wheat, and have read the account of the damage done by this little insect to that important grain; you are aware also that it is given in charge to three little parasites to keep it within due limits; yet at first it was the general opinion of unscientific men, that these destrorers of our enemy were its parents, and the original source of all the mischief. ${ }^{1}$ Middleton, in his "Agriculture of Middlesex," speaking of the Plant.Jouse that is so injurious to the bean, tells us that the lady-hirds are supposed either to generate or to feed upon them. ${ }^{2}$ Had he been an entomologist, he would have been in no doubt whether they were beneficial or injurious; on the contrary, he would have recommended that they shonld be encouraged as friends to man, since no insects are greater devourers of the Aphides. The confounding of the apple Aphis, or American blight $\left(\right.$ A. lanigera ${ }^{3}$ ), that has done such extensive injury to our orchards, with others, has led to proceedings still more injurious. This is one of those species from the skin of which transpires a white cottony secretion. Some of the proprietors of orchards about Evesham, observing an insect which secreted a similar substance upon the poplar, imagined that from this tree the creature which they lad found so noxious was generated; and in consequence of this mistaken notion cut down all their poplars. ${ }^{4}$ The same indistinct ideas might have induced them to fell all their larches and beeches, since they also are infested by Aphides which transpire a similar substance. Had these persons possessed any entomological knowledge, they would have examined and compared the insects before they had formed their opinions, and being convinced that the poplar and apple Aphis are distinct species, would have saved their trees.

But could an entomological observer even ascertain the species of any noxious insect, still in many cases, without further information, he may fuil short of his purpose of prevention. Thus we are told that in Germany the gardeners and country people, with great industry, gather whole baskets full of the caterpillar of the destructive cabbage moth (Mamestre Brassica), and then bury them, which, as Roesel well observes ${ }^{5}$, is just as

1 Kirby, in Linn. Trans. iv. 232. 235. See also a letter signed C. in the Gent. MIng. for August, 1795. This little insect prodnces no galls like many of the species of the genus (Latr. Gen. Crust. et Ins. iv. 253. Meig. Dipt. i. 94), yet it corresponds with the characters of Cecidomyia laid clown both by Latreille and Meigen.

2 P. 192.

3 See Latr. Familles Naturelies du Règne Animal, 420. This insect has had four generic names given to it.- Lachnus by Illiger, Friosoma by Leacn, Myzoxyle by Blot, and Schizoneura by Ilartig in Germar's Zeitschr. f. d. Eutomol.

+ Collett, in Mtonth. Mug. xaxii. 320 .

5 Roesel, I. iv. 170. 
if we should endeavour to kill a crab by covering it with water; for many of them being full grown and ready to pass into their next state, which they do underground, instead of destroying them by this manœuvre, their appearing again the following years in greater numbers is actually facilitated. Yet this plan applied to our common cabbage caterpillar, which does not go underground, would succeed. So that some knowledge of the manners of an insect is often requisite to enable us to check its ravages effectually. With respect to noxious caterpillars in general, agriculturists and gardener's are not usually aware that the best mode of preventing their attacks is to destroy the female fly before she has laid her eggs, to do which the moth proceeding from each must be first ascertained. But if their research were carried still further, so as to enable them to distinguish the pupa and discover its haunts, and it would not be at all difficult to detect that of the greatest pest of our gardens, the cabbage butterfly, the work might be still more effectually accomplished. Some larvæ are polyphagous, or feed upon a variety of plants; amongst others that of the yellow-tail moth (Porthesia chrysorrhca); yet gardeners think they have done enough if they destroy the web-like nests which so often deform our fruit-trees, without suspecting that new armies of assailants will wander from those on other plants which they have suffered to remain. Thus will thousands be produced in the following season, which, had they known how to distinguish them, might have been extirpated. Another instance occurred to me, when walking with a gentleman in his estate at a village in Yorkshire. Our attention was attracted by several circular patches of dead grass, each having a stick with rags suspended to it, płaced in the centre. I at once discerned that the larva of the cock-chafer had eaten the roots of the grass, which being pulled up by the rooks that devour this mischievous grub, these birds had been mistaken by the tenant for the cause of the evil, and the rags were placed to frighten away his best friends. On inquiry why he had set up these sticks, he replied, "He coukn't beer to see'd nasty craws pull up all'd gess, and sae he'd set'd bairns to hing up some and clouts to flay 'em away. Gin he'd letten 'em alean they'll sean hev reated up all'd close." Nor could I convince him by all that I could say, that the rooks were not the cause of the evil. Even philosophers sometimes fall into gross mistakes from this species of ignorance. Dr. Darwin has observed, that destroying the beautiful but injurious wood-peckers is the onfy alternative for preventing the injury they do to our forest trces by boring into them ${ }^{1}$; not being aware that they bore only those trees which insects have previously attacked, and that they diminish very considerably the number of such as are prejudicial to our forests.

From these facts it is sufficiently evident that entomological knowledge is necessary both to prevent fatal inistakes, and to enable us to check with effect the ravages of insects. But ignorance in this respect is not only unfit to remedy the evil; on the contrary, it may often be regarded as its cause. A large proportion of the most noxious insects in every country are not indigenous, but have been imported. It was thus that the moth (Galleria MIfllonella) so destructive in beehives, and the asparagus beetle (Crioceris Asparagi), were made denizens of Sweden. ${ }^{2}$ The insect that has destroyedall the peach trees in St. Helena was imported from the Cape; and at home (not to mention bugs and cock-roaches) the great pest of our 
orchards, before mentioned, the apple Aphis, there is good reason to believc was introduced with some foreign apple-trees. Now, extensive as is our commerce, it is next to impossible, by any precautions, to prevent the importation of these noxious agents. A cargo of wheat from North America might present us with the famed Hessian fly, which some years ago caused such trepidation in our cabinet; but though introduced, the presence of these insects, were Entomology a more general pursuit, would soon be detected, and the evil at once nipt in the bud; whereas in a country where this science was not at all or little cultivated, they would most probably have increased to such an extent before they attracted notice, that every effort to extirpate them would be ineffectual.

It is needless to insist upon the importance of the study of insects, as calculated to throw light upon some of the obscurest points of general physiology ; nor would it be difficult, though the task might be invidious. to point out how grossly incorrect and deficient are many of the speculitions of our most eminent philosophers, solely from their ignorance of this important branch of Natural History. How little qualified would that physiologist be to reason conclusively upon the mysterious subject of generation, who should be ignorant of the wonderful and unlooked-for fact, brought to light by the investigations of an entomologist, that one sexual intercourse is sufficient to fertilise the eggs of numerous generations of Aphides! And how defective would be all our reasonings on the powers of nutrition and secretion, had we yet to learn that in insects both are in action unaccompanied by the circulating system and glands of larger animals!

In another point of view entomological information is very useful. A great deal of unnecessary mischief is produced, and unnecessary uneasiness occasioned, by what are called vulgar errors, and that superstitious reliance upon charms, which prevents us fiom having recourse to remedies that are really efficacious. Thus, for instance, eating figs and sweet things has been supposed to generate lice. ${ }^{1}$ Nine lirve of the moth of the wild teasel enclosed in a reel or goose quill have been reckoned a remedy for ague. ${ }^{2}$ Matthiolus gravely affirms that every oak-gall contains either a fly, a spider, or a worm ; and that the first foretells war, the second pestilence, and the third famine. ${ }^{3}$ In Sweden the peasants look upon the grub of the cock-chafer as furnishing an unfuiling prognostic whether the ensuing winter will be mild or severe; if the animal have a bluish hue (a circumstance which arises from its being replete with food) they affirm it will be mild, but, on the contrary, if it be white, the weather will be severe: and they carry this so far as to foretell, that if the anterior part be white and the posterior blue, the cold will be most severe at the beginning of the winter. Hence they call this grub Bemärkelse-mask, or prognostic worm. ${ }^{4}$ A similar augury as to the harvest is drawn by the Danish peasants from the mites which infest the common dung beetle (Geotrupes stercorarius), called in Danish Skambosse or Torbist. If there are many of these mites between the fore feet, they believe that there will be an early

1 Amoreux, 276.

2 Rai. Cat. Cant. 45. Hist. Ins, 341.

3 Cominent, in Dioscor. 1. 1. c. 23. 214. Lesser L, ii. 280.

4 De Geer, iv. $275,276$. 
harvest, but a late one if they abound between the hind feet. ${ }^{1}$ The appearance of the death's head hawk-moth (Acherontin Atropos) has in some countries produced the most violent alarn and trepidation amongst, the people, who, because it ensits a plaintive sound, and is marked with what looks like a death's head upon its back, regarded it as the messenger of pestilence and death. ${ }^{2}$ We learn from Linné that a similar superstition, built upon the black hue and strange aspect of that beetle, prevails in Sweden with respect to Blaps mortisaga ${ }^{3}$; and in Barbadoes, according to Hughes, the ignorant deem the appcarance of a certain grasshopper in their houses as a sure presage of illness to some of the fanily. ${ }^{4}$

One would not think that the excrements of insects could be objects of terror; yet so it has been. Many species of Lepidoptera, when they emerge from the pupa state, discharge from their anus a reddish fluid, which, in some instances, where their numbers have been considerable, has produced the appearance of a slower of blood; and by this natural fact, all those bloody showers, recorded by historians as preternatural, and regarded where they happened as feartul prognostics of impending evils, are stripped of their terrors, and reduced to the class of events that happen in the common course of nature. That insects are the cause of these showers is no recent discovery; for Sleidan relates that in the year 1553 a vast multitude of butterfies swarıned through a great part of Germany, and sprinkled plants, leaves, buildings, clothes, and men, with blondy drops, as if it had rained blood. ${ }^{5}$ But the most interesting account of an event of this kind is given by Reaumur, from whom we learn that in the beginning of July, 1608, the suburbs of Aix, and a considerable extent of country round it, were covered with what appeared to be a shower of blood. We may conceive the amazement and stupor of the populace upon such a discovery, the alarm of the citizens, the grave reasonings of the learned. All agreed however in attributing this appearance to the powers of darkness, and in regarding it as the prognostic and precursor of some direful misfortune about to befall then. Fear and prejudice would have taken deep root upon this occasion, and might have produced fatal effects upon some weak minds, had not M. Peirese, a celebrated philosoplser of that place, paid attention to insects. A chrysalis which he preserved in his cabinet let him into the secret of this mysterions shower. Hearing a fluttering, which informed him his insect was arrived at its perfect state, he opened the box in which he kept it. The animal flew out and left behind it a red spot. He compared this with the spots of the bloody shower, and found they were alike. At the same time he observed there was a prodigious quantity of butterflies flying about, and that the drops of the miraculous rain were not to be found upon the tiles, nor even upon the upper surface of the stones, but chiefly in cavities and places where rain could not easily come. Thus did this judicious observer dispel the ignorant fears and terror which a natural phenomenon had caused. ${ }^{6}$

The same author relates an instance of the gardener of a gentleman being thrown into a horrible fright by digging up some of the curious cases

1 Detharding de Insectis Coleopteris Danicis, 9.

2 Reaum. ii. 289. This insect and its caterpillar is finely figured in Mr. Curtis's elegant and scientific British Entomology, t. 147.

3 Faun, Suec, 822.

5 Quoted in Mouffet, 107.

4 Nat. Hist. of Barbad. 85 .

6 Reaum. i. 667. 
which I shall hereafter describe to you, of the leaf-cutter bees, and which he conceived to be the effect of witcheraft portending some terrible misfortnne. By the advice of the priest of the parish he even took a journey from Rouen to Paris, to show them to his nuaster: but he, happily having more sense than the nian, carried them to $\mathrm{M}$. Nollet, an eminent naturalist, who having seen similar productions was aware of the cause, and opening one of the cases, while the gardener stood aghast at his temerity, pointed out the grub that it contained, and thus sent him back with a light heart, relieved from all his apprehensions. ${ }^{1}$

Every one has heard of the death-watch, and knows of the superstitious notion of the vulgar, that in whatever house its drum is lieard one of the family will die before the end of the year. These terrors, in particular instances, where they lay hold of weak minds, especially of sick or hypocliondriacal persons, may cause the event that is supnosed to be prognosticated. A small degree of entomological knowledge would relieve them from all their fears, and teach them that this heart-sickening tick is cansed by a small beetle (Anobium tessellatum) which lives in timber, and is merely a call to its companion. Attention to Entomology may therefore be renclered very useful in this view, since nothing certainly is more desirable than to deliver the human mind from the dominion of superstitious fears and faise notions, which, having considerable influence on the conduct of mankind, are the cause of no small portion of evil.

But as we cannot well guard against the injuries produced by insects, or remove the evil, whether real or arising from misconceptions respecting then, which they occasion, unless we have some knowledge of them ; so neither without such knowledge can we apply them, when beneficial, to our use. Now it is extremely probable that they might be made vastly more subservient to our advantage and profit than at present, if we were better acquainted with them. It is the remark of an anthor, who himself is no entomologist: "We have not taken animals enough into alliance with us. The more spiders there were in the stable, the less would the horses suffer from the flies. The great American fire-fly should be inported into Spain to cateh mosquitos. In hot conntries a reward shonld be offered to the man who conld discover what insects feed upon fleas." 2 It wonld be worth our while to act upon this hint, and a similar one of Dr. Darwin. Those insects might be collected and preserved that are known to destroy the Aplides and other injurious tribes; and we should thus be cnabled to direct their operations to any quarter where they would be most serviceable; but this can never he done till experimental agriculturists and gardeners are conversant with insects, and aequainted with their propertics and economy. How is it that the Great Being of beings preserves the system which he has created from permanent injury, in consequence of the too great redundancy of any individual species, but by employing one creature to prey upon another, and so overruling and directing the instincts of all, that they may operate most where they are most wanted! We cannot better exercise the reasoning powers and faculties with which he has endowed us, than by copying his example. We often employ the larger animals to destroy each other, but the smaller, especially insects, we have totally neglected. Some may think, pcrhaps, that in aiming to do

1 Reaum. vi. 99, 100. Kirby MIon. Ap. Ang. i. 157, 158.

2 Southey's Mudor, 4to. Notes, 519. 
this we should be girilty of presumption, and of attenpting to take the government and direction of things out of the hands of Providence : but this is a very weak argument, which might with equal reason be adduced to prove that when rats and mice become troublesome to us, we ought not to have recourse to dogs, ferrets, and cats to exterminate them. When any species multiplies upon us, so as to become noxious, we certainly have a just right to destroy it, and what means can be more proper than those which Providence itself has furnished? We can none of us go further or do more than the Divine Will permits; and he will take care that our efforts shall not be injurious to the general welfare, or effect the annihilation of any individual species.

Again, with regard to insects that are employed in medicine or the arts, if the apothecary cannot distinguish a Cantharis or blister-beetle from a Carabus or Cetonia, both of which beetles I have found mixed with the former, how can he know whether his druggist furnishes him with a good or bad article? And the same observation may with still greater force apply to the dyer in his purchase of cochineal, since it is still more difficult to distinguish the wild sort from the cultivated. There are, it is probable, many insects that might be employed with advantage in both these departments; but unless Entomology be more generally studicd by scientific men, who are the only persons likely to make discoveries of this kind, than it has hitherto bcen, we must not hope to derive further profit fiom them. It seems more particularly incumbent upon the professors of the divine art of healing to become conversant with this as well as the other branches of Natural History; for not only do they derive some of their most useful drugs from insects, but many also of the diseases upon which they are consulted, as we shall see hereafter, are occasioned by them. For want of this kind of information medical men run the risk of confounding diseases perfectly distinct, at least as to the animal that causes them. It would be a most desirable thing to have professors in eacli brancls of Natural History in our universities, and to make it indispensable, in order to the obtaining of any degree in physic, that the candidate should have attended these lectures. We may judge from the good effects that the arts have derived from the present very general attention to Chenistry how beneficial would be the consequence if Entomology were equally cultivated; and I shall conclude this paragraph with what I think may be laid down as an incontrovertible axiom : - That the profit we derive from the works of creation will be in proportion to the accuracy of our knowledge of them and their properties.

I trust I have now said enough to convince you and every thinking man that the study of insects, so far from being vain, idle, trifling, or unprofitable, may be attended with very important advantages to mankind, and ought at least to be placed upon a level with many other branches of science, against which such accusations are never alleged.

But I must not conceal from you that there are objectors who will still return to the charge. They will say, "We admit that the pursuits of the cntomologist are important when he directs lis views to the destruction of noxious insects; the discovery of new ones likely to prove beneficial to man; and to practical experiments upon their medical and econoinical properties. But where are the entomologists that in fact pursue 
this course? Do they not in reality wholly disregard the econonical department of their science, and content themselves with making as large a collection of species as possible ; ascertaining the names of such as are already described; describing new ones; and arranging the whole in their cabinets under certain families and genera? And can a study with these sole ends in view deserve a better epithet than trifling? Even if the entomologist advance a step further, and invent a new system for the distribution of all known insects, can his laborious undertaking be deemed any other than busy idleness? What advantage does the world derive from having names given to ten or twenty thousand insects, of which numbers are not bigger than a pin's head, and of which probably not a hundredth part will ever be of any use to mankind?"

Now in answer to this supposed objection, which I have stated as forcibly as I an able, and which, as it may be, and often is, urged against every branch of Natural History as at present studied, well deserves a full consideration, I might in the first place deny that those who have the highest claim to rank as entomologists do confine their views to the systematic department of the science to the neglect of econonical observations; and in proof of my assertion, I might refer abroad to a Linné, a Reaunuur, a De Geer, a Huber, and various other names of the highest reputation; and at home to a Ray, a Lister, a Derham, a Marsham, a Curtis, a Clark, a Roxburgh, \&c. But I do not wish to conceal that though a large proportion of entomologists direct their views much further than to the mere nomenclature of their science, there exists a great number, probably the majority, to whom the objection will strictly apply. Now I contend, and shall next endeavour to prove, that entomologists of this description are devoting their time to a most valuable end; and are conferring upon society a benefit incalculably greater than that derived from the labours of many of those who assume the privilege of despising their pursuit.

Even in favour of the mere butterfly-bunter - he who has no higher aim than that of eollecting a picture of Lepidoptera, and is attached to insects solely by their beauty or singularity, - it would not be difficult to say much. Can it be necessary to declaim on the superiority of a people amongst whom intellectual pleasures, however trifling, are preferred to mere animal gratifications? Is it a thing to be lamented that some of the Spitalfields weavers occupy their leisure hours in searching for the Adonis butterfly (Polyommatus Adonis). and others of the more splendid Lepidoptera ${ }^{1}$, instead of spending them in playing at skittles or in an alehouse? Or is there in truth any thing more to be wished than that the cutlers of Sheffield were accustomed thus to employ their Saint Mondays; and to recreate themselves after a hard day's work, by breathing the pure air of their surrounding hills, while in search of this " untaxed and undisputed game ${ }^{2}$;" and that more of the Norwich weavers were fond of devoting

1 Haworth, Lepid. Brit. 44. 57.

2 Oft have I smiled the happy pride to see Of humble tradcsmen in their evening glee, When of some-pleasing fancied good possest, Each grev alert, was busy and was blest: Whether the call-bird yield the hour's delight, Or magnified in microscope the mite; Or whether tumblers, croppers, carriers seize The gentle mind; they rule it and they p!ease. 
their vacant time to plant-hunting, like Joseph Fox, recorded by Sir James Smith as the first raiser of a Lycopodium from seed? 1

Still more easy is it to advocate the cause of another description of entomologists - the general collectors. These, though not concerning themselves with the system, contribute most essentielly to its advancement. We cannot expect that princes, noblemen, and others of high rank or large fortune who collect insects, should be able or willing to give up the time necessary for studying them systematically; but their nuseums being accessible to the learned entomologist, afford him the use of treasures which his own limited funds or opportunities could never have brought together. As to others of less consequence that content themselves with the title of collectors, they also have their use. Having devoted themselves to this one department, they become more expert at it than the philosopher who combines deep researches with the collection of objects; and thus are many species brought together for the use of the systematist, that would otherwise remain unknown.

But to proceed to the defence of the systematic entomologists. - These may be divided into two great classes: the first comprising those who confine themselves to ascertaining the names of the insects they collect; the second, those who, in addition, publish descriptions of new species, new arrangements of intricate genera, or extrications of entangled synonyms, and who, in other respects, actively contribute to the perfection of the system.

Now with regard to the first class, setting aside what may be urged in behalf of the study of insects considered as the work of the Creator, it is easy to show that, even with such restricted views, their pursuit is as commendable, and as useful both to themselves and the community, as many of those on which we look with the greatest respect. To say the least in their favour, they amuse themselves innocently, which is quite as much as can be urged for persons who recreate their leisure hours with music, painting, or desultory reading. They furnish themselves with an unfailing provision of that "grand panacea for" the todium vite" - employment- no unimportant acquisition, when even Gray was forced to exclaim, with reference to the necessity of "always having something going forward" towards the enjoyment of life, "Happy they who can create a rose-tree or erect a honey-suckle; that can watch the brood of a hen, or see a fleet of their own ducklings launch into the water!"2 And, like the preceding class, they collect valuable materials for the use of more active labourers, being thus at least upon a par with the majority of book-collectors and antiquaries.

There is $m y$ friend the weaver; strong desires

Reign in his breast; 'tis beauty he admires :

See to the shady grove he wings his way,

And feels in hope the rapture of the day -

Eager he looks, and soon to glad his eyes,

From the sweet bower by nature form'd arise

Bright troops of virgin moths, and fiesh-born butterflies.

He fears no bailiff's wrath, no baron's blame;

His is untax'd and undisputed game.

1 Linn. Trans. ii. 315.

Crabbe's Borough, p. 110.

2 Letter to Dr. Wharton. Mason's Life of Gray, p. 28. 
But this is the smallest half of the value of their pursuit. With what view is the study of the mathematics so generally recommended? Not certainly for any practical purpose-not to make the bulk of those who attend to them astronomers or engineers. But simply to exercise and strengthen the intellect - to give the mind a habit of attention and of investigation. Now for all these purposes, if I do not go so far as to assert that the mere ascertaining of the names of insects is equal to the study of the mathematics, I have no hesitation in affirming that it is nearly as effectual ; and with respect to giving a habit of minute attention, superior. Such is the intricacy of nature, such the imperfection of our present arrangenents, that the discovery of the name of almost any insect is a problem, calling in all cases for acuteness and attention, and in some for a balancing of evidence, a calculation of the chances of error as arduons as are required in a perplexed law case, and a process of ratiocination not less strict than that which satisfies the mathematician. In proof of which assertion I need only refer any competent judige to the elaborate disquisitions of Laspeyres, called for by one work alone on the lepidopterous insects of a single district-the Viener Verzeichniss, which occupy above two hundred octavo pages ', and must have cost the learned author nearly as much labour of mind as the Ductor Dubitantium did Bishop Taylor.

Do not apprebend that this occasional perplexity is any deduction from the attractions of the science : though in itself, in some respects, an evil, it forms in fact to many minds one of the chief of them. The pursurit of Truth, in whatever path, affords pleasure : but the interest would cease if she never gave us trouble in the chase. Horace Walpole used to say, that from a child he could never bring himself to attend to any hook that was not full of proper names ; and the satisfaction which he felt in dry investigations conceruing noble authors, and obscure painters, is experienced by many an entomologist who spends hours in disentangling the synonymy of a doubtful species. Nor would it be easy to prove that the wordy researches of the one are not to every practical purpose as valuable as those of the other. We smile at the Frenchman told of by Menage, that was so enraptured with the stirdy of heraldry and genealogy as to lament the hard case of our forefather Adam, who conld not possibly amuse himself with such investigations. ${ }^{2}$ But many an entoriologist, who has felt the delicious sensation attendant upon the indisputable ascertainment of an insect's name after a long search, will feel inclined to indulge in similar grief for the unhappy lot of his successors, when all shall be smooth sailing in the science.

But in behalf of those who are more eminently entitled to be called entomologists - those who, not content with collecting and investigating insects, occupy themselves in naming and describing such as bave been before mobserved; in instituting new genera or reforming the old; and, to say all in one word, in perfecting the system of the science, - still higher claims can be urged. Suppose that at this moment our dictionaries of the Frencls and German languanges were so very defective, that we were unable by the use of them to profit from the discoveries of their philosophers: the lahours of a Michaelis being a sealed book to our theologists, and those of La Place to onr astrononers. On this supposition, would 
not one of the most important literary undertakings be the compilation of more perfect dictionarics, and would not the humblest contributor to such an end be dcemed most meriteriously engaged? Now precisely what an accurate dictionary of a particular language is towards enabling the world to participate in the discoveries published in that language, is a system of Entomology towards enabling mankind to derive advantage from any discoveries relative to insects. A good system of insects, containing ail the known species arranged in appropriate genera, families, orders, and classes, is in fact a dictionary, putting it within our power to ascertain the nane of any given insect, and thus to learn what has been observed respecting its properties and history, as readily as we determine the meaning of a new word in a lexicon. In order to impress upon you more forcibly the absolute need of such a system, I inust enter into still further detail.

There is searcely a country in which several thousand insects may not be found. Now, without some scientific arrangement, how is the observer of a new fact respecting any one of them to point out to distant countries, and to posterity, the particular insect he had in view? Suppose an observer in England were to find a certain beetle which he had demonstrated to be a specific for consumption; and that it was necessary that this insect, which there was reason to believe was common in every part of the world, should be administered in a recent state. Would he not be anxious to proclaim the happy discovery to sufferers in all quarters of the globe? As his remedy would not admit of transportation, he would have no other means than by describing it. Now the question is, whether, on the supposition that no system of Entomology existed, he would be able to do this, so as to be intelligible to a physician in North America, for instance, eager to administer so precious a medicine to his expiring patient? It would evidently be of no use to say that the specific was a beetle : there are thousands of different beetles in North America. Nor would size or colour be any better guide : there are hundreds of beetles of the same size and the same colour. Even the plant on which it fed would be no sufficient clue; for many insects, resembling each other to an unpractised eye, feed on the same plant, and the same insect in different countries feeds upon different plants. His only resource, then, would be a coloured figure and full description of it. But every entomologist knows that there exist insects perfectly distinct, yet so nearly resembling each other, that no engraving nor any language other than that strictly scientific can possibly discriminate them. After all, therefore, the chances are that our discoverer's renedy, invaluable as it might be, must be confineal to his own immediate neighbourhood, or to those who came to receive personal information from him. But with what ease is it made known when a system of the science exists! If the insect be already described, he has but to mention its generic and trivial names, and by the aid of two words alone, every entomologist, though in the most distant region - whether a Swede, a German, or a Frenchman - whether a native of Europe, of Asia, of America, or of Africa, knows instantly the very species that is meant, and can that moment ascertain whether it be within his reach. If the species be new and undescribed, it is only necessary to indicate the genus to which it belongs, the species to which it is most nearly allied, and to describe it in scicntific terms, which may be done in fer words, and it can at once be recognised by every one acquainted with the science. 
You will think it hardly credible that there should be so much dificulty in describing an insect intelligibly without the aid of system; but an argumentum ad homincm, supported by some other facts, will, I conjecture, render this matter more comprehensible. You have doubtless, like every one else, in the showery days of summer, felt no little rage at the flies, which at such times take the liberty of biting our legs, and contrive to make a comfortable meal through the interstices of their silken or cotton coverings. Did it, I pray, ever enter into your conception that these bloodthirsty tormentors are a different specics from those flies which you are wont to see extending the lips of their little proboscis to a piece of sugar or a drop of wine? I dare say not. But the next time you have sacrificed one of the former to your just vengeance, catch one of the latter and compare them. I question if, after the narlowest comparison, you will not still venture a wager that they are the very same species. Yet you would most certainly lose your bet. They are not even of the same genus - one belonging to the genus Musca (M.domestica), and the other to the genus Stomoxys (S. calcitrans); and on a second examination you will find that, however alike in most respects, they differ widely in the shape of their proboscis; that of the Stomoxys being a horny sharp-pointed weapon, capable of piercing the flesh, while the soft blunt organ of the Musca is perfectly incompetent to any such operation. In future, while you no longer load the whole race of the house-fly with the execrations which properly belong to a quite different tribe, you will cease being surprised that an ordinary description shonld be insufficient to discriminate an insect. It is to this insufficiency that we must attribute our ignorance of so many of the insects mentioned by the older naturalists, previously to the systematic improvements of the iumortal Linné : and to the same calise we must refer the impossibility of determining what species are alluded to in the accounts of many modern travellers and agriculturists who have been ignorant of Entomology as a science. Instances without number of this impossibility might be adduced, but I shall confine myself to two.

One of the greatest pests of Surinam and other low regions in Sonth America, is the insect called in the West Indies; where it is also troublesome, the chigoe (Pulex penetrans), a minute species, to the attacks of which I shall again have occasion to advert. This insect is mentioned by almost all the writers on the countries where it is found. Not less than eight or ten of them have endeavoured to give a full description of it, and some of them have even figured it ; and yet, strange to say, it was not certainly known whether it was a flea (Pulex L.), a îonse (Pediculus L.), or a mite (Acarus L.), till a competent naturalist undertook to investigate its history, and in a short paper in the Swedish Transactions ${ }^{1}$ proved that Limué was not mistaken in referring it to the former tribe, with which also the more recent investigations of in cminent British entomologist, J. O. Westwood, Esq., have shown that it must be arranged, though, from some difference in its structure as well as habits, he has adopted the generic name (slightly altered) proposed by the Rev. L. Guilding, and has called it Sarcopsylla penetrans. ${ }^{2}$

The sccond instance of the insufficiency of popular description is cven

1 Swartz in Kongl. Vet. Ac. nya IIandl. ix. 40.

2 Trans. Ent. Soc. Lond. ii. 192-203. 
more extraordinary. In 1788 an alarm was excited in this country by the probability of imperting, in cargoes of wheat from North America, the insect known by the name of the Hessian fly, whose dreadful ravages wil! be adverted to hereafter. However the insect tribes are in general despised, they had on that occasion ample revenge. The privy council sat day after day anxiously debating what measures should be adopted to ward off the danger of a calamity mole to be dreaded, as they well knew, than the plague or pestilence. Expresses were sent off' in all directions to the officers of the customs at the different outports respecting the examination of cargoes - despatches written to the ambassadors in France, Austria, Prussia, and America, to gain that information of the want of which they were now so sensible; and so important was the business deemed, that the minutes of council and the documents collected from all quarters fill upwards of two hundred octavo pages. ${ }^{1}$ Fortunately England contained one illustrious naturalist, the most authentic source of information on all subjects which conncet Natural History with Agriculture and the Arts, to whom the privy. council had the wisdom to apply; and it was by Sir Joseph Banks's entomological knowledge, and through his suggestions, that they were at length enabled to form some kind of judgment on the subject. This judgment was, a ter all, however, very imperfect. As Sir Joseph Banks had never seen the Hessian fly, nor was it described in any entomological system, he called for facts respecting its nature, propagation, and economy, which could be had only from America. These were obtained as speedily as possible, and consist of numerous letters from individuals, essays from magrazines, the reports of the British minister there, \&c. \&c. One would have supposed that firom these statements, many of them drawn up by farmers who had lost entire crops by the insect, which they profess to have examined in evcry stage, the requisite information might have been acquired. So far, however, was this from being the case, that many of the writers seemed ignorant whether the insect be a moth, a fly, or what they term a bug. And though from the concurrent testiniony of several, its being a two-winged fly seemed pretty accurately ascertained, no intelligible description was given from which any naturalist conkl infer to what genus it belonged, or whether it was a known species. With regard to the history of its propagation and economy the statements were so various and contradictory, that though he had such a mass of materials before lim, Sir Joseph Banks was mable to reach any satisfactory conclusion. ${ }^{2}$

Nothing can more incontrovertibly demonstrate the importance of studying Entomology as a science than this fact. Those observations, to which thousands of unscientific sufferers proved themselves incompetent, would have been readily made by one entomologist well versed in his science. He would at once have determined the order and genus of the insect, and whether it was a known or new species; and in a twelvemonth at furthest he would have ascertained in what manner it made its attacks, and whether it were possible that it might be transmitted along with grain into a foreign country; and on these solid data he could have satisfactorily pointed out the best mode of eradicating the pest, or preventing the extension of its ravages.

1 Young's Annals of Agriculture, xi. 406.

2 The American Entomologist Say was the first who satisfactorily determined the species and genus of the insect in question. Say on Cecidomyia Destructor, in Tourn Acud. Nat. Sc. Philadelph., i. ; and Kirby in Loudon's MI:g. Nat. Hist., i. 
But it is not merely in travellers and popular observers that the want of a systematic knowledge of Entomology is so deplorable. A great portion of the labours of the profoundest naturalists has been from a similar cause lost to the world. Many of the insects concerning which Reaumur and Bonnet have recorded the most interesting circumstances, cannot, from their neglect of system, be at this day ascertained.1 The former, as Beckmamn ${ }^{2}$ states on the authority of his letters, was before his death sensible of his great error in this respect; but Bonnet, with singular inconsistency, constantly maintained the inntility of system, even on an occasion when, from his ignorance of it, Sir James Smith, speaking of his experiments on the barberry, found it quite impossible to make him comprehend what plant he referred to. ${ }^{3}$

So great is the importance of a systematic arrangement of insects. Yet no such arrangement has hitherto been completed. Various fragments towards it, indeed, exist. But the work itself is in the state of a dictionary wanting a considerable proportion of the words of the language it professes to explain; and placing those which it does contain in an order often so arbitrary and defective, that it is difficult to discover even the page containing the word you are in search of. Can it be denied, then, that they are most meritoriously employed who devote themselves to the removal of these defects-to the perfecting of the system-and to clearing the path of future economical or physiological observer's from the olstructions which now beset it? And who that knows the vast extent of the science, and how impossible it is that a divided attention can embrace the whole, will contend that it is not desirable that some labourers in the field of literature should devote themselves entirely and exclusively to this object? Who that is aware of the importance of the comprehensive views of a Fabricius, an Illiger, or a Latreille, and the infinite saving of time of which their inquiries will be prodnetive to their follower's, will dispute their clain to rank amongst the most honourable in science?

II. No objection, I think, now remains against addicting ourselves to entomological pursuits, but that which seems to have the most weight with you, and which indeed is calculated to make the deepest impression upon the best minds - I mean the charge of inhumanity and cruelty. That the science of Entomology cannot be properly cultivated without the death of its ohjects, and that this is not to be effected without putting them to some pain, must be allowed; but that this substantiates the charge of cruelty, I altogether deny. Cruelty is an unnecessary infliction of suffering, when a person is fond of torturing or destroying God's creatures from mere wantonness, with no useful enu in view ; or when, if their death be useful and lawful, he has recourse to circuitous modes of killing them where direct ones would answer equally well. This is cruelty, and this with you I abominate ; but not the infliction of death when a just occasion calls for it.

They who see no cruelty in the sports of the field, as they are called, ean never, of course, consistently allege such a charge against the Entonologist; the tortures of wounded birds, of fich that swallow the hook and break the

1 No one knew Reaumur's Abeille Tapissiere, until Latreille, happily combining system with attention to the economy of insects, proved it to be a new species his Megachile Papaveris.-Wist. de Fourmis, 297.

2 Bibliothek, vii. 310.

3 Tour on the Continent, iii. 150. 
line, or of the hunted hare, being, beyond comparison, greater than those of insects destroyed in the usual mode. With respect to utility, the sportsman who, though he adds indeed to the general stock of food, makes amusement his primary object, must surely yield the palm to the entomologist, who adds to the general stock of mental food, often supplies hints for useful improvements in the arts and sciences, and the objects of whose pursuit, unlike those of the former, are preserved, and may be applied to use for many years.

But in the view even of those few who think inhumanity chargeable upon the sportsman, it will be easy to place considerations which may rescue the entomologist from such reproof. It is well known that, in proportion as we descend in the scale of being, the sensibility of the objects that constitute it diminishes. The tortoise walks about after losing its head; and the polypus, so far from being injured by the application of the knife, thereby acquires an extension of existence. Insensibility almost equally great may be found in the insect world. This, indeed, might be inferred $\dot{c}$ priori; since Providence secms to have been more prodigal of insect life than of that of any other order of creatures, animalcula perhaps alone excepted. No part of the creation is exposed to the attack of so many enemies, or subject to so many disasters ; so that the few individuals of each Lind which enrich the valued museum of the entomologist, many of which are dearer to him than gold or gems, are snatched from the ravenous maw of some bird or fish or rapacious insect-would have been driven by the winds into the waters and drowned, or trodden underfoot by man or beast; for it is not easy, in some parts of the year, to set foot to the ground without crushing these ninute animals; and thus also, instearl of being buried in oblivion, they luave a kind of immortality conferred upon them. Can it be believed that the beneficent Creator, whose tender mercies are over all his works, would expose these helpless beings to such innumerable enemies and injuries, were they endued with the same sense of pain and irritability of nerve with the higher orders of animals?

But this inference is reduced to certainty, when we attend to the facts which insects every day present to us, proving that the very converse of our great poct's couclusion, as usually interpreted,

\section{- The poor beetle that we tread upon \\ In corporal sufferance finds a pang as great \\ As when a giant dies,}

must be regarded as nearer the truth. ${ }^{1}$ Not to mention the peculiar organisation of insects, which strongly favours the iclea I am inculcating, but which will be considered more properly in another place, their sang-froid upon the loss of their limbs, eren those that we account most necessary to life, irrefragably proves that the pain they suffer cannot be very acute. Had a giant lost an arm or a leg, or were a sword or spear run through his body, he would feel no great inclination for running about, dancing or eating; yet a crane-fly (Tipula) will leave half its legs in the hands of an

1 Shakspeare's intention, however, in this passage, was evidently not, as is often supposed, to excite compassion for the insect, but to prove that

The sense of Death is most in apprehension, the actual pang being trifling.-Measure for Measure, Act iii. Sc. 1. 
unlucky boy who has endeavoured to catch it, and will fly liere and there with as much agility and unconcern as if nothing had happened to it; and an insect impaled upon a pin will often devour its prey with as much avidity as when at liberty. Were a giant eviscerated, his body divided in the middle, or his head cut off, it would be all over with him ; he would move no more; he would be dead to the calls of hunger, or the emotions of fear, anger, or love. Not so our insects. I have seen the common cock-chafer walk about with apparent indifference after some bird had nearly emptied its body of its viscera : an humble-bee will eat honey with greediness though deprived of its abdomen; and I nyself lately saw an ant, which had been brought out of the nest by its comrades, walk when deprived of its head. The head of a wasp will attempt to bite after it is separated from the rest of the body; and the abdomen under similar circumstances, if the finger be moved to it, will attempt to sting. And, what is more extraordinary, the headless trunk of a male Mantis has been known to unite itself to the other $\operatorname{sex}^{1}$; and a dragon-fly to eat its own tail, as we learn from J. F. Stephens, Esq., author of the valuable "Illustrations of British Entomology," who, while entomologising near Whittleseamere, having directed the tail of one of these insects which he had canght to its month, to make an experiment whether the known voracity of the tribe would lead it to bite itself, saw to his astonishment that it actually bit off and ate the four terminal segments of its body, and then by accident escaping flew away as briskly as ever ! ${ }^{2}$ These facts, out of hundreds that might be adduced, are surely sufficient to prove that insects do not experience the same acute sensations of pain with the higher order of animals, which Providence has endowed with more ample means of avoiding them. And since they were to be exposed so universally to attack and injury, this is a most merciful provision in their favour; for, were it otherwise, considering the wounds, and dismemberments, and lingering deaths that insects often suffer, what a vast increase would there be of the general sum of pain and misery! You will now, I think, allow that the most humane person need not hesitate a moment whether he shall devote himself to the study of Entomology on account of any cruelty attached to the pursuit.

But if some morbid sentimentalist should still exclaim, "Oh! but I cannot persuade myself, even for scientific purposes, to inflict the slightest degree of pain upon the most insensible of creatures - " Pray, sir or madam, I would ask, should your green-house be infested by Aphides, or your grapery by the semianimate Coccus, would this extreme of tenderness induce you to restrict your gardener from destroying them? Are you willing to deny yourself these unnecessary gratifications, and to resign your favourite flowers and fruit at the call of your fine feelings? Or will you give up the shrimps, which by their relish enable you to play a better part with your bread and butter at breakfast, and thus, instead of adding to it, contribute to diminish the quantity of food? If not, I shall only desire you to recollect that, for a mere personal indulgence, you cause the death of an infinitely greater number of animals than all the entomologists in the world destroy for the promotion of science.

To these considerations, which I have no doubt you will think conclusive as to the unreasonableness and inconsistency of the objections made against

1 Dr. Smith's Tour, i. 162 . Journ. de Phys xxv. 336.

2 Stephens in Ent. Mag. i. 518. 
the study of entomology on the score of cruelty, I shall only add that $I$ do not intend them as an apology for other than the most speedy and least painful modes of destroying insects. Every degree of unnecessary pain beconies cruelty, which I need not assure you I abhor ; and from my own observations, however ruthlessly the entonologist may seem to devote the few specimens wanted for scientific purposes to destruction, no one in ordinary circumstances is less prodigal of insect life. For my own part, I question whether the drowning individuals, which I have saved from destruction, would not far outnumber all that $I$ ever sacrificed to science.

My next letter will be deroted to the metamorphoses of insects, a subject on which some previous explanation is necessary to enable you to understand those distinctions between their different states which will be perpetually alluded to in the course of our correspondence; and having thus cleared the way, I shall afterwards proceed to the consideration of the injuries and benofits of which insects are the canse.

I an, \&c. 


\section{LETTER III.}

\section{METAMORPHOSES OF INSECTS.}

WERE a naturalist to announce to the world the discovery of an animal which for the first five years of its life existed in the form of a serpent; which then penetrating into the earth, and weaving a shroud of pure silk of the finest texture, contracted itself within this covering into a body without external mouth or limbs, and resembling, more than anything else, an Egyptian mummy; and which, lastly, after remaining in this state without food and without motion for three years longer, should at the end of that period burst its silken cerements, struggle through its earthly covering, and start into (lay a winged bird, - what think you would be the sensation excited by this strange piece of intelligence? After the first doubts of its truth were dispelled, what astonishment would succeed! Amongst the learned, what surmises! - what investigations! Amongst the vulgar, what eager curiosity and amazenent! All would be interested in the history of such an unheard-of phenomenon; even the most torpid would flock to the sight of such a prodigy.

But, you ask, "To what do all these improbable suppositions tend?" Simply to rouse your attention to the metamorphoses of the insect world, almost as strange and surprising, to which I am now about to direct your view, - miricles which, though scarcely surpassed in singularity by all that poets have feigned, and though actually wrought every day beneath our cyes, are, because of their commonness, and the minuteness of the objects, unheeded alike by the ignorant and the learned.

That butterfly which amuses you with his aedral excursions, one while extracting nectar from the tube of the honeysuckle, and then, the very image of fickleness, flying to a rose as if to contrast the hue of its wings with that of the flower on which it reposes, did not come into the world as you now behold it. At its first exclusion from the egg, and for some months of its existence afterwards, it was a worm-like caterpillar, crawling upon sixteen short legs, greedily devouring leaves with two jaws, and seeing by means of twelve eyes so minute as to be nearly imperceptible without the aid of a microscope. You now view it furnished with wings capable of rapid and extensive flights: of its sixteen feet ten have lisappeared, and the remaining six are in most respects wholly unlike those to which they have succeeded: its jaws have vanished, and are replaced by a curled-up proboscis suited only for sipping liquid sweets; the form of its head is entirely changed, - two long horns project from its upper surface; and instead of twelve invisible eyes, you behold two, very large, and composed of at least seventeen thousand convex lenses, each supposed to be a distinct and effective eye!

Were you to push your exanination further, and by dissection to compare the internal conformation of the caterpillar with that of the butterfly, you would witness clianges even more extraordinary. In the former you would find some thousands of muscles, which in the latter are replaced by others of a form and structure entirely different. Nearly the whole body of the 
caterpillar is occupied by a capacious stomach. In the butterfly it has become converted into an almost imperceptible thread-like viscus; and the abdomen is now filled by two large packets of eggs, or other organs not visible in the first state. In the former, two spirally-convoluted tubes were filled with a silky gum; in the latte; toth tubes and silk have almost totally vanished; and changes equally great have taken place in the economy and structure of the nerves and other organs.

What a surprising transformation! Nor was this all. The change from one form to the other was not direct. An intermediate state not less singular intervened. After casting its skin even to its very jaws several times, and attaining its full growth, the caterpillar attached itself to a leaf by a silken girth. Its body greatly contracted: its skin once more split asunder, and lisclosed an oviform mass, without exterior mouth, eyes, or limbs, and exhibiting no other symptom of life than a slight motion when touched. In this state of death-like torpor, and without tasting food, the insect existed for several months, until at length the tomb burst, and out of a case not more than an inch !ong, and a quarter of an inch in diameter, proceeded the butterfly before you, which covers a surface of nearly four inches square.

Almost every insect which you see has undergone a transformation as singular and surprising, thongli varied in many of its circumstances. That active little fly, now an unbidden guest at your table ${ }^{2}$, whose delicate palate selects your choicest riands, one while extending his proboscis to the margin of a drop of wine, and then gaily flying to take a more solid repast tiom a pear or a peach; now gamboling with his comrades in the air, now gracefully currying his furled wings with his taper feet, was but the other day a disgusting grub, without wings, without legs, without eyes, wallowing, well pleased, in the midst of a mass of excrement.

The "grey-coated gnat," whose humming salutation, while she makes her airy circles about your bed, gives terrific warning of the sanguinary operation in which she is ready to engage, was a few hours ago the inhahitant of a stagnant pool, more in shape like a fish than an insect. Then to have been taken out of the water would have been speedily fatal ; now it could as little exist in any other element than air. Then it breathed through its tail ; now through openings in its sides. Its shapeless head, in that period of its existence, is now exchanged for one adorned witl elegantly tufted antennæ, and furnished, instead of jaws, with an apparatus more artfully constructed than the cupping-glasses of the phlebotomist an apparatus, which, at the same time that it strikes in the lancets, composes a tube for pumping up the flowing blood.

The "shard-born beetle," whose "sullen horn," as he directs his "droning flight" close past your ears in your evening walk, calling up ii poetic association the lines in which he has been alluded to by shakspeare, Collins, and Gray, was not in his infancy an inhabitant of air, the first period of his life being spent in gloomy solitude, as a grub, under the surface of the earth. The shapeless maggot, which you scarcely fail to meet with in some one of every handful of nuts you crack, would not always have grovelled in that humble state. If your unlucky intrusion upon its vaulted dwelling had not left it to perish in the wide world, it

1 "Cœnis etiam non rocatus ut Musca adrolo." Aristophon in" Pythagorista apud Athenaum. (Mouffet, 56.) 
would have eontinued to reside there until its full growth had been attilined. Then it would have gnawed itself an opening, and, having entered the earth, and passed a few months in a state of inaction, would at length have emerged an elegant beetle furnished with a slender and very long ebony beak: two wings, and two wing cases, ornamented with yellow bands : six feet; and in every respect unlike the worm from which it proceeded.

That bee but it is needless to multiply instances, a sufficient number has been adduced to show that the apparently extravagant supposition with which I set ont may be paralleled in the insect world; and that the metamorphoses of its inhabitants are scarcely less astonishing that would be the transformation of a serpent into an eagle.

These changes I do not purpose explaining minutely in this place: they will be adverted to more fully in subsequent letters. Here I mean merely to give you such a general view of the subject as shall impress you with its claius to attention, and such an explanation of the states through which insects pass, and of the different terms made use of to designate them in each, as shall enable you to comprehend the frequent allusions which must be made to them in our future correspondence.

The states through which insects pass are four: the egg; the larva; the pupa; and the imago.

The first of these need not be here adverted to. In the second, or immediately after the exclusion from the egg, they are soft, without wings, and in shape usually somewhat like worms. This Limné called the larva state, and an insect when in it a larva, adopting a Latin word signifying a mask, because he considered the real insect while under this form to be as it were masked. In the English language we have no common term that applies to the second state of all insects, thongh we have several for that of different tribes. Thus we eall the coloured and often hairy larvæ of butterflies and moths caterpillars; the white and more compact larvæ of fijes, many beetles, \&c., grubs or maggots ${ }^{1}$; and the depressed larvæ of nany other insects worms. The two former terms I shall sometimes use in a similar sense, rejecting the last, which ought to be confined to true vermes; but I shall more commonly adopt Linnés term, and call insects in their second state, larve.

In this period of their life, during which they eat voraciously and east their skin several times, insects live a shorter or longer period, some only a few days or weeks, others several months or years. They then eease eating; fix themselves in a secure place; their skin separates once more and discloses an oblong body, and they have now attained the third state of their existence.

From the swathed appearance of most insects in this state, in which they do not bally resemble in miniature a child trussed up like a munny in swarldling clothes, according to the barbarous fashion once prevalent

1 Gentils, or gentles, is a synonymous word employed by our old authors, but is now obsolete, except with anglers. 'Thus 'Tusser, in a passage pointed out to ine by Sir Joseph Banks:-

"Rowerd not thy sheep when ye take off his cote

With twitches and patches as brode as a grote;

Let not such ungentlenesse happen to thine,

Least fly with her gentils do make it to pine." 
here, and still retained in many parts of the Continent, Linné has called it the pupa state, and an insect when under this form a pupa - terms which will be here adopted in the same sense. In this state most insects eat no food; are incapable of locomotion; and, if opened, seem filled with a watery fluid, in which no distinct organs can be traced. Externally, however, the shape of the pupx of different tribes varies considerably, and different names have been applied to them.

Those of the beetle and bee tribes are covered with a membranous skin, enclosing in separate and distinct sheaths the external organs, as the antennæ, legs, and wings, which are consequently not closely applied to the body, but have their form for the most part clearly distinguishable. To these Aristotle originally gave the name of nymphae ${ }^{1}$, which was continued by Swammerdam and other authors prior to Linné (who calls them incomplete pupæ), and has been adopted by many English writers on insects.

Butterflies, moths, and some of the two-winged tribe, are in their pupa state also enclosed in a sinilar membranous envelope; but their legs, antennæ, and wings, are closely folded over the breast and sides; and the whole body enclosed in a common case or covering of a more horny consistence, which admits a much less distinct view of the organs beneath it. As these pupæe are often tinged of a golden colour, they were called fron this circminstance chrysalides by the Grecks, and aurclice by the Romans, both which terms are in some measure become anglicized; and though not strictly applicable to ungilded pupæ, are now often given to those of all lepidopterous insects. ${ }^{2}$ These by Limné are denoninated obtected pupæ.

I have said that most insects eat no food in the pupa state. This qualification is necessary, because in the metamorphoscs of insects, as in all her other operations, nature proceeds by measured steps, and a very considerable number (the tribe of locusts, cockroaches, bugs, spiders, \&c.) not only greatly resemble the perfect insect in form, but are equally capable with it of eating and moving. As these insects, lowever, cast their skins at stated periods, and undergo changes, though slight, in their

1 Hist. Anim. 1.5. c. 10.

2 In explanation of the terms Lepidoptera, Lepidopterous, Culeoptera, \&c., which will frequently occur in the following pages before coming regularly to definitions, it is necessary here to state that they have reference to the names given by entomologists to the different order's or tribes of jnsects, as under:-

1. Coleoptera, consisting of Beetles.

2. Strepsiptera, - of the genera Tenos and Stylops.

3. Dermaptera, — of the Earwigs.

4. Orthoptera, — of Cockroaclies, Locusts, Grasshoppers, Crickcts, Spectres, Mantes, Sic.

5. Hemiptera, consisting of Bugs, Cicuda, Water-scorpions, Water-boat-men, Plant-lice, Cochineal Insects, \&c.

6. Trichoptera, consisting of the flies produced by the various species of Caseworms, Phryganea, L.

7. Lepidoptera, consisting of Butterflics, Hawkmoths, and MIoths.

8. Neuroptera, consisting of Dragon-flies, Ant-lions, Ephemera, \&c.

9. Hymenoptera, consisting of Bees, Wusps, and other insects armed with a sting or ovipositor, and its valves.

10. Diptera, consisting of Flies, Gnats, and other two-winged iusects.

11. Aphaniptera, consisting of the Flea tribe.

12. Aptera, of Mites, Lice, \&c. 
external and internal conformation, they are regarded also as being subject to metamorphoses. These pupæ may be subdivided into two classes; first, those comprised, with some exceptions, under the Linnean Aptera, which in almost every respect resemble the perfect insect, and were called by Linné complete pupæ; and, secondly, those of the Limnean order Hemiptera, which resemble the perfect insect, except in having only the rudi. ments of wings, and to which the name of semi-complete pupa was applied by Linné, and that of semi-nymphs by some other authors. There is still a fifth kind of pupx, which are not, as in other instances, excluded from the skin of the larva, but remain concealed under it, and were hence called by Linné coarctate pupæ. These, which are peculiar to fies and some other dipterous genera, may be termed cased-mympls.

When, therefore, we employ the term pupa, we refer indifferently to the third state of any insect, the particular order being indicated by the context, or an explanatory epithet. The terns chrysalis (dropping aurelia, which is supertluous), mymph, semi-nymph, and cased-nymph, on the other hand, definitely pointing out the particular sort of pupa meant : just as in Botany, the common term pericarp applies to all seed-vessels, the several kinds being designated by the names of capsule, silicle, $\&$ c.

The envelope of cased-nymphs, which is formed of the skin of the larva, considerably altered in form and texture, may be conveniently called the puparium : but to the artificial coverings of different kinds, whether of silk, wood, or earth, \&xc., which many insects of the other orders fabricate for themselves previously to assuming the pupa state, and which have been called by different writers, pods, cods, husks, and beans, I shall continue the more definite French term cocon, anglicized into cocoon.

After remaining a shorter or longer period, some species only a few hours, others months, others one or more years, in the pupa state, the enclosed insect, now become mature in all its parts, bursts the case which enclosed it, quits the pupa, and enters upon the fourth and last state.

We now see it (unless it be an apterous species) furnished with wings, capable of propagation, and often under a form altogether different from those which it has previously borne - a perfect beetle, butterfiy, or other insect. This Linné termed the imago state, and the animal that had attained to it the imago; because, having laid aside its mask, and cast off its suraddling bands, being no longer disguised or confined, or in any respect imperfect, it is now become a true representative or image of its species. This state is in general referred to when an insect is spoken of without tlue restricting terms larva or pupa.

Such being the singularity of the transformations of insects, you will not think the ancients were so wholly unprovided with a show of argument as we are accustomed to consider them, for their belief in the possibility of many of the marvellons netamorphoses which their pocts recount. Utterly ignorant as they were of modern physiological discoveries, the conversion of a caterpillar into a butterfly must lave been a fact sufficient to put to a. nonplus all the sceptical oppugners of such transformations. And however we may snile, in this enlightened age, at the inference drawn not two centuries ago by Sir. Theodore Mayerne, the editor of Mouffet's work on insects, "that if animals are transmuted so may metals", it was not, in 
fact, with his limited knowledge on these subjects, so very preposterous. It is even possible that some of the wondrous tales of the ancients were grafted on the changes which they observed to take place in insects. The death and revivification of the phenix, from the ashes of which, before attaining its perfect state, arose first a worm $(\sigma \kappa \omega \lambda \eta \xi)$, in many of its particulars resembles what occurs in the metamorphoses of insects. Nor is it very unlikely that the doctrine of the metempsychosis took its rise from the same source. What argument would be thought by those who maintained this doctrine more plausible, in favour of the transmigration of souls, than the secming revivification of the dead chrysalis? What more probable thin that its apparent re-assumption of life should be owing to its receiving for tenant the soul of some criminal doomed to animate an insect of similar habits with those which had defiled his human tenement? ${ }^{1}$

At the present day, however, the transformations of insects have lost that excess of the marvellous, which might once have furnished arguments for the fictions of the ancients, and the dreams of Paracelsus. We call them metamorphoses and transformations, because these terms are in common use, and are more expressive of the sudden changes that ensue than any new ones. But, strictly, they ought rather to be termed a series of developments. A caterpiliar is not, in fact, a simple but a compound animal, containing within it the germ of the future butterfly, enclosed in what will be the case of the pupa, which is itself included in the three or more skins, one over the other, that will successively cover the larva. As this increases in size these parts expand, present themselves, and are in turn thrown off, until at length the perfect insect, which had been concealed in this succession of masks, is displayed in its genuine form. That this is the proper explanation of the plienomenon has been satisfactorily proved by Swammerdam, Malpighi, and other anatomists. The first-mentioned illustrious naturalist discovered, by accurate dissections, not only the skins of the larva and of the pupa encased in each other, but within them the very butterfly itself, with its organs iudeed in an almost fluid state, but still perfect in all its parts. ${ }^{2}$ if this fact you may convince yourself without Swammerdam's skill, by plunging into vinegar or spirit of wine a caterpillar about to assume the pupa state, and letting it remain there a few days for the purpose of giving consistency to its parts; or by boiling it in water for a few minutes. A very rough dissection will then enable you to detect the future butterfly; and you will find that the wings, rolled up into a sort of cord, are lodged between the first and second segment of the catcrpillar; that the antenna and trunk are coiled up in front of the head; and that the lcgs, however different their form, are actually sheathed in its legs. Malpighi discovered the eggs of the future moth in the chrysalis of a silkworm only a few days olit ${ }^{3}$, and Reaumur those of another noth (Hypogyma dispar) even in the caterpillar, and that seven

1 "I priest who has drunk wine shall migrate into a moth or fly, feerling on ordure. He who steals the gold of a priest shall pass a thousand times into the bodies of spiders. If a man shall steal honey, he shal? be born a great stinging gnat : if oil, an oil-drinking beetle; if salt, a cicada; if a household utensil, an ichneumon fly." Institutes of Menu, 353.

2 llill's Sưmm. ii. 24. t. $3 \overrightarrow{7}$. f. 2,4 .

$\because$ De Bomlyce, 29 . 
or eight days before its change into the pupa. ${ }^{1}$ A caterpillar, then, may he regarded as a locomotive egg, having for its embryo the included butterfy, which after a certain period assimilates to itself the animal substances by which it is surrounded; has its organs gradually developed; and at length breaks through the shell which encloses it.

This explanation strips the subject of every thing miraculous, yet by no means reduces it to a simple or uninteresting operation. Our reason is confounded at the reflection that a larva, at first not thicker than a thread, includes the germs of its own triple, or sometimes octuple, teguments; the case of a chrysalis, and of a butterfly, all curiously folded in each other; with an apparatus of vessels for breathing and digesting, of nerves for sensation, and of muscles for moving; and that these various forms of existence will undergo their successive evolutions, by aid of a few leaves received into its stomach. And still less able are we to comprehend how this organ shonld at one time be capable of digesting leaves, at another only honey; how one while a silky fluid should be secreted, at another none; or how organs at one period essential to the existence of the insect should at another be cast off, and the whole system which supported them vanish. ${ }^{2}$

Nor does this explanation, though it precludes the idea of that resemblance, in every particular, which, at one time, was thought to obtain between the metamorphosis of insects, especially of the Lepidoptera order, and the resurection of the body, do away that general analogy which cannot fail to strike every one who at all considers the subject. Even Swammerdam, whose observations have proved that the analogy is not so complete as had been imagined, speaking of the metamorphosis of insects, uses these strong words: "This process is formed in so remarkible a manner in butterties, that we see therein the resurrection painted before our eycs, and cxemplified so as to be examined by our hands." ${ }^{3}$ To see, indecl, a caterpillar crawling upon the earth sustained by the most ordinary kinds of food, which, when it has existed a few weeks or months under this humble form, its appointed work being finished, passes into an intermediate state of seeming death, when it is wound up in a kind of shroud and encased in a coffin, and is most commonly buried under the earth (though sometimes its sepulchre is in the water, and at others in various substances in the air), and after this creature and others of its tribe have remained their destined time in this death-like state, to behold earth, air, and water give up their scveral prisoners: to survey them, when, called by the warmth of the solar beam, they burst from their sepulchres, cast off their cerements, fiom this state of torpid inactivity, come forth, as a bride out of her chamber - to survey them, I say, arrayed in their nuptial glory, prepared to enjoy a new and more exalted condition of life, in which all their powers are developed, and they are arrived at the per-

1 Reaum. i. 359.

2 Dr. ITerold (Entwickelungs geschichte der Schmetterlinge), and other modern physiologists, deny that the germs of the skins of the caterpillar and chrysalis and of the future butterfly exist in the young caterpillar; but, for reasons assigned in detail in another place (vol. iii. edit. 5 . pp. $52-62$, , the theory of Swammerdam and Bonnet, as above explained, is here preferred.

3 Hill's Swamm. i. 127. a. 
fection of their nature; when no longer confined to the earth, they can traverse the fields of air, their food is the nectar of flowers, and love begins his blissful reign; - who that witnesses this interesting scene can help seeing in it a lively representation of man in his threefold state of existence, and more especially of that happy day, when, at the call of the great Sun of Righteousness, "all that are in the graves shall come forth, the sea shall give up her dead, and death being swallowed up of life, the nations of the blessed shall live and love to the ages of eternity?"

But aithough the analogy between the different state of insects and those of the body of man is only general, yet it is nuch more complete with respect to his soul. He first appears in his frail body-a child of the earth, a crawling worm, his soul being in a course of training and preparation for a more perfect and glorious existence. Its course being fiuished, it casts off the earthly body, and goes into a hidden state of being in Hades, where it rests from its works, and is prepared for its final consummation. The time for this being arrived, it comes forth clothed with a glorions body, not like its former, though germinating from it, for, though " it is sown an animal body, it shall be raised a spiritual body," endowed with augmented powers, faculties, and privileges commensurate to its new and happy state. And here the parallel holds perfectly between the insect and the man. The butterfly, the representative of the soul, is prepared in the larva for its future state of glory; and if it be not destroyed by the ichneumons and other enemies to which it is exposed, symbolical of the vices that destroy the spiritual life of the soul, it will come to its state of repose in the mipa, which is its Hades; and at length, when it assumes the imago, break forth with new powers and beauty to its final glory and the reign of love. So that in this view of the subject well might the Italian poet exclaim:

Non v' accorgete roi, che noi siam' vermi,

Nati a formar l' angelica farfalla ? 1

The Egyptian fable, as it is supposed to be, of Cupid and Psyche, seems built upon this foundation. "Psyche," says an ingenious and learned writer, "means in Greek the human soul; and it means also a butterfly" of which apparently strange double sense the undoubted reason is, that a butterfly was a very ancient symbol of the soul: from the prevalence of this symbol, and the consequent coincilence of the names, it happened that the Greek sculptors frequently represented Psyche as subject to Cupid in the shape of a butterfly; and that even when she appears in their works unler the human form, we find her decorated with the light and filmy wings of that gay insect." 3

The following beautiful little poen: falls in so exactly with the subject I have been discussing, that $I$ cannot resist the temptation $I$ feel to copy it

1 Do you not perceive that we are caterjillars, born to form the angelic butterfly?

2 It is worthy of remark, that in the north and west of England the moths that fy into candles are called saules (souls), perhaps from the old notion that the souls of the deal fly about at night in search of jight. For the same reason, probably the common jeople in Germany call them ghosts (Geistchen).

3 Nares's Essuys, i. 101, 102. 
for you, especially as I am not aware that it has appeared anywhere but in a newspaper : -

\section{THE BUTTERFLY'S BIRTH-DAY.}

BY THE AUTHOR OF " THE BUTTERFLY'S BALL."

The shades of night were seareely fled;

The air was mild, the winds were still;

And slow the slanting sun-beams spread

O'er wood and lawn, o'er heath and hill:

From fleecy clouds of pearly hue

Hal dropt a short but bàlmy shower,

That hung like gems of morning dew

On every tree and every flower:

And from the blackbira's mellow throat

Was ponr'd so loud and long a swell,

As echoed with responsive note

From mountain side and shadowy dell.

When bursting forth to life and light,

The offspring of enraptured May,

The Butrwifly, on pinions bright,

Launch'd in full splendour on the day.

Unconscious of a mother's eare, No infant wretchelness she knew;

But as she felt the vernal air, At once to full perfection grew.

Her slender form, ethereal light, Her velvet-textured wings infold;

With all the rainbow's colours bright, And dropt with spots of burvish'd goid.

Trembling with joy awhile she stood, And felt the sun's enlivening ray;

Drank from the skies the vital flood, And wondered at her plumage gay!

And balancel oft her broiderell wings, 'Through fields of air prepared to sail:

Then on her vent'rous journey springs, And floats along the rising gale.

Go, child of pleasure, range the fields, Taste all the joys that spring can give,

Partake what bonnteous summer yields, And live whilst yet 'tis thine to live.

Go, sip the rose's fragrant dew, 'The lily's honeyed eup explore,

From flower to flower the search renew, And rifle all the woodbine's store:

And let me trace thy vagrant flight, Thy moments too of short repose, And mark thee then with fresh delight: Thy golden pinions ope and elose.

But hark! whilst thus I musing stand P'ours on the gale an airy note, And breathing from a viewless band, Soft silvery tones around me float! 
- They cease - but still a voice I hear,

A whisper'd voice of hope and joy,

Thy bour of rest approaches near,

"Prepare thee, mortal! - thou must die!

"Yet start not! - on thy closing eyes

"Another day shall still unfold,

"A sun of milder radiance rise,

"A happier age of joys untold.

"Shall the poor worm that shocks thy sight,

"The humblest form in nature's train,

"Thus rise in new-born lustre bright,

"And yet the emblem teach in vain?

"Ah! where were once ler golden eves,

"Her glittering wings of purple priue?

"Concealed beneath a rude disguise,

"A shapeless mass to earth allied.

"Like thee the hapless reptile liverl,

"Like thee he toil'(3, like thee he spun,

"Like thine bis closing hour arrived,

"His labour ceased, lis web was done.

"And shalt thou, number'd with the deai,

"No happier state of being lnow?

"And shall no future morrow shed

"On thee a beam of brighter glow?

"Is this the bound of power divine,

"To animate an insect frame?

16 Or shall not He who moulded thine

"Wake at his will the vital flame?

"Go, mortal! in thy reptile state,

"Enough to know to thee is given;

"Go, and the joyful truth relate;

" Erail child of earth! high heir of heaven!"

A question here naturally presents itself-Why are insects subject to these changes? For what end is it that, instead of preserving, like other animals ${ }^{1}$, the same general form from infancy to old age, they appear at one period under a shape so different from that which they finally assume; and why should they pass through an intermediate state of torpidity so extraordinary? I can only answer that such is the will of the Creator, who donbtless had the wisest ends in view, although we are incompetent satisfactorily to discover them. Yet one reason for this conformation may be hazarded. A very important part assigned to insects in the economy of nature, as 1 shall hereafter show, is that of speedily removing superabundant and de-

1 A few vertebrate animals, viz. frogs, toads, and newts, undergo metamorphoses in some respects analogous to those of insects; their first form as tadpoles being very different from that which they afterwards assume. These reptiles, too, as well as suakes, cast their skin by an operation somewhat similar to that in larve. There is nothing, however, in their metamorphoses at all resembling the pupa state in insects. (See, however, Von Baer's article on the Analogies of the 'Transformations of Insects and the Higher Aninals in the Annales des Sciences Nat.) According to Mr. J. V. Thompson, both the common barnacles and many crustacea undergo metamorphoses, but to what extent these changes take place in the latter does not seem clearly ascertained. 
caying animal and vegetable matter. Forsuch agents an insatiable voracity is an indispensable qualification, and not less so unusual powers of multiplication. But these faculties are in a great degree incompatible. An insect occupied in the work of reproduction conld not continue its voracious feeding. Its life, therefore, after leaving the egg, is divided into three stages. In the first, as larva, it is in a state of sterility; its sole object is the satisfying its insatiable hunger; and, for digesting the masses of food which it consumes, its intestines are almost all stomach. This is usually by much the longest period of its existence. Having now laid up a store of materials for the development of the future perfect insect, it becomes a pupa; and during this inactive period the important process slowly proceeds, uninterrupted by the calls of appetite. At length the perfect insect is disclosed. It now often requires no food at all ; and scarcely ever more than a very small quantity; for the reception of which its stomach has been contracted, in some instances, to a tenth of its former bulk. Its almost sole object is now the multiplication of its kind, from which it is diverted by no other propensity ; and this important duty being performed, the end of its existence has been answered, and it expires.

It must be confessed that some objections might be thrown out against this hypothesis, yet I think none that would not admit of a plausible answer. To these it is foreign to my purpose now to attend, and I slsall conclude this letter by pointing out to you the variety of new relations which this arrangement introduces into nature. One individual unites in itself, in fact, three species, whose modes of existence are often as different as those of the most distantly related animals of other tribes. The same insect often lives successively in three or four worlds. It is an inhabitant of the water during one period; of the earth during another; and of the air during a thurd; and fitted for its various abodes by new organs and instruments, and a new form in each. Think (to use an illustration of Bonnet) but of the cocoon of the silk-worm! How many hands, how many machines does not this little ball put into motion! (if what riches should we not have been deprived, if the moth of the silk-worm had been born a moth, without having been previously a caterpillar! The domestic economy of a large portion of mankind would liave been formed on a plan altogether different from that which now prevails. 


\section{LETTER IV.}

\section{INJURIES CAUSED BY INSECTS.}

\section{DIRECT INJURIES.}

IN the letter which I devoted to the defence of Entomology, I gave you reason to expect, more effectually to obviate the objection drawn from the supposed insignificance of insects, that I should enter largely into the question of their importance to us both as instruments of good and evil. This I shall now attenipt; and, as I wish to leave upon your mind a pleasant impression with respect to my favonrites, I sluall begin with the last of these suljects-the injury which they do to us.

The Almighty ordains various instruments for the punishment of offend. ing nations; somctimes he breaks them to pieces with the iron rod of war; at others the elements are let loose against them; earthquakes and floods of fire, at his word, bring sudden destruction upon them; seasons unfriendly to vegetation threaten them with famine; the blight and mildew realise these threats; and often, the more to manifest and glorify his power, he employs means, at first sight, apparently the most insignificant and inadequate to effect their ruin; the numerous tribes of insects are his armies ${ }^{1}$, marshalled by him, and by his irresistible command impelled to the work of destruction: where he directs them they lay waste the earth, and famine and the pestilence often follow in their train.

The generality of mankind overlook or disregard these powerful, because minute, dispensers of punishment; seldom considering in how many ways their welfare is affected by them; but the fact is certain, that should it please (rod to give them a general commission against us, and should he excite them to attack, at the same tme, our bodies, our clothing, our houses, our cattle, and the produce of our fields and gardens, we should soon be refluced, in every possible respect, to a state of extreme wretcheciness; the prey of the most filthy and disgusting diseases, divested of a covering, unsheltered, except by caves and dungeors, from the inclemency of the seasons, exposed to all the extremitics of want and famine; and in the end, as Sir Joseph Banks, speaking on this sulject, has well observed ${ }^{2}$, driven with all the larger animals from the face of the earth. You may smile, perhaps, and think this a high-coloured picture, but you will recollect, I am not statiug the mischiefs that insects commonly do, iut what they would do, according to all probability, if certain counter-checks restraining them within due limits had not been put in action; and which they actually do, as you will see, in particular cases, when those counterchecks are diminished or removed.

Insects may be said, without hyperbole, to have established a kind of universal cmpire over the earth and its inhabitants. This is principally

1 Joel, ii. 25.

2 On the Blight in Corn, p. 9. 
conspicuous in the injuries which they occasion, for nothing in nature that possesses or has possessed animal or vegctable life is safe from their inroads. Neither the cunning of the fox, nor the swiftness of the horse or deer, nor the strength of the buffalo, nor the ferocity of the lion or tiger, nor the armour of the rhinoceros, nor the giant bulk or sagacity of the elephant, nor even the authority of imperial man, who bousts himself to be the lord of all, can secure them from becoming a prey to these despised beings. The air affords no protection to the birds, nor the water to the fish; insects pursue them all to their most secret conclaves and strongest citadels, and compel them to submit to their sway. Flora's empire is still more exposed to their cruel domination and ravages; and there is scarcely one of her innumerable subjects, from the oak, the glory of the forest, to the most minute lichen that grows upon its trunk, that is not destined to be the food of these next to nonentities in our estimation. And when life departs from man, the inferior animals, or vegetables, they become universally, sooner or later, the inheritance of insects.

I shall principally bespeak your attention to the injuries in question as they affect ourselves. These may be divided into direct and indirect. By direct injuries I mean every species of attack upon our own persons ; and by indirect, such as are made upon our property. To the former of these I shall confine myself in the present letter.

Insects, as to their direct attacks upon us, may be arranged in three principal classes. Those, namely, which seek to make us their food; those whose object is to prevent or revenge an injury which they either fear, or have received from us; and those which indeed offer us no violence, but yet incommode us extremely in other ways.

I hope I shall not too much offend your delicacy if I begin the first class of our insect assailants with a very disgusting genus, which Proviclence seerns to have created to punish inattention to personal cleanliness. But though this pest of man must not be wholly passed over, yet, since it is unfortunately too well known, it will not he at all necessary for me to enlarge upon its history. I shall only mention one fact which shows the astonishingly rapid increase of these animals, where they have once gotten possession. It is a vulgar notion, that a louse in twenty-four hours may see two generations; but this is rather overshooting the mark. Leeuwenlook, whose love for science overeame the nausea that such creatures are apt to excite, proves that their nits or eggs are not hatched till the eighth day after they are laid, and that they do not themselves commence laying before they are a month old. IIe ascertained, however, that a single female louse may, in eight weeks, witness the birth of five thousand descendants. ${ }^{1}$ You remember how wolves were extirpated from this country, but perhaps never suspected any monarch of imposing a tribute of lice upon his subjects. Yet we are gravely told that in IIIexico and Peru sucn a poll-tax was exacted, and that bags full of thęse treasures were found in the palace of Montezuma!!!? Were our own taxes paid in such coin, what little grumbling would there be!

Two other species of this genus, besides the common louse, are, in this

1 Leeuw. Epist. 9S. 1696.

2 Bingley, Aluim. Biogr. first edition, iii. 437. St. Picre's Studics, \&c., i. 312. 
country, parasites upon the human body.-But already I seem to hear you exclaim, "Why dwell so long on creatures so odious and nauseating, whose injuries are confined to the profanmm vulgus? Leave them therefore to the canaille - they are nothing to us." Not so fast, my friend recollect what historians and other writers have recorded concerning the Phthiriasis, or pedicular disease; and you must own that, for the quelling of human pride, and to pull down the high conceits of mortal man, this most loathsome of all maladies, or one equally disgusting, has been the inheritance of the rich, the wise, the noble, and the mighty; and in the list of those that have fallen victims to it, you will find poets, philosophers, prelates, princes, kings, and emperors. It seems more particularly to have been a judgment of God upon oppression and tyranny, whether civil or religions. Thus the inhuman Pheretima mentioned by Herodotus, Antiochus Epiphanes, the Dictator Sylla, the two Herods, the Emperor Maximin, and, not to mention more, the great persecutor of the Protestants, Philip the Second, were carried off by it.

I say by this malady, or one equally disgusting, because it is not by any means certain, though sone learned men have so sumposed, that all these instances, and others of a similar nature, standing also upon record, are to be referred to the same specific cause; since there is very sufficient reason for thinking that at least three different descriptions of insects are concerned in the various cases that have been handed down to us under the common name of Phthiriasis. As the subject of maladies connected with insects or produced by them, is both curious and interesting, although no writer, that $\mathrm{I}$ am aware of, has given a full consideration, and at the same time falls in with my general design, I hope you will not regard me as guilty of presumption, and of intruding into the province of medical men, if $I$ enter rather largely into it, and state to you the reasons that have induced me to embrace the above bypothesis, leaving you full liberty to reject it if you do not find it consonant to reason and fact. The three kinds of insects to which I allude, as concerned in eases that have been deemed Phthiriasis, are lice (Pediculi, L.), mites (Acari, L.), and Larvee in general. ${ }^{1}$

As far as the habits of the genus Pccliculus, whether inhabiting man or the inferior animals, are at present known, it does not appear from any well-ascertained fact, that the species belonging to it are ever subcutancous. For this observation, as far as it relates to man, I can produce the highest medical authority. "The louse feeds on the surface of the skin," says the learned Dr. Mead in his Medica Sacra; ant Dr. Willan, in his palmary work on Cutaneous Diseases, remarks with respect to the body-louse, " that the nits, or eggs, are deposited on the small hairs of the skin," and that "the animals are found on the skin or on the linen, and not under the cuticle, as some authors have represented.". And he further observes, that "many marvellous stories are related by Forestus, Schenkius, and others, respecting lice bred under the skin, and discharged in swarms from abscesses, strumous ulcers, and resications. The mode in which Pediculi are generated being now so well ascertained, no credit can be given to these accounts." "Thus far this great man, who however supposes (in

1 The terms Acariasis and Scholechiasis have been applied to the diseases produced by Acari and Larve. 
which opinion Di: Bateman eoneurs with him) that the authors to whom he alludes had mistaken for lice some other species of inseets, which are not unfrequently found in putrefactive sores.

If these observations be allowed their due weight, it will follow, that a disease produced by animals residing under the cuticle eannot be a true Phthiriasis, and therefore the death of the poet Aleman, and of Phereeydes Syrius the philosopher mentioned by Aristotle, must have been occasioned by some other kind of insect. For, speaking of the lice to which he attributes these catastrophes, he says that "they are produced in the flesh in small pustule-like tumours, which have no pus, and from which when punctured they issue."' For the same reason, the disorder which Dr. Heberden has deseribed in his Commentarics, from the communications of Sir E. Wilmot, under the name of Morbus pedicularis, must also be a different disease, sinee, with Aristotle, he likewise represents the insects as inhabiting tumours, from which they may be extracted when opened by a needle. He says, indeed, that in every respect they resemble the eommon lice, except in being whiter ; but medieal men, who were not at the same time entomologists, might easily mistake an Acarus for a Pediculıs. ${ }^{2}$

Dr. Willan, in one case of Prurigo senilis, observed a number of small insects on the patient's skin and linen. They were quick in their motion, and so minute that it required some attention to diseover them. He took them at first for small Pediculi; but muler a lens they appeared to him rather to be a nondescript species of Pulex ${ }^{3}$; yet the figure he gives has not the slightest likeness to the latter genus, while it bears a striking resemblance to the former. It is not elear whether his draughtsman meant to represent the insect with six or with einht legs: if it had only six, it was probably a Pedieulus; but if it had eight, it would form a new genus between the Acarina and the hexapod Aptera. Dr. Bateman, in reply to some queries put to him, at my lequest, by our common and lanented friend Dr. Reeve, relates that he understood from Dr. Willan, in conversation, that the insect in question jumped in its motion. This cireumstance he regards as conclusive against its being a Pediculus; but such a consequence does not necessarily follow, since it not seldom happens that inseets of the same tribe or genus either have or have not this fateulty; for instance, compare Scirtes with C'yphon, small beetles, and Acarus Scabiei with other Acari. ${ }^{4}$

Dr. Willan has quoted with approbation two eases from Amatus Lusitanus, which be seems to think correctly described as Phthiriasis. In one of them, however, which terminated fatally, the eircumstances seem rather hyperbolically stated - I mean, where it is said that two black servants had no other employment than earrying baskets full of these inseets to the sea!! Perhaps you will think I draw largely upon your eredulity if I call

1 Irist. Animal. 1. 5. c. 31.

2 From the terms employed by Aristotle and Dr. Nead in their accounts of these cases, it appears that the animal they meant could not be maggots, but something bearing a more gencral resemblance to lice.

3 On Cutaneous Diseases, 87, 88, and t. 7 . f. 4.

* Latreille at first considered this as belonging to a distinct genus from the common mite (Acarus domesticus), which he named Sarcoptes; but upon its being discovered that it also has mandibles, he suppressed it ( $N$. Dict. d'Hist. Nat. xxi. 221.); but it has been since resumed by M. Dugès and other authors. 
upon you to believe this; I shall therefore leave you to act as you please. - Thus much for pure Phthiriasis, which term ought to be confined to maladies produced by lice. I shall only further observe, that as many species as exist of these, wbich are the causes of disease, so many linds of Phthiriasis will there be. ${ }^{1}$

Acari, or mites, are the next insect sources of disease in the human species, and that not of one, but probably of many kinds, both local and general. 'They are distinguished firom Pediculi not only by their form, but also often by their situation, since they frequently establish themselves under the cuticle. With respect to local disorders, Dr. Aclams conjec. tures that Acari may be the cause of certain cases of Ophlhalmia. Sir J. Banks, in a letter to that gentleman, relates that some seamen belonging to the Endeavour brig, being tormented with a severe itching round the uxtremities of the eyelids, one of them was cured by an Otaheitan woman, who with two small splinters of bamboo extracted from between the cilia abundance of very minute lice, which were scarcely visible without a lens, though their motion when laid on the thumb was distinctly perceived. These insects were probably synonymous with the Ciron des paupières of Sanrages. ${ }^{2}$ - Le Jeune, a French physician quoted in Mouffet, describes a case, in which what seems a different species, since he calls them rather large, infested the white of the eye, exciting an intolerable itching. ${ }^{3}$ Dr: Mead, from the German Ephemerides, gives an account of a woman suckling her child, from whose breast procecded very minute vermicles. ${ }^{4}$ These were probably mites, and perhaps that species, which, from its feeding upon milk, Linné denominates Acarns Lactis. 'The great author last mentioned describes an insect, a native of America, uniler the name of Pediculus Ricinoides, which, upon the authority of Rolander, he informs us gets into the feet of people as they walk, sucks their blood, oviposits ${ }^{5}$ in them, and so occasions very daingerous ulcers. It would be an Acarus, he observes, but it has only six legs. Now Hermann affirms, that some species of Trombidizm (a genus separated by Fabricius from Acarus) have in no state more than six legs. ${ }^{6}$ Others of the tribe of Acarina, and the insect in question amongst the rest, may be similarly circumstanced; or those that Rolander examined might have been larva, which in this tribe are usually hexapods.

Liuné appears to have been of opinion that many contagious diseases are caused by mites. ${ }^{7}$ How far he was justified in this opinion I shall not here inquire; facts alone can decide the question, and observations made

1 For further information on this disease, see the valuable IIanual of Entomology by Dr. Burmeister, for an English translation of which we are indebted to Mir. Shuckard (p. 307.), where it is contended, but surely on inconclusive evidence, that Pediculus tubescentium, Alt. (Disscrtatio de Phthiriasis, Bonnx, 1820) is produced by spontaneous generation.

2 On Morbid Poisons, 306, 307.

4 Medica Sacra, 104, 105.

5 It is to be hoped this new word may be admitted, as the laying of eggs cannot otherwise be expressed without a periphrasis. For the same reason its substantive Oviposition will be employed.

6 IIém. Aptérologique, 19.

7 Insecta ejusmodi minutissima, forte Acaros diverse speciei causas esse diversorum morborum contagiosorum, ab analogia et expericntia hactenus acquisita, facili credimus negotio. Amon. Ac. r.94. 
by men acquainted with Entomology as well as the science of disease. Considerable deference and attention, however, are certainly due to the sentiments of so great a naturalist, in whom these necessary qualificitions were united in no common degree. With respect to the dysentery and the itch, he affirms that this had been manifested to his eyes. Yon will wish probably to know the arguments that may be adduced in confirmation of this opinion; I will therefore endeavour to satisfy you as well as I ain able. The following history given by Linné seems to prove the dysentery connected with these animals.

Rolander, a student in Entomology, while he resided in the house of the illustrious Swede, was attacked by the disease in question, which quickly gave way to the usual remedies. Eight days after it returned again, and was as before soon removed. A third time, at the end of the same period, he was seized with it. All the while he had been living like the rest of the family, who had nevertheless escaped. This, of course, occasioned no little inquiry into the cause of what had happened. Linné, aware that Bartholinus had attributed the dysentery to insects, which he professed to have seen, recommended it to his pupil to examine his freces. Rolauder, following this advice, discovered in them innumerable animalcules, which upon a close examination proved to be mites. It was next a question how he alone came to be singled out by them; and thus he accounts for it. It was his habit not to drink at his meals; but in the night, growing thirsty, he often sipped some liquid out of a vessel made of juniper wond. Inspecting this very narrowly, he observed, in the chinks between the ribs, a white line, which, when viewed under a lens, he found to consist of innumerable mites, precisely the same with those that he had voided. Various experiments were tried with them, and a preparation of rhubarb was found to destroy them most effectually. He afterwards discovered them in vessels containing acils, and often under the bungs of casks. ${ }^{1}$ In the instance here recorded, the dysentery, or diarrhœa, was evidently produced by a species of mite, which Linué hence called Acarus Dysenterice; but it would be going too far, I apprehend, to assert that they are invariably the cause of that disease.

That Scabies, or the itch, is occasioned by a mite, is not a doctrine peculiar to the moderns. Mouffet mentions Abinzoar, called also Avenzoar, a celebrated IIispano-Arabian physician of Seville, who flourished in the twelfth century, as the most ancient author that notices it. He calls these mites little lice that creep under the skin of the hands, legs, and feet, exciting pustules full of fluid. ${ }^{2}$ Joubert, quoted by the same author, describes them under the name of Sirones, as always being concealed beneath the epidermis, under which they creep like moles, gnawing it, and causing a most troublesome itching. It appears that Mouffet, or whoever was the author of that part of the Theatrum Insectornm, was himself also well acquainted with these animals, since he remarks that their habitation is not in the pustnle but near it; a remark afterwards confirmed by Linné ${ }^{3}$, and more recently by Dr. Adams. ${ }^{4}$ In common with the former of these authors,

1 Amœn. Ac. v. 94-98.

2 Mouffet, 266.

5 Acarus sub ipsa pustula minimè quarendus est, sed longrius recessit, sequendo rugam cuticule observatur. Aman. $A c$, v. 95. not. **.

4 Observations, \&e. 296. 
Mouffet further notices the effect of warmth upon them in exciting motion. ${ }^{3}$ Our intelligent conntryman also observes that they cannot be Pediculi, since they live under the euticle, which lice never do. ${ }^{2}$ In the epistle dedicatory, the editor speaks also of them as living in burrows which they have excavated in the skin near a lake of water; from which, if they be extracted with a needle and put upon the nail, they show in the sun their red head and the feet witl which they walk. ${ }^{3}$ And to close my veteran authorities, Junius thus explains the word Acarus, as I find him quoted in Gouldman's useful dictionary, "A small worm, which eats under the skin, and makes burrows in itching hands." 4

In more modern times, microscopical figures have been added to descriptions of the inseet. Bonomo first furnished this valuable species of elucidation. His figures, however, which are copied by Baker in his work on the microscope, are far from aceurate. ${ }^{5}$ Those of De Geer and Dr. Adams are much more satisfactory, and mutually confirm each other ${ }^{6}$ From them it is evident that the same insect inhabits the scabies of Sweden and Madeira. Dr. Bateman, in the letter before alluded to, informs his correspondent, that he had seen that from Madeira, and gives it as his opinion, that there cannot be a doubt of the cxistence of an Acarns Scabiei; an opinion which he repeats in his late work on Cutuneous Diseases, and which, according to Hermann ${ }^{7}$, has been also rendered unquestionable by Wichmann in his Etiologie de la Gale (Hanovre, 1786), a work I have not had an opportunity of consulting. From all this we may regard the point as so far settled that an animal of this kind exists at least as an occasional concomitant of scabies.

This fact being ascertained, a more complex inquiry remains, which branches out into two distinct questions. Is scabies always produced by these insects? Or, if this be not the casc, is the animate scabies a distinct disease from the inanimate?

It is very remarkable that Linné, a physician as well as a naturalist, and De Geer, one of the most accurate observers that ever existed, should both assign the insect in question as the undoubted eause of the common scabies of their country; the one applying to the disease he was speaking of the epithet of commmissima, and observing the fact to be notorious (crique liquet), and the other designating it by its well known French name, La Gale. ${ }^{8}$ And is it not equally remaikable that such

1 Extractus acu et super ungue positus, movet se si solis etiam calore adjuvetur. Ubi supr. Ungui impositus vix movetur : si vero oris calido halitu aftletur, agilis in ungue cursitat. Fn. Suec. 1975.

2 Teque Syrones isti sunt de pediculorum genere, ut Johannes Langius ex Áristotele videtur asserere: nam illi extra cutem vivunt, hi vero $110 n$. Ubi supr.

3 Imo ipsi Acari pra exiguitate indivisibles, ex cuniculis prope aqua lacum quos foderunt in cute, acu extracti et ungue impositi, caput rubrum, et pedes quibus gradiuntur ad solem produnt. p. vi.

4 Teredo sive exiguus vermiculus, qui subter cutem erodit agitque cuniculos in pruriginosis manibus. Gouldman tells us these Acari were also called Hand-uorms. Another English name is also given in Monffet, viz. Wheule-worms.

5 Osservazioni intorno à pellicclli del corpo umano fatte dal Dottor Gio. Cosimo Bonomo, \&c. f. 1-3. Baker, On Microsc. i. t.13.f. 2 .

6 De Geer, vii. t. 5. f. I2. 14 .

7 Mém. Aptérologique, 79.

I am informed by my learned friend Alexander MacLeay, Esq., late secretary 
men as John Hunter, Dr. Heberden, Dr. Bateman, Dr. Adams, and Mr. Baker, should never, in this conntry, have been able to meet with it? Did it indeed exist in our common scabies, it seems impossible that it could have escaped the observation of the two last of these gentlemen; Dr. Adams being so well qualified to detect it from his observations in Madeira, and Mr. Baker from his expertness in microscopical researches. Dr. Bateman, in the letter above quoted, says, "I have hunted it with a good magnifier in many cases of itch, both in and near the pustules, and in the red streaks or furrows, but always withont success." In his work on Cutaneous Diseases, he tells us, however, that he has seen it, in one instance, when it had been taken from the diseased surface by arother practitioner. And though Dr. Willan, in his book, speaks of the Acamis as the concomitant of this disease, yet his learned friend just mentioned observes, that he admitted that it was not to be found in ordinary cases, and indeed never seemed to have made up his mind upon the subject. When I was at Norwich, in 1812, Dr. Reeve very kindly accompanied me to the House of Industry there, to examine a patient whose body was very full of the pustulcs of this disorder; but though we used a good magnifier, we could discover nothing like an insect. I must observe, however, that our examination was made in Dicember, in severe weather, when the cold might, perhaps, render the animal torpid, and less easy to be discovered.

From the above facts it seems fair to infer that this animal is not invariably the cause of scabies, but that there are cases with which it bas no connection. Now, from this inference, would not another also follow, that the disease produced by the insect is specifically distinct from that in which it camnot be found? Sauvages and Dr. Adams are both of this opinion ${ }^{1}$, the former assigning to it the trivial name of rermicularis, and the latter proving by very satisfactory arguments that it is defferent from the other. If they were both animate diseases, but derived from two distinct species of animals (for it seems not impossible that even our common itch may be caused by a mite more minute than the other, and so more difficult to find), they would properly be considered as distinct species; much more, therefore, if one be animate and the other inanimate. Nay this, I should think, woulil lead to a doubt whether even their genus were the same. I shall disniss this part of my subject with the mention of a discovery of Dr. Adams, which seems to have escaped both Linné and De (ieer, that the Acarus Scrbiei is endowed with the faculty of leaping (in this respect resembling the insect found by Willan in Prurigo senilis nentioned above), for which purpose its four posterior thighs are in-

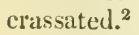

to the Linnean Society, that in the north of Scotland, the insect of the itch is well known, and easily discovered and extracted.

1 This opinion Dr. Bateman thinks probably the true one. Cutare. Dis. 197.

2 It may be mentioned here as a remarkable faet, that the Acarus Scalie $i$ was discovered by M. Latreille upon a New Holland quadruped (1'hascotomys fusca Geoffr.) of the Marsupian tribe. N. Dict. d'Hist. Nat. xxi. 22.2. Much light has recentiy been thrown on the history of Acarus Scaliei by $\mathrm{Ml}$. A. Dugès, who regards it as forming the clistinet genus Sarcoptes (Ann. de Sr. Nat.2nd. Serie, iii. 25.5.), and by MII. Linde, Iiemucci, Sédillot, and blainville, the last of whom has given a critisal 
But besides these Acarine diseases, there seems to be one (unless with Linné we regard the plague as of this class ${ }^{1}$ ) more fearful and fatal than them all. You will, perhaps, conjecture I am speaking of that deseribed by Aristotle and Sir E. Wilmot as the Phthiriasis, and your conjecture will be right." But some think, and those men of merited celebrity, that mites have nothing to do in these and similar cases, for that maggots were the parasites mistaken for lice. This, from the passage above quoted, appears to have been Dr. Willan's opinion, to which, in the letter so often referred to, Dr. Bateman subscribes, adding as a reason for excluding mites from being concerned, that "they are too minute, and never have been seen in such numbers as to be mistaken for lice." But both vary in size, some of the former being larger than some of the latter. And allowing them to be ever so minute, yet when they issue in swarms, as mites from a cheese, they would be very visible, were it only from their motion. Besides, as they are furnished with legs, their motions resemble those of lice infinitely more than do the contortions of maggots. So that a mite would be deemed a louse much sooner by an unentomological observer than would a maggot. Whether mites have ever been seen in such numbers as to be mistaken for liee, is the point in question, and therefore, by itself, cannot be admitted for a valid argument. Though Acarus Scatici does not appear to swarm in ordinary cases, yet this is certainly no reason why other species may not do so. Where it has once made a settlement, how incredibly, and in how short a space of time, does the Siro or cheese-nite multiply! Acarus destructor and many other species are equally rapid in their increase.-Millions of lice are said by Lafontaine, whom Hermann calls a very exact describer, to show themselves in Plica polonica, on the third day of the disease ${ }^{2}$; but whether the lastmentioned author be correct in thinking it more probable that they are mites ${ }^{3}$, I have not the means of judging.

I shall now produce two instances where mites were evidently concerned. Dr. Mead, from the German Ephemerides, relates the miserable ease of a French nobleman, from whose eyes, nostrils, mouth, and urinary passage, animalcules of a red colour, and excessively minute, broke forth day and night, attended by the most horrible and exeruciating pains, and at length occasioned his death. The account further says, that they were produced from his colrupted blood. This was probably a fancy originating in their red colour; but the whole history, whether we consiller the size and colour of the animals, or the places from which they issue, is inapplicable to larve or maggots, and agrees very well with mites, some of which, particularly Lcptus autumnalis, are of a bright red colour. The other ease, and a very similar one, is that recorled by Mouffet of Lady Penruddock, concerning whom he expressly tells us, that Acari swarmed in every part of her body-her head, eyes, nose, lips, gums, the soles of her feet, \&c., tormenting her day and night, till, in spite of evcry remedy, all the flesh of her body being consumed, she was at length relieved by death from this terrible state of suffering. Mouffet attributes her disease to the Acrarus Scabiei, but from the symptoms and

history of this parasite in bis report in the Nouv. Ann. du Mus. iv. 213. See also Raspail's Mémoire Comparatif sur t'Hist. N'at. de t'Insecte de la Gate.

1 Amøn. Ac. ubi supr. 101.

2 Traités de Chirargie, \&c. Leipsig, 1792. 5 Mém. Apterulug. 78. 
fatal result, it seems to have been a different and much more terrifie animal. He supposes in this instance the insect to have been generated by drinking goat's milk too copiously. This, if correct, would lead to a conjecture that it might have been the $A$. Lactis $\mathbf{L} .{ }^{1}$

These cases I lope will satisfy you that mites, as well as lice, are the cause of diseases in the human frame. This, indeed, as has been before observed, is allowed on all hands with respect to that of the itch; and it is, certainly, not more improbable that man should be exposed to the attack of several species of this genus, than that three or four kinds of Pediculus should infest him. If you are convinced by what I have written, you will concur with me in thinking that the one are as much entitled to give their name to the disease which they produce as the other; and the term Acariasis, by which, with due reverence to medical men, I propose to distinguish generically all acarine diseases, will not be refused its place amongst your Genera Morborum.

I shall now proceed to the remaining class of diseases mistaken for Phthiriasis; those, namely, which are produced by lavece. There are two

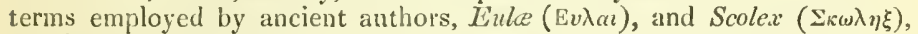
which seem properly to denote larva; but there is often such a want of precision in the language of writer's unacquainted with Natural History, that it is very difficult to make ont what objects they mean; and expressions which, strictly taken, should be understood of larvæ, may probably have sometimes been used to denote the cause of either the pedicular or acarine disease. Eiula, which term, thongh given by Hesychins as synonymous with Scolex, is by Plutarch used as of differert import ${ }^{2}$, scems properly to mean those larvæ which are generated in dead carcases, at. least so Homer lias more than once applied it ${ }^{3}$ : it is therefore a word of a much more restricted sense than Scolex, which probably belongs to the larvæ of every order of insects : for so Aristotle employs it, when he says that all insects produce a Scolex, or are larvyarous. ${ }^{4}$ Yet when Homer compares Harpalion stretched dead upon the ground to a Scolex ${ }^{5}$, it should seem as if he used the word for an earth-worn, which Aristotle commonly ealls by a figurative periphrasis, "Entrails of the earth." 6 In the Holy Scriptures this word is used to signify larve which prey upon and are the torment of living bodies. ${ }^{7}$ It may on this account, perhaps, be regarded as generally meaning such larvæ, to whatever order or genus they belong.

Dr. Mead, therefore, is most probably right when he eonsiders the disease stated by the ancients to be eaused by Eule or Scoleches, commonly translated worms, as distinct from Phthiriasis; and if so, the inhuman Pheretima, who swarmed with Eule, and Herod Agrippa, who was eaten of Scolcches $^{8}$, were probably neither of them destroyed either by Pediculi or Acari, but by larvæ or maggots. And when Galen prescribed a remedy for ulcers inhabited by Scoleches, observing that animals similar to those generated by putrid substances are often found in abscesses, he

1 A new species of mite has just been described by M. Simon, which lives in the diseased and normal hair-sacs of man. Mäller's Archiv. 1812, p. 278.
2 In Artaxerx.

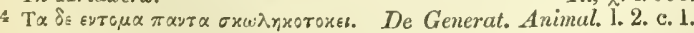
5 Il. v. 1.654, 655.

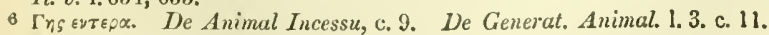
7 Mlark, ix. 44. 46. 48.

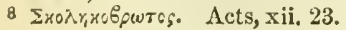


probably meant the same thing. The proper appellation of this genus of diseases wonld be Scolechiasis. ${ }^{i}$

This dissertation may perhaps appear to you rather prolix and tedious; yet to settle the meaning of terms is of the first importance. To inquire what ancient writers intended by the words which they employ, and whether such as have been usually regarded as synonymous are really so, may olten furnish us with a che to some useful or interesting truth; and not seldom enable us to rescue their reputation from much of the censure which has been inconsilerately cast upon it. Becanse they did not know everything, or so much as we do, we are too ajt to think that they knew nothing. That they fell into very considerable errors, especially in subjects connected with Natural History, cannot be denied; but then it onght to be considered that they possessed scarcely any of those advantages by which we are enabled to penetrate into nature's secrets. The want of the microscope alone was an effectual bar to their progress in this branch of science. Yet, in some instances, when they took a general view of a subject, they appear to have had very correct ideas. This observation particularly applics to the philosopher of Stagira, whose mighty mind and lyncean eye, in spite of those mists of prejudice and fable that enveloped the age io which he lived, enabled him in part to pierce through the gloom, and comprehend and behold the fair outline that gives symmetry, grace, and beanty to the whole of nature's form, though he mistook, or was not able to trice out, her less prominent features and minor lineaments.

It is now time to return from this long digression, which, however, is closely connected with the subject of this letter, to the point from which I deviated. Taking my leave of the disgusting animals which gave rise to it, I proceed to call your attention to another of our pigmy tormentors (Pulex irritans), which, in the opinion of some, seems to have been regarded as an agreeable rather than a repulsive object. "Dear miss," said a lively old lacly to a friend of mine (who had the misfortune to be confined to her bed by a broken limb, and was complaining that the fleas tormented her), don't you like fleas? Well, I think they are the prettiest little merry things in the world.-I never saw a dull flea in all my life." The celebrated Willoughby kept a favourite flca, which used at stated times to be admitted to suck the palm of his hand; and enjoyed this privilege for three months, when the cold killed it. And Dr. Townson, from the encomium which he bestows upon these vigilant little vaulters, as supplying the place of an alarum and driving us firm the bed of sloth, should seem to have regarded them with feelings much more complacent than those of Dr. Clarke and his friends, when their hopes of passing "one night free from the attacks of vernin" were changed into despair by the intormation of the langhing Sheik, that "the king of the fleas held his court at Tiberjas :" or than those of MM. Lewis and Clarke, who found them more tormenting than all the other plagnes of the Missouri country, where they sometimes compel even the natives to shilt their quarters. If you unhappily view them even in this unfivourable light, and have found ordinary methods unavailing for ridding yourself of these unbidden guests, I :an furnish you with a probatum est recipe, which the first-mentioned traveller telis us the Hungarian shepherds (who seem to have been

1 See Memoir by the Rer. F. Wr. Hope, containing a great number of cases of Sollechiasis, in the and volume of the Trans. of the Eint. Soc. of London. 
stupilly insensible to their value as alarums) find completely effectual to put to flight these insects and their neighbours the lice. This is not, as you may be tempted to think, by a remarkable aittention to cleanliness. Quite the reverse. - They grease their linen with hog's lard, and thus render themselves disgusting even to fleas! If this does not satisfy, I have another recipe in store for you. You may shoot at them with is cannon, as report says did Christina queen of Sweden, whose piece of artillery, of Lilliputian calibre, which was employed in this warfare, is still exhibited in the arsenal of Stockholm. ${ }^{1}$ But, seriously, if you wish for an effectual remedy, that prescribed by old Tusser, in the following lines, will answer your purpose :-

"While wormwood hath seed, get a handfull or twaine, To save against March, to make flea to refraine:

Where chamber is sweeped, and wormwool is strown, No tlea for his life dare abide to be known."

To this family belongs an insect, ahundant in the West Indies and South America, the attacks of which are infinitely more serious than those of the common flea. You will readily conjecture that I am speaking of the celebrated Chigoe or Jiggers, called also Nigua, Tungua, and Pique ${ }^{2}$ (Pulcx [Sarcopsylla] penetrans), one of the direst personal pests with which the sins of man have been visited. All disputes concerning the genus of this insect would have been settled long before Swartz's time (who first gave a satisfactory description and figure of it, proving it to be a Pulex, as has been observed above), had success attended the patriotic attempt of the $\mathrm{Ca}$ puchin friar recorded by Walton in his History of St. Domingo, who brought away with him from that island a colony of these animals, which he permitted to establish themselves in one of his fcet; but unfortunately for himself, and for science, the foot entrusted with the precious deposit mortified, was obliged to be amputated, and with all its inhabitants committed to the waves. According to Ulloa, and his opinion is confirmed hy Jussieu, there are two South American species of this mischievous insect. It is described as generally attacking the feet and legs ${ }^{3}$, getting, without being felt, between the skin and the flesh, usually under the nails of the toes, where it nidificistes and lays its eggs, which previously swell out the abdomen to a rreat size; and if timely attention be not paid to it, which, as it occasions no other uneasiness than itching (the sensation at first, I an assured, is rather pleasing than otherwise), is sometimes neglected, it multiplies to such a clegree, as to be attended by the most fatal consequences, often, as in the above instance, rendering amputation necessary, and sometimes causing death. ${ }^{4}$ The female slaves in the West Indies are frequently employed to extract these pests, which they do with uncommon dexterity. Yarico, so celebrated in prose and verse, performed this kiud office for

1 Linn. Lach. Lapp. ii. 32. note *.

2 Isatreille after 1 e Geer (vii. 153.) supposes the Pique and Nigua of Ulloa to be sinonymous with Ixodes americanus, L. Hist. Nat. vii. 364 ; but it is evident from IIlloc's descriptions (Voy. i. 63. Engl. Trans.) that they are synonymous with the Chigne, or Pulex penetrans.

3 Captain Hancock, late commander of His Majesty's ship the Foudroyant, to whose friendly exertions 1 am indebted for one of the finest collections of Brazil insects ever brought to England, informs me that they will attack any exposed part or the body. He had them once in his hand.

4 Piso and Margr. Ind 289. 
nonest Ligon, who says, in his History of Barbadoes, "I have had ten (Chegoes) taken out of my feet in a morning, by the most unfortunate Yarico, an Indian woman." Humboldt observes, "that the whites born in the torrid zone walk barefoot with impunity in the same apartment where a European recently landed is exposed to the attack of this animal. The Nigua therefore distinguishes what the most delicate chemical analysis could not distinguish, the cellular membrane and blood of a European from those of a creole white." 2

You have already, perhaps, been satiated with the account before given of our enemies of the Acarus tribe; there are a few, however, which I could not with propriety introduce there, as they do not take up their abode and breed in us, which nevertheless annoy us considerably. One of these is a hexapod so minute, that, were it not for the uncommon brilliancy of its colour, which is the most vivid crimson that can be conceived, it would be quite invisible. It is known by the name of the harvest-bug (Leptus autumnalis), and is so called, I imagine, from its attacking the legs of the labourers employed in the harvest, in the flesh of which it buries jtself at the root of the hairs, producing intolerable itching, attended by inflammation and considerable tumours, and sometimes even occasioning fevers. ${ }^{3}-\mathrm{A}$ similar insect is found in Brazil, abounding in the rainy season, particularly during the gleams of sunshine, or fine days that intervene, as small as a point, and moving very fast. These animals get upon the linen and cover it in a moment; afterwards they insinuate themselves into the skin and occasion a most intolerable itching. They are with difficulty extracted, and leave behind them large livid tumours, which subside in a day or two. An insect very tormenting to the wood-cutters and the settlers on the Mosquito shore and the bay of Honduras, and called by them the doctor, is thought to be synonymous with this. ${ }^{4}$ - More serious consequences have bcen known to follow the bite of another mite related to the above, if not the same species, common.in Martinique, and called there the Bête rouge. When our soldiers in camp were attacked by this animal, dangerous ulcers succeeded the symptoms just mentioned, which, in several cases, became so bad, that the limb affected was obliged to be taken off. ${ }^{5}$

I was once collecting insects in Norwood, near London, when my hands were covered by a number of small hungry ticks, which were so greedy after blood, that they penetrated deep into my flesh, giving me no little pain; and it was not without difficulty that 1 extracted them. " I suspect that this was the dog-tick (Irodcs Ricinus) which is often found on plants; but I am not certain, as I neglected to cxamine it, my attention at that time being almost wholly given to Coleoptera. Lyonnet seens to have been attacked, in one of his entomological excursions, hy the same or a similar insect, which he broke, so firmly had it fixed itself, in endeavouring to

1 P. 65.

2 Personal Narrative, E. T. v. 101. See Mr. Westwood's description of this insect (which, as before observed, he has separated as a distinct genus under the name of Sarcopsylla penetrans) in Trans. Lint. Soc. Lond. ii. 199.; and also Mr. Sell's observations on its economy and habits, ii. 196.

3 Natural Miscell. ii. t. 42.

4 Lindley in the Royal Military Chronicle for March 1515, p. 459.

5 I owe this information to the late Rubinsun Kittoe, Esq., formerly Cle:k of the Cheque in the King's Yard, Woolwich. 
extract it ; and he was obliged to lay open the place, lest an abscess should be formed. ${ }^{1}$ But the worst of all the tick tribe is the American (Ixodes americanus) described by Professor Kalm. This insect, which is related to the preceding, is found in the woods of North America, and is equally an enemy to man and beast. They are there so infinitely numerous, that if you sit down upon the ground, or upon the trunk of a tree, or walk with naked feet or legs, they will cover you, and, plunging their serrated rostrum into the bare places of the body, begin to suck your blood, going deeper and deeper till they are half buried in the flesh. Though at first they occasion no uneasiness, when they have thus made good their settlement, they produce an intolerable itching, followed by acute pain and large tumours. It is now extremely difficult to extract them, the animal rather suffering itself to be pulled to pieces than let go its hold; so that the rostrum and head, being often left in the wound, produce an inflammation and suppuration which render it deep and dangerous. These ticks are at first very small, sometimes scarcely visible, but by suction will swell themselves out till they are as big as the end of one's finger, when they often fall to the ground of themselves. ${ }^{2}$ The serrated laustellum of the ticks, which, like the barbed sting of a bee, cannot be extracted unless the animal co-operates, is well worth your inspection; and the species which infests our dogs is so common that you will have no difficulty in procuring one for examination. $^{3}$

$I$ have now introduced you to the principal insects of the Aplera order of Linné, which, in spite of all his care and all his power, assail the lord of the creation, and make him their food. You will here, however, perhaps accuse me of omitting one very prominent annoyer of our comfort and repose, which you think belongs to this tribe - the bed-bug (Cimex lcctularius). When you are a more practised entomologist, you will see clearly that this, though it has no wings, appertains to another order: nevertheless it may be introduced here without impropriety. Though now too common and well known in this country, it was formerly a rare insect. Had it not, two noble ladies, mentioned by Mouffet, would scarcely have been thrown into such an alarm by the appearance of bur-bites upon them; which, until their fears were dispelled by their physician, who happened also to be a naturalist, they considered as nothing less than synjtoms of the plague. Being shown the living cause of their fright, their fears gave place to mirth and laughter. ${ }^{4}$ Conmerce, with many good things, has also introduced amongst us many great evils, of which noxious insects form no small part; and one of her worst presents were doubtless the disgusting animals now before us. They seem, indeed, as the above fact proves, to have been prochuctive of greater alarm at first than mischief, at least if we may julge from the change of name which took place upon their becoming common. Their original English name was Chinche or Wall-louse ${ }^{5}$; and the term $\mathrm{Bug}$, which is a Celtic word, signifying a ghost or goblin, was applied to them after Ray's time, most probably because they were con-

1 Lesser $L$. ii. 222 . note*

2 De Geer, vii. 154. 160.

3 The renowned vemomous bug of Persia (Malleh de Mianch) has been aseertained to be a species of Argus by Count Fiseher de Waldheim.

4 Theatr. Ins. 270. This happened in 1503; which circumstance refutes Southall's opinion that bugs were not known in England before 1670 .

5 Rai, Ilist. Ins. 7. Mouffet, 269. They were called also punez, from the French punaise. 
sidered as "terrors by night."1 But however horrible bugs may have been in the estimation of some, or nauseating in that of others, many of the good people of London seem to regard them with the greatest apathy, and take very little pains to get rid of them; not generally, however, it is to be hoped, to such an extent as the predecessor of a corresfondent in Nicholson's Joumal, who found his house so dreadfully infested by them, that it resembled the Banian hospital at Surat ${ }^{2}$, all his endeavours to destroy them being at first in vain. And no wonder ; for, as he learned from a neighbour, his predecessor would never suffer them to be listurbed or his betsteads to be removed, till, in the end, they swarmed to an incredible degree, crawling up even the wails of his drawing-room; and after his death millions were found in his bed and chamber furniture. ${ }^{3}$

The winged insects of the order to which the bed-bug beiongs, often iuflict very painful wounds. - I was once attacked by a snall species. near Cimex Nemorum L. (Hylophila K.), which put me nearly to as much torture as the sting of a wasp. The water boatman (Notonecta glanca), an insect related to the Cimicide, which always swims upon its back, made me suffer still more severely, as if I had been hurued, by the insertion of its rostrum; but the wound was not followed by auy inflammation; and long before me Willoughby had made the same discovery and observation. ${ }^{4}$ st. Pierre, in his Voyage to Mauritius, mentions a species of bug found in that island, the bite of which is more venomous than the sting of a scolpion, and is succeeded by a tumour as bir as the egr of a pigeon, which continues for forl or five days. ${ }^{5}$ You are well acquainted with the history and properties of the Raia Torpedo and Gymmotus electrieus : but I dare aver, have no idea that any insect possesses their extraordinary powers. - Yet I can assure you, upon good authority, that Redurus scrratus, commonly known in the West Indies by the name of the whecl-bug, can, like them, communicate an electric shock to the person whose flesh it touches. The late Majorgeneral Davis, of the Royal Artillery, well known as a most accurate observer of nature, and an indefatigable collector of her treasures, as well as a most admirable paintcr of them, once informed me, that when abroad, having taken up this aninal and placed it upon his hand, it gave him a considerable shock, as if from an elcctric jar, with its legs, which he felt as

1 Hence our English word Bug-bear. In Matthews's Bible, Ps. xci, 5, is rendered, "Thou shalt not nede to be afraid of any bugs by night." The word in this sense oftens occurs in Shakspeare, Winter's Tule, act iii. sc. 2, 3. Hen. II. act r. sc. 2. Humlet, act v. sc. 2. See Douce's Iitustrations of Shakspeare, i. 329 . in quoting which work it may be observed that the author was a zealous entomologist. ( $L$ ife in Annual Obituary.)

2 The lianian hospital at Surat is a most remarkable institution. At my visit, the hospital contained horses, mules, oxen, sheep, goats, monkeys, poultry, pigeons, and a varjety of birls. The most extraordinary ward was that appropriated to rats and nice, bugs, and other noxious vermin. 'The overseers of the lospital frequently hire begrars from the streets, for a stipulated sum, to pass a night amongst the fleas, lice, and bugs, on the express condition of suffering them to enjoy their feast withont molestation. Forbes's Oriental Memoirs.

3 Nicholson's Journal, xvii. 40.

4 Proboscis in cutem intrusa acerrimum dolorem excitat, qui tamen brevi cessat. Rai, Hist. Ins. 58 .

5 'The Benchucha, or great black bug of the Pampas of South America, a species of Reduvius, is a far more obnoxions species than our common bed-bug. See C. Darwin's Personal Narrative, iii. 403. 
high as his shoulders; and, dropping the creature, he observed six marks upon his hand where the six feet had stood. ${ }^{1}$

You may now possibly think that I have nearly gone through the catalogue of our personal assailants of the insect tribes. If such, however, is your expectation, I fear you will be disappointed, since I have nany more, and some tremendous ones, to enumerate : but as a small compensation for such a detail of evils and injuries to which our species is exposed from foes seemingly so insignificant, and of acts of rebellion of the vilest and most despised of our subjects against our boasted supremacy, the objects to which I shall next eall your attention are not, like most of our apterous enemies, calculated to excite disgust and nausea when we see them or speak of them; nor do they usually steal upon us during the silent hours of repose (though I must except here the gnat or mosquito), but are many of them very beatiful, and boldly make their attack upon us in open day, when we are best able to defend ourselves. Borne on rapid wings, wherever they find us, they endeavour to lay us under contribution, and the tribute they exact is our blood. Wonderful and various are the weapons that enable them to enforce their demand. What would you think of any large animal that should come to attack you with a tremendous apparatus of knives and laneets issuing from its mouth? Yet such are the instruments by means of which the fire-eyed and blood-thirsty lorse-fly ('T'tbanus L.) makes an incision in your flesh ; and then, forming a siphon of them, often earries off many drops of your blood. ${ }^{2}$ The pain they inflict, when they open a vein, is usually very acute. A fly of this kind not only occasioned Mr. Sheppard considerable pain by its bite, but also produced swelling and blackness round one eye ; and the flesh of his cheek and chin was so enlarged from it as to hang down. And Mr. W. S. MacLeay thus deseribes to me the annoyance he suffered from one of them. "I went down the other day to the country, and was fairly driven out of it by the Hamatopola pluvialis, which attacked me with such fury, that although I did not at last venture beyond the toor without a veil, my face and hands were swelled to that degree as to be seareely yet recovered from the effects of their venom. I was ohliged, on my return to town, to stay two days at home. Whenever this insect bites me it has this effect, and I have never been able to discover any remedy for the torture it puts me to." In this country, however, the attacks of these flies are nsnally not frequent enough to make them more than a minor "misery of human life;" but the burning-fly (brûlot) or sand-fly of America ${ }^{3}$ and the West Indies, which seem to be the same inseet, catuses a much inore intolerable anguish, which has been compared to what a redhot needle or a spark of fire would occasion us to endure. Lambert, in

1 Two similar instances of effects on the human system, resembling electric shocks, produced by insects, have been communicated to the Entomological Society by Mr. Yarrell; one, mentioned in a letter from Lady de Grey, of Groby, in which the shock was caused by a beetle, one of the common Elaterida, and extended from the hand to the elbow on suddenly touching the insect; the other citused by a large hairy lepidopterous caterpillar, picked up in South America by Capt. Blakeney, R.N., who felt on touching it a sensation extending up his am, similar to an electric shock, of such force that he lost the ase of the arm for a time, and his life was even considered in danger by his medical attendant. (Trans, Ent. Soc. Lond, iii. proc. viii. $\mathrm{xxiii.)}$

2 One took eight drops from lieaumur, iv. 230.

3 Bartram's Travels, 383. 
his Travels throngh Canada, \&rc. says, "They are so very small as to be hardly pereeptible in their attacks; and your forehead will be streaming with blood before you are sensible of being amongst them ${ }^{\mathbf{1}}$;"- and Captain Back, in his Joumey to the Arctic Sea (p. 117.), speaking of the misery occasioned by these little tormentors, the lrûlots (including also mosquitos), observes, "There is certainly no form of wretchedness among those to which the chequered life of a Voyageur is exposed, at once so great and so humiliating, as the torture inflicted by these puny bloodsuckers. To avoid them is impossible. At last, subdued by pain and faticue, he throws himself in despair with his face to the earth, and half suffocated in his blanket, groans away a few hours of sleepless rest." We have one species (Slomoxys calcirans), alluded to in a former letter, as so nearly resembling the common house-fly, which, though its oral instruments are to appearance not near so tremendous, is a much greater torment than the horse-hy. This little pest, I speak feelingly, incessantly interrupts our studies and comfort in showery weather, making us even stamp like the cattle by its attacks on our legs; and, if we drive it away ever so often, retuming again and again to the charge. In Canada they are infinitely worse. "I have sat down to write," says Lambert (who though he calls it the house-fly, is evidently speaking of the Stomoxys), "and have been obliged to throw away my pen in consequence of their irritating bite, which has obliged me every moment to raise my hand to my eyes, nose, month, and ears in constant succession. When I could no longer write, I began to rcad, and was always obliged to keep one hand constantly on the move towards my head. S̈ometimes in the course of a few minutes I would take half a dozen of my tormentor's from my lips, between which I caught them just as they perched." "2

The swallow-fly (Cruterina Hirundinis ${ }^{3}$ ), whose natural food is the bird after which it is named, has been known to make its repast on the human species. One found its way into a bed of the Rev. R. Sheppard, where it first, for several nights, sorely annoyed a friend of his, and afterwards himself, without their suspecting the culprit. After a close search, however, it was discovered in the form of this fly, which, forsaking the nest of the swallow, had by some chance taken its station between the sheets, and thus glutted itself with the blood of man. - In travelling between Edam and Purmerend in North Holland (July 21. 1815), in an open vehicle, I was mach teased by another bird-Ay (Ornilhomyia avicularia) (two individuals of which I caught) alighting on my head, and inserting its rostrum into my flesh.-Mr. Sheppard remarks, as a reason for this dereliction of their appropriate food, that no sooner does life depart from the bird that these fies infest than they immediately desert it and take flight, alighting upon the first living creature that they meet with; which if it be not a bird they soon quit, but, as it should seem from the above fuets, not before they have made a trial how it will suit them as food.

But of all the insect-tormentors of mau, none are so loudly and universally complained of as the species of the genus Culcx L., whether known by the name of gnats or mosquitos. ${ }^{4}$ Pliny', after Aristotle, distinguishes

1 i. 127. The West India sand-fly was noticed by the late Robinson Kittoc, Esq., who howerer did not recollect their fetching blood.

2 Travels, Sc. i. 126 .

3 See Curtis's Brit. Ent. t. 122.

4 It has been generally supposed by naturalists, that the Mosquitos of America belong to the Linnean genus Culex; but the celebrated traveller Humboldt asserts 
well between Hymenoptera and Diptera, when he says the former have their sting in the tail, and the latter in the mouth; and that to the one this weapon is given as the instrunent of vengeance, and to the other of avidity. ${ }^{1}$ But the instrument of avidity in the genus of which I am speaking, is even more terrible than that of vengeance in most insects that are armed with it ; like the latter also, as appear's from the consequent inflammation and tumour, it instils into its wound a poison; the principal use of which, however, is to render the blood more fluid, and fitter for suction. This weapon, which is more complex than the sting of hymenoptcrous insects, consisting of five pieces besides the exterior sheath, some of which seem simply lancets, while others are barbed like the spicula of a bee's sting, is at once calculated for piercing the flesh and forming a siphon adapted to imbibe the blood. ${ }^{2}$ There are several species of this genus whose bite is severe, but none is to be compared to the common gnat (Culex pipiens L.), if, as has been generally affirmed, it be synonymous with the mosquito (though, in all probability, several species are confounded under both names); and to this, the most insatiable of bloodsuckers, I shall principally direct your attention. ${ }^{3}$

In this country they are justly regarded as no trifing evil; for they follow us to all our haunts, intrude into our most secret retirements, assail us in the city and in the country, in our houses and in our fielcls, in the sun and in the shade; nay, they pursue us to our pillows, and either keep us awake by the ceaseless hum of their rapid wings (which, according to the Baron C. de Latour, are vibrated 3000 times per minute ${ }^{4}$ ), and their incessant endeavours to fix themselves upon our face, or some uncovered part of our body; or if in spite of them wo fall asleep, awaken us by the acute pain which attends the inscrion of their oral stings; attacking with most avidity the softer sex, and trying their temper by clisfiguring their beauty. But although with us they are usually rather teasing than injurious, yet upon some occasions they have approached nearer to the character of a plague, and emulated with success the mosquitos of other climates. Thus, we are told that in the year 1736 they were so numerons, that rast columns of them were seen to rise in the air from Salisbury Catliedral, which at a distance resembled columns of smoke, and occasioned many people to

that the term Mosquito, signifying a little fly, is applied there to a Simulium Latr. (Simulia Meig.), and that the Culices, which are equally numerous and annoying, are called Zuncudoes, which means long legs. 'The former, he says, are what the French call Moustiqucs, and the latter Afuringouins. (Personal Aurrative, T. T. v.93.) IIumboldt's remark, lowever, refers only to South America; Mr. Westwood informing ns that Mosquito is certainly applied to a species of Culex in the United States, the inliabitants giving the nane of black-fy to a small simulium. See "An Introduction to the Modern Classification of Insects, by J. O. Westwood, F.L.S." 2 rols. Lond. 1839-184l (ii. 510.), a work invaluable to the entomologist both for its systematic details and vast mass of original and collected facts relative to the aflinities, babits, and economy of insects.

1 Plin. Hist. Nat. 1. xi. c. 28. Aristot. Hist. Animal. 1. i. c. 5.

2 Pliny was aware of this double office of the proboscis of a gnat, and has well described it. "Telum vero perfodiendo tergori quo spiculavit ingenio? Atque ut in eapaci, cum cerni non possit exilitas, ita reciproca geminavit arte, ut fodicndo acuminatum pariter sorbendogue, fistulosmon esset." IIist. Nat. 1. xi. c. 2.

3 Humboldt has described several South American species. Personal Narrative, v. 97. note*. Engl. Tr.

* Westwood, Mod. Clas, of Ins. ii. 509. 
think that the cathedral was on fre. A similar oceurrence, in like manner giving rise to an alarm of the chureh being on fire, took place in July 1812 at Sagan in Silesia. ${ }^{1}$ In the following year at Norwich, in May, at about six o'clock in the evening, the inhabitants of that city were alarmed by the appearance of smoke isstung from the upper window of the spire of the cathedral, for which at the time no satisfactory account could be given, but which was most probably produced by the same cause. And in the year 1766, in the month of August, they appeared in such incredible numbers at Oxford as to resemble a black cloud, darkening the air, and almost totally intercepting the bcams of the sun. One day, a little before sunset, six columns of them were observed to aseend from the boughs of an appletree, some in a perpendicular and others in an oblique direction, to the height of fifty or sixty feet. Their bite was so envenomed, that it was attended by violent and alarming inflammation: and one when killed usually contained as much blood as would cover three or four square inches of wall." Our great poet spenser seems to have witnessed a similar appearance of them, which furnished him with the following beautiful simile:-

"As when a swarme of gnats at eventide
Out of the fennes of Allan doe arise,
Their murmuring small trumpets sownden wide,
Whiles in the air their clist'ring army tlies,
That as a cloud doth seem to dim the skies:
Ne man nor beast may rest or take repast
For their sharp wounds and noyous injuries.
Till the fierce northern wind with blust'ring blast
Doth blow them quite away, and in the ocean cast."

In Marshland in Norfolk, as I learn from a lady who had an opportunity of personal inspection, the inhabitants are so annoyed by the gnats, that the better sort of them, as in many hot climates, have recourse to a gauze covering for their beds, to keep them off during the night. Whether this practice obtains in other fen districts I do not know. ${ }^{3}$

But these evils are of small account compared with what other eountries, especially when we approach the poles or the line, are destined to suffer from them: for there they interfere so much with ease and comfort, as to become one of the worst of pests and a real misery of human life. We may be disposed to smile perhaps at the story Mr. Weld relates from General Washington, that in one place the musquitos were so powerful as to picre through his boots ${ }^{4}$ (probably they crept within the boots): but in various regions scarcely any thing less impenetrable than leather can withstand their insinuating weapons and unwearied attacks. One would at first imagine that regions where the polar winter extends its icy reign would not be much annoyed by insects : but however probable the supposition, it is the reverse of fact, for nowhere are gnats more numerous. These animals, as well as numbers of the 'Tipularia of Latreille, seem en-

1 Germar's Magazin de Entomologie, i. 137.

2 Philos. Trans. 1767, 111. 113. I once witnessed a similar appearance at Maidstone in Kent.

3 A small British species of Cerutopogon (one of the midge family of Tipulida) is occasionally very troublesome by settling upon the uncovered parts of the body and sucking the blood.

4 Well's Travels, 8vo. edit. 205. Yet Mouffet affirms the same: "Morsu crudeles et venenati, triplices caligas, imo ocreas, item perforantes." 81. 
dowed with the privilege of resisting any degree of cold, and of bearing any degree of heat. In Lapland thcir numbers are so prodigious as to be compared to a flight of snow when the flakes fall thickest, or to the dust of the earth. The natives cannot take a mouthful of food, or lie down to sleep in their cabins, unless they be fumigated almost to suffocation. In the air you cannot draw your breath without having your mouth and nostrils filled with them; and unguents of tar, fish-grease, or cream, or nets steeped in fetid birch-oil, are scarcely sufficient to protect even the ease-hardened cuticle of the Laplander from their bite. I In certain districts of France, the accurate Reaumur informs us that he has seen people whose arms and legs have become quite monstrous from wounds inflicted by gnats; and in some cases in such a state as to render it doubtful whether amputation would not be necessary. ${ }^{2}$ In the neighbourhood of the Crinea the Russian soldiers are obliged to slecp in sacks to defend themselves from the mosquitos; and even this is not a sufficient security, for several of them die in consequence of mortification produced by the bites of these furious blood-suckers. This fact is related by Dr. Clarke, and to its probability his own painful experience enabled hin to speak. He informs us that the bodies of himself and his companions, in spite of gloves, clothes, and handkerchiefs, were rendered one entire wound, and the consequent excessive irritation and swelling excited a considerable degree of fever. In a most sultry night, when not a brcath of air was stirring, exhausted by fatigue, pain, and heat, he songht shelter in his carriage; and though ahmost suffocated, could not venture to open a window for fear of the mosquitos. Swarms nevertheless found their way into his hiding-place; and, in spite of the handkerchiefs with which he had bounu up his head, filled his mouth, nostrils, and ears. In the midst of his torment he succeeded in lighting a lamp, which was extinguished in a moment by such a prodigious number of these insects, that their carcases actually filled the glass chimney, and formed a large conical heap over the burner. The noise they make in flying cannot be conceived by persons who have only heard gnats in England. It is to all that hear it a most fearful sound. ${ }^{3}$ 'Travellers and mariners who have visited warmer climates give a similar account of the torments there inflicted by these Jittle demons. One traveller in Africa complains that after a fifty miles jommey they would not suffer him to rest, and that his fice and hands appeared, from their bites, as if he was infected with the small-pox in its worst stage. ${ }^{4}$ In the East, at Batavia, Dr. Arnold, a most attentive and accurate observer, relates that their bite is the most venomous he ever felt, occasioning a most intolerable itching, which lasts several days. The sight or sound of a single one either prevented him from going to bed for a whole night, or obliged him to rise many times. This species, which I have examined, is distinct from the common gnat, and appears to be nondescript. It approaches nearest to C. ammulatus, but the wings are black and not spotted. And Captain Stedman in America, as a proof of the dreadful state to which he and his soldiers were reduced by them, mentions that they were forced to sleep with their heads thrust into holes made in the earth with their bayonets, and their necks wrapped round with their hammocks. ${ }^{5}$

\footnotetext{
1 Acerbi's Travels, ii. 5. 34, 35. 51. Linn. Flor. Lapp. 380, 381. Laeh. Lapp. ii. 108. De Geer, vi. 303,504 .

5 Dr. Clarke's Travels, i. 388.

5 Trucels, ii. 93 . Mr. WW. S. MacLeay, in a letter I received from him, ob-
} 
From Humboldt also we learn that "between the little harbour of Higuerote and the mouth of the Rio Unare the wretched inhabitants are accustomed to stretch themselves on the ground, and pass the night buried in the sand three or four inches deep, leaving ont the head only, which they cover with a handkerchief." This illustrious traveller has given an account in detail of these insect plagues, by which it appears that amongst them thcre are diurnal, crepuscular, and nocturnal species, or genera: the MTosquitos or Sinulia flying in the day; the Temporaneros, probably a kind of Culex, fiying during twilight; and the Zancudos or Culices in the night. So that there is no rest for the inhabitants from their torment day or night, except for a short interval between the retreat of one species and the attack of another. We learn from this author that the sting or bite of the Simulium is as bad as that of the Stomoxys before noticed. ${ }^{1}$

The Rhagio Columbaschensis of Fabricius, a native of Banat and the adjacent parts of the banks of the Danube, is a species of Simulium, and one of the most obnoxions of all the insects which attack man and clomestic animals. (See Köllar's work on Obnoxions Insects; a translation of part of which, by the Misses Loudon, has recently been published. The work of Pohl and Köllat on the obnoxious insects of Brazil also contains many notices of their attacks upon man.)

It is not therefore incredible that Sapor, king of Persia, as is related, should have been compelled to raise the siege of Nisibis by a plague of gnats, which, attacking his elephants and beasts of burthen, so caused the rout of his army, whatever we may think of the miracle to which it was attributed $^{2}$; nor that the inhabitants of various cities, as Mouffet has collected from different authors ${ }^{3}$, should, by an extraordinary multiplication of this plague, have been compelled to desert them; or that by their power to do mischief, like other conqueror's who have been the torment of the human race, they should have attained to fame, and have given their name to bays, towns, and even to considerable territories. ${ }^{4}$

served, speaking of his residence at the IIavana. "The disagreeables are ants, scorpions, mygales, and mosquitos. The latter were quite a pest on my first arrival within the tropies; but now I mind them abont as much as I did gnats in England."

1 Humboldt's Personal Narrative, E.T. v. 87. Most writers by the term mosquitos meau guats; ancl for them it is chietly employed, but may be regarded as including both plagues.

2 Theodorit. Hist. Eccl. 1. ii. c. 30.

5 Moufiet, 85. Amoreux, 119.

4 Viz. Mosquito Bay in St.Christopher's; Mosquitos, a town in the Island of Cuba ; and the Mosquito country in Nortls America. Though in many cases it may be impossible to prevent the attacks of guats, it is certain that a little eare would often secure the inmates of houses, distant from stagnant waters, from these pests, for which they have solely to thank their open water-tubs or cisterns in their gar.dens, in which they are constantly breedirg. Ds. Franklin, whose admirable habit of minute observation embraced all subjects, long since pointed this ont, and I myself found that the gnats which so annoyer us in the honse we occupied at Pisa late in the antumn of 1830 , as to require gauze mosquito curtains to all the beds, thongh it was far distant from the river or any pond, all proceeded from an open ornamental stone cistern in the garden, constantly left half full of water; and I am persuaded that to a similar canse may be chiefly attributed the gnats so often found in continental towns not situated near to canals or stagnant jools. The remedy is equally obvious and easy. Either open water-tubs and eisterns should be proseribed, or a few small fish kejt in them to destroy the larva of the guats as fast as they breed Trees being 
And now, which seems to you the greatest terror, that the forest should resound with the roar of the lion or the tiger, or with the hum of the gnat? Which evil is the most to be deprecated, the neighbourbood of these ferocinus animals, terrible as they are for their cruelty and strength, or to live amidst the polar or tropical inyriads of mosquitos, and be subject to the torture of their incessant attacks: When you consider that from the one, prudence and courage may secure or defend us without any material sacrifice of our daily comforts; while to be at rest from the other, we must either render ourselves disgusting by filthy unguents, or be suffocated by fumigations, or be content to be bound, head, hand, and foot, shut out from the respiration of the common air, and even thus scarcely escape from their annoyance; you will feel convinced that the former is the more tolerable evil of the two, and be inclined to think that those cities, from which the lions were driven away by the more powerful gnats, were no great gainers by the exchange. ${ }^{1}$ With what grateful hearts ought the privileged inhabitants of these happy islands to acknowledge and glorify the goodness of that kind Providence which has distinguished us from the less favoured nations of the globe, by what nay be deemed an immunity from this tormenting pest! for the inroads which they make on our comfort, when contrasted with what so many other neople of every climate suffer from them, are mere nothing. When we behold on one side of us the ravages of the wide-wasting sword, on another those of infectious disease or pestilence, on a third famine destroying its myriads, and on a fourth life rendered uncoinfortable by the terror of " noisome beasts," and the attack of noxious insects; and when we look at home and see every one eating his bread in peace, protected in his enjoyments by equal laws without fearing the sword of the oppressor; not scourged by pestilence or famine, exposed to the attack of no ferocious animal, and comparatively speaking but slightly visited by the annoyance of insect tormentors; and especially when we firther reflect that it is his mercy and not our merits which has induced him thus to overwhelm us with blessings, while other countries have been made to drink deep of the cup of his fury, we shall sce reason for an increased degree of thankfulness and gratitude, and, instead of repining, be well content with our lot, though our offences have not wholly becn passed over, and we have been "beaten witi few stripes."

Besides the insects that seek to make us their food, there are others which, although we are apt to regard them witl the greatest horror, do not attack us with this view, but usually to revenge some injury which they have received, or apprehend from us. Foremost in the list of these are those with four wings, which, according to the observation of Pliny before quoted, carry their weapon, an instrument of revenge, in their tail.

generally found to harbour gnats, are, on this account, banished from the neighbourhood of dwelling houses in America and other hot countries, to the great loss of the occupants in other respects; but I have been informed by a friend that at 'Trieste it has been observed that horse-chestnnt trees planted near a house, so fur from encouraging gnats, irive them away, none ever appearing in houses surrounded with these trees, though abundant where other kinds prevail, a fact which, if contirmed in other comntrics, would be well worth acting upon.

1 Mouffet, 85 . 
These all belong to the Linnean order Hymenoptera; and the tremendous arms with which they annoy us, are two darts finer than a hair, furnished on their onter side at the end with several barbs not visible to the naked eye, and each moving in the groove of a strong and often curved sheath, frequently mistaken for the sting, which, when the darts enter the flesh, usually injects a drop of subtle venom, furnished from a peculiar vessel in which it is secreted, into the wound, occasioning, especially if the darts be not extracted, a considerable tumoul, accompanied by very acute pain. Many insects are thus armed and have this power. Twice I have been stung by an Iehneumon; first by one with a concealed sting, and afterwards by another of the family of Pimpla Manifestatur, with a very long exserted one. I had held the insect by its sting, which it withdrew from between my fingers with surprising force, and then, as if in revenge, stung ne. Pompilus viaticus, one of the spider-wasps, once, in this way, gave me acute pain. Mr. IV. S. Macleay states that at the Havana he was once stung by a gigantic Pompilus (probably P. Heros), from which he suffered a very short-lived pain, but the wound bled as if punctured by a pin. The bleeding, he conjectures, carried off the venom. But the insects which in this respect principally attract our notice by exciting our fears, are the hive-bee, the wasp, and the hornet. The first of these, the bee, sometimes manifests an antipathy to particular individuals, whom it attacks and wounds without provocation; but the two last, though apparently the most formidable, are not so ill-tempered as they are conceived to be, seldom molesting those who do not first interfere with or disturb them. We learn from Scripture that the homet (but whether it was the comimon species is uncertain) was employed by Providence to drive out the impious inhabitants of Canaan, or subdue them under the hands of the Istaelites. ${ }^{1}$ - The effect produced by the sting of these animals is difierent in different persons. To some they oceasion only a very slight inconvenience or a momentary pain; otheis feel the smart of the wounds which they inflict for several days, and are thrown into fevers by them; and to sone they have even proved fatal. ${ }^{2}$ Yet these insects are certainly, in general, but a trifing evil. They become, however, especially wasps, a very serious one to many, from the mere dread of being stung by then, even though they should not carry their fears to the same length with the lady mentioned by Dr. Finirfax ${ }^{3}$, in the Philosophical Transactions, who bad such a horror of them that during the season in which they abound in houses, she always confined herself to her apartment. An insect of a tribe never hefore suspected of being endowed with such a mode of annoyance, one of the order Lepidoptera, found at the Cape of Good Hope, is said to dcfend itsclf when captured by stinging, whence it is there named the Bee-moth, and it is added that the puncture, which is very painful, is speedily followed by swelling and inflammation. ${ }^{4}$

Ants are insects of this order, which, though our indigenous species may be regarded as harmless, in some countries are gifted with double means of annoyance, both firom their sting and their bite. A green kind in New Sonth Wales was observed by Sir Joseph Banks to inflict a wound

1 Deut. vii. 20. Josh. xxir. 12.

2 Amoreux, 242.

3 Trilos. Trans, i. 201 .

4 Oken's Isis, 1831, p. 1917., from a letter received by Dr. Reich, from the Cape of Good Ilope, quoted in Burmeister's Manual of Ent. p. iss1. 
scarcely less painful than the sting of a bee. ${ }^{1}$ Another, from the intolerable anguish occasioned by its bite, which resembles that produced by a spark of fire and seems attended by venom, is called the fire-ant. Captain Stedman relates that this caused a whole company of soldiers to start and jump about as if scalded with boiling water; and its nests were so numerous that it was not easy to avoid them. ${ }^{2}$ We are told of a third species, which emulates the scorpion in the malignity of its sting or bite. ${ }^{3}$ Knox, in his account of Ceylon, mentions a black ant, called by the natives Coddia, which he says "bites desperately, as bad as if a man were burnt by a coal of fire; but they are of a noble nature, and will not begin unless you disturb them." The reason the Cinghalese assign for the horrible pain occasioned by their bite is curions, and will serve to amuse you. "Formerly these ants went to ask a wife of the Noya, a venomous and noble kind of snake; and because they had such a high spirit to dare to offer to be related to stich a generons creature, they had this virtue bestowed upon them that they should sting after this manner. And if they had obtained a wife of the Noya, they shonld have had the privilege to sting full as bad as he." 4 Stedman's story of a large ant that stripped the trees of their leaves, to feed, as was supposed, a blind serpent under ground $^{5}$, is somewhat akin to this: as is also another, related to me by a friend of mine, of a species of Mantis, now in ny cabinet, taken in one of the Indian Islands, which, according to the received opinion amongst the natives, was the parent of all their serpents. Whence, umless perhaps from their noxious qualities, could this idea of a connexion between insects and these reptiles be derived? But to return from this digression Madame Merian's Ant of Visitation (Atta cephalotes) will he considered in a subsequent letter : but I cannot here onit a circumstance mentioned by Don Felix de Azara, a Spanish traveller, who confirms her account, that these animals are so alarming and tremendous in their attacks, that if they enter a bouse in the night, the inhabitarts are obliged to rise with all speed and run off in their shirts.

I must next direct your attention to an insect, which perhaps more than any other has been in every age an object of terror and abhorrence - I mean the redoubted scorpion. And though I shall not, with Aristotle, tell you of Persian kings enploying armies for several days in destroying them; or, with Pliny, of comtries that they have depopulated; yet my account will not be devoid of that species of interest which the dread of its powel to do us injury imparts to any object. Could you see one of these ferocious animals, perhaps a foot in length, a size to which they sometimes attain, advancing towards you in their usual menacing attitude, with its claws expanded, and its many-jointed tail tirned over its head ; were your heart ever so stout, I think you would start back and feel a horror come across you; and though you knew not the animal, you would conclude that such an aspect of malignity must be the precursor of malignant effects. Nor would you be mistaken, as you will presently see. This alarming animal, though, like hymenopterous insects, it is armed with a sting, is in no respect related to that order, and forms the only genus, at present known, of the others that is so armed. Even its sting is totally different

1 Hawkesworth's Cook, iii. 223.

5 Bingley, iii. 385 . first edit.
2 Stedman, ii. 94.

4 Knox's C'eylon, 24.
Stedman, ii. 142. 
from that of bees, wasps, and other Hymenoptera, being more analogous to the venomous tooth of serpents; it wounds us with no barbed darts concealed in a sheath, but only with a simple incurved mucro terminating an ampullaceous joint. Two orifices, or, according to some, three, are said to instil the poison, which, we are inforned, is sometimes as white as milk. This venom in our European species is seldom attended, accept to minor animals, by any very serious consequences; yet when it is comnunicated by the scorpion of warmer clinutes it produces more baneful effects. The sting of certain kinds common in South America causes fevers, numbness in various parts of the body, tumours in the tongue, and dimness of sight, which syniptoms last fron twenty-four to forty-eight hours. The only means of siving the lives of our soldiers who were stung by them in Eqypt, was amputation. (One species is said to occasion maduess; and the black scorpion, both of South American and Ceylon, frequently inflicts a mortal wound. ${ }^{1}$ No known animal is more cruel and ferocious in its manners; they kill and devour their own young without pity as soon as they are born, and they are equally savage to their fellows when grown up. Terrible however and revolting as these creatures appear, we are gravely told by Naudé, that there is a species of scorpion in Italy which is domesticated, and put between the sheets to cool the beds during the heats of summer!!?

I nust next say something of insects that annoy us solely by their jaus. Of this description is (raleodes aranevides, which is related to the scorpion, although devoid of a sting. The bite of this animal, which is a native of the Cape of Good Hope and of Russia ${ }^{3}$, is represented to be often fatal both to man and beast. Another species of Galcodes is described by Professor Lichtenstem, which, from the trivial name that he has given it (futalis), may be supposed to be as venomous as the former. ${ }^{4}$

The bite of one of the centipedes (Scolnpendra morsitans) - the under jaws, or rather arms, of which are armed with a strong clisw, furnished like the sting of the scorpion with an orifice, visible under a common lens, from which poison issues - is less tremendous than that of the animal last mentioned: but though not mortal, its wounds are more painful than those produced by the sting of the scorpion; and as these animals creep everywhere, even into beds, they nust be very anno ing in warm climates where they abound. Dr. Martin Lister in his Travels, has given us a figure of an insect related to this genus, that he saw in Plumier's collection, which appear's to have been eighteen inches in length, and three quarters of an inch in width, having ninety-five legs on each side, the first eight of which are armed with donble claws, and two inches of the tiil being without legs. It may form a distinct gerus, and is probably a native of Sonth America. Yet even this monstrons insect is nothing to those at Carthagema, mentioned by Ulloa (if indeed we may credit his account, or if his translator has not mistaken his meaning), which sometimes exceeded a yard in length and five inches in breadth! The bite of this gigantic serpent-like creature, he tells

1 Ulloa's Toy. i. 61, 62. Dr. Clarke's Travels, i. 486. Amoreux, 197. Mr. W. S. NacLeay relates to me that soon after his arival at the Havana he wasstung by an immense scorpion, but was agreeably surprised to find the pain considerably less than the sting of a wasp, and of incomparably shorter duration.

2 Andrew's Anecdotes, 427. See on the subject of Scorpions, Amoreux, 41-54. $176-205$.

3 Fib. Suppl, 294. 2.

\& Catal. Ilum, 1797, 151-195. 
us, is mortal, as well it may, if a timely remedy be not applied. From its cylindrical form it should be a Julus. ${ }^{1}$

In this catalogue of noxious insects I nust not omit those which everywhere force themselves upon our notice, and are viewed with general clisgust. I mean the numerous family of Arachne, the insidious spiders. Few of these, however, are really personal assailants of man. The principal is that which has given rise to so mueh discussion, and has so much employed the pens of naturalists and physieians - the fumous Taranlula (Lycosa Tarentula). The effects ascribed to its wounds, and their wonderful eure supposed to be wronght by music and dancing, have long been eelebrated: but after all there seems to have been more of fraud than of truth in the business : and the whole evil appears to consist in swelling and inflammation. Dr. Clavitio submitted to be bitten by this animal, and no bad effects ensued; and the Count de Borch, a Polish nobleman, bribed a man to undergo the same experiment, in whom the only result was a swelling in the hand, attended by intolerable itching. The fellow's sole remedy was a bottle of wine, which charmed away all his pain without the aid of pipe and tabor. ${ }^{2}$

There is, however, a spider (Theridium 13-guttatum) the bite of which is said to be very dangerous, and even mortal. Thiébaut de Berneaud, in his Toyage to Elba ${ }^{3}$, affinms that in the Volterrano he knew that several country people and domestic animals died in consequence of it. And, aceording to Mr. Jackson, a spider, called there the Tendaramen, is found in Marocco, which has venomous powers equally formidable. The bite of this iusect, which is about the size and colour of a hornet, but rounder, and spins a web so fine as to be almost invisible, is said to be so poisonous that the person bitten survives but a few hours. In the cork-forests the sportsman, eager in his pursuit of game, frequently carries away on his garments this fatal insect, which is asserted always to make towards the head before inflicting its deadly wound. ${ }^{4}$

I suspect you will think this list long enough ; and I believe it includes the most remarkable insects that assail the surface of our bodies, to answer either the demands of hunger or the stimulus of revenge. There is however a third class of insect annoyers, as I observed at the beginning of this letter, which, though they neither make us their food, nor attack us under the impulse of fear or revenge, incommode us extremely in other ways. These must now be detailed to you.

How extremely moleasant is the sensation which that very minute ffy (Thrips physupus) excites in sultry weather, merely by creeping over our skin! I have sometimes found this almost intulerable. A similar torment, reckoned by Ulloa a kind of mosquito, infests the inhabitants of Carthagena in South America. They are there called Mantas Blancas, and creeping letween the threads of the gauze curtains that keep off the former pest, thongh they do not bite, oceasion an itching that is dreadfully tormenting. ${ }^{5}$ But these are nothing compared with the teasing attacks of

1 Ulloa's Voyage, i. 61.

3 p. 31 .

2 Amoreux, 217. 226. See also 67-70.

4 Jackson's Murocro, second edit.

5 Llloa, i. 64. Probahly the Cafufi, a white fly noticed by Itumboldt, is synonymous with this of Ulloa, which conld only be prevented from creeping lietween the threads of the curtains by keeping thern wet. Persont Nurrutive. L. T. v. $10 \%$. 
another gnat (Simulium reptans), which, as Linné informs us, who misnamed it a Culex, is so incredibly numerous in Lapland, as entirely to cover a man's body, turning a white dress into a black one, occupying the whole atmosphere, filling the mouth, nostrils, eyes, and ears of travellers, and thus preventing respiration, and almost choking them. These little animals, he says, do not bite, but torture incessantly by their titillation. ${ }^{1}$ - In New South Wales a small ant was observed by Sir Joseph Banks, inhabiting the roots of a plant, which when disturbed rushed out by myriads, and running over the uncovered parts of the body, produced a sensation of this kind that was worse than pain.

The common house-fly is with us often sufficiently annoying at the close of summer, so as to have led the celebrated Italian Ugo Foscolo, when residing here, to call it one of his three "miseries of life." ${ }^{2}$ But we know nothing of it as a tormentor compared with the inhabitants of southern Europe.-- "I met (says Arthur Young in his interesting Travels through France), between Pradelles and Thuytz, mulberries and flies at the same time; by the term fies I mean those myriads of them which form the most disagreeable circumstance of the southern climates. They are the first torments in Spain, Italy, and the Olive district of France: it is not that they bite, sting, or hurt, but they buzz, tease, and worry ; your mouth, eyes, ears, and nose, are full of them; they swarm on every eatable, -fruit, sugar, milk, everything is attacked by them in such myriads, that if they are not incessantly driven away by a person who has nothing else to do, to eat a neal is impossible. They are, however, caught on prepared paper and other contrivances with so much ease and in such quantities, that, were it not from negligence, they could not abound in such incredible quantities. If I farmed in these comntries, I think I should manure four or five acres every year with dead flies. - I have been much surprised that the late learned Mr. Harmer should think it odd to find, by writers who treated of southern climates, that driving away flies was an object of importance. Had he been with me in Spain and in Languedoc in July and August, he would have been very far from thinking there was anything odd in it." "s

1 Lach. Lapp. i. 208, 209. Fl. Lapp. 382, 383. It appears, however, from other authors, that they do bite.

2 Annual Obituary, 1828, p. 393.

3 Young's Travets in France, i. 298. These flics are equally troublesome and tormenting in Sweden (see Amon. Acad. iii. 343.), and also in the United States, where Mr. Stewart and Capt. Marryat make frequent and grievous complaints ot them, the latter asserting that in some places they were fity to the square inch, as I believe they literally were in a small inn where we took breakfast in September, 1830 , on our roail to Chamouni from Geneva.

It is a remarkable, arid, as yet, unexplained fact, that if nets of thread or string with meshes a tull inch square, be stretched orer the open windows of a room in summer or autumn, when flies are the greatest nuisance, not a single one will venture to enter from without; so that by this simple plan a house may be kept free from these pests, while the adjoining ones which have not load nets applied to their windows, will swarm with them. In order, however, that the protection should be efficient, it is necessary that the rooms to which it is applied shoull have the light enter by one side only; for in those which have a thorough light the flies pass through the meshes without scruple. For a fuller account of these singular facts, the reader is referred to a paper by V.. Spence in Trans. Ent. Soc. Lond. vol.i. p. 1., and also to one in the same work, vol.ii. p. 45 . by the Tiev. E. Stanley (subsequently Bishop of Norvich), who having male some of the experiments suggested by Mlr. Spence, 
Our friend Captain Green, of the sixth regiment of the East India Company's native troops, relates to me, that in India, when the mangoes are ripe, which is the hottest part of the summer, a very minute black fly makes its appearance, which, hecause it flies in swarms into the eves, is very troublesome, and causes much pain, is called there the eye-fly. At this season the eyes are attacked lyy a disease, supposed to be occasioned by eating the mangoes, but more probably the result of the irritation produced by the fly in question, which, however, they admit carries the infection from one person to another.

You know that the hairs taken from the pods of Dolichos pruriens and urens L., commonly called Cowhage and Cow-itch', occasion a most violent itching, but perhaps are not aware that those of the caterpillars of several moths will produce the same disagreeable effect. One of these is the procession-moth (Cnethocampa processionca), of which Reamur has given so interesting an account. In consequence of their short stiff hairs sticking" in his skin, after handling them, he suffered extremely for several days : and being ignorant at first of the cause of the itching, and rubbing his eyes with his hands, he brought on a swelling of the eyelids, so that he cuuld scarcely open them. Ladies were affected even by going too near the nest of the animal, and found their necks full of troublesome tumours, occa-

found that by extending over the ontside of his windows nets of a very fine packthread with meshes $1 \frac{1}{4}$ inch to the square, so fine and comparatively invisible that there was no apparent diminution either of light or the distant view, he was enabled for the remainder of the summer and autumn to enjoy the fresh air with open windows without the annoyance he had previously experienced from the intrusion of flies, often so troublesome that he was obliged on the hottest rlays to forego the luxury of admitting the air by even partially raising the sashes. "But no sooner (he observes) had I set my nets than I was relieved from my disagreeable visitors. I could perceive and hear them hovering on the other side of my barriers; but thougl they now and then settled on the meshes, I do not recollect a single instance of one venturing to cross the boundary."

It is singular, ton, as was first pointed ont by Mr. W. B. Spence (Ent. Trans. i. 7.) that Herodotus 2200 years ago stated that the Egyptian fishermen protected themselves in a similar manner trom the attacks of mosquitos by spreating their fishing-nets over their beds; a fact which has greatly puzzled all his commentators, who, not conceiving the possibility of mosquitos being kept off by fishing-nets, which must necessarily lave wide meshes, have supposed the father of history to have alluded to some protection of fine linen similar to the gauze nets now used against these insects. But in this, as in so many other instances, the supposed error is not that of Herodotus, but of lis commentitors, who, ignorant of the fact above related as to flies being excluded by wide-meshed nets, could not conceive of it in the case of mosquitos; yet, in confirmation of its accuracy, I liave been told by a friend that he was assured by a gentleman, who had travelled in America, that he had often had mosquito nets with meshes an inch square put over his bed, and had found them a perfect security from their bites, though, as is well known, they will creep through any small hole in an orlinary gauze net.

In conclufing this long note it may be observed that the number of honse flies might be greatly lessened in large towns, if the stable dung, in which their larva are chiefly supposed to feed, were kept in pits closed by trap doors, so that the females could not deposit their eggs in it. At Venice, where no horses are kept, it is said there are no house flics; a statement which I regret not having heard before being there, that I might liave inquired as to its truth.

1 Cowhage has been administered with success as an anthelmintic, as has likewise spun glass pounded; the spicula of these substances destroying the worms. The hair of the eaterpillars here alluded to, and perhaps also of the larva of Euprepia Caja (the Tiger-Moth), might probably be equally efficacious. 
sioned by short hairs, or fragments of hair, brought by the wind.1 of this nature also, is the famous Pityocampa of the ancients, the moth of the fir (Cnethocampa Pityocampa), the hairs of which are said to occasion a very intense degree of pain, heat, fever, itcling, and restlessness. It was so accounted by the Romans a very deleterions poison, as is evident from the circumstance of the Cornelian law "De sicariis" being extended to persons who administered Pilyocampa. ${ }^{2}$

In these cases the injury is the consequence of irritation produced by the hair of the animal; but there are facts on record, which prove that the juices of many insects are equally deleterious. Amoreux, from a work of Turner, an English writer on cutaneous diseases, has giving the following remarkible history of the ill effects produced by those of spiders. When Tumer was a young practitioner, he was called to visit a woman, whose custom it was, every time she went into the cellar with a candle, to burn "the spiders and their webs. She had often observed when she thus cruelly amused herself, that the odom of the burning spiders had so much affected her head, that all objects seemed to turn round, which was occasionally succeeded by faintings, cold sweats, and slight romitings: but, notwithstanding this, she found so much pleasure in tormenting these poor animals, that nothing could cure her of this madness, till she met with the following accident: the legs of one of these unhappy spiders happened to stick in the cancile, so that it could not disengage itself ; and the body at length bursting, the venom was ejaculated into the eyes and upon the lips of its persecutrix. In consequence of this, one of the former became inflamed, the latter swelled excessively, even the tongue and gums were slightly affected, and a continual romiting attended these symptoms. In spite of every remeily the swelling of the lips continued to increase, till at length an old woman, by the simple application for filteen days of the leaves and juice of plantain, together with some spider's web, ran away with all the glory of the cure. ${ }^{3}$ Ulioa gives us a remarkable account of a species of spider, or perhaps mite, of a fiery red colour, common in Popayan, called Coya or Coyba, and usually found in the corners of walls and among the herbage, the venom of which is of such malignity, that on crushing the insect, if any fall on the skin of either man or beast, it immediately penetrates into the flesh, and causes large tumours, which are soon succeeded by death. Yet, he further observes, if it be crushed between the palms of the hands, which are usually callous, no bad consequence ensues. People who travel along the valleys of the Neyba, where these insects abound, are warned by their Indian attendants, if they feel anything stinging them, or crawling on their neck or face, not so inuch as to lift up their hand to the place, the texture of the Coya being so delicate that the least force causes then to burst, without which there is no danger, as they seem otherwise harmless animals. The traveller points out the spot where he feels the creature to one of his companions, who, if it be a Coya, blows it away. If this account does not exaggerate the

1 Reaum. ii. 19l. 195. According to Dr. Nicholai, the processionary caterpillars also secrete from the external surface of their skin a sharp juice which assumes a farinaceous form, and is very injurious to those that inspire it, causing workmen, who are occupied in woods where the caterpillars are numerous, to sicken very rapidly. (Burmeister, Manual of Ent.510.)

2 Mouffet, 185. Plin. Hist. Nat. l. xxxviii. c. 9. Amoreux, 15 S.

5 Amoreux, 210-21:. 
deleterious quality of the juices of this insect, it is the most venomous animal that is known; for he describes it as much smaller than a bug. The only remedy to which the natives have recourse for preventing the ill effects arising from its venom is, on the first appearance of the swelling, to swing the patient over the flame of straw or long grass, which they do with great dexterity : after this operation he is reckoned to be out of danger. ${ }^{1}$ - The poisoned arrows which Indians employ against their enemies have been long celebrated. The Coya may, in the western world, have furnished the poison for this purpose. An author quoted in Lesser tells us that an ant as big as a bee is sometimes nsed, and that the wound inflicted by weapons tinctured with their venom is incurable. Patterson also gives a receipt by which the natives of the southern extremity of Africa prepare what they reckon the most effectual poison for the point of their arrows. They mix the juice of a species of Euphorbia, and a caterpillar that feeds on a lind of sumach (Rhus L.), and when the nixture is dried it is fit for use. ${ }^{2}$

And now I think you will allow that I have made out a tolerable list of insects that attack or annoy man's body externally, and a sufficiently doleful history of them. That the subject, however, may be complete, I shall next enimerate those that, not content with afflicting him with exterior pain or evil, whether on the surface or under the skin, bore into his flesh, descend even into his stomach and viscera, derange his whole system, and thus often occasion his death. The punitive insects here employed are usually larva of the various orders, and they are the cause of that genus of diseases I before noticed, and proposed to call Scholcchiasis.

I shall begin my account with the first order of Linne, because people in general seen not aware that any beetlcs make their way into the human stomach. Yet there is abundant evidence, which proves beyond controversy that the meal-worm (Tenebrio Molitor), although its usual food is flour, has often been voided both by male and female patients; and in one instance is stated to have occasioned death. ${ }^{3}$ How these grubs should get into the stomach it is difficult to say - perhaps the eggs may have been swailowed in some preparation of $\mathrm{H}$ uur. But that the amimal should be able to sustain the heat of this organ, so far exceeding the temperature to which it is usually aceustomed, is the most extraordinary circumstance of all. - Dr. Martin Lister, who to the skill of the physician added the most

1 Ulloa's Voyage, b. vi. c. 3. Hamilton (Travels in Colombia, as quoted in the Iiterary Gazette, April 28. 1827) also mentions a spider callel the Caya, rather large, found in the broken ground and among the rocks, from the body of which a poison so active is emitted, that men ani mules have died in an hour or two after the venomous moisture had fallen on them. This is evidently the same insect with that mentioned by Uiloa, and confirms the above account of its venomous effects.

2 Waterton (Wanderings in S. Amcrica. 53.) gives the recipe by which the Macousho lmbians prepare the poison in which they dip their arrows. It consists of a vine called the Wourali, which is the principal ingredient; the roots and stalks of some other plants; two species of ants, the sting of one of which is so venomous that it produces a fever; a quantity of the strongest Indian pepper ( $C a p$ sicum), aud the pounded fangs of two kinds of serpents.

3 Tulpius, Obs. Med. 1. ii. c.51. t. 7. f. 3. Lidinb. Med. and Surg. Journ. n. 35. 42-18. Derham, Physic. Theol. 378. note 6 . Lowthorp, 1'hilis. T'rans. iii. 135. 
profound knowledge of nature, mentions an instance, communicated to him by Mr. Jessop, of a girl who voided three hexapod larva similar to what are found in the carcases of birds ${ }^{1}$, probably belonging either to the genus Dermestes, or Anthrenus: and in the German Ephemerides the case also of a girl is recorded, from an abscess in the calf of whose leg crept black worms resembling heetles. ${ }^{2}$

The larvæ of some beetle, as appears from the description, seem to have been ejected even from the lungs. Four of these, of which the largest was nearly three quarters of an inch long, were discovered in the mucus expelled after a severe fit of coughing by a lady aftlicted with a pulmonary disease; and similar larvæ of a smaller size were once afterwards discharged in the same way. ${ }^{3}$

No one would suppose that caterpillars, which feed upon vegetable sibstances, could be met with alive in the stomach; yet Dr. Lister gives an account of a boy who vomited up several, which, he observes, had sixteen legs. ${ }^{4}$ The eggs perhaps might have been swallowed in salad; and, as vegetables make a part of most people's daily diet, enough might have passed into the stomach to support them when hatehed. - Linné tells us that the caterpillar of a moth (Aglossa pinguinalis), common in houses, has also been found in a similar situation, and is one of the worst of our insect infesters. - In a very old tract, which gives a figure of the insect, a caterpillar of the almost incredible length of the middle finger is said to have been voided from the nostrils of a young man long afflicted with dreadful pains in his head. ${ }^{5}-$ But the most extraordinary account with respect to lepidopterous larvæ (unless he has mistaken his insects) is giren by Azara, the Spanish traveller before quoted; who says that in South America there is a large brown moll, which deposits its young in a kind of saliva upon the flesh of persons who sleep nalied: these introduce themselves under the skin withont being perceived, where they occasion swelling attended by inflammation and violent pain. When the natives discover it, they squeeze out the larva, which usually amount to five or six. ${ }^{6}$

But amongst all the orders, none is more fruitful in devourers of man than the Diptera. The Bot-fly (GEstrus L.) you have, doubtless, often heard of, and how sorely it annoys our cattle and other quadrupeds; but I suspect have no notion that there is a species appropriated to man. The existence, indeed, of this species scems to have been overlooked by entomologists (though it stands in Gmelin's edition of the Systema Nature ${ }^{7}$, upon the authority of the younger Linné), till Humboldt and Bonpland mentioned it again. Speaking of the low regions of the torrid zone, where the air is filled with those my riads of musquitos which render uninhabitable a great and beautiful portion of the globe, they observe that to these may be joined the OEstrus Hominis, which deposits its eggs in the skin of man, causing there painful tumours. ${ }^{8}$ Gmelin says that it remains beneath the

1 Philos. Trans. 1665, x. 391. Shaw's Abridg. ii. 224.

2 Mead, Med. Sacr. 105.

4 Phitos. Trans. ubi suprì.

5 Fulvius Angelinus et Vincentius Alsarius, De vcrme admirando per nares egresso. liavenna, 1610 .

${ }^{6}$ Azara, 217. I cannot help suspecting this to be synonymous with the CEstrus Hominis next mentioned.

7 From Pallas, N. Nord. Beytr. i. 157.

8 Essai sur la Géograph. des Plantes, 136. 
skin of the abdomen six months, penetrating deeper, if it be disturbed, and becoming so dangerous as sometimes to oceasion death. The imago he describes as being of a brown colour, and about the size of the common honse-fly; so that it is a sinall species compared with the rest of the genus. ${ }^{1}$ Even the gad-fly of the ox, leaving its proper food, bas been known to oviposit in the jaw of a woman, and the bots produced firom the eggs finally caused her ckath. ${ }^{2}$ Other flies also of various kinds thus penetrate into us, either preying upon our flesh, or getting into our intestines. Leeuwenhoek mentions the case of a woman whose leg had been enlarging with glandular bodies for some years. Her surgeon gave lim one that he had cut from it, in which were many small magrgots: these he fed with flesh till they assumed the pupa, when they produced a fly as large as the flesb-fly ${ }^{3}$ - A patient of Dr. Reeve of Norwich, after suffering for some time great pain, was at last relieved by voiding a considerable number of maggots, which arree precisely with those described by De Geer as the larva of his Musca domestica minor (Anthomyju canicularis Meig.), a fly which he speaks of as very common in apartments. ${ }^{4}$ - In Paraguay the flesh-fies are said to be uncommonly numerous and noxious. Azara relates ${ }^{5}$ that, after a storm, when the heat was excessive, he was assailed by sueh an army of them, that in less than half an bour his elothes were quite white with their egrs, so that he was forced to serape them off with a knife; adding, that he has known instances of persons, who, after having bled at the nose in their sleep, were attacked by the most violent headaches; when at length several great maggots, the offspring of these flies, issuing from their nostrils, gave them relief.-In Jamaica a large thue fly buzzes about the sick in the last stages of fever; and when they sleep or doze with their mouths open, the nurses find it very difficult to prevent these flies from laying their eggs in the nose, mouth, or gums. An instance is recorded of a lady, who, after reeovering from a fever, fell a vietim to the maggots of this fly, which from the nose found their way through the os cribriforme into the cavity of the skull, and afterwards into the brain. ${ }^{6}$ One of the most shocking cases of Scholechiasis I ever met with is related in Bell's Weekly Messenger in the following words: "On Thursday June 25. died at Asbornby (Lincolnshire), John Patge, a pauper belonging

1 For an investigation of the question, whether man is attacked by a distinct species of CEstrus, see a report on the statements of M.M. Roulin, Howship, Say, Guerin, \&c., made to l'Académie des Sciences, 1833, by MM. Isidore, Geoffroy Saint Ifilaire, and Dumeril (copied in Ann. Soc. Ent. de France, ii. 518.), who, on the whole, though with some hesitation, pronounce for the aflirmative. Yet most of the facts passed in review seem rather to support the iclea that species of $C_{\text {strus, }}$ whose proper abode is in other animals, occasionally attack man.

2 Clark, in Linn. Trans. iii. 323. note.

3 Leeuw. Epist, Oct. 17, 1687, ubi suprà. De Geer, vi. 26, 27.

4 Edin. Med. and Surg. Journ. 5 p. 216.

6 Lempriere, On the Diseases of the Army in Jamaica, ii. 182. See Trans, Ent. Soc. Lond. i. proc. xlvi. in which various cases are recorded by IV. Sells, Lsq. (an acute observer, whose untimely death lintomology has recently had to deplore), as coming under his own observation in Jamaica, of flies being liatched in the human borly; in one instance, in a neglected blister on the chest; in another, in the gums and inside of the cheek; in a thircl, in the ear; and iu a fourth, in the passages of the nostrils, out of which the negro who was the sufferer counted not fewer than 235 larva (of, Mr. Sells believes, the blue-bottle-fly), which in a fortnight dropped out by applications of oil and tobacco smoke. 
to Silk-Willoughby, under eircumstances truly singular. He being of a restless disposition, and not choosing to stay in the parish workhouse, was in the labit of strolling about the neighbouring villages, subsisting on the pittance obtained from door to door : the support he usually received from the benevolent was breal and meat; and after satisfying the cravings of nature, it was his custom to deposit the surplus provision, particularly the meat, betwixt his shirt and slin. Having a considerable portion of this provision in store, so deposited, he was taken rather unwell, and laid himself down in a field in the parisls of Scredington - when, from the heat of the season at that time, the meat speedily became putrid and was of course struck by the flies: these not only proceeded to devour the inanimate pieces of fiesh, but also literally to prey upon the living substance; and when the wretched man was accidentally found by some of the inhabitants, he was so eaten by the maggots that his death seemed inevitable. After clearing away as well as they were able these shocking vermin, those who found Page conveyed him to Asbornby, and a surgeon was immediately procured, who declared that his body was in such a state that dressing it must be little short of jnstantaneous death; and in fact the man did survive the operation but a few hours. When first found, and again when examined by the surgeon, he presented a sight loatlisome in the extreme; white maggots of enomous size were crawling in and upon his body, which they had most shockingiy mangled, and the removing of the external ones served only to render the sight more horrid." 1 - A medical fricnd of mine, at Ipswich, gave me this winter an apode larva, voided by a person of that place with his urine, which I now preserve in spirits, and can show you when you visit me. It appears to me to belong to the Diptera order, yet not to the fly tribes (Tanystoma Latr.) but rather to the Tipularice of that author, with which, however, it does not seem to agree so entirely as to take away all doubt. It is a very singular larva, and I can find none in any author that I have had an opportunity of consulting which at all resembles it. That you may know it, should you chance to meet with it, I shall here describe it. Body, threefourths of an inch in length, and about a line in breadth; opaque, of a pale yellow colour; cylindrical, tapering somewhit at each extremity; consisting of twenty articulations withont the head; head reddish brown, heart-shaped, much smaller than the following joint; armed with two unguiform mandibles; with a biarticulate palpus attached exteriorly to the base of each. These mandibles appear to be mored by a varrow black central tendon under the dorsal shin, terminating a little beyond the base of the first segment; besides, this, there are four others, two on each side of it, the onter ones diverging, mnch slenderer, and very short. The last or anl joint of the boly very minute; exserting two short, filiform horns, or rather respiratory organs. I could discover, in this animal, no respiratory plates, such as are found in the larve of Muscide, $\mathcal{S} c$, nor were the tracheæ visible. When given to me it was alive and extremely active, writhing itself into varions contortions with great agility. It moved, like other dipterons larvæ, by means of its mandibles. Upon wetting my fingers more than once, to take it up when it had fallen fiom a table upon

I In passing throtgh this parish in the spring of 1814, I inquired of the mailcoachman whether he had heard of this story; and he said the fact was well kilown. 
which it was placed, the saline taste with which it was imbued was so powerful that it was some time before it was dissipated fiom my mouth. ${ }^{1}$ -I shall only mention one more instance, because it is a singular one. The larva of Helophilns pendulus, a fly peculiarly forned by nature for inhabiting fluids, has been found in the stomach of a woman. ${ }^{2}$

You will smile when I teli you that I have met with the prescription of a famous urine-doctor, in which he recommends to his credulons patient to take a certain number of sow bugs per diem, by this name distinguishing, as I supposc, the pill-millepede (Armadillo vulgaris), once a very favourite remedy. What effect they produced in this ense I was not informed; but the learned Bonnet relates that he had seen a ccrtificite of an English physician, dated July 1763 , stating that, some time before, a young woman who had swallowed these animals alive, as is nsually done, threw up a prodigious number of them of all sizes, which must bave bred in her stomach. ${ }^{3}$ - Another apterous species appears to have been detected in a still more remarkable situation. Hermann, the author of the admirable riémoire Apterologique, whose untimely death is so much to be lamented, informs us that in Acarus, figured and described in his work (A. marginatus), was observed by his artist running on the corpus callosnm of the brain of a patient. in the military hospital at Strashourg, which had been opened but a ninute before, and the two hemispheres and the pia mater just scparated. He adds that this is not the first time that insects have been found in the brain. Cornetius Gemma, in his Cosmocritica, p. 2tl., says that on dissecting the brain of a woman there were found in it abundance of vermicles and punaises. ${ }^{4}$

It was customary in many countries in ancient times to punish certain malefuetors by exposing them to be devoured by wild beasts: but to expose them to insects for the same purpose was a refinement in eruelty which seems to have been peeuliar to the despots of Persia. We are informed that the most severe punishment amongst the Persians was that of shutting up the offender between two boats of equal sizc; they laid him in one of them upon his back, and covered him with the other, his hands, feet, and head being left bare. His face, which was placed full in the sun, they moistened with honey, thus inviting the flies and wasps, which tormented lim no less than the swarms of maggots that were bred in his excrements and body, and devoured him to the very entrails. He was compelled to take as much food as was necessary to support life, and thus existed sometimes for severil days. Plutarch informs us, that Nithridates, whom Artaxerxes Longimanus condemned to this punishment, lived seventeen days in the utmost agony; and that, the uppermost boat being taken of at his death, they found his flesh all consumed, and myriads of worms gnawing his howels. ${ }^{5}$ Could any natural objects be made more horrible and effectual instruments of torture than insects were in this most diabolical invention of tyranny ? 6

1 Specimens of a dipterous larva, of which, like the above, several had becn discharged with the urine of a patient, were exhibited to the Entomolngical Society A pril 4. 1840, by P'rofessor Owen, who pointed out the great singularity of the case, and the difficulty of accounting for the existence of the larva in the bladder. (Proceedings of Ent. Soc. Lond. p. 7.)

2 I'hilos. Mag. ix. 366.

3 Bonnet, v, 144.

4 Mém. Apterolog. 79.

5 Universal IIistory, iv. 70, el. 1779.

6 For numerous cases of insects oecasionally found in the human body, see is 
In this enumeration of evils derived from insects, I must not wholly pass over the serious and sometimes fital effects produced upon some persons by eating honey, or even by drinking mead. I once knew a lady upon whom these acted like poison, and have heard of instances in which death was the consequence. Sometimes, when bees extract their honey from poisonous plants, such results have not been confined to individuals of a particular habit or constitution. A remarkable proof of this is given by Dr. Barton in the fifth volume of The American Philosophical Transactions. In the autumn and winter of the year 1790 an extensive mortality was produced amongst those who had partaken of the honey collected in the neighbourhood of Philadelphia. The attention of the American government was excited by the general distress, a minute inquiry into the cause of the mortality ensued, and it was satisfactorily ascertained that the honey had been chiefly extracted from the flowers of Kalmia latifolia. Though the honey mentioned in Xenophon's well-known account of the effect of a particular sort eaten by the Grecian soldiers during the celebrated retreat after the death of the younger Cyrus did not operate fatally, it gave those of the soldiers who ate it in small quantities the appearance of being intoxicated, and such as partook of it freely, of being mad or about to die, numbers lying on the ground as if after a deleat. A specimen of this honey, which still retains its deleterious properties, was sent to the Zoological Society in 1834, from Trebizond on the Black Sea, by Keith E. Abbott, Esqi. ${ }^{1}$

Amongst other direct injuries occasioned by these creatures, perbaps, out of regard for the ladies, I ought to notice the alarm which many of them occasion to the loveliest part of the creation. When some females retire from society to avoid a wasp, others faint at the sight of a spider, and others, again, die with terror if they hear a death-watch : these groundless apprehensions and superstitious alarns are as much real evils to those who foel them as if they were well-founded. But having already adverted to this subject, I shall here only quote the observation of a wise man, that "Fear is a betraying of the succours that reason offereth." 2 The best remedy, therefore, in such cases, is going to reason for succour. In a few instances, indeed, the evil may take root in a constitutional defect; for there seems to be some foundation for the doctrine of natural antipathies: but, generally speaking, in consequence of the increased attention to Natural History, the reign of imaginary evils is ceasing amongst us, and what used

very valuable paper in Trans. Ent. Soc. Lond. ii. 257. by the Rev. F. W. Hope, F.R.S., in which the whole are brought together in a tabular form, so that the kind of insect, the local affection, anil various other particulars, can be seen at a glance. Mr. Iope proposes to adopt the term Canthariasis for those diseases which originatewith coleopterous insects, whether in the perfect or larva state; that of Myasis for those caused by dipterous larvx, while he restricts the term Scholechiasis to those resulling from lepidopterous larva. Of the first (including two cases arising from the earwig), he enumerates thirty-eight cases; of the second, sixtyfour; and of the third, seven. He suggests that the eggs of many of these larva have been introduced into the stomach with bread, butter, cheese, and even upon cooked food, upon which they have been leposited by the parent beetles or flies in our larters and cellars, \&c.; others with ripe fruit or raw vegetables, as lettuces, watercresses, \&c.; and others again in impure and turbid water.

1 Xenophon, Anabas. 1. iv. Trans. Ent. Soc. Lond. i. proc. xxxi.

2 Wisd. xvii. 12. 
to shake the stout hearts of our superstitious ancestors with anile terrors is become a subject of interesting inquiry to their better informed descendants, even of the weaker sex.

And now, my friend, I flatter myself you feel disposed to own the truth of my position, however it might startle you at first, and will candidly acknowledge that I have proved the empire of these despised insects over man's person; and that, instead of being a race of insignificant creatures, which we may safely overlook, as having no concern with, they may, in the hands of Divine Providence, and even of man, become to us fearful instruments of evil and of punishment. I shall next endeavour to give you some idea of the indirect injuries which they occasion us by attacking our property, or interfering with our pleasure or comfort - but this must be the subject of another letter.

I am, \&c. 


\section{LETTER V.}

\section{INJURIES CAUSED BY INSECTS.}

INDIRECT INJURIES.

Mavivg detailed to you the direct injuries which we suffer from insects, I am now to call your attention to their indirect attacks upon us, or the injury which they do our property ; and under this view also you will own, with the fullest conviction, that they are not beings that can with prudence or safety be disregarded or despised. Our property, at least that part exposed to the annoyance of these creatures, may be regarded as consisting of animal and vegetable productions, and that in two states; when they are living, namely, and after they are dead. I shall therefore endeavour to give you a sketch of the mischief which they occasion, first to our living animal property, then to our living vegetable property; and, lastly, to our dead stock, whether animal or vesetable.

Next to our own persons, the animals which we employ in our business or pleasures, or fatten for food, individually considered, are the most valuable part of our possessions - and at certain seasons, hosts of insects of various kinds are incessant in their assaults upon most of them.-To begin with that noble animal the horse. See him, when turned out to his pasture, unable to touch a morsel of the food he has earned by his labours. He flies to the shade, evidently in great uneasiness, where he stands continually stamping from the pain produced by the insertion of the weapons sheathed in the proboscis of a little fly (Stomoxys calcitranis) before noticed as attacking ourselves. ${ }^{1}$ This alights upon him sometimes in one place and sonetimes in another, and never lets lim rest while the day lasts. See him again when in harness and travelling. He is bathed in blood flowing from innumerable wounds made by the knives and lancets of various horse-flies (Tabanus L.), which assail him as he goes, and allow him no respite ${ }^{2}$; and consider that even this is nothing to what he suffers in other climates from the same pest. In North America, rast clouds of different speciesso abundant as to obscure every distant object, and so severe in their bite as to merit the appcllation of burning flies - cover and torment the horses to such a degree as to excite compassion even in the hearts of the packliorsemen. Some of them are nearly as big as humble-bees; and, when they pierce the skin and reins of the unhappy beast, make so large an orifice that, besides what they suck, the blood flows down its neck, sides, and shoulders in large drops like tears, till, to use Bartran's expression, "they are all in a gore of blood." Both the dog-tick and the American tick before mentioned, especially the latter, also intest the horse. Kalm affirms, that he has seen the under parts of the belly, and other places of the body,

1 See above, p. 25.

2 Once travelling through Cambridgeshire with a brother entumologist in a gig, our horse was in the condition here described, from the attack of Tabinus rusticus. 
so covered by them, that he could not introluce the point of a knife between them. They were deeply buried in the flesh; and in one instance that he witnessed, the miserable creatmre was so exhausted by continual suction, that it fell, and afterwards died in great agonies.'

No quadruped is more infested by the gad- or bot-fly, sometimes also improperly called the breese ${ }^{2}$, than the horse. In this country no fewer than three species attack it. The most common sort, known by the name

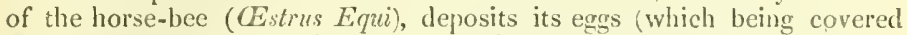
with a slimy substance adhere to the hairs) on such parts of the body as the animal ean reach with its tongue; and thus, uncouscious of what it is doing, it unwarily introduces into its own citalel the troops of its enemy. Another species (CE. hamorrhoidalis) is still more troublesome to it, ovipositing upon the lips; and in its endenvours to effeet this, from the excessive titillation it occisions, giving the poor heast the most distressing uneasiness. At the sight of this fly horses are alwars much agitated, tossing their heads ahout in the air to drive it away; and, if this does not answer, galloping off' to a distant part of their pasture, and, as their last resource, taking refuge in the water, where the gad-flies never follow them. We learn from Reaumur, that in France the grooms, when they observe any bots (which is the vulgar name for the larve and pupie of these flies) about the anus of a horse or in its dung, thrust their hand into the passage to search for more; but this seems a useless precantion, which must occasion the animal great pain to answer no good end ; for when the bots are passing through the body, having ceased feeding, they can do no further injury. In Sweden, as De Geer informs us, they act much more sensibly: those that have the care of horses are accustomed to clean their months and throats with a particular kind of brush, by which method they free them from these disagreeable inmates beiore they lave got into the stomach, or can be at all prejudicial to them. ${ }^{3}$

Providenee has doubtiess created these animals to answer some heneficial purpose; and Mr. Clark's judicious conjectures are an index which points to the very kind of good our cattle may derive from them, as acting the part of perpetual stimuli or blisters : yet when they exceed eertain limits, as is often the case with similar animals employed for purposes equally beneficial, they become certainly the causes of disease, and sometimes of death.

How troublesome and teasing is that cloud of flies (Anthomyia meteorica) which you must often have noticed in your summer rides hovering round the head and neck of your horse, accoupanying him as he goes, and causing a perpetual tossing of the former ! ${ }^{4}$ - And still more annoying in Lapland, as we learn fiom Linné ${ }^{5}$, is the furious assault of the minute borsegnat (Culex equinus L.), which infests these beasts in infinite numbers, running under the mane and amongst the hair, and piercing the skin to suck their blood. - An insect of the same genus is related to attack them in a particular district in India in so tremendous a manner as to eause in-

1 Te Geer, vii. 158.

2 See Mr. W. S. MacLeay in Linn. Trans. xiv. 355.

3 De Geer, vi. 295.

4 Amon. Acad. iii. 358.

5 Linn. Flor. Lapp. 376. Lach. Lapp. i. 233, 234. This insect from Linnés description is probably no C'ulex, but perhaps a Simulium Latr. (Simulia Meig.) 
curable cancers, which finally destroy them. ${ }^{1}$ - But of all the insect tormentors of these useful creatures, there is none more trying to them than the forest-fy (Hippobosca equina). Attaching themselves to the parts least covered with hair, particularly under the belly between the hind legs, they irritate the quietest horse, and make him kick so as often to hazard the safety of his rider or driver. This singular animal runs sideways or backwards like a crab; and, being furnished with an unusual number of claws, it adheres so firmly that it is not easy to take it off'; and even if you snceed in this, its substance is so hard, that by the utmost pressure of your finger and thumb it is difficult to kill it; and if you let it go with life, it will immediately return to the charge. - Amongst the inseet plagues of horses, I should also have enmmerated the larva of Lixus paraplecticus, which Linné considers as the cause of the equine disease called in Sweden, after the Phellandrinom aquaticum, "Slâkra," had not the observations of the accurate De Geer rendered it doubtful whether the inseet be at all conneeted with this malady. ${ }^{2}$

Another quadruped contributing greatly to our domestie eomfort, from which we derive a considerable portion of our animal food, and which, on account of its patient and laborious character when employed in agriculture, is an excellent substitute for the horse (you will directly perceive I an speaking of the $o x$, whether male or female), is also not exempt from insect domination. At certain seasons the whole terrified herd, with their tails in the air, or turned upon their backs, or stiffy stretched ont in the direction of the spine, gallop about their pastures, making the country reecho with their lowings, and finding no rest till they get into the water. Their appearance and motions are at this time so grotesquc, elumsy, and seemingly umnatural, that we are tempted rather to langh at the poor beasts than to pity them, though evidently in a situation of great terror and distress. The cause of all this aqitation and restlessness is a small gad-or bot-fly ( $Q$ E. Bovis) less than the horse-bec, the objeet of which, though it be not to bite them, but merely to oviposit in their hides, is not put into execution without giving them considerable pain.

When oxen are employed in agriculture, the attack of this fly is often attended with great danger, since they then become perfectly unmanageable; and, whether in harness or yoked to the plough, will run directly forward. At the season when it infests them, close attention should be paid, and their himess so constructed that they may easily be let loose.

Reaumur has minutely described the ovipositor, or singular organ by which these insects are enabled to bore a round hole in the skin of the animal and deposit their eggs in the wound. The anus of the female is furnished with a tube of a corneous substance, consisting of four pieces, which, like the pieces of a telescope, are retractile within each other. The last of these terminates in five points, three of which are longer than the others, and hooked : when united together they form an instrument very much like an auger or gimlet; only, having these points, it can bite with more effect. ${ }^{3}$ He thinks the inflietion of the wound is not attended by much pain, except where very sensible nerves are injured, when the

- Life of General Thomas, 186.

2 Linu. It. Scand, 182. De Geer, v. 227-230.

3 Mr. Clark, however, is of opinion that the gad-fly does not pierce the skin of the animal, but only glues its eggs to it; the young larvin when hatched burrowed into the fiesh. Essay on the Bots of Horses and other Lnimals, p.47. 
animal, appearing to be seized with a kind of frenzy, begins to gambol, and run with such swiftness that nothing can stop it. From this semblance of temporary madness in oxen when pursued and bored by the Estrus, the Greeks applied the term to any sudden fit of fury or violent impulse in the human species, calling such ebullition an Estrus. The female fly is observed to be very expeditions in oviposition, not more than a few seconds; and while she is performing the operation, the animal attempts to lash her off, as it does other flies, with its tail. The circular hole, made by the augur just described, always continues open, and iucreases in diameter as the larva increases in size; thus enabling it to receive a sufficient supply of air by means of its anal respiratory plates, which are usually near the orifice.-But though these insects thus torment and terrify our cattle, they do them no material injury. Indeed, they occasion considerable tumours under the skin, where the bots reside, varying in number from three or four to thirty or forty ; but these seem unattended by any pain, and are so far from heing injurious, that they are rather regarded as proofs of the goodness of the animal, since these flies only attack young and healthy subjects. The tanners also prefer those hides that have the greatest number of bot-holes in them, which are always the best and strongest. ${ }^{1}$

The Stomoxys, and several of the other flies before enumerated, as well as the dog and American ticks, are as prejudicial to the ox as to the horse. One species of Hippobosca, I bave reason to believe, is appropriated to them; yet, since a single specimen only has hitherto been taken ${ }^{2}$, little can be said with respect to it.-A worse pest than any hitherto enumerated is a minute $f y$, concerning the genus of which there is some doubt, Fabricius considering it as a Khagio ( $R$. columbaschensis) and Latreille as a Simulium $^{3}$; but to whatever genus it may belong, it is certainly a most destructive little creature. In Servia and the Bannat it attacks the cattle in infinite numbers, penetrates, according to Fabricius, their generative organs, but according to other accounts their nose and ears, and by its noisonous bite destroys them in the short space of four or five hours. Much injury was sustained in 1813 from this insect in the palatinate of Arad, in Hungary, and in the Bannat; in Banlack not fewer than two hundred horned cattle perishing from its attacks, and in Versetz, five hundred. It appears towards the latter end of April or beginning of May in such indescribable swarms as to resemble clouds, proceeding, as some think, from the region of Mehadia, but according to others from Turkey. Its approach is the signal for miversal alarm. The cattle fly from their pastures; and the herdsman hastens to shut up his cows in the house, or, when at a distance from home, to kindle fires, the smoke of which is found to drive off this terrible assailant. Of this the cattle are sensible,

1 Much of the infirmation here colleeted is taken from Reaum. iv. Mem. 12.; and Clark in Linn. Trans. jii. 289.

2 The writer of the present letter is possessor of this specimen, which he took on himself in a field where oxen were feeding.

3 In the Systema Antliatorum (p.56.) Fabricius most strangely considers this inseet as synonymous with Culex reptans L., ealling it Scatopse reptans, and dropping his former referenee to l'allas, and aecount of its injurious properties. Meigen (Lipt. i. 294.) makes this inseet a Simulia, under the name of $\$$. maculata. It is represented by Coquebert, whose tigure is copied in the translation of Köllar's work referred to above, and also in the next page. 
and as soon as attacked run towards the smoke, and are generally preserved by it. ${ }^{1}$

Tabani in this country do not seem to annoy our oxen so much as they do our horses; perhaps for this immunity they may be indebted to the thickness of their hiles; but Virgil's beautiful description of the annoyance shows that the Grecian Estrus, called by the Romans Asilus, evidently is one of the Tabanide. As the passage has not been very correctlv translated, I shall turn poet on the occasion, and attempt to give it you in a new dress.

Through waving groves where Selo's torrent fows,
And where, Alborno, thy green Ilex grows,
Mlyriads of insects flutter in the gloom,
(Gistrus in Greece, Asilus named at Pome,
Fierce and of cruel lnum. By the dire sound,
Driven from the woods and shatly glens around,
The universal herds in terror fly ;
Their lowings shatke the woods and shake the sky,
And Negro's arid shore--

In some parts of Africa also insects of this tribe do incredible mischief. What would you think, should you be told that one species of fly drives both inhabitants and their cattle from a whole district? Yet the terrible Tsaltsalya or Zimb of Bruce (and the world secms now disposed to give more credit to the accounts of that traveller) has power to produce such an effect. This fly, which is a native of Abyssinia, both from its habits and the figure appears to belong to the Tabanide, and porhaps is congenerous with the CEstrus of the Greeks. ${ }^{2}$

1 Fabr, Ent. Syst. Em. iv. 276. 22. Latr. Hist. Nat. \&c. xiv. 283. Leips. Zeit. July 5. 1813, quoted in Germar's Mug. der Ent. ii. 185. In Köllar's Treatise on Insects injurious to Gardeners, Foresters, and Farmer's.(Lond. 18t0), a valuable work, for a translation of which from the German into English we are indebted to the Misses Loudon, it is stated (p. 70.) that Dr. Scliönbauer, late Professor of Natural History at Pestl, has ascertained that the swarms of this fly, which he calls Simulia Culumbaschensis, instead of proceeding, as the Wallachians universally believe, from the jaws of the dragon killed by St. George, and buried in certain caves in the limestone mountains near Columbaez in Servia, out of the moutls of which they issue like smoke, in fact are bred in the extensive swamps in the district, passing all their states of egg, larva, and nymph in water. Vast swarms appeared in 1830 in a large tract of Austria, Hungary, and Moravia, overflowed by the river Marsch, and hundreds of horses, cows, and swine perished from their bite. Men are equally attacket by this scourge, but can more easily defend themselves; and there are not wanting solitary examples of little children dying from the excessive inflammation consequent on their numerons punctures.

2 It is by no means clear that the CEstrus of modern entomologists is synonymous with the insects which the Grceks distinguish by that name. Aristotle rot only describes these as Ulood-suckers (Hist. Animal. l. viii. c. 11.), but also as furnished with a strong proboscis (1. iv. ¿.7.) He observes likewise that they are produced from an animal in habiting the $w$ aters, in the vicinity of which they most abound (l. viii. c. 7 .). And Elian (Hist. 1.vi. c. 38.) gives nearly the same account. Comparing the Cstrus with the Myops (synonymous perhaps with Tabanus Latr., except that Aristotle affirms that its lirva live in wood, 1. v. c. 19.), he says, the Cistrus for a fly is one of the largest; it has a stiff and large sting (meaning a proboscis), and emits a certain humming and harsh sound; but the Mlyops is like the Cynomyiait hums more loudly than the Estrus, though it has a smaller sting.

These characters and circumstances do not at all agree with the modern Estrus, which: so fur from being a blood-sucker furnished with a strung proboscis, 
Small as this insect is, we must acknowledge the elephant, rhinoceros', lion, and tiger, vastly his inferiors. The apjearance, nay the very sound of it, occasions more trepidation, movements, and disorder, hoth in the human and brute creation, than whole herds of the most ferocious wild beasts in tenfold greater mumbers than they ever are would prodcce. As soon as this plague appears, and their buzzing is heard, all the eattle forsake their food, and run wildly about the plain till they die worn out with fatigue, fright and hunger. No remedy remains for the residents on such spots but to leave the hlack earth and hasten down to the sands of Atbara, and there they remain while the rains last. Camels, and even telejhants and rhinoceroses, though the two last coat themselves with an armour of mud, are attacked by this winged assassin, and afticted with mumerous tumours. All the inliahitants of the sea-coast of Melinda down to Cape Gardefui, to Saba and the Sonth of the Red Sea, are obliged in the beginning of the rainy season to remove to the next sand to prevent all their stock of eattle from being destroyed. This is no partial enigration - the inhabitants of all the countries from the mountains of Alyyssinia northward, to the confluence of the Nile and Astalsoras, are once a yeas obliged to change their abode and seek protection in the sands of Beja; nor is there any alternative or means of avoiding this, tluough a hostile band were in the way capalle of spoiling them of half their substance. ${ }^{2}$ This fly is truly a Beelzebub ${ }^{3}$; and perhaps it was this, or some species related to it, that was the prototype of the Philistine idol worshipped under that name and in the form of a fly.

I must not conclude this subject of insects hurfful to our cattle without noticing a beetle much takked of by the ancients for its mischievons properties in this respect. You will soon and rightly conjecture that I am speaking of the Buprestis ${ }^{4}$, so called from the injury which it has been supposed to occasion to oxen or kine.

Modern writers have been much divided in their opinion to what genus this celebrated insect belongs. All, indeed, have regarded it as of the Coleoptera order; but here their agreement ceases. Limné should seem to have looked upon it as a species of the genus to which he has given its name; but these, being timber insects, are not very likely to be swallowed by cattle with their food. Gcoffroy thinks it to be a Carabus or Cicindcla, but with as little reason, since the species of these genera do not feed amongst the herbage; and though they are sometimes found running

has scarcely any mouth. It shuns also the vicinity of water, to which our cattle generally fly as a refuge from it. It seems more probable that the CEstrus of Greece was related to Bruce's Zimb, represented in his tigure with a long jroboscis, which makes its appearance in the neighbourhood of rivers, and belongs to the Tabanida, For further information the rearler slould consult Mr. IV.S. NacLeay's learned paper on the insect called Oistros and Asilus by the ancients. Linn. Trans. xiv. 353.

1 The larva of a species of (Estrus which infests the rhinoccros is figured in the Trans. Fnt. Soc. of London, vol. ii. pl.22. fig. 1.

2 Bruce's Travels, 8 vo, ii. 315.

3 Heb. בוב בע לו literally "Lord-Fly." See 2 Kings, i. 2.; and Bochart, IIierozoic. pis. 11. 1.4. c. 9. p. 49!9.

4 Burn-Cow or Ox, from fous, bos, and $\pi p r_{1} 9 \omega$, inflammo. M. Latreille translates it, Crève-bœuf, but improperly. 
there, yet their motions are so rapid, that it is not very likely that cattle would often swallow them while feeding.

M. Latreille, in an ingenions essay on this insect ${ }^{1}$ suspects it to belong to the genus Alelöc, and as this feeds upon herbs (MI. Proscarabceus and M. violaceus, upon the Ranunculi, so widely disseminated in our pastures), his opinion seems to rest upon more solid grounds than that of his predecessors; but yet, I think, the insect in question rather belongs to Mylabris, and for the following reason.

In order rightly to ascertain what insect this really was, we must endeavour to trace it in the country in which it received its name and character. This country was certainly Greece; and there such an animal, retaining nearly its own name, and accused of being the cause of the same injury to cattle, still exists. For Belon informs is, that on Mount Athos there is found a winged insect like the blister-bectle, but yellow, larger, and of a very offensive smell, which feeds upon various plants, and is called l'oupristi by the caloyers or monks, who assert that when horses or other cattle even feed upon the herbs which the animals have touched they die from inflammation, and that it is an immediate poison to oxen. ${ }^{2}$ This, therefore, most probably was the Buprestis of the Greek writers; and as Pliny usually compiled from them, it may be regarded as his also, which he tells us was a caustic insect, and prepared in the same manner as the blister-beetle. ${ }^{3}$ He further observes that it was scarce in Italy. The Greek insect of Mount Athos M. Latreille supposes to be a Mylabris, and in this I agree with him; and, therefore, this is the proper genus to which the original Greek Buprestis, the true type of the insect in question, ought to be referred, and not Melöe.

Whether this animal be really guilty to the extent of which it is accused admits of considerable doubt; but as $I$ have not the means of ascertaining this, I shall leave the question for others who are better informed to decide.

But of all our cattle none are more valualle and important to us than our flocks; to them we look not only for a principal part of oill food, but also for clothing and even light. Thick as is their coat of wool, it does not shield them fiom the attack of all-subduing insects: on the contrary, it affords a confortable shelter to one of their enemics of this class, regarded by Linné as a species of Hippobusca, but properly separated from that genus by Latreille under the name of Miclophagus. ${ }^{4}$ This is commonly called the sheep-louse, and is so tenacious of life, that we are told by Ray it will exist in a flece twelve montlis after it is shorn, and its excrements are said to give a green tinge to the wool very difficult to be discharged.- You have doubtless often observed in the heat of the day the shcep shaking their heads and striking the ground violently with their fore feet; or running away and getting into ruts, dry dusty spots or gravel pits, where crowding together they hold their noses close to the ground. The object of all these actions and movements is to keep the gad-fly appropriated to them ( $O E$. Ovis) from getting at their nostrils, on the inner margin of which they lay their eggs, from whence the maggots make their

1 Annales du Mruséum. - $\mathrm{I}^{\circ}$ Ann. No xi. p. 129.

2 Observations de plusieurs Singularités, Sc., 1.1. c. 45. p. 73. of the edition in Sir Joseph lBanks's library.

3 Hist. Nat. 1. xxix. c. 4.

4 See Curtis, Brit. Ent. t. 142. 
way into the head, feeding in the maxillary and frontal sinuses on the mncilage there produced. When full-grown, they fall throush the nostrils to the ground, and assume the pupa. Whether the animal suffers much pain from these trouhlesome assailants is not ascertained. Sometimes the maggots make their way even into the brain. I have been informed by a very accurate and intelligent friend, that, on opening the head of one of his sheep which died in consequence of a vertigo, three maggots were found in it in a line just above the cyes, and that bebind them there was a bladder of water. - Perhaps you are not aware that the bots we are speaking of; or ratler those in the head of goats, have been prescribed as a remedy for the epilepsy, and that from the tripod of Delphos. Yet so we are told on the authority of Alexander Trallien. Whether Democrates, who consulted the oracle, was cured by this remedy loes not appear; the story shows however that the ancients were aware of the station of these larvæ. - The common saying that a whimsical person is maggoty, or has got maggots in his head, perhaps arose from the freaks the sheep have been observed to exhibit when infested by their bots. - The flesh-fly is also a great annoyance to the fleecy tribe, especially in fenny countries; and if constant attention be not paid them, they are soon devoured by its insatiable larvæ. In Lincolnshire, a principal profit of the druggists is derived from the sale of a mercurial ointment used to destroy them. - In tropical countries the sheep frequently suffer from the ants. Bosman relates that when in Guinea, if one of his was attacked by them in the night, which often bappened, it was invariably destroyed, and was so expeditiously devoured that in the morning only the skeleton would be left.

Of our domestic animals the least infested by insects, I mean as to the number of species that attack it, is the swine. With the exception of its louse, which seems to annoy it principally by exciting a violent itching, it is exposed to scarcely any other plague of this class, unless we may suppose that it is the biting of flies, which in hot weather drives it to "its wallowing in the mire."

Under this head we may include the deer tribe, for though often wild, those kept in parks may strictly be deemed domestic; and the rein-deer is quite as much so to the Laplander as our oxen and kine are to us. We learn from Reaumur that the fallow-deer is subject to the attack of two species of gad-fly ${ }^{1}$ : one which, like that of the ox, deposits its eggs in an orifice it makes in the skin of the animal, and so produces tumours ; and another, in imitation of that of the sheep, ovipositing in such a manner that its larvæ when hatched can make their way into the head, where they take their station, in a cavity near the pharynx. He relates a curious notion of the hunters with respect to these two species. Conceiving them both to be the same, they imagine that they mine for themselves a painful path under the skin to the root of the horns; which is their common rendezvous from all parts of the body; where, by uniting their labours and gnawing indefatigably, they occasion the annual casting of these ornamental as well as powerful arms. This fable, improbable and ridiculous

1 Mr. Curtis (Brit. Ent. t. 106.) under the name of CEstrus pictus has figured a fine species of gad-fly taken in the New Forest, which he conjectures may be bred from the deer. It may probably be one of the species here alluded to. 
as it is, has had the sanction of grave authorities. ${ }^{1}$ - The Estri last mentioned inhahit, in considerable numbers, two fleshy bags as big as a hen's egg, and of a similar shape, near the root of the tongue. Reaumur took between sixty and seventy bots from one of them, and even then some had escaped. What other purpose these two remarkable purses are intended to answer, it is not easy to conjecture. He supposes that the parent fly must enter the nostrils of the deer, and pass down the air passages to oviposit in them ; but probably such a manœuvre is unnecessary, since there seems no reason, supposing the eggs to be laid in the nostrils, why the larva when hatched cannot itself make its way down to the above station, as easily as that of the sheep into the maxillary sinuses. Or, which perhaps is more likely, when the animal draws in the air, the eggs or larvæ may be earried down with it, in both eases, to the place assigned to them by Providence.

No animal, however, is so cruelly tormented by Estri as the rein-deer; for besides one synonymons apparently with this of the deer ( $C$. nasalis), fiom which they endeavour to relieve themselves by snorting and blowing ${ }^{3}$, they have a second which produces bots under their skin; not improbably the same species that in a similar way attacks the latter, as I have stated above. We have heard that the vaccine disease is derived fiom the cow and the horse, and the small-pox is stid to have originated in the heels of the camel; but neither the ingenious Dr. Jenner nor any other writer on this subject has informed us that the rein-deer is subject to the distemper last named; yet Linné guotes the learned work of a Swedish physician on Syplitis, who gravely gives this as a fact!! 4 The inoculator, in truth, is the gad-fy, the tumours it causes are the pustules, and its larva are the pus. - It is astonishing how dreadfully these poor animals in hot weather are terrified and injured by them : ten of these flies will put a herd of five hundred into the greatest agitation. They cannot stand still a minute, no not a monient, without changing their posture, puffing and blowing, sueezing and snorting, stamping and tossing continually; every individual trembling and pushing its neighbour about. The ovipositor of this fly is similar to that of the ox-breese, consisting of several tubular joints which slip into each other; and therefore Linné was probably mistaken in supposing that it lays its eggs upon the skin of the animal, and that the bot, when it appears, eats its way throngh it ${ }^{5}$ : there can be little dotibt (or else what is the use of such an apparatus?) that it bores a hole in the skin and there deposits the eggs. About the beginning of July the rein-deer slieds its hair, which then stands crect - at this time the fly is always fluttering about it, and takes its opportunity to oviposit. The bots remain under the skin throngh the whole winter, and grow to the size of an acorn. Six or eight of these are often to be found in a single

1 Reaum. v. 69. Dictionnaire de Trevoux, article Cerf.

2 For the account of the (Estrus of the deer, see lieaum. v. $67-77$.

3 Linn. Lach. Lapp. ii. 45. In the passagre here referred to, Linné speaks of two species of Estrus, though the mode of expression indicates that he considered then as the same. One was $C$. nasalis, from which they freed themselves by snorting, \&c., the other $E$. Tarandi, which formed the pustu!es in their backs. In $S_{y s t}$. $\boldsymbol{N} / t$ t. 969. 3. he strangely observes under the former species, "Habitat in equorum fauce, per nares intrans!" confounding probably $C$. veterinus of Mr. Clark with the true $C$. nasulis.

4 Lach. Lapp. i. 280.

5 K'lor. Lit?p. 79. 
rein-deer that has only seen one winter; and these so emaciate them, that frequently one-third of their number perish in consequence. Even those that are full-grown suffer greatly from this insect. The fly follows the animals over precipices, valleys, the snow-covered mountains, and even the highest alps; to which, in order to avoid it, they often fly with great swiftness in a direction contrary to the wind. By this constant agitation and encleavour to escape from the attack of their enemy they are kept from eating during the day, standing always upon the watch, with erect ears and attentive eyes, that they may observe whether it comes near them. ${ }^{1}$ The rein-deer are teased also by a peculiar species of Tabanus (T'. tarandinus), which, by a singular instinct, instead of their skin, makes its incision in their horns when tender.

Our dogs, the faithful guardians of our other domestic animals and possessions, the attached companions of our walks, and instruments of miny of our pleasures and amusements, cannot defend themselves from insect annoyance. They have their peculiar louse, and the flea sucks their blood in common with that of their master; you must also often have noticed how much they suffer from the dog-tick, which, when once it has fixed itself in their flesh, will in a short time, from the size of a pin's head, so swcll itself out by gorging their blood that it will equal in dimensions what is called the tick-bean. In the West Indies these ticks, or one like them, get into the ears and head of the dogs, and so annoy them and wear them out that they either clie or are obliged to be killed. ${ }^{2}$

Some of the nost esteemed dainties of our tables are supplied from such of the winged part of the creation as we have domesticated. These also have a louse (Nirmus) appropriated to them, and the gorgeous peacock is infested by one of extraordinary dimensions and singular form. Pigeons, in addition, often swarm with the bed-bug, which makes it advisable never to have their lockers fixed to a dwelling-house. In their young, if your curiosity urges you to examine them, you may find the larva of the flea, which in its perfect state often swarms in poultry.

Amongst our most valuable domestic animals $\mathbf{I}$ shall be very unjust and nngrateful if I do not enumerate those industrious little creatures the bees, from whose incessant labours and heaven-taught art we derive the two precious productions of honey and wax. They are also infested by numerous insect-enemies, some of which attack the bees themselves, while others despoil them of their treasures. - They have parasites of a peculiar genus (if indeed they are not the young larva of Melöe), although at present regarded as belonging to Pediculıs ${ }^{3}$, and mites (Gamasus

1 Linn. Flor. Lapp. 37:9

2 Mr. Kiftoe.

3 Melittoplergus MLus. Kírby. See MIon. Ap. Angl. ii. 168. (Triungulinus Dufour.) I copy the fullowing memnrandum respecting $\Lambda$. . melitte from my common-place book, Mlay 7.181:. On the flowers of Ficaria, Taraxacum, and Bellis, I found a great number of this insect, which seemed extremely restless, running here and there over the flowers, and over each other, with great swiftness, mounting the anthers, and sometimes lifting themselves up above them, as if looking for something. One or two of them leaped upon my lsand. Near one of these flowers I found a small Andrena or Halictus, upon which some of these creatures were busy sucking the poor animal, so that it seemed unable to fly away. When disclosed from the egg, I imagine they get on the top of these flowers to attach themselves to any of the Andrenida that may alight on them, or come suficiently near for them to leap on it. $-K$. 
symnopterorum) are frequently injurious to them. In Germany the beelouse (Braula caca Nitsch), which is about the size of a flea and allied to the Hippobosce, often infests populous hives so as greatly to annoy the bees by fixing itself upon them (sometimes two, three, or more on a single bee), and making them restless and indisposed to their usual labours. ${ }^{1}$ That universal plunderer the wasp, and his formidable congener the hornet, often seize and devour them, sometimes ripping up their body to come at the honey, and at others carrying off that part in which it is situated. The former frequently takes possession of a hive, having cither destroyed or driven away its inhabitants, and consunes all the honey it contains. Nay there are certain idlers of their own species, called by apiarists corsair-bees, which plunder the hives of the industrious. - From the curious account which Latreille has given us of Philanthus apivorus, a wasp-like insect, it appears that great havoc is made by it of the unsuspecting workers, which it seizes while intent upon their daily labours, and carries off to feed its young. ${ }^{2}$ Another insect, which one wonld not have suspected of marauding propensities, must here be iucroduced. Kulm informs us, that long ago (in 1799) some inonks who kept bees, observing that they made an unusual noise, lifted up the hive, when an animal flew out, which, to their great surprise no doubt, for they at first took it for a bat, proved to be the death's head hawk-moth (Acherontia atropos), already celebrated as the innocent canse of alarm; and he remembers that several, some years before, had been found dead in the bee-houses. ${ }^{3}$ M. Huber, also, in 1804 , discovered that it had made its way into his hives and those of his vicinity; and had robbed them of their honey. In Africa, we are told, it has the same propensity; which the Hottentots observing, in order to monopolise the honey of the wild bees, lave persuaded the colonists that it inflicts a mortal wound.4 This moth has the faculty of emitting a remarkable sound, which he supposes may produce an effect upon the bees of a live somewhat similar to that caused by the voice of their queen, which as soon as uttered strikes them motionless, and thus it may be enabled to commit with impunity such devastation in the midst of myriads of armed bands. ${ }^{5}$ The larve of two species of moth (Galleria cereana, and Mellonella) exhibit equal hardihood with equal impunity. They, indeed, pass the whole of their initiatory state in the midst of the combs. Yet in spite of the stings of the bees of a whole republic, they continue their depredations unmolested, sheltering themselves in tubes made of grains of wax, and lined with silken tapestry, spun and wove by themselves, which the bees (however disposed they may be to revenge the nischiet which they do them by devouring what to all other animals would be indigestible, their wax) are unable to penetrate. These larvæ are sometimes so numerous in a hive, and commit such extensive ravages, as to force the poor bees to desert it and seek another habitation.

I shall not delay you longer upon this subject by detailing what wild animals suffer from insects, further than by observing that the two creatures of this description in which we are rather interested, the hare and the

1 Köllar on Ins. inj. to Gurdeners, \&c. 73.

2 Latreille, Hist. des Fourmis, 307-320.

5 Naturforscher, Stk. xvi. 74.

1 Quoter from Campbell's Travels in South Africa, in the Quarterly Review for July, $1815,315$.

5 Hulser, Pref. xi-xiii. 
rabbit, do not escape their attack. The hare in Lapland is more tormented by the gnats than any other quadruped. To aroid this pest it is obliged to leave the cover of the wonds in full day, and seek the plains: hence the hunters say, that of three litters which a hare produces in a year, the first dies by the cold, the second by gnats, and only the third escapes and comes to maturity. ${ }^{1}$ - We learn from the ingenious Mr. Clark, that the American rabbit and hare are infested by the largest species of CEstrus $^{2}$ yet cliscovered; and our domestic rabbits sometimes swarm with the bed-bug. This was the case with some kept by two young gentlemen at my house last summer to such a degree, that I found it necessary to have them killed.

Nor are the inhabitants of the waters sheltered by their peculiar element from these universal assailants. The larvæ of Dytisci, fixing themselves by their suctorious mandibles to the body of fish, doubtless destroy an infinite number of the young fry of our ponds. Some speçies of salmon (Salmo fario L.) are the food of an animal which Linné has arranged under Pediculus; and probably many others of the finny tribes may, like the birds, have their peculiar parasites. Even shell-fish do not escape, for the Nymphon grossipes enters the shell of the muscle and devours its inhabitant.

I am, \&c.

1 De Geer, ii. 83.

2 Considered by Mr. Clark as a new genus, which he has named Cuterebra, and of which he has described three species. - Essay on the Bots of Horses, \&c. p. 65. เ. 2 . . . $2+1-29$. 


\section{LETTER VI.}

\section{INJURIES CAUSED BY INSECTS.}

\section{INDIRECT INJURIES - continued.}

Having endeavonred to give you some idea of the mode in which insects establish and maintain their empire over man and his train of dependent animals, I shall next call your attention to his living vegetable possessions, whether the produce of the forest, the field, or the garden; whether necessary to him for his support, convenient for his use, or ministering to his comfort, pleasure, and delight: - and here you will find these little creatures as busily engaged in the work of mischief as ever, destroying what is necessary, deranging what is convenient, marring what is beautiful, and turning what should give us pleasure into an object of disgust.

Let us begin with the producc of our fields. - Bread is called "the staff of life:" yet should Dirine Providence in anger be pleased to give the rein to the various insects which, in the different stages of its growth, attack the plant producing it, how quickly would this staff be broken! From the moment that wheat begins to emerge from the soil, to the time when it is carried into the barn, it is exposed to their ravages. One of its earliest assailints in this country is that of which Mr. Walford has given an account in the Limean 'Transactions, taking it for' the wire-worm; but, as Mr. Marsham observed, not correctly, it being probably the larva of some colcopterous insect, perhaps of one of the numerous tribe of Brachyptera or rove-beetles, which are not universally carnivorous. This animal was discovered to infest the wheat in its earliest stage of growth after vegetation had commenced; and there was reason to believe that it began even with the grain itself. It eats into the young plant about an inch below the surface, devouring the central part ; and thus, vegetation being stopped, it dies. Out of fifty acres sown with this grain in 1802, ten had been destroyed by the grub in question so early as October. ${ }^{1}$ Other predaceous Coleoptera will also at tack young corn. This is done by the larva of "Zabrus gibbus, both with respect to wheat and barley. In the spring of 1813 not less than twelre German hicles (Hufen), equal to two hundred and thirty English acres, of wheat, were destroyer by it in the canton of Seeburg, near Halle, in Germany; and Germar (who, with other members of the Socicty of Natural History at that place, ascertained the fact) suspects that it was the same insect deseribed by Cooti, an Italian author, which caused great destruction in Upper Italy in 1776. Not only is the larva, which probably lives in that state three years, thus injurious, but, what one would not have expected, the perfect beetle itself attacks the grain, both of wheat and barley, when in the ear, clambering

1 Linn, Trans. ix. 156-161. 
up the stems at niglt in vast numbers to get at it. The Rev. G. T. Rudd, when residing at Kimpton near Andover, Hants, where this insect abounds, not only saw it, as did his brother, gnaw off the tip of the husk from the end of a grain of harley, and then gradually draw the milky grdin out of its sheath, consuming it as it came forth, till the whole grain had disappeared, and repeating the operation till seven or eight grains had been eaten, but was fully satisfied, on lilling and dissecting it, that it had fed on the juicy immature grain. ${ }^{1}$ Along with the larva of this insect were found in the proportion of about one fourth, those of another beetle (Melolontha ruficomis), which seemed to contribute to the mischief.? Other beetles, generally supposed to be carnivorous, as Amara communis trivialis, \&c., are also stated by M. Zimmermann to feed on wheat. ${ }^{3}$

The caterpillars of a moth (A grotis segetum) occasionally devastate large tracts of wheat and rye by cating the roots, stem, and leaves, in Northern Germany, Prussia, Poland, and Russia ${ }^{4}$; but this species with us is chiefly injurious to turnips and garden vegetables.

Mr. Markwick has given us the history of a fly that attacks wheat in a later period of its growth, which, if it be not incleed the same, appears to be nearly related to the Musca punilionis of Bierkander ${ }^{5}$ (Oscinis F.), accused by him of being extremely injurious to rye in the spring. Our insect was discovered on the tirst-sown wheats early in that season, making its lodgement in the very heart of the principal stem just above the root, which stem it invariably destroyed, giving the crop at first at most unpromising appearance, so that there seemed scarcely a hope of any produce. But it proved in this and other instances that year (1791) that the plant, instead of being injured, derived great benefit from this circumstance; for, the main stem perishing, the root (which was not hurt) thirew out fiesh shoots on every side, so as to yield a more abundant crop than in other fields where the insect had not been busy. These flies, therefore, seem to belong to our insect benefuctors; and I should not have introdnced them here, had it not been probable that in some instances later in the spring they may attack the lateral shoots of the wheat, and so be in. jurious. It is also not unlikely that the new progeny, which is disclosed in May, may oviposit in barley or some other spring corn, which would bring the next generation out in time for the wheat sown in the autumn. These flies are amongst the last, and, in some seasons, the most numerous, that take shelter in the windows of our apartments when the first frosts indicate the approach of winter, previous to their becoming torpid during that season. When this little animal was first observed in England, it created no small alarm amongst agriculturists, lest it should prove to be the Hessian fly, so notorious for its depredations in North America; but Mr. Marshan, by tracing out the species, proved the alarm to be un-

\section{Ent. MIag. ii. 182.}

2 Germar's Mug. der Ent. i. 1-10. Mr. Stephens, in his Illustrations of British Entomology (No. I. p. 4.) very judiciously asks, "May not these lerbivorous larva have been the principal cause of the mischief to the wheat, while those of the Zubrus contributed rather to lessen their numbers than to destroy the corn?" Ijut this query does not account for their being found, when in the perfect state, attacking the ear. I have seen comnate beetles devouring the seeds of unbellifcrous plants.

3 Silbermann, liev. Ent. ii. 201.

1 Köllar on Ins. injurious to Gardeners, \&c. 9:-101.

5 Act. Stockh. 17т8, 3. n. 11, and 4. n. 4. Marsham in Linn. Trans, ii. 79. 
founded. ${ }^{1}$ That there was sufficient cause for apprehension, should it. have so turned out, what I have formerly stated concerning the latter insect, and the additional facts which I shall now adduee, will amply show.

The ravages of the animal just alluded to, which was first noticed in 1776 , and received its name from an erroneous iclea that it was carried by the Hessian troops in their straw from Germany, were at one time so universal as to threaten, where it appeared, the total abolition of the culture of wheat; though the injury which it now occasions is much less than at first. It commences its depredations in antumn, as soon as the plant begins to appear above ground, when it devours the leaf and stem with equal voricity until stopped by the frost. When the return of spring brings a milder temperature the fly appears again, and deposits its egrg in the heart of the main stems, which it perforates, and so weakens, that when the ear begins to grow heavy, and is about to go into the milky state, they break down and perish. All the crops, as far as it extended its flight, fell before this ravager. It first showed itself in Long Island, from whence it proceeded inland at about the rate of fifteen or twenty miles annually, and by the year 1789 had reached 200 miles from its original station. I must observe, however, that some accounts state its progress at first to have been very slow, at the rate only of seven miles per annum, and the damage inconsiderable; and that the wheat crops were not materially injured by it before the year 1788. Thongh these insect hordes traverse such a tract of country in the course of the year, their flights are not more than . Sve or six feet at a time. Nothing intercepts them in their destructive career, neither mountains nor the broadest rivers. They were seen to cross the Delaware like a cloud. The number's of this fly were so great, that in wheat-harvest the houses swarmed with them, to the extreme annoyance of the inhabitants. They filled every plate or vessel that was in use ; and five hnndred were counted in a single glass tumbler exposed to them a few minutes with a little beer in it. ${ }^{2}$

America suffers also in its wheat and maize from the attack of an insect of a different order; which, for what reason I know not, is called the chintz buy-fly. It appears to be apterous, and is said in scent and colour to resemble the bed-bug. They travel in immense columns from field to field, like locusts, destroying every thing as they proceed; but their injuries are confined to the states south of the 40th degree of north latitude. ${ }^{3}$ Trom this account the clepredator here noticed should belong to the

\section{Linn. Trans. ii. $76-80$.}

2 Encyclopad. Britann, viii, 489-495. Though the ravages of the Hessian fly in the United States have not been so extensive of late, much injury is still occasionally suffered from it, as stated by Mr. Say, who described it under the name of Cecidomyia destructor, anil as I learn from E. C. Herrick, Esq. of New Ilaven, Connecticut, who has taken great pains to ascertain the metamorphosis and economy of this insect; and either this or an allied species described by M. Küllar, destroyed a large proportion of the wheat crops in Hungary in 1833, and extended itself also to France. Dr. Hammerschmidt, who has also given an account of this insect, has called it Cecidomyia tritici, snpposing it to be the same with the insect described by Mr. Marsham and Mr. Kirby; bnt as the mischief done by the larva of the former is caused by its enting into the stem and weakening the whole plant, while the latter is injurions by destroying the pollen of the blossom, the two insects are evidently very distinct, as indeed their different colour proves.-Lóllar on Ins. injurious to Gurdeners, \&e. 118.

3 Young's Annals of Agriculture, xi. 471. 
tribe of Geocorisce Latr.; but it seems very difficult to conceive how an insect that lives by suction, and has no mandibles, could destroy these plants so totally.

When the wheat blossoms, another marauder, to which Mr. Marsham first called the attention of the public, takes its turn to make an attack upon it, under the form of an orange-coloured gnat, which introducing its long retractile ovipositor into the centre of the corolla, there deposits its eggs. These being hatched, the larva, perhaps by eating the pollen, prevent the impreg.ration of the grain, and thus in some seasons destroy the twentieth part of the crop. ${ }^{1}$

Nuch mischief is also sometimes done by a species of Thrips ( $T$. cerea. tina Haliday), a minute insect, often abundant on flowers, which, insinuating itself between the internal valve of the corolla and the grain, inserts its rostrum into this last, and canses it to shrivel ${ }^{2}$; and according to Vassali Eandi ${ }^{3}$, as quoted by Mr. Haliday, the same species also attacks the stem at a still earlier period, cansing the abortion of the ears, and sometimes to such an extent that in 1805 (in which year the wheat in England, also, suffered apparently from this cause) one third of the wheat crop on the richest plains of Piedmont was destroyed by this seemingly insignificant little insect. ${ }^{4}$

One would think, when laid up in the barn or in the granary, that wheat would be secure from injury; but even there the weevil (Calandra granaria), in its imago as well as in its larva state, devours it; and sometimes this pest becomes so infinitely numerous, that a sensible man, engaged in the brewing trade, once told me, speaking perhaps rather hyperbolically, that they collected and destroyed them by bushels : and no wonder, for a single pair of these destroyers may produce in one yeur above 6000 descendants. There are three other insects that attack the stored wheat, which are more injurions to it than even the weevil. One is a minute species of moth (Tinea granella L.), of which Leeuwenhoek has given us a full bistory under the name of the wolf. Another is a sprecies of the same genus, at present not named, which, as we are informed by Du Hamel, at one time committed dreadful ravages in the province of Angoumois in France. The third is Trogosita caraboides, a kind of beetle, the grub of which, called Cadelle, Otivier tells us did more damage to the housed grain in the southern provinces of France than cither the weevil or the wolf. ${ }^{5}$

In this place, too, must be noticed the caterpillars of a moth (Caradrina cubienlaris), which Mr. Raddon told me were found in such quantities in a wheat-stack near Bristol, when taken down to be thrashed, that he could have gathered them up by handfuls, and they had done much injury to the grain. ${ }^{6}$

Here I may just mention a few other insects which devour grains that are the food of man, concerning which I have collected no other facts. The rice-weevil (C'alandra oryzc) is very injurions to the useful grain after which it is named; as is likewise another small beetle, Lyetus dentatus $\mathbf{F}$. (S Sylvanus Latr.); and an Indian grain, called in the country Joharre, which

1 Tipula tritici K., belonging to Latreille's genus Cecidomyia. - Marsham and Kirby in Linn. Trans. iii. 242-245. iv. 225-239. v. 96-110.

2 Ǩrby in Linn. Trans. iii. 242.

4 Haliday in Entom. Mug. v. 414.

- Trans. Ent. Soc. Lond, ii. proc. xlii.

3 Mem. Acad. Turin. xvi. Ixxvi.

5 Oliv. ii. n. 19 3, 4 . 
appears to be a species of Holeus or Milium, is the appropriate food of another species of Calandra ${ }^{1}$, whieh I found abundant in it.

Rye, in this island, is an article of less importance than wheat; but in some parts of the Continent it forms a principal portion of the breadcorn. Providence has also appointed the insect means of eausing a scarcity of this species of food. The fly before noticed (Oscinis pumilionis) introduces its eggs into the heart of the shoots of ryc, and occasions so many to perish, that from eight to fourteen are lost in a square of two feet. ${ }^{2}$ This fy, in 1839, did much damage to the rye at Grignon, in France ${ }^{3}$, and in 18 th to that near Kingston, surrey. ${ }^{4} \mathrm{~A}$ small moth, also (Margarita secalis), which cats the euhn of this plant within the ragina, thus destroys many ears. In common with wheat and barley, it also suffers from Leeuwenhoek's wolf and the weevil, when stored in granaries.

Barley likewise, another of our most valuable grains, has several insect foes, besides the beetle (Zabrus gibbus), already alluded to (p. 134.). The gelatinous larva of a saw-fly (Tenlhredo L.) preys upon the upper surface of the leaves, and so occisions them to wither, MIusca hordei of Bierkander also assails the plant. A tenth part of the produce of this grain, Linné affirms, is annually destroyed in Sweden by another fly not yet discovered in Britain (Oscinis frit), which does the mischief by getting into the ear; as does likewise $O$. lineata F. Dr. J. N. Santer has ileseribed a Ay which he calls Tipula cerealis (nost probably a species of Cecidomyia), the larvæ of which, eating the stem of barley and spelt (a kind of dwarf wheat), did great injury to these erops in the grand duchy of Baden in 1813 and 1816 ; and the sane, or an allied species, is supposed to have formerly destroyed the oats in Styria and Carinthia. ${ }^{5}$ A suall species of moth deseribed by Reaumur, though not named by Jinné, which may be called Tinea hordei (I'psolophus granellus?), devours the graiu when laid up in the granary. This fly deposits several eggs, perhaps twenty or thirty, on a single grain : but as one grain only is to be the portion of one larva, they disperse when hatched, each selecting one for itsclf, which it enters from without at a place more tender than the rest; and this single grain furnishes a sufficient supply of food to support the eaterpillar till it is ready to assume the pupa. Concealed within this contracted habitation, the little animal does nothing that may betray it to the watehful eye of man, not even ejeeting its exerements fiom its habitation; so that there maly be millions within a heap of corn, where you would not suspect there was one. ${ }^{6}$

1 Circulio testaceus, Ent. Brit.

2 Mlarsham in Linn. Traus. ii. S0. De Geer notices the injury done by this fy to rye, and ubserves that before it had been attributed to frost, ii. 68 .

' 4 An. Ent. Soc. de France, viii. p. xiii.

4 l'roceed. of Eint. Soc. Lond. Oct. 5. 1810.

5 Kïllar on Ths. inj, to Gurdeners, Sic. 124.

6 Act. Stockh. 1750, 12s. Reaum. ii. 480, \&c. Barley, like wheat, and indeed all white corn, is much injured in the granaries of the corn-dealer by the larva of the little moth (Tinea grunella L.), the wolf of Leeuwenhoek before referred to. On visiting those of Messrs. Hellicar, Bristol, in Outober, 1837, with my friend, W. Faldon, Esq., we found the barley lying on the floors covered with a ganzelike tissue formed of the fine silken threads spun by the larve in traversing its surface, on recently quitting it for the purpose of undergoing their metamorphosis in the ceiling of the granary, formed of the joists and wooden floor of the story above. What was remarkable, as $\mathrm{Mr}$. Raddon communicated to the Entomological 
I have not observed that oats suffer from insects, except from the universal sulterranean destroyer of the grasses, the wire-worm, of which shall give you a more full account hereafter; and occusionally from an Aphis.

Bucliwheat (Polygonum frgopyrum), a grain little cultivated with us, except as food for pheasants, but which is an important crop on the Continent on poor sandy soils, is sometimes wholly cut off, by the larva of a moth (Agrotis fritici), which afterwards devour's the rye sown to replace the buckwheat; and millet, also a considerable continental crop, is occasionally much damaged by the larve of another moth (Botys silacealis), which, eating into the stem of the plants, causes them to wither and die. ${ }^{1}$

The only important grain that now remains unnoticed is the maize, or Indian corn. Besides the chintz bug-fly, a little betle ${ }^{2}$ (Phaleria cormata) appears to devour it; and it has probably other unrecorded enenies. The Guinea corn of America (Holcus bicolor), as well as other kinds of grain, is, according to Abbot, often much injured by the larva of a moth (Noctude fragiperda Smith), which feeds upon the main shoot. ${ }^{3}$

Next to grain pulse is useful to us, both when cultivated in our gardens and in our fields. Peas and beans, which form so material a part of the produce of the farm, are exposed to the attack of a numerous host of insect depredators; indeed the former, on account of their ravages, is one of the most uncertain of our crops. The animals from which in this

Society (Trans. ii. proc. Ixvii.), was the great depth to which the larve had bored in the wood, even through knots filled with turpentine, so as to convert portions of the wood-work in places quite into a honey-comb, and thus to be almost is injurious to the building as to the corn stored in it. Our first idea was that this boring was simply for the purpose of gnawing off portions of wood with which to form their cocoons before becoming pupx, but the powdery masses hanging from the entrance of the holes had, when viewed under a leus, so completely the appearance of excrement, that we were at last forced to the conchision, howerer strange and improbable it may stem, that these larva, alter eating ad libitum of barley, voluntarily quit it, and actually eat and digest fir-wood, even to the very knots saturated with turpentine. In fact, the great depth to which they bore is inconsistent with the supposition of their object being merely to detach woody fibres as a covering for their cocoons. That their main purpose (whether we suppose the excavated wood to be eaten and digested or not) is to provide a retreat for the larva, which remain in this state the whole winter, and do not become pupre till spring, is proved by the fact that it is from the mouths of these holes (after every portion of the excrement hanging from them has been swept away, and the whole ceiling thickly lime-washed, as it is every autumn) that the moths emerge by thousands in the month of June, as yearly takes place in Messrs. Hellicar's granaries. 'The further investigation, which is so evidently required, as to the strange anomaly of these larwe seeming to eat and digest wood after devouring as much barley as they choose, 1 have recommended to my friend G. H. K. Thwaite, lisq. of 1Bristol, whose habits of close obscrvation so well fit him for throwing light on the subject; and meanwhile it may be here observed, that the facts stated of the great damage flone to vessels thit bring bones, hoofs, and horns from Brazil, and in one case to a large parcel of cork-woot, by the larva of Dermestes vulpinus, which, after eating their fill of animal matter, attack wook and cork, seem of an analogous kind to those above mentioned, unless in these instances the wood and cork are merely gnawed, and not eaten and digested. -(See Trans. Ent. Soc. Lond. ii. proc. Ixviii. : and Sluckard's Elements of Brit. Ent. i. 189.)

1 Köllar on Ins. inj. to Gardeners, \&e. 102-110.

2 This insect was taken in maize by $\mathrm{Ml}$. Sparshall of Norwich.

3 Smith's Albott's Insects of Georgia, 191. 
country both these plants suffer most are the Aphides, commonly called leaf-lice, but which properly should be denominated plant-lice. As almost every animal has its peculiar louse, so has almost every plant its peculiar plant-lonse; and, next to locusts, these are the greatest enemies of the vegetable world, and, like them, are sometimes so numerous as to darken the air. ${ }^{1}$ The multiplication of these little creatures is infinite, and almost incredible. Providence has endued them with privileges promoting fecunlity which no other insects possess: at one time of the year they are viviparous, at another oviparous; and, what is most remarkable and without parallel, the sexual intercourse of one original pair serves for all the generations which proceed from the female for a whole succeeding year. Reaumur has proved that in five generations one Aphis may be the progenitor of $5,904,900,000$ lescendants; and it is supposed that in one year there may be twenty generations. ${ }^{2}$ This astonishing fecundity exceeds that of any known aninal; and we cannot wonder that a creature so prolific should be proporticnably injurious : some species, however, seem more so than other's, Those that attack wheat, oats, and barley, of which there are more kinds than one, seldom multiply so fast as to be very noxious to those plants; while those which attack pulse spread so rapidly, and take such entire possession, that the crop is greatly injured, and sometimes destroyed by them. This was the case with respect to peas in the year 1810 , when the produce was not much more than the seed sown; and many farmers turned their swine into their pea-fields, not thinking them worth harvesting. The damage in this instance was caused solely by the Aphis, and was universal throughout the kingdom, so that a sufficient supply for the navy could not be obtained. The earlier peas are sown the better chance they stand of escaping, at least in part, the effects of this vegetable Phthiriasis. Beans are also often great sufferers fiom another species of plant-louse, in some districts, from its black colour, called the Collier, in other's the Dolphin, which begins at the top of the plaut, and so kecps nultiplying clowuwards. The best remedy in this case, which also tends to set the heans well, and improves hoth their quality and quantity, is to top them as soon as the Aphides begin to appear, and carrying away the tops to burn or bury them. In a late stage of growth great havoc is often made in peas by the grub of a snuall beetle (bruchus granarizs), which will sometimes lay an eges in every pea of a pou, and thus destroy it. Something similar, I have been told (I suspect it is a shortsnouted weevil), occasionally injurcs beans. In this country, however, the mischief caused by the Bruchus is scldom very serions; but in North America another species (B. pisi), which is also found here, but not to any very injurious extent, is most alarmingly destructive, its ravages having been at one time so universal as to put an end in some places to the cultivation of that favourite pulse. No wonder, then, that Kalm should have been thrown into such a trepidation upon discovering some of these pestilent insects just disclosed in a parcel of peas he had brought from that country, lest ne should be the instrument of introducing so fatal an evil into his beloved Swelen. ${ }^{3}$ In the year 1780 an alarm was spread in

1 I say this upon the authority of Mr. Wolnough of Hollesley (late of Boyton) in Suffolk, an intelligent agriculturist, and a most acute and accurate observer of nature.

2 Reaum, vi, 566 . 3 Kalm's Travels, i. 173. 
some parts of France, that people had been poisoned by eating vormeaten peas, and they were forbidden by authority to be exposed for sale in the market; but the fears of the public were soon removed by the examination of some scientifie men, who found the cause of the injury to be the insect of which I am now speaking. ${ }^{1}$ Another species of Bruchus (B. pectinicomis) devours the peas in (hina and Barbary. A leguminous seed, much used when boiled as food for horses in India, known to Europeans by the name of Gram, but in the Tamul dialect called Koloo, and by the Moors Cooltec, is the appropriate food of a fourth kind of Bruchus, related to the last, but having the antennæ, which in the male are peetinated, much shorter than the body. It is, perhaps, $B$, scutellaris. A parcel of this seed ${ }^{2}$ given me by Ciptain Green was full of this inseet, several grains containing two. Indeed, in tropical climates, the seeds of almost every pod-bearing plant, as of the genera Gleditschia, Theobroma, Mimosa, Robinia, \&c. are caten by some species of Bruchus, as are the cocoa-nut and palm-nut. ${ }^{3}$ Molina, in his History of Chili, tells us of a beetle, which he names Iucanus pilmus, that infests the beans in that country; - a circumstance quite at variance with the habits of the $L u$ canide, which all prey upon timber. This insect was probably a Phaleria, in which genus the mandibles are protruded from the lead, like those of Lueanus; and one species, as we have seen above, feeds upon maize.

Great profits are sometimes derived by farmers from their crops of clover-seed: but this does not happen very often; for a small weevil (Apion flavifemoratum), which abounds everywhere at almost all times of the year, fceds upon the seed of the purple clover, and in most seasons does the crop considcrable damage ; so that a plant of the fairest appearanee will, in eonsequence of the voraeity of this little enemy, produce scarcely any thing. Another species (Apion flavipes) infests the Dutch or white elover: ${ }^{4}$ The young plants of purple clover, when just sprung, are often, as Mr. Joseph Stickney pointed out to me, much injured by the same little jumping beetles (Haltica) that at ack the turnips. In Germany, where Rape is more extensively grown than with us for the seed, the erop sometines wholly fails from the attacks of a small grub, supposed to be that of a weeril of the genera Nedyus or Ceutorhynehus, which, piercing the stalks from the base to the summit, deprives the blossom of the due supply of sap, and thus causes it to perish. ${ }^{5}$

But not only, if let loose to the work of destruction, might insects annihilate our grain and pulse, they would also deprive the earth of that beautiful green carpet which now eovers it, and is so agreeable and so refreshing to the sight. When you see a large tract of land lying fallow, as is sometimes the case in open distriets, with no intervening patches of verdure, low unpleasant and uncomfortable is it to your eye! What then would be your sensations were the whole face of the earth bare, and not dressed by Flora? But such a state of things would soon take place if, to

1 Amoreux, 288.

2 I have raised plants from this seed, which appear from the foliage to belong either to Phaseolus un Dolichos.

3 Westwood, Mod. Class of Ins. i. 330.; and in Loudon's Gardener's Mag. No. 87. p. $28 \overline{\%}$.

4 Markwick, Marsham, and Lehmann, in Linn. Trans, vi. 142-, ; and Kirby in ditto, ix. 37.42. n. 19,23 .

s Keferstein in Silbermann's Revue Ent. i. 135. 
punish us, or to teach us thankfulness to the great Arbiter of our fate, the insects that feed upon the grass of our pastures were to become as generally numerous as they are occasionally permitted to do. One of the worst of these ravagers is the grub of the common cockchafer (Melolontha vulgaris). This insect, which is found to remain in the larva state four years, sometimes destroys whole acres of grass, as I can aver from my own observation. It undermines the richest meadows, and so loosens the turf that it will roll up as if cut with a turfing-spade. These grubs did so much injury about seventy years ago to a poor farmer near Norwich, that the court of that city, out of compassion, allowed him $25 \%$, and the man and his servant declared that he had gathered eighty bushels of the beetle. ${ }^{1}$ In the year 1785 many provines of France were so ravaged by them, that a premium was offered by the government for the best mode of destroying them. They do not confine themselves to grass, but eat also the roots of corn; and it is to feast upon this grub more particularly that the rooks follow the plough. ${ }^{2}$

The larva also of another species of a cognate genus (Hoplia pulverulenta) is extremely destructive in moist meadows, rooting under the herbage, so that, the soil becoming loose, the grass soon withers and dies. swine are very fond of these grubs, and will devour vast numbers of them, and the rooks lend their assistance.

Amongst the Lepidoptera, the greatest enemy of our pastures is the Charcas Gramimis, which, however, is said not to touch the foxtail grass. In the years $1740,1741,1742,1748,1749$, they multiplied so prodigiously and committed such ravages in many provinces of Sweden, that the meadows became quite white and $\mathrm{dry}$, as if a fire had passed over them. ${ }^{3}$ This destructive insect, though found in this country, is luckily scarce amongst us; but our northern neighbours appear occasionally to have suffered greatly from it. In 1759, and again in 1802, the high sheep farms in Tweeddale were dreadfully infested by a caterpillar, which was probably the larva of this moth; spots of a mile square were totally covered by them, and the grass devoured to the root. ${ }^{4}$ In 1835, the larvæ of this moth so infested some districts in Buhemia, that Prince Clary, by employing two hundred men for four and a half days, collected twenty-three bushels, computed to contain fon and a half millions of caterpillars. ${ }^{5}$

Grasses, both natural and artificial, are attacked by the larva of several species of beetles. Those of Coccinella impanctata (which with C. Argus Scriba, and other species, live on vegetable food) destroy, in Germany, sainfoin, clover, and tares; those of Colaspis barbara, in Spain, whole fields of lucerns (Medicago sutiva ${ }^{6}$ ); and those of Galleruca Tanaceti, natural pasturage, having greatly injured that of Mount Jura in Switzerland in

1 Plilos. Trans. 1741. 581.

2 There would seem to be a prospect of cockchafers being made in some degree to repay the previous injury they cause, if the statement in the newspapers (June. 1841) be correct, that M. Treard, mayor of IIonfleur in France, and proprietor of an oil-mill, having offered one franc per bushel for cockchafers, procured serenteen bushels, from which lie obtained twenty-eight quarts of good lamp-oil. A kind of grease has also lately been made from them in Hungary.

3 De Geer, ii. 341. Amen. Acad. iii. 355.

4 Farmer's Mag. iii. 487.

5 Köllar on Ins. injurious to Gardeners, Sc. 105. 126.

6 Dufour, Ann. Soc. Ent. de France, v. 372. 
1833. ${ }^{1}$ Even the seeds of grasses have their insect enemies. Mr. H. Gibbs stated at the meeting of the Royal Agricultural Society, May 5, $18+1$, that generally not one in a dozen of the seeds of the Foxtail grasses (Alopecurus) vegetate, owing to their vitality being destroyed by a small orange-coloured grub (Cecidomyia? ${ }^{2}{ }^{2}$

Most of the insects I have hitherto mentioned attack our crops partially, confining themselves to one or two kinds only; but there are some species which extend their ravages indifferently to all. Of this clescription is the Pyralis (?) frumentalis, which moth, Pallas tells us, is an almost universal pest in the government of Kasan in Russia, often eating the greater part of the spring corn to the root. ${ }^{3}$ To this we are fortunately strangers ; but another, well known by the name of the wire-worm, causes annually a large diminution of the produce of our fields, destroying indiscriminately wheat, rye, oats, and grass. This insect, which has its name apparently from its slender form and uncommon hardness and toughness, is the grub of one of the elastic beetles termed by Linné Elater lineatus, but by Bierkander, to whom we are indebted for its history, E. Segetis ${ }^{4}$ (Agriotcs lineatus Eschscholtz). The late ingenious Mr. Paul of Starston in Norfolk (well known as the inventor of a machine to entrap the turnipbeetle, which may be applied by collectors with great advantage to general purposes), has also succeeded in tracing this insect from the larva to the imago state. I His larvæ produced Elater obscurus of Mr. Marsham, which, however, comes so near to $E$. Segetis that it is doubtful whether it be more than a variety. The other species, however, of the genus have similar larvæ, many of which probably contribute to the mischief. When told that it lives in its first (or feeding) state not less than five year's, during the greatest part of which time it is supported by devouring the roots of grain, though it will also attack and often much injure turnips, potatoes, \&c., you will not wonder that its ravages should be so extensive, and that whole crops should sometimes be cut off by it. As it abounds chiefly in newly broken-up land, though the roots of the grasses supply it with food, it probably does not do any great injury to our meadows and pastures. ${ }^{5}$

1 Dufour, Ann. Soc. Ent. de France, iii. 19.

2 Gardener's Chronicle, Is+1. p. 311.

5 Pallas's Travels in South Russia, i. 30.

4 Mursham iu Communications to the Board of Agriculture, iv. 412. Plate xviii. fig. 4. and Linn. Trans. ix. 160.

5 The wire-worm is particularly destructive for a few years in gardens recently converted from pasturc-ground. In the Botanic Garden at II ull thus circumstanceil a great proportion of the annuals sown in 1813 were destroyed by it. A very simple and effectual remedy in such cases was mentioned to me by Sir Joseph Banks. He recommended that slices of potato stuck upon skewers should be buried near the seeds sown, examined every day, and the wire-worms which collect upon them in great numbers destroyed.

This plin of decoying destructive animals from our erops by offering them more tempting food is excellent, and deserves to be pursued in other instances. It was very successfully employed in 1813 by J. M. Rindwell, Esq., of Barliam Hall, near Ipswich, one of the most skilful and best-informed agriculturists in the county of Suffolk, to preserve some of his wheat-fields from the ravages of a small grey slug, which threaten to demolish the plant. Having heard that turnips had been used with success to entice the slugs from wheat, he caused a sufficient quantity to dress eight acres to be got together; and then, the tops being divided and the apples slieed, ho directed the pieces to be laid separitely, dressing two stetches with them and omit- 
Here also may be included the larva of the long-legged gnat (Tipula oleracea), known in many parts by the name of the grub, which is sometimes very prejudicial to the grass in marshy lands, and at others not less so to corn. Reaumur informs us that in Poitou, in certain years, the grass of whole districts has been so destroyed by it, as not to produce the food necessary for the sustenance of the eattle. ${ }^{1}$ In many parts of England, in Holderness particularly, it euts off a large proportion of the wheat crops, especially if sown upon clover-liys. ${ }^{2}$ Reaumur concludes from the observations he made that it lives solely upon earth, and eonsequently that the injury which it occasions arises from its loosening the roots of corn and grass by burrowing amongst them : but my friend Mr. Stickney, the intelligent anthor of a treatise upon this insect, is inclined to think from his experiments that it feeds on the roots thenselves. However this may be, the evil produced is evident; and it appears too fiom the observations of the gentleman last mentioned, that this animal is not killed by lime applied in much larger doses than usual. ${ }^{3}$

Our national heverage, ale, so valuable and heartening to the lower orders, and so infinitely preferable to ardent spirits, is indebted to another vegetable, the hop, for its agrecable conservative bitter. This plant, so precious, has numerous enemies in the Lilliputian world to which I am introducing you. Its roots are sulject to the attack of the caterpillar of a singular species of moth (Hepialus Humuli), known to collectors by the mame of the ghost, that sometimes does them eonsiderable injury. ${ }^{4}-$ A small beetle, also (Haltica concinna) is particularly destructive to the tender shoots early in the year; and upon the presence or absence of Aphides, known by the name of the fly, as in the case of peas, the erop of every year depends; so that the hop-grower is wholly at the mercy of insects. They are the barometer that indicates the rise and fall of his wealth, as well as of a very important branch of the revenue, the difference in the amount of the duty on hops being often as mueh as 200,000l. per annum, more or less in proportion as the fly prevails or the contrary. ${ }^{5}$

ting two alternately, till the whole field of eight acres was gorve over. On the following morning he employed two women to examine and free from the slugs, which they did into a measure, the tops and slices: and when cleared, they were haid upon those stetches that had been omitted the day before. It was observed invariably, that in the stetches dressed with the tumips no slugs were to be found upon the wheat or crawling upon the land, though they abounded upon the turnips; while on the undressed stetches they were to be seen in great numbers both on the wheat and on the land. The quantity of slugs thus collected was near a bushel. - Mr. Rodwell is persuaded that by this plan he saved his wheat from essential injury.

1 Realum. v. 11.

2 Two species are confomded under the appellation of the grub, the larve namely of Tipula oleraeca and cornicina, which last is very injurious, though not equally with the first. In the rich district of Sunk Island in Holderness, in the spring of 1813 , hundreds of acres of pasture were entirely destroyed by them, being rendered as completely brown as if they had suffered a three month's drought, and destitute of all vegetation except that of a few thistles. A square foot of the dead turf being lug $11 \mathrm{p}, 210$ grubs were counted in it! and what furnishes a striking proof of the prolitic powers of these insects, the next year it was dificult to tind a single ore.

3 Stickney's Observations on the Grub.

4 De Geer, i. $45 \pi$.

5 It woukl not be difficult to show that nearly the whole of this large sum, and their own still greater losses, are thrown away by the hop plauters from their ighorance 
If the beer-drinker be thus interested in the history of these animals, equally so is the drinker of tea. Indeed sugar is an article so universally useful and agrecable, that what concems the cane that produces it seems to concern every one. This also affords a tempting food to insects. The citterpillar of a white moth, called the borer, for destroying which a gold medal has been long offered by the Society of Arts, is, in this respect, a great nuisance, boring into the centre of the stem, and often destroying a great proportion of the crop. This insect (for his essay on which he received the offered medal) has been described by the Rev. L. Guilding, in the Transactions of the Society of Arts (xlvi. 143.), under the name of Diatraa Sacchar, which, however, Mr. Westwood conceives is identical with Phalana saccharalis Fab. ${ }^{1}$ An ant also (Formica analis) makes a lodgment in the interior of the sugar-cane in Guinea, and destroys it.-Another species of the latter genus does not devour it, and it therefore improperly called Formica saccharivora by Linné; but, by making its nest for sielter under the roots, so injures the plints that they become unhealthy and unproductive. These insects about seventy years ago appeared in such infinite hosts in the island of Granada, as to put a stop to the cultivation of this plant ; and a reward of 20,000\%. was offered to any one who should discover an effectual mode of destroying them. Their numbers were incredible. They descended from the hills like torrents, and the plantations, as well as every path and road for miles, were filled with them. Many domestic quadrupeds perished in consequence of this plague. Rats, nice, and reptiles of every kind became an easy prey to thein: and even the: birds, which they attacked whenever they alighted on the ground in search of food, were so harassed as to be at length unable to resist them. Streams of water opposed only a temporary obstacle to their progress, the foremost rushing blindly on to certain death, and fresh armies instantly following, till a bank was formed of the carcases of those that were drowned sufficient to dam up the waters, and allow the main body to pass over in satety below. Even the all-devouring element of fire was tried in vain. When lighted to arrest their route, they rushed into the blaze in such myriach of

of entomology, Led by their old prejudices of the fly being produced by cold winds, \&e., they do nothing towards its destruction, though if aware of the way in which it is generated (as lately explained), and that by killing each female as it appears early in the spring, they would prevent the birth not of thousands but of millions of uphides; were they to take measures for thus lessening the number of their destructive enemy, they might in great measure secure themselves from its attacks. 'The aphides being so soft are killed with the slightest pressure; so that it is merely necessary to rub an infested leaf between tle thumb and fingers, with a force quite insufficient to injure its texture, to destroy every aphis upon it ; and, from experiments which I myself made in the hop-grounds of Worcestershire when at Malvern in 1838 , I am persuadel that every leaf of each hop plant might be thus cleared of the female aphides, first attacking it in spring, by women or children mounter on step-ladters for this purpose, in ten minutes or less; so that six plants being cleared per hour, sixty might be cleared per day at an expense of a shilling for libour, and the first cost of a few step-ladilers; and by repeating the operation every week or fortnight, there can be no doubt a hop plantation might be effectually. preserved from the fly ; as it might earlier in the spring from the flea (IIultica concinna), by shaking them into a kind of wide and deep sieve (divided into two halves with a circular space for the hop poles and hop stems) with a linen bottom and bay for preventing them from jumping out again.

1 Westwood, Modern Classif. of Ins. ii. 411. 
millions as to extinguish it. Those that thus patriotically devoted themselves to certain death for the common good, were but as the pioneers or advanced guard of a countless army, which by their self-sacrifice was enabled to pass unimpeded and unhurt. The entire crops of standing canes were burnt down, and the earth dug up in every part of the plantations. But vain was every attempt of man to effect their destruction, till in 1780 it pleased Providence at length to arnihilate them by the torrents of rain which accompanied a hurricane most fatal to the other West India Islands. This dreadful pest was thought to have been imported.1 More recently great mischief has been done to the sugar plantations in the island of St. Vincent, by a species of mole-cricket (Gryllotalpa didactyla Latr.), which destroys the young shoots and bores into the plant ${ }^{2}$; and to those of the island of Granada by the Delphax saccharivora, an homopterous insect, allied to that producing the cuckoo-spit, which attacks the leaves in such numbers and with such voracity, that some plantations which formerly made three hundred hogsheads of sugar per annum, had not made more than eighty or ninety in 1834 , at which time, as stated by J. C. Johnstone, Esq., two thirds of the island were suffering from its ravages, and the insect was extending itself to the neighbouring islands. ${ }^{3}$ Besides these enemies, the sugar-cane has also its Aphis, which sometimes destroys the whole crop ${ }^{4}$; and, according to Humboldt and Bonpland, the larva of Elatcr noctilucus feeds on it ${ }^{5}$, as do two weevils (Calandra Palmarum and $C$. Sacchari, Guild.), whose history has been given by the late Rev. L. Guilding. 6

Three other vegetable productions of the New World, cotton, tobacco, and coffee, which are also valuable articles of commerce, receive great injury from the depredations of insects. M'Kinnen, in his tour through the West Indies, states that in 1788 and in $179 \pm$ two thircts of the crop of cotton in Crooked Island, one of the Bahamas, was destroyed by the chenille (probably a lepidopterons larva ${ }^{7}$ ); and the rod bug, an insect equally noxious, stained it so much in some places as to render it of little or no value. Browne relates that in Jamaica a bug destroys whole fields of this plant, and the caterpillar of that beautiful butterfly Helicopis Cupido also feeds upon it. ${ }^{8}$ That of a hawk-moth, Sphinx Carolina, is the greatest pest of tobacco: and it is attacked likewise by the larva of a moth, Phalana Rhcria Smith ${ }^{9}$, and by other insects of the names and kind of which I am ignorant; and the coffee plantations in Guadeloupe and other of the West Indian Islands are ravaged by the kirya of a little moth (Elachista Coffeella). ${ }^{10}$

Roots are another important object of agriculture, which, however, as to

1 Castle in Phitos. Trans. xxx. 346.

2 Trans. Ent. Soc, Lond. ii. proc. x, xxiv. xxxi.

3 Trans. Ent. Soc. Lond. i. proc. Xxvii. Ixx, and Westwood, in MLag. Nat. Hist. vi. 407.

4 Browne's Civit and Nat. Hist. of Jamaica, 430.

5 Essai sur ta Géograplie des I'lantes, 136.

6 Westwood, Modern Class. of Ins. i. 347.

7 At the meeting of the lintomological Society on the 6th June, 1842, Mr. W. W. Saunders read a memoir on Depressuria Gossypiella, a small moth, the caterpillar of which is very destructive to the cotton crops in India.

8 M'Kimnen, 171. Browne, ubi supr. Mierian, Ins. Sur. 10.

9 Smith and Abbot, Insects of Georgia, 199.

10 Guérin-Héneville, Rev. Zoot. 1S42, p. 24. 
many of then, they may seem to be defended by the earth that covers them, do not escape the attack of insect-enemies.-The carrot, which forms a valuable part of the crop of the sand-land farms in Suffolk, is often very much injured, as is also the parsnip, by a small centipede (Geophilus clectricus), and another polypod (Polydesmus complanatus), which eat into various labyrinths the upper part of their roots; and they are both sometimes totally destroyed by the maggot of some dipterous insect, probably one of the Muscide. I had an opportunity of noticing this in the month of July, in the year. 1812, in the garden of our valued friend the Rev. Revett Sheppard. of Uffton in Suffolk. 'The plants appeared many of them in a dying state; and upon drawing them out of the ground to ascertain the cause, these larve were found with their head and half of their body immersed in the root in an oblique direction, and in many instances they had eaten off the end of it. ${ }^{1}$ The larva of a little moth (Hamilis dancella), described by Bouché, feeds upon the seeds both of the carrot and parsnip, covering the umbel with a silken web, and in some years destroys the whole crop. ${ }^{2}$

America has made us no present more extensively beneficial, compared with which the mines of Potosi are worthless, than the potato. This invaluable root, which is now so universally cultivated, is often, in this country, considerably injured by the two insects first mentioned as attacking the carrot, and also by the wire-worm. The Death's-head liawk-moth (Acherontia Atropos) in its larva state feeds upon its leaves, though without much injury. In America it is said to suffer much from two beetles (Cantharis cinerea and vittat $t$ ), of the same genus with the blister-beetle ${ }^{3}$; and another species, $C$. verticalis, in 1839, wholly destroyed the leaves of the crops at Volterra in Tuscany. ${ }^{4}$ In the island of Barbadoes some hemipterous insect, supposed to be a Tettigonia, occasionally attacks them. In 1734 and 1735 vast swarms devoured almost every vegetable production of that island, particularly the potato, and thus occasioned such a failure of this excellent esculent, especially in one parish, that a collection was made thronghout the island for the relief of the poor, whose principal food it forms.

The chief dependence of our farmers for the sustenance of their cattle in the winter is another most valuable root, the turnip, the introduction of which into our system of agriculture has added millions to our national revenue; and they have often to lament the loss and distress occasioned by a failure in this crop, of which these minor animals are the cause. Un its first coming up, as soon as the cotyledon leaves are unfolded, a whole host of little jumping beetles, composed chiefly of Haltica Nemorum, called by furmers the fly ${ }^{5}$ and black jack, but assisted also by other species,

1 The larva above noticed were probably those of Psila Rose Meigen (Psitomyia Rosa Macquart), which Köllar (p. 161.) describes as attacking carrots, residing chiefly in the main root near the end.

2 Köllar on Ins. inj. to Gardeners, \&c. 155.

3 Illiger, Mag. i. 256.

4 Passerini, quoted in Rev. Zool. 1841. p. 354.

5 The farmers would do well to change the name of this insect from turnip-fly to turnip-flea, since, from its diminutive size and activity in leaping, the latter name is much the most proper. The term, the fly, might with propriety be restricted to the Hop-aphis, and other species of the same genus; and this is the more desirable, because the hop is also subject to the attack of a Ilaltica, which the hop planters are judiciously beginning to distinguish by the name of the " $f l e u . "$ 
as $I I$. concinna, attack and devour them; so that, on account of their ravages, the land is often obliged to be resown, and frequently with no better snccess. It has been calculated by an eminent agriculturist, that from this cause alone the loss sustained in the turnip crops in Devonshire, in 1786, was not less than 100,000l.1 Much damage is also sometimes occasioned by a little weevil (Nedyus contractus), which in the same manner pierces a hole in the cuticle. When the plant is more advanced, and out of danger from these pigmy foes, the black larve of a saw-fly (Alhalia Centifolice), called by the farmers the "black" and "nigger" caterpillars, take their place, aud occasionally do no little mischief, whole districts being sometimes nearly stripped by them; so that in 1782 and 1783, many thousand acres were on this account plonghed up: and in 1835,1836 , and 1837 , the injury was not less extensive. ${ }^{2}$ The caterpillar of the cabbage-butterfly (Pontia Brassica), is also sometimes found upon the turnip in great numbers; and Sir Joseph Banks informs me that forty or fity of the insects before mentioned, called by Mr. Wallord the wireworn, but more probably, as thcre observed, the larva of one of the tribe of Brachyptera or rove-beetles, have been discovered in October just below the leaves in a single bulb of this plant. - The small knob or tubercle often observable on these roots is inhabited by a grub, which resembles one found in similar knobs on the roots of Sinapis arvensis (from which I have bred Nedyus contractus, and $N$. assimilis, small weevils nearly related to each other), and like it produces a small weevil, Centorhynehus sulcicollis. This, however, does not seem to affect their growth. Great mischief is occasionally done to the young plants by the wire-worm. I was shown a field last stmmer in which they had destroyed one fourth of the crop, and the gentleman who showed them to me calculated that his loss by them would be $100 l$. One year he sowed a field thrice with turnips, which were twice wholly, and the third time in great part, cut off by this insect. ${ }^{3}$ The roots are also sometimes seriously injured by the caterpillars of the moth (Agrotis Segetum) before mentioned as destructive to wheat crops on the Continent. Whether the disease to which turnips are subject in some parts of the kinglom, from the form of the excrescences into which the

1 Young's Annals of Agriculturc, vii. 102. For a full history of Haltica Nemomum, from the egg to its perfect state, see the very valuable paper of Henry Le Keux, Esq., in the Transactions of the Entomological Socicty of London (ii. 24.), who, though no entomologist or agriculturist, has by his prictical good sense and habits of patient and accurate observation, thrown more light on this previously obscure snbject than all his predecessors.

2 Mlarshal in Phitos. Trans. 1xxiii. 1783. See Trans. Ent. Soc. Lond. i. proc. 1xvi., ii. proc. Ixxviii. and the admirable Prize Essay, containing a full history of this insect by G. Newport, Esq., 1838. See also the valuable papers en this insect, and on the turnip-flea, in Journat of the Royat Agriculturul Socicty of England, vol. ii., by John Curtis, Esq.

3 Trans. Soc. Ent. Lond. ii. proc. xxx. A striking instance of the use of handpicking (in most cases by far the most effective mode of getting rid of insects) appeared in the West Briton, a provincial paper, in November, 1838, stating that MIr. G. Pearce of Pennare Goran lad saved an acre and a lialf of turnips, sown to replace wheat destroyed by the wire-worm and attacked by hosts of these larva, by setting boys to collect them, who, at the rate of three half-pence per 100 , grathered 18,000 , as many as 50 having been taken fron one turnip. 'I hus at an expense of only 1l. 2 s. $6 d$. an acre and a half of turnips, worth from $5 l$. to $7 \%$. or more, was saved; while as the boys could each collect 600 per day, 20 day's' employment was givesi to them at $9 d$. per day, which they would not otherwise have had. 
bulb shoots, called fingers and toes, he occasioned by insects, is not certainly known.' Another root, the Beet, which has within the last twenty years been almost as extensively cultivated in France for the manufacture of sugar as turnips with us, is much injured by a small beetle, a new species of Cryptophagus described by M. Macquart (C. Betce), which devours the plants as soon as they appear above ground. ${ }^{2}$

We have wandercl long enough about the fields to observe the progress of insect devastation : let us now return home to visit the donains of Flora and Pomona, that we may see whether their sulpjects are exposed to equal maltreatment. If we begin with the kitchen-gardon, we shall find that its various productions, ministering so materially to our daily comfort and enjoyment, almost all suffer more or less from the attack of the animals we are considering. - Thus, the earliest of our table dainties, radishes, are devoured by the maggot of a fly (Anthomyia Radicum), assisted by those of a very small beetle (Latridius porcatus ${ }^{3}$ ), and our lettuces by the catcrpillars of several species of moth ; one of which is the beautiful tiger-noth (Euprepia Caja), another the pot-herb moth (Mamestra oleracca), a third anonymous, described by Reaumur, as beginning at the root, eating itself a mansion in the stem, and so destroying the plant before it cabbages. ${ }^{4}$ And when they are come to their perfection and appear fit for the table, their beanty and delicacy are often marred by the troublesome earwig, which, insinuating itself into them, defiles them with its excrements : while the seed is often nearly wholly destroyed (as was the case in Suffolk in 1836 and the three following years) by the grubs of a fly (Anthomyia Lactuce Bouché) which live in the involucre, and feed on the seeds and receptacle. ${ }^{5}$ What more acceptable vegetable in the spring than brocoli? Yet how dreadfully is its foliage often ravaged in the autumn by numerous hordes of the cablage-butterfly ; so that, in an extensive garden, you will sometimes see nothing left of the leaves except the veins and stalks. What more useful, again, than the cabbage? Besides the same insect, which injures them in a similar way, and a species of field-bug (Pentatoma ornata), which pierces the leaves like a sicve ${ }^{6}$, in some countries they are infested by the caterpillar of a most destructive moth (Mamcstra Brassica), to which I have before alluded; which, not content with the leaves, penetrates into the very heart of the plant. ${ }^{7}$ - One of the most delicatc and

1 Spence's Observations on the Disease in Turnips called Fingers and Toes, Hull, 1812,8 vo.

2 Ann. Sc. Nat. xxiii. 94. quoter by Westwood, NIod. Class. of Ins. j. 148.

3 Kyber in Germar's Mag. der Entom. i. 1.

4 Reaum, ii. 471.

5 Curtis in Gardener's Chronicle, 1841, p. 363.

6 Köllar on Ins. inj. to Gardeners, \&c. p. 148.

7 De Geer,ii. 440. In the summer of 1826, when at Brussels, I observed that delicious vegetable of the cabbage tribe so largely cultivated there under the mame of Jets de choux, and which in England we call Brussets sprouts, to be materially injured in the later stages of its growth by the attacks of the turnip-flea, and other Jittle betles of the same genus (Haltica), which were so mumerous and so universally prevalent, that I scarcely ever exainined a full-grown plant from which a vast number miglit not have been collected. Some plants were almost black with them, the species most abundant being of a dark copper tinge. 'They' had not merely eroded the cuticle in various parts, so as to give the leaves a brown blistered apperirance, but had also eaten them into large looles, at the margin of which I often saw them in the act of gnawing; and the stunted and unhealthy appearauce of the plants 
admired of all table vegetables, concerning which gardeners are most apt to pride themselves, and bestow much pains to produce in perfection, I mean the cauliflower, is often attacked by a fly, which, ovipositing in that part of the stalk covered by the earth, the maggots, when hatched, occasion the plant to wither and die, or to produce a worthless head. ${ }^{\mathbf{1}}$ Even when the head is good and handsome, if not carefully exanined previous to being cooked, it is often rendered disgusting by earwigs that have crept into it, or the green caterpillar of Pontia Rape. In 1836, as we learn from Mr. Westwood, great injury was done in the market gardens to the west of London to the cauliflowers and other plants of the cabbage tribe by a species of aphis covered with a purple powder, which had not been before observed by the gardeners, who called it a new kind of blight. ${ }^{2}$

Our peas, beans, carrots, parsnips, turnips, and potatoes are attacked in the garden by the same enemies that injure them in the fields ${ }^{3}$; I shall therefore dismiss them without further notice, and point out those which infest another of our most esteemed kinds of pulse, kidney beans. These are principally Aphides, which in dry seasons are extremely injurious to the!n. The fluid which they secrete, falling upon the leaves, causes them

sufficiently indicated the injurious effect of this interruption of the proper office of the sap. What was particularly remarkable, considering the locomotive powers of these insects, was that the young turnips, sown in August after the wheat and rye, close to acres of Brussels sprouts (which all round Brussels are planted in the open fields among other crops), infested by myriads of these insects, were not more eaten by them than they usually are in England, and produced good average crops. It would seem, agreeably to a fict which I shall mention in its place in speaking of the food of insects, that they prefer the taste of leares to which they lave been accustomed, to younger plants of the same natural family; and hence perhaps the previous sowing of a crop of cabbage-plants in the corner of a field meant for turnips, might allure and keep there the great bulk of these insects-present in the vicinity, until the turnips were out of danger.

1 Perhaps this fly is the same which Linné confounded with Tachina Larvarum, which he says he lad found in the roots of the cabbage (Syst. Nat. 992. 78.). I say "confounded," because it is not likely that the same species should be parasitic in an insect, and also inhabit a regetable. It is obviously the same described by liöllar from Bouché under the name of Anthomyia Brassica (159.), which he states often destroys whole fields of cabbages by boring into the roots and stalks.

2 Trans. Ent. Soc. Lond. ii. proc. xxi.

5 On examining some young garden peas and beans about four inches high, I observel the margins of the leaves to be gnawed into deep scollops by a little weevil (Sitona lincata), of which I found from two to eight on each pea and bean, and many in the act of eating. Not only were the larger leaves of every plant thus eroded, but in many cases the terminal young sloots and leaves were apparently irreparably injured. I have often noticed this and another of the short-snouted Curculios (S.tibialis) in great abundance in pea and bean fields, but was not aware till now that either of tiem was injurious to these plants. Probably both are so, but whether the crop is materially affected by them must be left to further inquiry. Garden beans still more than the field kinds, Mr. Curtis informs us, greatly suffered in 1841, from the holes which lumble bees (Bombus terrestris and lucorum) made in the blossoms (as they usually lo) to get out tho honey contained in the nectary, which operation injuring the pods in their earliest state, four-fiftlis of them were destroyed, and produced no beans. (Curtis in Gardener's Chron. 1841, p. 485.) When at Shrewshury in August 1839, I found alnost every pod of the garden peas brought to market inhabited by a single yellowish-white lepidopterous larva, three or four lines long, which had eaten more or less of each pea, but which, though several assumed the pupa state and entered the earth in the box in which they wero placed, never became perfect meths. 
to turn black as if sprinkled with soot ; and the nutriment being subtracted from the pods by their constant suction, they are prevented from coming to their proper size or perfection. The beans also which they contain are sometimes devoured by the caterpillar of a small moth. ${ }^{1}$ - Onions, which add a relish to the poor man's crusts and cheese, and form so material an ingredient in the most savoury dishes of the rich, are also the favourite food of the maggot of a fly, that often does considerable damage to the crop.From this maggot (for a supply of onions containing which I have to thank my friend Mr. Campbell, surgeon of 'Hedon, near Hull, where it is very injurious, particularly in light soils) I have succeeded in breeding the fly, which proves of that tribe of the Linnean genus Musca, now called Anthomyia. Being apparently undescribed, and new to ny valued correspondent Count Hoffinansegg, to whom I sent it, I call it A. Ceparum.The diuretic asparagus, towards the close of the season, is sometimes rendered unpalatable by the numerous eggs of the asparagus beetle (Crioceris Asparagi), and its larvæ feed upon the foliage after the heards branch out. - Cucumbers with us enjoy an immunity from insect assailants; but in America they are deprived of this privilege, an unascertained species, called there the cucumber fly, doing them great injury. ${ }^{2}$ - The plants of spinach are sometimes eaten bare by the blackish-brown caterpillars of the lovely little moth Glyphypteryx Rasella. ${ }^{3}$ - Horse-radish (as well as the cabbage tribe) is attacked by the larva of another moth, Mesographe for ficalis. ${ }^{4}$ - And to name no more, mushrooms, which are frequently cultivated and much in request, often swarm with the maggots of various Diptera and Coleoptera.

The insects just enumerated are partial in their attacks, confining themselves to one or two kinds of our pulse or other vegetables. But there are others that devour more indiscriminately the produce of our gardens ; and of these in certain seasons and countries we have no greater and more universal enemy than the caterpillar of a moth called by entomologists Plusia Gamma, from its having a character inscribed in gold on its primary wings, which resembles that Greek letter. This creature affords a pregnant instance of the power of Providence to let loose an aninal to the work of destruction and punishment. Though common with us, it is seldom the cause of more than trivial injury; but in the year 1735 it was so incredibly multiplied in France as to infest the whole country. On the great roads, wherever you cast your eyes, you might see vast numbers traversing them in all directions to pass from field to field; but their ravages were particularly felt in the kitchen-gardens, where they devonred every thing, whether pulse or pot-herbs, so that nothing was left besides the stalks and veins of the leaves. The credulous multitude thought they were poisonous, report affirming that in some instances the eating of them had been followed hy baneful effects. In consequence of this alarming idea, herbs were banished for several weeks from the soups of Paris. Fortunately these destroyers did not meddle with the corn, or famine would have followed in their train. Reaumur has proved that a single pair of these insects might in one season produce 80,000 ; so that were the friendly Ichneumons renoved, to which the mercy of Heaven has given it

1 Reaum. ii. 479.

3 Köllar's Ins. inj. to Gurdeners, \&c. p. 157.

2 Jarton in Philos. MTagaz. ix. 62.

4 Ibid. p. 155. 
in charge to keep their nımbers within due limits, we should no longer enjoy the comfort of vegetables with our animal food, and probably soon become the prey of scorbutic diseases. ${ }^{1}$ - I must not overlook that singular animal the mole-cricket (Gryllotalpa vulgaris), which is a terrible devastator of the produce of the kitchen-garden. It burrows under ground, and devouring the roots of plants thus occasions them to wither, and even gets into hot-beds. It does so much mischief in Germany, that the author of an old book on gardening, after giving a figure of it, exclaims, "Hayply are the places where this pest is unknown!"

The flowers and shubs that form the ornament of our parterres and pleasure-grounds, seem less exposed to insect depredation than the produce of the kitchen-garden; yet still there are not a few that suffer from it. The foliage of one of our greatest favourites, the rose, suffers from the caterpillars of the little rose-moths, Tinea (Omix) rodophagella Köllar, Tortrix (Argyrotoza) Bergmanniana ${ }^{2}$, and of several other moths, and often loses all its loveliness and lustre from the excrements of the Aphides that prey upon it. The leaf-cutter bee also (Megachile ${ }^{3}$ centuncularis), by cutting pieces out to form for its young its cells of curions construction, disfigmes it considerably; and the froth frog-hopper (Aphrophora spumaria), aided by the saw-fly of the rose (Hylotoma Rosa), as well as others of the same family, contributes to check the luxurance of its growth, and to diminish the splendour of its beaty ; but all these evils are nothing compared with the wholesale devastation sometimes made on the roots of this shrub by the larve of cockchafers, which in two years destroyed, at Chenevières sur Maine in France, 100,000 rose-trees in M. Vibert's nurseries, which he was forced to abandon. Reaumur has given the history of a fly (Merodon Narcissi) whose larva feeds in safety within the bulbs of the Narcissus, and destroy's them; and also of another, though he neglects to describe the species, which tarnishes the gay parterre of the florist, whose delight is to observe the freaks of nature exhibited in the varions many-coloured streaks which diversify the blossom of the tulip, by devouring its bulbs. ${ }^{4}$ - Sedums, and other out-of-door plants in pots, are often greatly injured by having the upper part of their roots gnawed by the larræ of a beetle, Otiorhynchus sulcatus. ${ }^{5}$ - Ray notices another insect mentioned by Swammerdam, probably Bibio hortulana, which he calls the deadliest enemy of the flowers of the spring. He accuses it of despoiling the gardens and fields of every blossom, and so extinguishing the hope of the year. ${ }^{6}$ But you must not take up a prejudice against an innocent creature, even under the warrant of such weighty authority ; for the insect which our great naturalist has arraigned as the author of such devastation is scarcely guilty, if it be at all a culprit, in the degree here alleged against it. As it is very numerous early in the year, it may perbaps discolour the vernal blossoms, but its mouth is furnished with no instrument to enable it to devour them. Lastly, to omit various other enemies of our parterres, as the wire-worm, \&cc., I may mention that universal pest, the earwig

1 Reaum, ii. 337.

2 Westwood in Loudon's Gard. Mag. Sept. 1837.

5 Apis.**, c. 2, a. K.

5 Mestwood in Loudon's Gard. MIag. 1837. No. 85.

6 Iiai, Hist. Ins. Prolegom. xi.

1 Reaum, iv. 499. 
against which the florist is obliged to use varions precautions to protect his choicest carnations, pinks, and dahlias from its ravages.

In our stoves and greenhouses the Aphides often reign triumphant; for, if they be not discovered and destroyed when their numbers are small, their increase becomes so rapid, and their attack so indiscriminate, that every plant is covered and contaminated by them, beauty being converted into deformity, and oljects before the most attractive now exciting only nausea and disgust. The coccus (C. Hesperidum) also, which looks like an inanimate scale upon the bark, does considerable injury to the two prime ornaments of our conservatories, the orange and the myrtle; drawing off the sap by its pectoral rostrum, and thus depriving the plant of a portion of its nutriment, at the same time that it causes unpleasant sensations in the beholder from its resemblance to the pustule of some cutancous disease. Similar injury is done by the mealy-bug (Coccus Adonidum L.) to many soft-leaved dicotyledonous plants, such as the coffee-tree, Justicia, \&c., as well as to MLusa, Canna, \&c.; and varions species of scale insects, separated from Coccus by Bouché under the names of Aspidiolus Nerii, Rosce, \&c., attack the oleanders, roses, bays, cactuses, \&c.; while the red spider (Erylhraus tclarius), spinning its web over the under surface of the leaves, draws out their juices with its rostrum, and thus cnfeebles, and, if unmolested, in the end, destroys them. ${ }^{1}$

I must uext conduct you from the garden into the orchard and fruitery; and here you will find the same enemies still more busy and successful in their attempts to do us hurt. The strawberry, which is the earliest and at the same time most grateful of our fruits, enjoys also the privilege of being almost exempt from insect injury. A jumping weevl ( $\mathrm{Or}$ chestes Frasaria) is said by Fabricius to inhabit this plant; but as the same species is abundant in this country upon the beech, the beaty of which it materially injures by the numberless holes which it pierces in the leaves, and has, I believe, never been taken upon the strawberry, it seems probable that Smidt's specimens might have fallen upon the latter from that tree. ${ }^{2}$ The only insect I have observed feeding upon this fruit is the ant, and the injury that it does is not material. The raspberry, the fruit of which arrives later at maturity, has more than one species of these animals for its foes. Its foliage sometimes suffers much from the attack of $M c$ lolonitha horticola ${ }^{3}$, a little beetle related to the cockchafer: when in flower, the footstalks of the blossom are occasionally eaten through by a more minute aninal of the same order, Byturus tomentosus, which I once saw prove fatal to a whole crop, and of which the larva feeds upon the fruit itself; and bees frequently anticjpate us, and, by sucking the fruit with their proboscis, spoil it for the table. Gooselierries and currants, those agrceable and useful fruits, a common object of cultivation both to

1 Köllar on Ins. imj. to Gardeners, Stc. 178-182.

2 This kind of misnomer frequently occurs in entomologieal anthors. - Thus, for instance, the Curculio (Rhynchites) Alliarice of Linné, feeds upon the hawthorn, and Curculio (Cryptorlunchus) Lapathi upon the willow (Curtis in Linn. Trans. i. 86.); but as Alliaria is common in hawthorn helges, and docks often grow under wiliows, the mistake in question easily happened; when, however, such nistakes are discovered, the Trivial Name ousht certainly to be altered.

$s$ I consider this insect as the type of a new subrenus (Phyllopertha K. MS.), which connects those tribes of Melolontha $\mathbf{F}$., that have a mesostemal prominence with those that have not. Of this subgenus I possess six species. It is elearly dis tinet from Anisoplia, under which De Jean arranges it 
poor and rich, have their share of enemies in this class. The all-attacking Aphides do not pass over them, and the former especially are sometimes greatly injured by them; their excrement falling upon the berries renders them clanmm and disgusting, and they soon turn quite black from it. In July, 1812, İ saw a currant-bush miserably ravaged by a species of Coccus, very much resembling the Coccus of the vine. "The eggs were of a beautiful pink, and enveloped in a large mass of cotton-like web, which conld be drawn ont to a considerable length. Sir Joseph Banks once showed me a branch of the same shrub perforated down to the pith by the caterpillar of Egeria tipuliformis: the diminished size of the fruit pointing ont, as he observed, where this enemy has been at work. In Germany, where, perhaps, this insect is more numerous, it is said not seldom to destroy the larger bushes of the red currant. ${ }^{1}$ 'The foliage of these fruits often suffers much from the black and white caterpillar of Abraxas grossulariata, and sometimes from those of Halias Vanaria; but their worst and most destructive enemy is that of a small saw-fly (Nematus Grossularice Dablbon). This larva is of a green colour, shagreened as it were with minute black tubercles, which it loses at its last moult. The Hy attaches its eggs in rows to the under side of the leaves. When first hatched, the little animals feed in society ; but having consumed the leaf on which they were born, they scparate from each other, and the work of devastation proceeds with such rapidity, that frequently, where many families are produced on the same bush, nothing of the lcaves is left but the veins, and all the fruit for that year is spoiled. ${ }^{2}$

Upon the leaves of the cherry, which usually succecds the gooseberry, in common with those of the pear and several other fruit-trees, the slimy larva of another saw-fiy (Selandria Cerasi) makes its repast, yet without being the cause of any very material injury. But in North America, a second species nearly related to it, known there by the name of the slugworm, has hecome prevalent to such a degree as to threaten the destruction not only of the cherry, but also of the pear, quince, and plum. In 1797, they were so numerous that the smaller trees were covered by them; and a breeze of air passing through those on which they abounded became charged with a very disagreealle and sickening odour. Twenty or thirty were to be scen on a single leaf; and many trees, being quite stripped, were obliged to put forth fresh foliage, thus anticipating the supply of the succeeding year, and cutting off the prospect of fruit. ${ }^{3}$ - In some parts of Germany the cherry-tree has an enemy equally injurious. A splendid beetle of the weevil tribe (Rhynchites Bacchus) bores with its rostrum through the balf-grown fruit into the soft stone, and there deposits an egg. The grub produced from it feeds upon the kernel, and, when about to

1 Wiener. Verzeich. 8vo. 29.

2 Fabricins seems to have regarded the saw-fly that feeds upon the sallow (Nematus Caprea), not only as synonymous with that which feeds upon the osier, but also with our little assailant of the gooseberry and currant. Tet it is very evident from Reaumur's account, whose accuracy may be depended upon, that they are all distinct species. Fabricius's description of the $f l y$ agrees with the insect of the gooseberry, but that which he has given of the larva belongs to the animal inlabiting the sallow. Jrobably, confounding the two species, he described the imago from the insect of the tormer, and the larva (if he dict not copy from lieaumur or Linné) from that of the latter. Linné was correct in regarding leaumur's three insects as distinct species, though he appears to be mistaken in reterring to him under $N$. flavus, as the saw-fly of the currant and gooseberry is not wholly yellow.

3 I'eck's Nat. Hist. of the Slug-worm, 9. 
become a pupa, gnaws its way through the cherry, and sometimes not one in a thousand escapes. ${ }^{1}$ This insect is furtunately rare with us, and has usually been found upon the black thorn. The cherry-fly also (Tepluritis Cerasi) provides a habitation for its maggot in the same fruit, which it invariably spoils. ${ }^{2}$

The different varieties of the plum are every year more or less injured by Aphides; and a Coccus (C. Persice? ?) sometinies so abounds upon them that every twig is thickly beaded with the red semiglobose bodies of the gravid females, whose progeny in spring exhaust the trees by pumping out the sap. In Germany, as we learn from M. Schmidberger, while the plumtrees suffer from having their bark injured by two bark-boring beetles (Scolytus hamorrhous and S. Pruni), their fruit is destroyed by the larva of a beetle (Rhynchites cupreus), of a moth (Carpocapsa nigricana), and of a saw-fly (Tenthredo MTorio). ${ }^{3}$

The pear-tree is liable to have its bark pierced in this country by the larvæ of Carpocapsa IVceberana, which often lays the foundation of canker ${ }^{4}$; and in America by those of two beetles (Scolytus pyri, and Strobi Peck ${ }^{5}$ ); its sap is injuriously drawn off by Psylla pyri; its leaves have their parenchyma eaten away from under the cuticles, so as to give them a blistered appearance, by the larva of the pretty little moth Tinea Clerkella L.; and while the blossoms are rendered abortive by the attacks of the grub of a beetle (Anthonomus pyri Köllar), the fruit is caused to drop off prematurely and rot by the larvæ of not fewer than three minute tipulidan flies (Sicara pyri Schmidberger, Sciara Sclmidbergeri Köllar, and Cecidomyia nigra Meigen ${ }^{6}$ ), and also by that of a four small winged fly, observed by Mr. Knight, which would seem to be a saw-fly, and is probably the species which Reaumur saw enter the blossom of a pear before it was quite open, doubtless to deposit its eggs in the embryo fruit. He often found in young pears, on opening them, a larva of this genus. ${ }^{7}$ A little moth likewise is mentioned by Mr. Forsyth as very injurious to this tree. ${ }^{8}$

But of all our fruits none is so useful and important as the apple, and none suffers more from insects, which according to Mr. Knight are a more frequent cause of the crops failing than frost. Here, as in the pear-trees, the bark, and consequently the whole tree, suffers from the larvæ of Carpocapsa Weberana, and of Tinea corticella L., as well as of a Scolytus nearly related to $S$. destructor, but perhaps distinct, which I found infesting it in Guernsey in 1836; and in Austria the larva of another beetle (Trypodendron dispar) pierces into the heart of young healthy trees, and destroyed M. Schmidbcrger several of his stock. ${ }^{9}$ The sap is often injuriously drawn off by $P$ sylla mali ${ }^{10}$; and by a minute Coccus, of which the female has the exact shape of a mussel-shell ( $C$. arbortum lincaris Geoffr.), and which Reaumur has accurately described and figured. ${ }^{11}$ This specics so abounded in 1816 on an apple-tree in my garden, that the whole bark was covered with it in every part; and I have since been informed

1 Trost Kleiner Beytrag. 38.

2 Reaum. ii. $47 \%$.

3 Köllar on Ins. inj. to Gardeners, \&c. 237. 232. 268.

4 See observations on this insect in Trans. of HIort. Soc. ii. 25. by WV. Spence.

5 Westwood, Mod. Class. of Ins. i. 353.

\& Köllar, ubi supr. 250.289. 292.

- Reaum. ubi supr. 475.

9 Köllar on Ins. inj. to Gardeners, \&c. 256.

10 Reaum. iv. 69. t. 5 . f. 6,7 .

8 On Fruit Trees, 271.

21 Ibid. 278. 
hy Joshua Haworth, jun. Esq., of Hull, that it equally infests other trees in the neighbourhood. Even the frnit of a golden pippin which he sent me were thickly beset with it. But the insect which most injures our apple-trees by drawing off their sap, and which has been known in this coimtry only since the year 1787, is the apple-aphis, called by some the Coccus, and by others the American blight. This is a minute insect, covered with a long cotton-like wool transpiring from the pores of its body, which takes its station in the chinks and rngosities of the bark, where it increases abundantly, and, hy constantly extracting the sap, causes ultimately the destruction of the tree. Whence this pest was first introduced is not certainly known. Sir Joseph Banks triced its origin to a nursery in Sloane Street; and at first he was led to conclude that it had been imported with some apple-trees from France. On writing, however, to gardeners in that country, he fomnd it to be wholly unknown there. It was therefore, if not a native insect, most probably derived from North Imerica, from whence apple-trees had aiso been imported by the proprietor of that nursery. Whatever its origin, it spread rapilly. At first it was confined to the vicinity of the metropolis, where it destroyed thousands of trees. But it has since found its way into other parts of the kingdom, particularly into the cyder counties; and in 1810 so many perished from it in Gluucestershire, that, if some mode of destroying it were not discovered, it was feared the making of cyder must be abandoned. Sir Joseph Banks long ago extirpated it from his own apple-trees, by the simple method of taking off all the rugged and dead old bark, and then scrubbing the trunk and branches with a hard brush. ${ }^{1}$

Even in the very commrencement of their existence our choicest appletrees are attacked ly insects; for the young grafts, as I am informed by an intelligent friend Mr. Scales, are frequently destroyed, sometimes many hundreds in one night, in the nurseries about London, hy Curculio vastator Marsh. (Otiorhynchus notatus), one of the short-snouted weevils; as are in the neighbourhood of Warsaw the grafts of this and other finit-trees by a smaller weevil Polydrusus (Nemoicus) oblongus ${ }^{2}$, which with us eats the leaves of both apple and pear trees. The blossoms, in common with those of the pear and cherry, are attacked by the figure-of-cight moth (Episemrs coruleocephal"), which Linné denominates the pest of Pomona; and still more effectually by the grub of a reddish long-snouted weevil (Anthonomus pomorum), which, eating both the blossom and organs of fructification, precludes all hope of fruit. If this danger be escaped, and the fruit be set, it is then in Austria often destroyed by Rhynchites Bacchus, the same splendid weevil which attacks the cherry ; and Reaumur has given us the history of a species of moth common in this country (Carpocapsa pomonella), the caterpillar of which feeds in the centre of our apples, thus occasioning

1 This Aphis is evidently the insect deseribed in Illiger's Magazin, i. 450. under the name of $A$. lanigcra, as having done great injury to the apple-trees in the neighbourhood of Bremen in 1801 . That it is an Aphis and no Coccus is clear from its oral rostrum and the wings of the male, of whieh Sir Joseph Banks had an adnirable drawing by Mr. Bater. On this Aphis see Forsyth, 265.; Monthly Mag. xxxii. 320.; and also for August, 1811; and Sir Joseph Banks in the Horticultural Society's Transurtions, ii. 16:. Those Aplides that transpire a cottony excretion are now consilered, as before stated, as belonging to a distinct genus, under the mame of Lachnus, Illig.; Myzoxyle, Blot ; Friosoma, Leach.

2 Ann. Soc. Lint. de France, viii. Bull. viii. 
them to fall; as does also the larva of one of the saw-flies (Tenthredo testudinea), as observed by Mr. Westwood, and the first instance known of one of this tribe feeding in the interior of fruits. ${ }^{1}$

Our more dainty and delicate fruits, at least such as are usually so accounted, the apricot, the peach, and the nectarine, originally of Asiatic origin, are not less subject to the empire of insects than the homelier natives of Europe. Certain Aplides form a convenient and sheltered babitation for themselves, by causing portions of the leaves to rise into hollow red convexities; in these they rcside, and with their rostrum pumping out the sap, in time occasion them to curl up, and thus deform the tree and injure the produce. The fruit is attacked by various other enemies of this class, against which we find it not easy to secure it: wasps, earwigs, flies, wood-lice, and ants, which last communicate to it a disugrecuble flavour, all share with us these ambrosial treasures; the first of them as it were opening the door, by making an incision in the rind, and letting in all the rest. The nucleus of the apricot is also sometimes inhabited by the caterpillar of a moth, which, feeding on the kernel, causes the fruit to fall prematurely. ${ }^{2}$ And much injury is done to this tree by the larva of a little moth (Ditula angustiorana), by devouring the young blossom-buds and tying the young shoots together with its silken thread, so as to stop their growth. ${ }^{3}$ In this country, however, these fruits may be regarded as mere luxuries, and therefore are of slight consequence; but in North America they constitute an important part of the general produce, at least the peach, serving both as food for swine, and furnishing by distillation a spirit. The ravages committed upon them there by insects are so serious, that premiums have been offered for extirpating them. A species of weevil, perhaps a Rhynchites, enters the finit when unripe, probably laying its eggs within the stone, and so destroys them. And two kinds of Zygana, by attacking the roots, do a still greater injury to the trees. ${ }^{4}-\mathrm{A}$ Coccus, as it should seem from the description, imported about thirty years ago from the Mauritins, or else with the Constantia vine from the Cape of Good Hope, has destroyed nearly nine tenths of the peach trees in the Island of St. Helena, where formerly they were so abundant, that, as in North America, the swine were fel with their fruit. Various means have heen employed to destroy this plague, but hitherto withont success. ${ }^{5}$ - The imperial pine apple, the glory of our stores, and the most esteemed of the gilts of Pomona, cannot, however precious, be defended from the injuries of a singular species of mite, before mentioned, the rcd Spider of gardeners, (Erythraus telarius), which covers it, and other stove plants, with a most delicate, but at the same time very pernicious, web; and the Coccus bromclia is often as great a pest, preying upon the leaves and young fruit beneath a white downy secretion. ${ }^{6}$ - The olive-tree, so valuable to the

1 Trans, Ent. Soc, Lond. iii. proc. xxxii.

2 M. de la llire in Reaum. ii. 478.

5 Westwood in Loudon's Gardener's Mag. No. 94. Jan. 1838.

4 Dr. Smith Barton's Letter in Philos. Magaz. xxii. 210. - William Davy, Esq., American Consul of the port of Hull, lowg resident in the United states, informed me, that though he had abundance of peaches at his country-honse, German Town, near Philadelphia, he couli never succeed with the nectarine, the fruit constantly falling off, perforated by the grub of some insect.

5 ijcser. of the I. of St. Helena, 147.

6 Trans. Ent. Soc. Lond. i. proc. lxiv.; and see also Westwood's Obs. i. 206. 
inhabitants of the warmer regions of Europe, often nourishes in its berries the destructive maggot of a fly (Dacus olea); and the caterpillar of a little moth (Tinea oleella), which preys upon the kernel of the uncleus, occasions them to fall before they are ripe. The larvæ of two beetles Hylesinus oleiperda and Phloiotribus olece, attack the bark and alburnum of the young branches; another beetle, Otiorhynchus meridionalis Schön., devour's the young shoots and leaves; and the sap is injuriously abstracted by Coccus olese, and by Psylla olece Fons. ${ }^{1}$, as well as by Thrips physapus, which in Tuscany has of late years threatened the olive trees of some districts with destruction, by attacking the young leaves and buds. ${ }^{2}$ Every one who eats nuts knows that they are very often iuhabited by a small white grub; this is the offspring of a weevil (Balaninus mucum), remarkable for its long and slender rostrum, with which it perforates the shell when young and soft, and deposits an egg in the orifice. In France it sometimes happens, when the chestnuts promise an abundant crop, that the fruit falls before it comes to maturity, scarcely any remaining upon the trees. The caterpillar of a moth which eats into its interior is the cause of this disappointment. ${ }^{3}$ of fruits the date has the hardest nucleus; yet an inseet of the same tribe with the above, that feeds upon its kernel, is armed with jaws sufficiently strong to perforate it, that it may make its escape when the time of its change is arrived, and assume the pupa between the stone and the flesh. And another noth, the Pyralis brumea, feeds on the pulp of the firuit, and there undergoes its metamorphosis. ${ }^{4}$ The date is eaten also by a beetle which Hasselquist calls a Dermcstes. ${ }^{5}$ Another foreign fruit, the tamarind, has its stone, which is nearly as hard as that of the date, attacked by a weevil of the same genus as the corn-weevil of which, in the larva state, sometimes as many as forty are found in a single stone. ${ }^{6}$ The pomegranate, in the East Indies, has its interior eaten by the caterpillar of the hair-streak butterfy (Thecla Isocrutes), of whose economy Mr. Westwood has given so interesting an account. ${ }^{7}$

In these last-named fruits, however, we have a far slighter interest than in another of our imported ones, the orange, of which, in 1841 (including lemons), we consumed upwards of 302,000 chests, paying a gross duty of $63,975 l$, and which may be regarded as the most valuable of the whole, combining a highly intrinsic excellence with a price which brings it within the reach of all. It appears, however, from the interesting and important facts stated by W. S. MacLeay, Esq., that we might have oranges still cheaper, were it not for a little fly ('́eratitis citriperda), which lays its eggs in them before their shipment firom the Azores; and the grubs subsequently disclosed often so greatly injure them, that the orange merchants calculate on losing one third of their average importations, and of course reimburse themselves by a proportionate advance of the price to the consumers. ${ }^{8}$

1 M. Boyer de Fonscolombe in Arn. Soc. Ent. de France, ix. 101.

2 Passerini, Alcuni Notizie, \&c.

3 Reaum. ii. $505 . \quad 4$ Guérin-Méneville, Revne Zoolog. 1841, p. 246.

5 Ibid. ii. 507. and Hasselquist's Travels in the Levant, 428.

6 Christy in Trans. Ent. Soc. Lond. i.

7 Ibid. ji. 1.

8 Zootogical.Journ. iv. 475. This Hy, which Dr. Heineken states is common in Madeira, and that he has also hatched it from lemons and peaches (Zoot. Journ. v. 199.), seems to be the same species with Petalophora (Trypeta Wied.), capitata Macq. (Dipteres, ii. 454.), so named from the two singular clavale processes between the eyes of the male. It may be easily obtained from decaying oranges, on the outside of whieh the grub assumes the pupa state. 
One of the most delicious, and at the same time most useful, of all our fruits is the grape : to this, as you know, we are indebted for our raisins, for our currants, for our wine, and for our brandy ; you cannot therefore but feel interested in its history, and desire to be informed, whether, like those before enumerated, this choice gift of Heaven, whose produce "cheereth God and man," must also be the prey of insects. There is a singular beetle, common in Hungary (Lethrus C'ephalotes), which gnaws off the young shoots of the vine, and drags them backward into its burrow, where it feeds upon them : on this account the country people wage continual war with it, destroying rast numbers. ${ }^{2}$ Five other beetles also attack this noble plant: three of them, mentioned by French authors (Rhynchites Bacchus, Eumulpus vitis, and Haltica oleracca), devour the young shoots, the foliage and the footstalks of the fruit, so that the latter is prevented from coming to maturity ${ }^{3}$; a fourth (C. corruptor Host), by a German, which seems closely allied to Otiorlynchus notatus, before mentioned, if jt be not the same insect, which destroys the young vines, often killing them the first year, and is accounted so terrible an enemy to them, that not only the animals, but even their eggs, are searched for and destroyed, and to forward this work people often call in the assistance of their neighbours. ${ }^{4}$ And a fifth, Otiorhynchus sulcatus, also oceasionally does considerable injury to the vine in this country, by gnawing off the young shoots. ${ }^{5}$ Various lepidopterous larvæ are still more injurious to the vine. In the Crimen the small caterpillar of a Procris or Ino (genera separated from Sphinx L.), related to $I$. statices, is a most destructive enemy. As soon as the buds open in the spring, it eats its way into them, especially the fruit-buds, and devours the germ of the grape. Two or three of these caterpillars will so injure a vine, by creeping from one germ to another, that it will bear no fruit nor produce a single regular shoot the succeeding year. ${ }^{6}$ In Italy, especially in Piedmont and Tuscany, the vines are often devastated by the larva of another specius of the same genus, Procris antpclophag $a$ Passerini ${ }^{7}$; in Germany a difierent species does great injury to the young branches, preventing their expansion by the webs in which it involves them ${ }^{8}$; and a fourth (Tortrix fascinna) makes the grapes themselves its food: a similar insect is alluded to in the threat contained in Deuteronomy ${ }^{9}$, while in France it is the caterpillar of a small moth, the Tortrix vitana Bosc. (Pyralis vitana and Pillerana Fab., P. danticana Walck.), which does the most injury by snawing the footstalk of the leaves and branches of grapes ${ }^{10}$, and of late years to such an extent in the Maconnais and other districts, that the attention of the government haviug

I That is, "High and Low," Judges, ix, 13.

2 Sturm, Deutschland's Fanın, i. כ.

3 Latreille, Hist. Nat. xi, 66. 331.-According to Köllar '(163.), however, in Austria it is $R$. betuleti, and not R. Bucchus which is injurious to the vines; and the case is the same, according to M. Sibermann, as to the vines of Alsatia and the banks of the lihine.

4 Ilost in Jaequin. Collect. iii. 297.

5 Westwood in Loudon's Gurdener's MIay. for April, 1837.

6 Pallas's Truvels in S. Russia, ii. 241.

7 Memoria sopra due Specie d' Insetti noscivi, \&c.

8 Jacquin. Collect. ii. 97.

9 Dent. xxriii. 39.

10 Walckenaer in Ann. Snc. Ent. de France, iv. 687.; Guérin, art. Pyrale, Dict. Pittoresque d'Trist. Siut. pp. $409-416$. 
been called to the mischief, under their direction, my lamented friend Professor Audouin was, at the period of his untimely death, which Entomology so deeply deplores, engaged on a fine work embracing a complete history of the insect, with figures of it in every state, and an account of the best means of destroying it. The worst pest of the vine in this country is its Cocens (C. vitis). This animal, which fortunately is not sufficiently hardy to endure the common temperature of our atmosphere, sometimes so abounds upon those that are cultivated in stoves and greenhouses, that their stems seem quite covered with little locks of white cotton; which appearance is caused by a filamentous secretiou transpiring through the skin of the animal, in which they envelop their eggs. Where they prevail, they do great injury to the plant by subtracting the sap from its foliage and fruit, and causing it to bleed ${ }^{3}$; and, to close the list without extending it by alluding with M. Walckenaer to the insects only occasionally injurious to the vine, you are perfectly aware of the eagerness with which wasps, flies, and other insects, attack the grapes when ripe, often leaving nothing but the mere skin for their lordly proprietor.

There are some of these creatures that attack indiscriminately all fruittrees. One of these is the Cicada seplendecim (so called because, according to Kalm, it appears only once in seventeen years ${ }^{2}$ ). The female oviposits in the pith of the twigs of trees, where the grubs are hatched and do infinite damage both to fruit and forest-trees. ${ }^{3}$ Birds greedily devour them; and a curious fact is mentioned by Dr. Harlan of Philadelphia (who confirms their septendecenary appearance), that young fowls which eat them lay eggs with colourless yolks. ${ }^{4}$ Another, the caterpillar of the butterfly of the hawthorn (Pieris crategi), which, in 1791, in some parts of Germany stripped the fruit-trees in general of their foliage. ${ }^{5}$ In France also, in 1731 and 1732, that of a moth, which seems related to the brown-tail moth (Por/hesia aurifua), whose history has been given by the late Mr. Curtis, was so numerous as to occasion a general alarm. The oaks, elms, and white-thorn hedges looked as if some burning wind had passed over them and dried up their leaves; for, the insect devouring only one surface of them, that which is left becomes brown and dry. They also laid waste the fruit-trees, and even devoured the fiuit, so that the parliament published an edict to compel people to collect and destroy them; but this would in a great measure have been ineffectual, had not some cold rains fallen, which so completely annihilated then that it was difficult to meet with a single individual. ${ }^{6}$ In Germany, according to M. Schmidberger, the larvæ of the following moths, Porthesia chrysorman, Clisiocampa neustria, IHypogymna dispar, Episema ceeruleocephala, Yponomeuta padella, and especially (Thcimatobia brumata, which he calls the most ruinous of the whole, are all more or less injurious to fruittrees generally. ${ }^{7}$ In the north of France, as we learn from Mr. Westwood, one of these caterpillars, that of the small ermine moth (Y r ponomenta

1 According to M. Walckenaer, in his elaborate and learned Essay on the Insects injurious to the Vine (Amn. Soc. Ent. de France, iv. 687.) it is the Coccus adonidum which is injurious to vines in hot-houses in France, while the Coccus vitis attacks those in the open air.

2 Travels, ii. 6.

3 Collinson in Philos. Trans. liv, x. 65.

4 Trans. Ent. Soc. Lond. i. proc. xxx.

5 Rösel, I. ii. 15.

6 lieaum. ii. 122.

7 Köllar on Ins. inj. to Gardeners. \&.c. $190-229$. 
padelia), is often so numerous as to defoliate the apple trees by the road sides for miles. ${ }^{1}$ Three species of beetles also, Rhynchites alliarice, which in the larva state bores into the young shoots, and Nemoicus oblongus and Phyllopertha horticola, which attack the leaves as perfect insects, join their lepidopterous brethren in Germany in a general assault on fruit-trees.

If we quit the orchard and fruit-garden for a walk in our plantations and groves, we shall still be forced to witness the sad effects of insect devastation; and when we see, as sometimes happens, the hedges and trees entirely deprived of their foliage, and ourselves of the shade we love from the fervid beam of the noonday sun; when the singing birds have deserted then; and all their music, which has so often cnchanted us by its melody, variety, and swcetness has ceased-we shall be tempted in our hearts to wish the whole insect race was blotted from the page of creation. Numerous are the agents cmployed in this work of destruction. Amongst the beetles, various cockchafers (Melolontha vulgaris, Amphimalla solstitialis, and Phyllopertha horticola), in their perfect state, act as conspicuous a part in injuring the trees as their grubs do in destroying the herbage. Besides the leaves of the funit-trees, they devour those of the sycamore, the lime, the beech, the willow, and the elm. They are sometimes especially the common one, astonishingly numerous. NIouffet relates (but one would think that there must be some mistake in the date, since they are never so carly in their appearance) that on the 24th of February, 1574, such a number of them fell into the river Severn as to stop the wheels of the water-mills. ${ }^{2}$ It is also recorded in the Philosophical Transactions, that in $\mathbf{1 6 8 8}$ they filled the hedges and trees of part of the county of (xalway in such infinite numbers, as to cling to each other in clusters like bees when they swarm; on the wing they darkened the air, and produced a sound like that of distant drums. When they were feeding, the noise of their jaws might be mistaken for the sawing of timber. Travellers and pcople abroad were very much annoyed by their continual fying in their faces; and in a short time the leaves of all the trees for some miles round were so totally consumed by them, that at midsummer the country wore the aspect of the depth of winter. ${ }^{3}$

But the criminals to whom it is principally owing that our groves are sometimes stripped of the green robe of summer are the various tribes of Lepidoptera, especially the nightfliers or moths, myriads of whose caterpillars, in certain scasons, despoil whole districts of their beanty, and our walks of all their pleasure. Some of these, like the cockchafers, or the caterpillars of Clisiocampa neustria, Porthesia chrysorrhaa, \&c., before mentioned as attacking most fruit-trees, are also general feedors on forest trees, though some of the sjecies usually prefer particular kinds when accessible. Thus in 1731 the oaks of France were terribly devistated by the larva of Hypogyma dispar ${ }^{4}$; as are often those of Germany by that

1 Loudon's Gardener's IITag. Oct. 1837.

2 Nlouftet, 160.

3 Philos. Trans. xix. 741.

4 lieaum. i. 387. These larvæ were so extremely numerous in 1826 on the lines of the Allee Verte at Brussels, that many of the trees of that noble avenue, though of great age, were nearly deprived of their leaves, and afforded little of the shade which the unusual heat of the summer so nrgently required. The moths which in antumn proceeded from them, when in motion towards night, swarmed like bees, and subsequently on the trunk of every tree might be seen scores of fomales depositing 
of Cnethocampa processionea; and those of England by the leaf.rolling caterpillar of the pretty little green moth Tortrix viridana. Our elms have their leaves frequently drilled into boles by the little jumping weevil, Orchestes fagi, and the beech, alder, \&c., are partially disfigured by other species of this saltatorial tribe. In France, however, the elms sustain a much more serious injury from the larva of another larger beetle (Galleruca calmaricnsis), the leaves being sometimes so covered with them, and rendered so brown, as to have the appearance of having been struck by lightning, as was the case with the fine promenades of Rouen, when I was there in 1836. Cheimatobia brumata is likewise a fearful enemy to the foliage of almost every kind of tree. ${ }^{1}$ The woods in certain provinces of North America are in some years entirely stripped by the caterpillar of another moth, which eats all kinds of leaves. This happening at a time of the year when the heat is most excessive, is attended by fatal consequences; for, being deprived of the shelter of their foliage, whole forests are sometimes entirely dried up and ruined. ${ }^{2}$ The brown-tail moth, before alluded to, which occasionally bares our hawthorn hedges, has been rendered fanous by the alarm it caused to the inhabitants of the vicinity of the metropolis in 1782, when rewards were offercd for collecting the caterpillars, and the churchwardens and overseers of the parishes attended to see them burnt by bushels. You may have observed, perhaps, in some cabinets of foreigi insects, an ant, the head of which is very large in proportion to the size of its body, with a piece of leaf in its mouth many times bigger than itself. These ants, called in Tobago parasol ants (Atta cephalotes), cut circular pieces out of the leaves of various trees and plants, which they carry in their jaws to their nests ; and they will strip a tree of its leaves in a night, a circumstance which has been confirmed to ne by Captain Hancock. ${ }^{3}$ Stedman mentions another very large ant, being at least an inch in length, which has the same instinct. It was a pleasant spectacle, be observes, to behold this army of ants marching constantly in the same dircction, and each individual with its bit of green lcaf in its

their down-covered patch of eggs. In the Park they were also very abnndant; and it may be safely asserted that if one half of the eggs deposited were to be hatched, in 1827 scarcely a leat would remain in either of these favourite places of public resort. Happily, however, this calamity was prevented by natural means. Of the vast number of patches of eggs which I saw on almost every tree in the Park about the end of September, I could two months afterwards, to my no small surprise, discover scarcely one, though the singularity of the fact made me examine closely. For their disappearance I have no doubt the inhabitants of Brussels are indebted to the tit-monse (Parus), the tree-creeper (Certhia familiaris), and other small birds known to derive part of their food from the eggs of insects, and which abound in the Park, where they may be often seen running up and down the trunks of the trees, at once providing their own food and rendering a service to man, which all his powers would be inadequate completely to effect.

Reaumur (ii. 106.) in certain seasons found these patches of eggs so numerous, that in the Bois de Boutogne there was scarcely an oak, the under side of the branches of which were not covered by them for an extent of seven or eiglit feet. He informs us that the eggs are not hatched till the following spring.

1 De Geer, ii. 452.

2 Kalm's Travets, ii. 7.

3 The same intelligent gentleman related to me, that a person having taken some land at Bahia in the Brazils, he was compelled by these ants, which were so numerons as to render every effort to destroy them ineffectual, to relinquish the occupation of it. Their nests were excavated to the astonishing depth of fourteen feet. Mlerian, Insect. Sur. 18. Smeathman on Termites, Phit. Trans. Ixxi. 39. note 3j. 
mouth. ${ }^{1}$ The insects injurious to deciduous trecs mostly leave the fir and pine tribes untouched; but these on the other hand, are subject to have their foliage ravaged by a great variety of insect enemies peculiar to themselves, to some extent in this country, but far more on the Continent, as by the larvæ of various motlss (Dendrolimus pini, Psilura monacha, Achatia piniperda, Bupalus pininins, Orthotcenia turionana and resinella, Sc.); and of not fewer than three species of saw-fly (Lophyrus pini and rufus and Pamplilius erythroceplata). ${ }^{2}$ The injury thus caused to trees by insects is not confined to the mere loss of their leaves for one season ; for it occasions them to draw upon the funds of another, by sending forth prema,ture shoots, and making gems unfold, that, in the ordinary course, would not have put forth their foliage till the following year.

Other insects, though they do not entirely devour the leaves of trees and plants, yet considerably diminish their beauty. Thus, for instance, sometimes the subcutaneous larvæ undermine them, when the leaf exhibits the whole course of their labyrinth in a pallid, tortuous, gradually dilating line - at others, the Tortrices disfigure them by rolling them up, or the leaf-cutter bees by taking a piece out of them, or certain Tinece again by eating their under surfice, and so causing them to wither either partially or totally. You have doubtless observed what is called the honeydew upon the maple and other trees, concerning which the learned Roman naturalist Pliny, gravely hesitates whether he shall call it the sweat of the heavens, the saliva of the stars, or a liquid produced by the purgation of the air !! ${ }^{3}$ Pcrhaps you may not be aware that it is a secretion of Aphides, whose excrement has the privilege of emulating sugar and honey in sweetness and purity. It, however, often tarnishes the lustre of those trees in which these insects are numerous, and is the lure that attracts the swarms of ants which you may often see travelling up and down the trunk of the oak and other trees. ${ }^{4}$ The larch in particular is inhabited by an Aphis transpiring a waxy substance like filaments of cotton : this is sometimes so infinitely multiplied upon it as to whiten the whole tree, which often perishes in consequence of its attack. The beech is infested by a similar one. Some animals also of this genus inhabiting the poplar, elm, lime, and willow, reside in galls they have produced, that disfigure the leaves or their footstalks. Perhaps those resembling fruit, or flowers, or moss, produced by the Aphis of the fir (Aplis abictis), the different species of gallgnats (Cecidomyia), or occasioned by the puncture and oviposition of the various kinds of gall-flies (C'ynips), may be regarded rather as an ornament

Stedman, ii. 142.

2 Köllar, on Ins. inj. to Gardeners, \&c. 323-356.

3 Hist. Nut. I. xi. c. 1:.

4 It is contended by some observers, that besides the honey-dew caused by Aphides, there is another arising solely from a morbid exudation of the saccharine juices of trees. This is certainly possibie; but I may observe, that in the course of more than thirty years which I have attended to this subject (seven of them spent on the Continent, where the greater heat might be supposed likely to cause morbid vegetable action), I have never met witl any honey-dew which did not seem to me very clearly referable to Aphides as its origin; though, from the circumstance of their laving been all swept away by the attacks of their natural enemies and other causes, while their saccharine excretion remains on the leaves for weoks in a dry time, and after being moistened by a slight dew may have every appearance of being a recent morbid exudation, and may, even after very copious dews, fill on the ground, a casual obscrver may often be plausibly led to a different comclusion. 
than as an injury to a tree or shrub; yet when too numerous they must deprive it of its proper nutriment, and so occasion some defect. And probably the enormous wens, and other monstrosities and deformities observable in trees, may have been originally produced by the bite or incision of insects.

Besides exterior insect enemies, living trees are liable to the ravages of many that are interior. These interior feeders may be divided into two great classes - those which bore into the heart and substance of the wood, and those which feed upon the inner bark, with the adjoining alburnum or sap-wood. Amongst the former the larva of a large weevil (Cryptorhynchus lapalhi) bores into the wood of the willow and sallow, which thus in time often become so hollow as to be easily blown down. The stag-beetle tribe, or Lucanida, have a similar appetite; but the most extensive family of timber-borers are the Capricorn beetles ${ }^{2}$, inclnding the Fabrician genera of Prionus, Cerambyx, Lamia, Stenocorus, Leptura, Rhagizm, Gnoma, Saperda, Callidium ${ }^{3}$, and Clytus. The larva of these, as soon as hatched, leaves its first station between the bark and wood, and begins to make its way into the solid timber (some of them plunging even into the iron heart of the oak), where it eats for itself tortuous paths, at its first starting, perhaps, not bigger than a pin's head, but gradually increasing in dimensions as the animal increases in magnitude, till it attains in some instances to a diameter of one or two inches. Only conceive what havoc the grub of the vast Prionus giganteus must make in a bean! Percival is probably speaking of this beetle, when, in his account of Ceylon, he tells us, "There is an insect found here which resembles an immense overgrown beetle. It is called by us a carpenter, from its boring large holes in timber, of a regular form, and to the depth of several feet, in which, when finished, it takes up its habitation." " Seeing the perfect insect come out of these holes, an unentomological observer would naturally conclude that the beetle he saw had formed it, and lived in it; but, doubtless, the whole was the work of the grub. Of all the Coleopterous genera, there is none the species of which are generally so rich, resplendent, and beautiful, as those of Buprestis: these likewise, in their first state, theie is abundant reason to believe, dcrive their nutriment from the produce of the forest, in which they sometimes remain for many years before they assume their perfect state, and appear in their full splendour, as if nature required more time than usual to decorate these lovely insects. We learn from $\mathrm{Mr}$.

1 Lewin in Linn. Trans. iii. 1. Curtis in ditto, i. 86.

2 See Kirby in Linn. Trans. v. 250 - Nore than a hundred species of the Capricorn tribe, many of them nondescripts, were collected near lio de Janeiro by Captain Hancock of the Foudrovant.

3 The larva of a Callidium (which Dr. Leach has discorered to be $\boldsymbol{C}$. bajulum) sometimes does material injury to the wood-work of the roofs of houses in London, piercing in every direction the fir-rafters (in which it most probably took up its residence while they were growing as trees), and, when arrived at the perfect state, making its way out even through sheets of lead, one sixth of an inch thick, when they liappen to have been nailed upon the rafter in which it has assumed its final metamorphosis. I am indebted to the kindness of Sir Joseph Banks for a specimen of such a sheet of lead, which, though only eight inches long and four broad, is thus pierced with twelve oval holes, of some of which the longest diameter is a quarter of an inch! Mr. Charles Miller first discovered lead in the stomach of the larva of this insect.

4 P. 310. 
Marsham that the grub of $B$. splendida was ascertained to have existed in the wood of a deal table more than twenty years. ${ }^{1}$

Another tribe of internal wood-borers belongs to the genus Sirex of the order Hymenoptera. Mr. Stephens informs ine that the fir-trees in a plantation of Mr. Foljambe's, in Yorkshire, were destroyed by the larva of Sirex gigas: while those of another, belonging to the same gentleman, in Wiltshire, met with a similar fate from the attacks of Sirex juvencus. In proof of the ravages made by this last insect, Mr. Raddon exhibited to the Entomological Society a portion of the wood of a fir-tree from Bewdley Forest, Worcestershire, of which twenty feet of its length was so perforated by its larva as to be only fit for fire-wood ; and being placed in an out-house, five or six of the perfect insects eame out every morning for several weeks, ${ }^{2}$ When fir-trees thus attacked are cut down, it often happens that the larvæ of the species of Sirex inhabiting them have not attained their full mowth at the time the wood has been employed as the joists or planks for floors, out of which the perfect inseets, even years after, emerge, to the no small surprise, and even alarm, of the inmates. An instance of this, where several specimens of $S$. gigas were seen to come out of the floor of a nursery in a gentleman's house, to the great discomfiture both of nurse and children, is related by Mr. Marsham, on the authority of Sir Joseph Banks ${ }^{3}$; and a similar circumstance, stated by Mr. Ingpen, oceurred in the house of a gentleman at Henlow, Bedfordshire, from the joists of the floors of which whole swarms, hiterally "thousands," of Sirex duplex Shuckard ${ }^{4}$, energed from iunumerable holes, large enough to admit a small pencil-case, causing great terror to the occupants. As the house had been built about three years (the joists of British timber), there could be no doubt of the larvæ having been more than that time in arriving at their perfect state..$^{5}$ Amongst the most formidable wood-borers with us is the larva of the great goat-moth (Cossus ligniperda ${ }^{6}$ ), which atticks willows, poplars, and oceasionally even elms and oaks; and from its larme size, and living above two years in the larva state, the holes which it makes are a great deduction from the value of the tree, even if it be not entirely destroyed. The larva of Zerzera escui $i$, though much smaller, has similar habits, and is injurious by boring into apple, pear, and walnut trees.

The inscets which attack the bark of trees mostly belong to the family of Scolytida IVestwood (including the genera Seolytus, Hylesints, IIylurgus, $T$ (mieus, \&c.) ; a numerous tribe of beetles, the larva of which, alter being hatched from the ergs deposited by the parent beetle, excavate in the substance of the inner bark, and partly aiso in the adjoining alburnum or sap-wood, lateral parallel channels more or less sinuous, proceeding on each side from a central one (that in which the egers were placed), and thus giving to the under side of the detached bark and exposed atburnum, that pinnated labyrinthine appearance, and fancied resemblance to letters, which made Linné affix to one of these insects, to be presently alluded to, the trivial name of Typographus. When in small numbers these larvæ

1 Linn. Trans, x. 399 .

2 Trans. Ent. Soc, Lond. i. proc. Ixxxv.

3 Linn. Trans. x. 403.

4 This species inhabits the Spruce-fir (Pinus nigra). - Shuckard in Loudon's IIreg. of Nat. IIist. 1837, p. 632.

5 Trans, Ent. Soc, Loud. ii. proc, lxxxii. : and iii. proc. ii.

6 Curtis, Brit. Ent. t. 6o. 
may do no great injury; but where they abound, as they often do, by interrupting the course of the descending sap, and admitting wet between the bark and wood, decay speedily ensues, and the tree perishes. Almost every kind of tree is liable to the assaults of one or more species of this tribe of insects. Even fiuit-trees, as the apple, plum, \&c., have each their Scolylus; and at Rouen I found a species, I believe undescribed, which feeds on the mountain ash. It is to our large forest-trees, however, that they are most injurious. Thus the common ash is assailed by Mylcsinus fraxini, the pionated labyrinths of whose larvæ you can hardly fail to observe on the first piece of loose bark you detach from the rough-split posts and rails made of this wood; while the bark-borer of the oak is a small beetle of an allied genus, Scolytus pygmous, which with us does no great harm, but so abounded of late years in the Bois de Vincennes, near Paris, that 40,000 trees were killed by it ; and many of the finest elms in St. James's Park and Kensington Gardens' ${ }^{1}$, as well as in the promenades of varions cities in the north of France, have fallen victims to another of this tribe, Scolytus deslructor, whose trivial name well characterises the frequency and severity of its ravages. ${ }^{2}$

\section{MacLeav in Edin. Phil. Journ. xi. 123.}

2 While residing at Brussels in the spring of 1836 , having pointed ont to Dr. George, Professor of Botany at the University, that many of the elms in the park were infested with this insect, and that there was imminent risk of this noble promenade, which eonsists almost wholly of elms, being destroyed by it, he brought the subject under the notice of the burgomaster and nunieipal conneil, who very wisely had the diseased trees eut down, as well as the many much younger but equally infested trees of the Houlevards, and the bark of the whole peeleu of and carefully burnt. I afterwarls found, in a tour along the north coist of France througl Normanly, \&c., that the elms in the promenades (almost always formed of this tree), in all the large towns, were in a course of rapid destruction by this same Scolytus lestructor, particularly at Calais, Woulogne, Ronen, Havre, and Caen; and numerous observations convinced me that the general opinion that these inseets attack only those trees which are previously diseased from natural decay is altogether erroneous, and that Professor Audoun's discovery is as important and correct as novelmanely, that thongh it is quite true that the female Scolyti never lay their eggs except in trees which are in a declining state; yet it is equally certain that the healthiest cims, where Scolyti aboumb, are constantly brought into this languishing state by the attacks of the males, or, as M. Audouin conceives, of both sexes (see remarks on this point by WV. Spence in Trans. Ent. Sne. Lond. ii. proc. xlv.), upon the bark for food; so thit in consequence of the loss of sap fiom the numerous holes which they gllaw, and the subsequent mischief from the rain penetrating into them, the trees are soon brought into that unhealthy condition which the instinct of the female requires to incluce her to lay her egers in thein. (Spence in Trans. Ent. Soc. Lond. ii. proc. xiii. xv. $\mathrm{xx}$. xiv.; Audouin in Ann. Lnt. Soc. de France, Bull. Jan. 4, 1ऽ37; Silbermann, Rev. Entom. iv. 115., where Dr. latzeburg is quoted as stating that the large meevil (Pissodes notatus) in like manner attacks the bark of young pines with its trunk, and thus renders the trees unhealthy before the female leposits her eggs in them.) For a further description of the mischief done by Scolutus destructor, and the means of preventing its extension, see a communication by W. S. unler the article Ulmas, in Mr. Loulon's Arboretum et Fruticetum Britannicum; to which admirable work the reater is also referred for more complete details than -could be here given in the valuable contributions by $\mathrm{Mr}$. Westwood relative to insects injurious to this and other species of forest-trees.

It may be lsere mentioned, though somewhat out of place, for the purpose of drawing the attention of lintomologists to a new tribe of insect-parasites of which no account appears to have been given in books, that in examining closely the pupæ of Scolytus destructor at Brussels, I found them lined in different parts of their external surfice, but especially on the thorax and about the cases of the elytra, with numer- 
It would occupy too much space to notice in detail all the bark-boring beetles which attack the various species of pine and fir trees, which are very numerous, comprising Tomicus pinastri, Laricis, micrographus, typographus, and chalcographus (which I found in 1837, in the larva, pupa, and inago states, in the bark of Norway fir nasts imported to Southampton), Hylurgus piniperda, as well as two large weevils, Pissodes notatus and pini, which have similar habits, \&c. \&c. ; and I will conclude the list with stating as a sample of the whole the ravages committed by one of the tribe, Tomicus typographus, in Germany, where it sometimes attacks the inner bark in such vast numbers, 80,000 being sometimes found in a single tree, that it is infinitely more noxious than any of those that bore into the wood; and such is its vitality, that though the bark be battered and the tree plunged into water, or laid upon the ice or snow, it remains alive and unluurt. The leaves of the trees infested by these insects first become yellow; the trees themselves then die at the top, and soon entirely perish. Their ravages have long been known in Germany under the name of Wurm trölimiss (decay caused by worms); and in the old liturgies of that country the animal itself is formally mentioned under its vulgar appellation, "The Turk."

ous transparent eel-shaped vermicles, not easily visible to the naked eye from their small size, being not more than one eighth or one tenth of a line in length, but perceptible through a pocket lens, especially when exposure to the air or the warm breath had made them elevate their tails (or heads, whichever they may be), a movement which sometimes takes place speedily, but at others only after a considerable examination, when they present the appearance of so many animated hairs twisting and eurling themselves in various directions. These vermicles, under M. Wesmael's powerful compound microscope, with which he was so good as to assist me in examining them, exhibit not the slightest trace either of mouth or other external organ, nor of intestines, nor of internal vessels of any kind, which, if any such existed, might be easily seen through their transparent skin and body. This absence of all appearance of external and internal organs (the inside of the body seeming filled with granular molecules), added to their shape, which is filiform and very slender, sharply attenuated at each extremity, and their hyaline colour, with very indistinct traces under a high magnifying power of ahout twenty segments, each as long as broad, are all the characters they afford. These characters, or rather negation of charaeters, might perhaps suffice to bring these vermicles under the genus Vibrio as formerly extended by Müller and Bory de St. Vincent (to which, from their resemblanee to the so-called vinegar eels, Vibrio anguilla, I at first referred thein), but scarcely as it has been recently restricted by Ehrenberg, especially as all his species of this genus (Vibrio) reside in water. From their connection with an animal, they might be regarled as referable to the Oxyuri, were it not that neither my own nor M. Wesmael's elose examination could erer discover any trace of their existence in the interior of either the larva, pupa, or imago of Scolytus. Their wholly exterior habitat seems also to exclude them from coming under Professor Owen's genus Trichina, of lis group Protelmintha, which, from its shape and simplicity of structure, might possibly include them, but which inhabits the cellular tissue between the muscular fibres, enclosed in a cyst in which it lies coiled up. Leaving it to future examination to decide the true genus and relations of these vermicles, I shall here merely observe, in addition to what has been above said, that I have found them upon a large proportion of the pupe of Scolyfus destructor, and occasionally on some of the larve in an advanced stage of growth, and also on the pupe of IIylesinus fraxini; and in such distant localities, and at such different periods of the year, that I am persuaded that their occurrence was not accidental, but that they are true external parasites, of the family of Scolytidce in the pupa (and partly in the larva) state, in which, however, they do not seem materially to injure them, nor prevent them from becoming perfect insects. (See Spence in Trans. Ent. Soc. Lond. ii. proc. xv.) 
This pest was particularly prevalent and caused incalculable mischief, about the year 1665. In the beginning of the last century it again showed itself in the Hartz forests - it re-appeared in 1757, redoubled its injuries in 1769 , and arrived at its height in 1783, when the number of trees destroyed by it in the above forests alone was calculated at a million and a half, and the inhabitants were threatened with a total suspension of the working of their mises, and consequent ruin. At this period these Tomici, when arrived at their perfect state, migrated in swarms like bees into Suabia and Franconia. At length, between the years 1784 and 1789, in consequence of a succession of cold and moist seasons, the numbers of this scourge were sensibly diminished. It appeared again, however, in 1790 ; and so late as 1796 there was great reason to fear for the few fir-trees that were left. ${ }^{1}$

When the sap flows fiom a tree in consequence of the attacks of the above-mentioned insects, or any other cause ${ }^{2}$, it is attended by various - beetles, as Cetonia aurata, several Nitidule and Brachyptera, \&c., which prevent it from healing; and if the bark be anywhere separated from the wood, a numerous al'my of wood-lice, earwigs, spiders, field-bugs, and similar subcorical insects take their station there, and prevent a reunion.

The seeds of forest as well as of fruit-trees are doubtless subject to injuries from insects; but these being more out of the reach of observation, have not been much noticed. Acorns, however, a considerable article with nurserymen, are said to lave both a moth and a beetle that prey upon them; and, what is remarkable, though sometimes one larva of each is found in the same acorn, yet two of either kind are never to be met with together. ${ }^{3}$ The beetle is probably the Curculio (Balaninus) glandium of Mr. Marsham, and is nearly related to the species whose grub inhabits the nut.

Having now conducted you round, and exhibited to you the melancholy proofs of the universal dominion of insects over our regetabie treasures while growing or endued with the principle of vitality, in their separate departments, I must next introduce you to a pest worse than all put together, which indiscriminately attacks and destroys every vegetable substance that the earth produces, and which, wherever it prevails, carries famine, pestilence, and death in its train. Happily for this country - and we cannot be too thankful for the privilege - we know this scourge of nations only ly report. The name of Locust, which has been such a sound of horror in other countries, here only suggests an object of interesting inquiry. But the ravages of locusts are so copious a theme that they merit to be considered in a separate letter.

$$
\text { I am, \&c. }
$$

1 Wilhelm's Recreations from Nat. Hist., quoted by Latreille, Hist. Nat. xi. 194.

2 While attending to the Scolyti infesting the common elm during the tour in the north of France in 1836, above referred to, I noticed in the liquid matter so often seen constantly oozing from the large ulcers in this tree, a dipterous larva in considerable numbers, of which this exudation is evidently the natural food; and having bred some of them, they produced very minute gnat-like flies, of the genus Ceratopogon, probably (but I lave not the specimens now at hand to compare with his description) C. flavifrons of Guérin (Ann. Soc. Ent. de France, ii. 165.), which he found in a similar situation.

3 leaum, ii. 502. 


\section{LETTER VII.}

\section{INJURIES CAUSED BY INSECTS.}

\section{INDIRECT INJURIES - continued.}

To look at a locust in a cabinet of insects, you would not, at first sight, deem it capable of being the source of so much cvil to mankind as stands on record against it. "This is but a small creature," you wonld say, "and the mischief which it causes cannot be far beyond the proportion of" its bulk. The locusts so celebrated in history must surely be of the Indian kind mentioned by Pliny, which were three feet in length, with legs so strong that the women used them as saws. I see, indeed, some resemblance to the horse's head, but where are the eyes of the elephant, the neck of the bull, the horns of the stag, the chest of the lion, the belly' of the scorpion, the wings of the eagle, the thighs of the camel, the legs of the ostrich, and the tail of the serpent, all of which the Arabians mention as attributes of this widely-dreaded insect destroyer'; but of which in the insect before me I discern little or no likeness?" Yet, although this animal be not very tremendous for its size, not very terrific in its appearance, it is the very same whose ravages have been the theme of naturalists and historians in all ages, and upon a close examination you will find it to be peculiarly fitted and furnished for the execution of its office. It is armed with two pairs of very strong jaws, the upper terminating in short and the lower in long teeth, by which it can both lacerate and grind its food-its stomach is of extraordinary capacity and powers-its hind legs enable it to leap to a considerable distance, and its ample vans are calculated to catch the wind as sails, and so to carry it sometimes over the sea; and although a single individual can effect but little evil, yet when the entire surface of a country is covered by them, and every one makes bare the spot on which it stands, the mischief produced may be as infinite as their numbers. So well do the Arabians know their power, that they make a locust say to Mahomet, "We are the army of the great God; we produce ninety-nine eggs ; if the hundred were completed, we should consume the whole earth and all that is in it." 2

Since it is possible you may not have paid particular attention to the accounts given by various authors, both ancient and modern, of the almost incredible injury done to the human race by these creatures, I shall now lay before you some of the most striking particulars of their devastations that I have been able to collect.

The earliest plague of this kind which has been recorded, appears also to have been the most direful in its immediate effects that ever was inflicted upon any nation. I am speaking, as you may well suppose, of the locusts

1 Dochart, IIierozoic. P. ii. 1. iv. c. 5. 475.

2 Ibid., uli supr. c. 6. 485. 
with which the Eqyptian tyrant and his people were visited for their oppression of the Israelites. Only conceive to yourself a country so covered by them, that no one can see the face of the ground-a whole land darkened, and all its produce, whether herb or tree, so devoured that not the least vestige of green is left in either. ${ }^{1}$ But it is not necessary for me to enlarge further upon a history, the circumstances of which are so well known to yoll.

To this species of devastation Africa in general seems always to have been peculiarly subject. This may be gathered from the law in Cyrenaica, mentioned by Pliny, by which the inhabitants were enjoined to destroy the locusts in three different states, three times in the year-first their eggs, then their young, and lastly the perfect inseet. ${ }^{2}$ And not without reason was such a law enacted; for Orosius tells us that in the year of the world 3800 , Africa was infested by such infinite myriads of these animals, that having devoured every green thing, after flying off to sea they were drowned, and being cast upon the shore they emitted a stench greater than could have been produced by the carcasses of 100,000 men. ${ }^{3}$ St. Augustine also mentions a plague to have arisen in that country from the same cause, which destroyed no less than 800,000 persons (octingenta hominum millia) in the kingdom of Masanissa alone, and many more in the territories bordering upon the sea. ${ }^{4}$

From Africa this plague was occasionally imported into Italy and Spain ; and a historian, quoted in Mouffet, relates that in the year 591 an infinite army of locusts, of a size unusually large, grievously ravaged part of Italy ; and being at last cast into the sea, from their stench arose a pestilence which carried off near a million of men and beasts. In the Venetian territory, also, in 1478 , more than 30,000 persons are said to have perished in a famine occasioned by these terrific scourges. Many other instances of their devastations in Europe, in France, Spain, Italy, Germany ${ }^{5}$, \&c., are recorded by the same author. In 1650, a cloud of them was seen to enter Russia in three different places, which from thence passed over into Poland and Lithuania, where the air was darkened by their numbers. In some places they were seen lying dead, heaped one upon anotlier to the depth of four feet; in others they covered the surface like a black cloth, the trees bent with their weight, and the damage they did exceeded all computation. ${ }^{6}$ At a later period, in Languedoe, when the sun become hot they took wing and fell upon the corn, devouring both leaf and ear, and that with such expedition that in three hours they would consume a whole field. After having eaten up the corn, they attacked the vines, the pulse, the willows, and lastly the hemp, notwithstanding its bitterness. ${ }^{7}$ Sir H. Davy informs us $^{8}$ that the Freneh government in 1813 issued a decree with a view to oecasion the destruction of grasshoppers.

Even this happy island, so remarkably distingnished by its exemption from most of those scourges to which other nations are exposed, was once

1 Exod. x. 5. 14, 15.

2 Hist. Nut. l. xi. c. 29. A similar law was enacted in Lemnos, by which every one was compelled to bring a certain measure of locusts annually to the magistrates. Plin. ibid.

3 Oros. contra Pag. l. v. c. 2.

5 Mouffet, 123.

4 Lesser, L. 247. note 46.

7 Philos. Trens. 1686.

8 Elements of Agricultural Chemistry, 233.

0 Bingley, iii. 258. 
alarmed by the appearance of loeusts. In 1748 they were observed here in considerable numbers, but providentially they soon perished without propagating. These were evidently stragglers from the vast swarms which in the preceding year did stich infinite damage in Wallachia, Moldavia, Transylvania, Hungary and Poland. One of these swarms, which enterect Transylvania in August, was several hundred fathoms in width (at Vienna the breadth of one of them was thrce miles), and extended to so great a length as to be four hours in passing over the Red Tower; and sueh was its density that it totally intereepted the solar light, so that when they flew low one person could not see another at the distance of twenty paces? A similar account has been given me by a friend of mine ${ }^{2}$ long resident in India. He relates that when at Poonah he was witness to an immense army of loeusts which ravaged the Mahratta country, and was supposed to come from Arabia (tliis, if correct, is a strong proof of their power to pass the sea under favourable circumstances). The column they composed, my friend was informed, extended five hundred miles; and so compaet was it, when on the wing, that, like an eelipse, it eompletely hid the sun, so that no shadow was cast by any object, and some lofty tombs distant from his residence not more than two hundred yards were rendered quite invisible. This was not the Locusta migratoria, but a rect speeies; which eircumstanee much inereased the horror of the scene; for, elustering upon the trees after they had stripped them of their foliage, they imparted to them a sanguine hue. The peach was the last tree that they touched.

Dr. Clarke, to give some idea of the infinite numbers of these animals, compares them to a flight of snow when the flakes are carried obliquely by the wind. They eovered his earriage and horses, and the Tartars assert that people are sometimes suffocated by them. The whole face of nature might have been deseribed as covered by a living veil. They consisted of two speeies, L. tatarica and migratoria; the first is almost twice the size of the second, and, because it preeedes it, is ealled by the Tartars the herald or messenger. ${ }^{3}$ The aecount of another traveller, Mr. Barrow, of their ravages in the southern parts of Africa (in 1784 and 1797) is still more striking; an area of nearly two thonsand square miles might be said literally to be covered by them. When driven into the sea by a N.W. wind, they formed upon the shore for fifty miles a bank three or four feet ligh, and when the wind was S. E. the stench was so powerful as to be smelt at the distance of 150 miles. ${ }^{4}$

From 1778 to 1780 the empire of Marocco was terribly devastated by them; every green thing was eaten up, not even the bitter bark of the orange and pomegranate eseaping - a most dreadful fanine cnsued. The poor were seen to wander over the eountry deriving a miserable subsistence from the roots of plants; and women and ehildren followed the camels from whose dung they picked the undigested grains of barley, which they devoured with avidity : in consequence of this, vast number's perished, and the roads and streets exhibited the unburied eareasses of the dead. On this sad occasion fathers sold their children, and husbands

1 Philos. Trans, xlvi. 30.

2 Major Moor, author of The Narrative of Cuptrin Little's Detachnent, The Hindu Pantheon, \&c.

3 Travels, i. 248.

4 Truvels, Sc. $25 \%$. 
their wives. ${ }^{1}$ When they visit a country, says Mr. Jackson, speaking of the same empire, it behoves every one to lay in provision for a famine, for they stay from three to seven years. When they have devoured all other vegetables, they attack the trees, consuming first the leares and then the bark. From Hogador to Tangier, before the plague in 1799 , the face of the earth was covered by then :-at that time a singular incident occurred at El Araiche. The whole region from the confines of the Sahara was ravaged by them ; but on the other side of the river El Kos not one of them was to be seen, though there was nothing to prevent their flying over it. Till then they had proceeded northward; but upon arriving at its banks they turned to the east, so that all the comntry north of El Araiche was full of pulse, fruits, and grain - exhibiting a most striking contrast to the desolation of the a!joining district. At length they were all carried by a violent hurricane into the Western Ocean ; the shore, as in former instances, was covered by their carcasses, and a pestilence was caused by the horrid stench which they emitted: but when this evil ceased, their devastations were followed ly a most alumdant crop. The Arabs of the Desert, "whose hands are against every man," 2 and who rejoice in the evil that befalls other nations, when they behold the elouds of locusts proceeding from the north, are filled with gladness, anticipating a general mortality, which they call El-hihere (the benediction); for, when a country is thus laid waste, they emerge from their arid cleserts and pitch their tents in the desolated plains. ${ }^{3}$ - The neighbouring kingdom of Spain has often suffered from the ravages of locusts. So recently as May, 1841, an article in the Constitutionnel French newspaper states as follows: "Such inmense quantities of locusts have appeared this year in Spain that they threaten in some places entirely to destroy the erops. At Daimiel, in the province of Ciudad-Real, three hundred persons are constantly eniployed in collecting these destructive insects, and though they destroy seventy or eighty sacks every day, they do not appear to diminish. There is something firghtful in the appearance of these locusts proceeding in divisions, some of which are a lcague in length and 2000 paces in breadth. It is sufficient if these terrible eolumns stop half an hour on any spot, for every thing growing on it - vines, olive-trees, and corn - to be entirely destroyed. After they have passed, nothing remains but the large branches and the roots, which, being under ground, have escaped their voracity." And in a late work of travels in the same country we find the following passige :- "During our ride (fron Cordora to Seville), we observed a number of men advancing in skimishing order across the country, and thrashing the ground most savagely with long flails. Curious to know what could be the motives for this Xerxes-like treatment of the earth, we turned out of the roal to inspect their operations, and found they were driving a swarm of locusts into a wide piece of linen, spread on the ground some distance before them, wherein they were made prisoners. These animals are about three times the size of an English grasshopper. They migrate from Africa, and their spring visits are very destructive ; for in a single night they will entirely eat up a field of corn." 4

1 Southey's Thalaba, i. 171.

2 Gen. xivi. 1:2.

3 Jackson's Travels in Marocco, 51.

4 Scott's Excursions in the Montains of Ronda and Grunuda. The same plan is adopted for the destruction of these insects in some parts of the United States: deep trenches being dug at the end of fields into which the grasshoppers are driven with branches, and then destroyed by throwing the earth upon them. 
The noise the locusts make when engaged in the work of destruction has been compared to the sound of a flame of fire driven by the wind, and the effect of their bite to that of fire. ${ }^{1}$ The poet Southey has very strikingly described the noise produced by their flight and approach :-

"Onward they came, a dark continuous cloud
Of congregated myriads numberless,
The rushing of whose wings was as the sound
Of a broad river headlong in its course
Plunged from a mountain summit, or the roar
Of a wild ocean in the antumn storm,
Shattering its billows on a shore of rocks!" 2

But no account of the appearance and ravages of these terrible insects, for correctness and sublimity, comes near that of the prophet Joel, " $\Lambda$ day of darkness and of gloominess, a day of clouds and of thick darkness, as the morning spread upon the mountains; a great people and a strong: there hath not been ever the like, neither shall be any more after it, even to the years of many generations. A fire devoureth before then, and behind them a flame burneth: the land is as the garden of Eden before them, and behind them a desolate wilderness; yea, and nothing shall escape them. Like the noise of chariots ${ }^{3}$ on the tops of mountains shall they leap, like the noise of a flame of fire that devoureth the stubble, as a strong pcople set in battle array. Before their faces the people shall be much pained : all faces shall gather blackness. They shall run like mighty men; they shall climb the wall like men of war; and they shall march every one on his ways, and they shall not break their ranks; neither shall one thrust another; they shall walk every one in his path : and when they fall upon the sword they shall not be wounded. They shall run to and fro in the city; they shall run upon the wall; they shall climb up upon the houses; they shall enter in at the windows like a thief. The earth shall quake before them, the heavens shall tremble : the sun and the moon shall be dark, and the stars stall withdraw their shining!" The usual way in which thcy are destroyed is also noticed by the prophet. "I will rcmove far off from you the northern army, and will drive him into a land barren and desolate, with his face toward the east sea, and his hinder part toward the utmost sea, and his stink shall come up, and his ill savour shall come up, because he hath done great things!" 4

I think, after a serious consideration of all these well-attested facts, when locusts contend with the two-legged destroyers of the human race for proud pre-eminence in mischief, you will find it difficult to determinc to which the palm should be decreed; and you will admire the propriety with which, in the above and other passages of Holy Writ, they are selected as symbols of the great ravagers of the earth of our own species.

In many of the above instances these devastators appear to have crossed the seas, but Hasselquist asscrts that they are not formed for such extensive flights. "The grasshopper or locust," says he, "is not formed for travelling orer the sea, - it cannot fly far, but must alight as soon as it

1 See Bochart, IIierozoic. P. 1. iv. c. 5. 474, 475.

3 Southey's Thalaba, i. 169.

3 Of the symbolical locusts in the Apocalypse it is said- "And the sound of their wings was as the sound of chariot3, of many horses ruming to buttle," ix. 9.

$\&$ Joel, ii. $2-10.20$. 
rises; for one that came on board us a hundred certainly were drowned. We observe in the months of May and June a number of these inseets coming from the south, and directing their course to the northern shore; they darken the sky like a thick eloud; but scarcely have they quitted the shore, when they, who a moment hefore ravaged and ruined the country, eover the surface of the sea with their dead bodies. By what instinct do these ereatures undertake this dangerous flight? Is it not the wise institution of the Creator to destroy a dreadful plague to the country?"1 Loeusts, however, as we have seen, take inuch longer flights than this author supposes them able to co. It is probable that their ability in this respect may depend a good deal upon their species, their age, and the state and direetion of the wind; for, as was the ease with the Egyptian plague,

\section{"—a pitchy cloud}

Of locusts warping on the eastern wind"

may by a powerful blast be carried over a broad river, or even the sea, from one country to another. This idea is strongly confirmed by an account, exhibiting internal marks of authenticity, which appeared in the Alexandria Herald, an American newspaper; in which it is stated, that at the distance of 200 miles from the Canary Islands, the nearest land, the ship Georgia, Capt. Stokes, from Lisbon to Savannah, while sailing with a fine breeze from the south-east, was, on the 21 st of Nov. 1811, all at once beealmed. "A light air afterwards sprung up from the north-east, at which time there fell from the cloud an innumerable quantity of large grasshoppers, so as to eover the deek, the tops, and every part of the slip they could alight upon. They did not appear in the least exhausted; on the contrary, when an attempt was made to take hold of them, they instantly jumped, and endeavoured to elude being taken. The calm, or a very light air, lasted fully an hour, and during the whole of the time these insects continued to fall upon the ship and surround her: such as were within reach of the vessel alighted upon her; but immense numbers fell into the sea, and were seen floating in masses by the sides." Two hottles of them were preserved for inspection; the insects were of a reddish lue, with red and grey speckled wings. It is clear from this account, if it be admitted as authentic, that locusts can go far from land when the wind is strong, and likewise it seems equally clear that in a calm they eannot support themselves in the air. The prineipal diffieulty is, how these locusts could make their way against the wind, which they must have done if they eane with the black cloud, as the words seem to intimate. Perhaps this cloud was brought by a different current of air from that which impelled the ship. A sinilar statenent is given in the Essex (Massachusetts) Register, in an extract from a letter of the mate of the brig Levant of Boston, who writes, "that after having encountered a severe gale on the 13th September (1839), when in lat. $18^{\circ}$ north, and the nearest land being over 450 miles, they were surrounded for two days by large swarms of locusts of a large size; and in the afternoon of the secord diy, in a squall from the worth-west, the sky was completely black with them. They covered every part of the brig immediately, sails, rigging, cabin, \&c. It is 
a little singular how they could have supported themselves in the air so long, as there was no land to the north-west for several thousand miles. Two days afterwards, the weather being moderate, the brig sailed throngh swarms of them floating dead upon the waters." ${ }^{1}$

With respect to the course which the locusts pursue, Hasselquist has observed that they migrate in a direct meridian line from south to north, passing from the deserts of Arabia, which is the great cradle of them, to Palestine, Syria, Caramania, Natolia, Bithynia, Constantinople, Poland, \&c.-they never turn either to the east or to the west. ${ }^{2}$ But this must be a mistaken notion; for those which Major Moor saw at Poonah, of which I have given an account above ${ }^{3}$, must have come due east. Mr. Jackson also noticed their course north of the line to be towards the south ${ }^{4}$; and Sparrman tells us that those south of the line migrate in the same direction. ${ }^{5}$

I fear that Hasselquist's question.-Could they not by fright, or some other method, be turned from their dreadful course, to steer for some river, and by that means be obliged to destroy themselves ${ }^{6}$ - must be answered in the negative. All such experiments, it is to be apprehended, would be about as effectual as sending an army, with all the apparatus of war, to take the field against them, as this author says is done in Syria, where the Bashaw of Tripoli once raised a force of 4000 soldiers to fight the locusts, and very summarily ordered all to be hanged who, thinking it beneath them to waste their valour upon such pigmy foes, refused to join the party. ${ }^{7}$

I am, \&c.

1 Ann. Nat. Hist. vi. 527. The authenticity of the above accounts is fully prover by a fact mentioned by Mr. Darwin,-that a large grasshopper (Acrydium) Hlew on board the Beagle when she was to windward of the Cape de Verd Islands, and when the nearest point of land, not directly opposed to the trade-wind, was Cape Blanecr, on the west of Africa, 370 miles distant. (Journal in Voyages of the Adventure and Beagle, p. 186.)

2 Toyage to the Levant, p. 446, 447.

4 Travels, うั4.

6 Travels 455.

5 See p. $12 \pi$.

5 Tracels, i. 366.

- Travels, 447. 


\section{LETTER VIII.}

\section{INJURIES CAUSED BY INSECTS.}

\section{INDIRECT IXJURIES - concluded.}

I HAVE not yet arrived at the end of my catalogue of noxions insects. I have introduced you, indeed, to those that annoy man in his own person, in his domestic animals, in the prodnce of his fields, gardens, orchards, and forests; in a word, in every thing that is endued with the vital principle: but I have as yet said nothing of the injuries which he receives from them in that part of his property, consisting either of animal or vegetable matter, from which that principle is departed. And with these I shall conclude this melancholy detail of evils inflicted upon us by the very animals I am enticing you to study. The rest of my correspondence, I flatter myself, will paint them in more inviting colours.

The insects to which I now allude may be divided into those that attack and injure our food, our drugs and medicines, our clothes, our houses and furniture, our timber, and even the objects of our studies and amusements.

Various are those that attempt to share our food with us. Flour and meal are eaten by the grub of Tenebrio molitor, best known by the name of the meal-worm, which will remain in it two years before it goes into its state of inactivity :-its ravages, however, are not confined to flonr alone, for it will cat any thing made of that article, such as bread, cakes, and the like. Old flour is also very apt to be infested by a mite (Acarns farince). ${ }^{1}$ In long voyages the biscuit sometimes so swarms with the weevil and another beetle (Dermestes panicens L.), that they are swallowed with every mouthful; and even the ground peas so abound with these little vermin that a spoonful of soup cannot be taken free from them. ${ }^{2}$ Bread is also devoured by Trogosita caraboides, a larger beetle before allnded to.

Every one is aware that our animal food suffers still more than our farinaceous from insects; but perhaps you would not expect that our hams, bacon, and dried meats should have their peculiar beetle. Yet so it is; and this beetle (Dermestes lardarins), when a grub, sometimes commits

1 Amœn. Acad. iii. 345.

2 Sparman, i. 103. This insect, by Swedish entomologists, is supposed to be a species of Anobium F. (Ptinus L.); but the specimen preserved in the Limnean cabinet is Silpha rosea of Mr. Marsham (Cacicula pectoralis Meg.). A small beetle of the first family of Cryptophagios Gyllenhal swarms often in the ship biscuit, and may probably be the insect Sparman liere complains of under the name of Dermestes panicens. It is probable, however, that there is a mistake as to the specimen in the Linnean cabinet, as there is no doubt that Anobium paniceum Stephens is very injurious to biscuit, of which Mr. Raddon exhibited to the Entomological Society several perforated in all clirections by the larve of this insect, which, strange to say, he found to feed also on Cayenne pepper. (Trans. Ent. Soc. Lond. i. proc. Ixxxv. ii. proc. $(x \mathrm{xi}$.) 
great devastation in them; as does that of another described by De Geer under the name of Tcnebrio lardarins. ${ }^{1}$ How much our fresh meat of all kinds, our poultry and fish, are exposed to the flesh-fly, whose maggots will turn us disgusted from our tables, if we do not carefully guard these articles from being blown by then, you well know; - and assailants more violent, hornets, wasps, and the great rove-bcetle (Creophilus maxillosus), if butchers do not protect their shambles, will carry off no inconsiderable portion of their meat. A small cockroach (Blatta lapponica), which I have taken upon our eastern coast, swarms in the huts of the Laplanders, and will sometimes annihilate in a single day, a work in which a carrionbeetle (Silplea lapponica) joins, their whole stock of dried fish. ${ }^{2}$ The quantity of sugar that flies and wasps will clevour if they can come at it, especially the latter, the diminutive size of the creatures considered, is astonishing:-in one year long ago, when sugar was much cheaper than it is now, a tradesman told me he calculated his loss, by the wasps alone, at twenty pounds. A singular spectacle is exhibited in India (so Captain Green relates) by a small red ant with a black head. They march in long files, about three abreast, to any place where sugar is kept; and when they are saturated, return in the same order, but by a different route. If the sugar, upon which they are busy, be carried into the sun, they immediately desert it. What is very extraordinary, these ants are also fond of oil. Sweetmeats and preserves are very subject to be attacked by a minute oblong transparent mite with very short legs and without any hair upon its body. Our butter and lard are stated to be eaten by the caterpillar of a moth (Aglossa pinguinalis). Typophaga ${ }^{3}$ casci, the parent fly of the jumping cheese maggot, loses no opportunity, we know, of laying its eggs in our tresh chceses, and when they get dry and old the imite (Acarus siro) settles her colonies in them, which multiply incredibly. Other substances, more unlikely, do not escape from our pigmy depredators. Thus Reaumur tells us of a little moth whose larva feeds upon chocolate, observing very justly that this could not lave been its original food. ${ }^{4}$ Both a moth and a beetle (Sylvanus firmentarius?) were detected by Leeuwenhoek preying upon two of our spices, the mace and the nutmeg.' The maggots of a fly (Drosoplizla cellaris) are found in vinegar, in the manufactories of which the perfect insects swarm in incredible numbers; others I have found in wine, which turn to a minute fly, of a yellow colour, with dark eyes and abdomen, which, though near Anthomyza as to its wings, appears to belong to a distinct genus not published by Meigen, which in ny MS. stands under the name of Oinopota ventralis ${ }^{6}$; and some-

1 De Geer, $\nabla .46$. This insect appears nearly related to Mr. Marsham's Corticariu pulta (E. B. i. 11. 14.; Latridius porcatus Herbst), if it be not the same insect.

2 Amæn. Acad. iii. 345.

3 This name has long been given to this insect, and the characters of the genus were drawn by Mr. Curtis before the publication of Meigen's fifth volume (in which the genus is called Pioplita); it is therefore retained. (See Curtis, Brit. Ent. t. 126.)

4 Iieaum. iii. 276.

5 Leeuwenh. Epist. 99.

6 Though our foreign wines, after being deposited in bottles in our cellars, would seem secure from the attacks of insects, a friend of S. S. Saunders, Esq., found, on removing his stock from one cellar to another, that the corks of many of the bottles had been so eaten as to let the wine leak out. The authors of this mischief seem to Lave been chiefly cockroaches, which had gnawed off the corks of the claret only so 
times even water in the casks of ships, in long voyages, so abounds with larvæ of this tribe as to render it extremely disgusting. Browne, in lis History of Jamaica, mentions an ant (Formica omivora L.), probably belonging to Myrmica, that consumes or spoils all kinds of food; which perhaps may be the same species that has been observed in Ceylon by Percival, and is described by him as inhabiting dwelling-houses, and speedily devouring every thing it can meet with. If at table any one drops a piece of bread, or of other food, it instantly appears in motion as if animated, from the vast number of these creatures that fasten upon it in order to carry it off. They can be kept, he tells us, by no contrivance from invading the table, and settling in swarms on the bread, sugar, and such things as they like. It is not uncommon to see a cup of tea, upon being poured ont, completely covered with these creatures, and floating dead upon it like a scum.'

In some comntries the number of flies and other insects that enter the house in search of fool, or allured by the light, is so great as to spoil the comfort of almost every meal. We are told that during the rainy season in India, insects of all descriptions are so incredibly numerous, and so busy every where, that it is often absolutely necessary to remove the lights fiom the supper table:- were this not done, moths, flies, bugs, beetles, and the like, would be attracted in such numbers as to extinguish them entirely. When the lights are retained on the table, in some places they are put into glass cylinders, which St. Pierre tells us is the custom in the Island of Mauritius ${ }^{2}$; in others the candlesticks are placed in soup plates, into which the insects are precipitated and drowned. Nothing can exceed the irritation caused by the stinking bugs when they get into the hair or between the linen and the body; and if they be bruised upon it the skin comes off: ${ }^{3}$ To use the language of a poet of the Indies from whom some of clie above facts are selected, -

" On every dish the booming beetle falls,

The cockroach plays, or caterpillar crawls:

A thousand shapes of variegated hues

Parade the table or inspect the stews.

To living walls the swarming luudreds stick,

Or court a dainty meal, the oily wick :

Heaps over heaps their slimy bodies drench,

Out go the lamps with suffocating stench.

When hideous insects every plate defile,

The laugh low empty and how forced the smile!":

far as they were unimpregnated with the wine; but finding the sweet flavour of the Persian shiraz and old hock more to their taste, laad encroached upon the corks of these so deeply as to allow the wine to escape. A few individuals of two minute l.eetles Cryptophagus cellaris and Mycatoa hirta, a minute Acarus, and Atropos lignarius, were found on the corroded corks, but seem more likely to have been attracted by the oozing wine than to have originally caused the damage. (Trans. Ent. Soc. Lond. i. proc. Iv.) Mr. Thwaites suggests that Blaps mortisaga is more likely to have eaten the corks than cockroaches, which do not usually frequent cellars, whereas the former are found very generally in those of Bristol ; and, as he has observed the stomach of the individuals of these insects which he dissected to be filled with what seemed saw-dust, they may probably also eat corks, which indeed he fomd they did on putting them into a box along with the insects.

1 Ceylon, 3̊07.

3 Williamson's East India Vade Mecum.
2 Voyage, \&c. 72.

4 Calcutta, a Poem, 85. 
Drugs and medicines also, though often so nauseous to us, form oceasionally part of the food of insects. A small beetle (Sinodendrum pusillum ${ }^{1}$ ) eats the roots of rhubarb, in which I detected it in the East Indian Com. pany's warehouses. Opium is a dainty morceau to the white ants ${ }^{2}$; - and, what is more extraordinary, Anobium janiceum ${ }^{3}$ has been known to devour the blister-beetle (Canthuris vesicatoria), and even, as has been already observed, Cayenne pepper. Swammeruam amongst his treasures mentions "a detestable beetle," produced from a worm that eats the roots of ginseng; and he likewise notices another, the larva of which devours the bag of the musk. ${ }^{4}$ The cochineal, at Rio de Janeiro, is the prey of an insect resembling an Ichneumon, but furnished with only two wings; its station is in the cotton that envelops the Coccus. Previous to its assumption of the pupa, it ejects a large globule of pure red colouring matter. ${ }^{5}$ And lastly, the Coccus that produces the lac $(C$. lacca $)$ is, we are told, devoured by various inseets. ${ }^{6}$

Perhaps you imagine that these universal destroyers spare at least our garments, in which you may at first conceive there can be nothing very tempting to excite even the appetite of an insect. Your housekeeper, however, would probably tell you a different story, and enlarge upon the trouble and pains it costs her to guard those under her care against the ravages of the moths. Upon further inquiry you would find that nothing made of wool, whether cloth ol stuff, comes amiss to them. There are five species described by Linné, which are more or less engaged in this work:- Tinea vestianella, tapetzella, pellionclla, Laverna sarcitclla, and Galleria mollonella. Of the first we have no particular history, except that it destroys garments in the summer; but of the other's Reaumur has given a complete one. T. tapctzella, or the tapestry moth, not uncommon in our houses, is most injurious to the lining of carriages, which are more exposed to the air than the furniture of our apartments. These do not construct a moveable habitation like the common speeies, but, eating their way in the thickness of the cloth, weave themselves silken galleries in which they reside, and which they render close and warm by covering them with some of the eroded wool. ${ }^{7} \quad T$. pellionclla is a most destructive insect; and ladies have often to deplore the ravages which it commits in their valuable furs, whether made up into muffs or tippets. It pays no more respect to the regal ermine than to the woollen habiliments of the poor; its proper food, indeed, being hair, though it devours both wool and fur: This species, if hard pressed by hunger, will even eat horse-hair, and make its habitation, a moveable house or case in which it travels from place to place, of this untractable material. These little creatures will shave the hair from a skin as neatly and closely as if a razor had been employed. ${ }^{8}$ The most natural food of the next species, $L$. sarcitella, is wool ; but in

\section{Ptinus piceus Marsh.}

2 On examining ninety-two chests of opium, part of the cargo saved from the Charlton, previously to reshipping them from Chittagong for China, thirteen were found to be full of white ants, which had almost wholly devoured the opium. (Article from Chittagong, Nov. 1812, in one of the Ncwspapers, July 31, 1813.)

3 P'tinus rubellus Marsh.

5 Sir Geo. Staunton's Voy. 8ro. 189.

7 Reaum. iii. 260.
4 Bibl. Nat. i. 125. b. 126. a.

6 Kerr in Philos. Trans. 1781.

8 Ibid. 59. 
case of necessity it will eat fur and hair. To woollen cloths or stuffs it often does incredible injury, especially if they are not kept dry and well aired. ${ }^{1}$ Of the devastation committed by Galleria mellonella in our beehives $I$ have before given you an account : to this I must here add, that if it cannot come at wax, it will content itself with woollen cloth, leather, or even paper. ${ }^{2}$ Mr. Curtis found the grub of a beetle (Ptimus fur) in an old coat, which it deroured, naking holes and channels in it; and another unsect of the same order (Attagenus pellio), Linné tells us, will sometimes entirely strij) a fur garment of its hair. ${ }^{3}$ A small beetle of the Capricorn tribe (Callidin pygmanm Fabr.) I have good reason to believe devours leather, since I have found it abundant in old shoes. ${ }^{4}$

Next to our garments, our houses and buildings, which shelter us and our property from the inclemency and injuries of the atmosphere, are of consequence to us: yet these, solid and substantial as they appear, are not secure from the attack of insects; and even our furniture often suffers from them. A great part of our comfort within doors depends upon our apartments being kept clean and neat. Spiders by their webs, which they suspend in every angle, and flies by their excrements, which they scatter indiscriminately upon every thing, interfere with this comfort, and add much to the business of our servants. Eren ants will sometimes plant their colonies in our kitchens (I have known the horse-ant, Formica rufa, do this), and are not easily expelled. ${ }^{5}$ Those of Sierra Leone, as I was once informed by the learned Professor Afzelius, make their way by millions through the houses. They resolutely pursue a straight course; and neither buildings nor rivers, even though myriads perish in the attempt, can divert them from it. Several tribes of insects seek their food in the timber employed in our houses, buildings, gates or fences, or made up into furniture. The large oaken heams, which, according to the old mode of building, support the joists of the upper floors in the houses at Brussels, as I had an opportunity of observing when there in 1836, have often their extremities so eaten away like a honeycomb by the larvæ of a beetle (Anobium tessellatum, some of the dead perfect insects of which $I$ found in their holes.), that it is necessary to replace them at great expense to prevent the floors coming down; and I subsequently saw beans similarly attacked which had been removed from houses at Antwerp. ${ }^{6}$ M. Audouin has laid before the French Academy an account of the injury done by T'ermes lucifugus to the wood-work of buildings at Rochefort and La Rochelle; and of that of the new galleries of the Museum of Natural History at Paris by the larva of a small bectle (Lyctus canaliculatus Fab.), which feeds on the

1 Reaum. iii. 42.

2 Ibid. 257.

3 Amon. Acad. 346.

4 Hides and skins are attacked by sereral species of Dermestes, which are sometimes so injurious in the large skin warehouses of London, that the merchants offered $20,000 l$, as a reward for an arailable remedy. (Westwood, Mod. Ctress. Ins. i. p. 158.)

5 Within the last few years, a very minute yeliow ant ( $\boldsymbol{N}$ yrmica domesticu Slunckard) has become a great pest in many houses in Brighton, London, and Liverpool; in some cises to so great an extent as to cause the occupants to leave them. Dr. Bostock was obliged to replace the floor of his kitchen, under which they swarmed in incredible numbers, by a new one resting on tiles imbelded in cement. (Trans. Ent. Soc. Lond. ii. 66. proc. li. lii.; Shuckard in Mag. Nat. Hist. IIS. ii. 626.)

6 Spence in Trans. Ent. Soc. Lond. ii. proc. x. 
sapwood, in which its eggs had probably been deposited before the wood was worked up. ${ }^{1}$ Of one of the timber-cating beetles (Anobium pertinax) Linné complains "terebravit et destruxit sedilia mea;"2 and I can renew the same complaint against $A$. striatum, which not only has destroyed my chairs, but also picture-frames, and has perforated in every direction the deal floor of my chanber, from which it annually emerges through little round apertures in great numbers. The utility of entomological knowledge in economics was strikingly exemplified when the great naturalist just mentioned, at the desire of the King of Sweden, traced out the cause of the destruction of the oak-timber in the royal dock-yards; and, having detected the lurking culprit under the form of a beetle (Lymexylon navale), by directing the timber to be immersed during the time of the metamorphosis of that insect and its season of oviposition, furnished a remedy which effectually secured it from its future attacks. ${ }^{3}$ No Coleopterous insects are more singular than those that belong to the genus Paussus L.; and one of them, at least, remarkable, it is said, for enitting a phosphoric light from the globes of its antennæ, is also a timber-feeder ${ }^{4}$; and the genus Trypoxylon, many species of Crabro, Eumenes parietum, Latreille's genera Xylocopa, Chelostoma, Heriades, Megachile, and Anthrophora (all separated from Apis L.), perforate posts and rails and other tinber, to form cells for their young. ${ }^{5}$

The Linnean order Aptera furnishes another timber-eating insect, a kind of wood-louse (Limnoria terebrans of Dr. Leach), which though scarcely an eighth of the size of the common one, in point of rapidity of execution seems to surpass all its European brethren, and in many cases may be productive of more serious injury than any of them, since it attacks the woods work of piers and jetties constructed in salt water, and so effectually as to threaten the rapid destruction of those in which it has established itself. In December, 1815, I was favoured by Charles Lutwilge, Esq. of Hull, with specimens of wood from the piers at Bridlington Quay, which wofully confirm the fears entertained of their total ruin by the hosts of these pigmy assailants that have made good a lodgment in them, and which, though not so big as a grain of rice, ply their masticatory organs with such assiduity as to have reduced great part of the wood-work which constitutes their food into a state resembling honeycomb. One specimen was a portion of a three-inch fir plank nailed to the North Pier about three years before, which is crumbled away to less than an inch in thickness - in fact, deducting the space occupied by the cells, which cover both surfaces as closely as possible, barely half an inch of solid wood is left; and though its progress is slower in oak, that wood is equally liable to be attacked by it. $^{6}$ If this insect were easily introduced to new stations, it might soon prove as destructive to our jetties as the Teredo navalis to those of Holland, and induce the necessity of substituting stone for wood universally, what-

1 Guérin-Méneville, Revue Zootog. 1810, p. 151.

2 Syst. Nat. 565. 2.

3 Smith's Introduction to Botany, Pref xv.

4 Afzelius in Linn. Trans. iv. 261.

5 Kirby, Mon. Ap. Ang. i. 152. 194. Latreille, Gen. jv. 161-.

$\checkmark$ See the elaborate-memoir of Mr. Coldstream in Edin. New Phit. Journ. April, 1834; remarks on this insect by the Rev. F. W. Hope in Trans. Ent. Soc. Lond. i. 119.; also by Dr. Moore, in Mag. of Nat. Hist. N.S. ii. 206., who states that its injurious effects have been known at least forty years in the harbour at Plymouth, where it is called the "gribule." 
ever the expense: but happily it seems endowed with very limited powers of migration; for, though it has spread along both the South and East Piers of .Bridlington harbour, it has not yet, as Mr. Lutwidge informs me, reached the dolphin nor an insulated jetty within the harbour. No other remedy against its attacks is known than that of keeping the wood free from salt water for three or four days, in which case it dies; but this method, it is obvious, can be rarely applicable. ${ }^{1}$

How dear are their books, their cabinets of the various productions of nature, and their collections of prints and other works of art and science, to the learned, the scientific, and the virtuosi! Even these precious treasures have their insect enemies. The larva of Aglossa pinguinalis, whose ravages in another quarter $I$ have noticed before ${ }^{2}$, will establish itself upon the binding of a book, and spinning a robe, which it covers with its own excrement ${ }^{3}$, will do it no little injury; as also does a minute beetle of the fumily of Scolytide (Hypothenemus ernditus Westw.), which Mr. Westwood found burrowing in considerable numbers in the same situation. ${ }^{4}$ A mite (Cheyletus eruditus) eats the paste that fastens the paper over the edges of the binding, and so loosens it. ${ }^{5} \quad I$ have also often observed the caterpillar of another little moth, of which I have not ascertained the species, that takes its station in damp old books, between the leaves, and there commits great ravages; and many a black-letter rarity, which in these days of Bibliomania would have been valued at its weight in gold, has been snatched by these destroyers from the hands of bookcollectors. The little wood-boring beetles before mentioned (Anobium pertinax and striatum) also attack books, and will even bore through several volumes. M. Peignot mentions an instance where, in a public library but little frequented, twenty-seven folio volumes were perforatel in a straight line by the same insect (probably one of these species), in such a manner that, on passing a string through the perfectly round lole made by it these twenty-seven volumes could be raised at once. ${ }^{6}$ The animals last mentioned also destroy prints and drawings, whether framed or preserved in a portefeuille, and even paintings ; it appearing from a parlia. mentary report on the state of the paintings in the National Gallery, and subsequent observations of M. Waagen, that the paste applied to the canvas of the fine picture of the Raising of Lazarus, by Sebastian del Piombo, has been so attacked by the larvæ of an insect (supposed to be Anobium panicenm) that its destruction is to be feared if some remedy cannot be found. The same insect has done considerable injury, as we learn from Mr. Holme, to the Arabic manuscripts in the Cambridge

1 In order to ascertain how far pure sea water is essential to this insect, and consequently what danger exists of its being introduced into the wood-work of our docks and piers conmmicating with our salt-water rivers, as at Hull, Liverpool, Bristol, Ipswich, \&c., where it might be far more injurious tlan even on the coast, I have, since December 15th, 1815, when Mr. Lutwidge was so kind as to furuish me with a piece of oak full of the insects in a living state, poured a weak solution of common salt over the wood every other day, so as to keep the insects constantly wet. On examining it this day (Feb. 5th, 1816) I found them alive; and, what seems to prove them in as good health as in their natural habitat, numbers having establislied themselves in a piece of fir-wood which I nailed to the oak, and have in this short interval, and in winter too, bored many cells in it.

2 See p. 133.

4 Trans, Ent. Soc. Lond. j. $34 . \quad 5$ Schrank, Enum. Ins. Austr. 513. 1058.

6 Horne's Introd. to Bibliography, i. 311. 
Library brought from Cairo by Burckhardt. ${ }^{1}$ Our collections of quadrupeds, birds, iusects, and plants have likewise several terrible insect enemies, which, without pity or remorse, often destroy or mutilate our most highly prized specimens. Ptinus fur and Anthrenus musceorum, two minute beetles, are amongst the worst; especially the latter, whose singular gliding larva, when once it gets amongst them, makes astonishing havoc, the birds soon shedding their feathers, and the insects falling to pieces. Mr. W. S. MacLeay informs ine that at the Havana it is exceedingly difficult to preserve insects, \&c., as the ants devour every thing. One of the worst plagues of the entomologist is a mite (Acarts destructor Schrank): this, if his specimens be at all damp, eats up all the muscular parts (Cantharis vesicatoria being alnost the only insect that is not to its taste), and thus entirely destroys them. If spiders by any means get amongst them, they will do no little mischief. - Some I have observed to be devoured by a minute moth, perhaps Tinea insectella ${ }^{2}$; and in the posterior thighs of a species of Locusla from China I once found, one in each thigh, a small beetle congenerous with Antherophagus pallens, that had devoured the interior. It is, I believe, either Acarus destructor or Cheyletus eruditus that eats the gum employed to fasten down dried plants.

There are other insects which do not confine themselves to one or two articles, but malie a general and indiscriminate attack upon our dead stock. Ulloa mentions one peculiar to Carthagena, called there the comegen, whlich he describes as a kind of moth or maggot so minute as to be scarcely visible to the naked eye. ${ }^{3}$ This destroys, says he, the furniture of houses, particularly all kinds of hangings, whether of clotl, linen or silk, gold or silver stuffs, or lace ; in short, every thing except solid metal. It will in a single night ruin all the goods of a warehouse in which it has got footing, reducing bales of merchandise to dust without altering their appearance, so that the mischief is not perceived till they come to be handled. ${ }^{4}$ If we make some deduction from this account for exaggeration, still the amount of damage will be very considerable.

There are three kinds of insects better known, to whose ravages, as most prominent and celebrated, I shall last call your attention, The insects 1 mean are the cock-roach (Blalta orientalis), the house-cricket (Gryllus domesticus), and the various species of white ants (Termes). The last of these, most fortunately for us, are not yet naturalised.

The cock-roaches hate the light, at least the kind that is most abundant in Britain (for $B$. germanica, which abounds in some honses, is bolder, making its appearance in the day, and running up the walls and over the tables, to the great annoyance of the inhabitants), and never come forth from their hiding-places till the lights are removed or extingnished. In the London houses, especially on the ground-floor, they are most abundant, and consume every thing they can find, flour, bread, meat, clothes, and even shoes. $^{5}$ As soon as light, natural or artificial, reappears, they all scamper off as fast as they can, and vanish in an instant. These pests are not

1 Trans. Ent. Soc. Lond. ii. proe. xlii. xliii.; proc. 18. ix.

2 Atropos putsatorius does much mischief by devouring the more delicate parts of minute insects in collections in which camphor or some other insectifuge is not kept.

3 It appears from Humboldt (Personat Narrative, E. T. v. 116.) that the destructive insects called by this name are Termites.

4 Ulloa, i. 67.

5 Amœn. Acad. iii. 345. 
indigenous here, and perhaps nowhere in Europe, but are one of the evils which commerce has imported; and we may think ourselves well off that others of the larger species of the genus have not been introduced in the same way - as, for instance, Blatta gigantea, a native of Asia, Africa, and America, many times the size of the common one, which, not content with devouring meat, clothes, and books, even attacks persons in their sleep, and the extremities of the dead and dying. 1

The house-cricket may perhaps be deemed a still more annoying insect than the common cock-roach, adding an incessant noise to its ravages; since, although for a short time, it may not be unpleasant to hear

\section{"the cricket chirrup in the hearth,"}

so constant a din every evening must very much interrupt comfort and conversation. These garrulous animals, which live in a kind of artificial torrid zone, are very thirsty souls, and are frequently found drowned in pans of water, milk, broth, and the like. Whatever is moist, even stockings or linen hung ont to dry, is to them a bonne bouche; they will eat the scummings of pots, yeast, crumbs of bread, and even salt, or any thing within their reach. Sometimes they are so abundant in houses as to become absolute pests, flying into the candles and into people's faces.

At Cuddapa, in the ceded districts to the northward of Mysore, Captain Green was much annoyed by a jumping insect, which, fiom his description, I should take for the larva of a species of cricket. They were of a dun colour, and from half to three-fourths of an inch in length. They abounded at night, and were very injurious to papers and books, which they both discoloured and devoured; leather also was eaten by them. Such was their boldness and avidity, that they attacked the exposed parts of the body when you were asleep, nibbling the ends of the fingers, particularly the skin under the nails, which was only discoverable by a slight soreness that succeeded. So great was their agility that they could seldom be caught or crushed. They were a mute insect, but probably the imago would make noise enough.

But the white ants, wherever thcy prevail, are a still worse plague than either of these insects - they are the great calamity, as Limmé terms them, of both the Indies. When they find their way into houses or warehouses, nothing less hard than metal or glass escapes their ravages. Their favourite food, however, is wood of all kinds, except the teak ('Tectona grandis) and iron-wood (Sideroxylon), which are the only sorts known that they will not touch ${ }^{2}$; and so infinite are the multitudes of the assailants, and such is the excellence of their tools, that all the timber-work of a spacious apartment is often destroyed by them in a few nights. Exteriorly, however, every thing appears as if untouched; for these wary depredators, and this is what constitutes the greatest singularity of their history, carry on all their operations by sap and mine, destroying first the inside of solid

1 Drury's Insects, iii. Preface.

2 It is uot its hardness that protects the teak, as the Asiatic Termites attack Lignum Vitæ, but probably some essential oil disagreeable to them with which it is impregnated. This is the more likely, siuce they will eat it when it is old and has beeu long exposed to the air. Tannin has been conjectured to be the protecting substance, but erroneously, as leather of every kind is devoured by them. (IVilliamson's East India Vade Necum, ii. 56.) It is its harduess probably that protects the iron-wood from the African Termites. (Smeathman in Philos. Trans. 1781, 11. 47.) 
substances, and scarcely ever attacking their outside, until first they have concealed it and their operations with a coat of clay. A general similarity runs through the proceedings of the whole tribe; but the large African species (called by Smeathman Termes bellicosus), T. futalis, is the most formidable. These insects live in large clay nests, from whence they excavate tunnels all round, often to the extent of several hundred feet; from these they will descend a considerable depth below the foundation of a house, and rise again through the floors; or, boring through the posts and supports of the building, enter the roof, and construct there their galleries in various directions. If a post be a convenient path to the roof, or has any weight to support, which how they discover is not easily conjectured, they will fill it with their mortar, leaving only a track-way for themselves ; and thus, as it were, convert it from wood into stone as hard as many kinds of freestone. In this manner they soon destroy houses, and sometimes even whole villages when deserted by their inhabitants, so that in two or three years not a vestige of them will remain.

These insidious insects are not less expeditious in destroying the wainscoting, shelves, and other fixtures of a house, than the house itself. With the most consummate art and skill they eat away the inside of what they attack, except a few fibres here and there, which exactly suffice to keep the two sides, or top and bottom, connected, so as to retain the appearance of solidity after the reality is gone; and all the while they carefully avoid perforating the surface, unless a book or any other thing that tempts them should be standing upon it. Kampfer, speaking of the white ants of Japan, gives a remarkable instance of the rapidity with which these miners proceed. Upon rising one morning he observed that one of their galleries of the thickness of his little finger had been formed across his table; and upon a further examination he found that they had bored a passage of that thickness up one foot of the table, formed a gallery across it, and then pierced down another foot into the floor: all this was done in the few hours that intervened between his retiring to rest and bis rising. ${ }^{1}$ They make their way also with the greatest ease into trunks and boxes, even though made of mahogany, and destroy papers and every thing they contain, constructing their galleries, and sometimes taking up their abode in them. Hence, as Humboldt informs us, throughout all the warmer parts of equinoctial America, where these and other destructive insects abound, it is infinitely rare to find papers which go fifty or sixty years back.? In one night they will devour all the boots and shoes that are left in their way : clotb, linen, or books are equally to their taste; but they will not eat cotton, as Captain Green informs me. I myself have to deplore that they entirely consumed a collection of insects made for me by a friend in India, more especially as it sickened him of the employment. In a word, scarcely any thing, as I said before, but metal or stone comes amiss to them. Mr. Smeathman relates that a party of them once took a fancy to a pipe of fine old Madeira, not for the sake of the wine, almost the whole of which they let ont, but of the staves, which however I suppose were strongly imbued with it, and perbaps on that account were not less to the taste of our epicure 'Termites. Having left a compound microscope in a warehouse at Tobago for a few months, on his return he found that a colony of a small species of white ant had established themselves in it, and hail 
devoured most of the wood-work, leaving little besides the metal and glasses. ${ }^{1}$ A shorter period sufficed for their demolition of some of Mr. Forbes's furniture. On surveying a room which had been locked up during an absence of a few weeks, he observed a number of advanced works in various directions towards some prints and drawings in English frames; the glasses appeared to be uncommonly dull, and the frames covered with dust. "On attempting," says he, "to wipe it off, I was astonished to find the glasses fixed to the wall, not suspended in frames as I left them, but completely surrounded by an incrustation cemented by the white ants, who had actually eaten up the deal frames and back-boards, and the greater part of the paper, and left the glasses upheld by the incrustation or covered way, which they had formed during their depredation." 2 It is even asserted that the superb residence of the GovernorGeneral at Calcutta, which cost the East India Company such inmense sums, is now rapidly going to decay in consequence of the attacks of these insects. ${ }^{3}$ But not content with the dominions they have acquired, and the cities they have laid low on Terra Firma, encouraged by success, the white ants have also aimed at the sovereignty of the ocean, and once had the hardihood to attack even a British ship of the line; and in spite of the efforts of her commander and his valiant crew, having boarded they got possession of her, and handled her so roughly, that when brought into port, being no longer fit for service, she was obliged to be broken up. ${ }^{4}$

And here, I think, I see you throw aside my papers, and hear you exclaim - "Will this enumeration of scourges, plagues, and torments never be finished? Was the whole insect race created merely with punitive views, and to mar the fair face of universal nature? Are they all, as our Saviour said figuratively of one genus, the scorpion, the powerful agents and instruments of the great enemy of mankind?"5 If you view the subject in another light, you will soon, my friend, be convinced that, instead of this, insects generally answer the most beneficial ends, and promote in various ways, and in an extraordinary degree, the welfare of man and animals; and that the series of the evils I have been engaged in enumerating mostly occur partially, and where they exceed their natural limits; God permitting this occasionally to take place, not merely with punitive views, but also to show us what mighty effects he can produce by instruments scemingly the most insignificant; thus calling upon us to glorify his power, wisdom, and goodness, so evidently manifested whether he relaxes or draws tight the reins by which he guides insects in their course, and regulates their progress; and more particularly to acknowledge his overruling Providence so conspicuously exhibited by his measuring them, as it

1 This account of the Termites is chiefly taken from Smeathman in Philos. Trans. 1781, and Percival's Ceylon, 307.

2 Oriental Memoirs, i. 362.

3 Morning Herald, Dec. 31st, 1814.

4 The slip here alluded to was the Albion, which was in such a condition from the attack of insects, supposed to be white ants, that had not the ship been firmly Jashel! tegether, it was thought she would have foundered on her voyage home. The late Mr. Kittoe informed me that the Droguers or Jraguers, a kind of lighter employed in the West Indies in collecting the sugar, sometimes so swarm with ants, of the common kind, that they lave no other way of getting rid of these troublesome insects than by sinking the vessel in shallow water.

s Luke, x. 19. 
were, and weighing them, and telling them out, so that their numbers, forces, and powers being annually proportioned to the work he has prescribed to them, they may neither exceed his purpose nor fall short of it.

From the picture I have drawn, and I assure you it is not overcharged, you will be disposed to admit, however, the empire of insects over the works of creation, and to own that our prosperity, comfort, and happiness are intimately connected with them ; and consequently that the knowledge and study of them may be extremely useful and necessary to promote these desirable ends, since the knowledge of the cause of any evil is always a principal, if not an indispensable, step towards a remedy.

I shall now bid adieu to this unpromising subject, which has so long occupied ny pen, and I fear wearied your attention, and in my next bring before you a more agreeable scene, in which you will behold the benefits we receive by the min stry of insects.

I am, \&:. 


\title{
LETTER IX.
}

\section{BENEFITS DERIVED FROM INSECTS.}

\author{
INDIRECT BENEFITS.
}

Mr last letters eontained, I must own, a most melancholy though not an overcharged picture of the injuries and devastation which man, in varions ways, experiences through the instrumentality of the insect world. In this and the following I hope to place before you a more agreeable scene, since in them I shall endeavour to point out in what respects these minnte animals are made to benefit us, and what advantages we reap from their extensive agency.

God, in all the evil which be permits to take place, whether spiritual, moral, or natural, has the ultimate good of his creatures in view. The evil that we suffer is often a countercheck which restrains us from greater cvil, or a spur to stimulate us to good: we should therefore consider every thing, not according to the present sensation of pain, or the present loss or injury that it occasions, but according to its more general, remote, and permanent effects and bearings; - whether hy it we are not impelled to the practice of many virtues which otherwise might lie clormant in us whether our moral habits are not improved - whether we are not rendered by it more prondent, cautious, and wary, more watchful to prevent evil, more ingenious and skilful to remedy it - and whether our higher faculties are not brought more into play, and our mental powers more invigorated, by the meditation and experiments necessary to secure ourselves. Viewed in these lights, what was at first regarded as wholly made up of evil, may be discovered to contain a considerable proportion of good.

This reasoning is here particularly applicable : and if the ultimate benefit to man seems in any case problematical, it is merely because to discover it requires more extended and remote views than we are enabled by our limited faculties to take, and a knowledge of distant or concealed results which we are incompetent to calculate or discover. The common good of this terraqueous globe requires that all things endowed with regetable or animal life should bear certain proportions to each other; and if any individual species exceeds that proportion, from beneficial it becomes noxions, and interferes with the general welfire. It was requisite therefore for the benefit of the whole system that certain means should be provided, by which this hurtful luxuriance might be checked, and all things taught to keep within their proper limits : hence it became necessary that some should prey upon others, and a part be sacrificed for the good of the whole.

Of the counterchecks thus provided, none act a more important part than insects, particularly in the vegetable kinglom, every plant having its insect enemies. Man, when he takes any plant from its natural state, and 
makes it an object of cultivation, must expect that these agents will follow it into the artificial state in which he has placed it, and still prey upon it ; and it is his business to exert his faculties in inventing means to guard against their attacks. It is a wise provision that there sliould exist a race of beings empowered to remove all her superfluous productions from the face of nature ; and in effecting this, whatever individual injury may arise, insects must be deemed general benefactors. Even the locusts, which lay waste whole countries, clear the way for the renovation of their vegetable productions, which were in danger of being destroyed by the exuberance of some individual species, and thus are fulfilting the great law of the Creator, that of all which he has made nothing should be lost. A region, Sparrman tells us, which had been choked up by shrubs, perennial plants, and hard half-withered and unpalatable grasses, after being made bare by these scourges, soon appears in a far more beautiful dress, clothed with new herbs, superb lilies, and fresh anmual grasses, and young and juicy shoots of the perennial kinds, affording delicious herbage for the wild cattle and game. ${ }^{1}$ And though the interest of individual man is often sacrificed to the general good, in many cases the insect pests which he most execrates will be found to be positively beneficial to him, unless when suffered to increase beyond their due bounds. Thus the insects that attack the roots of the grasses, and, as has been before observed, so materially injure our herbage, the wire-worm, the larvæ of Melolontha vulgaris, Tipula oleracea, \&c., in ordinary seasons onty devour so much as is necessary to make room for fresh shoots, and the production of new herbage ; in this manner maintaining a constant succession of young plants, and causing an annual though partial renovation of our meadows and pastures. In the rich fields near Rye in Sussex I particularly observed this effect; and I have since at home remarked, that at certain times of the year dead plants may be everywhere observed, pulled up by the cattle as they feed, whose place is supplied by new offsets. So that, when in moderate numbers, these insects do no more harm to the grass than would the sharp-toothed harrows which it has been sometimes advised to apply to hide-bound pastures, and the beneficial operation of which in loosening the sub-soil these insect borers closely imitate.

Nor would it be difficult to show that the ordinary good effects of some of those insects, which torment ourselves and our cattle, preponderate over their evil ones. Mr. Clark is inclined to think that the gentle irritation of $Q$ istrus Equi is advantageous to the stomach of the horse rather than the contrary. On the same principle it is not improbable that the Tabani often act as useful phlebotomists to our full-fed animals; and that the constant motion in which they are kept in summer by the attacks of the Stomoxys and other flies may prevent diseases that would be brought on by indolence and repletion. And in the case of man himself, if $I$ do not go so far as Linné to give the louse the credit of preserving full-fed boys from coughs, epilepsy, \&c., we may safely regard as no small good the stimulus which these, and others of the insect assailants of the persons of the dirty and the vicious, afford to personal cleanliness and purity.

I might enlarge greatly upon the foregoing view of the sulject, but this is unnecessary, as numerous facts will occur in subsequent letters which you will readily perceive have an intimate bearing upon it; and I shall, there- 
fore, proceed to point out the more evident benefits which we derive from insects, arranging them under the two great heads of direct benefits, and those which are indirect; beginning with the latter.

The insects which are indireetly beneficial to us may be considered under three points of view; first, as removing various nuisances and $d c$ formilies from the face of nature ; secondly, as destroying other insects, that but for their agency would multiply so as greatly to injure and annoy us; and, thirdly, as supplying food to uscful animals, partieularly to fish and birds.

To advert in the first place to the former. All substances must be regarded as nuisances and defornities, when considered with relation to the whole, which are deprived of the principle of animation. In this relation stand a dead carcass, a dead tree, or a mass of excrement, which are clearly ineumbranees that it is desirable to bave removed; and the office of effecting this removal is chiefly assigned to insects, which have been justly ealled the great scavengers of nature. Let us consider their little but effective operations in each of their voeations.

How disgusting to the eye, how offensive to the smell, would be the whole face of nature, were the vast quantity of excrement daily falling to the earth from the various animals which inhabit it, suffered to remain until gradually dissolved by the rain, or decomposed by the elements! That it does not thus offend us, we are indebted to an inconceivable host of iusects which attack it the moment it falls; some immediately beginning to devour it, others depositing in it eggs from which are soon hatched larvæ that concur in the same office with tenfold voracity; and thus every particle of dung, at least of the most offensive kinds, speedily swarms with inhabitants which consume all the liquid and noisome particles, leaving nothing but the undigested remains, that soon dry, and are scattered by the winds, while the grass upon which it rested, no longer smothered by an impenetrable mass, springs up witli inereased vigour.

Numerous are the tribes of inseets to which this office is assigned, though ehiefly, if not entirely, selected from the two orders, Coleoptera and Diptera. A large proportion of the genera formed, by different authors, from Scarabaus of Linné, viz. Scarabaus, Copris, Ateuchus, Sisyphus, Onitis, Onthophagus, Aphodius, and Psammodius; also Hister, Sphavidium; and amongst the Brachyptera, the majority of the Staphylinida, many Aleocharce, especially of Graventiorst's third family, many Oryteli, and some Omalia, Tachini, and Tachypori, of that author, including in the whole many hundred species of beetles, unite their labours to effect this useful purpose: and what is renarkable, though they all work their way in these filthy masses, and at first can have no paths, yet their bodies are never soiled by the ordure they inhabit. Many of these insects content themselves with burrowing in the dung alone; but Atcuchus filularius ${ }^{1}$, a speeies

1 The Coprion, Cantharus, and Heliocantharus of the ancients was evidently this beetle, or one nearly related to it, which is described as rolling backwards large masses of dung, and attracted sucl general attention as to give rise to the proverb Cuntharus pilulam. It sliould seem trom the name, derived from a word signifying an ass, that the Grecim beetle made its pills of usses' dung; and this is confirmed ly a passage in one of the plays of Aristophanes, the Irene, where a beetle of this kind is introdnced, on which one of the characters ricles to lieaven to petition Jupiter for peace. The play begins with one domestie desiring another to feed the Cantharus with some liead, who afterwards orders his companion to give him another kind of bread made of asses' dung. 
called in America the Thmbledung, whose singular manœurres I sha!l subsequently have to advert to, Copris lunaris, Geotrupes stercurarius, and many other lamellicorn beetles, make large cylindrical holes, often of great depth under the heap, and there deposit their eggs surrounted by a mass of dung in which they have previously enveloped them; thus not only dispersing the dung, but actually burying it at the roots of the atjoining plants, and by these means contributing considerably to the fertility of our pastures, supplying the constant waste by an annual converances of fresh dung laid at the very root; by these canals, also, affording a convenient passage for a portion of it when dissolved to be carried thither by the rain.

The coleopterous insects found in dung inhahit it in their perfect as well as imperfect states; but this is not the case with those of the order Diptere, whose larvæ alone find their nutriment in it; the imago, which would be suffoeated did it attempt to burrow into a material so soft, only laying its egrgs in the mass. These also are more select in their choice than the Coleoplera - not indeed as to delicacy, - but they do not indiscriminately oviposit in all kinds, some preferring horse-dung, others swine'sechnig, others cow-dung, which seems the most favourite pabulum of all the dungloving insects, and others that of birds. ${ }^{1}$ The most disgusting of all is the rat-tailed larva that inhabits our privies, which ehanges to a fly (Eristalis tenax), somewhat resembling a bee.

Still more would our olfactory nerves be offended, and our health liable to fatal injuries, if the wisdom and goodness of Providence had not provided for the removal of anotlier nuisance from our globe - the dead carcasses of animals. When these begin to grow putrid, every one linows what dreadful miasmata exhale from them, and taint the air we breathe. But no sooner does life depart from the body of any creature, at least of anv which from its size is likely to become a nuisance, than myriacts of different sorts of insects attack it, and in various ways. First come the Histers, and pierce the skin. Next follow the flesh.flies, some, that no time may be lost (as Sarcoplaga carnaria, \&c.), depositing upon it their young already hatched; others (Musca ('cesar, \&c.), covering it with millions of egrgs, whence in a day or two proceed innumerable devourers. An idea of the dispatch made by these gourmands nay be gained from the combined eonsideration of their numbers, voracity, and rapid development. One female of $S$. carnaria will give birth to 20,000 young; and the larve of many flesh-flics, as Redi aseertained, will in twenty-four hours devour so much food, and grow so quickly, as to increase their veight two lundredfold! In five days after being hatehed, they arrive at their full growth and size, which is a remarkable instance of the care of Providenco

1 According to M. Robineau Desvoidy, the dumg of the badger, which is placed in a separate chamber of its subterranean galleries, lias its jeculiar fly, which he mames Leria melina, the larva of which there feed mpon it; and the jarent flies never ascend to the surface, but constantly reside in this dark and damp abode, and can only be obtained by digging into it. Another Hy, his Thelida respertilioner, in like manner, lives in the larva state on the dung of bats deposited by them at the cond of the grottoes of W'Arey-sur-Eure more than one hundred toises distant from their entranee; and he describes a third flv, Leria mustelina, which he believes to feet on the dung of the weasel, and names other distinct species to which the dunc of the fox, the rabbit, the water-rat, and the field-mouse respectively affurd subsistcnce. (Ann. Sioc. Lint. de France, x. 25j-260.) 
in fitting them for the part they are destined to act: for if a longer time was required for their growth, their food would not be a fit aliment for them, or they would be too long in removing the nuisance it is given in charge to them to dissipate. Thus we see there was some ground for Linnés assertion, under M. vomitoria, that three of these flies will devour a dead horse as quickly as would a lion.

As soon as the various tribes of Muscida have opened the way, and devoured the softer parts, a whole host of beetles, Ncerophori, Silphice, Dermestes, Choleve, and Staphylinida, actively second their labours. WVasps and hornets also come in for their portion of the spoil ; and even ants, which prowl every where, rival their giant competitors in the quantity consumed by them; so that in no very long time, especially in warm climates, the muscular covering is removed from the skeleton, which is then cleansed from all remains of it by the little Corynetes ceruleus and ruficollis. (which last is so interesting, as having been the means of saving the life of Latreille $^{1}$ ), and several Nilidule. ${ }^{2}$ Even the horns of animals have an appropriate genus (Trox) which inhabits them, and feeds upon their contents. And not only are large animals thus disposed of, even the smallest are not suffered long to annoy us. The burying beetle (Necrophorus Irespillo), inters the bodies of small animals, such as mice, several assisting each other in the work ${ }^{3}$; and those to which they commit their eggs afford an ample supply of fond to their larvæ.4 Ants also in some degree emulate these burying insects, at least they will carry off the carcasses of insects into their nests; and I once saw some of the horseants dragging away a half-dead snake of about the size of a goose-quill. ${ }^{5}$ In fact in the extensive plains of South America and other tropical regions, where ants are both larger and far more numerous than with us, M. Lund conceives that they take the place of the Carabida, Silphida, and other carnivorous tribes of more temperate climes, there rarely met with, in removing all putrefying animal matter. ${ }^{6}$ Some insects will even attack living animals, and make them their prey, thus contributing to keep then within due linits. The common earth-worm is attacked and levoured by a centipede (Geophilus electriens). Mr. Sheppard saw one attack a worm ten times its own size, round which it twisted itself like a serpent, and which it finally mastered and devoured.

But insects are not only useful in removing and dissipating dead animal matter; they are also intrusted with a similar office with respect to the vegetable kingdom. The interior of rotten trees is inhabited by the larve

1 See Latr. Gen. j, 275.

2 This property in the carrion insects may be turned to a good account by the comparative anatomist, who las only to flay the body of one of the smaller animals, anoint it with honev, and bury it in an ant-hill : and in a short time he will obtain a perfect skeleton, ienudated of every fibril of muscle, though with the ligaments and cartilages untonched.

3 In India, as we learn from Col. Hearsey, a large species of Platynotus replaces the Necrophori in their burying habits.

4 Gleditsch, Abhandlungen, iii. 200.

5 It is to be observed that in our cold climates, during the winter months, when excrement and putrescent animal matter are not so ofiensive, they are left to lhe action of the elements, insects being then torpid.

6 Lund in Ann. Soc. Tat., Jume 1831, quoted in Westwood's Mod. Class. of Ins.' ii. 239 . 
of a particular kind of crane-fly with pectinated antennæ (Ctenoploora ${ }^{1}$ ), and other insects, which there find an appropriate nutriment; and it sinilar diet is furnished to the grubs of the rose-beetle (C'etonia aurata) by the dead leaves and stalks usually to be found in the ant's nest. Staphiylinide, Sphceridia, and other Coleoptera, are always found under heaps of putrescent vegetables; and an infinite number are to be met with in decomposing fungi, which seem to be a kind of substance intermediate between animal and vegetable. The Boleti, in particular, have one genus of coleopterous insects appropriated to them ${ }^{2}$, and the Lycoperdons another. - Stagnant waters, which would otherwise exhale putrid miasmata, and be often the cause of fatal disorders, are purified by the innumerable larvæ of gnats, Ephemerce, and other insects which live in them and abstract from them all the unwholesome part of their contents. This, Linné says, will easily appear if any one will make the experiment by filling two vessels with putrid water, leaving the larvie in one and taking them out of the other ; for then he will soon find the water that is full of larva pure and without any stench, while that which is deprived of them will continue stinking. ${ }^{3}$

Benefits equally great are rendered by the wood-destroying insects. We indeed, in this country, who find use for ten times more timber than we produce, could dispense with their services; but to estimate them at their proper value, as affecting the great system of nature, we should transport ourselres to tropical climes, or to those under the temperate zones, where millions of acres are covered by one interninable forest. How is it that these untrodden regions, where thousands of their giant inhabitants fall victims to the slow ravages of time, or the more sudden operations of lightning and hurricanes, should yet exhibit none of those scenes of ruin and desolation that might have been expected, but are always found with the verdant characters of youth and beanty? It is to the insect world that this great charge of keeping the habitations of the Dryads in perpetual freshness has been committed. A century would almost elapse before the removal from the face of nature of the mighty ruins of one of the hard-wooded tropical trees, by the mere influence of the elements. But how speedy its decomposition when their operations are assisted by insects! As soon as a tree is fallen, one tribe attacks its bark $^{4}$, which is often the most indestructible part of it ; and thousands of orifices into the solid trunk are bored by others. The rain thus insinuates itself into every part, and the action of heat promotes the decomposition. Various fungi now take possession and assist in the process, which is followed up by the incessant attacks of other insects, that fced only upon wood in an incipient state of decay. And thus in a few months a mighty mass, which scemed inferior in hardness only to iron, is mouldered into dust, and its place occupied by younger trees full of life and vigour. The

1 Curtis, Brit. Ent. t. 5.

2 Surely Mr. Marsham's name for this gerus, Bnletaria, is much more proper than that of Fabricius, Mycetophagus (Agaric-Eater), since these insects seldom eat agarics.

3 Econ. Nat. Amœn. Ac. ii. 50. Stillingfleet's Tracts, 122.

4 Maupertnis observes, that in Lapland he saw many birch trees lying on the ground, which had probably been there for a very long time, with the bark entire, though the wood was decayed. Hence we may probably infer, that in that country there are few or none of the bark-boring insects. 
insects to which this duty is intrusted have been already mentioned in a former letter; but none of them do their business so expeditiously or effectually as the Termites, which ply themselves in such numbers and so unremittingly, that Mr. Smeathman assures us they will in a few weeks destroy and carry away the trunks of large trees, without leaving a particle behind; and in places where, two or three years before, there has been in populous town, if the inhabitants, as is frequently the case, have chosen to abandon it, there shall be a very thick wood, and not the vestige of a post to be seen.

I observed in a former letter, that the devastations of insects are not the same in every scason, their power of misehief being evident only at certain times, when Providence, by permitting an unusual increase of their numbers, gives them a commission to lay waste any particular country or district. The great agents in preventing this increase, and keeping the noxions species within proper limits, are other insects; and to these I shali now call your attention.

Numerous are the tribes upon which this important task clevolves, and incalculable are the benefits which they are the means of bestowing upon uss; for to them we are indebted, or rather to Providence who created them for this purpose, that our crops and grain, our cattle, our fruit and forest-trees, our pulse and flowers, and even the verdant covering of the earth, are not totally destroyed. Of these insects, so friendly to man, some exercise their destructive agency solely while in the larva state; others in the perfect state only; other's in both these states; and, lastly, others again in all the three states of larva, pupa, and imago. For order's sake, and to give you a more distinct view of the subject, I shall say something on cach separately.

The first, those which are insectivorous only in their larva state, may be further subdivided into parasites and imparasites, meaning by the former term those that feed upon a living insect, and only destroy it when ther have attained their full growth; and by the latter, those that prey upon insects already dead, or that kill them in the act of devouring them.

The imparasitic insect devourers chiefly belong to the Hymenoptera order; and though it is in the larva state that their prowess is cxhibited, the task of providing the prey is usually left to the female, of which each species for the most part selects a particular kind of insect. Thus many species of Cereeris and the splendid Chryside or golden wasps feed upoii insects of their own order. One of the latter (Parnopes inearnata) commits her eggs to the progeny of Bember rostrata: another (Clurysis biden'ata) attaeks the young of Epipone spinipes.

Bembex and Mellinus confine themselves to Diptera, the former preying upon Eristalis tenax, Bombylii, and the like ${ }^{1}$; the latter, amongst other's, ridding us of the troublesome Stomoxys ealeitrans. One of these last I have observed stationed on dung watching for flies, which, when seized, she carried to her burrow. The numerous species of Crabro Fab. also store up chicfly dipterous insects in their cells, some confining themselres to one and the same species, others apparently taking any that offer.

Epipone spinipes, belonging to the family of Wasps, feeds upon certain green apol larve, of which the female deposits ten or twelve with cach

1 Latreille, Observations nouvelles sur les IYjménoptères. Annal. de IIus. 11. 
eag. The common sand-wasp (Ammophila vulgaris) destroys caterpillars of a larger size, and most of the other Vespoid and Sphecoid IIymenoptera, viz. Trypoxylon, Philanthus, Larra, \&c. assist in this great work.

Pompilus, to which genus probably several species mentioned by Reaumur as preying on these insects should be referred, has it in charge to keep the number of spiders within due bounds : and some sand-wasps lend their aid. One of these last, mentioned by Catesby (Sphex caruleus), has been known to seize a spider eight times its own weight. ${ }^{1}$ Another species of this genus, which is common in the Isle of France, attacks an insect still more difficult, one would think, to turn to its purpose, the all-devouring Blatta, or cockroach, and is therefore one of the great benefactors to mankind. When this insect perceives a Blatta (called there Kakerlac and Cancrelas), it stops immediately: both animals eye each other; but in an instant the sand-wasp darts upon its prey, seizes it by the muzzle with its strong jaws, and, bending its abdomen underneath it, pierces it with its fatal sting. Sure of its victim, it now walks or flies away, leaving the poison to work its effect! but in a short time returns, and, finding it deprived of power to make resistance, seizes it again by the head, and drags it away, walking backwards to deposit it in a hole or chink of a wall. ${ }^{2}$

Grasshoppers are the prey of another sand-wasp, supposed to be the Sphcx pennsylvanica of Linné, a native of North America, each of which in its larva state devours three of a large green species with which its mother has provided it. ${ }^{3}$

From none of the imparasitic insectirorous larvæ do we derive more advantage than from those which devour the destructive Aphides, whose ravages, as we have seen above, are more detrimental to us in this island than those of any other insect. A great variety of species of different ordcrs and genera are employed to keep then within due limits. There is a beautiful genus of foul-winged flies, whose wings resemble the finest lace, and whose eyes are often as brilliant as burnished metals (Hemerobius), the larva of which, Reaumur, from their being insatiable devourers of them, has named the lions of the Aphides. The singular pelunculated egrs; from which these larva proceed, I shall describe when we come to treat upon the egrs of insects; the-larva themselves are furnished with a pair of long crooked mandibles resembling horns, which terminate in a sharp point, and, like those of the ant-lion, are perforated, serving the insect instead of a nouth; for through this orifice the nutriment passes down into the stomach. When amongst the Aphides, like wolves in a sheep-fold, they make dreadful havoc: half a minute suffices them to suck the largest; and the individuals of one species clothe themselves, like Hercules, with the spoils of their hapless victims.

Next in importance to these come the aphidivorous flies (many species of Syrphide), whose grubs are armed with a singular mandible, furnished like a trident with three points, with which they transfix their prey. They may often be seen laid at their ease under a leaf or upon a twig, environed by such hosts of Aphides, that they can devour hundreds without changing their station; and their silly helpless prey, who are provided with no

1 Nat. Hist. of Carolina, ii. 105.

2 Reaum. vi. 28:. St. Pierre's Voyage, 72.

3 Bartram in Philos. Trans. xlvi. 120. 
means of defence, so far from thinking of escaping, frequently walk over the back of their enemy, and put themselves in his way. When disposed to feed, he fixes himself by his tail, and, being blind, gropes about on every side, as the Crclops did for Ulysses and his companions, till he touches one, which he immediately transfixes with his trident, elevates into the air, that he may not be disturbed by its struggles, and soon devours. The havoc which these grubs make amongst the Aphides is astonishing. It was but last week that I observed the top of every young shoot of the currant-trees in my garden curled up by myriads of these insects. On examining them this day, not an individual remained; but beneath each leaf are three or four full-fed larva of aphiclivorous flies, surrounded with heaps of the skins of the slain, the trophies of their successful warfare; and the young shoots, whose progress has been entirely checked by the abstraction of sap, are again expanding vigorously.

But even these serviceable insects must yield the palm to the lady-bird or lady-cow (Coccinella), the favourite of our chilthood, which, as well as most of its congeners, in the larva state, feeds entirely on $A$ phides ${ }^{1}$; and the havoc made amongst them may be conceived from the myriads upon myriads of these little interesting animals, which are often to be seen in years when the plant-louse abounds. In 1807 the shore at Brighton, and all the watering places on the south-coast, was literally covered with them, to the great surprise, and even alarm, of the inhabitants, who were ignorant that their little visitors were emigrants from the neighbouring hopgrounds, where, in their larva state, each had slain his thousands and tens of thousands of the Aphis, which, under the name of the Fly, so frequently blasts the hopes of the hop-grower. It is fortunate that in most countries the children have taken these friendly Coccinellæ under their protection. In France they regard them as sacred to the Virgin, and call them Vaches à Dieu, Bêtes de la Vierge, Sc.; and with us, commiseration for the hard fate of a mother, whose "house is on fire and cbildren at home," insures them kind treatment and liberty. Even the hop-growers are becoming sensible of their services, and, as I am informed, hire boys to prevent birds from destroying them. If we could but discover a mode of increasing these insects at will, we might not only, as Dr. Darwin has suggested, clear our hot-houses of Aphides by their means, but render our crops of hops much more certain than they now are. Even without this knowledge nothing is more easy, as I have experienced, than to clear a plant or small tree by placing upon it several larva of Coccinellæ or of aphidivorous flies collected from less valuable vegetables.

Lastly, to close this list of imparasitic insectivorous larræe, I may mention those of Geoffroy's genus Volucella, so remarkable for their radiated anus, which live in the nests of humble bees ( $V$. bombylans), braving the fury of their stings and devouring their young; those of another species of the

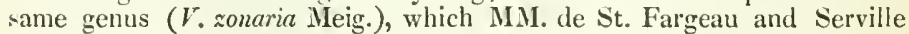
have ascertained to live in wasps' nests and destroy great numbers of their

2 The larrx of some species of Coccinella feed, according to Prof. D. Reich, solely on the leaves of plauts; as that of C.hieroglyphica, which eats the leaves of common lieath (Erica vulgaris) after the manner of the larvo of Lepidoptera. Der Gesellschaft naturf. Fr. in Berlin Mag. \&c. iii, 294. The larva of Coccinella Argus, Scriba (C. 11-maculata Fab.), in like manner, Prof. Audouin found to feed on the leares of the common Bryonia. (Westwood, Mod. Class. of Ins. i. 397.) 
larvæl' and the ant-lion (MYyrmeleon) and Reaumur's improperly named worm-lion (Leptis), whose singular stratagems will be detailed in a subsequent letter, both of which destroy numerous insects that are so unfortunate as to fall into their toils.

The Parasitic larvæ, an extremely numerous tribe, must next be considered. These chiefly belong to the order Hymenoptera, and were included by Linné under his vast genus Ichneumon, so named from the analogy between their services and those of the Egyptian Ichnemmons (Iviverra lchneumon), the former as destroyers of insects, being equally important with the latter as devourers of serpents, the eggs of crocodiles, \&c.

The habits of the whole of this tribe 2 , which properly includes several families (Ichneumonide, Chalcillide, \&c.) and a great number of distinct genera, are similar. They all oviposit in living insects, chiefly while in the larva state, sometimes while pupæ (Misocampus Puparum); at others while in the egg state (Pteromalus ovulorum, and bifasciatus, Chrysolampus tristis, \&c.). The eggs thus deposited soon hatch into grubs, which immediately attack their victim, and in the end insure its destruction. The number of eggs committed to each individual varies according to its size, and that of the grubs which are to spring fiom them; being in most cases one only, but in others anounting to some hundreds.

From the observations hitherto made by entomologists, the great body of the Ichneumon tribe is principally employed in keeping within their proper limits the infinite host of lepidopterous larvæ, destroying, however, many insects of other orders; and, perhaps, if the larva of these last fell equally under our observation with those of the former, we might discover that few exist uninfested by their appropriate parasite. Such is the activity and address of the Ichneumonidans, and their minute allies (Pupivora Latr.), that scarcely any concealment, except, perhaps, the waters, can secure their prey from them; and neither bulk, courage, nor ferocity avail to terrify them from effecting their purpose. They attack the ruthless spider in his toils; they discover the retreat of the little bee, that for safety bores deep into timber; and though its enemy Ichneumon cannot enter its cell, by means of her Jong ovipositor she reaches the helpless grub, which its parent vainly thought secured from every foe, and deposits in it an egg, which produces a larva that destroys it.. ${ }^{3}$. In vain does the destructive Cecidomyia of the wheat conceal its larvæ within the glumes that so closely cover the grain; three species of these minute benefactors of our race, sent in mercy by Heaven, know how to introduce their eggs into them, thus preventing the mischief they would otherwise occasion, and saving mankind from the horrors of famine. ${ }^{4}$ In vain, also, the Cynips by its magic touch produces the curjous excrescences on various trees and plants, called galls, for the nutriment and defence of its progeny ; the parasite species attached to it discovers its secret chamber,

1 Macquart, Dipteres, i. 482 .

2 Latreille denominates this family, as he calls it, Pupivora; if by this he alludes to their devouring the young of insects, from the classical meaning of the word pupa, the term is very proper; but this should be borne in mind, as the majority of readers would imagine it to refer to the pupa state of insects, in which they are not so generally devoured by their parasites.

3 Marsham in Linn. Trans. iii. 26.

4 See above, pp. 92, 93. 
pierces its wall, howerer thick, and commits the destroying egg to its offspring. Even the elover-weevil is not secure within the legumen of that plant ; nor the wire-worm in the earth, from their ichneumonidan foes.

I have reeeived from the late Mr. Marwick that of the former, and Mr. Paul has shown me the destroyer of the latter, which belongs to Latreille's genus Proctotrupes. Others are not more secured by the repulsive nature of the substance they inhabit ; for two species at least of Ichneumon ${ }^{1}$ know how to oviposit it in stereorarious larve without soiling their wings or bodies.

The ichneumonidan parasites are either external or internal. Thus the species above alluded to, which attacks spiders, does not live within their bodies, but remains on the outside ${ }^{2}$; and the larva of Ophion luteum, which adheres by one end to the shell of the bulbiriferous egg that produced it, does not enter the eaterpillar of Euprepia viflica, the moth upon which it feeds. ${ }^{3}$ But the great majority of these animals oviposit within the body of the insect to which they are assigned, from whence, after laving consumed the interior and become pupæ, they emerge in their perfeet state. An idea of the serviees rendered to us by those Ichneumons which prey upon noxious larve may be formed from the fact, that out of thirty individuals of the common cabbage caterpillar (the larvæ of Pontia Brassica) which Reaumur put into a glass to feed, twenty-five were fatally pierced by an Ichneumon (Microgaster globatus ${ }^{4}$ ). And if we compare the myriads of eaterpillars that often attack our cabbages and brocoli with the small number of butterflies of this speeies which usually appear, we may conjecture that they are commonly destroyed in some such proportion-it circumstance that will lead us thankfully to acknowledge the goodness of Providence, which, by providing such a check, has prevented the utter destruction of the Brassica genus, ineluding some of our most esteemed and useful vegetables.

The parasites are not wholly confined to the order Hymenoptera: a considerable number are also found amongst the tribe of flies, many of the species of the Dipterous genera Tachina Meig. ; and those separated from it (as Echinomyia, Nemorea, \&c.), as well as of Anthrax, and other genera depositing their eggs in eaterpillars and other larvæ, often in such great numbers, that from a larva of Sphinx atropos, bred by MI. Serville, and which had sufficient strength to assume the pupa state, not fewer than eighty flies of Senometopia atropivora came out of it. ${ }^{5}$ Many beetles also are parasitic in their larva state, as the singular Ripiphorus paradoxus, which is found in the nests of wasps ; those of the genus Sitaris, which are fornd in the nests of wild hees of the genus Anthophora ${ }^{6}$, and those of Brachytarsus scabrosus, which feed on Coccide ${ }^{7}$, \&c.

1 Alysia Manducator; and another species allied to Alomyia Debellator, which I have named $A$. Stercorator.

2 De Geer, ii. 863 .

4 Reaum. ii. 419.

5 Macquart, Dipteres, ii. 105. Comp. De Geer, i. 196. vi. 14. 24. Reanm. ii. $440-444$.

6 Ann. Soc. Ent. de France, viii. Bull. xvii. xlvii. Much obscurity exists as to the conomy of these insects, chiefly in consequence of the curious facts observed by my friend M. Pecchioli of Pisa with regard to his new species Situris solieri, described by him in the Ann. Soc. Ent. de France, riii. 5. 27. He always found bath sexes of this species, even in distant localities, on plants of rosemary; and these

For note ${ }^{7}$ see $1 \cdot 150$. 
Generally speaking, parasitic larva do not attack insects in their perfect state; but to this rule there are several exceptions. M. Dufour found in a beetle (C'assida viridis) a parasitic larva, from which he bred a tly of the genus Tachina Meig. (Cassidemyia Macq.); and also in a field-bug (Pentutoma grisea), from which proceeded another fly (Ocyptera bicolor) ${ }^{1}$; and Latreille, Dufour, and other entomologists have confirmed the discovery of Baumhauer, that the larva of flies of the genus Conops live in humblebees, which M. Robineau-Desvoidy has seen pursued by them, apparently to deposit their eggs on them. ${ }^{2}$ The larva of a beetle (Simbius Blattarum) is parasitic in the bodies of Blatta Americann on board of ships, and M. Audouin found Coccinella 17-punctata, to be subject to the parasitic attack of A.Ticroctonus terminalis Wesmael, and Encryins flaminins Dalman."

The order also of Strepsiptera appears to be wholly parasitic ; but these extraordinary animals are found only upon Hymenoptera in their perfect state, and do not appear to destroy the insects upon which they prey, but probably prevent their breeding. The species at present known are formed into four genera, Xenos Rossi, Stylops Kirby, Elenchus Curtis; and Halictophagers Dale. The first is found in different species of wasps (Iespa, Polistes, Odynerus, and also of Sphex); the second in the genus separated from Melitta K. under the name of Andrana, in upwards of fourteen species of which Mr. Pickering has found them; the third in Polistes (?); and the fourth in Halictus (Melitta K.) ; but it is probable, from the fact of M. L. Dufour's having also found a larva of one of these insects between the abdomiual segments of Ammophila Sabulosa, that many other hymenopterous insects will be found to be infested with them."

plants, when M. Audouin examined them with him near Pisa in 1835, were covered with eggs, which the former recognised as altogether similar to those of Sitaris humeralis, with which he was well acquainted. As the species of Sitaris are known to be found in the nests of different Hymenoptera, and particularly in those of a wild bee (Anthophora) on the larve of which their larva are probably parasitic, the question occurs, with what view these eggs were placed on the rosemary? The most plansible supposition perhaps would seem to be that after the eggs are hatched the larve attach themselves, like the supposed larve of Meloe (Pediculus Melitte K.) to which they are related, to the Anthophore, frequenting the rosemary for lioney, and are thus conreyed into their cells; but nothing certain can be inferred on this head till the contradictory statements as to these last-named larva are cleared up; and it seems as yet almost equally donbtful (as it is also in the case of the other parasitic coleopterons genera Horia, Ripiphorus, and Zonitis) whether the larræare parasitic on the larve of the insects in whose cells they are found, or on their stored-up food.

7 Westwood, Mod. Class. of Ins. i. 332.

1 Macquart, Dipteres, ii. 69.

2 Ibid. ii. 23. Westwood, MIod. Class. of Tus. ii. 561.

3 Westwood, Mod. Class. i. 295. 397.

4 Kirby, Mon. Ap. Ang. ii. 110.113. and in Linn. Trans, xi. 86. Westwood's Mod. Class. of Ins. ii. $288-305$, to which last the realer is referred for a full and very interesting account of the facts hitherto recorded respecting these remarkable insects, and references to the varions works in which they occur. My friend G. II. K. Thwaites, Esq., has had the singular gcod fortune, which has perhaps occurred to no other entomologist, of seeing on the wing in Hay, 1838, not merely a single stylops or two, but a small swarm of at least twenty, and in as singular a situation, the garden of his residence, situated in the sulmrbs of the populous city of liristol. This was most probably owing to the circumstance of the garden having had bronght into it a quantity" of fresh earth, whirh apparently hail been dug 
The next description of insect destroyers are those which devour them in their first and last states. No beetles are more common after the summer is confirmed than the species of the genus Telephorns. Preysler informs us that the grub of $T$. fuscus destroys a great many other larvæ ${ }^{1}$; and I have observed the imago devour these and also Diptera. Linné has with justice denominated the Cicindele the tigers of insects. Though decorited with brilliant colours, they prey upon the whole insect race; their formidable jaws which cross each other are armed with fearful fangs, showing to what use they are applicable; and the extreme velocity with which they can either run or fly, renders hopeless any attempt to elude their pursuit. Their larvæ are also equally tremendous with the imago, having eight eyes, four on each side, seated on a lateral elevation of the head, two above, and two very minute below, which look like those of spiders, and, besides their threatening jaws armed with a strong internal tooth, being furnished with a pair of spines resembling somewhat the sting of a scorpion, which stard erect upon the back of the abdomen, and give them a most ferocious aspect. This last apparatus, according to Clairville, serves the purpose of an anchor for retaining them at any height in their deep cells. ${ }^{2}$ Most of the aquatic beetles, at least the Gyrini and Dytisci, prey upon other insects both in their first and final state. The larva of the latter have long been observed and described under the name of Squillce, and are remarkable for having their mandibles adapted for suction like those of Hemerobius and Myrmeleon; but they are not, like them, deprived of a mouth, being able to devour by mastication as well as by suction. Another tribe of this order which abounds in species, those predaceous bectles which form Linné's great genus Curabus (Eutrechina ${ }^{3}$ ), is universally insectivorous. One of the most destructive is the grub of a very beautiful species, an English specimen of which would be a great acquisition to your cabinet, it being one of our rarest insects ${ }^{4}$, I mean Calosoma Sycophanta. This animal takes up its station in the nests of Cnethocampa processionea and other moths, and sometimes fills itself so full with these caterpillars, which we cannot handle or even approach without injury, as to be rendered incapable of motion, and appear ready to burst. Another beautiful insect of this tribe, Carabus auratus, known

from some bank or pathway, containing many of the nests of Andrena convexiuscula, which also abounded in the garlen at the same time, and of which Mr. Thwaites captured several, all containing the larva of a Stylops (in one instance of three), or evident signs of a Stylops having escaped from them. These singular little animals, whose economy and systematic place are equally perplexing, Mr. Thwaites informs us, "are exceedingly graceful in their flight, taking long sweeps as if carried along by a gentle breeze," which, and their large expanse of wing, give them an appearance in flying very different from that of any other insect. (Thwaites in Trans. Ent. Soc. Lond, iii. 67.)

1 Preys. Bömisch. Insekt. 59, 61.

- 2 Entom. Helvetique, ii. 158

3 In the former edition of this work (Vol. IV. p. 392.), this tribe is denominated Eupodina; but as this seems too near to M. Latreille's Eupoda, belonging to a different tribe of beetles, we havesubstituted the above name, which means the same.

4 One was taken at Aldeburgh in Suffolk by Dr. Crabbe, the celebrated poet; another by a young lady at Southwold, which is now in the cabinet of Joseph Hooker, Esq. ; and a third by a boy at Norwich, crawling up a wall, which was purchased of him by S. Wilkin, Esq. 
in France by the name of linaigrier, is supposed to destroy more cockchafers than all their other enemies, attacking and killing the females at the moment of oviposition, and thus preventing the birth of thousands of young grubs. ${ }^{1}$ Lastly come the Brachyptera, many of which prey upon inseets as well as on putreseent substanees. Mr. Lehmann tells us that some of them are very useful in destroying a weevil (Apion favifemoratum $^{2}$ ), the great eneny of our crops of elover seed.

Amongst the devourers of insects in their perfect state only, must be ranked a few of the social tribes, ants, wasps, and hornets. The firstmentioned indefatigable and industrions ereatures kill and earry off great numbers of insects of every description to their nests, and prodigious are their efforts in this work. I have seen an ant dragging a wild bee many times bigger than itself; and there was brought to me this very morning, while writing this letter, an Elater, quite alive and active, which thrce or four ants, in spite of its struggles, were carrying off. An observing firiend of mine ${ }^{3}$, who was some time in Antigua, informed me that in that island, a kind of ant which construct their nests in the roofs of houses, when they meet with any animal larger than they ean carry off alive, such as a cockroach, $\mathcal{E} c$., will hold it by the legs so that it cannot move, till some of them get upon it and dispateh it, and then, with ineredible labour, carry it up to their nest. Madame Merian, in her account of the periodical ants mentioned to you before, and which is eonfirmed by Azara ${ }^{4}$, notices their clearing the houses of coekroaches and similar animals; and Myrmica ommivora is very useful in Ceylon in destroying the former insect, the larger ant, and the white ant. ${ }^{5}$

You are not perhaps aceustomed to regard wasps and hornets as of any use to us; but they certainly destroy an infinite number of flies and other annoying insects. The year 1811 was renarkable for the small number of wasps, though many females appeared in the spring, scarcely any neuters being to be seen in the autumn ${ }^{6}$; and probably in consequence of this eircumstance, flies in many places were so extremely numerous as to be quite a nuisance. Reaumur has observed that in France the butchers are very glad to have wasps attend their stalls for the sake of their services in driving away the flesh-fly; and, if we may believe the author of Hector St.Jobn's American Letters, the farmers in some parts of the United States are so well aware of their utility in this respect, as to suspend in their sitting rooms a hornet's nest, the occupants of which prey upon the flies without molesting the family. There are other devourers of insects in their perfect state, the manners and food of whose larve we are unacquainted with. St. Pierre speaks of a lady-bird, but it probally belonged to some other genus, of a fune violet colour, with a head like a ruby, which he saw carry off a butterfy.. ${ }^{7}$ Linné informs us that Clerus formicarizs devours Anobium pertinax. A fly related to Panorpa communis appears created to instil terror into the pitiless hearts of the

1 Latr. Hist. Nat. x. 181.

2 Linn. Trans. vi. 149." Kirby, Ibid. ix. 42, 43.

5 The late R:: Kittoe, Esq.

4 Voyages, i. 185.

5 Percival's Ceylon, $80 \bar{i}$.

- Mr. Knight made the same observation in 1806, and supposes the scarcity of neuters arose from the want of males to impreguate the females. Philos. Truns. 1807, p. 243.

7 St. Pierre, Toy. 72 
tyrants of our lakes and pools - the all-devouring Libellulina. The Asili also, which are always upon the chase, seize insects with their anterior legs and suck them with their haustellum. The cognate genus Dioctria, particularly $D$. celandica, prey upon Hymenoptera, by some unknown means, instantaneously lilling the insect they seize. Many species also of Empis, whose haustellum resembles the beak of a bird, carry off in it Tipularice and other small Diptera; and, what is remarkable, you ean seldom take these inseets in coitu, but the female has a gnat, some fly, or sometimes a beetle, in her mouth. Can this be to deposit her egrs in, as soon as they are impregnated by the male? or is it designed for the nuptial feast? Even Scatophaga stercoraria and scybalaria, and probably many others of the same tribe, feed upon small flies, though their proboscis does not seem so well adapted for animal as for vegetable food.

The most unrelenting devourers of insects appear to be those belonging to my fourth division, which attack them under cvery form. These begin the work of destruction when they are larvæ, and continue it during the whole of their existence. The earwig that haunts every close place in our gardens, and defiles whatever it enters, probably in some degree niakes up for its ravages by diminishing the number of other insects. The cowardly and cruel Mantis, which runs away from an ant, will destroy in abundance helpless flies, using its anterior tibia, with which the thigh form a kind of forceps, to seize its prey. The water-scorpions (Nepa, Ranatra, and Naucoris), whose fore-legs are made like those of the IIantis, the water-boatman (Notonecta), which always swims upon its back, and Sigara, all live by rapine, and prey upon aquatic insects. Some of this tribe are so savage that they seem to love destruction for its own sake One (Nepa cinerca), which was put into a basin of water with several young tadpoles, killed them all without attempting to eat one.

Those remarkable genera of the tribe of water-bugs (Hydrocorisce Latr.), which glide over the surface of every pool with such rapiclity, being gifted with the faculty of walking upon the water, Hydrometra, Velia, and Gerris, subsist also upon aquatic insects. A large number of the landbugs (Geocorisce Latr.), plunge their rostrum into the larva of Lepidoptera, and suck the contents of their bodies; and Roduvins personatus, which ought on that account to be encouraged, is particularly fond of the bed-bug, is, according to Kuhn, is Pentatoma bidens, six or eight of which, shut up in a room swarming with the bed-bug, for several weeks, completely extirpated the latter. ${ }^{2}$.

But of all the insects that are locomotive and pursue their prey in every state, none are greater enemies of their fellow tribes than the Libeilulina, and none are provided with more powerful and singular.instruments of assault. In the larva and pupa states, during which they live in the water and prey upon aquatic insects, they are furnished with two pair of strong jaws, covered by a kind of mask amed with a pair of forceps or claws, which the animal has the power of pushing from it to eatch any thing at a distance. ${ }^{3}$ When an aquatic insect passes within its reach, it

1 I.esser, L. i. 263. note.

2 Naturforscher, St. 6. and Fallen, Homipt. Suec. 112. nquoted by Westwood. MI:d. Clress. of Ins. ji. 486.

3 Reaum. vi. 400 . t. 36-38. 
suddenly darts forth the mask, opens the forceps, scizes the unfortunate victim, and brings it within the action of its jaws.

When they assume the imago state, their habits do not, like those of the white ants, become more mild and gentle, but, on the contrary, are more sanguinary and rapacious than ever; so that the name given to them in England, "Dragon-flies," seems much more applicable than "Demoiselles," by which the French distinguish them. Their motions, it is true, are light and airy; their dress is silky, brilliant, and variegated, and trimmed with the finest lace: so far the resemblance holds; but their purpose, except at the time of love, is always destruction, in which surely they have no resemblance to the ladies. I have been much amused by observing the proceedings of a species not uncommon here, Anar Imperator. of Dr. Leach. It keeps wheeling round and round, and backwards and forwards, over a considerable portion of the pool it fiequents. If one of the same species comes in its way, a battle ensues; if other species of Libellulina presume to approach, it drives them away, and it is continually engaged in catching case-worm flies and other insects (for the species of this tribe all. catch their prey when on the wing, and their large cyes seem given them to enable them the more readily to do this) that fly over the water, pulling off their wings with great adroitness, and devouring in an instant the contents of the body. From the number of insects of this tribe which are everywhere to be observed, we may conjecture how useful they must be in preventing too great a multiplication of the other species of the class to which they belong.

Lastly, under this head, not to dwell upon some other apterous genera, devourers of insects, as the scorpion and centipede, Phalangium, Galeodes, must be enumerated the whole world of Spiders, extremely numerous, both in species and individuals, which subsist entirely upon insects, s)reading with infinite art and skill their nets and webs to arrest the flight of the heedless and unwary summer tribes that fill the air, which are hourly caught by thousands in their toils; one of them (Theridium 13guttatum Rossi), we are told, even attacking the redoubted Scorpion. ${ }^{1}$

So much for the insect benefactors to whom it is given in charge to leep the animals of their own class within their proper limits; and I cannot doubt that you will recognise the goodness of the Great Pareut in providing such an army of comterchecks to the natural tendency of almost all insects to incalculable increase. But before I quit this subject I nust call your attention to what may be denominated comibal insects, since, in spite of those declaimers who would persuade us that man is the only animal that preys upon his own species ${ }^{2}$, a large number of insects are guilty of the same offence. Reaumur tells us, that having put into al glass vessel twenty caterpillars of the same species, which he was careful to supply with their appropriate food, they nevertheless devoured each other

1 Thiebaut de Berneaud's Foyage to Elba, p. 31.

2 "E'en Tiger fell and sullen Bear

Their likeness and their lineage spare.

Man only mars kind Nature's plan,

And turns the fierce pursuit on Man."

Scott's Rokcly, canto iii. 1 
until one only survived ${ }^{1}$; and De Geer relates several similar instances.? The younger larvæ of Calosoma Sycophanta often take advantage of the helpless inactivity into which the gluttony of their maturer comrades has thrown them, and from mere wantonness, it should seem, when in no neer of other food, pierce and devour them. A ferocity not less savage exist: amongst the Mantes. These insects have their fore-legs of a constructiol. not unlike that of a sabre; and they can as dexterously cleave their antagonist in two, or cut off his head at a stroke, as the most expert hussar. In this way they often treat each other, even the sexes fighting with the most savage animosity. Rösel endeavoured to rear several specimens of 11. religiosa, but always failed, the stronger constantly devouring the weaker. ${ }^{3}$ This ferocious propensity the Chinese children have, according to Mr. Barrow, employed as a source of barbarous amusement, selling to their comrades bamboo cages containing each a Mantis, which are put together to fight. You will think it singular that both in Europe and Africa these cruel insects have obtained a character for gentleness of disposition, and even sanctity. This has arisen from the upright or sitting position, with the fore-legs bent, assumed in watching for their prey, which the vulgar have supposed to be a praying posture, and hence adopted the belief that a child or traveller that had lost his road would be guided by taking one of these pious insects in his hand, and observing what way it pointed. Mantis fausta, though not as some suppose worshipped by the Hottentots, is yet greatly esteemed by them, and they regard the person upon whom it alights as highly fortunate. ${ }^{4}$ A similar unnatural ferocity is exhibited by Gryllus campcstris, of which, having put the sexes into a box, I found on examining them that the female had begun to make her meal off her companion. The malign aspect of the scorpion leads us to expect from it unnatural cruelty, and its manners fulfil this expectation. Maupertuis put a hundred scorpions together, and a general and murderous battle immediately began. Almost all were massacred in the space of a few days without distinction of age or sex, and devoured by the survivors. He informs us also that they often devour their own offspring as soon as they are born. ${ }^{5}$ Spiders are equally feroeious in their habits, fighting sanguinary battles, which sometimes end in the death of both combatants; and the females do not yield to the Mantes in their unnatural cruelty to their mates. Woe be to the male spider that, after an union, does not with all speed make his escape from the fangs of his partner! Nay, De Geer saw one that, in the midst of his preparatory caresses was seized by the object of his attentions, enveloped by her in a web, and then devoured -a sight which, he observes, filled him with horror and indignation. ${ }^{6}$

Such are the benefits which we derive from the insects that keep each other in check. Here they are the destroyers to which we are chiefly indebted; but we are in another point of view under nearly equal obligations to the destroyed; for they are insects, either wholly or in part, that

1 Reaumur, ii. 413. This habit is well known to our practical Lepidopterists, who liave given the name of the AIonster Caterpillar to one of these cannibal species; a memoir npon which by Mr. Thrupp was lately read before the Entomological Society.

2 De Geer, i. 533. iii. 361. v. 400 . vi. 91.

3 Rï̈sel, iv. 96.

4 Thunberg's Trarels, ii. 66.

5 De Geer, vii. 335 .

6 Ibid. 180. 
form the food of some of our most esteemed fishes, and of birds that ure not more valuable to us as articles for the tahle, than as the songsters that nliven our groves. But beforc procecling to the details which this view the subject involves, I ought not to omit pointing out to you that many radrupeds, which, though not all of direct utility to us, are doubtless of sportance in the scale of being, derive a considerable part of their substence from insects.

The harmless hedgehog and the mole, to begin at the lower end of he series, are both said to be insectivorous ${ }^{1}$; the latter devouring large fuantities of the wire-worms. The greedy swine will root up whole acres in scarch of the grubs of cockchaters, of which they are very fond; and perhaps the good they do is greater than the harm, if their attack be confined to grass that, having been undermined by these grubs, would soon die; they also dig up the larve of the destructive Cicade seplendecim, called the American locust ${ }^{2}$, on which, when in their perfect state, the sguirrels are said to grow fat. ${ }^{3}$ The hadger, Lesser informs us, will eat beetles; and its kinsman the bear has the character of being very fond of ants and of honey; which last is also said to be a favourite article with the fox, who has sometimes the audacity to overturn bee-hives, and even to attack wasps' nests in search of it. He will also ent beetles.

Sparman has given an amusing aceount of the honey-ratel (Viverra mellixora), which has a particular instinct enabling it to discover bees, and attack them in their entrenchments. Near sunset the ratel will sit and hold one of his paws before his eyes, in order to get a distinct view of the object of his pursuit ; and when, in consequence of his peering about in this manner, he sees any bees flying, he knows that at this time of the day they are making for their habitations, whither he follows them, and so attains his end. ${ }^{4}$ Another species of Viverra ( $\boldsymbol{V}$. prehcnsilis) is also reputed to be an eager insect hunter. The ycung armadillos feed on a species of locust ; but no quadruped can with more prepriety be called insectivorous than the ant-eaters (Myrmecoplaga), which, as their name imports, live upon ants. The great ant-cater, when he comes to an ant-hill, scratches it up with his long claws, and then unfolds his slender worm-like tongue (which is more than two feet long, and wet with saliva), and when covered with ants draws it back into his mouth and swallows thousands of them alive, renerving the operation till no more are to be found. He also climbs trees in search of wood-lice and wild honey. Bats, as every one knows, are always flitting about in summer evenings, lawking for insects: and the lemur and monkeys will also eat them.

Insects likewise afford a favourite kind of food to many reptiles : the tortoise; frogs and toads; and lizards too of different kinds. St. Pierre mentions a small and very handsome species in the island of Mauritius, that pursues them into the houses, climbs up the walls, and even walks over glass, watching with great patience for an opportunity of catching them. ${ }^{5}$ The common snake also is said to receive part of its nutriment from them.

But to revert to insects as indirectly advantageous to us, by furnishing food to fishes and birds, beginning with the former.

1 Pingley, ii. 374.

5 Collinson in Philos. Trans. 1763.

5 St. Pierre, Voy. 73.
2 Bingley, iii. 27.

+ Sparman, ii. 180. 
Our rivers abound with fish of various kinds, which at particular seasons derive a principal part of their food lirom insects, as the numerous species of the salmon and carp genus. These chiefly prey upon the various kinds of Trichoptera, in their larva state called case- or caddis-worms, and in their inago may-flies (though this last denomination properly belongs only to the Sialis hutaria, which generally appears in that month) and Ephemerc. Besides these, the waters swarm with insects of every order as numerous in proportion to the space they inhabit, as those that fill the air, which form the sole nutriment of multitudes of our fish, and the partial support of almost all.

Reaumur has given us a very entertaining account of the infinite hosts of Ephemerce that by myriads of millions emerge at a certain season of the vear from some of the livers in France, which, as it is well worth your attention, I shall ahridge for you.

These insects, in their first and intermediate state, are aquatic: they cither live in holes in the banks of rivers or brooks below the water, so that it enters into their habitations, which they seldom quit; or they swim about and walk upon the bei of the stream, or conceal themselves under stones or upon pieces of stick. Though their life, when they assume the perfect state, is usually extremely short, some being disclosed after sunset, laying their eggs and dying before sunrise; and many not living more than three hours; yet in their preparatory state their existence is much longer, in some one, in others two, in other's even three years.

The different species assume the imago at different times of the year; but the same species appear regularly at nearly the same period amually, and for a certain number of days fill the air in the neighbourhood of the rivers, emerging also from the water at a certain hour of the day, Those which Swammerdam observed began to fly about six o'clock in the evening, or about two hours before sunset; but the great body of those noticed by Reaunur did not appear till after that time; so that the season of different harvests is not better known to the farmer, than that in which the Ephemeræ of a particular river are to emerge is to the fisherman. Yet a greater degree of heat or cold, the rise or fall of the water, and other circumstances we are not aware of, may accelerate or retard their appearance. Between the 10th and 15th of Aughist is the time when those of the Seine and Marne, which Reaumur described, are expected by the fishermen, who call them manna: and when their season is come, they say, "The manna begins to appear, the mamma fell abundantly such a night; "-alluding, by this expression, either to the astonishing quantity of food which the Ephemeræ afford the fish, or to the large quantity of fish which they then take.

Reaumur first observed these insects in the year 1738, when they did not begin to show themselves in numbers till the 18th of August. On the 19th, having received notice from his fishermen that the flies had appeared, he got into his boat about three hours before sunset, and detached from the banks of the river several masses of earth filled with pupæ, which he put into a large tub full of water. This tub, after staying in the boat till about eight o'clock, without seeing any remarkable number of the flies, and being threatened with a storm, he cansed to be landed and placed in his garden, at the foot of which ran the Name. Before the people had landed it, an astonishing number of Ephemeræ emerged from it. Every piece of earth that was above the surface of the water was covered by them, some 
beginning to quit their slongh, others prepared to fly, and others already on the wing; and every where under the water they were to be seen in a greater or less degree of forwardness. The storm coming on, he was obliged to quit the amusing scene; but when the rain ceased to foll, he returned to it. As soon as the cloth with which he had ordered the tub to he corered was removed, the number of flies appeared to be greatly augmented, and kept continually increasing; many flew away, but more were drowned. Those already transformed, and continually transforming, would lave been sufficient of themselves to have made the tub seem full; but their number was soon very much enlarged by others attracted by the light. To prevent their being drowned, he caused the tnb to be again covered with the cloth; and over it he held the light, which was soon concealed by a layer of these flies, that might have been taken by handfuls from the candlestick.

But the scene round the tub was nothing to be compared with the wonderful spectacle exhibited on the harks of the river. The exclamations of his gardener drew the illustrious naturalist thither; and such a sight he had never witnessed, and could scarcely find words to describe. "The myriads of Ephemeræ," says he, "which filled the air over the current of the river, and over the bank on which I stood, are neither to be cxpressed nor conceived. When the snow falls with the largest flakes, and with the least interval between them, the air is not so full of them as that which surrounded us was of Ephemeræ. Scarcely had I remained in one place a few minutes, when the step on which I stood was quite concealed with a layer of them from two to four inches in depth. Near the lowest step a surfice of water of five or six feet dimensions every way was entirely and thickly covered by them; and what the current carried off was continually replaced. Many times I was obliged to abandon my station, not being able to bear the shower of Ephemeræ, which, falling with an obliquity less constant than that of an ordinary shower, struck continually, and in a manner extremely uncomfortable, every part of my face - eyes, mouth, and nostrils were filled with them." "To hold the flambeau on this occasion was no pleasant office. The person who filled it had his clothes covered in a few moments with these flies, which came from all parts to overwhelm him. Before ten o'clock this interesting spectacle had ranished. It was renewed for some nights afterwards, but the flies were never in such prodigious numbers. The fishermen allow only three successive days for the great fall of the manna; but a few flics appear both before and after, their number increasing in one case, in the other diminishing. Whatever be the temperature of the atmosphere, whether it be cold or hot, these flies invariably appear at the same hour in the evening, that is, between a quarter and half-past eight; towards nine they begin to fill the air; in the following half-hour they are in the greatest numbers; and at ten there are scarcely any to be seen. So that in less than two hours this infinite host of flies emerge from their parent strcan, fill the air, perform their appointed work, and vanish. A very large proportion of them falls into the river, where the fish have their grand festival and the fishermen a good harvest. ${ }^{1}$

Under this head I may observe how much the patient angler is indebted to insects for some of his choicest baits, for the best opportunities of 
showing his skill, and for the most gratifying part of his diversion. The case-worm and several other larve are the best standing bait for many fish. The larva of the Ephemera, there called bait and bank-bait I, is much used in some parts of Holland. The case-worms, and grubs (I suppose of flies) from the tallow-chandlers, and the larvæ of wasps taken out of the comb, are in request with us for roach and dace; and I am told by an acute observer of these things, the Rev. R. Sheppard, that the Geotrupes and Melolonthe are good baits for chub.2 But to be an adept in fly-fishing, which requires the most skill and furnishes the best diversion, the angler ought to be conversant in Entomology, at least snfficiently so to distinguish the different species of Phryganea and other 7richoptcra, and to know the time of their appearance. The angler is not only indebted to insects for some of his best baits, but also for the best material to fasten his hooks to, and even for making his lines for smaller fish - the Indian grass or gut, as it is called (termed in France Cheveux de Florence), which is said to be prepared in China from the matter contained in the silk reservoirs of the silk-worm, but according to Latreille is the silk vessel itself when dried. ${ }^{3}$

One of the most important ends for which insects were gifted with such powers of multiplication, giving birth to myriads of myriads of individuals, was to furnish the feathered part of the creation with a sufficient supply of food. The number of birds that derive the whole or a principal part of their subsistence from insects is, as is universally known, very great, and includes species of almost every order.

Amongst the Accipilies the kestril (Falco tinnunculus L.) devours abundance of insects. A friend of mine, upon opening one, found its stomach full of the remains of grasshoppers and beetles, particularly the former, which he suspects constitute great part of the food of this species. One of the shrikes, also, or butcher-birds (Lanius collurio) - and it is probable that other species of this numerous genus may have the same habits - is known to feed upon insects, which it first impales alive on the thorns of the sloe and other spinous plants, and then devours. If meat be given it, when kept in a cage, it will fix it upon the wires before it eats it. Lanius excubitor also impales insects; but Heckewelder denies that it feeds upon them. If he be correct, the object of this singular procedure with that species may be to allure the birls which it preys upon to at particular spot. ${ }^{+}$

Amongst the Pice or Pies the Crotophaga, called the Ani, which is a

1 Swamm. Bib. Nat. i. c. 4. 106. b.

2 In Col. Tenable's Experienced Angler, a rast number of insects are enumerated as good baits for fish, under the names of Bob, Cadbuit, Cankers, Caterpillars, Palmers, Gentles, Barkworms, Oak-worms, Colewort-worms, Flag-worms, Green-flies, Ant-flies, Butterflics, WIasps, Hornets, Bees, Humble-bees, Grasshoppers, Dors, Bcetles, a great brou'n fiy that lives upon the oak like a Scarabee (Melolontha vutgaris, or Amplimalla solstitialis?), and fies (i. e. May-flies) of various sorts.-See also IIr. Ronalds' Fly"-fisher's Entomology.

3 Anderson's Recreations in Agricult. Sc. iv. 478.; Latr. Hist. Nat. xiv. 154.

4 According to Mr. Heckewelder ('Trans. Amer. Phit. Soc. iv. 124.), L. exeubitor, called in America the nine-killer, from an iclea that it transfixes nine individuals daily, treats in this manuer Grasshoppers only; while $L$. collurio would seem to restrict itself chiefly to Geotrupes, two of which Mr. Sheppard once observed transfised in a hedge that he knew to be the residence of this bird. Fugellan even 
native of Africa and America, lives upon the locusts and Ixodes ricinus, which it picks in great numbers from the backs of cattle; but none are greater devourers of insects in this order than rooks. It is for the grubs of Melolontha, Tipula, \&e., that they follow the plough; and they always frequent the meadows in which these larva abound, destroying them in vast numbers. Kalm tells us, that when the little crow was extirpated from Virginia at an enormons expense, the inhabitants would willingly have them brought back again at double the price. ${ }^{1}$ The icteric oriole is kept by the Americans in their houses for the sake of clearing them of insects; and the purple grackle is so useful in this respect, that when, on account of their consuming grain, the Ameriean farmers in New England offered a reward of three-pence a head for them, and they were in consequence nearly extirpated, insects increased to such a degree as to cause a total loss of the herbage, and the inhabitants were obliged to obtain hay for their cattle not only from Pennsylvania, but even from Great Britain.2 Of this order also is the bee-cuckoo (Cuculus indicator), so celebrated for its instinct, by which it serves as a guide to the wild bees' nests in Africa. Sparrman describes this bird, which is somewhat larger than a common sparrow, as giving this information in a singular manner. In the evening and morning, which are its meal-times, it excites the attention of the Hottentots, colonists, and honey-ratel, by the ery of cherr, cherr, cherr, and conducts them to the tree or spot in which the bees' nest is concealed, continually repeating this ery. When arrived at the spot, it hovers over it; and then alighting on some neighbouring tree or bush, sits in silence, expecting to come in for its share of the spoil, which is that part of the comb containing the brood. ${ }^{3}$ The wryneck and the woodpeckers, the nuthatch and tree-creeper, live entirely upon insects and their eggs ${ }^{4}$, which they piek out of decayed trees, and ont of the bark of living ones. The former also frequents grass-plots and ant-hills, into which it darts its long flexible tongue, and so draws out its prey. The woodpecker likewise draws insects out of their holes by means of the same organ, which for

thinks that it impales only $G$. vernalis, which he has often found transfixed, but never $G$. stereorarius. (Schneid. IIag. 259.) I must remark, however, that I last summer observed two humble-bees quite alive impaled on the thoms of a hedge ne:ur my house, which had most probably been so placed by this species, $L$. excubitor being rarely found except in mountainous wilds. (Bewick's Birds, i. 61.) And Prot. Sander states that on opening this bird ( $L$. collurio) he has sometimes found in its stomach nothing but grasshoppers, and at others small beetles and other insects. (Nuturforseher, Stk. xviii. 234.) Mr. Dunlop, in a letter in Loudon's Gardener's Magazine for May, 1842 (No. cxlvi. p. 259.), states, that upon examining a branch of liawthorn on which he had for some days observed a pair of fly-catchers feeding their young, he found upwards of a dozen humble-bees (Bombus terrestris) fixed apon the spines as securely as it done by the band of man, some being alive, and others dead and partly devoured. Mr. Dunlop, after removing the bees to watch the process of the birds in plaeing them, had soon the satisfuction of seeing the flycatchers catch them on the wing, earry tliem direet to the branch (which was a dead one, apparently on account of the greater hardness of the spines), and thrust them on the spines as above deseribed. Mr. IV. W. Saunders found a number of the yellow undertwing moth (Triphana pronuba) thus fixed.

1 Stillingfl. Tracts, 175. Linn. Trans, v. 105. note b.

2 Bingley, ii. $287-290$.

3 Sparrman, ii. 186.

4 Bewick's Birds, i. I'ref. xxii. 130. 
this purpose is bony at the end and barbed, and furnished with a curious apparatus of muscles to enable them to throw it forward with great force. Some species spit the insects on their tongue, and thus bring them into their mouth. In Americ:1, the tree-creeper is furnished with a box at the end of a long pole to entice it to build in gardens, which it is found to be particularly useful in clearing from noxious insects.

Amongst the Gralle or Waders, many of the long-billed birds eat the larvæ of insects as well as worms; and they form also no inconsiderable part of the food of our domestic poultry, especially turkeys, which may be daily seen busily engaged in hunting for them, and, as well as ducks, will greedily devour the larger insects, as cockchafers, and in North America, Cicadce. Mr. Sheppard was much amused, one day in July, with observing a cow which had taken refuge in a pond, probably from the gad-fly, and was standing nearly up to its belly in water. A fleet of ducks surrounded it, which kept continually jumping at the flies that alighted upon it. The cow, as if sensible of the service they were rendering her, stood perfectly still, though assailed and pecked on all sides by them. The partridge takes her young brood to an ant-hill, where they feast upon the larvæ and pupæ, which Swammerdam informs us were sold at market in his time to feed various kinds of birds. ${ }^{\prime}$ Dr. Clarke also mentions having seen them, as well as the ants themselves, exposed to sale in the market at Moscow, as a food for nightingales. ${ }^{2}$ Latreille tells us that singing birds are fed in France with the larve of the horse-ant (Formica rufa).

But the Linnean order of Passeres affords the greatest number of insectivorous birds; indeed ahmost all the species of this order, except perhaps the pigeon-tribe, and the cross-bill, and other Loxiæ, more or less eat insects. Amongst the thrush tribe, the blackbird, though he will have his share of our gooseberries and currants, assists greatly in clearing our gardens of caterpillars; and the locust-eating thrush is still more useful in the countries subject to that dreadful pest; these birds never appear but with the locusts, and then accompany them in astonishing numbers, preying upon them in their larva state. The common sparrow, though proscribed as a most mischievous birl, destroys a vast number of insects. Bradley has calculated that a single pair, having young to maintain, will destroy 3360 caterpillars in a week. ${ }^{3}$ They also prey upon butterflies and other winged insects. The fly-catchers (Muscicapa), and the warblers (.Motacilla), which include our sweetest songsters, are almost entirely supported by insects; so that were it not for these despised creatures we should be deprived of some of our greatest pleasures, and half the interest and delight of our vernal walks would be done away. Our groves would no longer be vocal; our little domestic favourites the red-breast and the wren would desert us; and the heavens would be depopulated. We should lose too some of the most esteemed dainties of our tables, one of which, the wheat-ear, is said to be attracted to our downs by a particular insect. ${ }^{4}$ Lastly, insects are the sole food of swallows, which are alway's on the wing hawking for them, and their fight is regulated by that of their prey. When the atmosphcre is dry and clear, and their small game flies high, they seek the skies: when moist, and the insects are low or upon the ground, they descend, and just skim the surface of the earth

1 Bib. Nat. i. 126. b.

3 Reaum, ii. 408.
2 Travels, i. 110.

4 Bingley, ii. 374. 
and waters; and thus by their flight are regarded as prognosticating fair or wet weather. I was one summer much interested and amused by observing the tender care and assiduity with which an old swallow supplied her young with this kind of food. My attention was called to a young brood, that, having left their nest before they were strong enough to take wing, were stationed on the lead which covers a bay-window in my house. The mother was perpetually going and returning, putting an insect into the mouth first of one, then of the others in succession, all fluttering and opening their mouths to receive her gift. She was scarcely ever more than a minute away, and continued her excursions as long as we had time to observe her. When the little ones were satisfied, they put their heads under their wings and went to sleep. The number of insects caught by this tribe is inconceivable. But it is not in summer only that birds derive their food from the insect tribes : even in winter the pupæ of Lepidontera, as Mr. White tells us, are the grand support of those that have a soft bill.ı

I shall close my list of the indirect benefits derived from insects, by adverting to the very siugular apparent subserviency of some of them to the functions of certain vegetables.

You well know that some plants are gifted with the faculty of catching fies. These.vegetable Muscicape, which have been enumerated by Dr. Barton of Philadelphia, who has published an ingenious paper on the subject ${ }^{2}$, may be divided into three classes : - First, those that entrap insects by the irritability of their stamina, which close upon them when touched. Under this head come Apocymum androscemifolum, Asclepias syriaca and curassavica, Nerizm oleander, and a grass deseribed by Michaux under the name of Lecrsia lcnticularis. The second class includes those which entrap them by some viscosity of the plant, as many species of Rhododendron, Tralmia, Robinia, Silene, Lythrum, Populus balsamifera, \&c. ${ }^{3}$ And under the third class will arrange those which ensnare by their leaves, whether from some irritability in them, as in Dionca, Drosera, \&c., or merely from their forming hollow vessels containing water into which the flies are enticed cither by their carrion-like odour, or the sweet fluid which many of them sccrete near the faux; as in Sarracenia, Nepenthes, Aquarium, Cephalotus, \&c., the tubular leaves of which are usually found stored with putrefying insects. In this last class may be placed the common $\mathrm{Di}$ psacus of this country, the connate leaves of which form a kind of basin round the stem that retains rain-swater, in which many insects are drowned. To these a fourth class might be added, consisting of those plants whose flowers, smelling like carrion (Stapelia lirsuta, \&c.), entice flies to lay their eggs upon them, which thus perish.

The number of insects thus destroyed is prodigions. It is scarcely possible to find a flower of the Mruscicape asclepiadec that has not entrapped its victim, and some of them in the United States closely cover hundreds of acres together.

1 White's Sellorne, i. 181.

2 Philos, Mag, xxxix, 107.

3 Small flies are sometimes found sticking to the glutinous stigma of some of the Orchile:e like birds on a limed twig (Sprengel, Entdecktes Geheimniss, 21.); and ants are not unfrequently detained in the milky juice which the touch of even their light feet causes to cxucle from the calyxes of the common garden lettuce.-Ann, of Dot. ij. $5 \% 0$. 
What may be the precise use of this faculty is not so apparent. Dr. Barton cloubts whether the flowers that catch insects, being only temporary organs, can derive any nutriment fiom them; and he does not think it probable that the leaves of Dioncen, \&.c., which are usually found in rich boggy soil, can have any need of additional stimulus. As nothing, however, is made in vain, there can be little doubt that these ensnared insects are subservient to some important purpose in the economy of the plants which are endowed with the faculty of taking them, though we may be ignorant what that purpose is ; and an experiment of Mr. Knight's, nurseryman in King's Road, London, seems to prove that, in the case of Dioncer at least, the very end in view, contrary to Dr. Barton's supposition, is the supplying the leaves with animal manure; for he found that a plant upon whose leaves he laid fine filaments of raw beef was much more huxuriant in its growth than others not so treated. ${ }^{1}$ Possibly the air evolved from the putrefying insects with which Sarracenia purpurea is sometimes so filled as to scent the atmosphere round it, may be in a similar manner favourable to its vegetation.

Most of the insects which are found in the tubular leaves of this and similar plants enter into them voluntarily; but Sir James Smith mentions a curious fact, from which it appears that in some cases they are deposited by other species. One of the gardeners of the Liverpool Botanic Garden observed an insect, from the description one of the Crabronide, which dragged several large flies to the Sarracenirt adunca, and having with some dificulty forced them under the lid or cover of its leaf, deposited them in its tubular part, which was half filled with water ; and on examination all the leaves were found crowded with dead or drowning flies. ${ }^{2}$ What was the object of this singular manœuvre does not seem very obvious. At the first glance one might suppose that, having deposited an egg in the fly, it intended to avail itself of the tube of the leaf instead of it burrow. "Yet we know of no such strange deviation from natural instinct, which would be the more remarkable, because the insect was European, while the plant was American, and growing in a hot-house. And, at any rate it does not seem very likely that the insect would commit her egg to the tube without having previously examined it ; in which case she must have liscovered it to be half full of water, and consequently unfit for her purpose. It is not so wonderful that many large flies should, as Professor Barton informs us, drop their ergss into the Ascidia furnished with dead carcasses; and it seems very probable that Dytisci oviposit in them; for the Squilla, which Rumphius found there, was probably one of their larva, this being the old name for them. ${ }^{9}$

However problematical the agency of insects caught by plants as to their mutriment, there can be no doubt that many species perform an important function with regard to their impregnation, which indeed withont their aid would in some cases never take place at all. 'Thus, for the due fertilisation of the common Barberry (Berberis vulgaris), it is necessary that the irritable stamens should be brought into contact with the pistil by the application of some stimulus to the base of the filament; but this would never take place were not insects attracted by the melliferous glands of the flower to

1 Elements of the Science of Botumy, 62.

2 Smith's Introduction to Botany, 195

3 Mouffet, 319. 
insinuate themselves amongst the filaments, and thus, while seeking their own food, unknowingly fulfil the intentions of nature in another department. ${ }^{1}$

The agency of these little operators is not less indispersable in the beautiful tribe of Iris. In these, as appears from the observations of Kölreuter, the true stigma is situated on the upper side of a transverse membrane (areus eminens of Haller), which is stretched across the middle of the under surface of the petal-like expansion or style-fing, the whole of which has been often improperly regarded as fulfilling the office of a stigma. Now, as the anther is situated at the base of the style-flag which cover's it, at a considerable distance from the stigma, and at the same time cut of from all access to it by the intervening barrier formed by the areus eminens, it is clear that but for some extraneous agency the pollen could never possibly arrive at the place of its destination. In this case the lumble-bec is the operator. Led by instinct, or, as the ingenious Sprengel supposes, by one of those honey marlis (Saftmaal) or spots of a different colour from the rest of the corolla, which, according to him, are placed in many flowers expressly to guide insects to the nectiries, she pushes herself between the stiff style-flar and elastic petal, which last, while she is in the interior, presses her close to the anther, and thus causes ber to brush off the pollen with her hairy back, which ultimately, though not at once, conveys it to the stigma. Having exhausted the nectar, she retreats backwards: and in doing this is indeed pressed by the petal to the arcus eminens; but it is only to its lower or negative surface, which cannot influence impregnation. She now takes her way to the second petal, and insinuating herself under its style-flag, her back comes into close contact with the true stigma, which is thus impregnated with the pollen of the first visited anther; and in this manner migrating fron one part of the corolla to another, and from flower to flower, she fructifies one with pollen gathored in her search after honey in another. Sprengel found that not only are insects indispensable in fructifying the different species of Iris, but that some of them, as $I$. xiphinm, require the agency of the larger humble-bees, which alone are strong enough to force their way beneath the style-flag; and hence, as these insects are not so common as many others, this Iris is often barren, or bears inperfect seeds. ${ }^{2}$ Sprengel also contends, that insects are essentially necessary in the impregnation of Asclepiadec; in which opinion he is confirmed by the conclusive testimony of the celebrated botanist Robert Brown, Esq., who states ${ }^{3}$ that there can be no doubt that the agency of insects is very frequently, though not always, employed in the fecundation of Orchidece, "but that in those Asclcpiadece that have been fully examined, the atsolute necessity for their assistance is manifest."

Aristolochia clematitis, according to Professor Willdenow, is so formed, that the anthers of themselves cannot impregnate the stigma; but this important affiur is devolved upon a particular species of gnat (Cecidomyic pemicomis). The throat of the flower is lined with dense hair, pointing downward, so as to form a kind of funnel or entrance like that of some kinds of mouse-traps; through which the insects may easily enter, but not

1 Smith's Tracts, 165. Kölreuter, Ann. of Bot. ii. 9.

2 Chr. Conr. Sprengel, Entdecktes Geheimniss, \&c. Berlin, 1793, 4to.; quoted in Ann. of Bot. i. $41 \%$.

3 On the Organs and DIode of Fecundation in Orchidece and Asclepiadec. Linn. Trans. xvi. 731. 
return ; several creep in, and, uneasy at their confinement, are constantly moving to and fro, and so deposit the pollen upon the stigma; but when the work entrusted to them is completed, and impregnation has taken place, the hair which prevented their escape shrinks, and adheres closely to the sides of the flower, and these little go-betweens of Flora at length leave their prison. ${ }^{1}$ Sir James Smith supposes that it is for want of some insect of this hind that Aristoluchia sipho never forms fruit in this country.

Equally important is the agency of insects in fructifying the plants of the Limnean classes Moncecia, Dicecia, Polygamia, in which the stamens are in one blossom and the pistil in another. In exploring these for honey and pollen, which last is the food of several insects besides bees ${ }^{2}$, it becomes involved in the hair with which in many cases their bodies seem provided for this express purpose, and is conveyed to the germen requiring ite fertilising influence. Sprengel supposes that with this view some plants have particular insects appropriated to them; as to the diocious net1le Catheretes urtice, to the toal-flax Catheretes gravidus, both minute beetles, \&c. Whether the operations of Cymips psencs be of that advantage in fertilising the fig which the cultivators of that fruit in the East have long supposed, is doubted by Hasselquist and Olivier ${ }^{3}$, both competent observers, who have been on the spot. ${ }^{4}$ Our own gardeners, however, will admit their obligations to bees in setting their cucumbers and melons, to which they find the necessity of themselves conveying pollen from a male flower, when the early season of the y'ear precludes the assistance of insects. Sprengel asserts that, apparently with a view to prevent hybrid mixtures, insects which derive their honey or pollen from different plants indiscriminately will, during a whole day, confine their visits to that species on which they first fixed in the morning, provided there be a sufficient supply of it $^{5}$; and the same observation was long since made with respect to becs by our countryman Dobbs. ${ }^{6}$

Thus we see that the flowers which we vainly think are

"- born to blush unseen,

And waste their fragrance on the desert air,"

though unvisited by the lord of the creation, who boasts that they were made for him, have nevertheless myriads of insect visitants and admirers, which, though they pilfer their sweets, contribute to their fertility.

I am, \&c.

1 Grundriss der Kräuterkunde, 353. A writer, however, in the Annuat Medical Review (ii. 400.) doubts the accuracy of this fact, on the ground that he could never find $C$. pennicornis, though $A$. clematitis has produced fruit two vears at Brompton. Meigen (Dipt. i. 100. e.) places this amongst his doubtful Cecidomyia. Fabricius considers it as a Chironomus.

2 I have frequently observed Dermestes flavescens, Ent. Brit. (Byturus) eat both the petals and stamens of Stellirice holosteum; and Mordelte will open the anthers with the securiform joints of their palpi to get at the pollen.

3 Hasselquist's Travels, 253. Latr. Hist. Nat. xiii. 204.

4 For a full account of the various opinions on this disputer point, see an interesting article by MIr. Westwood in Trans. Ent. Soc. Lond. ii. 214.-224.

5 Willd. Grundriss, 352.

${ }^{6}$ Phil. Trans. xlvi. 536 


\title{
LETTER X.
}

\section{BENEFITS DERIVED FROM INSECTS.}

\author{
DIRECT BENEFITS.
}

Mr last letter was devoted to the indirect advantages which we derive from insects; in the present 1 shall enumerate those of a more direct nature for which we are indebted to them, beginning with their use as the food of man, in which respect they are of more importance than you may have conceived.

One class of animals, which, till very lately, have been regarded as belonging to the entomological world, I mean the Crustacen, consisting principally of the genus Cancer of Linné, are universally reckoned amongst our greatest dainties; and they who would turn with disgust from a locust or the grub of a bettle, feel no symptoms of nausea when a lobster, crab, or shrimp is set before them. The fact is, that habit has reconciled us to the cating of these last, which, viewed in themselves, with their threatening claws and many feet, are really more disgusting than the former. Had the habit been reversed, we should have viewed the former with appetite and the latter" with abhorrence, as do the Arabs, "who are as much astonished at our eating crabs, lobsters, and oysters, as we are at their eating locusts."1 That this would have been the case is clear, at least as far as regards the former position, from the practice in other parts of the world, both in ancient and modern times, to which, begging you to lay asicte your English prejudices, I shall now call your attention ; first observing by the war, that the insects used as food, generally speaking, live on vegetable substances, and are consequently much more select and cleanly in their diet than the swine or the duck, which form a favourite part of ours. ${ }^{2}$

Many larv ${ }^{3}$ that belong to the order Colcoptera are eaten in different parts of the world. The grub of the palm-weevil (Cortylia ${ }^{4}$ palmarum),

1 Walpole in Clarke's Traiels, ii. 187. Even Mr. Boyle speaks with abhorrence of eating raw oysters. - Walton's Angler, Life, p. 12.

2 See a long and interesting paper by the liev. F. W. Hope upon edible insects in the Trans. Ent. Soc. (vol. iii. part 2.).

3 Baron II umboldt asks (Person. Nurr. VI. i. 8. note) - "What are those worms (Loul in Arabie) which Captain Lyon, the fellow-traveller of my brave and unfortumate friend Mr. Ritehie. found in the pools of the desert of Fezzan, which served the Arabs for food, and which have the taste of caviare? Are they not inseets' eggs resembling the Aguautle, which I saw soll in the narkets of Mexico, and which are collected on the surface of the lakes of Texcrico?" For this latter fact he refers to the Gazeta de Litteratura de Mexico, 1794, iij. No. 26. p. 201. It appears from this note of the illustrious traveller, that insects are used as food in their egg as well as their other states.

4 IIerbst and Schönherr call this distinct genus Rhyncophorus; but as this is too near the name of the tribe (Rhyncophora), we have adopted Thunberg's name altering the termination, to distinguish it from Cordyle, a genus of Lizards. 
which is the size of the thumb, has been long in request in both the Indics. Elian spealss of an Indian king, who for a dessert, instead of fruit, set before his Grecian guests a roasted worm taken from a plant, prohably the larva of this insect, which he says the Indians esteem very delicious - a character that was confirmed by some of the Greeks who tasted it. ${ }^{1}$ Madame Merian has figured one of these larve, and says that the natives of Surinam roast and eat them as something very exquisite. ${ }^{2}$ A friend of mine, who has resided a good deal in the West Indies, where the palm grub is called Grugru, informs me that the late Sir John La Forey, who was somewhat of an epicure, was extremely fond of it when properly cooked.

The larve also of the litrger species of the capricorn tribe (Ceramby $x$ L.; Longicornes Latr.) are accounted very great delicacies in many countries; and the Cossus of Pliny, which he tells us the Roman epicures fattened with flonr ${ }^{3}$, most probably belonged to this tribe. Linné indeed, following the opinion of Raly ${ }^{4}$, supposes the caterpillar of the great goat-moth, the anatomy of which has been so wonderfully traced by the eye and pencil of the incomparable Lyonet, to be the Cossns. But there scems a strong reason against this opinion; for Linnés Cossus lives most commonly in the willow, Pliny's in the oak; and the former is a very disagreeable, ugly, and fetid larva, not very likely to attract the Roman epicures. Probably they were the larve of Prionus coriarizs, which I have myself extracted from the oak, or of one of its congeners. ${ }^{5}$ The grub of $P$. demicomis, which is of the thickness of a man's finger, is eaten at Surinam, in America, and in the West Indies, both by whites and blacks, who empty, wash, and roast them, and find them delicious. ${ }^{6} \mathrm{Mr} \mathrm{Hall}$ informs me, that in Jamaica this grab is called Macanco, and is in request at the principal tables. A sinilar insect is dressed at Mauritius under the name of Moutac, which the whites as wcll as negroes eat greedily. ${ }^{7}$ The larva of $P$. cervicornis, is, according to Linué, held in equal estimation: and that of Acanthocinus tribulus, when roasted, forms an article of food in $\Lambda$ frica. ${ }^{8}$ It is probable that all the species of this genus might be safely eaten, as well as many other arubs of Coleoptera; and although I do not feel disposed to recommend with Reaumur ${ }^{9}$, that the larva of Oryctes nasicomis should be songht for "dans les couches de fitmier," yet I thiuk with Dr. Darwin ${ }^{10}$, that those of the cockchafer which feed upon the roots of grass, or the perfect insects themselves, which, if we may judge from the eagerness with which cats, and turkeys and other birds, devour them, are no despicable bonne

1 Elian, ITist. 1. xiv. c. 13.; quoted in Reaum. ii. 343.

2 Ins. Sur. 48.

3 Hist. Nat. 1. xvii. c. 24.

4 Wisdom of God, 9th ed. 307. Ray first adopted the opinion here maintained, that the Cossi were the larvo of some beetle; but afterwards, from observing in the caterpiliar of Cossus ligniperdic a power of retracting its jrolegs within the body; he conjectured that the hexapod larva from Janaica (Prionus damicornis?), given him by Sir Ilans Sloane, might have the same faculty, and so be the caterpillar of a Bombyx.

5 Amoreux has collected the different opinions of entomologists on the subject of Pliny's Cossus, which has been supposed to be the larva of Cordylia palmarum by Geoffroy; of Lucanus cervus by Scopoli, and cf Prionus damicornis by Drury. The first and last, being neither natives of Italy, nor inhabiting the oak, are ont of the question. The larvo of Lucanus cervus and Prionus coriarius, which are found in the oak as well as in other trees, may each have been eaten under this name, as their difference would not be discernible either to collectors or cooks. - Amoreux, 154.
6 Merian, Ins. Sur. 24.
7 St. Pierre, Foy, 72.
8 Smeathman, 32 .

9 Reamm. ii. 844.

10 Phytol. 361. 
bouche, might be added to our cutrenets. This would be one means of keeping down the numbers of these occasionally destructive animals. The Mexican Indians, according to M. Vasselet and Madame Sallé and her son, who have transmitted such numbers of fine insects from Mexico to M. Chevrolat of Paris, prepare a liquor from a beetle (Cicindela currata) by macerating it in water or spirit, which they apparently use as a stimulating beverage. ${ }^{1}$

In the next order of insects, the Orthoptera, the Gryllus, or locust tribe, as they are the greatest destroyers of food, so as some recompense they furnish a considerable supply of it to numerous nations. They are recorded to have done this from the most remote antiquity, some Ethiopian tribes having been named from this circumstance $A$ crido h ha $^{2}$ (locust-cater's). ${ }^{2}$ Pliny also relates that they were in high esteem as meat amongst the Parthians. $^{3}$ Hasselquist, in reply to some inquiries which he made on this subject with respect to the Arabs, was informed that at Mecca, when there was a scarcity of corn, as a substitute for flour they would grind locusts in their hand-mills, or pound them in stone mortars; that they mixed this flour with water into a dough, and make their cakes of it, which they baked like their other bread. He adds, that it is not unusual for them to eat locusts when there is no fannine; but then they boil them first a good while in water, and afterwards stew them with butter into a kind of fricassee of no bad flavour. ${ }^{4}$ Leo Africanus, as quoted by Bochart, gives a similar account. ${ }^{5}$ Sparrman informs us that the Hottentots are highly rejoiced at the arrival of the locusts in their country, although they destroy all its verdure, eating them in such quantities as to get visibly fatter than before, and making of their eggs a brown or coffee-coloured soup. He also relates a curious notion which they have with respect to the origin of the locusts-that they proceed from the good-will of a great master-conjuror a loing way to the north, who having removed the stone from the mouth of a certain leep pit, lets loose these animals to be food for them. ${ }^{6}$ This is not unlike the account given by the author of the Apocalypse, of the origin of the symbolical locusts, which are said to ascend upon an angel's opening the pit of the abyss. ${ }^{7}$ Clenard, in his letters quoted by Bochart, says that they bring waggon-loads of locusts to Fez, as a usual article of food. ${ }^{8}$ Major Moor informs me, that when the elond of locusts noticed in a former letter visited the Mahratta country, the common people salted and ate them. This was anciently the custom with many of the Afican nations, scme of whom also smoked them. ${ }^{3}$ They appear even to have been an article of foed offered for sale in the markets of (rreece ${ }^{10}$; and on a subject so well known, to quote no other writers, Jackson observes that, when he was in Barbary in 1799, dishes of locusts were generally served up at the principal tables and esteemed a great delicacy. They are preferred by the Moors to pigeons; and a person may eat a plateful of two or three hundred without feeling any ill cficcts. They usually boil them in water half an hour (having thrown away the head,

1 Silbermann, Révue Entom. i. 238.

2 Diorl. Sic. 1. iii. c. 29. Strabonis Geog. 1. xri. \&c.

3 II ist. Nat. l. xi. c. $29 . \quad 4$ Traveis, 232.

6 Spurrman, i. 367.

8 Hieroz. ii. l. 4. c. 7.492.

7 Rev. ix. 2, 3.

5 Hieroz. ii. l. 14. c. 7.

10 Id. ibid.

9 Pliny, Hist. Nat. l. vi. c. 30. 
wings, and legs), then sprinkle them with salt and pepper, and fry them,

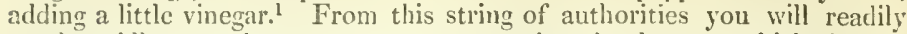
see how idle was the controversy concerning the locusts which formed part of the sustenance of John the Baptist, agreeing with Hasselquist ${ }^{2}$, that they could be nothing but the animal locust, so common a food in the East; and how apt even learned men are to perplex a plain question, from ignorance of the customs of other countries.

In the hemipterous order of insects, none are more widely dispersed, or (if you will forgive me a pun) have made more noise in the world, than the Cicala tribe. From the time of Homer, who compares the garrulity of age to the chirping of these insects ${ }^{3}$, they have been celebratel by the poets; and Anacreon, as you well know, has inscribed a very beautiful little ode to them. We learn from Aristotle, that these insects were eaten by the polished Greeks, and accounted very delicious. The worm (larva), he says, lives in the earth where it takes its growth: that it then becomes a Tettigomelra (pupa), when he observes they are most delicions, just before they burst from their covering. From this state they change to the Tettix or Cicada, when the males at first have the best flavour ; but after impregnation the females are preferred on account of their white eggs. ${ }^{4}$ Athenæus also and Aristophanes mention their being eaten; and Flian is extremely angry with the men of his age, that an animal sacred to the Muses should be strung, sold, and greedily devoured. ${ }^{5}$ Pliny tells us that the nations of the East, even the Parthians, whose wealth was abundant, use them as food. ${ }^{6}$ The imago of the Cicada septendecim, is still eaten by the Indians in America, who pluck off the wings and boil them ${ }^{7}$; and the ahorigines of New South Wales, as we learn from Mr. Bennett, formerly used various species of the Cicadida as food, stripping off the wings and eating them raw. They are aware that the sounds made by these insects which they call galang-galcng, are peculiar to the males, and depend upon their drums, observing to Mr. Bennett, in their peculiar English, "Old woman galang-galang no got, no make a noise." 8

This ancient Greek taste for Cicadce seems now much gone out of fashion ; but perhaps if it were revived in those conntries where the insects are to be found, for they inhabit only warm clinates ${ }^{9}$, it would be ascertained that so polished a people did not relish them without reason.

No insects are more numerous in this island than the caterpillars of Lepidoptern: if these could be used in aid of the stock of food in times of scarcity, it might subserve the double purpose of ridlding us of a nuisance, and relieving the public pressure. Reaumur suggests this mode of diminishing the numbers of destructive caterpillars, speaking of that of Plasia Gamma, a moth which did" such infuite mischief in France in the year

1 Jackson's Travels in Marocco, 53. The Rev. R. Sheppard caused some of our large English grasshoppers (Acrida viridissina) to be cooked in the way here recommended, only substituting butter for vinegar, and found them excellent.

2 Travels, 230.

4 Arist. Ilist. An. 1. v, c. 30.

5 Vide Bochart, Hieroz. ii. 1. 4. c. 7., 491.

6 Itist. Nut. 1. xi. c. 26.

7 T. Collinson in Phil. Trans. 1763, n. x.

8 Bennett's Wanderings in New South Wules, i. 237., quoted in Eutom. Mug. iii. 211.

9 One species, howerer, has been found in Hamphire in the New Forest. Ste Samonelle's Entomologist's Useful Compendium, t. 5. t. 2. 
1735. If, however, we were to take to eating caterpillars, I should for my own part be of the nind of the red-breasts, and eat only the naked ones. ${ }^{2}$ But you will see that there is some encouragement from precedent to make a meal of the caterpillars which infest onr cabbages and cauliflowers. Amongst the delicacies of a Boshies-man's table, Sparrman reckons those caterpillars from which butterflies proceed. ${ }^{3}$ The Chinese, who waste nothing, after they have unwound the silk from the cocoons of the silkworm, send the chrysalis to table : they also eat the larva of a haw $\mathrm{k}$-moth $(S p)$ hin $\left.x^{4}\right)$, some of which tribe, Dr. Darwin tells us, are, in his opinion, very delicious ${ }^{5}$ : and lastly, the natives of New Holland eat the caterpilars of a species of moth of a singular new genus, to which my friend, Alexander MacLeay, Esq. has assigned characters, and from the circumstance of its larva coning out only in the night to feed, has called it Nycterobizs. A species of butterfly also (Euplaea hamala MacLeay), as we learn from Mr. Bennett, congregates on the insulated granitic rocks in a particular district, which he visited in the months of November, December, and January, in such countless myriads (with what object is unknown), that the native blacks, who call them Bugong, assemble from far and near to collect them, and, after removing the wings and down by stirring them on the ground previously heated by a large fire, and wimnowing them, eat the hodies, or store them up for use by pounding and smoking them. The bodies of these butterflies abound in an oil with the taste of nuts; and when first eaten, produce violent vomitings, and other debilitating effects : but these go off after a few days, and the natives then thrive and fatten exceedingly on this diet, for which they have to contend with a black crow, which is also attracted by the Bugongs in great numbers, and which they despatch with their clubs, and use as food ${ }^{6}$

The next order, the Neuroptera, contains the white ant tribe (Termes), which, in return for the mischief it does at certain times, affords an abundant supply of food to some of the African nations. The Hottentots eat them boiled and raw, and soon get into good condition upon this food.? König, quoted by Smeathman, says that in some parts of the East Indies the natives make two holes in the nests of the white ants, one to the windward and the other to the leeward, placing at the latter opening a pot rubbed with an aromatic herb, to receive the insects driven out of their nest by a fire of stinking materials made at the former. ${ }^{8}$ Thus they catch great quantities, of which they make with flour a variety of pastry, that they can afford to sell cheap to the poorer people. Mr. Smeathman says he has not found the Africans so ingenious in procuring or dressing them. They are content with a very small part of those that fall into the waters at the time of swarming, which they skim off with calabaches, bring large kettles full of them to their habitations, and parch them in iron pots over a gentle fire, stirring them about as is done in roasting coffee. In that state, without sance or other addition, they serve them up as delicious food, and

1 Reaum. ii, 341.

4 Sir G. Staunton's Voy. jii. 246 .

6 Bennett's Wanderings, ubi suprà, i. $265-270$.

7 Sparrman, i. 363.

8 Captain Green relates that, in the eeded districts in India, they place the branches of trees over the nests, and then by means of smoke drive out the insects; which, attempting to fly, their wings are broken off by the mere touch of the branches. 
eat them by handful's as we do comfits. He has eaten them dressed this way several times, and thought them delicate, nourishing, and whol i some, being sweeter than the grub of the weevil of the palns (Cordyl. Palmarum), and resembling in taste sugared cream or sweet almond paste. The female ant, in particular, is supposed by the Hindoos to be endowed with highly nutritive properties, and, we are told by Mr. Bronghton, was carefully songht after and preserved for the use of the debilitated Surjee Rao, prime-minister of Scindia, chief of the Mahrattas. ${ }^{2}$

The Hymenopterc order also furnishes a few articles to add to this head. I do not allude to the nectar which the bees collect for us. But perhaps you do not suspect that bees themselves in some places serve for food, yet Knox tells us that they are eaten in Ceylon ${ }^{3}$ : - an ungrateful return for their honey and wax, which I would on no account recommend. Piso speaks of yellow ants called Capiá inhabiting Brazil, the abdomen of which noany used for food, as well as a laryer species under the name of Tamaw jour ${ }^{4}$; which account is confirmed by Humboldt, who informs us that ants are eaten by the Marivatanos and Margueritares, nixed with resin for sauce; as are those of Yariba in Africa, as Lander informs us, stewed in butter. Ants, I speak from experience, have no unpleasant flavour ; they are very agreeably acid, and the taste of the trunk and abdomen is different ; so that I am not so much surprised, as Mr. Consett seems to have been, at the avidity with which the young Swede mentioned by him sat down to the siege of an ant's nest. ${ }^{5}$ 'This author states, that in some parts of Sweden ants are distilled along with rye, to give a flavour to the inferior kinds of brandy. ${ }^{6}$ Under this head may not improperly be mentioned several galls, the product of different species of gall-flics ( $\dot{C}_{y m i p s}$ ), particularly those found on some kinds of Sage, viz. Salvia pomifera, S. triloba, and S. offeinalis, which are very juicy like apples, and crowned with rudiments of leaves resembling the calyx of that fruit. They are esteemed in the Levant for their aromatic and acil flavour, especially when prepared with sugar, and form a considerable article of commerce from Scio to Constantinople, where they are regularly exposed in the market. ${ }^{7}$ The galls of ground-ivy have also been eaten in France; but Reaumur, who tasted them, is doubtful whether they will ever rank with good fruits. ${ }^{8}$

To the IDiptera order, as a source of food, man can scarcely be said to be under any obligation; the larva of Tyrophaga casei, which is so commonly found in cheese, being the only one ever eaten - a dainty as some think it, of whom you will perhaps say with Scopoli, "quibus has delicias non invideo." 9

The order Aptera, now that the Crustacea are excluded, does not much more abound in esculent insects than the Dinterd. The only species which have tempted the appetite of man in this order are the cheese-mite (Acarus Siro)-lice, which are eaten by the Hottentots and natives of the western coast of Africa, who, from their love of this game, which they not only collect themselves from their well-stored capital pasture, but employ

1 Smeathman, 31.

2 Letters written in a Maluratta Camp in 1809.

3 Knox's Ceylon, 25.

4 1'iso, Ind. I. v. c. $18,291$.

5 Trarels in Surecien, 118.

6 Ibid.

7 Smith's Introd to Bot. 346. Olivier's Trarels, i, 139.

8 Peaum. iii. 410.

9 Scop. Curniol. 337. 
1 ir wives in the chase, have been sometimes called Phthirophagi. 1. jects of the class Arachnida, which you will think still more repulsive an the last tribe, form an article in Sparrman's list of the Boshies-man's ainties ${ }^{2}$; and Labillardière tells us that the inhabitants of New Caledonia seek for and eat with avidity large quantities of a spider nearly an inch long (which he calls Aranea edulis), and which they roast over the fire ${ }^{3}$ Even individuals amongst the more polished nations of Europe are recorded as having a similar taste; so that, if you could rise above vulgar prejudices, you would in all probability find them a most delicious morsel. If you require precedents, Reaumur tells us of a young lady who when she walked in her grounds never saw a spider that she did not take and crack upon the spot. ${ }^{4}$ Another female, the celebrated Anna Maria Schurman, used to eat them like nuts, which she affirmed they much resembled in taste, excusing her propensity by saying that she was born under the sign Scorpio. ${ }^{5}$ If you wish for the authority of the learned, Lalande the celebrated French astronomer was, as Latreille witnessed ${ }^{6}$, equally fond of these delicacies. And lastly, if not content with taking them serialim, you should feel desirons of cating them by handfuls, you may shelter yourself under the authority of the German immortalised by Rösel 7, who used to spread them upon his bread like butter, observing that he found them very useful, "um sich anszulaxiren." These edible Aplera and Arachnida are all sufficiently disgusting; but we feel our nausea quite turned into horror when we read in Humboldt, that he has seen the Indian children drag out of the earth centipedes eighteen inches long and more than half an inch broad, and devom them. ${ }^{8}$

After all I have said, you may perhaps still feel a prejudice against insects as food; but I think, when you recollect that Oberon and his queen Titania, that renowned personage Robin Goodfellow, "with all the fairy elves that be," number insects amongst their choicest cates, you will no longer be heretical in this articlc, bnt yield with a good grace; and as a reward I will copy out for you a beautiful poetical description of Oberon's feast, which was pointed out to me by a learned bibliographical friend, John Crosse, Esq. of Hull, in Herrick's Hesperides, 1658.

\footnotetext{
"Shapcot, to thee the fairy state

I with discretion dedicate;

Because thou prizest things that are

Curious and unfamiliar.

Take first the feast; these dishes gone,

We'll see the fairy court anoll.

A little mushroom table spread;

After short prayers, they set on bread,

A moon-parch'd grain of purest wheat,

With some small glitt'ring grit to eat

His choicest bits with; then in a trice

They make a feast less great than nice.

But all this while his eye is served,

We must not think his ear was starved;

But that there was in place to stir

His spleen, the chirring grasshopper,
}

1 Latr. Hist. Nat. viii. 93

3 Toyage à la Recherche de la Pérouse, ii. 240.

5 Shaw, Nat. Misc.

7 Rösel, iv. $25 \%$.
2 Sparrman. i. 201.

4 Reaum. ii. 342.

6 Hist. Nat. vii. 227.

8 Personal Travels, ii. 205. 
The merr cricket, puling fir,

The piping gnat for minstrelsy:

And now we must imagine first

The elves present, to quench his thirst,

A pure seed pearl of infant lew,

Brought and besweeten'd in a blue

And pregnant violet; which done,

His kitling eres begin to run

Quite througli the table, where he spies

The horns of papery buttertlies,

Of whicl he eats, and tastes a little

Of what we call the cuckoo's spittle;

A little furze-ball pudding stauds

By, yet not blessed by his hands,

That was too coarse; but then forthwith

He ventures boldly on the pith

Of sugar'd rush, and eats the sag

And well be-strutted bee's sweet bag;

Gladding his palate with some store

Of emmet's eggs: what would he more?

But beards of mice, a newt's stew'd thigh,

A bloated earwig and a fly:

With the red capp'd worm that's shut

Within the concave of a nut,

Brown as his tootls; a little moth

Late fatten'd in a piece of cloth,

With witler'd cherries, mandrakes' ears,

MIoles' eyes; to these the slain stag's tears;

The unctuous dewlaps of a snail;

The broke lieart of a nightingale

O'ercoule in music;

"—This done, conmended

Grace by his priest, the feast is ended," -

Having considered insects as adding to the general stock of food, I shall next request your attention while I detail to you how far the medical science is indebted to them. Had I addlessed you a century ago, I could have made this an ample history. Amongst scores of infallible panaceas, I should have recommended the wood-louse as a solvent and aperient; powder of silk-worm for vertigo and convulsions ; millepedes against the jaundice; earwigs to strengthen the nerves; powdered scorpion for the stone and gravel; fly-water for clisorders in the eyes; and the tick for erysipelas. I should have prescribed five gnats as an excellent purge; wasps as diuretics; lady-lireds for the colic and measles; the cockchafer for the bite of a mad $\log$ and the plague; and ants and their acid I should have loudly praised as incomparable against leprosy and deafness, as strengthening the memory, and giving vigour and animation to the whole bodily frame. ${ }^{1}$ In short, I could have easily added to the miscrably meagre list of modern pharmacopœias, a catalogue of approved insectremedies for every disèase and evil

\section{"that flesh is heir to!"}

But these good times are long gone by. You would, I fear, laugh at my nrcscriptions notwithstanding the great, authorities I could cite in their

1 For this list of remedies, see Lesser, L. ii. 171-173. 
favour ; and even donbt the efficacy of a morc modern specific for toothache, promulgated by a learned Italian professor ', who assures us that a finger once imbued with the juices of Rhinobatus antiodontalgicus (a name enough to give one the toothache to pronounce it) will retain its power of curing this disease for a twelvemonth! I must content myself, therefore, with expatiating on the virtues of the very few insects to which the sons of Ifippocrates and Galen now deign to have recourse. At the same time I cannot help observing that their proscription of the remainder may have been too indiscriminate. Mankind are apt to run from one extreme to the other. From having ascribed too much efficacy to insectremedies, we may now ascribe too little. Many insects emit very powerful odaurs, and some produce extraordinary effects upon the human frame; and it is an idea not altogether to be rejected, that they may concentrate into a smaller compass the properties and virtues of the plants upon which they feed, and thus afford medicines more powerful in operation than the plaints themselves. It is at least worth while to institute a set of experiments with this view.

Medicine at the present day is indebted to an ant (Formica bispinosa Oliv., fungosa F.) for a kind of lint colfected by that insect from the Bombax or silk cotton-trec, which as a styptic is preferable to the puff-ball, and at Cayenne is successfully used to stop the bloot in the most violent hrmorrhages $^{2}$; and gum aminoniac, according to Mr. Jackson ${ }^{3}$, oozes out of a plant like fennel, from incisions made in the bark by a beetle with a large horn. But, with these exceptions (in which the remedy is rather collected than produced by insects), and that of spiders' webs, which are said to have been recently administered with sticcess in ague, the only insects which directly supply us with medicine are some species of Cantharis and Mylabris. These beetles however amply make up in efficacy for their numerical insignificance; and almost any article could be better spared from the Materia Medica than one of the former usually known under the name of Cantharides, which is not only of incalculable inportance as a vesicatory, but is now administered internally in many cases with very good effect. In Europe, the insect chiefly used with this view is the Cantharis vesicatoria ${ }^{4}$; but in America the C. cincrea and vittata (which are extremely common and noxions insects, while the $C$. vesicatoria is sold there at sixteen dollurs the pound) have been substituted with great success, and are said to vesicate more speedily, and with less pain, at the same time that they canse no strangury ${ }^{5}$ : and in China they have long employed the Mylabris cichorei, which seenus to have been considered the most powerful vesicatory amongst the ancients, who however appear to have been acquainted with the common Cantharis vesicatoria also, and to have made use of it, as well as of C'ctonia aurata and some other insects mentioned by

1 Gerbi. Storia Naturali d'un Nuov. Inset. 1794. The same virtues have been ascriberl to Coccinella septempunctatr, L.

2 Latr. Hist. Nut. des Fourmis, 48. 134.

3 Jackson's Murocco, 83 . Some doubt, however, attaches to this statement, from the circumstance of the figure which Mr. Jackson gives of lis beetle (Dibben Fashonk) being clearly a mere copy of that of Mr. lince's Z $\mathrm{imb}$.

4 This incect, generally so rare in England, appeared in the summer of 1837 in great numbers in Essex, Suffolk and the Isle of Wight. (Ent. Riag. v.208. 516.)

5 Illiger, Mag. i. 256. 
Pliny. ${ }^{1}$ Another species of Mylabris has been described by MajorGeneral Hardwicke in the Asiatic Transactions ${ }^{2}$, plentiful in all parts of Bengal, Bahar, and Oude, which is fully as efficacious as the common Spanish fly; and in other parts of India Cantharis gigas and violacea are employed, as is $C$. ruficeps in Sumatra and Java ; C. atomaria in Brazil; C. Syriaca in Arabia ; and in some parts of Europe Lydus (Mylabris Fab.) trimaculatus. ${ }^{3}$

But it is as supplying products valuable in the arts and manufactures that we are chiefly indebted to insects. In adverting to them in this view, I shall not dwell upon the articles derived from a few species in particular districts, and confined to these alone, such as the soap which in some parts of Africa is manufactured from a beetle (Chlconius saponarius ${ }^{4}$ ); the oil which, Molina tells us, is obtained in Chili from large globular cellules found upon the wild rosemary, and supposed to be produced by a kind of gall-fly ${ }^{5}$; and the manure for which Scopoli informs us the hosts of Ephemera that annnally emerge in the month of June from the Laz, a river in Carniola, are employed by the husbandmen, who think they have had a bad harvest unless every one has collected at least twenty loads. ${ }^{6}$

Still less is it my intention to detain you in considering the purpose to which in the West Indies and South America the fire-flies are put by the natives, who employ them as lanterns in their journeys, and lamps in their houses ${ }^{7}$; - or the use as ormaments to which some insects are ingeniously applied by the ladies, who in China embroider their dresses with the elytra and crust of a brilliant species of beetle (Bupresiis viltata); in Chili and the Brazils form splendid necklaces of the golden Chrysomclida and brilliant diamond beetles, \&c. ${ }^{8}$; in some parts of the Continent string together for the same purpose the burnished violet-colonred thighs of Geotrupes stercorarins, \&c. ${ }^{9}$; and in India, as I am informed by Major Moor and Captain Green, even have recourse to fire-flies, which they inclose in gauze, and use as ornaments for their hair when they take their evening walks. I shall confine my details to the more important and

1 Hist. Nat. 1. xix. c. 4.

2 Vol. v. 213

3 Westwood's Mod. Class. of Ins. i. 297. See also Burmeister's Manual of Ent. p. 562., who says that the species used by the ancients appears to have been Mylaliris Füeslini Panz., which is very abunclant in the south of Europe, and is sometimes found in Germany. The active blistering principle in all these insects has been detected by M. Robiquet, and named by him Cantharidine, which has been ascertained by $\mathbf{M}$. Bretonneau, and especially by MI. Leclerc, who has examined a great number of insects with this view, to be found amongst coleopterous insects of the family of Cantharide only, though not in all the species of this fumily, nor even in all the species of the same genus. M. Leclerc, who conceives that Cantharidine is secreted by a peculiar apparatus, states that it is not destroyed either by the action of the air or of time; and as it must exist in a spider of the United States (Tegenaria medicinalis Hentz.; Journ. Acad. Nat. Sci. of Pliladelphia, 1821, p. 53. pl.5.), which is there extensively employed as a vesicatory, he examined if this principle is to be found in the Tegenaric of France or in other spiders, but without success. (Leclerc, Essai sur les Epipastiques, Paris, 1835, quoted in Guérin, Bulletin Zoologique, i. 95 )

4 Carabus Oivv., Entom. iii. 69. t. iii. f. 26. Compare Philanthropist, ii. 210.

5 Molina's Chili, i. 174.

8 Ent. Carniol. 264.

7 Captain Green was accustomed to put a fire-fly under the glass of his watch, when he had occasion to rise very early for a march, which enabled him without difficulty to distingnish the hour.

8 Molina, i. 171.285.

9 Latr. Hist. Nut. x. 113. 
general products which they supply to the arts, beginning with one indispensable to our present correspondence, and adverting in succession to the insects affording dyes, lae, wax, honey, and silk.

No present that insects have made to the arts is equal in utility and universal interest, comes more home to our best affections, or is the instrument of producing more valuable finits of human wisdom and genius, than the product of the animal to which I have just alluded. You will readily conjecture I mean the fly that gives birth to the gall-mut, from which ink is made. How infinitely are we indebted to this little creature, which at once enables is to converse with our absent friends and connections, be their distance from us ever so great, and supplies the neans by which, to use the poet's language, we can

\section{A local habitation and a name!"}

enabling the poet, the philosopher, the politician, the moralist, and the divine, to embody their thoughts for the anusement, instruction, direction, and reformation of mankind. 'The insect which produces the gall-nut is of the genus Cynips of Linné, but was not known to him or to Fabricius. Oliver first described it under the name of Diplolepis galle tinctorice. ${ }^{1}$ The galls originate on the leaves of a species of oak (Quercus infectoria) very common throughout Asia Minor, in many parts of which they are collected by the poorer inhabitants, and exported from Smyrna, Aleppo, and other ports in the Levant, as well as from the East Indies, whither a part of those collected are now carried. The galls most esteemed are those known in commerce under the name of blue galls, being the produce of the first gathering before the fly has issued from the gall. It will not be uninteresting to you to know, that from these when bruised may occasionally be obtained perfect specimens of the insect, one of which I lately procured in this way. The galls which have escaped the first searches, and from most of which the fly has energed, are called white galls, and are of a very inferior quality, containing less of the astringent principle than the blue galls in the proportion of two to three. ${ }^{2}$ The white and blue galls are usually imported mixed in about equal proportions, and are then called "galls in sorts." If no substitute equal to galls as a constituent part of ink has been discovered, the same may be said of these productions as one of the most important of our dyeing naterials constantly employed in lyeing black. It is true that this colour may be communicated without galls, but not at once so cheaply and effectually, as is found by their continued large consumption, notivithstanding all the improvements in the art of dyeing.

Other dyeing drugs are afforded by insects, the principal of which are Chermes, the Scarlet Grain of Poland, Cochineal, Lac-lake, and Lac-dye, all of which are furnished by different species of Coccus.

The first of these, the Coccus Ilicis, found abundantly upon a small species of evergreen oak (Quercus coccifera), common in the south of France, and many other parts of the world, has been employed to impart a blood red or crimson dye to cloth from the earliest ages, and was known

1 Encyclop. Insect vi. 281. It had better, perhaps, as compound trivial names aro bad, be called Cynips Scriptorum.

2 Olivier's Travels in Ligypt, \&c. ii. 64. 
to the Phœnicians before the time of Moses under the name of Tola or Thola (y) ת ), to the Greeks under that of Coccus (Kоккоs), and to the Arabians and Persians under that of Kermes or Alkermes; whence, as Beckmann has shown, and from the epithet vermiculatum given to it in the middle ages, when it was ascertained to be the produce of a worm, have sprung the Latin coccincus, the French cramoisi and vermeil, and our crimson and vermilion. It was most probably with this substance that the curtains of the tabernacle (Exod. xxvi. \&c.) were dyed dcep red (which the word scarlet, as our translator's have rendered "gw nus, then implied, not the colour now so called, which was not knoivn in James the First's reign when the Bible was translated), - it was with this that the Grccians and Romans produced their crimson; and from the same source were derived the imperishable reds of the Brussels and other Flemish tapestries. In short, previons to the discovery of cochineal, this was the material universally used for dyeing the most brilliant red then known ; and though that production of the New World has, in some respects undeservedly ${ }^{1}$, supplanted it in Europe, where it is little attended to except by the peasantry of the provines in which it is found, it still continues to be $\mathrm{cm}$. ployed in a great part of India and Persia. ${ }^{2}$

The scarlet grain of Poland (Coccus polonicus) is found on the roots of the perennial knawel (Sclcrantluts peremnis, a scarce plant in this country, but abundant in the neighbourhood of Elvedon in Suftolk), and was at one time collected in large quantities for dyeing red in the Ukraine, Lithuania, Sc. But though still employed by the Turks and Armenians for dyeing wool, silk, and, hair, as well as for staining the nails of women's fingers, it is now rarely used in Europe except by the Polish peasantry. A similar neglect has attended the Coccus found on the roots of Potcrium Sanguisorba ${ }^{3}$, which was nsed by the Moors for dyeing silk and wool a rose colour; and the Coccus Uva-uersi, which with alum affords a crimson dye. ${ }^{4}$

Cochineal, the Coccus cacti, is doubtless the most valuable product for which the dyer is indebted to insects, and, with the exception perhaps of indigo, the most important of dyeing materials. Though the Spaniards found it employed by the natives of Mexico, where alone it is cultivated, on their arrival in that country in 1518, its true nature was not accurately ascertained for nearly two centuries afterwaris. Acosta, indeed, as early as 1530, and Herrara and Hernandez subsequently, had stated it to be an insect: but, led apparently by its external appearance, notwithstanding the conjectulles of Lister and assertions of Perc Plumier to the contrary, it was believed by Europeans in general to be the sced of a plant, until Hitrtsoeker in 169t, Leeuwenhoek and De la Hire in 170t, and Geofiroy',

I The colour communicated by Kermes, with alum, the only mordant formerly employed, is blood red; but Dr. Isancroft found (i. 404.) that with the solution of tin used with cochincal it is capable of imparting a scarlet quite as brilliant as that dye, and perhaps more permanent. At the same time, however, as ten or twelve pounds contain only as much colouring matter as one of cochineal, the latter at its ordinary price is the cheapest.

2 Bochart, Herozoic. ii. l.iv. c. 27. Beckmann's History of Inventions, Engl. Trans. ii. 171-205. Bancroft on Permanent Colours, i. 393. See also Parkhurst's Heb. Lexicon under $y$ ? $\pi$ and 9 \%

3 Liai. Hist. Plant. i 401.

4 Bancroft, i. 401 
ten years later, by dissections and microscopical observations, incontrovertibly proved its real origin. ${ }^{1}$

This insect, which comes to us in the form of a reddish shrivelled grain covered with a white powder or bloom, feeds on a particular kind of Indian fig, called in Mexico, where alone cochineal is produced in any quantity, Nopal, which has always been supposed to be the Cactus cochinilifer, but according to Humboldt is unquestionably a distinct species, which bears fruit internally white.

Cochineal is chiefly cultivated in the Intendency of Oaxaca ; and some plantations contain 50,000 or 60,000 nopals in lines, each being kept about four feet high for more easy access in collecting the dye. The cultivators prefer the nuost prickly varieties of the plant, as affording protection to the cochineal from insects; to prevent which from depositing their eggs in the flower or fruit, both are carefully cut off. The greatest quantity, however, of cochineal employed in commerce, is produced in small nopaleries belonging to Indians of extreme poverty, called Nopaleros. They plant their nopaleries in cleared ground on the slopes of mountains or ravines two or three leagues distant from their villages; and when properly cleaned, the plants are in a condition to maintain the cochineal in the third year. As a stock, the proprietor in April or May purchases branches or joints of the Tuna de Castilla, laden with small cochineal insects recently hatched (Semilla). These branches which may be bought in the market of Oaxaca for about three francs $(2 s .6 d$.) the hundred, are kept for twenty days in the interior of their huts, and then exposed to the open air under a shed, where, from their succulency, they continue to live for several months. In August and September the mother cochineal insects, now big with young, are placed in nests made of a speeies of Tillandsia called Paxtle, which are distributed upon the nopals. In about four months, the first gathering, yielding twelve for one, may be made, which in the course of the year is succeeded by two more profitable harvests. This period of sowing and harvest refers chiefly to the districts of Sola and Zimatlan. In colder climates the semilla is not placed upon the nopals until October or even December, when it is necessary to shelter the young insects by covering the nopals with rush mats, and the harvests are proportionably later and unproductive. In the immediate vicinity of the town of Oaxaca the Nopaleros feed their cochineal insects in the plains from October to April, and at the beginning of the remaining months, during which it rains in the plains, transport them to their plantations of nopals in the neighbouring mountains, where the weather is more favourable.

Much eare is necessary in the tedious operation of gathering the cochineal from the nopals, which is performed with a squirrel or stag's tail by the Indian women, who for this purpose squat down for hours together beside one plant; and notwithstanding the high price of the cochineal, it is to be doubted if the cultivation would be profitable were the value of labour more considerable.

The cochineal insects are killed either by throwing them into boiling water, by exposing them in heaps to the sun, or by placing them in the ovens (Temazealli) used for vapour baths. The last of these methods, which is least in use, preserves the whitish powder on the body of the

1 Bancroft, i. 413 . Reaum. iv. 88. 
cochineal, which, being thus less subject to the adulterations so often practised by the Indians, bears a higher price both in America and Europe. ${ }^{1}$

The quantity annually exported from South America was said by Humboldt to be at the time he wrote 32,000 arrobas, there worth $500,040 l$. sterling ${ }^{2}$; - a vast amount to arise from so small an insect, and well calculated to show us the absurdity of despising any animals on account of their minuteness. So important was the acquisition of this insect r'egarded, that the Court of Directors of the East India Company formerly offered a reward of $6000 \%$. to any one who should introduce it into India, where hitherto the Company had only succeeded in procuring from Brazil the wild kind producing the sylvestre cochineal, which is of very inferior value. The true cochineal insect and the Cactus on which it feeds are said to have been of late years successfully introduced into Spain and the new French colony of Algiers, and now exist both in the stores of the Jardin des Plantes at Paris, and in those of King Leopold at Claremont. ${ }^{3}$

Lac is the produce of an insect formerly supposed to be a kind of ant or bee ${ }^{4}$, but now ascertained to be a species of Coccus; and it is collected from various trees in India, where it is found so abundantly, that, were the consumption ten times greater than it is, it could be realily supplied. This substance is made use of in that country in the manufacture of beads, rings, and other female ornaments. Mixed with sand; it forms grindstones; and added to lamp or ivory black, being first dissolved in water with the addition of a little borax, it composes an ink not easily acted upon when dry by damp or water. In this country, where it is distinguished by the names stick-lac, when in its native state, unseparated from the twigs to which it adheres; seed-lac, when separated, pounded, and the greater part of the colouring matter extracted by water; lump-lac, when melted and made into cakes; and shell-lac, when strained and formed into transparent laminæ; it hus hitherto been chiefly employed in the composition of varnishes, japanned ware, and sealing-wax : butt for several years past it has been applied to a still more important purpose, originally snggested by Dr. Roxburgh - that of a substitute for cochineal in dyeing scarlet. The first preparations from it with this view were made in consequence of a hint from Dr. Bancroft, and large quantities of a substance termed lac-lake, consisting of the colouring matter of stick-lac precipitated from an alkaline lixivium by alum, were manufactured at Calcutta and sent to this country, where at first the consumption was so considerable, that in the three years previous to $1810, \mathrm{Dr}$. Bancroft states that the sales of it at the India House equalted in point of colouring matter half a million of pounds weight of cochineal. More recently, however, a new preparation of tac colour, under the name of lac-dyc, has been inported from India, which has been substituted for the lac-lake, and with such advantage, that the East India Company are said to have saved in a few months $14,000 \%$. in the purchase of scarlet cluths dyed with this colour

1 Humboldt's Political Essay on New Spain, iii. 72-79.

2 Ibid. iii. 64. - Dr. Bancroft estimated the annual consumption of cochineal in Great Britain at about 750 bags, or $150,000 \mathrm{lbs}$; worth $375,000 \%$.
3 Trans. Ent. Soc. Lond. jij. proc. ix.
4 Lesser, L. ii. 165. 
and cochineal conjointly, and without any inferiority in the colour obtained. ${ }^{1}$

Some other insects besides the Cocci afford dyes. Reaumur tells us, that in the Levant, Persia, and China, they use the galls of a particular species of Aphis for dyeing silk crimson, which he thinks might lead us to try experiments with those of our own country. ${ }^{2}$ That dyes might be thus obtained seems probable from an observation of Linnés, in his Lapland Tour, upon the galls produced by Aphis pini on the extremities of the lcaves of the spruce-fir, which, he informs us, when arrived at maturity, burst asunder, and discharge an orange-coloured powder which stains the clothes ${ }^{3}$; and Mr. Sheppard confirms this observation, the galls of this Aphis abounding upon fir trees in his garden. In fact, we are told that Terminalia citrina, a tree common in India, yields a species of gall, the product of an insect, which is sold in every niarket, being one of the most useful dyeing drugs known to the natives, who dye their best and most durable yellow with it. ${ }^{4}$ A species of mite (Trombidium tinctorium), a native of Guinea and Surinam, is also employed as a dye; and it would be worth while to try whether our $T$. holosericeum, so remarkable for the dazzling brilliancy of its crimson and the beautiful velvet texture of its down, which seems nearly related to $T$. tinctorinm, would not also afford a valnable tincture. It is not likely, perhaps, that many better and cheaper dyes than we now possess can be obtained from insects; but Rcaumur has suggested that water-colours of beautiful tints, not otherwise easily obtainable, might be procured from the excrements of the larva of the common clothes-moth, which retain the colour of the wool they have eaten unimpared in its lustre, and mix very well with water. To get a fine red, yellow, blue, green, or any other colour or shade of colour, we should merely have to feed our larva with cloth of that tint. ${ }^{5}$

Wax, so valuable for many minor purposes, and deemed with us so indispensable to the comfort of the great, is of still more importance in those parts of Europe and America in which it forms a considerable branch of trade and manufacture, as an article of extensive use in the religious ceremonies of the inhabitants. Humboldt informs us, that not fewer than 25,000 arrobas, value upwards of $83,000 \%$, were formerly annually exported from Cuba to New Spain, where the quantity consumed in the festivals of the Church is immense, even in the smallest villages; and that the total export of the same island in 1803 was not less than 42,670 arrobas, worth upwards of $130,000 l^{6}$ Nearly the whole of the wax employed in Europe, and by far the greater part of that consumed in America, is the produce of the common hive-bee; but in the latter quarter of the globe a quantity by no means trifling is obtained from various wild spccies. According to Don F. de Azara, the inhabitants of Santiago del Estero gather every year not less than 14,000 pounds of a whitish wax from the trees of Chaco.?

In China wax is also produced by another insect, which from the description of it by the Abbe Grosier seems to be a species of Coccus.

1 Bancroft on Permanent Colours, ii. 20. 49.

2 Reaum. iii. Prefuce, xxxi.

3 Lach. Lapp. i. 258.

5 Reaum. iii. 95.

6 I'ulitical Essay, iii. 62.

4 Trans. of the Soc. of Arts, xxiii. 411.

7 Voyage dans l'Amer. Mérid. i. 162. 
With this insect the Chinese stock the two kinds of tree (Kan-la-chu and Choni-l(t-chu), on which alone it is found, and which always afterwards Jetain it. Towards the bcginning of winter sinall tumours are perceived, which increase until as big as a walnut. These are the nests (abdomens of the females) filled with the eggs that are to give birth to the Cocci, which, when hatched, disperse themselves over the leaves, and perforate the bark under which they retire. The wax (called Pe-la, white wax, because so by nature) begins to appear about the middle of June. At first a few filaments like fine soft wool are perceived, rising from the bark round the body of the insect, and these increase more and more until the gathoring, which takes place before the first hoar frosts in September. The wax is carried to court, and reserved for the emperor, the princes, and chief mandarins. If an ounce of it be adkled to a pound of oil, it forms a wax little inferior to that made by bees. The physicians employ it in several diseases; and the Chinese, when about to speak in public, and assurance is necessary, previously eat an ounce of it to prevent swoonings ${ }^{1}$; a use of it for which happily our less cliffident orators bave no call. This account is in the main confirmed by Geomelli Careri, except that he calls the wax insect a worm which bores to the pith of certain trees; and says that it produces a sufficient supply for the whole empire, the different provinces of which are furnished from Xantung, where it is bred in the greatest perfection, with a stock of eggs. ${ }^{2}$ A very different origin, however, is assigned to the Pe-la by Sir George Staunton, who informs us that it is produced by a species of Cicada (Flata limbata), which in its larva state feeds upon a plant like the privet, strewing upon the stem a powder, which when collected forms the wax. ${ }^{3}$ But as he merely states that this powder was "supposed" to form it, and does not himself appear to have nade the experiment of dissolving it in oil, it is most probable that his information was incorrect, and that Grosier's statement is the true one.

This probability is nearly converted into certainty by the fact that many Aphides and Cocci secrete a wax-like substance, and that a kind of wax very analogous to the Pe-la, and of the same class with bees' wax, only containing more carbon, is actually produced in India by a nondescript species of Coccus remarkable for providing itself with a small quantity of honey like our bees. This substance, for specimens of which $I$ an indebted to the kindness of Sir Joseph Banks, was first noticed by Dr. Anderson, and called by him whitc-lac. It could be obtained in any quantity from the neighbourhood of Madras, and at a much cheaper rate than bees'wax : but the experiments of Dr. Pearson do not afford much ground for supposing that it can be advantageously employed in making candles. ${ }^{4}$ De Azara speaks of a firm white wax apparently similar, and the produce of an insect of the same tribe, which is collected in South America in the form of pearl-like globules from the small branches of the Quabirâmy, a small shrub two or three fect high. ${ }^{5}$

Insects in some countries not only furnish the natives with wax, but with resin, which is used instead of tar for their ships. Molina informs us that, at Coquimbo in Chili, resin, either the product of an insect or the

1 Grosier's China, i. 439.

2 Quoted in Southey's Thalaba, ii. 166.

4 Phil. Trans. 1794. xxi. 
consequence of an insect's biting off the buds of a particular species of Origanum, is collected in large quantities. The insect in question is a small smooth red caterpillar about half an inch long, which changes into a yellowish moth with black stripes upon the wings (Phal. ceraria Molina). Early in the spring vast numbers of these caterpillars collect on the branches of the chila, where they form their cells of a kind of soft white wax or resin, in which they undergo their transformations. This wax, which is at first very white, but by degrees becomes yellow and finally brown, is collected in autumn by the inhabitants, who boil it in water, and make it up into little cakes for market. ${ }^{+}$

Honey, another well-known product of insects, has lost much of its importance since the discovery of sugar; yet at the present day, whether considered as a delicious article of food, or the base of a wholesome vinous beverage of home manuficture, it is of no mean value even in this country ; and in many inland parts of Europe, where its saccharine substitute is much dearer than with us, few articles of rumal economy, not of primary importance, would be dispensed with more reluctantly. In the Ukraine some of the peasants have 400 or 500 bee-hives, and make more profit of their bees than of $\operatorname{corn}^{2}$; and in Spain the number of bee-hives is said to be incredible; a single parish priest was known to possess $5000 .^{3}$

The domesticated or hive-bee, to which we are indebted for this article, is the same, according to Latreille in every part of Europe, except in some districts of Italy, where a different species (Apis liguslica of spinola) is kept - the same probably that is cultivated in the Norea and the istes of the Archipelago. ${ }^{4}$ Honey is obtained, however, from many other species both wild and domestic. What is called rock honey in some parts of America, which is as clear as water and very thin, is the produce of wild bees, which suspend their clusters of thirty or forty waxen cells, resembling a bunch of grapes, to a rock ${ }^{5}$ : and in South Anierica large quantities are collected from the nests built in trees by Trigona Amallhca, and other species of this genus recently separated from Apis ${ }^{6}$; under which probably should be included the Bamburos, whose honey, honest Robert Knox informs us, whole towns in Ceylon go into the woods to gather. ${ }^{7}$ According to Azara, one of the chief articles of food of the Indians who live in the woods of Paraguay is wild honey. ${ }^{8}$ Captain Green observes that, in the island of Bourbon, where he was stationed for some time, there is a bee which produces a kind of honey much esteemed there. It is quite of a green colour, of the consistency of oil, and to the usual sweetness of honey superadds a certain fragrance. It is called green honey, and is exported to India, where it bears a high price. ${ }^{9}$ One of the species that has probably been attended to ages before our hive-bee, is Apis fascinla of Latreille, a kind so extensively cultivated in Egypt, that Niebuhr states he fell in upon the Nile, between Cairo and Damietta, with a convoy of 4000

1 Molina's Chili, i. 174.

2 Communications to the Board of Agricult. vii. 286.

3 Mills on Bees, 77.

4 Latr. in Humboldt and Bonpland, Recueil a'Observ. de Zoologie, Sc. (Paris, 1805), 300 .

6 Latr. uli supr. 300 .

7 Knox's Ceylon, 25.

5 IIill in Swammerdam, i. 181. note.

Toy. daus 1 Amer. Merid. 1. 162.

color. Mém. sur les Abeilles, 8.39. 
hives, which were transporting from a region where the season for flowers had passed, to one where the spring was later. ${ }^{1}$ Colnmella says that the Greeks in like manner sent their bee-hives every year from Áchaia into Attica; and a similar custom is not unknown in Italy, and even in this country in the neighbourhood of heaths. In Madagascar, according to Latreille, the inhabitants have domesticated Apis unicolor; A. indica is cultivated in Inclia at Pondicherry and in Bengal; A. Adansonii Latr. at Senegal $^{2}$; and Fabricius thinks that $A$. acraensis (Centris Syst. Piez.) laboriosa, and others in the East and West Indies, might be domesticated with greater advantage than even $A$. mellifica. ${ }^{3}$

Here also must be mentioned the manna used as an agreeable food in the East, which, though not directly produced by insects, is caused to flow from the Tamarix mannifera by the punctures of a small species of Coccus. ${ }^{4}$

The last, and douhtless the most valuable, product of insects to which I have to advert is Sill. To estimate justly the importance of this article, it is not sufficient to view it as an appendage of luxury unrivalled for richness, lustre, and beanty, and without which courts would lose half their splendour; we must consider it, what it actually is, as the staple article of cultivation in many large provinces in the south of Europe, amongst the inhabitants of which the prospect of a deficient crop causes as great alarm as a scanty harvest of grain with us; and after giving employment to tens of thousands in its first production and transportation, as furnishing subsistence to hundreds of thousands more in its final manufacture, and thus hecoming one of the most important wheels that give circulation to national wealth. ${ }^{5}$

But we must not conine our view to Europe. When silk was so scarce in this country, that James I., while King of Scotland, was forced to beg of the Earl of Mar the loan of a pair of silk stockings to appear in before the English ambassador, enforcing his request with the cogent appeal, "For ye would not, sure, that your king should appear as a scrub before strangers ;" nay, long before this period, even prior to the time that silk was valued at its weight of gold at Rome, and the Emperor Aurelian refused his empress a robe of silk because of its dearness - the Chinese peasintry in some of the provinces, millions in number, were clothed with this material; and for some thousand years to the present time, it has been both there and in India (where a class whose occupation was to attend silk-worms appears to have existed from time immemorial, being

1 Latr. Hist. Nat. xir. 20.

2 Latr. in Hinmboldt and Boupland, Recueil, \&c. 302.

3 Torlesungen, 324.

4 Burmeister, Manual of Ent. 561.

5 The following facts and calculations from the Courrier de Lyon, 1810, as to the silk manufactured at Lyons, are worth preserving:- Raw silk anmully consumed there one million of kilogrammes, equal to 2,205,714 pounds English, on which the waste in manufacturing is five per cent. As four cocoons produce one graine (grain) of silk, four thousind milions of cocoons are anually consumed, making the number of caterpillars reared (including the average allowance for caterpillars dying, bad cocoons, and those kept for eg(rs) $4,29: 2,400,000$. The length of the silk of one cocoon averages 500 metres ( 1526 feet English), so that the length of the total quantity of silk spun at Lyons is 6,000,000,000,000 (or six and a half billions) of English feet, equal to fourteen times the mean radius of the earth's orbit ; or 5494 times the radius of the moou's orbit; or 52,505 times the equatorial circumference of the earth ; or 200,000 times the circumference of the moon. 
mentioned in the oldest Sanscrit books ${ }^{1}$ ), one of the chief objects of cultivation and manufacture. You will admit, therefore, that when nature

"- set to work millions of spinning worms,

That in their green shops weave the smooth-hair"d silk

To deck her sons,"2

she was conferring upon them a benefit scarcely inferior to that consequent upon the gift of wool to the fleecy race, or a fibrous rind to the flax or hemp plants; and that mankind is not under much less obligation to Pamphila, who, according to Aristotle, was the discoverer of the art of un winding and weaving silk, than to the inventors of the spinning of those products. ${ }^{3}$

It seems to have been in Asia that silk was first manufactured; and it was from thence that the ancients obtained it, calling it, from the name of the country whence it was supposed to be brought, Sericum. Of its origin they wcre in a great measure ignorant, some supposing it to be the entrails of a spider-like insect with eight legs, which was fed for four years upon a kind of paste, and then with the leaves of the green willow, until it burst with fat ${ }^{4}$; others that it was the produce of a worm which built clay nests, and collected wax ${ }^{5}$; Aristotle, with more truth, that it was unwound fiom the pupa of a large horned caterpillar. ${ }^{6}$ Nor was the mode of producing and manufacturing this precious material known to Europe until long after the Christian era, being first learnt about the year 550, by two monks, who procured in India the eggs of the silk-worm moth, with which, concealing them in hollow canes, they hastened to Constantinople, where they speedily multiplied, and were subsequently introduced into Italy, of which country silk was long a peculiar and staple commodity. It was not cultivated in France until the time of Henry IV., who, considering that mulberries grew in his kingdom as well as in Italy, resolved, in opposition to the opinion of Sully, to attempt introducing it, and fully succeeded.

The whole of the silk produced in Europe, and the greater proportion of that manufactured in China, is obtained from the common silk-worm ; but in India considerable quantities are procured from the cocoons of the larvæ of other moths. Of these the most important species known are the Tussel and Arindy silk-worms, of which an interesting history is given by Dr. Roxburgh in the Linnean Transactions. ${ }^{7}$ These insects are both natives of Bengal. The first (Saturnia Paphia) feeds upon the leaves of the Jujube tree (Rhammus Jujuba), or Byer of the Hindoos, and of the Terminalia alata glabra Roxburgh, the Asseen of the Hindoos, and is found in such abundance as from time immemorial to have afforded a constant supply of a very durable, coarse, dark-coloured silk, which is woven into a cloth called 'Tussehdoot'hies, much worn by the Brahmins and other sects, and would, doubtless, be highly useful to the inhabitants of many parts of America, and of the south of Europe, where a light and cool, and at the

1 Colebrook in Asiatic Researches, v. 61.

2 Milton's Comus.

3 Hist. Animal. l. v. c. 19.

5 Pliny, Ifist. Nat. I. xi. c. 22.

6 Aristot. ubi supr. He does not expressly say the pupa, but this we must suppose. The larva he means could not be the common silkworm, since be describes it as large, and having as it were horns.

7 vii. 33-48. Compare Lord Valentia's Travels, i. 78. 
same time cheap and durable dress, such as this silk furnishes, is much wanted. The durability of this silk is indeed astonishing. After constant use for nine or ten years it does not show any signs of decay. These insects are thought by the natives of so much consequence, that they guard them by day to preserve them from crows and other birds, and by night from the bats. The Arindy silk-worm (Satumia Cynthia Drury), which feeds solely on the leaves of the Palma Christi, produces remarkably soft cocoons, the silk of which is so delicate and flossy, that it is impracticable to wind it off: it is, therefore, spun like cotton; and the thread thus manufactured is woven into a coarse kind of white cloth of a loose texture, hut of still more incredible durability than the last, the life of one person being seldon sufficient to wear out a garment made of it. It is used not only for clothing, but for packing fine cloths, \&c. Some manufacturers in Eniland to whom the silk was shown seemed to think that it could be made here into shawls equal to any received from India. A moth allied to this last species, but distinct, has been described and figured by Colonel Sykes, who met with its leather-like cocoons composed of silk so strong, that a single filament supported a weight of 198 grains, in that part of the Deccan in India lying between the sources and junction of the Béma and Mota Mola rivers. These cocoons are called kolésurra by the Mahrattas, who use them cut into thongs, which are more durable than leather for binding the matchlock barrel to the stock; bit as far as Colonel Sykes could ascertain, no use is made of the silk in Western India, though there can be little doubt that it might be advantageously produced, as the caterpillars which spin it feed indiscriminately on the Teak tree ('Teclone grandis), the Mulberry (Morus indica), the Bor (Zizyphus Jujuba), and the Osana ('Terminalia alata glabra) ${ }^{1}$

Other species, as may be inferred from an extract of a letter given in Young's Annals of Agriculture ${ }^{2}$, are known in China, and have been introduced into India. "We have obtained," says the writer, "a monthly silk-worm from China, which I have reared with my own hands, and in twenty-five days have had the cocoons in my basins, and by the twentyninth or thirty-first day a new progeny feeding in my trays. This makes it a mine to whoever would undertake the cultivation of it."

Whether it will ever be expedient to attenupt the breeding of the larvæ of any European moths, as Catocala pacia, sponsa, \&c. proposed with this view by Fabricius ${ }^{3}$, seems doubtful, though certainly many of them afford a very strong silk, and inight be readily propagated; and I have now in my possession some thread more like cotton than silk spun by the larva of a moth, which when I was a very young cntomologist I observed (if my memory does not deceive me) upon the Euonymus, and from the twigs of which (not the cocoon) I unwound it. It is even asserted that in Germany a manufucture of silk from the cocoons of the emperor moth (Salurnia Pavonia major) was at one time established. ${ }^{4}$ There seems no question, however, that silk might be advantageously derived from many native silk-worms in America. An account is given in the Philosophical Transactions of one found there, whose cocoon is not only heavier and more productive of silk than that of the common kind, but is so much

1 Trans. Royal Asiat. Soc. 1834, vol. iii.

3 Vorlesungen, 325.
2 xxiii. 235.

4 Latr. Hist. Nat. xiv. 150. 
stronger that trenty threads will carry an ounce more. ${ }^{1}$ Don Luis Neé observed on Psadium pomiferum and pyriferum ovate nests of caterpillars eight inches long, of grey silk, which the inhabitants of Chilpancingo, Tixtala, \&c., in America, manufacture into stockings and handkerchiefs. ${ }^{2}$ Great numbers of similar nests of a dense tissue, resembling. Chinese paper, of a brilliant whiteness, and formed of distinct and separable layers, the interior being the thinnest and extraordinarily transparent, were observed by Humboldt in the provinces of Mechoacan and the mountains of Santarosa, at a height of 10,500 fect above the level of the sea, upon the Arbutus Madrono, and other trees. The silk of these nests, which are the work of the social caterpillar's of a Bombyx (B. MIadrono), was an object of commerce even in the time of Montezuma ; and the ancient Mexicans pasted together the interior layers, which may be written upon without preparation, to form a white glossy pasteboard. Handkerchiefs are still manufactured of it in the Intendency of Oaxaca. ${ }^{3}$ De Azara states that in Paraguay, a spider, which is found to near the thirtieth degree of latitude, forms a spherical cocoon (for its eggs) an inch in diameter, of a yellow silk, which the inhabitants spin on account of the permanency of the colour. ${ }^{4}$ And according to M. B. de Lozières, large quantities of a very beautiful silk, of dazzling whiteness, may be collected fiom the cocoons even of the Ichnemnons that destroy the larvæ of some moth in the West Indies, which feed upon the indigo and cassada. ${ }^{5}$

It is probable, too, that otlier articles besides silk might be obtained from the larvæ which usually produce it, particularly cements and varnishes of different kinds, some hard, others elastic, from their gum and silk reservoirs, from which it is said the Chinese procure a fine varnish, and fabricate what is called by anglers Indian grass. ${ }^{6}$ The diminutive size of the animal will be thought no objection, when we recollect that the very small quantity of purple dye afforded by the Purpura of the ancients did not prevent them from collecting it.

I now conclude this long series of letters on the injuries caused by insects to man, and the benefits which he derives from them; and I think you will readily admit that I have sufficiently made good my position, that the study of agents which perform such important functions in the economy of nature must be worthy of attention. Our subsequent correspondence will be devoted to the most interesting traits in their history as their affection to their young, their food and modes of procuring it, habitations, societies, \&c.

I am, \&c.

1 Pullein in Phil. Trans. 1759.54.

2 Annals of Botany, ii. 104.

5 Political Essay on N. Spain, iii. 59.

4 Voyage dans ''Amer. MLérid. i. $21^{\circ}$. It may here be observed as a benefit derived by the higher walks of philosophy from insects, that astronomers employ the strongest thread of spiders, the one namely that supports the web, for the divisions of the micrometer. By its duetility this thread acquires about a fith of its ordinary length. Nouv. Hict. d'IIist. Nut. ii, 280.

5 American Phil. Trans. v. 325.

- Anderson's Recreations in Agriculture, Sic. iv. 399. 


\section{LETTER XI.}

\section{ON THE AFFECTION OF INSECTS FOR THEIR YOUNG.}

Anongst the larger animals, every observer of nature has witnessed with admiration, that love of their offspring which the beneficent Creator, with equal regard to the happiness of the parent and the progeny, has interwoven in the constitution of his creatures. Who that has any sensibility, has not felt his heart dilate with gratitude to the Giver of all good, in observing amongst the domestic animals which surround him, the effects of this divine storge, so fruitful of the most delightful sensations? Who that is not a stock or a stone has read unmoved the anecdote recorded in books of Natural History, of the poor bitch, which in the agonies of a cruel dissection licked with parental fondness her new-born offspring ; or the affecting account of the she-bear related in Phipps's Voyage to the North Pole, which, herself severely wounded by the same shot that killed her cubs, spent her last moments in tearing and laying before them the food she had collected, and died licking their wounds?

These feelings you must have experienced, but it has scarcely occurred to you that you wonld have any room for exercising them in your new pursuit. You have not, I dare say, suspected that any similar example could have been adduced amongst inseets, to which at the first glance there secms even something absurd in attributing anything like parental affection. An animal not so big perhaps as a grain of wheat, feel love for its offspring - how preposterous! we are ready to exclaim. Yet the exclamation would be very much misplaced. Nothing is more certain than that insects are capable of feeling quite as much attachment to their offspring as the largest quadrupeds. They undergo as severe privations in nourishing them; expose themselves to as grcat risk in defending them; and in the very article of death exhibit as much anxiety for their preservation. Not that this can be said of all insects. A very large proportion of them are doomed to die before their young come into existence. But in these the passion is not extingnished. It is mercly modified, and its direction changed. And when you witness the solicitude with which they provide for the sccurity and sustenance of their future young, you can scarcely deny to them love for a progeny they are never destined to behold. Like affectionate parents in similar circumstances, their last efforts are employed in providing for the children that are to succeed them.

I. Observe the motions of that common white butterfly which you see flying from herb to herb. You perceive that it is not food she is in pursuit of: for flowers have no attraction for her. Her object is the discovery of a plant that will supply the sustenance appropriated by Providence to her young, upon which to deposit her eggs. Her own food 
has been honey drawn from the nectary of a flower. This, thereforc, or its neighbourhood, we might expect would be the situation she would sclect for them. But no: as if aware that this food would be to them poison, she is in search of some plant of the cahbage tribe. But how is she to distinguish it from the surrounding vegetables? She is taught of God!' Led by an instinct far more unerring than the practised eye of the botanist, she recognises the desired plant the moment she approaches it ; and upon this she places her precious burden, yet not without the further precaution of ascertaining that it is not pre-occupied by the eggs of some other butterfly! Having fulfilled this duty, from which no obstacle short of absolute impossibility, no danger however threatening, can divert her, the affectionate mother dies.

This may serve as one instance of the solicitude of insects for their future progeny. But almost every species will supply examples similar in principle, and in their particular circumstances even more extraordinary. In every case (except in some renurkable instances of mistakes of instinct, as they may be termed, which will be subsequently adverted to), the parent unerringly distinguishes the food suitable for her offspring, however dissinilar to ber own; or at least invariably places her eggs, often defended from external injury by a variety of admirable contrivances, in the exact spot where, when hatched, the larvæ can have access to it.The dragon-fy is an iubabitant of the air, and could not exist in water: yet in this last element, which is alone adapted for her young, she ever carefully drops ber eggs. The larva of the gad-fly (OEstrus equi), whose history has been before described to you, are destined to live in the stomach of the horse. How shall the parent, a two-winged fly, convey them thither? By a mode truly extraordinary. Flying round the animal, she curiously poises her lody for an instant while she glues a single egg to one of the hairs of his skin, and repeats this process until she has fixed in a similar way many hundred eggs. These, after a few days, on the application of the slightest moisture attended by warmith, hatch into little grubs. Whenever, therefore, the horse chances to lick any part of his body to which they are attached, the moisture of the tongue discloses one or more grubs, which, adhering to it by means of the saliva, are conveyed into the mouth, and thence find their way into the stomach. But bere a question occurs to you. It is but a small portion of the horse's body which he can reach with his tongue: what, you ask, becomes of the eggs deposited on other parts? I will tell you how the gad-fly avoids this dilemua; and I will then ask you if she does not discover a provident forethought, a depth of instinct, which almost casts into shade the boasted reason of man? She places her eggs only on those parts of the skin which the horse is able to reach with his tongue; nay, she confines them almost exclnsively to the knee or the shoulder, which he is sure to lick. What could the most refined reason, the most precise adaptation of means to an end, do more? ${ }^{1}$

Not less aduirable is the parental instinct of that vast tribe of insects already introduced to you by the name of Ichncumons, whose young are destined to feed upon the living bodies of other inseets. These, as you know, are so numerous, that scarcely an insect exists, which in its larva state is not exposed to the attacks of one or other of them; and even the

1 Clark in Linn. Trans. iii. 304. 
pupx, nay the very eggs of these animals, are not safe from their insidious manouvres. The size of the different species varies in proportion to that of the bodies which are to be their food; some being so inconceivably small that the egg of a butterfly not bigger than a pin's head is of sufficient magnitude to nourish two of them to maturity ${ }^{1}$; others so linge that the body of a full-grown eaterpillar is not more than enough for one. They are the larvæ of these Ichneumons which make such havoc of our pigmy tribes: the perfect insect is a four-winged fly, which takes no other food than a little honey; and the great object of the female is to discover a proper nidus for her eggs. In search of this she is in constant motion. Is the caterpillar of a butterfly or moth the appropriate food for her voung? you see her alight upon the plants where they are most usually to be met with, run quickly over then, carefully examining every leaf, and, having found the unfortunate object of her search, insert her sting into its flesh, and there deposit an egg. In vain her victim, as if conscious of its fate, writhes its body, spits out an acid fluid, menaces with its tentacula, or brings into action the other organs of defence with which it is provided. The active Iehneumon braves every danger, and does not desist until her courage and address have insured subsistence for one of her future progeny. Perhaps, however, she discovers, by a sense the existence of which we perceive, though we have no conception of its mature, that she lias been forestalled by some precursor of her own tribe, that has already buried an egg in the caterpillar she is examining. In this case she leaves it, aware thint it would not suffice for the support of two, and proceeds in search of some other yet unoceupied. The process is of course varied in the case of those minute species of which several, sometimes as many as 150, can subsist in a single caterpillar. The little Ich. neumon then repeats her operations, until she has darted into her victim the requisite number of eggs.

The larvæ hatched from the eggs thus ingeniously deposited, find a delicious banquet in the body of the caterpillar, which is surc eventually to fall a victim to their ravages. So accurately, however, is the supply of food proportioned to the demand, that this event does not take place until the young Ichneumons have attained their full growth; when the caterpillar either dies, or retaining just vitality enongh to assume the pupa state, then finishes its existence; the pupa disclosing not a moth or a butterfly, but one or more full-grown Ichneumons.

In this strange and apparently crucl operation one circumstance is truly remarkable. The larva of the Ichneminn, though every day, perhaps for months, it gnaws the inside of the eaterpillar, and though at last it has devoured almost every part of it except the skin and intestines, carefully all this time avoids injuring the vilal organs, as if aware that its own existence depends on that of the insect on which it preys! Thus the caterpillar continues to eat, to digest, and to move, apparently little injured, to the last, and only perishes when the parasitic grub within it no longer requires its aid. What would be the impression which a similar instance amongst the race of quadrupeds would make upon us:" If, for examplc, an animal - such as some impostors have pretended to carry within them should be found to feed upon the inside of a dog, devouring only those parts not essential to life, while it cautiously left uninjured the heart, 
arteries, lungs, and intestines, - should we not regard such an instance as a perfect prodigy, as an example of instinctive forbearance almost miraculous?

Some Ichneumons, instead of burying their eggs in the body of the larvie that are to serve their young for food, content themselves with gluing them to the skin of their prey. This is the case with Scolia flavifrons, which my learned entomological friend M. Passerini of Florence has found places its eggs on the larva of a large beetle (Oryctcs nasicornis), upon which when hatched the larva of the Scolia feeds, by introducing the three first segments of its 'body into the belly of its victim, always between the sixth and seventh segment, so that this insect is a semi-internal parasite. ${ }^{1}$ Another tribe, whose activity and perseverance are equally conspicuous, which includes the beautiful genus Chrysis and many other hymenopterous and dipterous insects, imitating the insidious cuckoo, contrive to introduce their eggs into the nests in which bees and other insects have deposited theirs. With this view they are constantly on the watch, and the moment the unsuspecting mother has quitted her cell for the purpose of collecting a store of fool or materials, glide into it and leave an egg, the germ of a future assassin of the larva that is to spring from that deposited by its side.

The females of the insects of which we have been speaking, in providing for their offspring, are saved the trouble of furnishing them with any habitation. 'Either they occupy that of another insect, or find a con venient abode within the body of that on which they feed. But upon the maternal affection of another large hymenopterous tribe, belonging to Latreille's Family of Burrowers (Fossores), whose young in like inanner feed on other insects, is imposed the arduous task not merely of collectins a supply of food, but of inclosing it along with their eggs in cells or burrows often of considerable depth, and dug with great labour in sand, wood, or the solid earth.

The general economy of these insects is similar. Having first dug a cylindrical cavity of the requisite dimensions, and deposited an egg at the bottom, they inclose along with it one or more caterpillars, spiders, or other insects, each particular species for the most part selecting a distinct kind, as a provision for the young one when hatched, and sufficiently abundant to nourish it until it becomes a pupa. Many thus furnish several cells. This process, however, is varied by different species, some of whose operations are worthy of a more detailed description.

One of the most early histories of the procedure of an insect of this kind, probably the common sand-wasp (Ammophila vulgaris), is left us by the excellent Ray, who observed it along witl his friend Willoughby: On the $22 \mathrm{nd}$ of June, 1667 , he tells us, they noticed this insect dragging a green caterpillar thrice as big as itself, which, after thus conveying about fifteen feet, it deposited at the entrance of a hole previously dug in the sand. Then removing a pellet of earth from its mouth, it descencled into the cavity, and, presently returning, dragged along with it the caterpillar. After staying awhile it again ascended, then rolled pieces of earth into the liole, at intervals scratching the dust into it like a dog with its fore feet, and entering it as if to press down and consolidate the mass, flying also

1 Osservazioni sulle Larve, Ninfé, Sc. (Pise, 1840). Guérin-Méneville, Revue Zoolog. 1841, p. 210. 
once or twice to an adjoining fir-tree, possibly to procure resin for agglutinating the whole. Having filled the burrow to a level with the surrounding earth so as to conceal the entrance, it took two fir-leares lying at band, and placed them near the orifice, as if to mark the place. - Such is the anecdote left on record by our illustrious countrynan, of whose accuracy of observation there can be no doubt. ${ }^{\text {? }}$ Who that reads it can refrain from joining in the reflection which it calls from him, "Quis hec non mihi miretur et stupeat? Quis hujusmodi opcra merce machina possit attribuere?" 2

I mysclf, when walking with a friend some months ago, observed nearly sinilar mancuvres perforned by another hynenopterous insect which may be called a spider-wasp (Pompilus), which attracted onr attention as it was dragging a spider to its cell. The attitude in which it carried its prey, namely, with its feet constantly upwards; its singular mode of walking, which was backwards, except for a foot or two when it went forwards, moving by jerks and making a sort of pause every few steps; and the astonishing agility with which, notwithstanding its heavy burtlen, it glided over or between the grass, weeds, and other numerous impediments in the rough path along which it passed - together formed a spectacle which we contemplated with admiration. The distance which we thus observed it to traverse was not less than twenty-seven feet; and great part of its journey had probably been performed before we saw it. Unce or twice, when we first noticed it, it laid down the spider, and making a small circuit returned and took it up again. But for the ensuing twenty or twenty-five feet it never stopped, but proceeded in a direct line for its burrow with the utmost speed. When opposite the bole, which was in a sand bank by the way side, it made a sharp turn, as evidently aware of being in the neighbourhood of its abode, but when advanced a little further laid down its burthen and went to reconnoitre. At first it climbed up the bank, but, as if discovering that this was not the direction, soon retumed, and after another survey, perceiving the hole, took up the spider and dragged it in after it.

In the two instances above given, one dead caterpillar or spider only was deposited in each hole. But an insect describcd by Reaunur under the name of the mason-wasp (Epipone spinipes), very common in some parts of England, after having excavated a burrow, with an ingenuity to which on a future occasion I shall draw your attention, places along with its ego as food for the future young, about twelve little green grubs withou feet, which it has carefully selected full grown and conveyed without injuring them. You will inquire, Why this difference of procedure? With regard to the choice of a number of suall grubs rather than of one large caterpillar, what I have said in a former letter on the smbject of different species of this tribe being appointed to prey upon and thus keep within due limits the larvæ of different kinds of insects, will be a sufficient answer. But one circumstance creditable to the talents of the mason-wasp as a skilful pul-

1 The Rev. Dr. Sutton of Norwich made similar observations upon the proceedings of this insect in his garden for two successive seasons.

2 Rai. Hist. Ins. 254. For an interesting account of the procedures of a female of this species in dragging a very large spider up the nearly perpendicular side of a sand-bank at least twenty feet high, as well as of other curious facts in the economy of sand-wasps, the reader is referred to the very excellent "Essay on the Indigenous Fossorial IJymenoptera," by IV. E. Shuckard, Esq., p. 77, \&c. 
veyor should not be omitted, namely, that the number of grubs laid up is not always the same, but is exactly proportioned to their size, eleven or twelve being stored when they are small, but only eight or nine when larger. With respect, however, to the caution of the wasp in selecting full-arown grubs and conveying them uninjured to her hole, a satisfactory explanation may be given. If those that are but partly grown were chosen, they would die in a short time for want of food, and putrefyiog would destroy the enclosed egg, or the young one which springs from it. But when larva of any kind have attained their full size, and are about to pass into the pupa state, they can exist for a long period without any further supply. By selecting these, therefore, and placing them uninjured in the hole, however long the interval before the erg hatches, the disclosed larva is sure of a sufficiency of fresh and wholesome nutriment.-To prevent the possibility of any injury to its egg from the motions or voracity of this living prey, the wasp is careful to pack the whole so closely, each grub being coiled above the other in a series of rings, and to consolidate the earth so firmly above them, that they have not the slightest power of motion. ${ }^{1}$ - Those which select more powerful caterpillars, or revenge the injuries of their insect brethren by levoting spiders to the destruction they have so often caused, take care to sting them in such a manner as, without killing them outright, will incapacitate them from doing any injury.

Zeal and activity in providing for the well-being of their future progeny, not inferior to what are exhibited by the tribe of Ichneumons, Sphecinc ${ }^{2}$, and mason-wasps, though less cruelly exerted, are also shown by various species of wild bees, of which we have in this country a great number. Having first excavated a proper cell with a dexterity and persevering labour never enough to be admired, they next deposit in it an egg, which they cover with a mass of pollen or honey collected with unwearied assiduity from a thousand flowers. As soon as the grub is hatched, it finds itself enveloped in this delicious banquet provided for it by the cares of a mother it is cloomed never to behold; and so accurately is the repast proportioned to its appetite and its wants, that as soon as the whole is consumed it has no longer need of food; it clothes itself in a silken cocoon, becomes a pupa, and after a deep sleep of a few days bursts from its cell an active bee.

A considerable number of wild bees, however (those of the genera Nomada, Melecta, \&c.), being unprovided with an apparatus for collecting pollen, save themselves not only this Jabour, but also that of excavating cells; and gliding into those in which their more industrious brethren have deposited their eggs and the necessary supply of pollen moistened with honey for food, they also, cuckoo-like, insinuate their own eggs (imitating in this respect the carnivorous parasites lately noticed), the larva from which live at the cost of the rightful occupants.

No circumstance connected with the storge of insects is more striking than the herculean and incessant labour which it leads them cheerfully to mindergo. Some of these exertions are so disproportionate to the size of the insect, that nothing short of ocular conviction could attribute them to

1 Reaum. vi. 252.

2 By this term 1 would distinguish the tribe of Fossores of Latreille, which the French call Wusp-Ichneumons, and which form the Limean genus Sphex, divisible into several families, as Sphecida, Pompilida, Bembecida, \&ic. 
such an agent. A wild bee or a Sphex, for instance, will dig a hole in a hard bank of eartb some inches deep and five or six times its own size, and labour unremittingly at this arduous undertaking for several days, scarcely allowing itself a moment for eating or repose. It will then occupy as much time in searching for a store of food; and no sooner is this task finished, than it will set about repeating the process, and before it dies will bave completed five or six similar cells or even more. If you would estimate this industry at its proper value, you should reflect what kind of exertion it would require in a man to dig in a few days out of hard clay or sand, with no other tools than his nails and teeth, five or six caverns twenty feet deep and four or five wide - for such an undertaking would not be comparatively greater than that of the insects in question.

Similar laborious exertions are not confined to the bee or Sphex tribe. Several beetles in depositing their eggs exhibit examples of industry equally extraordinary. The common dor or clock (Geotrupes stercorarius), which may be found beneath every heap of dung, digs a deep cylindrical hole, and carrying down a mass of the dung to the bottom, in it deposits its eggs. And many of the species of the Scarabceide ${ }^{1}$ roll together wet dung into round pellets, deposit an egg in the midst of each, and when dry push them backwards by their hind feet, sometimes three or four assisting, into holes of the surprising depth of three feet, which they have previously dug for their reception, and which are often several yards distant. Frequently the road lies across a depression in the surface, and the pellet when nearly pushed to the summit rolls back again. But our patient Sisyphi are not easily discouraged. They repeat their efforts again and again, and in the end their perseverance is rewarded by success. ${ }^{2}$ The attention of these insects to their egg-balls is so remarkable, that it was observed in the earliest ages, and is mentioned by ancient writers, but with the aldition of many fables, as that they were all of the male sex, that they became young again every year, that they rolled the pellets containing their eggs from sunrise to sunset every day, for twenty-eight days without intermission ${ }^{3}$, \&c. It is one of

$1 \mathrm{Mr}$. W. S. MacLeay in his very remarkable and learned work (Horce Entomologica) has very properly restored its name to the true Scarabcus of the ancients, which gives its name to this gromp.

2 The precise mode in which these dung pellets are formed, and the object of rolling them greater distances than would seem to be required for merely depositing them in their holes, which it might have been supposed would, like those of our common dung. beetle, be made close to (if not under) the dung employed, do not appear to have been rely clearly ascertained. According to a newspaper extract given from the travels of an author, whose name is not given, the Scarabcida frequenting the Egyptian deserts form their egg-balls of a mixture of clay (sand?) and camel's dung, and they keep rolling them the whole day, apparently to dry the surface, as they ceased rolling them if clouds overshadowed the sun in the day time; and invariably at sunset (thus confirming the ancient idea) betaking themselves to their holes, and leaving their egg-balls, till sunrise the next day. If this account be supposed to be correct only as respects clay (or sand) entering into the composition of the exterior crust of the egg-balls, it may perhaps throw light on the formation of the singnlar shot-like balls, two inches in diameter, with a very hard shell, of which Col. Sykes has given an interesting account (Trans. Ent. Soc. Lond. i. 130.), which produced specimens of the Indian dung-beetle, Copris Midas. In fact, the mere long rolling of a ball of very moist dung upon sand or powdery clay would press so much of either into the surface as to give it when dry a very hard shell, which would remain much as Col. Sykes describes when the larva had eaten all tho central portion of dung.

5 Mouffet, 153. 
this tribe of beetles ( $S$. sacer) whose image is so often met with amongst the hieroglyphics of the Egyptians, with whom it was a symbol of the world, of the sun, and of a courageous warrior. Of the world, as P. Valerianus supposes, on account of the orbieular form of its pellets of dung, and the notion of their being rolled from sunrise to sunset; of the sun, because of the angular projections from its head resembling rays, and the thirty joints of the six tarsi of its feet answering to the days of the month ; and of a warrior, from the idea of manly courage being connected with its supposed birth from a male only. It was as symbolical of this last that its image was worn upon the signets of the Roman soldiers; and as typical of the sun, the source of fertility, it is yet, as Dr. Clarke informs us, eaten by the women to render them prolific. ${ }^{2}$

These beetles, however, in point of industry must yield the palm to one (Necrophorus Vespillo), whose singular history was first detailed by M. Gleditsch in the Acts of the Berlin Society for 1752. He begins by informing us that he had often remarked that dead moles when laid upon the ground, especially if upon loose earth, were almost sure to disappear in the course of two or three days, often of twelve hours. To ascertain the cause, he placed a mole upon one of the beds in his garden. It had vanished by the third morning; and on digging where it had been laid, he found it buried to the depth of three inches, and under it four beetles, which seemed to have been the agents in this singular inhumation. Not perceiving any thing particular in the mole, he buried it again; and on examining it at the end of six days he found it swarming with maggots apparently the issue of the beetles, which M. Gleditsch now naturally concluded had buried the carcass for the food of their future young. To determine these points more clearly, he put four of these insects into a glass vessel half filled with earth and properly secured, and upon the surface of the earth two frogs. In less than twelve hours one of the frogs was interred by two of the beetles : the other two ran about the whole day as if busied in measuring the dimensions of the remaining corpse, which on the third day was also found buried. He then introduced a dead linnet. A pair of the beetles were soon engaged upon the bird. They began their operations by pushing out the earth from under the body so as to form a cavity for its reception; and it was curions to see the efforts which the beetles made by dragging at the feathers of the bird from below to pull it into its grave. The male having driven the female away, continued the work alone for five hours. He lifted up the bird, changed its place, turned it, and arranged it in the grave, and from time to time came out of the hole, mounted upon it and trod it under foot, and then retired below and pulled it down. At length, apparently wearied with this uninterrupted labour, it came forth and leaned its head upon the earth beside the bird without the smallest motion as if to rest itself, for a full hour, when it again crept uncler the earth. The next day in the morning the bird was an inch and a half under ground, and the trench remained open the whole day, the corpse seeming as if laid out upon a bier, surrounded with a rampart of mould. In the evening it had sunk half an inch lower, and in

1 J. Pierii Valeriani IFieroglyphica, 93-95. Mouffet, 156.

2 Travels, ii. 306. Compare M. Latreille's learned IIemoir entitled Des Insectes peints ou sculptes sur les Monumens antiques de l'Egypte. Ann. du Mus. 1819; and also the Rev. F. W. Hope's Observations in Trans. Lnt. Soc. Lond. ii. 172. 
another day the work was completed and the bird covered. - M. Gleclitsch continued to add other small dead animals, which were all sooner or later buried : and the result of his experiment was, that in fifty days four beetles had interred in the very small space of earth allotted to them, twelve carcasses; viz. four frogs, three small birds, two fishes, one mole, and two grasshoppers, besides the entrails of a fish, and two morsels of the lungs of an ox. In another experiment a single beetle buried a mole forty times its own bulk and weight in two days. ${ }^{1}$ It is plain that all this labour is incurred for the sake of placing in security the future young of these industrious insects along with a necessary provision of food. One mole would have sufficed a long time for the repast of the beetles themselves, and they conld have more conveniently fed upon it above gronnd than below. But if they had left thus exposed the carcass in which their eggs were deposited, both would have been exposed to the imminent risk of being destroyed at a mouthful by the first fox or kite that chanced to espy them.

At the first view I dare say you feel almost inclined to pity the little animals doomed to exertions apparently so disproportioned to their size. You are ready to exclaim that the pains of so short an existence, engrossed with such arduous and incessant toil, must far ontweigh the pleasures. Yet the inference would be altogether erroneous. What strikes us as wearisome toil, is to the little agents delightful oceupation. The kind Author of their being has associuted the performance of an essential duty with feelings evidently of the most pleasurable description; and, like the affectionate father whose love for his children sweetens the most painful labours, these little insects are never more happy than when thus actively engaged. "A bee," as Dr. Paley has woll observed, "amongst the flow er"s in spring ( hen it is occupied without intermission in collecting farina for its young or honey for its associates), is one of the cheerfullest objects that can be looked upon. Its life appears to be all enjoyment - so busy and so pleased." 2

Of the sources of exquisite gratification which every rural walk will open to you, while witnessing in the animals themselves those marks of affection for their unseen progeny of which I have endeavoured to give you a slight sketch, it will be none of the least fertile to examine the various and appropriate instruments with which insects have been furnished for the effective execution of their labours. The young of the sawfly tribe (Serrifera ${ }^{3}$ ) are destined to feed upon the leaves of rose-trees and various other plants. Upon the branches of these the parent fly deposits her eggs in cells symmetrically arranged; and the instrument with which she forms them is a saw, somewhat like our's, but fur more ingenious and perfeet, being toothed on each side, or rather consisting of two distinet saws, with their backs (the teeth or serratures of which are themselves often serrated, and the exterior flat sides scored and toothed), which play alternately; and, while their vertical effect is that of a saw, act laterally as a rasp. When by this alternate motion the incision, or cell, is made, the two saws, receling from each ofher, conduct the $\mathrm{egg}$ between them

1 Glerlitsch, Physic. Bot. Econ. Abhandl. iii. 200-227.

2 Natural Theology, 497 .

3 Latreille denoninates this tribe Securifera; but as the tool of these inscets resembles a saw and not a hatchet, we have ventured to change it to Serrifcra, which is more appropriate. 
into it. ${ }^{1}$ The Cicada, so celebrated by the poets of antiquity, which lays its eggs in dry wood, requires a stronger instrument of a different construction. Accordingly it is provided with an excellent domble auger, the sides of which play alternately and parallel to each other, and bore a hole of the requisite depth in very hard substances without ever being displaced.2

The construction of the sting or ovipositor with which the different species of Ichneumon are provided, is not less nicely adapted to its various purposes. In those which lay their eggs in the bodies of caterpillars that feed exposed on the leaves of plants it is short, often in very lan'ge species not the eighth of an inch long : having free access to their victims, a longer sting would have been useless. But a considerable number oviposit in larve which lie concealed where so short an instrument could not possibly approach them. In these, therefore, the sting is proportionably elongated, so much so that in some small species it is three or four times the length of the body. Thus in Pimpla Mranifestator, whose economy has been so pleasingly illustrated hy Mr. Marsham ${ }^{3}$, and which attacks the larva of a wild bee (Chelostoma ${ }^{4}$ maxillosa) lying at the bottom of deep holes in old wood, the sting is nearly two inches long; and it is not mucis shorter in the more minute $I$. Strobilella L., which lays its eggs in larvæe concealed in the interior of fir cones, which without such an apparatus it wonld never be able to reacl.

The tail of the females of many moths, whose eggs require to be protected from too severe a cold and too strong a light, is furnished, evidently for application to this very purpose, with a thick tuft of bair. But how shall the moth detach this non-conducting material and arrange it upon her eggs? Her ovipositor is provided at the end with an instrument resembling a pair of pincers, which for this purpose are as good as hands. With these, having previonsly deposited her eggs upon a leaf, she pulls off her tuft of hairs, with which she so closely envelops them as effectually to preserve them of the retguired temperature, and having performed this last duty to her progeny she expires.

The ovipositor of the capricorn beetles, an infinite host, is a flattened retractile tube, of a hard substance, by means of which it can introduce its eggs under the bark of timber, and so place them where its progeny will find their appropriate food. ${ }^{5}$ The auger used by certain species of CEstrus, to enable them to penetrate the hides of oxen or deer and form a nidus for their eggs, has been before described. - But to enumerate all the varicties of these instruments would be endless.

The purpose which in the insects above mentioned is answered by their anal apparatus is fulfilled in the numerous tribes of weevils by the long slender snout with which their head is provided. It is with this that $B a$ laninus Nucum pierces the shell of the nut, and the weevil (C'alandra gra-

1 Prof. Peck's Nat. Hist. of the Slug-uorm, t. 12. f. 12-14.

2 Dr. Burmeister and M. Doyere consiler the central piece of the borer of the Cicade as tho really piercing organ, and the lateral files as only serving as a point of support; but Mr. Westwood states that numerous dissections of these parts have convinced him of the correctness of Reaumur's description, that the lateral serrated pieces are the real organs of perforation. (MIod. Class. of Ins. ii. 424.)
3 Linn. Trans. iii. 23.
5 See Kirby in Lirn. Trans. v. 254. t. 12. f 15 
naria) the skin of the grains of wheat, in which they respectively deposit their eggs, prudently introducing one only into each nut or grain, which is sufficient, but not more than sufficient, for the nourishment of the grub that will inhabit it.

II. Hitherto I have adverted to those insects only which perish before their young cone into existence, and can therefore evince their affection for them in no other way than by placing the eggs whence they are to spring in secure situations stored with food; and these include by far the largest portion of the race. A very considerable number, however, extend their cares nuch further: they not only watch over their eggs after depositing them, but attend upon their young when excluded, with an affectionate assiduity equal to any thing exhibited amongst the larger animals, and in the highest degree interesting. Of this description are some solitary insects, as several species of the Linnean genus Sphex, earwigs, field-bugs, and spiders: and those insects which live in societies, namely, ants, bees, wasps and termites : the most striking traits of whose history in these respects I shall endeavour to lay before you.

You heve seen that the greater number of the Sphecina, after depositing their eggs in cells stored with a supply of food, take no further care of them. Some, however, adopt a different procedure. One of these, called by Bonnet the Mason-wasp, but different from Reaumur's, not only incloses a living caterpillar along with its eggs in the cell, which it carefully closes, but at the expiration of a few days, when the young grub has appeared and has consumed its provision, re-opens the nest, incloses a second caterpillar, and again shuts the mouth : and this operation it repeats until the young one has attained its full growth. ${ }^{1}$ A similar mode, according to Rolander, is followed by Ammophila vulgaris, as well as by the yellowish wasp of Pennsylvania, described by Bartram in the Philosophical Transactions $^{2}$, and by another related to Mellinus arvensis, observed by Duhamel ${ }^{3}$; both of which, however, instead of caterpillars, supply their larvæ with a periodical provision of living flies.

What a crowd of interesting reflections are these most singular facts calculated to excite! With what forcsight must the parent insect be endowed, thus to be aware at what period her eggs will be hatched into grubs, and how long the provision she has laid up will suffice for their support! What an extent of judgment, thus, in the midst of various other occupations, to know the precise day when a repetition of her cares will be required! What an accuracy of memory to recollect with such precision the entrance to her cell, which the most acute eye could not discover; and without compass or direction unerringly to fly to it, often from a great distance, and after the inost intricate and varied wanderings! If we refer the whole to instinct, and to instinct doubtless it must in the main if not wholly be referred, our admiration is not lessened. Instinct, when simple and directed to one object, is less astonishing; but such a complication of instincts, applied to actions so varied and dissimilar, is beyond our conception. We can but wonder and adore!

The female of Perga Lewisii (Westwood), one of the Tenthredinida, or Saw-flies, was observed by Mr. Lew is at Hobarton, Van Diemen's Land, to sit upon the leaf into which she has inserted her eggs, about eighty in

1 Bonnet, ix. 398.

2 liii. 37. Pelop๕us spirifex?

3 Reaum. vi. 269. 
number, till they are hatched. This takes place in a few days; and afterwards she carefully feeds them in the larva state, in which the brood keeps together, whether eating or sleeping, in an oval mass, sitting upon them with outstretched wings, shading them from the heat of the sun, and protecting them with admirable perseverance from the attacks of parasites anct other enemies, for a period of from four to six weeks; until her death. ${ }^{1}$

According to M. Schmidberger, the female of a small wood-boring beetle (Trypodendron dispar Steph.) bores in young healthy apple-trees passages of about an inch and a half in length, penetrating near to the centre, and deposits at the end of them in a sort of chamber from seven to ten eggs, the larvæ from which when excluded arrange themselves in the passages one after another, and there feed on a white powdery substance, which he calls ambrosia, and supposes to be prepared by the female from the sap. This femalc, he says, never quits the passages and chambers in which her larvæ reside, but remains with them two months or more, till they are become perfect bectles, and he conceives is occupied partly in laying other eggs, but partly also in preparing "ambrosia" for them and defending them from their enemies. ${ }^{2}$ These procedures are certainly very different from those we should expect in an insect in this tribe; yet as the facts are stated so fully and circumstantially by a close observer, they deserve farther investigation from entomologists who have an opportunity of studying the economy of this species.

We are indebted to De Geer for the history of a field-bug (Acanthosoma grisea), a species found in this country, which shows marks of affection for her young, such as I trust will lead you, notwithstanding any repugnant association that the name may call up, to search upon the birch tree, which it inhabits, for so interesting an insect. The family of this field-bug consists of thirty or forty young ones, which she conducts as a hen does her chickens. She never leaves them; and as soon as she begins to move, all the little ones closely follow, and whenever she stops assemble in a cluster round her. De Geer having had occasion to cut a brancli of birch peopled with one of those families, the mother showed every symptom of excessive uneasiness. In other circumstances such an alarm would have caused her inmediate flight; but now she never stirred from her young, but kept beating her wings incessantly with a very rapid motion, evidently for the purpose of protecting them from the apprehended danger. ${ }^{3}-$ As far as our knowledge of the economy of this tribe of insects extends, there is no other species that manifests a similar attachment to its progeny; but such may probably be discovered by future observers. It is De Geer also that we have to thank for a series of interesting observations on the maternal affection exhibited by the common earwig. This curious insect, so unjustly traduced by a vulgar prejudice,- as if the Creator had willed that the insect world should combine within itself examples of all that is most

1 Trans. Ent. Soc. Lond. i. 233. For a figure of Perga Lewisit see Mr. Westwood's valuable and beautiful "Arcana Entomologica," No. 2. plate 7. fig. 1.

2 Köllar's Ins. inj. to Gardeners, Sc. 25 - 262 . There seems to be a considerable resemblance between the "ambrosia "above mentioned and the globules of a kind of "mucor," found by Smeatliman and König in the nurseries of the $A$ frican and East Indian Termites, and still more the "gelatinous particles not unlike gum arabic," which Latreille observed in the galleries of Termes lucifugus in the trunks of pines and oaks. (See LetTer XVII. On Perfect Societies of Insects - White Ants.

8 De Geer, iii. 262. 
remarkable in every other department of nature,-still more nearly approaches the habits of the hen in her care of her family. She absolutely sits upon her eggs as if to hatch them - a fact which Frisch appears first to have noticed - and guards them with the greatest care. De Geer, having found an earwig thus occupied, removed her into a box where was some earth, and scattered the eggs in all directions. She soon, however, collected them one by one with her jaws into a heap, and assiduously sat upon them as before. The young ones, which resemble the parent except in wanting elytra and wings, and, strange to say, are as soon as born larger than the eggs which contained them, immediately upon being hatched creep like a brood of chickens under the belly of the mother, who very quietly suffers them to push between her feet, and will often, as De Geer found, sit over them in this posture for some hours. ${ }^{1}$ This remarkable fact I have myself witnessed, having found an earwig under a stone which I accidentally turned over, sitting ppon a cluster of young ones, just as this celebrated naturalist has described.

We are so aecustomed to associate the ideas of cruelty and ferocity with the nane of spider, that to attribute parental affection to any of the tribe seems at first view ahmost preposterous. Who, indeed, could suspect that animals which greedily devour their own species whenever they have opportunity, should be susceptible of the finer feelings? Yet such is the fact. There is a spider common uncler clods of earth (Lycosa saccata) which may at once be listinguished by a white globular silken bag about the size of a pca, in which she has deposited her eggs, attached to the extremity of her body. Never miscr clung to his treasure with more tenacious solicitude than this spider to her bag. Though apparently a considerable incumbrance, she carries it with her everywhere. If you deprive her of it, she makes the most strenuous efforts for its recovery; and no personal danger ean force her to quit the precious load. Are her efforts ineffectual? a stupifying melancholy seems to seize her, and, when deprived of this first object of her cares, existence itself appears to have lost its charms. If she succeeds in regaining her bag, or you restore it to her, her actions demonstrate the excess of her joy. She eagerly scizes it, and with the utmost agility runs off with it to a place of security. Bonnet put this wonderful attachment to an affecting and decisive test. He threw a spider with her bag into the cavern of a large ant-lion, a ferocious insect which conceals itself at the bottom of a conical hole constructed in the sand for the purpose of catching any unfortunate victim that may chance to fall in. The spider endeavoured to run away, hut was not sufficiently active to prevent the ant.lion from seizing her bag of eggs, which it attempted to pull under the sand. She made the most violent efforts to defeat the aim of her invisible foe, and on her part struggled with all her might. The gluten, howerer, whieh fastened her bag, at length gave way, and it separated: but the spicler instantly regained it with her jaws, and redoubled her efforts to reseue the prize from her opponent. It was in vain: the ant-lion was the stronger of the two, and in spite of all her struggles dragged the object of contestation under the sand. The unfortunate mother might have preserved her own life from the enemy: she had hut to relinquish the bag, and escape out of the pit. But, wonderful cxample of maternal affection! she preferred allowing herself to be buried 
alive along with the treasure dearer to her than her existence; and it was only by force that Bonnet at length withdrew her from the unequal conflict. But the bag of eggs remained with the assassin: and thongh he pushed her repeatedly with a twig of wood, she still persisted in continuing on the spot. Life seemed to have become a hurden to her, and all her pleasures to have been buried in the grave which contained the germ of her progeny! ${ }^{3}$ The attachment of this affectionate mother is not confined to her eggs. After the young spiders are hatched, they make their way out of the bag by an orifice which she is careful to open for them, and without which they could never escape ${ }^{2}$; and then like the young of the Surinam toad (Rana pipa), they attach themselves in clusters upon her back, belly, head, and even legs; and in this situation, where they present a very singular appearance, she carries them about with her and feeds them until their first moult, when they are big enough to provide their own subsistence. I have more than once been gratified by a sight of the former part of this interesting spectacle; and when I nearly touched the mother, thus covered by hundreds of her progeny, it was most amusing to see them all leap from her back and run away in every direction. ${ }^{3}$

A similar attachment to their eggs and young is manifested by many other species of the same tribe, particularly of the genera Lycosa and Dolomedes. Clubiona holosericea was found by De Geer in her nest with fifty or sixty young ones, when manifesting nothing of her usual timidity, so obstinately did she persist in remaining with them, that to drive her away it was necessary to cut her whole nest in pieces. ${ }^{4}$

I nust now conduct you to a hasty survey of those insects which live together in societies, and fabricate dwellings for the community, such as ants, wasps, bees, humble-bees, and termites, whose great object (sometimes combined, indeed, with the storing up of a stock of winter provisions for themselves) is the nutrition and elucation of their young. Of the proceedings of many of these insects we know comparatively nothing. There are, it is likely, some hundreds of distinct species of bees which live in societies, and form nests of a different and peculiar construction. The constitution of these societies is probably as various as the exterior forms of their nests, and their habits possibly curious in the highest degree; yet our knowledge is almost confined to the economy of the hive-bee and of some species of humble-bces. The same may be said of wasps, ants, and termites, of which, though there is a vast variety of different kinds, we are acquainted with the history of but a very few. You will not, therefore, expect more than a sketch of the most interesting traits of affection for their young manifested by the common species of each genus.

1 Bonnet, ii. 435.

2 De Geer, vii. 194.

3 I). Heineken, whose zeal for Entomology as manifested by lis valuable communcations in spite of ill health, to the Zoological Journal,shows how great a loss the science sustained by his untimely death, states that having placed a large female Lyrosi covered with her young, just hateherl, in al cage so constructed that they could quit it while she could not, he fed her with flies for fifteen days, but never observed her to feel her young ones, nor them to quit their station on her body, nor to seem at all interested or excited when she was engaged in eating. At length, fifteen days after their birth, they quitterl the mother and escaped from the cage. Wr. Ileineken, however, admits that observations of this kind made on insects in confinement are by no means conclusive. (Zool. Journ. v. 192.)

4 De Geer, vii. 268. 
One circumstance must be premised with regard to the education of the young of most of those insects which live in society, truly extraordinary, and without parallel in any other department of nature; nanely, that this office, except under particular cireumstances, is not undertaken by the female which has given birth to them, but by the workers, or neuters, as they are sometimes called, which, though bound to the offspring of the common mother of the society by no other than fraternal ties, exhibit towards them alt the marks of the most ardent parental affection, building habitations for their use, feeding them, and tending them with incessant solicitude, and willingly sacrificing their lives in defence of the precious charge. Thus sterility itself is made an instrument of the preservation and multiplication of species; and females too fruitful to educate all their young are indulged by Providence with a privilege without which nine tenths of their progeny must perish.

The most determined despiser of insects and their concerns - he who never deigned to open his eyes to any other part of their economy - must yet have observed, even in spite of himself, the remarkable attachment which the inhabitants of a disturbed nest of ants manifest towards certain smatl white oblong bodies with which it is usually stored. He must have perceived that the ants are much less intently occupied with providing for their own safety, than in carrying off these little bodies to a place of security. To effect this purpose the whole community is in motion, and no danger can divert them from attempting its accomplishment. An observer having cut an ant in two, the poor mutilated aninal did not relax in its affectionate exertions. With that half of the body to which the head remained attached it contrived previously to expiring to carry off ten of these white masses into the interior of the nest! You will readily divine that these attractive objects are the young of the ants in one of the first or imperfect states. They are, in fact, not the eggs, as they are vulgarly called, but the pupæe, which the working ants tend with the most patient assiduity. But I must give you a more detailed account of their operations, beginning with the actual egrgs.

These, which are so small as to be searcely visible to the naked eye, as soon as deposited by the queen ant, who drops them at random in her progress through the nest, are taken cliarge of by the workers, who immediately seize them and carry them in their mouths, in small parcels, incessantly turning them backwards and forwards with their tongue for the purpose of moistening them, without which they would come to nothing. They then lay them in heaps, which they place in separate apartments ${ }^{1}$, and constantly tend until hatched into larva ; frequently in the course of the day removing them from one quarter of the nest to another, as they require a warmer or cooler, a moister or drier atmosphere; and at intervals brooding over them as if to impart a genial warnth. ${ }^{2}$ Experiments have been made to ascertain whether these assiduous nurses could distinguish their eggs if intermixed with particles of salt and sugar, which, to an ordinary observer, they very much resemble; but the jesult was constantly in fivour of the sagacity of the ants. They invariably selected the eggs from whatever materials they were mixed with, and re-arranged them as before. ${ }^{\mathrm{s}}$ 
New and more severe labours succeed the birth of the young grubs which are disclosed from the eggs after a few days. The working ants are now almost without remission engaged in supplying their wants and forwarding their growth. Every evening an hour before sunset they regularly remove the whole brood, as well as the eggs and pupæ, which in an old nest all require attention at the same time, to cells situated lower down in the earth, where they will be safe from the cold; and in the morning they as constantly remove them again towards the surface of the nest. It; however, there is a prospect of cold or wet weather, the provident ants forbear on that day transporting their young from the inner cells, aware that their tender frames are unable to withstand an inclement sky. What is particularly worthy of notice in this herculean task, the ants constantly regulato their proceedings by the sun, removing their young according to the earlier or later rising and setting of that luminary. As soon as his first rays begin to shine on the exterior of the nest, the ants that are at the top go below in great haste to rouse their companions, whom they strike with their antennæ, or, when they do not seem to comprehend them, drag with their jaws to the summit, til! a swarm of busy labourers fill every passage. These take up the larvæ and pupæ, which they hastily transport to the upper part of their habitation, where they leave them a quarter of an hour, and then carry them into apartments where they are sheltered from the sun's direct rays.'

Severe as this constant and unrenitted daily labour seems, it is but a small part of what the affection of the working ants leads them readily to undertake. The feeding of the young brood, which rests solely upon them, is a more serious charge. The nest is constantly stored with larvæ the year round, during all which time, except in winter, when the whole society is torpid, they require feeding several times a day with a viscid halfdigested fluid that the workers disgorge into their mouths, which when hungry they stretch out to meet those of their nurses. Add to which, that in an old nest there are generally two distinct broods of different ages requiring separate attention, and that the observations of Huber make it probable that at one period they require a more substantial food than at another. It is true that the youngest brood at first want but little nutriment; but still, when we consider that they must not be neglected, that the older brood demand incessant supplies, and in a well stocked nest amount to 7000 or 8000 , and that the task of satisfying all these cravings, as well as providing for their own subsistence, falls to the lot of the working ants, we are almost ready to regard the burden as greater than can be borne by such minute agents; and we shall not wonder at the incessant activity with which we see them foraging on every side.

Their labour does not end here. It is necessary that the larvæ should be kept extremely clean; and for this purpose the ants are perpetually passing their tongue and mandibles over their body, rendering them by this means perfectly white. ${ }^{2}$ After the young grubs have attained their full growth, they surround themselves with a silken cocoon and become pupe, which, food excepted, require as nuch attention as in the larva state. Every morning they are transported from the bottom of the nest to the surface, and every evening returned to their former quarters. And if, as is often the case, the nest be thrown into ruins by the unlucky foot 
of a passing animal, in addition to all these daily and hourly avocations is superadded the immediate necessity of collecting the pupx from the earth with which they have been mixed, and of restoring the nest to its pristine state. ${ }^{1}$

Nothing can be more curious than the view of the interior of a fully peopled ants' nest in summer. In one part are stored the eggs; in another the pupæ are heaped up by hundreds in spacions apartments; and in a third we see the larvæ surrounded by the workers, some of which feed them, while others keep guard, standing erect upon their hind legs with their abdomen elevated in the position for ejaculating their acid,. than which, gunpowder would not be more formidable to the majority of their foes. Some again are occupied in cleaning the alleys from obstructions of various kinds; and others rest in perfect repose, recruiting their strength for new lahours.

Contrary to what is observed amongst other insects, even the extrication of the young ants from the silken cocoon which incloses them is imposed upon the workers, who are taught, by some sensation to us incomprehensible, that the perfect insect is now ready to burst from the shrond, but too weak to effect its purpose unaided. When the worker's discover that this period has arrived, a great bustle prevails in their apartment. Three or four mount upon one cocoon, and with their mandibles begin to open it where the head lies. First they pull off a few threads to render the place thinner; they then make several small openings, and with great patience cut the threads which separate them, one by one, till an orifice is formed sufficiently large for extricating the prisoner; which operation they perform with the utmost gentleness. The ant is still enveloped in its pellicle; this the workers also pull off, carefully disengaging every member from its case, and nicely expanding the wings of such as are furnished with them. After thus liberating and afterwards feeding the newhorn insects, they still for several days watch and follow them everywhere, teaching them to unravel the paths and winding labyrinths of the common habitation ${ }^{2}$; and when the males and females at length take flight, these affectionate stepmothers accompany them, mounting with thein to the summit of the highest herbs, showing the most tender solicitude for them (some even endeavour to retain them), feeding them for the last time, caressing them ; and at length, when they rise into the air and disappear, seenuing to linger for some seconds over the footsteps of these favoured beings, of whom they have taken such exemplary care, and whom they will never behold again. ${ }^{3}$

In the above account, exclusive of the bare fact of their laying the eggs, no mention is made of the female ants, the real parents of the republic. Yon are not from this to suppose that they never feel the influence of this divine principle of love for their offspring. When, indeed, a colony is established and peopled, they have enough to do to furnish it with eggs

1 The Russian shepherds ingeniously avail themselves of the attachment of ants to their roung, for obtaining with little trouble a collection of the pupx, which they sell as a dainty food for nightingales. They scatter an ants' nest upon a dry plot of ground, surrounded with a shallow trench of water, and place on one side of it a few fir branches. Under these the ants, having no other alternative, carefully arrange all their pupe, and in an hour or two the shepherd finds a large heap clean and ready for market. Anderson's Recreations in Agriculture, \&c. iv. 158.

2 Huber, 83.

3 Ilid. 93. 
to produce its necessary supply of future females, males, and workers, which, according to Gould, are laid at three different seasons. ${ }^{1}$ This is the ordinary dity assigned to them by Providence. Yet at the first formation of a nest, the female acts the kind part, and performs all the maternal offices which I have just described as peculiar to the workers; and it is only when these become sufficiently numerous to relieve her, that she resigns this charge and devotes herself exclusively to oviposition. ${ }^{2}$

There is one circumstance occurring at this period of their history which affords a very affecting example of the self-denial and self-devotion of these admirable creatures. If you lave paid any attention to what is going forward in an ant hill, you will have observed some larger than the rest, which at first sight appear, as well as the workers, to have no wings, but which upon a closer examination exhibit a small portion of their base, or the sockets in which they were inserted. These are females that have cast their wings, not accidentally but by a voluntary act. When an ant of this sex first emerges from the pupa, she is adorned with two pairs of wings, the uppe̊r or outer pair being larger than her body. With these, when a virgin, she is enabled to traverse the fields of ether, surrounded by myriads of the other sex, who are candidates for her favour. But when once connubial rites are celebrated, the unhappy husband dies, and the widowed bride seeks only how she may provide for their mutual off'spring. Panting no more to join the choir of aërial dancers, her only thonght is to construct a subterranean abode in which she may deposit and attend to her eggs, and cherish her embryo young till, having passed through their various changes, they arrive at their perfect state, and she can devolve upon them a portion of her maternal cares. Her ample wings, which before were her chief ornament and the instruments of her pleasure, are now an encumbrance which incommode her in the fulfilment of the great duty uppermost in her mind; she therefore, without a moment's hesitation, plucks them from her shoulders. Might we not then address females who have families, in words like those of Solomon, "Go to the ant, ye mothers ; consider her ways, and be wise?"

M. P. Huber was more than once witness to this proceeding. He saw one female stretch her wings with a strong effort so as to bring them before her head - she then crossed them in all directions - next she reversed them alternately on each side - at last, in consequence of some violent contortions, the four wings fell at the same moment in his presence. Another, in addition to these motions, used her legs to assist in the work. ${ }^{3}$

Thus, from the very moment of the extrusion of the egg to the maturity of the perfect insect, are the ants unremittingly occupied in the care of the young of the society, and that with an ardour of affectionate attachment to which, when its intensity and duration are taken into the account, we may fairly say there is nothing parallel in the whole animal world. ${ }^{4}$ Amongst

1 p. 35.

2 lluber, 110.

3 Huber, 109. - Gould had, long before Huber, observed that the female ants cast their wings. pp. 59. 62. 64. I have frequently observed them, sometimes with only one wing, at others with only fragments of the wings; and again, at others they were so completely pulled off, that it could not be known that they formerly had them, only by the sockets in which they were iuserted.

1 IIuber, 93. 
birds and quadrupeds we have instances of affection as strong perhaps while it lasts ; but how much shorter the period during which it is exertell! In a month or two the young of the former require no further attention; and if in a state of nature some of the latter give suck to their offspring for a longer period, it is on their parts without effort or labour ; and in both cases the time given up to their young forms a very small part of the life of the animal. But the little insects in question not only spend a greater portion of time in the education of their progeny, but devote even the whole of their existence, from their birth to their death, to this one occupation!

The common hive-bee and the wasp in their attention to their young exhibit the same general features. Both build for their reception hexagonal cells, differing in size according to the future sex of the included grubs, which as soon as hatched they both feed and assiduously tend until their transformation into pupx. There are peculiarities, however, in their modes of procedure, which require a distinct notice.

The economy of a nest of wasps cliffers from that of bees, in that the eggs are laid not by a single mother or queen, but by several ; and that these mothers take the same care as the workers in feeding the young grubs : indeed those first hatched are fed entirely by the fenale which produced them, the solitary founder of the colony. The sole survivor probably of a last year's swarm of many thousands, this female, as soon as revived by the warmth of spring, proceeds to construct a few cells, and deposits in them the eggs of working wasps. The eggs are covered with a gluten, which fixes them so strongly against the sides of the cells, that it is not easy to separate them unbroken. These eggs seem to require care from the time they are laid, for the wasps many times in a day put their heads into the cells which contain them. When they are hatchel, it is amusing to witness the activity with which the female runs from cell to cell, putting her head into those in which the grubs are very young, while those that are more advanced in age thrust their heads out of their cells, and by little movements seem to be asking for their food. As soon as they receive their portion, they draw them back and remain quiet. These she feeds until they become pupr; and within twelve hours?after being excluded in their perfect state, they eagerly set to work in constructing fresh cells, and in lightening the burden of their parent by assisting her in feeding the grubs of other workers and females which are by this time born. In a few weeks the society will have received an accession of several hundred workers and many females, which without distinction apply themselves to provide food for the growing grubs, now become exceedingly numerous. With this object in view, as they collect little or no honey from flowers, they are constantly engaged in predatory expeditions. One party will attack a hive of bees, a grocer's sugar hogshead, or other saccharine repository ; or, if these fail, the juice of a ripe peach or pear. You will be less indignant than formerly at these audicious robbers now you know that self is little considered in their attacks, and that your ravaged fruit has supplied an exquisite banquet to the most tender grubs of the nest, into whose extended months the successful marauders, running with astonishing agility from one cell to another, disgorge successively a small portion of their booty in the same way that a bird supplies her young. ${ }^{1}$ Another party is charged with providing more

1 See Willoughby in Rai. Hist. Ins. 251. and Reaum. 
substantial aliment for the grubs of maturer growth. These wage war upon bees, flies, and even the meat of a butcher's stall, and joyfully return to the nest laden with the well-filled bodies of the former, or pieces of the latter as large as they can carry. This solid food they distribute in like manner to the larger grubs, which may be seen eagerly protruding their hearls out of the cells to receive the welcome meal. As wasps lay up no store of food ${ }^{1}$, these exertions are the task of every day during the summer, fresh broods of grubs constantly succeeding to those which have become pupæ or perfect insects; and in autumn, when the colony is augmented to 20,000 or 30,000 , and the grubs in proportion, the scene of bustle which it presents may be readily conceived.

Though such is the love of wasps for their young, that if their nest be broken almost entirely in pieces they will not abandon it $^{2}$, yet when the cold weather approaches, a melancholy change ensues, followed by a cruel catastrophe, which at first you will be apt to regard as ill comporting with this affectionate character. As soon as the first sharp frost of October has been felt, the exterior of a wasp's nest becomes a perfect scene of horror. The old wasps drag ont of the cells all the grubs and unrelentingly destroy them, strewing their dead carcasses around the door of their now desolate habitation. "What monsters of cruelty!" I hear you exclaim; "what detestable barbarians!" But be not too hasty. When you hive coolly considered the circumstances of the case, you will view this seemingly cruel sacrifice in a different light. The old wasps have no stock of provisions : the benumbing hand of Winter is about to incapacitate them from exertion; while the season itself affords no supply. What resource then is left? Their young must linger on a short period, suffering all the agonies of hunger, and at length expire. They have it in their power at least to shorten the tem of this misery - to cut off its bitterest moments. A sudden death by their own hands is comparatively a merciful stroke. This is the only alternative; and thus, in fact, this apparent ferocity is the last effort of tender affection, active even to the end of life. I do not mean to say that this train of reasoning actually passes through the mind of the wasps. It is more correct to regard it as having actuated the benevolent Author of the instinct so singularly, and without doubt so wisely, excited. Were a nest of wasps to survive the winter, they would increase so rapidly, that not only would all the bees, flies, and other animals on which they prey, be extirpated, but man hinself find them a grievous pest. It is necessary, therefore, that the great mass should annually perish; but that they may suffer as little as possible, the Creator, mindful of the happiness of the smallest of his creatures, has endowed a part of the society, at the destined time, with the wonderful instinct which, previously to their own death, makes them the executioners of the rest.

1 There are, however, cxceptions to this rule, as in the nests of some species of Polistes, which fix them to trees, \&c., are found about a dozen cells filled with honey at the time these nests contain cells destined to receive the larvæ of females and of males, which renders the opinion of $\mathbf{M}$. Lepelletier de Saint-Fargeau probable, that this honey is destined in part to nourish the former and to exercise some influence on the development of their genital organs. Polistes Lecheguana, found in Paraguay and Monte Video, also stores up lioney as before mentioned. (Lacordaire, Introd. is l'Entom. ii. 511.). as does Myrapetra scutellaris, White. (Ann. Nat. Hist. vii, 320.)

2 Reaum. vi. 174. 
Wasps in the construction of their nests bave solely in view the accommodation of their young ones; and to these their cells are exclusively devoted. Bees, on the contrary (I am speaking of the common hive-bee), appropriate a considerable number of their cells to the reception of honey intended for the use of the society. Yet the education of the young brood is their chief object; and to this they constantly sacrifice all personal and selfish considerations. In a new swarm the first care is to build a series of cells to serve as cradles; and little or no honey is collected until an ample store of bee-bread, as it is called, has been laid up for their food. This bee-bread is composed of the pollen of flowers, which the workers are incessantly employed in gathering, flying from flower to flower, brushing from the stamens their yellow treasure, and collecting it in the little baskets with which their hind legs are so admirably provided; then hastening to the hive, and having deposited their booty, returning for a new load. The provision thus furnished by one set of labourers is earefully stored up by another, until the eggs which the queen-bee has lajd, and which, adhering by a ghtinous covering, she places nearly upright in the botton of the cell, are hatched. With this bee-bread, after it has undergone a conversion into a sort of whitish jelly by being received into the bee's stomach, where it is probably mixed with honey ${ }^{3}$ and regurgitated, the young brood immediately upon their exclusion, and until their change into nymphs, are diligently fed by other bees, which anxiously attend upon them and several times a day afford a fresh supply. Different bees are seen successively to introduce their heads into the cells containing them, and after remaining in that position some moments, during which they replace the expended provision, pass on to those in the neighbourhood. Others often immerliately succeed, and in like manner put in their heads as if to see that the young ones have everything necessary ; which being ascertained by a glance, they immediately proceed, and stop only when they find a cell almost exhausted of food. That the office of these purveyors is no very simple affair will be admitted, when it is understood that the food of all the grubs is not the same, but that it varies according to their age, being insipid when they are young, and, when they have nearly attained maturity, more sugary and somewhat acid. The larvæ destined for queen-bees, too, require a food altogether different from that appropriated to those of drones and workers. It may be recognised by its sharp and pungent taste.

So accurately is the supply of food proportioned to the wants of the larva, that when they have attained their full growth and are ready to become nymphs, not an atom is left unconsumed. At this period, intuitively known to their assiduous foster-parents, they terminate their cares by sealing up each cell with a lid of wax, convex in those containing the larvæ of drones, and nearly flat in those containing the larvæ of workers, bencath which the enclosed tenants spin in security their cocoon. In all these labours neither the queen nor the drones take the slightest share. They fall exclusively upon the workers, who, constantly called upon to tend fresh brools, as those broughit to maturity are clisposed of, devote nearly the whole of their existence to these maternal offices.

1 It is not unlikely that it may undergo some other alteration in the bee's stomach, which may possibly secrete some peculiar substance, as Joln Hunter discovered that the crop of the pigecn does. 
Humble-bees ${ }^{1}$, which in respect of their general policy must, when compared with bees and wasps, be regarded as rude and untutored villagers, exinibit, nevertheless, marks of affection to their young quite as strong as their more polished neighbours. The females, like those of wasps, take a considerable share in their education. When one of them has with great labour constructed a commodions waxen cell, she next furnishes it with a store of pollen moistened with honey; and then, having deposited six or seven eggs, carefully closes the orifice and minutest interstices with wax. But this is not the whole of her task. By a strange instinct, which, however, may be necessary to keep the population within due bounds, the workers, while she is occupied in laying her eggs, endeavour to seize them from her, and, if they succeed, greedily devour them. To prevent this violence, her utmost activity is scarcely adequate; and it is only after she has again and again beat off the murderous intruders and pursued them to the furthest verge of the nest, that she succeeds in her operation. When finished, she is still under the necessity of closely guarding the cell, which the gluttonous workers wonld otherwise tear open, and devour the eggs. This duty she performs for six or eight hours with the vigilance of an Argus, at the end of which time they lose their taste for this food, and will not touch it even when presented to them. Here the labours of the mother cease, and are succeeded by those of the workers. These know the precise hour when the grubs have consumed thcir stock of food, and from that time to their maturity regularly feed them with either honey or pollen, introduced in their proboscis through a small hole in the cover of the cell opened for the occasion and then carefully closed.

They are equally assiduous in another operation. As the grubs increase in size, the cell which contained them becomes too small, and in their exertions to be more at ease they split its thin sides. To fill up these breaches as fast as they occur with a patch of wax is the office of the workers, who are constantly on the watch to discover when their services are wanted; and thus the cells daily increase in size, in a way which to an observer ignorant of the process seems very extraordinary.

The last duty of these affectionate foster-parents is to ansist the young bees in cutting open the cocoons which have enclosed them in the state of pupa. A previous labour, however, must not be omitted. The workers adopt similar measures with the hive-beefor maintaining the young pupre concealed in these cocoons in a genial temperature. In cold weather and at night they get upon them and imprart the necessary warmth by lrooding over them in clusters. ${ }^{2}$ Connected with. this part of their domestic eco-

1 Dr. Johnson was ignorant of the etymology of this word. It is clearly derived from the German Hummel or Hummel Biene, a name probably given it from its sound. Our English name would be more signifieant were it altered to Ilummingbee or Bonming-bee.

2 A new and very remarkable fact observed by Mr. Newport, and communicated in his valuable paper on the temperature of insects, is that in the process of incubation above referred to, especially that adopted ten or twelve hours before the nymph makes its appearance as a perfect humble-bee, the required augmentation of heat is producel by the nurse or brooding-bees voluntarily increasing the number of their respirations, which at first are very gradual, but become more and more frequent until they reach sometines 120 or 130 per minute; and Mr. Newport has seen a bee on the combs continue perseveringly to respire at this rate for eight or ten hours till its temperature was greatly increased and its body bathed in perspiration, when she would generally discontinue her office for a time, and an individual occasionally take 
nomy, M. P. Huber, a worthy scion of a celebrated stock, and an inheritor of the science and merits of the great Huber as well as of his name, in his excellent paper on these insects in the sixth volume of the Linnean Transactions, from which most of these facts are drawn, relates a singularly curious anecdote.

In the course of his ingenious and numerous experiments, M. Huber put under a bell-glass about a dozen humble-bees without any store of wax, along with a comb of about ten silken cocoons so unequal in height that it was impossible the mass should stand firmly. Its unsteadiness disquieted the humble-bees extremely. Their affection for their young led them to mount upon the cocoons for the sake of imparting warmth to the enclosed little ones, but in attempting this the comb tottered so violently that the scheme was almost impracticable. To remedy this inconvenience, and to make the comb steady, they had recourse to a most ingenious expedient. Two or three bees got upon the comb, stretched themselves over its edge, and with their heads downwards fixed their fore feet on the table upon which it stood, whilst with their hind feet they kept it from falling. In this constrained and painful posture, fresh bees relieving their comrades when weary, did these affectionate little insects support the comb for nearly three days. At the end of this period they had prepared a sufficiency of wax, with which they built pillars that kept it in a firm position: but by some accident afterwards these got displaced, when they had again recourse to thcir former mancuvre for supplying their place; and this operation they perseveringly continued until Mi. Huber, pitying their hard case, relieved them by fixing the object of their attention firmly on the table. ${ }^{1}$

It is impossible not to be struck with the reflection that this most singular fact is inexplicable on the supposition that insects are impelled to their operations by a blind instinct alone. How could mere machines have thus provided for a case which in a state of nature has probably never occurred to ten nests of humble-bees since the creation? If in this instance these little animals were not guided by a process of reasoning, what is the distinction between reason and instinct? How could the most profound architect have better adapted the means to the end - how more dexterously shored up a tottering edifice, until his beans and his props were in readiness?

With respect to the operations of the termites or white ants in rearing their young, I have not much to observe. All that is known is, that they build commodious cells for their reception, into which the eggs of the queen are conveyed by the workers as soon as laid, and where when hatched they are assiduously fed by them until they are able to provide for themselves.

In concluding this subject, it may not be superfuons to advert to an objection which is sometimes thrown out against regarding with any parti-

her place. From an observation made at noon, July 13., he found that while the thermometer stood at $70^{\circ .2}$ in the external air, and at $80^{\circ} \cdot 2$ on the topls of the cells of the hive not brooded on, it stood at 920.5 when placed in contact with the bodies of the incubating nurse-bees, which thus by their voluntary rapid respiration imparted an additional heat of $12^{\circ} .3$ to the enclosed nymph. (Phil. Trans. 1837, p. 296.)

1 Linn. Trans, vi. 247, \&c. 
cular sympathy the affection of the lower animals to their young, on the ground that this feeling is in them the result of corporeal sensation only, and wholly different from that love which human parents feel for their offspring. It is true that the latter involves moral considerations which cannot have place in the brute creation; but it would puzzle such objectors to explain in what respect the affection which a mother feels for her new-born infant the moment it. has seen the light differs from that of an insect for its progeny. T'he affection of both is purely physical, and in each case springs from sensations interwoven by the Creator in the constitution of his creatures. If the parental love of the former is worthy of our tenderest sympatinis, that of the latter cannot be undeserving of some portion of similar feeling.

I am, dxc. 


\section{LETTER XII.}

\section{ON THE FOOD OF INSEC'TS.}

INSECTs, like other animals, draw their food from the vegetable and animal kingdoms : but a very slight survey will suffice to show that they enjoy a range over far more extensive territories.

To begin with the vegetable kingdom. - Of this vast field the larger animals are confined to a comparatively small portion. Of the thousands of plants which clothe the face of the earth, when we have separated the grasses and a trifling number of herbs and shrubs, the rest are disgusting to them, if not absolute poisons. But how infinitely more plenteous is the feast to which Flora invites the insect tribes! From the gigantic banyan which eovers acres with its shade, to the tiny fungus scarcely visible to the naked eye, the vegetable creation is one vast banquet at which her insect guests sit down. Perhaps not a single plant exists which does not afford a delicious food to some insect, not excluding even those most nauseous and poisonous to other animals, - the acrid euphorbias, and the lurid henbane and nightshade. Nor is it a presumptuous supposition, that a considerable proportion of these vegetables were created expressly for their entertainment and support. The common nettle is of little use either to mankind or the larger animals ; but you will not doubt its importance to the class of inseets, when told that at least thirty distinct species feed upon it; and however important the oak may be to us, it is still more so to the insect world, of which Rösel calculated that two hundred species either feed upon it, or upon other insects which do. But this is not all. The larger herbivorous animals are confined to a foliaceous or farinaceous diet. They can subsist on no other part of a plant than its leaves and seeds, either in a recent or dried state, with the addition sometimes of the tender twigs or bark. Not so the insect race, to different tribes of which every part of a plant supplies appropriate food. Some attack its roots; others select the trunk and branches; a third class feed upon the leaves; a fourth, with yet more delicate appetite, prefer the flowers; and a filth the fruit or seeds. Even still further selection tilkes place. Of those which feed upon the roots, stem, and branches of vegetables, some larvæ eat only the bark; others both the inner bark and alburnum ( $S_{C O}-$ lytus, \&e.); others the exuding resinous or other excretions (Orthotania resinella); a third class the pith (EEgeria tipuliformis); and a fourth penetrate into the heart of the solid wood (Prionus, Lamia, Corambyx, \&c.). Of those which prefer the leaves, some taste nothing but the sap which fills their veins (Aphides in all their states); others eat only the parenchyma, never touching the cuticle (subcutaneous Tinece) ; others only the lower surface of the leaf (many Tortrices); while a fourth description devour the whole substance of the leaf (most Lepidoptera). And of the flower- 
feeders, while some eat the very petals (Cucullia Verbasci, Xylina Linama, Se.), others in their perfeet state select the pollen whieh swells the anthers (bees, Lepturce, and Mordelle); and a still larger elass of these the honey seereted in the neetaries (most of the Lepidoptera, Hymenoptera, and Diptera).

Nor are inseets confined to vegetables in their recent or unmanufaetured state. A beam of oak, when it has supported the roof of a castle five hundred years, is as much to the taste of some (Anobia) as the same tree was in its growing state to that of others; another elass (Ptini) would sooner feast on the herbarium of Brunfelsius than on the greenest herbs that grow ; and a third (some Tinece, Termites), to whom

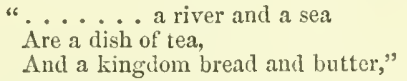

would prefer the geographical treasures of Saxton or Speed, in spite of their ink and alum, to the freshest rind of the flax plant. The larva of a little fly (Oscinis cellaris), whose economy, as I can witness from my own observations, is admirably deseribed by Mentzelins ${ }^{1}$, disclains to feed on anything but wine or beer, whieh, like Boniface in the play, it nay be said both to eat and drink; though, unlike its toping counterpart, indifferent to the age of its liquor, which, whether sweet or sour, is equally accejtable.

A diversity of food almost as great may be boasted by the insects which feed on animal substances. Some (flestr-flies, carrion-beetles, \&c.) devour dead eareasses only, which they will not touch until imbued with the haut goût of putridity. Others, like Mr. Bruee's Abyssinians, preferring their meat before it has passed through the hands of the butcher, seleet it from living vietims, and may with justice pride themselves upon the peculiar freshness of their diet. Of these last, different tribes follow different procedures. The Iclmenmons devour the flesh of the insects into which they have insinuated themselves. Some of the $Q E$ stri, fixed in a spacious apartment beneath the skin of an ox or deer, regale themselves on a purulent secretion with which they are surrounded. Others of the same tribe, partial to a higher temperature, attach themselves to the interior of the stomach of a horse, and in a bath of ehyme of 102 degrees of Fahrenheit revel on its juices. The various species of horse-flies dart their sharp lancets into the veins of quadrupeds, and satiate themselves in living streams; while the gnat, the flea, the bug, and the louse, plunge their proboseis even into those of us lords of the ereation, and banquet on "the ruddy drops which warm our hearts." Some make their repast upon birds only, as the fly of the swallow, and other Omithomyice, and the bird-lonse ; inseets nearly allied, though one is dipterous and the other apterous. And a most singular animal belonging to the latter tribe (Nycleribia Vespertilionis) revenges upon the bat its ravages of the insect world ${ }^{2}$; while snails give subsistence to Drilus flavescens, a beetle, and its singular apterous female, in the larva state, as well as to the larva of glow-worms. ${ }^{3}$

1 Ephem. German. Ann. xii. Obs. 58. Ray, Hist. Ins. 261.

2 Linn. Trans, xi. 11. t. 3. f. 5-7.

3 Desmarest and Audouin in $A n n$, des Sciences Nut. i. 67.; ii. 129. 443. ; vii. 353.; . quoted in Burmeister's Manuct of Ent. p. $55 \%$. 
Another numerous class kill their prey outright, either devouring its solid parts, as the predaceous and rove-beetles, $\mathcal{S}$ c., or imbibing its juices only, as the infinite hordes of the field-bug tribe. And the larva of the gnat, chameleon (Stratyomis), and other flies aquatic in that state, the leviathans of the world of animalcules, swallow whole hosts of these minute inhabitants of pools and ponds at a gulp, causing, with their oral apparatus, a vortex in the water, down which myriads of victims are incessantly hurried into their destructive maw.

But not only animals themselves, almost every animal substance that can be named, is the appropriate food of some insect. Multitudes find a delicious nutriment in excrements of various kinds. Matters apparently so indigestible as hair, wool and leather, are the sole food of many moths in the larva state ('Tinea tapetzella, pellionella, \&c.). Even feathers are not rejected by others; and the grub of a beetle (Anthrenus Muscorum), with powers of stomach which the dyspeptic sufferer may envy, will live luxuriously upon horn, ${ }^{1}$

For the most part, insects feeding upon animal substances will not touch vegetables, and vice versâ. You must not, however, take the rule without exceptions. Many caterpillars (as those of Thyatira derasa, Chariclea Delphinii, \&c.), though plants are their proper food, will occasionally devour other caterpillars, and sometimes even their own species. The large green grasshopper (Acrida viridissima), and probably others of the Order, will eat smaller insects as well as its usual regetable food ${ }^{2}$; so also will the larvæ of many Phryganex. Allantus marginellus, as I was last summer amused by wituessing, like many Scatophagce, sips the nectar of umbelliferous plants only till a fly comes within its reach, pouncing upon which it gladly quits its vegetable for an aninal repast. Anobizm paniceum, which ordinarily feeds upon biscuit, was, as I have before mentioned, once fonnd by Mr. Sheppard, in great abundance living upon the dried Cantharides (Cantharis vesicatoria) of the shops. On the other hand, Necrophorus mortuorum, which subsists on carcasses, and many other carnivorous species, will make a hearty meal of a putrid fungus. Ptinus Fur devours indifferently dried birds or plants, not refusing even tobacco; and from the impossibility that one of a million of the innumerable swarms of gnats which abound in swampy places, particularly in regions which but for then would be lost to sensitive existence, should ever taste blood, it seems clear that they are usually contented with regetable aliment. Indeed the males, as well as those of the horse-fly, of which even tlie females readily imbibed the sugared fluid offered to them by Reaumur ${ }^{3}$, never suck blood at all ; so that they must either feed on vegetable matter, which in fact I have observed them do, or fast during their whole existence in the perfect state.

Though insects, generally consilered, have thus a much more extensive bill of fare than the larger animals, each individnal species is commonly limited to al more restricted diet. Many both of animal and vegetable feeders are absolutely confined to one kind of food, and cannot exist upon any other. The larva of CEstris Equi can subsist nowhere but in the stomach of the horse or ass ; which animals, therefore, this insect might boast with some show of reason to have been created for its use rather than 
for ours, belng to us useful only, but to it indispensable. The larvæ of Scceva Pyrastri, according to De Geer, eat no other Aphis but that of the rose. Most Ichneumons and Sphecina prey each upon a single species of insect only, which therefore they would seem to have been formed for the express purpose of keeping within due limits. Reaumur mentions having once found in a parcel of decaying wood the nests of six different kinds of the latter tribe, each of which was filled with flies of a distinct species. ${ }^{2}$ Cerceris anvitus and Philanthus lectus in the larvas state feed solely on the weevil tribe of Coleoptera, the latter being restricted even to the short-rostrumed family, as Otiorkynchus raucus, \&c. ${ }^{3}$; while Bembex rostrata, another hymenopterous insect, selects flies, as Musca Casar, Sc. ${ }^{4}$

A very large proportion of species, however, are able to subsist on several kinds of food. Amongst the carnivorous tribes, it is indifferent to most of those which prey upon putrid substances from what source they have been derived: and the predaceous insects, such as the Libellulina, Telephorns, Empis, the Araneidce, \&c., will attack most smaller insects inferior to them in strength, not excepting in many instances their own species. The wax-moth larva (Galleria Cercana) will for want of wax eat paper, wafers, wool, \&c..5; another Tinea described by Reaumur, and before adverted to, attacks chocolate ${ }^{6}$, which cannot have been its natural food, even selecting that most highly perfumed; and the Tinece which devour dressed wool, but happily for the farmer and wool-stapler refuse it when unwashed, must have existed when no manufactured wool was accessible. The vegetable feeders are under great restrictions, yet probably the majority can subsist on different kinds of food. This is certainly true of most lepidopterous larvæ, several of which, as well as many Coleoplera (Haltica oleracea, \&c.) are polyphagous, eating alnost every plant. It is worthy of remark, however, that when some of these have fed for a time on one plant they will die rather than eat another, which would have been perfectly acceptable to them if accustomed to it fiom the first. ${ }^{7}$ Here too it must be borne in mind, that by far the greater part of insects feed upon different substances in their different states of existence, eating one kind of food in the larva and another in the imago state. This is the case with the whole order Lepidoptera, which in the former eat plants chiefly, in the latter nothing but honey or the sweet juices of fruit, which they have often been observed to inbibe; and the same rule obtains also in regard to most dipterous and hymenopterous insects. Those which eat one kind of food in both states are chiefly of the remaining orders.

I have said that insects, like other animals, draw their sulsistence from the vegetable or animal kingdoms. But I ought not to omit noticing that some authors have conceived that several specics feed upon mineral substances. ${ }^{8}$ Not to dwell upon Barchewitz's idle tale of East Indian ants

1 De Geer, vi. 112.

2 Reaum. vi. 271.; and M. L. Dufour has recently deseribed a species of sandwasp (Cerceris) which selects various species of Buprestis as the food of its progeny, some of which are of the greatest rarity to collectors.

3 Entonologische Bemerkungen (Braunschweig, 1799), p. 6.

4 Latreille, Obs. sur les Hymenoptères. Ann. de MIus. xiv. 412.

5 Reaum. iii. 257.

7 Ibid. ii. 334.

${ }^{8}$ For an instance in which an insect, usually subsisting upon animal food, derived nutriment from a mineral substance, see Philos Mag. Scc. for January 1823. 
which eat iron ${ }^{1}$, or on the stone-eating caterpillars recorded in the Mcmoirs of the French Academy ${ }^{2}$, which are now known to erode the walls on which they are found solely for the purpose of forming their cocoons, Reaumur and Swammerdam have both stated the food of the larvæ of Ephemerce to be earth, that being the only substance ever found in the stomachs and intestines, which are filled with it. This supposition, which if correct renders invalid the definition by which Mirbel (and my firend Ds. Alderson of Hull long before him) proposed to distinguish the animal and vegetable kingdoms, is certainly not inadmissible ; for, though we might not be inclined to give much weight to Father Paulian's history of a flinteater who digested flints and stone 3 , the testimony of Humboldt seems to prove that the human race is capable of drawing nutriment from earth, which, if the odions Ottomaques can digest and assimilate, may doubtless afford support to the larvæ of the Ephemeræ. Yet, after all, it is perhaps more probable that these insects feed on the decaying vegetable matter intermixed with the earth in which they reside, from which after being swatlowed it is extracted by the action of the stomach : like the sand that, from being found in a similar situation, Borelli erroneously supposed to be the food of many 'Tesiacea, though in fact a mere extraneous snbstance.

The majority of insects, either imbibing their food in a liquid state, or feeding on succulent substances, require no aqueous fluid for diluting it. Water, however, is essential to bees, ants, and some other tribes, which drink it with avidity; as well as in warm climates to many Lepidoptera, which are there chiefly taken in court-yards, near the margins of drains, \&c. ${ }^{4}$ Even some larvæ which feed upon juicy leaves have been observed to swallow drops of dew : and one of them (Odonestis potatoria), which (according to Goedart) after drinking lifts up its head like a hen, has received his name from this circumstance. That it is not the mere want of succulency in the food which induces the necessity of drink is plain from those larvæ which live entirely on substances so dry that it is almost unaccomntable whence the juices of their body are derived. The grub of an Anobium will feed for months upon a chair that has been baking before the fire for half a century, and from which even the chemist's retort could scarcely extract a drop of moisture; and will yet have its body as well filled with fluids as that of a leaf-fed caterpillar.

By far the greater part of insects always feed themselves. The young, however, of those which live in societies, as the hive and humble-bees, wasps, ants, \&c., are fed by the older inhabitants of the community, which also frequently feed each other. Many of these last insects are distinguished from the majority of their race, which live from day to day and take no thought for the morrow, by the circumstance of storing up food. ()f those which feed themselves, the larger proportion have imposed upon them the task of providing for their own wants ; but the tribe of Splieges, wild bees, and some others, are furnished in the larva state by the parent insect with a supply of food sufficient for their consumption until they have attained maturity.

1 Lesser, L. i. 259.

2 ×. 458.

3 Dictionnaire Physique.

4 Mr. Doubleday bas observed the habit which butterflies have of settling on lamp mud on roal sides in the United States, where they congregate in groups, sometimes literally consisting of hundreds of individuals clustered together on a few yards of mud (Westwood, Arc. Ent. i. p. 14t.) The same habit may occasionally be noticed in this country. 
As to their time of feeding, insects may be divided into three great classes: the day-feeders, the night-feeders, and those which feed indifferently at all times. Yon have been apt to think, I dare say, that when the sun's warmer beans have waked the insect youth, and

"Ten thousand forms, ten thousand different tribes, People the blaze,"

you see before you the whole insect world. You are not aware that a host as numerous shun the glare of day, and, like the votarics of fashion, rise not from their couch until their more vilgar brethren have retired to rest. While the painted butterfly, the "fervent bees," and the quivering uations of flies, which sport

"Thick in yon stream of light, a thousand ways,

Upward and downward thwarting and convolved,"

love to bask in the sun's brightest rays, and search for their food amidst his noontide fervour, an immense multitude stir not before the sober time of twilight, and eat only when night has overshadowed the earth. Then only the vast tribe of motlis quit their hiding-places; the "shard-born" beetle with his drowsy hum," accompanied by numerous others of his order, sallies forth ; the airy grrat-flies institute their dances; and the solitary spider stretches his net. All these retire into concealment at the approach of light. Some few larvæ (Agrotis exclamalionis, \&c.) have similar habits, and those of one singular genus before adverted to ( $\left.\Lambda^{\prime} y c l e r o b i u s\right)$ are remarkable for providing in the uight a store of food which they consume in the day: but to the generality of these the period of feeding is indifferent, and most of them seem to eat with little intermission night and day.

Insects, like other animals, take in their food by the mouth (in Chermes and Coccus, indeed, the rostrum seems to be, but really is not, inserted in the breast, between the fore-legs); but there is one exception to this rule. The singular Uropoda vegetans, which is such a plague to some beetles, derives its nutriment from them by means of a filiform pedicle or umbilical cord attached to its anus; and what increases the singularity, sometimes several of these mites form a kind of chain, of which the first only is fixed

1 In the controversy between the commentators on Shakespeare as to whether shard* means wing-eases, dung, or a fragment of earthen-ware, and whether born should be spelled with or without the $e$, it might have thrown some weight into the scale of those who contend for the orthography adopted above, and that the meaning of shard in this place is dung, if they hal been aware that the beetle (Geotrupes stercorarius) is actually born amongst dung, and nowhere else: and that no beetle which makes a hum in flying ean with propriety be stid, as Dr. Johnson has interpreted the epithet in his Dictionary, "to be born amidst broken stones or pots." 'That Shakespeare alluded to the Beetle, and not to the Cockchafer (Melolontha vulgaris), seems clear from the fact of the former being to be heard in all places almost every fine evening in the summer, while the latter is common only in particular districts, and at one period of the year. $-\mathrm{S}$.

* Sharn is the cornmon name of cow-dung in the North; therefore Shakespeare probably wrote sharn-born. ( $M r$. MacLeay.) See for various authorities on this question a note by Mr. Bennett in the Zoological Journal, v. 198.; and Mr. Patterson's "Letters on the Natural History of the Insects mentioned in Shakespeare's Plays." 
by its perlicle to the beetle, each of the remainder being similarly connected with the one that precedes it; so that the nutriment drawn from the bectle passes to the last through the bodies and umbilical cords of the individuals which are intermediate. ${ }^{1}$ Some have regarded these bodies as true eggs; and their analogy with the pedunculated eggs of Trombidinm aquatieum, which als'o seem to derive nourishment from the water-boatmen, Ecc, to which they are fixed, and still more the circumstance of their ultimately losing their pedicle and detaching themselves from the infested beetlês, give plausibility to the idea. Yet these animals are certainly furnished with feet, and have, according to De Geer ${ }^{2}$, a part resembling a mouth - characters which cannot be attributed to any egg.

In the variety of their instruments of nutrition, which you must bear in mind are often quite difierent in the larva and perfect states, insects leave all other animals far behind. In common with them, a vast number (the orders Coleoptera, Hymenoptera, and Orthoptera, and the larvæ of Lepidoptera, some Diptera, \&c.) are furnished with jaws, but of very different constructions, and all admirably adapted for their intended services; some sharp, and arused with spines and branches for tearing flesh, others hooked for seizing, and at the same time hollow for suction; some calculated like shcars for gnawing leaves, others more resembling grindstones, of a strength and solidity sufficient to reduce the hardest wood to powder : and this singularity attends the major part of these insects, that they possess in fact two pairs of jaws, an upper and an under pair, both placed horizontally, not vertically; the former apparently in nost cases for the seizure and mastication of their prey; the latter, when hooked, for retaining and tearing, while the upper comminute it previously to its being swallowed.

To the remainder of the class of insects, a inighty host, jaws would have been useless. Their refined liquid food requires instruments of a different construction, and with these they are profusely furnished. The innumerable tribes of moths and butterflies eat nothing but the honey secreted in the nectaries of flowers, which are frequently situated at the bottom of a tube of great length. They are accordingly provided with an organ exquisitely fitted for its office- a slender tubular tongue, more or less long, sometimes not shortcr than three inches, but spirally convoluted when at rest, like the mainspring of a watch, into a convenient compass. This tongue, which they have the power of instantly unrolling, they dart into the bottom of a flower, and, as through a siphon, draw up a supply of the delicious nectar on which they feed. A letter would scarcely suffice for describing fully the admirable structure of this organ. I must content myself, therefore, with here briefly observing that it is of a cartilaginous substance, and apparently composed of a series of innumerable rings, which, to be capable of such rapid convolution, nust be moved by an equal number of distinct muscles; and that, though seemingly simple, it is in fact composed of three distinct tubes - the two lateral ones cylindrical and entire, intended, as Rcumur thinks, for the reception of air, and the intermediate one, through which alone the honey is conveyed, nearly square, and formed of two separate grooves projecting from the lateral tubes; which grooves, by means of a most curious apparatus of hooks like those in the laminæ of a feather, inosculate into each other, and 
can be either united into an air-tight canal, or be instantly separated, at the pleasure of the insect. ${ }^{1}$

Another numerous race, the whole of the order Hemipter a, abstract the juices of plants or of animals by means of an instrument of a construction altogether different - a holtow grooved beak, often jointed, and containing four bristle-formed lancets, which at the same time that they pierce the food, apply to each other so accurately as to form one air-tight tube, through which the little animals suck up ${ }^{2}$ their repast; thus forming a pump, which, more effective than ours, digs the well from which it draws the fluid.

A third description of insects, those of the order Diptera, comprising the whole tribe of flies, have a sucker formed on the same general plan as that last described, but of a much more complicated and varied structure. It is in like manner composed of a grooved case and several included lancets; but the case, although horny, rigid, and beak-like in some, is in others fleshy, flexible, and more resembling the proboscis of an elephant, and terminates in two turgid liplets: and the accompanying lancets are themselves included in an upper hollow case, in connexion with which they probably compose an air-tight tube for suction. The number and form of these instruments are extremely various. In some genera (Musca) there is but one, which resembles a sharp lancet. Others "(Empis, Asilus) have three, the two lateral ones needle-shaped, that in the middle like a scimitar; together forming so kcen an apparatus, that De Geer has seen an Asilus pierce with it the elytra of a lady-bird; and I have myself caught them with not only an Elater and weevil, but even a Hister in theil mouths. In many horse-flies we find four; two precisely resembling lancets, and two, even to the very handles, buck-hafted carving knives. The blood-thirsty gnat has five, some acutely lanced at the extremity, and others serrated on onc side. The flea, the spider, the scorpion, have all instruments for taking their food of a construction altogether different. But it is inpossible here to attempt even a sketch of the variations in these organs which take place in the apterons genera, and in many of the dipterous larvæ. Suffice it to say, that they all manifest the most consummate skill in their adaptation to the purposes of the insects which are provided with them, and which can often employ them not only as instruments for preparing food, but as weapons of offence and defence, as tools in the building of their nests, and even as feet.

Some insects in their perfect state, thongh furnished with organs of fceding, make no use of them, and consume no food whatever. Of this description are the moth which proceeds from the silk-worm, and several others of the same orler; the different species of gad-flies, and the Ephemeræ-insects whose history is so wcll known as to afford a moral or a simile to those most ignorant of natural history All these live so short a time in the perfect state as to need no food. Indeed it may be laid down as a general rule, that almost all insects in this state eat much less than

1 For a full description of this instrument, see Reaum. i. 125, \&c.

2 The mode, however, in which this is effected, in all inscets furmished with a proboscis, can scarcely be by suction, strictly so called, or the abstraction of air, since the air-vessels of insects do not communicate with their mouths: it is more probably performed in part by capillary attraction: and, as Lamarek has suggested (Syst. des Anim. sans Vertëbres, p. 193.), in part by a succession of undulatious and contractions of the sides of the organ. 
in that of larvæ. The voracious caterpillar, when transformed into a butterfly, needs only a small quantity of honey; and the gluttonous maggot, when become a fly, contents itself with an occasional drop or two of any sweet liquid.

While in the state of larvæ the quantity of food consumed by insects is vastly greater in proportion to their bulk than that required by larger animals. Many caterpiliars eat daily twice their weight of leaves, which is as if an ox, weighing sixty stone, were to devour every twenty-four hours three quarters of a ton of grass - a power of stomach which our graziers may thank their stars that their oxen are not endowed with. A probable proximate cause for this voracity in the case of herbivorous larvæ has been assigned by John Hunter, who attributes it to the circumstance of their stomach not having the power of dissolving the vegetable matters received into it, but merely of extracting from them a juice. ${ }^{1}$ This is proved both by their excrement, which consists of coiled-up and hardened particles of leaf, that being put into water expand like tea: and by the great proportion which the excrement bear's to the quantity of food consumed. From experiments, with a detail of which he has favoured me, made by Cotonel Machell of Beverley on the caterpillars of Euprepia Caja, he ascertained that, though a larva weighing thirty-six grains voided every twelve hours from fifteen to eighteen grains' weight of excrement, it did not increase in weight in the same period more than one or two grains. On the other luand, many carnivorous larva increase in weight in full proportion to the food consumed, and that in an astonishing degree. Redi found that the maggots of flesh-flies, of which, one day, twenty-five or thirty did not weigh above a grain, the next weighed seven grains each; having thus in twenty-four hours become about two hundred times heavier than before. ${ }^{2}$

Some insects have the faculty of sustaining a long abstinence from all kinds of food. This seems to depend upon the nature of their habits. If the insect feeds on a substance of a deficiency of which there is not nuch probability, as on vegetables, \&c., it commonly requires a fiequent supply ; if, on the contrary, it is an insect of prey, and exposed to the danger of being long deprived of its food, it. is often endowed with a power of fasting, whicl would be incredible but for the numerous facts by which it is guthenticated. The ant-lion will exist without the smallest supply of food, apparently uninjured, for six months; though, when it can get it, it will devour ditily an insect of its own size. Vaillant, whose authority may be here taken, assures us that he kept a spider without food under a sealed glass for ten months, at the end of which time, though shrunk in size, it was as vigorous as ever. ${ }^{3}$ And Mr. Baker, so well known for his microscopical discoveries, states that he kept a darkling beetle (Blaps mortisaga) alive for three years without food of any kind. ${ }^{4}$ Some insects, not of a predaceous description, are gifted with a similar power of abstinence. Leeuwenhoek tells us that a mite, which he had gummed alive to the point of a needle and placed before his microscope, lived in that situation eleven weeks ${ }^{5}$; and Mr. Stephens, having, in June, 1831, put a specimen of

1 Obs. on the Animal Economy, p. 221. Compare Reaum. ii. 167.

2 Redi de Insectis, 39.

3 New Travels, i. xxxix.

4 Phil. Trans. 1740 , p. 441. I confess, notwithstanding Mr. Baker's general acctracy, that I suspect sonie mistake here.

- Leeuw. Op. ii. 363. 
Lepisma saccharina (the common "wood" or "sugar fish") in a pill-box containing only a few grains of magnesia, found it, to his great surprise, alive and active in June, 1833, after this protracted confinement, without food, of two years. ${ }^{1}$

In some cases the very want of food, however paradoxical the proposition, seems actually to be a mean of prolonging the life of insects. At least one such instance has fallen under my own observation. The aphidivorous flies, such as Scceva Pyrastri, \&c., live in the larva state ten or twelve days, in the pupa state about a fortnight, and as perfect insects possibly as long, the whole term of their existence in sunmer not exceeding at the very utmost six weeks. But one ${ }^{2}$, which I put under a glass on the $2 \mathrm{~d}$ of Junc, 1811, when about half-grown, and, after supplying it with Aphides once or twice, by accident forgot, I found, to my great astonishment, alive three months after; and it actually lived until the June following without a particle of food. It had, therefore, existed in the larva state more than eight times as long as it would have lived in all its states, if it had regularly undergone its metamorphoses, which is as extraordinary a prolongation of life as if a man were to live 560 years. It is true that its existence was not worth having even to the larva of a fly. For the last eight months it remained without motion, attached by its posterior pair of tubercles to the paper on which it was placed, nanifestiag no other symptoms of life than by moving the fore part of the body when touched, and replacing itself on its belly if turned upon its back. But this was quite enough to prove it still alive. I can attribute this singular result to no other circumstance than its having been deprived of a sufficient quantity of food to bring it into the pupa state, though provided with enough for the attainment of nearly its full growth as larva. Possibly the same remote cause might act in this case, as operates to prolong the term of existence of annual plants that have been prevented from perfecting their seed ; and it would almost seem to favour the hypothesis of some physiologists, who contend that every organised being has a certain portion of irritability originally imparted to it, and that its life will be long or short as this is slowly or rapidly excited - no great consolation this for the advocates for fast-living, unless they are in good earnest in their affected preference of a "short life and a merry one ;" though it must be admitted that they wonld have the best of the argument, were the alternative such a state of torpid insensibility as that with which our larva purchased the prolongation of its existence.

After this general view of the food of insects, and of circumstances connected with it, I proceed to give you an account of some peculiarities in their modes of procuring it.

1 Entom. Mag. i. 526.

2 Not having ever met with another specimen, 1 am unable to say of what precise species of aphidivorous fly it is the larva; nor can I find a figure of it, tlough it approaches near to one given l,y De Geer (vi. t. 7. f. $1-3$ ). Its shape is oblong-oval, length about four lines, and colour pale red speckled with black. Each of the sevel or eight segments which compose the body projects on each side into three serrated flat aculei or teeth; three or four similar but smaller aculei arm the head ; and two. much larger than the rest, the anus, one on each side of the usual bifit protuberance which bears the respiratory plates. A bifid tubercular elevation is also placed in the middle of the back of each seginent. 
The vegetable feeders have, for the most part, but little difficulty in supplying their wants. In the larva state they generally fund themselres placed by the parent insect upon the very plant or substance which is to nourish them; and in their perfect state their wings or feet afford a ready conveyance to the banquet to which, by an unerring sense, they are directed. All nature lies before them, and it is only when their numbers are extraordinarily increased, or in consequence of some unusual destruction of their appropriate aliment, that they perish for want. The description of their food renders unnecessary those artifices to which many of the carnivorous insects are obliged to have recourse; and none of them, if we except the white ants, whose cunning mode of insinuating themselves into houses in tropical climates has been detailed in a former letter, can be said to use stratagem in obtaining their food.

Of the carnivorous species, the greater proportion attack their prey by open violence; such as the predlaccous beetles, the Iclineumons, burrowing wasps, and true wasps; the preying insects (Mantis); the bugs (Geocorisce Latr.); dragon flies (Libellulina), \&c., which have been before adverted to. But a very considerable number, chiefly, however, of one tribe, that of spiders, provide their sustenance solely by artifice and stratagem, the singularity of which, and the admirable adaptation of the instruments by which they take.their prey to the end in view, afford a most wonderful instance of the power and wisdom of the Creator, and have attracted admiration in all ages. A description of these, however, which will require a detailed survey, I must defer to another letter. 


\section{LETTER XIII.}

\section{FOOD OF INSECTS-continued.}

\section{STRATAGEMS EMPLOYED IN PROCURING IT.}

Tre stratagems of insects in obtaining their food are now to engage our attention. I shall not dwell on those inartificial modes of surprising their prey, of which examples may be found amongst almost every order of insects, such as watching behind a leaf or other objeet affording concealment until its approach, but shall proceed to describe the various artifices of the race of spiders, of which there are several hundred distinct species, differing essentially fiom each other both in eharacters and manners.

Many of these are constantly under our eyes; and were it not that we are accustomed to neglect what is the subject of daily oecurrence, we should never behold a spider's web without astonishment. What, if we had not witnessed it, would seem more incredible than that any animal should spin threads; weave these threads into nets more admirable than ever fowler or fisherman fabricated; suspend them with the nicest judgment in the plaee most abounding in the wished-for prey, and there, concealed, watch patiently its approach? In this ease, as in so many others, we neglect actions in minute animals, which in the larger would excite our cndless admiration. How would the world crowd to see a fox which should spin ropes, weave them into an accurately meshed net, and extend this net between two trees for the purpose of entangling a flight of birds! Or should we think we had ever expressed sufficient wonder at seeing a fish which obtained its prey hy a similar contrivance? Yet there would, in reality, be nothing more marvellous in their procedures than in those of spiders, which, indeed, the minuteness of the agent renders more wonderful.

All spiders do not spin webs. A considerable number adopt other means for catching insects. Of these I shall speak hereafter. At present I shall endeavour to give you a clear jdea of the operations of the weavers, explaining successively the instruments by which they spin, the mode of forming their nets, together with the various descriptions of them, and the manner in which they entrap and secure their prey.

The thread spun by spiders is in substance similar to the silk of the silkworm and other caterpillars, but of a much finer quality. As in them, it proceeds from reservoirs, into which it is secreted in the form of a viscid gum ; but in the mode of its extrication is very dissimilar, issuing not from the mouth, but the hinder part of the abdomen. If you examine a spider, you will perceive in this part four or six little teat-like protuberances or spinners. These are the machinery through which, by a process more singular than that of rope-spinning, the thread is drawn. Each spinner 
is furnished with a multitude of tubes, so numerous and so exquisitely fine, that a space often not much bigger than the pointed end of a pin is furnished, according to Reaumur ${ }^{1}$, with a thousand of them. From each of these tubes, consisting of two pices, the last of which terminates in a point infinitely fine, proceeds a thread of inconceivable tenuity, which, inmediately after issuing from it, unites with all the other threads into one. Hence from each spinner proceeds a compound thread; and these four (or six) threads, at the distance of about one-tenth of an inch from the apex of the spinners, again unite, and form the thread we are accustomed to see, which the spider uses in forming its web. The threads, however, are not all of the same thickness, for Leeuwenhoek observed that some of the tubes were larger than others, and furnished a larger thread. Thus, a spider's threat, even spun by the smallest species, and when so fine that it is almost imperceptible to our senses, is not, as we suppose, a single line, but a rope composed of at least four thousand strands. ${ }^{2}$ But to feel all the wonder of this fact we must follow Leeuwenhoek in one of his calculations on the subject. This renowned microscopic observer estimated that the threads of the minutest spiders, some of which are not larger than a grain of sand, are so fine that four millions of them would not equal in thickness one of the hairs of his beard - a tenuity utterly beyond the power of the imagination to conccive. Of the probable accuracy of this calculation you may any day in summer convince yourself, by taling one of the large diadem spiders (Epeira Diadema), and, after pressing its abdomen against a leaf or other substance, so as to attach the threads to the surface-the same preliminary step which the spider adopts in spinning -drawing it gradually to a small distance. You will plainly perceive that the proper thread of the spider is formed of four smaller threads, and these again of threads so fine and numerous, that there cannot be fewer than a thousand issue from each spinner; and if you pursue your researches with the microscope, you will find that precisely the same takes place in the minutest species that spins. You will inquire what can be the end of

1 Teaum. Mém. de T Acad. de Paris, An. 1713. 211.-De Geer, vii. 187. See also Hoole's Leeuwenhoek, i. 41.-t. 2. f. 20-22. Leeuwenhoek examined a spinner that was not so big as a eommon grain of sand, and the number of tubes issuing from it was more than a liundred. He affirms that, besides the larger spinners, in the space between them there are four smaller oues, each furnished with organs for spinning threads, but smaller and fewer in number. Latreille speaks only of a thousand spinners from each teat, and of six thousand threads from the wholebut he does not enter further into the subject. Nout. Dict. d'Hist. Nat. ii. 2is.

$2 \mathrm{Mlr}$. Blackwall, however, as the result of his examinations with microscopes of high powers, denies that spiders' threads are compused of so many fine lines as Leenwenhoek, Lyonnet, Treviranus, \&c., have supposed. He has not, he says, found that any lines ever issue, as they describe, from the minute apertures without projecting margins, situated between the papilla or spinning tubes, which last alone he regards as the sole line-forming instruments, and the total number of these in the larger adult species of Epeira, which are best provided with them, he does not esti. mate at much above a thousand, while in the common house spider they are below four hundred, and in other species not above one hundred, and in some much fewer. As the statements of sucli careful and generally accurate observers as Reaumur, De Geer, Leeuwenlioek, Lyonnet, Trevirants, and other eminent naturalists, all in the main agreeing and confirming each other, ought not to be hastily set aside and withont the fullest investigation, it has been thought best, without materially altering the text, simply to point out in the present note Nr. Blackwall's different conclusions, and to refer the reader for the details on which they rest to his paper on tile Hammule of Spiders in the 18th vol. of the Linnaan Transactions, p. 219. 
machinery so complex? One probable reason is, that it was necessary for drying the gum sufficiently to form a tenacious line, that an extensive surface should be exposed to the air, which is admirably effected by dividing it at its exit from the abdomen into such numerous threads. But the chief eanse, perhaps, is the occasion (hereafter to be adverted to) which the spider sometimes has to employ its threads in their fuer and unconneeted state before they unite to form a single one. The spider is gifted by her Creator with the power of closing the orifices of the spinners at pleasure, and can thus, in dropping from a height by her line, stop her progress at any point of her descent; and, according to Lister ${ }^{1}$, she is also able to retract her threads within the abdomen; but this is doubted, and with apparent reason, by De Geer. ${ }^{2}$

The only other instruments employed by the spider in weaving are her feet, with the claws of which she usually guides, or keeps separated into two or more, the line from behind ; and in many species these are admirably adapted for the purpose, two of them being furnished underneath with teeth like those of a comb, by means of which the threads are kept asunder. But another instrument was wanting. The spider, in ascending the line by which she has droppet herself from an eminence, winds up the superfluous cord into a ball. In performing this the pectinated claws would not have been suitable. She is therefore furnished with a third elaw between the other two ${ }^{3}$, and is thus provided for every occasion.

The situations in which spiclers place their nests are as varions as their construction. Some prefer the open air, and suspend them in the midst of shrubs or plants most frequented by flies and other small insects, fixing them in a horizontal, a vertical, or an oblique direction. Others select the corners of windows and of rooms, where prey al ways abounds; while many establish themselves in stables and neglected out-houses, and even in cellars and desolate places in which one wonld scarcely expeet a fly to be caught in a month. It is with the operations of these last especially that we are accustomed to associate the ideas of neglect and desertion by man -associations which, both in painting and allegory, have been often happily applied. Hogarth, when he wished to produce a speaking picture of neglected charity, clothed the poor's box in one of his pieces with a spider's net; and the Jews, in one of the fables with which they have disfigured the records of Holy Writ, have not less ingeniously availed themselves of the same idea. They relate that the reason why Saul did not discover David and his men in the cave of Adullam ${ }^{4}$ was, that God had sent a spider which had quickly woven a web across the entrance of the cave in which they were concealed; which being observed by Saul, he thonght it useless to investigate further a spot bearing such evident proofs of the absence of any human being. ${ }^{5}$

The most incurious observer must have remarked the great difference which exists in the construction of spiders' webs. Those which we most

\section{Hist. Anim. Ang. p. 8.}

2 De Geer, vii. 189. Mr. Blackwall has explained that this apparent retraction which is chiefly perceptible in the line forming the concentric circles of the greometric spiders, is an optical illusion, depending upon its extreme elasticity, which admits of its being exlended several inches and of contracting again into a minuto globule. (Zool. Journ. v. 187.)

3 Leeuw. Opusc. iii. $317, \mathrm{f} .1$.

4 Sam. xxiv. 4. 
commonly see in houses are of a woven texture similar to fine ganze, and are appropriately termed webs; while those most frequently met with in the fields are composed of a series of concentric circles united by radii diverging from the centre, the threads being remote from each other. These last, which in their simple state, or still more when studded with dew drops, you must have a thousand times admired, are with greater propriety termed nets; and the insects which form them proceeding on geonetrical principles may be called geometricians, while the former can aspire only to the humbler denomination of weavers. I shall endeavour to describe the process followed in the construction of both, beginning with the latter.

The weaving spider which is found in houses, laving selected some corner for the site of her web, and determined its extent, presses her spinners aqainst one of the walls, and thus glues to it one end of her thread. She then walks along the wall to the opposite side, and there in like manner fastens the other end. This thread, which is to form the outer margin or selvage of her web, and requires strength, she triples or quadruples by a repetition of the operation just described; and from it she draws other threads in various directions, the interstices of which she fills up by running from one to the other, and connecting them by new threads until the whole has assumed the gauze-like texture which we see. Books of natural history, all copying from one another, have described these kinds of web as fabricated of a regular warp and woof, or of parallel longitudinal lines crossed at right angles by transverse ones glued to them at the points of intersection. This, however, is clearly erroneous, as you will see by the slightest examination of a web of this kind, in which no such regularity of texture can be discovered.

The webs just described present merely a simple horizontal surface, but others more frequently seen in out-houses and amongst bushes possess a very artificial appendage. Besides the main web, the spider carries up from its edges and surface a number of single threads, often to the height of many feet, joining and crossing each other in various directions. Across these lines, which may be compared to the tackling of a ship, flies seem unable to avoid directing their flight. The certain consequence is, that in striking against these ropes they become slightly entangled, and, in their endeavours to disengage themselves, rarely escape being precipitated into the net spread underneath for their reception, where their doom is inevitable.

But the net is still incomplete. It is necessary that our hunter should conceal her grim visage from the game for which she lies in wait. She does not, therefore, station herself unon the surface of her net, but in a small silken apartment constructed below it, and completely hidden from view. "In this corner," to use the quaint translation of Pling by Philemon Holland, Doctor in Physic", "with what subtiltie dotl" she retire, making semblance as though she meant nothing less than that she doth, and as if she went about some other business! nay, how close lieth she, that it is impossible to see whether any one be within or no!" But thus removed to a distance fiom her net and entirely ont of sight of it, how is she to know when her prey is entrajped? For this difficulty our ingenious weaver has provided. She has tiken care to spin several threads 
from the edge of the net to thai of her hole, which at once inform her by their vibrations of the capture of a fly, and serve as a bridge on which in an instant she can run to secure it.

Another speeies, Chubiona atrox, for an account of whose habits we are indebted to Mr. Blackwall, resides in a funnel-shaped silken tube of slight texture, in the corners of windows, or erevices in old walls, \&c., whence it extends lines intersecting each other irregularly at varions angles, to which it attaches other lines, or rather fasciculi, of very fine zig-zag threads of a pale blue tint when recent, and of a much more eomplieaterl structure than the former, and which adhere strongly to any flies, \&c., coming into contact with them, not from any viscidity, but from their extremely fine filaments attaching themselves to the inequalities in the surface of their prey. These pale-blue fasciculi $M \mathrm{r}$. Blackwall found to proceed from two additional spinners (or mammulæ) peculiar to this species and to three species of Drassus, which are also all four remarkable for having the metatarsal joint of their posterior legs furnished with a very curious combing or rather curling instrument, composed of two parallel rows of eurved spines, named by Mr. Blackwall Calamistrum, with which they comb out the peenliar silky material as it issues from these mammulæ into that flocculous texture which gives the pale-blue fasciculi in question their power of retaining the insects that touch then.. ${ }^{1}$

You will readily conceive that the geometrical spiders, in forming theil concentric cireled nets, follow a process very different from that just described, than which, indeed, it is in many respects more curious. As the net is usually fixed in a perpendicular or somewhat oblique direction, in an opening between the leaves of some shrub or plant, it is obvious that round its whole extent will be required lines to which can be attached those ends of the radii that are furthest from the centre. Accordingly the construction of these exterior lines is the spider's first operation. She seems careless about the shape of the area which they enclose, well aware that she can as readily inseribe a circle in a triangle as in a square, and in this respect she is guided by the distance or proximity of the points to which she can attach them. ${ }^{2}$ She spares no pains, however, to strengthen

1 Linn. Trans. xvi. 472. and xviii. 223. According to MI. Walckenaer's arrangement, the genus Clubioma comes under his division of Errantes, or Wanderers, but certainly C. atrox, which, since ny attention was clirected to it by Mr. Blackwall's very interesting accunt of its economy as above, I liave very frequently observed in its natural abode and in glasses in which I liare kept it, ranges better under his Sédentuires or Selentary Spiders, as I have placed it, as I do not believe that it ever stirs from its nest until summoned by the vibrations of its net extended round the opening; and this net, though more irregular in its structure, is as truly a net as thuse of Epeira. I may here mention respecting this species two facts not noticel by Mr. Blackwall, that it has not the power of elimbing up a vertical surface of glass; and that, however old and dusty its main net may be, the pale blue curled or looped fasciculi seem very often renewed, as a pocket-lens rarely fails to detect them in a recent state.

2 It sometimes happens that the end of the lower line of the triangle in which the geometric spilers usually fix their nets, having been attached to a small pebble (or bit of gravel) lying on the ground, this pebble (probably from the spider's tightening its horizontal lines) is drawn up to a considerable height, and swings like a pendulum, as I saw many instances, at first, to my no small surprise, in the Giardino Publico of Milan in 1832 (vide Spence in Ioudon's MIag. of Nat. Hist. v. 689.) ; and as has since been observed by W. W. Samders, Esq. at IVandsworth. (Trans. Ent. Soc. Lond. i. 127.) In an American newspaper, the Louell Courier, 
and keep them in a proper degree of tension. With the former view she composes each line of five or six or even more threads glued together; and with the latter she fixes to them from different points a numerous and intricate apparatus of smaller threads. Having thus completed the foundations of her snare ${ }^{1}$, she proceeds to fill up the outline. Attaching a thread to one of the main lines, she walks along it, guiding it with one of her hind feet that it may not touch in any part and be prematurely glued, and crosses over to the opposite side, where, by applying her spinners, she firmly fixes it. To the middle of this diagonal thread, which is to form the centre of her net, she fixes a second, which in like manner she conveys and fastens to another part of the lines encircling the area. Her work now proceeds rapidly. During the preliminary operations she sometimes rests, as though her plan required meditation. But no sooner are the marginal lines of her net firmly stretched, and two or three radii spun from its centre, than she continues her labour so quickly and unremittingly that the eye can scarcely follow her progress. The radii, to the number of about twenty, giving the net the appearance of a wheel, are speedily finished. She then proceeds to the centre, quickly turns herself round, and pulls each thread with her feet to ascertain its strength, breaking any one that seems defective and replacing it by another. Next, she glues immediately round the centre five or six small concentric circles, distant about half a line from each other, and then four or five larger ones, each separated by a space of half an inch or more. These last serve as a sort of temporary scaffolding to walk over, and to keep the radii properly stretched while she glues to them the concentric circles that are to remain, which she now proceeds to construct. Placing herself at the circumference, and fastening her thread to the end of one of the radii, she walks up that one, towards the centre, to such a distance as to draw the thread from her body of a sufficient length to reach to the next; then stepping across, and conducting the thread with one of her hind feet, she glues it with her spinners to the point in the adjoining radius to which it is to be fixed. This process she repeats until she has filled up rearly the whole space from the circumference to the centre with concentric circles, distant from each other about two lines. She always, however, leaves a vacant interval around the smallest first spun circles that are nearest to the centre, but for what end I am unable to conjecture. Lastly, she runs to the centre and bites away the small cotton-like tuft that united all the rarlii, which being now held together by the circular threads, have thus probably their clasticity increased; and in the circular opening resulting from this procedure, she takes her station and watches for her prey. ${ }^{2}$

was an account of a watchmaker having found one morning a gold ring weighing twelve grains, which he had left on his bench, suspended an inch high to a spider's thread, by which in the course of a week it was elevated eight inches.

I I am not certain whether the garden spiler does not more frequently form one or two of the principal radii of the net before she spins the exterior lines.

2 Mr. Blackwall, in his valuable paper "On the Manner in which the Geometric Spiders construct their Nets," in the Zoological Journal, vol. v. p. 181., has remarked that the above description is not applicible thronghout to all geometric spiders, as some of them do not entırely surromnd the radii of their nets with concentric circles, but leave one radius free, which serves as a sort of ladder for access to the net ; and as in general they do not bite away the small cotton-like tuft that unites the rulii in the centre, nor place themselves there to watch their prey, but retire under a leaf 
In the above description, which is from my own observations, I have supposed the spider to fix the first and main line of her net to points from one of which she could readily climb to the other, dragging it after her ; and many of these nets are placed in situations where this is very practicable. They are frequently, however, stretched in places where it is quite impossible for the spider thus to convey her main line - between the branches of lofty trees having no connection with each other; between two listinct and elevated buildings; and even between plants growing in water. Here then a difficulty occurs. How does the spider contrive to extend her main line, which is often many feet in length, across inaccessible openings of this description?

With the view of deciding this question, to which I could find no very satisfactory answer in books, I made. an experiment, for the idea of which I am indehted to a similar one recorded by Mr. Knight', who informs us that if a spider be placed upon an upright stick having its bottom immersed in water, it will, after trying in vain all other modes of escape, dart out numerous fine threads so light as to float in the air, some one of which, attaching itself to a neighbouring object, furnishes a bridge for its escape. It was clear that if this mode is pursued by the geometric spiders, it would go considerably towards furnishing a solution of the difficulty in question. I accordingly placed the large diadem spider (Épeira Diadema) upon a stick about a foot long, set upright in a vessel containing water. After fastening its thread (as all spiders do before they move) at the top of the stick, it crept down the side until it felt the water with its fore feet, which seem to serve as antennæ: it then immediately swung itself from the stick (which was sliglutly hent) and climbed up by the thread to the top. This it repeated perhaps a score times, sonietimes creeping down a different part of the stick, but more frequently down the very side it had so often traversed in vain. Wearied with this sameness in its operations, I left the room for some hours. On my return I was surprised to find my prisoner escaped, and not a little pleased to discover, on further examination, a thread extended from the top of the stick to a cabinct.

or other shelter, and there construct a cell in which the spicler remains concealed till the vibrations of a strong line of communication, composed of several united threads, which she has spun fiom the centre of the net to her cell, inform her of the capture of a fly, to which she then rushes along this briclge. This criticism as to the too extensive generalisation of the procednres of the garden spider above described is perfeetly just, as my own observations since the publication of the last edition of this work, but long before 1 had seen Mr. Blackwall's paper, had shown. me. My excuse must be that the observations above recorled (which are left precisely as originally written about the year 1512), having been made on the spur of the oceasion in my garden at Lrypool, near Hull, when to my surprise 1 could not find in books any intelligible account of the way in which the geometric spiders construct their nets, were necessarily confined to the common garden species alone found there, and my attention having been subsequently fully occupiel in other directions, it did not occur to me that probably the operations of other species might differ from those 1 had witnessed. These variations, however, do not affect the aceuracy of the description above given of the procedures of the speeies referred to, one of the commonest of the tribe, which deseription also, except in the two particulars above stated, is generally applicable to the whole geometric race, and has been in great part adopted by Mr. Blackwall in lis more full detail of their operations.

1 Treatise on the Apple and Pear, p. 97. 
seven or eight inches distant, which thread had doubtless served as its brilge. Eager to witness the process by which the line was constructed, I replaced the spider in its former position. After frequently creeping down and mounting up again as before, at length it let itself drop from the top of the stick, not as before by a single thread, but by two, each distant from the other about the twellith of an inch, guided as usial by one of its hind feet, and one apparently smaller than the other. When it had suffered itself to descend nearly to the surface of the water, it stopped short, and, by some means which I could not distinctly see, broke off close to the spinners the smallest thread, which, still adhering by the other end to the top of the stick, floated in the air, and was so light as to be carried about by the slightest breath. On approaching a pencil to the loose end of this line, it clid not adhere from nere contact. I therefore twisted it once or twice round the pencil, and then drew it tight. The spider, which had previously climbed to the top of the stick, immediately pulled at it with one of its feet, and finding it sufficiently tense, crept along it, strengthening it as it proceeded by arother thread, and thus reached the pencil. ${ }^{1}$

That this therefore is one mode by which the geometric spiders convey the main line of their nets between distant oljects, there can be no doubt, but that it is the only one is not so clear. If the position of the main line be thus determined by the accidental infuence of the wind, we might expect to see these nets arranged with great irregularity, and crossing each other in every direction; yet it is the fact that, however closely crowded they may be, they constantly appear to be placed not by accident but design, commonly ruming parallel with ench other at right angles with the points of support, and never interfering. Another objection too presents itself. From the experiment related, it is clear that the main line of the net can never be longer than the height of the object from which the spider dropped in forming it. But it is no uncommon thing to see nets in which these lines are a yard or two long fastened to twigs of grass not a foot in height, and yet separated by obstacles effectually precluding the possibility of the spider's having dragged the lines from one to the other. Here, therefore, some other process munst have been used.

Both these difficulties would be removed by adopting the explanation of an anonymons antlor in the Journal de Physique ${ }^{2}$, founded, as he asserts, on actual observation. He says that he saw a small spider, which he had forced to suspend itself hy its thread from the point of a feather, shoot out obliquely in opposite clirections other smaller threads, which attached themselves in the still air of a room, withont any influence of the wind, to the oljects towards which they were directed. He, therefore, infers that

1 Some time after making this experiment I stumbled upon a passage in Redi (De Insectis, p. 119.), from which it appears that Blancanus, in his Commentaries upon Aristolle, has related a series of observations which led him to precisely the same result. Lehmann, too, in a paper in the Transactions of the Society of Naturalists at Berlin (translated in the Philosophical Mugazine, xi. 323.), has given an explanation somewhat similar of the operations of this very spider, but 1 an inclined to think erroneous in some particulars. He describes it as emitting uumerous floating threads at the commencement of its descent. That he is mistaken in supposing these threads to be more than one, is proved by the fact which I have observed - that even that one sometimes breaks by the weight of the spider. How then conld an insect almost as big as a gooseberry be supported by a line of tho tenuity here attributed to it?

${ }_{2}$ An. vii. Viudémiaire. Trauslated in Phil. Mag. ii. 275. 
spiders have the power of shooting out threads and directing them at pleasure towards a determined point, judging of the distance and position of the object by some sense of which we are ignorant. Something like this manceuvre I once myself witnessed in a male of the smatl garden spider (Epeira? reticulati). It was standing midway on a long perpendicular fixed thread, and an appearance caught my eye of what seemed to be the emission of threads fiom its projected spinners. I therefore moved my arm in the direction in which they apparently proceeded, and, as I suspected, a floating thread attached itself to $\mathrm{my}$ coat, along which the spicler crept. As this was connected with the spinners of the spicler, it could not have been formed in the same way with the secondary thread of $E$. Diadema above described.

Probably in this case, as in so many others, we bewilder ourselves by attempting to make nature bend to generalities to which she disclains to submit. Different spiders may lay the foundations of their net in a different manner; some on the plun adopted by E. Diadema; others, as Lister long ago conjectured ', by shooting ont threads in the mode of the flying species, as in the instances recorded by the anonymons observer and Mr. Knight. Nor is it improbable that the same species has the power of varying its procedures according to circumstances.

How far these suppositions are correct it is impossible to determine without further experiments, which it is somewhat strange should not before now have been instituted. Pliny thought it nothing to the credit of the philosophers of his day, that while they were disputing about the number of heroes of the name of Hercules, and the site of the sepulchre of Bacchus, they should not have decided whether the queen bee had a sting or not ${ }^{2}$; but it seems much more discreditable to the entomologists of ours, that they should yet be innorant how the geometric spiders fix their nets. One excuse for them is, that these insects generally hegin their operations in the night, so that, though it is very eusy to see them spinning their concentric circles, it is seldom that they can be caught linying the foundations of their snares. Yet doubtless the lucky moment might be hit by an attentive observer, and I shall be glad if my attempt to describe their more ordinary operations should induce you to aim at signalising yourself by the discovery. If you failed in solving every difficulty, you would at least be rewarded by witnessing their industry, ingenuity, and patience.

For the latter virtue they have no small oceasion. Incapable of actively pursuing their prey, they are dependent upon what chance conducts into their toils, which, especially those spread in neglected buildings, often remain for a long period empty. Even the geometricil spiders, which fix themselves in the midst of a well-peopled district in the open air, have freciuently to sustain a protracted abstinence. A continued storm of wind and rain will demolish their nets, and preclude the possibility of reconstructing them for many days or sometimes weeks, during which not even a single gnat regales their sharp-set appetites. And when at length formed anew or repaired, an unlucky bee or wasp, or an overgrown fly, will perversely entangle itself in toils not intended for insects of its bulk, and in disengaging itself once more leave the net in ruin. All these trials move not our philosophic race. They patiently sit in their watching place in the same posture, scarcely even stirring but when the expected prey appears. 
And however repeatedly their nets are injured or destroyed, as long as their store of silk is unexhausted, they repair or reconstruet them without loss of time.

The web of a house-spider will, with oceasional repairs, serve for a considerable period; but the nets of the geometric spiders are in favourable weather renewed eithei wholly, or at least their concentric circles, every twenty-four hours, even when not apparently injured. This difference in the operations of the two tribes depends upon a very remarkable peculiarity in the conformation of their snares. The threads of the housespider's web are all of the same kind of silk; and flies are canght in them from their claws becoming entangled in the fine neshes which form the texture. On the other hand, the net of the garden spider is composed of two distinct kinds of silk; that of the radii not adhesive, that of the circles extremely riscit. ${ }^{1}$ The cause of this difference, which, when it is consilered that both sorts of silk proceel from the same instrument, is truly wonderful, may be readily perceived. If you examine a newly formed net with a microscope, you will find that the threads composing the outline and the radii are simple, those of the circles closely studded with minute dew-like globules, which, from the elasticity of the thread, are easily separable from each other. That these are in fact globules of viseid gum, is proved by their adhering to the finger and retaining dust thrown upon the net, while the unadhesive radii and exterior threads remain unsoiled. It is these gummed threads alone which retain the insects that fly into the net; and as they lose their viseid properties by the action of the air, it is necessary that they shonld be frequently renewed. ${ }^{2}$

1 May not the spinners mentioned by Leeurenhoek be peculiar to the retiary spiders, and furnish this viscid thread?

2 The accuracy of the fact above stated as to the essential difference between the radii and concentric circles from the presence of globules of gum on the latter only has been denierl by the author of Insect Architecture; but as it has been fully confirmed by Mr. Blackwall, and as any one, who will exanine a newly-made spider"s net with a common pocket lens, and throw a little dust on it, will see for himself what is here describen, it is neetless to refute an error that has most probably arisen from the examination of old nets, which, after being exposed to wind and rain, often lose the globules of gum from the circles. (Vide Spence in Loudon's ILag. of Nat. Hist. 1832 , vol. v. p. 689.)

When the writer of these letters on the food of insects, in examining for himself the whole process, from first to last, of the construction of the nets of the garden geometric spicler, obscrved this remarkable difference between the radii and concentric circles, he had certainly no iden that lie hid made any discovery, as he never dreamed that so obvious a peculiarity in objects so constantly in view had not been very frequently noticel, and even described, in books, though he had not himself chancel to meet with any such description. But the denial of the fact itself haring subsequently drawn his attention to the subject, he is inclined to believe (but without speaking positively on a question which he has not now an opportunity of investigating) that the existence of these gum globules and their peculiar object were first distinctly made known in the present work*; a circumstance which, if the fact

* Dr. Ilooke, indeed, in a passage in his Micrographia, p. 202., quoted by Mr. Blackwall (Iimn. Trans. xvi, 479.), speaks of the radii of geometric spiders' nets being "all over knotted or pearled with small tramsparent globules, not unlike small crystal beads or seed-pearls strung on a clew of silk;" but, as he immediately adds, "which, whether they were so spun by the spider or by the adventitious moisture of a fog (which I have observed to cover all those filaments with such crystalline beads), I shal' not now dispute;" it is clear that he liad no distinct or correct ideas as to the origin of these globules, nor the slightest conception of their use. 
In this renewal, as above hinted, the geometrical spiders are constantly regulated by the future probable state of the atmosphere, of which they have such a nice perception, that M. Q. D'Isjonval, to whom we are indebted for the fact, has proposed them as most arcurate barometers. He asserts that if the weather be about to be viriable, wet and stormy, the main threads which support the net will be certainly short; but if fine settled weather be on the point of commencing, these threals will be as invariably very long. ${ }^{1}$ Without going the length, with M. D'Isjonval, of deeming his discoveries important enough to regulate the march of armies, or the sailing of fleets, or of proposing that the first appearance of these barometrical spiders in spring should be announced by the sound of trumpet, I have reason to suppose from my own observations that his statements are in the main accurate, and that a very good idea of the weather may be formed from attending to these insects.

The spiders which form geometrical nets differ from the weavers also with respect to the situation in which they watch for their prey. They do not conceal themselves under their net, but either place themselves

prove to have been so, deserves being held out to the young entomologist in proof how widle a tield of discovery must yet remain to be explorel, when points at once so curious and yet obvious in the economy of a spider, found in every garden, had so long remained unnoticed.

Another reason for directing attention to this fact is to recommend strongly to comparative anatomists and microscopical observers an investigation of the node in which the geometric spiders are enabled to spin two different kinds of silk, one gummy and the other not, and whether the spinners noted by Leeuwenhoek, as suggested in a preceding note, are concerned in the process - points to which Mr. Blackwall, in his examination of the spinning apparatus of spiders (Linn. Trans. xviii. 219.), has not adverted. It is obvious that these spiders must either have two distinet sets of spinners, of which one spins the gummy and the other the unadhesive threads, or else, if all the threals proceed from the same spinners, the spider must have the means of passing the threads of the concentric circles through a reservoir of gum so as to stud them with the globules of this substance which give them their fly-catching viscidity. There is, however, a considerable difficulty in the way of this last supposition, for as the threads at their issuing from the spinners are, as has been already explained, so numerous, it is not easy to conceive how, after being united into one, they can be passed through any gum reservoir, nor how, if they were so passed, the gum, instead of being applied to the entire surface of the threads, should come to be divided in the process into distinct and bearl-like globules. The subject is certainly lighly curious and interesting, and well deserves investigation for an additional reason originally noticed above and confirmed by Mr. Blackwall, that the circular lines differ from the radii and main lines of the net, not only in being studded with gum globules, but in being fir more elastic, which elasticity (as well as the viscidity of the gum globules) he found remained unimpaired for more than seven months in a net of Epeira diadema constructed in a glass jar which was placed in a dark closet. (Linn. Trans, xvi. 479.)

Before concluding this long note, an omission in the account of the geometric spirlers' forming their nets, in the text, which las been supplied by Mr. Blackwall, should be given, namely, that in the process of spinning the concentric gummy circles, the spider, as she proceeds, destroys the first made distunt unadhesive circles which had served her as a sciffolding in placing the former. (Zool. Journ. v. 183.) A curious calculation, also, of MIr. Blackwill's, as to the number of distinct globules of gum in a geometric spiter's net, should be noticed. 'These he found to be 87,350 in a net of arerage dimensions, and 120,000 in a large net of fourteen or sixteen inches diameter; and yet Epeira apoclysa will, if uninterrupted, complete its snare on an average in fort $y$ minutes. $(1,478$.)

1 Brez, La Flore des Insectophiles, 129. 
in the centre with their head downwards, and retire to a little apartment formed on one side under some leaf of a plant, only when obliged by danger or the state of the weather, or as before stated, constantly hide themselves in a similar retreat. The moment an unfortunate fly or other insect touches the net, the spider rushes towards it, seizes it with her fangs, and if it be a small species at once earries it to her little cell, and, having there at leisure sucked its juices, throws ont the earcass. If the insect be larger, and struggle to escape, with surprising address she envelopes it with threads in various directions, until both its wings and legs being effectually fastened, she carries it off to her den. If the captured insect be a bee or a large fly so strong that the spider is sensible that it is more than a match for her, she never attempts to seize or even entangle it, but on the contrary assists it to disengage itself, and often breaks off that part of the net to which it hangs, content to be rid of such an unmanageable intruder at any price. - IThen larger booty is plentiful, these spiders seem not to regard smaller insects. I have observed them in autumn, when their nets were almost covered with the Aphides which filled the air, impatiently pulling them off and dropping them untouched over the sides, as though irritated that their meshes should be occupied with such insignificant game. - A speeies of spider described by Lister (Epeira conica), more provident than its brethren, suspends its prey in the meshes above and below the eentre, and it is not uneommon to see its larder thus stored with several flies. ${ }^{1}$

You must not infer that the toils of spiders are in every part of the world formed of such fragile materials as those which we are accustomed to see, or that they are everywhere contented with small inseets for their food. An author in the Philosophical Transactions asserts, that the spiders of Bermudas spin webs between trees seven and eight fathoms distant, which are strong enough to ensnare a bird as large as a thrush. ${ }^{2}$ And Sir G. Stamton informs us, that in the forests of Java, spiclers' webs are met with of so strong a texture as to require a sharp cutting instrument to make way through thenı. ${ }^{3}$ The nets of a large geometric spider, Nephila (Epeira) clavipes, are sufficiently strong to arrest and entangle the smaller species of humming-birds; but Mr. W. S. MacLeay, in whose garden at Cuba these nets abounded, never saw or heard of any birds being eaught in thenı. ${ }^{4}$ On the other hand, however, he observed in the grounds of Elizabeth Bay, near Sydney (Australia), in the beginning of 1840, a young bird (Zosterops dorsalis), which had been apparently dead some days, suspended in the geometrieal net of an enormons undescribed spider of the same family (Epeiride), which was in the act of sueking its juices; and his father, Alexander MacLeay, Esq., informed him that he had also been witness to a similar oecurrence; but he considers these facts as exceptions to the general rule of this spider's insectivorous habits and to be of rare occurrence, since, as far as lie could learn, no other persons had observed them. ${ }^{5}$

Nor must you suppose that all the spiders of this country which eatch their prey by means of snares follow the same plan in construeting them as the weavers and geometricians whose operations I have endeavoured to deseribe. The form of their snarcs and the situation in which they place

1 Lister, Hist. Anim. Ang. 32, tit. 4.

2 Phil. Tr. 1668, p. 792.

3 Fimbassy to China, i. 343.

4 Trans. Zool. Soc, Lond, i. 193.

5 Ann, Nat. Hist, viii. si24. 
them are so various, that it is impossible to enumerate more than a few of the most remarkable. Agelene labyrintlica extends over the blades of grass a large white horizontal net, having at its margin a cylindrical cell, in the bottom of which, secure from birds and defended from the rays of the sun, the spiler lies concealed, whence, on the slightest movement of her net, she rushes ont upon her prey. Aranea latens $\mathrm{F}$. conceals itself under a small net spun upon the upper surface of a leaf, and thence seizes upon any insect that chances to pass over it. Theridium 13-gutlatum forms under stones and in slight furrows in the ground a net consisting of threads spun without any regularity in all directions, but so strong as to entrap grasshoppers, which are said to be its prineipal food; and a similar inartificial snare of simple threads is often spun in windows by Theridium bipunctatum and several other species. Segestria senoculata and its affinities conceal themselves in a long cylindrical straight silken tube, from the mouth of which they stretch out their six anterior feet, whose extremities rest upon as many diverging threads: thus, as soon as an insect walks across any of the threads (which are eight or ten inches long) the insect's toes give it warning of prey being at hand, when it rushes out and seldom fails to secure its vietim.

"The spider's touch, how exquisitely fine!

Feels at each thread, and hres along the line."

M. Homberg tells us that he has seen a vigorous wasp carried off and destroyed by one of these species.

The spiders to which I have hitherto adverted seize their prey by uneans of webs or nets; but a very large number, though, like the former, they spin silken cocoons for containing their eggs, and often line their cells and places of retreat with silk, never employ the same material in constructing similar snares, of which they make no use.

These may be separated into two grand divisions : the first comprising those which conceal themselves and lic in ambuscade for their prey, and sometimes run after it a short distance; the second, those which are constantly roaming about in every direction in search of it, and seize it by open violence. The former Walckenaer, in his admirable work on spiders, has designated by the name of Vagrants, the latter by that of Hunters; terming those already mentioned which spin webs and nets, Sedentaries: if to these you add the Swimmers, or those species which eatch their prey in the water, you will have an idea of the general manners of the whole race of spiders. ${ }^{2}$

The artifices of that tribe which Walckenaer has named vagrants are various and singular. Several species conceal themselves in a little cell formed of the rolled up leaf of a plant, and thence dart upon any insect which chances to pass; while others select for their place of ambush a hole in a wall, or lurk behind a stone, or in the bark of a tree. Aranca calycina L. more ingeniously places herself at the botton of the calyx of a dead flower, and pounces upon the unwary flies that come in search of honey; and $A$. armondinacea buries herself in the thick panicle of a reed, and seizes the luckless visitors enticed to rest upon her silvery concealment. Many

1 Some slight alterations in M. Walckenaer's original divisions, but which need not be here particularised, have been made in his later works or spiders 
of this tribe at times quit their habitations, and by various stratagems contrive to come within reach of their prey, as by pretending to be dead, hiding, themselves behind any slight projection, \&c. A white species I have often observed squatted in the blossom of the hawthorn or on the flowers of umbelliferous plants, and is thus effectually concealed by the similarity of colour.

Foremost amongst the spiders comprehended by Walekenaer under the general name of hunters, which seareh after and openly seize their prey, must be enumerated the monstrous Mygale avicularia, at least two inches long, and the expansion of whose feet has been sometimes found to extend nearly a foot wide, which takes up its abode in the woods of South Ameriea, and has been reputed by Madame Merian to seize and devour even small birds; but this is wholly denied by Langsdorf, who deelares that it eats only insects ${ }^{1}$; a conclusion which is confirmed by Mr. W. S. MacLeay from his own observations on this species, which was very common in his garden in Cuba, and did him great service by devouring the $J_{u l l}$, Achetce, eockroaches, \&e., which are so injurious there to eultivated vegetables. It issues from its hole at night only (never in the day time), to attack these insects; and so far from having any bird-eatching propensities, Mr. MacLeay having placed a living humming-bird in the tube of a Mygale, it deserted it, leaving the bird untonehed. ${ }^{2}$ It is, however, very possible that other speeies may attack birds, as is asserted of Mygale Blondii by Palisot de Beauvais, of Mr. fuscinta by Pereival in his Account of Ceylon, and of a species common in Martinique by M. Moreau de Jonnès. ${ }^{3}$ Mygale avicularia, as well as other tropical species, the European Cteniza cementaria, and many others, construct in the ground very singular eylindrieal eavities, and therein earry and devour their prey. These, being rather the habitations of insects than snares, I shall describe in a subsequent letter. Lycosa saccata, the species whose affection for its young I have before detailed, and not a few others of the same family, common in this country, in like manner seize their prey openly, and when caught carry it to little inartificial eavities under stones. Dolomedes fimbriatus ${ }^{4}$ hunts along the margins of pools; and Lycosa piratica and its congeners not only chase their prey in the same situation, but, venturing to skate upon the surface of the water itself,

\section{". . . bathe unwet their oily forms, and dwell}

With feet repulsive on the dimpling well."

The Rev. R. Sheppard has often noticed, in the fen ditches of Norfolk, a very large spider, which actually forms a raft for the purpose of obtaining its prey with more facility. Keeping its station upon a ball of weeds abont three inehes in diameter. probuhly held together by slight silken cords, it is wafted along the surfaee of the water upon this floating island, which it quits the monent it sees a drowning insect, - not, as you may conceive, for the sake of applying to it the process of the Ifumane Society, but of

1 Bermerknngen auf einer Reise um die Welt, i. 63.

2 Trans. Zool. Soc. Lond. i. 191.

3 Shuckhard in Ann. of Nat. Hist. viii. 436.

4 Accorling to M. Wailckenaer this spider (Aranea fimbriata L.), A. marginata and A. paludosa De Geer; as well as Jolomedes limbatus Hahn, and D. marginutus of his Faune Française, are mere varieties of the same species. (Ann. Soc. Ent, de France, ii. 424. 
hastening its exit by a more speedy engine of destruction. The booty thus seized it devours at leisure upon its raft, under which it retires when alarmed by any danger.

The last of the tribe of hunters that it is necessary to particularise are those which, like the tigers, amongst the larger animals, seize their victims by leaping upon them. To this division belongs a very pretty small banded species, Salticus scenicus, which in summer may be seen running on every wall.

To Walckenaer's swimmers, the last of his grand tribes of spiders, including the single genus and species, Argyroneta aquatica, the first line of the above quotation from Dr. Darwin is particularly applicable; for these actnally seize their food by diving under the water, their bodies being kept unwet by a coating of air which constantly sirrounds them.-Thus one single race of insects exemplify in miniature almost all the modes of obtaining food which prevail anongst predaceous quadrupeds-the andacious attack of the lion, the wily spring of the tiger, the sedentary cunning of the lynx, and the amphibious dexterity of the otter.

This general view of the stratagems by which the spider tribe obtain their food, imperfect as it is, will, I trust, have interested you sufficiently to drive away the associations of disgust with which yon, like almost every one, have probably been accustomed to regard these insects. Instead of considering then as repulsive compounds of cruelty and ferocity, you will henceforward see in their procedures only the ingenious contrivances of patient and inclustrious hunters, who, while obeying the great law of nature in procuring their sustenance, are actively serviceable to the human race in destroying noxious insects. You will allow the poet to stigmatise them as

\section{".... cunning and fierce, Nisture abliorred!"}

but you will see that these epithets are in reality as unjustly applied to them (at least with reference to the mode in which they procure their necessary subsistence) as to the patient sportsman who lays snares for the birds that are to serve for the dinner of his family; and when you hear

\section{“.... the fluttering wing \\ And shriller sound declare extreme distress,"}

you will as little think it the part of true mercy to stretch forth "the helping hospitable hand" to the entrapped fly as to the captive birds. The spider requires his meal as well as the Indian ; and, however, to our weak capacity, the great law of creation "eat or be eaten" may scem crucl or unnecessary, knowing as we do that it is the ordinance of a beneficent Being, who does all things well, and that in fact the sum of bappiness is greatly angmented by it, no man, who does not let a morbid sensibility get the better of his judgment, will on account of their subjection to this rule, look upon predaceous animals with abhorrence.

One more instance of the stratagems of insects in procuring their prey shall conclude this letter. Other cxanples night be adduced, but the ennmeration would be tedions. This, from an order of insects widely differing from that which includes the race of spiders, is perhaps more curious and interesting than any of those hitherto recited. 'The insect to 
which I allude, an inhabitant of the south of Europe, is the larva of a species of ant.lion (MIyrmeleon), so called from its singular manners in this state. It belongs to a genus between the dragon-fly and the Hemerobius. When full grown its length is about half an inch: in shape it has a slight resemblance to a wood-louse, but the outline of the body is more triangular, the anterior part being considerably wider than the posterior: it has six legs, and the mouth is furnished with a forceps consisting of two incurved jaws, which give it a formidable appearance. If we looked only at its external conformation and habits, we should be apt to conclude it one of the nost helpless animals in the creation. Its sole food is the juices of other insects, particularly ants; but at the first view it seems impossible that it should ever secure a single meal. Not only is jts pace slow, but it can walk in no other direction than backwards; you may judge, therefore, what would be such a hunter's chance of seizing an active ant. Nor would a stationary posture be more favourable; for its grim aspect would infallibly impress upon all wanderers the prudence of keeping at a respectful distance. What then is to become of our poor ant-lion? In its appetite it is a perfect epicure, never, however great may be its hunger, dejgning to taste of a carcass unless it has previously had the enjoyment of killing it; and then extracting only the finer juices. In what possible way can it contrive to supply such a succession of delicacies, when its ordinary habits seem to mifit it for obtaining even the coarsest provision? You shall hear. It accomplishes by artifice what all its open efforts would have been unequal to. It digs in loose sand a conical pit, in the bottom of which it conceats itself, and there seizes upon the insects which, chancing to stumble over the margin, are precipitated down the sides to the centre. "How wonderful!" you exclaim: but you will be still more surprised when I have described the whole process by which it excavates its trap, and the ingenious contrivances to which it has recourse.

Its first concern is to find a soil of loose dry sand, in the neighbourhood of which, indeed, its provident mother has previously taken care to place it, and in a sheltered spot near an old wall, or at the foot of at tree. This is necessary on two accounts: the prey most acceptable to it abounds there, and no other soil would suit for the construction of its suare. Its next step is to trace in the sand a circle, which, like the furrow with which Romulus marked out the limits of his new city, is to determine the extent of its future abode. This being done, it proceeds to excavate the cavity by throwing out the sand in a mode not less singular than effective. Placing itself in the inside of the circle which it has traced, it thrusts the hind part of its body under the sand, and with one of its fore-legs, serving as a shovel, it charges its flat and square head with a load, which it immediately throws over the outside of the circle with a jerk strong enough to carry it to the distance of several inches. This little manouvre is executed with surprising promptitude and address. A gardener does not operate so quickly or so well with his spade and his foot, as the ant-lion with its head and leg. Walking backwards, and constantly repeating the process, it soon alrives at the part of the circle from which it set out. It then traces a new one, excavates another furrow in a similar manner, and, by a repetition of these operations, at length arrives at the centre of its cavity. One circumstance deserves remark, - that it never loads its head with the sand lying on the outside of the circle, though it would be as easy to do this with the outward leg, as to remave the sand within the circle by the 
inner leg. But it knows that it is the sand in the intcrior of the circle only that is to be excavated, and it therefore constantly uses the leg next the centre. It will readily occur, however, that to use one leg as a shovel excinsively throughout the whole of such a toilsome operation, would be extremely wearisome and painful. For this dificulty our ingenious pioneer has a resource. After fiushing the excavation of one circular furrow, it traces the next in an opposite direction; and thus alternately exercises each of its legs without tiring either.

In the course of its labour's it freguently meets with small stones : these it places upon its head one by one, and jerks over the margin of the pit. But sonetimes, when near the bottom, a pebble presents itself of a size so large that this process is impossible, its head not being sufficiently broad and strong to bear so great a weight, and the height being too considerable to admit of projecting so large a body to the top. A more impatient labourer would despair, but not so our insect. A new plan is adopted. By a manœure, not easily described, it lifts the stone upon its back, keeps it in a steady position by an alternate motion of the segments which compose that part; and carefully walking up the ascent with the burthen, deposits it on the outside of the margin. When, as occasionally happens, the stone is round, the labour becomes most difficult and painful. A spectator watching the motions of the ant-lion feels an inexpressible interest in its behalf. He sees it with vast exertion elevate the stone, and begin its arduous retrograde ascent : at every moment the burthen totters to one side or the other : the adroit porter lifts up the segments of its back to balance it, and has already nearly reached the top of the pit, when a stumble or a jolt mocks all its efforts, and the stone tumbles headlong to the bottom. Mortified, but not despairing, the ant-lion returns to the charge; again replaces the stone on its back ; again ascends the side, and artfully arails himself, for a road, of the channel formed by the falling stone, against the sides of which he can support his load. This time possibly he succeeds; or it may he, as is often the case, the stone again rolls down. When thus unfortunate, our little Sisyphus has been seen six times patiently to renew his attempt, and was at last, as such heroic resolution deserved, successful. It is only after a series of trials have demonstrated the impossibility of succeeding that our engineer yields to fate, and, quitting his half-excavated pit, begins the formation of another.

When all obstacles are overcome, and the pit is finished, it presents itself as a conical hole rather more thin two inches deep, gradually contracting to a point at the bottom, and ahout three inches wide at the top. ${ }^{1}$ The ant-lion now takes its station at the bottom of the pit, and, that its gruff" appearance may not scare the passengers which approach its den, covers itself with sand all except the points of its expanded forceps. It is not long before an ant on its travels, fearing no harm, steps upon the margin of the pit, either accidentally or for the purpose of exploring the depth below. Alas! its curiosity is dearly gratified. The faithless sand slicles from under its feet; its struggles but hasten its descent; and it is pre-

1 The nests of this animal which I saw at Fontainebleau (in the pit producing the fossil named after that place) were scarcely half the dimensions here given, but they miglit probably be younger insects. I kept one in a box of sand several days, in which it regularly formed its pit, whenever obliterated by shaking. The bottom of the box minfortunately came out as I was upon my return to England, and the animal was killed. 
cipitated headlong into the jaws of the concealed devourer. Sometimes, however, it chances that the ant is able to stop itself midway, and with all haste scrambles up again. No sooner does the ant-lion perceive this (for, heing furnished with six eyes on each sicle of his head, he is sufficiently sharp-sighted), than, shaking off his inactivity, he hastily shovels loads of sand upon his head, and vigorously throws them up in quick succession upon the escaping insect, which, attacked by such a heavy shower from below, and treading on so unstable a path, is almost inevitably carried to the bottom. The instant his victim is fairly within reach, the ant-lion seizes him between his jaws, which are admirable instruments, at the sime time hooked for holding, and grooved on the inner side, so as to form with the adjoining maxillæ, which move up and down in the groove, a tube for sucking, and at his leisure extracting all the juices of the body, regales upon formic acid. The dry carcass he subsequently jerks out of his den, that it may not encumber him in his future contests, or betray the "horrict secrets of his prison-house:" and if the sides of the pit have received any damage, he leaves his concealment for awhile to repair it; which having done, he resumes his station.

In this manner in its larva state this insect lives nearly two years, during all which time it receires no food but what has been caught through the artifice above described. Though all living insects, for I have fed it with flies, are equally acceptable to it, as the winged tribe can easily take flight from its pit should they chance to fall into it, its prey consists chiefly of apterous species, of which ants form by far the largest portion, with occasionally an unwary spider or wood-louse. When the full period of its growth is attained, it retires under the sand; spins with its anus a silken cocoon; remains a chrysalis a few weeks; and then breaks forth a four-winged insect, resembling, as before observed, the dragon-fly both in appearance and manners, and preying, in like manner, on moths, butterflies, and other insects. ${ }^{1}$

The larva of Myrmeleon Formicaleo is not the only insect which avails itself of a trap for obtaining its prey. A plan in most respects similar is adopted by that of a fly (Leptis V crmileo), in form somewhat resembling the common flesh maggot. This also digs a fumnel-shaped cavity in loose earth or sand, but deeper in proportion to its width than that of $M$. Formicaleo, and excavated not by regular circles, but by throwing out the earth obliquely on all sides. When its trap is finished, it stretches itself near the bottom, remaining stiff and without motion like a piece of wood. and the last segment bent at an angle with the rest, so as to form a strong point of support in the struggles which it often necessarily has with vigorous prey. The moment an insect falls into the pitfall, the larra writhes itself round it like a serpent, transfixes it with its mandibles, and sucks its juices at its ease. If the insect escapes, the larva casts above it jets of sand with surprising rapidity. ${ }^{2}$

I am, $\mathcal{d c}$.

1 Reaum. ri. $333-378$. Bonnet, ii. 380.

\& Bonnet, ix, 414. De Geer, vi. 168. t. 10. 


\section{LETTER XIV.}

\section{HABITATIONS OF INSECTS.}

Is forming an estimate of the civilisation and intellectual progress of a newly discovered people, we usually pay attention to their buildings, and other proofs of architectural skill. If we find them, like the wretched inhabitants of V an Diemen's Land, without other abodes than natural caverns or miserable penthouscs of bark, we at once regard them as the most jgnorant and unhumanised of their race. If, like the natives of the South Sea Isles, they have advanced a step further, and enjoy houses formed of timber, thatched with leaves, and furnished with utensils of different kinds, we are inclined to place them considerably higher in the scale. When, as in the case of ancient Mexico, we discover a uation inhabiting towns, containing stone houses, regularly disposed into streets, we do not hesitate withont other inquiry to decide that it must have been civilised in no ordinary degree. And if it were to chance that some future Park in Africa should stumble upon the ruins of a large city, where, in addition to these proofs of science, every building was constructed on just geometrical and architectural principles; where the materials were so employed as to unite strength with lightness, and a confined site so artfully occupied as to ohtain spacious symmetrical apartments, we should eagerly inquire into the history of the inhabitants, and sigh over the remains of a race whose intellectual advances we should infer with certainty were not inferior to our own.

Were we hy the same test to estimate the sagacity of the different classes of animals, we should, beyond all cloubt, assign the highest place to insects, which, in the construction of their habitations, leave all the rest far behind. The nests of birds, from the rook's rude assemblage of sticks to the pensile dwellings of the tailor bird, wonderful as they doubtless are, are indisputably eclipsed by the structures formed by many insects; and the regular villages of the beaver, by far the most sagacious architect amongst quacrupeds, must yield the palm to a wasps' nest. You will think me here guilty of exaggeration, and that, blinded by my attaehment to a favourite pursuit, 1 am elevating the little objects, which I wish to recommend to your stuly, to a rank beyond their just claim. So far, however, am I firom being conscious of any such prejudice, that I do not hesitate to go further, and assert that the pyramids of Egypt, as the work of man, are not more wonderful for their size and solidity than are the structures built by some insects.

To describe the most remarkable of these is my present object: and that some method may be observed, I shall in this letter describe the hahitations of insects living in a state of solitude, and built each by a single architect; and in a subsequent one, those of insects living in so- 
cicties, built by the united labours of many. The former class may be conveniently subdivided into habitations built by the parent insect, not for its own use, but for the convenience of its future young; and those which are formed by the insect that inhabits them for its own accommodation. To the first I shall now eall your attention.

The solitary insects which construct habitations for their future young without any view to iheir own aecommodation, ehiefly belong to the order Hymenoptera, and are principally lifferent species of wild bees and wasps. Oit these the most simple are built by Colletes ${ }^{2}$ succincta, fodiens, \&c. The situation which the parent bee chooses, is either the dry earth of a bank, or the vacuities of stone walls eemented with earth instead of mortar. Having excavated a eylincler about two inches in depth, rumning usually in a horizontal direction, the bee occupies it with three or four cells about half an inch long, and one sixth broal, shaped like a thimble, the end of one fitting into the mouth of another. The substance of which these cells are formed is two or three layers of a silky membrane, composed of a kind of glue seereted by the animal, resembling gold-beater's leaf, but much finer, and so thin and transparent that the colour of an included ohject may be seen through them. As soon as one cell is completed, the bee deposits an egg within, and nearly fills it with a paste composed of pollen and honey ; which having done, she proceeds to form another cell, storing it in like manner until the whole is finished, when she carefully stops up the mouth of the orifice with earth. Our countryman Grew seems to have found a series of these nests in a singular situation - the middle of the pith of an old elder branch - in which they were placed length wise one after another with a thin boundary between each. ${ }^{2}$

Cells composed of a similar membranaceous substance, but placed in a different situation, are constructed by Anthidium manicatum. ${ }^{3}$ This gay insect does not excavate holes for their reception, but places them in the cavities of old trees, or of any other object that suits its purpose. Sir Thomas Cullum discovercd the nest of one in the inside of the lock of a garden-gate, in which I have also since twice found them. It should seem, however, that such situations would be too cold for the grubs without a coating of some non-conducting substance. The parent bee, therefore, after having constructed the eells, laid an egg in each, and filled them with a store of suitable food, plasters them with a covering of vermiform masses, apparently composed of honey and pollen; and having done this, aware, long before Count Rumforl's experinents, what materials concluet heat most slowly, she attacks the woolly leaves of Siachys lanata, Agrostemma coronaria, and similar plants, and with her mandibles industriously scrapes off the wool, which with her fore-legs she rolls into a little ball and carries to her nest. This wool she sticks upon the plaster that covers her cells, and thus closely envelops them with a warm coating of down, impervious to every change of temperature. ${ }^{4}$

1 Melitta.*. a. K.

2 Grew's Rarities of Gresham College, 154. Kirby, Mon. Ap. Angl. i. 131. Melilta. *. a.

3 Curtis, Brit. Ent. t. 61.

4 Mon. Ap. Angt. i.173. Apis. **. c. 2. a. From later observations I am inclined to think that these cells may possibly, as in the case of the humble bee, be in fact formed by the larva previolisly to becoming a pupa, after having eaten the provision 
The bee last described may be said to exercise the trade of a clothier. Another numerous family would be more properly compared to carpenters, boring with incredible labour out of the solid wood long cylindrical tubes. and dividing them into various cells. Amongst these, one of the most remarkable is Yylocopa ${ }^{1}$ violncea, a large species, a native of midlle and southern Europe, distinguished hy beautiful wings of a deep violet colour, and found commonly in gardens, in the upright putrescent espaliers or vine-props of which, and occasionally in the garden seats, doors, and window-shutters, she makes her nest. In the beginning of spring, after repeated and careful surveys, she fixes upon a piece of wood suitahle for her purpose, and with her strong mandibles begins the process of boring. First proceeding obliquely downwards, she soon points her course in a direction parallel with the sides of the wood, and at length with unwearied exertion forms a cylindrical hole or tunnel not less than twelve or fitteen inches long and half an inch broad. Sometimes, where the diameter will admit of it, three or four of these pipes, nearly parallel with each other, are bored in the same piece. Herculean as this task, which is the labour of several days, appears, it is but a smail part of what our industrious bee cheerfully undertakes. As yet she has completed but the shell of the destined habitation of her offispring; each of which, to the number of ten or twelve, will require a seprarate and distinct apartment. How, you will ask, is she to form these? With what materials can she construct the floors and ceilings? Why truly GoD "doth instruct her to discretion and doth teach her." In excavating her tunnel she has detached a large quantity of fibres, which lie on the ground like a lieap of saw-dust. This material supplies all her wants. Having deposited an egg at the bottom of the cylinder along with the requisite store of pollen and honey, she next, at the height of about three quarters of an inch (which is the depth of each cell), constructs of particles of the saw-dust glued together, and also to the sides of the tunnel, what may be called an anuular stage or scatfolding. When this is sufficiently hardened, its interior edge affords support for a second ring of the same materials, and thus the ceiling is gradually formed of these concentric circles, till there remains only a small orifice in its centre, which is also closed with a circular mass of agglutinated particles of saw-dust. When this partition, which serves as the ceiling of the first cell and the flooring of the second, is finished, it is about the thickness of a crown-piece, and exhibits the appearance of as many concentric circles as the animal has male pauses in her labour. One cell being finished, she proceeds to another, which she furnishes and completes in the same manner, and so on until she has divided her whole tunnel into ten or twelve ajartments.

Here, if you have followed me in this detail with the interest which I wish it to inspire, a query will suggest itself. It will strike you that such a laborious undertaking as the constructing and furnishing these cells cannot be the work of one or even of two days. Considering that every

of pollen and honey with which the parent bee had surrounded it. The vermicular shape, however, of the masses with which the cases are surrounded does not seem easily reconcileable with this supposition, unless they are considered as the excrement of the larva.

1 Apis. **. d. 2, , . K. 
cell requires a store of honey and pollen, not to be collected but with long toil, and that a considerable interval must be spent in agglutinating the floors of each, it will be very obvions to you that the last egg in the last cell must be laid many days after the first. We are certain, therefore, that the first egg will become a grub, and consequently a perfect bee, many days before the last. What then becomes of it? you will ask. It is impossible that it should make its escape through eleven superincumbent cells withont destroying the immature tenants; and it seems equally impossible that it should remain patiently in confinement below them until they are all disclosed. This dilemma our heaven-taught architect has provided against. With forethought never enough to be admired she has not constructed ber tunnel with one opening only, but at the further end has pierced another orifice, a kind of back door, through which the insects produced by the first-laid eggs successively emerge into lay. In fact, all the young bees, even the uppermost, go out by this road; for, by an exquisite instinct, each grub, when about to become a pupa, places itself in its cell with its head downwards, and thus is necessitated, when arrived at its last state, to pierce its cell in this direction. ${ }^{1}$

Ceratina albilabris of Spinola, who has given an interesting account of its manners, forms its cell upon the general plan of the bee just described, but, more economical of labour, chooses a branch of briar or bramble, in the pith of which she excarates a canal about a foot long, and one line, or sometimes more in diameter, with from eight to twelve cells separated fiom each other by partitions of particles of pith ghed together ${ }^{2}$; and from the dead sticks of the same plants, in which they had formed their cells in a similar way, MM. Dufour and Perris have bred in the sandy district of the Landes in the south-west of France not fewer than twelve distinct species of wild bees and other Hymenoptera, namely, four species of Osmia, two of Ceratina, three of Odynerns, two of Solcuine, and Trypoxylon figulus, besides fifteen species of parasitic Hymenoptera of the genera Stelis, Prosopis, Ichneumon, Chrysis, \&c., making in all twenty-seven species of Hymenopterous insects obtained from this prolific habitat, for which, too, they were indebted for very rare insects, which they had never before met with. ${ }^{3}$ Mr. Thwaites has been also very successful in obtaining Hymenoptera from this source, having bred from dead bramble sticks found near Bristol Hylceus ammularis and a new species, Ceratina albilabris Sp. cyanea K., Osmia lcucomelana, Epipone leripes, Cemonus unicolor, Spilomena Troglodytes, a new species of Trypoxylon, and an unascertained one of Cladius, besides seven species of parasitic Hymenoptera, including Stelis minuta, Chrysis cyanca, Hedychrum auratum, Cryptus bellosus, and three other Ichneumonidr, in all, sixteen species. - Crabro tibialis, which M. Perris says is parasitic on Hymenoptera residing in bramblc-sticks (Am. Soc. Ent. dc France, ix. 407.), has been also found in this babitat near Bristol by Thomas Lighton, Esq.

Such are the curious liabitations of the carpenter bees and their analogues. Next I shall introduce you to the not less interesting structures of another group of bees, which carry on the trade of masuns (Mlegachile muraria), building their solid houses solely of artificial stone. The first step of the mother bee is to fix upon a proper situation for the future

3 Reaum. vi. 39-52. MIon. Ap. Angl. i. 189. Apis. **. ${ }^{*}$. 2. $\beta_{0}$

2 Ann. du Mus. X. 236.

3 Ann. Soc. Ent. de France, ix. 1-53. 
mansions of her ofispring. For this she usually selects an angle, sheltered by any projection, on the south side of a stone wall. Her next care is to provide materials for the structure. The chief of these is sand, which she carefully selects grain by grain from such as contains some mixture of earth. These grains she glues together with her viscid saliva into masses the size of small shot, and transports by means of her jaws to the site of her castle. ${ }^{1}$ With a number of these masses, which are the artificial stone of which her building is to be composed, united by a cement preferable to ours, she first forms the basis or foundation of the whole. Next she raises the walls of a cell, which is about an inch in length, and half an incl broad, and, before its orifice is closed, in form resembles a thimble. This, after depositing an egr and a supply of honey and pollen, she covers in, and then proceeds to the erection of a second, which she finishes in the same manner, until the whole number, which varies from four to eight, is completed. The vacuities between the cells, which are not placed in any regular order, some being parallel to the wall, others perpendicular to it, and others inclined to it at different angles, this laborious architect fills up with the same material of which the cells are composed, and then bestows upon the whole group a common covering of coarser grains of sand. The form of the whole nest, which when finished is a solid mass of stone so hard as not to be easily penetrated with the blade of a knife, is an irregular oblong of the same colour as the sand, and to a casual observer more resembling a splash of mud than an artificial structure. These bees sometimes are more economical of their labour, and repair old nests, for the possession of which they have very desperate combats. One would have supposed that the inhabitants of a castle so fortified might defy the attacks of every insect marauder. Yet an Ichneumon and a beetle (Clerus apiarius) both contrive to introduce their eggs into the cells, and the larva proceeding from them devour their inhabitants. ${ }^{2}$

Other bees of the same group with that last described use different materials in the construction of their nests. Some employ fine earth made into a kind of mortar with gluten. Another (Osmia ${ }^{3}$ carulescens), as we learn from De Geer, forms its nest of argillaceous earth mixed with chalk, upon stone walls, and sometimes probably nidificates in chalk pits. $O$. bicomis, according to Reaumur, selects the hollows of large stones for the site of its dwelling; but in England seems to prefer rotten posts and palings, in which it bores upwards, and then forms the partitions of its cells of clay and sand glued together. One species of this genus (O. gallaram) saves itself trouble by placing its cells in an abandoned gall of the oak, and

1 Reaumur plausibly supposes that it has been from observing this bee thus loaded that the tale mentioned by Aristotle and Pliny, of the hive-bee's ballasting itself with a bit of stone previously to flying home in a high wind, has arisen.

2 Reaum. vi. 57-88. Mon. Ap. Augl. j. 179. According to M. Goureau, licaunur and sueceeding entomologists have always confounded under Megachile muraria two very distinct species. The first, which he considers the true one, constructs its nest in April, - selecting the exposed surface of a rock, stone, or wall (not an angle), and preferring solitiry places distant botl from the noise of the abode of man and from the habitations of its own tribe; whereas the other, which does not begin its nest till the end of May or beginning of June, always places it in the angle of some wall or pilaster, \&c. of a building, seeming to preter inliabited lrouses and to be near others of its species, close to whose nests it often places its own. (Ann. Soc. Ent. de France, ix. 118.)

3 Apis. **. c. $2 . \mathrm{\delta}_{\text {. K. }}$ 
others select, with the like ohject, empty snail-shells. ${ }^{1}$ One remarkable peculiarity of some of these insects is, that they conceal the place where their cells are situated with some extraneous material. Thus $O$. gallarum hides the galls it has adopted by glueing round them oak leaves, and a species which M. Goureau conceives to be $O$. bicolor employed a whole day in arranging over the mouth (as he supposes) of its cell pieces of grass about two inches long, in a conical or tent-like form ${ }^{2}$ : and that this species employs this material for some purpose connected with its nest is confirmed by Mr. Thwaites, who observed a feniale for a consiclerable time fetching similar pieces of grass, and laying them over a snail-shall, where he had every reason to believe she had formel her cells. Unfortunately neither M. Goureau nor Mr. Thwaites could pursue their observations, not having been able the following day to find any trace of the labours they had observed on that preceding.

The works thus far described require in general less genins than labour and patience : but it is far otherwise with the nests of the last tribe of artificer's amongst wild bees, to which I shall advert-the hangers of tapestry, or upholsterers-those which line the holes exeavated in the earth for the reception of their young with an elegant conting of flowers or of leaves. Amongst the most interesting of these is Megachile ${ }^{3}$ Papaveris, a species whose manners have been admirably deseribed by Reaumur. This little hee, as though fascinated with the colour most attractive to our eyes, invariably chooses for the hangings of her apartments the most brilliant scarlet, selecting for its material the petals of the wild poppy, which she dexterously cuts into the proper form. Her first process is to excavate in some path way a burrow, cylindrical at the entrance, but swelled out below to the depth of about three inches. Having polished the walls of this little apartment, she next flies to a neighbouring field, cuts out oval portions of the flowers of poppies, seizes them between her legs and returns with them to her cell; and though separated fiom the wrinkled petal of a half. expanded flower, she knows how to straighten their folds, and, if too large, to fit them for her purpose by entting off the superfiuous parts. Beginning at the bottom, she overlays the walls of her mansion with this brilliant tapestry, extending it also on the surface of the ground round the margin of the orifice. The bottom is rendered warm by three or four coats, and the sides have never less than two. The little upholsterer, having completed the hangings of her apartment, next fills it with pollen and honey to the height of about half an inch; then, after committing an egg to it, she wraps over the poppy lining so that even the roof may be of this material, and lastly closes its month with a snall hillock ol" earth.4 The great depth of the eell compared with the space which the single egg and the accompanying food deposited in it occupy deserves particular notice. This is not more than half an inch at the bottom, the remaining two inches and a half being subsequently filled with earth.-When you next favour me with a visit, I can show you the cells of this interesting insect, as yet unknown to British entomologists, for which I am indebted to the lininess of M. Latreille, who first scientifically described the species. ${ }^{5}$

Megaclite centuncularis, $M$. Willughbiella, and other species of the same

1 Testwood, Mod. Class. of Ins. ii. 27 t.

2 Ann. Soc. Ent. de France, ix. 123.

4 Reaum. vi. $139-148$.

3 Apis. **. c. 2. $\alpha . \mathrm{K}$.

s Latr. Hist. Nut. des Fourmis, 297. 
family, like the preceding, cover the walls of their cells with a coating of leaves, but are content with a more sober colour, generally selecting for their hangings the leaves of trees, especially of the rose, whence they have been known by the name of the leaf-cutter bees. They differ also from M. Papaveris in excavating longer burrows, and filling them with several thimble-shaped cells composed of portions of leaves so curiously convoluted, that, if we were ignorant in what school they have been taught to construct them, we should never credit their being the work of an insect. Their entertaining history, so long ago as 1670 , at tracted the attention of our countrymen Ray, Lister, Willughby, and Sir Edward King; but we are indebted for the most complete account of their procedures to Reaumur.

The mother-bee first excavates a cylindrical hole eight or ten inches long, in a horizontal direction, either in the ground or in the trunk of a rotten willow-tree, or occasionally in other decaying wood. This cavity she fills with six or seven cells wholly composed of portions of lear, of the shape of a thimble, the convex end of one closely fitting into the open end of another. Her first process is to form the exterior coating, which is composed of three or four pieces of larger dimensions than the rest, and of an oval form. The second coating is formed of portions of equal size, narrow at one end, but gradually widening towards the other, where the width equals half the length. One side of these pieces is the serrate margin of the leaf from which it was taken, which, as the pieces are made to lap one over the other, is kept on the outside, and that which has been cut within. The little animal now forms a third coating of similar materials, the middle of which, as the most skilful workman would do in similar circumstances, she places over the margins of those that form the first tube, thus covering and strengthening the junctures. Repeating the same process, she gives a fourth and sometimes a fifth coating to her nest, taking care, at the closed end or narrow extremity of the cell, to bend the leaves so as to form a convex termination. Having thus finished a cell, her next busmess is to fill it to within half a line of the orifice with a rose-coloured conserve composed of honey and pollen, usially collected fiom the flowers of thistles; and then having deposited her egg, she closes the orifice with three pieces of leaf so exactly circular, that a pair of compasses could not define their margin with more truth ; and coinciding so precisely with the walls of the cell, as to be retained in their situation merely by the nicety of their adaptation. After this covering is fitted in, there remains still a concavity which receives the convex end of the succeeding cell; and in this manner the indefatigable little animal proceeds until she has completed the six or seven cells which compose her cylinder.

The process which one of these bees employs in cutting the pieces of leaf that compose her nest is worthy of attention. Nothing can be more expeditions : she is not longer about it than we should be with a pair of scissors. After hovering for some moments over a rose-bush, als if to reconnoitre the ground, the bee alights upon the leaf which she has selected, usually taking lier station upon its edge, ss that the margin passes between her legs. With her strong mandibles she cuts without intermission in a curve line, so as to detach a triangular portion. When this hangs by the last fibre, lest its weight should carry her to the ground, she balances her little wings for flight, and the very moment it parts from the leaf flics off with it in triumph; the detached portion remaining bent between her legs 
in a direction perpendicular to her body. Thus, without rule or compasses do these diminutive creatures mete out the materials of their work into portions of an ellipse, into ovals or circles, accurately accommodating the dimensions of the several pieces of each figure to each other. What other architect could carry impressed upon the tablet of his memory the entire idea of the edifice which he has to erect, and, destitute of square or plumbline, cut out his materials in their exact dimensions without making a single mistake? Yet this is what our little bee invariably does. So far are human art and reason excelled by the teaching of the Almighty. ${ }^{1}$

Other insects besides bees construct habitations of different kinds for their young, as various species of burrowing wasps (Fossores), Geotrupes, \&c., which deposit their eggs in cylindrical excavations that become the abode of the future larva. In the procedures of most of these, nothing worth particularising occurs; but one species, called by Reaumur the mason-wasp (Odynerus murarius), referred to in a former letter, works upon so singular a plan, that it would be improper to pass it over in silence, especially as these nests may be found in this country in most sandy banks exposed to the sun. This insect bores a cylindrical cavity from two to three inches deep, in hard sand which its mandibles alone would be scarcely capable of penetrating, were it not provided with a slightly gluti. nous liquor which it pours out of its mouth, that, like the vinegar with which Hannibal softened the Alps, acts upon the cement of the sand, and renders the separation of the grains easy to the double pickaxe with which our little pioneer is furnished. But the most remarkable circumstance is the mode in which it disposes of the excavated materials. Instead of throwing them at random on a heap, it carefully forms them into little oblong pellets, and arranges them round the entrance of the hole so as to form a tunnel, which, when the excavation is completed, is often not less than two or three inches in length. For the greater part of its height this tunnel is upright, but towards the top it bends into a curve, always, however, retaining its cylindrical form. The little masses are so attached to each other in this cylinder as to lcave numerous vacuities between them, which give it the appearance of filagree-work. You will readily divine that the excavated hole is intended for the reception of an egg, but for what purpose the external tunnel is meant is not so apparent. One use, and perhaps the most important, would seem to be to prevent the incursions of the artful Ichneumons, Chrysida, \&c., which are ever on the watch to insinuate their parasitic young into the nests of other insects: it may reuder their access to the nest more difficult; they may dread to enter into so long and dark a defile. I have seen, however, more than once a Chrysis come out of these tunnels. That its use is only temporary is plain from the circumstance that the insect employs the whole fabric, when its egg is laid and store of food procured, in filling up the remaining vacuity of the hole; taking down the pellets, which are very conveniently at hand, and placing them in it until the entrance is filled. ${ }^{2}$ - Latreille informs us that a nearly similar tunnel, but composed of grains of earth, is built at the entrance of its cell by a bee of his family of pioneers. ${ }^{3}$

The habitations hitherto described are used simply as an abode for the future larva springing from the cgg deposited in them by the parent female, and as a storehouse for its food; but in another class of insect habitations

1 Reaum. vi. 971-24. Mon. Ap. Angl, i. 157. Apis.**. c. 2. a.

2 Realm. vi. $251-257$. t. xxvi. f. 1 .

3 Latr. Fourmis, 419. 
the house itself serves both for the protection of the occupant and also for its subsistence, the larva eating the inner portion of its very walls.

This is the case with the habitations constructed for their future larva by the beantiful weevils or long-snouted beetles of the genera Rhynchites, Attelabus, and Apoderus, which consist of the whole, or more commonly a part, of a leaf of the tree on which they are to feed, rolled up with great alt by the mother into a sort of cylinder sometimes resembling a little hom, and at others a wallet more or less elongated, thus giving a singular appearance to the leaves so treated, which, while their basal portion retains its usual form, have their extremities metamorphosed into these oddlooking appendages. A very interesting description of the mode in which these nests are constructed has been lately given by M. Huber of Geneva ${ }^{1}$, who has detailed the procedures of Rhynchites Bacelus with the leaves of the vine, of $R$. Populi with those of the poplar, of $R$. Betule with those of the beech and birch, of Apoderus Coryli with those of the hazel, and of Attelahus Curculionvides with those of the oak, of which last, as more fully described by M. Goureau, I will give you a short account. The female having deposited a single eggr, which adheres by its natural gluten, near the mid-rib of the end of the upper side of the leaf she has selected, passes to the mder surface, and slightly but repeatedly guaws with her small jaws both the mid-rib and epidernis in every part until both are rendered perfectly pliable. If the leaf be a small one, she treats the whole of it in this way and rolls up the whole; if a large one, she thus prepares only about one-third or one-half of it, and cuts it across, all except the mid-rib, with her jaws at the proper point, so as to leave a sufficient extent of pliable leaf for her operations. Her next business is to roll up this terminal portion of the leaf, in effecting which she thus procceds. First she folds it together longitudinally so as to cover her egg, the midrib forming one edge of the folded part, and its marginal serratures the other. Next she places herself at a right angle with the mid-rib, towards which her tail is directed while her head points to the serratures; and fixing the claws of her two hind left legs into the leaf, she employs those of the two hind right legs to pult the point of it toward her; and by a repetition of these manœuvres, not easily described, she at last succecds in rolling the whole into a little cylinder having at one end the mid-rib whose spirals there resemble those of the main-spring of a watch, and at the other, which is of a less regular shape, the serratures of the leaf, so pushed in by means of her trunk and fore-legs as to retain the whole in its cylmdrical form. The larva procecding trom the egg thus deposited towards the end of May is hatched early in June, and never quits the habitation which its provident and truly laborious mother (for each egy requires its separate leaf and the long process above described) has prepared for it, eating in succession the different rolls of its eylinder, till it has attained its full growth. ${ }^{2}$

Under this head, too, may be most conveniently arranged the very sin-

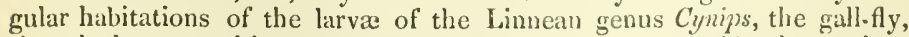
though they can with no propriety be said to be constructed by the mother, who, provided with an instrument as potent as an enehanter's wand, has

1 Mémoires de la Société de Physique ct d'Tristoire Naturelle de Genc̀ve, viii. 2me partie, 1839, quoted by M. Goureau, Ann. Soc. Ent. de France, x. 21.

2 Ann. Soc. Ent. de France, x. 21 - 27. 
but to pierce the site of the foundation, and commodious apartments, as it by magic, spring up and surround the germ of her future descendants. I allude to those vegetable excrescences termed galls, some of which resembling beautiful berries and others apples, you must have frequently observed on the leaves of the oak, and of which one species, the Aleppo gall, as I have before noticed, is of such importance in the ingenious art "de peindre la parole et de parler aux yeur." All these tumours owe their origin to the deposition of an egg in the substance out of which they gr'ow. This egg, too small almost for perception, the parent insect, a little four-winged fly, introduces into a puneture made by her curious spiral sting, and in a few hours it becomes surrounded with a fleshy chamber, which not only serves its young for shelter and dofence, but also, like those luabitations last described, for food; the future little hermit feeding upon its interior and there undergoing its metamorphosis. Nothing can be more varied than these habitations. Some are of a globular form, a bright red colour, and smooth fleshy consistence, resenbling beautiful fruits, for which, indeed, as you have before been told, they are eaten in the Levant: others, beset with spines or clothed with hair, are so much like seed-vessels, that an eminent modern chemist has contended respecting the Aleppo gall that it is actually a capsule. ${ }^{1}$ Some are exactly round; others like little mushrooms; others resemble artichokes; while others again might be taken for flowers; in short, they are of a hundred dificrent forms, and of all sizes from that of a pin's head to that of a walunt. Nor is their situation on the plant less diversified. Some are found upon the leaf itself; others upon the foot-stalks only; others upon the roots, and others upon the buds. ${ }^{2}$ Some of them cause the branches upon which they grow to shoot out into such singular forms, that the plants producing them were esteemed by the old botanists distinct species. Of this kind is the Rose-uillow, which old Gerard figures and describes as " not only making a gallant shew, but also yeelding a most cooling aire in the heat of sumner, being set up in houses for the decking of the same." This willow is nothing more than one of the common species, whose twigs, in conseguence of the deposition of the egg of a Cynips in their stimmits, there shoot ont into numerous leaves totally different in shape from the other leaves of the tree, and arranged not much unlike those composing the flower of a rose, adhering to the stem even after the others fall off. Sir James Snith mentions a similar lusus on the Provence willows, which at first he took for a tufted lichen. ${ }^{3}$ From the same cause the twigs of the conmon wild rose often shoot out into a beautiful tuft of numerous reddish moss-like fibres wholly dissimilar from the laves of the plant, deemed by the old naturalists a very valuable medical substance, to which they erroneously gave the name of Bedeguar. None of these variations is accidental or common to several of the tribe, but each peculiar to the galls formed by a single and distinet species of cynips.

The P'ome Sodomitica, mala insana, or apples of the Dead Sea, beautiful to the eye, but filling the mouth with bitter ashes if tasted, whose exist-

1 Aikin's Dictionary of Chemistry, i. 455. What have probably been taken by Mr. Aikin for "kernels," in the imperforated nuts, are the cocoons of the inhabitants of these galls in the pupa state, which often extremely resemble the seeds of a capsule, as lieammur (iii. 429.) lias remarked.

2 Reaum. iii. 117 , \&. .

3 Introd. to Botany, 319. 
ence, though mentioned by Tacitus, Strabo, and Josepluns, has been questioned by Riland, Maundrell, and Shaw, and respecting which numerous contradictory and erroneous opinions by more reecnt suthors have been collected by Mir. Conder in his ALodern 'Travelles, have at lengti had their true history developed by the late venerable vice-president of the Limnean Society, A. B. Lambert, Esq. ${ }^{1}$, Walter Eiliot, Esq., and J. O. Westwood, Esq. ${ }^{2}$ From their combined observations, it has been ascertained that the Poma Sodomitica are actual galls, two inches long and an inch and a half in diameter, of a beautiful rich glossy purplish red exteriorly, and filled with an intensely bitter, porous, and easily pulverised substance, surrounding the insect (Cymips insend Westwood), which has given birth to them, and were found by Mr. Elliot growing on various species of dwarf oaks beyond the Jordan and in the Troad, to the twigs of which Mr. Westwood remarks they are attached in a curions manner, unlike what he has seen in any other galls, the narrow end "rising upwards on each side and bending inwards, so as to clasp the extremity of the twig somewhat like a pair of wide and curved nippers."

How the mere insertion of an egg into the substance of a leaf or twig, even if accompanied, as some imagine, by a peculiar fluid, should canse the growth of such singular protuberances around it, philosophers are as little able to explain as why the insertion of a particle of variolous matter into a child's arm should cover it with pustules of small pox. In both cases the effects seem to proceed from some action of the foreign substance upon the secreting vessels of the animal or vegetable: but of the nature of this action we know nothing. Thus much is ascertained by the observations of Reaumur and Malpighi - that the production of the gall, which, however large, attains its fill size in a day or two ${ }^{3}$, is caused by the egrg or some accompanying fluid; not by the larva, which does not appear until the gall is fully formed ${ }^{4}$ : that the galls which spring from lcaves almost constantly take their origin from nerves ${ }^{5}$; and that the egg, at the same time that it causes the growth of the gall, itself derives nourishment from the substance that surrounds it, becoming considerably larger before it is latched than it was when first depo.ited. ${ }^{6}$ When chemically analyser, galls are found to contain only the same principles as the plant from which they spring, but in a more concentrated state.

No produetions of nature seem to have puzzled the ancient philosophers more than gails. The commentator on Dioscorides, Mathiolıs, who agreeably to the doctrine of those days aseribed their origin to spontaneous generation, gravely informs us that weighty prognostications as to the events of the ensuing year may be deduced from ascertaining whether they contain spider's, worms, or flies. Other plilosopher's, who knew that, except by rare accident, no other animals are to be found in galls besides grubs of difierent kinds, which they rationally conceived to spring from eyses, were chiefly at a loss to account for the conveyauee of these eggs into the middle of a substance in which they could find no external orifice. They therefore inferred that they were the eggs of insects deposited in the earth, which had been drawn up by the roots of trees along with the sap, and after passing through different vessels had

1 Limn. Trans. xvii. 415.

3 lieaum. iit. 47.1.

5 Ituid. 501.
2 Trans. Ent. Soc. Lond. ii. 16.

4 Ibid. 479 .

B Ibid. 479. 
stopped, some in the leaves, other in the twigs, and had there hatched and produced galls! Redi's solution of the difficulty was even more extraordinary. This philosopher, who had so triumphantly combated the absurdities of spontaneous generation, fell himself into greater. Not having been able to witness the deposition of eggs by the parent flies in the plants that produce galls, he took it for granted that the grubs which he found within them could not spring from eggs: and he was equally unwilling to admit their origin from spontaneous generation, - an admission which would have been fatal to his own most brilliant discoveries. He therefore cut the knot, hy supposing that to the same vegetative soul by which fruits and plants are produced is committed the charge of creating the larvæ found in galls! ${ }^{1}$ An instance truly humiliating how little we can infer, from a man's just ideas on one point, that he will not be guilty of the most pitiable absurdity on another!

'Though by far the greater part of the vegetalle excrescences termed galls are caused by insects of the genus Cymips, they do not always originate from this tribe. Some are produced by weevils of different genera and species. Thus those on the roots of kedlock (Sinapis arvensis) I have ascertained to be inhabited by the larvæ of Nedyus contractus and assimilis. From the knob-like galls on turnips, called in some places the ambury, I have bred another of these weevils (Curculio plear ostigma Marsh., Rynchicenus sulcicollis (ryll.) and I have little donbt that the same insects, or species allied to them, cause the clubbing of the roots of cabbages. ${ }^{2}$ It seems to be a beetle of the same family that is figured by Reaumur ${ }^{3}$ as causing the galls on the leaves of the lime-tree. Mr. Westwood has traced the transformations of a minute species of Balaninus, which resides in the large and fleshy galls on the leaves of willows, occasionally in company with the larvæ of Nematus intercas; Bouché has also described the larva of Balanimus salicivorus Schon., which is found in the galls on the leaves of Salix vitellina, and that of Gymmatron villosulus, which lives in a gall formed on Veronica beccabunga. According to Hammersclumidt Cleopus affinis also resides in galls upon the roots of Sinapis arvensis, Cleonus $L i$ narice in galls at the roots of Antirrhinum Linaric, and Baris carulescens in the stems of Reseda lutea, all in their larva state ${ }^{4}$; and Mr. Perris has obtained an Apion (A. uticicola P.) from galls on the young branches of Ulex nanus ${ }^{5}$, an interesting fact, as proving, with a similar one observed by Mr. Westwood as to Apion Radiolum which he found undergoing its transformations in the stems of the hollyhock ${ }^{6}$, that all the species of this genus do not pass their larva state in the interior of seeds as most of them do. Other galls owe their origin to moths as those resembling a nutmeg

1 De Insectis, 233, Sc.

$2 \mathrm{Mr}$. Westwood informs us that he has not detected any other larva in the clubs at the roots of cabbages than those of a species of MIuscida (Anthomyia brassica), and which had evidently been produced from eggs laid in crevices of the already formed clubs.

3 Reaum. iii. t. 38. f. 2, 3.

4 Bouché Naturgesch, Sc. and Iammerschmidt Observ. Physiol. Pathol. de Plant. Gallarum Ortu, quoted in Westwood's Modern Classif. i. 34:. I have some suspicion that a little weevil, Leiosoma ovatula, of which I found ten or twelve early in the spring of 1842 , near Bristol, under the leaves of Ranunculus bulbosus, which they had pierced with numerous holes, may reside in the larra state in galls on the root of this plant.

${ }_{5}$ Aun. Soc, Ent. de France, ix. 90.

6 Westwood, ubi supra, i. 337. 
which Reaumur received fiom Cyprus ${ }^{1}$; and others again to two-winged lites, as the woody galls of the thistle caused by Trypeta Cardui ${ }^{2}$, and the cottony galls found on ground ivy, wild thyme, \&c., as well as a very singular one on the juniper resembling a flower, described by De Geer ${ }^{3}$, all which are the work of minute gall-gnats (Cecidomyice Latr.). Some of these last convert even the flowers of plants into a kind of galls, as T. Loti of De Geer ${ }^{4}$, which inhabits the blossoms of Lotus corniculalus; and one which I have myself observed to render the flowers of Eiysimum Barbarca like a hop blossom. A similar monstrous appearance is communicated to the flowers of Teucrim supinum by a little field-bug, Tingis Tucrii of Host $^{5}$, and to another plant of the same genus by one of the same tribe described by Reaumur. ${ }^{6}$. In these two last instances, however, the habitations do not seem strictly entitled to the appellation of galls, as they originate not from the egg, but from the larva, which, in the operation of extracting the sap, in some way imparts a morbid action to the juices, cansing the flower to expand unnaturally; and the same remark is applicable to the gall-like swellings formed by many Aphides, as A. Pistacia, which causes the leaves of different species of Pistacia to expand into red finger-like cavities; A. Abielis, which converts the buds or young shoots of the fir into a very beautiful gall, somewhat resembling a fir-cone, or a pine-apple in miniature; and A. Bursarice, which with its brood inhabits angular utriculi on the leaf-stalk of the black poplar, numbers of which I have observed on those trees by the road-side from Hull to Cottingham. The majority of galls are what entomologists liave denominated monothalamous, or consisting of only one chamber or cell; but some are polythalamous, or consisting of several.

Among the more remarkable galls are those so much resembling minute fungi as to have been actually described as such ; as Sclerotium fasciculatum Schumacher, which is a common gall on oak leaves; and the Rer. M. J. Berkeley has given an account of a similar one found by W. S. MacLeay, Esq., in Cuba, on the leaf of a plant of the order Oclinacce, which on a cursory examination was regarded by some of our first botanists as an epiphytous fungus, but proved on dissection to be a true gall, and distinguished from all previously known by its very curious operculum or lid, etidently meant for the more ready egress of the occupant (which has not yet been ascertained) in its perfect state. ${ }^{7}$

Having thus described the most remarkable of the habitations constructed by the parent insects for the accommodation of their future young, I proceed to the second kind mentioned; namely, those which are formed by the insect itself for its own use. These may be again subdivided into such as are the work of the insects in their larva state; and such as are formed by perfect insects.

Many larva of all orders need no other habitations than the holes which they form in seeking for, or eating, the substances upon which they feed. Of this description are the majority of subterranean larvæ, and those which feed on wood; as the Bostricli or labyrinth beetles; the Anobia, which excavate the little circular holes frequently met with in ancient fur-

1 Reaum. iii. 418.

4 Ibicl. vi. 421 .

3 Reaum. iii. 427.
2 Ibid. 455 .

5 Jacquin Collect. ii. 255.

7 Truns. Linn. Soc. xviii. $5 \pi 6$. 
niture and the wood-work of old houses; and many larvæ of other orders, particularly Lepidoptera. One of these last, the larva of Cossus ligniperda, differs from its congeners in fabricating for its residence during winter a habitation of pieces of wood lined with fine silk.' Under this division, too, come the singular habitations of the subcutaneous larvæ, so called from the circumstance of their feeding upon the parenchyma included between the upper and under cuticles of the leaves of plants, between which, though the whole leaf is often not thicker than a sheet of writingpaper, they find at once food and lodging. You must have been at some time struck by certuin white zigzag or labyrinth-like lines on the leaves of the dandelion, bramble, and numerous other plants: the next time you meet with one of them, if you hold it up to the light you will perceive that the colour of these lines is owing to the pulpy substance of the leaf having there been removed; and at the further end you will probably remark a dark-coloured speck, which, when carefully extricated from its covering, you will find to be the hittle miner of the tortuous galleries which you are admiring. Some of these minute larve, to which the parenchyma of a leaf is a vast country, requiring several weeks to be traversed by the slow process of mining which they adopt - that of eating the excavated materials as they proceed - are transformed into beetles (Cionus thapsi, \&c.); others into flies; and a still greater number into very minute moths, as Heribeia Clerkella, \&c. Nany of these last are little miracles of nature, which has lavished on them the most splendid tints tastefully combined with gold, silver, and pearl, so that, were they but formed upon a larger scale, they wonld far eclipse all other animals in richness of decoration.

Another tribe of larvæ, not very numerous, content themselves for their labitations with simple holes, into which they retire occasionally. Many of these are merely cylindrical burrows in the ground, as those formed by the larvæ of field-crickets, Cicindelæ, and Ephemeræ. But the larvæ of the very remarkable lepidopterous genus (Nycterobius of Mr. MacLeay) before alluded to, excavate for themselves dwellings of a more artificial construction; forming cylindrical holes in the trees of New Holland, particularly the different species of Banksia, to which they are very destructive, and defending the entrance against the attacks of the Mantes and other carnivorous insects by a sort of trap-door composed of silk interwoven with leaves and pieces of excrement, securely fastened at the upper end, but left loose at the lower for the free passage of the occupant. This abode they regularly quit at sunset, for the purpose of laying in a store of the leaves on which they feed. These they drag by one at a time into their cell until the approach of light, when they retreat precipitately into it, and there remain closely secluded the whole day, enjoying the booty which their nocturnal range has provided. One species lifts up the loose end of its door by its tail, and enters backward, dragging after it a leaf of Banksia serrata, which it holds by the foot-stalls. ${ }^{2}$

A third description of larvæ, chiefly of the two lepidopterous tribes of Tortricide and Tineida, form into convenient habitations the leaves of the plants on which they feed. Some of these merely comect together with a few silken threads several leaves so as to form an irregular packet, in the 
eentre of which the little hernit lives. Others confine themselves to a single leaf, of which they simply fold one part over the other. A third descrintion form and inhabit a sort of roll, by some species made cylindrical, by others conical, resembling the papers into which grocers put their sugar, and as accurately constructed; only there is an opening left at the smaller extremity for the egress of the insect in case of need. If you were to see one of these rolls, you would immediately ask by what mechanism it could possibly be made - how an insect without fingers could contrive to bend a leaf into a roll, and to keep it in that form until fastened with the silk which holds it together? The following is the operation. The little caterpillar first fixes a series of silken cables from one side of the leaf to the other. She next pulls at these cables with her feet; and when she has forced the sides to approach, she fastens them together with shorter threads of silk. If the insect finds that one of the larger nerves of the leaf is so strong as to resist her efforts, she weakens it by gnawing it here and there half through. What engineer could act more sagaciously? To form one of the conical or horn-shaped rolls, which are not composed of a whole leaf, but of a long triangular portion cut out of the edge, some other mancuvres are requisite. Placing herself upon the leaf, the caterpillar cuts ont with her jaws the piece which is to compose her roll. She does not, however, entirely detach it: it would then want a base. She detaches that part only which is to form the contour of the horn. This portion is a triangular strap, which she rolls as she cuts. When the body of the horn is funished, as it is intended to be fixed upon the leaf in nearly an upright position, it is necessary to elevate it. To effect this, she proceeds as we should with an inclined obelisk. She attaches threads or little eables towards the point of the pyramid, and raises it by the weight of her body. ${ }^{1}$

A still greater degree of dexterity is manifested in fabricating the habitations of the larva of some other moths which feed on the leaves of the rose-tree, apple, elm, and oak, on the under side of which they may in summer be often found. These form an oblong cavity in the interior of a leaf by eating the parenchyma lotween the two membranes composing its upper and under side, which, after having detached them from the surrounding portion, it joins with silk so artfully that the seams are scarcely discoverable even with a lens, so as to compose a case or horn, cylindrical in the middle, its anterior orifice circular', its posterior triangular. Were this dwelling cylindrical in every part, the form of the two pieces that conpose it would be very simple; but the different shape of the two ends renders it necessary that each side should have peculiar and dissimilar curvatures; and Reaumur assures us that these are as complex and difficult to imitate as the contours of the pieces of cloth that compose the back of a coat. Some of this tribe, whose proceedings I had the pleasure of witnessing a short time since upon the alders in the Hull Botanic Garden, more ingenious than their hrethren, and willing to save the labour of sewing up two seams in their dwelling, insinuate themselves near the edge of a leaf instead of in ts middle. Here they form their excavation, mining into the very crenatures between the two surfaces of the leal', which, being joinel together at the edge, there form one seam of the case, and from their dentated figure give it a very singular appearance, not unlike that of some 
fishes which have fins upon their backs. The opposite side they are necessarily forced to cut and sew up); but even in this operation they show an ingenuity and contrivance worthy of admiration. The moths which cut out their suit fiom the middle of the leaf wholly detach the two surfaces that compose it before they proceed to join them together; the serrated incisions made by their teeth, which, if they do not cut as fast, in this respect are unore effective than any scissors, interlacing each other so as to support the separated portions until they are properly joined. But it is obvious that this process cannot be followed by those moths which cut out their house from the edge of a leaf. If these were to detach the inner sicle before they had joined the two pieces together, the builder as well as his dwelling would inevitably fall. They therefore, before making any incision, prudently run (as a sempstress would call it) loosely together in distant points the two membranes on that side. Then putting out their heads they cut the intermediate portions, carefully avoiding the larger nerves of the leaf; afterwards they sew up the detached sides more closely, and only intersect the nerves when their labour is completed. ${ }^{1}$ The habitation made by a moth which lives upon a species of Astragalus is in like manner formed of the epidermis of the leaves; but in this several corrugated pieces project over each other, so as to resemble the furbelows once in fashion. ${ }^{2}$

Other larvæ construct their habitations wholly of silk. Of this description is that of a moth, whose abode, except as to the materials which compose it, is formed on the same general plan as that just described, and the larva in like manner feeds only on the parenchyma of the leaf. In the beginning of spring, if you examine the leaves of your pear trees, you will scarcely fail to meet with some beset on the under surface with several perpendicular downy russet-coloured projections, about a quarter of an inch high, and not much thicker than a pin, of a cylindrical shape, with a protuberance at the base, and altogether resembling at first sight so many spines growing out of the leaf. You would never suspect that these could be the habitations of insects; yet that they are is certain. Detach one of them, and give it a gentle squeeze, and you will sce energe fiom the lower end a minute caterpillar, with a yellowish body and black head. Examine the place from which you lave removed it, and you will perceive a round excavation in the cuticle and parenchyma of the leaf, the size of the end of the tube by which it was concealed. This excavation is the work of the above-mentioned caterpillar, which obtains its food by moving its little tent from one part of the leaf to the other, and eating away the space immediately under it. It touches no other part; and when these insects abound, as they often do, to the great injury of pear trees ${ }^{3}$, you will perceive every leaf bristled with them, and covered with little withered specks, the vestiges of their former meals. The case in which the caterpillar resides, and which is quite essential to its existence, is composed of silk spun from its nouth almost as soon as it is excluded from the egg. As it increases in size, it cnlarges its habitation by slitting it in two, and introducing a strip of new materials. But the most curious circumstance in the history of this little Arab, is the mode by which it retains its tent in a perpendicular posture. This it effects partly by attaching silken threads from the protuberance at the base to the surrounding surlace of the leaf. But being not

1 Reaum. iii. $100-120$.

2 Ibid. 146.

3 Forsyth on Fruit Trees, 4to. edit. $2 \% 1$. 
merely a mechanician, but a profound natural philosopher, well acquainted with the properties of air, it has another resource when any extralordinary violence threatens to overturn its slender turret. It forms a vacuum in the protuherance at the base, and thus as effectually fastens it to the leaf as if an air-pump had been employed! This vacuum is caused by the insect's retreating on the least alarm up its narrow case, which its body completely fills, and thus leaving the space below free of air. In detacliing one of these cases you may easily convince yourself of the fact. If you seize it suddenly while the insect is at the bottom, you will find that it is readily pulled off, the silken cords giving way to a very slight force ; hut if, proceeding gently, you give the insect timie to retreat, the case will be held so closely to the leaf as to require a much stronger effort to loosen it. As if aware that, should the air get admission from below, and thus render a vacum impracticable, the strongest bulwark of its fortress would be destroyed, our little philosopher carefully avoids gnawing a hole in the leaf, contenting itself with the pasturage afforded by the parenchyma above the lower epidermis; and when the produce of this area is consumed, it gnaws asunder the cords of its tent, and pitches it at a short distance as before. Having attainel its full growth, it assumes the pupa state, and after a while issues out of its confinement a small brown moth, with long hind legs, the Phalena Tinea serratella of Linné. ${ }^{1}$

Some larvæ, which form their covering of pure silk, are not content with a single coating, but actually envelop themselves in anotlier, open on one side, and very much resembling a cloak; whence Reaumur called them "Teignes à fourreau à mantean." What is very striking in the construc. tion of this cloak is, that the silk, instead of being woven into one uniform close texture, is formed into nunerous transparent scales overwrapping each other, and altogether very much resembling the scales of a fish. ${ }^{2}$ These mantle-covered cases, one of which I once had the pleasure of discovering, are inhabited by the larva of a little moth apparently first described by Dr. Zincken genannt Sommer, who calls it Tinea palliatella. ${ }^{3}$

Various substances besides silk are fabricated into habitations by other larræ, though usually joined together either with silk or an analogous gummy material. Thus Diumea? lichenum forms of pieces of lichen a dwelling resembling one of the turreted Helices, many of which I observed in June, 1812, on an oak in Barham. The larva of another moth, which also feeds upon lichens, instead of employing these vegetables in forming its habitation, composes it of grains of stone eroded from the walls of buildings upon which its food is found, and connected by a silken cement. These insects were the subject of a paper in the Memoirs of the French Academy ${ }^{4}$, by M. de la Voye, who, from the circumstance of their being found in great abundance on mouldering walls, attributed to them the power of eating stone, and regarded them as the authors of injuries procecding solely from the hand of time; for the insects themselves are so minute, and the coating of grains of stone composing their cases is so trifling, that Reaumur observes they could scarcely make any perceptible impression on a wall from which they had procured matcrials for ages. ${ }^{5}$

1 Goeze, Nutur. Menschenleben und Vorsehung. Anderson's Recreations, ii. 409. See above, p. 8.

2 Reaum, iii. 200.

4 x. 458 .

3 Germar's Mag. für Entomologie, i. 40.

5 leaum. iii. 183.

s 3 
Another lepidopterous larva, but of a much larger size and different genus, the case of which is preserved in the cabinct of the late President of the Linnean Society, who pointed it out to me, employs the spines apparently of some species of MTimosa, which are ranged side by side, so as to form a very elegant fluted cylinder. A similar arrangement of pieces of small twigs is observable in the habitation of the females ${ }^{1}$ of the larvæ of a moth referred by Von Scheven to Bombyx vestita F. (which Ochsenheimer regards as synonymons with Psyche graminella); while P. Viciella of the Wiener Verzeichniss covers itself with short portions of the stems of grasses placed transversely, and united by means of silk into a five or six-sicled case. The habitation of a third larva of the same family, described and figured by Reaumur ( $P$. Graminella Ochsenh., just named), is composed of squarish pieces of the leaves of grass fastened only at one end, and overwrapping each other like the tiles of a house; and that of another noticed by the same author, of portions of the smallest twigs of broom arranged on the same plan. ${ }^{2}$ Indeed the larvæ of the whole of this tribe of moths, now separated into a distinct genus (Psyche Schrank, Ochsenh., Fumea Haworth), but which, according to Germar, needs further subdivision, reside in cases or sacks (whence they are called by the Germans Sacklräger) composed of silk, and fragments of grass, bark, \&c. ${ }^{3}$

The larvæ of a small beetle (Clytra longimana) reside in oviform cases, apparently of a calcareous or earthy substance, joined by a gummy cement, and covered with red hairs, the origin of which Huibner, who first discovered them, could not account for ; and from the observations of Amstein and the French translator of Fuessly's Archives, it seems probable that the larvæ of all the species of Clytra, and, according to Zschorn, at least of one species of Cryptocephalus (C. duodecimpunctatus), live in moveable cases ${ }^{4}$; as do also the larvæ of Chlamys, a splendid Brazilian genus of the same family, and those of the equally hrilliant genus Lamprosoma, forming them of their excrement, which in the former assume a singular appearance, fiom a very large and conical hollow mantle fitted to the month of the case. ${ }^{5}$ The larva of a species of Limuins (L. ceneus.) inhabit a fixed case made of particles of stone or sand; and the same materials probably serve for the abode of the other species of this and those of allied genera which reside under water.

$W a x$ is the principal substance employed in the habitations of the larvæ before mentioned, occasionally so destructive to bee-hives. These insidions depredators, which are mentioned by Aristotle ${ }^{6}$, tying together, with silk, grains of wax (which, and not honey, forms their food), construct

1 The larva of the males intermix with the pieces of twigs, which are less closely and regularly arranged, bits of dried leaves and other light materials. See the excellent elucidation of the history of this tribe, whose mole of generation is so singular, by Von Scheven, in the Naturforscher, Stk. xx. 61., \&c.; also a valuable paper by Dr. Zincken genannt Sommer, in Germar's Mag. fur Ent. i. 19-10.

2 Reaum. iij. 148, 149. n. 11. f. 10, 11 .

3 In the hotter regions of the globe, this group is replaced by the gigantic Oiketici, several specics of wlich have been figured by the late L. Guilding in the Transactions of the Linnean Society. The cases of some of these insects exhibit an extraordinary degree of instinct in their construction, an? are of a much larger size than a hen's egg. (See Westw. Mod. Class. Ins. ii. 385.)

4 Fuessly, Archiv. 53. t. 31. Germar's Mag. für Ent, i. 136.

5 Westwood in Trans. Ent. Soc. Lond. iii. proc. xxviii.

6 Aristot. Hist. Anim. 1. viii. c. 27. 
galleries of a considerable length; and thus concealed from the sight, and protected from the stings of the armed people whom they have attacked, push their mines into the very heart of the fortress, and pursue their robberies in perfect safety. ${ }^{1}$

As many of the habitations which I have been deseribing fit the body of the insects as elose as a coat, they might perhaps with more propriety, be called clothes. This is certainly the most appropriate designation of the abodes of some species of T'inere (the elothes' moths), which not only cover themselves with a coat, but employ the very same matcrial in its composition as we do in ours, forming it of wool or hair curiously felted together. Like us, they are born naked; but not, like us, helpless at that period: scarcely have they breathed before they begin to clothe themselves; thus contradicting Dr. Palley's assertion, that " the human animal is the only one which is naked, and the only one which can clothe itself ${ }^{2}$ :" and, wisely inattentive to change of fashion, the same suit serves them fiom their birth to mature age. The shape of their clress is adapted to that of their body - a cylindrieal ease open at both ends. The stuff of which it is composed is the manufacture of the larva of the moth (Tinea), which incorporates wool or hair, artfully eut from our clothes or furniture, with silk drawn from its own mouth, into a warm and thick tissue; and as this would not be soft enough for its tender skin, it also lines the inside of its coat with a layer of pure silk. Since this suit of clothes during the earliest age of the insect accurately fits its body, you will readily conceive that it will frequently require enlarging. This the little occupant accomplishes as dexterously as any tailor. If the case merely requires lengthening, the task is easy. All that is needful is to ald a new ring of hair or wool and silk to each end. But to enlarge it in width is not so simple an affair. Yet it sets to work precisely as we should, slitting the ease on the two opposite sides, and then adroitly inserting between them two pieces of the requisite size. It does not, however, cut open the case from one end to the other at once : the sides would separate too far asunder, and the insect be left naked. It therefore first cuts each side about half way down, and then, after having filled up the fissure, proceeds to cut the remaining half; so that, in fact, four enlargements are made, and four separate pieces inserted. The colour of the habit is always the same as that of the stuff from which it is taken. Thus, if its original colour be blue, and the insect previously to enlarging it be put upon red cloth, the circles at the end aud two stripes down the middle will be red. If placed alternately upon cloths of different hues, its dress will be parti-coloured, like that of a Harlequin. The injury occasioned to us by these insects is not confined to the quantity of materials consumed in clothing and feeding themselves. In moving from place to place they seem to be as much incommoded by the long hairs which surround them as we are by walking amongst high grass; and accordingly, marching scythe in hand, with their teeth they cut ont a smooth road, from time to time reposing themselves, and anchoring their little case with small silken cables.

If, as I hope, you are induced to investigate the manners of these insects, you have but to leave an old coat for a few months undisturbed in a dark closet, and you may be pretty certain of meeting with an abundant colony.

1 Reaum. iii. mém 8.

2 Nat. Theol. 230. 
Not merely wool or hair, but another substance analogous to one employed in our dress, is adopted for their clothing by other insects. The larva of a fly which lives on the seeds of willows makes itself a very beautiful case of their cottony down, not only impervious to wet and cold, but serving, if accidentally blown into the water, which, from the situation of these trees, frequently happens, as a buoyant little barge which is watted safely to the shore. ${ }^{2}$

The habitations which we have hitherto been considering are formed by larva that live on land: but others equally "emarkable are constructed by aquatic species, the larvæ of the various Phryganece L., a tribe of fourwinged insects, which an ordinary observer would call moths, but which are even of a distinct order (Trichoptera), not having their wings covered by the scales which adorn the lepidopterous race. If you are desirous of examining the insects to which I am alluding, you have only to place yourself by the side of a clear and shallow pool of water, and you cannot fail to observe at the bottom little oblong moving masses, resembling pieces of straw, wood, or even stone. These are the larvæ in question, well known to fishermen by the title of Caddis-zorms, and which, if you take them out of the water, you will observe to inhabit cases of a very singular conformation. Of the larva itself, which somewhat resembles the caterpillars of many Lepidoptera, nothing is to be seen but the head and six legs, by means of which it moves itself in the water, and drags after it the case in which the rest of the body is inclosed, and into which on any alarm it wholly retires. The construction of these habitations is very various. Some select four or five pieces of the leaves of grass, which they glue together into a shapely polygonal case; others employ portions of the stems of rushes, placed side by siue, so as to form an elegant fluted cylinder ; some arrange round them pieces of leaves like a spirally-rolled ribbon; others inclose themselves in a mass of the leaves of any aquatic plants united without regularity; and others again form their abode of minute pieces of wood, either fresh or decayed.2 One, like the Sabellce ${ }^{3}$, forms a horn-shaped case composed of grains of sand, so equal in size, and so nicely and regularly gummed together, the sides throughout being of the thickness of one grain only, that the first tinte I viewed it I could scarcely persuade myself it could be the work of an insect. The case of Leptocerus bimaculatus, which is less artificially constructed of a nixture of mud and sand, is pyriform, and has its end curiously stopped by a plate formed of grains of sand, with a central aperture. ${ }^{4}$ Other species construct houses which may be called alive, forming them of the shells of various aquatic snails of different kinds and sizes, even while inhabited, all of which are immoveably fixed to it, and dragged about at its pleasure - a covering as singular as if a savage, instead of clothing himself with squirrels' skins, should sew together into a coat the animals themselves. However various may be the form of the case externally, within it is usually cylindrical, and lined with silk; and though seldom apparently wider than just to admit the body of the insect, some species have the power of turning round in it, and of putting out their head at either end. ${ }^{5}$ Some larvæ constantly make their cases of the same materials; others employ indifferently any that are at hand; and the

1 Reaum. iii. 130.

3 Sowerby's Nat. Miscell. No. ix. t. 51.

- De Geer, ii. 561 .
2 Ibid. 156-159.

5 Ibid. 
new ones which they construct as they increase in size (for they have not the faculty, like the larva of the moth, of enlarging them) have often an appearance quite dissimilar to that of the old. Even those that are most careless about the nature of the materials of their house are solicitously attentive to one circumstance respecting them, namely, their specific gravity. Not having the power of swimming, but only of walking at the bottom of the water by aid of the six legs attached to the fore part of the body, which is usually protruded out of the case, and the insect itself being heavier than water, it is of great importance that its house should be of a specific gravity so nearly that of the element in which it resides, as while walking neither to incommode it by its weight, nor by too great buoyancy; and it is as essential that it should be so equally ballasted in every part as to be readily moveable in any position. Under these circumstances our caddisworms evince their proficiency in hydrostatics, selecting the most suitable substances; and, if the cell be too heavy, glueing to it a bit of leaf or straw; or, if too light, a shell or piece of gravel. It is from this necessity of regulating the specific gravity, that to the cases formed with the greatest regularity we often see attached a seemingly superfuous piece of wood, leaf, or the like. ${ }^{1}$

A larva of one of the aquatic Tipularia lives in cases somewhat similar to those of some Phryganea. Several of these of a fusiform shape, and brown colour, composed partly of silk, and partly perhaps of fragments of leaves, and inhabited by a red larva, apparently of a C'hironomus, were found by Reaumur upon dead leaves in a pool of water in the Bois de Boulogne. ${ }^{2}$

In concluding this head I may observe, that here might have been described the various abodes which solitary larræ prepare for themselves previous to assuming the pupa, and intended for their protection in that defenceless stage of existence; but as I shall have occasion again to refer to them in speaking of the larva state of insects, I shall defer their descrip. tion to that letter, to which they more strictly belong.

From the next division of the habitations of insects, those formed by solitary perfect insects for their own accommodation, I shall select for description only two, both the work of spiders, and alluded to in a former letter; which indeed, with the exception of the inartificial retreats made by the Grylli, Cicindcla, and a few others, are the only ones properly belonging to it.

The habitation of one of these (Cteniza camentaria) is subterrancous; not a mere shallow cavity, but a tube or gallery upwards of two feet in length, and half an inch broad. This tumel, so vast compared with the size of the insect, it digs by means of its strong jaws in a steep bank of bare clay, so that the rain may readily run off without penetrating to its dwelling. Its next operation is to line the whole from top to bottom with a web of fine silk, which serves the double purpose of preventing the earth that composes the walls from falling in, and, by its connection with the door of the orifice, of giving information to the spider of what is passing

1 For a description of various other habitations of this tribe, and of peculiarities in their construction, see M. Pictet's valuable work, Recherches pour servir à l'IIis. toire et à l'Anatomie des Phryganides, in which the Linnean genus Phryganea is divided into seven genera, and the metamorphoses of fifty-two species are described.

2 Reaum, iii. 179. 
above. You cloubtless suppose that in saying door, I am speaking metaphorically. It could never enter into your conception that any animal, much less an insect, could construct anything really deserving of that name - anything like our doors, turning upon a hinge, and accurately fitted to the frame of the opening which it is intended to close. Yet such a door, incredihle as it may seem, is actually framed by this spider. It does not, indeed, like us, compose it of wood, but of several coats of dried earth fastened to each other with silk. When finished, its outline is as perfectly circular as if traced with compasses; the inferior surface is convex and smooth, the superior flat and rough, and so like the aljoining earth as not to be distinguishable from it. This door the ingenions artist fixes to the entrance of her gallery by a hinge of silk, which plays with the greatest freedom, and allows it to be opened and shut with case; and, as if acquainted with the laws of gravity, she invariably fixes the binge at the highest side of the opening, so that the door when pusked up shuts again by its own weight. She has not less sagaciously left a little edge or groove just within the entrance, upon which the door closes, and to which it fits with s!ch precision that it seems to make but one surface with it. Such is the astonishing structure of this little animal's abode; nor is its defence of its subterraneous cavern less surprising. If an observer adroitly insimuates the point of a pin under the edge of the door, and elevates it a little, he immediately perceives a very strong resistance. What is its cause? The spider, warned by the vilmations of the threads which extend from the door to the bottom of her gallery, runs with all speed to the door, fastens its legs to it on one side, and on the other to the walls, and, turning upon its back, pulls with all its might. Tlus the door is altermately shnt or opened, as the exertion of the observer or of the spider prevail. It is easy to guess which will in the end conquer; and the spider, when it finds all resistance ineffectual, betakes itself to flight, and retreats. If, to make a further experiment, the observer fastens down. the door so that it caunot be forced open, the next morning he will find a new entrance, with a new loor formed at a small distance; or, if he take the door entirely away, another will he constructed in less than twelve hours.

The habitation thus singularly formed and defended is not at all used as a snare, but merely as a safe aborle for the spider, which hunts its prey at night only ; and, when caught, devours it in security at the bottom of its den, which is generally strewed with the remains of coleopterous insects. ${ }^{1}$ From some curious observations of Mr. Dorthes on this species in the second volume of the Linnean Transactions, it appears that both the male and female spider, and as many as thirty young ones, occasionally inhabit one of these galleries. Mygale Sauvagesï of Rossi (M. fodiens Walck.), which is a distinct species found in Corsica, forms a similar habitation, of which MI. Audouiu has given us an interesting description.2

The galleries just described are the work of European spiders; but similar ones are fabricated by Actinopus nidulans, an inhabitant of the West India islands, as well as by many other tropical species. I lave seen one of these, which laad been dug out of the earth, in the cabinet of 'Thomas Hall, Esq., F.L.S., that was nearly a foot in length, and above an inch in

1 Sauvages, Hist. de l'Acad. des Sc. de Paris, 1758, p. 26.

2 Audouin in Ann. Soc. Ent. de France, ii, 69. 
diameter, forming a cylindrical bag of dark-coloured silk, closed at the bottom, and accurately fitted at the top by a door or lid. ${ }^{1}$

The habitation of Argyroneta aquatica, the other spider to which I alluded, is chiefly remarkable for the element in which it is constructed and the materials that compose it. It is built in the milst of water, and formed, in fact, of air! Spiders are usually terrestrial, but this is aquatic, or rather amphibious; for though she resides in the midst of water, in which she swims with great celerity, sometimes on her belly, but more frequently on her back, and is an admirable diver, she not unfrequently hunts on shore, and having caught her prey, plunges with it to the bottom of the water. Here it is she forms her singular and unique abode. She would evidently have but a very uncomfortable time were she constantly wet, but this she is sagacious enough to avoid; and by availing herself of some well-known philosoplical principles, she constructs for herself an apartment in which, like the mermaids and sea-nympls of fable, she resides in comfort and security. The following is her process. First she spins loose threads in various directions attached to the leaves of aquatic plants, which may be called the frame-work of her chamber, and over them she spreads a transparent varnish resembling liquid glass, which issues from the middle of her spinners, and which is so elastic that it is capable of great expansion and contraction; and if a hole be made in it, it immediately closes again. Next she spreads over her belly a pellicle of the same material, and ascends to the surface. The precise mode in which she transfers a bubble of air beneath this pellicle is not accurately known; but from an observation made by the ingenious author of the little work from which this account is abstracted, he concludes that she draws the air into her body by the anus, which she presents to the surfuce of the pool. and then pumps it out from an opening at the base of the belly between the pellicle and that part of the body, the hairs of which keep it extended. Clothed with this aërial mantle, which to the spectator seems formed of resplendent quicksiver, she plunges to the bottom, and, with as much dexterity as a chemist transfers gas with a gas-holder, introduces her bubble of air beneath the roof prepared for its reception. This manœuvre she repeats ten or twelve times, until at length in about a quarter of an hour she has transported as much air as suffices to expand her apartment to its intended extent, and now finds herself in possession of a little aërial edifice, I had almost said an enchanted palace, affording her a commodious and dry retreat in the very midst of the water. Here she reposes unmoved by the storms that agitate the surface of the pool, and devours her prey at ease and in safefy. Both sexes form these lodgings. At a particular season of the year the male quits his apartment, approaches that of the female, enters it, and enlarging it hy the bubble of air that he carries with hin, it becomes a common abode for the happy pair. $^{2}$ The spider which forms these singular labitations is one of the largest European species, and in some countries not uncommon in stagnant pools. I am, \&c.

I See several Memoirs upon this and some allied species by Messrs. Sells, Saunders, and Westwood, in the Trans. of the Ent. Soc. of London, vols. ii. and iii.

\& Mćmoire pour servir à commencer l'Histoire des Araignées Aquatiques, 12mo 


\section{LET'TER XV.}

\section{IABITATIONS OF INSECTS - continued.}

Tue habitations of insects which I shall next proceed to describe are those formed by the united labour of several individuals. The societies which thus combine their operations nay be divided into two kinds: 1st, those of which the object is simply the conservation of the individuals composing them; and 2ndly; those whose object is also the nurture and education of their young. To the last head belong bees, wasps, \&c. : to the former the larvæ of some species of moths, whose labours, being the most simple, I shall first describe.

You cannot fail to have observed in gardens the fruit trees disfigured, as you would probably think them, with what at first view seem very strong and thick spiders' webs. If you have bestowed upon these webs the slightest attention, you must have likewise remarked that they differ very materially in their construction from those spun by spiders, inclosing on every side an angular space, and being besides filled with caterpillars. These are the larvæ of Porthesia chrysormeen, and the web which contains them is spun by their united labour for the protection of the common society. As soon as the cluster of eggs deposited by the parent moth is latched, the young caterpillars, to the number of three or four hundred, commence their operations. At first they content themselves by forming a sort of hammock of the single leaf upon which they find themselves assembled, covering it with a roof composed of a number of silken threads drawn from one edge to the other ; and under one or more of these temporary habitations they reside for a few dars, until they are become large and strong enough to undertake a more solid and spacious building sufficient to contain the whole society. In constructing this new habitation, they spin a close silken web round the end of two or three adjoining twigs and the leaves attached to them, so as to include the requisite space. They are not curions in giving any particular form to the edifice: sometimes it is flat, often roundish, but always more or less angular. The interior is divided by partitions of silk into several irregular apartments, to each of which there is pulposely left an appropriate door. Within these the caterpillars retire at night, or in rainy weather, quitting the nest on fine days, and dispersing themselves over the neighbouring leaves, upon which they feed. Here, too, they repose during the critical period of the change of their skins. On the approach of winter the whole community shut themsclves up in the nest, which, by the addition of repeated layers of silk, has at this time become so thick and strong as to be impervious to the wind and rain. They remain in a state of torpidity during the cold nomtlus, but towards the beginning of April are awakened to activity by 
the genial breath of spring, and hegin to feed with greediness upon the young leaves that surround their habitation, which, as they soon greatly increase in size, they find it necessary to enlarge. One might fear that a structure formed of such materials wonld at this period be sadly damaged hy the growth of the young shoots and leaves of the twigs which it encloses; but the inluabitants, as if to guard against such an aceident, have gnawed off all the buds within their dwelling, and thus secured themselves from this inconvenience. ${ }^{1}$

The nest of the larvæ of another species of moth, the Cnethocampa processionea, unfortunately not a native of this country, to which, on account of their singular manners, that will be detailed to you in a subsequent letter, Reaumur has given the title of processionary caterpillars, is somewhat different in its construction from that just described, though formed of the same material. As the caterpillars which fabricate it feed upon the leaves of the oak, it is always found upon this tree, attached not to the branches but the trunk, sometimes at a considerable height from the ground. In shape it resembles an irregular knob or protuberance, and the sitk which composes it being of a grey colour, at a distance it would be taken for a mass of lichens. Sometimes this nest is upwards of eighteen inches long, and six broad, rising in the midlle about four inches from the surface of the tree. Between the trunk and the silken covering, a single hole is left which serves for the entrance and exit of the inhabitants. These differ in their manners firom those last mentioned. While very young they have no fixed habitation, contenting themselves with a succession of different temporary camps until they have attained two-thirds of their growth. Then it is they unite their labours in spinning the net just described; and in this they continue to reside in harmony until they become perfect insects, assuming in it even the state of ehrysalis. ${ }^{2}$

Habitations similar, as to their general structure, to the above, though differing in several minute circumstances, are formed by the larvæ of several other moths, as of Porthesia phaorrhea, Clisiocampa nenstria, \&c., as well as those of Vanessa Io, Mclitca Cinxia, and some other butterflies $^{3}$, and even of some saw-flies (Serrifera), which, however, have each a separate silken covering. But as it would be tedious to describe these particularly, I pass on to the habitations formed by insects in their perfect state, which have in view the education of their young as well of self-preservation, describing in succession those of ants, bees, wasps, and white ants.

Of these the most simple in their structure are the nests of different kinds of ants, many of which externally present the appearance of hillocks more or less conical, formed of earth or other substances.

The nest of the large red or horse ants $(F$. ruf $a$ ), which are common in woods, at the first aspect seems a very confused mass. Exteriorly it is a conical mount composed of picces of straw, fragments of wood, little stones, leaves, grain ; in short, of any portable materials within their reach.

1 Reaum. ii. 128.

2 Ibid. 179 .

3 The habits of a Mexican species of butterfly (Eucheira socialis Westw.), of which the larva construct a strong white parchment-like bag, in which they resido and undergo their transformations, lave been described by $\mathrm{Mr}$. Westwood in the Trans. of the Ent. Soc. of Londisn, vi. pl. vi. 
But however rude its outward appearance, and the articles of which it consists, interiorly it presents an arrangement admirably calculated at once for protection against the excessive heat of the sun, and yet to retain a due degree of genial warmth. It is wholly composed of numerous small apartments of different sizes, communicating with each other by means of galleries, and arranged in separate stories, some very deep in the carth, others a considerable height above it : the former for the reception of the young in cold weather and at night, the latter adopted to their use in the daytime. In forming these, the ants mix the earth excavated from the bottom of the nest with the other materials of which the nount consists, and thus give solidity to the whole. Besides the avenues which join the apartments together, other galleries varying in dimensions communicate with the outside of the nest at the top of the mount. These open doors would seem ill-calculated for precluding the admission of wet or of nocturnal enemies : but the ants alter their dimensions continually according to circumstances; and they wholly close them at night, when all grachally retire to the interior, and a few sentinels only are left to guard the gates. On rainy days, too, they keep them shut, and when the sky is cloudy open them partially. ${ }^{1}$

The halitations of these ants are much larger than those of any other species in this country, and sometimes as big as a small laycock; but they are mere molelills when compared with the enormous mounds which other species, apparently of the same fimily, but much larger, construct in warmer climates. Malonet states, that in the forests of Guiana, he once saw anthills which, though his companion would not suffer him to approach nearer than forty paces for fear of his being devoured, seemed to him to be fifteen or twenty feet high, and thirty or forty in diameter at the base, assuming the form of a pyramid, truncated at one-third of its height ${ }^{2}$; and Stedman, when in Surinam, once passed ant-hills six teet high, and at least one hundred feet in circumference. ${ }^{3}$ In the plains of Paraguay, where the ants commit great devastations, a species described by Dobrizhoffer forms conical earthen nests three or more ells high, and as hard as stone; and in the Bungo forest in New South Wales, a very small ant builds nests of indurated clay eight or ten feet high. ${ }^{4}$

The nest of Formica brumea is composed wholly of earth, and consists of a great number of stories, sometimes not fewer than forty, twenty below the level of the soil, and as many above, which last, following the slope of the ant-hill, are concentric. Each story, scparately examined, exhibits cavities in the shape of saloons, narrower apartments, and long galleries which preserve the commanication between both. The arched roofs of the most spacious rooms are supported by very thin walls, or occasionally by small pillars and trie buttresses; soine laving only one entrance from above, others a second communicating with the lower story. The main galleries, of which in some places several meet in one large saloon, conmunicating with other sulterranean passages, which are often carried to the distance of several feet from the hill. These insects work chiefly after sunset. In building their nest they employ soft clay only, scraped from its * bottom when sufficiently moistened by a shower, which, fitr from injuring,

Huber, Recherches sur les Mours des Fourmis, pp. 21-29.

2 Ibid. p. 168.

1 IVestwood, Mod. Class. of Ins, ii. 223. 231. 
consolidates and strengthens their architecture. Different labourers convey small masses of this ductile material between their mandibles, and with the same instrument they spread and mould it to their will, the antennæ aceompanying every movement. They render all firm by pressing the surface lightly with their fore feet; and however numerons the masses of clay composing these walls, and though eonneeted by no glutinous material, they appear when finished one single layer, well mited, consolidated and smoothed. Having traced the plan of their structure, by placing here and there the foundations of the pillars and partition-walls, they add suecessively new portions; and when the walls of a gallery or apartment, which are half a line thick, are elevated about half an inch in height, they join them by springing a flattish arch or roof from one side to the other. Nothing can be a more interesting spectacle than one of these cities while building. In one place vertical walls form the outline, which conmunicate with different eorridors by openings made in the masonry; in another we see a true saloon, whose vaults are supported by numerous pillars ; and further on are the cross ways or squares yhere several streets meet, and whose roofs, though ofien more than two inches across, the ants are under no difficulty in constructing, beginning the sides of the areh in the angle formed by two walls, and extending them by successive layers of clay till they meet; while crowds of masons arrive from all parts with their partiele of mortar, and work with a regularity, harmony, and activity, which can never enough be admired. So assidnous are they in their operations, that they will complete a story with all its saloons, vaulted roofs, partitions and galleries, in seven or eight hours. If they begin a story, and for want of moisture are unable to fiuish it, they pull down again all the crumbling apartments that are not eovered in. ${ }^{1}$

Another species of ants (M. fusca) are also masons. When they wish to heighten their habitations, they begin by eovering the top with a thick layer of elay, which they transport from the interior. In this layer they trace out the plan of the new story, first hollowing out little cavities of almost equal depth at different distances fiom each other, and of a size adapted for their purposes. The elevations of earth left between them serve for bases to the interior walls, which, when they have removed all the loose earth from the floors of the apartments, and reduced the foundations to a due thickness, they heighten, and lastly eover all in. M. Huber saw a single working ant make and cover in a gallery which was two or three inches long, and of which the interior was rendered perfectly eoncave, without as istance. ${ }^{2}$

The societies of $F$. fuliginosa make their habitations in the trunks of old oaks or willow trees, gnawing the wood into numberless stories more or less horizontal, the ceilings and floors of which are about five or six lines asunder, black, and as thin as card, sometimes supported by vertical partitions, forming an infinity of apartments which communicate by small apertures; at others by small light eylindrical pillars furnished with is base and capital which are arranged in colonnades, leaving a communication perfectly fiee throughout the whole extent of the story. ${ }^{3}$

Two other tribes of carpenter ants ( $F$. athiops and $F$. flava) use sawdust in forming their buildings. The former applies this material only to

1 Huber, Recherches, \&c. $30-40$. 
the building of walls and stopping up chinks : the latter composes whole stages or stories of it made into a sort of papier mâclié with earth and spiders' web. ${ }^{\text {l }}$

Some ants form their nests of the leavcs of trees. One of these was observed by Sir Joseph Banks in New South Wales, which was formed hy glueing together several leaves as large as a hand. To keep these leaves in a proper position, thousands of ants united their strength, and if driven away the leaves spring back with great violence. ${ }^{2}$ Another species of ant (Ayrmica Kirbii sykes), found in the Poona Collectorate, India, described by Colonel Sykes, forms its globular battoon-shaped nest, which is composed of a congeries of tile-like laminæ of cow-dung, with"the usual assemblage of cells and nurseries, \&c., composed of the same material, in the branches of trees and shrubs. ${ }^{3}$ Another East Indian species (Formica smaragdina) forms its nest of a very thin but double silk-like tissue ${ }^{4}$; while Formica elata Lund builds its nest on the trunks of trees of earth mixed with leaves, and other species use the hairs of plants for the same purpose. ${ }^{5} F$. bispinosa in Cayenne employs the down enveloping the seeds of the Bombax criba, which it felts into a sort of cottony substance. $^{6}$

The most profound philosopher, equally with the most incurious of mortals, is struck with astonishment on inspecting the interior of a bechive. He beholds a city in miniature. He sees this city divided into regular streets, these streets composed of houses constructed on the most exact geometrical principles and the most symmetrical plan, some serving for store-houses for food, others for the habitations of the citizens, and a few, much more extensive than the rest, destined for the palaces of the sovereign. He perccives that the substance of which the whole city is built is one which man, with all his skill, is unable to fabricate; and that the edifices in which it is employed are such, as the most expert artist would find himself incompetent to erect. And the whole is the work of a society of insects! "Quel abime (he exclaims with Bonnet) aux yeux du sage qu'une ruche d'Abeilles! Quelle sagesse profonde se cache dans cet abime! Quel philosophe osera le fonder!" Nor have its mysteries yet been fathomed. Philosophers have in all ages devoted their lives to the subject; from Aristomachus of Soli in Cilicil, who, we are told by Pliny, for fifty-eight years attended solely to bees, and Philiscus the Thracian, who spent his whole time in forests investigating their manners, to Swammerdam, Reaunur, Hunter, and Huber of modern times. Still the construction of the combs of a bee-hive is a miracle which overwhelms our faculties.

You are probably aware that the hives with which we provide bees are not essential to their labours, and that they can equally form their city in the hollow of a tree or any other cavity. In whatever situation it is placed, the general plan which they follow is the same. You have seen a honeycomb, and must have observed that it is a flat tish cake, composed of a vast number of cells, for the most part hexagonal, regularly applied to each other's sides, and arranged in two strata or layers placed end to end.

1 Huber, Recherches, \&c. 61.

3 Trans. Ent. Soc. Lond. i. 101.

5 Westwood, Mod. Class. of Ins, ii. 223.

6 Lacordaire, Intr. ̀̀ l'Entom. ji. 503.
2 Hawkesworth's Cook's Voyages, iii. 223.

4 Ibid. i. proc. Ixxii. 
The interior of a bee-hive consists of several of these combs fixed to its upper part and sides, arranged vertically at a small distance from each other, so that the cells composing them are placed in a horizontal position, and have their openings in opposite clirections - not the best position one would have thought for retaining a fluid like honey, yet the bees find no inconvenience on this score. The distance of the combs from each other is about half an inch, that is, sufficient to allow two bees busied upon the opposite cells to pass each other with facility. Besides these vacancies, which form the high roads of their community, the combs are here and there pierced with holes which serve as posterns for easy communication from one to the other without losing time by going round.

The arrangement of the combs is well adapted for its purpose, but it is the construction of the cells which is most admirable and astonishing. As these are formed of wax, a substance secreted by the bees in no great abundance, it is important that as little as possible of such a precious material should be consumed. Bees, therefore, in the formation of their cells, have to solve a problem which would puzzle some geometers, namely, a quantity of wax being given, to form of it similar and equal cells of a determinate capacity, but of the largest size in proportion to the quantity of matter employed, and disposed in such a manner as to occupy in the hive the least possible space. Every part of this problem is practically solved by bees. If their cells had been cylindrical, which form seems best adapted to the shape of a bee, they could not have been applied to each other with. out leaving numberless superfluous vacuities. If the cells were made square or triangular, this last objection, indeel, would be removed: but besides that a greater quantity of wax would have been required, the shape would have been inconvenient to a cylindrical-bodied animal. All these difficulties are obviated by the adoption of hexagonal cells, which are admirably fitted to the form of the insect, at the same time that their sides apply to each other without the smallest vacant intervals. Another important saving in materials is gained by making a common base serve for two strata of cells. Much more wax as well as room would have been required, had the combs consisted of a single stratum only. But this is not all. The base of each cell is not an exact plane, but is usually composed of three rhomboidal or lozenge-shaped pieces, placed so as to form a pyramidal concavity. From this form it follows that the base of a cell on one side or stratum of the comb is composel of portions of the bases of three cells on the other. You will inquire, Where is the advantage of this arrangement? First, a greater degree of strength; and, secondly, precisely the same as results from the hexagonal sides - a greater capacity with less expenditure of wax. Not only has this been indisputably ascertained, but that the angles of the base of the cell are exactly those which require the smallest quantity of wax. It is obvious that these angles might vary infinitely; but, by a very accurate admeasurement, Maraldi found that the great angles were in general $109^{\circ} 28^{\prime}$, the smaller ones $70^{\circ} 32^{\prime}$. Reaumur, ingeniously suspecting that the object of choosing these angles from amongst so many was to spare wax, proposed to M. König, a skilful geometrician, who was ignorant of Maraldi's experiments, to determine by calculations what ought to be the angle of a hexagonal cell, with a pyramidal bottom formed of three similar and equal rhomboid plates, so that the least matter possible might enter into its construction. For the solution of this problem the geometrician had recourse to the infinitesimal calculus, and found 
that the great angles of the rhombs should be $109^{\circ} 26^{\prime}$, and of the small angles $70^{\circ} 34 .^{\prime 1}$ What a surprising agreement between the solution of the problem and the actual admeasurement $!^{2}$

Besides the saving of wax effected by the form of the cells, the bees adopt another economical plan suited to the same end. They compose the bottoms and sides of wax of very great tenuity, not thicker than a sheet of writingpaper. But as walls of this thinness at the entrance would be perpetually injured by the ingress and egress of the workers, they prudently make the margin at the opening of each cell three or four times thicker than the walls. Dr. Barclay discorered that, though of such excessive tenuity, the sides and bottom of each cell are actually double, or, in other words, that each cell is a distinct, separate, and in some mensure an independent structure, agglutinated only to the neighbouring cells, and that when the agglutinating substance is destroyed, each cell may be entirely separated from the rest. ${ }^{3}$

You must not imagine that all the cells of a hive are of precisely similar dimensions. As the society consists of three orders of insects differing in size, the cells which are to contain the larva of each proportionally differ, those built for the males being considerably larger than those which are intended for the workers. The abode of the larvæ of the queen bee differs still more. It is not only much larger than any of the rest, but of a quite different form, being shaped like a pear or Florence flask, and composed of a material much coarser than common wax, of which above one hundred times as much is used in its construction as of pure wax in that of a common cell. The situation, too, of these cells (for there are generally three or four, and sometimes many more, even up to thirty or forty, in each hive) is very different from that of the common cells. Insteal of being in a horizontal they are placed in a vertical direction, with the mouth downwards, and are usually fixed to the lower edge of the combs, from which they irregularly project like stalactites from the roof of a cavern. The cells destined for the reception of honey and pollen differ from those which the larve of the males and workers inhabit only by being dceper, and thus more capacious; in fact, the very same cells are successively applied to both purposes. When the honey is collected in great abundance, and

I Reaum. v. 390 .

2 Father Boscovich observes, that all the angles that form the planes which compose the cell are equal, $i . e \cdot 120^{\circ}$; and he supposes that this equality of inclination facilitates much the construction of the cell, which may be a motive for preferring it, as well as economy. He shows that the bces do not economise the wax necessary for a flat bottom in the construction of erery cell, near so much as MM. König and Reaumur thought.

MacLaurin says, that the difference of a cell with a pyramidal from one with a flat bottom, in which is comprised the economy of the bees, is equal to the fourth part of six triangles, which it would be necessary to add to the trapeziums, the faces of the cell, in order to make them right angles.

M. L'Hullier, professor of Geneva, values the economy of the bees at $\frac{1}{31}$ of the whole expense; and he shows that it might have been one-fifth if the bees had no other circumstances to attend to ; but he concludes, that if it is not very sensible in every cell, it may be considerable in the whole of a comb, on accont of the mutual setting of the two opposite orders of cells. Huber, Nouvelles Observations, \&c., ii. 34 ,

3 ITemoirs of the Wernerian Society, ii. 259. This, howerer, has been denied by Mr. Waterhouse, and seems inconsistent with the account giren by Huber hereafter detailed; but Mr. G. Newport asserts that even the virgin cells are lined with a delieate membrane. Westwood, Mod. Class. of Ins, ii. 284. 
there is not time to construct fresh cells, the bees lengthen the honey cells by adding a rim to them.

You will be anxious to learn the process which these ingenious artificers follow in constructing their habitations; and on this head I am happy that the recent publication of a new edition of the celebrated Huber's New $\mathrm{Ob}$ servations on Bees, in which this subject is for the first tine elucidated, will enable me to gratify your curiosity.

But in the first place you must be told of an important and unlooked-for discovery of this unrivalled detector of the hidden mysteries of naturethat the workers or neuters, as they are called, of a hive consist of two descriptions of individuals, one of which he calls abeilles nourrices, or petites abeilles, the other abeilles cirières. The former, or nurse bees, are smaller than the latter; their stomach is not eapable of such distension; and their office is to build the combs and cells after the fonndation has been laid by the cirières, to collect honey, and to feed the larvæ. The abeillcs cimières are the makers of wax, which substance Huher has now indisputably ascertained to be secreted, as John Hunter long ago suspected, beneath the rentral segments, from between which it is takeu by the bees when wanted, in the form of thin scales. The apparatus in which the wax is secreted consists of four pair of membranous hags or wax-pockets, situated at the base of each intermediate segment, one on each side, which can only be seen by pressing the aldomen so as to lengthen it, being usually concealed by the overlapping of the preceding segments. It should be observed that this discovery was nearly made by our countryman Thorley, who, in his Female Monarchy (174t), says that he has taken bees with six pieces of wax within the plaits of the abdomen, three on each side. In these pockets the wax is secreted by some unknown process from the food taken into the stomach, which in the wax-making bees is much larger than in the nursebees, and afterwards transpires throngh the membrane of the wax-pocket in thin lamina. The nurse-bees, however, do secrete wax, but in very small quantitics. When wax is not wanted in the hive, the wax-makers disgorge their honey into the cells.

The process of building the combs in a bee-hive, as observed by Huber, is as follows:-

The wax-makers, having taken a due portion of honey or sugar, fiom either of which wax can be elaborated, suspend themselves to each other, the claws of the forelegs of the lowermost being attached to those of the hind pair of the uppermost, and form themselves into a cluster, the exterior laver of which looks like a kind of curtain. This cluster consists of a series of festoons or garlands, which cross each other in all directions, and in which most of the bees turn their back upon the observer : the curtain has no other motion than what it receives fiom the interior layers, the fluctuations of which are commmnicated to it. All this time the unrse-becs preserve their wonted activity and pursue their usual employments. The wax-makers remain immoveable for athout twenty-four hours, during which period the formation of wax takes place, and thin laminæ of this material may be generally perceived under their abdomen. One of these bees is now seen to detach itself from one of the central garlands of the chister, to nıake a way amongst its companions to the middle of the vault or top of the hive, and by turning itself round to form a kind of void, in which it can move itself freely. It then suspends itsclf to the centre of the space, which it has cleared, the diameter of which is about an inch. It 
next seizes one of the laminæ of wax with a pincer formed by the posterior metatarsus and tibia ${ }^{1}$, and drawing it from beneath the abdoninal segnent, one of the anterior legs takes it with its claws and carries it to the mouth. This leg holds the lamina with its claws vertically, the tongue rolled up serving for a support, and, by elevating or depressing it at will, causes the whole of its circumference to be exposed to the action of the mandibles, so that the margin is soon gnawed into pieces, which drop as they are detached into the double cavity, bordered with hairs, of the niandibles. These fragments, pressed by others newly separated, fall on one side of the mouth, and issue from it in the form of a very narrow riband. They are then presented to the tongne, which impregnates them with a frothy liquor like a bouillie. During this operation the tongue assumes all sorts of forms ; sometimes it is flattened like a spatula ; then like a trowel, which applies itself to the riband of wax; at other times it resembles a pencil terminating in a point. After having moistened the whole of the riband, the tongue pushes it so as to make it re-enter the mandibles, but in an opposite direction, where it is worked up anew. The liquor mixed with the wax communicates to it a whiteness and opacity which it had not before; and the object of this mixture of bouillie, which did not escape the observation of Reaumm ${ }^{2}$, is cloubtless to give it that ductility and tenacity which it possesses in its perfect state.

The foundress-bee, a name which this first beginner of a comb deserves, next applies these prepared parcels of wax against the vault of the hive, disposing them with the point of her mandibles in the direction which she wishes them to take: and she continues these manœurres until she has employed the whole lamina that she had separated from her body, when she takes a second, proceeding in the same manner. She gives herself no care to compress the molecules of wax which she has heaped together; she is satisfied if they adhere to each other. At length she leaves her work, and is lost in the crowd of her companions. Another succeeds, and resumes the employment; then a third; all follow the same plan of placing their little masses; and if any by chance gives then a contrary direction, another coming removes them to their proper place. The result of all these operations is a mass or little wall of wax with uneven surfaces, five ol' six lines long, two lines high, and half a line thick, which descends perpendicnlarly below the vault of the hive. In this first work is no angle nor any trace of the figure of the cells. It is a simple partition in a right line without any infection.

The wax-makers having thus laid the foundation of a comb, are succeeded by the nurse-bees, which are alone competent to model and perfect the work. The former are the labourers, who convey the stone and mortar; the latter the masons, who work them up into the form which the intended structure requires. One of the nurse-bees now places itself horizontally on the vault of the hive, its head corresponding to the centre of the mass or wall which the wax-makers have left, and which is to form the partition of the comb into two opposite assemblages of cells; and with its mandibles, rapidly moving its head, it moulds in that side of the wall a cavity which is to form the hase of one of the cells, to the dianeter of which it is equal. When it has worked some minutes it departs, and

1 Vide Mon. Ap. Ang. t. 12. * * e. 1. neut. fig. 19.

2 Reaum. v. 421. 
another takes its place, decpening the cavity, heightening its lateral margins by heaping up the wax to right and left by means of its teeth and forefeet, and giving them a more upright form. More than twenty bees successively employ themselves in this work. When arrived at a certain point, other bees begin on the yet untouched and opposite side of the mass, and, commencing the bottom of two cells, are in turn relieved by others. While still engaged in this labour, the wax-makers return and add to the mass, augmenting its extent every way, the nurse-bees again continuing their operations. After having worked the bottoms of the cells of the first row into their proper forms, they polish them and give them their finish, while others begin the outline of a new series.

The cells themselves, or prisms, which result from the reunion and meeting of the sides, are next constructed. These are engrafted on the borders of the cavities hollowed in the mass. The bees begin them by making the contour of the bottoms, which at first is unequal, of equal height; thus all the margins of the cells offer an uniformly level surface from their first origin, and until they have acquired their proper length. The sides are heightened in an order analogous to that which the insects, follow in finishing the bottoms of the cells; and the length of these tubes is so perfectly proportioned that there is no observable inequality between them. It is to be remarked, that though the general form of the cells is hexagonal, that of those first begun is pentagonal, the side next the top of the hive, and by which the conb is attached, being much broader than the rest; whence the comb is more strongly united to the hive than if these cells were of the ordinary shape. It of course follows that the base of these cells, instead of being formed, like those of the hexagonal cells, ot three rhomboids, consist of one rhomboid and two trapeziums.

The form of a new comb is lenticular, its thickness always diminishing towards the edges. This gradation is constantly observable whilst it keeps enlarging in circumference; but as soon as the bees get sufficient space to lengthen it, it begins to lose this form, and to assume parallel surfaces : it has then received the shape which it will always preserve.

The bees appear to give the proper forms to the bottoms of the cells by means of their antennæ, which extraordinary organs they seem to employ as directors by which their other instruments are instructed to execute a very complex work. They do not remove a single particle of wax until the antenn have explored the surface that is to be sculptured. By the use of these organs, which are so flexible and so readily applied to all parts, however delicate, that they can perform the functions of compasses in measur. ing very minute objects, they can work in the dark, and raise those wonder ful combs the first production of insects.

Every part of the work appears a natural consequence of that which preceles it, so that chance has no share in the admirable results witnessed. The bees camnot depart from their prescribed route, except in consequence of particular circumstances which alter the basis of their labour. The original mass of wax is never augmented but by an uniform quantity ; and, what is most astonishing, this augmentation is made by the wax-makers who are the depositaries of the primary matter, and possess not the art of sculpturing the cells.

The bees never begin two masses for combs at the same time; but scarcely are some rows of cells constructed in the first, when two other masses, one on each side of it, are established at equal distances from it 
and parallel to it, and then again two more exterior to these. The combs are always enlarged and lengthened in a progression proportioned to the priority of their origin ; the middle comb being constantly advanced beyond the two adjoining ones by some rows of cells, and they beyond those that are exterior to them. Was it permitted to these insects to lay the foundation of all their combs at the same time, they could not be placed conveniently or parallel to each other. So with respect to the cells, the first cavity determines the place of all that succeed it.

A large number of bees work at the same time on the same comb; but they are not moved to it by a simultaneous but by a successive impulse. A single bee begius every partial operation, and many others in succession add their efforts to hers, each appearing to act individually in a direction impressed either by the workers who have preceded it, or by the condition in which it finds the work. The whole population of wax-makers is in a state of the most completc inaction till one bee goes forth to lay the foundations of the first comb. Immediately others second her intentions, adding to the height and length of the mass; and when they cease to act, a bee, if the term may be used, of another profession, one of the nurse-bees, gocs to form the draft of the first cell, in which she is succeeded by others. ${ }^{1}$

The diameters of the cells intended for the larva of workers is always $2 \frac{2}{5}$ lines, that of those meant for the larva of the males or drones $3 \frac{1}{3}$ lines. The male cells are generally in the midlle of the combs, or in their sides, rarely in their upper part. They are never insulated, but form a corresponding group on both sides the comb. When the bees form male cells below those of neuters, they construct many rows of intermediate ones, the diameter of which augments progressively till it attains that of a male cell ; and they observe the same method when they revert from male cells to those of neuters. It appears to be the oviposition of the queen which deeides the kind of cells that are to be made: while she lays the eggs of workers, no male cells are constructed; but when she is about to lay the eggs of males, the neuters appear to know it, and act accordingly. When there is a very large harvest of honey, the bees increase the diameter and even the length of their cells. At this time many irregular combs may be scen with cells of twelve, fifteen, and even eighteen lines in length. Sometimes, also, they have occasion to shorten the cclls. When they wish to lengthen an old comb, the tubes of which have acquired their full dimensions, they gradually diminish the thickness of its edges, gnawing down the sides of the cells till it assumes the lenticular form; they then engraft a mass of wax round it, and so proceed with new cells.

Variations, as has been already hinted, sometimes take place in the position and even form of the combs. Occasionally the bees construct

1 Some late physiologists and entomologists have contended with Buffon that there is in fact nothing wonderful in the hexagonal form of the cells of bees, which are at first really cylindrical (thus corrcsponting with the form of their bodies), but forced to assume the six-sided form by the pressure on their siles of the multitude of bees engaged upon them; but surely it these authors had read Huber's work with attention they inust have perceived that the fact stated by him above, that howerer large the number of bees at work on a comb, they do not work simultaneously, but successively, " each appearing to act individually in a direction impressed either by the workers who have preceded it, or by the condition in which it finds the work," is utterly at variance with their theory, as is indeed the whole of Huber's lucid and distinct relation. 
cells of the common shape upon the wood to which the combs are fixed, without pyramidal bottoms, and from them continue their work as usual. These cells with a flat hottom, or rather with the wood for their botton, are more ịregular than the common ones; some of their orifices are not angular, and their dimensions are not exact, but all are more or less hexagonal. Once when disturbed, Huber observed them to begin their combs on one of the vertical sides of the hive insteal of on the roof. When particular circunstances caused it, as, for instance, when glass was introduced, to which they do not like to fix their combs, he remarked that they constantly varied their direction; and by repeating the attempt he forced them to form their combs in the most fantastic manner. Yet glass is an artificial sub:tance, against which instinct merely cannot have provided them : there is nothing in hollow trees, their natural habitation, resembling it. When they change the direction of their combs, they enlarge the cells of one side to two or three times the diameter of those of the other, which gives the requisite curve.

To complete the detail of these interesting discoveries of the elder Huber, I must lay before you the following additional observations of his son.

The first base of the combs upon which the bees work holds three or four cells, sometimes more. The comb continues of the same willth for three or four inches, and then begins to widen for three quarters of its length. The bees engaged at the hottom lengthen it downwards; those on the sides widen it to right and left; and those which are employed above the thickest part extend its dimensions upwards. The more a comb is enlarged below, the more it is necessary that it should be enlarged upwards to the top of the hive. The bees that are engaged in lengthening the comb work with more celerity than those which increase its widtls; and those that ascend or increase its wilth upwards, more slowly than the rest. Hence it arises that it is longer than wide, and narrower towards the top than towards the middle. The first formed cells are usually not so deep as those in the middle ; but when the comb is of a certain height, they are in haste to lengthen these cells so essential to the solidity of the whole, sometimes even making them longer than the rest. The cells are not perfectly horizontal; they are almost always a little higher towards their mouth than at their base, so that their axis is not perpendicular to the partition that separates the two assemblages. They sometimes vary from the horizontal line more than $20^{\circ}$, usually $4^{\circ}$ or $5^{\circ}$. When the bees enlarge the diameter of the cells preparatory to the formation of male cells, the bottoms often consist of two rhomboids and two hexagons, the size and form of which vary, and they correspond with four instead of three opposite cells. The works of bees are symmetrical less perhaps in minute details than considered as a whole. Sometimes, indeed, their combs have a fantastic form; but this, if traced, will be found to be caused by circumstances; one irregularity occasions ancther, and both usually have their origin in the dispositions which we make them adopt. The inconstancy of climate, too, occasions frequent interruptions, and injures the symmetry of the combs; for a work resumed is always less perfect than one followed up until completed.

At first the substance of the cells is of a dead white, semi-transparent, soft, and though even, not smooth: but in a few days it loses most of thcse qualities, or rather acquires new ones; a yellow tint spreads over the 
cells, particularly their interior surface : their edges become thicker, and they have acquired a eonsistenee, which at first they did not possess. The combs, also, when finished are heavier than the unfinished ones; these last are broken by the slightest touch, whereas the former will bend sooner than break. Their orifices also have something adhesive, and they melt less readily ; whence it is evident that the finished combs contain something not present in the unfinished ones. In examining the orifice of the yellow cells, their contour appeared to the younger Huber to be besmeared with a reddish varnish, unctuous, strong-scented, and similar to, if not the same as, propolis. Sometimes there were red threads in the interior, which were also applied round the sides, rhombs, or trapeziums. This solder, as it may be called, placed at the point of contact of the different parts, and at the summit of the angles formed by their meeting, seemed to give solidity to the cells, romnd the axis of the longest of which there were sometimes one or two red zones. From subsequent experiments, M. Huber ascertained that this substance was aetually propolis, colleeted from the buds of the poplar. He saw them with the mandibles draw a thread from the mass of propolis that was most conveniently situated, and, breaking it by a sudden jerk of the head, take it with the claws of their fore-legs, and then, entering the cell, place it at the angles and sides, \&c., which they had previously planished. The yellow colour, however, is not given by the propolis, and it is not certain to what it is owing. The bees sometimes mix wax and propolis and make an amalgam, known to the ancients and called by them mitys and pissoceros, which they use in rebuilding cells that have been destroyed, in order to strengthen and support the edifice. ${ }^{1}$

We know but little of the proceedings of the species of bees not indigenous to Europe, which live in soeieties and construct combs like that eultivated by us. A traveller in Brazil mentions one there which builds a kind of natural hive: "On an excmrsion towards Upper Tapagippe,". says he, "and skirting the dreary woods which extend to the interior, I observed the trees more loaded with bees' nests than even in the neighbourhood of Porto Seguro. They consist of a ponderous shell of elay, cemented similarly to martins' nests, swelling from high trees about a foot thick, and forming an oval mass full two feet in diameter. When broken, the wax is arranged as in our hives, and the honey abundant." 2

Humble-bees are the only tribe besides the hive-bee, that in this part of the world construct nests by the united labour of the society. The habitations composing them are of a rude construetion, and the streets are ar. ranged with little architectural regularity. The number of inhabitants, too, is small, rarely exeeeding two or three humdred, and often not more than twenty. The nests of some speeies, as of Bombus lapidarius, terrestris, \&ce, are found under-ground, at the depth of a foot or more below the surface; but as the internal structure of these does not essentially differ from that of the more singular habitations of $B$. muscornm, and as some of the subterranean species occasionally adopt the same situation, I shall confine my deseription to the latter.

1 Nouvelles Observations sur les Abeilles, par François Huber, ii. 101-288. I have observed the bees collecting propolis in the spring from the buds of Populus balsamifera.

2 Lindley in R. Military Chronicle, March 1815, 449.

3 Apis. * *. e. $2 . \mathrm{K}$. 
These nests, which do not exceed six or eight inches in diameter, are generally found in meadows and pastures, and sometimes in hedge-rows where the soil is entangled with roots. The lower half occupies a cavity in the soil, either accidentally found ready made, or excavated with great labour by the bees. The upper part or dome of the nest is composed of a thick felted covering of moss, having the interior ceiling coated with a thin roof of coarse wax for the purpose of keeping out the wet. The entrance is in the lower part, and is generally through a gallery or covered way, sometimes more than a foot in length and half an inch in diameter, by means of which the nest is more effectually concealed from observation. On removing the coping of moss, the interior presents to our view a very different scene from that witnessed in a bee-hive. Instead of numerous vertical combs of wax, we see merely a few irregular horizontal combs placed one above the other, the uppermost resting upon the more elevated parts of the lower, and connected together by small pillars of wax. Each of these combs consists of several groups of pale-yellow oval bodies of three different sizes, those in the mildle being the largest, closely joined to each other, and each group connected with those next it by slight joinings of wax. These oval bodies are not, as you might suppose, the work of the old bees, but the silken cocoons spun by the young larvæ. Some are closed at the upper extremity ; others, which chiefly occupy the lower combs, have this part open. The former are those which yet include their inmature tenants : the latter are the empty cases from which the young bees have escaped. On the surface of the upper comb are seen several masses of wax of a flattened spheroidal shape, and of very varions dimensions : some above an iuch, and others not a quarter of an inch, in diameter ; which, on being opened, are found to include a number of larvæ surrounded with a supply of pollen moistened with honey. These, which are the true cells, are chiefly the work of the female, which, after depositing her eggs in them, furnishes them with a store of pollen and honey; and, when this is consumed, supplies the larvæ with a daily provision, as has been described in a former letter, until they are sufficiently grown to spin the cocoons before spoken of. Lastly, in all the corners of the combs, and especially in the middle, we observe a considerable number of small goblet-like vessels, filled with honey and pollen, which are not, as in the case of the hive-bee, the fabrication of the workers, but are chiefly the empty cocoons left by the larvæ. It falls to the workers, however, to cut off the fragments of silk from the orifice of the cocoon, which, after giving it a regular circular form, they strengthen by a ring or elevated tube of wax made in a different shape by different species; and to coat them internally with a lining of the same material. They even occisionally construct honcy-pots entirely of wax. ${ }^{1}$

The most curions circumstance in the construction of these nests is the mode in which the bees transport the moss employed in forming the roof. When they have discovered a parcel of this material conveniently situated upon the ground, five or six insects place themselves upon it in a file, turning the binder part of their bodies towards the quarter to which it is meant to be conveyed. The first takes a small portion, and with its jaws and fore-legs, as it were, felts it together. When the fibres are suffieiently

1 Huber, Linn. Trans. vi. $215-298$. 
entangled, it pushes them under its body by means of the first pair of legs; the intermediate pair receives the moss, and delivers it to the last, which protrudes it as far as possible beyond the anus. When by this process the insect has formed behind it a small ball of well-carded moss, the next bee pushes it to the third, which consigns it, in like manner, to that behind it ; and thus the balls are conveyed to the foot of the nest, and fiom thence elevated to the summit much in the same way that a file of labourers transfer a parcel of cheeses from a vessel or cart to a warehouse. ${ }^{3}$ It is easy to perceive that a vast saving of time must ensue from this well-contrived division of labour; the structure rising much more rapidly than if every individual bad been employed first in carding his materials, and then in transferring them to the spot.

Wasps, though ferocious and cruel towards their fellow-insects, are civilised and polished in their intercourse with each other, and form a community whose architectural labours will not suffer on comparison even with those of the peaceful inhabitants of a bee-hive. Like these, the great object of their inlustry is the erection of a structure for their beloved progeny, towards which they discover the greatest tenderness and affection, and they even, in like mannes, construct combs consisting of hexagonal cells for their reception; but the substance which they make use of is very dissimilar to the wax employed by bees ; and the general plan of their city differs in many respects from that of a bee-hive.

The common wasp's nest, usually situated in a cavity underground, is of an oval figure, about sixteen or eighteen inches long by twelve or thirteen broad. Externally, it is surrounded by a thick coating of numerous leaves of a sort of greyish paper, which do not touch each other, but bave a small interval between cach, so that if the rain should chance to penctrate one or two of them, its progress is speedily arrested. On removing this external covering, we perceive that the interior consists of from twelve to fifteen circular combs of different sizes, not ranged vertically as in a beehive, but horizontally, so as to form so many distiuct and parallel stories. Each comb is composed of a numcrous assemblage of hexagonal cells formed of the same paper-like substance as the exterior covering of the nest, and, according to Dr. Barclay, each, as in those of bees, a distinct cell, the partition walls being double. ${ }^{2}$ These cells, which, as wasps do not store up any food, serve merely as the habitations of their young, are not, like those of the honcy-bee, arranged in two opposite layers, but in one only, their entrance being always downwards : consequently their upper part of the comb, composed of the bases of cells, which are not pyramidal but slightly convex, forms a nearly level floor, on which the inhabitants can conveniently pass and repass, spaces of about half an inch high being left between each comb. Although the combs are fixed to the sides of the nest, they would not be sufficiently strong without further support. The ingenious builders, therefore, connect each comb to that below it by a number of strong cylindrical columns or pillars, having according to the rules of architecture their base and capital wider than the shaft, and composed of the same paper-like material used in other parts of the nest, but of a more compact substance. The niddlle combs are connected by a rustic

1 Reaum. vi. 7-10.

2 Memoirs of the Wernerian Society, ii. 260. 
colonnade of from forty to fifty of these pillars; the upper and lower comls by a smaller number.

The cells, which in a populous nest are not fewer than 16,000, are of different sizes, corresponding to that of the three orders of individuals which compose the community; the largest for the grubs of females, the smallest for those of workers. The last always occupy an entire conb, while the cells of the males and females are often intcrmixed.-Besides openings which are left between the walls of the combs to admit of access from one to the other, there are at the bottom of each nest two holes, by one of which the wasps uniformly enter, and through the other issue from the nest, and thus avoid all confusion or interruption of their common labours. As the nest is often a foot and a half under ground, it is requisite that a covered way shonld lead to its entrance. This is excavated by the wasps, who are excellent miners, and is often very long and tortuous, forming it beaten road to the subterranean eity, well known to the inhabitants, though its entrance is concealed from incurious eyes. The cavity itself, which contains the nest, is either the abandoned habitation of moles or field-mice, or a cavern purposely dug out by the wasps, which exert themselves with such industry as to accomplish the arduous undertaking in a few days.

When the cavity and entrance to it are completed, the next part of the process is to lay the foundations of the city to be included in it, which, contrary to the usual custom of builders, wasps begin at the top, continuing downwards. I have already told you that the coatings which compose the dome are a sort of rough but thin paper, and that the rest of the nest is composed of the same substance variously applied. "Whence," yon will inquire, "do the wasps derive it?" They are manufacturers of the article, and prepare it from a material even more singnlar than any of those which have of late been proposed for this purpose; namely, the fibres of wood. ${ }^{1}$ These they detach by means of their jaws from window-frames, posts, and rails, \&c., and when they have amassed a heap of the filament, moisten the whole with a few drops of a viscid glue from their mouth, and, kneading it with their jaws into a sort of paste or papier mâché, fly off with it to their nest. This ductile mass they attach to that part of the building upon which they are at work, walking backwards and spreading it into laminæ of the requisite thinness by means of their jaws, tongue, and legs. This operation is repeated several times, until at length, by aid of fresh supplies of the material and the combined exertion of so many workmen, the proper number of layers of paper that are to compose the roof is finished. This paper is as thin as that of the letter which you are reading; and you may form an idea of the labonr which even the exterior of a wasp's nest requires, on being told that not fewer than fifteen or sixteen sheets of it are usually placed above each other with slight intervening spaces, making the whole upwards of an inch and a half in thickness. When the dome is completed; the uppermost comb is next begun, in which, as well as all the other parts of the building, precisely the same material and the same process, with little variation, are employed. In the structure of the connecting pillars, there $\mathrm{secms}$ a

1 Reaumur says decaving wood, vi. 182. ; but White asserts (and my own observations confirm his opinion) that wasps obtain their paper from sound timber; hornets, only from that which is decayed. White's Nat. Hist. by Markwick, ii. 228. 
greater quantity of glue made use of than in the rest of the work, doubtless with the view of giving then a superior solidity. When the first comb is finished, the continuation of the roof or walls of the building is brought down lower; a new comb is erected; and thus the work successively proceeds until the whole is finished. As a comparatively small proportion of the society is engaged in constructing the nest, its entire completion is the work of several months: yet, though the fruit of such severe labour, it las not been finished many weeks before winter comes on, when it merely serves for the abode of a few benumbed females, and is entirely abandoned at the approach of spring; wasps never using the same nest for more than one season. ${ }^{1}$

The nests of the hornet in their general construction resemble those of the common wasp, but the paper of which they are composed is of a much more rough texture; the columns which support the comb are higher and more massive, and that in the centre larger than the rest.

These last, as well as wasps, conceal their nest, suspending it in the corners of out-houses, \&c.; but there are other species which construct their habitations in open daylight, affixing them to the branches of shrubs or trees.

One of these, deseribed by Latreille, the work of Vespa holsatica, a speeies not uncommon with us, resensbles in shape a cone of the cedar of Lebanon, and is composed of an envelope and the comb, the former consisting of three partial envelopes. The comb comprises about thirty hexagonal cells circularly arranged, those of the circumference being lower and smaller. ${ }^{2}$

A vespiary somewhat similar to the above, but of a depressed globular figure, and composed of more numerous envelopes, so as to assume a con-

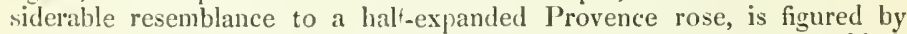
Reaumur ${ }^{3}$ : and for a very beautiful specimen apparently of the same kind, except that it contains but one stage of cells, which was found in the marden at East Dale, I am indebted to the kindness of Henry Thompson, Esq., of Hull.

Another species ${ }^{4}$ attaches its small group of about twenty inverted crucible-like cells to a pieee of wood without any covering ${ }^{5}$, and similar nests, having their cells exposed without any gencral envelope, and fixed laterally to the stems of plants, walls, \&c., are formed by Polistes gallica, and others of the same genus.

But all these yield in point of singularity of strueture to the habitation of Chartergus vidulans, a native of Cayenne, which constructs its nest of a beantifully polished white and solid pasteboard, impenetrable by the weather. These are in shape somewhat like a bell, often a foot and a half long, or even more, and fixed by their upper end to the branch of a tree from which they are securely suspended. Their interior is composed of numerous concave horizontal combs, with the openings of the cells turned

1 Reaum. vi. mém. 6.

3 vi. t. 13 , f. i. 2 .

5 liösel, II. viii. 30 . Descriptions of several other wasps' nests have been published in various works; but much uncertainty exists as to the different species forming each, and as to how far their apparent dissimilarity has resulted from one having been in a more or less forward state than another. See Westwood's Mod. Class. of In.s. ii. 250., and Shuckard's Notes on the Pensile Nests of British Wasps in Mag. Vat. Hist, ii. 458. 
downwards, fastened to the sides without any pillars, and having a hole through each to admit of access ta the uppermost. ${ }^{1}$ A nest constructed on a similar plan, but having its exterior surface beset with mumerous conical knobs, is constructed by another South American wasp, remarkable for collecting honey, for a valuable article on which we are indebted to Mr. Adum White, who has named it Myrapetra scutellaris. ${ }^{2}$

I close my account of the habitations of insects with the description of those constructed by the white ants, or Tcrmites, a tribe alluded to in tormer letters.

The different species, which are numerous, build nests of various forms. Some (T. atrox and mordax) construct upon the ground a cylindrical turret of clay about three-quarters of a yard high, surrounded by al projecting conical roof, so as in shape considerably to resemble a mushroom, and composed interiorly of innumerable cells of various figures and dimensions. Others (as T. destructor, T. arboram Sn..) prefer a more elevated site, and build their nests, which are of different sizes, from that of a hat to that of a sugar-cask, and composed of pieces of wood glued together, amongst the branches of trees often seventy or eighty feet high. But by far the most curious habitations, and to which, therefore, I shall confine a minute description, are those formed by the Termes fatalis, a species very common in Guinea and other parts of the coast of Africa, of whose proceedings we have a very particular and interesting account in the 7 lst volume of the Philosoplical Transactions, from the pen of Mr. Smeathman.

These nests are formed entirely of clay, and are generally twelve feet high and broad in proportion, so that when a cluster of them, as is often the case, are placed together, they may be taken for an Indian village, and are in fact sometimes larger than the buts which the natives inhabit. The first process in the erection of these singular structures is the elevation of two or three turrets of clay abont a foot high, and in shape like a sugarloaf. These, which seem to be the scaffolds of the future building, rapidly increase in number and height, until at length being widened at the base, joined at the top into one dome, and consolidated all round into a thick wall of clay, they form a building of the size above mentioned, and of the shape of a hay-cock, which, when clothed, as it generally soon becomes, with a coating of grass, it at a distance very much resembles. When the building has assumed this its final form, the inner turrets, all but the tops, which project like pinnacles from different parts of it, are removed, and the clay employed over again in other services.

It is the lower part alone of the building that is occupied by the inhabitants. The upper portion or dome, which is very strong and solid, is left empty, serving principally as a defence fiom the vicissitudes of the weather, and the attacks of natural or accidental enemies, and to keep up in the lower part a genial warmth and moisture necessary to the hatching of the eggs and cherishing of the young ones. The inhabited portion is occupied by the royal chamber, or habitation of the king and queen, the nurseries for the young, the storehouscs for food, and innumerable galleries, passages, and empty rooms, arranged according to the following plan.

In the centre of the building, just under the apex, and nearly on a level

1 Reaum. ri. 224. Compare Lacordairc, Introd. a l'Entom, ii. 508

- Annals of Nat. Hist. vii. 315. 
with the surface of the ground, is placed the royal chamber, an arched vault of a semi-oval shape, or not unlike a long oven; at first not above an inch long, but enlarged as the queen increases in bulk to the length of eight inches or more. In this apartment the king and queen constantly reside; and from the smallness of the entrances, which are barely large enough to admit their more diminutive subjects, can never possibly come out; thus, like many human potentates, purchasing their sovereignty at the dear rate of the sacrifice of liberty. Immediately adjoining the royal chamber, and surrounding it on all sides to the extent of a foot or more, are placed what Mr. Smeathman calls the royal apartments, an inextricable labyrinth of innumerable arched rooms of different shapes and sizes, either opening into each other or communicating hy common passages, and intended for the accommodation of the soldiers and attendants, of whom many thousands are always in waiting on their royal master and mistress. Next to the royal apartments come the nurserics and the magazines. The former are invariably occupied by the eggs and young ones, and in the infant state of the nest are placed close to the royal chamber; but when the queen's augmented size requires a larger apartment, as well as additional rooms for the increased number of attendants wanted to remove her eggs, the small nurseries are taken to pieces, rebuilt at a greater distance, a size bigger, and their number increased at the same time. In substance they differ from all the other apartments, being formed of particles of wood apparently joined together with gums. A collection of these compact, irregular, and small wooden chambers, not one of which is half an inch in width, is inclosed in a common chamber of clay sometimes as bir as a child's head. Intermixed with the nurseries lie the magazines, which are chambers of clay always well stored with provisions, consisting of particles of wood, gums, and the inspissated juices of plants.

These magazines and nurseries, separated by small empty chambers and galleries which run round them or communicate from one to the other, are continued on all sides to the outer wall of the building, and reach up within it two-thirds or three-fourths of its height. They do not, however, fill up the whole of the lower part of the hill, but are confined to the sides, leaving an open area in the middle, under the dome, very much resembling the nave of an old cathedral, having its roof supported by three or four very large Gothic arches, of which those in the middle of the area are sometimes two and three feet higl, but as they recede on each side, rapidly diminish like the arches of aisles in perspective. A flattish roof, imperforated in order to keep out the wet, if the dome should chance to be injured, covers the top of the assemblage of chambers, nurseries, \&c.; and the area, which is a short height above the royal chamber, has a flattish floor, also water-proof, and so contrived as to let any rain that may chance to get in rull off into the subterraneous passages.

These passages or galleries, which are of an astonishing size, some being ahove a foot in diameter and perfectly cylindrical, lined with the same kind of clay of which the hill is composed, served originally, like the catacombs in Paris, as the quarries whence the materials of the building were derived, and afterwards as the grand outlets by which the Termites carry on their depredations at a distance from their habitations. They run in a sloping direction under the bottom of the hill to the depth of three or four feet, and then branching out horizontally on every side, are carried 
under-ground, near to the surface, to a vast distance. At their entrance into the interior they communicate with other smaller galleries, which ascend the inside of the outer shell in a spiral manner, and, winding round the whole building to the top, intersect each other at different heights, opcning either immediately into the dome in varions places, and into the lower half of the building, or eommunicating with every part of it by other smaller circular or oval galleries of different diameters. The necessity for the vast size of the main under-ground galleries evidently arises from the circumstance of their being the great thoronghfares for the inhalitants, by which they fetch their clay, wood, water, or provision; and their spiral and gradual ascent is requisite for the easy access of the Termites, which cannot but with great difficulty ascend a perpendicular. To avoid this inconvenience, in the interior vertical parts of the building, a flat pathway, half an inch wide, is often made to wind gradually, like a road cut out of the side of a mountain, by which they travel with great facility up ascents otherwise impracticable. The same ingenious propensity to shorten their labour seems to have given birth to a contrivance still more extraordinary. This is a kind of bridge of one vast arch, sprung from the floor of the area to the upper apartments at the side of the building, which answers the purpose of a flight of stairs, and must shorten the distance exceedingly in transporting egrs from the royal chambers to the upper nurseries, which in some hills would be four or five feet in the straightest line, and much more if carried through all the winding passages which lead through the inner chambers and apartments. Mr. Smeathman measured one of these bridges, which was half an inch broad, a quarter of an inch thick, and ten inches long, making the side of an elliptic arch of proportionable size, so that it is wonderful it did not fall over or break by its own weight before they got it joined to the side of the column above. It was strengthened by a small arch at the bottom, and had a hollow or groove all the length of the upper surface, either made purposely for the greater safety of the passengers, or else worn by frequent treading. It is not the least surprising circumstance attending this bridge, the Gothic arches before spoken of, and in general all the arches of the various galleries and apartments, that, as $\mathrm{Mr}$. Smeathman saw every reason for believing, the Termites project their arches, and do not, as one wonld have supposed, excavate them.

Consider what incredible labour and diligence, accompanied by the most unremitting activity and the most unwearied celerity of movement, must be necessary to enable these creatures to accomplish, their size considered, these truly gigantic works. That such diminutive insects, for they are searccly the fourth of an inch in length, however numerous, should, in the space of three or four years, be able to erect a binilding twelve feet ligh and of a proportionable bulk, covered by a vast dome, adorned without by numerous pinnacles and turrets, and sheltering under its ample arch myriads of vaulted apartments of various dimensions, and constructed of different materials - that they should moreover excavate, in different directions and at different depths, innumerable subterranean roads or tunnels, sone twelve or thirteen inches in diameter, or throw an arch of stone over other roads leading from the metropolis into the adjoining country to the distance of several hundred feet - that they should project and finish the, for them, vast interior staircases or bridges lately described - 
and, finally, that the millions necessary to execute such Ficrculean labours, perpetually passing to and fro, should never interrupt or interfere with each other, is a miracle of nature, or rather of the Author of nature, far exceeding the most boasted works and structures of man : for, did these creatures equal him in size, retaining their usual instincts and activity, their buildings would soar to the astonishing height of more than half a mile, and their tunnels would expand to a magnificent cylinder of more than three hundred feet in diameter; before which the pyramids of Egypt and the aqueducts of Rome would lose all their celebrity, and dwindle into nothings.' So that when in the eommencement of my last letter I promised to introduce you to insects whose labours produced edifices more astonishing tiıan those of the mightiest Egyptian monarchs, the pyramids, my promise, whatever you then thought of it, was the reverse of hyperbolical.

I am, \&c.

1 The most elerated of the pyramids of Egypt is not more than 600 feet high, which, setting the average height of man at only five feet, is not more than 120 times the height of the workmen employed. Whiereas the nests of the Termites being at least twelve feet high, and the insects themselves not exceeding a quarter of an inch in stature, their edifice is upwards of 500 times the height of the builders; which, supposing them of human dimensions, would be more than half a mile. The shaft of the Roman aqueducts was lofty enough to permit a man on borseback to travel in them.

\section{Addition to the note on Scolytus destructor, p. $12 \%$.}

Since writing the note abore referrel to upon Scolytus destructor, I have seen in passing through Paris to ltaly, so striking an instance of the way in which the little beetle to which it refers hias revenged the neglect and contempt thrown upon its class by destroying in a great degree the effect of one of the most vaunted and costly productions of modern architecture, that the fact may be worth recording as an instructive warning for the future. 'The avenue of elms connecting the Place sle la Concorde and Champs Elysées with the Barrière de l'Etoile leading to Nevilly, St. Germains, Sc., has always been described as the most magnificent approach to Paris, and was on that account selected by Napoleon for the cntrée of his new empress Marie-Louise, and as the site, at its most elevated point, of the "Are de Triomphe," commemorating his rictories and companions in arms, of which he laid the foundations, but which has only recently been completed at a vast expense. It is needless to point out how essentially the effect of this splendid monument of art must depend upon the sizc, health, and beauty of the lines of trees connecting it with those which occupy the Champs Elysées, and garden of the Tuileries; yet at this time (September 10. 1842) there are lying fron twenty to thirty of their finest elms very lately cut down, in consequence of liaving died from the attacks of Scolyti; and as many others hat been previonsly removed and replaced by young trees, and the full-grown ones offer, from their dead tops, the numerous holes in their bark, and the oozing sap, ample proof that their pigmy but effective assailants are silently at work on the rest, it is evident that the whole avenue is eventually roomed to destruction, and that a century must elapse before it can resume that grandeur which it might have retained for ages hat the economy of these insects been understood, and the proper measures for extirpating them taken at the outset. It has been well observed, that in many cases a palace had better be burnt than the fine old trees that surround and ornament it destroyed, as the former may bo 
rebuilt in a few years, while no cost can replace the latter; and a reflection some. what similar must have passed througl the mind of Napoleon, had he lived to witness the present broken, patched, and miserable aspect of one of the most striking and indispensable features of his trimphal arch. and to see in prospect, that even when the last victims to the destructive attacks of the despised Scolytifoes which, from his ignorance of Entomology, had conquered even bim - shonld have been cut down, and the unsightly gaps attempted to be filled up by planting young trees in their place, neither he nor his succes ior could ever witness in this the proudest monument of his reign the mingled splendour and grace which it would have exhibited, if approached, as he meant it to have been, through a fullgrown, entire, and majestic avenue. 


\title{
LETTER XV1.
}

\section{SOCIETIES OF INSECTS.}

\author{
IMPERFECT SOCIETIES.
}

I sEE already, and I see it with pleasure, that you will not content yourself with being a mere collector of insects. To possess a cabinet well stored, and to know by what name each described individual which it contains should be distinguished, will not satisfy the love already grown strong in you for my favourite pursuit; and you now anticipate with a landable eagerness, the discoveries which you may make respecting the history and economy of this most interesting department of the works of our Creator. I hail with joy this intention to emulate the bright example, and to tread in the hallowed steps of Swammerdam, Leeuwenhoek, Redi, Malpighi, Vallisnieri, Ray, Lister, Reaumur, De Geer, Lyonnet, Bonnet, the Hubers, \&c. ; and I am eonfident that a man of your abilities, discernment, and observation will contribute, in no small degree, to the treasures already poured into the general fund by these your illustrious predecessors.

I feel not a little flattered when you inform me that the details eontained in my late letters relative to this subject have stimulated you to this noble resolution. Assure yourself I shall think no labour lost which has been the means of winning over to the science I love the excrtions of a mind like yours.

But if the faets already related, however extraordinary, have had power to produce such an effect upon you, what will be the momentum, when I lay before you more at large, as I next purpose, the more striking particulars of the proceedings of insects in society, and show the almost incredibly wonderful results of the combined instincts and labours of these minute beings? In comparison with these, all that is the fruit of solitary efforts, though some of them suffieiently marvellous, appears trifling and insignificant; as the works of man himself, when they are the product of the industry and genius of only one, or a few individuals, though they might be regarded with admiration by a being who had seen nothing similar before, yet when contrasted with those to whieh the union of these qualities in large bodies has given birth, sink into nothing, and seem unworthy of attention. Who would think a hut extriordinary by the side of a stately palaee, or a small village when in the vicinity of a populous and magnificent city?

Insects in society may be viewed under several lights, and their associations are for various purposes and of different durations.

There are societies the object of whieh is mutnal clefence; while that of others is the propagation of the species. Some form marauding parties, and associate for prey and plunder ; others meet, as it should seem, under 
certain eircumstances, merely for the sake of company ; again, others are brought together by accidental causes, and disperse when these cease to operate; and, finally, others, which may be said to form proper societies, are associated for the nurture of their young, and, by the union of their labours and instincts, for mutual society, help and comfort in erecting or repairing their common habitation, in collecting provisions, and in defending their fortress when attacked.

With respect to the duration of the societies of insects, some last only during their first or larva state, and are occasionally even restricted to its earliest period; some again only associate in their perfect or imago state; while with others, the proper societies for instance, the association is for life. But if I divide societies of inseets into perfect and imperfect, it will, I think, enable me to give you a clearer and better view of the subject. By perfect societies I mean those that are associated in all their states, live in a common habitation, and unite their labours to pronote a common object ; and by imperfect societies, those that are either associated during part of their existence only, or else do not dwell in a common habitation, nor unite their labours to promote a common object. In the present letter I shall confine myself to giving you some account of imperfect societies.

Imperfect societies may be considered as of five descriptions : associations for the sake of company only; associations of males during the season for pairing; associations formed for the purpose of travelling or emigrating together; associations for feeding together; and associations that undertake sone common work.

The first of these associations consists chiefly of insects in their perfect state. The little beetles called whirlwigs (Gyrinus), which may be seen clustering in groups under warm banks in every river and every pool, and wheeling round and round with great velocity, at your approach dispersing and diving under water, but as soon as you retire resuming their accustomed movements, seem to be under the influence of the social principle, and to form their assemblies for no other purpose than to enjoy together, in the sunbeam, the mazy dance. Impelled by the same feeling, in the very depth of winter, even when the earth is covered with snow, the tribes of Tipularice (usually, but improperly, ealled gnats) assemble in sheltered situations at mid-day, when the sun shines, and form themselves into' choirs, that alternately rise and fall with rapid evolutions. ${ }^{1}$ To see these little aëry beings apparently so full of joy and life, and feeling the entire force of the social principle in that dreary season, when the whole animal creation appears to suffer, and the rest of the insect tribes are torpid, always convey's to my mind the most agreeable sensations. These little creatures may always be seen at all seasons amusing themselves with these choral dances, which Mr. Wordsworth, in one of his poems ${ }^{2}$, bas alluded to in the following beautiful lines: -

\footnotetext{
"Nor wanting here to entertain the thought,

Creatures that in communities exist

Less, as might seem, for general guardianship

Or through dependence upon mutual aid,

Than by narticipation of delight,

And a strict love of fellowship combined.
}

1 See also Markwick in White's Nat. Irist. ii. 256.

2 The E.rcursion. 
What other spirit can it be that prompts

The gilded summer flies to mix and weare

Tlyeir sports together in the solar beam,

Or in the gloom and twilight hum their joy ?"

Another association is that of males during the season of pairing. Of this nature seems to be that of the cockehafer and fernchafer (Melolonthe vulgaris and Amplimalla solstitialis), which, at certain periods of the year and hours of the day, hover over the summits of the trees and hedges like swarms of bees, affording, when they alight on the ground, a grateful food to cats, pigs, and poultry. The males of another root-devouring beetle (Hoplia argentea) assemble by myriads before noon in the meadows, when in these infinite hosts you will not find even one female. ${ }^{1}$ After noon the congregation is dissolved, and not a single individual is to be seen in the $\mathrm{air}^{3}$ : while those of M. vulgaris and A. solstitialis are on the wing only in the evening.

At the same time of the day some of the short-lived Ephemeræassemble in numerous troops, and keep rising and falling alternately in the air, so as to exhibit a very amusing scene. Many of these, also, are males. They continue this dance fiom about an hour before sun-set, till the dew becomes too heavy or too cold for them. In the beginning of September, for two successive years, I was so fortunate as to witness a spectacle of this kind, which afforded me a more sublime gratification than any work or exhibition of art has power to communicate. The first was in 1811. Taking an evening walk near my house, when the sun, declining fast towards the horizon, shone forth without a cloud, the whole atmesphere over and near the stream swarmed with infinite myriads of Ephemeræ and little gnats of the genus Chironomus, which in the sumbeam appeared as numerous and more jucid than the drops of rain, as if the heavens were showering down brilliant gems. Afterwards, in the following ycar, one Sunday, a little before sunset, I was enjoying a stroll with a friend at a greater distance from the river, when in a field by the road side the same pleasing seene was renewed, but in a style of still greater magnificence; for, from some cause. in the atmospliere, the insects at a distance looked much larger than they really were. The choral dancers consisted principally of Ephemerce, but there were also some of Chironomi: the former, how ever, being most conspicuous, attracted our chicf attention. Alternately rising and falling, in the full beim they appeared so transparent and glorions, that they scarcely resembled any thing material; they reminded us of angels and glorified spirits drinking life and joy in the effulgence of the Divine favour. ${ }^{3}$ The bard of Twickenham, fiom the terms in which his beatiful description of his sylphs is conceived in The Rape of the Lock, secms to have witnessed the pleasing scene here described :-

\footnotetext{
"Some to the sun their insect wings unfold,

Waft on the breeze, or sink in clonds of gold;

Transparent forms, too fine for mortal sight,

Their fluid bodies half dissolved in light;
}

1 The females (Scarabcus argenteus Marsh.) have red legs, and the males (Scarubous pulcerulentus Nlarsh.) black.

2 Kirby in Linn. Trens. v. 256.

3 The authors of this work were the witnesses of the magnificent scene here described. It was on the second of September. The first was on the nintl of that muntl. 
Loose to the wind their airy garments few,

Thin glittering textures of the filmy dew,

Dint in the richest tincture of the skies,

Where light disports in ever mingling dyes,

While erery beam new trinsient colours flings,

Colours that cliange whene'er they wave their wings."

I wish you may have the good fortune next year to be a spectator of this all but celestial dance. In the meantime, in May and June, their season of love, you may often receive much gratifieation from observiog the motions of a comtless host of little black flies of the genus Hildra (H. maura), which at this period of the year assemble to wheel in aëry circles over stagnant waters, with a rush resembling that of a basty shower driven by the wind.

Here, also, must be noticed the bombardier beetles (Brachinus cropilans), which, with several others of the same family, are usually found together in considerable numbers under stones, \&ce, and the red field-burs Cimex (Pyprhocoris) apterus, which, in like manner, have a very social propensity, rhough in both instances we are ignorant of any common labours or other motive than the love of society, which can lead them to associate. The same may be also said as to the numerous assemblages of a moth (Scotophila 'Tragopoginis), mentioned by M. de Villiers, which he finds in July under the bark of willows, ranged side by side, generalty touching each other, and with the head always turned the same way, and which if you disturb them do not attempt to fy, but rmn upon the backs of their companions, which exhibit no marks of alarm. ${ }^{1}$

The next description of insect associations is of those that congregate for the purpose of travelling or emigrating together. De Geer has given an account of the larva of certain gnats ('Tipularia) which assemble in considerable numbers for this purpose, so as to form a band of a finger's breadth, and of from one to two yards in length. And, what is remarkable, while upon their mareb, which is very slow, they adbere to each other by a kind of glutinous secretion ; but when clisturbed they separate without difficulty. ${ }^{2}$ Kuhm mentions another of the same tribe-fiom the antennæe in his figure, which is very indifferent, it should seen a speeies of agaricgnat (IIycetophila), - the larvæ of which live in society, and emigrate in files, like the caterpillar of the procession-moth. First goes one, next follow two, then three, \&c., so as to exhihit a serpentine appearance, probably from their simultaneous undulating motion, and the continuity of the files, whence the common people in Germany eall them (or rather the file when on mareh) hcerwurm, and view them with great dread, regarding them as ominous of war. These larve are apodes, white, sub-transparent, with black heals. ${ }^{3}$ The caterpillars of a moth Noctua (Xylophasin?) Eivingii Westw., a native of Van Diemen's Land, exhibited a singular migrating propensity as described by Thomas I. Ewing, Eisq., who has given them the name of the "migrating eaterpillars." Passing, about December 20th, from a barley field which had been ploughed up, and

1 Ann. Soc. Ent. de France, xi. bull, xii.

2 De Geer, vi. 338.

3 Naturforsch. xvii. 226. 
which seemed literally in motion with them, they proceeled up the rond, entered at the gateway into the lawn, then crossed the verandah in front of the house, and through two gardens until they reached a field laid down with English grasses, on which they eommitted sad havoc. Many of them did not stop there, as the whole road from the field to the town was black with them. They did not cease migrating for a fortnight, proceeding with a quick and almost running motion over every obstacle, whether walls or shrubs, \&c., and making a sudden halt at noon wherever they chancel to be, and reposing in that spot till four the next morning, when they were again in motion. ${ }^{1}$ It is probable that these caterpillars were in search of fresh pasture like others feeding on trees, of which instances are on record of a whole army having at once quitted a forest of which they had entirely. consumed the leaves in quest of another. One of these hosts (as we may conclude) is stated by an American newspaper, the Charleston Cutrier, to have availed themselves in May, 18t2, in passing from Richland to the st. Mathew`s shore, of a new railway there rumning over the Cangaree Swamp, as a convenient bridge, in such countless swarms that a solid eolumn of them filled the railway for upwards of a mile, and actually arrested the course of a locomotive drawing a full train of waggons laden with iron, though moving with a speed of ten to twelve miles an hour, and which was only able to proceed by throwing sand on the fore wheels.

But of insect emigrants none are more celebrated than the locusts, which, when arrived at their perfect state, assemble, as before related, in such numbers, as in their flight to intercept the sunbeams, and to darken whole countries, passing from one region to another, and laying wastc kingdom after kinglom; but upon these I have already said much, and shall have occasion again to enlarge. The same tendency to shift their quarters has heen observed in our little indigenous devourers, the Aphides. Mir. White tells us, that about three o'clock in the afternoon of the lst of August, 1785, the people of the viliage of Selborne were surprised by a shower of Aphides or smother flies, which fell in those parts. Those that walked in the street at that juncture found themselves covered with these insects, which settled also upon the hedges and in the gardens, blackening all the vegetables where they alighted. His ammals were discoloured by them, and the stalks of a bed of onions quite coated over for six days after. These armies, he observes, were then, no doubt, in a state of emigration, and shifting their quarters, and might have come from the great hop plantations of Kent or Sussex, the wind being all that day in the east. They were observed at the same time in great clonds abont Farnham, and all along the vale from Farnham to Alton. ${ }^{2}$ A similar emigration of these flies I once witnessed, to $m y$ great annoyance, when travelling later in the year, in the Isle of Ely. The air was so full of them, that they were incessantly flying into my eyes, nostrils, \&c., and my clothes were covered by them. And in 1814, in the autumn, the Aphides were so abundant for a few days in the vicinity of Ipswich, as to be noticed with surprise by the most incurious observers; as they were september 26 th and 27 th, 1836 , at Hull, where, as the local newspapers stated, such swarms filled the air that it was impossible to walk with comfort from their entering the eyes and mouth at every step; and on the same days they were equally numerous at York and Derby. 
As the locust-eating thrush (Turdus Gryllivorus) accompanies the locusts, so the lady-birds (Coccinella) seem to pursue the Aphides; for I know no other reason to assign for the vast number that are sometimes, especially in the antumn, to be met with on the sea-coast, or the banks of large rivers. Many years ago, those of the Humber were so thickly strewed with the common lady-bird ( $C$. Septempunctata), that it was difficult to avoid treading upon them. Some years afterwards I noticed a mixture of species, collected in vast numbers, on the sand-hills on the sea-shore, at the north-west extremity of Norfolk. My friend, the Rev. Peter Lathbury, made long since a similar observation at Orford, on the Suffolk coast ; and about five or six years ago they covered the cliff', as I have before remarked, of all the watering places on the Kentish and Sussex coasts, to the no small alarm of the superstitious, who thought them forerunners of some direful evil. ${ }^{1}$ These last probably emigrated with the Aphides from the hop grounds. Whether the latter and their devourers cross the sea hias not been ascertained; that the Coccinellæ attempt it, is evident from their alighting upon ships at sca, as I have witnessed myself. ${ }^{2}$ This appears clearly to have been the case with another emigrating insect, the saw-fly (Athalia centifolice) of the turnip. ${ }^{3}$ It is the general opinion in Norfolk, MIr. Marshall informs us ${ }^{4}$, that these insects come from over sca. A farmer declared he saw them arrive in clonds so as to clarken the air; the fishermen asserted that they had repeatedly seen flights of them pass over their heads when they were at a distance from land; and on the beach and clifis they were in such quantities, that they might have been taken up by shorelfuls. Three miles inland they were described as resembling swarms of bees. This was in Angnst, 178\%. Unentomological observers, such as farmers and fishermen, might easily mistake one lind of insect for another; but supposing them correct, the swarms in question migint perhaps have passed from Lincolnshire to Norfolk. Meinecken tells us, that he once saw in a village in Anbalt, on a clear day, about four in the afternoon, such a cloud of dragon-flies (Libellulina) as almost concealed the sun, and not a little alarmed the villagers, under the idea that they were locusts $^{5}$; several instances are given by Rösel of similar clouds of these insects haring been seen in Silesia and other districts ${ }^{6}$; and Mr. Woolnough of Hollesley in Suffolk, a most attentive observer of nature, once witnessed such an army of the smaller dragon-flies (Agrion) Aying inland from the sea as to cast a slight shadow over a field of four acres as they passed. A migration of dragon-flies was witnessed at Weimar in Germany in 1816, and one far more considerable, perhaps the greatest on record, May 30 th and 3 !st

1 Some such terrific idea would seem to bave entered the sapient heads of the authorities of one of the principal towns of lierkshire, which in October, 1835 , according to the Reading Mercury, having had " a most formidable invasion of this beautiful insect [laty-birds] . . the parish engines, as well as private ones, were called into requisition, with tobacco-fumigated water, to attack and disperse them." $[! ! !]$

2 Mr. Curtis informs us that the aphidivorous flies (Scava Ribesii, Pyrastri, \&.c.), like the lady-birds, sometimes appear in myriarls on the sea-eoast, all Hying in one direction, and not even avoiding objects that lie in their course. (Brit. Ent. ful. 509.)

5 Fn. Germ. Init. xlix. 18.

5 Nuturforsch. vi. 110.

4 Philos. Trans, lxxiii. 21\%. 6 ii. 135. 
1539, when clond-like swarms of these insects (chicfly $L$. depressa) were seen at Weimar, Eisenach, Leipsig, Halle, and Göttingen, and the intervening country, extending over a very large district. ${ }^{1}$ Professor Walch states, that one night about eleven o'clock, sitting in his study, his attention was attracted by what seemed the pelting of hail against his window, which surprising him by its long continuance, he opened the window, and found the noise was occasioned by a flight of the fioth frog-hopper (Aphrophora spumaria), which entered the room in such numbers as to cover the tablc. From this circumstance, and the continuance of the pelting, which lasted at least half an hour, an idea may be formed of the vast host of this insect passing over. It passed from east to west; and as his window faced the south, they only glanced against it obliquely. ${ }^{2}$ He alterwards witnessed, in August, a similar emigration of myriads of a kind of ground beetle (Amara vulgaris). ${ }^{3}$ But the most remarkable migrations of beetles are those recorded by M. Lacordaire, who informs us that for two suecessive years, when he was at Buenos Ayres, that eity was for about eight days in the spring of each year inundated by such milions of Harpalus cupripemis, which arrived daily towards nightfall, that it was neeessary every morning to sweep them from the exterior of the houses to a height of several feet above the ground.4 Another writer in the Naturforscher, H. Kapp, observed on a ealm sunny day a prodigions flight of the noxious cabbage butterfly (Pontia Brassica), which passed from north-east to sunth-west, and lasted two hours. ${ }^{5}$ Kalm saw these last insects midway in the British Channel. ${ }^{6}$ A similar migratory eolumn of the universally spread Vanessa C'ardui, of from ten to fitteen feet in breadth, and the passage of which ocenpied two hours, was observed in 1836 in the eanton of Vand, Srvitzerland. ${ }^{7}$ Lindley, a writer in the Royal Military Chromicle, tells us, that in Brazil, in the beginning of March, 1803, for many days successively there was an inmense fight of white and yellow butterties, probably of the same tribe as the cabbage butterfly. They were observed never to settle, but proceeded in a direetion from north-west to south-east. No buildings seemed to stop them from steadily pursuing their course, which being to the ocean, at only a small distance, they must consequently perish. It is remarked that at this time no other lind of butterfy is to be seen, though the country usually ahounds in such a variety. ${ }^{8}$ In the instanee of the butterflies inostly of a species similar to, if not identical with, the common English Colias Eidusa, seen by Mr. Darwin and Captain Fitzroy when at sea, about ten miles from the bay of st. Blas, on the coast of Sunth America, and which were in such countless myriads (occupying, aceording to Captain Fitzroy's calculation, a space of not less than a mile in wilth, several miles in length, and two hundred yards in height) that the sailors exelaimed, "It is snowing butterflics:" their object in flying out so far to sea would seem to have been a voluntary migration, as Mr. Darwin states that the day had been fine and calm. ${ }^{9}$ Major Moor, while stationed at

1 Treissenborn in MIag. Nat. IIist. X. S. iii. 516.

2 Naturforsch. vi. 111.

4 Lacorilaire, Introd. à l'Entom. ii. 494.

5 Naturforsch. 94.

7 Silbermann, Revue Entom. ii. 142.

8 R. Wilit. Chron, for March 1815 , p. 452.

9 Narrative of the surveying Ioyages of his Majesty's Ships Adventure and Beagle. iii. $18 \tilde{\jmath}$

3 Ibid. xi. 95.

6 Travels, i. 13. 
Bombay, as he was playing at cliess one evening with a friend in Old Woman's Island, near that place, witnessed an immense flight of bugs (Geocorise) which were going westward. They were so numerous as to cover every thing in the apartment in which he was sitting. When staying at Aldeburgh, on the eastern coast, I have, at certain times, seen innumerable insects upon the beach close to the waves, and apparently washed up by them. Though wetted, they were quite alive. It is remarkable, that of the emigrating insects here enumerated, the majority - for instance, the lady-birds, saw-flies, dragon-flies, ground-beetles, from-hoppers, \&c. - are not usually social insects, but seem to congregate, like swallows, merely for the purpose of emigration. What incites them to this is one of those mysteries of nature, which at present we cannot penetrate. A scarcity of food urges the locusts to slift their quarters, and too confined a space to accommodate their numbers occasions the bees to swarm; but neither of these motives can operate in causing unsocial insects to congregate. It is still more difficult to account for the impulse that urges these creatures, with their filmy wings and fragile form, to attempt to cross the ocean, and expose themselves, one would think, to inevitable destruction. Yet, though we are unable to assign the cause of this singular instinct, some of the reasons which induced the Creator to endow them with it may beconjectured. This is clearly one of the modes by which their numbers are kept within due limits, as, doubtless, the great inajority of these adventurers perish in the waters. Thus, also, a great supply of food is furnished to those fish in the sea itself, which at other seasons ascend the river's in search of them: and this probably is one of the means, if not the only one, to whicl the numerous islands of this globe are indebted for their insect population. Whether the insects I observed upon the beach, wetted by the waves, had flown from our own shores, and falling into the water had been brought back by the tide; or whether they had succeeded in the attempt to pass from the continent to us, by flying as far as they could, and then falling had been brought by the waves, cannot certainly be ascertained but Kalm's observation inclines me to the latter opinion.

The next order of imperfect associations is that of those insects which feed together: these are of two descriptions; those that associate in their first or last state only, and those that associate in all their states. The fir'st of these associations is often very short-lived : a patch of eggs is glued to a leaf; when hatched, the little larve feed side by side very amicably, and a pleasant sight it is to see the regularity with which this work is often done, as if by word of command; but when the leaf that served for their cradle is consumed, their society is dissolved, and each goes where lie can to seck his own lortune, regardless of the fate or lot of his brethren. Of this kind are the larvæ of the saw-fly of the gooscberry, whose ravages I have recorded before, and that of the cabbage butterfly ; the latter, however, keep longer together, and seldom wholly sejarate. In their final state, I have noticed that the individuals of Thrips Physapus, the fly that causes 11 in hot weather such intolerable titillation, are very fond of each other's company when they feed. Towards the latter end of last July, walking through a wheat-field, I observed that all the blossoms of Convolvulus arvensis, though very numerous, were interiorly turned quite black by the infinite number of these insects, which were coursing about within them.

But the most interesting insects of this order are those which associate 
in all their states. Two populous tribes, the great devastators of the vege. table world, the one in warm and the other in cold climates, to which I have already alluded under the head of emigration - yon perceive I am speaking of Aphides and Locusts - are the best examples of this order : although, concerning the societies of the first, at present we can only say that they are merely the result of a common origin and station; but those of the latter, the loeusts, wear more the appearance of design, and of being produced by the social principle.

So much as the world has suffered from these animals, it is extraordinary that so few observations have been made upon their history, economy, and mode of proceeding. One of the best accounts seems to be that of Professor Pallas, in his Travels into the Southern Provinces of the Russian Empire. The species to which his principal attention was paid appears to have been the Locusta Italica, in its larva and pupa state. "In serene warm weather," says he, "the locusts are in full motion in the morning immediately after the evaporation of the dew ; and if no dew has fallen, they appear as soon as the sun imparts his genial warmth. At first some are seen lunning abont like messengers among the reposing swarms, which are lying partly compressed upon the ground, at the side of small eminences, and partly attached to tall plants and shrubs. Shortly after, the whole body begins to move forward in one direction, and with little deviation. They resemble a swarm of ants, all taking the same course, at small distances, bnt without touching each other : they uniformly travel towards a certain region as fist as a fly can run, and without leaping, unless pursued; in which case, indeed, they disperse, but soon collect again and follow their former route. In this manner they advance from morning to evening without. halting, frecyuently at the rate of a hundred fathoms and upwards in the course of a day. Although they prefer marching along high roads, footpaths, or open tracts, yet when their progress is opposed hy bushes, hedges, and ditches, they penetrate throngh them: their way can only be impeded by the waters of brooks or canals, as they are apparently terrified at every kind of moisture. Often, however, they endeavom to gain the opposite bank with the aid of overhanging boughs; and if the stalks of plants or shrubs be laid across the water, they pass in close columns over these temporary bridges, on which they even seem to rest and enjoy the refreshing coolness. Towards sunset the whole swarm gradually collect in parties, and creep up the plants, or encamp on slight eminences. On coid, clondy, or rainy days they do not travel. As soon as they acquire wings they progressively disperse, but still fly about in large swarms." 1

"In the month of May, when the ovaries of these insects were ripe and turgid," says Dr. Shaw ${ }^{2}$ " each of these swarms began gradually to disappear, and retired into the Mettijiah, and other adjacent plains, where they deposited their eggs. These were no sooner hatched in June, than each of the broods collected itself into a compact body, of a furlong or more in square, and marehing afterwards direetly forwards toward the sea, they let nothing escape them - they kept their ranks like men of war; climbing over, as they advanced, every tree or wall that was in their way; nay, they entered into our very houses and bed-chambers, like so many thicves. A day or two after one of these hordes was in motion, others were already 
inatched to march and glean after them. Having lived near a month in this mamner, they arrived at their full growth, and threw off their namphastate by casting their outward skin. To prepare thenselves for this change, they chung by their hinder feet to some bush, twig, or corner of a stone; and immediately, by using an undulating motion, their heads would furst break out, and then the rest of their bodies. The whole transformation was performed in seven or eight minutes, after which they lay for a small time in a torpid and seemingly in a languishing condition ; but as soon as the sum and the air had hardened their wings, by drying up the moisture that renained upon them after casting their sloughs, they reassumed their former voracity, with an addition of strength and agility. Yet they continned not long in this state before they were entirely dispersed." The species Dr. Shaw here speaks of is probably not the Locusta migratoria.

The old Arabian fable, that they are dirceted in their flights by a leader or king $^{1}$, has been adopted, but I think without sufficient reason, by severa! travellers. Thus Benjamin Bullivant, in his "Observatious on the Natural History of New England2," says that "the locusts have a kind of regimental discipline, and as it were some commanders, which show greater and more splendid wings than the common ones, and arise first when pursued by the fowls or the feet of the traveller, as I have often seriously re. marked." And in like terms Jackson observes, that "they have a government amongst themselves similar to that of the bees and ants; and when the (Sultan Jerraad) king of the locusts rises, the whole body follow him, not one solitary straggler being left behind." 3 But that locusts have leaders, like the bees or ants, distinguished from the rest by the size and splendour of their wings, is a circumstance that has not yet been established by any satisfactory evidence; indeed, very strong reasons may loe urged against it. The nations of bees and ants, it must be observed, are housed together in one nest or hive, the whole population of which is originally derived from one common mother, and the leaders of the swarms in each are the females. But the armies of locusts, though they herd together, travel together, and feed together, consist of an infinity of separate families, all derived from different mothers, who have laid their eggs in separate cells or houses in the earth; so that there is little or no analogy between the societies of locusts and those of bees and ants; and this pretended suitan is something quite different from the queen bee or the female ants. It follows, therefore, that as the locusts have no common mother, like the bees, to lead their swarms, there is no one that nature, by a different organisation and ampler dimensions, and a more angust form, has destined to this high office. The only question remaining is, whether one be elccted from the rest by common consent as their leader, or whether their instinct impels them to follow the first that takes flight or alights. This last is the learnel Bochart's opinion, and seems much the most reasonable. ${ }^{4}$ The absurdity of the other supposition, that an election is made, will appear from such queries as these, at which you may smilc. Who are the elcetors? Arc the myriads of millions all consulted, or is the clective franchise confined to a few? Who holds the conts and takes the votes? Who casts them up and declares the result? Wheu is the election made? The larva appear to be as much under government as the perfect insect.

1 Bochart, Hierozoic. ii. 1. 4. c. 2. 460 .

3 Jackson's Marocco. 51.
2 In Philos. Trans, for 1698.

4 Bcchart, Hierozoic. ubi suprà 
Is the monarch then ehosen by his peers when they first leave the egg and emerge from their subterranean caverns? or have larva, pupa, and imago each their separate king? The account given us in Scripture is certainly much the most probable, that the locusts have no king, though they observe as much order and regularity in their movements as if they were under military discipline, and had a ruler over them." Some species of ants, as we learn firom the admirable history of them by M. P. Huber, though they go forth by common consent upon their military expeditions, yet the order of their columns keeps perpetually changing; so that those who lead the van at the first setting out soon fall into the rear, and others take their place: their successors do the same; and such is the constant order of their mareh. It seems probable, as these columns are extended to a considerable length, that the objeet of this successive change of leaders is to convey constant intelligence to those in the rear of what is going forward in the van. Whether anything like this takes place for the regulation of their motions in the innumerable loeust-armies, which are sometimes co-extensive with vast kingdoms; or whether their instinet simply direets them to follow the first that moves or flies, and to keep their measured distance, so that, as the prophet speaks, "one does not thrust another, and they walk every one in his path"," must he left to fu-. ture naturalists to ascertain. And I think that you will join with me in the wish that travellers, who have a taste for Natural History, and some knowledge of insects, would devote a share of attention to the proceedings of these celebrated animals, so that we might have facts instead of fables.

The last order of inperfect associations approaches nearer to perfect societies, and is that of those insects which the social principle urges to unite in some common work for the benefit of the community.

Amongst the Coleoplera, Atenchus pilularius, a beetle before mentioned, acts under the influence of this prineiple. "I have attentively admired their industry and mutual assisting of each other," says Catesby, "in rolling those globular balls from the place where they made them to that of their interment, which is usually the distance of some yards, more or less. This they perform breeh foremost, by raising their lind parts, foreing along the ball with their hind feet. "Two or thrce of them are sometimes engaged in trundling one ball, whieh, from meeting with impediments from the unevenness of the ground, is sometimes deserted by them: it is, however, attempted by other's with success, unless it happens to roll into some deep hollow chink, where they are constrained to leave it; but they continue their work by rolling off the next ball that comes in their way. None of them seem to know their own balls, but an equal care for the whole appears to affect all the community." 3

Many larva also of Lepidoptera assoeiate with this view, some of which are social only cluring part of their existenec, and others during the whole of it. The first of these contimue together, while their united labours are beneficial to them; but when they reach a certain period of their life, they disperse and become solitary. Of this kind are the caterpillars of a little bntterfly (Melitca Cinxia). which devour the narrowleaved plantain. The families of these, usually amounting to about a hundred, unite to form a pyramidal silken tent, containing several apart-

1 Proverbs, $\underset{3 x x}{\max } 27$.

2 Joel, ii. 8.

3 Catesby's Carolina, ii. 111. 
ments, which is pitched over some of the plants that constitute their food, and shelters them both from the sun and the rain. When they have consumed the provision which it covers, they construct a new one over other roots of this plant; and sometimes four or five of these encampments may be seen within a foot or two of each other. Against winter they weave and erect a stronger habitation of a rounder form, not divided by any partitions, in which they lie heaped one upon another, each being rolled up. About April they separate, and continue solitary till they assune the pupa.

Reaumur, to whom I am indebted for this account, has also given us an interesting history of another insect, the gold-tail moth (Porthesia chrysorrhoca) before mentioned, whose caterpillars are of this description. They belong to that family of Bombycide which envelop their egos in hair plucked from their own body. As soon as one of these young caterpillars is disclosed from the egg, it begins to feed ; another quickly joins it, placing itself by its side; thus they proceed in succession till a file is formed across the leaf: - a second is then begum ; and after this is completed a third, - and so they proceed till the whole upper surface of the leaf is covered : - but as a single leaf will not contain the whole family, the remainder take their station upon the adjoining ones. No soomer bave they satisfied the cravings of hunger, than they begin to think of erecting a common habitation, which at first is only a vaulted web, that covers the leaf they inhabit, but by their united labours, as I have clescribed in a former letter, in due time grows inco a magnificent tent of sill; containing various apartments sufficient to clefend and shelter them all from the attacks of enemies and the inclemency of the seasons. As oum caterpillars, like eastern monarchs, are too delicate to adventure their feet upon the rough bark of the trce upon which they feed, they lay a silken carpet over every road and pathway leading to their palace, which extends as far as they have occasion to go for food. To the habitation just described, they retreat during heavy rains, and when the sun is too hot: - they likewise pass part of the night in them; - and, indeed, at all times some may usually be found at home. Upon any sudden alarn they retreat to them for safety, and also when they cast their skins : - in the winter they are wholly confined to them, enierging again in the spring: but in May and June they entirely desert them; and, losing all their love for society, live in solitude till they hecome pupæ, which takes place in about a month. When they clesert their nests the spiders take possession of them; which has given rise to a prevalent though most absurd opinion, that they are the parents of these caterpillars. ${ }^{1}$

With other caterpillars the association continues during the whole of the larva state. De Geer mentions one of the saw-flies (Serrifera) of this description which form a common nidus by connecting leaves torrether with silken threads, each larva moreover spinning a tube of the same material for its own private apartment, in which it glides backwards and forwards upon its lack. ${ }^{2}$ I have observed similar nidi in this country; the iusects that form them belong to the Fabrician genus $L$, yda.

A small East Indian hair-streak butterfly (Thecla Isocrates), of whose econony Mr. Westwood has given an interesting account, resides in the larva state in small societics of at lcast seven or eight individuals in the 
inside of the pomegranate, on the seeds and pulp of which it feeds. The firuit being thus rendered weak and unable to support its own weight would be liable to have its stalk broken and to fall to the ground with the first wind and there rot, in which state it would most probably be destructive to the inclosed larræ. To obviate this evil, the caterpillars when full fed have the remarkable instinct to gnaw a hole about a quarter of an inch in diameter through the hard shell of the fruit while it still remains on the tree, and issuing through this hole to spin in common (as it would seem) a silken web attached both to the stalk and the base of the fruit, and sufficiently strong to support the ponegranate from falling in the event of the stalk bing broken by the wind; and having thus secured the stability of their chamber, they retire again into it, and there undergo their metamorphosis, the butterflies while their wings are still unexpanded creeping out of the hole above mentioned, which thus serves a second important purpose in their economy, of allowing them a free passage in their perfect state through the bard shell of the pomegranate, which, if this door in it had not previously been prorided by the caterpillar with its jaws, would have proved a fatal prison to the butterfly, which has no such instruments. ${ }^{1}$

The most remarkable insects, however, that arrange under this class of imperfect associates, are those that observe a particular order of march. Though they move without beat of dirum, they maintain as much regularity in their step as a file of soldiers. It is a most agreeable sight, says one of Nature's most favoured admirers, Bonnet, to see several bundreds of the larve of Clisiocampa neustria marching after each other, some in straight lines, others in curves of various inflection, resembling, from their fiery colour, a moving cord of gold stretched upon a silken riband of the purest white; this riband is the carpeted causeway that leads to their leafy pasture from their nest. Equally anusing is the progress of another moth, the Pityocampa, before noticed; they march together from their common citadel, consisting of pine leaves united and inwoven with the silk which they spin, in a single line; in following each other they describe a nultitude of graceful curves of varying figure, thus forming a series of living wreaths, which change their shape every moment:- all move with at uniform pace, no one pressing too forward or loitering behind; when the first stops, all stop, each defiling in exact military order. ${ }^{2}$

A still more singular and pleasing spectacle, when their regiments march out to forage, is exhibited by the caterpillars of the Processionary moth (Cncthoeampa processionca). This moth, which is a native of France, and has not yet been found in this country, inhabits the oak. Each family consists of from 600 to 800 individuals. When young, they have no fixed habitation, but encamp sometimes in one place and sometimes in another, under the shelter of their web: but when they have attained two-thirds of their growth, they weave for themselves a common tent, before described. About sunset the regiment leaves its quarters; or, to make the metaphor harmonise with the trivial name of the animal, the monks their cœnobium. At their head is a chief, by whose movements their procession is regulated. When he stops, all stop, and proceed when he proceeds; three or four of

1 Westwood in Trans. Ent. Soc. Lond. ii. 1. tab. 1. The Mexican butterfly (Eucheira socialis Westw.), previously noticed, is also (as its name implies) social in its larva state.

2 Bonnet, ii. 57. 
his inmediate followers succeed in the same line, the head of the second touching the tail of the first : then comes an equal series of pairs, next of threes, and so on as far as fifteen or twenty. The whole procession moves regularly on with an even pace, each file treading upon the steps of those that precede it. If the leader, arriving at a particular point, pursues a different direction, all march to that point before they turn. Probably in this they are guided by some scent imparted to the tracks by those that pass over then. Sometimes the order of procession is different; the leader, who moves singly, is followed by two, these are succeeded by three, then come four, and so on. When the leader, - who in nothing differs from the rest, and is probably the caterpillar nearest the entrance to the nest, followed, as I have described, - has proceeded to the distance of ahont two feet, more or less, he.makes a halt ; during which those which remain come forth, take their places, the company forms into files, the march is resumed, and all follow as regularly as if they kept time to music. These larva may be occasionally found at mid-day out of their nests, packed close one to another without making any movement; so that, although they occupy a space sufficiently ample, it is not easy to discover" then. At other times, instead of being simply laid side by side, they are formed into singular masses, in which they are heaped one upon another, and, as it were, interwoven together. Thus, also, they are disposed in their nests. Sometimes their families divide into two bands, which never afterwards unite. ${ }^{1}$

The proeessionary caterpillars of the fir (those of Cnethocampa pityocampa), like the preceding, live in a common silken net placed at the extremities of its branches, on which they feed; and when they leave one tree to proceed to another, they also move in procession, but with this striking difference, that they all range themselves in a single file, the head of each so exactly touching the tail of that before it as to form apparently one vast caterpillar of from fifteen to twenty feet long, and thus traversing by a continuous and occasionally slightly jerking motion, without ever breaking their line, the path they have chosen. What is singular is, that if the first caterpillar of the file be touched with the hand or a stick, it shrinks and is visibly agitated, as if it feared to be stung by an Iclneumon, and the last of the file, even if composed of six hundred, makes at the same instant, as well as every intermediate individual, the same movements, as if struck by an electric shock. ${ }^{2}$ - The individuals of another processionary caterpillar, the perfect insect of which Mr. Ewing had not been able to rear, he informs us march in circles, or rather ovals, and, when young, follow one another round and round for hours together $!^{3}$

I have nothing further of importance to communicate to you on imperfect societies : in my next I shall begin the most interesting subject that Entomology offers; a subject, to saly the least, including as great a portion both of instruction and amusement as any branch of Natural History affords; - I mean those perfect associations which have for their great object the multiplication of the species, and the education, if such a term may be here cmployed, of the young. This is too fertile a theme to be confined to a single letter, but must occupy several.

1 Reaumur, ii. 180.

2 De Villiers, Aun. Soc. Ent. de France, i. 201.

$s$ Westwood in Trans. Ent. Soc. Lund. ii. proc, Iv. 


\section{LETTER XVII.}

\section{SOCIETIES OF INSECTS - continued.}

\section{PERFECT SOCIETIES. (WHITE ANTS AND ANTS.)}

THE associations of insects of which my last letter gave you a detail were of a very imperfect kind, both as to their object and cluration: but those which I am now to lay before you exhibit the semblance of a nearer approach, both in their principle and its results, to the societies of man himself. There are two kindred sentiments that in these last act with most powerful energy-desire and affection. From the first proceed nany wants that cannot be satisfied without the intercourse, aid, and co-operation of others; and by the last we are impelled to seek the good of certain ohjects, and to delight in their society. Thus self-love combines with philanthropy to produce the social principle, both desire and love alternately urging us to an intercourse with each other; and from these in union originate the multiplication and preservation of the species. These two passions are the master-movers in this business; but there is a third subsidiary to them, which, though it trenches upon the social principle, considered abstractedly, is often a powerful bond of union in separite societies-you will readily perceive that I am speaking of fear;-mel the influence of this passion these are drawn closer together, and unite more intimately for defence against some common enemy, and to raise works of munition that may resist his attack.

The main instrument of association is language, and no association can be perfect where there is not a common tongue. The origin of nationality was difference of speech : at Babel, when tongues were divided, nations separated. Language may be understood in a lirger sense than to signify intlections of the voice, - it may well include all the means of making yourself understood by another, whether by gestures, sounds, signs, or words : the first two of these kinds inay be called natural language, and the last two arbitrary or artificial.

I have said that perfect societies of insects exhibit the semlance of a nearcr approach, both in their principle and its results, to the societies of man himself, because, unless we could perfectly understand what instinct is, and how it acts, we cannot, without exposing ourselves to the charge of temerity, assert that these are precisely the same.

But when we consider the object of these societies, the preservation and multiplication of the species, and the means by which that olject is attained, the united labours and co-operation of perhaps millions of individuals, it seems as if they were impelled by passions very similar to those main-springs of human associations which I have just enumerated. Desire appears to stimulate them - love to allure them - fear to alarm them. They want a habitation to reside in, and food for their subsistence. Does 
not this look as if desire were the operating cause, which induces them to unite their labours to construct the one and provide the other? Their uests contain a numerous family of helpless broou. Does not tove here seem to urge them to that exemplary and fond attention, and those nnremitted and indefatigable exertions manifested by the whole community for the benefit of these dear oljects? Is it not ilso evideneed by their general and singular attachment to their females, by their mutnal caresses, by their feeding each other, by their apparent sympathy with suffering individuals and endeavours to relieve them, by their readiness to help those that are in diffieulty, and finally by their sports and assemblies for relaxation? That fear produces its influence upon them seems no less evident, when we see them agitated by the approach of enenies, endeavour to remove what is most dear to them beyond their reach, unite their efforts to repel their atticks, and to construct works of defence. They appear to have besides a conmon language; for they possess the faculty, by significative gestures and sounds, of communicating their wants and ideas to each other. $^{1}$

There are, however, the following great differences between human societies and those of insects. Man is susceptible of individual attachment, which forms the basis of his happiness, and the source of his purest and dearest enjoyments : whereas the love of insects seems to be a kind of instinctive patriotism that is extended to the whole comnunity, never distinguishing individuals, unless, as in the instance of the female bee, con nected with that great olject.

Man also, endowed with reason, forms a judgment from circumstances, and by a variety of means can attain the same end. Besides the language of nature, gestures, and exclamations, which the passions prodnce, he is gifted with the divine faculty of speech, and can express his thoughts by articulate sounds or artificial language. - Not so our social insects. Every species has its peculiar mode of proceeding, to which it adheres as to the law of its nature, never deviating but under the courtrol of imperious circumstances: for in particular instances, as you will see when I come to treat of their instincts, they know how to vary, though not very materially, from the usual mode. ${ }^{2}$ But they never depart, like man, from the general system ; and, in common with the rest of the animal kingdom, they have no articulate language.

Human associations, under the direction of reason and revelution, are also formed with higher views, - I mean as to government, morals, and religion:-with respect to the last of these, the social insects of conrse can have nothing to do, except that by their wonderful proceedings they give man an occasion of glorifying his great Creator ; but in their instincts, extraordinary as it may seem, they exhibit a semblance of the two former, as will abundantly appear in the course of our correspondence.

I shall not detain you longer by prefatory remarks from the amusing

1 It is not here moant to be asserted that insects are actuated by these passions in the same way that man is, but only that in their various instincts they exhibit the semblanee of them, and, as it were, symbolise them.

2 "Plusieurs d'entre eux (Insectes) sarent user" de ressourees ingruieuses dans les circonstances difliciles: ils sortent alors de leur routiue aecoutumée, et sfmblent agir d'après la position dans laquelle ils se trouvent; e'est là saus foute l'un des phénomines les plus eurieux de l'histoire naturelle." Huber, Niurelles Cbscrution sur les Aleilles, ii. 198.-Compare also ibic. 250. note N. L. 
secne to which I am eager to introduce you; but the following observations of M. P. Huber on this subject are so just and striking, that I cannot refiain from copying them.

"The history of insects that live in solitude consists of their generation, their peculiar habits, the metamorphoses they undergo, their manner of life under each strcessive form, the stratagems for the attack of their enemies, and the skill with which they construct their habitation : but that of insects which form numerous societies is not confined to some remarkable proceedings, to some peculiar talent: it offers new relations, which arise fron common interest, from the equality or superiority of rank, from the part which each member supports in the society; and all these relations suppose a connection between the different individuals of which it consists that can scarcely exist but by the intervention of language : for such may be called every mode of expressing their wishes, their wants, and even their ideas, if that name may be given to the impulses of instinct. It would be difficult to explain in any other way that concurrence of all wills to one end, and that species of harmony which the whole of their institution exhibits."

The great end of the societies of insects being the rapid multiplication of the species, Providence has employed extraordinary means to secure the fulfilment of this object, by creating a particular order of individuals in each society, which, freed from sexual pursuits, may give themselves wholly to lahour, and thus absolve the females from every employment but that of furnishing the society from time to time with a sufficient supply of eggs to keep up the population to its proper standard. In the case of the Termites, the office of working for the society, as these insects belong to an order whose metamorphosis is semi-complete, devolves upon the larva; the neuters, unless these should prove to be the larva of males, being the soldiers of the commmity.

From this circumstance perfect societies may be divided into two classes; the first including those whose workers are larve, and the second those whose workers are neuters. ${ }^{1}$ The white ants belong to the former of these classes, and the social Iymenoptera to the latter.

Before I begin with the history of the societies of white ants, I must notice a remark that has been made applying to societies in general - that numbers are essential to the full development of the instinct of social animals. This has been observed by Bonnet with respect to the beaver ${ }^{2}$; by Reaumur of the hive-bee; and by M. P. Huber of the humble-bee. ${ }^{3}$ Amongst hymenopterous social insects, however, the observation seems not universally applicable, but only under particular circumstances ; for in incipient societies of ants, humble-bees, and wasps, one female lays the foundation of them at first by herself, and the first brood of neuters that is hatched is very snuall.

I have on a former occasion given you some account of the devastation produced by the white ants, or Termites, the species of which constitute

1 I employ occasionally the term neuters, thongh it is not perfectly proper, for the sake of contenience;-strictly speaking, they may rather be regarded as in:-purfect or sterile females. Tet, certininly, as the imperfection of their organisation unfits them for sexnal purposes, the tem neuter is not absolutely improper.

2 (Fuv. ix. 163.

3 11. 1'. Huber in Linn. Trans. vi. 256. Reamm.. 
the first class of perfect societies; I shall now relate to you some further particulars of their history, which will, I hope, give you a better opinion of them.

The majority of these animals are natives of tropical countries, though two species are indigenous to Europe; one of which, thought to have been imported, is come so near to us as Bordeaux. The fullest account hitherto given of their history is that of Mr. Smeathman, in the Philosophical Transactions for 1781, which, since it has in many particulars been confirmed by the observations of succeeding naturalists, though in some things he was evidently mistaken, I shall abridge for you, correcting him where he appears to be in error, and adding from Latreille, and the MS. of a French naturalist resident on the spot, kindly furnished by Professor Hooker, what they have observed with respect to those of Bordeaux and Ceylon. The white ants, though they belong to the Neuroptera order, borrow their instinct from the hymenopterous social tribes, and in conjunction with the ants (Formica) connect the two orders. Their societies consist of five descriptions of individuals - workers or larva-nymphs or pupx - neuters or soldiers - males and females.

1. The workers or larvx, answering to the hynrenopterous neuters, are the most numerous and at the same time the most active part of the community, upon whom devolves the office of erecting and repairing the buildings, collecting provisions, attending upon the female, conveying the eggs when laid to what Smeathman calls the nurseries, and feeding the young larva till they are old enough to take care of themselves. They are distinguished from the soldiers by their diminutive size, by their round heads and shorter mandibles.

2. The nymphs or pupæ. These were not noticed by Smeathman, who mistook the neuters for them: they differ in nothing from the larræ, and probably are equally active, except that they have rudiments of wings, or rather the wings folded up in cases (pterotheca). They were first observed by Latreille; nor did they escape the author of the MS. above alluded to, who mistook them for a different kind of larva.

3. The neuters, erroneously called by Smeathman pupx. These are much less numerous than the workers, bearing the proportion of one to one hundred, and exceeding them greatly in bulk. They are also distinguishable by their long and large head, armed with very long subulate mandibles. Their office is that of sentinels; and when the nest is attacked, to them is conmitter the task of defending it. These neuters are quite unlike those in the Hymenoptera perfect societies, which seem to be a kind of abortive females, and there is nothing analogous to them in any other department of Entomology.

4. and 5. Males and females, or the insects arrived at their state of perfection, and capable of continuing the species. There is only one of each in every separate society; they are exempted from all participation in the labours and employments occupying the rest of the community, that they may be wholly devoted to the furnishing of constant accessions to the population of the colony. Though at their first disclosure fiom the pupa they have four wings, like the femate ants they soon cast them ; but they may then be distinguished from the blind larvæ, pupæ, and neuters, by their large and prominent eyes. ${ }^{1}$

1 The neuters in all respects bear a stronger analogy to the larva than to the perfect insects; and, after all, may possibly turn ont to be larva, perhaps of the $x$ 2 
The first establishment of a colony of Termites takes place in the following manner. In the evening, soon after the first tornacto, which at the latter end of the dry season proclaims the approach of the ensuing rains, these animals having attained to their perfect state, in which they are firnished and adorned with two pair of wings, emerge from their clay-built citadels by myriads and myriads to seek their fortune. Borne on these ample wings, and carried by the wind, they fill the air, entering the houses, extinguishing the lights, and even sometimes being driven on board the ships that are not far from the shore. The next morning they are discovered covering the surface of the earth and waters: deprived of the wings which before enabled them to avoid their numerous enemies, and which are only calculated to carry them a few hours, and looking like larce magrots ; from the most active, industrious, and rapacious, they are now become the most helpless and cowardly beings in nature, and the prey of innumerable enemies, to the smallest of which they make not the least resistance. Insects, especially ants, which are always on the hunt for them, leaving no place umexplored; birds, reptiles, beasts, and even man himself, look upon this event as their harvest, and, as rou have been told before, make them their food; so that scarcely a single pair in many nillions get into a place of safety, fulfil the first law of nature, and lay the foundation of a new community. At this time they are seen running upon the ground, the male after the female, and sometimes two chasing one, and contending with great eagerness, regardless of the innumerable dangers that surround them, who shall win the prize.

The workers, who are continually prowling about in their covered ways, occasionally meet with one of these pairs, and, being impelled by their instinct, pay them homage, and they are elected as it wcre to be king and queen, or rather father and mother, of a new colony ${ }^{1}$; all that are not so fortunate inevitably perish; and, considering the infinite host of their enemies, probably in the course of the following day. The workers, as soon as this election takes place, begin to inclose their new rulers in a small chamber of clay, before described, suited to their size, the entrances to which are only large enough to admit themselves and the neuters, but much too small lor the royal pair to pass through; - so that their state of royalty is a state of confinement, and so contimues during the remainder of their existence. The impregnation of the female is supposed to take place after this confincment, and she soon becins to furnish the infant colony with new inhabitants. The eare of feeding her and her male conpanion devolves upon the industrious larve, who supply them both with every thing that they want. As she increases in dimensions, they keep enlarging the cell in which she is detained. When the business of oriposition commences, they take the eggs fiom the female, and deposit them in the

males. Huber seems to doubt their being nenters. Nour. Ols. ii. 441. note *. Great differences of opinion continue to exist amongst entomologists as to the real nature of the individuals above described of this very anomalous tribe, for the details of which, and of the arguments employed, see iVestwood, IVod. Ciassif. of Ins. ii. 15.

1 In this these animals rary from the usnal instinct of the social Hymenoptera, the ants, the wasps, and the humble-bees - witl whom the females lay the first fomdations of the colonies, massisted ly any neiters ; - but in the swarms of the hive-bee an election may perhaps in some instances be said to take place. 
nurseries. Her abdomen now begins gradually to extend, till in process of time it is enlarged to 1500 or 2000 times the size of the rest of her body, and her bulk equals that of 20,000 or 30,000 workers. This part, often more than three inches in length, is now a vast matrix of eggs, which make long circumvolutions through numberless slender serpentine vessels: it is also remarkable for its peristaltic motion (in this resembling the female ant ${ }^{1}$ ), which, like the undulations of water, produces a perpetual and successive rise and fall over the whole surface of the abdomen, and occasions a constant extrusion of the eggs, amounting sometimes in old females to sixty in a minute, or eighty thousand and upwards in twentyfour hours. ${ }^{2}$ As these females live two year's in their perfect state, how astonishing must be the number produced in that time!

This incessant extrusion of eggs must call for the attention of al large number of the workers in the royal chamber (and indeed it is always full of them), to take them as they come forth and carry them to the nurseries; in which, when hatched, they are provided with food, and receive every necessary attention till they are able to shilt for themselves.-One remarkable circumstance attends these nurseries - they are always covered with a kind of mould, amongst which rise numerous globules about the size of a small pin's head. This is probably a species of Mucor, and by Mr. König, who found them also in nests of an East India species of Termes, is conjectured to be the food of the larvæ.

The royal cell has, besides some soldiers in it, a kind of body-guard to the royal pair that inhabit it: and the surrounding apartments contain always many, both labourers and soldiers in waiting, that they may suceessively attend upon and defend the common father and mother, on whose safety depend the happiness and even existence of the whole comminity, and whom these faithful subjects never abandon even in their last distress.

The manner in which the Termites feed the young brood before they commence their active life and are admitted to share in the labours of the nest, has not, as far as I know, been recorded by any writer. I shall, therefore, leave them in their nu'series, and introduce you to the bustling scene which these creatures exhibit in their first state after they are become useful. To do this, in vain should I carry you to one of their nests - you would scarcely see a single one stirring - though, perhaps, under your feet there would be millions going and returning by a thousand different ways. Un'ess I possessed the power of Asmodeus in Le Diable Boiteux, of showing you their houses and covered ways with their roof's removel, you wonld return home as wise as you caine; for these little busy creatures are taught by Providence always to work under cover. If they have to travel over a rock or up a tree they vault with a eoping of earth the route they mean to pursue, and they form subterranean paths and tumels, some of a clianeter wider than the bore of a latre cannon, on all sides from their habitation to their various objects of attack; or which sloping down (for they cannot well mount a surface quite perpendicular) penetrate to the depth of three or four feet under their nests into the earth, till they arrive at a soil proper to be used in the erection of their buildings. Were they, indeed, to expose themselves, the race avould soon be annihilated by

1 Gould's Account of English Ants, 22.

2 John Hunter dissected two youngr queens. In the abdomen he found twc ovaries, consisting of many hundred oviduets, each containing innumerable erger. 
their innumerable enenies. This circumstance bas deceived the anthor of the MS. acconnt of those in Ceylon, who, speaking of the nests of these insects in that island, which he describes as twelve feet bigh, observes, that "they may be considered as a larce city, wbich contains a great number of houses, and these houses an infinite number of cells or apartments:- these cells appear to me to communicate with each other, but not the houses. I have convinced myself, by bringing together the broken walls of one of the cavities of the nest or cone, that it does not communicate with any other, nor with the exterior of the cone, - a very curious circumstance, which I will not undertake to explain. Other cavities communicate by a very narrow tunnel." By not looking for subterranean communications, be was probably led into this error.

You have before heard of their diligence in building. Does any accident happen to their various structures, or are they dislodged from any of their covered ways, they are still more active and expeditious in repairing. Getting ont of sight as soon as possible - and they run as fast or faster than any iusect of their size - in a single night they will restore a gallery of three or four yards in length. If, attacking the nest, you divide it in inalves, leaving the royal chamber, and thus lay open thousands of apartments, all will be shut up with their sheets of clay by the next morning; - nay, even if the whole be demolished, provided the king and the queen be leit, every interstice between the ruins, at which either cold or wet can possibly enter, will be covered, and in a year the building will be raised nearly to its printine size and grandeur.

Besides building and repairing, a great deal of their time is occupied in making necessary alterations in their mansion and its approaches. The loyal presence-chamber, as the female increases in size, nust be gradually enlarged, the nurseries must be removed to a greater distance, the chambers and exterior of the nest receive daily accessions to provide for a daily increasing population; and the direction of their covered ways must often be varied, when the old stock of provision is exhausted and new discorered.

The collcction of provisions for the use of the colony is another employment, which necessarily calls for incessant attention: these to the naked eye appear like raspings of wood; - and they are, as you have seen, great destroyers of timber, whether wronght or inwrought: - but when examined by the microscope, they are found to consist chiefly of gums and the inspissated juices of plants, which, formed into little masses, are stored up in magazines of clay.

When any one is bold enough to attack their nest and make a breach in its walls, the labourers, who are incapable of fighting, retire within, and give place to another description of its inlabitants, whose office it is to defend the fortress when assailed by enemies:- these, as observed before, are the neuters or soldiers. If the breach be made in a slight part of the building, one of these comes out to reconnoitre; he then retires and gires the alarm. Two or three others next appear, scrambling as fist as they can one after the other; - to these succed a large body, who rush forth with as much speed as the breach will permit, their numbers continually increasing during the attack. It is not casy to describe the rage and fury by which these diminutive heroes seem actuated. In their haste the firequently miss their holu, and tumble down the sides of their hill : they soon, however, recover themselves, and, being blind, bitc every thing they 
run against. If the attack proceeds, the bustle and agitation increase to a tenfold degree, and their fury is raised to its higliest pitch. Woe to him whose hands or legs they can come at! for they will nake their fanged jaws meet at the very first stroke, drawing as much blood as will counterpoise their whole body, and never quitting their hold, even though they are pulled limb from limb. The naked legs of the Negroes expose then frequently to this injury; and the stockings of the European are not sufficient to defend him.

On the other hand, if, after the first attack, you get a little out of the way, giving them no further intermption, supposing the assailant of their citadel is gone beyond their reach, in less than half an hour they will jetire into the nest; and before they have all entered, you will see the labourers in motion, hastening in various directions towards the breach, every one carrying in his mouth a mass of mortar half as big as his bol.y ${ }^{\text {, }}$ ready tempered : - this mortar is made of the finer parts of the gravel, which they probably select in the subterranean pits or passages before clescribed, which, worked up to a proper consistence, hardens to the solid substance, resembling storie, of which their nests are constructed. As fist as they come up, each sticks its burden mpon the breach; and this is done with so much regularity and despatch, that although thousands, nay, millions, are employed, they never appear to embarrass or interrupt one another. By the united labours of such an infinite host of creatures the wall soon rises, and the breach is repaired.

While the labourers are thus employed, almost all the soldiers have retired quite out of sight, except here and therc one, who saunters about amongst them, but never assists in the work. One, in particular, places himself close to the wall which they are building; and turning himself leisurely on all sides, as if to survey the proceedings, appears to act the part of an overseer of the works. Every now and then, at the interval of a minute or two, by lifting up his head and striking with his forceps upon the wall of the nest, he makes a particular noise, which is answered by a loud hiss from all the labourers, and appears to be a signal for despatch; for, every time it is lieard, they may be seen to redouble their pace, and apply to their work with increased diligence. Renew the attack, and this amusing scene will be repeated : - in rush the labourers, all disappearing in a few seconds, and out march the military as numerous and vindictive as before. When all is once more quiet, the busy labourers reappear, and resume their work, and the soldiers vanish. Repeat the experiment a hundred times, and the same will always be the result; you will never find, be the peril or emergency ever so great, that one orcler attempts to fight, or the other to work.

You have seen how solicitous the Ternites are to move and work under cover and concenled from olsservation; this, however, is not always the case; - there is a species larger than $T$. bellicosus, whose proceedings I have been principally describing, which Mr. Smeathman calls the marching Termes ('T'ermes viarum). He was once passing through a thick forest, when on a sudden a loud hiss, like that of serpents, struck him with alam. The next step produced a repetition of the sound, which he then re-

1 The anonymous author before alluded to, who observed the Ceylon white ants' says, that such was the size of the masses, which were tempered with a strong gluten, that they adhered though laid on the upper part of the breach. 
cognised to be that of white ants; yet he was surprised at seeing none of their hills or covered" ways. Fullowing the noise, to his great astonishment and delight he saw an army of these creatures emerging from a hole in the gronnd; their number was prodigions, and they marched with the unmost celerity. When they had proceeded about a yard they divider into two columns, chiefly composed of latourers, about fifteen abreast, following each other in close order, and going straight forward. Here and there was seen a soldier, carrying his vast head with apparent difficulty, ind looking like an ox in a flock of shecp, who marehed on in the same manner. At the distance of a foot or two from the columus many other soldiers were to be seen, standing still or pacing about as if upon the lookout, lest some enemy should sudilenly surprise their unwarlike comrades; - other soldiers, which was the most extraordinary and amusing part of the scene, having mounted some plants and placed themselves on the points of their leaves, elevated from ten to fifteen inches from the ground, hung over the army marching below, and by striking their forceps upon the leaf, produced at intervals the noise before mentioned. To this signal the whole army returned a hiss, and obered it hy increasing their pace. The soldiers at these sirnal stations sat quite still during the intervals of silence, except now and then making a slight turn of the head, and seemed as solicitous to keep their posts as regular sentinels. The two columns of this army united after continuing separate for twelve or filteen paces, having in no part been above three yards asunder, and then descended into the earth by two or three holes. Mr. Smeathman contimued watching them for above an hour, during which time their numbers appeared neither to increase nor diminish:- the soldiers, however, who quitted the line of n:arch and acted as sentinels, became much more numerous before he quitted the spot. The larva and neuters of this species are furnished with eyes.

The societies of Termes lucifugus, discovered by Latreille at Bordeanx, are very numerous; but instead of erecting artificial nests, they make their lodgment in the trunks of pires and oaks, where the branches diverge from the tree. They eat the wood the nearest the bark, or the alburnum, without attacking the interior, and bore a rast number of holes and irregular galleries. That part of the wood appears moist, and is covered with little gelatinous particles, not unlike gum-arabic. These insects seem to be furnished with an acid of a very penetrating odour, which perhaps is useful to them for softening the wood. ${ }^{1}$ The soldiers in these societies are as about one to twenty-five of the labourers. ${ }^{2}$ 'The anonymous author of the observations on the Termites of Ceylon seems to have discorered a sentry-box in his nests. "I found," says he, "in a very small cell in the mieldle of the solid mass (a cell about half an inch in height, and very natrow), a larva with an enormous head. Two of these individuals were in the same cell: - one of the two seemed placed as sentinel at the entrance of the cell. I amised myself by forcing the door two or three times:the sentinel immediately appeared, and only retreated when the door was on the point to be stopped up, which was done in three minutes by the labourers."

I hope this account has reconciled you in some degree to the dest:tic-

Latr. Hist. Nat. xiil. 64.

2 N. Dict. d'Hist. Nat. xxii. 57, 58. 
tive Termites: - I shall next introdnce you to social inseets, concerning most of which you have probably conceived a more favourable opinion I mean those whieh constitute the second class of perfect societies, whose workers are not larva, but neuters. These all belong to the Hymenoplera order of Linné : - there are four kinds of insects in this order (which you will find as fertile in the instruters of nankind, as you bave seen it to be in our benefactors), that, varying eonsiderably from each other in their proceelings as social animals, separately merit your attention; namely, ants, wasps, and hornets, humble-bees, and the hive-bee. I begin with the first.

Full of interesting traits as are the history and economy of the white ants, and however earnestly they may induee you to wish you conld be a spectator of them, yet they seareely exceed those of an industrious tribe of insects which are constantly passing under our eye. The ant has attracted universal notice, and been celebrated from the earliest ages, both by sacred and profane writers, as a pattern of prudence, foresight, wisdom, and diligence. Upon Solonon's testimony in their favour I have enlarged before; and for those of other ancient writers, I must refer you to the learned Boehart, who has colleeted them in his Hierozoicon.

In reading what the ancients say on this subject, we must be careful, however, to separate truth firom error, or we shall attribute much more to ants than of right belongs to them. Who does not smile when he reads of ants that enulate the wolf in size, the dog in shape, the lion in its feet, and the leopard in its skin - ants, whose employnent is to mine for gold, and from whose vengeanee the furtive Indian is constrained to fls on the swift canel's back? 1 But when we find the writers of all nations and ages unite in affirming, that, having deprived it of the power of vegretating, ants store up grain in their nests, we feel disposed to give larger creclit to ail assertion, which, at first sight, seems to savour more of fact than of fable, and does not attribute more sagacity and foresight to these insects than in other instances they are found to possess. Writers in general, therefore, who have considered this subject, and sone even of very late date, have taken it for granted that the ancients were correct in this notion. But when observers of nature began to examine the manners and economy of these creatures more narrowly, it was found, at least with respect to the European speeies of ants, that no snch hordes of grain were made by them, and, in faet, that they had no magazines in their nests in which provisions of any kind were stored up. It was therefore surmised that the ancients, ohserving them carry about their pupc, which, in shape, size, and colour, not a little resemble a grain of corn, and the ends of which they sometimes jull open to let out the enelosed insect, mistook the one for the other, and this action for depriving the grain of the coreulum. Mr. Gould, our countryman, was one of the first historians of the ant who discovered that they did not store up eorn; and since his time naturalists have generally suliscribed to that opinion.

Till the manners of exotic ants are more aceurately explored, it would, however, be rash to affirm that no ants have magazines of provisions; for although, during the eold of the winters in this country, they remain in a state of torpidity, and have no need of food, yet in warmer regions, during the rainy seasons, when they are probably confined to their nests, a store

1 Bochart, Hierozoic. ii. 1. iv. c. 22. 
of provisions may be necessary for them. ${ }^{1}$ Even in northern climates, against wet seasons, they may provide in this way for their sustenance and that of the young brood, which, as Mr. Smeathman observes, are very voracious, and cannot bear to be long deprived of their food; else why do ants earry worms, living insects, and many other such things into their nests? Solomon's lesson to the sluggard has been generally addnced as a strong confirmation of the ancient opinion: it can, however, only relate to the species of a warm climate, the habits of which, as I have just observed, are probably different from those of a cold one; - so that his words, as commonly interpreted, may be perfeetly correct and consistent with nature, and yet be not at all applicable to the species that are indigenous to Europe. But I think, if Solomon's words are properly considered, it will be found that this interpretation has been fathered upon them, rather than fairly deduced from them. He does not affirm that the ant, which he proposes to his shggard as an example, laid up in her magazines stores of grain : "Go to the ant, thou shggrard, consider her ways, and be wise; which, having neither captain, overseer, nor ruler, prepares her bread in the summer, and gathers her food in the harvest." These words may very well be interpreted simply to mean, that the ant, with commendable prudence and foresight, makes use of the proper seasons to collect a supply of provision sufficient for her purposes. There is not a word in them implying that she stores up grain or other provision. She prepares her bread and gather's her food, - namely, such food as is suited to her, -in summer and harvest, - that is, when it is most plentiful, - and thus shows her wisdom and prudence by using the advantages offered to her. The words thus interpreted, which they may be withont any violence, wil! apply to our European species as well as to those that are not indigenous.

I shall now bid farewell to the ancients, and proceed to lay before you what the observations of modern anthors have enabled me to add to the history of ants:- the prineipal of these are Leeuwenhoek, Swammerdam (who was the first that had recourse to artificial means for observing their proceedings), Linné, Bonnet, and especially the illustrious Swedish entomologist, De Geer. Gould, also, who, though no systematical naturalist, was a man of sense and observation, has thrown great light upon the history of ants, and anticipated several of what are accounted the discoveries of more modern writers on this subject. ${ }^{2}$ Latreille's Tatural

1 This supposition has been rerifierl by Col. Sykes's discovery at Poona in India of a species of ants (Atta providens Srles), which store up the seeds of a lind of grass (Panicum) at the period of their being ripe in January and February, and which he saw them in June and October bringing ap and exposing on the outside of their nests to the sun in heaps as big as a handful, apparently for the purpose of drying them after being wetted by the rains of the monsoon. (Trans. Ent. Soc. Lond. i. 103.) It does not seem easy to assign any plausible reason for the original collecting and storing, and subsequent drying and airing of these secds, except on the supposition of their being intenderl in some way for fool; and though we have no previously recordecl instance of ants feerling on any other vegetable substance than such as are sacchariue, yet, as all our experience proves how constantly in entomology exceptions are occurring to supposed general laws, there seems good reason to believe that this is one of them. (See the Rev. F. W. Hope's remarks on this subject in Trans. Ent. Soc. Lond. ii. 211.)

2 M. P. Huber, in the account which, in imitation of De Geer, he has given of the discoveries made by his preclecessors in the history of ants, having passed without notice, probably igmorant of the existence of such a writer, those of our intel- 
History of Ants is likewise extremely valuable, not only as giving a systematic arrangement and descriptions of the species, but as concentrating the accounts of preceding authors, and adding several interesting facts ex proprio penu. The great historiographer of ants, however, is M. P. Huber, who bas lately published a most admirable and interesting work upon them, in which he has far outstripped all his predecessors. Such are the sources from which the following account of ants is principally drawn, intermixed with which you will find some occasional observations

ligent countryman Gould, I shall here give a short analysis of them; from which it will appear that he was one of their best, or rather their very best, historian, till M. Huber's work came ont. His Account of English Ants was published in 1747; long before either Linné or De Geer had written upon the subject.

I. Speries. He describes five species of English ants; viz. 1. The hill-ant (Formica mufu L.). 2. The jet ant ( $F$. fuliginosu Latr.). 3. The red ant (Hyrmicu rubra Latr., Formica Lin.). He olserves. that this species alone is armed with a sting; whereas the others make a wound with their mandibles, and inject the formic acid into it. 4. The common yellow ant ( $F$. flava Latr.). And 5. The small black ant ( $F$. fusca L.).

II. Egg. He observes that the eggs producing males and females are laid the earliest, and are the largest:- he seems, however, to have confounded the black and brown eggs of Aphides with those of ants.

III. Larva. These, when first hatched, he observes, are hairy, and continue in the larva state twelve months or more. He, as well as De Geer, was aware that the larva of Myrmica rubra do not, as other ants do, spin a cocoon when they assume the pupa.

IV. Pupa. He found that female ants continue in this state about sis weeks, and males and nenters only a month.

V. Imago. He knew perfectly the sexes, and was aware that females cast their wings previously to their becoming mothers; that at the time of their swarms large numbers of both sexes become the prey of birds and fishes; that the surviving females, sometimes in numbers, go muder-ground, particularly in mole-hills, and lay eggs; lut he had not discovered that they then act the part of nenters in the care of their progeny. Ile knew also, that when there was more than one queen in a nest, the rivals lived in perfect harmony.

With respect to the neuters, he had witnessed the homage they pay their queens or fertile females continued even after their death; - this homage he, however, observes, which is noticed by no other author, appears often to be temporary and local - ceasing at certain times, and being renewed upon a change of residence. He enlarges upon their exemplary care of the eggs, larra, and pupæ. He tells us that the eggs, as soon as laid, are taken by the neuters and deposited in heaps, and that the neuters brood them. He particularly notices their carrying them, with the larva and pupx, daily from the interior to the surface of the nest and back again, according to the temperature; and that they feed the larve by disgorging the tood from their own stomach. He speaks also of their opening the cocoons when the pupx are ready to assume the imago, and disengaging them from them. With regard to their labours, he found that they work all night, except during violent rains; that their instinct varies as to the station of their nest; that their masonry is consoliclated by no cement, but consists merely of monld; that they form roads and trackways to and from their nests; that they carry each other in sport, and sometimes lie heaped one on another in the sun. Ile susjeots that they occasionally emigrate; - he proves by a variety of experiments that they lo not hoari up provisions. He found they were often infested by a particular kind of Gordius: - he had noticed, also, that the neuters of $F$. mafa and flava (which escaped M. Huber, though he olsserved it in Polyergus rufescens Latr.) are of two sizes, which the writer of this note can confirm by producing specimens; - and, lastly, with Swammerdam, he had recourse to artificial colonies, the better to enable him to examine their proceedings, lut not comparable to the ingenious apparatus of M. Huber. 
- which your partiality to your friend may, perhaps, induce you to think not wholly devoid of interest - that it has been my fortune to make.

The societies of ants, as also of other Hymenoptera, differ from those of the Termites in having inactive larve and pupæ, the neuters or workers combining in themselves both the military and civil functions. Besides the helpless larve and pupæ which have no locomotive powers, these societies consist of females, males, and workers. The office of the females, at their first exelusion distinguished by a pair of ample wings (which, however, as you have heard, they soon cast), is the foundation of new colonies, and the furnishing of a constant supply of eggs for the maintenance of the population in the old nests as well as in the new. These are usually the least numerous part of the community. ${ }^{1}$ The office of the males, which are also winged, and at the time of swarming are extremely numerous, is merely the impregnation of the females : after the season for this is past, they die. Upou the workers ${ }^{2}$ devolves, except in naseent colonies, all the work, as well as the defence of the community, of which they are the most numerous portion. In some societies of ants the workers are of two dimensions. In the nests of $F$. rufa and flava such were ohserved by Gould, the size of one exceeding that of the other about one-third. ${ }^{3}$ (In my specimens, the large workers of $F$. rufa are nearly three times, and of $F$. flava, twice, the size of the small ones.) All were equally engaged in the labour's of the colony. Large workers were also noticed by M. P. Huber in the nests of Polyergus rufescens ${ }^{4}$, but he could not ascertain their offiee. More light, however, has been of late thrown on this subject by the observations of M. Lacordaire and M. Lund upon these large workers, as they oecur in the nests of South American ants. They have ascertained them to be strictly the soldiers, which, though of a different origin, like those of the Termites before described, have it expressly in charge to defend the rest of the community; for which office their size-full twice that of the other workers - and their immense heads and jaws in proportion, admirably adapt them. M. Lacordaire informs us that, both in Cayenne and Brazil, he has been a thousand times witness of the accuracy of the ficts stated by M. Lund as to the military office of these large and big-headed workers of Attra cephalotes, and allied species, during the marches and excursions undertaken by the society. They never mix themselves with the mass of the moving columns ; but, stationed on their flumks, they are scen sometimes to march forward; then to return and halt a moment, as if to

1 Gould sars that the males and females are nearly equal in number (p. 6*2); lout from Huber's observations it seems to follow that the former are most numerous (1).96.).

2 That the neuter ants, like those of the hive-bee, are imperfectly organised females, appears from the following observation of M. Huber (Nouv. Observ. \&c. ii. 443.) - "Les fotmmis nous ont encore offert à cet égard une analogie trèsfrappante; à la vérité, nous n'avons jamais vu pondre les ouvrières, mais nous avons été témoins de lenr accouplement. Ce fait pourroit être attesté par plusieurs membres de la Société d'Histoire Naturelle de Genève, à qui nous l'arons fait voir; l'apyroche du mâle étoit toujours suivie de la mort de l'ouvrière; leur conformation ne permet done pas qu'elles deviennent mères, mais l'instinct du mâle prouve. du moins que ce sont des f'emelles."

3 Goult, 103.

4 M. Huber calls this an apterous female; yet he could not discover that they laid eggs; and he owns that they more nearly resemble the workers than the femakes, and that he should have considered them as such, had he seen them mix with them in their excursions. - Huber, p. 251. 
observe the troop defile before them; traversing its ranks; hastening to any point where their presence seems necessary, especially if it have met with any obstacle on its route ; and even climbing, as M. Lacordaire hats often witnessed, up the adjoining plants, and perched on the margin of a leaf, surveying its passage from this elevated position. ${ }^{1}$ M. Lund observed four of these large-headed neuters of a Brazilian species of AMyrmicu to guard the entrance to their nest, and others attending the column while on march, and hastening to the spot and alarming their comrades when some of the ants were purposely killed. ${ }^{2}$

An equally singular modification of form and function takes place in the neuters of a Mexican ant-Myrmecocystus Mexicanus of M. Wesmael, who has described their economy in a paper read to the Académie k'oyale of Brussels. (Of this species, while some of the nenters have the ordinary form, others, which never quit the nest and are almost inactive, have their abdomen swollen into an immense subdiaphanous sphere, filled by a kind of honey which they are solely occupied in elaborating, and which they subsequently discharge into cells analogons to those of bees. ${ }^{3}$

Having introduced you to the individuals of which the associations of ants consist, I shall now advert to the principal events of their history, relating first the fates of the males and females. In the warm dans that occur from the end of July to the beginning of September, and sometimes later, the habitations of the various species of ants may be seen to swarm with winged insects, which are the males and females preparing to quit for ever the scene of their nativity and education. Every thing is in motion; and the silver wings, contrasted with the jet bodies which compose the animated mass, add a degree of splendour to the interesting scene. The bustle increases, till at length the males rise, as it were by a general impulse, into the air, and the females accompany them. The whole swarm alternately 'rises and falls with a slow movenent to the height of about ten feet, the males flying obliquely with a rapid zigzag motion, and the females, though they follow the general movement of the column, appearing suspended in the air, like balloons, seemingly with no individual motion, and having their heads turned towards the wind.

Sometimes the swarms of a whole district unite their infuite myriads, and, seen at a distance, produce an effect resembling the flashing of an aurora-borealis. Rising with incredible velocity in distinct columns, they soar above the clouds. Each column looks like a kind of slender net-work, and has a tremulous undulating motion, which has been observed to be produced by the regular alternate rising and falling just alluded to. The noise emitted by myriads and myriarls of these creatures does not exceed the hum of a single wasp. The slightest zephyr disperses them; and if in their progress they chance to be over your head, if you walk slowly on they will accompany you, and regulate their motions by yours. The fenales continue sailing majestically in the centre of these numberless males, who are all candidates for their favour, each till some fortunate lover darts upon her, and, as the Roman youth did the Sabine virgins, drags his bride from the sportive crowd, and the nuptials are consummiated in mid-ail ; thougin sometimes the union takes place on the sumnit of plants, but rarely in the

1 Lacordiure, Introd. à l' Entom. ii. 498.

2 Lund in Ann. des Sciences Nut. xxiii. 113.; quoted by Lacordaire, ubi suyr., and Westwood, Morl. Cluss, ii. $2 \cdot 25$.

s Bull. Acad. Loy. Bruxell. v. 751.; quoted by Westwood, ubi supr. ii. 225. 
nests.' After this danse de l'amour is celebrated, the males disappear, probably dying, or becoming, with many of the females, the prey of birds or fish $^{2}$; for, since they do not return to the nest, they cannot be destroyed, as some have supposed, like the drone bees, by the neuters. That many, both males and females, become the prey of fish, I am enabled to assert from my own observation. In the beginning of August, 1812, I was going up the Orford river in Suffolk, in a row-boat, in the evening, when my attention was caught by an infinite number of winged ants, both males and females, at which the fish were evcrywhere darting, floating alive upon the surface of the water. While passing the river these had probably been precipitated into it, either by the wind, or by a heavy shower which had just fallen. And M. Huber after the same event observed the earth strewed with fenales that had lost their wings, all of which could not form colonies. ${ }^{3}$

Captain Haverfield, R.N., gave me an account of an extraordinary appearance of ants observed by him in the Medway, in the autumn of 1814, when he was first-lieutenant of the Clorinde, which is confirmed by the following letter addressed by the surgeon of that ship, now Dr. Bromley, to Mr. MacLeay :-

"In September, 1814, being on the deck of the luulk to the Clorinde, my attention was drawn to the water by the first-lieutenant (Haverfield) observing there was something black floating down with the tide. On looking with a glass, I discovered they were insects. The boat was sent, and brought a bucket full of them on board; - they proved to be a large species of ant, and extended from the upper part of Salt-pan Reach out towards the Great Nore, a distance of five or six miles. The colnmn appeared to be in breadth eight or ten feet, and in height about six inches, which I suppose must have been from their resting one upon another." Purchas seems to have witnessed a similar phenomenon on shore. "Other" sorts (of ants)," says he, "there are many, of which some become winged and fill the air with swarms, which sometimes bappens in England. On Bartholomew, 1613, I was in the Island of Foulness on our Essex shore, where were such clouds of these flying pismires, that we could nowhere fiy from them, but they filled our clothes; yca the floors of some houses where they fell were in a manuer covered with a black carpet of creeping ants: which they say drown themselves about that time of the year in the sea." 4

These ants were winged; whence, in the first instance here related, this immense column came was not ascertained. From the numbers bere anglomerated, one would think that all the ant-hills of the counties of Kent and surrey could scarcely have furnished a sufficient number of males and females to form it.

When Colonel Sir Augustus Frazer, of the Ilorse Artillery, was surveying on the 6th of October, 1813 , the scene of the battle of the Prrenees from the summit of the mountain called Pena de Aya, or Les Quatre Couromes, he and his friends were enveloped by a swarn of austs, so numerous as entirely to intercept their view, so that they were glad to remove to another station, in order to get rid of them.

The females that escape from the injury of the elements and their various

1 De Geer, ii. 110 .

5 Huber. 10 s.
2 Gould, 92.

4 Pilgrimage, 1000. 
enemies become the founders of new colonies, doing all the work, as I have related in a former letter, that is usually done by the neuters. ${ }^{2}$ M. P. Huher has found incipient colonies, in which were only a few workers engaged with their mother in the care of a small number of larva; and M. Perrot, his friend, once discovered a small nest, occupied by a solitary female, who was attending upon four pupæ only. Such are the foundation and first establishment of those populous nations of ants with which we everywhere meet.

But though the majority of females produced in a nest probably thus desert it, all are not allowed this liberty. The prudent workers are taught by their instinct that the existence of their community depends upon the presence of a sufficient number of females. Some, therefore, that are fecundated in or near the spot they forcibly detain, pulling off their wings, and keeping them prisoners till they are ready to lay their eggs, or are reconciled to their fate. De Geer in a nest of $F$. mufa observed that the workers compelled some females that were cone out of the nest to reenter it ${ }^{2}$; and from M. P. Huber we learn that, being seized at the moment of fecundation, they are conducted into the interior of the formicary, when they become entirely dependent upon the neuters, who hanging pertinaciously to each leg prevent their going out, but at the same time attend upon them with the greatest care, feeding them regularly, and conducting them where the temperature is suitable to them, but never quitting them a single moment. By degrees these females become recon. ciled to their fate, and lose all desire of making their escape; - their abdomen enlarges, and they are no longer detained as prisoners, yet each is still attended by a body-guard - a single ant, which always accompanies her, and prevents her wants. Its station is remarkable, it being mounted upon her abdomen, with its posterior legs upon the ground. These sentinels are constantly relieved; and to watch the moment when the female begins the important work of oviposition, and carry off the eggs, of which she lays four or five thousand or more in the course of the year, seenis to be their principal office.

When the female is acknowledged as a mother, the workers begin to pay her a homage very similar to that which the bees render to their queen. All press round her, offer her food, conduct her by her mandib!es through the difficult or steep passages of the formicary; nay, they sometimes even carry her about their city; - she is then suspended upon their jaws, the ends of which are crossed; and, being coiled up like the tongue of a butterfly, she is packed so close as to incommode the carrier but little. When she sets her down, others surround and caress her, one after another tapping her on the head with their antennr. "In whatever apartment," says Gould, "a queen condescends to be present, she commands obedience and respect. An universal gladness spreads itself through the whole cell, which is expressed by particular acts of joy and exultation. They have a particular way of skipping, leaping, and standing upon their lind-legs, and prancing with the others. These frolics they make use of, both to congratulate each other when they meet, and to show their regard for the

1 M. Huber observes that fecundatei females, after they have lost their wings, make themselves a subterranean cell; some singly, others in common. From which it appears that some colonies have more than one female from their first establishment.

2 ii. $10 \%$. 
queen; some of them gently walk orer her, others dance round her: she is generally encircled with a cluster of attendants, who, if you separate them from her, soon collect themselves into a body, and enclose her in the midst." ${ }^{1}$ Nay, even if she dies, as if they were unwilling to believe it, they continue sometimes for months the same attentions to her, and treat her with the same courtly formality as if she were alive, and they will brush her and lick her incessantly.?

This homage paid by the workers to their queens, according to Gould, is temporary and local; - when she had laid eggs in any cell, their attentions, he observed, seemed to relax, and she beeame unsettled and uneasy. In the summer months she is to be met with in various apartments in the colony ; and eggs also are to be seen in several places, which induced him to believe that, having deposited a parcel in one, she retires to another for the same purpose, thus frequently changing her situation and attendants. As there are always a number of lodgnents void of eggs, but full of ants, she is never at a loss for an ngreeable station and submissive retinue; and by the time she has gone her rounds in this manner, the eggs first laid are brought to perfection, and her old attendants are glad to receive her again. Yet this inattention after oviposition is not invariable; the female and neuter sometimes unite together in the same cell after the eggs are laid. On this occasion the workers divide their attention; and if you disturb them, some will run to the defence of their queen, as well as of the eggs, which last, however, are the great objects of their solicitude. This statement differs somewhat from M. Huber's; but different species vary in their instincts, which will account for this and similar dissonances in authors who have observed their proceedings. Mr. Gould also noticed but very few females in ant-nests, sometimes only one ; but NI. Huber, who had better opportunities, found several, which he says live very peaceably together, showing none of that spirit of rivalry so remarkable in the queen-bee.

And here I must elose my narrative of the life and adventures of male and female ants; but, as it will be followed by a history of the still more interesting proceedings of the workers, I think you will not regret the exchange. I shall show these to you in many different views, under each of which you will find fresh reason to admire them and their wonderful instincts. My only fear will be lest you should think the picture too highly coloured, and deem it incredible that creatures so minute should so far exceed the larger animals in wislon, foresight, and sagacity, and make so near an approach in these respects to man himself. My fincts, however, are derived from anthorities so respectable, that I think they will do away with any bias of this kind that you may feel in your mind. ${ }^{3}$

I need not here repeat what $I$ have said in a former letter concerning the exemplary attention pail by these kind foster-mothers to the young brood of their colonies; nor shall I enlarge upon the building and nature

1 Gould, p. 24-.

2 Compare Gould, p. 25., with Huber, 125. note (1).

3 It may be thought that many of the anectotes related in the following history of the proceedings ot neuter ants could not have been observed by any one, unless he had been admitted into an ant-hill; but it must be recollected that H. P. Huber, from whose work the most extraordinary facts are copied, invented a kind of anthive, so constructed as to enable him to obscre their proceedings without disturbing them. 
of their habitations, which have becn already noticed:- but, without either of these, I have matter enough to fill the rest of this letter with interesting traits, while I endeavour to teach you their language, to develop their affections and passions, and to delineate their virtues, - while I show them to you when engaged in war, and enable you to accompany them both in their military expeditions and in their emigrations, - while I make you a witness of their indefatigable industry and incessant labours, or invite you to be present, during their hours of relaxation, at their sports and ammsements.

That ants, though they are mute animals, have the means of communieating to each other information of various occurrences, and use a kind of language which is mutually understood, will appear evident from the following facts.

If those at the surface of a nest are alarmed, it is wonderful in how short a time the alarm spreads through the whole nest. It runs from quarter to quarter ; the greatest inquietude seems to possess the comnunity; and they carry with all possible despatch their treasures, the larvæ and pupæ, down to the lowest apartments. Amongst those species of ants that do not go much from home, sentinels seem to be stationed at the avenues of their city. Disturbing once the little heaps of earth thrown up at the entrances into the nest of $F$. flava, which is of this description, I was struck by observing a single ant immediately come out, as if to see what was the matter, and this three separate times.

The $F$. herculanea inhabits the trunks of hollow trees on the Continent (for it has not yet been found in England), upon which they are often passing to and fro. M. Huber observed, that when he disturbed those that were at the greatest distance from the rest, they ran towards them, and, striking their head against them, communicated their cause of fear or anger,--that these, in theil turn, conveyed in the same way the intelligence to others, till the whole colony was in a ferment, those neuters which were within the tree running out in crowds to join their companions in the defence of their habitation. The same signals that excited the courage of the neuters produced fear in the males and females, which, as soon as the news of the danger was thus communicated to them, retreated into the tree as to an asylum.

The legs of one of this gentleman's artificial formicaries were plunged into pans of water, to prevent the escape of the ants; - this proved a source of great enjoyment to these little beings, for they are a very thirsty race, and lap water like $\operatorname{logs}_{*}{ }^{1}$ One day, when he observed many of them tippling very merrily, he was so cruel as to disturb them, which sent most of the ants in a fright to the nest; but some more thirsty than the rest continued their potations. Upon this, one of those that bad retreated returns to inform his thoughtless companions of their danger ; one he pushes with his jaws; another he strikes first upon the belly, and then upon the breast; and so obliges three of them to leave off their carousing, and mareh homewards; but the fourth, more resolute to drink it out, is not to be discomfited, and pays not the least regard to the kind blows witl which his compcer, solicitous for his safety, repeatedly belahours him. At length, deternined to have his way, he seizes him by one of his hind-legs, and gives him a violent pull : - upon this, leaving his liquor, the loiterer turns

: Gould, 92. De Geer. ii. 1067. Huber, 132. 
round, and opening his threatening jaws with every appearance of anger, goes very coolly to drinking again; but his monitor without further ceremony, rushing before him, seizes him by his jaws, and at last drags him off in triumph to the formicary.'

The language of ants, however, is not confined merely to giving intelligence of the approach or presence of danger: it is also coextensive with ill their other occasions for communicating their ideas to each other.

Some, whose extraordinary history I shall soon relate to you, engage in military expeditions, and often previously send out spies to collect information. These, as soon as they return from exploring the vicinity, enter the nest; upon which, as if they had communicated their intelligence, the army immediately assembles in the suburbs of their city, and begins its march towards that quarter whence the spies had arrived. Upon the march, communications are perpetually making between the van and the rear; and when arrived at the camp of the enemy, and the battle begins, if necessary, couriers are despatched to the formicary for reinforcements. ${ }^{2}$

If you scatter the ruins of an ants' nest in your apartment, you will be furnished with another proof of their language. The ants will take a thousand different parts, each going by itself, to increase the chance of discovery; they will meet and cross each other in all directions, and perhaps will wander long before they can find a spot convenient for their reunion. No sooner does any one discover a little chink in the floor, through which it can pass below, than it returns to its companions, and, by means of certain motions of its antennæ, makes some of them comprehend what route they are to pursue to find it, sometimes even acconpanying them to the spot ; these, in their turn, become the guides of others, tiil all know which way to direct their steps. ${ }^{3}$

It it well known, also, that ants give each other information when they have discovered any store of provision. Bradley relates a striking iustance of this. A nest of ants in a nobleman's garden discovered a closet, many yards within the house, in which conserves were kept, which they constantly attended till the nest was destroyed. Some in their rambles must have first discovered this depot of sweets, and informed the rest of it. It is remarkable that they always went to it by the same track, scarcely varying an inch from it, though they had to pass through two apartments: nor could the sweeping and cleaning of the rooms discomfit them, or cause them to pursue a different route. ${ }^{4}$

Here may be related an amusing experiment of Gould's. Having deposited several colonies of ants $(F . f u s c a)$ in flower-pots, he placed them in some earthen pans full of water, which prevented them from making excursions from their nest. When they had been accustomed some day's to this imprisonment, be fastened small threads to the upper part of the pots, and extending them over the water-pans fixed them in the ground. The sagacious ants soon found out that by these bridges they could escape from their moated castle. The discovery was communicated to the whole society, and in a short time the threads were filled with trains of busy workers passing to and fro. ${ }^{5}$

Ligon's account of the ants in Barbadoes affords another most convincing

1 Huber, 133.

4 Bradley, 134.
2 Ibid. 167. 217. 237.

5 Gould, 85.

3 Ibid. 137. 
proof of this : as he has told his tale in a lively and interesting manner, 1 shall give it nearly in his own words.

"The next of these moving little animals are ants or pismires, and these are but of a small size, but great in industry; and that which gives them means to attain to this end is, they have all one soul. If I should say they are here or there, I should do them wrong, for they are everywhere; under ground, where any hollow or loose earth is ; amongst the roots of trees; upon the bodics, branches, leaves, and fruit of all trees; in all places without the houses and within; upon the sides, walls, windows, and roofs without; and on the floors, side-walls, ceiling6, and windows within; tables, cupboards, beds, stools, all are covered with them, so that they are a kind of ubiquitaries. We sometimes kill a cockroach, and throw him on the ground; and mark what they will do with him: his body is bigger than a hundred of them, and yet they will find the means to take hold of him, and lift him up ; and having him above ground, away they carry him, and some go by as ready assistants, if any be weary; and some are the officers that lead and show the way to the hole into which he must pass; and if the vancouriers perccive that the body of the cockroach lies across, and will not pass through the hole or arch through which they mean to carry him, order is given, and the body turned endwise, and this is done a foot before they come to the hole, and that without any stop or stay; and thi; is observable, that they never pull contrary ways. A table being cleared with great care, by way of experiment, of all the ants that were upon it, and some sugar being put upon it, some, after a circuitous route, were observed to arrive at it, when, again departing without tasting the treasure, they hastened away to inform their friends of their discovery, who npon this came by myriads; and when they are thickest upon the table," says he, "clap a large book (or any thing fit for that purpose) upon them, so hard as to kill all that are under it; and when you have done so, take away the book, and leave them to themselves but a quarter of an hour, and when you cone again you shall find all those bodies carried away. Other trials we make of their ingenuity, as this : - take a pewter disil, and fill it half full of water, into which put a little gallipot filled with sugar, and the ants. will presently find it and come upon the table; but when they perceive it environed with water, they try abont the brims of the dish where the gallipot is nearest; and there the most venturous anongst them commits himself to the water, though he be conscious bow ill a swimmer he is, and is drowned in the adventure : the next is not warned by his example, but ventures too, and is alike drowned; and many more, so that there is a small foundation of their bodies to venture; and then they come faster than ever, and so make a bridge of their own bodies." 1

The fact being certain that ants impart their ideas to each other, we are next led to inquire by what means this is accomplished. It does not appear that, like the bees, they emit any significative sounds; their language, therefore, must consist of signs or gestures, some of which I shall now detail. In communicating their fear or expressing their anger, they run from one to another in a semicircle, and strike with their head or jaws the trunk or abdomen of the ant to which they mean to give information of any subject of alarm. But those remarkable organs, their antennæ, are the principat instruments of their speech, if I may so call it, supplying the

1 Hist. of Barbadoes, p. 63. 
place both of voice and words. When the military ants before alluded to go upon their expeditions, and are out of the formicary, previously to setting off they touch each other on the trunk with their antemna and forehead:- this is the signal for marcling; for, as soon as any one has received it, he is immediately in motion. When they have any discovery to communicate, they strike with them those that they meet in a particularly impressive manner. If a hungry ant wants to be fed, it touches with its two antennæ, moving them very rapidly, those of the individual from which it expects its meal; and not only ants understand this language, but even Aphides and Cocei, which are the milch kine of our little pismires, do the same, and will yield them their saccharine fluid at the touch of these imperative organs. The helpless larvæ also of the ants are informed by the same means when they may open their months to reeeive their food.

Next to their language, and searcely different from it, are the modes by which they express their affections and aversions. Whether ants, with man and some of the larger animals, experience any thing like attachment to individuals, is not easily ascertained; but that they feel the full force of the sentiment which we term patriotism, or the love of the community to which they belong, is evident from the whole series of their proceedings, which all tend to promote the general good, Distress or difficulty falling upon any member of their soeiety generally exeites their sympathy, and they do their utmost to relieve it. MI. Latreille once cut off the antennæe of an ant; and its companions, evidently pitying its sufferings, anointed the wounded part with a drop of transparent fluid from their mouth ; and whoever attends to what is going forward in the neighbourhood of one of their nests, will be pleased to observe the readiness with which they seem disposed to assist each other in difficulties. When a burthen is too heavy for one, another will soon come to ease it of part of the weight; and if one is threatened with an attack, all hasten to the spot, to join in repelling it.

The satisfaction they express at meeting after absence is very striking, and gives some degree of individuality to their attachment. M. Huber witnessed the gesticulations of some ants, originally belonging to the same nest, that, having been entirely separated from each other four months, were afterwards bronght together. Though this was equal to one fourth of their existence as perfect insects, they immediately recognised each other, saluted mutually with their antennæ, and united once more to form one family.

They are also ever intent to promote each other's welfare, and ready to share with their absent companions any good thing they may meet with. Those that go abroad feed those which remain in the nest; and if they aiscover any stock of favomite food, they inform the whole community, as we have seen above, and teach them the way to it. M. Huber, for a particular reason, having produced heat, by means of a flambeau, in a ccrtain part of an artificial formicary, the auts that happened to be in that quarter, after enjoying it for a time, hastened to convey the welcome intelligence to their compatriots, whom they even carried suspended upon their jaws (their usual mode of transporting each other) to the spot, till hundreds might be seen thus laclen with their friends.

If ants feel the force of love, they are equally susceptible of the emo. tions of anger; and when they are menaced or attacked, no insects show a greater degree of it. Providence, moreover, bas furnished them with 
wcapons and faculties which render it extremely formidable to their insect enemies, and sometimes, as I have related in a former letter, a great anmoyance to nuan himself. Two strong mandibles arm their mouth, with which they sometimes fix themselves so obstinately to the object of their attack, that they will sooner be torn limb from limb than let go their hold; and after their battles, the heal of a conquered enemy may often be seen suspended to the antennæ or legs of the victor, a trophy of his valour, which, however troublesome, he will be compelled to carry about with him to the day of his death. Their abdomen is also furnished with a poison-bag (Ioterium), in which is secreted a powerfinl and venomous fluid, long celebrated in chemical researches, and called formic acid ${ }^{1}$, which, when their enemy is beyond the reach of their maudibles (I speak here particularly of the hill-ant, or $F$. rufa , standing erect on their hind legs, they ejaculate from their auus with considerable force, so that from the surface of the nest ascends a shower of poison, exhaling a strong sulphureous odour, sufficient to overpower or repel any insect or small animal. Such is the fury of some species, that with the acid, according to Gould ${ }^{2}$, they sometimes partly eject, drawing it back however directly, the poison-bag itself. If a stick be stuck into one of the nests of the hill-ant, it is so saturated with the acid as to retain the scent for many hours. A more formidable weapon arms the species of the genus Myrmica Latr.; for, besides the poison-bag, they are furnished with a sting; and their aspect is also often rendered peculiarly revolting by the extraordinary length of their jaws, and by the spines which defend their head and trunk.

But weapons without valour are of but little use ; and this is one distinguishing feature of our pigmy race. Their courage and pertinacity are unconquerable, and often sublimed into the most inconceivable rage and fury. It makes no difference to them whether they attack a mite or an elephant; and man himself instils no terror into their warlike breasts. Point your finger towards any individual of $F$, rufa, instead of running away, it instantly faces about ; and, that it may make the most of itself, stiffening its legs into a nearly straight line, it gives its body the utmost elevation it is capable of, and thus

\section{"Collecting all its might dilated stands"}

prepared to repel your attack. Put your finger a little nearer, it immediately opens its jaws to bite you, and, rearing upon its hind legs, bends its abdomen between then, to ejaculate its venom into the wound. ${ }^{3}$

This angry people, so well armed and so courageous, we may readily imagine, are not always at peace with their neighbours: causes of dissension may arise to light the flame of war between the inbabitants of nests not far distant from each other. To these little bustling creatures a square foot of earth is a territory worth contending for ; their droves of Aphides equally valuable with the flocks and herds that cover our plains; and the bocly of a fly or a beetle, or a cargo of straws and bits of stick, an acquisition as important as the treasures of a Lima fleet to our seamen. Their

1 This acid may be prepared artificially, and with all the properties of that produced by ants, by distillation from a mixture of sulphuric acid, black oxide of manganese, and starch.

2 p. 34.

3 see Fourcroy, Annales du Mruséum, No. 5. 343. 
wars are usually between nests of different specics; sometimes, however, those of the same, when so near as to interfere with and incommode each other, have their battles ; and with respect to ants of one species, Myrmica rubra, combats occasionally take place, contrary to the general habits of the tribe of ants, between those of the same nest. I shall give you some :ccount of all these conflicts, beginning with the last. But I must first observe, that the only warriors amongst onr ants are the neuters or workers; the males and females being very peaceable creatures, and always glad to get out of harm's way.

The wars of the red ant ( $M . r u b r a)$ are usually between a small number of the citizens ; and the object, according to Gould, is to get rid of a useless member of the community (it does not argue much in favour of the humanity of this species if it be by sickness that this member is disabled), rather than any real civil contest. "The red colonies," say's this author, " are the only ones I could ever observe to feed upon their own species. You may frequently discern a party of from five or six to twenty surrounding one of their own kind, or even fraternity, and pulling it to pieces. The ant they attack is gencrally feeble, and of a languid complexion, occasioned, perhaps, by some disorder or other accident." I Ince saw one of these ants dragged out of the nest by another, without its head; it was still alive, and could crawl about. A lively inagination might have fancied that this poor ant was a criminal, condemned by a court of justice to suffer the extreme sentence of the law. It was nore probably, however, a champion that had been decapitated in an unequal combat; unless we admit Gould's idea, and suppose it to have suffered because it was an unprofitable member of the community. ${ }^{2}$ At another time $I$ found three individnals that were fighting with great fury, chained together by their mandibles; one of these had lost two of the legs of one side, yet it appeared to walk well, and was as eager to attack and seize its opponents as if it was unhurt. This dicl not look like languor or sickness.

The wars of ants that are not of the same species take place usually between those that differ in size; and the great endeavouring to oppress the small are nevertheless often outnumbered by them, and defeated. Their battles have long been celebrated; and the date of them, as if it were an event of the first importance, has been formally recorded. Eneas Sylvius, after giving a very circumstantial account of one contested with -great obstinacy by a great and small species on the trunk of a pear tree, gravely states, "This action was fonght in the pontificate of Eugenius IV., in the presence of Nicholas Pistoriensis, an eminent lawyer, who related the whole history of the battle with the greatest fidelity!" A similar engagement between great and small ants is recorded by Olaus Maguus, in which the small ones being victorions are said to have buried the bodies of their own soldiers, but left those of their giant enemies a prey to the birds. This event happened previous to the expulsion of the tyrant Christiern II. from Sweden. ${ }^{3}$

1 Gould, 104.

2 One would think the writer of the account of ants in Mouffet had been witness to something similar. "If they see any one idle," says he, "they not only drive him as spurious, without food, from the nest; but likewise, a eircle of all ranks being assembled, cut off his head before the gates, that he may be a warning to their ehildren not to give themselves up for the future to idleness and eftèminacy." -Theatr. Ins. 241.

3 Ibid. 242. 
M. P. Huber is the only modern author that appears to have been witness to these combats. He tells us that, when the great attack the smali, they seek to take them by surprise (probably to avoid their fastening themselves to their legs), and scizing upon them by the upper part of the body, they strangle them with their nandibles; but when the small have time to foresee the attack, they give notice to their companions, who rusls in crowds to their succour. Sometimes, however, after suffering a signal defeat, the smaller species are obliged to shift their quarters, and to seek an establishment more out of the way of danger. In order to cover their march, many small bodies are then posted at a iittle distance from the nest. As soon as the large ants approach the camp, the foremost sentinels instantly fly at them with the greatest rage; a violent struggle ensues ; multitudes of their friends come to their assistance; and, though no match for their enemies singly, by dint of numbers they prevail, and the giant is either slain or led captive to the hostile camp. The species whose proceedings M. Huber observed were $F$. herculanea and $F$. sanguinea, neither of which liave yet been discovered in Britain. ${ }^{1}$

But if you would see more numerous armies engaged, and survey war in all its forms, you must witness the combats of ants of the same species; you must go into the woods where the lill-ant of Gould ( $F$. rufu) erects its habitations. There you will sometimes behold populous and rival cities, like Rome and Carthage, as if they had vowed eacl other's destruction, pouring forth their myriads by the various roads that, like rays, diverge on all sides from their respective metropolises, to decide by an appeal to arms the fate of their little world. As the exploits of frogs and nice were the theme of Homer's muse, so, were I gifted like him, might I celebrate on this occasion the exhibition of Myrmidonian valour; but, alas! I am Davus, not Edipus; you must, therefore, rest contented, if I do my best in plain prose; and I trust you will not complain if, being unable to ascertain the name of any one of my heroes, my Mymidonomachia be perfectly anonymous.

Figure to yourself two of these cities equal in size and population, and situated about a hundred paces from each other; observe their countless numbers, equal to the population of two mighty empires. The whole space which separates them for the brealth of twenty-four inches appears alive with prodigious crowds of their inhabitants. The armies meet midway between their respective habitations, and there join battle. Thonsands of champions, mounted on more elevated spots, engage in single combat, and seize each other with their powerful jaws; a still greater number are engaged on both sides in taking prisoners, which make vain efforts to escape, as if conscious of the cruel fate which awaits them when arrived at the hostile formicary. The spot where the battle most rages is about two or three square feet in dimensions : a penetrating odour exhales on all sides, - numbers of ants are here lying dead covered with venom, - others, composing groups and chains, are hooked togrether by their legs or jaws, and drag each other alternately in contrary directions. These groups are formed gradually. At first a pair of combatants seize each other, and rearing upon their hind legs mutually spirt their acid; then closing, they fall and wrestle in the dust. Again recovering their feet, each endeavours to drag off his antagonist. If their strength be 
equal, they remain immoveable till the arrival of a third gives one the advantage. Both, however, are often succoured at the same time, and the battle still continues undecided; others take part on each side, till chains are formed of six, eight, or sometimes ten, all hooked together, and struggling pertinaciously for the mastery ; the equilibrium remains unbroken, till a number of champions from the same nest arriving at once compel them to let go their hold, and the single combats recommence. At the approach of night, each party gradually retreats to its own eity; bnt before the following dawn the combat is renewed with redoubled fury, and occupies a greater extent of ground. These daily fights continue till violent rains separating the combatants, they forget their quarrel, and peace is restored.

Such is the account given by M. Huber of a battle he witnessed. In these engagements, he observes, their fury is so wrought up, that nothing can divert them from their purpose. Though he was close to them examining their proceedings, they paid not the least attention to him, being absorbed by one sole object, that of finding an enemy to attack. What is most wonderful in this history,--though all are of the same make, colour, and scent, every ant seemed to know those of his own party; and if by mistake one was attacked, it was immediately discovered by the assailant, and caresses succeeded to blows. Though all was fury and carnage in the space between the two nests, on the other side the paths were full of ants going to and fro on the ordinary business of the society, as in a time of peace; and the whole formicary exhibited an appearance of order and tranquillity, except that on the quarter leading to the field of battle crowds might always be seen, either marching to reinforce the army of their compatriots, or returning home with the prisoners they had taken ${ }^{1}$, which it is to be feared, are the devoted victims of a cannibal feast.

Having, I apprehend, satiated you with the fury and carnage of Myrmidonian wars, I shall next bring for'ward a seene still nore astonishing, which at first, perhaps, you will be disposed to regard as a mere illusion of a lively imagination. What will you say when I tell you that certain ants are affirmed to sally forth from their nests on predatory expeditions, for the singular purpose of procuring slaves to employ in their domestic business; and that these ants are usually a ruddy race, while their slaves themselves are black? I think I see you here throw down my letter and exclaim "What! ants made slave-dealers! This is a fact so extraordinary and improbable, and so out of the usual course of nature, that nothing but the most powerful and convincing evidence shall induce me to believe it." In this I perfectly approve your caution; such a solecism in nature ought not to be believed till it has undergone the ordeal of a most thorough investigation. Unfortunately in this country we have not the means of satisfying ourselves by ocular demonstration, since none of the slave-dealing ahts appear to be natives of Britin. We must be satisfied, therefore, with weighing the evidence of others. Hear what M. P. Huber, the discoverer of this almost incredible deviation of nature from her general laws, has advanced to convince the world of the accuracy of his statement; and you will, I am sure, allow that he has thrown over his history a colouring of verisimilitude, and that his appeal to testimony is in a very high degree satisfactory. 
"My readers," says he, "will perhaps be tempted to believe that I have suffered myself to be carried away by the love of the marvellous, and that, in order to inpart greater interest to my narlation, I have given way to an inclination to embellish the fitcts that I have observed. But the more the wonders of nature lave attractions for me, the less do I feel inclined to alter them by a mixture of the reveries of imagination. I have sought to divest myself of every illusion and prejudice, of the ambition of saying new things, of the preprossessions often attached to perceptions too rapid, the love of system, and the like. And I have endeavoured to keep myself, if I may so say, in a disposition of mind perfectly nenter, and ready to admit all facts, of whatever nature they might be, that patient observation should confirm. Amongst the persons whom I have taken as witnesses to the discovery of mixed ant-hills, I can cite a distingnished philosopher (Prof. Jurine), who was desirous of verifying their existence by examining himself the two species united." 1

He afterwards appeals to nature, and calls upon all who doubt it to repeat his experiments, which he is sure will soon satisfy them, - a satisfaction which, as I have just observed, in this country we cannot receive, for want of the slave-making species. And now to begin my history.

There are two species of ants which engage in these excursions, Polyergus rufescens and Formica sanguinea; but they do not, like the African kings, make slaves of adults, their sole object being to carry off the helpless infants of the colony which they attack, the larvæ and pupæ; these they educate in their own nests till they arrive at their perfect state, when they undertake all the business of the society. ${ }^{2}$ In the following account I shall chiefly confine myself to what Huber relates of the first of these species, and conclude my extracts with his history of an expedition of the latter to procure slaves.

The rufescent ants ${ }^{3}$ do not leave their nests to go upon these expeditions, which last about ten weeks, till the males are ready to emerge into the perfect state; and it is very remarkable, that if any individuals attempt to stray abroad earlier, they are cletained by their slaves, who will not suffer then to proceed :- a wonderful provision of the Creator to prevent the black colonies from being pillaged when they contain only male and female brood, which would be their total destruction, without being any benefit to their assailants, to whom neuters alone are useful.

Their time of sallying forth is from two in the afternoon till five, but more generally a little before five; the weather, however, must be fine, and the thermometer must stand at above $36^{\circ}$ in the shade. Previously to marching there is reason to think that they send out scouts to explore the vicinity; upon whose retum they emerge from their subterranean city,

1 Huber, 287. Jurine, Hyménoptères, 273.

2 It is not clear that our Willughby had not some knowledge of this extraordinary fact; for in his description of ants, speaking of their care of their pulax, he says, "that they also carry the aurelice of others into their nests, as if they were their own." (Rai. Hist. Ins. 69.) Gould remarks concerning the hill-ant, "T'his species is very rapacious after the vermicles and nymphs of otlier ants. If you place a parcel before or near their colonies, they will, with remarkable greediness, seize and carry them off." 91. note*. Query - Do they do this to devour them, or educate them? White made the same observation (Nat. Hist. ii. 278).

s This species forms a kind of link which connects Latreille's two genera Formica and Myrmica, borrowing the abdominal squama from the former, and the sting from the latter. 
directing their course to the quarter from which the scouts came. They have various preparatory signals, such as pushing each other with the mandibles or forehead, or playing wich the antennæ; the object of which is probably to excite their martial ardonr, to give the word for marching, or to indicate the route they are to take. The advanced guard usually consists of eight or ten ants, but no sooner do these get beyond the rest than they move back, wheeling round in a semicircle, and mixing with the main body, while other's succeed to their station. They have "no captain, overseer, or ruler," as Solomon observes, their army being composed entirely of neuters, without a single female: thus all in their turns take their place at the head, and then, retreating towards the rear, make room for others. This is the usual order of their march ; and the object of it may be to communicate intelligence more readily from one part of the column to another.

When winding through the grass of a meadow they have proceeded to thirty feet or more from their own habitation, they disperse: and, like dogs with their noses, explore the glound with their antennæ to detect the traces of the game they are pursuing. The negro formicary, the object of their search, is soon discovered; some of the inhabitants are usually keeping guard at the avenues, which dart upon the foremost of their assailants with inconceivable fury. The alarm increasing, crowds of its swarthy inhabitants rush forth from every apartment : but their valour is exerted in vain; for the besiegers, precipitating themselves upon them, by the ardour of their attack compel them to retreat within, and seek shelter in the lowest story; great number's entering with them at the gates, while others with their mandibles make a breach in the walls, through which the victorious army marches into the besieged city. In a few minutes, by the same passages, they as hastily evacuate it, each carrying off in its mouth a larva or pupa which it has seized in spite of its unhappy guardians. On their return home with their spoil, they pursue exactly the route by which they went to the attack. Their success on these expeditions is rather the result of their impetuosity, by which they damp the courage of the negroes, than of their superior strength, though they are a larger animal ; for sometimes a very snall body of them, not more than 150 , has been known to succed in their attack and to carry off their booty. ${ }^{1}$

1 Since the publication of the first edition of this volume I have met with fresh confirmation of the extraordinary history here related. Having been induced to visit Paris, and calling upon M. Latreille (so justly celebrated as one of the first entomologists of the age, and to whom I feel infinitely indebted for the friendly attentions which he paid to me during my too short stay in that metropolis), he assured me, that h had verjied all the principal facts advanced by Huber. He has also said the same in his Considérations nouvelles et générules sur les Insects vivant en Sociúté. (Mém. du Mus. iii. 407.) At the same time be informed me that there was a nest of the rufescent ants in the Bois de Bonlogne, to which place he afterwards was so good as to accompany me. We went on the 25 th of June, 1817. The day was excessively hot and sultry. A little before five in the afternoon we began on search. At first we conld not discern a single ant in motion. In a minute or two, however, my friend directed my attention to one individual - two or three more next appeared - abd soon a numerous army was to be seen winding through the long grass of a low ridge in which was their formicary. Just at the entrance of the wood trom Paris, on the right hand and near the road, is a bare place, paled in for the Sunday amusement of the lower orders - to this the ants directed their march, and upon entering it divided into two columms, which traversed it rapidly and with great apparent eagerness; all the while exploring the ground with their antennx, 
When, from their proximity, they are more readily to be come at than those of the negroes, they sometimes assault with the same view the nest of another species of ant, which I shall call the miners ( $F$. cunicularia).

This species being more courageous than the other, on this account the rufescent host marches to the attack in closer order than usual, moving with astonishing rapidity. As soon as they begin to enter their habitation, 1:yyrials of the miners rushing out fall upon them with great fury; while others, well aware of their purpose, making a passage through the midst of them, carry off in their mouth the larve and pupæ. The surfice of the nest thus becomes the scene of an obstinate conflict, and the assailants are often deprived of the prey which they had seized. The miners dart upon them, fight them foot to foot, dispute every inch of their territory, and defend their progeny with unexampled courage and rage. When the rufescents, laden with pillage, retire, they do it in close order - a precaution highly necessary, since their valiant enemies, pursuing them, impede their progress for a considerable distance from their residence.

During these combats the pillaged ant-hill presents in miniature the spectacle of a besieged city; hundreds of its inhabitants may be seen making their escape, and carrying off in different directions, to a place of security, some the young brood, and others their females that are newly excluded : but when the danger is wholly passed, they bring them back to their city, the gates of which they barricade, and remain in great numbers near them to guard the entrance.

Formica sanguinea, as I observed above, is another of the slave-making ants; and its proceedings merit separate notice, since they differ considerably from those of the rufescents. They construct their nests under hedges of a southern aspect, and likewise attack the hills both of the

as beagles with their noses, evidently as if in pursuit of game. Those in the ran, as IIuber also observed, kept perpetually falling back into the main body. When they had passed this inclosure, they appeared for some time to be at a loss, making no progress, but only coursing about: but after a few minutes' delay, as if they had received some intelligence, they resumel their march and soon arrived at a negro nest, which they entered by one or two apertures. We could not olserve that any negroes were expecting their attack outside the nest, but in a short time a few came out at another opening, and seemed to be making their escape. Perhaps some conflict might have taken place within the nest, in the interval between the appearance of these negroes and the entry of their assailants. However this might be, in a few minutes one of the latter made its appearance with a pupa in its month; it was followed by three or four nore; and soon the whole army began to emerge as fast as it could, almost every individual carrying its burthen. Most that I ob. served seemed to have pupæ. I then traced the expectition back to the spot from which I first saw them set out, which according to my steps was about 156 feet from the negro formicary. The whole business was transacterl in little more than an hour. Though I could trace the ants back to a certain spot in the rilge before mentioned, where they first appeared in the long grass, I dill not succeed in finding the entrance to their nest, so that I was deprived of the pleasure of seeing the mixed society. As we dined at an auberge close to the spot, I proposed renewing. my researches after dimner; bnt a violent tempest of thunder and rain, though I attempted it, prevented my succeeding; and afterwards I had no opportunity of revisiting the place.

M. Latreille very justly observes that it is physically impossible for the rufescent ants (Polyergus rufescens), on account of the form of their jaws, and the accessory parts of their mouth, either to prepare habitations for their family, to procure food, or to feed them. - Considérutions nouvelles, \&c., p. 408. 
negroes and miners. On the 15th of July, at ten in the morning, Huber observed a small band of these ants sallying forth from their formicary, and mareling rapilly to a neighbouring nest of negroes, around which it dispersed. The inhabitants, rushing out in crowds, attaeked them and took several prisoners: those that escaped advanced no further, but appeared to wait for suecours: small brigades kept frequently arriving to reinforce them, which emboldened them to approach nearel to the city they had blockaded; upon this their anxiety to send couriers to their own nest seemed to increase; these spreading a general alarm, a large reinforcement immediately set out to join the besieging arny; yet even then they did not begin the battle. Almost all the negroes, eoming out of their fortress, formed themselves in a body about two feet square in front of it, and there expected the enemy. Frequent skirmishes were the prelude to the main conflict, which was begun by the negroes. Long before suecess appeared dubions they earried off their pupæ, and heaped them up at the entrance to their nest, on the side opposite to that on which the enemy approached. The young females also fled to the same quarter. The sanguine ants at length rush upon the negroes, and attacking them on all sides, after a stout resistance the latter, renouneing all defence, endeavour to make off to a distance with the pupæ they have heaped up:- the host of assailauts pursues, and strives to force from them these objects of their eare. Many also enter the formieary, and begin to earry off the young brood that ire left in it. A continued chain of ants engaged in this en:ployment extends from nest to nest, and the day and part of the night pass before all is finished. A garrison being left in the eaptured eity, on the following morning the business of transporting the brood is renewed. It often bappens (for this species of ant loves to change its habitation) that the conquerors emigrate with all their family to the aequisition which their valour has gained. All the incursions of $F$. sanguinea take place in the space of a month, and they make only five or six in the year. They will sometimes travel 150 paces to attack a negro colony.

After reading this account of expeditions undertaken by ants for so extraordinary a purpose, you will be curious to know how the slaves are treated in the nests of these marauders - whether they live happily, or labour under an oppressive yoke. You must recollect that they are not carried off, like our negroes, at an age when the amor patrice and all the elarities of life which bind them to their country, lindred, and friends, are in their full strength, but in what may be called the helpless days of infaney, or in their state of repose, before they can have formed any associations or imbibed any notions that render one place and society more dear to then than another. Preconceived ideas, therefore, do not exist to influence their happiness, which must altogether depend upon the treatment which they experience at the hands of their new masters. Here the goodness of Providence is conspicuous; which, although it has gifted these ereatures with an instinet so extraordinary, and seemingly so unnatural, has not made it a source of misery to the objeets of it.

You will here, perhaps, imagine that I have not sufficiently taken into consideration the anxiety and privations undergone by the poor neuters, in beholding those foster-ehildren, for which they have all along manifested such tender solicitude, thus violently snatched from them : but when you reflect that they are the common pioperty of the whole colony, and that, consequently, there can scarcely be any separate attachment to particular 
individuals, you will admit that, after the fright and horror of the conflict are over, and their enemies have retreated, they are not likely to experience the poignant affliction felt by parents when deprived of their children; especially when you further consider, that most probably some of their brood are rescucd from the general pillage; or at any rate their females are left uninjured, to restore the diminished population of their colonies, and to supply them with those objects of attention, the larvæ, \&c., so necessary to that development of their instincts in which consists their happiness.

But to return to the point from which I digressed. - The negro and miner ants suffer no diminution of happiness, and are exposed to no unusual hardships and oppression in consequence of being transplanted into a foreign nest. Their life is passed in much the same employments as would have occupied it in their native residence. They build or repair the common dwelling; they make excursions to collect food ; they attend upon the females; they feed them and the larva; and they pay the necessary attention to the daily sumning of the eggs, larvæ, and pupæ. Besides this they have also to feed their masters and to carry them about the nest. This you will say is a serious addition to the ordinary occupations of their own colonies : but when you consicler the greater division of labour in these mixed societies, which sometimes unite both negrocs and miners in the same dwelling, so that three distinct races live together, from their vast numbers so fir exceeding those of the native nest, you will not think this too severe employment for so industrious an animal.

But you will here ask, perhaps, - "Do the masters take no part in these domestic employments? At least, surely, they direct their slaves, and see that they keep to their work? " - No such thing, I assure you - the sole motive for their predatory excursions seems to be mere laziness and hatred of labour. Active and intrepid as they are in the field, at ill other times they are the most helpless animals that can be imagined; - unwilling to feed themselves, or even to walk, their indolence exceeds that of the sloth itself. So entirely dependent, indeed, are they upon their negroes for every thing, that upon some occasions the latter seem to be the masters, and exercise a kind of authority over them. They will not suffer them, for instance, to go out before the proper season, or alone; and if they return from their excursions withont their usual booty, they give them a very indifferent reception, showing their displeasure (which, however, soon ceases) by attacking them ; and when they attempt to enter the nest, dragging them out. To ascertain what they would do when obliged to trust to their own exertions, Huber shut up thirty of the rufescent ants in a glazed box, supplying them with larve and pupe of their own kind, with the addition of several ncgro pupæ, exclucling very carefully all their slaves, and placing some honey in a corner of their plison. Incredible as it may seem, they made no attempt to feed themselves: and though at first they paid some attention to their larva, carrying them here and there, as if too great a charge they soon laid them down again; most of them died of hunger in less than two days, and the few that remained alive appeared extremely weak and languid. At length, commiseratiug their condition, he admitted a single negro; and this little active creature by itself re-established order-made a cell in the earth; collected the larva and placed them in it ; assisted the pupæ that were rualy to be developed; and pregerved the life of the nenter rufescents that still survived. What a picture of beneficent industry, contrasted with the baleful effects of sloth, does this 
interesting aneclote afford! Another experiment which he tried made the contrast equally striking. He put a large portion of one of these mixed colonies into a woollen bag, in the month of which he fixed a small tube of wood, glazed at the top, which at the other end was fitted to the entrance of a kind of hive. The second day the tube was crowded with negroes going and returning: - the indefatigable diligence and activity manifested by them in transporting the young brood and their rufescent masters, whose bodies were suspended upon their mandibles, was astonishing. These last took 110 active part in the busy scene, while their slaves showed the greatest anxiety about them, generally carrying them into the hive; and if they sometimes contented themselves with depositing them at the entrance of the tube, it was that they might use greater dispatch in fetchin' the rest. The rufescent when thus set down remained for a moment coiled up without motion, and then leisurely unrolling itself, looked all around, as if it was quite at a loss what direction to take; -it next went up to the negroes, and by the play of its antennæ seemed to implore their succour, till one of them attending to it conducted it into the hive.

Beings so entirely dependent as these masters are upon their slaves, for every necessary, comlort, and enjorment of theil life, can scarcely be supposed to treat them with rigour or unkindness:- so far from this, it is evident from the preceding details that they rather look up to them, and are in some degree under their control.

The above observations, with respect to the indolence. of our slavedealers, relate principally to the rufescent species; for the sanguine ants are not altogether so listless and helpless; they assist their negroes in the construction of their nests, they collect their sweet fluid from the Aphides; and one of their most nsual occupations is to lie in wait for a small specius of ant, on which they feed; and when their nest is menaced by an enemy they show their value for these faithifl servants by carrying them down into the lowest apartments, as to a place of the greatest security. Sometimes even the rufescents rouse themselves from the torpor that usually benumbs them. In one instance, when they wished to emigrate from their own to a deserted nest, they reversed what usially takes place on such occasions, and carried all their negroes themselves to the spot they had chosen. At the first foundation also of their societies by impregnated females, there is good reason for thinking, that, like those of other species, they take upon themselves the whole charge of the nascent colony. I must not here omit a most extracrdinary aneclote related by M. Huber. He put into one of his artificial formicaries pupx of both species of the slave-collecting ants, which, under the care of sone negroes introduced with them, arrived at their imago state, and lived together under the same roof in the most perfect anity.

These facts show what effects edncation will produce even upon insects; that it will impart to them a new bias, and modify in some respects their usual instincts, rendering them faniliar with objects which, had they been educated at home, they would have feared, and causing them to love those whom in that case they would have abhorred. - It occasions, however, no further change in their character, since the master and slave, brought up with the same care and under the same superintendence, are associated in the mixed formicary under laws entirely opposite.

I See IIuber, chap. vii-xi. Mixed societies, similar to the above describet, have been observed amongst exotic ants by M. Lund, who mentions a species of 
Unparalleled and unique in the animal kingdom as this history may appear, you will searcely deem the next I have to relate less singular and less worthy of admiration. That ants should have their milch cattle is as extraordinary as that they should have slaves. Here, perhaps, you may again feel a fit of incredulity shake you ; - but the evidence for the fact I an now stating being abundant and satisfactory, I flatter myself it will not shake you long.

The loves of the ants and the Aphides (for these last are the kine in question) have long been celebrated; and that there is a comnexion between them you may at any time, in the proper season, convince yourseif; for you will always find the former very busy on those trees and plants on which the latter ahound : and if you examine more closely, you will discover that their object in thus attending upon them is to obtain the saccharine fluid, which may well be denominated their milk ', that they secrete.

This fluid, which is scarcely inferior to honey in sweetness, issues in limpid drops from the abdomen of these insects, not only by the ordinary passage, but also by two setiform tubes placed, one on each side, just above it. Their sucker being inserted in the tender bark, is without intermission employed in absorbing the sap, which, after it has passed through the system, they keep continually discharging by these organs. When no ants attend them, by a certain jerk of the body, which takes place at regular intervals, they ejaculate it to a distance: but when the ants are at hand, watching the moment when the Aphides emit their fuid, they seize and suck it down immediately. This, however, is the least of their talents; for they absolutely possess the art of making them yield it at their pleasure; or, in other words, of milking them. On this occasion their antennæe are their fingers; with these they pat the abdomen of the aphis on each side alternately, moving them very briskly; a little drop of fluid imnediately appears, which the ant takes into its month, one species (Myrmica rubra) conducting it with its antennæ, which are somewhat swelled at the end. When it has thus milked one, it proceeds to another, and so on, till being satiated it returns to the nest.

But you are not arrived at the most singular part of this history, - that ants make a property of these cows, for the possession of which they contend with great earnestness, and use every means to keep them to themselves. Sometimes they seem to claim a right to the Aphicles that inhabit the branches of a tree or the stalks of a plant; and if stranger ants attempt to share their treasure with them, they endeavour to drive them alway, and may be seen running about in a great bustle, and exhibiting every sympltom of inquietude and anger. Sometimes, to rescue them from their rivals, they take their Aphides in their mouth; they generally keep guard round them, and when the branch is conveniently situated, they have recourse to an expedient still more effectual to keep off interlopers, - they inelose it in a

Myrmica ( $M$. paleata) found in Brazil, whose nest contains the neuters (doubtless employed as slaves, though unfortunately M. Lund had not an opportunity of observing the excursions in which the pupe they sprung from were capturel) of a neighbouring species, $M$. erythrothorax. (Lacordaire, Introl. à l'Entom. ii. 503.)

1 The ant ascends the tree, says Linné, that it may milk its cous, the Aphides, not kill them. Syst. Nat. 962. Sp. 3. 
tube of earth or other materials, and thus confine them in a kind of pad. dock near their nest, and often communicating with it.

The greatest cow-keeper of all the ants is one to be met with in most of our pastures, residing in hemispherical formicaries, which are sometimes of considerable diameter. I mean the yellow ant of Gould (F.fava). This species, which is not fond of roaming from home, and likes to have all its conveniences within reach, usually collects in its nest a large herd of a kind of Aphis that derives its nutriment from the roots of grass and other plants (Aphis radicum); these it transports from the neighbouring roots, probably by subterranean galleries, excavated for the purpose, leading from the nest in all directions ${ }^{1}$; and thus, without going out, it las always at hand a copious supply of food. These creatures share its care and solicitude equally with its own offipring. To the eggs it pays particular attention, moistening them with its tongue, carrying them in its mouth with the utmost tenderness, and giving them the advantage of the sun. This last fact I state from my orvn observation; for once upon opening one of these ant-hills early in the spring, on a sunny day, I observed a parcel of these eggs, which I knew by their black colour, very near the surface of the nest. My attack put the ants into a great ferment, and they immediately began to carry these interesting objects down into the interior of the nest. it is of great consequence to them to forward the hatching of these eggs as much as possible, in order to insure an early source of food for their colony; and they liad doubtless in this instance brought them up to the warmest part of their dwelling with this view. M. Huber, in a nest of the same ant, at the foot of an oak, once found the eggs of Aphis Quercus.

Our yellow ants are equally careful of their Aphides after they are hatched; when their nest is disturbed conveying them into the interior; fighting fiercely for them if the inhabitants of neighbouring formicaries, as is sometimes the case, attempt to make them their prey; and carrying them about in their mouths to change their pasture, or for some other purpose. When you consider that from them they receive almost the whole nutriment both of themselves and larve, you will not wonder at their anxiety about them, since the wealth and prosperity of the community is in proportion to the number of their cattle. Several other species keep Aphides in their nests, but none in such numbers as those of which I am speaking. ${ }^{2}$

Not only the Aphides yield this repast to the ants, but also the Cocci, with whom they have recourse to similar manceurres, and with equal suc. cess; only in this case the movement of the antennæe over their body may be compared to the thrill of the finger over the keys of a piano-forte; and in the tropical regions of India and Brazil (where no Aphides occur) it appears, from the observations of General Hardwicke, M. Lund, M. Bescke, and MNI. Spix and Martius, that the ants milk the larva and pupa of various species of Cercopis and Membracts. ${ }^{3}$ But what is still more extraordinary, even beetles are occasionally made cows of by Formica flava, the

1 Huber, 195. I have more than once found these Aphides in the nests of this species of ant.

2 See Huber, chap. vi. I have found Aphirles in the nest of Myrmica mura. Boisier de Sturages speaks of ants keeping their own Aphides, and gives an interesting account of them. Journ. de Physique, i 195.

3 Westwood, Mod. Class of Ins. ii. 239. 434. 
yellow ant, which, according to Miiller's very curious account of its habits, confirmed by M. Wesmael, keeps in its nest the singular little Claviger foveolatus (which Mr. Westwood has discovered in this abode in England), and obtains from the bristles terminating its elytra a gummy secretion which it uses for food, as it does that obtained from Aphides, feeding the Clavigers in return for this service, and carefulty guarding them from straying, which if they attempt it seizes them with its jaws. ${ }^{1}$ Their herds of these hard-coated yellow cattle are often numerous; for when paying a visit in 1829 to my friend Professor Germar at Halle in Prussia, he showed me a whole row of specimens from which he begged me to select at pleasure, all of which, if I recollect right, he had obtained from one ant's nest. It is probable that another species of Claviger ( $C$. longicornis), which M. Robert found also in an ant's nest, is made a similar use of by them.

One of the singular circumstances in the history of ants, and which requires further explanation, is, that besides the two beetles just named, many other species of the same tribe, mostly of small size, are also found in their nests, and so constantly, that it cannot arise from accident. My friend M. Chevrolat of Paris, who has been more successful in procuring new and rare coleopterous insects from this habitat than perhaps any other entomologist, has obtained the greatest number from the nests of Formica rufa Latr., in which he has found Lomechusa stmmosa and dentata, a new species of Xantholimus, Dendrophilus pygmans Payk., D. formicetornm Aubé, and D. Guerini Chevr., and Monotoma conicollis, and M. formicetoim Chevr. He has also found several specimens of Lomechusa paradoxn in the nest of Formica cunicularia Latr., and Abraus globulus Payk., Batrisus formicarins De la Porte, and B. oculatns, and B. venustus Aubé, as well as his singular new insect Myrmechixemus subterraneus, in other nests; and M. Reiche has also found IIceterius quadralus in the nest of Myrmica unifasciala, as bas Mr. MacLeay a crepitating species of Cerapterus in ants' nests in Australia. ${ }^{2}$ Besides the above, M. Chevrolat has observed in some of these ants' nests isolated larva, as he supposes, of a Clythre clothed with a case of gluten combined with particles of earth and small stones $^{3}$; and Mr. Westwood states that he has often found in the nests both of Formice and Myrmice many very young specimens of a white colour of a species of Oniscus, of which genus also, M. Lund in Brazil observed many of the ants of a column of Myrmica typhlos to carry each an individual beneath the abdomen. ${ }^{4}$ Thus we have sixteen or seventeen coleopterous insects of different genera and species, besides one or more species of Oniscus, habitually residing in ants' nests; but whether these, like the Clavigers, are subservient to the purposes of the ants, or whether they make the ants subservient to theirs, or what is the precise object of the companionship, must be left for future investigation, and are points to which I would strongly recommend your attention. ${ }^{5}$

1 Germar, Magazin der Entom, iii. t. 2. Westwood, Mod. Class. of Ins. i. 170.

2 Westwood, Mod. Class. of Ins. i. xii.

3 Silbermann, Revue Entom, iii. 263.

4 Westwood, Mod. Class. of Ins. ii. 234.

5 As there can be little doubt that several of M. Chevrolat's insects might be found in ants' nests in this country, as well as Claviger foveolatus, if sought for in the way which this indefatigable entomologist employs, it may not be amiss to indicate his mode of procedure. Before attacking an ants' nest he ties the legs of his pantaloons over his boots and puts on gloves, and then proceeds to shovel tho 
When the population exceeds the produce of a country, or its inhabitants suffer oppression, or are not comfor table in it, emigrations frequently take place, and colonies issue forth to settle in other parts of the globe; and sometimes whole nations leave their own country, either driven to this step by their enemies, or excited by cupidity to take possession of what appears to them a more desirable residence. These motives eperate strongly on some insects of the social tribes. Bees and ants are particularly influenced by them. The former, confincd in a narrow hive, when their society becomes too numerous to be contained conveniently in it, must necessarily send forth the redunclant part of their population to seek for new quarters; and the latter-thongh they usually can enlarge their awelling to any dimensioss which their numb, is may require, and therefore do not send forth colonies, unless we may distinguish by that name the departure of the males and females from the nest - are often disgusted with their present habitation, and seek to entablish themselves in a new one:either the near neighbourhood of enemies of their own species; annoyance from frequent attacks of man or other arimals; their exposure to cold or wet from the removal of some species of shelter; or the discovery of a station betier circumstanced or more abundant in Aphides; - all these may operate as inducements to them to change their residence. That this is the case might bc inferred from the circumstance noticed by Gould ${ }^{2}$, which I have also partly witnessed myself, that they sometimes transport their young brood to a considerable distance from their home. But M. Huber, by his interesting observations, has placed this fact beyond all controversy; and his history of their enigrations is enlivened by some traits so singular, that I am impatient to relate them to you. They concern chiefly the great hill-ant ( $\boldsymbol{F}$. rufu), though several other species occasionally emigrate.

Some of the ncuters baving found a spot which they judge convenient for a new habitation, apparently without consulting the rest of the socicty, determine upon an emigration, and thus they compass their intention :The first step is to raise recruits: with this view they eagerly accost several fellow citizens of their own order, caress them with their antennæ, lead them by their mandibles, and evidently appear to propose the journey to them. If they seem disposed to accompany them, the recruiting officer, for so he may be called, prepares to carry off his recruit, who, suspending himself upon his mandibles, hangs coiled up spirally under his neck; -all this passes in an amicable manner after mutual salutations. Sometimes, however, the recruiter takes the other by surprise, and drags him from the ant-hill without giving him time to consider or resist. When arrived at the proposed habitation, the suspended ant uncoils itself, and, quitting its conductor, becomes a recruiter in its turn. The pair return to the old nest, and each carries off a fresh recruit, which being arrived at the spot joins in the undertaking:- thus the number of recruiters keeps pro. gressively increasing, till the path hetween the new and the old city is full of goers and comers, each of the former laden with a recruit. What a

whole contents of the nest (of course to the rery bottoun) into a bag, of the contents of which he spreads successive portions upon a cloth so as to allow the ants to escape, and afterwards eximines what renains at his leisure. M. Markel has recently published a memoir on the coleopterous insects found in ants' nests in Saxon Switzerlaud, amounting to nearly lifty species. (Germar's Zeitschrift, iii. 203.)

1 Gould, 42. 
singular and amusing scene is then exhibited of the little people thus employed! When an enigration of a rufescent colony is going forward, the negroes are seen carrying their masters; and the contrast of the red with the black renders it peculiarly striking. The little turf-ants (Myrmica? caspitum) upon these occasions carry their recruits uncoiled, with their head downwards and their body in the air.

This extraordinary scene continues several days; but when all the nenters are acquainted with the road to the new city, the recruiting ceases. As soon as a sufficient number of apartments to contain them are prepared, the young brood, with the males and females, are conveyed thither, and the whole business is concluded. When the spot thus selected for their residence is at a considerable distance from the old nest, the ants construct some intermediate receptacles, resembling small ant-hills, consisting of a cavity filled with fragments of straw and other materials, in which they form several cells; and here at first they deposit their recruits, males, females, and brood, which they afterwards conduct to the final settlement. These intermediate stations sometimes become permanent nests, which, however, maintain a connection with the capital city. ${ }^{1}$

While the recruiting is procceding it appears to occasion no sensation in the original nest; all goes on in it as usual, and the ants that are not yet recrtited pursue their ordinary occupations: whence it is evident that the change of station is not an enterprise undertaken by the whole community. Sometimes many neuters set about this business at the same time, which gives a short existence (for in the end they all re-unite into one) to many separate formicaries. If the ants dislike their new city, they quit it for a thirl, and cven for a fonth : and what is remarkahle, they will sometimes return to their original one before they are entirely settled in the new station; when the recruiting goes in opposite directions, and the pairs pass each other on the road. You may stop the emigration for the present, if you can arrest the first recruiter, and take away his recruit. ${ }^{2}$

These European emigrations, however, are somewhat insignificant when conpared with those which the neuters of some of the tropical species.undertake, the extent of which would be incredible if not so well anthenticated. M. Lund states that he once followed one of these vast hosts for five days; and M. Lacordaire informs us that when in Cayenne he saw a nigratory army of this description pass his residence which was abont a humdred paces broad, and which occupied more than a day and a half in passing, though the ants marched rapidly and made no halt. It is to a specics of the ants making these migrations, that Madame Merian gave the name of Ants of Visitation, before alluded to, as so useful by entering all the houses on their march, and clearing them of all noxious insects or other animals. M. Lacordaire, however, denies that any such object actuates these migrating ants, which he says often pass houses withont entering them; and that when they do, it is for want of food on thcir route; thongh he admits that in this case they leave no living animal in the houses which

1 Walking one day early in July in a spot where I used to notice a single neat of Formica rufi, I observed that a new colony had been formed of considerable mainitude; and between it and the original nest were six or seven smaller settlements.

2 See Huber, chap. iv. \$3. 
they visit, as he himself once witnessed at Cayenne. ${ }^{l}$ But whatever may be the fact as to the migrating ants of Cayenne, the Chasseur-Ants of Trinidad would seem to migrate for the express purpose of scouring human habitations for food, according to the account given by Mrs. Carmichael, which presents so graphic a picture of their proceedings, that I shall give it to you entire, especially as its minute and circumstantial details seem to vouch for its accuracy :-

“ One morning my attention was arrested at Laurel Hill by an unusual number of black birds, whose appearance was foreign to me: they were smaller, but not unlike an English crow ; and were perched on a calibashtree near the kitchen. I asked the house-negress, who at that moment came up from the garden, what could be the cause of the appearance of those black birds? She said, 'Misses, dem be a sign of the blessing of God; dey are not de blessing, but only de sign, as we say, of God's blessing. Misses, you'll see afore noontime how the ants will come and clear the houses.' At this moment I was cailed to breakfast, and thinking it was some superstitious idea of hers, I paid no further attention to it.

"In about two hours after this, I observed an uncommon number of chasseur-ants crawling about the floor of the room : my children were annoyed by them, and seated themselves on a table, where their legs did not communicate with the floor. The ants did not crawl upon my person, but I was now surrounded by them. Shortly after this, the walls of the room became covered by them; and next they began to take possession of the tables and chairs. I now thought it necessary to take refuge in an adjoining room, separated only by a few ascending steps from the one we occupied, and this was not accomplished without great care and generalship, for had we trodden upon one we should have been summarily punished. There were several ants on the top of the stair, but they were not nearly so numerous as in the room we had left; but the upper room presented a singular spectacle, for not only were the floor and the walls covered like the other roon, but the roof was covered also.

“The open rafters of a West India house at all times afford shelter to a numerous tribe of insects, more particularly the cockroach; but now their destruction was inevitable. The chasseur-ants, as if trained for battle, ascended in regular, thick files, to the rafters, and threw down the cockroaches to their comrades on the floor, who as regularly marched off with the dead bodies of cockroaches, dragging them away by their united efforts with amazing rapidity. Either the cockroaches were stung to death on the rafters, or else the fall killed them. The ants never stopped to devonr their prey, but conveyed it all to their storehouses.

"The windward windows of this room were of glass, and a battle now ensued between the ants and the jack-spaniards on the panes of glass. The jack-spaniard may be called the wasp of the West Indies ; it is twice as large as a British wasp, and its sting is in proportion more painful: it builds its nests in trees and old houses, and sometimes in the rafters of a room. These jack-spaniards were not quite such easy prey as the cockroaches had been, for they used their wings, which not one cockroach hat attempted to do. Two jack-spaniards, hotly pursued on the window, alighted on the dress of one of my children. I entreated her to sit still,

1 Lacordaire, Introd. à l'Entom. ii. 504. 
and remain quict. In an inconceivably short space of time, a party of ants crawled upon her frock, surrounded, eovered the two jack-spaniards, and crawled down again to the floor, dragging off their prey, and doing the child no harm.

"From this room I went to the adjoining bed-chamber and dressingroom, and found them equally in possession of the chasseurs. I opened a large military chest full of linen, which had been much infested; for I was determined to take every alvantage of such able hunters. I found the ants already inside; I suppose they must have got in at some opening at the hinges. I pulled out the linens on the floor, and with them hundreds of coekroaches, not one of which escaped.

"We now left the house, and went to the chambers built at a little distance; but these also were in the same statc. I next procecled to open a store-room at the end of the other house for a place of retreat; but, to get the key, I had to return to the under room, where the battle was now more hot than ever. The ants had commenced an attack upon the rats and mice, which, strange as it may appear, were no match for their apparently insignificant foes. They surrounded them as they had the insect tribe, covered them over, and dragged them off with a celerity and union of strength, that no one who has not watehed such a seene can eomprehend. I did not see one rat or mouse eseape, and I am sure I saw a score carried off during a very short period. We next tried the kitchen, for the store-room and boys ${ }^{3}$ pantry were already oceupied; but the kitchen was equally the field of battle, between rats, mice, cockroaches, and ants killing them. A huckster negro came up selling cakes; and seeing the uproar, and the family and servants standing out in the sun, lie said, 'Ah, misses, you've got the blessing of God to-day, and a great blessing it is to get such a eleaning.'

"I think it was about ten when I first observed the ants; alout twelve the battle was formidable; soon after one o'clock the great strife began with the rats and mice; and about three the houses were cleared. In a quarter of an hour more the ants began to decamp, and soon not one was to be seen within doors. But the grass round the house was full of them; and they seemed now feasting on the remnants of their prey, which had been left on the road to their nests; and so the feasting continued till about four o'clock, when the black birds, who had never been long absent from the calibash and poisdoux trees in the neighbourhood, darted down among them, ant destroyed by millions those who were too sluggish to make good their retreat. By five o'clock the whole was over; before sun-down, the negro-houses, were all cleared in the same way ; and they told me that they had seen the black birds hovering abont the almond trees close to the negro-houses, as early as seven in the morning. I never saw those black birds before or since, and the negroes assured me that they were never scen but at such times."1

I shall now relate to you some other portions of Myrmidonian History, which, thongh perhaps not so striking and wonderful as the preceding details, are not devoid of interest, and will serve to exemplify their incredible diligence, labour, and ingenuity.

1 Mrs. Carmichael on the West Indies, quoted in Saturday Magazine, 1833, p. 150 . 
In this country it is commonly in March, earlier or later according to the season, that ants first make their appearance, and they continue their labours till the middle or latter end of October. They emerge usualiy from their subterranean winter-quarters on some sunny day; when, assembling in erowds on the surface of the formicary, they may be observed in continual motion, walking incessantly over it and one another, without departing from home; as if their object, before they resumed their employments, was to habituate themselves to the action of the ail and sun. This preparation requires a few days, and then the business of the year commences. The earliest employment of ants is most probably to repair the injuries which their habitation has received during their statc of inactivity: this observation more particularly applies to the hill-ant $(F . v u f a)$, all the upper stories of whose dwellings are generally laid flat by the winter rains and snow; but every speeies, it may well be supposed, has at this season some deranged apartments to restore to order, or some demolished ones to rebuild.

After their annual labours are begun, few are ignorant how incessantly ants are engaged in building or repairing their habitations, in collecting provisions, and in the care of their young brood; but searcely any are aware of the extent to which their activity is carried, and that their labours are going on even in the night. Yet this is a certain fact. Long ago Aristotle affirmed that ants worked in the night when the moon was at the full" ; and their historian Gould observes, "that they even exceed the painful industrious bees. For the ants employ each moment, by day and night, almost without intermission, unless hindered by excessive rains." 3 M. Huber also, speaking of a mason-ant, not found with us, tells us that they work after sunset, and in the night. ${ }^{4}$ To these I can add some observations of my own, which fully confirm these accounts. My first were made at nine o'clock at night, when I found the inhabitants of a nest of the red ant (Mryrmica rubra) very busily employed; I repeated the observation, which I could conveniently do, the nest heing in my garden, at various times from that hour till twelve, and always found some going and coming, even while a heavy rain was falling. Haring in the day noticed some Aphides upon a thistle, I examined it again in the night, at about eleven o'clock, and found my ants busy milking their cows, which did not for the sake of repose intermit their suction. At the same hour another night, I observed the little negro-ant ( $F$. fusca) engaged in the same employment upon an eldcr. About two miles from my residence was a nest of Gould's hill-ant $(F$, rufu $)$, which, according to NI. Huber, shut their gates, or rather barricade them, every night, and remain at home. ${ }^{5}$ Being desirous of ascertaining the accuracy of his statement, early in October, about two o'clock one morning, İ visited this nest in company with an intelligent friend; and to our surprise and admiration we found our ants at work, some being engaged in carrying their usual burden, sticks and straws, into their habitation, others going out from it, and several were climbing the neighbouring oaks, doubtless to milk their Aphides. The number of comers and goers at that hour, however, was nothing compared with the myriads that may always be

1 Gould, 67. De Geer, ii, 105t.

3 Gould, 68.

5 Huber, 23.
2 Hist. Animal. 1. ix. c. 38.

4 Huber, 35. 42. 
seen on these nests during the day. It so happened that our visit was paid while the moon was near the full; so that whether this species is equally vigilant and active in the absence of that luminary yet remains uncertain. Perhaps this circumstance might reconcile Huber's observation with ours, and confirm the accuracy of Aristotle's statement before quoted. To the red-ant, indeed, it is perfectly indifferent whether the moon shine or not; they are always busy, though not in such numbers as during the day. It is probable that these creatures take their repose at all hours indifferently ; for it cannot be supposed that they are employed day and night without rest.

I have related to you in this and former letters most of the works and employments of ants, but as yet I have given you no account of their roads and trackways. Don't be alarmed, and imagine I am going to repeat to you the fuble of the ancients, that they wear a path in the stones $^{1}$; for I suppose you will scarcely be brought to believe that, as Hannibal cut a way for the passage of his army over the Alps by means of vinegar, so the ants may with equal effect employ the formic acid : but more species than one do really form roads which lead from their formicaries into the adjoining country. Gould, speaking of his jet-ant ( $F$. fuliginosa), says that they make several main track-ways (streets he calls them), with smaller paths striking off from them, extending sometimes to the distance of forty feet from their nest, and leading to those spots in which they collect their provisions; that upon these roads they always travel, and are very careful to remove from them bits of sticks, straw, or any thing that may impede their progress; nay, that they even kecp low the herbs and grass which grow in them, by constantly biting them off ${ }^{2}$, so that they may be said to mow their walks. But the best constructors of roads arc the hill-ants ( $F$. rufu). Of these De Geer says, "When you keep yourself still, without making any noise, in the woods peopled with these ants, you may hear them very distinctly walking over the dry leaves which are dispersed upon the soil, the claws of their feet producing a slight sound when they lay hold of them. They make in the ground broad paths, well beaten, which may be readily distinguished, and which are formed by the going and coming of innumerable ants, whose custom it is always to travel in the same route." ${ }^{3}$ From Huber we further learn that these roads of the hill-ants arc sometimes a hundred feet in length, and several inches wide; and that they are not formed merely by the tread of these creatures, but hollowed out by their labour. ${ }^{4}$ Virgil alludes to their tracks in the following animated lines, which, though not altogether correct, are very beautiful :-

"So when the pismires, an indnstrious train,
Embodied rob some golden heap of"grain,
Studious ere stormy winter frowns to lay
Safe in their darksome cells the treasured prey;
In one long track the dusky legions lead
Their prize in triumph through the verdant mead;
Here, bending with the load, a panting throng
With force conjoin'd heave some huge grain along.

1 Plin. Nat. Hist. Ixi. c, 29.

s De Geer, ii. 1067.

2 Gould, 87.

4 IIuber, 146. 
Some lash the stragglers to the task assign'd,

Some to their ranks the bands that lag behind :

They crowd the peopled path in thick array,

Glow at the work, and darken all the way."

Bonnet, observing that ants always keep the same track both in going from and returning to their nest, imagines that their paths are imbued with the strong scent of the formic acid, which serves to direct them ; but, as Huber remarks, though this may be of some use to them, their other senses must be equally employed, since it is evident, when they have made any discovery of agreeable food, that they possess the means of directing their companions to it, though it is scarcely possible that the path can have been sufficiently impregnated with the acid for them to trace their way to it by scent. Indeed the recruiting system, described above, proves that it requires some pains to instruct ants in the way from an old to a new nest; whereas, were they directed by scent, after a sufficient number had passed to and fro to imbue the path with the acid, there would be no occasion for further deportations. ${ }^{1}$

Though ants have no mechanical inventions to diminish the quantum of labour, yet by numbers, strength, and perseverance they effect what at first sight seems quite beyond their powers. Their strength is wonderful. I once, as I formerly observed, saw two or three of them haling along a young snake not dead, which was of the thickness of a goose-quill. St. Pierre relates, that he was highly amused with seeing a number of ants carrying off a Patagonian centipede. They had seized it by all its legs, and bore it along as workmen do a large piece of timber. ${ }^{2}$ The Mahometans hold, as Thevenot relates, that one of the animals in Paradise is Solomon's ant, which, when all creatures in obedience to him brought him presents, dragged before him a locust, and was therefore preferred before all others, because it had brought a creature so much bigger than itself. They sometimes, indeed, aim at things beyond their strength; but if they make their attack, they pertinaciously persist in it thongh at the expense of their lives. I have in my cabinet a specimen of Colliuris longicollis Latr., to one of the legs of which a small ant, scarcely a thirtieth part of its loulk, is fixed by its jaws. It had probably the audacity to attack this giant, compared with itself, and, obstinately refusing to let go its hold, was starved to death. ${ }^{3}$ Professor Afzelins once related to me some particulars with respect to a species of ant in Sierra Leone, which proves the same point. He says that they march in columns that exceed all powers of numeration, and always pursue a straight course, from which nothing can cause them to deviate: if they come to a house or other building, they storm or undermine it; if a river comes across them, though millions perish in the attempt, they endeavour to swim orer it.

This quality of perseverance in ants on one occasion led to very important results, which affected a large portion of this habitable globe; for the celebrated conqueror Timour, being once forced to take shelter from his enemies in a ruined building, where he sat alone many hours,

1 Euv. de Bonnet, i. 535. Huber, 197.

2 Voy. to Muurit. 71.

3 I was much amused, when dining in the forest of Fontainebleau, by the pertinacity with which the hill-ant $(F \cdot$ rufa ) attacked our food, haling from our very plates, while we were eating, long strips of meat many times their own size. 
desirous of diverting his mind from his hopeless condition, he fixed his observation upon an ant that was carrying a grain of corn (probably a pupa) larger than itself up a high wall. Numbering the efforts that it made to accomplish this olject, he found that the grain fell sixty-nine times to the ground, but the seventieth time it reached the top of the wall. "This sight (said Timour) gave me courage at the moment; and I have never forgotten the lesson it conveyed."

Madame Merian, in her Surinam Insects, speaking of the large-headed ant (Atta cephalotes), affirms that, if they wish to emigrate, they will collstruct a living bridge in this manner : - one individual first fixes itself to a piece of wood by means of its jaws, and remains stationary ; with this a second connects itself; a third takes hold of the second, and a fourth of the third, and so on till a long connected line is formed fastened at one extremity, which floats exposed to the wind, till the other end is blown over so as to fix itself to the opposite side of the stream, when the rest of the colony pass over upon it, as a bridge. ${ }^{2}$ This is the process, as far as I can collect it from her imperfect account. As she is not always very correct in her statements, I regarded this as altogether fabulous, till I met with the following history of a similar proceeding in De Azara, which induces me to give more credit to it.

He tells us that in low districts in South America that are exposed to inundations, conical hills of earth may be observed, about three feet high, and very near to each other, which are inhabited by a little black ant. When an inundation takes place, they are heaped together out of the nest into a circular mass, about a foot in diameter, and four fingers in depth. Thus they remain floating upon the water while the inundation continues. One of the sides of the mass which they form is attached to some sprirg of grass, or piece of wood; and when the waters are retired, they return to their habitation. When they wish to pass from one plant to another, they may often be seen formed into a bridge, of two palms' length, and of the breadth of a finger, which has no other support than that of its two extremities. One would suppose that their own weight would sink them ; but it is certain that the masses remain floating during the inundation, which lasts some days. ${ }^{3}$

You must now be fully satiated with this account of the constant fatigue and labour to which our little pismires are doomed by the law of their nature; I shall therefore endeavour to relieve your nind by introducing you to a more quiet scene, and exhibit them to you during their intervals of repose and relaxation.

Gould tells us that the hill-ant is very fond of basking in the sun, and that on a fine serene morning you may see them conglomerated like bees on the surface of their nest, from whence, on the least disturbance, they will disappear in an instant. ${ }^{4}$ M. Huber also observes, after their labours are finished, that they stretch themselves in the sun, where they lie heaped one upon another, and seem to enjoy a short interval of repose; and in the interior of an artificial nest, in which he had confined some of this species, where he saw many employed in various ways, he noticed some reposing which appeared to be asleep..$^{5}$

1 Related in the Quarterly Review for August, 1816, p. 259.

2 Insect. Surinam. p. 18. In her plate the ants are represented so connected.

3 Voyages dans 't'Amérique Mérid. i. 187.

4 Gould, 69.

5 Huber, 73. 
But they have not only their time for repose; they also devote some to relaxation, during which they amuse thenselves with sports and games. "You may frequently perceive one of these ants ( $F$. rufu) (says our Gould) run to and fro with a fellow-labourer in his forceps, of the same species and colony. It appeared first in the light of provisions; but I was soon undeceived by observing that after being carried for some time it was let go in a friendly manner, and received no personal injury. This amusement, or whatever title you please to give it, is often repeated, particularly amongst the hill-ants, who are very fond of this sportive exercise." 1 A nest of ants which Bonnet found in the head of a teazle, when enjoying the full sun, which seems the acmé of formic felicity, amused themselves with carrying each other on their backs, the rider holding with his mandibles the neck of his horse, and embracing it closely with its legs. ${ }^{2}$ But the most circumstantial account of their sports is given by Huber. "I approached one day," says he, "one of their formicaries (he is speaking of F. ruf $(u)$ exposed to the sun and sheltered from the north. The ants were heaped together in great numbers, and seemed to enjoy the temperature which they experienced at the surface of the nest. None of them were working : this multitude of accumulated insects exhibited the appearance of a boiling fluid, upon which at first the eye could scarce fix itself without difficulty. But when I set myself to follow each aut separately, I saw them approach each other, moving their antennæ with astonishing rapidity; with their fore feet they patted lightly the checks of other ants : after these first gestures, which resembled caresses, they reared upon their hind-legs by pairs ; they wrestled together; they seized one another by a mandible, by a leg or an antenna; they then let go their hold to renew the attack; they fixed themselves to each other's trunk or abdomen; they embraced; they turned each other over, or lifted each other up by turns - they soon quitted the ants they had seized, and endeavoured to catch others. I have seen some who engaged in these exercises with such eagerness, as to pursue successively several workers; and the combat did not terminate till the least animated, having thrown his antagonist, accomplished lis escape by concealing himself in some gallery." 3 He compares these sports to the gambols of two puppies, and tells us that he not only often observed them in this nest, but also in his artificial one.

I shall here copy for you a memorandum I formerly made. "On the 9th of May, at half past two, as I was walking on the Plumstead road near Nor wich, on a sunny bank I observed a large number of ants (Formica fusca) agglomerated in crowds near the entrances of their nest. They seemed to make no long excursions, as if intent upon enjoying the sunshine at home; but all the while they were coursing about, and appeared to accost each other with their antennæ. Examining them very attentively, I at length saw one dragging another, which it absolutely lifted up by its antennæ, and carrying it in the air. I followed it with my eye, till it concealed itself and its autagonist in the nest. I soon noticed another that had recourse to the same manœurres; but in this instance the ant that was attacked resisted manfully, a third sometimes appearing inclined to interfere: the result was, that this also was dragged in. A third was haled in by its legs, and a fourth by its mandibles. What was the precise object of these procendings, whether sport or violence, I could not ascertain. I walked

1 Gould, 103 -

2 Bonnet, ii. 407.

3 Huber, $170-$. 
the same way on the following morning, but at an earlier hour, when only a few comers and goers were to be seen near the nest." And soon lcaving the place, I had no further opportunity to attend to them.

And now having conducted you through every apartment of the formicary, and shown you its inhabitants in every light, I shall leave you to meditate on the extraordinary instiacis with which their Creator has gifted them, rescrving what I have to say on the other social insects for a future occasion. 


\section{LETTER XTII.}

\section{SOCIETIES OF INSECTS-continued.}

\section{PERFECT SOCIETIES - continued. (WASPS AND HUMBLE-BEES.)}

I shall now call your attention to such parts of the history of two other descriptions of social insects, wasps, namely, and humble-bees, as have not been related to you in my letters on the affection of insects for their young, and on their habitations. What I have to communicate, though not devoid of interest, is not to be compared with the preceding account of the ants, nor with that which will follow of the hive-bee. This, however, may arise more from the deficiency of observations than the barrenness of the subject.

The first of these animals, wasps (Vespa) - with whose proceedings I shall begin - we are apt to regard in a very unfavourable light. They are the most impertinent of intruders. If a door or window be open at the season of the year in which they appear, they are sure to enter. When they visit us, they stand upon no cercmony, but make free with everything that they can come at. Sugar, meat, fruit, wine, are equally to their taste ; and if we attempt to drive them away, and are not very cautious, they will often make us sensible that they are not to be provoked with impunity. Compared with the bees, they may be cousidered as a horde of thieves and brigands; and the latter as peaceful, honest, and industrious subjects, whose persons are attacked and property plundered by them. Yet with all this love of pillage and other bad propensities, they are not altogether disagreeable or unamiable; they are brisk and lively; they do not usually attack umprovoked; and their object in plundering us is not purely selfish, out is principally to provide for the support of the young brood of their colonies.

The societies of wasps, like those of ants and other social Hymenoptera, consist of females, males, and workers. The females may be considered as of two sorts: first, the females by way of eminence, much larger than any other individuals of the community, equalling six of the workers (from which in other respects they do not materially differ) in weight, and laying both male and female eggrs. Then the small females, not bigger than the workers, and laying only male eggs. This last description of females, which are found also both amongst the humble-bees, and live-bees, were first observed amongst the wasps by M. Perrot, a friend of Huber's.' The large females are produced later than the workers, and make their appearance in the following spring; and whoever destroys one of them at that time destroys an entire colony of which she would be the founder. They 
are more worthy of praise than the queen-bee: since upon the latter, from her very first appearance in the perfect state, no labour devolves all her wants being prevented by a host of workers, some of which are constantly attending upon her, feeding her, and permitting her to suffer no fatigue; while others take every step that is necessary for the safety and subsistence of the colony. Not so our female wasp; - she is at first an insulated being that has had the fortune to survive the rigours of winter. When in the spring she lays the foundation of her future empire, she has not a single worker at her disposal; with her own hands and teeth she often hollows out a cave wherein she may lay the first foundations of her paper metropolis; she must herself build the first houses, and produce from her own womb their first inhabitants, which in their infant state she must feed and educate, before they can assist her in the great design. At length she receives the reward of her perseverance and labour; and from being a solitary unconnected individual, in the autumn is enabled to rival the queen of the hive in the number of her children and subjects, and in the edifices which they inhabit - the number of cells in a vespiary sometimes amounting to more than 16,000 , almost all of which contain either an egg, a grub, or a pupa, and each cell serving for three generations in a year; which, after making every allowance for lailures and other casualties, will give a population of at least 30,000 . Even at this time, when she has so numerous an army of coaljutors, the industry of this creature does not cease, but she continues to set an example of diligence to the rest of the community. If by any accilent, before the other females are hatched, the queen-mother perishes, the neuters cease their labours, lose their instincts, and die.

The number of females in a populous vespiary is considerable, amounting to several humdrcd; they emerge from the pupa about the latter end of August, at the sane time with the males, and fly in September and October, when they pair. Of this large number of females, very few survive the winter. Those that are so fortumate remain torpid till the vernal sun recalls them to life and action. They then fly forth, collect provision for their young brood, and are engaged in the other labours necessary for laying the foundation of their empire; but in the summer months they are never seen out of the nest.

The male wasps are much smaller than the female, but they weigh as much as two workers. Their antennæ are longer than those of either, not, like theirs, thicker at the end, but perfectly filiform; and their abdomen is distinguished by an additional segment. Their numbers about equal those of the females, and they are produced at the same time. They are not so wholly given to pleasure and idleness as the drones of the hive. They do not, indeed, assist in building the nest, and in the care of the young brood; but they are the scavengers of the community; for they sweep the passages and streets, and carry off all the filth. They also remove the bodies of the dead, which are sometimes heavy burdens for them; in which case two unite their strength to accomplish the work; or, if a partner be not at land, the wasp thus employed cuts off the head of the defunct, and so effects its purpose. As they make themselves so useful, they are not, like the male bees, devoted by the workers to an universal massacre when the impregnation of the females, the great end of thcir creation, is answered; but they share the general lot of the community, and are suffered to survive till the cold cuts off them and the workers together. 
The workers are the most numerous, and to us the only troublesome part of the community; upon whon devolves the main business of the nest. In the summer and antumnal months, they go forth by myriads into the neighbouring country to collect provisions; and on their return to the common den, after reserving a sufficiency for the nutriment of the young: lrood, they divide the spoil with great impartiality; - part being given to the females, part to the males, and part to those workers that have been engaged in extending and fortifying the vespiary. This division is voluntarily made, without the slightest symptom of compulsion. Several wasps assemble ronnd each of the returning workers, and receive their respective portions. It is curions and interesting to observe their motions upon this occasion. As soon as a waip, that has been filling itself with the juice of fruits, arrives at the nest, it perches upon the top, and, disgorging a drop of its saccharine fluid, is attended sometimes by two at once, who share the treasure : this being thus clistributed, a second and sometimes a third drop is produced, which falls to the lot of others.

Wasps do not in general store up honey, but it is found in the cells of some European species of Polistes, as well as in those of America; and M. A. de St. Hilaire was nearly poisoned by eating that collected by $P$. lecheguana, which inhabits Paragnay and Monte Video." Another wasp before. referred to under "Habitations of Inseets," as forming a nest somewhat similar to that of Chatergns nidulans, also stores up honey, as we learn from the intcresting paper of Mr. Adam White, who has named it Myrapctra scutellaris. ${ }^{2}$

Another principal employment of the workers is the enlarging and repairing of the nest. It is extremely amusing to see them engaged upon this foliaceous covering. They work with great celerity ; and though a large number are occupied at the sime time, there is not the least confusion. Each individual has its portion of work assigned to it, extending from an inch to an inch and a half, and is furnished with a ball of ligneous fibre, scraped or rather plucked by its powerful jaws fromposts, rails, and the iike. This is carried in its mouth, and is thus ready for immediate use:but upon this subject I have enlirged in a former letter. The workers also clean the cells and prepare them to receive another egg, after the inago is disclosed and has left it.

There is good reason for thinking, and the opinion has the sanction of Sir Joseph Banks, that wasps have sentinels plitced at the entrances of their nests, which if you can once seize and destroy, the remainder will not attack you. This is confi:med by an observation of Mr. Knight's in the Philosophical Transactions ${ }^{3}$, that if a nest of wasps be approached without alarming the inhabitants, and all communication be suddenly cut off between those out of the nest and those within it, no provocation will induce the former to defend it and themselves. But if one escapes from within, it comes with a very difficrent temper, and appears commissioned to avenge public wrongs, and prepared to sacrifice its life in the execution of its orders. He discovered this when quite a boy.

It sometimes happens that when a large number of female wasps have been observed in the spring, and an abundance of workers has in consequence been expected to make their attack upon us in the sunmer and 
autumn, but few have appeared. Mr. Knight observed this in 1806, and supposes it to be caused by a failure of males. ${ }^{1}$ I have since more than once made the same observation; and Major Moor, as well as myself; noticed it in the year 1815. What took place here in the following year may in some degree account for it. Though the summer had been very wet, and one may almost say winterly, there were in the neighbourhood in which I reside abundance of wasps at the usual time; but except on some few warm days, in which they were very active, benumbed by the cold, they were crawling about on the floors of my house, and seemed unable to fly. In this vicinity numbers make their nests in the banks of the river. In the beginning of the month of October there was a very considerable inundation, aftcr which not a single wasp was to be seen. The continued wet that produces an inundation may also destroy those nests that are out of the reach of the waters; and perhaps this cause may have operated in those years above alluded to ill, which the appearance of the workers in the summer and autumn did not correspond with the large numbers of females observed in the spring.

In ordinary seasons, in the month lately mentioned, October, wasps seem to became less savage and sanguinary ; for even flies, of which earlier in the summer they are the pitiless destroyers, may be seen to enter their nests with impunity. It is then, probably, that they begin to be first affected by the approach of the cold season, when nature teaches them it is useless longer to attend to their young. They themselves all perish, except a few of the fenales, upon the first attack of fiost.

Reaumur, from whom (see the sixth Memoir of his last volume) most of these observations are taken, put the nests of wasps under gliss.hives, and succeeded so effectually in reconciling these little restless creatures to them that they carried on their various works under his eyc; and if you leel disposed to follow his example, I have no doubt you will throw light upon many parts of their history, concerning which we are now in darkness.

Having given you some idea, imperfect indeed from the want of materials, of the societies of wasps, I must next draw up for you the best account I can of those of the humble.becs. ${ }^{2}$ These form a kind of intermediate link between the wasps and the live-bees, collecting honcy indecd and making wax, but constructing their combs and cells without the greometric precision of the latter, and of a more rude and rustic kind of architecture; and distinguished from both, though they approach nearer to the bees, by the extreme hairiness of thejr bodies.

The population of a humble-bees' ncst may be divided into four orders of individuals : the large females; the small females; the males; and the workers.

The large females, like the female wasps, are the original founders of their republics. They are often so large, that by the side of the small ones or the worker's, which in every other respect they exactly resemble, they look like giants opposed to pigmies. They are excluded from the pupa in the antumn; and pair in that season, with males produced from the eggs of the small fernales. They pass the winter underground, and, as appears from an observation of M. P. Huber, in a particular apartment,

1 Plit. Trans for $180 \pi, 243$.

2 Dombus $A$ pis **. e. 2. K. 
separate from the nest, and rendered warm by a carpeting of moss and grass, hut without any supply of food. Early in the spring (for they make their first appearance as soon as the catkins of the sallows and villows are in flower), like the female wasps, they lay the foundations of a new colony without the assistance of any neuters, which all perish before the winter. In some instances, however, if a conjecture of $\mathbf{M}$. de la Billardière be correct, these creatures have an assistant assigned to them. He says, at this season (the approach of winter) be found in the nest of Bombus Sylvarum some old feniales and workers, whose wings were fastened together to retain them in the nest by bindering them from flying; these wings in each individual were fastened together at the extremity, by means of some very brown wax applied above and below. ${ }^{1}$ This he conceives to be a precaution taken by the other bees to oblige these individuals to remain in the nest, and take care of the brood that was next year to renew the population of the colony. I feel, however, great hesitation in admitting this conjecture, founded upon an insulated and perhaps an accidental fact. For, in the first place, the young females that come forth in the autumn, and not the old ones, are the founders of new colonies, and their instinct directs them to fulfil the great laws of their nature without such compulsion ; and in the next, the workers are never known to survive the cold of winter.

The employment of a large female, besides the care of the young brood before described, and the collecting of honey and pollen, is principally the constructing of the cells in which her eggs are to be laid; which M. P. Huber seems to think, though they often assist in it, the workers are not able to complete by themselves. So rapid is the feniale in this work, that to make a cell, fill it with pollen, commit one or two eggs to it, and cover them in, requires only the short space of half an hour. Her family at first consists only of workers, which are necessary to assist her in her labours; these appear in May and June; but the males and fentales are later, and sometimes are not produced before Angust and September. ${ }^{2}$ As in the case of the live-bee, the food of these several individuals differs; for the grubs that will turn to workers are fed with honey and pollen mixed, while those that are destined to be males and females are supplied with pure honey.

The instinct of these larger females does not develop itself all at once : for it is a remarkable fact, that when they are first hatched in the autumn, not being in a condition to become mothers, they are no object of jealousy to the small queens (as we shall soon see shey are when engaged in oviposition), and are employed in the ordinary labours of the parent nest - that is, they collect honey and pollen, and make wax; but they do not construct cells. The building instinct seems as it were in suspense, and does not manifest itself till the spring; when the maternal sentiment impels them at the same time to lay eggs, and to construct the cells in which they are to be deposited.

I have told you above, that anongst the wasps a small kind of female has been discovered: this is the case also amongst the humble-bees, in whose societies they are more readily detected; not, indeed, by any observable

I Mémoires du Muséum, S.c. i. 55.

2 P. Huber, in Linn. Trans. vi. 264. - This author says, however, in another place (ibid. 285.), that the male eggs are laid in the spring, at the same time with those that are to produce worker's. Perhaps by the former he means the male offspring of the small females, and by the latter those of the large? 
difference between them and the workers, but chiefly by the diversity of their instincts :- from the other females they are distinguished solely by their diminutive size. Like those of the wasps and hive-bees, these minor queens produce only male eggs, which come out in time to fertilise the young females that found the vernal colonies. M. P. Huber suspects that, as in the case of the female bee, it is a different kind of food that develops their ovaries, and so distinguishes them from the workers. They are generally attended by a small number of males, who form their court.

M. Huber, watching at midnight the proceedings of a nest which he kept under a glass, observed the inhabitants to be in a state of great agitation ; many of these bees were engaged in making a cell; the queen-mother of the colony, as she may be called, who is always extremely jealous of her pigmy rivals, came and drove them away from the cell; - she in her turn was driven away by the others, which pursued her, beating their wings with the utmost fury, to the bottom of the nest. The cell was then constructed, and two of them at the same time oviposited in it. The queen returned to the charge, exhibiting similar signs of anger ; and, chasing them away again, put her head into the cell, when, seizing the eggs that had been laid, she was observed to devour them with great avidity. The same scene was again renewed, with the same issue. After this, one of the small females returned, and covered the empty cells with wax. When the mother-queen was removed, several of the small females contended for the cell with indescribable rage, all endeavouring to lay their eggs in it at the same time. These small females perish in the autumn.

The males are usually smaller than the large females, and larger than the small ones and workers. They may be known by their longer, more filiform, and slenderer antennæ; by the clifferent shape and by the beard of their mandibles. Their posterior tibiæ also want the corbicula and pecten that distinguish the individuals of the other sex, and their posterior plantie have no auricle. We learn from Reaumur that the nale humble-bees are not an idle race, but work in concert with the rest to repair any damage or derangement that may befal the common habitation. ${ }^{1}$

The workers, which are the first-fruits of the queen-mother's vernal parturition, assist her, as soon as they are excluded from the pupa, in her various labours. To them also is committed the construction of the waxen vault that covers and defends the nest. When any individual larva has spun its cocoon and assumed the pupa, the workers remove all the wax from it; and as soon as it has attained to its perfect state, which takes place in about five days, the cocoons are used to hold honey or pollen. When the bees discharge the honey into them upon their return from their excursions, they open their mouths and contract their bodies, which occasions the honey to fall into the reservoir. Sixty of these honey-pots are occasionally found in a single nest, and more than forty are sometimes filled

1 It should be here observed that, besides the proper occupants of some liumblebees' nests, there are oecasionally met with in them individuals of another genus of the same tamily, so closely resembling them as to be often confounded with them, which, being unprovided with the usual polliniferons organs, are supposed to be, in their larva state, parasitic inhabitants of the nest. 'This genus, which inclules $A$ pis rupestris F. \&e., has been named Apathus by Mr. Newman, Psithyrus by M. de St. Fargeau, and Pseudo-Bombus by Mr. Stepheus. In like manner, the exotic grenus Chrysantheda is supposed to be parasitie on the metallic Euglossce (Hist. of Ins. by Swainson and Shuckard, 169. Westwood's Mod. Class, of Ins. ii. 281.).

A A 
in a day. In collecting honey, humble-bees, if they cannot get at that contained in any flower by its natural opening, will often make an aperture at the base of the corolla, or cven in the calyx, that they may insert their proboscis in the very place where nature has stored up her nectar. ${ }^{1}$ M.

1 Hub. Nouv. Olsserv. ii. 375. Of the especial love of humble-bees for the nectar of the Passion-flower (Passiflora camleu), and the effect which it has on them, the following paragraph gives a graphic description.

"We reuret extremely to announce that some honest humble-bees of our acquaintance have taken to drinking, and to such excess that they are daily found reeling and tumbling about the door of their houses of call - the blossoms of the Passion-flower, which flow over with intoxicating beverage; and there, not content with drinking like decent bees, they plunge their great hairy heads into the beantiful goblet that nature has formed in such plants, thrusting each other aside, or climbing over each other's shoulders, till the flowers bend beneath their weight. After a time they become so stupid that it is in vain to pull them by the skirts, and advise them to go lome, instead of wasting their time in tippling : they are how ever, gool-natured in their cups, and show no resentment at being disturbed ; on the contrary, they cling to their wine goblet. and crawl back to it as fast as they are pulled away, unless, indeet, they fairly lose their legs and tumble down, in which case they lie sprawling on the ground, quite unable to get up again." (Gardener's Chronicle, 1841, p. 519.) If this account be not overcoloured. these jovial, reckless proceedings of humble-bees are in strong contrast with the temperate habits of hive-bees, which, to judge from the interesting account MIr. WVailes has given us of their visits to his l'assion-flowers (Ent. Mag. i. 525.), hurried back to the hive as soon as they had imbibed their supply of nectar; and certainly the aneclote given below, from Huber, of the way in which humble-bees suffered themselves to be cajoled out of their honey by hive-bees indicates such a good-natured weakness of disposition as may easily be supposed to be combined with a propensity to carousing when the opportunity presents itself. To speak seriously, however, it would be well worth ascertaining, by exact observations, whether as great a contrast between the temperance of humble-bees and hive-bees in feeling really exists, as between their easiness of temper. There can be no doubt that some races of insects vary as much in this last respect as some races of $m e n$. The difference as to irritability between the temper of wasps and that of bees is known to every one, but has never been so happily hit off as by Christopher North, whose universal genius adorns every subject, in the description of it which he has put into the montl of the "Sliepheril," in one of the Noctes, and which well deserves transeription liere from the pages of the volmminous periodical in which it has lain entombed these sixteen years.

"Shepherd. - O' a' God's creturs the wasp is the only ane that's eternally out o" temper. 'There's nae sic thing as pleasin' him. In the gracious sunshine, .... when the bees are at work murmurin' in their gauzy flight, although no gauze indeed be comparable to the filaments o' their woven wings, or, clinging silently to the flowers, sook, sookin' out the hiney-dew, till their verra doups dirl wi' delight, - when a' the flees that are ephemeral, and weel contented wi' the licht and the heat $0^{\prime}$ ae single sun, keep dancin' in their burnished beauty, up and down, to and fro, and backwards and forwards, and sideways, in millions upon millions, and yet are never joistling anither, but a' harmoniously blended together in amity, like imagination's thochts, - why, amid this 'general dance of minstrelsy, in comes a shower $o^{\prime}$ infuriated wasps, red het, as if let out $o^{\prime}$ a fiery furnace, pickin' quarrels wi' their ain shadows - then rom' and roun' the hair o' your head, bizzin' against the drum o' your ear till you think they are in at the ae hole and out at the itherback again after makin' a circuit, as if they had repentit o' lettin' you be unharmed, dashin' against the face o' you who are wishin' ill to nae liviu' thing, and although you are engaged out to dinner, stickin' a lang poishoned stang in just below your ee, that afore you can rin lame frae the garden swells up to a tearsome hicht, makin' you on that side look like a blackamoor, and on the opposite white as death, sae intolerable is the agony frae the tail o' the yellow imp that, according to his bulk, is stronger fat than the dragon o' the desert." (Blackwood's Edinburgh. Mug. Oct. 1826.) 
Huber relates a singular anecdote of some hive-bees paying a visit to a nest of humble-bees placed under a box not far from their hive, in order to steal or beg their honey, which places in a strong light the good temper of the latter. This happened in a time of scarcity. The hive-bees, after pillaging, had taken almost entire possession of the nest. Some humble-bees, which renained in spite of this disaster, went out to collect provisions; and bringing home the surplus after they had supplied their own immediate wants, the hive-bees followed them, and did not quit them until they had obtained the fruit of their labours. They licked them, presented to them their proboseis, surrounded them, and thus at last persuaded them to part with the contents of their honey-bags. The humble-bees after this flew away to collect a fresh supply. The hive-hees did them no harm, and never once showed their stings; - so that it seems to have been persulasion rather than force that produced this singular instance of self-denial. This remarkable manœurre was praetised for more than three weeks; when the wasps heing attracted by the same cause, the humble bees entirely forsook the nest. ${ }^{1}$

The workers are the most numerous part of the community, but are nothing when compared with the numbers to be found in a vespiary or a bee-hive : two or three hundred is a large population for a humble-bees' nest, in some species it not being more than fifty or sixty. They may more easily be studied than either wasps or hive-bees, as they seem not to be disturbed or interrupted in their works by the eye of an observer. ${ }^{2}$

$$
\text { I am, \&c. }
$$

1 Iub. Nouv. Observ. ii. 373.

2 This account of the proceedings of humble-bees is chiefly taken from Reaumur, vi. Mém. 1.; and M. P. Huber in Linn. Trans. vi 214. 


\section{LETTER XIX.}

\section{SOCIETIES OF INSECTS.}

\section{PERFECT SOCIETIES - continued. (THE HIVE-BEE.)}

lne glory of an all-wise and omnipotent Creator, you will acknowledge, is wonderfully manifested by the varied proceedings of those social tribes of which I have lately treated; but it slines forth with a brightness still more intense in the instincts that actuate the common live-bee (Apis mellifica ${ }^{1}$ ), and which I am next to lay before you. Of all the insect associations, there are none that have more excited the attention and admiration of mankind in every age, or been more universally interesting, than the colonies of these little useful creatures. Both Greek and Roman writers are loud in their praise ; nay, some philosophers were so enamoured of them, that, as I observed before, they devoted a large portion of their time to the study of their history. Whether the knowledge they acquired was at all equivalent to the years that were spent in the attainment of it, may be doubted; for, were it so, it is probable that Aristotle and Pliny would have given a clearer and more consistent account of the inhabitants of the hive than they have done. Indeed, had their discoveries borue any proportion to the long tract of time asserted to have been employed by some in the study of these insects, they ought to have rivalled, and even exceeded, those of the Reaumurs and Hubers of our own age.

Numerous, and wonderful for their absurdity, were the errors and fables which many of the ancients adopted and circulated with respect to the generation and propagation of these busy insects. For instance, that they were sometimes produced from the putrid bodies of oxen and lions; the kings and leaders from the brain, and the vulgar herd from the flesh; - a fable, derived probably from swarms of bees having been observed, as in the case of Samson ${ }^{2}$, to take possession of the dried carcasses of these animals, or, perhaps, from the myriads of flies (for the vulgar do not readily distinguish flies from bees) often generated in their putrescent flesh. They adopted another notion equally absurd, - that these insects collect their young progeny from the blossoms and foliage of certain plants. Amongst others, the Cerintlus, the reed, and the olivetree had this virtue of generating infant bees attributed to them. 3 These specimens of ancient credulity will suffice.

But do not think that all the ancients imbibed such monstrous opinions. Aristotle's seatiments seem to have been much more correct, and not rery wide of what some of our best modern apiarists have advanced. Ac-

I Apis. * . I. K.

2 Judges, xiv. 8, 9.

5 See Aristot. Hist. Animal. 1. r. c. 22. ; Tirgil, Georgic. 1. iv.; and Moufiet, 12. 
cording to him, the kings (so he denominates the queen-bee) gencrate both kings and workers; and the latter the drones. This he seems to have learned from keepers of bees. The kings, says he, in another place, are the parents of the bees, and the drones their children. It is right, he observes again, that the kings (which by some were called mothers) should remain within the hive unfettered by any employment, because they are made for the multiplication of the species. ${ }^{1}$ To the same purpose Riem of Lauten of the Palatinate Apiarian Soeiety, and Wilhelmi of the Lusatian, affirm that the queen lays the eggs which produce the queens and workers; and the workers those that produce the drones or males. ${ }^{2}$ Aristotle also tells us that some in his time affirmed that the bees (the workers) were the females, and the drones the males: an opinion which he combats - from an analogy, pushed rather too far, that nature would never give offensive armour to females. ${ }^{3}$ In another place he appears to think that the workers are hermaphrodites:- his words are remarkable, and seem to indicate that he was aware of the sexes of plants; "having in themselves," says he, "like plants, the male and the fcmale." 4

Fables and absurdities, however, are not confined to the ancients, nor even to those moderns who lived before Swammerdam, Maraldi, Reaumur, Bonnet, Schirach, John Hunter, Huber, and their followers, by their observations and discoveries, had thrown so much light upon this interesting subject. Even in our own times, a Neapolitan professor, Monticelli, asserts, on the anthority of a certain father 'Tanoya, that in every hive there are three sorts of bees independent of each other ; viz., male and female drones - male and female, I must not say queens - call them what you will - and male and female workers ; and that each construct their own cells!!! Enough, however, upon this subject. I shall now endeavour to lay before you the best authenticated facts in the history of these animals; but you inust not expect an account of them complete in all its parts ; for, much as we know, Bonnet's observation will still hold good: "The more I am engaged in making fresh observations upon bees, the more steadfast is my conviction that the time is not yet arrived in which we can draw satisfactory conclusions with respect to their policy. It is only by varying and combining experiments in a thousand ways, and by placing these industrious thes in circumstances more or less removed from their ordinary state, that we can hope to ascertain the right direction of their instinct, and the true principles of their government." 5

What $I$ have further to say concerning these admirable creatures will be principally taken from the two authors who have given the clearest and most satisfactory account of them, Reaumur and the elder Huber ; though I shall add from other sources such additional observations as may serve better to elucidate their history.

The society of a hive of bees, besides the young brood, consists of one female or queen; several bundreds of males or drones; and many thousand workers.

The female, or queen, first demands our attention. Two sorts of females have been observed amongst the bees, a large one and a small. Mre.

I Aristot. ubi supr. c. 21. De Generat. Animal. 1. iii. c. 10., where there is some curious reasoning upon this subject.

2 Bonnet, x. 199. 236.

4 De Generat. Animal. 1. iii. c. 10.

3 Fist. Animal. 1.v. c. 22.

5 (Fuvr. x. 194. 
Needlam was the first that observed the latter ; and their existence, $\mathbf{M}$. P. Huber tells us, has been confirmed by several observations of his father. They are bred in cells as large as those of the common queens, from which they differ only in size. Though they have ovaries, they have never been observel to lay eggs. ${ }^{1}$ Having never seen one of these, for they are of very lare occurrence, my description must be confined to the common female, the genuine monarch of the hive. ${ }^{2}$

1 Bonnet, x. P. IIuber in Linn. Trans. vi. 283. Reaumur (v. 373.) observes that some queens are much larger than others; but he attributes this difference of their size to the state of the eggs in their body.

2 As every reader is not aware of the differences of form, \&c., that distinguish the females, males, and workers from each other (I have seen the male mistaken for a distinct species, and placed in a cabiuet as Apis lagopoda L.), I shall here subjoin a description of each.

i. The body of the Female bee is considerably longer than that of either the drone or the worker. The prevailing colour in all three is the same, black or black-brown; but with respect to the female this does not appear to be invariably the case: for - not to insist upon Virgil's royal bees glittering with ruddy or goldeu spots and scales, where allowance must be nade for poetic lieence-Reaumur aflirms, after describing some differences of colour in different inclividuals of this sex, that a queen may always be distinguislied, both from the workers and males, by the colour of her body.* "If this observation be restricted to the colour of some parts of her body, it is correct; but it will not apply to all generally (unless, as I suspect may be the case, by the term body he means the abdomen), for, in all that I have had an opportunity of examining, the prevailing colour, as I have stated it, is the same.

The head is not larger than that of the workers; but the tongue is shorter and more slender, with straighter maxilla. The mandibles are forficate, and do not jut out like theirs into a prominent angle; they are of the colour of pitch with a red tinge, and terminate in two teeth, the exterior being acute, and the interior blunt or truncated. The labrum or upper lip is fulvous; and the antenna are piceous.

In the trunk, the trgula or scales that defend the base of the wings are rufo-piceous. The uings reach only to the tip of the third abdominal segment. 'The tarsi and the apex of the tibia are rufo-fulvous. The posterior tibia are plane above, and covered with short adpressed hairs, having neither the corbicula (or marginal fringe of hairs for carrying the masses of pollen) nor the pecten; and the posterior plante have neither the brush formed of hairs set in strie, nor the auricle at the base.

The abdomen is considerably longer than the head and trunk taken together, receding from the trunk, elongato-conical, and rather sharp at the anus. The dersal segments are fulvous at the tip: covered with very short, pallid, and, in certain lights, shining adpressed hairs; the first segment being very sliort, and covered with longer hairs. The ventral segments, except the anul, which is black, are fulvescent or rufo-fulvous, and covered with soft longer hairs. The vagina of the spicula (commonly called the sting) is curved.

ii. The Male bee, or drone, is quite the reverse of his royal paramour; his body being thick, short, and elumsy, and very obtuse at each extremity. $\dagger$ It is eovered also, as to the head and trunk, with dense hairs.

The head is depressed and crbicular. The tongre is shorter and more slender than that of the female; and the mandibles, though nearly of the same shape, are smaller. The eyes are very large, meeting at the back part of head. In the space between them are placed the antenna and stemmata. 'The former consist of

* Reaumur, v. 375.

$\dagger$ Virgil seems to have regarded the drone as one of the sorts of kings or leaders of the bees, when he says, speaking of the latter,

$$
\text { "....... Ille horridus alter }
$$

Desidiâ, latamque trahens inglorius alvun."

Georgic. iv. 1. 93. 
There are two descriptions of males - one not bigger than the workers, supposed to be produced from a male egg laid in a worker's cell. The common males are much larger, and will counterpoise two workers.

I have before observed to you that there are two sorts of workers, the wax-makers and nurses. ${ }^{1}$ They may also be further divided into fertile and sterile ${ }^{2}$ : for some of them, which in their infancy are supposed to have partaken of some portion of the royal jelly, lay male eggs. There is found in some hives, according to Hnber, a kind of bees, which, from having less down upon the head and thorax, appear blacker than the others, by whom they are always expelled from the hive, and often killed. Perfect ovaries, upon dissection, were discovered in these bees, though not furnished with eggs. This discovery induced Mlle. Jurine, the lady who dissected them, to examine the common workers in the same way ; and she found in all that she examined, what had escaped Swamnerdam, perfect though sterile ovaries. ${ }^{3}$ It is worth inquiry, though M. Huber gives no hint of this kind, whether these were not in fact superannuated bees, that could no longer take part in the labours of the hive. Thorley remarks, which confirms this idea, that if you closely observe a hive of bees in July, you may perceive many amongst them of a clark colour, with

fourteen joints, including the radicle, the fourth and fifth being very short, and not easily distinguished.

The trunk is large. The wings are longer than the body. The legs are slort and slender. The posterior titia are long, club-shaped, and covered with iveonspieuous hairs. The posterior planta are furnished underneath with thick-set scopula, which they use te biush their bodies.

The claw joints are fulvescent.

'I'he abdomen is cordate, very short, being scarcely so long as the head and trunk together, consisting of seven segments, which are fulvous at their apex. The first segment is longer than any of the succeeding ones, and covered above with rather long hairs. The second and third dorsal segments are apparently naked; but, under a triple lens, in a certain light, some alpressed hairs may be perceived ; - the remaining ones are hairy, the three last being inflexed. The ventral segments are very narrow, hairy, and fulvous.

iii. 'The body of the Workers is oblong.

The head triangular. The mandibles are prominent, so as to terminate the head in an angle, toothless, and foreipate. The tongue and maxille are long and ineurved; the labrum and antenna black.

In the trunk the tegule are black. The wings extend only to the apex of the fourth segment of the abiomen. The logs are all black, with the digits only rather piceous. The posterior tihic are naked above, exteriorly longitudinally coneave, ant interiorly longitudinally convex; furnished with lateral and reeumbent hairs to form the corticula, and armed at the ent with the pccten. 'I'be upper surface of the posterior planta resembles that of the titia ; underneath they are furnished with a scopula or brush of stiff hairs set in rows: at the base they are armed with stiff bristles, and exteriorly with an acute appendage or auricle.

The abdomen is a little longer than the liead aul trunk together; olulong, and rather heart-shaped: a transverse section of it is triangular. It is covered with longish, flavo-pallid hairs: the first segment is short with longer hairs; the bise of the three intermediate serments is covered, and as it were banded, with pale hairs. 'The apex of the three intermediate ventral segments is rather fulvescent, and their base is distinguished on each sile by a trapeziform wax pocket covered by a thin membrane. The sting or rather vagina of the spicula, is straiglit.

1 See p. 275.

2 In hives where a queen laying male eggs has been killed, the workers continue to make only male cells, though supplied with a fertile queen, and tho fertile workers lay eggs in them. Schirach, 258.

3 Huber, ii. $4: 250$ 
wings rent and tor' ; but that in September not one of them is to be seen. ${ }^{1}$ Huber does not say whether the wings of the bees in question were lacerated; but in superannuated insects the hair is often rubbed off the body, which gives then a darker hue than that of more recent individuals of the same species. Should this conjecture turn ont true, their banishment and destruction of the seniors of the hive would certainly not show our little crcatures in a very amiable point of view. Yet it seems the law of their nature to rid their community of all supernumerary and useless members, as is evident from their destruction of the drones after their work is done.

It is not often that insects have been weighed; but Reaumur's curiosity was excited to know the weight of bees; and he found that 336 weigheil an ounce, and 5376 a pound. According to John Hunter, an ale-house pint contains 2160 workers.

I have described to you the persons of the different individuals that compose the society of the bee-hive more in detail than I should otherwise have done, in order that you may be the better able to form a judgment upon a most extraordinary circumstance in their history, which is supprriced by evidence that seens almost incontrovertible. The fact to which $i$ allude is this - that if the bees are deprived of their queen, and are supplied with comb containing young worker brood only, they will select one or more to be educated as queens; which, by having a royal ccll erected for their habitation, and being fed with royal jelly for not more than two days, when they emerge from the pupa state (though, if they had remained in the cells which they originally inhabited, they would have turned out workers) will come forth complete queens, with their form, instincts, and powers of generation entirely different. In order to produce this effect, the grub must not be more than three days old; and this is the age at which, according to Schirach (the first apiarist who called the public attention to this miracle of nature), the bees usually elect the larvæ to be royally educated ; though it appears from Huber's observations, that a larra two dars or even twenty-four hours old will do. ${ }^{2}$ Having chosen a grub, they remove the inhabitants and their food from two of the cells which join that in which it resides; they next take down the partitions which separate these three cells; and, leaving the bottoms untouched, raise round the selected worm a cylindrical tube, which follows the horizontal direction of the other cells : but since at the close of the third day of its life its habitation must assume a different form and direction, they gnaw away the cells below it, and sacrifice without pity the grubs they contain, using the wax of which they were formed to construct it new pyramidal tube, which they join at right angles to the horizontal one, the diameter of the former diminishing insensibly from its base to its mouth. During the two days which the grub inhabits this cell, like the common royal cells now become vertical ${ }^{3}$, a bee may always be obsersed with its head plunged into it ; and when one quits it another takes its place. These bees keep lengthening the cell as the worm grows older, and duly supply it with food, which they place before its mouth, and

1 Thorley On Bees, 179.

2 Ifuber, i. 137.

3 Reaumur, who was, however, unacquainted with this extraordinary fact, has figured one of these cells. v. $t .32 . f .3 . h$. 
round its body. The animal, which can only move in a spiral direction, keeps incessantly turning to take the jelly deposited before it ; and thus slowly working downwards, arrives insensibly near the orifice of the cell, just at the time that it is ready to assume the pupa ; when, as before described, the workers shut up its cradle with an appropriate covering.

When you have read this account, I fear, with the celebrated John Hunter, you will not be very ready to believe it; at least you will call upon me to bring forth my "strong reasons" in support of" it. What ! you will exclaim - can a larger and warmer house (for the royal cells are affirmed to enjoy a higher temperature than those of the other bees ${ }^{2}$ ), a different and more pungent kind of food, and a vertical instead of a horizontal posture, in the first place, give a bee a differently shaped tongue and mandibles; render the surfice of its posterior tibiæ flat instead of concave; deprive them of the fringe of hairs that forms the basket for carrying the masses of pollen; of the auricle and pecten which enable the workers to use these tibia as pincers ${ }^{3}$; of the brush that lines the inside of their plantæ? Can they lengthen its abdomen; alter its colour and clothing; give a curve to its sting; deprive it of its wax-pockets, and of the vessels for secreting that sulstance; and render its ovaries more conspicuous, and capable of yielding female as well as male eggs? Can, in the next place, the seemingly trivial circumstances just enumerated altogether alter the instinct of these creatures? Can they give to one description of animals address and industry ; and to the other astonishing fecundity? Can we conceive them to change the very passions, tempers, and manners? That the very same foetus, if fed with nore pungent food, in a higher temperature and in a vertical position, shall become a female, destined to enjoy love, to burn with jealousy and anger, to be incited to vengeance, and to pass her time withont labour - that this very same fcetus, if fed with more simple food, in a lower temperature, in a more confined and horizontal habitation, shall come forth a worker zealous for' the good of the community, a defender of the public rights, enjoying an immunity from the stimulus of sexual appetite and the pains of parturition - laborious, industrious, patient, ingenious, skilful - incessantly engaged in the nurture of the young; in collecting honey and pollen; in elaborating wax ; in constructing cells, and the like! - paying the most respectful and assiduous attention to objects which, had its ovaries been developed, it would have hated, and pursued with the most vindictire fury till it had destroyed them! Further, that these factitious queens (I mean those that the bees elect from amongst worker brood, and educate to supply the place of a lost one in the manner just described) shall differ remarkably from the natural queens (or those that have been wholly educated in a royal cell), in being altogether mute. ${ }^{4}$ All this, you will think at first sight so improbable, and next to impossible, that you will require the strongest and most irrefragable evidence hefore you will believe it.

In spite of all these powerful probabilities to the contrary, this astonishing and seemingly incredible fact rests upon strong foundations, and is estallished by experiments made at different times, by different persons of the highest credit, in different parts of Europe. The first who brought it before the public (as I lately observed) was MI. Schirach, secretary

1 Compare Bonnet, x. 156. with Huber, i. 131.

s IIuber, t. 4. f; 4-6.

2 Schirach, 69.

4 Huber, i. 292. 
of an Apiarian Society established at Little Battzen in Upper Lusatia. He observed that bees, when shut up with a portion of comb containing only worker brood, would soon erect royal cells, and thus obtain queens: - the experiment was frequentiy repeated, and the result was almost uniformly the same. In one instance he tried it with a single cell, and it succeeded. ${ }^{3}$ This curious fact was communicated to the celebrated Bonnet, who, though he hesitated long before he admitted it, was at length fully convinced. M. Wilhelmi (Schirach's brother-in-law), though at first he accounted for the fact upon other principles, and objected strongly to the doctrine in question, induced by the powerful evidence in favour of it, at last gave up his former opinion, and embraced it. And, to mention no more, the great Aristonachus of modern times, M. Huber, by experiments repeated for ten years, was fully convinced of the truth of Schirach's position. $^{2}$

The fact in question, though the public attention was first called to it by the lattcr gentleman, had indeed been mractically known long before he wrote. M. Vogel, in a letter to Wilhelmi, asserts that numerous experiments confirming this extraordinary fact had been made by more than a hundred different persons, in the course of more than a hindred years; and that he himself had known old cultivators of bees who had unanimously declared to him, that, when proper precautions were taken, in a practice of more than fifty years, the experiment had never failed. ${ }^{3}$ Signor Monticelli, the Neapolitan professor before mentioned, informs us that the Greeks and Turks of the Jonian Islands know how to make artificial swarms; and that the art of producing queens at will has been practised by the inhabitants of a little Sicilim island called Favignana, from very remote antiquity; and he even brings arguments to prove that it was no secret to the Greeks and Romans ${ }^{4}$, though, had the practice been common, it would surely have been neticed by Aristotle and Pliny.

Bonner, a British apiarist, asserts that he has had successful reconrse to the Lusatian experiment ${ }^{5}$; and Mr. Payne of Shipdam in Norfolk (who for many years has been engaged in the culture of bees, and has paid particular attention to their proceedings) relates that he well remembers that the bees of one of his hives, which he discovered had lost their queen, were engaged in erecting some royal cells upon the ruins of some of the common ones. He also informs we that he has found Huber's statements, as far as he has had an opportunity of verifying them, perfectly accurate. ${ }^{6}$

As I think you will allow that the evidence just detailed to you is

I Bonnet, $\mathbf{x}$.

2 Hiuber, i. 132.

4 Huber, ii. 453.

3 Schirach, 121.

5 Bonner On Bees, 56.

6 The same gentleman subsequently sent me the following memoranda:-

July 10.1820. A late seconil swarm was hived into a box constructed so that each comb could be taken out and examined separately. On the Tth of August the queen was remored, and each comb taken out and closely examined; there was not the least appearance of any royal cells, but much brood and eggs in the common ones. On the $14 \mathrm{th}$, three royal cells were observed nearly finished, with a large grub each. On the 16 th, the three cells were sealed. On the 18 th and 21 st, they remained in the same state. On the $22 \mathrm{~d}$, two queens were found hatched; one was removed, and the other left with the stock, the remaining roval cell being still closed. On the morning of the $23 \mathrm{~d}$, a dead queen was thrown out of the hive; upon which examination being made, the royal cell left closel on the $22 \mathrm{~d}$ was found open, and a living queen in the stock, which was allowed to remain. 
abundantly sufficient to establish the fact in question, we will now sce whether any satisfactory account can be given for such changes being produced by such causes. "It does not appear to me improbable," says Bonnet, "that a certain kind of nutriment, and in more than usual abundance, may cause a development in the grubs of bees of organs which would never be developed without it. I can readily conceive, also, that a habitation considerably more spacious, and differently placed, is absolutely necessary to the complete development of organs which the new nutriment may cause to grow in all directions." I And again, with respect to the wings of the queen-bee, which lo not exceed those of the workers in length, he thinks that this may arise from their being of a substance too stiff to admit of their extension. Those parts and points that were in a state to yield most easily to the action which this hind of nutriment produced would be most prominent ; and the vertical position of the grub and pupa, since nature does nothing in vain, may probably assist this action, and render the parts of the animal more capable of such extension than if it continued in a horizontal position.

We know, with respect to the human species and the larger animais, that numerous differences, both as to the form and relative proportion of parts, occur continually. The cause of these differences we cannot always ascertain; yet in many instances they may either be derived from the nutriment which the embryo receives in the womb, or from the greater or less dimensions or ligher or lower temperature of that organ - a case that analogically would not be very wide of that of the grub or embryo of a bee enclosed in a cell. Some of the differences in man I now allude to may often be caused by a particular diet in childhood ; a warmer or a colder, a looser or a tighter dress, or the like. Thus, for instance, the Egyptians, who went bare headed, had their skulls remarkably thick; while the Persians, who covered the head with a turban or mitre, were distinguished by the tenuity of theirs. Again the inhabitants of certain districts are often remarkable for peculiarities of form, which atre evidently produced by local circumstances.

The following reasoning may not be inapplicable to the development or non-development, according to their food and habitation, of the ovaries of these insects. An infant tightly swathed, as was formerly the custom, in swaddling bands, without being allowed the free play of its little limbs, fed with unwholesome food, or uncherished by genial warmth, may from these circumstances have so jmperfect a development of its organs as to be in consequence devoted to sterility. When a cow brings forth two calves, and one of them is a female, it is always barren, and partakes in part of the characters of the other sex. ${ }^{2}$ In this instance, the space and food that in ordinary cases are appropriated to one, are divided between two ; so that a more contracted dwelling and a smaller share of nutriment seem to prevent the development of the ovaries.

The following observations, mostly taken from an essay of the celebrated anatomist John Hunter, in the Philosophical Transactions, since they are intimately connected with the subject that we are now considering, will not be licre misplaced. In animals just born or very young, there are no peculiarities of shape, exclusive of the primary distinctions, by

1 Huber, ii. 445.

3 See J. Hunter's Treatise on certain Parts of the Animal QEconomy. 
which onc sex may be known fiom the other. Thus secondary distinctive characters, such as the beard in men, and the breasts in women, are produced at a certain period of life ; and these secondary characters, in some instances, are changed for those of the other sex; which does not arise from any action at the first formation, but takes place when the great command, "increase and multiply," ceases to operate. Thus women in advanced life are sometimes distinguished by beards; and, after they have done laying, hen-birds occasionally assume the plumage of the cock : this has been observed more than once by ornithologists, more particularly with respect to the pheasant and the pea-hen. ${ }^{1}$ For females to assume the secondary characters of males, seems certainly a more violent change, than for a worker bee, which may be regarded as a sterile female, in consequence of a certain process, to assume the secondary characters of a fertile female.

With respect to the variations of instinct and character which result from the different modes of training the young bees that we are now considering, it would not, I think, be difficult to prove that causes at first sight equally inadequate have produced effects fully as important on the habits, tempers, and characters of men and other animals; but as these will readily occur to you, I shall not now enlarge upon them.

Did we know the causes of the various deviations, as to form and the like, observable in the three kingdoms of nature, and could apply them, we should be able to produce these deviations at our pleasure. This is exactly what the bees do. Their instinct teaches them that a certain kind of food, supplied to a grub inhabiting a certain dwelling, in a certain position, will produce certain effects upon it, rendering it different from what it would have been under ordinary circumstances, and fitted to answer their peculiar wants.

I trust that these arguments and probabilities will in some degree reconcile you to what at first sight seems so extraordinary and extravagant a doctrine. If not yet fully satisfied, I can only recommend your having recourse to experiments yourself. Leaving you, therefore, to this best mode of proof, I shall proceed to another part of my history : - but first I must mention an experiment of Reaumur's, which seems to come well in here. To ascertain whether the expectation of a queen was sufficient to keep alive the instinct and industry of the worker bees, he placed in a glazed hive some royal cells containing both grubs and pupe, and then introduced about 1000 or 1500 workers and some drones. These workers, which had been deprived of their queen, at first destroyed some of the grubs in these cells; but they clinstered around two that were covered in, as if to impart warmth to the pupre they contained; and on the following day they began to work upon the portions of comb with which he had supplied them, in order to fix and lengthen them. For two or three days the work went on very leisurely, but afterwards their labours assumed their usual character of indefatigable industry. ${ }^{2}$ There is no difficulty, therefore, when a hive loses its sovereign, to supply the bees with an object that will interest them, and keep their works in progress.

There are a few other facts with respect to the larvæ and pupæ of the

1 Philos. Trans, 1792, viii. 167. Iunter On certain Parts of the Animal OEconomy, p. 65. Latham, Synops, ii. 672. t. 60.

2 lieaun. v. 271. 
bees, which, before I enter upon the history of then in their perfect form, I shall now detail to you. Sixteen days is the time assigned to a queen for her existence in her preparatory states, before slie is ready to enierge from her cell. Three she remaius in the egg ; when hatched she continues feeding five more; when covered in slye begins to spin her cocoon, which occupies another day ; as if exhausted by this labour, she now remains perfectly still for two days and sixteen hours; and then assumes the pupa, in which state she remains exactly four days and eight hours - making in all the period I have just named. A longer time, by four days, is required to bring the workers to perfection; their preparatory states oceupying twenty days, and those of the male even twenty-four. The former consumes half a day more than the queen in spinning its coconn, - a circumstance most probably occasioned by a singular difference in the structure and dimensions of this envelop, which I shall explain to you presently. Thus you see that the peculiar circumstances which change the form and funetions of a bee aceelerate its appearance as a perfect insect ; and that by choosing a grub three days old, when the bees want a queen, they actually gain six days ; for in this case she is ready to eone forth in ten days, instead of sixteen, which would be required was a recently laid egg fixed upon. ${ }^{1}$

The larvæ of bees, though without feet, are not altogether without motion. They advance from their first station at the bottom of the cell, as I before hinted, in a spiral direction. This movement, for the first three dars, is so slow as to be scarcely perceptible; but after this it is more easily discerned. The animal now makes two entire revolutions in about an hour and three quarters; and when the period of its metamorphosis arrives, it is scarcely more than $t$ wo lines from the mouth of the cell. It attitude, which is always the same, is a strong curve. ${ }^{2}$ This occasions the inlabitants of a horizontal cell to be always perpendicular to the horizon, and that of a vertical one to be parallel with it.

A most renarkable difference, as I lately observed, takes place in spinning their cocoons, - the grubs of workers and drones spinning complete cocoons, while those that are spun by the females are incomplete, or open at the lower end, and covering only the head and trunk and the first serment of the abdomen. This variation is probably occasioned by the different forms of the cells : for if a female larva be placed in a worker's celi, it will spin a complete cocoon; and, vice versâ, if a worker larva be placed in a royal cell, its cocoon will be incomplete. ${ }^{3}$ No provision of the Great Author of nature is in vain. In the present instance, the faet which we are considering is of great importanee to the bees; for, were the females wholly covered by the thick texture of a cocoon, their destruction by their rival competitors for the throne could not so readily be accomplished; they either would not be able to reach them with their stings, or the stings might be detained by their barbs in the meshes of the cocoon, so that they would not be able to disengage them. On the use of this instinctive and murderous hatred of their rivals I shall soon enlarge.

1 Huber, i. 215. Schirach asserts, that in cold weather the disclosure of the jmago takes place two days later than in warm; and liem, that in a bad season: the eggs will remain in the cells many months without hatching. (Schirach, 79. 241.)

3 Schirach, t. 3. f. 10.

3 Iíuber, i. 224. 
When our young prisoners are ready to emerge, they do not, like the ants, require the assistance of the workers, but themselves eat through the cocoon and the cell that incloses it. By a wise provision, which prevents the injury or destruction of a cell, they generally make their way through the cover or lid with which the workers had shut it up; though sometimes, but not often, a female will break through the side of her prison.

Having thus shown you our little chemists in their preparatory states, and carried you from the egy to the cocoon, both of which may be deemed a kind of cralle, in which they are nursed to fit them for two rery different conditions of existence, I must now introduce you to a scene more interesting and diversified, in which all their wonderful instincts are displayed in full action, and we see them exceed some of the most vaunted products of human wisdom, art, and skill.

The queen-mother here demands our first attention, as the personage upon whom, when established in her regal dignity, the welfare and happiness of the apiarian community altogether depend. I shall begin my history with the events that befall her on her quitting the royal cradle, and appearing in the perfect state. And here you will find that the first moments of her life, prior to her election to lead a swarm or fill a vacant throne, are moments of the greatest uneasiness and vexation, if not of extreme peril and vindictive and mortal warfare. The Homeric maxim, that " the government of many is not good ${ }^{1}$," is fully adopted and rigorously adhered to in these societies. The jealous Semiramis of the hive will bear no rival near her throne. There are usually not less than sixteen, and sometimes not less than twenty, royal cells in the same nest; you may therefore conceive what a sacrifice is made when one only is suffered to live and to reign. But here a distinction obtains which should not be overlooked: in some instances a single queen only is wanted to govern her native hive ; in others several are necessary to lead the swarms. In the first case, inevitable death is the lot of all but one ; in the other, as many as are wanted are preserved from destruction by the precautions taken on that occasion, under the direction of an all-wise Providence, by the workers. I shall eularge a little on each of these cases. In the formicary, as we have seen, rival queens live together very harmoniously without molesting each other; but there is that instinctive jealousy in a queen-bee, that no sooner does she discover the existence of another in the hive than she is put into a state of the most extreme agitation, and is not easy until she has attacked and destroyed her.

Naturalists had observed that when there were two queens in the same hive, one of them soon perished; but some supposed (this was the opinion of Schirach and Riem) that the workers destroyed the supernumeraries. Reaumur, however, conjectured that these queens attacked each other; and his conjecture has been since confirmed by the actual observation of other naturalists. Blassiere, the translator of Schirach, tells us, as what he had himself witnessed, that the strongest queen kills her rival with hei sting; and the same is asserted by Huber, whose opportunities of observation were greater than those of any of his precursors. ${ }^{2}$

The queen that is first liberated from her confinement, and has assumed

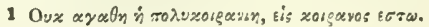

2 Schirach, 209. note *. Huber, i. 17\%. 
the perfect or imago state (it is to be supposed that the author is here speaking of a hive which has lost the old queen), soon after this event goes to visit the royal cells that are still inhabited. She darts with fury upon the first with which she meets; by means of her jaws she gnaws a hole large enough to introduce the end of her abdomen, and with her sting, before the included female is in a condition to defend herself or resist her attack, she gives her a mortal wound. The workers, who remain passive spectators of this assassination, after she quits the victim of her jealousy, enlarge the breach that she has made, and drag forth the carcass of a queen just emerged from the thin membrane that envelops the pupa. If the object of her attack be still in the pupa state, she is stimulated by a less violent degree of rage, and contents herself with making a breach in the cell : when this bappens, the death of the inclosed insect is equally certain, for the workers enlarge the breach, pull it out, and it perisbes. ${ }^{1}$ If it happens, as it sometimes does, that two queens are disclosed at the same time, the care of Providence to prevent the bive from being wholly despoiled of a governor is singularly manifested by a remarkable trait in their instinct, which, when mutual destruction seems inevitable, makes them separate from each other as if panic-struck. "Two young queens," says M. Huber, "left their cells one day, almost at the same moment; as soon as they came within sight, they darted upon each other, as if inflamed by the most ungovernable anger, and placed themselves in such an attitude that the antennæ of each were held by the jaws of its antagonist; hearl was opposed to head, trunk to trunk, abdomen to abdomen; and they had only to bend the extremity of the latter, and they would have fallen reciprocal victims to each other's sting." But nature having decreed that these duels should not be fatal to both combatants, as soon as they were thus circumstanced a panic fear seemed to strike them, and they disengaged themselves, and each fled away. After a few minutes were expired, the attack was renewed in a similar manner with the same issue; till at last one suddenly seizing the other by her wing, mounted upon her and inflicted a mortal wound. ${ }^{2}$

The combats I have here described to you took place between virgin queens; but M. Huber found that those which had been impregnated were actuated by the same animosity, and attacked royal cells with a fury equally destructive. When another fertile queen had been introduced into this hive, a singular scene ensued, which proves how well aware the workers are that they cannot prosper with two sovereigns. Soon after she was introduced, a circle of bees was formed round the stranger, - not to compliment her on her arrival, or pay her the usual homage, but to confine her, and prevent her escape; for they insensibly agglomerated themselves in such numbers round her, and hemmed her in so closely, that in about a minute she was completely a prisoner. While this was transacting, what was equally remarkable, other workers assembled in clusters round the legitimate queen, and impeded all her motions; so that soon she was not more at liberty than the intruder. It scemed as if the bees foresaw the combat that was to ensue between the two rivals, and were impatient for the event; for they ouly confined them when they appeared to avoid each other. To witness the homage, respect, and love that they usually manifest to their lawful ruler, the anxiety concerning her 
which they often exhibit, and the distrust which for a time (as we shall see hereafter) they usually show towards strange ones even when deprived of their own, one would expect that, rather than permit such a perilous combat, they would unite in the defence of their sovereign, and cause the interloper to perish under the stroke of their fatal stings. But no; the contest for empire must be between the rival candidates; no worker must interfere in any other way than that which I have described; no contending armies must fight the battles of their sovereigns, for the law of succession seems to be "detur fortiori." But to return to my narrative. The legitimate queen appearing inclined to move towards that part of the comb on which her rival was stationed, the bees immediately began to retire from the space that intervened between them, so that there was soon a clear arena for the combat. When they could discern each other, the rightful queen, rushing furiousiy upon the pretender, seized her with her jaw's near the root of the wings, and, after fixing her without power of motion against the comb, with one stroke of her sting despatched her, If ever so many queens are introduced into a live, all but one will perish, and that one will have won the throne by her own unassisted valour ard strength. Sometimes a strange queen attempts of herself to enter a hive: in this case the workers, who are upon the watch, and who examine every thing that presents itself, immediately seize ber with their jaws by thic legs or wings, and hem her in so straitly with a clustered circle of gurirds, turning their heads on all sides towards her, that it is impossible for her to penetrate within. If they retain her prisoner too long, she dies either from the want of food or air, but never from their stings. ${ }^{1}$

Here you may perhaps feel curious to know, supposing the reigning queen to die or be killed, and the bees to have discovered their loss, whether they would then receive a foreigner that offers herself to them or is introduced amongst them. Reaumur says they would do this immediately ${ }^{2}$; but Huber, who had better means of observing them, and studied them with more undivided attention, affirms that this will not be the case, unless twenty-four hours have elapsed since the death of the old queen. Previonsly to this period, as if they wcre absorbed by grief at their calanity, or indulged a fond hope of her revival, an intruder would be treated exactly as I have describerl. But when the period just mentioned is past, they will receive any queen that is presented to them with the customary homage, and she may occupy the vacunt throne. ${ }^{3}$

I must now beg you to attend to what takes place in the second case that I mentioned, where queens are wanted to lead forth swarms. Here you will, with reason, suppose that nature has instilled some instinct into the bees, by which these necessary individuals are rescued from the fury of the reigning sovereign.

Did the old queen of the hive remain in it till the young ones were ready to come forth, her instinctive jealousy would lead her to attack them all as successively produced; and being so much older and stronger, the probability is that she would destroy them, in which case there could be no swarms, and the race wonld perish. But this is wisely prevented by a circunstance which invariably takes place - that the first swarm is conducted by this queen, and not by a newly disclosed one, as Reaumur and others have supposed. Previously to her departure, after her great laying

1 Huber, j. 86.

2 Reaum. r. 268.

S Huber, i. 190. 
of male eggrs in the month of May, she oviposits in the royal cells when about three or four lines in length, which the workers have in the meantime constructed. These, however, are not all furnished in one day, - a most essential provision, in consequence of which the queens come forth successively, in order to lead successive swarms. There is something singular in the manner in which the workers treat the young queens that are to lead the swarms. After the cells are covered in, one of their first employments is to remove here and there a portion of the wax from their surface, so as to render it unequal ; and immediately before the last metamorphosis takes place, the walls are so thin that all the motions of the inclosed pupa are perceptible through them. On the seventh day the part covering the head and trunk of the young female, if I may so speak, is almost entirely unwaxed. This operation of the bees facilitates her exit, and probably renders the evaporation of the superabundant fluids of the body of the pupa more easy.

You will conclude, perhaps, when all things are thus prepared for the coming forth of the inclosed female, that she will quit her cell at the regular period, which is seven days :- but you would be mistaken. Were she indeed permitted to pursue her own inclinations, this would be the case : but here the bees show how much they are guided in their instinct by circumstances and the wants of their society ; for did the new queen leave her cell, she would inmediately attack and destroy those in the other cells; a proceeding which they permit, as I have before stated, when they only want a successor to a defunct or a lost sovereign. As soon, therefore, as the workers perceive - which the transparency of the cell permits them to do - that the young queen has cit circularly through her cocoon, they immediately solder the cleft up with some particles of wax, and so keep her a prisoner against her will. Upon this, as if to complain of such treatment, she emits a distinct sound, which excites no pity in the breasts of her subjects, who detain her a prisoner two days longer than nature has assigned for her confinement. In the interim, she sometimes thrusts her tongue through the cleft she has made, drawing it in and out till she is noticed by the workers, to make them understand that she is in want of food. Upon perceiving this they give her honey, till her hunger being satisfied she draws her tongue back - upon which they stop the orifice with wax. ${ }^{1}$

You may think it perhaps extraordinary that the workers should thus endeavour to retard the appearince of their young females beyond its natural limit; but when I explain to you the reason for this seeming incongruity of instinct, you will adore the wisdom that implanted it. Were a queen permitted to leave her cell as soon as the natural term for it arrived, it would require some time to fit her for flight, and to lead forth a swarm; during which interval a troublesone task would be imposed upon the workers, who must constantly detain her a prisoner to prevent her from destroying her rivals, which would require the labours and attention of a much larger number than are necessary to keep her confined to her cell. $9 \mathrm{n}$ this account they never suffer her to come forth till she is perfectly fit to take her flight. When at length she is permitted to do this, if she approaches the other royal cells the workers on guard seem greatly irritated against her, and pull and bite and chase her away; and she enjoys tran-

1 Huber, i. 256. 
quillity only while she keeps at a distance from them. As her instinct is constantly urging her to attack them, this procceding is frequently repeated. Sometimes, standing in a particular and commanding attitude, she utters that authoritative sound which so much affects the bees; they then all hang down their heads and remain motionless; but as soon as it ceases, they resume their opposition. At last she becomes violently agitated, and conmunicating her agitation to others, the confusion more and more increases, till a swarm leaves the hive, which she either precedes or follows. In the same manner the other young queens are treated while there are swarms to go forth; but when the hive is sufficiently thinned, and it hecomes troublesome to guard them in the manner here described, they come forth unnoticed, and fight unimpeded till one alone remains to fill the deserted throne of the parent hive. You see here the reason why the eggs that produce these queens are not laid at the same time, but after some interval, that they may come forth successively. For did they all make their appearance together, it would be a much more laborious and difficult task to keep them from destroying each other.

When the bees thus delay the entrance of the young queens into their world, they invariably let out the oldest first; and they probably know their progress to maturity by the emission of the sound lately mentioned. The accurate Huber took the trouble to mark all the royal cells in a bive as soon as the workers had covered them in, and he found that they were all liberated according to seniority. Those first covered first emit the sound, and so on successively; whence he conjectures that this is the sign by which the workers discover their age. As their captivity, however, is sometimes prolonged to eight or ten days, this circumstance in that time may be forgotten. In this case he supposes that their tones grow stronger as they grow older, by which the workers may be enabled to distinguish them. It is remarkable that no guard is placed round the mute queens bred accorling to the Lusatian method, which, when the time for their appearance is come, are not detained in captivity a single moment; but, as you have heard, are left to fight, conquer, or die. ${ }^{1}$

You must not think, however, from what I have been saying, that the old queen never destroys the young ones previonsly to her leading forth the earliest swarm. She is allowed the most uncontrolled liberty of action ; and if she chooses to approach and destroy the royal cells, her subjects do not oppose her. It sometimes happens, when unfavourable weather retards the first swarm, that all the royal progeny perishes by the sting of their nother, and then no swarm takes place. It is to be observed that she never attacks a royal cell till its inhabitant is ready to assume the pupa; therefore much will depend upon their age. When they arrive at this state, her horror of these cells, and aversion to them, are extreme : she attacks, perhaps, and destroys several; but finding it too laborious, for they are often numerous, to destroy the whole, the same agitation is caused in her as if she were forcibly prevented, and she becomes disposed to depart, rather than remain in the midst of her rivals, though her own offspring.

But though the bees, in one of these cases, appear such unconcerned spectators of the destruction of royal personages, or rather the applanders and inciters of the bloody fact, and in the other show little respect to them, put such a restraint upon their persons, and manifest such disregard to 
their wishes; yet when they are once acknowledged as governors of the hive, and leaders of the colony, their instinct assumes a new and wonderful direction. From this moment they become the "publica cura," the objects of constant and universal attention ; and wherever they go, are greeted by a homage which evinces the entire devotion of their subjects. You seemed anused and interested in no slight degree by what I related in a former letter of the marked respect paid by the ants to their females ${ }^{1}$; but this will bear no comparison with that shown by the inhabitants of the hive to their queen. She appears to be the very soul of all their actions, and the centre of their instincts. When they are deprived of her, or of the means of replacing ber, they lose all their activity, and pursue no longer their daily labours. In vain the flowers tempt them with their nectar and ambrosial dust: they colleet neither; they elahorate no wax, and build no cells; they scarcely seem to exist; and, indeed, wonld soon perish, were not the means of restoring their monarch put within their reach. But, if a small piece of comb, containing the brood-grubs of workers, be given to them, all seem endued with new life: their instincts revive; they immediately set about building royal cells : they feed with their appropriate food the grubs they have selected, and everything proceeds in the usual routine. Virgil has described this attachment of the bees to their sovereign with great truth and spirit in the following lines:-
" Lydian nor Mede so much his king adores,
Nor tliose on Nilus' or Hydaspes' shores:
The slate united stands while he remains;
But should he fall, what dire confusion reigns?
Their waxen combs and honey, late their joy,
With grief and rage distracted, they destroy:
He guards the works, with awe they him surround,
And crowd about him with triumphant sound;
Ihim frequent on their duteous shoulders bear,
Bleed, fall, and die for him in glorious war."

M. Huber thus describes the consequences of the loss of a queen. When the queen is removed from a hive, at first the bees seem not to pereeive it, their order and tranquillity not being disturbed, and their labours proceeding as usual. Alout an hour after her departure, inquietude begins to manifest itself amongst them; the care of the young brood no longer engages their attention, and they run here and there as if in great agitation. This agitation, however, is at first confined to a sinall portion of the community. The bees that are first sensible of their loss meet with others; they mutually cross their antennæ, and strike them lightly. By this action they appear to conmunicate the sad intelligence to those who receive the blow, who in their turn, impart it in the same way to others. Disorder and confusion increase rapidly, till the whole population is in a tumult. Then the workers may be seen running over the combs, and against each other, impetuously rushing to the entrance and quitting the live ; from thence they spread themselves all around ; they re-enter and go out again and again. The hum in the live becomes very loud, and increases the tunult, which lasts two or three hours, rarely four or five: they then return, and resume their wonted care of the young; and if the hive be visited twenty-four hours after the departure of the queen, it will be seen

1 See above, p. 320.

B $\mathrm{B} 2$ 
that they have taken steps to repair their loss by filling some of the cells with a larger quantity of jelly than is the usual portion of common larvæ; which, however, is intended, it seems, not for the food of the inhabitant, but for a cushion to elevate it, since it is found unconsumed in the cell when the grub has descended into the pyramidal habitation afterwards prepared for it.?

If, after being removed, their old queen is restored to the hive, they instantly recognise her, and pay lier the usual attentions; but if a strange one be introduced within the first twelve hours after the old one is lost, she is kept a close prisoner till she perishes: if twenty-four hours, as I have before hinted, have expired since they lost their queen, and you introduce a new one, at the moment you set this stranger upon a conb the workers that are near her first touch her with their antennæ, and then pass their proboscis over all parts of her body; place is next given to others, who salute her in the same manner; all then beat their wings at the same time, and range themselves in a circle round their new sovereign. A kind of agitation is now communicated to the whole surface of the comb, which brings all the bees upon it to see what is going forward. This may be called the first shout of the applauding multitude to welcome the arrival of their new sovereign. The circle of courtiers increases; they vibrate their wings and bodies, but without tumult, as if their sensations were very agreeable. When she begins to move, the circle opens to let her pass, and all follow her steps. She is received with similar demonstrations of loyalty in the other parts of the hive, is soon acknowledged queen by all, and begins to lay eggs. Reaumur put some bees into a hive without their queen, and then introduced to them one that he bad taken when half perished with cold, and kept in a box, in which she had covered herself with porvder. The bees immediately owned her for their queen, employed themselves very anxiously in cleaning her and warming her, sometimes turning her upon her back for this purpose, and then began to construct cells in their new habitation. ${ }^{2}$ Even when the bees have got young brood, have built or are building royal celis, and are engaged in feeding these hopes of their hive, knowing that their great ain is already accomplished, they cease all these employments when this intruder comes amongst them.

With regard to the ordinary attention and homage that they pay to their sovereigns, the bees do more than respect their queen, says Reaunur; they are constantly on the watch to make themselves useful to lier, and to render her every kind office; they are for ever ofiering her honey; they lick her with their proboscis, and wherever she goes she has a court to attend upon her. ${ }^{3}$ It may here be observed, that the stimulant which excites the bees to these acts of homage is the pregnant state of their queen, and her fitness to maintain the population of the hive: all they do being with a view to the public good; for while she remains a virgin she is treated with the utmost indifference, which is exchanged, as soon as impregnation has taken place, for the above marks of attachment. ${ }^{4}$

The instinct of the bees, however, does not always enable them to distinguish a partially fertile queen from one that is universally so. What I mean is this; a queen, whose impregnation is retarded beyond the twenty-

1 Huber, ii. 396.

$s$ Ibid. v. Pref. $x v$.
2 Reaum. v. 262.

4 Huber, i. 269. 
eighth day of he: whole existence, lays only male eggs, which are of no use whatever to the community, unless they are at the same time provided with a sufficient supply of workers. Yet even a queen of this description, and sometimes one that is entirely sterile, is treated by them with the same respect and homage as a fertile one. This seems to evince an amiable feeling in these creatures, attachment to the person as well as to the functions of the sovereign; which is further manifested by their unwillingness at first to receive a new sovereign upor the loss or dcath of their old one. Nay, this respect is sometimes shown to the carcass of a defunct queen, which Huber assures us he has scen bees treat with the same attention that they had shown her when alive, for a long time preferring her inanimate corpse to the fertile queens that he offered to them. ${ }^{1}$ He attributes this to some agreeable sensation which they experience from their queens, independent of their fecundity. But since virgin queens, as we have seen, do not excite it, more probably it is a remnant of their former attachment, first excited by her fecundity, and aftcrwards strengthened and continued by habit.

I may here introduce an interesting anecdote related by Reaumur, which strongly marks the attachment of bees to their queen when apparently lifeless. He took one out of the water quite motionless, and seemingly dead, which had lost part of one of its legs. Bringing it lome, he placed it amongst some workers, that he had found in the same situation, most of which he had revived by means of warmth ; some, however, still being in as bad a state as the poor queen. No sooner did these revived workers perceive the latter in this wretclied condition, than they appeared to compassionate her case, and did not cease to lick her with their tongues till she showed signs of returning animation: which the bees no sooner perceived, than they set up a general hum, as if for joy at the happy event. All this time they paid no attention to the workers, who were in the same miserable state. ${ }^{2}$

On a former occasion I have mentioned the laying of the eggs by the queen; but as I did not then at all enlarge upon it, I shall now explain the process more in detail. In a subsequent letter I shall notice what has puzzled learned apiarists - her fecundation; which is now ascertained beyond contradiction, from the observations of M. Huber, to take place in the open air, and to be followed by the death of the unfortunate malc. ${ }^{3}$ It is to be recollected that, from September to April, generally speaking, there are no males in the hives; yet during this period the queen often oviposits : a former fecundation, therefore, must fertilise all the eggs laid in this interval. The impregnation, in order to cnsure complete fertility, must not be too long retarded: for, as I before observed, if this be delayed beyond the twenty-cighth day of her existence, her ovaries become so vitiated that she can no longer lay eggs that will produce workers, but can only furnish the hive with a male population; which, however high a privilege it may be accounted amongst men, is the reverse of it amongst the bces. When this is the case, the abdomen of the queen becomes so clnlarged that she is no longer able to $\mathrm{fly}^{4}$; and what is remarkable, she loses that instinctive animosity which stimulates the fertile ones to attack their rivals. ${ }^{5}$ Thus she seens to own that she is not equal to the duties of her

1 Huber, i. 322.

4 Schirach, $25 \%$.
2 Reaum. v. 265.

B B 3
3 Huber, i. 63-.

5 Huber, i. 310-. 
station, and can tolerate another to discharge them in her room. When we consicier how much virgin queens are slighted by their subjects, we may suppose that nature urges them to take the opportunity of the first warm day, when the males fly forth, to pair with one of them.

When fecundation has not been retarded, forty-six hours after it has taken place the queen hegins to lay eggs that will produce workers, and continues for the subsequent eleven months, more or less, to lay them solely; and it is only after this peiod that an uninterrupted laying of male eggs commences. But when it has been retarded, after the same number of hours she begins laying male eggs, and continues to produce these alone during her whole life. From hence it should seen to follow that the former kind of cags are first in the oviducts, and if impregnation be not effected within a given time, that all the worker embryos perish. Yet how this can take place with respect to those that in a fertile queen should succeed the laying of male eggs, or be produced in the second year of her life, seems difficult to conceive; - or how the male embryos escape this fate, which destroys all the female, both those that are to precede them and those that are to follow them. Is it impossible that the sex of the embryo may be determined by the period at which the aura seminalis vivifies it, and by the state of the ovary at that time? In one state of the ovary this principle nay cause the embryos to become workers, in another males. And something of this kind perhaps may be the cause of hermaphrodites in other animals. But this I give nerely as conjecture ${ }^{1}$ : the truth seems enveloped in mystery that we cannot yet penetrate. Huber is of opinion that a single impregnation fertilises all the eggs that a queen will produce during her whole life, which is sometimes more than two years. $^{2}$ But of this enough.

I said that forty-six hours after impregnation the queen hegins laying worker eggs; - this is not, however, invariable. When her impregnation takes place late in the year, she does not begin laying till the following spring. Schirach asserts, that in one season a single female will lay from 70,000 to 100,000 eggs. ${ }^{3}$ Reaumur says, that upon an average she lays about two hundred in a day, a moderate swarm consisting of 12,000 , which are laid in two months; and Huber, that she lays above a hundred. All these statements, the ohservations being made in different clinates, ancl perhaps under different circumstances, may be true. The laying of worker eggs begins in February, sometimes so early as January. ${ }^{4}$ After this, in the spring, the great laying of male eggs commences, lasting thirty days; in which time alout 2000 of these eggs are laid. Another laying of them, but less considerable, takes place in autumn. In the season of oviposition, the queen mav be discerned traversing the combs in all directions with a slow step, and seeking for cells proper to receive her eggs. As she watks she keeps her head inclined, and seems to examine, one by one, all the cells she meets with. When she finds one to her purpose, she imme-

1 This conjecture receives strong confirmation from the following observations of Sir E. Home, which I met with snce it came into my mind. From the nipples present in man, which sometimes even afford milk, and from the general analogy between the male and female organs of generation, he supposes the germ is originally fitted to become either sex; and that which it shall be is determined at the time of impregnation by some unknown causc.-Philos. Trans., 1799, 157.

2 i. 106 -

4 Schirach, 13. Thorley, 105. 
diately gives to her abdomen the curve necessary to enable it to reach the orifice of the cell, and to introduce it within it. The eggs are set in the angle of the pyramidal bottom of the cell, or in one of the hollows formed by the conflux of the sides of the rhombs, and being besmeared with it kind of gluten, stand upright. If, however, it be a female that lays only male eggs, they are deposited upon the lowest of the sides of the cell, as she is unable to reach the bottom. ${ }^{1}$

While our prolific lady is engaged in this employment, her court consists of from four to twelve attendants, which are clisposed nearly in a circle, with their heads turned towards her. After laying from two to six eggs, she remains still, leposing for eight or nine minutes. During this interval the bees in her train redouble their attentions, licking her fondly with their tongues. Generally speaking, she lays only one egg in a cell ; but when she is pressed, and there are not cells enough, from two to four have been found in one. In this case, as if they wcre aware of the consequences, the provident workers remove all but one. From an experiment of Huber's, it appears that the instinct of the queen invariably directs her to deposit worlser eggs in worker cells; for when he confined one, during her course of laying worker eggs, where she could only come at male ceils, she refused to oviposit in them; and trying in vain to make her escape, they at length dropped from her; upon which the workers devoured them. Retarded queens, however, lose this instinct, and often, though they lay only male eggs, oviposit in worker cells, and even in royal ones. In this latter case the workers themselves act as if they suffered in their instinct from the imperfect state of their queen; for they feed these male larvæ with royal jelly, and treat them as they would in real qqueen. Though male eggs deposited in worker cells produce small males, their education in a royal cell with "royal dainties" adds nothing to their ordinary dimensions."

The swarming of bees is a very curious and interesting subject, to which, since a female is the sine quat non on this occusion, I may very pro. perly call your attention here. You will recollect that I said something upon the principle of emigrations, when I was amusing you with the history of ants; but the object with them seems to be merely a change of station for one more convenient or less exposed to injury, and not to diminish a superabumdant population. Whereas in the societies of the hive-bee, the latter is the general cause of emigrations, which invariably take place every year, if their numbers require it; if not, when the male eggs are laid no royal cells are constructed, and no swarm is led forth. What might be the case with ants, were they confined to hives, we cannot say. Formicaries in general are capable of indefinite enlargeinent, therefore want of room cloes not cause emigration; - but bees being confined to a given space, which they possess not the means of enlarging, to avoid the ill effects resulting from being too much crowded, when their population exceeds a certain limit they must necessarily emigrate. Sometimes - for instance, when wasps have got into a hive - the bees will leave it, in order to fly from an inconvenience or enemy which they cannot otherwise avoid ; but it does not very often happen that they wholly desert a hive.

A piarists tell us that, in this country, the best season for swarming is 
fiom the middle of May to tize middle of June; but swarms sometimes occur so early as the beginning of April, and as late as the middle of August. ${ }^{1}$ The first swarm, as I before observed, is led by the reigning queen, and takes place when she is so much reduced in size, in eonsequence of the number of eggs she has laid (for previously to oviposition her gravid body is so heavy that she ean scarcely drag it along), as to enable her to fly with ease. The most indubitable sign that a hive is preparing to swarm, - so says Reaumur, - is when on a sunny morning, the weather being favourable to their labours, few bees go out of a hive, from which on the preeeding day they had issued in great numbers, and little pollen is collected. This circumstance, he observes, must be very embarrassing to one who attempts to explain all their proceedings upon prineiples purely mechanical. Does it not prove, he asks, that all the inhabitants of a hive, or almost all, are aware of a project that will not be put in execution before noon, or some hours later? For why should bees, who worked the day before with so much activity, cease their labours in a habitation which they are to quit at noon, were they not aware that they should soon abandon it ? 2 The appearance of the males, ancl the clustering of the population at the mouth of the hive (though this last is less to be relied upon, being often oecasioned by extreme heat), are also indications of the approach of this event. A good deal depends, however, on the warmth of the atmosphere and the state of the weather either to accelerate or retard it. Another sign is a general hum in the evening, which is continued even cluring the night, - all seems to be in a bustle, the greatest restlessness agitates the bees. Sometimes to hear this hum, the ear must be placed close to the hive, when elear and sharp sounds may be distinguished, which appear to be produced by the vibration of the wings of a single bee. This hum by some has been gravely eonstrued into an harangue of the queen to animate her subjeets to the great undertaking which she now meditates - the founding of a new empire. There sometimes seem to happen suddenly amongst them, says Reaunur, events which put all the bees in motion, for whieh no account can be given. If you observe a hive with attention, you may often remain a long time and hear only a slight murmur ; and then, all in a moment, a sonorous hum will be excited, and the workers, as if seized with a panic terror, may be seen quitting their various labours, and running off in different directions. At these moments if a young queen goes out she will be followed by a numerous troop.

Huber has given a very lively and interesting account of the interior proceedings of the hive on this occasion. 'The queen, as soon as she began to exhibit signs of agitation, no longer laid her eggs as before, but irregularly, as if she did not know what she was about. She ran over the bees in her way; they in their turn struck her with their antennæ, and nounted upon her back; none offered her honey, but she helped herself to it from the eells in her path. The usual homage of a court attending round her was no longer paid. Those, however, that were excited by her motions followed her, rousing such as were still tranquil upon the combs. She soon had traverscd the whole hive, when the agitation becanie general. The worker's, now no longer attentive to the young brood, ran about in all directions; even those that returned from foraging, before the agitation was

1 Keys On Bees, 76.

2 Reaum. เ. 611. 
at its height, no sooner entered the hive than they participated in these tumultuous novements, and, neglecting to free themselves from the masses of pollen on their hind legs, ran wildly about. At length there was a general rush to the outlets of the hive, which the queen aceompanied, and the swarm took place. ${ }^{1}$

It is to be observed that this agitation, exeited by the queen, increases the customary heat of the hive to a very high temperature, which the action of the sun augments till it becomes intolerable, and which often eauses the bees aceumulated near the mouth of the hive to perspire so copiously, that those near the bottom, who support the weight of the rest, appear drenched with the moisture. This intolerable heat determines the most irresolute to leave the hive. Immediately hefore the swarming, a louder hum than usual is heard; many bees take flight; and if the queen be at their head, or soon follows them, in a moment the rest rise in erowds after her into the air, and the element is filled with bees as thick as the falling snow. The queen at first does not alight upon the braneh on which the swarm fixes; but as soon as a group is formed and elustered, she joins it : after this it thickens more and more, all the bces that are in the air hastening to their comnanions and their queen, so as to form a living mass of animals supporting themselves upon each by the claws of their feet. Thus they sometimes are so concatenated, each bee suspending its legs to those of another, as to form living chaplets. ${ }^{2}$ After this they soon become tranquil, and none are seen in the air. Before they are housed they often begin to construet a little eomb on the branch on which they alight. ${ }^{3}$ Sometines it happens that two queens go out with the same swarm ; and the result is, that the swarm at first clivides into two bodies, one under. each leader; but as one of these groups is generally mueh less numerous than the other, the smallest at last joins the largest, accompanied by the queen to whom they had attached themselves; and when they are hived, this unfortunate eandidate for empire falls sooner or later a vietim to the jealousy of her rival. Till this great question is decided, the bees do not settle to their usual labours. If no queen goes ont with a swarm, they return to the hive from whence they came.

As in regular monarehies, so in this of the bees, the first-born is probably the fortunate candidate for the throne. She is usually the most active and vigorous; the most able to take flight; and in the best condition to lay egrs. Though the queen that is victorious, and mounts the throne, is not, as Virgil asserts, resplendent with gold and purple, and her rival hideous, slothful, and unwieldy ${ }^{4}$, yet some differences ale observable; the suecessfiul eandidate is usually redder and larger than the others; these last, upon dissection, appear to have no eggs ready for laying, while the

1 Iluber, i. 251.

2 Some critics have found fault with Mr. Soutley for ascribing in his Curse of Ieliama, to Candeo, the Cupid of Indian mythology, a bow strung with bees. The sclea is not so absurd as they imagine; and the poet doubtless was led to it by his linowledge of the natural history of these animals, and that they form themselves into strings or chaplets.-See Reaum. v. t. xxii. f. 3.

3 lieaumur, $615-644$.

4

"Alter erit maculis auro squalentibus arlens

(Nam duo sunt genera), hic melior, insignis et ore,

Et rutilis clarus squanis : ille horridus alter

Desidiâ, latamque trahens inglorius alvum." 
former, which is a powerful recommendation, is usually full of them. Egrs are commonly found in the cclls twenty-four hours after swarning, or at the latest two or three days.

You may think, perhaps, that the bees which emigrate from the parent hive are the youth of the colony ; but this is not the case, for bees of all ages unite to form the swarms. The numbers of which they consist vary much. Reaumur calls 12,000 a moderate swarm; and he mentions one which amounted to more than three times that number $(40,000)$. A swarm seldom or never takes place except when the sun shines, and the air is calm. Somctimes, when everything seems to prognosticate swarming, a cloud passing over the sun calms the agitation; and afterwards, upon his shining forth again, the tumult is renewed, keeps augmenting, and the swarm departs. ${ }^{1}$ On this account, the confinement of the queens, before related, is observed to be more protracted in bad weather.

The longest interval between the swarms is from seven to nine days, which usually is the space that intervenes between the first and the second. The next flies sooner, and the last sometimes departs the day after that which preceded it. Fifteen or cighteen days, in favourable weather, are usually sufficient for throwing the four swarns. The old queen, when she takes flight with the first swarm, leaves plenty of brood in the cells, which soon renew the population. ${ }^{2}$

It is not without example, though it rarely happens, that a swarm conducted by the old queen increases so much in the space of three weeks as to send forth a new colony. Being already impregnated, she is iu a condition to oviposit as soon as there are cells ready to receive her eggs ; and an all-wise Providence has so ordered it that at this time she lays only such as produce workers. And it is the first employment of her subjects to construct cells for this purpose. ${ }^{3}$ The young queens that conduct the secondary swarms usually pair the day after they are settled in their new abode; when the indifference with which their subjects have hitherto treated them is exchanged for the usual respect and homage.

We may suppose that one motive with the bees for following the old queen is their respect for her; but the reasons that induce them to follow the virgin queens, to whom they noi only appear to manifest no attachment, but rather the reverse, seem less easy to be assigned. Probably the high temperature of the hive during these times of tumultuons agitation may be the principal cause that operates upon them. In a populous hive the thermometer commonly stands between $92^{\circ}$ and $97^{\circ}$; but during the tumult that precedes swirming it rises above $104^{\circ}$, a heat intolerable to these animals. ${ }^{4}$ This is M. Huber's opinion. Yet still, though a high temperature will well account for the departure of the swarm from the hive. with a virgin queen, if there were really no attachment (as he appears to think), is it not extraordinary, that when this cause no longer operates upon them, they should agglomerate about her, as they always do, be unsettled and agitated without her, and quiet when she is with them? Is it not reasonable to suppose that the instinct which teaches them what is necessary for the preservation of their society, - at the

1 Bees are generally thought to foresee the state of the weather: but they are not always right in their prognostics; for lieaumur witnessed a swarm, which atter leaving the hive at half-past one o'clock were overtaken by a very heavy shower at three.

2 Huber, i. 271.

3 Ibid. i. 305.

- 1bill. i. 280. 
same time that it shows them that without a queen that society cannot be preserved; - impels them in every case to the mode of treating her which will most effectually influence her conduct, and give it that direction which is most beneficial to the community?

Yet, with respect to the treatment of queens, instinct does not invariably direct the bees to this end. There are certain exceptions, produced perhaps by artificial or casual occurrenes, in which it seems to deviate, yet, as we should call it, amiably, from the ruie of the public advantage. hetarded queens, which, as I have observed, lay male eggrs only, deposit them in all cells indifferently, even in royal oncs. These last are treated by the workers as if they were actually to become queens. Here their instinct seems defcctive: - jt appears unaccountable that they should know these eggs, as they do when deposited in worker cells, and give them a convex covering when about to assume the pupa; unless, perhaps, the size of the larva directs them in this case.

The amputation of one of the antennæ of a queen-bee appears not to affect her perceptibly; but cutting off both these important organs produces a very striking derangement of all her proceedings. She secmis in a species of delirmm, and deprived of all her instincts; everything is done at random; yet the respect and homage of the workers towards her, though they are received by her with indifference, continue undiminished. If another in the same condition be put in the hive, the becs do not appear to discover the difference, and treat them both alike; but if a perfect one be introduced, even though fertile, they seize her, keep her in confiuement, and treat her very mhandsomely. Une may conjecture from this circumstance that it is by those wonderful organs, the antennx, that the bees know their own queen. If two mutilated queens meet, they show not the slightest symptom of resentment. While one of these continues in the hire, the workers never think of choosing another; but if she leaves it, they do not accompany her, probably because the heat is not increased by her putting them into the preparatory agitation. ${ }^{2}$ 


\title{
LETTER XX.
}

\section{SOCIETIES OF INSECTS.}

\author{
PERFECT SOCIETIES - concluded.
}

Having given you a history sufficiently ample of the queen or female bee, I shall next add some aecount of the drone or male bee; but this will not detain you long, since "to be born and die" is nearly the sum total of their story. Much abuse, from the earliest times, has been lavished upon this deseription of the inhabitants of the hive, and their indolence and gluttony have become proverbial. Indeed, at first sight, it seems extraorclinary that seven or eight hundred individuals should be supported at the nublic expense, and to common appearance do nothing all the while, that may be thought to earn their living. But the more we look into nature, the inore we discover the truth of that common axiom, - that nothing is made in vain. Creative Wisdom cannot be canght at fault. Therefore where we do not at present perceive the reasons of things, instead of cavilling at what we do not understand, we ought to adore in silence, and waic patiently till the veil is removed which, in any particular instance, conceals its final cause from our sight. The mysteries of nature are gradually opened to us, one truth making way for the discovery of another; but still there will always be in nature, as well as in revelation, even in those things that fall under our daily observation, mysteries to exercise our faith and humility ; so that we may always reply to the eaviller,-_"Thine own things and those that are grown up with thee hast thou not known; how then shall thy vessel comprehend the way of the Highest?"

Various have been the conjectures of naturalists, even in very recent times, with respect to the fertilisation of the eggs of the bee. Some have supposed,- and the number of males seemed to countenance the supposition, - that this was effected after they were deposited in the cells. Of this opinion Maraldi seems to have been the author; and it was adopted by Mr. Debraw of Cambridge, who asserts that he has seen the smaller males (those that are oceasionally produced in cells usually appropriated to workers) introduce their abdomen into cells containing egrgs and fertilise them: and that the eggs so treated proved fertile, while others that were not remained sterile. The common or large drones, which form the bulk of the male population of the hive, could not be generally destined to this office, since their abdomen, on account of its size, could only be introduced into male and royal cells. Bonnet, however, saw some motions of one of these drones, which, while it passed by those that were empty, appeared to strike with its abdomen the mouth of the cells containing 
eggs. ${ }^{1}$ Swammerdam thought that the female was impregnated by effuvia which issued from the male. ${ }^{2}$ Reaumur, frum some proceedings that he witnessed, was convinced that impregnation took place according to the usual law of nature, and, as he supposed, within the hive. ${ }^{3}$ The former part of this opinion Huber has confirmed by indubitable proofs; but he further discovered that these animals pair abroal, in the air, during the flight of the queen : a fact which renders a large number of nales necessary, to insure her impregnation in due time to lay eggs that will produce workers. ${ }^{4}$ Huber also observed those appearances which induced Debraw to adopt the opinion I mentioned just now, and was at first disposed to think them real; but afterwards, upon a nearer inspection, he discovereil that it was an illusion caused by the reflection of the rays of light. ${ }^{5}$

In fine weather the drones, during the warmest part of the day, take their flights, and it is then that they pair with the queen in mid air, the result being invariably the death of the drone. No one has yet discovered, unless the proceedings observed by Debraw and Bonnet may be so interpreted, that when in the hive they take any share in the business of it, their great employment within doors being to eat. Their life, however, is of very short duration, the eggs that produce drones being laid in the course of April and May, and their destruction being usually accomplished in the months of July and August. The bees then, as M. Huber observes, chase them about, and pursue them to the bottom of the hives, where they assemble in crowds. At the same time numerous carcasses of drones may be seen on the ground before the hives. Hence he conjectured, though he never could detect them engaged in this work upon the combs, that they were stung to death by the workers. To ascertain how their death was occasioned, he caused a table to be glazed, on which he placed six hives; and under this table he employed the patient and indefatigable Burnens, who was to him instead of eyes, to watch their proceeclings. On the 4 th of July this accurate observer saw the massacre going on in all the hives at the same time, and attended by the same circumstances. The table was crowded with workers, who, apparently in great rage, darted upon the drones as soon as they arrived at the bottom of the hive, seizing them by their antennæ, their legs, and their wings, and killing them by violent strokes of their sting, which they generally inserted betwcen the segments of the abdomen. The moment this fearfil weapon entered their body, the poor helpless creatures expanded their wings and expired. After this, as if fearful that they were not sufficiently despatched, the bees repeated their strokes, so that they often found it difficult to extricate their sting. On the following day they were equally busy in the work of slaughter; but their fury, their own having perished, was chiefly vented upon those drones which, after having escaped from the neighbouring hives, had sought refuge with them. Not content with destroying those that were in the perfect statc, they attacked also such male pupx as were left in their cells; and then dragging them forth, sucked the fluid from their bodies and cast them ont of the live. ${ }^{6}$

But though in hives containing a queen perfectly fertile (that is, which lays both worker and male eggs) this is the unhappy fate of the drones

1 Bonnet, x, 259.

3 Fieaum. v. 503-.

5 Ibid. 37 -
2 Bibl. Nat. i, 221. b. cd. Hill.

4 IIuber, i. 24-

0 Iuid. i. 195. 
yet in those where the queen only lays male eggs they are suffered to remain unmolested; and in hives deprived of their queen, they also find a secure asylum. ${ }^{1}$

What it is that, in the former instance, excites the fury of the bees against the males, is not easy to discover; but some conjecture may perhaps be formed fiom the circumstances last related. When only males are produced by the queen, the bees seem aware that something more is wanted, and retain the males; the same is the case when they have no queen; and when one is procured, they appear to know that she would not profit them without the males. Their fury then is connected with their utility: when the queen is impregnated, which lasts for her whole life, as if they knew that the drones could be of no further use, and wonld only consume their winter stores of provision, they destroy them; which surely is more merciful than expelling them, in which case they must inevitably perish from hunger. But when the queen only produces males, their numbers are not sufficient to cause alarm; and the same reasoning applies to the case when there is no queen.

Having brought the males from their cradle to their untimely grave, and amused you with the little that is known of their umeventfil history, I shall now, at last, call you to attend to the proceedings of the worliers themselves; and bere I am afraid, long as I have detained you, I must still press you to expatiate with me in a more ample field; but the spectacles you will behold during our excursion will repay, I promise you, any delay or trouble it may occasion.

When I consider the proceedings of these little creatures, both in the hive and out of it, they are so numerous and multifarious that I scarcely know where to begin. You have already, however, heard much of their internal labours, in the care and nurture of the young; the construction of their combs; and their proceedings with respect to their queens and their paramours. It will therefore change the scene a little, if we accompany them in their excursions to collect the various substances of which they have need. ${ }^{2}$ On these occasions the principal object of the bees is to

1 Huber, i. 199.

2 The following beautiful lines by Professor Smyth are extremely applicable to this part of a bee's labours:-

"Thon cheerful Bee! come, freely come, And travel round my woodbine bower;

Delight me with thy wondering hum, And rouse me from my musing hour.

Oh! try no more those tedious fielits,

Come taste the sweets my garden yields:

The treasures of each blooming mine,

The bud, the blossom, - all are thine.

"And, careless of this noontide heat, I'll follow as thy ramble gruicles;

To watch thee pause and chafe thy feet, And sweep them o'er thy downy sides:

Then in a flower's bell nestling lie,

And all thy envied ardour ply!

Then o'er the stem, tho' fail it grow,

With touch rejecting, glance, and gro. 
furnish themselves with three different materials : - the nectar of flowers, from which they elaborate honey and wax ; the pollen or fertilising dust of the anthers, of which they make what is called bee-bread, serving as food both to old and young; and the resinous substance called by the ancients Propolis, Pissoceros, \&c., used in varions ways in rendering the hive seeure and giving the finish to the combs. The first of these substances is the pure fluid secreted in the nectaries of flowers, which the length of their tongue enables them to reach in most blossoms. The tongue of a bee, you are to observe, though so long, and sometimes so inflated ${ }^{1}$, is not a tube through which the honey passes, nor a pump acting by suction, but a real tongue, whieh laps or licks the honey, and passes it down on its upper surface, as we do, to the mouth, which is at its base concealed by the mandibles. ${ }^{2}$ It is conveyed by this orifiee through the œsophagus into the first stomach, which we call the honey-bag, and which, from being very small, is swelled when full of it to a considerable size. Honey is never found in the second stomach (which is surrounded with muscular rings, and resembles a cask eovered with hoops from one end to the other), but only in the first : in the latter and the intestines the bee-bread only is discovered. How the wax is seereted, or what vessels are appropriated to that purpose, is not yet ascertained. Huber suspects that a cellular substance, consisting of bexagons, which lines the membrane of the waxpockets, may be concerned in this operation. This substance he also discovered in humble-bees (which, though they nake wax, have no waxpoekets), occupying all the anterior part or base of the segments. ${ }^{3}$ If you wish to see the wax-pockets in the hive-bee, you must press the abdomen so as to cause it to extend itself; you will then find on each of the four intermediate ventral segments, separated by the carina or elevated central part, two trapeziform whitish pockets, of a soft membranaceous texture: on these the laminæ of wax are formed, and they are found upon them in different states, so as to be more or less perceptible. I must here observe that, besides Thorley, who seems to have been the first apiarist that observed these laminæ, Wildman was not ignorant of them, nor of the wax being formed from honey ${ }^{4}$ : we must not, therefore, pernit foreigners to appropriate to themselves the whole credit of discoveries that have bcen made, or at least partially mate, by onr own countrymen.

Long before Linné had discovered the nectary of flowers, our industrious creatures had made themselves intimate with every form and variety of them ; and no botanist, even in this enlightened era of botanical science, can compare with a bee in this respect. The station of these re-

"O Nature kina! O labourer wise!

That roam'st along the summer's ray,

Glean'st every bliss thy life supplies,

And meet'st prepared thy wintry day?

Go, envied go-with crowded gates

The hive thy rich return awaits;

Bear home thy store, in triumph gay,

And shame each idler of the day."

1 Reaum. v. t. xxviii. f. 1, 2.

3 Huber, ii. 5. t. ii. f. 8 .
2 Ibid. f. 7.0.

4 Vildman, 43. 
servoirs, even where the armed sight of science cannot discover it, is in a moment detected by the microscopic eye of this animal.

She has to attend to a clouble task - to collect materials for bee-bread as well as for honey and wax. Observe a bee that has alighted upon an open flower. The hum produced by the motion of her wings ceases, and her employment begins. In an instant she unfolds her tongue, which before was rolled up under her head. With what rapidity does she dart this organ between the petals and the stamina! At one time she extends it to its full length, then she contracts it : she moves it about in all clirections, so that it may be applied both to the concave and convex surface of a petal, and wipe them both; and thus by a virtuous theft robs it of all its nectar. All the while this is going on, she keeps herself in a constant vibratory motion. The object of the industrious animal is not, like the more selfish butterfly, to appropriate this treasure to herself. It goes into the honey-bag as into a laboratory, where it is transformed into pure honey; and when she returns to the hive, she regurgitates it in this form into one of the cells appropriated to that purpose; in order that, after tribute is paid from it to the queen, it may constitute a supply of food for the rest of the community.

In collecting honey, bees do not solely confine themselves to flowers; they will sometimes very greedily absorb the sweet juices of fruits : this I have frequently observed with respect to the raspberries in my garden, and have noticed it, as you may recollect, in a former letter. They will also eat sugar, and produce wax from it ; but, from Huber's observations, it appears not calculated to supply the place of honey in the jelly with which the larvæ are fed. ${ }^{1}$ Though the great mass of the food of bees is collected from flowers, they do not wholly confine themselves to a vegetable diet; for, besides the honeyed secretion of the Aphicies, the possession of which they will sometimes dispute with the ants ${ }^{2}$, upon particular occasions they will eat the eggs of the queen. They are very fond also of the fluid that oozes from the cells of the pupæ, and will suck eagerly all that is fluid in their abdomen after they are lestroyed by their rivals." Several flowers that produce much honey they pass by ; in sonue instances, from inability to get at it. Thus, for this reason probably, they do not attempt those of the rrumpet-honeysuckle (Lonicera sempervirens), which, if separated from the germen after they are open, will yield two or three drops of the purest nectar. So that were this shrub cultivated with that view, much honey in its original state might be obtained from a small number of plants. In other cases, it appears to be the poisonous quality of their honey that induces bees to neglect certain flowers. You have doubtless observed the conspicuous white nectaries of the crown imperial (Fritillaria imperialis), and that they secrete abundance of this fuid. It tempts in vain the passing bee, probably aware of some noxious quality that it possesses. The oleander (Nerium Oleander) yields a honey that proves fatal to thousands of imprudent flies; but our bees, more wise and cantious, avoid it. Occasionally, perhaps, in particular seasons, when flowers are less numerous than common, this instinct of the bees appears to fail them, or to be overpowered by their desire to collect a sufficient store of honey for their pur-

1 Huber, ii. 82.

2 Abbé Boisier, quoted in Mills On Bees, 21.

3 Schirach, 4j. Huber, i. 479. 
poses, and they suffer for their want of self-denial. Sometimes whole swarms have been destrojed by merely alighting upon poisorous trees. This happened to one in the county of West Chester in the province of New York, which settled upon the branches of the poison-ash (Rhus vernix). On the following morning the imprudent animals were all found dead, and swelled to more than double their usual size. ${ }^{1}$ Whether the honey extracted fiom the species of the genus Kalmia, Andromeda, Rhododendron, \&c., be hurtful to the bees themselves, is not ascertained; but, as has been before observed, it is often poisonous to man; and that found at Trebisond on the Euxine coast, as I have formerly noticed, threatened fatal effects to such of the Greek army, in the cclebrated retreat after the death of the younger Cyrus, as partook of it. Pliny, who mentions this honey, calls it Menomenon, and observes that it is said to be collected from a kind of Rhododendron, of which Tournefort noticed two species there. ${ }^{2}$

When the stomach of a bee is filled with nectar, it next, by means of the feathered hairs ${ }^{3}$ with which its body is covered, pilfers from the flowers the fertilising dust of the anthers, the pollen; which is equally necessary to the society with the honey, and may be named the ambrosia of the hive, since from it the bee-bread is made. Sometimes a bee is so discoloured with this powder as to look like a differcut insect, becoming white, yellow, or orange, according to the flowers in which it has been busy. Reaumur was urged to visit the lives of a gentleman who on this aceonnt thought his bees were different from the common kind. ${ }^{4}$ He suspected, and it proved, that the circumstance just mentioned occasioned the nistaken notion. When the body of the bee is covered with farina, with the brushes of its legs, especially of the hind ones, it wipes it off; not as we do with our dusty clothes, to dissipate and disperse it in the air, but to collect every particle of it, and then to knead it and form it into two little masses, which she places, one in each, in the baskets formed by hairs ${ }^{5}$ on her hind legs.

Aristotle says that in each journey from the hive, bees attend only one species of flower ${ }^{6}$; Reaumur, however, seems to think that they fly indiscriminately from one to another: but Mr. Dobls, in the Philosophical Transactions ${ }^{7}$, and Butler before him, asserts that he has frequently followed a bee engaged in collecting pollen, \&c., and invariably observed that it continued collecting from the same kind of flowers with which it first began ; passing over every other species, however numerous, even though the flower it first selected was scarcer than others. His observations, he thinks, arc confirmed, and the idea seems not unreasonable, by the uniform colour of the pellets of pollen, and their different size. Reaumur himseif tells us that the bees enter the hive, some with yellow pellets, other's with red ones, others again with whitish ones, and that sometimes they are even green: upon which he observes, that this arises from their being collected from particular flowers, the pollen of whose anthers is of those colours. ${ }^{8}$ Sprengel, as before intimated, has made an observation similar to that of

1 Nicholson's Journal, xxiii. 287.

2 Xenoph. Anabas. 1. iv. Plin. Hist. Nat. 1. xxi. c. 13.

3 Reaum. v. t. xxvi. f. 1 .

4 Tieaum. 295.

5 Kirby, Monogr. Ap. Angl. i. t. 12. **. e. l. neut. f. 19, a. b.

6 Hist. Anim. I. ix. c. 40.

8 Ui suprì, 301.

7 xlvi. 536. 
Dobbs. It seems not improbable that the reason why the bee visits the same species of plants during one excursion may be this:- her instinct teaches her that the grains of pollen which enter into the same mass shoula be homogeneous, in order perhaps for their more effectual cohesion; and thus Providence also secures two important ends, - the impregnation of those flowers that require such aid, by the bees passing from one to another; and the avoiding the production of hybrid plants, from the application of the pollen of one kind of plant to the stigma of another. When the anthers are not yet burst, the bee opens them with her mandibles; takes a parcel of pollen, which one of the first pairs of legs receives and delivers to the middle pair, from which it passes to one of the hind legs.

If the contents of one of the little pellets be examined under a lens, it will be found that the grains have all retained their original shape. A botanist practised in the figure of the pollen of the different species of common plants might easily ascertain, by such an examination, whether a bee had collected its ambrosia from one or more, and also from what species of flowers.

In the months of April and May, as Reaumur tells us, the bees collect pollen from morning to evening; but in the warmer months the great gathering of it is from the time of their first leaving the hive (which is sometimes so early as four in the morning) to about 10 o'clock A. M. About that hour all that enter the hive may be seen with their pellets in their baskets ; but during the rest of the day the number of those so furnished is small in comparison of those that are not. In a hive, however, in which a swarm is recently established, it is generally brought in at all parts of the day. He supposes, in order for its being formed into pellets, that it requires some moisture, which the heat evaporates after the above hour; but in the case of recently colonised hives, that the bees go a great way to seek it in moist and shady places. ${ }^{1}$

When a bee has completed her lading, she returns to the hive to dispose of it. The honey is disgorged into the honey pots or cells destined to receive it, and is discharged from the honey-hag by its alternate contraction and dilatation. A cell will contain the contents of many honey-bags. When a bee comes to disgorge the honey, with its fore legs it breaks the thick cream that is always on the top, and the honey which it yields passes under it. This cream is honey of a thicker consistence than the rest. which rises to the top in the cells like cream on milk: it is not level, but forms an oblique surface over the honey. The ceils, as you know, are usually horizontal; yet the honey does not run out. The cream, aided probably by the general thickness of the honey, and the attraction of the sides of the cell, prevents this. Bees, when they bring bome the honey, do not always disgorge it; they sometimes give it to such of their companions as have been at work within the hive. ${ }^{2}$ Some of the cells are filled with honey for daily use, and some with what is intended for a reserve, and stored up against bad weather or a bad season: these are covered with a waxen lid. ${ }^{3}$

The pollen is employed as circumstances direct. When the bee laden

1 Reaum. v. 302.-comp. 433. I have seen bees out before it was light.

2 Huber observes that the honey for store is collected by the wax-making bees only (abeilles cirieres), and that the nurses (abeilles nourrices) gather no more than what is wanted for themselves and companions at work in the hive. (ii. 66.)

1 Reaum. v. 448. 
with it arrives at the live, she sometimes stops at the entrance, and very leisurely detaches it by piecemeal, devours one or both the pellets on her legs, chewing them with her jaws, and passing them then down the little orifice before noticed. Sometimes she enters the hive, and walks upon the combs; and whether she walks or stands, still keeps beating her wings. By the noise thus produeed, which seems a call to some of her fellow citizens, three or four go to her, and placing themselves round her, begin to lighten her of her load, each taking and devouring a small portion of her ambrosia; this they repeat if more do not arrive to assist them, three or four times, till the whole is disposed of. Wildman observed them on this oeeasion supporting themselves upon their two fore feet; and naking several motions with their wings and body to the right and left, which produced the sound that summoned their assistants. ${ }^{2}$ This bee-bread, as I said before, is generally found in the second stomach and intestines, but the honey never; which induced Reaumur to think (but he was mistaken) that the bees elaborated wax from it: and he observes that the bees devour this when they are busily engaged in construeting combs. ${ }^{3}$ When more pollen is colleeted than the bees have immediate occasion for, they store it up in some of the empty eells. The laden bee puts her two hind legs into the cell, and with the intermediate pair pushes off the pellets. When this is done, she, or another bee if she is toomuch fatigued with her day's labours, enters the cell with her head first, and remains there some time: she is engaged in diluting the pellets, kneading them, and packing then close; and so they proceed, till the cell is filled. ${ }^{4}$ A large portion of the cells of some combs are filled with this bread, which one while is found in insulated cells, at another in eells amongst those that are filled with honey or brood. Thus it is everywhere at hand for use. ${ }^{5}$

You have seen how the bees eollect and employ two of the materials that I mentioned; I must now advert to the third - the Propolis. Huber was a long time uncertain from whence the bees procured this gummy resin; but it at last occurred to him to plant some cuttings of a species of poplar (before their leaves were developed, when their leaf-buds were swelling and besmeared and filled with a viscid juice) in some pots which lie plaeed in the way of the bees that went from his hives. Alnost imme. diately a bee alighted upon a twig, and soon with its mandibles opened a loud, and drew from it a thread of the viscid matter which it contained; with one of its second pair of legs it took it from the mouth, and placed it in the basket : thus it proceeded till it had given them both their load. ${ }^{6}$ I have myself seen bees very busy collecting it from the Tacamahaca (Populus balsamifera). But this is an old discovery, confirmed by recent observation; for Mouffet tells us, from Cordus, that it is eollected from the gems of the trees, instancing the poplar and the birch. ${ }^{7}$ Riem observes that it is also collected from the pine and fir. The propolis is soft, red, will pull out in a thread, is aromatic, and imparts a gold colour to white polished metals. It is employed in the hive not only in finisinng the combs, as I related in my letter on Habitations; but also in stopping every chink or

I Reaum.v. 418 .

2 Ibid. $\nabla$. p. 38.

3 Uli suprà, 419.

4 Compare Reaum. 420., and Huber, ii. 24., with Wildman, 40.

5 For much valuable information on the economy of bees, the reader will do well to consult Dr. Bevan's very interesting work on the Honey Bee.

6 Huber, ii. 260.

I Insect. Theatr. 36. Schirach, 241. 
orifice by which cold, wet, or any enemy, can enter. They cover likewise with it the sticks which support the combs, and often spread it over a considerable portion of the interior of the hive. Like the pellets of pollen, it is carried on the posterior tibiæ, but the masses are lenticular. ${ }^{1}$

Mr. Knight mentions an instance of Bees using an artificial kind of propolis. He had caused the decorticated part of some tree to be covered with a cement composed of bees' wax and turpentine; finding this to theirpurpose, they attacked it, detaching it from the tree by their mandibles, and then, as usual, passing it from the first leg to the second, and so to the third. When one bee had thus collected its load, another often came behind and despoiled it of all it had collected; a second and third load were frequently lost in the same manner; and yet the patient animal pursued its labours without showing any signs of anger. ${ }^{2}$

Bees in their excursions do not confine themselves to the spot immediately contignous to their dwelling, but, when led by the scent of honey, will go a mile from it. Huber even assigns to them a radius of half a league round their hive for tljeir ordinary excursions; yet from this distance they will discover honey with as much certainty as if it was within their sight. To prove that it is by their scent that bees find it out, he put some behind a window-shutter, in a place where it could not be seen, leaving the shutter just open enough for insects, if they liked, to get at it. In less than a quarter of an hour, four bees, a butterfly, and some house-flies liad discovered it. At another time he put some into boxes, with little apertures in the lid, into which pieces of card were fitted, which he placed about two liundred paces from his hives. In about half an hour the bees discovered them, and traversing them very industriously, soon found the apertures, when, pushing in the pieces of card, they got to the honey. Tluat contained in the blossom of many plants is quite as much concealed ; yet the acuteness of their scent enables them to detect it.

These insects, especially when laden and returning to their nest, fly in a direct line, which saves both time and labour. How they are enabled to do this with such certainty as to make for their own abode without deviation, I must leave to others to explain. Connected with this circumstance, and the acuteness of their smell, is the following curious account, given in the Plilosophical Transactions for 1721, of the method practised in New England for discovcring where the wild hive-bees live in the woods, in order to get their honey. The honey-hunters set a plate containing honey or sugar upon the ground in a clear day. The bees soon discover and attack it : having secured two or three that have filled themselves, the hunter lets one go, which, rising into the air, flies straight to the nest: he then strikes off at right angles with its course a few hundred yards, and letting a second fy, observes its course by his pocket compass; and the point where the two courses intersect is that where the nest is situated. ${ }^{3}$

The natural station of bees is in the cavities of decayed trees; such trees Mr. Knight tells us they will discover in the closest recesses, and at an extraordinary distance from the live; in one instance it was a mile: and at swarming, they sometimes are inclined to scttle in such cavities. After the discovery of one, from twenty to fifty, who are a kind of scouts, may be found exumining and keeping possession of it. They seem to ex-

1 Reaum, ubı suprà, 437.

2 Philos. Trans. 1807, 242.

3 xxxi, 148. 
plore every part of it and of the tree with the greatest attention, even surveying the dead knots and the like. ${ }^{1}$ When a bive stands unemployed, a swarm will also sometimes send scouts to take possession of it.

How long our little active creatures repose before they take a second excursion I cannot precisely say. In a hive the greatest part of the inhabitants generally appear in repose, lying together, says Reaumur, but this probably for a short time. Huber tells us, that bees may always be observed in a hive with the head and thorax inserted into cells that contain egrs, and sometimes into empty ones; and that they remain in this situation fifteen or twenty minutes, so motionless that, did not the dilatation of the segments of the abdomen prove the contrary, they might be mistaken for dead. He supposes their object is to repose from their labours.? The queen, for this purpose, enters the large cells of the males, and continues in them without motion a very long time. Even then the workers form a circle round her, and brush the uncovered part of her abdomen. The drones, while reposing, do not enter the cells, but cluster in the combs, and sometimes remain without stirring a limb for eighteen or twenty hours. ${ }^{3}$

Reaunur observes, that in a hive the population of which amounts to 18,000 , the number that enters the hive in a minute is a hundred; which, allowing fourteen hours in the day for their labour, makes $\$ 4,000$ : thus every individual must make four excursions daily, and some five. In hives where the population was smaller, the numbers that entered were comparatively greater, so as to give six excursions or more to each bee. ${ }^{4}$ But in this calculation Reaumnr does not seem to take into the account those that are employed within the hive in building or feeding the young brood, which must render the excursions of each bee still more numcrous. He proceeds further to ground upon this statement a calculation of the quantity of beebread that may be collected in one day by such a hive; and he found, supposing only half the number to collect $j$, that it would amount to more than a pound; so that in one season one sucl a hive might collect a hundred pounds. ${ }^{5}$ What a wonderlul idea does this give of the industry and activity of these little useful creatures! And what a lesson do they read to the members of societies that have both reason and religion to guide their exertions for the common good! Adorable is that Great Being who has gifted them with instincts which render them as instructive to us, if we will condescend to listen to them, as they are profitable.

While I am upon this part of the story of bees, I camnot pass over the

1 Knight in Philos. Trans. for 1807, 237. Marshall, Agricult. of Norfolk.

2 It has been supposed, and the supposition was alopted originally in this work (Vol. I. 1st ecl. p. 37 1.), that the object in this case is brooding the eggs; but upon further consideration we incline to Iluber's opinion, that it his no connection with it, the ordinary temperature of the hive being sufficient for this purpose ; and the circumstance of their entering unoccupied cells proves that this attitude has no particular connection with the eggs. (Huber, i. 212.) "When large pieces of eomb," says Wildman (p. 45.), "were broken off anl left at the bottom of the hive, a great number of bees have gone and placed themselves upon them." This looks like incubation. Reaumur, however, attirms (p. 591.) that if part of a comb falls and loses its perpendicular direction, the bees, as if conscions that they would come to nothing, pull out and destroy all the larvi. They might perhaps remain perpendicular in the case observed by Wildman.

3 Reaum. v. 431. Huber, ii. 212.

5 Ibid. v. 434.

4 Reaum. v. 432. 
account Reaumur has given from Maillet of the transportation of hives in Egypt from one place to another, before alluded to ${ }^{1}$, to enable them to make in greater abundance their collections of honey, \&c. Towards the end of October, when the inundations of the Nile have ceased, and the husbandmen can sow their land, sainfoin is one of the first things that is sown; and as Upper Egypt is warmer than the Lower, the sainfoin gets there first into blussom. At this time, bee-hives are transported in boats from all parts of Egypt into the upper district, and are there heaped in pyramids upon the boats prepared to receive them; each being numbered by the individual to whom it belongs. In this station they remain some days; and when they are judged to have got in the harvest of honey and pollen that is to be collected there, they are removed two or three leagues lower down, where they remain the same time; and so they proceed till towards the middle of February, when, having traversed Egypt, they arrive at the sea, from whence they are dispersed to their several owners.

A transportation of bee-hives, in some respects similar, prevails, as we learn from Mr. Willock, at the present day throughout Persia, Asia Minor, and he believes Greece ; in which countries an inhabitant even of a town will sometimes possess fifty or sixty hives, from the honey and wax of which a considerable profit is derived. These hives are wicker-work cylinders, two feet eight inches long by nine inches in diameter, plastered inside and outside with cow-dung; having one end filled up with a circular earthenware plate, and the other with a circular wooden door, in the middle of which is a small hole for the entrance of the bees. In spring, when the herbage of the low country has become parched, the proprietor of the hives, after closing them, conveys them (six or seven being an ass load) to some village in the neighbouring mountains where fragrant shrubs abound; and having sealed the doors, leaves them in charge of a villager, whom he pays for watching them, when he removes them in October back to his lome. Near villages in the mountains of Sahund, in the vicinity of Tabreez, Mr. Willock has secn ranges of these hives thus put out to board to the number of 500 or $6000^{2}$

John Hunter observes, that when the season for laying is over, that for collecting honey comes on (he means, probably, for making the principal collection of it); and that when the last pupa is disclosed, the cell it deserts, after being cleaned, is immediately filled with it, and as soon as full is covered with pure wax : but this only holds with respect to the cells containing honey for winter use, those destined to receive ihat which forms their food when bad weather prevents them from going out being left open. ${ }^{3}$ Sometimes, when the year is remarkably favourable for collecting honey, the bees will destroy many of the larva to make room for it; but they never medule with the pupæ. When no more honey is to be collected, they renain quiet in the hive for the winter. Mr. Hunter found that a hive grew lighter in a cold than in a warm week; he fornd also that in three months (from November 10th to February 9th) a single hive lost $72 \mathrm{oz} .1 \frac{1}{2} \mathrm{dram} .{ }^{4}$

Water is a thing of the first necessity to these insects; but they are not very delicate as to its quality, but rather the reverse; often preferring

1 Reaum. v. 698.

2 Gardener's Chronicle, 1841, p. 84.

9 Philos. Trans. 1792, 160. Comp. Reaum. v. 450.

4 Reaum. ibid. 591. IIunter, ibid. I61. 
what is stagnant and putrescent to that of a running stream. ${ }^{1}$ I have frequently observed them busy in corners moist with urine; perhaps this is for the sake of the saline particles to be there collected.

A new-born bee, as soon as it is able to use its wings, seems perfectly aware, without any previous instruction, what are to be its duties and enployments for the rest of its life. It appears to know that it is born for society, and not for selfish pursuits; and therefore it invariably devotes itself and its labours to the benefit of the community to which it belongs. Walking upon the combs, it seeks for the door of the hive, that it may sally forth and be useful. Full of life and activity, it then takes its first flight ; and, unconducted but by its instinct, visits like the rest the subjects of Flora, absorbs their nectar, covers itself with their ambrosial dust, which it kneads into a mass and packs upon its lind legs, and, if need be, gathers propolis, and returns unembarrassed to its own hive. ${ }^{2}$

Instances of the expedition with which our little favourites accomplish their various objects you have had several; but this is never more remarkable than when they settle in a new hive. At this time, in twentyfour hours they will sometimes construct a comb twenty inches long by seven or eight wide; and the hive will be half filled in five or six days; so that in the first fifteen days as much wax is made as in the whole year besides. ${ }^{3}$

In treating of the various employments of the bees, I must not omit one of the greatest importance to them - the ventilation of their abode. When you consider the numbers contained in so confined a space, the high temperature to which its atmosphere is raised, and the small aperture at which the air principally enters, you will readily conceive how soon it must be rendered unfit for respiration, and be convinced that there must be some means of constantly renewing it. If you feel disposed to think that the ventilation takes place, as in our apartments, by natural means, resulting from the rarefaction of the air by the heat of the hive, and the consequent establishment of an interior and exterior current, a simple experiment will satisfy you that this cannot be. Take a vessel of the size of a bee-hive, with a similar or even somewhat larger aperture; introduce a lighted taper; and if the temperature be raised to more than $140^{\circ}$, it will go out in a short time. We must therefore admit, as Huber obscrves ${ }^{4}$, that the bees possess the astonishing faculty of attracting the external air, and at the same time of expelling that which has become corrupted by their respiration.

What would you say, should I tell you that the bees upon this occasion have recourse to the same instrument which ladies use to cool themselves when an apartment is overheated? Yet it is strictly the case. By means of their marginal hooks, they unite each pair of wings into one plane slightly concave, thus acting upon the air by a surface nearly as large as possible, and forming for them a pair of very ample fans, which in their vibrations describe an arch of $90^{\circ}$. These vibrations are so rapid as to render the wings almost invisible. When they are engaged in ventilation, the bees by means of their feet and claws fix themselves as firmly as possible to the place they stand upon. The first pair of legs is stretched out before; the second extended to the right and left; whilst the third,

1 Reaum. Phil. Trans. 1792, 697.

3 Ibid. 650.

2 Reaum. v. 602.

4 ii. 339. 
placed very near each other, are perpendicular to the abdomen, so as to give that part considerable elevation.

Maraldi, and after him Reaumur, long ago noticed this action of the bees; but they attributed to it an effect the reverse of that which it really produces; the former imagining it to occasion directly the high temperature of the hive, and the latter indirectly. ${ }^{1}$ It was reserved for Huber to discover the true cause of it; and from him the chief of what I have to say upon the subject will be derived. ${ }^{2}$

During the summer a certain number of workers - for it is to the workers solely that this office is committed - may always be observerl vibrating their wings before the entrance of their hive ; and the observant apiarist will find, upon examination, that a still greater number are engaged within it in the same employment. All those thus circumstanced that stand without turn their head to the entrance; while those that stand within turn their back to it. The station of these ventilators is upon the floor of the hive. They are usually ranged in files that terminate at the entrance; and sometimes, but not constantly, form so many diverging rays, probably to give room for comers and goers to pass. The number of ventilators in action at the same time varies: it seldom much exceels twenty, and is often more circumscribed. The time also that they devote to this function is longer or shorter, according to circumstances : some have been observed to continue their vibrations for nearly half an hour without resting, suspending the action for not more than an instant, as it should seem to take breath. When one retires, another occupies its place; so that in a hive well peopled there is never any interruption of the sound or humming occasioned by this action, by which it may always be known whether it be going on or not.

This humming is observable not only during the heats of summer, but at all seasons of the year. It sometimes seems even more forcible in the depth of winter than when the temperature of the atmosphere is higher. An employment so constant, which always occupies a certain number of bees, must produce as constant an effect. The column of air once disturbed within must give place to that without the hive; thus a current being established, the ventilation will be perpetual and complete.

To be convinced that such an effect is produced, approach your hand to a ventilating bee, and you will find that she causes a very perceptible motion in the air. Huber tried an experiment still more satisfactory. On a calm day, at the time when the bees had returned to their habitation - having fixed a screen before the mouth of the hive to prevent his being misled by any sudden notion of the external air - he placed within the screen little anemometers or wind-gauges, made of bits of paper, feather, or cotton, suspended by a thread to a crotch. No sooner did they enter the atmosphere of the bees than they were put in motion, being alternately attracted and repelled to and from the aperture of the hive with considerable rapidity. These attractions and repulsions were proportioned to the number of bees engaged in ventilation, and though sometimes less perceptible, were never entirely suspended. Burnerf tried a similar experiment in the winter, when the thermometer stood in the shade at $33^{\circ}$. Having selected a wcli-peopled hive, the inhabitants of which appeared full of life and sufficiently active in the interior, and luted

1 Reaum. 5.672.

2 Huber, ii. $338-362$. 
it all around, except the aperture, to the platform on which it stood, he stuck in the top a piece of iron wire which terminated in a bonk, to which he fastened a hair with a small square of very thin paper at the other end; this was exactly opposite to the aperture, at the distance of about an inch from it. As soon as the apparatus was fixed, the hair with its paper pendulum began to oscillate more or less, the greatest oscillations on both sides being an inch, by admeasurement, from the perpendicular; if the paper was moved by force to a greater distance, the vibrations did not take place, and the apparatus remained at rest. He then made an opening in the top of the hive, and poured in some liquid honey; soon atter, there arose a hum, the movement in the interior increased, and some bees came out. The oscillations of the pendulum upon this became more frequent and intense, and extended to fifteen lines or an inch and a quarter from the perpendicular; but when the paper was removed to a greater distance from the aperture, it remained at rest.

Huber, at the proposal of M. de Saussure, in order to ascertain whether artificial ventilators would produce an analogous effect, got a mechanical friend to construct for him a little mill with eighteen sails of tin. He also prepared a large cylindrical vase, into which he could, at an aperture in the box upon which it was fixed, introduce a lighted taper. In one side of this box was another aperture to represent that of a hive, but larger. The ventilator was placed below, and luted at the points of contact; and anemometers were suspended before the aperture. The first experiment was the introduction of the taper, without putting the ventilator in motion. Thongh the capacity of the vessel was about 3228 cubic inches, the flame soon diminished, and went out in about eight minutes, and the anemometers continued motionless. The same experiment was next repeated with the door shut, with precisely the same result. After the air of the vessel had been renewed, the taper was again introluced, and the ventilator set in motion: immediately, as appeared by the oscillations of the anemometers, two currents of air were established, and the brilliancy of the flame was not diminished during the whole conrse of the experiment, which might have been prolonged for an indefinite time. A thermometer placed in the lower part of the apparatus rose to $112^{\circ}$; and the temperature was evidently still more elevated at the top of the receiver.

The Creator often has one end in view in the actions of animals (and nothing more conspicnously displays the invisible hand that governs the universe), while the agents themselves have another. This probably is the case in the present instance, since we can searcely suppose that the bees beat the air with their wings in order to ventilate the hive, but rather to relieve themselves from some disagreeable sensation which oppresses them. The following experiments prove that one of their objects in this action, as it is with ladies when they use their fans, is to cool themselves when they suffer from too great lieat. When Huber once opened the shutter of a glazed hive, so that the solar rays darted upon the combs covered with bees, a humming, the sign of ventilation, soon was heard amongst them, while those which were in the shade remained tranquil. The bees composing the elusters which often are suspended from the hives in summer, when they are incommoded by the heat of the sum, fan themselves with great energy. But if by any means a shadow is cast over any portion of the group, the ventilation cetses there, while it continues in the 
part which feels the heat of the sun. The same cause produces a similar effect upon humble-bees, wasps, and hornets.

Amongst the bees, however, it is remarkable that ventilation goes on even in the depth of winter, when it cannot be occasioned by excess of heat. This, therefore, can only be regarded as a secondary cause of the phenomenon. From other experiments, which, having already detained you too long, I shall not here detail, it appears that penetrating and disagreeable odours produce the same effect. ${ }^{1}$ Perhaps, though Huber does not say this, the odlour produced by the congregated myriads of the hive may be anongst the principal motives that impel its inhabitants to this necessary action.

Whatever be the proximate cause, it is, I trust, now evident to you that the Author of nature, having assigned to these insects a habitation into which the air cannot easily penetrate, has gifted them with the means of preventing the fatal effects which would result from corrupted air. An indirect effect of ventilation is the elevated temperature which these animals maintain, without any effort, in their hive :- but upon this I shall enlarge hereafter.

Bees are extremely neat in their persons and habitations, and remove all nuisances with great assiduity, at least as far as their powers enable them. Sometimes slugs or snails will creep into a hive, which with all their address they cannot readily expel or carry out. But here their instinct is at no loss ; for they kill them, and afterwards embalm them with propolis, so as to prevent any offensive odours from incommoding them. An unhappy snail, that had travelled up the sides of a glazed hive, and which they could not come at with their stings, they fixed, a monument of their vengeance and dexterity, by laying this substance all around the mouth of its shell. ${ }^{2}$ When they expel their excrements they go apart, that they may not defile their companions; and in winter, when prevented by extreme cold, or the injudicious practice of wholly closing the door of the hive, from going out for this purpose, their bodies sometimes become so swelled from the accumulation of faces in the intestines, that when at last able to get out they can no longer fly, so that falling to the ground in the attempt, they perish with cold, the saerifice of personal neatness. ${ }^{3}$ When a bee is disclosed from the pupa and has left its cell, a worker comes, and taking out its envelop carries it fiom the hive; another removes the exuviæ of the larva; and a third any filth or ordure that may remain, or any pieces of wax that may have fallen in when the nascent imago broke from its confinement. But they never attempt to remove the internal lining of silk that covers the walls, spun by the larva previous to its metamorphosis; because, instead of being a nuisance, it renders the cell more solid.4

Having now described to you the usual employments of my little favourites both within doors and without, I shall next enlarge a little upon their language, memory, tempers, manners, and some other parts of their history.

"Brutes" (it is the remark of Mr. Knight) "have language to express sentiments of love, of fear, of anger; but they seem unable to transmit any impression they have received from external objects. But the language

1 Huber, ii. 359.

- Bonner On Bees, 102.
2 Reaun. v. 442.

4 Reaum. ubi suprà, 580-600. 
of bees is more extensive ; if not a language of ideas, it is something very similar." 1 You have seen above that the organ of the language of ants is their antenna. Huber has proved satisfactorily that these parts have the same use with the bees. He wished to ascertain whether, when they had lost a queen (intelligence which traverses a whole hive in about an hour), they diseovered the sad event by their smell, their touch, or any unknown cause. He first divided a hive by a grate, which kept the two portions about three or four lines apart; so that they could not come at each other though scent would pass. In that part in which there was no queen, the bees were soon in great agitation; and as they did not discover her where she,was confined, in a short time they began to construet royal eells, which quieted them. He next separated them by a partition through which they could pass their antenna, but not their heads. In this ease the bees ail remained tranquil, neither intermitting the care of the brood, nor abandoning their other employments; nor did they begin any royal cell. The means they used to assure themselves that their queen was in their vieinity, and to communieate with her, was to pass their antennæ through the openings of the grate. An infinite number of these organs might be seen at once, as it were inquiring in all directions ; and the queen was observed answering these anxious inquiries of her subjects in the most marked manner; for she was always fastened by her feet to the grate, crossing her antenuæ with those of the inquirers. Various other experiments, which are too long to relate, prove the importanee of these organs as the instruments of communicating with each other, as well as to direet the bee in all its proceedings. ${ }^{2}$ Besides their antennx, the bees also cause themselves to be understood by certain sounds, not indeed produced by the mouth, but by other parts of their body: - but upon this subject I shall have occasion to enlarge hereafter.

That bees can remember agreeable sensations at least, is evident from the following aneedote related by Huber.- One autumn some honey was placed upon a window - the bees attended it in crowds. The honey was taken away, and the window closed with a shutter all the winter. In the spring, when it was reopened, the bees returned, though no fresh honey had been placed there. ${ }^{3}$

From the earliest times our little citizens of the hive have had the character of being an irritable race. Their anger is without bounds, says Virgil ; and if they are molested, this charaeter is no exaggeration. Some intividuals, however, they will suffer to go near their hives, and to do almost anything; and there are others to whom they seem to take sueh an antipathy, that they will attack them unprovoked. A great deal will probably depend upon this - whether any thing has happened to put them out of humour. The bees do not usually attack me; but I remember one day last year, when the asparagus was in blossom, which a large number were attending, I happened to go between my asparagus beds; which discomposed them so much, that I was obliged to retreat with hasty steps, and some of them flew after me: I eseaped, however unstung. Thorley relates an aneedote of a gentleman, who, desirous of securing a swarm of bees that had settled in a hollow tree, rashly undertook to dislodge them. He succeeded; but though he had used the precaution of sceuring his head 
and hands, he was so stung by the furious animals that a violent fever was the consequence, and his recovery was for some time doubtful. The strength of his constitution at length prevailed; and the hole of the tree being stopped, the survivors of the battle settled upon a branch, were hived, and became the dear-bought property of their conqueror. ${ }^{1}$

In Mungo Park's last mission to A frica, he was much annoyed by the attack of bees, probably of the same tribe with our hive-bee. His people, in search of boney, disturbed a large colony of them. The bees sallied forth by myriads, and attacking men and beasts incliscriminately, put them all to the ront. One horse and six asses were either killed or missing in consequence of their attack; and for half an hour the bees seemed to have completely put an end to their journey. Isaaco upon another occasion lost one of his asses, and one of his men was almost killed, by them. ${ }^{2}$

Bees, however, if they are not molested, are not usually ill-tempered: if you make a captive of their queen, they will cluster upon your head, or any other part of your body, and never attempt to sting you. I remember, when a boy, seeing the celebrated Wildman exhibit many feats of this kind, to the great astonishment and apprehension of the uninformed spectators. The writer lately quoted (Thorley) was assisted once by his maid-servant to hive a swarm. Being rather afraid, she put a linen cloth as a defence over her heal and shoulders. When the bees were shaken from the tree on which they had alighted, the queen probably settled upon this cloth; for the whole swarm covered it, and then getting under it, spread themselves over her face, neck, and bosom, so that when the cloth was removed she was quite a spectacle. She was with great difficulty kept from running off with all the bees upon her" ; but at length her master quieted her fears, and began to search for the queen. He succeeded, and hoped when he put her into the hive that the bees would follow; but they only seemed to cluster more closely. Upon a second search he found another qucen (unless the same had escaped and returned), whom seizing he placed in the hive. The bees soon missed her, and crowded after her into it: so that in the space of two or three minutes not one was left upon the poor terrified girl. After this escape, she became quite a heroine, and would undertake the most hazardous employments about the hives. ${ }^{3}$

Many means have been had recourse to for the dispersion of mobs and the allaying of popular tumults. In St. Petersburgh (so travellers say) a fire-engine playing upon them does not always cool their choler; but were a few hives of bees thus employel, their discomfiture would be certain. The experiment has been tried. Lesser tells us, that in 1525, during the confusion occasioned by a time of war, a mob of peasants assembling in Holnstein (in Thuringia) attempted to pillage the house of the minister of Elende; who having in vain employed all his eloquence to dissuade them from their design, ordered his domestics to fetch his bee-hives, and throw them in the middle of this furions mob. The effect was what might be expected; they were immediately put to flight, and happy if they escaped unstung. ${ }^{4}$

The anger of bees is not confined to man; it is not seldom excited

1 Thorley, 16. The Psalmist alludes to the fury of these creatnres, when he says of his enemies, "They compassed me about like bees." (Ps. cxviii. 12.)

2 Park's Last Mission, 153. 297. Comp. Journal, 331.

3 Thorkey, 150.

4 Lesser, 1. ii. 171. 
against their own species. From what $I$ have said above respecting the biack bees ${ }^{1}$ and their fate, it seems not improbable that, when the workers become too old to be useful to the community, they are either killed or expelled the society. Reaumur, who observed that the inhabitants of the same hive had often mortal combats, was of opinion that this was their object in these battles ${ }^{2}$, which take place, he observes, in finc or warm weather. On these occasions the bees are sometimes so eager, that examining them with a lens does not part them : - their whole object is to pierce each other with their sting, the stroke of which, if once it penetrates to the muscles, is mortal. In these engagements the conqueror is not always able to extricate this weapon, and both perish. The duration of the conflict is uncertain; sometimes it lasts an hour, and at others is very soon determined : and occasionally it happens that both parties, fatigued and despairing of victory, give up the contest and fly away.

But the wars of bees are not confined to single combats; general actions now and then take place between two swarms. This happens when one takes a fancy to a hive that another has preoccupied. In fine warm weather, strange that wish to be receiverl amongst them meet with but an indifferent welcome, and a bloody battle is the consequence. Reaumur witnessed one that lasted a whole afternoon, in which many victims fell. In this case the battle is still between individuals, who at one time decide the business within the hive, and at another at some distance without. In the former case the victorious bee flies away, bearing her victim under her body between her legs, sometimes taking a longer and sometimes a shorter flight before she deposits it upon the ground. She then takes her repose near the dead body, standing upon her four anterior legs, and rubbing the two hinder ones against cach other. If the battle is not concluded within the hive, the enemy is carried to a little distance, and then dispatched.

This strange fury, however, does not always show itself on this occasion; for now and then some friendly intercourse seems to take place. Bees from a hive in Mr. Knight's garden visited those in that of a cottager a hundred yards distant, considerably later than their usual time of labour, every bee as it arrived appearing to be questioned. On the tenth morning, however, the intercourse ceased, ending in a furious battle. On another occasion, an intimacy took place between two hives of his own, at twice the distance, which ceased on the fifth day. Sometimes he observed that this communication terminated in the union of two swarms: as in one instance, where a swarm had taken possession of a hollow tree ${ }^{3}$, it is probable that the reception of one swarm by another may depend upon their numbers, and the fitness of their station to accommodate thems. Thorley witnessed a hattle of more than two days' continuance, occasioned by a strange swarm forcing their way into a hive. ${ }^{4}$ Two swarms that rise at the same time sometimes fight till great numbers have been destroyed, or one of the queens slain, when both sides cease all their ennity and unite under the survivor. ${ }^{5}$

1 See above, p. 359.

3 Philos. Trans. 1807, 234.

5 Thorley, ibid. Comp. Mills On Bees, 63.-The following account of an apiarian battle was copied from the Carlisle Patriot Newspaper :- On Saturilay last, in the village of Cargo, a combat of a truly novel description was witnessed. A hive of bees belonging to a professional gentlemau of this city swarmed on Thursday last; 
These apiarian battles are often fonght in defence of the property of the hive. Bees that are ill managed, and not properly fed, instead of collecting for themselves, will now and then get a habit of pillaging from their more industrions neighbours: these are called by Schirach corsair bees, and by English writers robbers. They make their attack chiefly in the latter end of July, and during the month of August. At first they act with caution, endeavouring to enter by stealth ; and then, emboldened by success, come in a body. If one of the queens be killed, the attacked bees unite with the assailants, take up their abode with them, and assist in plundering their late habitation. ${ }^{2}$ Schirach very gravely recommends it to apiarists whose hives are attacked by these depredators, to give the bees some honey mixed with brandy or wine, to increase and infame their courage, that they may more resolutely defend their property against their piratical assailants. ${ }^{2}$ It is, however, to be apprehended that this method of making them pot-valiant might induce them to attack their neighbours as well as to defend themselves.

Sometimes combats take place in which three or four bees attack a single individual, not with a design to kill, but merely to rob: one seizes it by one leg, another by another; till perhaps there are two on each side, each having hold of a leg; or they bite its head or thorax. But as soon as the poor animal that is thus haled about and maltreated unfolds its tongue, one of the assailants goes and sucks it with its own, and is followed by the rest, who then let it go. These insects, however, in their ordinary labours are very kind and helpful to each other; I have often seen two, at the same noment, visit the same flower, and very peaceably despoil it of its treasures, without any contention for the best share.

As the poison of bees exbales a penetrating odour, M. Huber was curious to observe the effect it might produce upon them. Having extracted with pincers the sting of a bee and its appendages impregnated with poison, he presented it to some workers, which were settled very tranquilly before the gate of their mansion. Instantaneously the little party was alarmed: none, however, took flight; but two or three darted upon the poisoned instrument, and one angrily attacked the observer. When, however, the poison was coagulated, they were not in the least affected by it.

after which they were hived in the regular way, and appeared to be doing well. On the Saturday after, a swarm of bees, from some neighbouring hive, appeared to be flying over the garden in which the hive above mentioned was placed, when they instantly darted down upon the hive of the new settlers, and completely covered it: in a little time they began to enter the hive, and poured into it in such numbers that it soon became completely filled. A loud humming noise was heard, and the work of destruction immediately eusued; the winged combatants sallied forth from the hire, until it became entirely empty; and a furious battle commenced in "upper air," between the besiegers and the besieged. A spectator informs us, that these intrepid little warriors were, so numerous, that they literally darkened the sky over-head like a cloud; meanwhile the destructive battle raged with furv on both sides, and the ground beneath was covered with the wounded and the slain; hundreds of them were lying dead, or crawling abour, disabled from reascending to the scene of action. To one party, however, the palm of victory was at last awarded; and they settled upon the branch of an adjoining apple-tree, from which they were safely placed in the empty hive, which had been the object of their valiant contention, and where they now continue peacefully and industriously employed in adding to the stores of their commonwealth.

1 Comp. Schirach, 49. Mills, 62. Thorley, 163. 
A tube impregnated with the odour of poison recently ejected being presented to them, affected them in the same manner. ${ }^{1}$ This circunstance may sometimes occasion battles amongst them that are not otherwise easy to be accounted for.

Anger is no useless or hurtful passion in bees : it is necessary to them for the preservation of themselves and their property, which, besides those of their own species, are exposed to the ravages of numerous enemies. Of these I have already enumerated several of the class of insects, and also some beasts and birds that have a taste for bees and their produce. The Merops apinster (which has been taken in England), the lark and other birds, catch them as they fly. Even the frog and the toad are said to kill great numbers of bees; and many that fall into the water probably become the prey of fish. The monse also, especially the field-nouse, in winter often commits great ravages in a hive, if the base and orifices are not well secured and stopped. ${ }^{2}$ Thorley once lost a stock by mice, which made a nest and produced young amongst the combs. ${ }^{3}$ The titmouse, according to the same author, will make a noise at the door of the hive, and when a bee comes out to see what is the matter, will seize and devour it. He has known them eat a dozen at a time. The swallows will assemble round the hives and devour them like grains of corn. ${ }^{4}$ I need only mention spiders, in whose webs they sometimes meet with their end; and earwigs and ants, which creep into the hive and steal the honey. ${ }^{5}$

Upon this sulject of the enemies of bees, I cannot persuade myself to omit the account Mr. White has given of an idiot boy, who from a child showed a strong propensity to bees. They were his food, his amusement, his sole object. In the winter he dozed away his time in his father's house, by the fireside, in a torpid state, seldom leaving the chimney corner; but in summer he was all alert and in quest of his game. Hivebees, humble-bees, and wasps were his prey, wherever he found then. $\mathrm{He}$ had no apprehension from their stings, but would seize them with naked hands, and at once disarm them of their weapons, and suck their bodies for the sake of their honey-bags. Sometimes he would fill his bosom hetween his shirt and skin with these animals: and sometimes he endeavoured to confine them in buttles. He was very injurious to men that kept bees; for he would glide into their bee-gardens, and sitting down before the stools, would rap with his fingers, and so take the bees as they came out. He has even been known to overturn the hives for the sake of the honey, of which he was passionately fond. Where metheglin was making, he would linger round the tubs and vessels, berging a draught of what he called bee-wine. As he ran about, he used to make a humning noise with his lips resembling the buzzing of bees. This lad was lean and sallow, and of a cadaverous complexion; and except in his favourite pursuit, in which he was wonderfully adroit, discovered no manner of understanding. Had his capacity been better, and directed to the same object, he had perhaps abated much of our wonder at the feats of a more modern exhibitor of bees; and we may justly say of him now,

$$
\text { "—_ Thou, }
$$

Had thy presiding star propitious shone,

Shouldst Wildman be." 8

$\begin{array}{lll}1 \text { ii. } 380 . & \text { 2 Schirach, } 53 . & 3170 . \\ 4 \text { Reaum. v. } 710 . & 5 \text { Thorley, 171. } & 6 \text { White's Nat. Hist. 8vo. i. 339. }\end{array}$


The worker bees are annual insects, though the queen will sometimes live more than two years; but, as every swarm consists of old and young, this is no argument for burning them. It is a saying of bee-keepers in Holland, that the first swallow and the first bee foretel each other. ${ }^{1}$ This perhaps may be correct there; but with us the appearance of bees considerably precedes that of the swallow ; for when the early crocuses open, if the weather be warm, they may always be found busy in the blossom.

The time that bees will inhabit the same stations is wonderful. Reaumur mentions a countryman who preserved bees in the same hive for thirty years. ${ }^{2}$ Thorley tells us that a swarm took possession of a spot under the leads of the study of Ludovicus Vives in Oxford, where they continued a hundred and ten years, from 1520 to $16300^{3}$ These circumstances have led authors to ascribe to bees a greater age than they can claim. Thus Mouffet, because he knew a bees' nest, which had remained thirty years in the same quarters, concludes that they are very long-lived, and very sapiently doubts whether they even die of old age at all ! ${ }^{4}$ which is just as wise as if a man should contend, becanse London had existed from before the time of Julius Casar, that therefore its inhabitants must be immortal.

Bees are subject to many accidents; partieularly, as I have said above, they often fall or are precipitated by the wind into water; and though like the cat a bee has not nine lives, nor

"Nine times emerging from the crystal flood, She mews to every watery god,"

yet she will bear submersion nine hours ; and, if exposed to sufficient heat, be reanimated. In this case their proboscis is generally unfolded, and stretched to its full length. At the extremity of this, motion is first perceived, and then at the end of the legs. After these symptoms appear, they soon recover, fold up the tongue, and plume themselves for flight. ${ }^{5}$ Experimentalists may therefore, without danger, submerge a hive of bees when they want to examine them particularly, for they will all revive upon being set to the fire. Reaumur says that in winter, during frosts, the bees remain in a torpid state. He must mean severe frosts; for Huber relates an instance, when upon a sudden emergency the bees of one of his hives set themselves to work in the middle of January ; and he observes that they are so little torpid in winter, that even when the thermometer abroad is below the freezing point, it stands high in populous hives. Swammerdam, and after him the two authors last quoted, found that sometimes, even in the middle of winter, hives have young brood in them, which the bees feed and attend to. ${ }^{6}$ In an instance of this kind, which fell under the eye of Huber, the thermometer stood in the hive at about $92^{\circ}$. In colder climates, however, the bees will probably be less active in the winter. They are then generally situated botween the combs towards their lower part.

1 Swamm. Bib. Nat. ed. Hill. i. 160.

2 I Jbi suprà, 665 .

4 Theatr. Ins. 21.

3178.

5 Reaum. v. 540 .

6 January 11, 1818. My bees were out, and very alert this day. The thermo. meter stood abroad in the shade at $51 \frac{10}{2}$. When the sun shone there was quite a cluster of them at the mouth of the hives, and great numbers were buzzing about in the air before them. 
But when the air grows milder, especially if the rays of the sun fall upon the hive and warm it, they awake from their lethargy, shake their wings, and begin to move and recover their activity; with which their wants returning, they then feed upon the stock of homey and bee-bread which they have in reserve. The lowest cells are first uncovered, and their contents consumed ; the highest are reserved to the last. The honey in the lowest cells being collected in the autumn, probably will not keep so well as the vernal.

The degree of heat in a hive in winter, as I have just hinted, is great. A thermometer near one, in the open air, that stood in January at $6 \frac{3}{4}^{\circ}$, below the freezing point, upon the insertion of the bulb a little way into the hive rose to $22 \frac{1}{2}^{\circ}$ above it ; and could it have been placed between the combs, where the bees themselves were agglomerated, the mercury, Reaumur conjectures, would have risen as ligh as it does abroad in the warm days in summer. ${ }^{1}$ Huber says that it stands in frost at $86^{\circ}$ and $88^{\circ}$ in populous hives. ${ }^{2}$ In May, the former author found in a hive in which he had lodged a small swarm, that the thermometer indicated a degrce of heat above that of the hottest days of summer. ${ }^{3}$ He observes that their motion, and even the agitation of their wings, increases the heat of their atmosphere. Often, when the squares of glass in a hive appeared cold to the touch, if either by design or chance he happened to disturb the bees, and the agglomerated mass in a tumult began to move different ways, sending forth a great hum, in a very short time so considerable an accession of heat was produced, that when he touched the same squares of glass he felt them as hot as if they had been held near a fierce fire. By teasing the bees, the heat generated was sometimes so great as to soften very much the wax of the combs, and even to cause them to fall. ${ }^{4}$

The above conclusions, however, of Reaumur and Huber, as to the great temperature of the interior of bee-hives in winter, are contrary to the results obtained by George Newport, Esq., from his minute and very valuable series of experiments to determine this point, which will be further adverted to in directing your attention to the hybernation of insects; but this excellent comparative anatomist, of whose labours British entomology is so justly proud, has not only fully confirmed what these entomologists have advanced as to the extra beat generated by bees in their hives in sumner, but, after showing that all insects have a temperature greater than that of the surrounding atmosphere, and that this temperature, as in vertebrate animals, is intimately dependent on the volume and velocity of their circulation, and the quantity and activity of their respiration, has proved that it is in consequence of the greater energy of this last function in bees and humble-bees, owing to the superior development and capacity of their tracheæ and vesicular dilatations, that their power of producing heat is so much greater than that of most other insects. If, as happened to myself a few days ago, a wild bee should chance to drop on a newspaper you are reading in the open air, and you observe it attentively, you will see it pant like a greyhound after a chase, the alternate rapid contraction and expansion of its abdominal segments corresponding with the numerous and rapid acts of respiration which the exertion of its recent flight has caused; and Mr. Newport found that in the hive-bee, when very mode- 
rately active, the number of respirations did not exceed 40 per minute, while, when in violent action or a state of excitement, they were from 110 to 120 per minute. The degree of heat developed by the hive-bee is thus always in proportion to the activity of its respiration, which again usually depends on the greater or less activity of its motions ; and hence it is in summer often $25^{\circ} \mathrm{Fahr}$. above that of the atmosphere, and as much or more even in winter, if the bees be in any way excited. ${ }^{1}$

And now, having detailed to you thus amply the wonderful history and proceedings of the social tribes of the insect world, you will allow, I think, that I have redeemed my pledge, when I taught you to expect that this history would exceed in interest and variety and marvellons results everv thing that I had before related to you. I trust, morcover, that you will scarcely feel disposed to subscribe to that opinion, though it has the sanction of some great names, which attributes these almost miraculous instincts to mere sensation; which tells us that the sensorium of these insects is so modelled with respect to the different operations that are given them in charge, that it is by the attraction of pleasure alone that they are determined to the execution of them; and that, as every circumstance relative to the succession of their different labours is preordained, to each of them an agreeable sensation is affixed by the Creator; and that thus, when the bees build their cells ; when they sedulonsly attend to the young brood; when they collect provisions; - this is the result of no plans, of no affection, of no foresight; but that the sole determining motive is the enjoyment of an agrecable sensation attached to each of these operations. ${ }^{2}$ Surely it would be better to resolve all their proceedings at once into a direct impulse from the Creator, than to maintain a theory so contrary to fact, and which militates against the whole history which M. Huber, who adopts this theory from Bonnet, has so ably given of these creatures. That they may experience agreeable sensations from their various cmployments, nobody will deny; but that such sensations instruct them how to perform their several operations, without any plan previously impressed upon their sensorium, is contrary both to reason and experience. Thev have a plan, it is evident; and that plan, which proves that it is not mere sensation, they vary according to circumstances. As to affection - that bees are irritable, and feel the passion of anger, no one will deny; that they are also susceptible of fear, is equally evident: and if they feel anger and fear, why may they not also feel love? Further, it they have recourse to precautions for the prevention of any evil that seems to threaten them, how can we refuse them a degree of foresight? Must we also resolve all their patriotism, and the singular regard for the welfare of their community which seems constantly to actuate them, and the sacrifices, even sometimes of themselves, that they make to promote and ensure it, into individual self-love? We would not set them up as rivals to man in intelligence, foresight, and the affections; but they have that degree of each that is necessary for their purposes. On account of the difficulties attending all theories that give them some degree of these qualities, to resolve all into mere sensation is removing one difficulty by a greater.

1 Newport "On the Temperature of Insects," in Phil. Trans. 1837, pp. 309. sิ11, \&c.

2 Huber, i. 315. 
That these creatures from mere selfishness build their combs, replenish them with the fruit of their unwearied labours, attend so assiduously to the nurture of the young brood, lavish their caresses upon their queen, prevent all her wants, give a portion of the honey they have eollected to those that remain in the hives, assist each other, defend their common dwelling, and are ready to sacrifice themselves for the public good-is an anomaly in rerum naturâ that ought never to be admitted, unless established by the most irrefiagable demonstration; and I think you will not be disposed without full proof to yield yourself to a mere theory, so contradictory of all the facts we know relative to this subject.

After all, there are mysteries, as to the primum mobile, amongst these social tribes, that with all our boasted reason we cannot fathom; nor develop satisfactorily the motives that urge them to fulfil in so remarkable though diversified a way their different destinies. One thing is clear to demonstration, that by these ereatures and their instinets the power, wisdom, and goodness of the Great Fatrier of the universe are loudly proclaimed; the atheist and infidel confuted; the believer confirmed in his faith and trust in Providence, which he thus beholds watching, with incessant care, over the welfare of the meanest of his creatures; and from which he may eonclude that he, the prince of the creation, will never be overlooked or forsaken : and from them what lessons may be learned of patriotism and self-devotion to the public good; of loyalty; of prudence, temperance, diligence, and self-denial. But it is time at length to put an end to this long disquisition. 


\section{LETTER XXI.}

\section{IEAX゙'S BI THICH INSECTS DEFEND THEMSELTES.}

WHEs a country is particularir open to attack, or surrounded by numerous enemies, who from cupidity o: bostl'e feelings are disposed to annor it, we are usually led to inquire in hat are is means of dejence? whether natural, or arising from the number, courace, or shill of is inhabitants. The insect tribes constitute such a nation; with them infinite hosts of enemies waye contirual mar, mane of thtom derire the whole of their subsistence firom them: and amonesi their own tribes there are numerous civil broils, the strong often preying upon the meak, and the cunning upon the simp'e: $\leqq 0$ that unless a watchiful Providence (which cares for all is crectures, eren the most insignificant) had scpplied them with some mode of resistance or escape, this innumerable race must soon be estirpated. That such is the case, it shall be mr endearour in this letter to prose; in which I sha!l detail to rou some of the most remarkable means of defence with which ther are provided. For the sake of distinctness I shall con-ider these under two separate heads, into which, indeed, sher naturali 5 divide themselres: Passice means of defence, such as are independeni of ans Esurts of the irsect: and actice means of defence, such as resu't from certain efforts of the insect, in the emplormer: of those instincts and instruments with which Providence has furnished it for this purfose.

I. The principal passice means of cefence with w bich insccss are provided are derired from their colour and form, br which ther eithez deceire daz. zle, alarm, or annoy their enemies; or from their substance, involuntary secretions, vitaity, and numbers.

Ther often ceceire them br imiating rarious substances. Sometimes ther so esactly resemble the soil which ther inhabit, tha: it mus: be a practised ese which can distingush them from it. Thus, one of our scarces: British weerils (Cleonis rebulosus), by its gray colour, spotied with blect, so closely imitaics the soil, consisting ot white sajd rired with blact' earth, on which I hare always found it, that its chance of escape, eren though it be bured for by the lyncean ere of an entomologist. is no: small. Another insect of the same tribe (Triylacites scabric-nis), of which I have obserted severa! sfecies of ground-beetles (Hapalus, St.) make grea: heroc, abounds in pits of a loams soil of the same colou: precisely with itself; a circumstance that doubtles occastoss many to escape f-om their pitiles foes. Sereral other weevils, for instance Chl riva rirez and cretacec, resemble chalk, and perbaps inhabit a chal't! o: white soil. But the most surprising irstance of this adaptation of the colour of an insect:o that of the soil whe:e it resides, is tound in some of the Mcris tribe separated by M. Leitbrre under the generic name of Eremispitalg, of which he bas given so interesing an accouns. These insects (which he met with in the $\mathrm{n}$ rmph siate onlr, in the rery mids: of the African desert, leading to the Ousis of Bahrrah, about forr doy" journer from the Nile, where he 
could not discover the slightest trace of any other insect or substance on which it could by possibility feed, but apparently passing a life of absolute solitude in the midst of these burning sands) had the most perfect identity of colour with that of the soil on which they were found, being brown where the soil was brown, and at not above a hundred paces distant of a silvery white, when found amongst the white particles of broken shells or calcareous rocks of a similar dazzling colour. That it was the same species which exhibited this change of colour, M. Lefebrre did not doubt, nor that the object was its protection from its enemies, which it was so well calculated to effect that he could scarcely detect it by the closest inspection; but he confesses himself unable to explain whether the different coloured Eremiaphile were confined to the soils of the same tints respectively, or, as in the case of the birds and quadrupeds which become white in winter in the Polar regions, they have the faculty of changing their colour as they change their abode. ${ }^{1}$

Many insects, also, are like pebbles and stones, both rough and polished, and of various colours; but since this resemblance sometimes results from their attitudes, I shall enlarge upon it under my second head: whether, however, it be merely passive, or combined with action, we may safely regard it as given to enable them to elude the vigilance of their enemies.

A numerous host of our little animals escape from birds and other assailants by imitating the colour of the plants, or parts of them, which they inhabit; or the twigs of shrubs or trees, their foliage, flowers, and fruit. Many of the mottled moths, which take their station of diurnal repose on the north side of the trunks of trees, are with difficulty distinguished from the gray and green lichens that cover them. Of this kind are Miselia aprilina and Acronycta Psi. The caterpillar of Bryophila Alge, when it feeds on the yellow Lichen juniperinus, is always vellow; but when upon the gray Lichen saxatilis its hue becomes gray. ${ }^{2}$ This change is probably produced by the colour of its food. Leptocerus atratus, a kind of May-fly, frequents the black flower-spikes of the common sedge (Carex riparia), which fringes the banks of our rivers. I have often been unable to distinguish it from them, and the birds probably often make the same mistake and pass it by. A jumping bug, very similar to one figured by Schellenberg $^{3}$, also much resembles the lichens of the oak on which I took it.

The spectre tribe (Phasma) go still further in this mimicry, representing a small branch with its spray. I have one from Brazil eiglit inches long, that, unless it was seen to move, conld scarcely be conceived to be any thing else; the legs, as well as the head, having their little snags and knobs, so that no imitation can be more accurate. Perhaps this may be the species mentioned by Molina ${ }^{4}$, which the natives of Chili call "The Devil's Horse." 6

Other insects, of various tribes, represent the leaves of plants, living, decaying, and dead ; some in their colour, and some both in their colour and shape. The catcrpillar of a moth (IIadena Ligustri) that feeds upon the privet is so exactly of the colour of the underside of the leaf, upon

1 Ann. Soc. Ent. de France, iv. 455.

2 Fabr. Vortesungen, 321.

3 Cimic. Helvet, t. iii. f. 3.

4 Hist. of Chili, i. 172.

5 Since the first edition of this volume was printed, a lady from the West Indies, looking at my cabinet, upon being shown this insect, exclaimed, "Ob, that is $T$, Devil's Ilorse!" 
which it usually sits in the day-time, that you may bave the leaf in your hand and yet not discover it. ${ }^{1}$ - The tribe of grass-hoppers called Locustce by Fabricius, though the true Locust does not belong to it, in the veining, colour, and texture of their elytra, resemble green leaves. ${ }^{2}$ - The tribe of Phasmina - named praying-insects and spectres - also of the Orthoptera order, often exhibit the same peculiarity.-Others of them, by the spots and mixtures of colour observable in these organs, represent leaves that are decaying in various degrees. - Those of several species of Mantidce likewise imitate dry leaves, and so exactly, by their opacity, colour, rigidity, and veins, that, were no other part of the animal visible even after a close examination, it would be generally affirmed to be nothing but a dry leaf. Of this nature is the Phyllium siccifolium, and two or three Brazilian species in my cabinet, that seem undescribed, which I will show you when you give me an opportunity. But these imitations of dry leaves are not confined to the Orthoptera order solely. Amongst the Hemiptera, the Phyllomorpha paradoxa, a kind of bug, surprised Sparrman not a little. He was sheltering himself from the mid-day sun when the air was so still and calm as scarcely to shake an aspen leaf, and saw with wonder what he mistook for a little withered, pale, crumpled leaf, eaten as it were by caterpillars, fluttering from the tree. The sight appeared to him so very extraordinary. that he left his place of shelter to contemplate it more nearly; and could scarcely believe his eyes, when he beheld a living insect, in shape and colour resembling a fragnent of a withered leaf with the edges turned up and eaten away as it were by caterpillars, and at the same time all over beset with prickles. ${ }^{3}$ - A British insect, one of our largest moths (Gastropacha quercifolia), called by collectors the Lappet moth, affords an example from the Lepidoptera order of the imitation in question, its wings representing, both in shape and colour, an arid brown leaf. Some bugs, belonging to the genus Dictyonota of Mr. Curtis ${ }^{4}$, simulate portions of leaves in a still further state of decay, when the veins only are left; for, the thorax and elytra of these insects being reticulated, with the little areas or meshes of the net-work transparent, this circumstance gives them exactly the appearance of small fragments of skeletons of leaves.

But you have probably heard of most of these species of imitation : I hope, therefore, you will give credit to the two instances to which I shall next call your attention, of insects that even mimic flowers and firuit. With respect to the former, I recollect to have seen, in a collection made by Mr. Mason at the Cape of Good Hope, a species of the orthopterous genus Pneumora, the elytra of which were of a rose or pink colour, which shrouding its vesiculose abdomen, gave it mucl the appearance of a fine flower.A most beautiful and brilliant beetle, of the genus Chlamys (Ch. Bacca), found by Captain Hancock in Brazil, by the inequalities of its ruby-coloured surface, strikingly resembles some kinds of fruit.-And to make the series of imitations complete, a minute black beetle, with ridges upon its elytra (Onthophilus sulcatus ${ }^{5}$ ), when lying without motion, is very like the seed of an umbelliferous plant. The dog-tick is not unlike a small bean; which

1 Brahm, Insecten Kalender, ii. 383.

2 Hence we have Locusta citrifolia, laurifolia, cameltifolia, myrtifolia, salvifolia, \&c., which, I believe, all belong to a genus I have named Pterophytla.

3 Toyage, Sc. ii. 16. Westw. Arc. Ent. Plite. II.

4 Brit. Ent. t. 154. 5 Oliv. Entomolog. i. no. 8. 17. 
resemblance has cansed a bean, commonly cultivated as food for horses, to be called the tick-bean. The Palma Christi, also, had probably the name of Ricinus given to it from the similitude of its seed to a tick.

Another tribe of these Jittle animals, before alluded to, is secured from harm by a different kind of imitation, and affords a beautiful instance of the wisdom of Providence in adapting means to their end. Some singular larvæ, with a radiated anus ', live in the nests of humble-bees, and are the offspring of a particular genus of flies ( $V$ olucella), many of the species of which strikingly resemble those bees in shape, clothing, and colour: Thus has the Author of nature provided that they may enter these nests and deposit their eggs undiscovered.

Did these intruders venture themselves amongst the humble-bees in a less kindred form, their lives would probably pay the forfeit of their presumption. Mr. Sheppard once found one of these larvæ in the nest of Bombus $^{2}$ Raiellus, but we could not ascertain what the fly was. Perhaps it might be Volncella bombylans, which resembles those humble-bees that have a red anus. ${ }^{3}$ In like manner Mr. W. S. MacLeay informs us that he has discovered that the larva of those tropical Bombylii which have such a bee-like form live on the larvæ of the bees they so strikingly represent; and he suggests that probably the object of nature in giving such an ant-like form to the singular spider described by him under the name of Myrmarachne melanocephale is to deceive the ants on which they prey. ${ }^{4}$

The brilliant colours in which many insects are arrayed may decorate them with some other view than that of mere ornament. They may dazzle their enemies. The radiant blue of the upper surface of the wings of a giant butterfly, abundant in Brazil (Morpho Menelaus), which from its size would be a ready prey for any insectivorous birds, by its splendour (which I am told, when the insect is flying in the sunshine, is inconceivably bright) may produce an effect upon the sight of such birds, that may give it no small chance of escape. Latreille has a similar conjecture with respect to the golden wasps (Chrysis L.). These animals lay their eggs in the nests of such Hymenoptera, wasps, bee-wasps (Bembex), and bees, as are redoubtable for their stings; and therefore have the utmost occasion for protection against these murderous weapons. Amongst other defences the golden wasps are adorned with the most brilliant colours, which, by their radiance, especially in the sunny situations frequented by these insects, - may dazzle the eyes of their enemies, and enable them to effect unhurt the purpose for which they were created. ${ }^{5}$

The frightful aspect of certain insects is another passive means of defence by which they sometimes strike beholders, especially children, often great insect tormentors, with alarm, and so escape. The terrific and pretended jaws of the stag-beetle (Lucanus Cervus) in Europe, and of the

1 Latreille, Gen. Crust, et Ins. iv. 322.

2 Apis. **. e. $2 . \mathrm{K}$.

3 Dr. Flening, however (in Literis), doubts whether the reason here assigned is the cause of the resemblance between the Bombus and Volucella; he thinks if a bee knows a stranger of its own species, it could not be deceived by a fly in the disguise of a bee. But the fact that these insects lay their eggs in their nests, and that they resemble humble-bees, seems to justify the conclusion drawn in the text. They must get in often undiscovered.

$\$$ Ann. Nat. Ilist. ii. 12. 5 Latreille, Annal. du Mus. 1810, 5. 
stag-horn capricorn beetle (Prionus Cervicornis) in America, may save them from the cruel fate of the poor cockchafer ${ }^{1}$, whose gyrations and motions, when transfixed by a pin, too often form the amusement of ill-disciplined children. The threatening horns also, prominent eyes, or black and dismal hue of many other Coleoptera belonging to Linnés genera Scarabceus, Cicindela, and Carabus, may produce the same effect.

But the most striking instances of armour are to be found amongst the homopterous Hemiptera. In some of these, the horns that rise from the thorax are so singular and monstrous, that nothing parallel to them can be found in nature. Of this kind is the Cicada spinosa Stoll ${ }^{2}$, the Centrotus clavatus $^{3}$, and more particularly the Centrotus globularis ${ }^{4}$, so remarkable for the extraordinary apparatus of balls and spines, which it appears to carry erect, like a standard, over its head. What is the precise use of all the varieties of armour with which these little creatures are furnished it is not easy to say, but they may probably defend them from the attack of some enemies.

Under this head I may mention the long hairs, stiff bristles, sharp spines, and hard tubercular prominences with which many caterpillars are clothed, bristled, and studded. That these are means of defence is rendered more probable by the fact that, in several instances, the animals so distinguished at their last moult, previous to their assuning the pupa (in which state they are protected by other contrivances), appear with a smooth skin, withont any of the tubercles, hairs, or spines for which they were before remarkable. ${ }^{5}$ Wonderful are the varieties of this kind which insects exhibit :- but I shall only here select a few facts more particularly connected with my present subject. The caterpillar of the great tigermoth (Euprepia Caja), which is beset with long dense hairs, when rolled up - an attitude it usually assumes if alarmed - cannot then be taken without great difficulty, slipping repeatedly from the pressure of the fingers. If its hairs do not render it distasteful, this may often be the means of its escape from the birds. That little destructive beetle Anthrenus Musorum, which so annoys the entomologist, if it gets into his cabinets, when in the larva state being covered with bunches of diverging hairs, glides fiom between your fingers as if it were lubricated with oil. The two tufts of hairs near the tail of this are most curious in their structure, being jointed through their whole length, and terminating in a sharp halberd-shaped point. ${ }^{6}$ I have a small lepidopterous caterpillar from Brazil, the upper side of which is thickly beset with strong, sharp, branching spines, which would enter into the finger, and would probably render it a painful morsel to any minor enemy.

The powers of annoyance by means of their hairs, with which the moth of the fir, and the procession-moth, before noticed, are gifted, are doubtless

1 One would almost wish that the same superstition prevailed here which Sparrman observes is common in Sweden, with respect to these animals. "Simple people," says he, "believe that their sins will be forgiven if they set a cockchafer ou its legs."-Voyage, i. 28.

2 Cigales, f. 85.

3 Ibid. f. 115. Coquebert, Illust. Ic. ii. t. xxviii. f. 5.

4 Stoll, Cigales, f. 163. Comp. Pallas, Spicil. Zool. t. i. f. 12.

5 Reaum. v. 94.

6 This was first pointed out to me by Mr. Briggs of the post-office, who sent me an accurate drawing of the animal and of one of its hairs. I did not at that time discover that it had been tigured by De Geer, iv. t. viii. f. 1. 7. 
a defensive armour to them. Madame Merian has figured an enormous caterpillar of this kind, - which unfortunately she could not trace to the perfect insect, - by the very touch of which her hands, she says, were inflamed, and that the inflammation was succeeded by the most excruciating pain. ${ }^{1}$ The vesicatory beetles, likewise (Cantharis vesicatoria, \&c.), are not improbably defended from their assailants by the remarkable quality, so useful to suffering mortals, that distinguishes them.

Your own observation must have proved to you, that insects often escape great perils, from the crush of the foot, or of superincumbent weights, by the hardness of the substance that covers great numbers of them The elytra of many beetles of the genus Hister are so nearly impenetrable, that it is very difficult to make a pin pass through them; and the sinaller stagbeetle (Dorcus parallelipipedus) will bear almost any weight - the head and trunk forming a slight angle with the abdomen - which passes over it upon the ground. Other insects are protected by the toughness of their skin. A remarkable instance of this is afforded by the common forest-fly (Hippobosca equina), which, as was before observed, can scarcely be killed by the utmost pressure of the finger and thumb.

The involuntary secretions of these little beings may also be regarded as means of defence which either conceal them from their enemies, nake them more difficult to be attacked, or render them less palatable. Thus, the white froth often observable upon rose-bushes, and other shrubs and plants, called by the vulgar frog-spittle, - but which, if examined, will be found to envelope the larva of a small hemipterous insect (Aphrophora spumaria), from whose anus it exudes, althongh it is sometimes ciscovered even in this concealment by the indefatigable wasps, and becomes their prey, - serves to protect the insect, which soon dies when exposed, not only from the heat of the sun and from violent rains, but also to hide it from the birds and its other foes. The cottony secretion that transpires through the skin of Eriosoma ${ }^{2}$, and some species of Coccus, and in which the eggs of the latter are often involved, may perhaps be of use to them in this view; either concealing them - for they look rather like little locks of cotton, or feathers, than anything animated - or rendering them distasteful to creatures that would otherwise prey upon them. The same remark may apply to the slimy caterpillars of some of the saw-fies (Selandria Cerasi, Allantus Scroplualarice, \&c.). The coat of slime of these animals, as Professor Peck observes ${ }^{3}$, retains its humidity though exposed to the fiercest sun. Under this head I shall also mention the phosphoric insects : the glow-worm (Lampyris); the lantern-fly (Fulgara); the fire-fly (Elater); and the electric centipede (Geophilus electricus); since the light emitted by these animals may defend them from the attack of some enemies. Mr. Sheppard once noticed a Carabus running round the lastmentioned insect, when shining, as if wishing, but afraid to attack it.

Various insects, doubtless, find the wonderful vitality ${ }^{4}$ with which they

Insect. Surinam. t. 57. Two different speeies of caterpillars apparently related to this of Madame Merian were in the late Mr. Francillon's cabinet, and are now in my possession.

2 To this genus belongs the apple Aphis, called $A$. lanigera.

3 Nat. Hist. of the Slug-worm, 7.

4 The penetrating genius of Lord Verulam discovered in a great degree the causes of this vitality. "They stirre," says he, speaking of insects, " a good while after their heads are off, or that they be cut in pieces; which is caused also for that their vital spirits are more diffused thorowout all their parts, and lesse confined to organs than in perfect creatures." Sylv. Sylvar. cent. vii. $\$ 697$. 
are endowed another means of defence ; at least of obviating the effects of an attack. So that, when to all appearance they are mortally wounded, they recover, and fulfil the end of their creation. Indeed female Lepidoptera, especially of the larger kinds, will scarcely die, do what you will, till they have laid their eggs. Dr. Arnold, a most acute observer, relates to Mr. MacLeay, that having pinned Scolic quadrimaculata, a hymenopterous insect, down in the same box with many others, amongst which was the humming-bird hawk-moth (Macroglossa stellatarum), its proper food; it freed itself from the pin that transfixed it, and, neglecting all the other insects in the box, attacked the Sphinx, and pulting it to pieces devoured a large portion of its abdomen.

We often wonder how the cheese-mite (Acarus Siro) is athand to attack a cheese wherever deposited; but when we learn from Leeuwenhoek that one lived eleven weeks gummed on its back to the point of a needle without food, our wonder will be diminished. ${ }^{1}$ Another species of mite (Uropoda vegetans) was observed by De Gecr to live some time in spirits of wine. ${ }^{2}$ This last circumstance reminds me of an event which befel myself, that I cannot refrain from relating to you, since it was the cause of my taking up the pursuit I am recommending to you. One morning I observed on my study window a little lady-bird yellow with black dots (Coccinella 22-puncta) - "You are very pretty," said I to myself, "and I should like to have a collection of such creatures." Immediately I seized my prey, and not knowing how to destroy it, I immersed it in geneva. After leaving it in this situation a day and a night, and seeing it without motion, I concluded it was dead, and laid it in the sun to dry. It no sooner, however, felt the warmth than it hegan to move, and afterwards flew away. From this time I began to attend to insects. - The chamæleon-fly (Stratyomis Chamcleon) was observed by Swammerdam to retain its vital powers after an immersion equally long in spirits of wine. Gœdart affirms that this $\mathrm{fly}$, on which account it was called chamæleon, will live nine months without food; a circumstance, if true, more wonderful than what I formerly related to you with respect to one of the aphidivorous flies. ${ }^{3}$ - If insects will escape unhurt fron a bath of alcohol, it may be supposed that one of water will be less to be dreaded by them. To this they are often exposed in rainy weather, when ruts and hollows are filled with water : but when the water is dried up, it is seldom that any dead carcasses of insects are to be secn in them. Mr. Curtis submerged the fragile aphides for sixteen hours; when taken out of the water they immediately showed signs of life, and out of four three survived the experiment :- an immersion of twenty-four hours, however, proved fatal to them. ${ }^{4}$

The late ingenious, learned, and lamented Dr. Reeve of Norwich, once related to me that he found in a hot fountain on the top of a mountain. near Leuk in Valais in Switzerland, in which the thermometer stood at $205^{\circ}$, transparent larvæ, probably of gnats, or some such insect. - Lord Bute also, in a letter to my late revered friend, the Rev. William Jones of Nayland, imparts a similar observation made by his Lordship at the baths of Abano, near the Euganian mountains, on the borders of the Paduan states. They are strong, sulphureous, boiling springs, oozing out of a rocky eninence in great numbers, and spreading over an acre of the top

1 Leeuw. Epist. 77., 1694.

3 Bib. Nat. ii. c. 3.
2 De Geer, vii. 127.

4 Linn. Trans, vi. 81. 
of a gentle hill. In the midst of these boiling springs, within three feet of five or six of them, rises a tepid one about blood-warm. But the most extraordinary circunstance which he relates is, that not only confervas were found in the boiling springs, but numbers of small black beetles, that died upon being taken ont and plunged into cold water. ${ }^{1}-$ And once, having taken in the hot dung of my cucumber-bed a small beetle (Synchita Juglandis), I immersed it in boiling water ; and, after keeping it submerged a sufficient time, as I thought, to destroy it, upon taking it out, and laying it to dry, it soon began to move and walk. Its native station being of so high a temperature, Providence has fitted it for it, by giving it extraoldinary powers of sustaining heat. Other insects are as remarkable for bearing any degree of cold. Some gnats that De Geer observed, survived alter the water in which they were was frozen into a mass of ice: and Reaumur relates many similar instances. ${ }^{2}$

The last passive means of defence that I mentioned, was the multiplication of insects. Some species, the Aphides for instance, and the Grasshoppers and Locusts, have such an infinite host of enemies, that were it not for their numbers the race would soon be annihilated.-But as passive means of defence have detained us sufficiently long, it is enough to have touched upon this head. Let us then now proceed to such as may be called active; in which the volition of the animal bears some part.

II. The active means of defence, which tend to secure insects from injury or attack, are much more numerous and diversified than the passive; and also more interesting, since they depend, more or less, upon the efforts and industry of these creatures theniselves. When urged by danger, they endeavour to repel it, either by having recourse to certain attitudes or motions; producing particular noises; emitting disagreeable scents or fluids; employing their limbs, or weapons, and valour ; concealing themselves in various ways, or by counteracting the designs and attacks of their enemies by contrivances that require ingenuity and skill.

The attitudes which insects assume for this purpose are various. Some are purely imitative, as in many instances cletailed above. I possess a diminutive rove-beetle (Aleockara complicans K. Ms.), to which my attention was attracted as a very minute, shining, round black pebble. This successful imitation was produced by folding its head under its breast, and turning up its abdomen over its elytra; so that the most piercing and discriminating eye would never have discovered it to be an insect. I have observed that a carrion beetle (Silpha thoracica) when alarmed has recourse to a similar manœuvre. Its orange-coloured thorax, the rest of the body being black, renders it particularly conspicuous. To obviate this inconvenience, it turns its head and tail inwards till they are parallel with the trunk and abcomen, and gives its thorax a vertical direction, when it resembles a rough stone. The species of another genus of beetles (Igathidium) will also bend both head and thorax under the elytra, and so assume the appearance of shining globular pebbles.

Related to the defensive attitude of the two last-mentioned insects, and precisely the same with that of the Armadillo (Dasypus) annongst quadrupeds, is that of one of the species of woodlouse (Armadilio vulgaris).

1 J. Mason Good's Anniversary Oration, delivered March 8. 1808, before the Medical Society of London, p. 31.

2 De Geer, vi. 355 . ; comp. 320, and Reaum. ii. 141-147. 
This inseet, when alarmed, rolls itself up into a little ball. In this attitude its legs and the underside of the body, which are soft, are entirely covered and defended by the hard erust that forms the upper surface of the animal. These balls are perfectly spherical, black and shining, and belted with narrow white bands, so as to resemble beautiful beads; and could they be preserved in this form and strung, would make very ornamental necklaces and bracelets. At least so thought Swammerdam's maid, who, finding a number of these insects thus rolled up in her master's garden, mistaking them for bearls, employed herself in stringing them on a thread: when, to her great surprise, the poor animals beginning to move and struggle for their libertv, crring out and running away in the utmost alarm, she threw down her prize. ${ }^{1}$ The golden-wasp tribe also (Chrysidida), all of which I suspect to be parasitic inseets, roll themselves up, as I have often observed, into a little ball when alarmed, and can thus secure themselves - the upper surface of the body being remarkably hard, and impenetrable to their weapons - from the stings of those Hymenoptera whose nests they enter with the view of depositing their eggrs in their offspring. Latreille noticed this attitude in Parnopes eamea, which, he tells us, Bembex rostrata pursues, though it attaeks no other similar insect, with great fury; and, seizing it with its feet, attempts to dispateh it with its sting, from which it thus secures itself. ${ }^{2}$ M. Lepelletier de Saint-Fargeau, to whom entomology is indebted for so many new facts relative to the manners of hymenopterous, inseets, has given us a striking account of a contest be. tween the art of one of these parasites (Hedychrum regizm) and the courage of one of the mason-bees, in endeavonring to defend its nest from its attack. The mason-bee had partly finished one of her cells, and flown away to collect a store of pollen and honey. During her absence the female parasitic Hedychrum, after having examined this cell by entering it head foremost, came out again, and walking backwards, had begun to introduce the posterior part of her body into it, preparatory to depositing an egg, when the mason-bee arriving laden with her pollen paste threw herself upon her enemy, which, availing herself of the means of defence above adverted to, rolled herself up into a compact ball, with nothing but the wings exposed, and equally invulnerable to the sting or mandibles of her assailant. In one point, however, our little defender of her domieile saw that her insidious foe was accessible; and, accordingly, with her mandibles eut off' her four wings, and let her fall to the ground, and then entering her eell with a sort of inquietude, deposited her store of food, and flew to the fields for a fresh supply; but scarcely was she gone before the Hedychrum, unrolling herself, and, faithful to her instinct and her object, though deprived of her wings, erept up the wall directly to the cell from whenee she had been precipitated, and quietly placed lyer egg in it against the side below the level of the pollen-paste, so as to prevent the mason-bee from seeing it on her return. ${ }^{3}$

Other insects endeavour to protect themselves from danger by simulating death. The common dung-ehafer (Geotrupes stercorarius), when touched, or in fear, sets out its legs as stiff as if they were made of ironwire - which is their posture when deal - and remaining perfectly motionless, thus deceives the rooks which prey upon them, and, like the

1 Hill's Suramm. i. 174.

¿ Encycl. Method. x. 8. Lacordaire, Introd. à t'Eutom. ii. 488.

2 Ann. du Mus. 1810, 5. 
ant-lion before celebrated, will eat them only when alive. A different attitude is assumed by one of the tree-chafers (Hoplia pulverulcuta), probably with the same view. It sometimes elevates its posterior legs into the air, so as to form a straight vertical line, at right angles with the upper surface of its body.- Another genus of insects of the same order, the pillbeetles (Byrrhus), have recourse to a method the reverse of this. They pack their legs, which are short and flat, so close to their body, and lie so entirely without motion when alarmed, that thcy look like a dead body, or rather the dung of some small animal. - Amongst the weevil tribe, most of the species of Germar's genus Cryptorynchus, including several modern genera or subgenera, when an entomological finger approaches them, as I have often experienced to my great disappointment, applying their rostrum and legs to the underside of their trunk, fall from the station on which you hope to entrap them to the ground or amongst the grass; where, lying without stirring a limb, they are scarcely to be distinguished from the soil around then. Thus also, doubtless, they often disappoint the bircls as well as the entomologist. - A little timber-boring beetle (Anobium pertinax, and others of the genus have the same faculty), which, when the head is withdrawn somewhat within the thorax, much resembles a monk with his hood, has long been famous for a most pertinacious simulation of death. All that has been related of the heroic constancy of American savages, when taken and tortured by their enemies, scarcely comes up to that which these little creatures exhibit. You may maim them, pull them linb from limb, roast them alive over a slow fire ${ }^{1}$, but you will not gain your end; not a joint will they move, nor show by the least symptom that they suffer pain. Do not think, however, that I ever tried these experiments upon them myself, or that I recommend you to do the same. I am content to believe the facts that I have here stated upon the concurrent testimony of respectable witnesses, without feeling any temptation to put the constancy of the poor insect again to the test. - A similar apathy is shown by some species of saw-flies (Scrifera), which, when alarmed, conceal their antennæ under their body, place their legs close to it, and remain without motion even when transfixed by a pin. - Spiders also simulate death by folding up their legs, falling from their station, and remaining motionless; and when in this situation they may be pierced and torn to pieces without their exhibiting the slightest symptom of pain. ${ }^{2}$

There is a certain tribe of caterpillar's called surveyor's (Gcometre), that will sometimes support themselves for whole hours, by means of their posterior legs, solely upon their anal extremity, forming au angle of various degrees with the branch on which they are standing, and looking like one of its twigs. Many concurring circunstances promote this deception. The body is kept stiff and immoveable with the separations of the segments scarcely visible; it terminates in a knob, the legs being applied close, so as to resemble the bud at the end of a twig; besiles which it often exhibits intermediate tubercles which inerease the resemblance. Its colour, too, is usually obscure, and similar to that of the bark of a tree. So that, doubtless, the sparrows and other birds are frequently deceived by this manœuvre, and thus baulked of their prey. Rösel's gardener, mistaking one of these caterpillars for a dead twig, started back in great

3 De Geer, iv. 220.

2 Smellie, Phil, of Nat. Hist. i. 150. 
alarm when upon attempting to break it off he found it was a living animal. ${ }^{1}$

But insects do not always confine themselves to attitudes by which they meditate escape or concealment ; they sometimes, to show their courage, put themselves in a posture of defence, and even have in view the annoyance as well as the repelling of their foes. The great rovebeetie (Goerius olens) presents an object sufficiently terrific, when with its large jaws expanded, and its abdomen turned over its head, like a scorpion, it menaces its enemies, some of which this ferocious attitude may deter from attacking it. Mr. Bingley informs us that the giant earwig (Labidura gigantea), il rare species that his researches have added to the catalogue of British insects, turns up over its head, in a similar manner, its abdomen, which, being armed at the end with a large forceps, must give it an appearance still more alarming. ${ }^{2}$

The caterpillars of some luaw-moths (Sphinx), particularly that which feeds upon the privet, when they repose, holding strongly with their prolegs the branch on which they are standing, rear the anterior part of their body so as to form nearly a right angle with the posterior; and in this position it will remain perfectly tranquil, - thus elnding the notice of its enemies, or alarming them, - perhaps for hours. Reaumur relates that a gardener in the employment of the celebrated Jussieu used to be quite disconcerted by the self-sufficient air of these animals, saying they must be very proud, for he had never seen any other caterpillars hold their heads so high. ${ }^{3}$ From this attitude, which precisely resembles that which sculptor's have assigned to the fabulous monster called by that name, the term Splinx has been used to designate this genus of insects. - The caterpillar of a moth (Lophopteryx camelina) noticed by the author just quoted, whenever it rests from feeding, turns its head over its back, then becomes concave, at the same time elevating its tail, the extremity of which remains in a borizontal position, with two short horns like ears behind it. Thus the six anterior legs are in the air, and the whole animal looks like a quadruped in miniature; the tail being its head - the horns its ears - and the reflexed head simulating a tail curled over its back. ${ }^{4}$ In this seemingly unnatural attitude it will remain without motion for a very long time.

Some lepidopterous larvæ, that fix the one half of the body and elevate the other, agitate the elevated part, whether it be the head or the tail, as if to strike what disturbs them. ${ }^{5}$ The giant caterpillar of a large North American moth (Ceracampa regalis) is armed behind the head and at the back of the anterior segments with seven or eight strong curved spines from half to three fourths of an inch in length. Mr. Abbot tells us that this caterpillar is called in Virginia the hickory-borned devil, and that when disturbed it draws up its head, shaking or striking it from side to side; which attitude gives it so formidable an aspect, that no one, he affirms, will venture to handle it, people in general dreading it as much as a rattlesnake. When, to convince the Negroes that it was harmless, he himself took hold of this animal in their presence, they used to reply that it could not sting bin, but would them. ${ }^{6}$ The species of a genus of beetles named

1 Rös. i v. 27.

2 Linn. Trans, $\mathrm{x}, 404$.

3 Reaum. ii. 253.

Reaum. ii. 260. t. 20. f. 10, 11 . Compare Sepp. IV.t. i. f. $3-7$.

5 Fieaum. i. 100.

6 Smith's Abbot's Ins. of Georgia, ii. 121. 
Malachius endeavour to alarm their enenies and show their rage by puffing out and inflating four vesicles from the sides of their body, which are of a bright red, soft, and of an irregular shape. When the cause of alarm is removed, they are retracted, so that only a small portion of them appears. $^{1}$

Insects often endeavour to repel or escape from assailants by their motions. Mr. White, mentioning a will bee that makes its nest on the summit of a remarkable hill near Lewes in Sussex, in the chalky soil, says :- "When people approach the place these insects begin to be alarmed, and with a sharp and hostile sound dash and strike round the heads and faces of intruders. I have often been interrupted myself while contemplating the grandeur of the scenery around me, and have thought myself in danger of being stung." 2- The hive-bee will sometimes have recourse to the same expedient, when her hive is approached too near, and thus give you notice what you may expect if you do not take her warning and retire.Humble-bees when disturbed, whether out of the nest or in it, assume some very grotesque and at the same time threatening attitudes. If you put your finger to them, they will either successively or simultaneously lift up the three legs of one side; turn themselves upon their back; bend up their anus and show their sting accompanied by a drop of poison. Sometimes they will even spirt out that liquor. When in the nest, if it be attacked, they also beat their wings violently and emit a great hum. ${ }^{3}$

These motions menace vengeance; those of some other insects are merely to effect their escape. Thus I have observed that the species of the May-fly tribe (Trichopter $a^{4}$ ), when I have attempted to take them, have often glided away from under my hand - without moving their limbs that I could discover - in a remarkable manner. ${ }^{5}$ M. de Villiers informs us that different species of moths of the genera Orthosin and Cerastis never avail themselves of their wings to escape the dangers which threaten them; but if you attempt to seize then immediately let themselves fall to the ground, and then begin running with such rapidity, that it is very difficult to obtain possession of them. ${ }^{6}$ And in like manner various Curculionide and other coleopterous insects, if they see any one approach, contract their legs, and suffer themselves to fall from the leaf or other surface on which they rest, among the grass or plants below, and thus escape. To notice the ordinary motions of insects, which are often means by which they avoid danger, would here be premature, since they will be fully considered in a subsequent letter. I shall, therefore, only mention the zigzag flight of butterflies and the traverse sailing of humble-bees, which certainly render it more difficult for the birds to catch them while on the wing.

Noises are another means of defence to which insects have occasional recourse. I have heard the lunar dung-beetle (Copris lunaris), when disturbed, utter a shrill sound. Dynastes Oromedon, another of the lamellicorn insects, was observed by Dr. Arnold to make, when alarmed, a kind of creaking noise, which it produced by rubbing its abdomen against its elytra. A third of the same tribe (Trox sabulosis) emits a small sibilant or chirping noise, as I once observed when I found several feeding in a ram's

1 De Geer, iv. 74.

2 Nat. Hist. ii. 268.

8 P. Huber, in Linn. Trans. vi. 219. Kirby, Mon. Ap. Angl. i. 201.

4 Kirby in Linn. Trans. xi. 87. note*.

5 Evidently by the action of the numerous spines on the legs all directed back wards, just as an ear of barley will mount up the sleeve of a coat.

e Ann. Soc. Ent. de France, xi. bull. xii. 
horn." The "drowsy hum" of beetles, humble-bees, and other insects in their flight, may tend to preserve them from some of their aërial assailants. And the angry chidings of the inhabitants of the hive, which are very distinguishable from their ordinary sounds, may be regarded as warning voices to those from whom they apprehend evil or an attack. I have before observed that the death's-head hawk-moth (Acherontia Atropos), when menaced by the stings of ten thousand bees enraged at her depredations upon their property, possesses the secret to disarm them of their fury. This insect, when in fear or danger, is known to produce a sharp, shrill, mournful cry, which, with the superstitious, has added to the alarm produced by the symbol of death which signalises its thorax. This cry, there is reason to believe, affects and disarms the bees, so as to enable her to proceed in her spoliations with impunity. ${ }^{2}$ One of these insects being once brought to a learned divine, who was also an entomologist, when he was unwell, he was so much moved by its plaintive noise, that, instead of devoting it to destruction, he gave the animal its life and liberty. I might say more upon this subject of defensive noises, but I shali reserve what I have further to communicate, to a letter which I purpose devoting to the sounds produced or enitted by insects.

You are acquainted with the singular property of the skunk (IViverra putorius L.), which repels its assailants by the fetid vapour that it explodes; but perhaps are not aware that the Creator has endowed many insects with the same property, and for the same purpose, some of which exhale powerful or disagreeable odours at all times, and from the general surface of their body; while they issue from others only through particular organs, and when they are attacked.

of the former description of defensive scents there are numerous examples, in almost every order; for, next to plants and vegetable substances, insects, of any part of the creation, afford the greatest diversity of odours. In the Coleoptera order a very common beetle, the whirlwig (Gyrinus natator), will infect your finger for a long time with a disagreeable rancid smell; while two other species, G. minutus and villosus, are scentless. Those unclean feeders, the carrion beetles ( Silpha L.), as might be expected from the nature of their food, are at the same time very fetid. Pliny tells us of a Blatta, which, from his description, is evidently the darkling-beetle (Blaps mortisaga), and which he recommends as an infallible nostrum, when applied with oil extracted from the cedar, in otherwise incurable nlcers, that was an object of general disgust on account of its ill scent, a character which it still maiutains ${ }^{3}$; which scent, from Mr. Thwaite's investigation of the internal anatomy of this insect, proceeds from two small oblong vesicles near the anus, the fluid contents of which, when they are extracted and dissected under water, rise in a bubble to the surface, and there becoming vaporised diffuse the fetid smell peculiar to the species. Numbers of the ground-beetles (Eutrechina), that are found under

1 Numerons other beetles make the same kind of sound, either by the friction of the head in the anterior prothoracic cavity, or by rubbing the narrowed front of the mesothorax against the sides of the posterior prothoracic cavity, or the abdomen against the elytra.

2 Huber appears to be of this opinion; he does not, however, lay great stress upon it. Yet there seems no other way of accounting for the impunity with which this animal commits its depredations. Huber, ii. 299.

3 Hist. Nat. 1. xxix. c. 6. 
stones, and in places that have not a free circulation of air, exhale a most disagreeable and penetrating odour, which De Geer observes resembles that of rancid butter, and is not soon got rid of. It is produced, he says, from an unctuous matter that transpires through the body ${ }^{1}$; but $I$ am rather inclined to think it proceeds from the extremity. I have noticed that some small beetles of the Omalium genus, for instance $O$. rivulare, and another species that $\mathbf{I}$ once found in abundance on the primrose $(O$. Primule $\mathrm{K}$. Ms.), especially the latter, are abominably fetid when taken, and that it requires more than one washing to free the fingers from it. Every one knows that the cock-roach (Blatta oricntalis), belonging to the Orthoptcra order, is not remarkable for a pleasant scent; but none are more notorious for their bad character in this respect than the bug tribe (Geocorise), which almost universally exhale an odour that mixes with the scent of cucumbers another extremely unpleasant and annoying. Some, however, are less disgusting, particularly Lygaus Hyoscyami, which yields, De Geer found, an agreeable odour of thyme. ${ }^{2}$ - Several lepidopterous larvæ are defended by their ill smell; but 1 shall only particularise the silk-worms, which on that account are said to be unwholesome. - Phryganea grandis, a kind of May-fly, is a trichopterous insect that offends the nostrils in this way; but a worse is Chrysopa Pcrla, a golden-eyed and lace-winged fly, of the next order, whose beauty is counterbalanced by a strong scent of human ordure that proceeds from it. - Numberless Hymenoptera act upon the olfactory nerves by their ill or powerful effluvia. One of them, an ant (Formica fctida De (reer, fotens Oliv.), has the same smell with the insect last mentioned. ${ }^{3}$ Our common black ant ( $F$. fuliginosa), whose curious nests in trees have been before described to you, is an insect of a powerful and penetrating scent, which it imparts to every thing with which it comes in contact; and Fabricius distinguishes another ( $F$. analis Latr., feetens F.) by an epithet (fotidissima) which sufficiently declares its properties. Many wild bees (Andrena) are distinguished by their pungent alliaceous smeli.

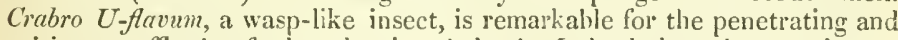
spirituous effluvia of ether that it exhales. ${ }^{4}$ Indeed there is scarcely any species in this order that has not a peculiar scent. - Some dipterous insects - though these in general neither offend nor delight us by it - are distinguished by their smell. Thus.Mesembrina mystacea, a fly that in its grub state lives in cow-dung, savours in this respect, when a denizen of the air, of the substance in which it first drew breath. ${ }^{5}$ And another (Sepsis cynipsea) emits a fragrant odour of beaum. ${ }^{6}$ - I have not much to tell you with respect to apterous insects, except that Iulus terrestris, a common millepede, leaves a strong and disagreeable scent upon the fingers when handled. ${ }^{7}$ Most of the insects $I$ have here enumerated, probably are defended from some enemy or injury by the strong vapours that exhale from them; and perhaps some in the list produce it from particular organs not yet noticed.

I shall next beg your attention to those insects that emit their smell from

1 iv. 86 .

2 De Geer, iii. 249. 374.

4 Kirby, Mon. Ap. Anql. i. 136. note $a$.

5 De Geer, vi. 131. Vleigen, Dipt. v. 12.

6 De Geer. vi. 135. 33.

3 Ibid. iii. 611 .

7 Ibid. vii. 581. 
particular organs. Of these some are furnished with a kind of scent-vessels which I shall call osmateria; while in others it issues from the intestines at the ordinary passage. In the former instance the organ is usually retractile within the body, being only exserted when it is used : it is generally a bifid vessel, something in the shape of the letter Y. Linné, in his generic character of the rove-beetles (Staphylinide), mentions two oblong vesicles as proper to this genus. These organs, - which are by no means common to the whole genus, even as restricted by late writers, - are its osmateria, and give forth the scent for which some species, particularly Ocypus brumipes, are remarkable. If you press the abdomen hard, you will find that these vesicles are only branches from a common stem; and you may easily ascertain that the smell of this insect, which mixes something extremely fetid with a spicy odour, proceeds from their extremity. A similar organ, half an inch in length, and of the same shape, issues from the neck of the caterpillar of the swallow-tail-butterfly (Papilio Machaon). When I pressed this caterpillar, says Bonnet, near its anterior part, it darted forth its horn as if it meant to prick me with it, directing it towards my fingers; but it withdrew it as soon as I left off pressing it. This horn smells strongly of fennel, and probably is employed by the insect, by means of its powerful scent, to drive away the flies and ichneumons that annoy it. A sinilar horn is protruded by the slimy larva of $P$. Anchises and many other Equites ${ }^{1}$, as also Parnassius Apollo. Another insect, the larva of a species of saw-fly described by De Geer, is furnished with osmateria, or scent-organs, of a different kind. They are situated between the first five pair of intermediate legs, which they exceed in size, and are perforated at the end like the rose of a watering-pot. If you touch the insect they shoot out like the horns of a snail, and emit a most nauseous odour, which remains long upon the finger; but when the pressure is removed they are withdrawn within the body. ${ }^{2}$ The grub of the poplar-beetle (Chrysomela Populi) also is remarkable for similar organs. (On each of the nine intermediate dorsal segments of its body is a pair of black, elevated, conical tubercles of a hard substance; from all of these when touched the animal emits a small drop of a white milky fluid, the smell of which, De Geer observes, is almost insupportable, being inexpressibly strong and penetrating. These drops proceed at the same instant from all the eighteen scent-organs; which forms a curious spectacle. The insect, however, does not waste this precious fluid : each drop instead of falling, after appearing for a moment and dispensing its perfume, is withdrawn again within its receptacle, till the pressure is repeated, when it re-appears. ${ }^{3}$

I shall now introduce you to the true counterparts of the skunk, which explode a most fetid vapour from the ordinary passage, and combat their enemies with repeated discharges of smoke and noise. The most fanous for their exploits in this way are those beetles which on this account are distinguished by the name of bombardiers (Brachinus). The most common species ( $B$. crepitans), which is found occasionally in many parts of Britain, when pursued by its great enemy, Calosoma inquisitor, seems at first to have no mode of escape : when suddenly a loud explosion is heard, and a blue

1 Merian Surinam, 17. Jones in Linn.Trans. ii. 64.

2 De Geer, ii. 989 . t. xxxvii. f. 6.

3 Ibid. v. 291. Compare Ray's Letters, 43. 
smoke, attended by a very disagreeable scent, is seen to proceed from its anus, which immediately stops the progress of its assailant: when it lias recovered from the effect of it, and the pursuit is renewed, a second discharge again arrests its course. The bombardier can fire its artillery twenty times in succession if necessary, and so gain time to effect its escape; and what is still more remarkable, Mr. Holme found that by pressing the abdomen near the anus, the discharges may be produced after death. In this way two specimens which had been dead eighteen hours gave, one fifteen, and the other nineteen discharges before being exhausted, and he even obtained explosions from some specimens which had been dead four days; but most of these, along with the noise, discharged a black grainy fluid without smoke. ${ }^{1}$ Another species ( $B$. displosor) makes explosions similar to those of $B$. crepitans: when irritated it can give ten or twelve good dis. charges; but afterwards, instead of smoke, it emits a yellow or brown fluid. By bending the joints of its abdomen it can direct its smoke to any particular point. M. Leon Dufour observes that this smoke has a strong and pungent odour, which has a striking analogy with that exhaled by nitric acid. It is caustic, reddening white paper, and producing on the skin the sensation of burning, and forming red spots, which pass into brown, and though washed remain several days. ${ }^{2}$ This burning sensation, M. Lacordaire informs us, when arising from the discharges of the large exotic species, is so painful, that he has often been obliged to let those which he had taken escape. The same power of emitting explosions, as a means of defence, is found also in some other coleopterous species, as in those of the genus Paussus, according to M. Payen, who had an opportunity of studying their habits in the isles of Sunda and the Moluccas ${ }^{3}$; in those of Ceropterus according to Mr. MacLeay ${ }^{4}$; and in those of $O z c e n a$ in a slight degree, according to M. Lacordaire.

Another expedient to which insects have recourse, to rid themselves of their enemies, is the emission of disagreeable fluids. These, some discharge from the mouth ; others from the anus; others again from the joints of the limbs and segments of the body ; and a few from appropriate organs.

You have doubtless often observed a black beetle crossing pathways with a slow pace, which feeds upon the different species of bedstraw (Galium), called by some the bloody-nose beetle (Timarcha tenebricosa). This insect, when taken, usually ejects from its mouth a clear drop or two of red fluid, which will stain paper of an orange colour. The carrionbeetles (Silpha and Necrophorus), as also the larger C'arabi, defile us, if handled roughly, with brown fetid saliva. Mr. Sheppard having taken one of the latter ( $C$. violaceus), applied it in joke to his son's face, and was surprised to hear him immediately cry out as if hurt : repeating the experiment with another of his boys, he complaincd of its making him smart : upon this he touched himself with it, and it caused as much pain as if, after shaving, he had rubbed his face with spirits of wine. This le observed was not invariably the case with this beetle, its saliva at other times being harmless. Hence he conjectures that its caustic nature, in the instance here recorded, might arise from its food; which he had reason to

1 Trans. Ent. Soc. Lond. ii. proc. vii.

2 Ann. du Mus. xviii. 70.

4 Westwood, Mod. Classif. of Ins, i. 151.

3 Lacordaire, Introd. à l'Entom. ii. 56. 
think had at that time been the electric centipede (Geophilus clectricus.) Lesser having once touched the anal horn of the caterpillar of some sphinx, suddenly turning its head round it vomited upon his hand a quantity of green viscous and very fetid fluid, which, though he washed it frequently with soap and fumed it with sulphur, infected it for two days. ${ }^{1}$ Lister relates that he saw a spider, when upon being provoked it attempted to bite, emit several times small drops of very clear fluid. ${ }^{2}$ Mr. Briggs observed a caterpillar canght in the web of one of our largest spiders, by means of a fluid which it sent forth, entirely dissolve the great breadth of threads with which the latter endeavoured to envelop it, as fast as produced, till the spider appeared quite exhausted.. ${ }^{3}$ The caterpillars also of a particular tribe of saw-flies, renarkable for the beautiful pennated antennæe of the males (Pteromus) ${ }^{4}$, when disturbed, eject a drop of fluid from their month. Those of one species inhabiting the fir-tree (Pt. Pini) are ordinarily stationed on the narrow leaves of that tree-which they devour most voracionsly in the manner that we eat radishes - with their head towards the point. Sometimes two are engaged opposite to each other on the same leaf. They collect in groups often of more than a hundred, and keep as close to each other as they can. When a branch is stripped they all move together to another. If one of these caterpillars be touched or disturbed, it immediately with a twist lifts the anterior part of its body, and emits from its mouth a drop of clear resin, perfectly similar both in odour and consistence to that of the fir. ${ }^{5}$ What is still more remarkable, no sooner does a single individual of the group give itself this motion, than all the rest, as if they were moved by a spring, instantaneously do the same. ${ }^{6}$ Thus these animals fire a volley, as it were, at their annoyers, the scent of which is probably sufficient to discomfit any ichneumons, flies, or predaceous beetles that may be desirous of attacking them.

Amongst those which annoy their enemies by the emission of fluids from their anus are the larger Carabi. These, if ronghly handled, will spirt to a considerable distance an acrid, caustic, stinking liquor, which, if it tonch the eyes or the lips, occasions considerable pain. ${ }^{7}$ - The rose. scented capricorn (Cerambyx moschatus) produced a similar cffect upon Mr. Sheppard by similar means. The fluid in this had a powerful odour of musk. - The acid of ants has long been celebrated, and is one of their most powerful means of defence. When the species that have no sting make a wound with their jaws, they insinuate into it some of this acid, the effluvia produced by which are so subtile and penetrating, that it is impossible to hold your head near the nest of the hill-ant (Formica rufa), when the ants are much disturbed, without being almost suffocated. This odour thus proceeding from myriads of ants is powerful enough, it is said, to kill

1 Lesser, 1. i. 284. note 6.

2 De Araneis, 27.

3 This gentleman is of opinion that spiders possess the means of re-dissolving their webs. He observed one, when its net was broken, run up its thread, and gathering a considerable mass of the web into a ball, suddenly dissolve it with fluid. He also observes that, when wiuding up a powerful prey, a spider can form its threads into a broad sheet.

+ Jurine, Hymenopt. t. vi. f. 8.

5 De Geer, ii. 971 .

61 owe the knowledge of this circumstance to Mr. MacLeay.

7 De Geer, iv. 86. Geofit. i. 141. 
a frog, and is probably the means of securing the nest from the attack of many enemies. - Dr. Arnold observed a species of bug (Scutellera) abundant upon some polygamous plants which he could not determine, and in all their different states. They were attended closely by hosts of ants, and when disturbed emitted a very stiong smell. One of these insects ejected a minute drop of fluid into one of his eyes, which occasioned for some hours considerable pain and inflammation. In the evening, however, they appeared to subside; but on the following morning the inflammation was renewed, became worse than ever, and lasted for three days.

Other insects, when under alarm, discharge a fluid from the joints and segments of their body. You have often seen what has been called the unctuous or oil beetle (Meloe Proscarabaus), and I dare say, when you took it, have observed orange-coloured or decp-yellow drops appear at its joints. As these insects feed upon acrid plants, the species of crow-foot or Ranunculus, it is probable that this fluid partakes of the nature of their food, and is very acrimonious - and thus may put to flight its insect assailants or the birds, from neither of which it could otherwise escape, being a very slow and sluggish, and at the same time very conspicuous animal. Another beetle (Elenophorus collaris) has likewise this ficulty. - The lady-bird, we know, has been recommended as a cure for the tooth. ache. This idea may have taken its rise from a secretion of this kind being noticed upon it. I have observed that one species (Coccinella bipunctata), when taken, ejects from its joints a yellow fluid, which yields a powerful but not agreeable scent of opium. - Asilus crabroniformis, a dipterous insect, once when I took it enitted a white milky fluid from its proboscis, the joints of the legs and abdomen, and the anus. The common scorpion-fly (Raphidia ophiopsis) likewise, upon the same occasion ejects from its proboscis a brown and fetid drop.' Some insects have peculiar organs from which their fluids issue, or are ejaculated. Thus the larva of saw-flies, when taken into the hand, cover themselves with drops, exuding from all parts of their body, of an unpleasant penetrating scent. ${ }^{2}$ That of Cimbex lutea, of the same tribe, from a small hole just above each spiracle, syringes a similar fluid in horizontal jets of the diameter of a thread, somctimes to the distance of more than a foot. ${ }^{3}$ - The caterpillar of the great cmperor moth (Saturnia Pavonia major) also spirts out, when the spines that cover them are touched, clear lymph from its pierced tubercles. ${ }^{4}-$ Willoughby has remarked a curions circumstance with respect to a water beetle (Acilius sulcatus) which ought not to be overlooked. A transverse line of a pale colour is observable upon the elytra of the male; where this line terminates certain oblong pores are visible, from which he affirms he has often seen a milky fluid exuding ${ }^{5}$; and what may confurm his statement, I bave nore than once observed such a fluid issue from the male of this genus. - The caterpillar of the puss-moth (Cerura vinula), as well as those of several other species, has a cleft in the neck between the heal and the first pair of legs. From this issues, at the will of the animal, a singular syringe, laterally bifid; the branches of which are terminated by a nipple perforated like the rose of a wateriur-pot. By means of this organ, when touchel, it will syringe a fluid to a considerable distance, wivich, if it enters the eyes, gives them acute, but not lasting pain. The animal when taken

1 De Geer, ii. 734 .

4 Rösel, iv. 162. De Geer, i. 273.
2 Reamur, v. 96 .

E E 3
3 De Geer, ii. 937. 5 Fai, Hist. Ins. 94. n. 3. 
from the tree on which it feeds, thongh supplied with its leaves, loses this faculty, with which it is probably endowed to drive off the ichneumons that infest it. ${ }^{1}$ - And, to name no more, the great tiger-moth (Euprepia Caja), when in its last or perfect state, has near its head a remarkable tuft of the most brilliant carmine, from amongst the hairs of which, if the thorax be touched, some minute drops of transparent water issue, doubtless for some sinilar purpose. ${ }^{2}$

The next active means of defence with which Creative Wisdom has endowed these busy tribes, are those limbs or weapons with which they are furnished. The insect lately mentioned, the puss-moth, besides the syringes just described, is remarkable for its singular forked tail, entirely dissimilar to the anal termination of the abdomen of most other caterpillars. This tail is composed of two long cylindrical tubes novable at their base, and beset with a great number of short stiff spines. When the animal walks, the two branches of the tail are separated from each other, and at every step are lowered so as to touch the plane of position; hence we may conclude that they assist it in this motion, and supply the place of hind legs. If you touch or otherwise incommode it, from each of the above branches there issues a long, cylindrical, slender, fleshy, and very flexible organ of a rose colour, to which the caterpillar can give every imaginable curve or inflection, causing it sometimes to assume even a spiral form. It enters the tube, or issues from it, in the same manner as the horns of snails or slugs. These tails form a kind of double whip, the tubes representing the handle, and the horns the thong or lash with which the animal drives away the ichneumons and flies that attempt to settle upon it. Touch any part of the body, and immediately one or both the horns will appear and be extended, and the animal will, as it were, lash the spot where it feels that you incommode it. De Geer, from whom this account is taken, says that this caterpillar will bite very sharply. ${ }^{3}$ - Several larvæ of butterflies, distinguished at their head by a semi-coronet of strong spines, figured by Madame Meriun, are armed with singular anal organs ${ }^{4}$, which may have a similar use. Rösel, when he first saw the caterpillar of the puss-moth, stretched out his hand with great eagerness, so he tells us, to take the prize; but when in addition to its grim attitude he beheld it dart forth these menacing catapults, apprehending they might be poisonous organs, his courage failed him. At length, without touching the monster, he ventured to cut off the twig on which it was, and let it drop into a box! ${ }^{5}$ The caterpillar of the gold-tail moth (Porthcsia chrysorhoca) has a remarkable aperture, which it can open and shut, surrounded by a rim on the upper part of each segment. This aperture includes a little cavity, from which it has the power of darting forth small flocks of 2 coitony metter that fills it. ${ }^{6}$ This manœuvre is probably connected with our present subject, and employed to defend it from its enemies. It also ejects a fluid from its anus.

There is a moth in New Holland, the larva of which annoys its foes in a different way : from eight tubercles in its back it darts forth, when alarmed, as many bunches of little stings, by which it inflicts very painful and venomous wounds.;

1 De Geer, i. 324.

3 Ibid. i. 322.

5 l. iv, 122 .

7 Lewin's Prodromus.
2 Ibid. i. 208.

4 Ins. Surinam. t. viii. xxiii. xxxiii.

6 Iieaum. ii. 155 . t. vii, f. $2-7$. 
The caterpillar of the moth of the beach (Stauropus Fagi), called the lobster, is distinguished by the uncommon length of its anterior legs. Mr. Stephens, an acute entomologist, relates to me that he once saw this animal use them to rid itself of a mite that incommoded it. They are probably equally useful in delivering it from the ichneumon and its other insect enenies. Dr. Arnold has made a curious observation (confirmed by Dr. Forsström with respect to others of the genus) on the use of the long processes or tails that distinguish the secondary wings of Thecla Iarbas. These processes, he remarks, resemble antennæ, and when the butterfly is sitting it keeps them in constant motion; so that at first sight it appears to have a head at each extremity ; which deception is much increased by a spot resembling an eye at the base of the processes. These insects, perhaps, thus perplex or alarm their assailants. - Goedart pretended that the anal horn with which the caterpillars of so many hawk-moths (Sphingide) are armed, answers the cnd of a sting, instilling a dangerous venom : but the observations of modern entomologists have proved that this is altogether fabulous, since the animal has not the power of moving them. ${ }^{1}$ Their use is still unknown.

Whether the long and often threatening horns on the head, the thorax, and even elytra, with which many insects are armed, are beneficial to them in the view under consideration, is very uncertain. They are frequently sexual distinctions, and have a reference probably rather to sexual purposes and the economy of the animal, than to anything else. They may, however, in some instances deter enemies from attacking them; and therefore it was right not to omit them wholly, though I shall not further enlarge upon them. Their mandibles or upper jaws, thougl 1 principally intended for mastication, - and in the case of the Hymenopterc, as instruments for various economical and mechanical uses, - are often employed to annoy their enemies or assailants. I once suffered considerable pain from the bite of the common water-beetle (Dytiscus marginalis), as well as from that of the great rove-beetle (Goerius olens); but the most tremendous and effectual weapon with which insects are armed - though this, except in the case of the scorpion, is also a sexual instrument, and useful to the females in oviposition - is their sting. With this they keep not only the larger animals, but even man himself, in awe and at a distance. But on these I enlarged sufficiently in a former letter. ${ }^{2}$

These weapons, fearful as they are, would be of but little use to insects if they had not courage to employ them : in this quality, however, they are by no means deficient ; for, their diminutive size considered, they are, nany of them, the most valiant animals in nature. The giant bulk of an elephant would not deter a hornet, a bee, or even an ant, from attacking it, if it was provoked. I once observed a small spider walking in my path. On putting my stick to it, it immediately turned round as if to defend itself. On the approach of my finger, it lifted itself up and stretched

1 De Geer, i. 149.

2 Mr. MacLeay relates to me, from the communications of Mr. E. Forster, the following particulars respecting the history of Mutilla coccinea, which from this account appears to be one of the most redoubtable of stinging insects. The females are most plentiful in Maryland in the months of July and August, but are never very numerous. They are very active, and have been observed to take flies by surprise. A person stang by one of them lost his senses in five minutes, and was so ill for several days that his life was despaired of. 
out its legs to meet it. - In Ray's Letters mention is made of a singular combat between a spider and a toad fought at Hetcorne near Sittinghurst ${ }^{1}$ in Kent; but as the particulars and issue of this famous duel are not given, I can only mention the circumstance, and conjecture that the spider was victorious! ${ }^{2}$ Terrible as is the dragon-fly to the insect world in general, putting to flight and devouring whole hosts of butterflies, Mayflies, and others of its tribes, it instils no terror into the stout heart of the scorpion-fly (Panorpa communis), though much its inferior in size and strength. Lyonnet saw one attack a dragon-fly of ten times its own bigness, bring it to the ground, pierce it repeatedly with its proboscis; and had he not by his eagerness parted them, he doubts not it would have destroyed this tyrant of the insect creation. ${ }^{3}$

When the death's head hawk-moth was introduced by Huber into a nest of humble-bees, they were not affected by it, like the hive-bees, but attacked it and drove it out of their nest, and in one instance their stings proved fital to it. ${ }^{4}$ A black ground-beetle devours the eggs of the mole cricket, or Gryllotalpa. To defend them, the female places herself at the entrance of the nest - which is a neatly smoothed and rounded chamber protected by labyrinths, ditches, and ramparts - and whenever the beetle attempts to seize its prey, she catches it and bites it asunder. ${ }^{5}$

I know nothing more astonishing than the wonderful muscular strength of insects, which, in proportion to their size, exceeds that of any other class of animals, and is likewise to be reckoned amongst their means of defence. Take one of the common chafers or dung-beetles (Geotrupes stercorarius, or Copris lunaris) into your hand, and observe how he makes his way in spite of your utmost pressure; and read the accounts which authors have left us of the very great weights that a flea will casily move, as if a single man should draw a waggon with forty or fifty hundred weight of hay: - but upon this I shall touch hereafter, and therefore only hint at it now.

We are next to consider the modes of conccalment to which insects have recourse in order to escape the observation of their encmies. One is by covering themselves with various substances. Of this description is a little water-beetle (Elophorus aquaticus) which is always found covered with mud, and so when feeding at the bottom of a pool or pond can scarcely be distinguished, by the predaceous aquatic insects from the soil on which it rests. Another very ninute insect of the same order (Liminius ancus) that is found in rivulets under stones and the like, sometimes conceals its elytra with a thick coating of sand, that becomes nearly as hard as stone. I never met with these animals so circumstanced but once; then, however, there were several which had thus defended themselves, and I can now show you a specimen. - A species of a minute coleopterous genus (Georyssas areniferus ${ }^{6}$ ), which lives in wet spots where the toad-rush (Juncus

1 Hedcorne near Sittingbourne.

5 Lesser, 1. i. 263. Note †.

4 Iluber, Nouv. Obs. ii. 301.

5 Bingley, Animal. Biogr. iii. 1st Ed. 247. White, Nat. Hist. ii. 82.

6 In former editions of this work this insect was stated to be synonymous with Trox dubius of Panzer, which it much resembles, except in the sculpture of the prothorax (Fn. Ins. Germ. Init. Ixii. t. 5.); but as Schönherr and Gyllenhall, who had better means of ascertaining the point, regarded Georyssus pygmecus Latr. as Panzer's insect, the reference is now omitted. $G$. areniferus differs considerably from G. pygmeus, as described by Gyllenhall (Insect. Suec. I. iii. 675.) The front is 
bufonius) grows, covers itself with sand; and another nearly related to it (Chcetophorus cretiferus $\mathrm{K}$.) which frequents chalk, whitens itself all over with that substance. As this animal, when clean, is very black, were it not for this manceuvre, it would be too conspicuous upon its white terlitory to have any chance of escape from the birds and its other assailants. - No insect is more celebrated for rendering itself hideous by a coat of dirt than the Reduvius personatus, a kind of bug sometimes found in houses. When in its two preparatory states, every part of its body, even its legs and antennæ, is so covered with the dust of apartments, consisting of a mixture of particles of sand, fragments of wool or silk, and similar matters, that the animal at first would be taken for one of the ugliest spiders. This grotesque appearance is aided and increased by motions equally awkward and grotesque, upon which I shall enlarge hereafter. If you touch it with a hair.pencil or a feather, this clothing will soon be removed, and you may behold the creature unmasked, and in its proper form. It is an insect of prey ; and amongst other victims will devour its more hateful congener the bed-bug, Its slow movements, combined with its covering, seem to indicate that the object of these manœuvres is to conceal itself from observation, probably, both of its enemies and of its prey. It is therefore properly noticed under my present head.

As Hercules, after he had slain the Nemean lion, made a doublet of its skin, so the larva of another insect (Hemerobius chrysops, a lace-winged fly with golden eyes) covers itself with the skins of the luckless Apluides that it has slain and devoured. From the head to the tail, this pigmy destroyer of the lielpless is defended by a thick coat, or rather mountain composed of the skins, limbs, and down of these creatures. Reaumur, in order to ascertain how far this covering was necessary, removed it, and put the animal into a glass, at one time with a silk cocoon, and at another with raspings of paper. In the first instance in the space of an hour it had clothed itself with particles of the silk; and in the second, being again laid bare, it found the paper so convenient a material, that it made of it a coat of unusual thickness. ${ }^{2}$

Insects in general are remarkable for their cleanliness ; - however filthy the substances which they inhahit, yet they so manage as to keep themselves personally neat. Several, however, by no means deserve this character; and I fear you will scarcely credit me when I.tell you that

not rugulose, the vertex is channelled, the antenna shorter than the liead; the prothorax is rather shining, marked anteriorly with several excavations, in the middle of which is a channel forming a reversed cross with a trausverse impression. MIr. Westwood remarks that the earth with which this insect is coated cannot be for concealment, as above stated, because it is but rarely found so covered, and only when it has by chance found its way into soft muddy ground. (Mod. Class of Ins. i. 119.) $\mathrm{My}$ own observations, lowever, lead to the different couclusion giren above. I remember as if yesterday, though thirty-six years since, the surprise with which I saw creeping in a moist (but not watery) sand-pit at Elloughton, near Hull, when entomologising, scores of what seemed little moving masses of sand, and my delight on finding the, to me, new and singular insect which was concealed beneath; and as I afterwards repeatedly found the same insect in similar situations, invariably coated with sand (not eartli), and never without this covering, I cannot think this circumstance accidental.

1 De Geer, iii. 283. Geoff. Hist. Ins. i. 437.

2 lieaum. iii. 391 . 
some shelter themselves under an umbrella formed of their own excrement! You will exclaim, perhaps, that there is not a parallel case in all nature ; - it may be so; - yet as I am bound to confess the faults of insects as well as to extol their virtues, I must not conceal from you this opprobrium. Beetles of three different genera are given to this Hottentot habit. The first to which I shall introduce you is one that has long been celebrated under the name of the beetle of the lily (Crioceris merdigera, Cantaride de' Gigli Vallisu.). The larvæ of this insect have a very tender skin, which appears to require some covering from the impressions of the external air and from the rays of the sun; and it finds nothing so well adapted to answer these purposes, and probably also to conceal itself from the birds, as its own excrement, with which it covers itself in the following manner. Its anus is remarkably situated, being on the back of the last segment of the body, and not at or under its extremity, as obtains in most insects. By means of such a position, the excrement when it issues from the body, instead of being pushed away and falling, is lifted up above the back in the direction of the head. When entirely clear of the passage, it falls, and is retained, though slightly, by its viscosity. The grub next, by a movement of its segments, conducts it from the place where it fell to the vicinity of the head. It effects this by swelling the segment on which the excrement is deposited, and contracting the following one, so that it necessarily moves that way. Although, when discharged, it has a longitudinal direction, by the same action of the segments the animal contrives to place every grain transversely. Thus, when laid quite bare, it will cover itself in about two hours. There are often many layers of these grains upon the back of the insect, so as to form a coat of greater diameter than its body. When it becomes too heavy and stiff, it is thrown off, and a new one begun. ${ }^{1}$ - The larvæ of the various species of the tortoisebeetles (Cassida L.) have all of them, as far as they are known, similar habits, and are furnished besides with a singular apparatus, by means of which they can elevate or drop their stercorarious parasol so as most effectually to shelter or shade them. The instrument by which they effect this is an anal fork, upon which they deposit their excrement, and which in some is turned up and lies flat upon their backs; and in others forms different angles, from very acute to very obtuse, with their body; and occasionally is unbent and in the same direction with it. ${ }^{2}$ In some species the excrement is not so disgusting as you may suppose, being formed into fine branching filaments. 'This is the case with $C^{\prime}$. maculata $\mathrm{L}^{3}{ }^{3}-$ In the cognate genus Imatidium, the larvæ also are merdigerous; and that of $I$.

- Leayanum Latr., taken by Major-General Hardwicke in the East Indies, also produces an assemblage of very long filaments, that resemble a dried fucus or a filamentous lichen. The clothing of the Tinece, clothes-moths, and others, and also of the case-worms, having enlarged upon in a former letter, I need not describe here.

Some insects, that they may not be discovered and become the prey of their enemies when they are reposing, conceal themselves in flowers. The male of a little bee (Heriades ${ }^{4}$ Campanularum), a true Sybarite, dozes voluptuously in the bells of the different species of Campanula - in which, in-

1 Reaum. iii. 220. Compare Vallisnieri, Esperienz. ed Osservaz. 195. Ed. 1726.

2 Reaum. 233.

4 Apis. * . c. 2. r. K. 5 Kirby in Lin. Trans. iii. 10. 
ãeed, I have often found other kinds asleep. Linné named another species florisomnis on account of a similar propensity. A third, a most curious and rare species (Andrena ${ }^{1}$ spinigera), shelters itself when sleeping, at least I once fonnd it there so circumstanced, in the nest-like umbel of the wild carrot. You would think it a most extraordinary freak of nature, should any quadruped sleep suspended by its jaws (some birds, however, are said, I think, to have such a habit, and Sus Babyronssa one something like it), - yet insects do this occasionally. Linné informs us that a little bee (Epeolus ${ }^{2}$ variegatus) passes the night thus suspended to the beak of the flowers of Geranium phenem: and I once found one of the vespiform bees (Nomada ${ }^{3}$ Goodeniana) hanging by its mandibles by the edge of a hazel-leaf, apparently asleep, with its limbs relaxed and folded. On being disengaged fiom its situation it became perfectly lively.

There is no period of their existence in which insects usually are less able to help themselves, than during that intermediate state of repose which precedes their coming forth in their perfect forms. I formerly explained to yon how large a portion of them during this state cease to be locomotive, and assume an appearance of death. In this helpless condition, unless Providence had furnished them with some means of security, they must fall an easy prey to the most insignificant of their assailants. But even here they are taught to conceal themselves from their enemies by various and singular contrivances. Some seek for safety by burying themselves, previously to the assumption of the pupa, at a considerable depth under the earth; others bore into the heart of trees, or into pieces of timber; some take their residence in the hollow stalks of plants: and many are concealegd under leaves, or suspend themselves in dark places, where they cannot readily be seen. But in this state they are not only defended fiom harm by the situation they select, but also by the covering in which numbers envelop themselves; for besides the leathery case that defends the yet tender and unformed imago, many of these animals know how to weave for it a costly shroud of the finest materials, through which few of its enemies can make their way ; - and to this curious instinct, as I long since observed, we owe one of the most valuable articles of commerce, the silk that gives lustre to the beauty of our females. These shrouds are sometimes double. Thus the laryæ of certain saw-flies spin for themselves a cocoon of a soft, flexible, and close texture, which they surround with an exterior one composed of a strong kind of net-work, which withstands pressure like a racket. ${ }^{4}$ Here nature has provided that the inclosed animal shall be protected by the interior cocoon from the injury it might be exposed to from the harshness of the exterior, while the latter by its strength and tension prevents it from being hurt by any external pressure.

But of all the contrivances by which insects in this state are secured from their enemies, there is none more ingenious than that to which the Mayflies ('I'richopter'a) have recourse for this purpose. You have heard before that these insects are at first aquatic, and inhabit curious cases made of a variety of materials, which are usually open at each end. Since they must reside in these cases, when they are become pupæ, till the time of their final change approaches, if they are left open, how are the animals, now

1 Melitta.**. c. $\mathrm{K}$.

3 Apis. b. * $\dot{\mathrm{K}}$.
2 Apis. * *. b. K.

1 Reaum. v. 100 . 
become torpid, to keep out their enemies? Or, if they are wholly closed, how is the water, which is necessary to their respiration and life, to be introduced? These sagacious creatures know how to compass both these ends at once. They fix a grate or portcullis to each extremity of their fortress, which at the same time keeps ont intruders and admits the water. These grates they weave with silk spun from their anus into strong threads, which cross each other, and are not soluble in water. One of them, described by De Geer, is very remarkable. It consists of a small, thickish, circular lamina of brown silk, becoming as hard as gum, which exactly fits the aperture of the case, and is fixed a little within the margin. It is pierced all over with holes disposed in concentric circles, and separated by ridges which go from the centre to the circumference, but often not quite so regularly as the radii of a circle or the spokes of a wheel. These radii are traversed again by other ridges, which follow the direction of the circles of holes; so that the two kinds of ridges crossing each other form compartments, in the centre of each of which is a hole. ${ }^{1}$

Under this head I shall call your attention to another circumstance that saves from their enemies innumerable insects : - I mean their coming forth for flight or for food only in the night, and taking their repose in various places of concealment during the chay. The infinite hosts of moths (Phalana L.) - amounting in this country to more than a thousand species with few exceptions, are all night-fliers. And a considerable proportion of the other orders - exclusively of the Hymenoptera and Diptera, which are mostly day-fliers - are of the same description. One of the well-known whirlwigs or water-fleas, Gyrimus (Orectocheilus villosus), differs from its congeners, according to the observations of M. Robert, in running along the surface of the water only at night, hiding itself under stones on the banks by day. ${ }^{2}$ Many larve of moths also come out only in the night after their food, lying hid all day in subterraneous or other retreats. Of this kind is that of Fumea pulla and Nycterobius, whose proceedings have been before described. The caterpillar of another moth (Noctua subterranea F.) never ascends the stems of plants, but remains, a true Troglodyte, always in its cell under ground, biting the stems at their base, which falling bring thus their foliage within its reach. ${ }^{3}$

The habitations of insects are also usually places of retreat, which sectre them from many of their enemies: but I have so fully enlarged upon this subject on a former occasion, that it would be superfuous to do more than mention it here.

I am now to lay before you some examples of the contrivances, requiring skill and ingennity, by. which our busy animals occasionally defend themselves from the designs and attack of their focs. Of these I have already detailed to you many instances, which I shall not here repeat ; my history, therefore, will not be very prolix. I observed in my account of the societies of wasps, that they place sentinels at the mouth of their nests. The same preeaution is taken by the hive-bees, particularly in the night, when they may expect that the great destroyers of their combs, Galleria mellonella and its associates, will endearour to make their way into the hive. Observe them by moonlight, and you will see the sentinels pacing about

1 Reaum. iii. 170. De Geer, ii. 519. 545.

2 Ann. Soc. Ent. de. France, jv. bull, lxxx.

Eab. Ent. Syst. Em. iii. 70. 200. 
with their antennæ extended, and alternately directed to the right and left. In the meantime the moths flutter round the entrance; and it is curious to see with what art they know how to profit of the disadvantage that the bees, which cannot discern objects but in a strong light, labour under at that time. But should they touch a moth with these organs of nice sensation, it falls an inmediate victim to their just anger. The moth, however, seeks to glide between the sentinels, avoiding with the utmost caution, as if she were sensible that her safety depended upon it, all contact with their antennæ. These bees upon guard in the night are frequently heard to utter a very short low hum ; but no sooner cloes any strange insect or enemy touch their antennæ than the guard is put into a commotion, and the hum becomes louler, resembling that of bees when they fly, and the enemy is assailed by workers fiom the interior of the live. ${ }^{1}$

To defend themselves fiom the deatb's-lead hawk-moth, they have recourse to a different proceeding. In seasons in which they are annoyed by this animal, they often barricade the entrance of their hive by a thick wall mate of wax and propolis. This wall is built immediately behind and sometimes in the gateway, which it entirely stops up ; but it is itself piercel with an opening or two sufficient for the passage of one or two workers. These fortifications are occasionally varied : sometimes there is only one wall, as just described, the apertures of which are in arcades, and placed in the upper part of the masonry. At others many little bastions, one behind the other, are erected. Gateways masked by the anterior walls, and not corresponding with those in them, are made in the second line of building. These casemated gates are not constructed by the bees without the most urgent necessity. When their danger is present and pressing, and they are as it were compelled to seek some preservative, they have recourse to this mode of defence ${ }^{2}$, which places the instinct of these animals in a wonderful light, and shows how well they know how to adapt their proceed. ings to circumstances. Can this be merely sensitive? When attacked by strange bees, they have rccourse to a similar manœuvre; only in this case they make but narrow apertures, sufficient for a single bee to pass through. - Pliny affirms that a sick bear will provoke a hive of bees to attack him in order to let him blood. ${ }^{3}$ What will you say, if humble-bees have recourse to a similar manœuvre? It is related to me by Dr. Leach from the communications of Mr.Daniel Bydder - an indefatigable and well-informed collector of insects, and observer of their proceedings - that Bombus ${ }^{4}$ terrestris, when labouring under Acariasis from the numbers of a small mite ( $G a$. masus Gymnopterorum) that infest it, will take its station in an ant-hill ; where beginning to scratch and kick, and make a disturbance, the ants immediately come out to attack it, and falling foul of the mites, they destroy or carry them all off; when the bee, thus delivered from its enemies, takes its flight.

In this long detail, the first idea that will, I should hope, strike the mind of every thinking being, is the truth of the Psalmist's observation - that the tender mercies of God are over all his works. Not the least and most insignificant of his creatures is, we see, deprived of his patcrnal care and attention; none are exiled from his all-directing providence. Why then should man, the head of the visible creation, for whom all the inferior

1 Huber, Nouv. Obs. ii. 412.

3 Hist. Nat. l, viii, c. 36.
2 Ibicl. ii. 294.

4 Apis * *. e. 2. K. 
animals were created and endowed; for whose well-being, in some sense, all these wonderful creatures with their miraculous instincts, whose history I am giving you, were put in action,- - why should he ever doubt, if he uses his powers and faculties rightly, that his Creator will provide him with what is necessary for his present state? - Why should he imagine that a Being, whose very essence is Love, unless he compels him by his own wilful and obdurate wickedness, will ever cut him off from his care and providence?

Another idea that upon this occasion must force itself into our mind is, that nothing is made in vain. When we find that so many seemingly trivial variations in the colour, clothing, form, structure, motions, habits, and economy of insects are of very great importance to them, we may safely conclude that the peculiarities in all these respects, of which we do not yet know the use, are equally necessary ; and we may almost say, reversing the words of our Saviour, that not a hair is given to them without our Heavenly Father.

I am, \&c. 


\section{LETTER XXI1.}

\section{MOTIONS OF INSECTS. (Larva and pupa.)}

Amongst the means of defence to which insects have recourse, I have noticed their motions. These shall be the subject of the present letter. I shall not, however, confine myself to those by which they seek to escape from their enemies; but take a larger and more comprehensive survey of them, including not only every species of locomotion, but also the movements they give to different parts of their body when in a state of repose : and in order to render this survey more complete, I shall add to it some account of the various organs and instruments by which they move.

Whenever you go abroad in summer, wherever you turn your eyes and attention, you will see insects in motion. They are flying or sailing everywhere in the air; dancing in the sun or in the shade; creeping slowly, or marching soberly, or running swiftly, or jumping upon the ground; traversing your path in all directions ; coursing over the surface of the waters, or swimming at every depth beneath; emerging from a subterranean habitation, or going into one; climbing up the trees, or descending from them; glancing from flower to flower; now alighting upon the earth and waters, and now leaving them to follow the impulse of their various instincts; sometimes travelling singly; at other times in countless swarms: these the busy children of the day, and those of the night. If ${ }^{*}$ you return to your apartment - there are these ubiquitaries - some flying about - others pacing against gravity up the walls or upon the ceiling - others walking with ease upon the glass of your windows, and some even venturing to take their station on your own sacred person, and asserting their right to the lord of the creation.

This universal movement and action of these restless little animals gives life to every part and portion of our globe, rendering even the most arid desert interesting. From their visitations every leaf and flower becomes animated; the very dust seems to quicken into life, and the stones, like those thrown by Deucalion and Pyrrha, to be metamorphosed into locomotive beings. In the variety of motions which they exhibit, we see, as Cuvier remarks ${ }^{1}$, those of every other description of animals. They walk, run, and jump with the quadrupeds; they fly with the birds; they glide with the serpents; and they swim with the fish. And the provision made for these motions in the structure of their bodies is most wonderful and various. "If I was minded to expatiate," says the excellent Derhan, " I might take notice of the admirable mechanism in those that creep; the curious oars in those amphibious insects that swim and walk; the incom- 
parable provision made in the feet of such as walk or hang upon smooth surfaces; the great strength and spring in the legs of such as leap; the strong-made feet and talons of such as dig; and, to name no more, the admirable faculty of such as cannot fly, to convey themselves with spced and safety, by the help of their webs, or some other artifice, to ntake their bodies lighter than the air." 1

Since the motions, and instruments of motion, of insects are usually very different in their preparatory states, from what they are in the imago or perfect state, I shall therefore consider then separately, and divide my subject into - motions of larvæ, motions of pupæ, and motions of perfect insects.

I. Amongst larve there are two classes of movers; Apodous larvæ, or those that move without legs, and Pedate larvæ, or those that move by means of legs. I must here observe, that by the term legs, which I use strictly, I mean only jointed organs, that have fiee motion, and can walk or step alternately; not those spurious legs without joints, that have no free motion, and cannot walk or take alternate steps; such as support the middle and anus of the larvæ of most Lepidoptera and saw-flies (Serrifera).

Apodous larvæe seldom have occasion to take long journeys; and many of them, except when ahout to assume the pupa, only want to change their place or posture, and to follow their food in the sulstance, whether animal or vegetable, to which, when included in the egg, the parent insect committed them. Legs, therefore, would be of no great use to them, and to these last a considerable impediment. They are capable of three kinds of motion; they either walk, or jump, or swim. I use walking in an improper sense, for want of a better term equally comprehensive: for some may be said to move by gliding, and others (I mean those that, fixing the head to any point, bring the tail up to it, and so proceed) by stepping.

The motion of serpents was ascribed by some of the ancients (who were unable to conceive that it could be effected! maturally, unless by the aid of legs, wings, or fins) to a pretcrnatural cause. It was supposed to resemble the "ineessus deorum," and procured to these animals, amongst other causes, one of the highest and most honourable ranks in the emblematical class of their false divinities. ${ }^{2}$ Had they known Sir Joseph .Banks's discovery, that some serpents push themselves along by the points of their ribs, which Sir E. Home found to be curionsly constructed for this purpose, their wonder would have been diminished, and their serpent gods undeified. But though serpents can no longer makc good their claim to motion more deorum, some insects may take their places; for there are numbers of larvæ that, having neither legs, nor ribs, ror any other points by which they can push themselves forward on a plane, glide along by the alternate contraction and extension of the segments of their body. Had the ancient Egyptians been aware of this, their catalogue of insect divinities would have been wofully crowded. In this annular motion, the animal alternately supports each segment of the body upon the plane of position, which it is enabled to do by the little bundles of muscles attached to the skin, that take their origin within the body. ${ }^{3}$

1 Physico-Theol. Ed. 13. 366.

2 Encyct. Brit., art. Physiology, 709.

3 Cuvier, Anat. Comp. i. 430. 
I shall begin the list of walkers, the movements of which are aided by various instruments, with one which is well known to most people, - the grub of the nut-weevil (Balaninus $\mathrm{N}$ ncum). When placed upon a table, after lying some time, perhaps, bent in a bow, with its head touching its tail, at last it begins to move, which, though in no certain direction, it does with more speed than might be expected. Rösel fancied that this animal had feet furnished with elaws; but in this, as De Geer justly observes, he was altogether mistaken, since it has not the least rudiment of them, its motion being produced solely by the alternate contraction and extension of the segments of the body, assisted, perhaps, by the fleshy prominenees of its sides. Other larvx have this annular motion aided by a sliny secretion, which gives them further hold upon the plane on which they are moving, and supplies in some degree the place of legs or claws. That of the weevil of the common figwort (Cionus Scrophularice) is always covered with slime, which enables it, thongh it renders its appearance disgusting, to walk with steadiness, by the mere lengthening and shortening of its segments, upon the leaves of that plant. ${ }^{1}$ Of this kind, also, are those larvæ, mentioned above, reeeived by De Geer from M. Ziervogel, which, adhering to each other by a sliny seeretıon, glide along so slowly upon the ground as to be a quarter of an hour in going the breadth of the hand: whence the natives eall their bands $G \ddot{a r} d s-d r a g .{ }^{2}$

As a further help, others again eall in the assistance of their unguiform mandibles. These, whieh are peeuliar to grubs with a variable membranaceous, or rather retractile head ${ }^{3}$, especially those of the fly tribe (Mnscidce), when the animal does not use them, are retracted not only within the head, but even within the segments behind it ${ }^{4}$; but when it is moving, they are protruded, and lay hold of the surface on which it is placed. They were long ago noticed by the aecurate Ray. "This blackness in the head," says he, speaking of the maggot of the common flesh-fly, "is eaused by two black spines or hooks, which when in motion it puts forth, and fixing them in the ground, so drags along its body." 5 The larve of the aphidivorous flies (Scceva, \&c.), the ravages of which amongst the Aphides I have before described to you, transport themselves from place to place in the same way, walking by means of their teeth. Fixing their hind part to the substances on which they are moving, they give their boity its greatest possible tension; and, if I may so speak, thus take as long a step as they can : next laying hold of it with their mandibles, by setting free the tail, and relaxing the tension, the former is brought near the head. Thus the animal proceeds, and thus will even walk upon glass. ${ }^{6}$ Some grubs, as those of the lesser house-fly (Anthomyia canicularis), have only one of these claw-teeth ; and in some they have the form as well as the office of legs. ${ }^{7}$ Bonnct mentions an apodous larva, that, before it can use its mandibles, is obliged to spin, at eertain intervals, little hillocks or steps of silk, of which it then lays hold by them, and so drags itself along.

Besides their mandibular hooks, some of these grubs supply the want of

1 De Geer, v. 210.

2 Ibid. vi. 338 .

3 See MacLeay in Philos. Mag. \&c., N. Ser. No. 9. 178.

4. De Geer, vi. 65.

s Hist. Ins. 270 .

- Reaumur, iii. 369 .

7 De Geer, vi. 76 . Reaumur, iv. 376. Swamm. Bibl. Nat. Ed. Hill, ii. 46. a. to xx.xix. f. 3. h. h. 
legs by means of claws at their anus. Thus that of the flesh-fly, Ray tells us in the place just quoted, pushes itself by the protruded spines of its tail. The larva, also, of a long-legged gnat (Limnobia replicata), which in that state lives in the water, is furnished with these anal claws, which, in con. junction with its annular tension and relaxation, and the hooks of its mouth, assist it in walking over the aquatic plants. ${ }^{1}$

A remarkable difference, according to their station, obtains in the bots of gad-flies $(E$ stridce) ; those that are subcutaneous (Cuticole Clark) having no unguiform mandibles; while those that are gastric (Gastricola Clark), and those that inhabit the maxillary sinuses of animals (Cavicole Clark), are furnished with them. In this we evidently see Creative Wisdom adapting means to their end, for the cuticular bots having no plane surface to move upon, and imbibing a liquid food, in them the mandibular hooks would be superfluous. But they are furnished with other means by which they can accomplish such motions, and in contrary directions, as are necessary to them; the anterior part of each segment being beset with numbers of very minute spines, not visible except under a strong magnifier, sometimes arranged in bundles, which all look towards the anus; and the posterior part is, as it were, paved with similar hooks, but smaller, which point to the head. Thus we may conceive, when the animal wants to move forward, that it pushes itself by the first set of hooks, keeping the rest, which would otherwise impede motion in that direction, pressed close to its skin, or it may depress that part of the segment, and when it would move backwards that it employs the second. ${ }^{2}$ The other descriptions of bots, not being embedded in the flesh, but fixed to a plane, are armed with the mandibles in question, by which they can not only suspend themselves in their several stations, but likewise, with the aid of the spines with which their segments also are furnished, move at their pleasure. ${ }^{3}$ Other larræ of fies, as well as the bots, are furnished with spines or hooks - by which they take stronger hold - to assist them in their motions. Those mentioned in my last letter as inhabiting the nests of humble-bees, besides the six radii that arm their anus, and which, perhaps, may assist them in locomotion, have the margin of their body fringed with a double row of short spines, which are, doubtless, useful in the same way.

The next order of walkers amongst apodous larvæ are those that move by means of fleshy tuberculiform or pediform prominences, - which last resemble the spurious legs of the caterpillars of most Lepidoptera. Some, a kind of monopods, have only one of suclı prominences, which, being always fixed almost under the head, may serve, in some degree, the purpose of an unguiform mandible. The grub of a kind of gnat (Clironomus stercorarius), and also another, probably of the Tipularian tribe (found by De Geer in a subputrescent stalk of Angelica, which he was unable to trace to the fly), have each a fleshy leg on the underside of the first segment, which points towards the head and assists them in their motions. ${ }^{4}$ Others again go a little further, and are supported at their anterior extremity by a pair of spurious legs. An aquatic larva of a most singular form, and of the same

1 De Geer, vi. 355.

2 Reaum. iv. 416. t. xxxvi. f. 5. Compare Clark On the Bots, \&c. 48.

3 Mr. Clark (ibid. 62.) observed only rough points on the bots of the sheep, but these also have spines or hooks looking towards the anus. Reaum. iv. 556.t. $x \times x$. f. 11. 13. 15. I also observed them myself in the same grub.

4 De Geer, vi. t. xxii. f. 15 . i. t. xviii. f. 8. p. 
tribe, figured by Reaumur, is thus circumstanced. In this case the processes in question proceed from the head, and are armed with claws. ${ }^{1}$ Would you think it - another Tipularian grub is distinguished by three legs of this kind? It was first noticed by De Geer under the name of Tipula maculata (Tanypus monilis Meig.), who gives the following account of its motions and their organs:- It is found, he observes, in the water of swampy places and in ditches, is not bigger than a horse-hair, and about it quarter of an inch in length. Its mode of swimming is like that of a serpent, with an undulating motion of the body, and it sometimes walks at the bottom of the water, and upon aquatic plants. The most remarkable part of it are its legs, called by Latreille, but it should seem improperly, tentacula. They resemble, by their length and rigidity, wooden legs. The anterior leg is attached to the under side, but towards the head, of the first segment of the body. It is long and cylindrical, placed perpendicularly or obliquely, according to the different movements the animal gives it, and terminates in two feet, armed at their extremity by a coronet of long moveable hooks. These feet, like the tentacula of snails, are retractile within the leg, and even within the body, so that only a little stump, as it were, remains without. The insect moves them both together, as a lame man does his crutches, either backwards or forwards. The two posterior legs are placed at the anal end of the body. They are similar to the one just described, but larger, and entirely separate from each other, being not, like them, retractile within the body, but always stiff and extended. These also are armed with hooks. In walking, this larva uses these two legs much as the caterpillars of the moths called Geometra do theirs. By the inflection of the anus it can give them any kind of lateral movement, except that it can neither bend nor shorten them, since like a wooden leg, as I have before observed, they always remain stiff and extended. ${ }^{2}$ Lyonet had observed this larva, or a species nearly related to it; but he speaks of it as having four legs, two before and two behind. Probably, when he examined them, the common base, from which the fect are branches, was retracted within the body. ${ }^{3}$

Generally speaking, however, in these apodous walkers the place of legs is supplied by fleshy and often retractile mamillæ or tubercles. By means of these and a slimy secretion, unaided by mandibular hooks, the caterpillar of a little moth (Apoda Testudo) moves from place to place. ${ }^{4}$ A subcutaneous larva belonging to the same order, that mines the leaves of the rose, moves also by tubercular legs assisted by slime. It has eighteen homogeneous legs, with which, when removed from its house of concealment, it will walk well upon any surface, whether horizontal, inclined, or even vertical. ${ }^{5}$ But the greatest number of legs of this kind that distinguish any known larva is to be observed in that of a two-winged fly (Sccena Pyrastri) that devours the Aphides of the rose. This animal has six rows of tubercular feet, with which it moves, each row consisting of seven, making in all forty-two. ${ }^{6}$ The grub of the weevil of the dock

1 Reaum. v. t. vi. f. $5 . \mathrm{m} \mathrm{m}$.

2 De Geer, vi. 395. Mr. WV. S. MacLeay is of opinion that these legs are pedunculated spiracles (Phitos. Mag. N. Series, No. 9. 178.) ; but it is avident from De (reer's account that the animal uses them as legs, and like legs they are armed with books or elaws.

3 Lesser, I. i. 96 . note $\uparrow$.

5 De Geer, i. 447 , t. xxxi. f. 17.

4 Klemann, Beitrüge, 324.

6 Ibid. vi. 111. 
(Hypera Rumicis) has twenty-four tubercular legs : but, what is remarkable, the six anterior ones, being longer than the rest, seem to represent the real legs, while the others represent the spurious ones, of lepidopterous tarix. These legs, however, are all fleshy tubercles, and have no claws, the place of which is supplied by slime, which covers all the underside of the body, and hinders the animal from falling. ${ }^{1}$ Another weevil (Lixus paraplecticus) produces a grub inhabiting the water-hemlock, which has only six tubercles that occupy the place and are representatives of the legs of the perfect insect. ${ }^{2}$

Some larvæ liave these tubercles armed with claws. The maggot of a fly described by De Geer (Volucella plumata) has six pair of them, each of which has three long claws. This animal has a radiated anus, and seems related to those flies that live in the nests of humble-bees. ${ }^{3}$

Insects, in the peculiarities of their structure, as we have seen in many instances, sometimes realise the wildest fictions of the imagination. Should a traveller tell you that he had seen a quadruped whose legs were on its back, you would immediately conclude that he was playing upon your credulity, and had lost all regard to truth. What then will you say to me, when I affirm, upon the evidence of two most unexceptionable witnesses, Reaumur and De Geer, that there are insects which exhibit this extraordinary structure? The grub of a little gall-fly, appearing to be Cynips Quercus inferus of Linné, which inhabits a ligneous gall resembling a berry to be met with on the underside of oak-leaves, was found by the former to have on its back, on the middle of each segment, a retractile fleshy protuberance that resembled strikingly the spurious legs of some caterpillars. A little attention will conrince any one, argues Reaumur, that the legs of insects circumstanced like the one under consideration, if it has any, should be on its back. For this grub, inhabiting a spherical cavity, in which it lies rolled up as it were in a ring, when it wants to move, will be enabled to do so, in this hollow sphere, with much more facility, by means of legs on the middle of its back, than if they were in their ordinary situation. ${ }^{4}$ So wisely has Providence ordered every thing. Another similar instance is recorded by De Geer, which indeed had been previously noticed, though cursorily, by the illustrious Frenchman. ${ }^{5}$ There is a little larva, he observes, to be found at all seasons of the year, the depth of winter excepted, in stagnant waters, which keeps its body always doubled as it were in two, against the sides of ditches or the stalks of aquatic plants. If it is placed in a glass half full of water, it so fixes itself against the sides of it, that its head and tail are in the water while the remainder of the body is out of it; thus assuming the form of a siphon, the tail end being the longest. When this animal is disposed to feed, it lifts its head and places it horizontally on the surface of the water, so that it forms a right angle with the rest of the body, which always remains in a situation perpendicular to the surface. It then agitates, with vivacity, a couple of brushes, formed of hairs and fixed in the anterior part of the head, which, producing a current towards the mouth, it makes its meal of the various species of animalcula, abounding in stagnant waters, that come within the

1 De Geer, v. 233.

3 Ibik. vi. 137 . t. viii. f. 8,9 .

-5 Ibid. Hém. de l'Acad. Roy. des Sciences de Paris, An. 1714. p. 203.
2 Ibid. v. 228.

4 Reaum. iii. 496 . t. xlv. f. 3. 
vortex thus produced. As these animals require to be firmly fixed to the substance on which they take their station, and their back is the only part, when they are doubled as just described, that can apply to it, - they are furnished with minute legs armed with black claws, by which they are enabled to adhere to it. They have ten of these legs : the four anterior ones, which point towards the head and are distant from each other, are placed upon the fourth and filth dorsal segments of the body ; and the six posterior ones, which point to the anus and are so near to each other as at first to look like one leg, are placed on the eighth, ninth, and tenth. When the animal moves, the body continues bent, and the sixth segment, which is without feet, and forms the summit of the curve, goes first. ${ }^{l}$ De Geer named the fly it produces Tipula amphibia: it seems not clear, from his figure, to which of the modern genera of the Tipularic it belongs; nor is it referred to by Meigen.

I come now to the jumping apodes; and one of this description will immediately occur to your recollection, - that I mean which revels in our richest cheeses, and produces a little black shining fly (Tyrophaga Casei). These maggots have long been celebrated for their saltatorious powers. They effect their tremendous leaps - laugh not at the term, for they are truly so when compared with what human force and agility can accomplish - in nearly the same manner as salmon are stated to do when they wish to pass over a cataract, by taking their tail in their mouth, and letting it go suddenly. When it prepares to leap, our larva first erects itself upon its anus, and then bending itself into a circle by bringing its head to its tail, it pushes lorth its unguiform mandibles, and fixes them in two cavities in its anal tubercles. All being thus prepared, it next contracts its body into an oblong, so that the two halves are parallel to each other. This done, it lets go its hold with so violent a jerk that the sound produced by its mandibles may be readily heard, and the leap takes place. Swamnerdam saw one, whose length did not exceed the fourth part of an inch, jump in this manner out of a box six inches deep; which is as if a man six teet high should raise himself in the air by jumping 144 feet! He had seen others leap a great deal higher. ${ }^{2}$ The grub of a little gnat lately noticed (Chironomus stercorarius) has a similar fuculty, though executed in a manner rather different. These larvæ, which inhabit horse-dung, though deprived of feet, cannot move by annular contraction and dilatation; but are able, by various serpentine contortions, aided by their mandibles, to move in the substance which constitutes their food. Should any accident remove them from it, Providence has enabled them to recover their natural station by the power I am speaking of. When about to leap, they lo not, like the cheese-fly, erect themselves so as to form an angle with the plane of position; but lying horizontally, they bring the anus neal the heat, regulating the distance by the length of the leap they mean to take; when fixing it firmly, and then suddenly resuming a rectilinear position, they are carried through the air sometimes to the distance of two or three inches. They appear to have the power of flattening their anal extremity, and even of rendering it concave : by means of which it may probably act as a sucker, and so be mine firmly fixable. ${ }^{3}$ The grub of a fly, whose proceedings in

1 De Geer, vi. 380. t. xxiv. f. 1-9. Mr. Westwood refers this insect to the modern genus Dixa. (Mod. Class, ii. p. 527.)

2 Swanm. Bibl. Nat. Ed. Hill, ii.64. b.

3 De Geer, vi. 389 . 
that state I have before noticed (Leptis Vermileo), will, when removed from its habitation, endeavour to recover it by leaping. Indeed this mode of motion seems often to be given to this description of larva by Providence, to enable them to return to their natural station, when by any accident they have wandered away from it.

Many apodous larvæe inhabit the water, and therefore must be furnished with means of locomotion proper to that element. To this class belongs the common gnat (Culex pipiens), which, being one of our greatest torments, compels us to feel some curiosity about its history. Its larva is a very singular creature, furnished with a remarkable anal apparatus for respiration, by which it usually remains suspended at the surface of the water. If disposed to descend, it seems to sink by the weight of its body ; but when it would move upwards again, it effects its purpose by alternate contortions of the upper and lower halves of it, and thus it moves with much celerity. The laminæ or swimmers, which terminate its anus ${ }^{1}$, are doubtless of use to it in promoting this purpose. It does not, that I ever observed, nove in a lateral direction, but only from the surface downwards, and vice versâ. - Another dipterous larva (Corethra culiciformis), which much resembles that of the gnat in form, differs from it in its motions and station of repose; for, instead of being suspended at the surface with its head downwards, it usually, like fishes, remains in a horizontal position in the middle of the water. When it ascends to the surface, it is always by means of a few strokes of its tail, so that its motion is not equable, sed per saltus. It descends again gradually by its own weight, and regains its equilibrium by a single stroke of the tail. ${ }^{2}$ - A well-known fly (Stratyomis Chamcleon), in its first state an aquatic animal, often remains suspended, by its radiated anus, at the surface of the water, with its head downwards. But when it is disposed to seek the bottom or to descend, by bending the radii of its tail so as to form a concavity, it includes in them a bubble of air, in brilliancy resembling silver or pearl; and then sinks with it by its own weight. When it would return to the surface it is by means of this bubble, which is, as it were, its air balloon. If it moves upon the surface or horizontally, it bends its body alternately to the right and left, contracting itself into the form of the letter $S$; and then extending itself again into a straight line, by these alternate movements it makes its way slowly in the water. ${ }^{3}$

I have dwelt longer upon the apodous larvæ, or those that are without what may be called proper legs, analogous to those of perfect insects, because the absence of these ordinary instruments of motion is in numbers of them supplied in a way so remarkable and so worthy to be known; and because in them the wisclom of the Creator is so conspicuously, or I should rather say, so strikingly manifested, since it is doubtless equally conspicuous in the ordinary routine of nature. But aberrations from her general laws, and modes, and instruments of action, often of rare occurrence, impress us more forcibly than any thing that falls under our daily observation.

I come now to pedate larva, or those that move by means of proper or articulate legs. These legs (generally six in number, and attached to the underside of the three first segments of the body) vary in larræ of the

1 Reaum. iv. t. 43, f. 3. nn.

2 De Geer, vi. 375. t. xxiii. f. 4,5 .

5 Swamm. Bibl. Nat. Ed. Hill, ii. 44. b. 47. a. 
different orders : but they seem in most to have joints answering to the hip (coxa); trochanter; thigh (femur) ; shank (tibia); foot (tarsus); of perfect insects, the legs of which they include. Cuvier, speaking of Coleoptera and some Neuroptera, mentions only three joints. But many in these orders (amongst which he included the Trichoptera) have the joints I have enumerated. To name no more, the Lamellicomia, Dytisci, Silphe, Staphylini, Cicindcla, and Gyrini, \&c. amongst coleopterous larvæ; and the Trichoptcra, as well as the Libellulina and Ephemerina, amongst Cuvier's Neuroptera, - have these joints, and in many the last terminates in a double claw. In some coleopterous genera the tarsus seems absent or obsolete. The larva of the lady-bird (Coccinella) affords an example of the former kind, and that of Chrysomelo of the latter. ${ }^{2}$ These joints are very visible in the legs of caterpillars of Lepidoptera, and their tarsus is armed with a single claw. ${ }^{3}$ The larvæ that have these legs walk with them sometimes very swiftly. In stepping they set forward at the same time the anterior and posterior legs of one side, and the intermediate one of the other; and so alternately on each side.

Pedate larva are of two descriptions; those that to perfect legs add spurious ones, with or without claws, and those that have only perfect legs. I begin with the former - those that have both kinds of legs. But first I must make a few remarks upon spurious legs. Because their muscles, instead of the horny substance that protects them in perfect legs, are covered only by a soft membrane, they have been usually denominated membranacens legs; since, however, they are temporary, vanishing altogether when the insect arrives at its perfect state, - are merely used, for they do not otherwise assist in this motion, as props to hinder its long body, when it walks, from trailing on the ground; to push against the plane of position; and, by means of their hooks or claws, to fix itself firmly to its station when it feeds or reposes, - I shall therefore call them prolegs ( propedes $^{4}$ ). These organs consist of three or four folds, and are commonly terminated, though not always, by a coronet or semicoronet of very minute crooked claws or hooks. These claws, which sometimes amount to nearly a hundred on one proleg, are alternately longer and shorter. They are crooked at both ends, and are attached to the proleg by the back by means of a membrane, which covers about two thirds of their length, leaving their two extremities naked. Of these the upper one is sharp, and the lower blunt. The sole, or part of the prolegs within the claws, is capable of opening and shutting. When the animal walks, that they may not impede its notion, it is shut, and the claws are laid flat with their points inwards; but when it wishes to fix itself, the sole is opened, becoming of greater diameter than before, and the claws stand erect with

1 For examples of larvæ having these joints, see De Geer, iv. 289. t. xiii. f. 20. t. xv. f. 14. ii. t. xii. f. 3 . t. xvi. f. 5,6 . t. xix. f. 4 , \&c.

2 Ibid. v. t. xi. f. 11. t. ix. f. 9. o.

3 Lyonet, Tr. Anat. t. iii. f. 8.

4 Mr. IV. S. MaeLeay, where quoted above, objects to this term; but as the organs in question are generally given to the animal to assist in its motions, and have been universally regarded as a kind of legs, it was judged best, for the sake of distinction, to give them a different name from perfect legs, and at the same time one that showed some affinity to them. 
their points outwards. Thus they can lay stronger hold of the plane of position. ${ }^{1}$

The number of these prolegs varies in different species and families. In the numerous tribes of saw-flies (Serrifera), the larvæ of which resemble those Lepidopter $a$, and are called by Reaumur spurious eaterpillars (fausses chenilles), one family (Loplyyrus) has sixteen prolegs; a second (Hylotoma, \&c.) fourteen; another (Tenthredo F.) twelve; and a fourth (Lyda) none at all, having only the six perfect legs. The majority of larvæ of Lepidopterc have ten prolegs, eight being attached, a pair on each, to the sixth, seventh, eighth, and minth segments of the body, and two to the twelfth or anal segment. ${ }^{2}$ The caterpillar of the puss-moth (Cerura Vimula) and some others, instead of the anal prolegs, have two tails or horns. A hemigeometer, described by De Geer, has only six intermediate prolegs, the posterior pair of which are longer than the rest, to assist the anal pair in supporting the body in a posture more or less erect. ${ }^{3}$ Other hemigeometers, of which kiud is the larva of Plusia Gamma, have only six prolegs, four intermediate and two anal. The true geometers or surveyors (Geometrce) have only two intermediate and two anal prolegs. Many grubs of Coleoptera, especially those of Staphylinide, Silphide, \&e., which are long and narrow, are furnished with a stiff joint at the anus, which they bend downwards and use as a prop to prevent their body from trailing. This joint, though without claws, may be regarded as a kind of proleg, which supports them when they walk ${ }^{4}$; and probably may assist their motion by pushing against the plane of position.

With respeet to the larvæ that have only perfect legs, having just given you an aceount of these organs, I have nothing more to state relating to their structure. I shall therefore now consider the motions of pedate larvæ, under the several heads of walking or running, jumping, climbing, and swimming.

Amongst those that wall, some are remarkable for the slowness of thei: motion, while others are extremely swift. The caterpillar of the hawk-moth of the Filipendula (Zygena Filipendule ) is of the former description, moving in the most leisurely manner; while that of Apatela leporina, a moth unknown in Britain, is named after the hare, from its great speed. The caterpillar of another moth, the species of whieh seems not to be ascertained, is celebrated by De Geer for the wonderful celerity of its notions. Wher tonched it darts away baekwards as well as forwards, giving its body an undulating motion with such force and rapidity, that it seems to fly from side to side. ${ }^{5}$ Cuvier observes, that the grubs of some coleopterous and neuropterous insects, which have only the six perfect legs, by means of them lay liold of any surrounding objeet, and, fixing themselves to it, drag the rest of their body to that point; and that those of many capricorn beetles and their affinities (but that of Callidium violaceum is an apode ${ }^{6}$ ) have these legs excessively minute and alınost nothing; that they move in the sinuosities which they bore by the assistance of their mandibles, with which they fix themselves, and also of several dorsal and rentral tubercles, by which they are supported against the sides of their cavity, and push

I Lyonet, 82. t iii. f. 10-16.

3 De Geer, i. 379. t. xxv. f. 1.3.

4 Ibid. i, 12. 40. t. i. f. 2 7. q. t. vi. f. 11. e.

5 lbid. i. 424 .
2 Ibid. t. i. f. 4.

6 Kirby in Linn. Trans. v. 258. 
themselves along, in the same manner as a chimney-sweeper-by the pressure of his knees, elbows, shoulder-blades, and other prominent parts - pushes himself up a chimney. "The larva of the ant-lion (Myrmelion), with the exception of one species, which moves in the common way, always walks backwards, even when its legs are cut off.

The jumpers, amongst pedate larvæ, as far as they are known, are not. very numerous, and will not detain you long. When the caterpillar of Lithosia Quadra, a moth not uncommon, would descend from one branch or leap to another, it approaches to the edge of the leaf on which it is stationed, bends its body together and retiring a little backwards, as if to take a good situation, leaps through the air, and, however high the jump, alights on its legs like a cat. That of another moth (Herminia rostralis) will also leap to a considerable height. ${ }^{2}$

Another species of motion which is peculiar to larvæ, - their mode I mean of climbing, - as it merits particular attention, will occupy more time. I have already related so many extraordinary facts in their history, that I promise myself you will not disbelieve me if $\mathbf{I}$ assert that insects either use ladders for this purpose, or a single rope. You may often have seen the caterpillar of the common cabbage-butterfly climbing up the walls of your house, and even over the glass of your windows. When next you witness this last circumstance, if you observe closely the square upon which the animal is travelling, you will find that, like a snail, it leaves a visible track behind it. Examine this with your microscope, and yon will see that it consists of little silken threads, which it has spun in a zigzag direction, forming a rope-ladder, by which it ascends a surface it could not otherwise adhere to. The silk as it comes from the spinners is a gummy fluid, which hardens in the air; so that it has no difficulty in making it stick to the glass. Many caterpillars that feed upon trees, particularly the geometers, have often occasion to descend from branch to branch, and sometimes, especially previously to assuming the pupa, to the ground. Had they to descend by the trunk, supposing them able to traverse with ease its rugged bark, what a circuitous route must they take before they could accomplish their purpose! Providence, ever watchful over the welfare of the most insignificant of its creatures, has gifted them with the means of attaining these ends, without all this labour and loss of time. From their own internal stores they can let down a rope, and prolong it indefinitely, which will enable them to travel where they please. Shake the branches of an oak or other tree in summer, and its inhabitants of this description, whether they were reposing, moving, or feeding, will immediately cast themselves from the leaves on which they were stationed; and however sudden your attack, they are nevertheless still provided for it, and will all descend by means of the silken cord just alluded to, and hang suspended in the air. Their name of geometer was given to a large division of the caterpillars which have this power of descending by silken threads, because they seem to measure the surface they pass over, as they walk, with at chain. If you place one upon your hand, you will find that they draw a thread as they go ; when they move, their head is extended as far as they can reach with it ; then fastening their thread there, and bringing up the rest of their body, they take another step; never moving without leaving this clue behind them; the object of which, however, is neither to measure, nor to mark its 
path that it may find it again; but thus, whenever the caterpillar falls or would descend from a leaf, it has a cord always ready to support it in the air, by lengthening which it can with ease reach the ground. Thus it can drop itself without danger from the summit of the most lofty trees, and ascend again by the same road. As the silky matter is fluid when it issues from the spinners, it should seem as if the weight of the insect wonld be too great; and its descent too rapid, so as to cause it to fall with violence upon the earth. The little animal knows how to prevent such an accident, by descending gradually. It drops itself a foot or half a foot, or even less, at a time; then making a longer or shorter pause, as best suits it, it reaches the ground at last without a shock. From hence it appears that these larvæ have power to contract the orifice of the spinners, so as that no more of the silky gum shall issue from it ; and to relax it again when they intend to resume their motion downwards: consequently there must be a muscular apparatus to enable them to effect this, or at least a kind of sphincter, which, pressing the silk, can prevent its exit. From hence also it appears that the gummy fluid which forms the thread must have gained a degree of consistence even before it leaves the spinner, since as soon as it emerges it can support the weight of the caterpillar. In ascending, the animal seizes the thread with its jaws as high as it can reach it ; and then elevating that part of the back that corresponds with the six perfect legs, till these legs become higher than the head, with one of the last pair it catches the thread; from this the other receives it, and so a step is gained : and thus it proceeds till it has ascended to the point it wishes to reach. At this time if taken it will be found to have a packet of thread, from which, how ever, it soon disengages itself, between the two last pairs of perfect legs. ${ }^{1}$ To see hundreds of these little animals pendent at the same time from the boughs of a tree, suspended at different heights, sonse working their way downwards and some upwards, affords a very amusing spectacle. Sometimes, when the wind is high, they are blown to the distance of several yards from the tree, and yet maintain their threads unbroken. I witnessed an instance of this last summer, when numbers were driven far from the most extended branches, and looked as if they were floating in the air.

Having related to you what is peculiar in the motions of pedate larvæ upon the earth and in the air, I must next say something with respect to their locomotive powers in the water. Numbers of this description inhabit that element. Amongst the beetles, the genera Dytiscus, Hydrophilus, Gyrinus, Limnius, Parnus, Heterocerus, Elophorus, Hydrcena, Ac. ; amongst the bug tribes, Gerris, Velia, Hydrometra, Notonecta, Sigara, Nepa, Ranatra, Naucoris; a few Lepidoptera ; the majority of Trichoptera; Libellula, Aeshna, Agrion, Sialis, Ephemera, \&c. amongst the Neuroptera; Culex and many of the Tipularice Latr. from the dipterous insects; and from the Aptera, Atax, some Podurce, and many of the Oniscida, \&c. All these, in their larva state, are aquatic animals.

The motions of these creatures in this state are various. Some walk on the ground under water; some move in mid-water, either by the same motion of the legs as they use in walking, or by strokes, as in swimming; others for this purpose employ certain laminæ, which terminate their tails as oars; others again swim like fish, with an equable motion; some move by the force of the water which they spirt from their anus; others

1 Reaum. ii. 375. 
again swim about in cases, or crawl over the submerged bottom; and others walk even on the surface of the water. I shall not now enlarge on all these kinds of water-motion, since many will come under consideration hereafter.

There are two descriptions of larvæ of Hydrophilide, one furnished with swimmers or anal appendages, by means of which they are enabled to swim; the other have them not, and hence are not able to rise from the bottom. ${ }^{1}$ The larvæ of Dytisci, by means of these natatory organs, will swim, though slowly, and every now and then rise to the surface for the sake of respiration. Those of Ephemerce, when they swim, apply their legs to the body, and swim with the swiftness and motions of fish. ${ }^{2}$ Those of the true May-fly (Sialis lutaria), on the contrary, use their legs in swimming, and at the same time, by alternate inflexions, give to their hodies the undulations of serpents. ${ }^{3}$ But the larvæ of certain dragonflies (Aeshna and Libellula) will afford you the most amusement by their motions. These larvæ commonly swim very little, being generally found walking at the bottom on aquatic plants: when necessary, however, they can swim well, though in a singular manner. If you see one swimming, you will find that the body is pushed forward by strokes, between which an interval takes place. The legs are not employed in producing this progressive motion, for they are then applied close to the sides of the trunk, in a state of perfect inaction. But it is effected by a strong ejaculation of water from the anus. When I treat upon the respiration of insects, I shall explain to you the apparatus by which these animals separate the air from the water for that purpose; in the present case it is subsidiary to their motions, since it is by drawing in and then expelling the water that they are enabled to swim. To sce this, you have only to put one of these larvæ into a plate with a little water. You will find that, while the animal moves forward, a current of water is produced by this pumping in a contrary direction. As the larva, between every stroke of its internal piston, has to draw in a fresh supply of water, an interval must of course take place between the strokes. Sometimes it will lift its anus out of the water, when a long thread of water, if I may so speak, issues from it. ${ }^{4}$

II. I am next to say something upon the motions of insects in their pupa state. This is usually to our little favourites a state of perfect repose; but, as I long since observed, there are several that, even when bccome pupæ, are as active and feed as rapaciously as they do when they are either larvæ or perfect insects. The Dermaptera, Orthoptera, Hemiptera, many of the Neuroptera, and the majority of the Aptera, are of this description. With respect to their motions, we may therefore consider pupæ as of two kinds - aetive pupæ, and quieseent pupæ.

The motions of most insects whose pupæ are active are so similar in all their states, except where the wings are concerned, as not to need any separate account. I shall therefore request you to wait for what I have to say upon them, till I enter upon those of the imago. One insect, however,

1 Miger, Ann. du Mus. xiv. 441.

2 De Geer, ii. 621.

5 Ibid. 725 .

4 Ibid. ii. 675. Compare Reuum. vi. 393. 
of this kind, moving differently in its preparatory states, is entitled to notice under the present head. In a late letter, I mentioned to you a bug (Reduvius personatus), which usually covers itself with a mask of dust, and fragments of various kinds, cutting a very grotesque figure. Its awkward motions add not a little to the effect of its appearance. When so disposed, it can move as well and as fast as its congeners; yet this does not usually answer its purpose, which is to assume the appearance of an inanimate substance. It therefore hitches along in the most leisurely manner possible, as if it was counting its steps. Having set one foot forwards (for it moves only one leg at a time), it stops a little before it brings up its fellow, and so on with the second and third legs. It moves its antennæ in a similar way, striking, as it were, first with one, and then, after an interval of repose, with the other. ${ }^{1}$ The pupæ of gnats also, as well as those of many other aquatic Diptera, retain their locomotive powers; not, however, the free motion of their limbs. When not engaged in action, they ascend to the surface by the natural levity of their bodies, and are there suspended by two auriform respiratory organs in the anterior part of the trunk, their abdomen being then folded under the breast; when disposed to descend the animal unfolds it, and by sudden strokes which she gives with it and her anal swimmers to the water, she swims to the right and left as well as downwards, with as much ease as the larva. ${ }^{2}$

Bonnet mentions a pupa which climbs up and down in its cocoon, - and that of the common glow-worm (Lampyris noctiluca) will sometimes push itself along by the alternate extension and contraction of the segments of its body. ${ }^{3}$ Others turn round when disturbed. That of a weevil (Hypere (trator), which spins itself a beautiful cocoon like fine gauze, and which it fixes to the stalks of the common spurrey (Sagina arvensis), upon my touching this stalk, whirled round several times with astonishing rapidity.

The chrysalis of a moth (IIypogymna dispar) when tonched turns round with great quickness; but, as if fearful of breaking the thread by which it is suspended by constantly twisting it in one direction, it performs its $g y-$ rations alternately from left to right and from right to left. ${ }^{4}$ Generally speaking, quiescent pupæ when disturbed show that they have life, by giving their abdomen violent contortions.

But the most extraordinary motion of pupæ is jumping. In the year 1810 I received an account from a rery intelligent young lady, who collected and studied insects with more than common ardour and ability, that a friend had brought her a chrysalis endued with this ficulty. It was scarcely a quarter of an inch in length; of an oval form; its colour was a semitransparent brown, with a white opake band round the middle. It was found attached, by one end, to the leaf of a bramble. It repcatedly jumped out of an open pill-box that was an inch in height. When put into a drawer in which some other insects were impaled, it skipped from side to side, passing over their backs for nearly a quarter of an hour with surprising agility. Its mode of springing seemed to be by balancing itself upon one extremity of its case. About the end of Octoher one end of the case grew black, and from that time the motion ceased; and about the middle of April, in the following year, a very minute ichneumon made its appearance by a hole it had made at the opposite end. Some time after I received

1 De Geer, iii. 281.

3 lbid. iv. 43.
3 Ibid. vi. 308.

4 Dumeril, Trait. Element. ii. 49. n. 603. 
this history, I happened to have occasion to look at Reaumur's memoir upon the enemies of caterpillars, where I met with an account of a similar jumping chrysalis, if not the same. Round the nests of the caterpillar of the processionary moth, before noticed, he found numerous little cocoons suspended by a thread three or four inches long to a twig or a leaf, of a shortened oval form, and close texture, but so as the meshes might be distinguished. These cocoons were rather transparent, of a coffee-brown colour, and surrounded in the middle by a whitish band. When put into boxes or glasses, or laid on the hand, they surprised him by leaping. Sometimes their leaps were not more than ten lines, at others they were extended to three or four inches, both in height and length. When the animal leaps, it suddenly changes its ordinary posture (in which the back is convex and touches the upper part of the cocoon, and the bead and anus rest upon the lower), and strikes the upper part with the head and tail, before its belly, which then becomes the convex part, touches the bottom. This occasions the cocoon to rise in the air to a height proportioned to the force of the blow. At first sight this faculty seems of no great use to an animal that is suspended in the air ; but the winds may probably sometimes place it in a different and unsuitable position, and lodge it upon a leaf or twig: in this case it has it in its power to recover its natural station. Reaumur could not ascertain the fly that should legitimately come from this cocoon ${ }^{1}$, for different cocoons gave different flies: whence it was evident that these ichneumons were infested by their own parasite. ${ }^{2}$ This might be the case with that of the lady just mentioned. Perhaps, properly speaking, in this last instance the motions ought rather to be regarded as belonging to a larva; but as it had ceased feeding, and had enclosed itself in its cocoon, I consider it as belonging to the present head.

You may probably here feel some curiosity to be inforned how the numerous larvæ that are buried in their pupa state, either in the heart of trees, under the earth, or in the waters, effect their escape from their various prisons and become denizens of the air, especially as you are aware that each is shrouded in a winding-sheet and cased in a coffin. In most, however, if you examine this coffin closely, you will see RESURGAM written upon it. What I mean is this. The puparium, or case of the animal, is furnished with certain acute points (adminicula), generally single, but in some instances forked, looking towards the anus, and usually placed upon transverse ridges on the back of the abdomen, but sometimes arming the sides or the margins of the segments. By this simple contrivance, aided by new-born vigour, when the time for its great change is arrived, the included prisoner of hope, if under ground, pushes itself gradually npwards, till reaching the surface its head and trunk emerge, when an opening in the latter being effected by its efforts, it escapes from its confinement, and once more tastes the sweets of liberty and the joys of life. Those that are inclosed in trees and spin a cocoon, are furnished with points on the head, with which they make an opening in the cocoon. The pupa of the great goat-moth (Cossus ligniperda) thus, by divers movements, keeps disengaging itself from this envelope, till it arrives at a hole in the tree which it had made when a caterpillar; when its anterior part having emerged, it stops

1 Mr. Westwood states that it belongs to the genus Perilitus, belonging to the Ichneumonidæ. See Mod. Class. Ins. ii. p. 149. for further notices upon it.

2 Reaum. ii. 450. 
short, and so escapes a fall that might destroy it. After some repose, in consequence of very violent efforts, it bursts through the front of the puparium, and thus escapes from its prison. ${ }^{1}$

The insects of the Trichoptera order, or case-worm flies, are quiescent when they first assume the pupa, but become locomotive towards the close of their existence in that state. Since they inhabit the water when they become pupæ, Providence has furnished them with the means of quitting that fluid without injury, when they are to exchange it for the air, which in their winged state is their proper sphere of action. I lave before described to you the grates which shut up their cases when they become quiescent ; if they had no means of piercing these grates, they would perish in the waters. The head of these pupæ is provided at first with a particular instrument, which enables them to effect this purpose; its anterior part is armed with a pair of hooks in form resembling the beak of a bird; and with this, previously to their last change, they make an opening in the grate, which, though it once defended, now confines them. But at this moment, perhaps, the insect has a considerable space of water to rise through before she can reach the surface. This is all wisely provided for; before she leaves the envelope which covers her body, she emerges from the water, and fixes herself upon some plant or other object, the summit of which is not overflowed. But you will here, perlaps, ask - How can a pupa in her envelope, with all her limbs set fast, do this? This affords another instance of the wise provision of the beneficent Father of the universe for the welfare of his creatures. The antennæ and legs of this tribe of insects, when they are pupæ, are not included, as is the case with most that are quiescent in that state, in the general envelope; but each in a separate one, so as to allow it free motion. Thus the insect, when the time is come for its last chauge, can use them (except the hind-legs, which being partly covered by the wing-cases remain without motion) with ease. It then stretches out its antennæ, and steering with its legs makes for the surface. De Geer saw one just escaped from its case run and swim with surprising agility over the bottom of a saucer, in which he had put some cases of these flies; and at last when he held a piece of stick to it, it got upon it, and having emerged from the water, prepared to cast its envelope. It is remarkable, that the envelope of the intermediate tarsi, like the posterior ones of Dytisci, is fringed on one side with hairs, to enable the insects to use them as swimming feet ${ }^{2}$, while those neither of the larva nor imago are so circumstanced.

$1 \mathrm{am}, \& \mathrm{c}$. 


\section{LETTER XXIII.}

\section{MOTIONS OF INSECTS. (Imago.)}

III. The motions of insects in their perfect or imago state are various, and for various purposes; and the provision of organs by which they are enabled to effect them is equally diversified and wonderful. It will be convenient to divide this multifarious subject; I shall therefore consider their motions under two principal heads : - motions of insects reposing - and motions of insects in action; - and this last head I shall further subdivide into motions whose object is change of place, and sportive motions.

The first of these, motions of insects reposing, will not detain us long. The most remarkable is that of the long-legged gnats or crane-flies (Tipule). When at rest upon any wall or ceiling, sometimes standing upon four legs, and sometimes upon five, you may observe them elevate arid depress their body alternately. This oscillating movement is produced by the weight of their body and the elasticity of their legs, and is constant and uninterrupted during their repose. Unless it be connected with the respiration of the animal, it is not easy to say what is the object of it. Moths when feeling the stimulus of desire, or under alarm, set their whole body into a tremor. ${ }^{1}$ A living specimen of the hawk-moth of the willow being once brought to me, upon placing it upon my hand, after ejecting a milky fluid from its anus, it put its wings and body in a most rapid vibration, which continued more than a minute, when it flew away. A butterfiy, called by Aurelians "The large skipper" (Hesperia sylvanus), when it alights, which it does very often, for they are never long on the wing, always turns half way round; so that, if it settles with its head from you, it turns it towards you.

Others of the motions in question are merely those of parts. Butterflies, when standing still in the sun, as you have doubtless often obscrved,

\section{"Their golden pinions ope and close;"}

thus, it should seem, unless this motion be connected with their respiration, alternately warming and cooling their bodies. You have probably noticed a very common little fly, of a shining black, with a black spot at the end of its wings (Seioptera vibrans ${ }^{2}$ ). It has received its trivial name

1 Peck in Linn. Trans. xi. 92.

2 Meigen considers this as an Ortalis; but its peculiar habit of constantly vitrating its wings indicates a distinct genus; especially as the habit is not contined to a single species. 
(vibrans) from the constant vibration which, when reposing, it imparts to its wings. This motion, also, I have reason to think, assists its respiration. Some insects when awake are very active with their antennæ, thongh their bodies are at rest. I remember one evening attending for some time to the proceedings of one of those caseworm-flies (Leptocerus), that are remarkable, like certain moths, for their long antennæ. It was perehed upon a blade of grass, and kept moving these organs, which were twice as long as itself, in all directions, as if by means of them it was exploring every thing that occurred in its vicinity. Many Tipulæ, and likewise some mites (Acarts vibrans and Gamasus motatorius), distinguished by long anterior legs, from this circumstance denominated pedes motatorii by Linné, holding them up in the air impart to them a vibratory motion, resembling that of the antennæ of some insects. ${ }^{1}$ I scarcely need mention, what nunst often have attracted your attention, the actions of flies when they clean themselves; how busily they rub and wipe their head and thorax with their fore legs, and their wings and abdomen with their hind ones. Perhaps you are not equally aware of the use to which the rovebeetles (Staphylinus L.) put their long abdomen. They turn it over their back not only to put themselves in a threatening attitude, as I lately related, but also to fold up their wings with it, and pack them under their short elytra.

With respect to the motions of insects in action, they may be sulsdivided, as was just observed, into motions whose object is change of place - and sportive motions.

The locomotions of these animals are walking, running, jumping, climbing, flying, swinming, and burrowing. I begin with the walkers.

The node of their walking depends upon the number and kind of their legs. With regard to these, insects may be divided into four classes; viz. ILexapods, or those that have only six legs : such are those of every order except the Aptera of Limne, of which only three or four genera belong to this class; - Octopods, or those that have eight legs, including the tribes of nites (Acarina); spiders (Araneida); long-legged spiders (Phalangida); and scorpions (Scorpionide) : - Polypods, or those that have fourteen legs, consisting of the wood-lice tribe (Oniscide) ; - and Myriapods, or those that have more than fourteen legs - often more than a hundred-composed of the two tribes of centipedes (Scolopendrida) and millepedes (Iulid $c)$. The first of these classes may be denominated proper, and the rest improper insects. The legs of all seen to consist of the same general parts; the hip, trochanter, thigh, shank, and foot; the four first being usially withont joints (though in the Araneide, \&c. the shank has two), and the foot having from one to above forty. ${ }^{2}$

1 De Geer, vi. 335 .

2 The most common number of joints in the tarsus is from two to five; but the Phalangila have sometimes more than forty. In these, under a lens, this part looks like a jointed antenna.

Geoffroy, and after him most modern entomologists, has taken the primary divisions of the Coleoptera order from the number of joints in the tarsus; but this, although perhaps in the majority of cases it may afford a natural division, will not universally. For - not to mention the instance of Pselaphus, clearly belonging to the Brachyptera - both Oxytelus Grav., and another genus that I have separated from it (Curpalimus K. Ms.), have only two joints in their tarsi. In this tribe, theretore, it can only be used for secondary divisions. $-\mathrm{K}$. 
In walking and ruming, the hexapods, like the larvæ that have perfect legs, move the anterior and posterior ley of one side and the intermediate of the other alternately, as I have often witnessed. De Geer, however, affirms that they advance each pair of legs at the same time ${ }^{1}$; but this is contrary to fact, and indeed would make their ordinary motions, instead of walking and running, a kind of canter and gallop. Whether those that have more than six feet move in this way, which is not improbable, from the clifficulty of attending at the same time to the movements of so many mem. ber's, is not easily ascertained.

The dog-tick (Ixodes Ricinus), if when young and active it moves in the same way that it does when swollen to an enormous size with blood, seems to afford an exception to the mode of walking just described. It first uses, says Ray, its two anterior legs as antennæ to feel out its way. and then fixing them, brings the next pair beyond them, which being also fixed, it takes a seeond step with the anterior, and so drags its bloated carcass along. ${ }^{2}$ Redi observes that when seorpions walk they use those remarkable comb-like processes at the base of their posterior legs to assist them in their motions, extending them and setting them out from the body, as if they were wings: and his observation is confirmed by Amorenx, who calls them ventral swimmers. ${ }^{3}$ I have often noticed a millepede (Inlus terrestris), frequently found under the bark of trees, and where there is not a free circulation of air, the motions of which are worthy of attention. Observed at a little distance, it seems to glicle over the surface, like a serpent, withont legs; but a nearer inspection shows how its movement is accomplished. Alternate portions of its numerous legs are extended beyond the line of the body, so as to form an obtuse angle with it ; while those in the intervals preserve a vertical direction, so that as long as it keeps moving, little bunches of the legs are alternately in and out from one end to the other of its long body ; and an amusing sight it is to see the undulating line of motion suecessively beginning at the head and passing off at the tail. The motion of centipedes (Scolopendra), as well as that of this in-ect and its congeners, is retrogressive as well as progressive. Put your finger to the common one (Lithobius forficalus), and it will immediately retrograde, and with the same facility as if it was going forwards. This differenee, however, is then observable - it uses its four hind legs, which, when it moves in the usual way, are dragged after it. Almost all the other aptcrous insects, as well as many of those in the other orders, ean move in all directions; backwards, and towards both sides, as well as forwards. Bonnet mentions a spider (not a spinner) that always walked baekwards when it attacked a large insect of its own tribe; but when it had succeeded in driving it from a captive fly, which," however, it did not eat, it walked forwards in the ordinary way. ${ }^{4}$

Insects vary much in their walking paces : some erawling along, others walking slowly, and others moving with a very quick step. The fieldcricket (Gryllus campcstris) ereeps very slowly - the bloody-nose beetle (Timarcha tenebricosa) and the oil-beetle (Meloe Proscarabcus) march very leisurely ; the spider wasps (Pompilus) walk by starts, as it were, vibrating their wings at the same time without expanding them; while flies, ichnenmons, wasps, Scc., and many beetles, walk as fist as they can. One insect,

1 De Geer, iii. 284.

3 Redi, Opusc. i. 80 . Amoreux, 44.
2 Ilist. Ins. 10.

4 Euvr. ii. 426 
a kind of snake-fly (Mantispa pagana), is said to walk upon its knees. The crane-flies (Tipula oleracea) and shepherd-spiders (Phalangium) have legs so disproportionately long, that they seem to walk upon stilts; but when we consider that they have to walk over and amongst grass - the former laying its eggs in meadows - we shall see the reason of this conformation. Insects do not always walk in a right line; for I have often observed the little midges (Psychoda Latr.), when walking up glass, moving alternately from right to left and from left to right, as humble-bees fly, so as to describe small zigzags.

Numerous are the insects that run. Almost all the predaceous tribes, the black dors, clocks, or ground-beetles (Eutrechina), and their fellow destroyers the Cicindcle, and other Eupterina - which Linné, with much propriety, has denominated the tigers of the insect world - are gifted with uncommon powers of motion, and run with great rapidity. The velocity, in this respect, of ants, is also very great. Mr. Delisle observed a $\mathrm{fly}$ - so minute as to be almost invisible - which ran nearly three inches in a demisecond, and in that space made 540 steps. Consequently it could take a thousand steps during one pulsation of the blood of a man in health. ${ }^{1}$ Which is as if a man, whose steps measured two feet, should run at the incredible rate of more than twenty miles in a minute! How astonishing, then, are the powers with which these little beings are gifted! The forestfly (Hippobosca), and its kindred genus Ornithyomia parasitic upon birds, are extremely difficult to take, as I have more than once experienced, from their extreme agility. I lost one from this circumstance two years ago, that I found upon the sea-lark (Charadrius Hiaticula), and which appeared to be nondescript. Another most singular insect, which though apterous is nearly related to these - I mean the louse of the bat (Nycteribia Vespertilionis), is still more remarkable for its swiftness. Its legs, as appears from the observations of Colonel Montague, are fixed in an unusual position on the upper side of the trunk. "It transports itself," to use the words of the gentleman just mentioned, "with sucl celerity from one part of the animal it inhabits to the opposite and most distant, although obstructed by the exireme thickness of the fur, that it is not readily taken." - When two or three were put into a small phial, their agility appeared inconceivalıly great ; for as their feet are incapable of fixing upon so smooth a body, their whole exertion was employed in laying hold of each other ; and in this most curious struggle they appeared actually flying in circles : and when the bottle was reclined, they would frequently pass from one end to the other with astonishing velocity, accompanied by the same gyrations : if by accident they escaped each other, they very soon became motionless; and as quickly were the whole put in motion again by the least touch of the bottle or the movement of an individual. ${ }^{2}$ Incredibly great also is the rapidity with which a little reddish mite, with two black dots on the anterior part of its back (Gamasus Baccarum), common upon strawberries, moves along. Such is the velocity with which it runs, that it appears rather to glide or fly than to use its legs.

When insects walk or run, their legs are not the only members that are put in motion. They will not, or rather cannot, stir a step till their antennæ are removed from their station of repose and set in action. When the chafers or petalocerous beetles are about to move, these organs, before

1 Lesser, 1. i. 248. note 24.

2 Linn. Trans. xi. 13. 
concealed, instantly appear, and the laminæ which terminate them being separated from each other as widely as possible, they begin their march. They employ their antennæ, however, not as feelers to explore surrounding objects,- - their palpi being rather used for that purpose,-but, it should seem, merely to receive vibrations, or impressions from the atmosphere, to which these laminæ, especially in the male cock-chafers, or rather treechafers (Melolonthe), present a considerable surface. Yet insects that have filiforn or setaceous antennæ appear often to use them for exploring. When the turnip-flea (Haltica oleracea) walks, its antennæe are alternately elevated and depressed. The same thing takes place with some woodlice (Oniscide), which use them as tactors, touching the surface on each side with them, as they go along. This is not, however, constantly the use of this kind of antennæ; for I have observed that Telephorus lividus, - a narrow beetle with soft elytra, common in flowers, - when it walks vibrates its setaceous antennæe very brishly, but does not explore the surface with them. The parasitic tribes of Hymenoptera, especially the minute ones, when they move, vibrate these organs most intensely, and probably by them discover the insect to which the law of their nature ordains that they should commit their eggrs; some even using them to explore the deep holes in which a grub, the appropriate food of their larva, lurks. ${ }^{1}$ But upon this subject I shall have occasion to enlarge when I treat of the senses of insects. Antennæ are sometimes used as legs. A gnat-like kind of bug (Plviaria vagabunda) has very short anterior legs, or rather arms; while the two posterior pair are very long. Its antennæ also are long. When it walks, which it does very slowly, with a solemn measured step, its forelegs, which perhaps are useful only in climbing, or to seize its prey, are applied to the body, and the anternæ being bent, their extrenity, which is rather thick, is made to rest upon the surface on which the animal moves, and so supply the place of fore-legs. ${ }^{2}$ Mr. Curtis suspects that Xyela musilla, a hymenopterous insect related to Xipluydria, uses its maxillary palpi as legs. ${ }^{3}$ I have observed that mites often use the long hairs with which the tail of some species is furnished, to assist them in walking.

Another mode of motion with which many insects are endowed is jumping. This is generally the result of the sudden unbending of the articulations of the posterior legs and other organs, which before bad received more than their natural bend. This unbending impresses a violent rotatory motion upon these parts, the impulse of which being communicated to the centre of gravity, causes the animal to spring into the air with a determinate velocity, opposed to its weight more or less directly. ${ }^{4}$ Various are the organs by which these creatures are enabled to effect this motion. The majority do it by a peculiar conformation of the hind legs; others, by a pectoral process; and others, again, by means of certain elastic appendages to the abdomen.

The hind legs of many beetles are furnished with remarkably large and thick thighs. Of this description are several species of weevils; for instance. Orchestes and Ramphus; the whole tribe of skippers (Haltica), and the splendid Asiatic tribe of Sagra ${ }^{5}, \& \mathrm{c}$. The object of these disproportioned and clumsy thighs is to allow space for morc powerful muscles, by

1 Marsham in Linn. Trans. iii. 26.

2 De Geer, iii. 324.

4 Cuvier, Anat. Comp. i. 396.

3 Brit. Ent. i. t. $\operatorname{xxx}$. f. 4.

5 Oliv. Entom. n. 90. t. i. 
which the tibiæ, when the legs are unbent, are impelled with greater force. In the Orthoptera order, all the grasshoppers, including the genera Gryllotalpa, Gryllus, Tridactylus, Locusta, Acrida, Ptcrophylla, Pneumora, Triuralis, Acrydium, Tetrix, \&c., are distinguished by incrassated posterior thighs; which, however, are much longer, more tapering and shapely (they are indeed somewhat clumsy in the two first genera, the crickets), than those of most of the Colcoptcra that are furnished with them. When disposed to leap, these insects bend their hind leg so as to bring the shank into close contact with the thigh, which has often a longitudinal furrow armed with a row of spines on each side to receive it. The leg being thus bent, they suddenly unbend it with a jerk, when, pushing against the plane of position, they spring into the air often to a considerable height and distance. A locust, which, however, is aided by its wings, it is said will leap two hundred times its own length. ${ }^{1}$ - Aristophanes, in order to make the great and good Athenian philosopher Socrates appear ridiculous, represents him as having measured the leap of a flea. ${ }^{2}$ In our better times scientific men have done this without being laughed at for it, and have ascertained that, comparatively, it equalled that of the locust, being also two hundred times its length. Being effected by muscular force, without the aid of wings, this is an astonishing leap. There are several insects, however, which, although they are furnished with incrassated posterior thighs, do not jump. Of this description are some beetles belonging to the genus Necydalis (CEdemera Oliv.), in which this seems a peculiarity of the male, and amongst the Hymenoptera, not to mention others, several species of Chalcis, and all that are known of that singular genus Lencospis.

Many insects, that jump by means of their posterior legs, have not these thighs. This is said to be the case with Scaphidium, a little tribe of beetles ${ }^{3}$ : and one of the same order, that seems to come between Anobinm and Ptilinus, found by our friend the Rev. R. Sheppard, and which I have named after him Choragus Sheppardi, is similarly circumstanced. In the various tribes of frog-hoppers (Cercopida, \&c.), the posterior tibiæ appear to be principally concerned in their leaping. These are often ver'y long, and furnished, on their exterior margin, with a fringe of stiff hairs, or a series of strong spines, by pressing which against the plane of position they are supposed to be aided in effecting this motion. On this occasion they bend their legs like the grasshoppers, and then unbending kick them ont with violence. ${ }^{4}$ Many of them, amongst the rest Anthrophora spumaria, have the extremity of the above tibix armed with a coronet of spines; these are of great use in pushing them off when the legs are unbended. This insect, when about to leap, places its posterior thighs in a direction perpendicular to the plane of position, keeping them close to the body : it next with great violence pushes them out backwards, so as to stretch the leg in a right line. These spines then lay hold of the surface, and by their pressure enable the body to spring forwards, when, being assisted by its wings, it will make astonishing leaps, sometimes as much as five or six feet, which is more than 250 times its own length; or as if a man of ordinary stature should be able at once to vault throngh the air to the distance of a quarter of a mile. Upon glass, where the spines are of no

1 Swamm. Bibl. Nat. Ed. IIill, i. 123. b.

2 Aristoph. Nubes, Act. i. Sc. 2.

8 Trost, Bciträge, 40 .

4 De Geer, iii. 161. 
use, the insect cannot leap more than six inches. ${ }^{1}$ The species of another genus of the homopterous Hemiptera (Chermes), that jump very nimbly by pushing out their shanks, are perhaps assisted in this motion by a remarkable horn looking towards the anus, which arms their posterior hip. Some bugs that leap well, Acanthia saltatoria, \&c., seem to have no particular apparatus to assist them, except that their posterior tibiæ are vely long. Several of the minute ichneumons also jump with great agility, but by what means I am unable to say. There is a tribe of spiders, not spinners, that leap even sideways upon their prey. One of these (Salticus scenicus), when about to do this, elevates itself upon its legs, and lifting its head seems to survey the spot before it jumps. When these insects spy a small gnat or fly upon a wall, they creep very gently towards it with short steps, till they come within a convenient distance, when they spring upon it suddenly like a tiger. Bartram olserved one of these spiders that jumped two fect upon a humble-bee. The most amusing account, howerer, of the motions of these animals is given by the celebrated Evelyn in his Travels. When at Rome, he often observed a spider of this kind hunting the flies which alighted upon a rail on which was its station. It kept crawling under the rail till it arrived at the part opposite to the $\mathrm{fl}$, when stealing up it would attempt to leap upon it. If it discovered that it was not perfectly opposite, it would immediately slide down again unobserved, and at the next attenipt would come directly upon the fly's hack. Did the fly happen not to be within a leap, it would move towards it so softly, that its motion seemed not more perceptible than that of the shadow of the gnomon of a dial. If the intended prey noved, the spider would keep pace with it as exactly as if they were actuated by one spirit, moving back. wards, forwards, or on each side withont turning. When the fly took wing, and pitched itself behind the huntress, she turned round with the swittness of thought, and always kept her head towards it, thongh to all appearance as immovable as one of the nails driven into the wood on which was her station : till at last, being arrived within due distance, swift as lightning she made the fatal leap and secured her prey. ${ }^{2}$ I have had an opportunity of observing very similar proceedings in Salticus scenicus.

But the legs of insects are not the only organs by which they leap. The numerous species of the elastic beetles (Eluter), skip-jacks as some call them, perform this motion by means of a pectoral process or mucro. These animals having very short legs, when laid upon their backs, cannot by their means recover a prone position. To supply this seeming defect in their structure, Providence has furnished them with an instrument which, when they are so circumstanced, enables them to spring into the air and recover their standing. If you examine the breast (pcctus) of one of these insects, you will observe between the bases of the anterior pair of legs a short and rather blunt process, the point of which is towards the anus. Opposite to this point, and a little before the basis of the intermediate legs, you will discover in the after-breast (postpectus) a rather deep cavity, in which the point is often sheathed. This simple apparatus is all that the insect wants to effect the above purpose. When laid upon its back, in your hand if you please, it will first bend back, so as to form a very obtuse angle with each other, the head and trunk, and abdomen and

1 De Geer, iii. 178.

2 Evelyn, quoted in IJooke's Microgr. 200.

a $a 3$ 
metathorax, by which motion the mucro is quite liberated from its sheatis, and then bending them in a contrary direction, the mucro enters it again, and the former attitude being briskly and suddenly resumed, the mucro flies out with a spring, and the insect rising, sometimes an inch or two in the air, regains its legs and moves off. The upper part of the body, by its pressure against the plane of position, assists this notion, during which the legs are kept close to its underside. Cuvier, when he says that man and birds are the only animals that can leap vertically ${ }^{1}$, seems to have forgotten the leap of Elaters, which is generally vertical, the trunk being vertically above the organ that produces the leap.

Other insects again leap by means of the abdomen or some organs attached to it. An apterous species, belonging to the Iclneumonida, and to the genus Cryptus, takes long leaps by first bending its abdomen inwards, as De Geer thinks, and then pushing it with force along the plane of position.2 There is a tribe of minute insects amongst the Aptera, found often under bark, sometimes on the water, and in various other situations, which Linné has named Podura, a term implying that they have a leg in their tail. This is literally the fact. For the tail, or anal extremity, of these insects is furnished with an inflexed fork, which, though usually bent under the body, they have the power of unbending; during which action, the forked spring, pushing powerfully against the plane of position, enables the animal to leap sonetimes two or three inches. What is more remarkable, these little animals are by this organ even empowered to leap upon water. There is a minute black species ( $P$.aquatica), which in the spring is often seen floating on that contained in ruts, hollows, or even ditches, and in such infinite numbers as to resemble gunpowder strewed upon the surface. When disturbed, these black grains are seen to skip about as if ignited, jumping with as much ease as if the fluid were a solid plane, that resists their pressure. The insects of another genus, separated from Podura by Latreille under the name of Sminthurus, have also an anal spring, which, when bent under the body, nearly reaches the head. These, which are of a more globose form than Podura, are so excessively agile that it is almost impossible to take them. Pressing their spring against the surface on which they stand, and unbending it with force, they are out of your reach before your finger can come near them. One of them, $S$. fuscus, besides the caudal fork, has a very singular organ, the use of which is to prevent it from falling from a perpendicular surface, on which they are often found at a great height from the ground. Between the ends of the fork there is an elevated cylinder or tube, from which the animal, when necessary, can protrude two long, filiform, flexible, transparent threads covered with a sliny secretion. By these, when it has lost its hold, it adheres to the surface on which it is stationed. ${ }^{3}$ Another insect related to the common sugar-louse, and called by Latreille Machilis polypoda, in some places common under stones ${ }^{4}$, has eight pair of springs, one on each ventral segment of the abdomen, by means of which it leaps to a wonderful distance, and with the greatest agility.

Climbing is another motion of insects that merits particular consideration: since, as this includes their power of moving against gravity - as we

1 Anat. Comp. i. 498.

2 ii. 910.

3 De Geer, vii. 38. t. iii. f. 10. $r$. $r$.

4 This insect abounds at Last Farleigh, near Majdstone. 
see flies and spiders do upon our ceilings, and up perpendicular surfaces cven when of glass, it aftords room for much interesting and curious inquiry. Climbing insects may be divided into four classes. Those that climb by means of their claws ; those that climb by a soft cushion of dense hairs, that, more or less, lines the underside of the joints of their tarsi, the claw-joint excepted; those that climb by the aid of suckers, which adhere (a vacuum being produced between them and the plane of position) by the pressure of the atmosphere; and those that are enabled to climb by means of some substance which they have the power of secreting.

'The first order of climbers - those that climb by means of their claws -includes a large proportion of insects, especially in the Coleoptera order - the majority of those that have five joints in their tarsi being of this description. The predaceous tribes, particularly the numerous and prowling ground-beetles (Eutrechina), often thus ascend the plants and trees after their prey. Thus one of them, the beautiful but ferocious Calosoma sycophanta, mounts the trunk and branches of the oak to commit fearful ravages anongst the hordes of caterpillars that inhabit it ${ }^{1}$. By these the less savage but equally destructive tree-chafers (Melolontha), and those enemies of vegetable beauty the rose-chafers (Cetonia aurata), are enabled to maintain their station on the trees and shrubs that they lay waste. And by these also the water-beetles (Dytiscus, Hydrophilus, \&c.) climb the aquatic plants. But it is unnecessary further to enlarge upon this head; I shall only observe, that in most of the insects here enumerated the claws appear to be aided by stiff hairs or bristles.

Other climbers ascend by means of foot-cushions (pulvilli) composed of hairs, as thick set as in plush or velvet, with which the under sides of the joints of their tarsi-the claw-joint, which is always naked, excepted - are covered. These cushions are particularly conspicuous in the beautiful tribe of plant-beetles (Chrysomelida). A common insect of this kind before mentioned, called the bloody-nose beetle (Timarcha tenebricosa), by the aid of these is enabled to adhere to the trailing plants, the various species of bed-straw (Galium), on which it feeds; and by these will support itself against gravity; for both this and Chrysomela Goettingensis will walk upon the hand with their back downwards, and it then requires a rather strong pull to disengage them from their station. The whole tribe of weevils (Khynchophora Latr.) are also furnished with these cushions, but not always upon all their joints, some having them only at their apex; and the palm-weevil (Cordylia Palmarum) at the extremity solely of the last joint but one. Those brilliant beetles the Bnprestes have also these cushions, as have likewise the numerous tribes of capricorn-beetles (Longicornes Latr.). The larva of these being timberborers, the parent insect is probably thus enabled to adhere to this substance whilst it deposits its eggs. Indeed, in some species of the former genus the cushions wear the appearance of suckers. While the linear species of Helops are without them, they clothe all the tarsi of H. aneus (Chalcites K. Ms). ${ }^{2}$ In two other genera of the same order, Silpha and Cicindela, the anterior tarsi of the males are furnished with them ; in these, therefore, they may be regarded, like the suckers of the large water-beetlcs

1 Reaum. ii. 457.

2 The insect here alluded to is figured by Olivier under the name of Tenebrio ritcrs (No. 57. t. i. f. 4.) : his IIclops aneus (No 58. t. i. f. 7.) is a different insect. 
(Dy/isci), as given for sexual purposes. ${ }^{1}$ The three first joints of the anterior tarsi of many of the larger rove-beetles (Strphylinus L.) are dilated so as to form, as in the last-mentioned insects, an orbicular patella, but covered hy cushions. Since in them this is not peculiar to the males, it is probably given that they may be able to support their long bodies when climbing.

But the most remarkable class of climbers consists of those that are furnished with an apparatus by which they can form a vacuum, so as to adhere to the plane on which they are moving by atnospheric pressure. That flies can walk upon glass placed vertically, and in general against gravity, has long been a source of wonder and inquiry; and various have been the opinions of scientific men upon the subject. Some imagined that the suckers on the feet of these animals were sponges filled with a kind of gluten, by which they were enabled to adhere to such surfaces. This idea, though incorrect, was not so absurd as at first it may seem ; since we have seen above in many instances, and very lately in that of the Sminthurus fuscus, that insects are often aided in their motions by a secretion of this kind. Hooke appears to have been one of the first who remarked that the suspension of these animals was produced by some mechanical contrivance in their feet. Observing that the claws alone could not effect this purpose, he justly concluded that it must be principally owing to the mechanism of the two palms, pattens, or soles, as he calls the suckers; these lye describes as beset underneath with small bristles or tenters, like the wire teeth of a card for working wool, which having a contrary direction to the claws, and both pulling different ways, if there be any irregularity or yielding in the surface of a body, enable the fly to suspend itself very firmly. That they walk upon glass he ascribes to some ruggedness in the surface; and principally to a smoky tarnish which adheres to it, by means of which the fly gets footing upon it. ${ }^{2}$ But these tenter-lrooks in the suckers of flies, and this smoky tamish upon glass, are mere fancies, since they can walk as well upon the cleanest glass as upon the most tarnished. Reaumur also attributes this faculty of these animals to the hairs upon their suckers. ${ }^{3}$ That learned and pious naturalist. Dr. Derhan, seems to have been one of the first who gave the true solution of this enigma. "Flies," says he, "besides their sharp hooked nails, have also skinny palms to their feet, to enable them to stick on glass and other smooth bodies by the pressure of the atmosphere." ${ }_{4}$ He compares these palms to the curious suckers of male Dytisci, before alluded to, and illustrates their action by a common practice of boys, who carry stones by a wet piece of leather applied to their top. Another eminent and excellent naturalist, the late Mr. White, adopted this solution. He observes that in the decline of the year, when the mornings and evenings become chilly, many species of flies retire into houses and swarm in the windows; that at first they are very brisk and alert ; but, as they grow more torpid, that they move with difficulty, and are scarcely able to lift their legs, which seem as if glued to the glass; and that by degrees many do actually stick till they die in the place. Then, noticing Dr. Derham's opinion as just stated, be further remarks that they easily overcome the atmospheric pressure when they are brisk and alert.

I See Kirby, in Fauna Boreali-Americana, on various modifications of these footcushions amongst some tribes of beetles.

2 Wicrogr. 170.

3 iv. 259.

4 Physico-Theol. ed. 13. 363, note $b$. 
But, he proceels, in the decline of the year this resistance becomes too mighty for their diminished strength ; and we see flies labouring along, and lingging their feet in windows as if they stuck fast to the glass. ${ }^{1}$

Sir Joseph Banks, to whom every branch of Natural History has been so much indebted, excited an inquiry, the results of which confirmed Derlam's system concerning this motion of animals against gravity. When abroad, he had noticed that a lizard, on account of the sound that it emits before rain, named the Gecko ${ }^{2}$ (Lacerta Gecko), could walk against gravity up the walls of houses; and comparing this with the parallel motions of flies, he was desirous of having the subject more scientifically illustrated than it had been. This inquiry was put into the hands of Sir Everard Home, who was assisted in it by the incomparable pencil of Mr. Bauer; and it was proved most satisfactorily that it is by producing a vacuum between certain organs destined for that purpose and the plane of position, sufficient to cause atmospheric pressure upon their exterior surface, that the animals in question are enabled to walk up a polished perpendicular, like the glass in our windows, and the chunam walls in India, or with their backs downward on a ceiling, without being brought to the ground by the weight of their bodies.

The instruments by which a fly effects this purpose are two suckers connected with the last joint of the tarsus by a narrow infundibular neck, which has power of motion in all directions, immediately under the root of each claw. These suckers consist of a membrane capable of extension and contraction ; they are concavo-convex, with serrated edges, the concave surface being downy, and the convex granulated. When in action they are separated from cach other, and the membrane expanded so as to increase the surface; by applying this closely to the plane of position, the air is sufficiently expelled to produce the pressure necessary to keep the animal from falling. When the suckers are disengaged, they are brought together again so as to be confined within the space between the two claws. This may be seen by looking at the movements of a fly in the inside of a glass tumbler with a common microscope. ${ }^{3}$ Thus the fly, you see, does no more than the leech has been long known to do, when moving in a glass vessel. Furnished with a sucker at each extremity, by means of these organs it marches up and down at its pleasure, or as the state of the atmosphere inclines it. ${ }^{4}$

1 Nat. Hist. ii. 274.

2 Amon. Acad. i. 549. The Gecko, probably, is not the only lizard that walks against gravity. St. Pierre mentions one not longer than a finger, that, in the Isle of France, elimbs along the walls, and even up the glass, after the flies and other insects, for which it watches with great patience. These lizards are sometimes so tame that they will feed out of the hand. (Joyage, \&e. 73.) Najor Moor and Captain Green observed several lizards in India, that run up the walls and over the ceilings after the mosquitos. Hasselquist says that the Gecko is very frequent at Cairo, both in the houses and without them, and that it exhales a very deleterions poison from the lobuli between the toes. He saw two women and a girl at the point of death, merely from eating a cheese on which it had dropped its venom. One ran orer the hand of a man, who endeavoured to catch it; and immediately little pustules, resembling those occasioned by the stinging-nettle, rose all over the parts the creature had tonched. (Voyage, 220.) M. Savigny, however, who examined this animal in Egypt, assures me that this account of Liassclquist's, as far as it relates to the venom of the Gecko, is not correct.

3 Philos. Trans. 1816,325 . t. xviii. f. $1-7$.

$4 \mathrm{Mr}$. Blackwall, in a paper "On the Pulvilli of Insects," having found that flies 
Dipterous insects, which in general have these organs, and some three on each foot ${ }^{1}$, are not exclusively gifted with them; for various others

could walk up the sides of an exhausted receiver, denies that their suckers have any such power of forming a vacuum as is above ascribed to them, and explained their ability to climb up vertical polished bodies, such as glass, by the mechanical action of the minute hairs which clothe the inferior surfaces of the suckers, nearly as Dr. Hooke had suggested; but further experiments liaving shown him that flies cannot walk up glass which is made moist by breathing on it, or is thinly coated with oil or flour, he was led to the conelusion that these hairs are in fact tubular, and excrete a riscid fluid, by means of which they adhere to dry polished surfaces; and on close inspection with an adequate magnifying power, he was always able to discover traces of this adhesive material on the track on glass both of flies and various insects with pulvilli, and of those spiders which have the same power of climbing polished surfaces, such as Salticus scenicus, \&c. (Linn. Trans, xvi. 490. 768. ; compare also Entom. Mug. i. 557.)

On repeating Mr. Blackwall's experiments, I found, just as he states, that when. a pane of glass of a window was slightly moistened by breathing on it, or dusted with flour, blue-bottle flies, the common honse-flies, and the common bee-fly (Eristalis tenax) all slipped down again the instant they attempted to walk up these portions of the glass ; and I moreover remarked that each time after thus slipping down, they immediately began to rub first the two fore tarsi, and then the two hind tarsi, together, as flies are so often seen to do, and continued this operation for some moments before they attempted again to walk. This last fact struck me rery forcibly, as appearing to give an importance to these habitual procedures of flies that has not hitherto, as far as I am aware, been attached to them. These movements I had always regarded as meant to remove any particle of dust from the legs, but simply as an affair of instinctive cleanliness, like that of the cat when she licks herself, and not as serving any more important object ; and such entomological friends as I have had an opportunity of consulting tell me that their view of the matter was precisely the same; nor does Mr. Blackwall appear to have seen it in a different light, since, though so strongly bearing on his explanation of the way in which files mount smooth vertical surfaces, he never at all refers to it. Yet, from the absolnte necessity which the flies on which I experimented appeared to feel of cleaning their pulvilli immediately after being wetted or clogged with flour, however frequently this occurred, there certainly seems ground for supposing that their usual and frequent operation for effecting this by rubbing their tarsi together is by no means one of mere cleanliness or amusement, but a very important point of their economy, essentially necessary for keeping their pulvilli in a fit state for climbing up smooth vertical substances by constantly removing from them all moisture, and still more all dust, which they are perpetually liable to collect. In this operation the two fore and two hind tarsi are respectively rubbed together for their whole length, whenee it might be inferred that the intention is to remove impurities from the entire tarsi ; but this I am persuaded is not usually the object, which is simply that of cleaning the under side of the pulvilli by rubbing them backward and forward along the whole surface of the hairs with which the tarsi are clothed, and which seem intended to serve as a brush for this particular purpose. Sometines, indeed, when the hairs of the tarsi are filled with dust throughout, the operation of rubbing them together is intended to cleanse these lairs; because without these brushes were themselves clean, they could not act upon the hairs of the under side of the pulvilli. Of this I witnessed an interesting instance in an Eristalis terzax, which by walking on a surface dusted with flour had the lairs of the whole length of the tarsi, as well as the pulvilli, thus clogged with it. After slipping down from the painted surface of the window-frame, which she in vain attempted to climb, she seemed sensible that before the pulvilli could be brushed it was requisite that the brushes themselves should be clean, and full two 
in different orders have them, and some in greater numbers. As I lately observed, the foot-cushions of the Buprestes are something very like them,

minutes were employed to make them so by stretching out her trunk, and passing them repeatedly along its sides, apparently for the sake of moistening the flour and causing its grains to adhere ; for after this operation, on rubbing her tarsi together, which she next proceeded to do, I saw distinct little pellets of flour fall down. A process almost exactly similar I have always seen used by blue-bottle flies and common house-flies which had their tarsi clogged with flour by walking over it, or by having it dusted over them; but these manœuvres are required for an especial purpose, and on ordinary occasions, as before observed, the object in rubbing the tarsi together is not to clean them, but the pulvilli, for which they serve as brushes. Besides rubbing the tarsi togetler, flies are often seen, while thus employed, to pass the two fore tarsi and tibie with sulden jerks over the back of the head and eyes, and the two hind tarsi and tibir over and under the wings, and especially over their outer margins, and occasionally also over the back of the abdomen. That one object of these operations is often to clean these parts from dust $I$ liave no douht, as on powdering flies with flour they thus employ themselves, sometimes for ten minutes, in detaching every part of it from their eyes, wings, and abdomen; but I an also inclined to believe that, in general, when this passing of the legs over the back of the liead and outer margin of the wings takes place in connection with the ordinary rubbing of the tarsi together, as it usually does, that the object is rather for the purpose of completing the entire cleansing of the tarsal brushes (for which the row of strong hairs visible under a lens on the exterior margin of the wings seems well adantedl), so that they may act more perfectly on the pulvilli. Here, too, it should be noticed, in proof of the importance of all the pulvilli being kept clean, that as the tarsi of the two middle legs cannot he applien to each other, flies are constantly in the habit of rubbing one of these tarsi and its pulvillus sometimes between the two fore tarsi, and at other times between the two hind ones. I ought also not to omit stating, that luaving taken out of a spider's net one of the minute Chalcidide just canght, and pulled away the threads attached to it, it spent some time in passing its hinder tarsi over its wings and abdomen, and then in passing its fore tarsi through its palpi, apparently, as in the case of flies, to clean its pulvilli from any remains of the spider's net; and that having surrounded a minute beetle (Meligethes aneus), which chanced to be on the window, with a slight circle of moisture, it was unable to pass through it, and repeatedly drew its wetted fore tarsi throngh its mouth, and rubbed the hind tarsi together; and that precisely the same results took place in the case of an Ichneumon placed in similar circumstances, only it spent mucl more time in rubbing both its fore and hind tarsi together after being wetted, and in passing the former over its antennze and through its mouth; and when powdered with flour, it spent, like the flies before mentioned, some minutes in cleaning itself by the same processes.

Thougl the above observations, hastily made on the spur of the occasion since beginning this note, seem to prove that it is necessary the pulvilli of flies and of some other insects should be kept free from moisture and dust to enable them to ascend vertical polished surfaces, they cannot be considered as wholly settling the question as to the precise way in which these pulvilli, and those of insects generally, act in effecting a similar mode of progression; and my main reason for here giving: these slight hints is the hope of directing the attention of entomological and microscopical observers to a field evidently, as yet, so imperfectly explored.

After writing the above, intended as the conclusion of this long note, I witnessed to-day (July 11, 1842), a fact which I cannot forbear adding to it. Observing a house-fly on the window, whose motions seemed very strange, I approached it, and found that it was making violent contortions, as thougl every leg were affected with St. Vitus's dance, in order to pull its pulvilli from the surface of the glass, to which they adhered so strongly that though it could drag then a little way, or sometimes by a violent effort get first one and then another letached, yet the moment they were placed on the glass again, they adhered as if their under side were smeared with bird-lime. Once it succeeded in dragging off its two fore legs, 
particularly those of $B$. fascicularis. A Brazilian beetle in my cabinet, belonging to the family of the Clerida, bnt not arranging well under any of Latreille's genera, which 1 have named Priocera variegata, has eurious involuted suckers on its feet. The strepsipterous genera Stylops and Xenos are remarkable for the vesicles of membrane that cover the under side of their tarsi, which, though flaceid in old specimens, appear to be inflated in the living aninal or those that are recent. ${ }^{1}$ It is not improbable that these vesicles, which are large and hairy, may act in some degree as suckers, and assist it in climbing.

The insects of the Orthoptera order are, many of them, remarkable for two kinds of appendages connected with my present subject, being furnished both with suckers and cushions. The former are concavo-convex processes, varying in shape in different species, being sometimes orbicular, sometimes ovate or oblong, and often wedge-shaped, which terminate the tarsus between the claw, one on each foot. They are of a hard substance, and seem capable of free motion. In some instances ${ }^{2}$, another minute cavity is discoverable at the base of the concave part, similar to that in Cimbex lutea. ${ }^{3}$ The latter, the foot-cushions, are usually convex appendages, of an oblong form, and often, though not always, divided in the middle by a very deep longitudinal furrow, attached to ihe under side of the tarsal joints. Sir E. Home is of opinion that the object of these footcushions is to take off the jar when the body of the animal is suddenly brought from a state of motion to a state of rest. ${ }^{4}$ This may very likely be one of their uses; but there are several circumstances which militate against its being the only one. By their elasticity they probably assist the insects that have them in their leaps; and when they climb they may in some degree act as suckers, and prevent them from falling. But their use will be best ascertained by a review of the principal genera of the order. Of these the cock-roaches (Blatta), the spectres (Phasma), and the praying insects (Mantis), are distinguished by tarsi of five joints. ${ }^{5}$ The grass-

when it immediately began to rub the pulvilli against the tarsal bruslies; but on replacing them on the glass they adhered as closely as before, and it was only by efforts almost convulsive, aud which seemed to threaten to pull off its limbs trom its body, that it could succeed in moving a quarter of an inch at a time. After watching it with much interest for five minutes, it at last by its continued exertions got its feet released and flew away, and alighted on a curtain, on which it walked quite briskly, but soon again flew back to the window, where it had precisely the same difficulty in pulling its pulvilli from the glass as before; but after observing it some time, and at last trying to catch it, that I might examine its feet with a lens, it seemed by a vigorous effort to regain its powers, and ran quite actively on the glass, and then fling away I lost sight of it. I am unable to give any satisfactory solution of this singular fact. The season, and the fly's final activity, preclude the idea of its arising from cold or debility, to which Mr. White attributes the dragging of flies' legs at the elose of autumu. 'The pulvilli certainly had much more the appearance of adlering to the glass by a viscid material than by any pressure of the atmosphere, and it is so far in favour of Mr. Blackwall's hypothesis on which one might conjecture that from some canse (perhaps of disease), the hairs of the pulvilli had pourel out a greater quantity of this viscid material than usual, and more than the muscular strength of the fly was able to cope with.

1 Kirby in Linn. Trans, xi. 106. t. viii, f. 13. $\boldsymbol{~}$.

2 I observed this in the hind legs of a rariety of Locusta migratoria.

5 Plilos. Trans. 1816., 325. t. xix. f. 5.

4 Ibid. p. 325.

5 In a specimen in my cabinet of Blatta gigantea, the posterior and anterior tarsi 
hoppers with setaceous antennæ (Acrida) have four tarsal joints. Those with filiform antennæ (Locusta and Acrydium), those with ensiform (Truxalis ${ }^{1}$ ), and the crickets (Gryllus), have only three. In Blatta, the variations with respect to the suckers and cushions (for many species are furnished with both) are remarkable. The former in some (Blatta gigantea) are altogether wanting; in others (B. Petiveriana) they are mere rudiments; and in others ( $B$. Mader $C$ ) they are more conspicuous, and rescinble those of the Gryllida. The foot-cushions also in some are nearly obsolete, and occupy the mere extremity of the four first tarsal joints (B. orientalis, Americana, Capensis, \&c.). In B. Petiveriana there is none upon the first joint; but upon the extremity of the four last, not excepting the claw-joint, there is a minute orbicular concave one, resembling a sucker. In others ( $B$. gigantea, \&c.), they extend the length of the four. first joints, and are very conspicuous. In some $(B . \text { Mouffeti K. })^{2}$, which have no claw-sucker, there appears to be a cavity in the extremity of the claw-joint, which may serve the purpose of one. These foot-cushions are usually of a pale colour; but in one specimen of a hairy female which I have, from Brazil, they are black. The spectre genus (Phasma) exhibits no particular varieties in this respect. The tarsal joints of the legs have cushions at their apex, which appear to be bifid. They have a large orbicular sucker between the claws. In Mantis the fore feet, have neither of the parts in question, and the others have no suckers. They have cushions on the four first tarsal joints of the two last pair of legs, which, though smaller, are shaped much like those in Phasma. In Acrida the feet have no suckers between the claws; but they are distinguished by two oval, soft, concave, and movable processes attached to the base of the first joint of the tarsus, which probably act as suckers. ${ }^{3}$ In this genus there are two foot-cushions on the first joint of the tarsi, and one on each of the two following ones. ${ }^{4}$ The species of the genus Locusta come next. This genus is called Acrydium by Latreille after Geoffioy; but, since it includes the true locust, it ought to retain the name Locusia given by Linné to the tribe to which it belongs. ${ }^{5}$ All these insects have the terminal sucker between the claws, three foot-cushions on the first joint of the tarsus, and one on the second ${ }^{6}$; and the same conformation also distinguishes the feet of Truxalis. In the species of Acrydium F. ('Tetrix Latr.), the foot-

of one sile have only four joints, while the intermediate one has five. On the other side the hind leg is broken off, but the anterior and intermediate tarsi have both five joints. In another specimen one posterior tarsus has four and the other five joints.

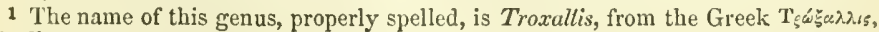
Gryllus.

2 This insect, which is remarkable for having the margin of its thorax reflexed, was long since well figured in Mouffet's work (130. fig. infima). It has not, lowever, been described by any other author I have met with. It is common in lirazil. Some specimens are pallid, while others are of a dark brown. It is to be observed that the Blattina are resolvable into several genera.

3 De Geer, iii. 421. t. xxi. f. 13. h. This author has also noticed the cushions in this genus and Locusta, and the claw-sucker in the latter, which he thinks aro analorous to those of the fly. Ibid. 462. t. xxii. f. 7,8.

4 Phitos. Trans. 1816.t. xxi. f. 8-13.

5 See Zool. Journ. for 1825, No. iv. 431.

6 Plitos. Trans. 1sit. t. xxi, f. 1-9. 
cushions, I believe - for in the dead insect they are the reverse of conspicuous - are arranged nearly as in the two preceding gevera, but these insects are without the claw-sucker. And lastly, Gryllus has neither suckers nor cushions. From this statement it seems to follow - since Blatta, Phasma, and Mantis, that do not leap, are provided with cushions, and Gryllus, a heavy tribe of insects that does, are without them - that their object cannot be exclusively to break the fall of the insects that have then. And for the same reason we may conclude that they must have some further use than augmenting their elasticity when they jump. When we consider that the Blattce, many of which have no suckers, or very small ones, are climbing insects (I have seen $B$. Germanica run up and down the walls of an apartment with great agility), and that the long and gigantic apterous spectres, \&c. (Phasma) require considerable means to enable them to climb the trees in which they feed, and to maintain their station upon them, we may conclude that these cushions, by acting in some degree as suckers, may promote these ends.

Amongst the homopterous Hemiptera, Chermes and many of the Corcopida $^{1}$ are furnished with the claw-suckers: but the noisy Cicada, as well as the heteropterous section, at least as far as my examination of them has gone, have them not. De Geer has observed, speaking of a small fly of this order (Thrips physapus), that the extremity of its feet is furnished with a transparent membranaceous flexible process, like a bladder. He further says that when the animal fixes and presses this vesicle on the surface on which it walks, its diameter is increased, and it sometimes appears concave, the concavity being in proportion to the pressure; which made him suspect that it acted like a cupping-glass, and so produced the adhesion. ${ }^{2}$ This circumstance affords another proof that the foot-cushions in the Orthoptera may act the same part ; they appear to be vesicular; and in numbers of specimens, after death, I have observed that they become concave, particularly in Acrida viridissima.

In Cimbex, and others amongst the saw-fly tribes, the claw-sucker is distinguished by this remarkable peculiarity, that its upper surface is concave $^{3}$, so that before it is used it must be bent inwards. Besides these, at the extremity of each tarsal joint these animals are furnished with a spoon-shaped sucker, which seems analogous to the cushions in the Gryllina, Locustina, \&c.; and, what is more remarkable, the two spurs (calcaria) at the apex of the shanks have likewise each a minute one. ${ }^{4}$ Various other insects of this order have the claw-suckers. Amongst others the common wasp (Vespa vulgaris) is by these enabled to walk up and down our glass windows.

We learn from De Geer that several mites (to finish with the Aptera) have something of this kind. Among these is the cheese-mite (Acarns siro) ; its four fore feet being terminated by a vesicle with a long neck, to which it can give every kind of inflexion. When it sets its foot down, it enlarges and inflates it; and when it lifts it up, it contracts it so that the vesicle almost entirely disappears. This vesicle is between two claws. ${ }^{5}$ The itch Acarus (A. scabiei) is similarly circumstanced. Ixodes Ricinus

1 De Geer, iii. 132.173.

2 Ibid. iii. 7 .

4 Philos. Trans, 1816. t. xix. f. 1-9.

3 Philos. Trans. 1816. t. xix. f. 3, 4.

5 De Geer, vii. 91, t. v. f, 6, 7 . 
and Reduvius have also these vesicles - which are armed with two claws - on all their feet. ${ }^{1}$

I am next to consider those climbers that ascend and descend, and probably maintain themselves in their station, by the assistance of a secretion which they have the power of producing. You will immediately perceive that I am speaking of the numerous tribes of spiders (Araneidce), which, most of them, are endowed with this faculty. Every body knows that these insects ascend and descend by means of a thread that issues from them 2; but perhaps every one has not remarked - when they wish to avoid a hand held out to catch them, or any other obstacle - that they can sway this thread from the perpendicular. When they move up or down, their legs are extended, sometimes gathering in and sometimes guiding their thread; but when their motion is suspended, they are bent inwards. These animals, although they have no suckers or other apparatus - except the hairs of their legs and the three claws of their biarticulate tarsi, to enable them to do it - can also walk against gravity, both in a perpendicular and a prone position. Dr. Hulse, in Ray's Letters, seems to have furnished a clue that will very well explain this. I give it you in his own homely phrase. "They" (spiders) "will often fasten their threads in several places to the things they creep up; the manner is by beating their bums or tails against them as they creep along." ${ }_{3}$ Fixing their anus by means of a web, the anterior part of their body, when they are resting, we can readily conceive, would be supported by the claws and hairs of their legs; and their motion may be accomplished by alternately fixing one and then the other. But you will remember I give you this merely as conjecture, having never verified it by observation. ${ }^{4}$

It may not be amiss to mention here another apterous insect that reposes on perpendicular or prone surfaces, without either suckers or any viscous secretion by which it can adhere to them. I mean the long-legged or shepherd spiders (Phalangizm). The tarsi of these insects are setaceous, and nearly as fine as a hair, consisting sometimes of more than forty joints, those towards the extremity being very ninute, and scarcely discernible, and terminating in a single claw. These tarsi, which resemble antennæ rather than feet, are capable of every kind of inflexion, sometimes even of a spiral one. These circumstances enable them to apply their feet to the inequalities of the surface on which they repose, so that every joint may in some measure become a point of support. Their eight legs also, which diverge from their body like the spokes from the nave of a wheel, give them equal hold of eight almost equidistant spaces, which, doubtless, is a great stay to them.

The next species of locomotion exhibited by perfect insects is fying. I am not certain whether under this head I ought to introduce the sailing of spiders in the air; but as there is no other under which it can be more properly arranged, I shail treat of it here. I shall therefore divide flying insects into those that fly without wings, and those that fly with them.

1 De Geer, 96. t. v. f. 13, 14. 17. 19. t. vi. f. 2.5.

2 The caterpillars of many Lepidopterous insects possess the same power.

365 .

4 Mr. Blackwall, as before stated, conceives that the power possessed by spiders which use no threads, such as Drassus melanoqaster, Salticus scenicus, \&c., of walking up polished surfaces, is derived from an adhesive fluid emitted from the tubular hair-like appendages of their tarsi. (Linn. Irans. xvi. 480. 769.) 
I dare say you are anxious to be told how any animals can fly without wings, and wish me to begin with them. As an observer of nature, you have often, without doubt, been astonished by that sight occasionally noticed in fine days in the autumn, of webs - commonly called gossamer webs - covering the earth and floating in the air; and have frequently asked yourself - What are these gossanier webs? Your question has from old times much excited the attention of learned naturalists. It was an old and strange notion that these webs were composed of dew burned by the sun.

"..... The fine nets which oft we woven see

Of scorched dew,"

says Spenser. Another, fellow to it, and equally absurd, was that adopted by a learned man and good natural philosopher, and one of the first Fellows of the Roval Society, Robert Hooke, the author of Micrographia. "Much resembling a cobweb," say's he, "or a confused lock of these cylinders, is a certain white substance which, after a fog, may be observed to fly up and down the air: catching several of these, and examining them with my microscope, I found them to be much of the same form, looking most like to a flake of worsted prepared to be spun; though by what means they snould be generated or produced is not easily imagined: they were of the same weight, or very little heavier than the air; and 'tis not unlikely but that those great white clouds, that appear all the summer time, may be of the same substance." 1 So liable are even the wisest men to error, when, leav. ing fact and experiment, they follow the guidance of fancy. Some French naturalists have supposed that these fils de la Vierge, as they are called, are composed of the cottony matter in which the eggs of the Coccus of the vine $(C$. Vitis $)$ are enveloped. ${ }^{2}$ In a country abounding in vineyards this supposition would not be absurd; but in one like Britain, in which the vine is confined to the fruit-garden, and the Coccus seldom seen out of the conservatory, it will not at all account for the phenomenon. What will you say, if I tell you that these webs (at least many of them) are airballoons, and that the aëronauts are not

"Lovers who may bestricle the gossamer

That idles in the wanton summer air,

And yet not full,"

but spiders, who, long before Montgolfier, nay, ever since the creation, have been in the habit of sailing througl the fields of ether in these air-light chariots! This seems to have been suspected long ago by Henry Moore, who says,

\section{"As light and thin as colwebs that do fly}

In the blew air, caus'd by the autuminal sun,

That boils the dew that on the earth doth lie,

May seem this whitish rag then is the scum;

Untess that wiser men make the field-spider's toom : "3

1 Microgr. 202. It has been objected to an excellent primitive writer (Ctemens Romanus), that he believed the absurd fable of the phœnix. But surely this may be allowed for in him, who was no naturalist, when a scientific natural philosopher could believe that the clouds are made of spiler's' web :

2 Latreille, Hist. Nat. sii. 388.

3 Quoted in the Athenaum, v. 126. 
where he also alludes to the old opinion of scorched dew. But the first naturalists who made this discovery appear to have been Dr. Hulse and Dr. Nartin Lister - the former first observing that spiders shoot their wels into the air ; and the latter, besides this, that they were carried upon them in that element. ${ }^{1}$ This last gentleman, in fine serene weather in September, had noticed these webs falling from the heavens, and in them discovered more than once a spider, which he named the bird. On another occasion, whilst he was watching the proceedings of a common spider, the animal, suddenly turning upon its back and elevating its anus, darted forth a long thread, and vaulting from the place on which he stood was carried upwards to a considerable height. Numerous observations afterwards confirmed this extraordinary fact; and he further discovered that while they fly in this manner, they pull in their long thread with their forc fect, so as to form it into a ball - or, as we may call it, air-balloon of flake. The height to which spiders will thus ascend he affirms is procigious. One day in the autumn, when the air was full of webs, he mounted to the top of the highest steeple of York minster, from whence he could discern the floating webs still very high above him. Some spiclers that fell and were entangled upon the pinnacles he took. They were of a kind that never enter houses, and therefore could not be supposed to have taken their flight from the steeple. ${ }^{2}$ It appears from his observations that this faculty is not confined to one species of spicler, but is conmon to several, though only in their young half-grown state ${ }^{3}$; whence we may inter that when full-grown their bodies are too heavy to be thus conveyed. One spider he noticed that at one time contented itself with ejaculating a single thread, while at others it darted ont several, like so many shining rays at the tail of a comet. Of these, in Cambridgeshire in October, he once saw an incredible number sailing in the air. ${ }^{4}$ "ipeaking of his $A r$. subfuscus minutissimis oculis, \&c., he says, "Certainly this is an excellent rope-dlancer, and is wonderfully delighted with darting its threads : nor is it only carried in the air, like the preceding ones ; but it effects itself its ascent and sailing : for, by means of its legrs closely applied to each other. it as it were balinces itself, and promotes and directs its course no otherwise than as if nature had furnished it with wings or oars." 5 A later but equally gifted observer of nature, Mr. White, confirms Dr. Lister's account. "Every day in fine weather in autumn," says he, "do I see these spiders shooting out their webs, and mounting aloft : they will go off from the finger if you take them into your hand. Last summer one alighted on my book as I was reading in the parlour; and ruming to the top of the page and shooting out a web, took its departure from thence. But what I most wondered at was, that it went off with considerable velocity in a place where no air was stirring; and $I$ am sure that $I$ did not assist it with my breath. So that these little crawlers seem to have while mounting some locomotive power without the use of wings; and move faster than the air in the air itself." ${ }^{6}$ A writer in the last number of

1 Ray's Letters, 36. 69.

2 Ray's Letters, 37. 87. Lister, De Aran. 80. Lister illustrates the force with which these creatures shoot their thread, by a homely though very forcible simile: "Resupinata (says he) anum in ventum dedit, filumque ejaculata est quo plane moda jobustissimus juvenis e distentissima vesicâ urinam."
3 De Araneis, 8. 27. 64, 75. 79.
4 Ibid. 79.
5 Ibid. 85.

6 Nut. Hist. i. 327 . 
Thomson's Annals of Philosophy ', under the signature of Carolan, has given some curious observations on the mode in which some geometric spiders shoot and direct their threads, and fly upon them; by which it appears that as they dart them out they guide them as if by magie, emitting at the same time a stream of air, as he supposes, or possibly some subtile electric fluid. One, which was running upon his hand, dropped by its thread about six inches from the point of his finger, when it inmediately emitted a pretty long line at a right angle with that by which it was suspended. This thread, though at first horizontal, quickly rose upwards, carrying the spider along with it. When it had ascended as far above his finger as it had dropped before below it, it let out the thread by which it had been attached to it, and continued flying smoothly upwards till it nearly reached the roof of the room, when it veered on one side and alighted on the wall. In flying, its motion was smoother and quicker than when a spider runs along its thread. He observes, that as the line lengthens behind them, the tendency of spiders to rise increases. I have myself more than once observed these creatures take their flight, and find the following memorandum with respect to their mode of proceeding : - "The spider first extends its thighs, shanks, and feet into a right line, and then elevating its abdomen till it becomes vertical, shoots its thread into the air, and flies off from its station." It is not often, however, that an observer can be gratified with this interesting sight, since these animals are soon alarmed. I have frecuently noticed them - for at the times when these webs are floating in the air they are very numerous - on the vertical angle of a post or pale, or one of the uprights of a gate, with the end of their abdomen pointing upwards, as if to shoot their thread previously to flying oft; when, upon my approaching to take a nearer view, they lave lowered it again, and persisted in disappointirg my wish to see them mount aloft. The rapidity with which the spider vanishes from the sight upon this occasion, and darts into the air, is a problem of no easy solution. Can the length of web that they dart forth counterpoise the weight of their bodies; or have they any organ analogous to the natatory vesicles of fishes ${ }^{2}$, which contributes at their will to render them buoyant in the air? Or do they rapidly ascend their threads in their usual way, and gather them up, till having collected them into a mass of suffieient magnitude, they give them sclves to the air, and are carried here and there in these chariots? I must here give you Mr. White's very eurious account of a shower of these webs that he witnessed. On the 21 st of September, 1741, intent upon field diversions, he rose before daybreak; but on going out he found the whole face of the country covered with a thick coat of cobweb, drenched with dew, as if two or three setting-nets had been drawn one over the other. When his dogs attempted to hunt, their eyes were so blinded and hoodwinked that they were obliged to lie down and serape themselves. This appearance was followed by a most lovely day. About nine A. M. a shower of these webs (formed not of single floating threads, but of perfect flakes, some near an inch broad, and five or six long) was observed falling from very elevated regions, which continued without interruption during the whole of the day; and they fell with a velocity which showed that they were considerably heavier than the atmosphere. When the most eleviteil station in the country where this was observed was ascended, the webs 
were still to be seen descending from above, and twinkling like stars in the sun, so as to draw the attention of the most incurious. The flakes of the web on this occasion hung so thick upon the hedges and trees, that baskets fuil might have been eollected. No one doubts, he observes, but that these webs are the production of small spiders, which swarm in the fields in fine weather in autumn, and have a power of shooting out webs from their tails, so as to render themselves buoyant and lighter than the air." In Germany these flights of gossamer appear so constantly in autumn, that they are there metaphorically called "Der fliegender Sommer" (the flying or departing summer); and authors speak of the web as often hanging in flakes like wool on every hedge and bush throughout extensive distriets.

Here we may inquire-Why is the ground in these serene days covered so thiekly by these webs, and what becomes of them? What oceasions the spiders to mount into the air, and do the same species form both the terrestrial and aërial gossamer? And what causes the webs at last to fall to the earth? I fear I cannot to all these queries return a fully satisfactory answer; but I will do the best I ean. At first one would conclude, from analogy, that the object of the gossamer which early in the morning is spread over stubbles and fallows - and sometimes so thickly as to make them appear as if covered with a carpet, or rather overflown by a sea of gauze, presenting, when studded with dew-drops, as I have often witnessed, a most enchanting spectacle - is to entrap the flies and other insects as they rise into the air from their noeturnal station of repose to take their diurnal flights. But Dr. Strack's observations render this very doubtful; for he kept many of the spiders that produce these webs in a large glass upon turf, where they spun as when at liberty, and he could never observe them attempt to catch or eat - even when entangled in their webs - the flies and gnats with which he supplied them ; though they greedily sucked water when sprinkled upon the turf, and remained lively for two months without other food. ${ }^{2}$ As the single threads shot by other spiders are usually their bridges, this perhaps may be the object of the webs in question; and thus the animals may be conveyed from furrow to furrow or straw to straw less circuitously, and with less labour, than if they had travelled over the ground. As these creatures seem so thirsty, may we not conjecture that the drops of dew, with which they are always as it were strung, are a secondary object with them? So prodigious are their numbers, that sometimes every stalk of straw in the stubbles, and every clod and stone in the fallows, swarms with them. Dr. Strack assures us that twenty or thirty often sit upon a single straw, and that he colleeted about $2000 \mathrm{in}$ half an hour, and could have easily doubled the number had he wished it: he remarks, that the eause of their escaping the notice of other observers is their falling to the ground upon the least alarm.

As to what becomes of this immense earpeting of web there are different opinions. Mr. White eonjectures that these threads, when first shot, might be entangled in the rising dew, and so drawn up, spiders and all, by a brisk evaporation, into the region where the clouds are formed. ${ }^{3}$ But this seems almost as inadmissible as that of Hooke, before rclated. An ingenious and

1 Nat. Hist. i. 325.

2 Neue Schriften der Naturforschenden Gessellschaft zu Halle, 1810, v. IIeft.

3 Nat. Hist. i. 326. 
observant friend, thinking the numbers of the flying spiders not sufficient to produce the whole of the phenomenon in quastion, is of opinion that an equinoctial gale, sweeping along the fallows and stubbles coated with the gossamer, must bring inany single threads into contact, which, adhering together, may gradually collect into flakes; and that being at length detached by the violence of the wind, they are carried along with it: and as it is known that such winds often convey even sand and earth to great heights, he deems it highly probable that so light a substance may be transported to so great an elevation as not to fall to the earth for some days after, when the weather has become serene, or to descend upon ships at sea, as has sometimes happened. This, which is in part adopted from the German authors, is certainly a much more reasonable supposition than the other; but some fucts seem to militate against it: for, in the first place, though gossamer often occurs upon the ground when there is none in the air, yet the reverse of this has never been observed; for gossamer in the air, as in the instance recorded by Mr. White, is always preceded by gossamer on the ground. Now, since the weather is constantly calm and serene when these showers appear, it cannot be the wind that carries the web from the ground into the air. Again, it is stated that these showers take place after several calm days ${ }^{1}$; but, if the web was raised by the wind into the air, it would begin to fall as soon as the wind ceased. Whence I am inclined to rhink that the cause assigned by Dr. Lister is the real source of the whole phenomenon. Though ordinary observers have overlooked them, he noticed these spiders in the air in such prodigious numbers, that he deemed them sufficient to produce the effect. I shall not, however, decide positively; but, having stated the different opinions, leave you to your own judgment.

The next query is, What occasions the spiders to mount their chariots and seek the clouds? Is it in pursuit of their food? Insects, in the fine warm days in which this phenomenon occurs, probably take higher flights than usual, and seek the upper regions of the atmosphere; and that the spiders catch them there, appears by the exuvire of gnats and flies, which are often found in the falling webs. ${ }^{2}$ Yet one would suppose that insects would fly high at all times in the summer in serene warm weather. Perhaps the flight of some particular species constituting a favourite food of our little charioteers - the gnats, for instance, which we have seen sometimes rise in clouds into the air - may at these times take place; or the species of spiders that are most given to these excursions may not abound in their young state - when only they can fly-at other seasons of the year.

Whether the same species that cover the earth with their webs produce those that fill the air, is to be our next inquiry. Did the appearance of the one always succeed that of the other, this might be reasonably concluded; but the former, as I lately observed to you, often occurs without being followed by the latter. Yet, since it should seem that the aërial gossamer, though it does not always follow it, is always preceded by the terrestrial, this warrants a conjecture that they may be synonymous. Two German authors, Bechstein ${ }^{3}$ and Strack ${ }^{4}$, have described the spider that produces gossamer in Germany under the name of Aranea obtextrix. But it is not

1 Ray's Letters, 36.

2 Ibid. 42. Lister, De Araneis, 8.

9 Lichtenberq und Toight Magazin, 1789, vi. 53.

4 Neue Schriften der Naturforsch. Sic. 1810, v. Heft. 41-56. 
clear, unless they have described it at different ages, when spiclers often greatly change their appearance, that they mean the same species. The former describes his as of the size of a small pin's head, with its eight eyes disposed in a circle, having a black brown body and light yellow legs: while Dr. Strack represents his A. obtextrix as more than two lines in length; eyes four in a square, and two on each side touching each other; thorax deep brown with paler streaks; abdomen below dull white, above dark copper brown, with a dentated white spot running longitudinally down the middle. The first of these, if distinct, as I suspect they are, agrees very well with the young of one which Lister observed as remarkable for taking aërial flights ${ }^{2}$, and which I have most usually seen so engaged. The other may possibly be that before noticed, which he found in such infinite numbers in Cambridgeshire. ${ }^{2}$ If this conjecture be correct, it will prove that the same species first produce the gossamer that covers the ground, and then, shooting other threads, nount upon them into the air.

My last query was, What causes these webs ultimately to fall to the earth? Mr. White's observation will, I think, furnish the best answer. "If the spiclers have the power of coiling up their webs in the air, as Dr. Lister affirms, then when they become heavier than the air they will fall." 3 The more expanded the web the lighter and more buoyant, and the more condensed the heavier it must be.

I trust you will allow, from this mass of evidence, that the English Arachnologists - may I coin this term? - were correct in their account of this singular phenomenon; and think, with me, that Swammerdam (who。 however, admits that spiders sail on their webs), and after him De Geer, were rather hasty when they stigmatised the discovery that these animals shoot their webs into the air, and so take flight, as a strange and unfounded opinion. ${ }^{4}$ The fact, though so well authenticated, is indeed strange and wonderful, and affords another proof of the extraordinary powers, unparalleled in the higher orders of animals, with which the Creator has gifted the insect world. Were, indeed, man and the larger animals, with their present propensities, similarly endowed, the whole creation would soon go to ruin. But these almost miraculous powers in the hands of these little beings only tend to keep it in order and beauty. Adorable is that Wisdom, Power, and Goodness, that has distinguished these next to nothings by such peculiar endowments for our preservation as if given to the strong and mighty would work our destruction.

After the foregoing marvellous detail of the aerial excursions of our insect air-balloonists, I fear you will think the motions of those which fly by means of wings less interesting. You will find, however, that they are not altogether barren of amusement. Though the wings are the principal instruments of the flight of insects, yet there are others subsidiary to them, which I shall here enumerate, considering them more at large under the. orders to which they severally belong. These are wing-cases (elytra tegmina, and hemelytra); winglets (alule); poiscrs (halteres); tailets (cauduke); hooklets (hamuli); base-covers (tegulce); \&c. Besides, their tails, legs, and even antema, assist them in some instances in this motion.

As wings are common to almost the whole class, I slall consider their structure here. Every wing consists of two membranes, more or less

I De Araneis, 60.

2 Ibid. 79.

3 Nat. Itist. i. 326.

4 Swam:. Bill. Nut, el. IIill, i, 25. De Geer, vii. 190.

$$
\text { II } \mathbf{H} 3
$$


transparent, applied to eaeh other : the upper membrane being very strongly attached to the nervures (neurce), and the lower adhering more loosely, so as to be separable from them. The nervures ${ }^{1}$ are a kind of hollow tube, - above elastic, horny, and convex ; and flat and nearly membranaceous below, - which take their origin in the trunk, and keep diminishing gradually, the marginal ones exeepted, to their termination. The vessels contained in the nervures consist of a spiral thread, whence they appear to be airvessels communicating with the tracher in the trunk. The expansion of the wing at the will of the insect is a problem that can only be solved by supposing that a subtile fluid is introduced into these vessels ${ }^{2}$, which seem perteetly analogous to those in the wings of birds, and that thus an impulse is communicated to every part of the organ suffieient to keep it in proper tension. We see by this, that a wing is supporterl in its flight like a sail by its cordage. ${ }^{3}$ It is remarkable that those insects which keep the longest on the wing, the dragon-flies (Libellulina) for instance, have their wings most eovered with nervures. The wings of insects in flying, like those of other flying animals, you are to observe, move vertically, or up and down.

In considering the flight of insects, I shall treat of that of each order separately, beginming with the Coleoptera or beetles. Their subsidiary instruments of flight are their wing-eases (elytra), and in one instanee winglets (alulce). The former, whicl in some are of a hard horny substance, and in others are softer and more like leather, though they are kept immoveahle in flight, are probably, by their resistanee to the air, not without their use on this occasion. The winglets are small concavo-convex scales, of a stiff membranaceous substance, generally fringed at their extremity. I know at present of only one eoleopterous insect that has them (Dytiscus margmalis). They are placed under the elytra at their base. Their use is unknown; but it may probably be conneeted with their flight. The wings of beetles are usually very ample, often of a substance between parehment and membrane. The nervures that traverse and extend them, though not numerous, are stronger and larger than those in the wings of insects of the other orders, and are so dispersed as to give perfeet tension to the organ. When at rest-exeept in Molorchus, Atractocerus, Necydalis, and some other genera - they are folded transversely under the elytra, generally near the middle, with a lateral longitudinal fold, but oecasionally near the extremity. When they prepare for flight, their antennæ being set out, the elytra are opened so as to form an angle with the body and admit the free play of the wings; and they then fly off, striking the air by the vertical motion of these organs, the elytra all the while remaining immoveable. The Cetonia, however, as noticed by M. Audouin, differ from most if not all other coleopterous insects in keeping their elytra closed during their flight. ${ }^{4}$ During their flight the bodies of insects of this order, as far as I have observed them, are always in a position nearly vertical, which gives to the larger sorts, the stag-beetle for instance, a very singular appearance. Olivier, probably having some of the larger and heavier beetles in his eye,

1 French naturalists use this term (nervure) for the reins of wings, leares, \&c., restric ing nerve (nerf) to the ramifications from the brain and spinal marrow. Wo have adopted the term, which we express in Latin by neura, from the Greek vevex.

2 Recent observations by several distingtuished microscopical naturalists fully con. firm this opinion.

3 Jurine, Hymenopt. 19.

4 Ann. Soc. Ent. de France, viii. p, xlviii. 
affirms that the wings of insects of this order are not usually proportioned to the weight of their bodies, and that the muscular apparatus that moves them is deficient in force. In consequence of which, he observes, they take flight with difficulty, and fly very badly. The strokes of their wings being frequent, and their flight short, uncertain, heavy, and laborions, they can use their wings only in very calm weather, the least wind beating them down. Yet he allows that others, whose borlies are lighter, rise into the air and fly with a little more ease, especially when the weather is warm and dry ; their flights, however, being short, though frequent. He asserts also, that no coleopterous insect can fly against the wind. ${ }^{1}$ These observations may hold, perhaps, with respect to many species; but they will by no means apply generally. The cockchafer (Melolontha vulgaris), if thrown into the air in the evening, its time of flight, will take wing before it falls to the ground. The common dung-chafer (Gcotrupes stercorarius) - wheeling from side to side like the humble-bee-flies with great rapidity and force, and, with all its dung-dlevouring confederates, directs its flight with the utmost certainty, and probably often against the wind, to its food. The root devourers or tree-chafers (Melolontha, Hoplia, \&c.) support themselves, like swarming bees, in the air and over the trees, flying round in all directions. The Brachyptera and Donacice, in warm weather, fly off from their. station with the utmost ease; - their wings are unfolded, and they are in the air in an instant, especially the latter, as I have often found when I have attempted to take them. None are more remarkable for this than the Cicindela, which, however, taking very short flights, are as easily marked down as a partridge, and afford as much amusement to the entomologist as the latter to the sportsman. It is to be observed that many insects in this order have no wings, and the female glow-worms neither wings nor elytra.

Many persons are not aware that the insects of the next order, the Dermaptera, can fly; but earwigs (Forficula), their size considered, are furnished with very ample and curious wings, the principal nervures of which are so many radii, diverging from a common point near the anterior margin. Between these are others, which, proceeding from the opposite margin, terminate in the middle of the wing. These organs, when at rest, are more than once folded both transversely and longitudinally.

Wings equally anzle, forming the quadrant of a circle, and with five or six nervures diverging from their base, distinguish the Strepsipterous tribe. When unemployed, these are folded longitudinally. ${ }^{2}$

Probably in the next order (Orthoptcra) the tegmina, or wing-covers since they are usually of a much thinner substance than elytra-assist them in flying. They are, however, quite covered by irregular reticulations, produced by various nervures sent forth by the longitudinal ones, and lunning in all directions. When at rest, the inner part of one laps over that of the other; but in different genera there is a singular variation in this circumstance. Thus in Blatta, Phasma, and male Acrida, and generally speaking, but not invariably, in Locusta and Truxalis, the left elytrum laps over the right; but in Mantis, Mantispa, some female Acrida, Gryllus, and

1 Entomol. i. 1.

2 It has been ascertained that the spurious elytra of these insects are serviceable in their flight. As M. Latreille now allows this, he ought to have restored its original name, which le had altered, to this order. 
Gryllotulpa, the right is laid over the left. The wings in this order, though always ampie and larger than the tegmina, do not invariably form a quadrant of a circle, falling often short of it. They are extended by means of nervtires, which, tike so many rays, diverge from the base of the wing; and are intersected alternately by transverse ones, which thus form quadrangular areas, arranged like bricks in a wall. When at rest, they are longitudinally folded. The flight of these insects, as far as it has been observed, much resembles, it is said, that of certain birds. Ray tells us that both sexes of the house-cricket (Gryllus domesticus) fly with an undulating motion, like a woodpecker, alternately ascending with expanded wings, and descending with folded ones. ${ }^{1}$ The field and mole-crickets (Gryllus campestris and Gryllotalpa vulgaris), as we learn from Mr. White ${ }^{2}$, and, since the structure of their wings is similar, probably the other Orthoptere, - fly in the same way.

Hemiptcrous insects, with respect to their hemelytra, may be divided into two classes. Those in which they are all of the same substance - varying from membrane to a leathery or horny crust - and those in which the base and the apex are of different substances; the first being generally corneous, and the latter menibranaceous. The former or homopterous division includes the Cicadariee Latr., Aphis, Chermes, Thrips, and Coccus ;and the latter the heteropterous division, comprehending, besides the Geocorise Latr., Notonecta, Sigara, Nepa, Ranatra, and Nancoris of Fabricius. The posterior tibia of some of this last division (Lygaeus phyllopus, foliacens, \&c. F.) are furnished on each side with a foliaceons process - which may act the part of outriggers, and assist them in their flight. $^{3}$ I can give you no particular information with respect to the aêrial movements of the insects of this order: the British species that belong to it are generally so minute that it is not easy to trace them with the naked eye; and unless some kind optician, which is much to be wished, would invent a telescope by which the proceedings of insects could be examined at a distance, there is no other way of stulying them.

The four wings of the next order, the Trichoptera or case-worn thies, both in their shape and nervures resemble those of many moths; only instead of scales they are usually covered with hairs, and the under wings, which are larger than the upper, fold longitutinally. Some of these flies, I have obscrved, move in a dircet line, with their legs set out, which makes them look as if they were walking in the air. In flying they often apply their antennæ to each other, stretehing them out straight, and thus probably are assisted in their motion.

The Lepidoptera vary so infinitely in the shape, comparative magnitude, and appendages of their wings, that I should detain you too long did I enlarge upon so multifarious is subject. I shall therefore only observe, that one spccies is described, both by Lyonet and De Gerr ${ }^{4}$ (Lobophora hexaptera), as having six wings; for, besides the four ordinary ones, it ha; a winglet (alula) attarhed to the base of the lower one, and placed, when the wings are folded, between it and the npper. These organs in this order, you know, are covered with scales of various shapes. Their ner-

1 Hist. Ins. 63.

2 Tat. IIist. ii. 82.

5 I have separated this tribe from the rest under the name of Petalnpus K. MIs.

4 Lesser, 1. i. 109, note*. De Geer, ii. 460. t. ix, f. 9. 
vures are diverging ray's, which issue either from a basal area or from the base itself, and terminate in the exterior margin. The wings of many male butterflies, hawk-moths, and moths, are distingnished by a remarkable apparatus, noticed by De Geer, and since by many other naturalists ${ }^{1}$, for liceping them steady and underanged in their flight. The upper wings, on their under side near their base, have a minute process, bent into a hook (hamus), and covered with hairs and scales. In this hook one or more bristles (tendo), attached to the base of the under wing, have their play. When the fly unfolds its wings, the hook does not quit its hold of the bristle, which moves to and fro in it as they expand or close. The females, which seldom fly far, often have the bristles, but never the hook. The hairy tails of some insects (Sesia) belonging to the hawk-moth tribe are expanded when they fly, so as to form a kind of rudder, which enables them to steer their course with more certainty.

The insects of this and every other order, except the Coleoptera, fly with their bodies in a horizontal position, or nearly so. As their wings are usually so ample, we need not wonder that the Lepidoptera are excellent fliers. Indeed they seem to flit untired from flower to flower, and from field to field; impelled at one while by hunger, and at another by love or materinal soliciture. The distance to which some males will Hy is astonishing. That of one of the silk-worm moths (Attacus Paphia) is stated to travel sometimes more than a hundred miles in this way. ${ }^{2}$ Our most beautiful butterfy, the purple emperor (Apatura Iris), when he makes his first appearance, fixes his throne on the summit of some lofty oak, from whence in sunny days, unattended by his empress, who does not ty, he takes his excursions. Launching into the air from one of the highest twigs, he mounts often to so great a height as to become invisible. When the sun is at the meridian his loftiest flights take place; and about fonr in the afternoon he resumes his station of repose. ${ }^{3}$ The large bodies of hawkmoths (Splinic F.) are carried by wings remarkably strong both as to nervures and texture, and their flight is proportionably rapid and direct. That of butterflies is by dipping and rising alternately, so as to form a zigzag line with vertical angles, which the animal often describes with a skipping motion, so that each zigzag consists of snaller ones. This doubt less renders it more difficult for the birds to take them as they fly; and thus the male, when paired, often flits away with the female.

Amongst the neuropterous tribes the most conspicuous insects are the dragon-flies (Libellulina), which - their netamorphosis, habits, mode of life, and characters considered - form a clistinct natural order of themselves. Their four wings, which are nearly equal in size, are a complete and beautiful piece of net-work, resembling the finest lace, the meshes of which are usually filled by a pure, transparent, glassy menbrane. In two

1 De Geer, i. 173. t. x. f. 4 . Linn. Trans. i. 135.

2 Linn. Truns. vii. 40.

3 Haworth, Lepidoyt. Brit. i. 19. Mr. Hewitson, in an interesting notice of this speeies, informs us that at Kissengen in Bararia, where he had an opjortunity of observing its habits in June and $J u l y, ~ i 839$, after long and rapid flights in the outskirts of a neighbouring forest, they would enter its most shady recesses to cool themselves, anl lap the moisture from any puddles of water (preferring the most filthy) with their long trunks; and were so eager in this occupation that he has harl seven under a small that net at once, and could even take them readily with his finger and thumb. (Entomolngist, June, 1842, p. 321.) 
of the genera belonging to this tribe the wings, when the animal is at rest, are always expanded, so that they can take flight in an instant, no previous unfolding of these organs being necessary. In Agrion, the other genus of the tribe, the wings when they repose are not expanded. I have observed of these insects, and also of several other's in different orders, that without turning they can fly in all directions - backwards, and to the right and left, as well as forwards. This ability to fly all ways, without having to turn, must be very useful to them when pursued by a bird. Leeuwenlioek once saw a swallow chasing an insect of this tribe, which he calls a Mordella, in a menagerie about a hundred feet long. The little creature flew with such astonishing velocity - to the right, to the left, and in all directions - that this bird of rapid wing and ready evolution was unable to overtake and entrap it; the insect eluding every attempt, and being generally six feet before it. ${ }^{x}$ Indeed, such is the power of the long wings by which the dragon-flies are distinguished, particularly in Atshna and Libellula, and such the force of the muscles that move them, that they seem never to be wearied with flying. I have observed one of the former genus (Anax imperator Leach) sailing for hours over a piece of water sometimes to and fro, and sometimes wheeling from side to side; and all the while chasing, capturing, and devouring the various insects that came athwart its course, or driving away its competitors - without ever seeming tired, or inclined to alight. Another species (Fshna variegata), very common in lanes and along hedges, which flies, like the Orthoptcra, in a waving line, is equally alert and active after its prey. This, however, often alights for a moment, and then resumes its gay excursive flights. A Libellula, resembling this last insect, flew on board the vessel in which Mr. Davis was sailing, Dec. 11. 1837, when at sea, and the nearest land was the coast of Africa, 500 miles distant - a striking proof of its powers of wing. ${ }^{2}$ The species of the genus Agrion cut the air with less velocity; but so rapid is the motion of their wings that they become quite invisible. Hawking always about for prey, the Agrions, from the variety of the colours of different individuals, form no uninteresting object during a summer stroll. With respect to the mode of flight of the other neuropterous tribes I have nothing to remark; for that of the Eplemer'e, which has been most noticed, I shall consider under another head.

The next order of insects, the Hymenoptern, attract also general attention as fliers, and from our carliest years. The ferocious hornet, with its trumpet of terror ; the intrusive and indomitable wasp; the booming and pacific humble-bee, the frequent prey of merciless schoolboys; and that universal favourite, the industrious inhabitant of the hive, - all belonging to it,-are familiar to every one; and in summer there is scarcely a flower or leaf in field or garden, which is not visited by some of its numerous tribes. The four wings of these insects, the upper pair of which are larger than the under, vary much in their nervures. From the saw-flies (Serrifera), whose wings are nearly as much reticulated as those of some Neuroptera, to the minute Chalcis and Psilus, in which these organs are without nervures, there is every intermediate variety of reticulation that can be imagined. ${ }^{3}$ It has been observed that the nervures of the wings are usually proportioned to the weight of the insect. Thus the saw-flies have 
generally bodies thicker than those of most other Hymenoptera, while those that have fewer nervures are more slender. This, however, does not hold good in all cases - so that the dimensions and cut of the wings, the strength of their nervures, and the force of their muscles, must also be taken into consideration. The wings of many of these insects, when expanded, are kept in the same plane by neans of small hooks (hamuli) in the anterior margin of the under wing, which lay hold of the posterior margin of the upper. ${ }^{1}$ Another peculiarity also distinguishes them. Base covers (tegule), or small concavo-convex shields, protect the base of the wings from injury ${ }^{2}$ or displacement.

The most powerful fliers in this order are the humble-bees, which, like the dung-chaters (Geotropes), traverse the air in segments of a circle, the arc of which is alternately to right and left. The rapidity of their fight is so great that, could it be calculated, it would be found, the size of the creature considered, far to exceed that of any bird, as has been proved by the observations of a traveller in a railway carriage proceeding at the rate of twenty miles an hour, which was accompanied, though the wind was against them, for a considerable distance by a humble-bee (Bombus subinterruptus K.) not merely with the same rapidity, but even greater, as it not unfre(quently flew to and fro about the carriage or described zig-zag lines in its thight. ${ }^{3}$ The aërial movements of the hive-bee are more direct and leisurely. When leaving the hive for an excursion, I have observed that as soon as they come out they turn about as if to survey the entrance, and then, wheeling round in a circle, fly off. When they return to the hive, they often fly from side to side, as if to examine before they alight. When swarming, the heads of all are turned towards the group at the mouth of their $\mathrm{d}$ welling; and upon rising into the air these little creatures fly so thick in every direction, as to appear like a kind of net-work with meshes of every angle. The queen, also, upon going forth, when her object is to pair, after returning to reconnoitre, begins her flight by describing circles of considerable diameter, thus rising spirally with a rapid notion. ${ }^{4}$ The object of these gyrations is probably to increase her chance of meeting with a drone. I have not much to tell you with respect to the flight of other insects of this order, except that a spider-wasp (Pompilus viaticus), whose sting is redoubtable, and which often, when we are in the vicinity of sandy sunny banks, accompanies our steps, has a kind of jumping movement when it flies.

The next order, the Diptera, consists altogether of two-winged flies; but, to replace the under wings of the tetrapterous insects, they are furnished with poisers, and numbers of them also with winglets. The poisers (haltcres) are little membranaceous threads, placed one under the origin of each wing, near a spiracle, and terminated by an oval, round, or triangular button, which seems capable of dilatation and contraction. The animal moves these organs with great vivacity, often when at rest, and probably when flying. Their winglets (aluke) are different from those of Dytiscus marginalis, and the moth before noticed. Like them they are of rigid membrane, and finged; but they consist generally of two concavo-convex pieces (sometimes surrounded by a nervure), situated between the wing and the

1 Kirby, Mon. Ap. Angl. i. 96. 108. t. xiii. f. 19.

2 lbid. i. 96.107 . t. v. f. $8 . d d$.

3 Philos. Mitg., quoted in Burmeister's Manual of Ent. 464.

1 Huber, i. 38. 
poisers, which, when the insect reposes, fold over each other like the valves of a bivalve shell; but when it flies they are extended. The use of neither of these organs seems to have been satisfactorily ascertained. Dr. Derham thinks they are for keeping the body steady in flight ; and asscrts that if either a poiser or winglet be cut off, the insect will fly as if one side over. balanced the other, till it falls to the ground; and that if both be cut off, they will fly awkwardly and unsteadily, as if they had lost some very necessary part. ${ }^{1}$ Shelver cut off the winglets of a fly, leaving both wings and poisers, but it conld no longer fly. He next cut off the poisers of another, leaving the wings and winglets, and the same result followed. He found, upon removing one of these organs, that they were not properly compared to balancers. Observing that a common crane-fly (Tipula crocata) moved the knee of the hinder tibia in comnection with the wing and poiser, he cut it off, and it could no longer fly: this last experiment, however, seems contradicted by the fact, which has been often observed, that the insects of this genus will fly when half their lears are gone. He afterwards cut off both its poisers, when it could neither fly nor walk. Hence he conjectures that the poisers are connected with the feet, and are air-holders. ${ }^{2}$ I have often seen flies move their poisers very briskly when at rest, particularly Seioptera vibrans, before mentioned. This renders Shelver's conjecture - that they are connected with respiration-not improbable. Perhaps by their action some effect may be produced upon the spiracle in their vicinity, either as to the opening or chosing of it.

There are three classes of fliers in this order, the form of whose bodies, as well as the shape and circumstances of their wings, is different. First are the slender flies - the gnats, guat-like flies, and crane-fies (Tipularia). The bodies of these are light, their wings narrow, and their legs long, and they have no winglets. Next to those whose bodies, though slender, are more weighty - the Asildde, Conopsida, \&c.; these have larger wings, shorter legs, and very minute and sometimes even obsolete winglets. Lastly come the flies, the Muscida, \&c., and their affinities, whose bodies being short, thick, and often very heavy, are furnished not only with proportionate wings and shorter legs, but also with conspicuous winglets. From these comparative differences and distinctions, we may conjecture in the first place - since the lightest bodies are furnished with the longest legs, and the heaviest. with the shortest-that the legs act as poisers and rudders, that keep them steady while they fly, and assist them in directing their course ${ }^{3}$; and in the next - since the winglets are largest in the heaviest bodies, and altogether wanting in the lightest - that one of their principal uses is to assist the wings when the insect is flying.

The flight of the Tipularian genera is very various. Sometimes, as I have observed, they fly up and down with a zigzag course; at others in vertical curves of small diameter, like some birds; at others, again, in horizontal curves : - all these lines they describe with a kind of skipping motion. Sometines they would seem to fit in every possible way-upwards, downwards, athwart, obliquely, and sometimes almost in circles. The common gnat (Culex pipiens) seems to sail along also in various de-

1 Phys. Theol. 13th ed, 366. note (i).

2 Wiedemann's Archiv. ii. 210.

3 To those that frequent meadows and pastures (Tipula oleracea L. \&c.) they are also useful, as I have before observed, as stilts to enable them to walk over the grass. Ieaum. v. Pref. i. t. iii. f. 10. 
rections. The motion of its wings, if it does not fly like a hawk, is so rapid as not to be perceptible. When the crane-fiy (Tipula oleracea) is upon the wing, its fore-legs are placed horizoutally, pointing forwards, and the four hind ones stretched ont in an opposite direction, the one forming the prow and the other the stern of the vessel, in its voyage through the ocean of air. The legs of another insect of this tribe (Hirtaa Marci) all point towards the anus in flight, the long anterior pair forming an acute angle with the body: - thus, perhaps, it can better cut the air.

I have often been amused in my walks with the motions of the hornetfly (Asilus crabroniformis), belonging to the second division just mentioned. This insect is carnivorous, living upon small flies. When you are taking your rambles, you may often observe it alight just before you ; as soon as you come up, it flies a little further, and will thus be your avant-courier for the whole length of a long field. This usually takes place, I seem to have obscrved, when a path lies under a hedge; and perhaps the object of this manœuvre may be the capture of prey. Your motions may drive a number of insects before you, and so be instrumental in supplying it with a meal. Other species of the genus have the same habit.

The aerial progress of the fly tribes, including the gad-flies (CEstrida), horse-flies ('Tabanida), carrion-fies (Muscida), and many other generawhich constitute the heavy horse amongst our two-winged fliers - is wonderfully rapid, and usually in a direct line. An CEstrus about to attack a horse urged to its full speed will yet keep close to it, and, at last, when foiled in its object, fly away before it at a still more rapid rate. ${ }^{1}$ The male Tabani, according to the observations of M. de St. Fargeau, when met with in the long avenues of the continental forests, are seen to dart impetuously from one end to the other, then to rest awhile immoveable, suspended in the air, and look around on every side, and again to rush with equal velocity to the other end, repeating these manœuvres till they have discovered a female, upon which they precipitate themselves, and then momnt together to a height which the eye cannot reach. ${ }^{2}$ An anonymous observer in Nicholson's Joumal ${ }^{3}$ calculates that, in its ordinary tlight, the common house-fiy (Musca domestica) makes with its wings about 600 strokes, which carry it five feet, every second. But if alarmed, he states, their velocity can be increased six or seven-fold, or to thirty or thirty-five feet in the same period. In this space of time, a race-horse could clear only ninety feet, which is at the rate of more than a mile in a minute. Our little fly, in her swiftest flight, will in the same space of time go more than the third of a mile. Now compare the infinite clifference of the size of the two animals (ten millions of the fiy would hardly counterpoise one racer), and how wonderful will the velocity of this minute creature appear! Did the fly equal the race-horse in size, and retain its present powers in the ratio of its magnitude, it would traverse the globe with the rapidity of lightning. I would here observe, however, that it scems to me, that it is not by muscular strength alone that many insects are enabled to keep so long upon the wing. Every one who attends to them must have noticed, that the velocity and duration of their flights depend much upon the heat or coolness of the atmosphere, especially the appeararce of the sun. The warmer and more 
unclonded his beam, the more insects are there upon the wing, and every diurnal species seems fitted for longer and more frequent excursions.

Having given you all the information that I can collect with respect to the motions of perfect insects in the air, I must next say something concerning their modes of locomotion in or upon the water. These are of two kinds, swimming and walking. Observe - I call that movement swimming, in which the animal pushes itself along by strokes - while in walking, the motion of the legs is not different from what it would be if they were on land. Most insects that swim have their posterior legs peculiarly fitted for it, either by a dense fringe of hairs on the shank and foot, as in the waterbeetles (Dytiscus), or the water-boatmen (Notonecta); or by having their terminal joints very much dilated - as in the whirlgig (Gyrinus) - so as to resemble the paddle of an oar. ${ }^{1}$ When the Dytisci rise to the surface to take in fresh air - a silver bubble of which may often be seen suspended at their anus - they ascend, as it should seem, merely in consequence of their being specifically lighter than the water; but when they descend or move horizontally, which they do with considerable rapidity, it is by regular and successive strokes of their swimming legs. While they remain suspended at the surface, these legs are extended so as to form a right angle with their body. The water-boatmen swim upon their back, which enables them to see readily and seize the insects that fall upon the water, which are their prey. Sigara, however, a cognate genus, separated from Notonecta by Fabricius, swims in the ordinary way. As the Gyrini are usually in motion at the surface, whirling round and round in circles, it is probable that their legs are best adapted to this movement. They dive down, however, with great ease and velocity when alarmed. The common water-bug (Gerris lacustris), though it never goes under water, will sometimes swim upon the surface, which it does by strokes of the intermediate and posterior legs. ${ }^{2}$

These, however, are neither fringed nor dilated, but very long and slender, with claws, not easily detected, situated under the apex of the last joint of the foot, which covers and conceals them. The under side of their body - as in the case with Elophorus, and many other aquatic insects-is clothed with a thick coat of grey hairs like satin, which in certain lights have no small degree of lustre, and protect its body from the effects of the water. Some insects, that are not naturally aquatic, if they fall into the water will swim very well. I once saw a kind of grasshopper (Acrydium), which by the powerful strokes of its hind legs pushed itself across a strean with great rapidity.

Other insects walk, as it were, in the water, moving their legs in much the same way as they do on the land. Many smaller species of water-beetles, belonging to the genera Hydrophilus, Elophorus, Hydrana, Parnus, Limnius, \&c., thus win their way in the waves. - Thus also the water-scorpion (Nepa) pursues its prey; and the little water-mites (IIydrachna) may be seen in every pool thus working their little legs with great rapidity, and moving about in all directions. - Some spiders also will not only traverse the surface of the waters, but, as you have heard with respect to one, descend into their bosom. There are other insects moving in this way that are not

1 Mr. Briggs observes that this insect appears to move all its legs at once, with wonderful rapidity, by which motion it produces a radiating vibration on the surface of the water.

\& De Geer, iii. 314. 
divers. Of this kind are the aquatic bugs (Gerris lacustris, Hydrometrce stagnorum, Velia rivulorum, \&c. Latr.). The first can walk, run, or even leap, which it does upon its prey, as well as swim upon the surface. The second, remarkable for its extreme slenderness, and for its prominent hemispherical eyes - which, though they are really in the head, appear to be in the middle of the body - rambles about in chase of other insects, in considerable numbers, in most stagnant waters. The Velia is to be met with chiefty in running streams and rivers, coursing very rapidly over their waves. $^{1}$ The two last species neither jump nor swim. The species of one genus of this group (Halobates Eschscholtz) course about on the surface of the sea between the tropics, and are remarkable for being the only insects that have adopted the sea for their abode ${ }^{2}$; at least if we except the genera of beetles Ripus, Pogonus, Bledius, Hesperophilus, Sc., which burrow in the sand while covered with the tide, and thus are partially inhabitants of the ocean. ${ }^{3}$ One species of Halobates (H. Streatfieldana Templeton) was captured nearly midway between the continent of Africa and America, by Colonel Streatfield, 87 th R. T. F., where numbers of them attended the Miedusæ. ${ }^{4}$

I am next to say a few words upon the motions of insects that burrow, either to conceal themselves or their young. Though burrowing is not always a locomotion, I shall consider it under this head, to preserve the unity of the subject. Many enter the earth by means of fore-legs particularly formed for the purpose. The flat dentated anterior shanks, with slender feet, that distinguish the chafers (Petalocera) - most of which in their first states live under ground, and many occasionally in their last enable them to make their way either into the earth or out of it. Two other genera of beetles (Scarites and Clivinn Latr.) have these shanks palmated, or armed with longer teeth at their extremity, for the same purpose. But the most remarkable burrower amongst perfect insects is that singular animal the mole-cricket (Gryllotalpa vulgaris). This creature is endowed with wonderful strength, particularly in its thorax and fore-legs. The former is a very hard and solid shell or crust, covering ${ }^{\circ}$ like a shield the trunk of the animal; and the latter are remarkably fitted for burrowing, both by their strength and construction. The shanks are very broad, and terminate obliquely in four enormous sharp teeth, like so many fingers: the foot consists of three joints - the two first being broad and tooth-shaped, and pointing in an opposite direction to the teeth of the shank; and the last small, and armed at the extremity with two sharp claws. This foot is placed inside the shank, so as to resemble a thumb, and perform the office of one. The direction and motion of these hands, as in moles, is outwards ; thus enabling the animal most effectually to remove the earth when it burrows. By the help of these powerful instruments, it is astonishing how instantaneously it buries itself. This creature works under ground like a field-mouse, raising a ridge as it goes; but it does not throw up heaps like its namesake the mole. They will in this manner undermine whole gardens; and thus in wet and swanpy situations, in which they delight, they excavate their curions apartments, before described. The field-cricket (Gryllus campestris) is also a burrower, but by means of different instruments; for with its strong jaws, toothed

1 Curtis, Brit. Ent. t. ii.

3 Spence in Trans, Ent. Soc. Lond. i, 180.

4 Templeton in Trans. Ent. Soc. Lond, i. 230. 
like the claws of a lobster, but sharper, in heaths and other dry situations. it perforates and rounds its curious and regular cells. The house-cricket (G. domesticus), which, on account of the softness of the mortar, delights, in new-built houses, with the same organs, to make herself a covered-way from room to room, burrows and mines between the joints of the bricks and stones. ${ }^{1}$

But of all the burrowing tribes, none are so numerous as those of the order Hymenoptera. Wherever you see a bare bank, of a sunny exposure, you usuatly find it full of the habitations of these insects; - and almost every rail and old piece of timber is with the same view perforated by them. Bees, wasps, bee-wasps (Bembex), spicler-wasps (Pompilus), fywasps (Mrellinus, Cerceris, Crabro), with many others, excavate subterranean or ligneous habitations for their young. None is more remarkable it this respect than the sand-wasp (Ammophila). It digs its burrows, by scratching with its fore-legs like a dog or a rabbit, dispersing with its hind ones, which are particularly constructed for that purpose, the sand so collected. ${ }^{2}$

Since most of these burrows are lesigned for the reception of the egas of the burrowers, I shall next describe to you the manner in which one of the long-legged gnats, or crane-flies (Tipula variegata) - a proceeding to which I was myself a witness - oviposits. Choosing a south bank bare of grass, she stood with her legs stretched out on each side, and kept turning herself half round backwards and forwards alternately. Thus the ovipositor, which terminates her long cylindrical pointed abdomen, made its way into the hard soil, and deposited her eggs in a secure situation. All, however, were not committed to the same burrow ; for she every now and then shifted her station, but not more than an inch from where she bored last. While she was thus engaged, I observed her male companion suspended by one of his legs on a twig, not far from her. The common turfboring crane-fly ( $T$. oleracca), when engaged in laying eggs, moves over the grass with her body in a vertical position, by the help - her four anterior legs being in the arr - of her two posterior ones, and the end of her abdomen, which performs the office of another. Whether in boring, like T. variegata, she turns half round and back, does not appear from Reanmur's account. ${ }^{3}$

I now come to motions whose object seems to be sport and amusement rather than locomotion. They may be considered as of three kinds hovering - gyrations - and dancing.

You have often in the woods and other places seen flies suspended as it were in the air, their wings all the while moving so rapidly as to be almost invisible. This hovering, which seems peculiar to the aphidivorous flies, has been also noticed by De Geer. ${ }^{4}$ I have frequently amused myself with watching them; but when I have endeavoured to entrap them with my forceps, they have immediately shifted their quarters, and resumed their amusement elsewhere. That their object is simply amusement seems proved by the fact noticed by $\mathbf{M r}$. Curtis, that "If you catch a dozen in your morning's walk, they are all males who are thus enjoying them-

1 White, Nat. Hist. ii. 72. 76. 80.

2 Linn. Trans. iv, 200. See Westw, in Trans. Ent. Soc. vol. i. p. 198. on the con struction of the burrows of this and some allied species.

3. v. 20 . 
selves." 1 The most remarkable insects in this respect are the sphinxes, and from this they doubtless took their name of hawk-molhs. When they unfold their long tongue, and wipe its sweets from any nectariferous flower, they always keep upon the wing, suspending themselves over it till they have exhansted them, when they fly away to another. The species called by collectors the humming-bird (Macroglossa stellatarum), and by some persons mistaken for a real one, is remarkable for this, and the motion of its wings is ineoneeivably rapid. ${ }^{2}$

The gyrations of insects take place either when they are reposing, or when they are flying or swimming. - I was once much diverted by observing the actions of a minute moth upon a leaf on which it was stationed. Making its head the centre of its revolutions, it turned round and round with considerable rapidity, as if it had the vertigo, for some time. ${ }^{3}$ I did not, however, sueceed in my attempts to take it. - Sealiger noticed a similar motion in the book-crab (Chelifer cancroides). ${ }^{4}$

Reanmur deseribes in a very interesting and lively way the gyrations of the Ephemeræ, before noticed, round a lighted flambeau. It is singulir, says he, that moths which fly only in the night, and shun the day, should be precisely those that come to seek the light in our apartments. It is still more extraordinary that these Ephemeræ - which appearing alter sunset, and dying before sunrise, are destined never to behold the light of that orb - should have so strong an inclination for any luminons object. To hold a flambeau when they appeared was no very pleasant office; for he who filled it, in a few seconds had his dress covered with the inseets, which rushed from all quarters to him. The light of the flambeau exhibited a spectacle which enchanted every one that beheld it. All that were present, even the most ignorant and stupid of his domestics, were never satisfied with looking at it. Never had any armillary sphere so many zones, as there were here circles, which had the light for their centre. There was an infinity of them - crossing each other in all directions, and of every imaginable inclination - all of which were nore or less eccentric. Each zone was composed of an unbroken string of Ephemeræ, resembling a piece of silver lace formed into a circle deeply notched, and consisting of equal triangles placed end to end (so that one of the angles of that which followed tonched the middle of the base of that which preceded), and moving with astonishing rapidity. The wings of the flies, which was all of them that could then be distinguished, formed this appearance. Each of these ereatures, after having deseribed one or two orbits, fell upon the earth or into the water, but not in consequence of being burned. ${ }^{5}$ Reaumur was one of the most accurate of observers; and yet I suspect that the appearance he deseribes was a visual deception, and for the following reason. I was once walking in the daytime with a friend ${ }^{6}$, when our attention was caught by myriads of small flies, which were dancing under cvery tree; - viewed in a certain light

1 Gardener's Chronicle, 1841, p. 52.

2 Iiai. Hist. Ins. 133, 1.

3 Mr. Westwood informs us that he has repeatedly observed the same proceeding, and that the insect is Simuctlis fabriciana.

4 Lesser, 1. i. 248. note 22.

5 Reaum. vi. 484 . t. xlv. f. 7.

6 The persons observing the appearance here related were the authors of this work. 
they appeared a concatenated series of insects (as Reaumur has here described his Ephemeræ) moving in a spiral direction upwards ; - but each series, upon close examination, we found was produced by the astonishingly rapid movement of a single fly. Indeed, when we consider the space that a fly will pass through in a second, it is not wonderful that the eye should be unable to trace its gradual progress, or that it should appear present in the whole space at the same instant. The fly we saw was a small male Ichneumon.

Other circular motions of sportive insects take place in the waters. Linné, in his Lapland tour, noticed a black Tipula which ran over the water, and turned round like a whirlwig, or Gyrinus. ${ }^{1}$ This last insect I have often mentioned; - it seems the merriest and most agile of all the inhabitants of the waves. Wonderful is the velocity with which they turn round and round, as it were pursuing each other in incessant circles, sometimes moving in oblique, and indeed in every other direction. Now and then they repose on the surface, as if fatigued with their dances, and desirous of enjoying the full effect of the sun-beam : it you approach they are instantaneously in motion again. Attempt to entrap them with your net, and they are under the water and dispersed in a moment. When the danger ceases they reappear, and resume their vagaries. Covered with lncid armour, when the sun shines they look like little dancing masses of silver or brilliant pearls. ${ }^{2}$

But the motions of this kind to which I particularly wish to call your attention are the choral dances of males in the air ; for the daneing sex amongst insects is the masculine, the ladies generally keeping themselves quiet at home. These dances occur at all seasons of the year, both in winter and summer, thougl in the former season they are confined to the hardy Tipulariæ. In the morning before twelve, the Hoplia, root-beetles before mentioned, have their dances in the air, and the solstitial and common cockchafer appear in the evening - the former generally coming forth at the summer solstice - and fill the air over the trees and hedges with their myriads and their hmm, Other dancing insects resemble moving columns - each individual rising and falling in a vertical line a certain space, and which will follow the passing traveller - often intent upon other business, and all unconscious of his aërial companions - for a considerable distance.

Towards sunset the common Ephemeræ (E.vulgata), distinguished by their spotted wings and three long tails (caudulce), commence their dances in the meadows near the rivers. They assemble in troops, consisting sometimes of several hundreds, and keep rising and falling continually, usually over some high tree. They rise beating the air rapidly with their wings, till they have ascended five or six feet above the tree; when they descend to it with their wings extended and motionless, sailing like hawks, and having their three tails elevated, and the lateral ones so separated as to form nearly a right angle with the central one. These tails seem given

1 Lach. Lapp. i. 194.

2 Compare Oliv. Entomol. iii. Gyrinus 4. One species, however, Gyrinus (Orechtocheilus) villosus, which, as before observed, pursues its dances only at night, differs also from its congeners in not having the same habit of diving, or at least not in the laytime, when if forced into the water from its hiling-places under stones, all its efforts are confined to endearouring to regain the shore. (Ann. Soc. Ent. de Erance, iv. bull. lxxx.) 
them to balance their bodies when they descend, which they do in a borizontal position. This motion continues two or three hours without ceasing, and commences in fine clear weather about an hour before sunset, lasting till the copious falling of the dew compels them to retire to their nocturnal station. ${ }^{1}$ Our most common species, which I have usually taken for the E. vulgatn, varies from that of De Geer in its proceedings. I found them at the end of May dancing over the meadows, not over the trees, at a much earlier hour - at half-past three - rising in the way just described, abont a foot, and then descending, at the distance of about four or five feet from the ground. Another species, common here, rises seven or eight feet. I have also seen Ephemeræ flying over the water in a horizontal direction. The females are sometimes in the air, when the males seize them, and they fly paired. These insects seem to use their forelegs to break the air; they are applied together before the head, and look like antennæ. - I Hilara maura, a little beaked fly, I have observed rushing in infinite numbers like a shower of rain driven by the wind, as before observed, over waters, and then returning back.

It is remarkable that the smaller Tipularic will fly unwetted in a heavy shower of rain, as I have often ohserved. How keen must be their sight, and how rapid their motions, to enable them to steer between drops bigger than their own bodies, which, if they fell upon them, must dash them to the ground!

Amidst this infinite variety of motions, for purposes so numerons and diversified, and performed by such a multiplicity of instruments and organs, who does not discern and adore the Great Fikst Mover? From him all proceed, by him all are endowed, in him all move : and it is to accomplish his ends, and to go on his errands, that these little but not insignificant beings are thus gifted; since it is by them that he maintains this terraqueous globe in order and beauty, thus rendering it fit for the residence of his creature man.

I am, \&c.

1 De Geer, ii. 638. 


\section{LETTER XXIV.}

\section{ON THE NOISES PRODUCED BY INSECTS.}

Trat insects, though they fill the air with a variety of sounds, have no voice, may seem to you a paradox, and you may be tempted to exclaim with the Roman naturalist, What, amidst this incessant diurnal hum of bees; this evening boom of beetles; this nocturnal buzz of guats; this merry chirp of crickets and grasshoppers; this deafening drum of Cieadæ, have insects no voice! If by voiee we understand sounds produced by the air expelled from the lungs, which, passing through the larynx, is modified by the tongue, and emitted from the mouth, - it is even so. For no insect, like the larger animals, uses its month for utterance of any kind: in this respect they are all perfectly mute ; and though incessantly noisy, are everlastingly silent. Of this fact the Stagyrite was not ignorant, since, denying them a voice, he attributes the sounds emitted by insects to another cause. But if we feel lisposed to give a larger extent to this word; if we are of opinion that all sounds, however produced, by means of which animals determine those of their own species to certain actions, merit the name of voice; then I will grant that insects have a voice. But, decide this question as we will, we all know that by some means or other, at certain seasons and on various occasions, these little creatures malie a great din in the worid. I must therefore now bespeak your attention to this department of their history.

In discussing this subject, I shall consider the noises insects emit during their motions - when they are feeding, or otherwise employed when they are calling or eommanding - or when they are under the influence of the passions; of fear, of anger, of sorrow, joy, or love.

The only kind of locomotion during which these animals produce sounds is flying: for though the hill-ants (Formica rufa), as I formerly observed, make a rustling noise with their feet when walking over dry leaves, I know of no other inseet the tread of which is accompanied by somnd-except indeed the flea, whose steps, a lady assures me, she always hears when it paces over her night-eap, and that it clicks as if walking on pattens! 'That the fight of numbers of insects is attended by a humming or booming is known to almost every one; but that the great majority move through the air in silence, has not pcrhaps been so often observed. Generally speaking, those that fly with the greatest force and rapidity, and with wings seemingly motionless, make the most noise; while those that fly gent!y and leisurely, and visibly fan the air with their wings, yield little or no sound.

Amongst the beetle tribes (Coleoptera) none is more noticed, or more celebrated for "wheeling its droning flight," than the common dungchafer (Gcotrupes sterccrarius) and its affinities. Linné affirms-but the 
prognostic sometimes fails - that when these insects fly in numbers, it indicates a subsequent fine day. ${ }^{1}$ The truth is, they only fly in fine werther. Mr. White has remarked, that in the dusk of the evening beetles begin to buzz, and that partridges begin to call exactly at the same time. ${ }^{2}$ The common cockchafer, and that which appears at the summer solstice (Melolontha vulgaris and Amphimalla solstitialis), when they hover over the summits of trees in numbers, produce a hum somewhat resembling that of bees swarming. Perhaps some insect of this kind may occasion the humming in the air mentioned hy Mr. White, and which you and I have often heard in other places. "There is," says he, "a natural occurrence to be met with in the highest part of our down on the hot summer days, which always amuses me much, without giving me any satisfaction with respect to the cause of it; - and that is a loud audible humming of bees in the air, though not one insect is to be scen.-Any person would suppose that a large swarm of bees was in motion, and playing about over his head."s

\section{"Resounds the living surface of the ground - Nor undelightful is the ceaseless hum \\ To him who muses through the woods at noon, Or drowsy shepherd as he lies reclined."}

The hotter the weather, the higher insects will soar; and it is not improbable that the sound produced by numbers may be heard, when those that produce it are out of sight. The burying beetle (Necrophorus Vespillo), whose singular history so much amused you, as well as Cicindela sylvatica of the same order, files likewise, as I have more than once witnessed, with a considerable hum.

Whether the innumerable locust armies, to which $I$ have so often called your attention, make any noise in their flight, I have not heen able to ascertain ; the mere impulse of the wings of myriads and myriads of these creatures upon the air, must, one wonld think, produce some sound. In the symbolical locusts mentioned in the Apocalypse ${ }^{4}$, this is compured to the sound of chariots rushing to battle: an illustration which the inspired author of that book would scarcely have had recourse to, if the real locusts winged their way in silence.

Amongst the Hemiptera, I know only a single species that is of noisy flight; though doubtless, were the attention of entomologists directed to that subject, others would be found exhibiting the same peculiarity. The insect I allude to (Corcus marginatus) is one of the numerous tribe of bugs; when flying, especially when hovering together in a sunny sheltered spot, they emit a hum as loud as that of the hive-bee.

From the magnitude and strength of their wings, it might be supposed that many lepidopterous insects would not be silent in their flight; and indeed many of the hawk-moths (Sphinx F.), and some of the larger moths (Bombyx F.), are not so; Cossus ligniperdn, for instance, is said to emulate the booming of beetles by means of its large stiff wings; whence in Germany it is called the humming-bird (Brumm-vogel). But the great body of these numerous tribes, even those that fun the air with "sail-broad vans," produce little or no sound by their motion. I must, therefore, leave

1 Sust. Nat. 42. 550.

3 White, Nat. Hist. ii. 256.
2 Nat. Wist, ii. $2 \tilde{j} 4$

4 liev. ix. 9. 
them, as well as the Trichoptera and Neuroptera, which are equally barren of insects of sounding wing, and proceed to an order, the Hymenoptera, in which the insects that compose it are, many of them, of more fame for this property.

The indefatigable hive-bee, as she flies from flower to flower, amuses the observer with her hum, which, though monotonous, pleases by exciting the idea of happy industry, that wiles the toils of labour with a song. When she alights upon a flower, and is engaged in collecting its sweets, her hum ccases; but it is resumed again the moment that she leaves it. The wasp and hornet also are strenuous hummers; and when they enter our apartments, their hum often brings terror with it. But the most sonorous flies of this order are the larger humble-bees, whose bombination, booming, or bombing, may be heard from a considerable distanee, gradually increasing as the animal approaches you, and when, in its wheeling flight, it rudely passes elose to your ear, almost stumning you by its sharp, shrill, and deafening sound. Many genera, however, of this order fly silently.

But the noisiest wings belong to insects of the dipterous order, a majority of which probably give notice of their approach by the sound of their trumpets. Most of those, however, that have a slender body, - the gnat genus (Culex) excepted, - explore the air in silence. Of this description are the Tipularice, the Asilide, the genus Empis, and their affinities. The rest are more or less insects of a humning flight; and with respect to many of them, their hum is a sound of terror and dismay to those who hear it. To man, the trumpet of the gnat or mosquito, and to beasts, that of the gad-fly, of varions kinds of horse-flies, and of the Ethiopian zimb, as I have before related at large, is the signal of intolerable annoyanee. Homer, in his Batrachomyomachia, long celebrated the first of these as a trumpeter:-

"For their sonorons trumpets far renown'd, Of battle the dire charge mosquitos sound."

Mr. Pope, in his translation, with his usual inaccuraey, thinking, no doubt, to improve upon his author, has turned the old bard's gnats into hornets. In Guiana these animals are distinguished by a name still more tremendous, being ealled the devil's trumpeters. ${ }^{1}$ I have observed that early in the spring, hefore their thirst for blood seizes them, ginats when flying emit no sound. At this moment (Feb. 18.) two females are flying about my windows in perfect silence.

After this short account of insects that give notice when they are upon the wing by the sounds that precede them, I must inquire by what means these sounils are produeed. Ordinarily, except perhaps in the ease of the gnat, they seem perfectly independent of the will of the animal; and in almost every instance, the sole instruments that cause the noise of flying inseets are their wings, or some parts near to them, which, by their fiction against the trunk, oecasion a vibration - as the fingers upon the strings of a guitar - yielding a sound more or less acute in proportion to the rapidity of their flight, the action of the air perhaps upon these organs giring it some modificitions. Whether, in the beetles that fly with noise, the elytra contribute more or less to produce it, seems not to have been clearly ascertained: yet, since they fly with force as well as velocity, the action of the air 
may cause some motion in them, enough to occasion friction. With respect to Diptera, Latreille contends that the noise of flies on the wing cannot be the result of friction, beeause their wings are then expanded; but though to us flies seem to sail through the air without moving these organs, yet they are doubtless all the while in motion, though too rapid for the eye to perceive it. When the aphidivorous flies are hovering, the ver. tical play of theil wings, though very rapid, is easily seen ; but when they fly oft it is no longer visible. Repeated experiments bave been tried to aseertain the cause of sound in this tribe, but it should seem with difierent results. De Geer, whose observations were made upon one of the flies just mentioned, appcars to have proved that, in the insect he examined, the sounds were produced by the firietion of the root or base of the wings against the sides of the eavity in which they are inscrted. To be convinced of this, he affirms, the observer has nothing to do but to hold each wing with the finger and thumb, and stretehing them out, taking eare not to hurt the animal, in opposite directions, thus to prevent their motion, and immediately all sound will eease. For further satisfaction he made the following experiment. He first cut off the wings of one of these flies very near the base; but finding that it still continned to buzz as before, he thought that the winglets and poisers, which he renarked were in a constant vibration, might occasion the sound. Upon this, cutting both of he examined the mutilated fly with a mieroseope, and found that the remaining fragments of the wings were in constant motion all the time that the buzzing continued; but that upon pulling them up by the roots all sound ceased. ${ }^{1}$ Shelver's experiments, noticed in my last letter, go to prove, with respect to the insects that he examined, that the winglets are more particularly concerned with the buzzing. Upon cutting off the wings of a fly - but he does not state that he pulled them up by the roots - ho found the sound continued. He next cut off the poisers-the buzzing went on. This experiment was repeated eighteen times with the same result. Lastly, when he took off the winglets, eitlier wholly or partially, the buzzing ceased. This, however, if correct, can only be a cause of this noise in the insects that have winglets. Numbers bave them not. He next, thelefore, cut off' the poisel's of a erane-fly ('Tipula crocata), and found that it buzzed when it moved the wing. He eut off half the latter, yet still the somd contimed; but when he had eut off the whole of these organs the sound entircly ceasecl. ${ }^{2}$

Dr. Burmeister, howcver, was led by his experiments to a different conclusion. Finding that the buzz of a large fly (Eristalis lenax) still continued after the winglets, the poisers, and even the wings had been quite cut off exeept their very stumps (only in this last case the sound was somewhat weaker and higher), he conceived that the spiraeles lying between the meso- and meta-thor'x must be the in-truments of the sound, which accordingly he found to cease entirely when they were stopped with gum, though while the wings were in vibration. Pursuing his researebes, he extracted one of these spirucles, and opening it carcfully, found its posterior and inner lip, which is directed towards the commencenent of the trachea, to be expanded into a small flat erescent-shaped plate, upon which are nine parallel very delicate borny lamina, the central one being the 
largest, while those on each side became gradually smaller and lower; and it is, he is persuaded, in consequence of the air being forcibly driven out of the trachea and touching these laminæ that they are made to vibrate and sound precisely in the same way with the glottis of the larynx. Dr. Burmeister (who remarks that Chabrier in his Essai sur le $\dot{V}_{\text {ol }}$ des Insectes, p. 45 , \&c., has also explained the hum of insects as produced by the air streaming from the thorax during flight, and also speaks of lamine which lie at the aperture of the spiracle), in order to be certain that the lamina in question in the posterior spiracles of the thorax are alone concerned in producing sound, also inspected the anterior ones, but without finding in them any trace of these lamina. He explains the weaker and sharper tones produced when the wings all but the very roots are cut off as resulting from the weaker vibrations of the contracting muscles, and consequent less forcible expulsion of the air when the vibratory organs are removed; and he thinks with Chabrier that some air may escape through the open trachea of the wings which are eut off. Though he regards these laminæ as the cause of humming in bees and flies, he does not decide that other causes may not produce the buzz of cockchafers, \&c., in the thoracie spiracles of which he could not discern them. ${ }^{1}$

Aristophanes, in his Clouds, deriding Socrates, introduces Chærephon as asking that philosopher whether gnats made their buzz with their mouth or their tail. ${ }^{2}$ Upon which Mouffet very gravely observes, that the sound of one of these insects approaching is much more acute than that of one re. tiring; from whenee he very sapiently conchudes, that not the tail but the mouth must be their organ of sound. ${ }^{3}$ But after all, the friction of the base of the wings against the thorax seems to be the sole cause of the alarming buzz of the ginat as well as that of other Diptera. The warmer the weather, the greater is their thirst for blood, the more forcible their flight, the motion of their wings more rapid, and the sound produced by that motion more intense. In the night - but perhaps this may arise from the mniversal stillness that then reigns - their hum appears louder than in the day: whence its tones may seem to be modified by the will of the animal.

Sounds, also, are sometimes emitted by insects when they are feeding or otherwise cmployed. The aetion of the jaws of a large number ol cockchaters produces a noise resembling the sawing of timber; that of the locusts has been compared to the crackling of a flame of fire driven by the wind ; indeed the eollision at the same instant of myriads of millions of their powerful jaws must be attended by a considerable sound. The timber-borers also - the Buprestes; the stag-horn beetles; and particularly the eapricorn-beetles - the nandibles of whose larvæ resemble a pair of mill-stones ${ }^{4}$ - most probably do not feed in silence. A little woodlouse (Atropos pulsatoria) - which on that account has been confounded with the death-watch - is said also, when so engaged, to emit a ticking noise. Certain two-winged flies seen in spring, distinguished by at very long proboseis (Bombylizis), hum all the time that they suck the honey from the flowers; as do also many hawk-moths, particularly that called from this circumstance the humming-bird (Macroglossa stellatarum), which, while it hovers over them, unfolding its long tongue, pilfers their sweets

1 Burmeister, Manuat of Ent. 468-470.

3 Houflet, 81 .
2 Act. i. Sc. 2.

4 Linn. Trans. v. 225 . t. xii. f. 7. b. 
without interrupting its song. The giant cock-roach (Blatta giganter) which abounds in old timber houses in the warmer parts of the world makes a noise when the family are asleep like a pretty suart lapping with the knuckles — three or four sometimes appearing to answer eacn other. On this account, in the West Indies it is called the Drummer; and they sometimes beat such a reveille, that only good sleepers can rest for them. ${ }^{1}$ As the animals of this genus generally come forth in the night for the purpose of feeding, this noise is probably connected with that object.

Insects also, at least many of the social ones, emit peculiar noises while engaged in their various employments. If an ear be applied to a wasps' or humble-bees' nest, or a bee-hive, a hun more or less intense may always be perceived. Were I disposed to play upon your credulity, I might tell you with Godart, that in every humble-bees' nest there is a trumpeter, who early in the morning, ascending to its summit, vibrates his wings, and sounding his trumpet for the space of a quarter of an hour, rouses tlie inhabitants to work! But since. Reaumur could never witness this, I shall not insist upon your believing it, though the relater declares that he had heard it with his cars, and seen it with his eyes, and liad called many to witness the vibrating and strepent wings of this trumpeter humble-bee. ${ }^{2}$ The blue sand-wasp (Ammophila? cyanea), which at all other times is silent, when engaged in building its cells, emits a singular but pleasing sound, which may be heard at ten or twelve yards' distance. ${ }^{3}$

Some insects also are remarkable for a peculiar mode of calling, commanding, or giving an alarn. I have before mentioned the noise made by the neviters or soldiers amongst the white ants, by which they keep the labourers, who answer it by a hiss, upon the alert and to their work. This noise, which is produced by striking any substance with their mandibles, Smeathman describes as a small vibrating sound, rather shriller and quicker than the ticking of a watch. It could be distinguished he says at the distance of three or four feet, and continued for a minute at a time witl very short intervals. When any one walks in a solitary grove, where the covered ways of these insects abound, they give the alarm by a loud hissing. which is heard at every step. — "When house-crickets are out," says Mr. White, " and running about in a room in the night, if surprised by a candle, they give two or three shrill notes, as it were for a signal to their followers, that they may escape to their crannies and lurking-holes to avoid danger." 5

Under this head I shall consider a noise before alluded to, which has been a cause of alarm and terror to the superstitious in all ages. You will perceive that I am spcaking of the cleath-watch - so called, because it emits a sound resembling the ticking of a watch, supposed to predict the death of some one of the family in the house in which it is heard. Thus sings the muse of the witty Dean of St. Patrick on this subject :

$$
\text { “. . . . . . A wood-worm }
$$

That lies in old wood, like a hare in her form:

1 Drury's Insects, iii. Preface.

2 Lister's Godart, 244. Compare Reaum. vi. 30.

3 Bingley, Animal Biogr. iii. 1st ed. 335. Mr. Westwood has also observed tho same peculiarity in Ammoptila hirsute whilst similarly engaged.

4 Philos. Trans. 1781, 48. 38. 5 Nat. IIist. ii. 262. 


\begin{abstract}
With teeth or with claws it will bite or will scratcl., And chambermaids christen this worm a death -watch : Because like a watch it always cries click ; Then woe be to those in the house who are sick ! For, sure as a gun, they will gire up the ghost, If the maggot cries click, when it scratches the post; lint a kettle of sealding hot water ejected, Infallibly cures the timber affected :

The omen is broken, the danger is over,

The maggot will die, and the sick will recover."
\end{abstract}

To add to the effect of this noise, it is said to be made only when there is a profound silence in an apartment, and every one is still.

Authors were formerly not agreed concerning the insect from which this sound of terror proceeded, some attributing it to a kind of wood-louse, as I lately observed, and others to a spider ; but it is a received opinion now, adopted upon satisfactory evidence, that it is produced by some little beetles belonging to the timber-boring genis Anobium. Swammerdan observes, that a small beetle, which he had in his collection, having firmiy fixed its fore legs, and put its inflexed head between them, makes a continual noise in old pieces of wood, walls, and ceilings, which is sometimes so lowd, that, upon hearing it, people have fancied that hobgoblins, ghosts, or fairies were wandering around them. ${ }^{1}$ Evidently this was one of the death-watches. Latreille observed Anobizm striatum produce the sound in question by a stroke of its mandibles upon the wood, which was answered by a similar noise from within it. But the species whose proceedings have been most noticed by British observers is A. tessellatum. When spring is far advanced, these insects are said to commence their ticking, which is only a call to each other, to which if no answer be returned, the animal repeats it in another place. It is thus produced. Raising itself upon its hind legs, with the body somewhat inclined, it beats its head with great force and agility upon the plane of position; and its strokes are so powerful as to make a considerable impression if they fall upon any substance softer than wood. The general number of distinct strokes in succession is fiom seren to nine or eleven. They follow each other quickly, and are repeated at uncertain intervals. In old houses, where these insects abound, they may be heard in warm weather during the whole day. The noise exactly resembles that produced by tapping moderately with the nail upon the table : and when familiarised the insect will answei rery readily the tap of the nail. ${ }^{2}$

The queen-bee has long been celebrated for a peculiar sound, producing the most extraordinary effects upon her subjects. Sometimes, just hefore bees swarm,-instead of the trreat hum usually heard, and even in the night, - if the ear be placed close to the mouth of the hive, a sharp clear sound may be distinguished, which appears to be produced by the vibration of the wings of a single bee. This, it has been pretended, is the harangue of the new queen to her subjects, to inspire them with courace to achieve the foundation of a new empire. But Butler gives to it a different interpretation. He asserts that the candidate for the new throne

1 Bibl. Nat. Ed. Hill, i. 125.

2 Slaw's Nat. Misc.iii. 101. Elément. ii. 91. n. 691.

Phil. Trans. xxxiii. 159, Compare Dumeril, Traité 
is then with earnest entreaties, lamentations and groans, supplicating the queen-mother of the hive to grant hur permission to lead the intendeal colony; - that this is continued, before she can obtain her consent, for two days; when the old queen relenting gives her fiat in a fuller and stronger tone. That should the former presume to imitate the tones of the sovereign, this being the signal of revolt, she would be executed on the spot, with all whom she had seduced from their luyalty. ${ }^{1}$ - But it is time to leave fables: I shall, therefore, next relate to you what really tal:es place. You have heard how the bees detain their young queens till they are fit to lead a swarm. - I then mentioned the attitude and sound that strike the former motionless. When she emits this authoritative sound, reclining her thorax against a comb, the queen stands with her wings crossed upon her back, which, without being uncrossed or further expanded, are kept in constant vibration. The tone thus produced is a very distinct kind of clicking, composed of many notes in the same key, which follow each other rapiliy. This sound the queens emit before they are permitted to leave their cells; but it does not then seem to affect the bees. But when once they are liberated from confinement and assume the above attitude, its effects upon them are very remarkable. As soon as the sound was lieard, Huber tells tis, bees that had been employed in plucking, biting, and! chasing the queen about, hung down their heads and remained altogether motionless; and whenever she had recourse to this attitude and sound, they operated upon them in the same manner. The writer just mentioned observed differences both with regard to the succession and intensity of the notes and tones of this royal song; and as he justly remarks, there may be still finer shades which, escaping our organs, may be distinctly perceived by the bees. ${ }^{2}$ He seems, however, to doubt by what means this sound is produced. Reasoning analogically, the motion of the wings should occasion it. We have seen that they are in constant motion when it is uttered. Probably the intensity of the tones and their succession are regulated by the intensity of the vibrations of the wings. Reaumur remarks, that the lifferent tones of the bees, whether more or less grave or acute, are produced by the strokes, more or less rapid, of their wings against the air; and that, perhaps, their different angles of inclination may vary the sound. The friction of their bases likewise against the sicles of the cavity in which they are inserted, as in the case of the fly lately mentioned, or against the base-covers (teguke), may produce or modulite their sounds, a bee whose wings are eradicated being perfectly mute. ${ }^{3}$ This last assertion, however, is contradicted by John Hunter, who affirms that bees produce a noise independent of their wings, emitting a shrill and peevish sound though they are cut off, and the legs held fust. ${ }^{4}$ Yet it does not appear from his experiment that the wings were eradicated. And if they were only cut off, the friction of their base might cause the sound. I have before noticed the remarkable fact, that the queens educated according to M. Schirach's method are absolutely mute; on which account the bees keep no guard around their cells, nor retain them an instant in then after their tranisformation. 5

The passions, also, which urge us to various exclamations, elicit from

1 Reaum. v. 615. Butler's Female Monarchy, c. v. \$4.

2 Huber, i. 260. ii. 292.

3 Reaum. v. 617 .

4 Philos. Trans, 1792.

5 Huber, i. 292. 
insects occasionally certain sounds. Fear, anger, sorrow, joy, or love an:l desire, they express in particular instances by particular noises. I shail begin with those which they emit when under any alarm. One larve only is recorded as uttering a cry of alarm, and it produces a perfect insect remarkable for the sane faculty: I allude to Acherontia Atropos. Its catcrpillar, if disturbed at all, draws back rapidly, making at the same time a rather lond noise, which has been compared to the crack of an electric spark, 'You would scarcely think that any quiescent pupe could show their fear's by a sound,-yet in one instance this appears to be the case. De Geer having made a small incision in the cocoon of a moth, which in. cluded that of its parasite Ichnemmon (I. cantator De G.), the insect concealed within the latter uttered a little cry, similar to the chirping of a small grasshopper, continuing it for a long time together. The sound was produced by the friction of its body against the elastic substance of its own coeoon, and was easily imitated by rubbing a knife against its surface. ${ }^{2}$

But to come to perfect insects. Many beetles when taken show their alarm by the emission of a shrill, sibilant, or creaking sound - which some compare to the chirping of young birds - produced by rubbing their elytra with the extremity of their abdomen. This is the case with the dungchafers (Geotrupes vernalis, stcrcorarins, and Copris lunaris); with the earrion-chafer (Trox sabulosus); and others of the lamellicorn beetles. The burying-beetle (Necroplorus Vcspillo), Crioceris melanopa and merdigera, and Hygrobia Hermani, and many other Coleoptera, produce a similar noise by the same means. When this noise is made, the movement of the abdomen may be perceived; and if a pin is introduced under the elytra it ceases. Long after many of these insects are dead the noise may be eaused by pressure.. Rösel found this with respect to the Serrabaida ${ }^{3}$, and I have repeated the experiment with success upon Necroploorus Vespillo. The capricorn tribes (Prionns, Lamia, Cerambyx, \&c.) emit under alarm an acute or creaking sound - which Lister calls querulous, and Dumeril compares to the braying of an ass ${ }^{4}-$ by the friction of the thorax, which they alternately elevate and depress, against the neck, and sometimes against the base of the elytra. ${ }^{5}$ On account of this, Prionus coriurius is called the fiddlor in Germany. ${ }^{6}$ Two other coleopterous genera, Cychrus and Clytus, nake their cry of Noli me tangerc by rubbing their thorax against the base of the elytra. Pimelia, another beetle, does the same by the friction of its legs against each other. ${ }^{7}$ And, doubtless, many more Coleoptera, if oh. served, would be found to express their fears by similar means.

In the other orders the examples of cries of terror are much less numerous. A bug (Cimex subripterus De G.) when taken emits a sharp sound, probably with its rostrum, by moving its head up and down. ${ }^{8}$ Ray makes a similar remark with respect to another bug (Relluvius personatus), the cry of which he compares to the chirping of a grasshopper. ${ }^{9}$ Mutilla Europae, a hymęnopterous insect, makes a sibilant chirping, as 1 once ob-

1 Fuessl. Archiv. 8, 10. Mr. Raddon assures me that on one occasion taking up the caterpillar of another moth, Gastropacha quercifotia, by the hairs, it uttered a distinct squeak.

2 De Geer, vii. 594.

3 Tiösel II. 208.

4 Ray, Hist. Ins. 384. Dumeril, Trait. Elément. ii. 100. n. 17.

5 De Geer, v. 58. 69. Rösel, II. iii. 5.

7 Latr. Hist. Nat. x. $264 . \quad 8$ De Geer, iii. 289.

Q Rösel, ibid.

9 II ist. Ins, 56. 
served at Southwold, where it abounds; but how produced I cannot say. The praying mantis (M. religiosa), as we learn from M. Goureau, when alarmed and having put itself in an attitude of defence, rubs the sides of the abdomen against the interior borders of the wings and elytra, so as to produce a noise like that of parchment rubbed together. ${ }^{1}$ 'The most remarkable noise, however, proceeding from insects under alarm, is that cmitted by the death's-head hawk-moth, and for which it has long been celebrated. The Lepidoptera, though some of them, as we have seen, produce a sound when they fly, at other times are usually mute insects; lut this alarmist - for so it may be called, from the terrors which it has occasioned to the superstitious - when it walks and more particularly when it is confined, o! taken into the hand, sends forth a strong and sharp cry, resembling, some say, that of a mouse, but more plaintive, and even lamentable, which it continues as long as it is held. This cry does not appear to be produced by the wings; for when they, as well as the thorax and abdomen are held down, it becomes still louder. Schrœeter says that the animal, when it utters its cry, rubs its tongue against its head ${ }^{2}$; and Rösel, that it produces it by the friction of the thorax and abdomen. ${ }^{3}$ But Reaumur believed, after the most attentive ezamination, that the cry came from the mouth, or rather from the tongue; and he thought that it was produced by the friction of the palpi against that organ. When, by means of a pin, he unfolded the spiral tongue, the cry ceased; but as soon as it was rolled up again between the palpi it was renewed. He next prevented the palpi from touching it, and the sound also ceased; and upon removing only one of them, though it continued, it became inuch more feeble. ${ }^{4}$ Huber, however, denies that it is produced by the friction of the tongue and $\mathrm{palpi}^{5}$ : as does M. Passerini, who conceives that it is owing to the alternate inspiration and expiration of air from the central canal of the proboscis into a peculiar cavity in the head destined for giving it the required resonance. But on the other hand MM. Duponchel, Aubé, Boischual, Pierret, and Rambur, members of the Entomological Society of France, who expressly instituted a series of experiments in order to ascertain the actual cause of the noise, came to the conclusion that it is not owing to any of those hitherto assigned, and yet remains to be discovered, and that the noise itself has little of the plaintive cry attributed to it, but has the greatest analogy with that made by most of the capricorn beetles (Prionus, Lamia, \&c.), as above described. ${ }^{6}$ If the observation of a friend of Mr. Raddon, that this noise is sometimes made by the moth just before issuing from the pupa ${ }^{7}$, be correct, it would go far to prove that it is simply owing, as Rösel thought, to the same cause as that of the capricorn beetles, since the confined posture of the insect in the pupa case, and the very limited quantity of air there inclosed, seem to forbid the supposition that this last has any share in producing it.

I must next say a few words upon the angry chidings of our little creatures; for their anger sometimes vents itself in sounds. I have often been amused with hearing the indignant tones of a humble-bee while lying on its back. When I held my finger to it, it kicked and scolded with all its

1 Ann. Soc. Ent. de France, x. bull. xviii.

3 III. 16.

5 Niruv. Ols ii. 300. note *.

6 Lun. Soc. Fint. de France, viii. 59. and ix. 125.

7 Tiuns. Ent. Soc. Lond. ii. proc. Ixxvi.
2 Naturforscher, Stk. xxi. \%.

4 Reaum, ii. 290. 
might. Hive-bees when irritated emit a shrill and peevish sound, cortinuing even when they are held under water, which John Hunter says vibrates at the point of contact with the air-holes at the root of their wings. ${ }^{2}$ This sound is particularly sharp and angry when they fly at an intruder. The same sounds, or very similar ones, tell us when a wasp is offended, and we may expect to be stung; - but this passion of anger in insects is so nearly connected with their fear that I need not enlarge further upon it.

Concerning their shouts of joy and cries of sorrow I have little to record: that pleasure or pain makes a difference in the tones of vocal insects is not improbable; but our auditory organs are not fine enongh tu catch all their different modulations. When Schirach had once smoket a hive to oblige the bees to retire to the top of it, the queen with some of the rest flew away. Upon this, those that remained in the hive sent forth a most plaintive sound, as if they were all deploring their loss; when thei: sovereign was restored to them, these lugubrious sounds were succeeder by an agreeable humming, which announced their joy at the event. ${ }^{2}$ Huber relates, that once, when all the worker-brood was removed from a hive, and only male brood left, the bees appeared in a state of extreme despondency. Assembled in clusters upon the combs, they lost all their activity. The queen dropped her eggs at randon ; and instead of the usual active hum, a dead silence reigned in the hive. ${ }^{3}$

But love is the soul of song with those that may be esteemed the most musical insects, the grasshopper tribes (Gryllina and Locustina), and the long celebrated Cicada. You would suppose, perhaps, that the laclies would bear their share in these anatory strains. Bnt here you would be nistaken - female insects are too intent upon their business, too coy and reserved to tell their love even to the winds. - the males alone

"Formosam resonare docent Amaryllida sylvas."

With respect to the Cicada, this was observed by Aristotle; and Pliny, as usual, has retailed it after him. ${ }^{4}$ The observation also holds good with respect to the Gryllina, \&c., and other insects, probably, whose love is musical. Olivier, however, has noticed an exception to this cloctrine ; for he relates, that in a species of beetle (Moluris striata), the female has a round granulated spot in the mirldle of the second segment of the abdomen, by striking which against any hard substance, she produces a rather loud sound, and that the male, obedient to this call, soon attends her, and they pair. ${ }^{5}$ Both sexes, also, in the genus Ephippiger, separated by Latreille from Acrida, and characterised as being without wings and with very short wing-covers, are musical (?). ${ }^{\theta}$

As I have nothing to communicate to you with respect to the love-songs

1 In Phitos. Trans. 1792. This fact strongly confirms Dr. Burmeister's experiments before related, showing that the humming of bees, as of flies, is caused not by the wings, but by the action of the air on the lamina of the thoracic spiracles as there described.

2 Sichirach, 73 .

5 i. 226 :

4 Aristot. Hist. Anim. 1. v. c. 30 . Plin. Hist. Nat. 1. xi. c. 26.

5 Oliv. Entomol. i. Pref. ix.

(6) Goureau, Ann. Soc. Ent. de France, ri. 31. and translation in Entom. Mag. ร. 93. 
of other insects, my firther observations will be confined to the tribes lately mentioned, the Gryllina, Sc., and the Cicadce.

No sound is to me more agreeable than the chirping of most of the Gryllina, Locustina, \&c.; it gives life to solitude, and always conveys to my mind the idea of a perfectly happy being. As these creatures are now very properly divided into several genera, I shall say a few words upon the song of such as are known to be vocal, separately.

The remarkable genus Pneumora - whose pellucid abdomen is blown up like a bladder, on which account they are called Blaazops by the Dutch colonists at the Cape-in the evening, for they are silent in the clay, make a tremulous and tolerably loud noise, which is sometimes heard on every side. ${ }^{1}$ The species of this genus have a claim to the name of Fiddlers, since their sound is produced by passing the hind-legs, which are furnished with a series of smooth elevated ridges, and may be called the fiddle-sticles, over a number of short transverse elevated ridges, of a similar though slightly different structure, on the abdomen, which may be called the strings. ${ }^{2}$

The cricket tribe are a very noisy race, and their chirping is caused by the friction of the cases of their elytra against each other. For this purpose there is something peculiar in their structure, which I shall describe to you. The elytra of both sexes are divided longitudinally into two portions; a vertical or lateral one, which covers the sides; and a horizontal or dorsal one, which eorers the back. In the female both these portions resembie each other in their nervures; which running obliquely in two directions, by their interseetion, form numerous small lozenge-sliaped or rhomboidal meshes or areolets. The elytra also of these have no elevation at their base. In the males the vertical portion does not materially differ from that of the females; but in the horizontal the base of each elytrum is elevated so as to form a cavity underneath. The nervures also, which are stronger and more prominent, run here and there very irregularly with various inflexions, describing curves, spirals, and other figures difficult and tedious to describe, and producing a variety of areolets of different size and shape, but generally larger than those of the female ; particularly towards the extremity of the elytrum you may observe a space nearly cir. cular, surrounded by one nervure, and divided into two areolets by another. ${ }^{3}$ The friction of the nervures of the upper or eonvex surface of the base of the left-hand elytrum - which is the undermost - against those of the lower or concave surface of the base of the right-hand - which is the uppermost one, will communicate vibrations to the areas of membrane, more or less intense in proportion to the rapidity of the friction, and thus produce the sound for which these creatures are noted ; which, however, according to M. Goureau, in his elaborate essay on the striclulation of insects, is chiefiy owing to the circumstance of one of the strong nervures called by him the bow (l'archct) being striated or cut transversely like a file, whence it has a much more powerful action on another collection of nervures which he calls the treblc-string (la chanterclle). ${ }^{1}$

The merry inhabitant of our dwellings, the house-cricket (Gryllus domesticus), though it is often heard by day, is most noisy in the night. As

1 Sparrman, Toy. 1. 312.

2 Charpentier in Silbermann's Revue Entom. iii. 314.

3 Compare De Geer, iii. 512.

4 Arn. Soc. Eut. de France, and Entom. Mag. v. 91. 
soon as it grows dusk, its shrill note increases till it becomes quite an annoyance, and interrupts eonversation. When the male sings, he elevates the elytra so as to form an acute angle with the body, and then rubs them against each other hy a horizontal and very brisk motion. ${ }^{1}$ The learned Scaliger is said to have been particularly delighted with the chirping of these animals, and was accustomed to keep them in a box for his amusement. We are told that they have been sold in Africa at a high price, and employed to procure sleep. ${ }^{2}$ If they could be used to sipply the place of laudanum, and lull the restlessness of busy thought in this country, the exchange would be beneficial. Like many other noisy persons, erickets like to hear nobody louder than themselves. Ledelius relates that a woman, who had tried in vain every method she could think of to banish them from her house, at last got rid of them by the noise made by drums and trumpets, which she had procured to entertain her guests at a wedding. They instantly forsook the house, and she heard of them no more. ${ }^{3}$

The field-cricket (Gryllus campestris) makes a shrilling noise - still more sonorous than that of the house-cricket - which may be heard at a great distanee. Mouffet tells us, that their sound may be imitated by rubbing their elytra, after they are taken off; against each other. ${ }^{4}$ "Sounds," says Mr. White, "do not always give us pleasure according to their sweetness and melody; nor do harsh sounds always displease.-Thus the shrilling of the field-ericket, though sharp and stridulous, yet marvellously delights some hearers, filling their minds with a train of summer ideas of every thing that is rural, verdurous, and joyons." One of these crickets when confined in a paper cage and set in the sun, and supplied with plants moistened with water-ior if they are not wetted it will die-will feed, and thrive, and become so merry and loud, as to be irksome in the same room where a person is sitting. ${ }^{5}$

Having never seen a female of that extraordinary animal the molecricket (Gryllotalpa vulyaris), I eannot say what difference obtains in the reticulation of the elytra of the two sexes. The male varies in this respect from the other male crickets, for they have no eircular area, nor do the nervures run so irregularly; the areolets, however, towards their base are darge, with very tense membrane. The base itself also is searcely at all elevated. Circumstances these, which demonstrate the propriety of consilering them distinet from the other crickets. This ereature is not, however, mute. Where they abound they may be heard about the middle of April singing their love-ditty in a low, dull, jarring, uninterrupted note, not unlike that of the goat-sucker (Caprimulgus Europaus), but more inward. ${ }^{6}$ I remember once tracing one by its shrilling to the very bole, under a stone in the bank of my canal, in which it was concealcd. We learn from Mr. Newport, who, in his very valuable treatise on

1 De Geer, iii. 517. See also White, Nat. IIist. ii. 76.; - and Ray, Hist Ins. 63 .

2 Mouftet, 136 ,

3 Goldsmith's Animat. Nat. vi. 28.

4 Ins. Theatr. 134.

5 Nat. Hist. ji. 73. Yet it would appear that when wholly removed from the scent of their mother-earth they are silent, for it is stated by Southey that on the ship of Cabeza de Vaca approaching the coast of Brazil, the proximity of land was inferred, aud as the result proved, truly, by a groumd-cricket which a sollier had brought from Cadiz then beginning again to sing. (Hist. of Brazil.)

6 Wat. Hist, ii. 81. 
insects in the Cyclopadin of Anatomy and Physiology, has so admirably illustrated their structure, both internal and external, that this low jarring sound is owing to the shortness of the nervures, and the nuch greater number of those on the under side of the wing-covers being scored with the same notches as in a file (p. 928.) ; pointed out in the crickets by 1. Goureat, who also saw them in the mole-cricket, but seems to have overlooked their extending to so many of the nervures as Mr. Newport has observed to be furnished with them.

Another tribe of grasshoppers (Acrida, Pterophylla, \&c.1) - the females of which are distinguished by their long ensiform ovipositor-like the crickets, make their noise by the friction of the bases of their elytra. And the chirping they thus produce is long, and seldom interrupted, which distinguishes it from that of the common grasshoppers (Locusta). What is remarkable, the grasshopper lark (Sylvia locustella), which preys upon them, makes a similar noise. Professor Lichtenstein, in the Limnean Transactions, has called the attention of naturalists to the eye-like area in the right elytrum of the males of this genus ${ }^{2}$; but he seens not to have been aware that De Geer had noticed it before him as a sexual character; who also, with good reason, supposes it to assist these animals in the sounds they produce. Speaking of Acrida viridissima - common with us - he says, "In our male grasshoppers, in that part of the right elytrum which is folded horizontally over the trunk, there is a round plate made of very fine transparent membrane, resembling a little mirror or picce of talc, of the tension of a drum. This membrane is surrounded by a strong and prominent nervure, and is concealed under the fold of the left elytrum, which has also several prominent nervures answering to the margin of the membrane or ocellus. There is," he further remarks, "every reason to believe that the brisk movement with which the grasshopper rubs these nervures against each other produces a vibration in the membrane augmeliting the sound. The males in question sing continually in the hedges and trees during the months of July and August, especially towards sunset and part of the night. When any one approaches, they immediately cease their song." 3 In these insects, as in the crickets, M. Goureau has detected in the strong horny ridge immediately behind the mirror or tympanum, near the base of the upper surface of the left elytrum, the same transverse notches as in Acheta and Gryllotalpa, while on the under surface of the right elytrum a similar but less strongly notched file-like ridge is found ; and it is obviously by the rubbing of these rasps against the projecting nervures of the borders of the wings, that the sounds resulting from the brisk friction of the elytra proceed. Dr. Burmeister conceives that they are chiefly caused by the forcible expiration of air from the thoracic tracheæ and spiracles, first driven against the inflected external margin of the wing, and subsequently arainst the tympanum, which is thus cansed to vibrate and resound; but Mr. Newport has pointed out that this cannot be the cause, because in Acrida brachelytra the elytra are so exceedingly short and narrow that they do not cover, nor are near, any part of the spiracles, so that the air in passing from these orifices cannot possibly be driven against the tympanum ; which, however, being accompanied by notched nervures, as in $A$. viridissima, though differently arranged,

1 See Kirby in Zool. Journ. p, iv. 429.

\& Linn. Trans. iv. 51.

3 De Geer, iii. 429. 
produces similar sounds. A still farther proof that these notched nervures or files are the main agents in producing the sounds, is afforded by the facts that their notches are more distinct in newly disclosed specimens, especially of Acrida viridissima, than in older inclividuals, in which they have been partially obliterated by use; and that the somnds, as M. Goureau has remarked, may be readily produced in the dead insect by gently rubbing the bases of the elytra together, which could not happen if the rushing of the air from the spiracles had any effect in producing them. ${ }^{1}$

The last description of singers that I shall notice amongst the Locustina, and which includes the migratory locust, are those that are more commonly denominated grasshoppers. To this genus belong the little chirpers that we hear in every sunny bank, and which make vocal every heath. They begin their song - which is a short chirp regularly interrupted, in which it differs from that of the Acrida-long before sunrise. In the heat of the day it is intermitted, and resumed in the evening. This sonnd is thus produced:- Applying its posterior shank to the thigh, the animal rubs it briskly against the elytrum ${ }^{2}$, doing this alternately with the right and left legs, which canses the regular breaks in the sound. But this is not their whole apparatus of song - since, like the Tettigonix, they have also a tympanum or drum. De Geer, who examined the insects he describes with the eye of an anatomist, seems to be the only entomologist that has noticed this organ. "On each side of the first segment of the abdomen," says he, "immediately above the origin of the posterior thighs, there is a considerable and decp aperture of rather an oval form, which is partly closed by an irregular flat plate or operculum of a hard substance, but covered by a wrinkled flexible membrane. The opening left by this operculum is semilunar, and at the bottom of the cavity is a white pellicle of considerable tension, and shining like a little mirror. On that side of the aperture which is towards the head there is a little oval hole, into which the point of a pin may be introduced withont resistance. When the pellicle is removel, a large cavity appears. In my opinion this aperture, cavity, and above all the membrane in tension, contribute much to produce and augment the sound emitted by the grasshopper." 3 This description, which was taken from the migratory locust ( $L$. migraloria), answers tolerably well to the tympanum of our common grasshoppers; only in them the aperture seems to be rather semicircular, and the wrinkled platewhich has no marginal hairs - is clearly a continuation of the substance of the segment. This apparatus so much resembles the drum of the Cicadre, that there can be little doubt as to its use. The vibrations caused by the friction of the thighs and elytra striking upon this drum are reverberated by it, and so intenseness is given to the sound. ${ }^{4}$ In Spain, we are told that peopie of fashion keep these animals - called there Grillo - in cages, which they name Grilleria, for the sake of their song. ${ }^{5}$

I shall conclude this diatribe upon the noises of insects with a tribe that have long been celebrated for their musical powers: I mean the Cicadiada,

1 Burmeister, Manual of Entom. 4i0. Gomreau, ubi supra. Newport, ubi supra, 929.

2 De Geer, iii. 470 .

3 Ibid. 471. t. xxiii. f. 2, 3.

4 Gourean (op. cit.) and Miiller (Burmeister, Munual, 572.) regard this drum as an ru litury orisan, but jrobably without suficient groands.

5 Usbeck's Foy. i. 71. 
including the genera Fulgora, Cicada, Tettix, and Tettigonia. ${ }^{1}$ The Fulgorce appear to be night singers, while the Cicade sing usually in the day. The great lantern-fly (Fukgora latemaria), from its noise in the evening - nearly resembling the sound of a cymbal, or razor-grinder when at work - is called Scare-sleep by the Dutch in Guiana. It begins regularly at sunset. ${ }^{2}$ Perhaps an insect mentioned by Ligon as making a great noise in the night, in Barbadoes, may belong to this tribe. "There is a kind of animal in the woods," savs he, "that I never saw, which lie all day in holes and hollow trees, and as soon as the sun is down begin their tunes, which are neither singing nor erying, but the shrillest voices I ever heard: nothing can be so nearly resembled to it as the mouths of a pack of small beagles at a distance; and so lively and chirping the noise is as nothing can be more delightful to the ear's, if there were not too much of it ; for the music has no intermission till morning, and then all is husht." ${ }^{3}$

The species of the other genus, Cicada, called by the ancient Greeksby whom they were often kept in cages for the sake of their song-'Tettix, seem to have been the favourites of every Grecian bard from Ifomer and Hesiod to Anacreon and Theocritus. Supposed to be perfectly harmless, and to live only upon the dew, they were addressed by the most endearing epithets, and were regarded as all but divine. One bard entreats the shepherds to spare the innoxious Tettix, that nightingale of the Nymphs, and to make those mischievous birds the thrush and blackbird their prey. Sweet prophet of the summer, says Anacreon, addressing this insect, the Muses love thee, Phœbus himself loves thee, and has given thee a shrill song ; old age does not wear thee out ; thou art wise, earth-born, musical, impassive, without blood; thou art almost like a god. ${ }^{4}$ So attached were the Athenians to these insects, that they were accustomed to fasten golden images of them in their hair, inplying at the same time a boast that they themselves, as well as the Cicadæ, were Terra fili. They were regarded indeed by all as the happiest as well as the most innocent of animals - not, we will suppose, for the reason given by the saucy Rhodian Xenarchus, when he says,

"Happy the Cicadas' lives,

Since they all have voiceless wives."

If the Grecian Tettix or Cicada had been distinguished by a harsh and deafening note, like those of some other countries, it would harlly have been an object of such affection. That it was not, is clearly proved by the connection which was supposed to exist between it and music. Thus the sound of this insect and of the harp were called by one and the same name. ${ }^{5}$ A Cicada sitting upon a haip was a usual cmblem of the science of music, which was thus accounted for:- When two rival musicians, Eunomus and Ariston, were contending upon that instrument, a Cicada flying to the former and sitting upon his harp supplied the place of at

1 Zoolog. Journ. No. iv. 429.

2 Stedman's Surinam, ii. 37. Dr. Hancock, however (Proceed. Zool. Soc. Ji:ne 24. 1834), states that the razor-grinder, or aria-aria of the natives, is a species of Cicadi (C. clarisonu), and that the F'ulgora rarely sing.

3 Hist. of Burbadoes, 65.

4 Epigramm. Delect. 45.234.

5 Gr. $\tau \xi \xi \varepsilon \tau เ \sigma \mu \alpha$.

I下 2 
broken string, and so secured to him the victory. ${ }^{1}$ To excel this animal in singing seems to have been the highest commendation of a singer ; and eren the eloquence of Plato was not thought to suffer by a comparison with it. ${ }^{2}$ At Surinam the noise of the Cicada Tibicen is still supposed so much to resemble the sound of a harp or lyre, that they are called there harpers (Lierman). ${ }^{3}$ Whether the Grecian Cicadæ maintain at present their ancient character for music, travellers do not tell us.

Those of other countries, however, have been held in less estimation for their powers of song; or rather have been execrated for the deafening din that they produce. Virgil accuses those of Italy of bursting the very shrubs with their noise ${ }^{4}$; and Sir J. E. Smith observes that this species, which is very common, makes a most disagreeable dull chirping. ${ }^{5}$ Another, Cicada septendecim - which fortunately, as its name imports, appears only once in seventeen years - makes such a continual din from morning to evening that pcople cannot hear each other speak. They appear in Pennsylvania in incredible numbers in the middle of May. "In the hotter months of summer," says Dr. Shaw, "espccially from midday to the middle of the afternoon, the Cicala, $\tau \varepsilon \tau \tau t^{z}$, or grasshopper, as we fatsely translate it, is perpetually stunning our ears with its nost excessively shrill and ungrateful noise. It is in this respect the most troublesome and impertinent of insects, perching upon a twig and squalling sometimes two or three hours without ceasing; thereby too often disturbing the studies, or short repose that is frequently indulged, in these hot climates, at those hours. The ritris of the Greeks must have had a quite different voice, more soft, surely, and melodious; otherwise the fine orators of Homer, who are compared to it, can be looked upon no better than loud loquacious scolds."7 An insect of this tribe, and $I$ am told a very noisy one, lias been found by Mr. Daniel Bydder, before mentioned (Cicada Anglica Curtis ${ }^{8}$ ) in the New Forest, Hampshire. Previonsly to this it was not thought that any of these insect musicians were natives of the British Isles. Captain Hancock informs me that the Brazilian Cicala sing so loud as to be heard at the distance of a mile. This is as if a man of ordinary stature, supposing his powers of roice increased in the ratio of his size, conld be heard all over the world. So that Stentor himself becomes a mute when compared with these insects.

You feel very curious, doubtless, to know by what means these little animals are enabled to cmit such prodigious sounds. I have lately mentioned to you the drum of certain grasshoppers: this, howevcr, appears to be an organ of a very simple structure; but since it is essentral to the cconomy of the Cicadre that their males should so much exceed all other insects in the londness of their tones, they are furnished with a much more complex, and indeed most wonderful, apparatis, rlich I shall now describe. If your look at the under side of the body of a male, the first thing that will strike you is a pair of large plates of an irregular form - in some semi-oral, in others triangular, in others again a segment of a circle of greater or less diameter-covering the anterior part of the belly, and fixed to the trunk

1 Mouffet, Theatr. 130.

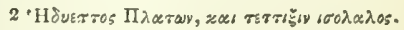

3 Merian, Surinam, 49.

4 "Et cantu querula rumpent arbusta cicadx." Georg. iii. 328.

5 Smith's Tour, iii. 95.

- Collinson in Philos. Trans. 1763. Stoll, Ciqales, 26.

7 Travels, 2 d ed. $156 . \quad 8$ Brit. Ent. t. 114. 
between the abdomen and the hind legs. ${ }^{1}$ These are the drum-covers or operenla, from beneath which the sound issues. At the base of the posterior legs, just above each operculum, there is a small pointed triangular process (pessellum) ${ }^{2}$, the object of which, as Reaumur supposes, is to prevent them from being too much elevated. When an operculum is removed, beneath it you will find on the exterior side a hollow eavity, with a mouth somewhat linear, which seems to open into the interior of the abdomen ${ }^{3}$ : next to this, on the inner side, is another large cavity of an irregular shape, the botton of which is divided into three portions; of these the posterior is lined obliquely with a beantiful membrane, which is very tense - in some species semi-opaque, and in others transparent - and reflects all the colours of the rainbow. This mirror is not the real organ of sound, but is supposed to modulate it. ${ }^{4}$ The middle portion is occupied by a plate of a horny substance, placed horizontally, and forming the bottom of the eavity. On its imer side this plate terminates in a carina or elevated ridge, cominon to both drums. ${ }^{5}$ Between the plate and the afterbreast (posipectus) incther membrane, folded transversely, fills an oblique, oblong, or semilunar cavity. ${ }^{6}$ In some species $I$ have seen this membrime in tension ; prohably the insect can stretch or relax it at its pleasure. But even all this apparatus is insufficient to produce the sound of these animals ; one still more important and curious yet remains to be described. This organ can only be discovered by dissection. A portion of the first anci second segments being removed from that side of the back of the abdonien which answers to the drums, two bundles of muscles vreeting each other in an acute angle, attached to a place opposite to the point of the mucro of the first ventral segment of the ablomen, will appear. ${ }^{7}$ In Reaumur's specimens these bundles of muscles seem to have heen eylindrical; but in one I disseeted (Cicada Capensis) they were tubiform, the end to which the true drum is attached being dilated. ${ }^{8}$ These bundles consist of a prodigious number of muscular fibres applied to each other, but easily separable. Whilst Reaumur was examining one of these, pulling it from its place with a pin, he let it go again, and immediately, though the animal had been long dead, the usual somnd was emitted. On each side of the drum-cavities, when the opereula are removed, another cavity of a lunulate shape, opening into the interior of the ablomen, is observable. ${ }^{9}$ In this is the true drum, the principal organ of sound, and its aperture is to the Cieada what our larynx is to us. If these ereatures are unable themselves to modulate their sounds, here are parts enough to do it for them: for the mirrors, the membranes, and the central portions, with their cavities, all assist in it. In the eavity last described, if you remove the lateral part of the first dorsal segment of the abdomen, you will discover a semi-opaque and nearly semicireular concavo-convex membrane with transverse folds: this is the drum. ${ }^{10}$ Each bundle of muscles, before mentioned, is terminated by a tendinous plate nearly eircular, firom which issue several little tendons that, foming a thread, pass through an aperture in the horny piece that supports the drum, and are attaehed to its under or concave surfice. Thus the

1 Reaum, v. t. xri. f. 5, u u.

5 leaum. ibid. f. $3 ., l l$.

5 Ibid. q.q. $c$.

7 Ibid. ubi supra, f, 6. $f f$.

- Ibid. f. $3 . l$.
2 Reaum. ubi supra, t. xvi. f. 11. b.

4 Ibid. ubi supra, f'. 3. $11 \mathrm{~m}$.

6 leaum, t. xvi, f. $3 . n$.

8 Ibil. f. 9. $f f$.

10 Ibid. f. 6. $t$ t. f. 9 . 
bumble of muscles being alternately and briskly relaxed and contracted, will by its play draw in and let out the drum: so that its convex surface being thus rendered concave when pulled in, when let out a sound will be produced by the effort to recover its convexity; which, striking upon the mirror and other membranes before it escapes from under the operculnm, will be modulated and angmented by them. I should imagine that the muscular bundles are extended and contracted by the alternate approach and recession of the trunk and abdomen to and from each other.

And now, my friend, what adorable wislom, what consummate art and skill are displayed in the admirable contrivance and complex structure of this wonderful, this unparalleled apparatus! The Great Creator has placed in these insects an organ for producing and emitting sounds, which in the intricaey of its construction seems to resemble that which he has given to man, and the larger animals, for receiving them. Here is a cochlea; a meatus; and, as it should seem, more than one tympanum.

I am, \&c 


\section{LETTER XXV。}

\section{ON IUMINOUS INSECTS.}

WE boast of our candles, our wax-lights, and our Argand lamps, and pity our fellow-men who, ignorant of our methods of producing artificial light, are condemned to pass their nights in darkness. We regard these inventions as the results of a great exertion of human intellect, and never conceive it possible that other animals are able to avail themselves of modes of illumination equally efficient, and are furnished with the means of guiding their nocturnal evolutions by actual lights, similar in their effect to those which we make use of. Yet many insects are thus provided. Some are forced to content themselves with a single candle, not more vivid than the rushlight which glimmers in the peasant's cottage; others exhibit two or three, which cast a stronger radiance; and a few can display a lamp little inferior in brilliancy to some of ours. Not that these insects are actually possessed of candles and lamps. You are aware that I am speaking figuratively. But Providence has supplied them with an effectual substitutea luminous preparation or secretion, which has all the advantages of our lamps and candles without their inconveniences; which gives light sufficient to direct their motions, while it is incapable of burning; and whose Justre is maintained without needing fresh supplies of oil or the application of the sunffers.

Of the insects thus singularly provided, the common glow-worm ( $\mathrm{Lam}$ pyris noctiluca) is the most familiar instance. Who that has ever enjoyed the luxury of a summer evening's walk in the country, in the southeri parts of our island, but has viewed with admiration these "stars of the earth and diamonds of the night?" And if, living like me in a rlistrict where it is rarely met with, the first time you saw this insect chanced to be, as it was in my case, one of those delightful evenings which an English summer seldom yields, when not a breeze disturbs the balny air, and "every sense js joy," and hundreds of these radiant worms, studding their mossy couch with mild effulgence, were presented to your wondering eye in the course of a gnarter of a mile, - you coukl not help associating with the name of glow-worm the most pleasing recollections. No wonder that an insect, which chiefly exhibits itself on occasions so interesting, and whose economy is so remarkable, should have afforded exquisite images and illustrations to those poets who have cultivated Natural History.

If you take one of these glow-worms home witl you for examination, you will find that in shape it somewhat resembles a caterpillar, only that it is much more depressed; and you will observe that the light proceeds from a pale-colonred patch that terminates the under side of the abdomen. It is not, however, the larva of an insect, but the perfect female of a winged 
beetle, from which it is altogether so different that nothing but actual observation conld have inferred the fact of their being the sexes of the same insect. In the course of our inquiries you will find that sexual differences even more extraordinary exist in the insect world.

It has been supposed by many that the males of the different species of Lampyris do not possess the property of giving out any light; but it is now ascertained that this supposition is inaccurate, though their light is much less vivid than that of the female. Ray first pointed out this fact with respect to $L$. noctiluca ${ }^{1}$, which has two luminous points on the penultimate abdominal segment. In the males of $L$. splendidula and of $L$. hemiptera the light is very distinct, and may be seen in the former while flying. ${ }^{2}$ The females, like the males, have the same faculty of extinguishing or concealing their light - a very necessary provision to guard them from the attacks of nocturnal birds; Mr. White even thinks that they regularly put it out between eleven and twelve every night ${ }^{3}$; and they have also the power of rendering it for a while more vivid than orlinary.

Authors who have noticed the luminous parts of the common female glow-worm having usually contented themselves with stating that the light issues from the three last ventral segnents of the abdomen ${ }^{4}$, I shall give you the result of some observations I once made upon this subject. Une evening, in the beginning of July, meeting with two of these insects, I placed them on my hand. At first their light was exceedingly brilliant, so as to appear even at the junctions of the upper or dorsal segments of the abdomen. Soon after I had taken them, one withdrew its light altogether, but the other continued to shine. While it did this it was laid upon its back, the abdomen forming an angle with the rest of its body, and the last or anal segment being kept in constant motion. This segment was distinguished by two round and very vivid spots of light; which, in the specimen that had ceased to shine, were the last that disappeared, and they scem to be the first parts that become luminous when the animal is disposed to vield its light. The penultimate and antepenultimate segments each exhibited a middle transverse band of yellow radiance, terminated towards the trunk by an obtusely-dentated line; a greener and fainter light being emitted by the rest of the segment.

Thengh many of the females of the Lampyride are without wings, and even elytra (in which circumstance they differ from all other apterous Coleoptera), this is not the case with alt. The female of Pygolampis ${ }^{5}$ Italica, a species common in Italy, and which, if we may trust to the accuracy of the account given ly Mr. Waller in the Philosophical Transactions for 1681, would seem to have been taken by him in Hertfordshire, is winged: and when a number of these moving stars are seen to dart throngh the air in a dark night, nothing can have a more beautiful effect. Sir J. E. Simith tell, us that the beaux of Italy are accustomed in an evening to adorn the heads of the ladies with these artificial diamonds, by sticking them into their hair ; and a similar custom, as I have before informed you, prevails amongst the ladies of India.

1 Hist. Ins. 81.

₹ Nat. Hist. ji. 279.

5 I call by this name all those Lampyrice whose heal is not at all, or but little. concealed by the slield of the prothorax, and both sexes of which are winged. 
Besides the different species of the genus Lampyris, all of which, to the number of nearly two hundred, now divided into several distinct genera, are probably more or less luminous, another insect of the beetle tribe, Elater noctilucus, is endowed with the same property, and that in a much higher degree. This insect, which is called the fire-fly, and is an inch long, and about one third of an inch broad, gives out its principal light from two transparent eye-like tubercles placed upon the thorax; but there is also a luminous patch in the posterior and inferior region of the metathorax, in a somewhat triangular and depressed cavity ordinarily concealed by the elytra, but when these are expanded in the aet of flying giving out a more considerable but more diffused light than the thoracic reservoirs; in fact the whole body is full of light, which shines ont between the abdominal segments when stretched; and being strongly reflected by the two basal abdominal segments, gives an appearance of the two luminous patches there which De Geer has described, but which do not actually exist. ${ }^{1}$ The light emitted by the two thoracic tubercles alone is so considerable, that the smallest print nuay be read by moving one of these insects along the lines; and in the West India Islands, particularly in St. Jomingo, where they are very common, the natives were formerly accustomed to employ these livin' lamps, which they call Cucuij, instead of candles in performing their evening household occupations. In travelling at night, they used to tie one to each great toe; and in fishing and hunting required no other flambeau. ${ }^{2}$ Southey has happily introduced this insect in his "Madoc," as furnishing the lamp by which Coatel rescued the British hero from the hands of the Mexican priests.

\footnotetext{
"She beckon'd and descended, and drew out From underneath her vest a cage, or net It rather might be call'd, so fine the twigs Which knit it, where, confined, two Fire-flies gave Their lustre. By that light did Matloc first Behold the features of his lovely guide."
}

Pietro Martire tells us that the Cucnij serve the natives of the Spanish West India Islands not only instead of candles, but as extirpators of the gnats, which are a dreadful pest to the inhabitants of the low grounds. They introduce a few fire-flies, to which the gnats are a grateful food, into their houses, and by means of these "commodious hunters" are soon rid of the intruders. "How they are a rcmedy," says the author, "for so great a mischiefe it is a pleasant thing to hear. Hee who understandeth he hath those trouble-ome guestes (the gnattes) at home, diligently hunteth after the Cucuij. Whoso wanteth Cuenij goeth out of the house in the first twilight of the night, carrying a burning fire-brande in his liande, and ascendeth the next hillock that the Cucuij may see it, and he swingeth the fire-brand about, calling Cucuins aloud, and beating the ayre with ofteni calling out Cucuic, Cucuie." He goes on to observe, that the simple pcople believe the insect is attracted by their invitations; but that, for his part, he is rather inclined to think that the fire is the magnet. Having obtained a sufficient number of Cucuij, the beetle-hunter returns home and lets them fly loose in the house, where they diligently seek the gnats about the beds

2 Pietro Martire, The Decudes of the New Wurld, quoted in MIudoc, p. 543. 
and the faces of those asleep, and devour them. ${ }^{1}$ - These insects are also applied to purposes of decoration. On certain festival days, in the month of June, they are collected in great numbers, and tied all over the garments of the young people, who gallop through the streets on horses similarly ornamented, producing on a dark evening the effect of a large moving body of light. On sucb occasions the lover displays his gallantry by decking his mistress with these living genns. ${ }^{2}$ And according to P. Martire, "many wanton wilde fellowes" rub their faces with the flesh of a killed Cucuius, as boys with us use phosphorus, "with purpose to meet theil neighbours with a flaming countenance," and derive amusement from their fright.

Besides Elater noctilucus, E. ignitus and several others of the same genus are luminous. Not fewer than twelve species of this family are described by Illiger in the Berlin Naturalist Society's Magazine ${ }^{3}$, under the name of Pyrophorus; and at least seventy species are.now known, all natives of the hot and temperate regions of America, from Chili to the south of the United States, where they are to be seen almost the whole year at the approach of night, both the sexes being equally luminous. ${ }^{4}$

The brilliant nocturnal spectacle presented by these insects to the inhabitants of the countries where they abound cannot be better described than in the language of the poet above referred to, who has thus related its first effect upon the Britisn visitors of the new world:-

\section{". . . . . . . Sorrowing we beheld}

The night come on; but soon did night display

More wonders than it veil'd: innmmerous tribes

From the wood-cover swarm'd, and darkness made

Their beauties visible: one while they stream'i

A bright blue radiance upon flowers that closed

Their gorgeous colours from the eye of day;

Now motionless and darls, eluded search,

Self-shrouded; and anon, starring the sky,

Kose like a shower of tire."

The beautiful poetical inagery with which Mr. Southey has decoratel this and a few other entomological facts, will make you join in my regret that a more extensive acquaintance with the science has not enabled bim to spread his embellishments over a greater number. The gratification which the entomologist derives from seeing his favourite study adorned with the graces of poetry is seldom unalloyed with pain, arising from the inaccurate knowledge of the subject in the poet. Dr. Darwin's description of the beetle to which the nut-maggot is transformed, may delight him (at

1 P. Martire, ubi supra. Dr. Burmeister disbelieves this acconnt, because EIaters are not carnivorous, but feed upon nectar and pollen (Manual, 492.); but considering what numerous exceptions we are constantly finding occur to all such supposed generaI rules, it seems premature to reject on such grounds the very circunstantial ietails of P. Martire. In the same way as some of the Carabida and Coccinellida have been ascertained to feed on vegetable food, though both families are in general carnivorous, it may he found that some of the Etateride prefer an animal diet and will eat guats.

2 Walton's Present State of the Spanish Colonies, i. 128.

3 Jahrgang, i. 141.

4 Lacordaire, Introd. d l'Entom. ii. 140. See Dr. Germar's monograph on this genus, containing deseriptions of seventy-nine speeies, in the Zeitschr. f. d. Ent. vol. iii. (1811.) 
least if he be an admirer of the Darwinian style) as he reads for the first time,

\author{
"So sleeps in silence the Curculio, shut \\ In the dark chamber of the cavern'd nut; \\ Erodes with ivory beak the vaulted shell, \\ And quits on filmy wings its narrow cell."
}

But when the music of the lines has allowed him room for pause, and he recollects that they are built wholly upon an incorrect supposition, the Curculio never inhabiting the nut in its beetle shape, nor employing its ivory or rather ebony beak upon it, but undergoing its transformation underground, he feels disappointed that the passage has not truth as well as sound. Mr. Southey, too, has fallen into an error: he confounds the fire-fly of St. Domingo (Elater noctilucus) with a quite different insect, the lantern-fly (Fulgora laternaria) of Madame Merian; but happily this crror docs not affect his poetry.

But to return from this digression. - If we are to believe Mouffet (and the story is not incredible), the appearance of the tropical fire-flies on one occasion led to a more important result than might have been expected from such a cause. He tells us, that when Sir Thomas Cavendish and sir Robert Dudley first landed in the West Indies, and saw in the evening an infinite number of moving lights in the woods, which were merely these insects, they supposed that the Spaniards were advancing upon them, and immediately betook themselves to their $\operatorname{ships}^{1}:-$ a result as well entitling the Elaters to a commemoration feast as a similar good office the land-crabs of Hispaniola, which, as the Spaniards tell (and the story is confirmed by an anniversary Fiesta de los ('angrejos), by therr elattering - mistaken by the eneny for the sound of Spanish cavalry close upon their heels - in like manner scared away a body of English invaders of the city of St. Domingo. ${ }^{2}$

An anecdote less improbable, perhaps, and certainly more ludicrous, is related by Sir J. E. Smith of the effect of the first sight of the Italian glow-worms upon some Moorish ladies ignorant of such appearances. These females had been taken prisoners at sea, and, until they could be ransomed, lived in a house in the outskirts of Genoa, where they were frequently visited by the respectable inhabitants of the city; a party of whom, on going one evening, were surprised to find the house closely shut up, and their Moorish friends in the greatest grief and consternation. On inquiring into the cause, they ascertained that some of the Pygolampis Italica had found their way into the dwelling, and that the ladies within had taken it into their heads that these brilliant guests were no otlier than the troubled spirits of their relations; of which idea it was some time before they conld be divested. - The common people in Italy have a superstition respecting these insects some what similar, believing that they are of a spiritual nature, and proceed out of the graves, and hence carefully avoid them.s

In addition to the Lampyride and Elatcride, it seems probable that other coleopterous families include luminous species. C'hiroscelis bifencstrata of

1112.

3 Tour on the Continent, 2 I Edit. iij. 85.

2 Walton's Hispuniola, i. 39. 
Lamarck, a beetle, has two red oval spots covered with a downy membrane on the second segment of the abdomen, which he thinks indicate some particular organ, perhaps luminous ${ }^{1}$; and M. Latreille informed me that a firiend of his, who saw one living which was brought from China to the Isle of France in wood, found that the ecelli in the elytra of Buprestis ocellata were luminous. One of the longicorn beetles, Dadoychus farocinctus Chevrolat (allied to Saperda), has the third and fourth segments of the abdomen with the same yellow colour and appearance of the luminous segments of the Lampyrida, whence M. Chevrolat infers that it is like them luminous; and M. de Laporte informs him that a considerable number of Brazilian Helopida, allied to Stenochia, present a similar character indicating a like property. ${ }^{2}$

The insects hitherto adverted to have been beetles, or of the order Coleoptera. But besides these, a genus in the order Hemiptera, called Fulgorn, includes several species which are supposed to emit so powerful a light as to luve obtained in English the generic appellation of Lantern-flies. Two of the most conspicuous of this tribe are the $F$. laternaria and $\vec{F}$. candelaria; the former a native of South America, the latter of China. Both, as indeed is the case with the whole genus, are supposed to have the material which diffuses their light included in a subtransparent projection of the head. In $F$. candelaria this projection is of a subcylindrical shape, recurved at the apex, above an inch in length, and the thickness of a small quill. In $F$. latemaria, which is an insect two or three inches long, the snout is much Jarger and broader, and more of an oval shape, and sheds a light the brilliancy of which is said to transcend that of any other luminous insect. Madame Merian informs us, that the first discovery which she made of this property caused her no small alarm. The Indians had brought her several of these insects, which by daylight exhibited no extraordinary appearance, and she inclosed them in a box until she should have an opportunity of drawing them, placing it upon a table in her lodging-room. In the middle of the night the confined insects made such a noise as to awake her, and she opened the box, the inside of which to her great astonishment appeared all in a blaze; and in her fright letting it fall, she was not less surprised to see each of the insects apprarently on fire. She soon, however, divined the cause of this unexpected phenomenon, and re-inclosed her brilliant guests in their place of confinement. She adds, that the light of one of these Fulgore is sufficiently bright to read in newspaper by: and though the tale of her having drawn one of these insects by its own light is without foundation, she doubtless might have done so if she had chosen. ${ }^{3}$

1 Latr. ITist. Nat. x. 262.

2 Chevrolat in Sibermann's Rev. Entom. i. t. 14.

3 Ins. Sur. 49.-The above account of the luminous properties of Fulgora laternara is given, because negative evidence ought not hastily to be allowed to set aside facts positively asserted by an author who could have no conceivable motive for inventing such a fable; but it is necessary to state, that not only have several of the inhabitants of Cavenne, according to the French Dictionnaire 'd' Fistoire Naturelle, denied that this insect shines, in which denial they are joined by M. Richard, who reared the species (Encyclopédie, art. Fulgora); but the learned and accurate Count 11 offmansegg informs us, that his insect collector sieber, a practised entomologist of thirty years' stinding, and who, when in the Brazils for some years, took many specimens, affirms that he never saw a single one in the least luminous. (Der Gessellschaft Naturf. Fr.* zu Berlin MIag. i. 153.) On the other hand M. Lacordaire states tlat. though he never saw a luminous individual of this species, either in Brazil or Cayenne, and 
In adaition to the insects already mentioned, some others have the power of diffusing light, as two species of Centipedes (Geophilus electricus and phosphoveus), and probably others of the same genus. In these the light is not confined to one purt, but proceesls from the whole body. $G$. electricus is a common insect in this country, residing under clods of earth, and often visible at night in gardens. G.? phosphoreus, a native of Asia, is an obscure species, described by Linné, on the authority of C. G. Ekeberg, the captain of a Swedish East Indiaman, who asserted that it dropped from the air, shining like a glow-worm, upon his ship, when sailing in the Indian Ocean a hundred miles (Swedish) from the continent. However singular this statement, it is not incredible. The insect may either, as Linné suspects, have been elevated into the atmosphere by wings, with which, accord. ing to him, one species of the genus is provided; or more probahly, perhaps, by a strong wind, such as that which raised into the air the shower of insects mentioned by De Geer as occurring in Sweden in the winter of 1749 , after a violent storm that had torn up trees by the roots, ancl carried away to a great distance the surrounding earth, and insects which had taken up their winter quarters amongst it. ${ }^{1}$ That the wind may convey the light body of an insect to the above-mentioned distance from land, you will not dispute when you call to mind that our friend Hooker, in his interesting Tour in Iceland, tells us that the ashes from the eruption of one of the Icelandic volcanoes in 1755 were conveyed to Ferrol, a distance of upwards of 300 miles. $^{2}$-Lastly, to conclude my list of luminous insects, Professor Afzelius observed "a dim phosphoric light" to be emitted from the singular hollow antennæ of Pausus sphcerocerus. ${ }^{3}$ A similar appearance has been noticed in the eyes of Acronycta Psi, Cossus ligniperda, and other noths; and M. Audouin stated to the Entomological Society of France that a Russian naturalist (M. Gimmerthal) had observed the cater-

though the majority of the inhabitants of the latter country whom he questioned on the subject equally denied its being luminous, yet that others asserter the fact ; and as lie himself, a cautious observer on the spot, asks if this contradictory testiniony may not be reconciled by supposing that one of the sexes is luminons and the other not, it seems clearly best to infer with this acute entomologist, that the limminosity of Fulgoria laternaria is a point rather requiring new olservations than yet absolutely decided eitlier way (Introd. à l'Ent. ii. 143.), especially when we find the Marquis "Spinola, in his elaborate paper on this tribe in the Ann. Soc. Ent. de France (viii. 163.), strongly contending for the luminous character of the cephalic protuberance of the whole tribe, and when noreover a friend of MI. Wesmael assured him that lie had himself seen $F$. laternaria Itminous when alive. (Westwood, Mod. Class. ii. 430.) We learn from Mr. Westwood that Dr. Cantor, who is at present (1842) engaged in the Clinese expeclition, has informed Mr. Hope that he has not observed the slightest luminosity in the common Chinese species.

1 De Geer, iv. 63. These insects, which were chiefly Brachyptera L., Aphcdii, spiders, caterpillars, but particularly the larve of Telephorus fuscus, fell in such abundance that they might have been taken fiom the snow by bandfuls. Other showers of insects whicl have been recorded, as that in Numgary, 20 th November, 1672 (Ephem. Nat. Curios. 1673, 80.), and one mentioned in the newspapers of July $2 \mathrm{~d}, 1810$, to have fallen in France the January preceding, accompanied by a shower of red snow, may evidently be explained in the sime manner.

2 p. 407.

3 Linn. Trans. iv. 261. Mr. Westwood, however, in his monograph on this genns, attributes this rather to the action of the light upon the highly polished surlince of the spherical club of the antenna. 
pillars of Noctua (Polia) occulla to be luminons. ${ }^{1}$ This observation as to another species has been confirmed by Dr. Boisduval, who one evening of the hot days of June found on the stems of grass catcrpillars which spread a phosphorescent light, and which he thought were those of Mamestra oleracea, though they seemed larger than eommon; and whether from want of care, or that their luminosity depended on disease, none of them assumed the pupa state. They eertainly, he says, were not the larvæ of Polia occulta. $^{2}$

But besides the insects here enumerated, others may be luminous which have not hitherto been suspected of being so. This seems proved by the following fact. A learned friend ${ }^{\mathbf{3}}$ has informed me, that when he was curate of Ickleton, Cambridgeshire, in 1780, a farmer of that place of the name of Simpringham brought to him a mole-erieket (Gryllotalpa vulgaris Latr.) and told him that one of his people, seeing a Jack-o'-lantern, pursued it and knocked it down, when it proved to be this insect, and the identical specimen shown to him.

This singular fact, while it renders it probable that some insects are Juminous which no one has imagined to be so, seems to afford a elue to the, at least, partial explanation of the very obscure subject of ignes fatui, and to show that there is considerable ground for the opinion long ago maintained by Ray and Willughby, that the majority of these supposed meteors are no other than luminons insects. That the large varying lambent flames, mentioned by Beccaria to be very eommon in some parts of Italy, and the luminous globes seen by Dr. Shaw ${ }^{4}$ eannot be thus explained, is obvions. These were probably electrieal phenomena : certainly not explosions of phosphuretted hydrogen, as has been suggested by some, which must necessarily have been momentary. But that the ignis fatuus mentioned by Derham as having been seen by himself, and which he describes as flitting about a thistle ${ }^{5}$, was, though he seems of a different opinion, no other than some luminous insect, I have little doubt. Mr. Sheppard informs me that, traveiling one night between Stamford and Grantham on the top of the stage, he observed for more than ten minutes a very large ignis fatuus in the low marshy grounds, which had every appearance of being an insect. The wind was very high : consequently, had it been a vapour it must have heen carried forward in a direct line; but this was not the ease. It had the same motions as a Tipula, flying upwards and downwards, backwards and forwards, sometimes appearing as settled, and sometimes as hovering in the air. - Whatever be the true nature of these meteors, of which so much is said and so little known, it is singular how few modern instances of their having been observed are on record. Dr. Darwin declares, that though in the comrse of a long life he had been out in the night, and in the places where they are said to appear, times without number, he had never seen any thing of the kind: and from the silence of other philosophers of our own times, it should seem that their experience is similar: ${ }^{6}$

I Ann. Soc. Ent. de France, i. 424.

5 liev. Dr. Sutton of Norwich.

5 Plit. Trans. 1729, 204.

6 A paper by Richard Chambers, Esq., in the MTagazine of Nat. Hist. (New Series, j. 353.), relates several facts observed by the celebrated botanists Mr. James Dickson, and Mr. Curtis, author of the Flora Londinensis. T. Stothard, Esq., R.A. (who wis, as before mentioned, a zealous entomologist), his father, Mr. A. Chambers, and 
With regard to the immediate source of the lnminous properties of insects, Mr. Macartney ascertained that in the common glow-worm, and in Elater roctilucus and ignitus, the light proceeds from masses of a substance not generally differing, except in its yellow colour, from the interstitial substance (corps graisseu. $x$ ) of the rest of the body, clowely applied underneath those transparent parts of the insects' skin which afford the light. In the glow-worm, besides the last-mentioned substance, which, when the season for giving light is passed, is absorbed, and replaced by the common interstitial sulistance, he observed on the inner side of the last abdominal segment two minute oval sacs formed of an elastic spirally-wound fibre similar to that of the trachea, containing a soft yellow substance of a closer texture than that which lines the adjoining region, and affording a more permament

Joseph Simpson, a fisherman, at Frieston near Boston, all strongly corroborating the above statements as to the probability that at least some ignes fatui are caused by luminous insects. George Wailes, Esq., on the other hand, has given in the Eutom. Mag: i. 351. the result of his father's observations and his own, and has also quoter? those of Miajor Blesson, from Jameson's Edinb. New Phit. Journ. for Jan. 1833, in proof "that the moving ignis fatuus of this country always owes its origin to the spontaneous ignition of gaseous particles" (meaning, I jresume, phosphuretted or carburetted hrdrogen gas), and consequently camot be an insect. Without pretending to deny thit these gases may be al cause of statronary ignes fatui, I confess myself quite unable to conceive of a small mass of these inflammable materials "about the size of the hand " moving at the height of "three feet from the surface of the ground " and "for the clistance of fifty yards nearly parallel with the road," as in the instance seen by Mir. Wailes's father, and being luminous all the time. A mass of hydrogen gas and its compounds, as is well known, whether large or small, when once inflamed (and if not inflamed it cannot be luminous), burns but for an instant except renewed by a fresh supply. In passing the Apennines between Bologna and Florence in 1827 , my two sons and myself amused ourselves the niglit we slept at Pietramala, in observing the well known miniature volcano of hydrogen gas, near to that place, which has been burming for centuries; but though there, if any where, as it is probable that hydrogen gas rises more or less from crevices in the whole adjoining district, there ought to be travelling or flitting lights, if such be possible, we neither saw nor heard of any thing of the kind. On the whole, therefore, the evidence up to this time would seem to be in favonr of the supposition that ignes futui which flit about and travel considerable distances are actually luminous insects as above supposed, how ever rarely they may have come under the notice of entomologists. In the ignes fului observed by M. Weissenborn (Mag. of Nat. Hist. N. S. i. 553.), which were clearly caused $b y$ " the explosion of plosphuretted hydrogen, there was "a succession of flashes " extending for perhaps halt a mile, but they passed over this distance " in less than a second," - an appearance entirely different from those leisurely morements mentioned by Mr. Chambers and Mr. Wailes, or that by Mr. Main (Mrg. of Nat. II ist. N. S. i. 549.), in which the farmer who said he had knocked the luminous object down, described it as exactly like a "Maggy long-legs" (Tipula oleraceu), the very same insect with which $M r$. Shepparl compared the luminous appearance he witnesset. I will conclude this long note with observing that a very strong argument for the possibility of some fiying insects being occasionally luminous is afforded by the facts above stated of luminous caterpillars having been within these few years observed for the first time since entomology has been attended to, anil that by observers every way competent. If caterpillars so very common as those of $M u$ mestra oleracea may sometimes, though so rarely, be luminous, and it, as Dr. Boisduval suggests, and is very probable, this appearance was caused by disease, it is obrious that flying insects may be also occasionally (though selkom) luminous from disease, - a supposition which will at once explain the rarity of the occurrence, and the circumstance that insects of such different genera, and even orders, are suid to have exhiloited this phenomenon. 
and brilliant light. This light he found to be less under the control of the insect than that from the adjoining luminous substance, which it has the power of voluntarily extinguishing, not by retracting it under a membrane, as Carradori imagined, but by some inscrutable change dependent upon its will; and when the latter substance was extracted from living glow-worms it afforded no light, while the two sacs in like circumstances shone uninterruptedly for several hours. Mi. Micartney conceives, from the radiated structure of the interstitial substance surrounding the oval yellow masses immediately under the transparent spots in the thorax of Elater noctilucus, and the subtransparency of the adjoining crust, that the interstitial substance in this situation has also the property of shining - a supposition which, adrerting to the luminous patch under its elytra, and the fact that the incisures between the abdominal segments shine when stretched, nay probably be extended to the whole of the interstitial substance of its body: What peculiar organisation contributes to the production of light in the hollow projection of Fulgora laternaria, the hollow antenna of Pausns spharocerus, and under the whole integument of Geophilus electricus, Mr. Macartney was unable to ascertain. Rexpecting this last he remarks, what I have myself observed, that there is an apparent effusion of a luminous Huid on its surface, that may be received upon the hand, which exhibits is phosphoric light for a few seconds afterwards; and that it will not shine zunless it have been previously exposed for a short time to the solur light. $^{2}$

1 The following interesting facts, in addition to those of Mr. Macartney, have been observed by M. Morren, Professor of Botany in the University of Liege. The corneous transparent cap (calotte), which covers the sac enclosing the lnminons matter in each luninous point of the penultimate abdominal segment of Lampyris noctiucu, presents on its exterior surface a network of hexagonal faccts, convex above and coneave below, constituting an apparatus absolntely similar to that inrented by Fresnet for increasing the diffusion of light, and when this exterior portion of the cap is removed, the luminous matter loses a great portion of its lustre, which mainly depends on this curious and beautiful contrivance for augmenting it. The central facets are larger and more regular than those of the margins, and each facet has in the middle a corneous hair bent backwards, which hairs M. Morren conceives are intended to prevent the adhesion of dust. The luminous masses contained in the two sacs are intersected in every part with a vast multitude of trachean ramifications, which compose also their common envelope, the whole proceeling from a large trachea, which issues from a spiracle situated immediately at the side of the luminons mass, with which it communicates by a small round lateral orifice near the marmin of this last; thus fully confirming the opinion of those physiologists who conceive that the luminous power under consideration is essentially connected with the act of respiration. In fact, M. Morren found that when the spiracle next to the luminous material is closed, the light is immediately extinguished, and re-appears when it is opence. If the luminons sac be remored with its accompanying trachea, it continues to shine; but if this trachea be taken away or compressed so as to hinder the access of air, the sac becomes obscure. This fact explains how, in the insects of the gemus Lrmpyris, as well as those of Etater (Pyrophorus). the light is not constant. but becomes more feeble at intervals, and why it is increased during the flight or other energetic morement of the insect, and diminished when it is in repose. It is, in fact, always in proportion to the energy of the respiration of the insect, which, having the power of opening or closing its spiracles at will, can lluus also increase or diminish its linht at pleasure, though whenever it respires it cannot prevent it from shining. some differences excepted, the luminous apparatus of Lampyris splendidula is similar to that of $L$. noctilue above describel; and it is probable that a similar organisation exints in the genus Pyrophorus.

2 l'hit. Truns. 1810, p. 281 . Mr. Macartney"s statement on this point is not very 
With respect to the remote cause of the luminous property of insects, philosophers are considerably divided in opinion. The disciples of modern chemistry have in general, with Dr. Darwin, referred it to the slow comhustion of some combination of phosphorus secreted from their fluids by an appropriate organization, and entering into combination with the oxygen supplied in respiration. This opinion is very plausibly built upon the ascertained existence of phosphoric acid as an animal secretion ; the great resemblance between the light of phosphorus in slow combustion and animal light; the remarkably large spiracula in glow-worms, and the decided connexion of their light with respiration; and upon the statement, that the light of the glow-worm is rendered more brilliant by the application of heat and oxygen gas, and is extingnished by cold and by hydrogen and carbonic acid gases. From these last facts Spallanzani was led to regard the luminous matter as a compound of hydrogen and carburetted hydrogen gas. Carradori having found that the luminous portion of the belly of the Italian glowworm (Pygolampis Itatica) shone in vacuo, in oil, in water, and when under other circumstances where the presence of oxygen gas was precluded, with Brugnatelli, ascribed the property in question to the imbibition of light separated from the food or air taken into the body, and afterwards secreted in a sensible form. ${ }^{1} \mathrm{Mr}$. Macartney having ascertained by experiment that the light of a glow-worm is not diminished by immersion in water, or increased by the application of heat ; that the substance affording it, though poetically employed for lighting the fairies' tapers ${ }^{2}$, is incapable of infiammation if applied to the flame of a candle or red-hot iron; and when senarated from the body exhibits no sensible heat on the thermometer's being applied to it - rejects the preceding hypothesis as unsatisfactory, but without substituting any other explanation ; suggesting, however, that the facts he ohserved are more favourable to the supposition of light being a 7uality of matter than a substance. ${ }^{3}$ Lastly, Dr. Todd finding that the luminous substance of Lampyris continues to shine when detached, sometimes for a longer and at others a shorter period, but never excceding twenty minutes, and that under mercury, various gases, water, and in vacuo, considers it solely as an effect of vitality. ${ }^{4}$

clear. He probably means that the insect will not shine in a dark place in the duytime, unless previously exposed to the solar light; for it is often seen to shine at night when it could have had no recent exposure to the sun.

1 Annal. di Chimica, xiii. 1797. Phil. Mug. ii. 80.

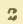

"And for night-tapers erop their waxen thighs, And light them at the fiery glow-worms' eyes."

3 Some experiments made by my firiend the Rev. R. Sheppard on the glow-worm are worthy of being recorded.-One of the receptacles being extracted with a penknife, continued luminous: but on being inmersed in camphorated spirit of wine. became immediately extinct. The animal with one of its receptacles uninjured. heing plunged into the same spirit, became apparently lifeless in less than a minute; but the receptacle continued luminous for five minutes, the light grindually disappearing:- Ilaving extracted the luminous matter from the receptacles, in two days they were healed, and filled with luminous matter as before. He found this matter to lose its luminous property, and become dry and glossy like gum, in abont two minutes; but it recovered it again on being moistened with stliva, and again lost it when dried. When the matter was extracted from two or three glow-worms, and covered with liquid gum-arabie, it continued luminous for upwards of a quarter of an hour.

$\$$ Plil. Trans. 18:4. 
Which of these opinions is the more correct $I$ do not pretend to decide. But though the experiments of Mr. Macartney seem fairly to bear him out in denying the existence of any ordinary combination of phosphorus in luminous insects, there exists a contradiction in many of the statements, which requires reconciling before final decision can be pronounced. The different results obtained by Forster and Spallanzani, who assert that glowworms shine more brilliantly in oxygen gas, and by Beckerheim, Dr. Hulme, and Sir H. Davy, who could perceive no such effect, may perhaps be accounted for by the supposition that in the latter instances the insects having been taken more recently, might be less sensible to the stimulus of the gas than in the former, in which perhaps their irritability was accumulated by a longer abstinence : but it is not so easy to reconcile the experiment of Sir H. Davy, who found the light of the glow-worm not to be sensibly diminished in hydrogen gas ${ }^{1}$, with those of Spallanzani and Dr. Hulme, who found it to be extinguished by the same gas, as well as by carbonic acid, nitrous and sulphuretted hydrogen gases. ${ }^{2}$ Possibly some of these contradictory results were occasioned by not adverting to the faculty which the living insect possesses of extinguishing its lights at pleasure. At the same time, however, it may be here observed, that as this luminous substance can be collected in considerable quantities, there can be no difficulty in deciding by chemical analysis whether it is really phosphoric or not; and that till this analysis has been made it is premature to build any hypothesis on the assumption of its being so, or to apply this epithet to it, as is so generally done.

The general use of this singular provision is not much more satisfactorily ascertained than its nature. I have before conjectured - and in an instance I then related it seemed to be so - that it may be a means of defence against their enemies. In different kinds of insects, however, it may probably have a different object. Thus in the lantern-flies (Fulgora), whose light precedes them, it may act the part that their name imports, enabling them to discover their prey, and to steer themselves safely in the night. In the fire-flies (Elater), if we consider the infinite numbers that in certain climates and situations present themselves everywhere in the niglat, it may distract the attention of their enemies or alarm them. And in the glowworm - since their light is usually most brilliant in the female; in some species, if not all, present only in the season when the sexes are destined to meet, and strikingly more vivid at the very moment when the meeting takes place ${ }^{3}$ - besides the above uses, it is most probably intended to conduct the sexes to each other. This seems evidently the design in view in those species in which, as in the common glow-worm ( $L$. noctiluca), the females are apterous. The torch which the wingless female, doomed to crawl upon the grass, lights up at the approach of night, is a beacon which unerringly guides the vagrant male to her "love-illumined form," however obscure the place of her abode. It has been objected, however, to this explanation, that - since both larva and pupa, as De Geer observed ${ }^{4}$, and the males shine as well as the females - the meeting of the sexes can scarcely be the object of their luminous provision. But this difficulty appear's to me easily surmounted. As the light proceeds from a peculiarly: organised substance, which probably must in part be elaborated in the larvia

1 Phil. Trans, 1810, p. 237.

5 Müller in Illig. Mlag. iv. 1-8.
2 Phil. Trans. 1801, p. 483.

4 iv. 49. 
and pupa states, there seems nothing inconsistent in the fact of some light being then emitted, with the supposition of its being destined solely for use in the perfect state: and the circumstance of the male having the same luminous property, no more proves that the superior brilliancy of the female is not intended for conducting him to her, than the existence of nipples and sometimes of milk in man proves that the breast of woman is not meant for the support of her offspring. We often see without being able to account for the fact, except on Sir E. Home's idea, that the sex of the ovum is undetermined ${ }^{1}$, traces of an organisation in one sex indisputably intended for the sole use of the other.

I am, \&c.

1 Phil. Trans. 1799, 157. 


\section{LETTER XYY.}

\section{ON THE HYBERNATION OF INSECTS.}

Ir insects can boast of enjoying a greater variety of food than many other tribes of animals, this advantage seems at first sight more than counterbalanced in our climates by the temporary nature of their supply. The graminivorous quadrupeds, with few exceptions, however scanty their bill of fare, and their carnivorous brethren, as well as the whole race of birds and fishes, can at all seasons satisfy, in greater or less abundance, their demand for food. But to the great majority of insects, the earth for nearly one half of the year is a barren desert, affording no appropriate nutriment. As soon as winter has stripped the vegetable world of its foliage, the vast hosts of insects that feed on the leaves of plants must necessarily fast until the return of spring: and even the carnivorous tribes, such as the predaceous beetles, parasitic Hymenoptera, Sphecina, \&c. would at that period of the year in vain look for their accustomed prey.

How is this difficulty provided for? In what mode has the Universal Parent secured an uninterrupted succession of generations in a class of animals for the most part doomed to a six months' deprivation of the food which they ordinarily devour with such voracity? By a beautiful series of provisions founded on the faculty, common also to some of the larger animals, of passing the winter in a state of torpor - by ordaining that the insect shall live through that period, either in an incomplete state of jts existence when its organs of nutrition are undeveloped, or, if the active epoch of its life has commenced, that it shall seek out appropriate $h y$ bernacula, or winter quarters, and in them fall into a.profound sleep, during which a supply of food is equally unnecessary.

In two of the four states of existence common to insects, in which different tribes pass the winter, namely, the egg and the pupa statc, the organs for taking food (except in some cases in the latter) are not developed, and consequently the animal is incapable of eating. The existence of insects in these states during the winter liffers from their existence in the same form in summer only in the greater length of its term. In both seasons food is alike unnecessary, so that their hybernation in these circunstances has little or nothing analogous to that of larger animals. With this, however, strictly accords their hybernation in the larva and imago states, in which their abstinence from food is solely owing to the torpor that pervades them, and the consequent non-expenditure of the vital powers.- I shall attend to the peculiarities of their hybernation in each of these states in the order just laid down; premising that we have yet much - to learn on this subject, no observations having been instituted respecting the state in which multitudes of insects pass the winter. 
It is probable that some insects of almost every order hybernate in the egg state; though that these must be eomparatively few in number, seems proved from two considerations : first, That the majority of insects assume the imago, and deposit their eggs in the summer and early part of autumn, when the heat suffices to hatch them in a short period; and secondly, That the eggs of a very large proportion of insects require, for their duc exclusion and the nutriment of the larve springing from them, eonditions oniy to be fulfilled in summer, as all those which are laid in young finits and seeds, in the interior and galls of leaves, in insects that exist only in summer, \&c. The insects which pass the winter in the egg state are chiefly such as have several broods in the course of the year, the females of the last of which lay eggs that, requiring more heat for their development tham then exists, necessarily remain dormant until the return of spring.

The situation in which the female insect places her egrs in order to their remaining there throngh the winter, is always admirably adapted to the degree of cold which they are capable of sustaining ; and to the ensuring a due supply of food for the naseent larva. Thus, with the former view, Acrida verrueivora and pany other insects whose eggs are of a tender consistence, deposit them deep in the earth out of the reach of frost ; and with the latter, Clisiocampa neustria, Liasiocampa castrensis, Hypogymna dispar, and some other moths, departing from the orlinary instinct of their congeners, which teaches them to place their eggrs upon the leaves of plants, fix theirs to the stem and branches only. That this variation of procedure has reference to the hythermation of the eggrs of these particular species, is abundantly obvious. Insects whose eggs are to be hatched in summer usually fix them slightly to the leaves upon which the larvæ are to feed. But it is evident that, were this plan to be adopted by those whose eggs remain through the winter, their progeny might be blown away along with the leaf to which they are attached, far from their destined food. These, therefore, choose a more stable support, and carefully fasten them, as has just been observed, either to the trunk or branches of the tree whose young leaves in spring are to be the food of the excluded larva. The latter plan is followed by the female of Clisiocampa neustria, which curiously gu:ns her eggs in bracelets round the twigs of the hawthorn, \&c. But another provision is demanded. Were these eggs of the usual delicate consistence, and to be attached with the ordinary slight gluten, they would have a poor chance of surviving the storms of rain and snow and hail to which for six or eight months they are exposed. They are therelore covered with a shell much more hard and thick than common; packed as closely as possible to each other; and the interstices are filled up with a tenacious gum, which soon hardens the whole into a solid mass almost capable of resisting a penknife. Thus secured, they defy the elements, and brave the blasts of winter uninjured. The female of Hypogymna dispar, whose eggs have a more tender shell, glues them in an oval mass to the stem of a trce (whence the German gardeners call the larræ Stamm-raupe), and then covers them with a warm non-conducting coat of hair's plucked from her own body, equally impervious to cold and wet.

Another of those beautiful relations between objects at first sight apparently unconnected, which at every step reward the votaries of lintomology, is afforded by the coincilence between the period of the hatching in spring of eggs deposited before winter, and of the leafing of the trees upon which they have been fixed, and on whose foliage the larva are to 
feed ; which two events, requiring exactly the same temperature, are always simultaneous. Of this fact I had a striking exemplification in the spring of 1816. On the 20th of February, observing the twigs of the birches in the Hull Botanic Garden to be thickly set, especially about the buds, with minute oval black eggs of some insect witl which I was unacquainted, I brought home a small branch, and set it in a jar of water in my study, in which is a fire daily, to watch their exclusion. On the 28th of March I observed that a numerous brood of Aphides (not $A$. betula, as the wings were without the dark bands of that species) had been hatched from them, and that two or three of the lower buds had expanded into leaves, upon the sap of which they were greedily feasting. This was full a month before either a leaf of the birch appeared, or the egg of an Aphis was disclosed in the open air. To view the relation of which I am speaking with due admiration, you must bear in mind the extremely different periods at which many trees acquire their leaves, and the consequent difference demanded in the constitution of the eggs which hybernate upon dissimilar species, to ensure their exclusion, though acted upon by the same temperature, earlier or later, according to the early or late foliation of these species. There is no visible difference between the conformation of the eggs of the Aphis of the birch and those of the Aphis of the ash : yet in the same exposure those of the former shall be hatched, simultaneously with the expansion of the leaves, nearly a month earlier than those of the latter; thus demonstrably proving that the hybernation of these eggs is not accidental, but has been specially ordained by the Author of nature, who has conferred on those of each species a peculiar and appropriate organisation.

A nuch greater number of insects pass the winter in the pupa than in the egg state; probably nine-tenths of the extensive order Lepidoptera, many in Hymenoptera, and several in other orders. In placing these pupæ in security from the too great cold of winter and the attacks of enemies, the larvæ from which they are to be metamorphosed exhibit an anxiety and ingenuity evidently imparted to them for this express design. A few are suspended without any covering, though usually in a sheltercd situation. But by far the larger number are concealed under leaves, in the crevices or in the trunk of trees, \&c., or inclosed in cocoons of silk or other materials, and often buried deep under ground out of the reach of frost. One reason why so many lepidopterous insects pass the winter as pupæ has been plausibly assigned by Rösel, in remarking that this is the case with all the numerous species which feed on annual plants. As these have no local habitation, dying one year and springing up from seed in another quarter the next, it is obvious that eggs deposited upon them in autumn would have no chance of escaping destruction; and that even if the larvæ were to be hatched before winter and to hybernate in that state, they would have no certainty of being in the neighbourhood of their appropriate food the next spring. By wintering in the pupa state, these iccidents are effectually provided against. The perfect insect is not ready to break forth until the food of the young, which are to proceed from its eggrs, is sprung up.

To the insects which hybernate in the larva state, of course belong, in the first place, all those which exist under that form more than one year; as many Melolonthe, Elateres, Cerambyces, Buprestes, and several species of Libellula, Ephemera, \&c. There are also many larvæ, which though their term of life is not a year, being hatched from the egg in autumn. 
necessarily pass the winter in that state, as those of several Anobia and other wood-boring insects; of Semasia Wreberane and others of the same family; of the second broods of several butterflies, \&c. Many of these residing in the ground, or in the interior of trees, need no other hybernacula than the holes which they constantly inhabit; some, as the aquatic larvæ, merely hide themselves in the sides or muddy bottom of their native pools; while others seek for a retreat under moss, dead leaves, stones, and the bark of decaying trees. Most of these can boast of no better winter quarters than a simple unfurnished hole or cavity ; but a few, more provident of comfort, prepare themselves an artificial habitation. With this view the larva of Cossus ligniperda, as formerly observed in describing the habitations of insects, forns a covering of pieces of wood lined with fine silk; those of Hepiolus Humuli, Xylina radicen, and some other moths, excavate under a stone a cavity exactly the size of their hodies, to which they give all round a coating of silk $^{1}$; and the larvæ of Pieris Cratcegi inclose themselves in autumn in cases of the same material ${ }^{2}$, and thus pass the cold season, in small societies of from two to twelve, under a common covering formed of leaves. Bonnet mentions a trait of the cleanliness of these insects which is almost ludicrous. He observed in one of these nests a sort of sack containing nothing but grains of excrement; and a friend assured him that he had seen one of these caterpillars partly protrude itself out of its case, the hind feet first, to eject a similar grain; so that it would seem the society have on their establishment a scavenger, whose business it is to sweep the streets and convey the rejectamenta to one grand repository $!^{3}$ This, however singular, is rendered not improbable from the fact that beavers dig in their habitations holes solely destined for a like purpose ${ }^{4}$, as also do badgers.

A very considerable number of insects hybernate in the perfect state, chiefly of the orders Coleoptera, Hemiptera, Hymenoptera, and Diptera, and especially of the first. Vanessa Urtica, Io, and a few other lepidopterous species, with a small proportion of the other orders, occasionally survive the winter; but the bulk of these are rarely found to hybernate as perfect insects. Of coleopterous insects, Sclrmid, to whom we are indebted for some valuable remarks on the present subject ${ }^{5}$, says that he never found or heard of any entomologist finding a hybernating individual of the common cock-chafer (Melolontha vulgaris), or of the stag-beetle (Lucanus Cervus) ; and suggests that it is only those insects which exist but a short period as larvæ, as most of the tribes of weevils, lady-birds, \&c., that survive the winter in the perfect state; while those which live more than one year in the larva state, as the species just mentioned, are deprived of this privilege.

1 Brahm. Ins. Kal. ii. 59. 118.

2 I have reason to think that the larra of some species of Hemerobius thus proLect themselves by a net-like case of silken threads; at least I found one to-day (Deccmber 3rd, 1816) inclosed in a case of this description concealed under the bark of a tree; and it is not very likely that it could be a cocoon, both because the inhabitant was not a pupa, which state, according to Reammur, is assumed soon after the cocoon is fabricated (iii.385.), and because the same author describes the cocoons of these insects as perfectly spherical and of a very close texture (384.), while this was oblong, and the net-work with rather wide meshes.

3 Euv. ii. 72.

4 Ibid. jx. $16 \%$.

5 Illig. Mag. i. 209-228. 
Towards the close of autumn the whole insect world, particularly the tribe of beetles, is in motion. A general migration takes place : the various species quit their usual haunts, and betake themselves in search of secure liybernacula. Different species, however, do not select precisely the same time for making this change of abode. Thus many lady-birds, field-bugs, and flies are found out of their winter quarters even after the commencement of frost; while others, as Schmid has remarked, make good their retreat long before any severe cold has been felt; in fact, I am led to believe, from my own observations, that this is the case with the majority of coleopterous insects; and that the days which they select for retirin to their bybernacula are some of the warmest days of autumn, when they may be seen in great numbers alighting on walls, rails, pathways, \&c., anil running into crevices and cracks, evidently in scarch of some object very different from those which ordinarily guide their movements. I have noticed this assemblage in different years, but more particularly in the autumn of 1816. Walking on the banks of the Humber on the Itth of Octolier about noon, - the day bright, calm, and delieiously mild, Fahrenheit's thermometer $58^{\circ}$ in the shade, - ny attention was first attracted by the pathways swarming with numerous species of rove-beetles (Staphylinns, Oxytelus, Alcochara, \&c.), which kept incessantly alighting, and hurrying about in every direction. On further examination I found a similar assemblage, with the addition of multitudes of other beetles, Haltice, Nitidula, Thyncophora, Cryptophagi, \&c., on every post and rail in my walk, as well as on a wall in the neighbourhood; and on removing the decaying mortar and bark, I found that some had already taken up their abode in holes, from their situation, with their antenna folded, evidently meant for winter quarters. I am not aware that any author has noticed this remarkable congregation of coleopterous insects previously to hybernating, whieh it is so difficult to explain on any of the received theories of torpidity, except the pious Lesser, who so expressly alludes to it, and without quoting any other authority, that he would seem to have derived the fact from his own observation. ${ }^{1}$

The site chosen by different perfect insects for their hybernacula is very various. Some are content with insinuating themselves under any large stone, a collection of dead leaves, or the moss of the sheltered side of an old wall or bank. Others prefer for a retreat the lichen or ivy-covered interstices of the bark of old trees, the decayed bark itself, especially that near the roots, or bury themselves decp in the rotten trunk; and a very great number penetrate into the earth to the depth of screral inches. The aquatic tribes, such as Dytisci, Mydrophili, \&c., burrow into the mud of their pools; but some of these are occasionally met with under stones, bark, \&.c. In every instance the selected dormitory is admirably adapted to the constitution, mode of life, and wants of the occupant. Those insects which can bear considerable cold without injury are careless of providing

1 Lesser, 1. i. 256. Lyonet inserts a note to explain that Lesser's remark is to be understood only of such insects as live in societies; and adds, that solitary species do not assemble to pass the winter together. Lesser, however, says nothing about these insects passing the winter together, as his translator erroneously understands him; but merely that they assemble as if preparing to retire for the winter, which my own observations, as above, confirm. His expression in the original German i: " Gleichsim als wenn sie sich zu ihrer Winter-ruhe fertig machen wolten." Edit. Frankfurt und Leipsig, 173s, p. 152. 
other than a slight covering; while the more tender species either enter the earth beyond the reach of frost, or prepare for themselves artificial cavities in substances, such as moss and rotten wood, which conduct heat with difficulty, and defend them from an injuriously low temperature. It does not appear that any perfect insect has the faculty of fabricating for itself : 1 winter abode similar to those formed of silk, \&c., by some larvæ. Schmid, indeed, has mentioned finding Rhagium mordar and Inquisitor in such abodes, constructed, as he thought, of the inner bark of trees; but these, as Illiger has suggested, were more probably the deserted dwellings of lepidopterous larvx, of which the beetles in question had taken possession. ${ }^{1}$ Nost insects place themselves in their hybernacula in the attitude which they ordinarily assume when at rest; but others choose a position peculiar to their winter abode. So nost of the ground beetles (Eutrechina) alhere by their claws to the under side of the stone which serves for their retreat, their backs being next to the ground; in which posture, probably, they are most effectually protected from wet. Gyrohypnus sanguino!entus, and other rove-beetles of the same genus, coils itself up like a snake, with the head in the centre.

The majority of insects pass the winter in perfect solitude. Occasionally, however, several individuals of one species, not merely of such insects as Anchomenus prasinus, a beetle, Pyprhocoris apterus, a bug, \&c., which usually in summer also live in a sort of society, but of others which are never seen thus to associate, as Haltiea oleracea, Carabus intricalus, and several Coceinello, \&c., are found crowded together. This is perhaps often more throngh accident than design, as individuals of the same species are frequently met with singly; yet that it is not wholly accidental seems proved by the fact that such assemblages are generally of the same genus and even species. Sometimes, however, insects of dissimilar genera and even orders are met with together. Schmid once in February found the rare Lomechusa strumosa torpid in an ant-hill, in the midst of a conglomerated lump of ants, with which it was closely intertwined. ${ }^{2}$

By far the greater proportion of insects pass the winter only in one or other of the several states of egg, pupa, larva, or imago, but are never found to hybernate in more than one. Some species, however, depart from this rule. Thus Aphis Rosce, Cardui, and probably many others of the genus, hybernate both in the egrg and perfect state $^{3}$; Cynithia Cardui, Goneptery.x Rhamni, and some other species, usually in the pupa, but often in the perfect state also ; and Vanessa Io, according to the accurate Brahm, in the three states of egg, pupa, and imago. ${ }^{4}$ It is probable that in these instances the perfect insects are females, which, not having been impregnated, have their term of life prolonged beyond the ordinary period.

The first cold weather, after insects have entered their winter quarters, produces effects upon them similar to those which occur in the dormouse, hedgehor, and others of the larger animals subject to torpor. At first a partial benumbment takes place; but the insect, if touched, is still capable of moving its organs. But as the cold increases all the animal functions cease. The insect breathes no longer, and has no need of a supply of air ${ }^{5}$; its nutritive secretions cease; no more food is required; and it has all the

1 Illig. Mag. i. 216.

2 Ibid. i. 491.

3 Kyber in Germar, Magazin der Entomologie, ii. 2.

I Iis. Kal. ii. 188.

5 Spallanzani, Rapports de l'Air, \&c., i. 30. 
external symptoms of death. In this state it continues during the existence of great cold, but the degree of its torpidity varies with the temperature of the atmosphere. The recurrence of a mild day, such as we sometimes have in winter, infuses a partial animation into the stiffened animal: if disturbed, its limbs and antennæ resume their power of extension, and even the faculty of spirting out their defensive fluid is re-acquired by many beetles. ${ }^{1}$ But however mild the atmosphere in winter, the great bulk of hybernating insects, as if conscious of the deceptious nature of their pleasurable feelings, and that no food could then be procured, never quit their quarters, but quietly wait for a renewal of their insensibility by a fresh accession of cold.

On this head I have had an opportunity of making some observations which, in the pancity of recorded facts on the hybernation of insects, you may not be sorry to have laid before you. The 2nd of December, 1816, was even finer than many of the preceding days of the season, which so happily falsified the predictions that the unprecedented dismal summer would be followed by a severe winter. The thermometer was $46^{\circ}$ in the shade; not a breath of air was stirring; and a bright sun imparted animation to troops of the winter gnat (Thichocera hiemalis), which frisked under every bush; to numerous Psychode; and even to the flesh-fly, of which two or three individuals buzzed past me while digging in my garden. Yet though these insects, which I shall shortly advert to as exceptions to the general rule, were thus active, the heat was not sufficient to induce their hybernating brethren to quit their retreats. Removing some of the dead bark of an old apple-tree, I soon discovered several insects in their winter quarters. Ot the little beetle Dromius quadrinotatus, I found six or eight individuals, and all so lively, that, though remaining perfectly quiet in their abode until disturbed, they ran about with their ordinary activity as soon as the covering of bark was displaced. The same was the case with a colony of earwigs. Two or three individuals of Dromins quadrimaculatus showed more torpidity. When first uncovered, their antennæ were laid back; and it was only after the sun had shone some seconds upon them that they exhibited symptoms of animation, and, after stretching out these organs, began to walk. Close by them lay a single weevil (Anthonomus Pomorum), but in so deep a sleep that at first I thought it dead. It gave no sign of life when placed on my hand, quite hot with the exercise of digging; and it was only after being kept there some seconds, and breathed upon several times, that it first slowly unfolded its rostrum, and then its limbs. It deserves remark, that all these insects, thus differently affected, were on the same side of the tree, under a similar covering of bark, and apparently equally exposed to the sun, which shone full upon the covering of their retreat. ${ }^{2}$

1 Schmid in Illig. Mag. i. 222.

2 Since writing the above, I have had another opportmnity of confirming the observations here made. The last week of January, 1817 in the neighbourhood of IIull, was most delicious weather - calm, sunny, dry, and genial - the wind southwest, the thermometer from $47^{\circ}$ to $52^{\circ}$ every day, and at night rarely below $40^{\circ}$; in fact, a week much finer than we can often boast of in May: the $2 \overline{7}^{-1}$ of the month was the most delightful day of the whole: the air swarmed with Trichocera hicmalis, Psychoda, and numerous other Diptcra, and the bushes were hung with the lines of the gossamer-spider as in autumn. Yet with the exception of Aphodius contuminatus, I did not observe a single coleopterous insect on the wing, nor even an individual tempted to crawl on the trunks of the trees, under the dead bark of which I found many in a very lively state. Five or six inclividuals of Haltica Nemarum 
All insects, however, do not undergo this degree of torpidity. In fact, there are some, though but few, which cannot, at least in our climate, strictly be said to hybernate, understanding by that term passing the winter in one selected situation in a greater or less degree of torpor, without food. Not to mention Cheimatobia brumata, and some other moths, which are disclosed from the pupæ in the middle of winter, and can therefore be scarcely regarded as exceptions to the rule, some insects are torpic only in very severe weather, and on fine mild days in winter come out to eat. This is the case with the larva of Euprepia fuliginosa ${ }^{1}$; and Lyonet asserts that there are many other caterpillars which eat and grow even in the midst of slight frost. ${ }^{2}$ Amongst perfect insects, troops of Trichocera hiemalis, the gnat whose choral dances have been before described, may be constantly seen gambolling in the air in the depth of winter, when it is mild and calm, accompanied by the little Psychoda, so common in windows, several Muscidee, spiders, and occasionally some Aphodii and Staphylinidee: and the societies of ants, as well as their attendant Aphides, are in motion and take more or less food during the whole of that season, when the cold is not intense. The younger Huber informs us that ants become torpid only at $2^{\circ}$ Reaum. below freezing ( $27^{\circ}$ Fahrenheit), and apparently endeavour to preserve themselves fron the cold, when its approach is gradual, by clustering together. When the temperature is above this point they follow their ordinary habits (he has seen them even walk upon the snow), and can then obtain the little food which they require in winter from their cows, the Aphides, which, by an admirable provision, become lethargic at precisely the same degree of cold as the ants, and awake at the same period with them. ${ }^{3}$ Humboldt also found insects upon the Cordilleras, above the limits of snow, which, although not natives of this altitude, retained their vivacity at this low temperature. ${ }^{4}$

Lastly, there are some few insects which do not seem ever to be torpid, as Podura nivalis L., Boreus hiemalis Latr., and the singular apterous insect, first described by Dalman, Chionea araneïles ${ }^{5}$, all of which run with agility on the snow itself; and which last, both from its spider-like form and sin. gular habitat, must, as Macquart has well observed ${ }^{6}$, have caused its fortunate discoverer as much astonishment as that felt by the botanist who first found the red-coloured Protococcus nivalis (whatever may be decided as to its being a plant or an animalcule) in a similar situation; or, as may be added, that of M. Lefebvre on first observing the MIantis (Eremiophila),

were still very lethargic; and two of Geotrupes stercorarius, which I accidentally dug up from their liybernacula in the earth, at the depth of six or eight inches, though the Acari upon them were quite alert, exhibited every symptom of complete torpor.

1 Brabin. Ins. Kal. ii. 31.

2 Lesser, 1. i. 255.

3 Recherches, 202. In digging in my garden on the 26th of January, 1817, I turned up in three or four places colonies of MIyrmica rubra Latr. in their winter retreats, each of which comprised apparently one or two hundred ants, with several larve as big as a grain of mustard, closely clnstered together, occupying a cavity the size of a hen's egr, in tenacious clay, at the depth of six inches from the surface. They were very lively; but though Fahrenheit's thermometer stood at $47^{\circ}$ in the shade, I did not then, nor at any other time during the very mild winter, see a single ant out of its hybernaculum.

4 Burmeister, Manual of Ent. 50 s.

5 Kongl. Vet. Acad. Hundling. 1816, 104.

- Dipteres, i. 74. 
mentioned in a former letter, living in an absolute solitude in the desert of Africa.

The common hive-bee, too, is probably never, strictly speaking, torpid, though with regard to the precise state in which it passes the winter a considerable difference of opinion has obtained.

Nany authors have conceived that it is the most natural state of bees in winter to be perfectly torpid at a certain degree of cold, and that their partial reviviscency, and consequent need of food in our climate, are owing to its variableness and often comparative mildness in winter ; whence they have advised placing bees during this season in an ice-house, or on the north side of a wall, where the degree of cold being more uniform, and thus their torpidity undisturbed, they imagine no food would be required. So far, however, do these suppositions and conclusions seem from being warranted, that Huber expressly affirms that, instead of being torpid in winter, the heat in a well-pcopled hive continues $+24^{\circ}$ or $25^{\circ}$ of Reaumur $\left(86^{\circ}\right.$ or $88^{\circ}$ Fahrenheit), when it is several degrees below zero in the open air ; that they then cluster together and keep themselves in motion in order to preserve their heat ${ }^{1}$; and that in the depth of winter they do not cease to ventilate the hive by the singular process of agitating their wings before described. ${ }^{2}$ He asserts also that, like Reaumur, he has in winter found in the combs brood of all ages; which, too, the observant Bonnet says he has witnessed ${ }^{3}$; and which is confirmed by Swammerdam, who expressly states that bees tend and feel their young even in the nidst of winter. ${ }^{4}$ To all these weighty anthorities may be added that of John Hunter, who, as before noticed, found a hive to grow lighter in a cold than in a warm week of winter; and that a hive from November 10th to February 9th lost more than four pounds in weight ${ }^{5}$; whence the conclusion seems inevitable, that bees do eat in winter.

On the other hand, Reaumur adopts (or rather, perhaps, has in great measure given birth to) the more commonly received notion, that bees in a certain degree of cold are torpid and consume no food. These are his words:- "It has been established with a wisdom which we cannot but admire, - with that wisdom with which every thing in nature has been made and ordained, - that during the greater part of the time in which the combly furnishes nothing to bees, they have no longer need to eat. The cold which arrests the vegetation of plants, which deprives our fields and meadows of their flowers, throws the bees into a state in which nourishment ceases to be recessary to them: it keeps them in a sort of torpidity (engourdissement), in which no transpiration from them takes place; or, at least, during which the quantity of that which transpires is so inconsiderable that it camnot be restored by aliment without their lives being endangcred. In winter, while it freezes, one may observe without fear the interior of hives that are not of glass; for we may lay them on their sides, and even turn them bottom upwards, without putting any bee into motion. We see the bees crowded and closely pressed one against the other : little space then suffices for them." 6 In anqther place, speaking of the custom in some countries of putting bee-hives during winter into out-houses and cellars, he says that in such situations the air, though

1 IInber, i. 134.

3 Bonnet On Bees, 104.

5 Plil. Trans. $1790,161$.
2 Ibid. ii. 344.358.

4 Huber, i. 354.

6 Reaum, v. 667 . 
more temperate than ont of doors during the greater part of winter, "is yet sufficiently cold to keep the bees in that species of torpidity which does away their need of eating." And lastly, he expressly says that the mitcler the weather, the more risk there is of the bees consuming their honey before the spring, and dying of bunger; and confirms his assertion by an account of a striking experiment, in which a hive that he transferred during winter into his study, where the temperature was usually in the day $10^{\circ}$ or $12^{\circ} \mathrm{R}$. above freezing $\left(54^{\circ}\right.$ or $59^{\circ} \mathrm{F}$.), though provided with a plentiful supply of honey, that if they had been in a garden would have served them past the end of April, had consumed nearly their whole stock before the end of February. ${ }^{2}$

Now, how are we to reconcile this contradiction? - for, if Huber be correct in asscrting that in frosty weather bees agitate themselves to keep off the cold, and ventilate their hive, - if, as both he and Swammerdam state, they feed their young brood in the depth of winter, - it seems inpossible to adnit that they ever can be in the torpid condition which Reaumur supposes, in which food, so far from being necessary, is injurious to them. In fact, Reaumur himself in another place informs us, that bees are so infinitely more sensible of cold than the generality of insects, that they perish when in numbers so small as to be unable to generate sufficient animal heat to counteract the extcrnal cold, even at $11^{\circ} \mathrm{R}$. above fieezing ${ }^{8}$ $\left(57^{\circ} \mathrm{F}\right.$ ) ; which corresponds with what Huber has observed (as quoted above) of the high temperature of well-peopled hives, even in very severe weather. We are forced, then, to conclude that this usually most accurate of observers has in the present instance been led into error, chicfly, it is probable, from the clustering of bees in the hives in cold weather; but which, instead of heing, as he conceived, an indication of torpidity, would seem to be intended, as Huber asserts, as a preservative against the benumbing effects of cold.

Bees, then, do not appear to pass the winter in a state of torpidity in our climates, and probably not in any others. Populous swarms inhabiting hives formed of the hollow trunks of trees, used in many northern regions, or of other materials that are bad conductors of heat, seem able to generate and keep up a temperature sufficient to counteract the intensest cold to which they are ordinarily exposed. At the same time, lowever, I think we may infer, that though bees are not strictly torpid at that lowest degrec of heat which they can sustain, yet that when exposed to that degree they consume considerably less food than at a higher temperature; and consequently, that the plan of placing hives in a north aspect in sunny and mild winter's may be adopted by the apiarist with advantage. John Hunter's experiment, incleed, cited above, in which he found that a hive grew lighter in a cold than in a warm week, seems opposed to this conclusion; but an insulated observation of this kind, which we do not know to have been instituted with a due regard to all the cireumstances that required attention, must not be allowed to sct aside the striking facts of a contrary description recorded by Reaumur and corroborated by the almost universal sentiment of writers on bces. After all, however, on this point, as well as on many others connected with the winter economy of these endlessly-

1 Reaum. v. 682.

2 Ibid. 668.

3 Ibid. 678. Compare also 673. 
wonderful insects, there is evidently much yet to be observed, and many doubts which can be satisfactorily dispelled only by new experiments. ${ }^{1}$

The degree of cold which most insects in their different states, while torpid, are able to endure with impunity is very various; and the habits of the different species, as to the situation which they select to pass the winter, are regulated by their greater or less sensibility in this respect. Many insects, though able to sustain a degree of cold sufficient to induce torpidity, would be destroyed by the freezing temperature, to avoid which they penetrate into the earth or hide themselves under non-conducting substances; and there can be little doubt that it is with this view that so many species while pupæ are thus secured from cold by cocoons of silk or other materials. Yet a very great proportion of insects, in all their states, are necessarily subjected to an extreme degree of cold. Many eggs and pupæ are exposed to the air without any covering; and many, both larvæ and perfect insects, are sheltered too slightly to be secure from the frost. This they are able to resist, remaining unfrozen though exposed to the sererest cold, or, which is still more surprising, are uninjured by its intensest action, recovering their vitality even after having been frozen into lumps of ice.

The eggs of insects are filled with a fluid matter, included in a skin infinitely thinner than that of hens' eggs, which John Hunter found to freeze at about $15^{\circ}$ of Fahrenheit. Yet on exposing several of the former, including those of the silk-worm, for five hours to a freezing mixture which made Fabrenheit's thernometer fall to $38^{\circ}$ below zero, Spallanzani found that they were not frozen, nor their fertility in the slightest degree im-

1 Mr. Newport from his numerous experiments on the temperature of the interior of bee-hives in winter, recorded in his valuable paper in the Philosoplical Transactions, "On the Temperature of Insects," has come to the conclusion that Huber is altogether in error in assigning a heat of $86^{\circ}$ or $88^{\circ} \mathrm{Fahr}$. to a populous hive, which, he contends, has its temperature sometimes (though rarely) lower than that of the freezing point (p. 303.), and in the winter months does not average more than from 7 to 9 degrees above that of the atmosphere, or about $52^{\circ}$ (Table XVI. p. 335.): though merely tapping on the outside of the hive, by exciting the bees, will, at any time, greatly increase the heat: in one instance (Feb. 2.) to $102^{\circ}$, when the temperature of an adjoining hive was only $48^{\circ} .5$ (p. 304.); and it is from this circumstance that he supposes Huber's error to have arisen, as the mere excitement caused by in. troducing a thermometer is sufficient to raise the heat to the point $\left(86^{\circ}\right.$ or $\left.88^{\circ}\right)$ which that observer mentions. Mr. Newport adnits that hive-bees are never strictly torpid, but pass the winter in a state of hybernating sleep, liable to constant interruption by considerable external variations of temperature or accidental excitement (p. 300.). - Wilhout entering on a discussion which would require much greater space than can here be given, it may be remarked that something nore than thermometrical observations seem required, before the express assertions. as above quoted, of such careful observers as Swammerdam and Bonnet-that bees feed and tend their young even in the midst of winter, and those of Huber, that bees then cluster together, and keep themselves in motion in order to preserve their heat, that they do not cease to ventilate the hive, and, on an emergency, set themselves to work in the middle of January - can be put aside as wholly unfounded. It may be true that Huber was deceived as to the actual thermonetrical heat of the interior of his hive, yet the result of Mr. Newport's own observations shows that bees preserve their activity, and even leave the hive and collect pollen, when the external temperature is $40^{\circ} .38$, and that of the hive only $47^{0.28}$ (Table XVI, Nov 6.), and they may, consequently, feed their brood, and attend to the usual interior occupations of the hive, at a temperature not lower than this, to which lower temperature it does not appear likely, from Mr. Newport's observations, the interior of their hives often descends in our winters. 
paired. Others were exposed even to $56^{\circ}$ below zero, without being injured. ${ }^{1}$

A less degree of cold suffices to freeze many pupæ and larvæ, in both which states the consistency of the animal is almost as fluid as in that of the egg. Their vitality enables them to resist it to a certain extent, and it must be consilerably below the freezing point to affect them. The winter of 1813-14 was one of the severest we had had for many years, Fahrenheit's thermometer having been more than once as low as $8^{\circ}$ when the ground was wholly fiee from snow ; yet almost the first objects which I observed in my garden, in the commencement of spring, were numbers of the caterpillar's of the gooseberry-moth (Abraxas grossulariata), which, though they had passed the winter with no other shelter than the slightly projecting rim of some large garden-pots, were alive and quite uninjured; and these and many other larvæ never in my recollection were so numerous and destructive as in that spring: whence, as well as from the corresponding fact recorded, with surprise, by Boerhaave, that insects abounded as much after the intense winter of 1709, during which Fahrenheit's thermometer fell to $0^{\circ}$, as after the mildest season, we may see the fallacy of the popular notion, that hard winters are destructive to insects.?

But though many larvæ and pupæ are ahle to resist a great degree of cold, when it increases to a certain extent they yield to its intensity and become solid masses of ice. In this state we should think it impossible that they should ever revive. That an animal whose juices, muscles, and whole body have been subjected to a process which splits bombshells, and converted into an icy mass that may be snapped asunder like a piece of glass, should ever recover its vital powers, seems at first view little less than a miracle; and if the reviviscency of the wheel animal (Rotifer vulgaris) and of snails, \&c., after years of desiccation, had not made us familiar with similar prodigies, might have been pronounced impossible; and it is probable that many insects when thus frozen never do revive. Of the fact, however, as to several species, there is no doubt. It was first noticed by Lister, who relates that he had found caterpillars so fiozen, that when dropped into a glass they chinked like stones, which nevertheless revived. ${ }^{3}$ Reaumur, indeed, repeated this experiment without success; and found that when the larvæ of Chethocampa Pityocampa were frozen into ice by a cold of $15^{\circ} \mathrm{R}$, below zero ( $2^{\circ} \mathrm{F}$. below zero), they could not be made to revive. ${ }^{4}$ But other trials have fully confirmed Lister's observations. My friend Mr. Stickney, before mentioned as the author of a valuable Essay on the Grub (larva of Tipula oleracea) - to ascertain the effect of cold in destroying this insect, exposed some of them to a severe frost, which congealed them into perfect masses of ice. When broken, their whole interior was found to be frozen. Yet several of these resumed their active powers. Bonnet had precisely the same result with the pupæ of Pontia Brassica, which, by exposing to a frost of $14^{\circ} \mathrm{K}$. below zero $\left(0^{\circ} \mathrm{F}\right.$ ), became lumps of ice, and yet produced butterflies ${ }^{5}$; and in an experiment made during Sir John Koss's voyage on the caterpillars of a moth (Laria Rossii) two of them revived, and one assumed the

\section{Tracts, 22.}

2 Vid. Spence in Transactions of the Horticult. Soc. of London, ii. 148. Compare Reaum. ii. 141.

3 Lister, Goedart, De Insectis, 76.

4 Reaum. ii. 142.

6 Euvres, vi. 12. 
imago state, after being four times in suecession exposed to a cold of $40^{\circ}$ below zero, and four times revivified by being brought into the warm atm mosphere of the eabin. Indeed, the circumstance that animals of a much more complex organisation than insects, namely serpents and fishes, have been known to revive after being frozen, is suffieient to dispel any doubts on this head. John Hunter, though himself unsuceessful in his attempts to reanimate carp and other animals that had been frozen, eonfesses that the fact itself is so well authenticated as to admit of no question. ${ }^{1}$

On what principle a faculty so extraordinary and so contrary to our eommon conceptions of the nature of animal life depends, I shall not attempt to explain. Nor ean anything very satisfactory be advanced with regard to the source of the power which many insects in some states, and almost all in the erg state, have of resisting intense degrees of cold without becoming frozen. It is elear that the usual explanation of the same faculty to a less degree in the warm-blooded animals - the constint production of animal heat from the calorie set free in the deeomposition of the respired air - will not avail us here. For many large larvæ, as Reaumur has observed, are destroyed by a less degree of cold than smaller species whose respiratory organisation is necessarily on a much less extensive scale; and the eggs of inscets, in which, though they probably are in some degree acted upon by the oxygen of the atmosphere, nothing like respiration takes place, can endure a much greater intensity of cold than either the larvæ or pupæ produced from then.

Nor can we refer the effect in question to the thinness or thiekness the greater or less non-conducting power-of the skin of the animal. Reammur found that the subterranean pupæ of many moths perished with a cold of $7^{\circ}$ or $8^{\circ} \mathbf{R}$. below zero $\left(14^{\circ} \mathrm{F}\right.$.), while the exposed pupæ of Pontia Rrassice and other species endured $15^{\circ}$ or $16^{\circ}$ without injury ${ }^{2}$; (a proof, by the way, that the different economy of these inseets, as to their choice of a situation in their state of pupre, is regulated by their power of resisting eold); but no difference in the substance of the exterior skin is perceptible. And the eggs of insects have usually thinuer skins than pupx, and yet they are unaffected by a degree of cold much superior.

In the present state, then, of our knowledge of animal physiology, we must confess our ignorance of the cause of these phenomena, which scem never to have been sufficiently adverted to by general speculators on the nature of animal heat. We nay conjecture, indeed, either that they are owing to some peculiar and varying attraction for caloric inherent in the fluids which compose the animal, and which in the egg state, like spirit of wine, resist our utmost producible artificial cold ; or that, as John Hunter seems to infer, with respect to a similar faculty in a minor degree in the hen's egg, the whole are to be referred to some imknown power of vitality. The latter seems the most probable supposition; for Spallanzani found that the blood of marmots, which remains fluid when they are exposed to a cold several degrees below zero of Fahrenheit, freezes at a much bigher temperature when drawn from the animal ${ }^{3}$; and it is reasonable to con-

1 Observations on the Animal Economy, 99.

2 Reaum. ii. 146-.

3 Rapports de l'Air, Sc. ii. 215. 
jeeture that the same result would follow if the fluids filling the eggs of insects were collected separately, and then exposed to severe cold.

Spring is, of course, the period when insects shake off the four or five months' sleep which has sweetly banished winter from their calendar, quit their dormitories, and again enter the active scenes of life. It is impossible to deny that the increased temperature of this season is the immediate cause of their reappearance; for they leave their rctreats much earlier in forward than in backward springs. Thus in the early spring of 1805 (to me a memorable one, since in it I began my entomological career, and had anxiously watched its first approaches in order to study practically the science of which I had gained some theoretical knowledge in the winter) insects were generally out by the midlle of March; and before the 30 th, I find, on referring to my entomological journal, that I had taken and investigated (I scarcely need add, not always with a correct result) fifty-eight coleopterous species; while in the untoward spring of 1816 I did not observe even a bee abroad until the 20th of April ; and the first butterfly that I saw did not appear until the 26th.

There are, however, circumstances connected with this reappearance, which seem to prove that something more than the mere sensation of warmth is concerned in causing it. I shall not insist upon the remarkable fict which Spallanzani has noticed, that insects reappear in spring at a temperature considerably lower than that at which they retired in autumn; because it may be plausibly enough explained by reference to their increased irritability in spring, the result of so long an abstinence from food, and their consequent augmented sensibility to the stimulus of heat. But if the mere perception of warmth were the sole cause of insects ceasing to hybernate, then we might fairly infer, that species of apparently similar organisation, and placed in similar circumstances, would leave their winter quarters at the same time. This, however, is far from being the case. Reaumur observed that the larvæ of Melitra Cinxin quitted their nest a full month sooner than those of Porthesia Chrysorrhea. ${ }^{1}$ The reason is obvious, but cannot be referred to mere sensation. The former live on grass and on the leaves of plantain, which they can meet with at the beginning of March - the period of their appearance; the latter eat only the leaves of trees which expand a month later. It night, indeed, be still contended, that this fact is susceptible of explanation by supposing that the organisation of these two species of larva, though apparently similar, is yet in fact different, that of the one being constituted so as to be acted upon by a less legrec of heat than that of the other; and this solution would be satisfactory if the torpidity of these larva were uninterrupted up to the very period at which they quit their nest. But facts do not warrant any such supposition. You have seen that the temperature of a mild day, even in winter, awakens many insects from their torpidity, though without inducing them to leave their hybernacula ; and it is thercfore highly improbable that the larwa of $P$. Chrysorrhea should not often have their torpid state relaxed during the month of March, when we have almost constantly occasional bright days elevating the thermometer to above $50^{\circ}$. Yet as they still do not, like the larva of M. Cinxia, leave their nest, it seems

1 Reaun. ii. 170. 
obvious that something more than the sensation of heat is the regulator of the movements of each. Not, however, to detain you here unnecessarily, I shall not enlarge on this point, but shall pass on, in concluding this letter, to advert to the causes which have been assigned for the hybernation and torpidity of animals, and to state my own ideas on the subject, which will equally apply to the termination of this condition in spring.

The authors who have treated on these phenomena have generally ${ }^{1}$ referred them to the operation of cold upon the animals in which they are witnessed, but acting in a different manner. Some conceive that cold, combined with a degree of fatness arising from abundance of food in autumn, produces in them an agreeable sensation of drowsiness, such as we know, firom the experience of Sir Joseph Banks and Dr. Solander in Terra del Fucgo, as well as from other facts, is felt by man when exposed to a very low temperature; yielding to which, torpidity ensues. Others adnitting that cold is the cause of torpidity, maintain that the sensations which precede it are of a painful nature; and that the retreats in which hybernating animals pass the winter are selected in consequence of their endeavours to escape from the disagreeable influence of cold.

I have before had occasion to remark the inconclusiveness of many of the physiological speculations of very eminent philosophers, arising from their ignorance of Eutomology, which observation forcibly applies in the present instance. The reasoners upon torpidity have almost all confined their view to the hybernating quadrupeds, as the marmot, dormouse, \&c., and have thus lost sight of the far more extensive series of facts supplied by hybernating insects, which would often at once have set aside their niost conficlently-asserted hypotheses. If those who adopt the former of the opinions above alluded to had been aware that numerous insects retire to their hybernacula (as has been before observed) on some of the finest days at the close of autumn, they could never have contended that this movement, in which insects display extraordinary activity, is caused by the agreeable drousiness consequent on severe cold; and the very same fact is equally conclusive against the theory that it is to escape the pain arising from a low temperature that insects bury themselves in their winter quarters.

In fact, the great source of the confused and unsatisfactory reasoning which has obtained on this subject is, that no author, as far as my knowledge extends, has kept steadily in view, or indeed his distinctly perceived, the difference between torpidity and hybernation; or, in other words, between the state in which animals pass the winter, and their selection of a situation in which they may become subject to that state.

That the torpidity of insects, as well as of other hybernating animals, is, with us, caused by cold, is unquestionable. However early the period at which a beetle, for example, takes up its winter quarters, it does not sufferthat cessation of the powers of active life which we understand by torpidity, until a certain degree of cold has been experienced; the degree of its torpidity varies with the variations of temperature; and there can be no doubt that, if it were kept during winter from the influence of cold, it

1 IIere must be excepted my lamented friend the late Dr. Reeve of Norwich, who, in his ingenious Fissay on the Torpidity of Animals, has come to nearly the same conclusion as is adopted in this letter: but, by omitting to make a distinction between torpidity and hyvernation, he has not done justice to his own ideas. 
would not become torpid at all - at least this has proved the fact with marnots and dormice thus treated; and the Aphis of the rose ( $\left.A . R(n) a^{\prime}\right)$, which becomes torpid in winter in the open air " retains its activity, and gives birth to a numerous progeny, !non rose trees preserved in greenhouses and warm apartments.

But can we, in the same way, regard mere cold as the cause of the liybernation of insects? Is it wholly owing to this agent, as most writers seem to think - to feelings either of a pleasurable or painful nature produced by it - that, previously to becoming torpid, they select or fabricate commodious retreats precisely adapted to the constitution and wants of different species, in which they quietly wait the accession of torpidity and pass the winter? In my opinion, certainly not.

In the first place, if sensations proceeding from cold lead insects to select retreats for hybernating, how comes it that, as above shown, a large proportion of them enter these retreats before any severe cold has been felt, and on days considerably warmer than many that preceded them? If this supposition have any meaning, it must imply that insects are so constituted that, when a certain degree of cold has been felt by them, the sensations which this feeling excites inpel them to seek out hybernacula. Now the thermometer in the shade on the 14th of October, 1816, when I observed vast numbers thus employed, was at $58^{\circ}$ : - this, then, on the theory in question, is a temperature sufficiently low to induce the requisite sensations. But it so happens, as I learn from my meteorological journal (which registers the greatest and least daily temperature as indicated by a Six's thermometer), that on the 31 st of August, 1816, the greatest heat was not more than $52^{\circ}$, or six clegrees lower than on the 14th of October: yet it was six weeks later that insects retired for the winter!

But it may be objected, that it is perbaps not so much the precise degree of cold prevailing on the day when insects select their hybernacula, that regulates their movements, as the lower degree which may have obtained for a few nights previonsly, and which may act upon their delicate organisation so as to influence their future proceedings. Facts, however, are again in direct opposition to the explanation; for I find that, for is week previously to the 14 th of October, 1816, the thermometer was never lower at night than $48^{\circ}$, while in the first week in August it was twice as low as $46^{\circ}$, and never higher than $50^{\circ} .^{2}$

As a last resource, the advocates of the doctrine I am opposing may u'ge, that possibly insects may even have their sensations affected by the

1 Kyber, in Germar's Mag. der Ent. ii. 3.

2 Since the publication of the first edition of this volume, I have had an opportunity of making some observations which strongly corroborate the above reasoning. The month of October in the year 1817 set in extremely cold. From the first to the $6 \mathrm{th}$, piercing north and north-west winds blew; the thermometer at Hull, though the sun shone brightly in the day-time, was never higher than from $52^{\circ}$ to $56^{\circ}$, nor at night than $38^{\circ}$; in fact on the 1 st and $3 d$ it sank as low as $34^{\circ}$, and on the $2 d$ to $31^{\circ}$ : and on those days, at eight in the morning, the grass was covered with a white hoar frost; in short, to every one's feelings the weather indicated De.. cember ratler than October. Here, then, was every condition fulfilled that the theory I am opposing car. require; consequently, according to that theory, such a state of the atmosphere should have driven every hybernating insect to its winter quarters. But so far was this from being the case, that on the 5 th, when I made an excursion purposely to ascertain the fact, I found all the insects still abroad which I had met with six weeks before in similar situations. 
cold some days before it comes on, in the same way as we know that spiders and some other animals are influenced by changes of weather previously to their actual occurrence. But once more I refer to my meteorological journal; and I find that the average lowest height of the thermometer, in the week comprising the latter end of October and beginning of November, 1816, was $431^{\circ}$; while in the week comprising the same dars of the month of the end of Angust and beginning of September it was only $445^{\circ}$ - a difference surcly too incousiderable to build a theory upon.

I have entered into this tedious detail, becanse it is of importance to the spirit of true philosophising to show what little agreement there often is between facts and many of the hypotheses which authors of the present day are, from their determination to explain everything, led to pronulgate. But in truth there was no absolute need for imposing this fatigue upon your attention ; for the single notorious consideration that in this climate, as well as in more southern ones, we not unfrequently have sharp nightfrosts in summer, and colder weather at that season than in the latter end of autumn and beginning of winter, and yet that insects do hybernate at the latter period, but do not at the former, is an ample refutation of the notion that mere coll is the cause of the phenomenon. If, indeed, the hybernacula of insects were simply the underside of any dead leaf, clod, or stone that chanced to be in the neighbourhood of their abode, it might still be contended, that such situations were always resorted to by them on the occurrence of a certain degree of cold, but that they remained in them only when its continuance had induced torpidity; and it seems to have been in this view that most reasoners on this subject have regarded the hybernation of the larger animals, to which they have exclusively directed their attention. But had they been acquainted (as surcly the investigators of such a question ought to have been) with the economy of the class of insects, in which not merely a few species as among quadrupeds, luut one half or three fourths of the whole, in our climates, hy bernate, they would have known that their hybernacula are in general totally distinct from their ordinary retreats in casual cold weather; and that many of them even fabricate habitations requiring considerable time and labour, expressly for the purpose of their winter residence - which last fact in particular, on their theory, admits of no satisfactory explanation. We may say, and truly, that the scnsation of fatigne causes man to lie down anil sleep; but we should laugh at any one who contended that this sensation forced him first to make a four-post bedstead to repose upon.

In the second place, if we grant for a moment that it is cold which drives insects to their hybernacula, there are other phenomena attending the state of hybernation, which, on this supposition, are inexplicable. If cold led insects to enter thcir winter quarters, then they ought to be led by the cessation of cold to quit then. But, as has been before observed, we have often days in winter milder than at the period of hybernating, and in which insects are so roused from their torpidity as to run about nimbly when molested in their retreats ; yet, though their irritability must have been increased by a two or three months' inactivity and abstinence, they do not leave them, but quietly remain until a fresh accession of cold again induces insensibility.

In short, to refer the hybernation of insects to the mere direct infuence of cold, is to suppose one of the most important acts of their existence given up to the blind guidance of feelings which in the variable climates of 
Europe would be leading them into perpetual and fatal errors - which in spring would be inducing them to quit their ordinary occupations, and prepare retreats and habitations for winter, to be quitted again as soon as a few fine days had dispelled the frosty feel of a Miny week; and in a mild winter's day, when the thermometer, as is often the case, rises to $50^{\circ}$ or $55^{\circ}$, would lure them to ail exposure that must destroy them. It is not, we may rest assured, to such a deceptious guide that the Creator has intrusted the safety of so important a part of his creatures : their destinies are regulated by feelings far less liable to err.

What, you will ask, is this regulator? I answer, Instinct - that faculty to which so many other of the equally surprising actions of insects are to be referred; and which alone can adequately account for the phenomena to be explained. Why, indeed, should we think it necessary to go further? We are content to refer to instinct the retirement of insects into the earth previously to becoming pupx, and the cocoous which they then fabricate; and why should we not attribute to the same energy their retreat into appropriate hybernacula, and the construction by many species of habitations expressly destined for their winter residence? The cases are exactly analogous; and the insect knows no more that its hybernaculum is to protect it from too severe a degree of cold during winter than does the full-fed caterpillar when it enters the earth that it shall emerge a bcauteous moth. ${ }^{1}$

I am, \&c.

1 The reasoning in the preceding pages, as to cold not being the sole and direct cause of hybernation in insects, is strongly confirmed by the facts observed with regard to the hybernation of snails by M. Gaspard, who found that he could not bring on this state of existence out of its proper season by submitting them to artificial cold nearly to the freezing point, while he ascertained that at the proper period they prepare for hybernating at very different degrees of temperature, varying from $3 i^{\circ}$ to $77^{\circ}$ Fahr. (Zoological Journ. i, 93.). If it be said that some change in the scrsations of insects, either from an internal or external cause, must probably exist, in order to lead them to adopt a state so different from that of their usual habits as hybernation, this is readily admitted; but what is contended in the preceding letter is, that tliese causes are not simply cold, and that we are as yet ignorant of their nature. Dr. Jenner has argued (Phil. Truns. 1823) that it is not cold, but the tumid state of the testes and ovaria in swallows, and other migratory birds, which is the proximate canse of their leaving us at the approach of winter; and some analogous, though different, internal change may have a share in causing insects to exercise their hybernating instinct; but this change remains to be ascertained. Mr. Newport's idea that it is caused by an accumulation of fat pressing upon the tracher, and thus inducing a plethoric condition of body, and consequent inclination to sleep, might explain why insects become torpid after entering their winter quarters; but not listinguishing, as it appears to me, the two very distinct actions of seeking ont for and preparing hybernacula, and becoming torpil after entering them, it leaves, as the theories of other physiologists have done, the former, which is so essential a peculiarity of hybernation, wholly unexplained: just as Dr. Jenner's hypothesis, though it may explain why swallows should be uneasy and desirous of changing their abode, throws no light on that mysterious faculty by which they are directed. with unerring certainty, throngh the trackless air to the very spots, perhaps a thousand miles distant, that suit their new corporeal sensations. An accumulation of fat, supposing it to exist, may induce drowsiness and torpor, whether in cold climates like ours, in winter, or in tropical regions, where insects, as well as lizards, and even crocodiles, \&c., retire under ground, and sleep during the excessive heat; but there is obrionsly no natural connection between this plethoric state and the act of seeking out and preparing and retiring to a suitable dormitory. If fat and plethora are sufficient to induce this propensity, why do not these conditions, which 
are constantly taking place in many European carnivorous perfect insects in summer, when their food is abundant, lead them then, in Europe as in tropical countries, to seek out or prepare a suitable retreat? Yet, however full fed insects in temperate climes may be in summer, we know that they do not retire to become torpid at that period. All, therefore, that the present state of our knowledge seems to entitle us to say, is, as expressed in the close of the above letter, written thirty years ago, that the act of hybernation is dependent on the instinct of the insect, and that though this instinct may be, and probably is, excited by some bodily sensation, we as yet know no more of the precise nature of this than of that of a thousand other sensations which may give rise to the endless instincts of different linds observed in the insect tribes. 


\section{LETTER XXVII.}

\section{ON THE INSTINCT OF INSECTN.}

THE greater part of those surprising facts connected with the manners and economy of insects, of which the relation has occupied the preceding letters, is to be referred, I have told you, to their instinct. But what, you will ask, is this instinct? - of what nature is this faculty which produces effects so extraordinary?

To this query $I$ do not pretend to give any satisfactory answer. As I am quite of Bonuet's opinion, that philosophers will in vain torment themselves to define instinct, until they have spent some time in the head of an animal without actually being that animal - a species of metempsychosis through which I have never passed - I shall not attempt to explain what this mysterious energy is. It will not, however, I imagine, be very difficult to show what it is not; and some observations with this view, followed by an enumeration of peculiarities which distinguish the instincts of insects from those of other tribes of animals, and a short inquiry whether their actions are guided solely by instinct, will form the substance of this letter.

I. It is quite superfluous at this day to controvert the explanations of instinct advanced by some of the philosophers of the old school, such as that of Cudworth, who referred this faculty to a certain plastic nature; or that of Des Cartes, who contended that animals are mere machines. Nor, I fancy, would you thank me for entering into an elaborate refutation of the doctrine of Mylius, that many of the actions deemed instinctive are the effect of painful corporeal feelings; the cocoon of a caterpillar, for instance, being the result of a fit of the colic, produced by a superabunrlance of the gum which fills its silk-bags, and which exuding is twisted round it by its uncasy contortions into a regular ball. Still less reed I advert to the notable discovery of some pupils of Professor Winckler, that the brain, alias the soul, of a bee or spider is impressed at the birth of the insect with certain geometrical figures, according to which models its works are constructed - a position which these gentlemen demonstrate very satis. fuctorily by a memorable experiment in which they themselves were able to hear triangles.

It is as unnecessary to waste any words in refutation of the nonsense (for it deserves no better name) of Buffon, who refers the instinct of societies of insects to the circumstance of a great number of individuals being brought into existence at the same time, all acting with equal force, and obliged by the similarity of their internal and external structure, and the conformity of their movements, to perform each the same actions, in the same place, in the most convenient mode for themselves, and least inconvenient for their companions; whence results a regular, well-pro- 
portioned, and symmetrical structure: and he gravely tells us that the boasted hexagonal cells of bees are produced by the reciprocal pressure of the cylindrical bodies of these insects against each other !! ${ }^{1}$

Nor is it requisite to advert at length to the explanations of instinctive actions more recently given by Steffens, a German author (one of the transcendentalists, I conclude, from the incomprehensibility of his book to my ordinary intellect), who says that the products of the vaunted instinct of insects are nothing but "shootings out of inorganic animal masses" (anorgische anschïsse) ${ }^{2}$; and by Lamarck 3 , who attributes them to certain inherent inclinations arising from habits impressed upon the organs of the animals concerned in producing them, by the constant efflux towards these organs of the nervous fluid, which, during a series of ages, has been displaced in their endeavours to perform certain actions which their necessities have given birth to. The mere statement of a hypothesis of which the enunciation is nearly unintelligible, and built upon the assumption of the presence of an unseen fluid, and of the existence of the animal some millions of years, is quite sufficient, and would even be nnnecessury if it were not of such late origin. Neither shall I detain you with any formal consideration of the hypothesis advanced by Addison and some other authors, that instinct is an immediate and constant impulse of the Deity; which, to onit other obvions objections, is sufficiently refuted by the fact, that animals in their instincts are sometimes at fault, and commit mistakes, which on the above supposition could not in any case happen.

The only doctrine on the subject of instinct requiring any thing like a formal refutation is that which, contending for the identity of this faculty with reason in man, maintains that all the actions of animals, however complicated, are, like those of the human race, the result of observation, invention, and experience. This theory, maintained by the sceptics, Pythagoras, Plato, and some other ancient plilosophers, and in modern times by Helvetius, Condillac, and Smellie, has been by none more ingeniously supported than by Dr. Darwin, who, in the chapter treating on instinct, in the first volume of his Zoonomia, has brought forward a collection of facts which give it a great air of plausibility. This plausibility, however, is merely superficial; and the result of a rigorous examination by any competent judge is, that the greater part of Dr. Darwin's facts bear more strongly in favour of the dissimilarity of instinct and reason than of their identity: and that those few which seem to support the latter position are built upon the relations of persons ignorant of natural history, who have confused together distinct species of animals. Thus, because some anonymous iuformant told him that hive-bees when transported to Barbadoes, where there is no winter, ceased to lay up a store of honey, Dr. Darwin infers that all the operations of these insects are guided by reason and the adaptation of means to an end-a very just inference, if the statement from which it is drawn

1 Hist. Nar. Edit. 1785, v. 277.

2 Beiträge zur innern Naturgeschichte der Erde, 1801, p. 298.

3 In his Philosophie Zooloqique, Paris, 1809 (ii. 325.) - a work which every zoologist will, I think, join with me in regretting should be devotel to metaphysical disquisitions built on the most gratuitous assumptions, instead of comprising that luminous generalisation of facts relative to the animal world which is so great a desideratum, and for performing which satisfactorily this eminent naturalist is so well qualified. 
were accurate; but that it is not so is known to every naturalist acquainted with the fact that many different species of bees store up honey in the hottest climates; and that there is no anthentic instance on record of the hive-bees altering, in any age or climate, their peculiar operations, which are now in the coldest and in the hottest regions precisely what they were in Greece in the time of Aristotle, and in Italy in the days of Virgil. Indeed the single fact, depending on the assertions of such accurate observers as Reaumur and Swammerdam, that a bee as soon after it is disclosed from the pupa as its body is dried and its wings expanded, and before it is possible that it should have received any instruction, betakes itself to the collecting of honey ol the fabrication of a cell, which operation it performs as adroitly as the most hoary inhabitant of the hive, is alone sufficient to set aside all the hearsay statements of Dr. Darwin, and should have led him, as it must every logical reasoner, to the conclusion, that these and similar actions of animals cannot be referred to any reasoning process, nor be deemed the result of observation and experience. It is true, it does not follow that animals, besides instinct, have not, in a degree, the faculty of reason also; and as I shall in the sequel endeavour to show, many of the cetions of insects can be adequately explained on no other supposition. But to deny, as Dr. Darwin does, that the art with which the caterpillar weaves its cocoon, or the unerring care with which the noth places her eggs upon food that she hersclf can never usc, are the effects of instinct, is as unphilosophical and contrary to fact as to insist that the eagerness with which, though it has never tasted milk, the infant seeks for its mother's breast, is the effect of reason.

Instinct, then, is not the result of a plastic nature; of a system of machinery; of diseased bodily action; of models impressed on the brain ; nor of organic shootings-out : - it is not the effect of the habitual determination for ages of the nervous fiuid to certain organs; nor is it either the impulse of the Deity, or reason. Without pretending to give a logical definition of it, which, while we are ignorant of the essence of reason, is impossible, we may call the instincts of animals those unknown faculties implanted in their constitution by the Creator, by which, independent of instruction, observation, or experience, and without a knowledge of the end in view, they are impelled to the performance of certain actions tending to the well-being of the individual and the preservation of the species: and with this description, which is, in fact, merely a confession of ignorance, we must, in the present state of metaphysical science, content ourselves.

I here say nothing of that supposed connection of the instinct of animals with their sensations, which has been introduced into many definitions of this mysterious power, for two reasons. In the first place, this definition merely sets the world upon the tortoise; for what do we know more than before about the nature of instinct, when we have called it, with Brown, a predisposition to certain actions when certain sensations exist, or with Tucker have ascribed it to the operation of the senses, or to that internal feeling called appetite? But, secondly, this comnection of instinct with bodily sensation, though probable enough in some instances, is by no means generally evident. We may explain in this way the instincts connected with hunger and the sexual passion, and some other particular facts, as the laying of the eggs of the flesh-fly in the flowers of Stropelir hirsula, instead of in carrion, their proper nidus, and of those of the common house-fly in 
snuff ${ }^{1}$ instead of dung; for in these instances the smell seems so clearly the guide, that it even leads into error. But what connection between sensation and instinct do we see in the conduct of the working-bees, which fabricate some of the cells in a comb larger than others, expressly to contain the eggs and future grubs of drones, though these eggs are not laid by themselves, and are still in the ovaries of the queen? So we may plausibly enough conjecture that the fury with which, in ordinary circumstances, at a certain period of the year, the working-bees are inspired towards the drones, is the effect of some disagreeable smell or emanation proceeding from them at that particular time : but how can we explain, on similar grounds, the fact that in a hive deprived of a queen, no massacre of the drones takes place? Lastly, to omit here a hundred other instances, as many of them will be subsequently adverted to, if we may with some show of reason suppose that it is the sensation of heat which causes bees to swarm, yet what possible conception can we form of its being borlily sensations that lead bees to send out scouts in search of a hive suitable for the new colony several days before swarming?

After these observations on the nature of instinct generally, I pass on to contrast in several particulars the instincts of insects with those of other animals; and thus to bring together some remarkable instances of the former which have not hitherto been laid before you, as well as to deduce from some of those already related inferences to which it did not fall in with my design before to direct your attention. This contrast may be conveniently made under the three heads of the exquisiteness of their instincts, their number, and their extraordinary development.

The instincts of by far the majority of the superior animals are of a very simple kind, only directing them to select suitable food; to propagate their species; to defend themselves and their young from harm; to express their sensations by various vocal modulations; and to a few other actions which need not be particularised. Others of the larger animals, in addition to these simpler instinctive propensities, are gifted with more extensive powers: storing up food for their winter consumption, and building nests or habitations for their young, which they carefully feed and tend.

All these instincts are common to insects, a great proportion of which are in like manner confined to these. But a very considerable number of this class are endowed with instincts of an exquisiteness to which the higher animals can lay no claim. What bird or fish, for example, catches its prey by means of nets as artfully woven and as admirably adapted to their Durposes as any that ever fisheriman or fowler fabricated? Yet such nets are constructed by the race of spiders. What beast of prey thinks ot digging a pitfall in the track of the animals which serve it for food, and at the bottom of which it conceals itself, paticntly waiting until some unhappy victim is precipitated down the sides of its cavern? ${ }^{2}$ Yet this is done by the ant-lion and another insect. Or, to omit the endless instances furnished by wasps, ants, the Termites, $\mathcal{S} c$., what animals can be adduced which, like the hive-bee, associating in societies, build regular cities composed of cells formed with geometrical precision, divided into dwellings

1 Dr. Zinken genannt Sommer says, that if in August and September a snuff-box be left open, it will be seen to be frequented by the common house-fy. (. Muscu domestica), the eggs of which will be found to have been deposited amongst the snutf. Germar, Mag. der Eni. I. ii. 189. 
adapted in capacity to different orders of the society, and storehouses for containing a supply of provision? Even the erections of the beaver, and the pensile dwelling of the tailor-bird, nust be referred to a less elaborate instinct than that which guides the procedures of these little insects, the complexness and yet perfection of whose operations, when contrasted with the insignificance of the architect, have at all times caused the reflecting observer to be lost in astonishment.

It is, however, in the deviations of the instincts of insects, and their accommodation to circumstances, that the exquisiteness of these faculties is most decidedly manifested. The instincts of the larger animals seem capable of but slight modification. They are either exercised in their full extent or not all. A bird when its nest is pulled out of a bush, though it should be laid uninjured close by, never attempts to replace it in its situation; it contents itself with building another. But insects in similar contingencies often exhibit the most ingenious resources, their instincts surprisingly accommodating themselves to the new circumstances in which they are placed, in a manner more wonderful and incomprehensible than the existence of the faculties themselves. Take a honeycomb, for instance. If evcry comb that bees fabricate were always made precisely alike - with the same general form, placed in the same position, the cells all exactly sinilar, or where varying with the variations always alike - this structure would perhaps in reality be not more astonishing than many of a much simpler conformation. But when we know that in nine instances out of ten the combs in a bee-hive are thus similar in their properties, and yet that the tenth one shall be found of a form altogether peculiar ; placed in a different 'position ; with cells of a different shape and all these variations evidently adapted to some new circumstances not present when the other nine were constructed, - we are constrained to admit that nothing in the instinct of other animals can be adduced exbibiting similar exquisiteness : just as we must confess an ordinary loom, however ingeniously contrived, far excelled by one capable of repairing its defects when out of order.

The examples of this variation and accommodation to circumstances among insects are very numerous; and as presenting many interesting facts in their history not liefore related, I shall not fear wearying you with a pretty copious detail of them, beginning with the more simple.

It is the instinct of Geotropes vernalis to roll up pellets of dung, in each of which it deposits one of its egys; and in places where it mects with cow or horse dung only, it is constantly under the necessity of having recourse to this process. But in districts where sheep are kept, this beetle wisely saves its labour, and ingeniously avails itself of the pellet-shaped balls ready made to its hands which the excrement of these animals supplics. ${ }^{1}$

A caterpillar described by Bonnet, which from being confined in a box was unable to obtain a supply of the bark with which its ordinury instinct directs it to make its cocoon, substituted pieces of paper that were given to it, tied them together with silk, and constructed a very passable cocoon with them. In another instance the same naturalist having opened several cocoons of a moth (Cucullia Verbasei), which are composed of a mixture of grains of earth and silk, just after being fuished, the larvæ did not repair the injury in the same manner. Some employed both earth and silk; 
others contented themselves with spinning a silken veil before the opening. ${ }^{1}$

The larva of the cabbage-butterfly (Pontia Brassica), when about to assume the pupa state, commonly fixes itself to the under side of the coping of a wall or some similar projection; but the ends of the slender thread which serves for its girth would not adhere firmly to stone or brick, or even wood. In such situations, therefore, it previously covers a space of about an inch long and half an inch broad with a web of silk, and to this extensive base its girth can be securely fastened. That this proceeding, however, is not the result of a blind unaccommodating instinct seems proved by a fact which has come under my own observation. Having fed some of these larva in a box covered by a piece of muslin, they attached themselves to this covering; but as its texture afforded a firm hold to their girth, they span no preparatory web.

Bombus ${ }^{2}$ Muscorum, and some other species of humble-bees, cover their nests with a roof of moss. M. P. Huber having placed a nest of the former under a bell-glass, he stuffed the interstices between its bottom and the irregular surface on which it rested with a linen cloth. This eloth, the bees, finding themselves in a situation where no moss was to be had, tore thread fiom thread, carded it with their feet into a felted mass, and applied it to the same purpose as moss, for which it was ncarly as well adapted. Some other lumble-bees tore the cover of a book with which he had closed the top of the box that contained them, and made use of the detached morsels in covering their nest. ${ }^{3}$

The larva of Cossus ligniquerda, which feed's in the interior of trees, previously to fabrieating a cocoon and assuming the pupa state, forms for the egress of the future moth a cylindrieal orifice, except when it finds a suitable hole ready made. When the moth is about to appear, the clirysalis with its anterior end forces an opening in the cocoon. If the orifice in the tree has been formed by itself, in which case it exactly fits its body, it entirely quits the cocoon, and pushes itself half way out of the hole, where it remains seeure from falling until the moth is disclosed. But if the orifice, having been adopted, be larger than it ought to have been, and thus not capable of supporting the pupa in this position, the provident inseet pushes itself only half way out of the cocoon, which thus serves for the support which in the former case the wood itself afforded. ${ }^{4}$

The variations in the procedures of the larva of a little moth described by Reaumur, whose habitation has been before noticed - one of those which constantly reside in a sub-eylindrical case-are still more remarkable. This little caterpillar feeds upon the elm, the kaves of which serve it at once for food and elothing. It eats the parenchyma or inner pulp, burrowing between the upper and under membranes; of portions of which cut out, and properly sewed together, it forms its case. Its usual plan is to insinuate itself between the epidermal membranes of the leaf, close to one of the edges. Parallel with this it excavates a cavity of suitable form and dimensions, gnawing the pulp even out of every projection of the serratures, but carefully avoiding to separate the membranes at the very edge, which with a wise saving of labour it intends should form one of the

1 CEurres, ii. 238. See above, p. 211.

3 Linn. Trans. vi. 254.
2 Apis, **. e. $2 . \mathrm{K}$.

4 Lyonet, Traité Anatomique, Sc. 16. 
seams of its coat; and as the little miner is not embarrassed with the removal of the excavated materials, which it swallows as it proceeds, a cavity sufficiently large is but the work of a few hours. It then lines it with silk, at the same time pushing it into a more cylindrical shape; and lastly, cutting it off at the two ends and inner side, it sews up the latter with such nicety that the suture is scarcely discoverable; and is now provided with a case or coat exactly fitting its body, open at the two ends, by one of which it feeds, and by the other discharges its excrement, having on one side a nicely joined seam, and the other - that which is commonly applied to its back - composed of the natural marginal junction of the membranes of the leaf.

Such are the ordinary operations of this insect, which - when it is considered that the case is lather fusiform than cylindrical ; that the end through which it eats is circular, and the other curiously three-cornered like a cocked hat; and that consequently its cloth requires to be very irregularly and artfully cut to be accommodated to such a figure, - it must be admitted, are the result of an instinct of no very simple kind. Complicated, however, as these manœuvres seem, our ingenious workman is not confined to them. By way of putting its resources to the test, Reaumur cut off the serrated edge from the neally finished coat of one of them, and exposed the little occupant to the day. He expected that it would have quitted its mutilated garment and conmenced another; and so it certainly would, had it been guided by an invariable instinct. But he calculated erroneously. Like one of its brother tailors of the biped race, it knew how, "to cut its coat according to its cloth," and immediately setting about repairing the injury sewed up the rent. Nor was this all. The scissors having cut off one of the projections intended to enter into the construction of the triangular end of its case, it entirely changed the original plan, and made that end the head which had been first designed for the tail.

On another occasion Reaumur observed one of these larva to cut out its coat from the very centre of a leaf, where it is obvious a series of operations wholly different must be adopted, the two membranes composing it necessarily requiring to be cut and sewed on two sides instead of on one only. But what was most striking in this new procerlure was the alteration which the caterpillar made in the period of sewing up its garment. When these larvæ cut out their case from the edge of a leaf, they scem aware that if they were to detach it entirely from the inner side before the process of sewing, lining, \&c., is conpleted, having no support on the exterior edge, it would be liable to fall down; at the same time they could not sew together the membranes composing it at the inner side, without cutting them in part from the leaf. While, therefore, they divide the major part of their inner side from the leaf, they artfully leave them attached to it by one of the large nerves at each end; and these supports they do not cut asunder until the intermediate space has been sewed up, and they are ready to step, with their house on their back, upon the terra firma of the disk of the leaf. In this instance, therefore, the larvæ do not wholly separate their case from the leaf, until it is sewed. But when the same larvæ cut ont their materials from the middle of the leaf, where, though completely cut round, they are retained in their situation securc from all danger of falling by the serratures of the incisions made by the jaws of the larva, these little tailors vary their mode, and entircly detacls 
the pieces from the surrounding leaf before they proceed to set a stitch into them. ${ }^{\mathrm{I}}$

A remarkable instance of variation of instinct in the common housespider (Aranea donestica) is mentioned by an anonymous writer in the Zoological Journal. He states that having placed one on a piece of wood fixed in the middle of a glass of water, the spider, finding its other efforts to eseape inefieetual, enveloped its abdomen by means of its hinder legs in a loose web which it spun, and then descended at onee without the least hesitation into the water, surrounded under its mantle with a bubble of air, evidently intended for respiration as it ineluded the spiracles; and in this extemporaneous diving-bell, like that of the water-spider (Argyroncta aquatica) before deseribed, it endeavoured to make its escape on every side, but, on account of the slipperiness of the glass, in vain ; and after remaining at the bottom of the water for thirteen minutes, it returned apparently much exhausted, as it coiled itself under its wooden platform without motion. $^{2}$ As we cannot refer so philosophical a contrivance to reason, we inust regard it as a variation of instinct; but certainly, if correctly reported, a very curious one, as the occasions on which the house-spider can want to escape through water must be very rare.

In the preceding instances the variation of instinct takes place in the same individual; but Bonnet mentions a very curious fact in which it occurs in different generations of the same speeies. There are annually, he informs us, two generations of the Angoumois moth, an insect whieh has been before mentioned as destructive to wheat: the first appear in May and June, and lay their eggs upon the ears of wheat in the fields; the second appear at the end of the summer or in autumn, and these lay their eggs upon wheat in the granaries. These last pass the winter in the state of larvæ, from which proceeds the first generation of moths. But what is extremely singular as a variation of instinct, those moths which are disclosed in May and $J_{u n e}$ in the granaries quit them with a rapid flight at sunset, and betake themselves to the yet unreaped fields, where they lay their eggs; while the moths which are disclosed in the granaries after harvest stay there; and never attenupt to go out, but lay their eggs upon the stored wheat. ${ }^{3}$ This is as extraordinary and inexg)licable as if a litter of rabbits produced in spring were impelled by instinct to eat vegetables, while another produced in autumn should be as irresistib!y clireeted to choose flesh.

It is, however, into the history of the hive-bee that we must look for the most striking examples of variation of instinct ; and here, as in every thing relating to this insect, the work of the elder Huber is an unfailing source of the most novel and interesting facts.

It is the ordinary instinct of bees to lay the foundation of their combs at the top of the hive, building them perpendieularly downwards; and they pursue this plan so constantly, that you might examine a thousand (probably ten thousand) hives, without finding any material deviation fiom it. Yet Huber in the course of his experiments foreed them to build their combs perpendicularly upward ${ }^{4}$; and, what seems even more remarkable, in an horizontal direction. ${ }^{5}$

The combs of bees are always at an uniform distance from each other,

1 Reaum. iii. 112-119.

2 Zoologicul Journ, i. 284.

4 Huber, ii. 134.

3 Eurres, ix. 370.

5 Ibid. ii. 216. 
namely, about one third of an inch, which is just wide enough to allow them to pass easily and have access to the young brood. On the approach of winter, when their honey-cells are not sufficient in number to contain all the stock, they elongate them considerably, and thus increase their capacitr: By this extension the intervals between the combs are unavoidably contracted ; but in winter well-stored magazines are essential, while from their state of comparative inactivity' spacious communications are less necessary. On the return of spring, however, when the cells are wanted for the reception of eggs, the bees contract the elongated cells to their former dimensions, and thus re-establish the just distances between the combs which the eare of their brood requires. ${ }^{1}$ But this is not all. Not only do they elongate the cells of the old combs when there is an extraordinary harvest of honey, but they actually give to the new cells which they construet on this emergency a much greater diameter as well as a greater depth. ${ }^{2}$

The queen-bee in ordinary circumstances places each egg in the centre of the pyramidal bottom of the eell, where it remains fixed by its natural gluten; but in an experiment of Huber, one whose fecundation had been retarded had the first segments of her abdomen so swelled that she was unable to reach the bottom of the cells. She therefore attached her eggs (which were those of males) to their lower side, two lines from the mouth. As the larvæalways pass that state in the place where they are deposited, those hatched from the eggs in question remained in the situation assigned them. But the working-bees, as if aware that in these eircumstances the cells would be too short to contain the larvæ when fully grown, added to their length, even before the eggs were hatched. ${ }^{3}$

Bees close up the cells of the grubs, previously to their transformation, with a cover or lid of wax; and in hanging its abode with a silken tapestry before it assumes the pupa state, the grub requires that the cell should not be too short for its movements. Bonnet having placed a swarm in a very flat glass hive, the bees constructed one of the combs parallel to one of the principal sides, where it was so straight that they could not give to the cells their ordinary depth. The queen, however, laid eggs in them, and the workers daily nourished the grubs, and closed the cells at the period of transformation. A few days afterwards he was surprised to perceive in the luds holes more or less large, out of which the grubs partly projected, the cells having been too short to admit of their usual movements. $\mathrm{He}$ was curious to know how the bees would proceed. He expected that they would pull all the grubs out of the cells, as they commonly do when great disorders in the combs take place. But he did not sufficiently give credit to the resources of their instinct. They did not displace a single grub they left them in their cells; but as they saw that these cells were not decp enough, they closed them afresh with lids much more convex than ordinary, so as to give to them a sufficient depth; and from that time no more holes were made in the lids.

The working-bees, in closing up the cells containing larvæ, invariably give a convex lid to the large cells of drones, and one nearly flat to the smaller ceils of workers; but in an experiment instituted by Huber to ascertain the mfluence of the size of the cells on that of the included larva, he trans. ferred the larvæ of workers to the cells of drones. What was the result? Did the bees still continue blindly to exercise their ordinary instinct? On
1 Huber, i. 348.
a Ibid. ii. 227.

3 Ibid. i. 119. 
the contrary, they now placed a nearly flat lid upon these large cells, as if well aware of their being occupied by a different race of inhabitants. ${ }^{\text {. }}$

On some occasions bees, in consequence of Huber's arrangements in the interior of their habitations, have begun to build a comb nearer to the adjoining one than the usual interval; but they soon appeared to perceive their error, and corrected it by giving to the comb a gradual curvature, so is to resume the ordinary distance. ${ }^{2}$

In another instance in which various irregularities had taken place in the form of the combs, the bees, in prolonging one of them, had, contrary to their usual custom, begun two separate and distinct continuations, which in approaching instead of joining would have interfered with each other, had not the bees, apparently foreseeing the difficulty, gradually bent their edges so as to make them join with such exactness that they conld afterwards continue them conjointly. ${ }^{3}$

In constructing their combs, bees, as you have been before told, in my Letter on the Habitations of Insects, form the first range of cells - that by which the comb is attached to the top of the hive - of a different shape from the rest. Each cell, instead of being hexagonal, is pentagonal, having the fifth broadest side fixed to the top of the hive, whence the comb is much more securely cemented to that part than if the first range of cells had been of the ordinary construction. For some time after their fabrication the combs remain in this state; but at a certain period the bees attack the first range of cells as if in fury, gnaw away the sides without touching the lozenge-shaped bottoms; and, having mixed the wax with propolis, they form a cement well known to the ancients under the names of Mitys, Commosis, and Pissoceros, which they substitute in the place of the removed sides of the cells, forming of it thick and massive walls and heavy and shapeless pillars, which they introduce between the comb and the top of the hive so as to agglutinate them firmly together. Huber, who first in modern times witnessed this remarkable modification of the architecture of bees, observed that not only are they careful not to touch the bottoms of the cells, but that they do not remove at once the cells on both sides of the comb, which in that case might fall down; but they work alternately, first on one side and then on the other, replacing the demolished cells as they proceed with mitys, which firmly fixes the comb to its support.

The object of this substitution of nitys for wax seems clear. While the combs are new and only partially filled with honey, the first range of cells originally established as the base and the guide for the pyramidal bottoms of the subsequent ones, serves as a sufficient support for them ; but when they contain a store of several pounds, the bees seem to foresee the danger of such a weight proving too heavy for the thin waxen walls by which the combs are suspended, and providently hasten to substitute for them thicker walls, and pillars of a more compact and viscid material.

But their foresight does not stop here. When they have sufficient wax, they make their combs of such a breadth as to extend to the sides of the hive, to which they cement them by constructions approaching more or less to the shape of cells. But when a scarcity of wax happens before they liave been able to give to their combs the requisite diameter, a large vacant space is left between tile elges of these combs, which are only fixed by their upper part, and the sides of the hive; and they might be pulled

1 IIuber, i. 233.

2 Ibid. ii. 239.

3 Ibid. ii. 240. 
down by the weight of the honey, did not the bees ensure their stability by introducing large irregular masses of wax between their edges and the sides of the hive. A striking instance of this art of securing their magazines occurred to Huber. A conb, not having been originally well fastened to the top of his glass hive, fell down during the winter amongst the other combs, preserving, however, its parallelism with them. The bees could not fill up the space between its upper edge and the top of the live, because they never construct combs of old wax, and they had not then an opportunity of procuring new : at a more favourable season they would not have hesitated to build a new comb upon the old one; but it being inexpedient at that period to expend their provision of honey in the elaboration of wax, they provided for the stability of the fallen comb by another process. They furnished themselves with wax from the other combs, by gnawing away the rims of the cells more elongated than the rest, and then betook themselves in crowds, some upon the edges of the fallen comb, others between its sides and those of the adjoining combs; and there securely fixed it, by constructing several ties of different shapes between it and the glass of the hive : some were pillars, others buttresses, and others beams artfully disposed and adapted to the localities of the surfaces joined. Nor did they content themselves with repairing the accidents which the masonry had experienced; they provided against those which might happen, and appeared to profit by the warning given by the fall of one of the combs to consolidate the others, and prevent a second accident of the same nature. These last had not been displaced, and appeared solidly attached by their base; whence Huber was not a little surprised to see the bees strengthen their principal points of connection by making them much thicker than before with old wax, and forming numerous ties and braces to unite them more closely to each other, and to the walls of their habitation. What was still more extraordinary, all this happened in the middle of January, at a period when the bees ordinarily cluster at the top' of the hive, and do not engage in labours of this kind. ${ }^{1}$

You will admit, I think, that these proofs of the resources of the architectural instinct of bees are truly admirable. If, in the case of the substitution of mitys for the first range of waxen cells, this procedure invariably took place in every bee-hive at a fixed period - when, for example, the combs are two-thirds filled with honey - it would be less surprising; but there is nothing of this invariable character about it. It does not, as Huber expressly informs us ${ }^{2}$, occur at any marked and regular period, but appears to depend on several circumstances not always combined. Sometimes the bees content themselves with bordering the sides of the upper cells with propolis alone, without altering their form or giving them greater thickness. And it is not less remarkable that, from the instances last cited, it appears that they are not confined to one kind of cement for strengthening and supporting their combs, but avail themselves of propolis, wax, or a mixture of both, as circumstances direct.

Not to weary you with examples of the modifications of instinct we are. considering, I shall introduce but three more:- the first, of the mode in which bees extend the dimensions of an old comb; the second, of that which they adopt in constructing the male cells and connecting them wits

1 Huber, ii. 280.

I Ibid. ii. 284. note *. 
the smaller cells of workers; and the last, of the plan pursued by them when it becomes necessary to bend their combs.

You must have observed that a comb newly made becomes gradually thinner at its edges, the cells there, on each side, progressively decreasing in length; but in time these marginal cells, as they are wanted for the purproses of the hive, are elongated to the depth of the rest. Now suppose bees, from an augmentation of the size of their hive, to have occasion to extend their combs either in length or breadth, the process which they adopt is this:-they gnaw away the tops of the marginal cells until the combs have resumed their original lenticular form, and then construct upon their edges the pyramidal lozenge-shaped bottoms of cells, upon which the hexagonal sidcs are subsequently raised, as in their operation of cell-building. This course of proceeding is invariable : they never extend a comb in any direction whatever without having first made its edges thinner, diminishing its thickness in a portion sufficiently large to leave no angular projection. Huber observes, and with reason, in relating this surprising law which obliges bees partially to demolish the cells situated upon the edges of the combs, that it deserves a more close examination than he found himself competent to give it ; for if we may to a certain point form a conception of the instinct which leads these animals to employ their art of building cells, yet how can we conceive of that which in particular circumstances forces them to act in an opposite direction, and determines them to demolish what they have so laboriously constructed ? 1

Drones, or male bees, are more bulky than the workers; and you have been told, in speaking of the habitations of insects, that the cells which bees construct for rearing the larvæ of the former are larger than those destined for the education of the larvæ of the latter. The diameter of the cells of drones is alway's $3 \frac{1}{3}$ lines (or twelfths of an inch), that of those of workers $2 \frac{2}{5}$ lines; and these dimensions are so constant in their ordinary cells, that some authors have thought they might be adopted as an universal and invariable scale of measure, which would have the great recommendation of being everywhere at hand, and at all events would be preferable to our barley-corns. Several ranges of male cells, sometimes firom thirty to forty, are usually found in each comb, generally situated about the middle. Now as these cells are not isolated, but form a part of the entire comb, corresponding on its two faces - by what art is it that the bees unite hexagonal cells of a small with others of a larger diameter, without leaving any void spaces, and without destroying the uniformity and regularity of the comb? This problem would puzzle an ordinary artist, but is easily solved by the resources of the instinct of our little workmen.

When they are desirous of constructing the cells of males below those of workers, they form several ranges of intermediate or transition cells, of which the diameter augments progressively, until they have reached that range where the male cells conmence; and in the same manner, when they wish to revert to the modelling of the cells of workers, they pass by a gradually decreasing gradation to the ordiuary diameter of the cells of this class. We commonly meet with three or four ranges of intermediate cells

1 Huber, ii. 228. 
before coming to those of males; the first ranges of which participate in some measure in the irregularity of the former.

But it is upon the construction of the bottoms of the intermediate ranges of cells that this variation of their architecture chiefly hinges. The bottonis of the regular cells of bees are, as you are aware, composed of three equal-sized rhomboidal pieces; and the base of a cell on one side of the comb is composed of portions of the bases of three cells on the other; but the bottoms of the intermediate cells in question (though their orifices are perfectly hexagonal) are composed of four pieces, of which two are hexagonal and two rhomboidal; and each, instead of corresponding with three cells on the opposite side, corresponds with four. The size and the shape of the four pieces composing the bottom vary; and these intermediate cells, a little larger than the third part of the three opposite cells, comprise in their contour a portion of the bottom of the fourth cell. Just below the last range of cells with regular pyramidal bottoms are found cells with bottoms of four pieces, of which three are very large, and one very small, and this last is a rhomb. The two rhombs of the transition cells are separated by a considerable interval; but the two hexagonal pieces are adjicent, and perfectly alike. A cell lower, we perceive that the two rhombs of the bottom are not so unequal: the contour of the cell has included a greater portion of the opposite fourth cell. Lastly, we find cells in pretty considerable number of which the bottom is composed of four pieces perfectly regular - namely, two elongated hexagons and two equal rhombs, but smaller than those of the pyramilal bottoms. In proportion as we remove our view from the cells with regular tetrahedral bottoms, whether in descending or from riglit to left, we see that the subsequent cells resume their ordinary form : that is to say, that one of their rhombs is gradually lessened until it finally disappears entirely; and the pyramidal form reexhibits itself, but on a larger scale than in the cells at the top of the comb. This regularity is maintained in a great number of ranges, namely, those consisting of nale cells; afterwards the cells diminish in size, and we again remark the tetrahedral bottoms just described, until the cells have once more resumed the proper diameter of those of workers.

It is, then, by encroaching in a smail degree upon the cells of the other face of the comb, that bees at length succeed in giving greater dimensions to their cells; and the graduation of the transition cells being reciprocal on the two faces of the comb, it follows that on both sides each hexagonal contour corresponds with four cells. When the bees have arrived at any degree of this mode of operating, they can stop there and continue to employ it in several consecutive ranges of cells; but it is to the intermediate degree that they appear to confine themselves for the longest period, and we then find a great number of cells of which the bottoms of four pieces are perfectly regular. They might, then, construct the whole comb on this plan, if their olject were not to revert to the pyramidal form with which they set ont. In building the male cells, the bees begin their foundation with a block or mass of wax thicker and higher than that employed for the cells of workers, without which it would be impracticable for them to preserve the same order and symmetry in working on a larger scale.

Irregularities (to use the language of Huber, from whom the above details are abstracted) have often been observed in the cells of bees. Reaumur, Bonnet, and other naturalists, cite them as so many examples of 
imperfections. What would have been their astonishment if they had been aware that part of these anomalies are calculated; that there exists, as it were, a moveable harmony in the mechanism by which the cells are composed? If in consequence of the imperfection of their organs, or of their instruments, bees occasionally constructed some of the cells unequal, or of parts badly put together, it would still manifest some talent to be able to repair these defects, and to compensate one irregularity by another; but it is far more astonishing that they know how to quit their ordinary routine when circumstances require that they should build male cells; that they should be instructed to vary the dimensions and the shape of each piece so as to return to a regular order; and that, after having constructed thirty or forty ranges of male cells, they again leave the regular order on which these were formed, and arrive by successive diminutions at the point from which they set out. How should these insects be able to extricate themselves from such a difficulty - from such a complicated structure? how pass from the little to the great, from a regular plan to an irregular one, and again resume the former? These are questions which no known system can explain. ${ }^{1}$

Here again, as observed in a former instance, the wonder would be less if every comb contained a certain number of transition and of male cells, constantly situated in one and the same part of it; but this is far from being the case. The event which alone, at whatever period it may happen, seems to determine the bees to construct male cells, is the oviposition of the queen. So long as she continues to lay the eggs of workers, not a male cell is founded; but as soon as she is about to lay male eggs, the workers seem aware of it, and you then see them form their cells irregularly, impart to them by degrees a greater diameter, and at length prepare suitable ranges of cradles for all the male race. ${ }^{2}$ You must perceive how absurd it would be to refer this astonishing variation of instinct to any mere change in the sensations of the bees; and to what far-fetched and gratuitous suppositions we must be reduced, if we adopt any such explanation. We can but refer it to an instinct of which we know nothing; and so referring it, can we help exclaiming with Huber, "Such is the grandeur of the views, and of the means of ordaining wisdom, that it is not by a minute exactness that she marches to her end, but proceeds from irregularity to irregularity, compensating one by another: the admeasurements are made on high, the apparent errors appreciated by a divine geometry; and order often results from partial diversity. This is not the first instance which science has presented to us of preordained irregularities which astonish our ignorance, and are the admiration of the most enlightened minds. So true it is that the more we investigate the general as well as particular laws of this vast system, the more perfection does it present." 3

It is olsserved by M. P. Huber, in his appendix to the account of his father's discoveries relative to the architecture of bees, that in general the form of the prisms or tubes of the cells is more essential than that of their bottoms, since the tetrahedral-bottomed transition cells, and even those cells which being built immediately upon wood or glass were entirely without bottoms, still preserved their usual shape of hexagonal prisms. But a reznarkable experiment of the elder Huber shows that bees can alter even

1 Huber, ii. 221-226. 244-247.

2 Ibid. ii. 226.

3 Ibid. ii. 220. 
the form of their cells when circumstances require it, and that in a way which one would not have expected.

Having placed in front of a comb which the bees were constructing a slip of glass, they seemed immediately aware that it would be very difficult to attach it to so slippery a surface ; and instead of continuing the comb in a straight line, they bent it at a right angle, so as to extend beyond the slip of glass, and ultimately fixed it to an adjoining part of the wood-work of the hive which the glass did not cover. This deviation, if the comb had been a mere simple and uniform mass of wax, would have evinced no small ingenuity; but you will bear in mind that a comb consists on each side, or face, of cells having between them bottoms in common; and if you take a comb, and, having softened the wax by heat, endeavour to bend it in any part.at a right angle, you will then comprehend the difficulties which our little architects had to encounter. The resources of their instinct, however, were adequate to the emergency. They made the cells on the convex side of the bent part of the comb much larger, and those on the concave side much smaller than usual; the former having three or four times the diameter of the latter. But this was not all. As the bottoms of the small and large cells were as usual common to both, the cells were not regular prisms, but the small ones considerably wider at the bottom than at the top, and conversely in the large ones! What conception can we form of so wonderful a flexibility of instinct? How, as Huber asks, can we comprehend the mode in which such a crowd of labourers, occupied at the same time on the edge of the comb, could agree to give to it the same curvature from one extremity to the other; or how they could arrange together to construct on one face cells so small, while on the other they imparted to them such enlarged dimensions? And how can we feel adequate astonishment that they should have the art of making cells of such different sizes correspond ? ${ }^{1}$

After this long but I flatter myself not wholly uninteresting enumeration, you will scarcely hesitate to admit that insects, and of these the bee preeminently, are endowed with a much more exquisite and flexible instinct than the larger animals. But you may be here led to ask, Can all this be referred to instinct? Is not this pliability to circumstances - this surprising adaptation of means for accomplishing an end-rather the result of reason?

You will not doubt my allowing the appositeness of this question, when I frankly tell you that so strikingly do nuany of the preceding facts seem at first view the effect of reason, that in my original sketch of the letter you are now reading, I had arranged them as instances of this faculty. But mature consideration has convinced me (though I confess the subject has great difficulties) that this view was fallacious; and that though some circumstances connected with these facts may, as I shall hereafter show, be referable to reason, the facts themselves can only be consistently explained by regarding them as I have here done, as examples of variations of particular instincts:- and this on two accounts.

In the first place, these variations, however singular, are limited in their extent: all bees are, and have always been, able to avail themselves of a certain number, but not to increase that number. Bees cemented their 
combs, when becoming heavy, to the top of the hive with mitys, in the time of Aristotle and Pliny as they do now ; and there is every reason to believe that then, as now, they occasionally varied their procedures, by securing them with wax or with propolis only, either added to the upper range of cells, or disposed in braces and ties to the adjoining combs. But if in thus proceeding they were guided by reason, why not under certain circumstances adopt other modes of strengthening their combs? Why not, when wax and propolis are scarce, employ mud, which they might see the martin avail herself of so successfully? Or why should it not come into the head of some hoary denizen of the hive, that a little of the mortar with which his careful master plasters the crevices between his habitation and its stand might answer the end of mitys? "Si seulement ils élevoient une fois des câbanes quarrées" (says Bonnet, when speaking as to what faculty the works of the beaver" are to be referred), "mais ce sont éternellement des câbanes rondes ou ovales:" 1 and so we might say of the phenomena in question-Show us but one instance of bees having substituted mud or mortar for mitys, pissoceros, or propolis, or wooden props for waxen ties, and there could be no doubt of their being here guided by reason. But since no such instance is on record; since they are still confined to the same limits - however surprising the range of these limits - as they were two thousand years ago; and since the bees emerged from their pupa but a few hours before will set themselves as adroitly to work, and pursue their operations as scientifically as their brethren, who can boast the experience of a long life of twelve months' duration; $\rightarrow$ we must still regard these actions as variations of instinct.

In the second place, no degree of reason that we can with any share of probability attribute to bees could be competent to the performance of labour's so complicated as those we have been considering, and which, if the result of reason, would involve the most extensive and varied knowledge in the agents. Suppose a man to have attained by long practice the art of modelling wax into a congeries of uniform hexagonal cells, with pyramidal bottoms composed each of three rhombs, resembling the cells of workers among bees. Let him now be set to make a congeries of similar but larger cells (answering to the male cells), and unite these with the former by other hexagonal cells, so that there should be no disruption in the continuity or regularity of the whole assemblage, and no racant intervals or patching at the junctions either of the tubes or the bottoms of the cells; - and you would have set him no very easy task - a task, in short, which it may be doubted if he would satisfactorily perform in a twelvemonth, though gifted with a clear head and a competent store of geometrical knowledge, and which, if destitute of these requisites, it may be safely asserted that he would never perform at all. How then can we imagine it possible that this difficult problem, and others of a similar kind, can be so completely and exactly solved by animals of which some are not two days old, others not a week, and probably none a year? The conclusion is irresistible - it is not reason but instinct that is their guide.

The second head, under which I proposed contrasting the instinct of insects with those of the larger animals, was that of their number in the name individual. In the latter this is for the most part very limited, not 
exceeding (if we omit those common to almost all animated beings) eight or ten distinct instincts. Thus in the common duck, one instinct leads it at its birth from the egrg to rush to the water; another to seek its proper food; a third to pair with its mate; a fourth to form a nest; a fifth to sit upon its eggs till hatched; a sixth to assist the young ducklings in extricating themselves from the shell; and a seventh to defend them when in danger until able to provide for themselves : and it would not be easy, as far as my knowledge extends, to add many more distinct instinctive actions to the enumeration, or to adduce many species of the superior classes of animals entowed with a greater number.

But how vastly more manifold are the instincts of the majority of insects! It is not necessary to insist upon those differences which take place in the same insect in its different states, leading it to select one kind of food in the larva and another in the perfect state-to defend itself in one mode in the former, and in another in the latter, \&c.; because, however remarkable these variations, they may be referred with great plausibility to those striking changes in the organic structure of the animal which occur at the two periods of its existence. It is to the number of instincts observable in the same individual of many insects in their perfect state that I now confine myself; and as the most striking example of the whole I shall select the hive-bee, - begging you to bear in mind that I do not mean to include those exhibited by the queen, the drones, or even those of the workers terned by Huber cirières (wax makers); but only to enumerate those presented by that portion of the workers terned by Huber nourrices or petites abeilles (nurses), upon whom, as you have been before told, with the exception of making wax, laying the foundation of the cells, and collecting honey for being stored, the principal labours of the hive devolve. It will be these individuals alone that I shall understand by the tern bees, under the present head; and though the other inhabitants of the hive may occasionally concur in some of their actions and labours, yet it is obvious that so many as are those in which they distinctly take part, so many instincts must we regard them as endowed with.

To begin, then, with the formation of the colony. By one instinct bees are directed to send out scouts previously to their swarming, in search of a suitable abode; and by another to rush out of the hive after the queen that leads forth the swarm, and follow wherever she bends her course. Having taken possession of their new abode, whether of their own selection or prepared for them by the hand of man, a third instinct tcaches them to cleanse it from all impurities ${ }^{1}$; a fourth to collect propolis, and with it to stop up every crevice except the entrance; a filth to ventilate the hive for preserving the purity of the air; and a sixth to keep a constant guard at the door. ${ }^{2}$

In constructing the houses and streets of their new city, or the cells and combs, there are probably several distinct instincts exercised; but, not to leave room for objection, I shall regard them as the result of one only : yet the opcrations of polishing the interior of the cells, and soldering their angles and orifices with propolis, which are sometimes not undertaken for weeks after the cells are built ${ }^{3} ;$ and the obscure, but still more curious one, of varnishing them with the yellow tinge observable in old combs, seem clearly relerable to at least two distinct instincts. The varnishing

1 Huber, ii. 102.

2 Ibid. i. 186. ii. 412.

3 Ibid. ii. 264. 
process is so little connected with that of building, that though it takes place in some combs in three or four davs, it does not in others for several months, though both are equally employed for the same uses. ${ }^{3}$ Huber ascertained by accurate experiments that this tinge is not owing to the heat of the hives; to any vapours in the air which they include; to any emanations from the wax or honey; nor to the deposition of this last in the cells; but he inclines to think it is occasioned by a yellow matter which the bees seem to detach from their mandibles, and to apply to the surface which they are varnishing, by repeated strokes of these organs and of the forefeet. ${ }^{2}$

In their out-of-door operations several distinct instincts are concerned. By one they are led to extract honey from the nectaries of flowers ; by another to collect pollen after a process involving very complicated manipulations, and requiring a singular apparatus of brushes and baskets ; and that must surely be considered a third which so remarkably and beneficially restricts each gathering to the same plant. It is clearly a distinct instinct which inspires bees with such dread of rain, that even if a cloud pass before the sun, they return to the hive in the greatest haste ${ }^{3}$; and that seems to me not less so, which teaches them to find their way back to their home after the most distant and intricate wanderings. When bees have found the direction in which their hive lies, Huber says they fly to it with an extreme rapidity, and as straight as a ball from a musket ${ }^{4}$; and if their hives were always in open situations, one might suppose, as Huber seems inclined to think, that it is by their sight they are conducted to them. But hives are frequently found in small gardens embowered in wood, and in the midst of villages surrounded and interspersed with trees and buildings, so as to make it impossible that they can be seen from a distance. If you had been with me in 1815, in the famous Pays de Waes in Flanders, where the country is a perfect flat, and the inhabitants so enamoured either of the beauty or profit of trees that their fields, which are rarely above three acres in extent, are constantly surrounded with a double row, making the whole district one vast wood, you would have pitied the poor bees if reduced to depend on their own eyesight for retracing the road homeward. In vain, cluring my stay at St. Nicholas, I sallied out at every outlet to try to gain some idea of the extent and form of the town. Trees - trees - trees - still met me, and intercepted the view in every direction; and I defy any inhabitant bee of this rural metropolis, after once quitting its hive, ever to gain a glimpse of it again until nearly perpendicularly over it. The becs, therefore, of the Pays de Waes, and consequently all other bees, must be led to their abodes by instinct, as certainly as it is instinct that directs the migrations of birds or of fishes, or domestic quadrupeds to find out their homes from inconceivable distances. ${ }^{5}$ When they have reached the hive, another instinct leads them to

1 Huber, ii. 274.

2 Ibid. ii. 275 .

3 Ibid. i. 356.

1 Ibid. ii. 367.

5 The following striking anecdote of this last species of instinct, in an animal not famed for sagacity, was related to me by Lieutenant (now Lieut.-Colonel) Alderson (Royal Engineers), who was personally acquainted with the facts. - In March, 1816, an ass, the property of Captain Dundas, R. N., then at Malta, was shipped on board the Ister frigate, Captain Forrest, bound from Gibraltar for that island. The ressel having struck on some sands off the Point de Gat, at some distance from the shore, the ass was thrown overboard to give it a chance of swimming to land 
regurgitate into the extended proboscis of their hungry companions who have been occupied at home a portion of the honey collected in the fields; and another directs them to unload their legs of the masses of pollen, and to store it in the cells for future use.

Several distinct instincts, again, are called into action in the important business of feeding the young brood. One teaches them to swallow pollen, not to satisfy the calls of hunger, but that it may undergo in their stomach an elaboration fitting it for the food of the grubs; and another to regurgitate it when duly concocted, and to administer it to their charge, proportioning the supply to the age and condition of the recipients. A third informs them when the young grubs have attained their full growth, and directs them to cover their cells with a waxen lid, convex in the male cells, but nearly flat in those of workers; and by a fourth, as soon as the young bees have burst into day, they are impelled to clean out the deserted tenements and to make them ready for new occupants.

Numerous as are the instincts I have already enumerated, the list must yet include those connected with that mysterious principle which binds the working-bees of a hive to their queen; the singular imprisonment in which they retain the young queens that are to lead off a swarm, until their wings be sufficiently expanded to enable them to fiy the moment they are at liberty, gradually paring away the waxen wall that confines them to their ceil to an extreme thinness, and only suffering it to be broken down at the precise moment required; the attention with which, in these circumstances, they feed the imprisoned queen by frequently putting honey upon her proboscis, protruded from a small orifice in the lid of her cell ; the watchfulness with which, when at the period of swarming more queens than one are required, they place a guard over the cells of those undisclosed, to preserve them from the jealous fury of their excluded rivals ; the exquisite calculation with which they invariably release the oldest queens the first from their confinement; the singular love of monarchical dominion, by which, when two queens in other circumstances are produced, they are led to impel them to combat until one is destroyed; the ardent devotion which binds them to the fate and fortunes of the survivor; the distraction which they manifest at her loss, and their resolute determination not to accept of any stranger until an interval has elapsed sufficiently long to allow of no chance of the return of their rightful sove. reign; and (to omit a further enumeration) the obedience which in the utmost noise and confusion they show to her well-known hum.

- a poor one, for the sea was running so high that a boat which left the ship was lost. A few days afterwards, however, when the gates of Gibraltar were opened in the morning, the ass presented himself for armittance, and proceeded to the stable of Mr. Weeks, a merchant, which he had formerly" occupied, to the no small surprise of this gentleman, who imagined that from some accident the animal had never been shipped on board the Ister. On the return of this vessel to repair, the mystery was explained; and it turned out that Valiante (so the ass was called) had not only swum safely to shore, but, without guide, compass, or travelling map, had found his way from Point de Gat to Gibraltar, a distance of more than two hundred miles, which he had never traversed before, through a mountainous and intricate country, intersected by streams, and in so short a period that he could not have made one false turn. His not having been stopped on the road was attributed to the circumstance of his luaving been formerly used to whip criminals upon, which was indicated to the peasants, who have a superstitious horror of such asses, by the holes in his ears, to which the persons flogged were tied. 
I have now instanced at least thirty distinct instincts with which every individual of the nurses amongst the working-bees is endowed; and if to the account be addled their care to carry from the hive the dead bodies of any of the community; their pertinacity in their battles, in directing their sting at those parts only of the bodies of their alversaries which are penetrable by it; their annual autumnal murder of the drones, \&c. \&c. - it is certain that this number might be very considerably increased, perhaps doubled.

At the first view you will be inclined to suspect some fallacy in this enumeration, and that this variety of actions ought to be referred rather to some general principle, capable of accommodating itself to different circumstances, than to so many different kinds of instinct. But to what principle? Not to reason, the faculty to which we assign this power of varying accommodation. All the actions above adduced come strictly under the description of instinctive actions, being all performed by every generation of bees since the creation of the world, and as perfectly a day or two after their birth as at any subsequent period. And as the very essence of instinct consists in the determinate character of the actions to which it gives birth, it is clear that every distinctly different action must be referred to a distinct instinct. Few will dispute that the instinct which leads a duck to resort to the water is a different instinct from that which leads her to sit upon her eggs ; for the hen, though endowed with one, is not with the other. In fact, they are as distinct and unconnected as the senses of sight and smell; and it appears to me that it would be as contrary to philosophical accuracy of language in the former case to call the two instincts modifications of each other, as in the latter so to designate the two senses; and as we say that a deaf and blind man has fewer senses than other men, so (strictly) we ought not to speak of instinct as one faculty (though to avoid circumlocution, I have myself often employed this common mode of expression), or say that one insect has a greater or less share of instinct than another, but more or fewer instincts. That it is not always easy to determine what actions are to be referred to a distinct instinct and what to a modification of an instinct, I am very realy to admit; but this is no solid ground for regarding all instincts as modifications of some one principle. It is often equally difficult to fix the limits between instinct and reason; but we are not on this account justified in deeming them the same.

This multitude of instincts in the same individual becomes more wonderful when considered in another point of view. Were they constantly to follow each other in regular sequence, so that each bee necessarily first began to build cells, then to collect honey, next pollen, and so on, we might plausibly enough refer them to some change in the sensations of the animal, caused by alterations in the structure and gradual development of its organs, in the same way as on similar principles we explain the sexual instincts of the superior tribes. But it is certain that no such consecutive series prevails. The different instincts of the bee are called into action in an order regulated solely by the needs of the society. If combs be wanted, no bee collects honey for storing until they are provided ${ }^{1}$; and if, when constructed, any accident injure or destroy them, every labour is suspended until the mischief is repaired or new ones substituted. When the crevices 
round the hive are effectually secured with propolis, the instinct directing the collection of this substance lies dormant; but transfer the bees to a new hive which shall require a new luting, and it is instantly re-excited. But these instances are superfluons. Every one knows that at the same moInent of time the citizens of a hive are employed in the most varjed and opposite operations. Some are collecting pollen; others are in search of honey; some busied at home in the first construction of the cells; others in giving then their last polish; others in ventilating the hive; others again in feeding the young brood and the like.

Now, how are we to account for this regularity of procedure - this undeviating accuracy with which the precise instinct wanted is excited - this total absence of all confusion in the employment, by each inhabitant of the hive, of that particular instinct out of so many which the good of the community requires? No thinking man ever witnesses the complexness and yet regularity and efficiency of a great establishment, such as the Bank of England or the Post-Office, without marvelling that even human reason can put together, with so little friction and such slight deviations from correctness, machines whose wheels are composed not of wood and iron, but of fickle mortals of a thousand different inclinations, powers, and capacities. But if such establishments be surprising even with reason for their prime mover, how much more so is a hive of bees whose proceedings are guided by their instincts alone! We can conceive that the sensations of hunger experienced on awaking in the morning should excite into action their instinct of gathering honey. But all are hungry ; yet all do not rush out in search of flowers. What sensation is it that detains a portion of the hive at home, unmindful of the gnawings of an empty stomach, busied in domestic arrangements, until the return of their roving companions? Of those that fly abroacl, what conception can we form of the cause which, while one set is gathering honey or pollen, leads another company to load their legs with pellets of propolis? Are we to say that the instinct of the former is excited by one sensation, that of the latter by another? But why should one sensation predominate in one set of bees, while another takes the lead in a second? - or how is it that these different instincts atre called up precisely in the degree which the actual and changing state of things in the hive requires? Of those which remain at home, what is it that determines in one party the instinct of building cells to prevail ; in another that of ventilating the hive; in a third that of feeding the young brood? For my own part, I confess that the more I reflect on this subject, and contrast the diversity of the means with the regularity and uniformity of the end, the more 1 am lost in astonishment. The effects of instinct seem even more wonderful than those of reason, in the same manner as the consentaneous movements of a mighty and divided army, which, though under the command of twenty generals, and from the most distant quarters, should meet at the assigned spot at the very hour fixed upon, would be more surprising than the steam-moved operations, however complex, of one of Boulton's inints.

For the sake of distinctness and compression, I have confined myself in considering the numbers of the instincts of individual insects to a single species, the bee ; but if the history of other societies of these animals wasps, ants, \&c., detailed in my former letters, - be duly weighed, it will be seen that they furnish examples of the variety in question fully as striking. These corroborating proofs I shall leave to your own inference, and 
proceed to the third head, under which I proposed to consider the instincts of insects - that of their extraordinary development.

The development of some of the instincts of the larger animals, such as those of sex, is well known to depend upon their age and the peculiar state of the bodily organs; and to this, as before observed, the succession of different instincts in the same insect, in its larva and perfect state, is closely analogous. But what I have now in view is that extraordinary development of instinct which is dependent not upon the age or any change in the organisation of the animal, but upon external events - which in individuals of the same species, age, and structure, in some circumstances slumbers unmoved, but may in others be excited to the most singular and unlooked-for action. In illustrating this property of instinct, which, as far as I am aware, is not known to occur in any of the larger animals, I shall confine myself as before to the hive-bee; the only insect, indeed, in which its existence has been satisfactorily ascertained, though it is highly probable that other species living in societies may exhibit the same phenomenous.

Several of the facts occurring in the history of bees might be referred to this head; but I shall here advert only to the treatment of the drones by the workers under different circumstances, and to the operations of the latter consequent upon the irretrievable loss of the queen - facts which have been before stated to you, but to the principal features of which my present argument makes it necessary that I should again direct your attention.

If a hive of bees be this year in possession of a queen duly fertilised, and consequently sure the next season of a succession of males, all the drones, as I have before stated, towards the approach of winter are massacred by the workers with the most unrelenting ferocity. To this seemingly cruel course they are doubtless impelled by an imperious instinct; and as it is legularly followed in every hive thus circumstanced, it would seem at the first view to be an impulse as intimately connected with the organisation and very existence of the workers, and as incapable of change, as that which leads them to build cells or to store up honey. But this is far from being the case. However certain the doom of the drones this autumn if the hive be furnished with a duly fertilised queen, their undisturbed existence over the winter is equally sure if the hive have lost its sovereign, or her impregnation have been so retarded as to make a succession of males in the spring doubtful. In such a hive the workers do not destroy a single drone, though the hottest persecution rages in all the hives around them.

Now, how are we to explain this difference of conduct? Are we to suppose that the bees know and reason upon this alteration in the circumstances of their community - that they infer the possibility of their entire extinction if the whole male stock were destroyed when without a queen - and that thus influenced by a wise policy they restrain the fury they would otherwise have exercised? This would be at once to make them not only gifted with reason, but endowed with a power of looking before and after, and a command over the strongest natural propensities, superior to what could be expected in a similar case even from a society of men, and is obviously unwarrantable. The only probable supposition is, clearly, that a new instinct is developed suited to the extraor- 
dinary situation in which the community stands, leading them now to regard with kindness the drones, for whom otherwise they would have felt the most violent aversion.

In this instance, indeed, it would perhaps be more strictly correct to say (which, however, is equally wonderful) that the old instinct was extinguished; but in the case of the loss of a queen, to which I am next to advert, which is followed by positive operations, the extraordinary develop ment of a new and peculiar instinct is indisputable.

In a hive which no untoward event has deprived of its queen, the workers take no other active steps in the education of her successors those of which one is to occupy her place when she has flown off at the head of a new swarm in spring - than to prepare a certain number of cells of extraordinary capacity for their reception while in the egig, and to feed them when become grubs with a peculiar food until they have attained maturity. This, therefore, is their ordinary instinct ; and it may happen that the workers of a hive may have no vecessity for a long series of successive generations to exercise any other. But suppose them to lose their queen. Far from sinking into that inactive despair which was formerly attributed to then, after the commotion which the rapidly-circulated news of their calamity gave birth to luas subsided, they betake themselves with an alacrity from which man when under misfortune night deign to take a lesson, to the active reparation of their loss. Several ordinary cells, as was before related at large, are without delay pulled down, and converted into a variable number of royal cells, capracious enough for the education of one or more queen-grubs selected out of the unhoused working grubs - which in this pressing emergency are mercilessly sacrificed - and fed with the appropriate royal food to maturity. Thus sure of once more acquiring a head, the hive return to their ordinary labours, and in about sixteen days one or more queens are produced; one of which, after being indebted to fortune for an elevation as singular as that of Catherine the First of Russia, steps into day and assumes the reins of state.

To this remarkable deviation from the usual procedures of the community, the observations above made in the case of the drones must be applied. We cannot account for it by conceiving the working-bees to be acquainted with the end which their operations have in view. If we suppose them to know that the queen and working-grubs are originally the same, and that to convert one of the latter into the former it is only necessary to transfer it to an apartment sufficiently spacious and to feerl it with a peculiar food, we confer upon them a depth of reason to which Prometheus, when he made his clay man, had no pretensions-an original discovery, in short, to which man has but just attained after some thousand years of painful research, having escaped all the observers of bees from Aristomachus to Swammerdam and Reaumur of modern times. We have no other alternative, then, but to refer this phenonienon to the extraordinary development of a new instinct suited for the exigency, however incomprehensible to us the manner of its excitement may appear.

II. Such, then, are the exquisiteness, the number, and the extraordinary development of the instincts of insects. But is instinct the sole guide of their actions? Are they in every case the blind agents of irresistible impulse? These queries, $I$ have already hinted, cannot in my opinion be replied to in the affirmative; and I now procecd to show that though in- 
stinct is the chief guide of insects, they are endowed also with no inconsiderable portion of reason.

Some share of reason is denied by few philosophers of the present day to the larger animals. But its existence has not generally (except by those who reject instinct altogether) been recognised in insects : probably on the ground that, as the proportions of reason and of instinct seem to coexist in an inverse ratio, the former might be expected to be extinct in a class in which the latter is found in such perfection. This rule, however, though it may hold good in man, whose instincts are so few and imperfect, and whose reason is so pre-eminent, is far from being confirmed by an extended survey of the classes of animals generally. Many quadrupeds, birds, and fishes, with instincts apparently not very acute, do not seem to have their place supplied by a proportionably superior share of reason; and insects, as I think the facts I have to adduce will prove, though ranking so low in the scale of creation, seem to enjoy as great a degree of reason as many animals of the superior classes, yet in combination with instincts much more numerous and exquisite.

I must premise, however, that in so perplexed and intricate a field, I am sensible how necessary it is to tread with cantion. A far greater collection of facts must be made, and the science of metaphysics generally be placed on a more solid foundation than it now can boast, before we can pretend to decide, in numerous cases, which of the actions of insects are to be deemed purely instinctive, and which the result of reason. What I advance, thercfore, on this head, I wish to be regarded rather as conjectures, that, after the best consideration I am able to give to a subject so much beyond my depth, seem to me plausible, than as certainties to which I require your implicit assent.

That reason has nothing to do with the major part of the actions of insects is clear, as I have before observed, from the determinateness and perfection of these actions, and from their being performed independently of instruction and experience. A young bee (I must once more repeat) betakes itself to the complex operation of building cells with as much skill as the oldest of its compatriots. We cannot suppose that it has any linowledge of the purposes for which the cells are destined; or of the effects that will result from its feeding the young larvæ, and the like. And if an individual bee be thus destitute of the very materials of reasoning as to its main operations, so must the society in general.

Nor in those remarkable deviations and accommodations to circumstances, instanced under a former head, can we, for considerations there assigned, suppose insects to be influenced by reason. These deviations are still limited in number, and involve acts far too complex and recondite to spring from any process of ratiocination in an animal whose term of life does not exceed two years.

It does not follow, however, that reason may not have a part in inducing some of these last-mentioned actions, though the actions themselves are purely instinctive. I do not pretend to explain in what way or degree they are combined; but certainly some of the facts do not seem to admit of explanation, except on this supposition. Thus, in the instance above cited from Huber, in which the bees bent a comb at right angles in order to avoid a slip of glass, the remarkable variations in the form of the cells can only, as I have there said, be referred to instinct. Yet the original determination to avoid the glass seems, as Huber himself observes, to indicate 
something more than instinct, since glass is not a substance against which nature can be supposed to have forewarned bees, there being nothing in hollow trees (their natural abodes) resembling it either in polish or substance; and what was most striking in their operations was, that they did not wait until they had reached the surface of the glass before changingr the direction of the comb, but adopted this variation at a considerable distance, as though they foresaw the inconveniences which might result from another mode of construction. ${ }^{1}$ However difficult it may be to form a clear conception of this union of instinct and reason in the same operation, or to define precisely the limits of each, instances of these mixed actions are sufficiently common among animals to leave little doubt of the fact. It is instinct which leads a greyhound to pursue a hare ; but it must be reason that directs " an old greyhound to trust the more fatiguing part of the chase to the younger, and to place himself so as to meet the hare in her doubles." 2

As another instance of these mixed actions in which both reason and instinct seem concerned, but the formel more decidedly, may be citel the account which Huber gives of the manner in which the bees of some of his neighbours protected themselves against the attacks of the death's head moth (Acherontia atropos), lail before you in a former letter, by so closing the entrance of the hive with walls, arcades, casements, and bastions, built of a mixture of wax and propolis, that these insidious marauders could no longer intrude themselves.

We can scarcely attribute these elaborate fortifications to reason simply; for it appears that hees have recourse to a similar defensive expedient when attacked even by other bees, and the means employed seem too subtle and too well adapted to the end to be the result of this faculty in a bee.

But, on the other hand, if it be most probable that in this instance instinct was chiefly concerned, if we inpartially consider the facts, it seems impossible to deny that reason had some share in the operations. Pure instinct would have taught the hees to fortify themselves on the first attack. If the occupants of a hive had been taken unawares by these gigantic aggressors one night, on the second, at least, the entrance should have been barricadoed. But it appears clear, from the statement of Huber, that it was not until the hives had heen repeatedly attacked and robbed of nearly their whole stock of honey, that the bees betook themselves to the plan so successfully adopted for the security of their remaining treasures; so that reason, taught by experience, seems to have called into action their dormant instincts. ${ }^{3}$

If it be thus probable that reason has some influence upon the actions of insects which must be mainly regarded as instinctive, the existence of this faculty is still more evident in numerous traits of their history where instinct is little if at all concerned. An insect is taught by its instincts the most unerring means to the attainment of certain ends; but these ends, as I have already had occasion more than once to remark, are limited in number, and such only as are called for by its wants in a state of nature. We cannot reasonably suppose insects to be gifted with instincts adapted for occasions that are never likely to happen. If, 
therefore, we find them, in these extraordinary and improbable emergencies, still availing themselves of the means apparently best calculated for ensuring their object; and if in addition they seem in some cases to gain knowledge by experience; if they can communicate information to each other; and if they are endowed with memory, - it appears impossible to deny that they are possessed of reason. I shall now produce facts in proof of each of these positions; not by any means all that might be adduced, but a few of the most striking that occur to me.

First, then, insects often, in cases not likely to be provided for by in. stinct, adopt means evidently designed for effecting their object.

A certain degree of warmth is necessary to hatch a hen's eggs, and we give her little credit for reason in sitting upon them for this purpose. But if any one had ever seen a hen make her nest in a heap of fermenting dung, among the bark of a bot-bed, or in the vicinity of a baker's oven, where, the heat being as well adapted as the stoves of the Egyptians to bring her chickens into life, she left off the habit of her race, and saved herself the trouble of sitting upon them, - we should certainly pronounce her a reasoning hen; and if this hen lad chanced to be that very one figured and so elaborately described by Professor Fischer with the profile of an old wo. man $^{1}$, a Hindoo metaphysician at leust could not doubt of her body, however hen-like, being in truth directed in its operations by the soul of some quondam amateur of poultry-breeding. Now societies of ants have more than once exhibited a deviation from their usual instinct, which to me seems quite as extraordinary and as indicative of reason as would be that supposed in a hen. A certain degree of warmth is required for the exclusion and rearing of their eggs, larvæ, and pupæ; and in thcir ordinary abodes, as you have been already told, they undergo great daily labour in removing their charge to different parts of the nest, as its temperature is affected by the presence or absence of the sun. But Reaumur, in refuting the common notion of ants being injurious to bees, tells us that societies of the former often saved themselves all this trouble, by establishing their colonies between the exterior wooden shutters and panes of his glass lives, where, owing to the latter substance being a tolerably good conductor of heat, their progeny was at all times, and without any necessity of changing their situation, in a constant, equable, and sufficient temperature. $^{2}$ Bonnet observed the same fact. He found that a society of ants had piled up their young to the height of several inches, between the flannel-lined case of his glass hives and the glass. When disturbed they ran away with them, but always replaced them. ${ }^{3}$

I am persuaded that, after duly considering these facts you will agree with me that it is impossible consistently to refer them to instinct, or to account for them without supposing some stray ant, that had insinuated herself into this tropical crevice, first to bave been struck with the thought of what a prodigious saving of labour and anxiety would occur to her compatriots by establishing their society here; that she had communicated her ideas to them ; and that they had resolved upon an enigration to this newdiscovered country - this Madeira of ants - whose genial clime presented

1 See Fischer's Beschreibung eines Huhns mit menschenähnlichem Profile, 8vo. St. Petersburg, 1816; and a trauslation in Thomson's Annals of Phil. vii. 241.

2 Reaum. v. 709. 
advantages which no other situation could offer. Neither instinct, nor any conceivable modification of instinct, could have taught the ants to avail themselves of a good fortune which but for the invention of glass hives would never have offered itself to a generation of these insects since the creation; for there is nothing analogous in nature to the constant and equable warmth of such a situation, the heat of any accidental mass of fermenting materials soon ceasing, and no heat being given out from a society of bees when lodged in a hollow tree, their natural residence. The conclusion, then, seems irresistible, that reason must have been their guide, inducing a departure from their natural instinct as extraordinary as would be that of a hen which should lay her eggs in a hot-bed, and cease to sit upon them.

The adaptation of means to an end not likely to have been provided for by instinct is equally obvious in the ingenious mode by which a nest of humble-bees propped up their tottering comb, the particulars of which having before mentioned to you, I need not here repeat.

There is perhaps no surer criterion of reason than, after having tried one mode of accomplishing a purpose, adopting another more likely to succeed. Insects are able to stand this test. A bee which Huber watched, while soldering the angles of a cell with propolis, detached a thread of this naterial with which she entered the cell. Instinct would have taught her to separate it of the exact length required; but after applying it to the angle of the cell, she found it too long, and cut off a portion so as to fit it to her purpose. $^{1}$

This is a very simple instance; but one such fact is as decisive in proof of reason as a thousand more complex, and of such there is no lack. Dr. Darwin (whose authority in the present case depending not on hearsay, but his own observation, may be here taken) informs us, that walking one day in his garden, he perceived a wasp upon the gravel walk with a large fly nearly as big as itself which it had caught. Kneeling down he distinctly saw it cut off the head and abdomen, and then, taking up with its feet the trunk or middle portion of the body to which the wings remained attached, fly away. But a breeze of wind acting upon the wings of the fly turned round the wasp with its burthen, and impeded its progress. Upon this it alighted again on the gravel walk, deliberately sawed off first one wing and then the other; and having thus removed the cause of its embarrassInent, flew off with its booty. ${ }^{2}$ Could any process of ratiocination be more perfect? "Something acts upon the wings of this fly and impedes my flight. If I wish to reach my nest quickly, I must get rid of them - to effect which, the shortest way will be to alight again and cut them off." These reflections, or others of similar import, must be supposed to have passed through the mind of the wasp, or its actions are altogether inexplicable. Instinct might have taught it to cut off the wings of all flies, previonsly to Aying away with them. But here it first attempted to fly with the wings on, - was impeded by a certain cause, - discovered what this cause was, and alighted to remove it. The chain of evidence seems perfect in proof that nothing but reason could have been its prompter. ${ }^{3}$

An analogous though less striking fact is mentioned by Reaumur, on the

1 Huber, ii. 268.

2 Zoonomia, i. 183.

3 Mr. Newport has argued, in a paper read to the Entomological Society (Trans. i. 228.), that the instinct of wasps is always to cut off the wings of ties 
anthority of M. Cossigny, who witnessed it in the Isle of France, where the Sphecina are accustomed to bury the bodies of cockroaches along with their eggs for provision for their young. He sometimes saw an insect of this tribe attempt to drag after it into its hole a dead cockroach, which was too big to be made to enter by all its efforts. After several ineffectual trials the animal came out, cut off its elytra and some of its legs, and thus reduced in compass drew in its prey without difficulty. ${ }^{1}$

Under this head I shall mention but one fact more. A friend of Gleditsch, the observer of the singular economy of the burying beetle (Necrophorus vespillo) related in a former letter, being desirous of drying a dead toad, fixed it to the top of a piece of wood which he stuck into the ground. But, a short time afterwards, he found that a body of these indefatigable little sextons had circumvented him in spite of his precautions. Not being able to reach the toad, they had undermined the base of the stick until it fell, and then burice both stick and toad. ${ }^{2}$

In the second place, insects gain knowledge from experience, which would be impossible if they were not gifted with some portion of reason. In proof of their thus profiting, I shall select from the numerous facts that might be brought forward four only, one of which has been already slightly adverted to.

II. P. Huber, in his valuable paper in the sixth volume of the Linnean Transactions, ${ }^{3}$ states that he has seen large humble-bees, when unable from the size of their head and thorax to reach to the bottom of the long tubes of the flowers of bcans, go directly to the calyx, pierce it as well as the tube with the exterior horny parts of their proboscis, and then insert their proboscis itself into the orifice and abstract the honey. They thus flew from Hower to flower, piercing the tubes from without, and sucking the nectar; while smaller humble-bees, or those with a longer proboscis, entered in at the top of the corolla. Now, from this statement, it seems evident that the larger bees did not pierce the bottoms of the flowers until they had ascertained by trial that they could not reach the nectar from the top; but that having once ascertained by experience that the flowers of beans are too strait to admit them, they then, without further attempts in the ordinary way, pierced the bottoms of all the flowers which they wished to rifle of their sweets. M. Aubert du Petit-Thouars observed that humble-bees and the carpenter-bee ( $X_{y}$ locopa ${ }^{4}$ violacea) gained access in a similar manner to the nectar of Antirrhimm Linaria and majus and Mirabilis Jalapa, as do the common bees of the Isle of France to that of Canna indicas; and I have myself more than once noticed holes at the base of the long nectaries of Aquilegia vulgaris, which I attribute to the same agency. ${ }^{6}$

before tlying away with them; and that, consequently, the above fact proves nothing as to the reason of insects. Here, however, I must beg to differ from him ; for supposing Dr. Darwin's statement to be accurate, which, from the minute particulars into which he enters, we have no right to doubt, the circum. stances of the wasp's first violating its natural instinct by flying away with the fly before cutting off its wings, and then, on finding the wind act upon them, alighting to do what it had neglected at first, cannot well be explained except on the supposition of some reasoning process having passed through its mind. In any case, there is 110 need of this particular fact to prove the existence of reason in insects, of which sueh numerous other instances have been adduced.

I Reaum, vi. 283.

2 Gleditsch, Physic. Bot. Econ. Alhandl. iii. 220.

3 P.222. 4 Apis * *. d. 2. $\beta$. K. 5 Nouv. Bul. des Sciences, i. 45.

6 See an interesting article by Mr. C. Darwin in the Gardener's Chronicle, 1811. 
A similar instance of knowledge gained by experience in the hive-bee is related by Mr. Wailes. He observed that all the bees, on their first visit to the blossoms of a passion-flower (Passiftora carulea) on the wall of his house, were for a considerable time puzzled by the numerous overwrapping rays of the nectary, and only after many trials, sometimes lasting two or three minutes, succeeded in finding the shortest way to the honcy at the bottom of the calyx; but experience having taught them this knowledge, they afterwards constantly proceeded at once to the most direct mode of obtaining the honey; so that he could always distinguish bees that had heen old visiters of the flowers from new ones, the last being invariably at first long at a loss, while the former flew at once to their object. ${ }^{1}$

My third fact is supplied by the same ants whose sagacious choice of the vicinity of Reaumur's glass hives for their colony has been just related to you. He tells us that of these ants, of which there were such swarms on the outside of the hive, not a single one was ever perceived within ; and infers that, as they are such lover's of honey, and there was no difficulty in finding crevices to enter in at, they were kept without, solely from fear of the consequences. ${ }^{2}$ Whence arose this fear? We have no ground for supposing ants endowed with any instinctive dread of bees ; and Reaumur tells us, that when he happened to leave in his garden hives of which the bees had died, the ants then never filied to enter them and regale themselves with the honey. It secms reasonable, therefore, to attribute it to experience. Some of the ants, no doubt, had tried to enter the peopled as they did the empty hive, but had been punished for their presumption; and the dear-bought lesson was not lost on the rest of the community.

The fourth instance under this head which I shall mention is that sup. plied by an Indian species of ant (Formica indefessa, Sykes). A colony of these voracious insects in Col. Sykes's house at Poona having been circumvented in their repeated and successfiul attacks on the sweetmeats alway's left on a side-board, when it was removed to a distance from the

p. 550 ., on the variations in the mode in which humble-bees pierce, as above described, the long-tubed corollas of different labiated plants. In Stachys coccinea, Mirabilis Julapa, and Salvia coccinea, each corolla had a hole on its upper side near the base, whereas in Salvia Grahami, which has a more elongated calyx, this part also was also invariably pierced ; and in Pentstcmon argutus the rather broader corolla had always two holes, in order to give the bees more ready access to the nectar on both sirles of the germen. All these holes are on the upper side of the base of the corolla ; but in the common Antirshinum they are on the under side, so as to be directly in front of the nectary. Town-educated humble-bees Mr. Dirwin found always draw off the nectar from these last-named flowers growing in the London Zoological Gardens through these artificial orifices ; while from two years' observations he is persuaded that thcir rustic brethren are less clever, and invariably gain access to the nectar of snap-dragons growing in the country by forcing open the elastic lower lip and creeping into the flower. Possibly different species or sexes of humble-bees may be here concerned; but one instance, in which the same individual bee cut holes in the base of some flowers of Rhododendron azaleoides and entered the mouth of others, seems as strong a proof of reason as can well be imagined, as the proceetlings of the little animal were evidently varied according to the varying necessity of the case; and if, as Mr. Darwin thinks be has observed, the hive-bees frequenting these flowers by degrees came to discover and avail themselves of the orifices made by the humble-bees, this fact, as he justly remarks, offers a very striking proof of acquired knowledge in insects.

1 Entom. Mug. i. 525.

2 Reaum. v. 709. 
wall sufficient to prevent their reaching it, climbed up the wall to the height of about a foot above its level, and then let themselves fall so as to alinht on the table, as Colonel Sykes himself witnessed with equal surprise and admiration. ${ }^{1}$ Here it is obvious that it was only after experience had shown the ants the inefficacy, in the altered position of the table, of their former modes of attacking the sweetmeats, that they adopted this novel and ingenious way of getting access to them, which, whether we refer it to reason or a variation of instinct, is equally remarkable.

Insects, in the third place, are able mutually to communicate and receive information, which, in whatever way effected, would be impracticable if they were devoid of reason. Under this head it is only necessary to refer you to the endless facts in proof, furnished by almost every page of my letters on the history of ants and of the hive-bee. I shall therefore but detain you for a moment with an additional anecdote or two, especially with one respecting the former tribe, which is valuable from the celebrity of the relator.

Dr. Franklin was of opinion that ants could communicate their ideas to each other; in proof of which he related to Kalm the Swedish traveller the following fact. Having placed a pot containing treacle in a closet infested with ants, these insects found their way into it, and were feasting very heartily when he discovered them. He then shook them ont, and suspended the pot by a string from the ceiling. By chance one ant remained, which, after eating its fill, with some difficulty found its way up the string, and thence reaching the ceiling, escaped by the wall to its nest. In less than half an hour a great company of ants sallied out of their hole, climbed the ceiling, crept along the string into the pot, and began to eat again. This they continued until the treacle was all consumed, one swarm running up the string while another passed down. ${ }^{2}$ It seems indisputable that the one ant had in this instance conveyed news of the booty to his comrades, who would not otherwise have at once directed their steps in a body to the only accessible route.

A German artist, a man of strict veracity, states that in his journey through Italy he was an eyewitness to the following occurrence. He observed a species of Scarabæus (Ateuchus pilularius?) busily engaged in making, for the reception of its egg, a pellet of dung, which when finished it rolled to the sumnit of a small hillock, and repeatedly suffered to tumble down its side, apparently for the sake of consolidating it by the earth which each time adhered to it. During this process the pellet unluckily fell into an adjoining hole, out of which all the cfforts of the beetle to extricate it were in vain. After sereral ineffectual trials, the insect repaired to an inljoining heap of dung, and soon returned with three of his companions. All four now applied their mited strength to the pellet, and at length succeeded in pushing it out ; which being done, the three assistant beetles left the spot and returned to their own quarters. ${ }^{3}$

Lastly, insects are endowed with memory, which (at least in connection with the purposes to which it is subservient) implies some degree of reason 
also; and their historian may exclaim with the poet who has so well sung the pleasures of this faculty,

"Hail, MEMrory, hail ! thy universal reign

Guards the least link of Being's glorious chain."

In the elegant lines in which this couplet occurs ${ }^{1}$, which were pointed out to me by my friend Dr. Alderson of Hull, Mr. Rogers supposes the bee to be conducted to its hive by retracing the scents of the various flowers which it has visited; but this idea is more poetical than accurate, bees, as before observed, flying straight to their hives from great distances. Here, as I have more than once had occasion to remark in similar instances, we have to regret the want of more correct entomological information in the poet, who might have employed with as much effect, the real fact of bees distinguishing their own hives out of numbers near them, when conducted to the spot by instinct. This recognition of home seems clearly the result of memory; and it is remarkable that bees appear to recollect their own hive rather from its situation, than from any observations on the hive itself $^{2}$ : just as a man is guided to his house from his memory of its position relative to other buildings or objects, without its being necessary for him even to cast a look at it. If, after quitting my house in a morning, it were to be lifted out of its site in the street by enchantment, and replaced by another with a similar entrance, I should probably even in the day-time enter it, without being struck by the change; and bees, if during their absence their old hive be taken away, and a similar one set in its place, enter this last; and if it be provided with brood-comb contentedly take up their abode in it, never troubling themselves to inquire what has become of the identical habitation which they left in the morning, and with the inbabitants of which, if it be removed to fifty paces distance, they never resume their connection. ${ }^{3}$

If pursuing my illustration, you should object that no man would thus contentedly sit down in a new house without searching after the old one, you must bear in mind that I am not aiming to show that bees have as pre-

"Hark ! the bee winds her small bnt mellow horn,
Blithe to salute the sunny snile of morn.
O'er thymy downs she bends her busy course,
And many a stream allures her to its source.
'Tis noon, 'tis night. That eye so finely wrought,
Beyond the search of sense, the soar of thought,
Now vainly asks the scenes she left behind;
Its orb so full, its vision so confined !
Who guides the patient pilgrim to her cell ?
Who bids her soul with conscious triumph swell ?
With conscious truth retrace the mazy clue
Of varied scents that charm'd her as sle flew?
Hail, MEmory, hail ! thy universal reign
Guards the least link of Being's glorious chain."

2 If a hive be removed out of its ordinary position, the first day after this removal the bees do not fly to a distance without having visited all the neighbouring objects. The queen does the same thing when flying into the air for fecundation. (Huber, Recherches sur les Fourmis, 100.)

3 See the account of the mode in which the Favignanais increase the number of their hives by thus dividing them. (Huber, ii. 459.) 
cise a memory as ours, but only that they are endowed with some portion of this faculty, which I think the above fact proves. Should you view it in a different light, you will not deny the force of others that have already been stated in the course of our correspondence: such as the mutual greetings of ants of the same society when brought together after a separation of four months; and the return of a party of bees in spring to a window where in the preceding autumn they had regaled on honey, though none of this substance had been again placel there. ${ }^{1}$

But the most striking fact, evincing the memory of these last-mentioned insects, has been communicated to me by my intelligent friend, Mr. William Stickney, of Ridgemont, Holderness. About twenty years ago, a swarm from one of this gentleman's hives took possession of an opening benenth the tiles of his house, whence, after remaining a few hours, they were dislodged and hivel. For many subsequent years, when the hives descended from this stock were about to swarm, a considerable party of scouts were observed for a few days before to be reconnoitring about the old hole under the tiles; and Mr. Stickney is persuaded that if suffered they would have established themselves there. He is certain that for eight years successively the descendants of the very stock that first took possession of the hole frequented it as above stated, and not those of any other swarms; having constantly noticed them, and ascertained that they were bees from the original hive by powvlering them while about the tiles with yellow ochre, and watching their return. And even at the present time there are still seen every swarming season about the tiles bees, which Mr. Stickney has no doubt are descendants from the original stock.

Had Dr. Darwin been acquainted with this fact, he would have adduced it as proving that insects can convey traditionary information from one generation to another; and at the first glance the circumstance of the descendants of the same stock retaining a knowledge of the same fact for twenty years, during which period there nust have been as many generations of bees, would seem to warrant the inference. But as it is more probable that the party of surveying scouts of the first generation was the next year accompanied by others of a second, who in like manner conducted their brethren of the third, and these last again others of the fourth generation, and so on, - I draw no other conclusion from it than that bees are endowed with memory, which I think it jroves most satisfactorily.

I am, \&c.

1 A remarkable fact, proving at once that insects are endowed with memory; association of ideas, and the sense of hearing, has been recorded by M. Goureau, the anthor of the raluable observations on the stridulation of insects, before referred to in treating of their noises. He kept for several days a praying mantis $(M$. religiosa) in a box, and fed it with flies. On first placing it in its new abode he irritated it with i pen, and at the same time gave a slight whistle. Apparentiy fearing an enemy, it put itself in a state of defence, reared up its long thorax, placed its fore feet as if to seize its prey, and half expanded its wings and elytra, rubbing its abdomen repeatedly against their sides, so as to produce a noise like that of parchment. "From the first moment (continues M. Goureau) to the la-t day that I kept it, every time that I visited it and gave the same slight whistle it assumed its defensive attitude, and did not quit it till it judged the danger past." ( Ann. Soc. Ent. de France, x. bull x riii.) 
APPENDIX. 



\section{A P P E N D I X.}

[CHAPTER XV. OF MR. FREEMAN'S LJFE OF MR. KIRBY.]

Ir is with a mournful pleasure I contribute to my friend Mr. Freeman's Life of Mr. Kirby a slight sketch of the history of our friendship of nearly half a century, and of the origin and progress of the "Introduction to Entomolgy," the source of so much interest and delight to us both ; partly from recollection, but chiefly from Mr. Kirby's letters to me during that time, and from mine to him.*

Our acquaintance began in this way. Chancing, one evening, in August 1805, when walking on the Humber bank, to meet my friend George Rodwell, Esq., then a resident at Hull, he told me he was about to visit Barham in a few days, and said if I had any insects to send to Mr. Kirby he should be happy to convey then. This offer I gladly

* These letters, with which Mr. Freeman has furnished me, are between four and five hundred in number; and those from Mr. Kirby, which I have preserved with as much care as he had mine, are nearly as many. About half of the two series of letters refer almost wholly to entomology and our book, but a great part of the remainder, exchanged during my eight years' travels and residerce on the Continent, and after my return to England, are more occupied with accounts of our tours, \&c., and of domestic matters. Our entomological letters, in those days of dear postage, were mostly written on sheets of large folio paper, so closely, that each would equal a printed sheet of sixteen pages of ordinary type. These we called our "first-rates,", or sometimes "seventy-fours," the few on ordinary-sized paper being "frigates ;" but one I find from Mfr. Kirby, which he calls tle "Foyal Harry," written on a sheet nearly the size of a "Times" supplement, and closely filled on three pages, and which he begins and concludes thus :- "Barham, March 23. 1816. My Dear Friend, - This doubtless will be the greatest rarity in the epistolary way that you ever received. I hope it will long be kept among your кєц not as a black, but as a black and white swan, which since the discovery of tine former in N. S. W., must be held as the true rara avis.... And now, haring manned this Royal Harry with as large a complement of men as I could muster, I shall launch her. I question whether ever one of equal tonnage before crossed the Humber." With the love of order which Mr. Kirby's study of natural history had so deeply implanted in lim, all my letters are folded across the sheet, so as to be of the same breadth of about two inches, and have an index on the back of each, referring to the various subjects (often 15 to 20) of the letter, which he marked in it by large figures in brackets, so as readily to catch the eye ; and they were then docketed with red tape into a packet for each year. 
accepted, and prepared a box, which was taken by Mr. Rodwell, along with a letter, which is placed first in Mr. Kirby's packet of mine of 1805, and which it is necessary to give here to make his reply intelligible.

\section{"Drypool, Hull, 26th August, 1805.}

"Sir, - Your friend Mr. Rodwell, knowing me to be a smatterer in that branch of natural history to the advanecment of which, in Britain, you have so largely contributed, told me the other day that he was about to visit your neighbourhood, and said he would be glad to convey to you any duplicates of insects I might have, that I judged might possibly be new to you. I embraced his offer with pleasurc, and $I$ have accordingly sent a few insects which $I$ have reason to think scarce, or not described in 'Entomologia Britannica.' If they are already known to you, as perhaps the major part are, I must beg you to take the will for the deed. Such as are new, if any be so, I request your acceptance of, as a small return for the high gratification I have derived from the perusal of your admirable papers in the 'Linnean Transactions,' and the introduction to your 'Monograph of English Bees.' From that work itself $I$ have not been able to derive the advantage which I have no doubt I shall reap from it when I have made a greater progress in entomology. At present, the order Coleoptera, to the investigation of which Mr. Marsham's excellent work, including so many of your discoveries, affords such facility, exclusively engages my attention. But I proceed to my immediate object, which is, to make a few short remarks on the insects I send.

"No. 1. is a Curculio belonging to Section A. b. ${ }^{* *}$ in E. B., which I do not find described there. I found it the other day in great numbers, feeding upon young oak trees, the leaves of which it corrodes in the same manner as Chrysomela vitellina, \&c. do those of willows. From its habitat, it should be C. ferrugineus of E. B.; bnt as neither its heal, rostrum, nor knecs are black, it cannot be that, and there appears to me no other in the section with which it at all accords. C. rufus I have, which is very different. Nay it not be C. Betuleti of Panzer's 'Entomologia Germanica?' which is the more likely, as $\mathbf{I}$ did find a few of the same insect upon Betulus Alnus, in the neighbourhood of the oaks upon which it chiefly was. It also strikes me that it, as well as Panzer's $C$. Betuleti, may possibly be C. Quercus of Limne, if that properly belongs to the Saltutorii section, which Fabricius seems to believe by his syronyming it with his $C$. Viminalis, for I do not believe that $C$. Quercus of Linné, which is 'pallide flarus,' cven though belonging to this section, can be synonymous with $C$. Viminalis, which if that be, and doubtless it is, C. rufus of E. B., is of a rufons colour, with the fore part of the abdomen, as well as the eyes, black. Fabricius appears to me extremely lax in his definition of colour; at least, if the insects he describes from be of the same colour as English ones. Neither $C$. Alni nor C. Viminalis are of a testaceous colour. C. No. 1., when first caught, has, in a certain light, a large triangular spot at the base of the elytra, of a lighter shade than the rest.

"No. 2., which has also incrassated hind thighs, appears to me undescribed in E. B. : indeed if I am correct in my supposition, it does not belong to any section there; for, as far as I can sec with the deepest magnifier I possess, its antennæ are not broken, but entire, though of this, owing to its minuteness, I am not positive. However that may be, I see no Curculio in Section A. b** of E. B. which, like this, is wholly black, with reddish antennæ. I found it on some species of willow, and then on Mespilus Oxyacantha.

"No. 3. is doubtless Curculio variabilis of Fabricius and Panzer. Whether Mi. Marsham had not seen it, or he decmed it a variety of $C$. nigrirostris, I know not, but it is not described in E. B. That it is a variety of that I can scarcely believe, though Paykull, on his usual plan of making as many varieties as possible, chooses to consider it so. I sent lately to Mr. Marsham, who has honoured 
me with a letter, ten or twelve Curculiones, which I am not able to name from E. B. Perhaps some of them are new, but I have no duplicates.

"Before I found the true Dytiscus recurvus, I had called, though in great donbt, No, 4. by that name. As it is not that, I see nothing in F. B. which it can he. D. lineatus I have: and though its linea are somewhat like those of that, yet the two-lobed spot on its thorax, and ferruginous abdomen, sufficiently distinguish it.

"No. 5. is dombtless D. Aexuosus. It is not unfrequent here; and as it appears from E. B. not very common, I send a couple of specimens.

"Mr. Marsham tells me that he has not Hydrophilus Cicindeloides, and as this may be the case with you, I send a specimen. It is not very uncommon here. Is not this Elophorus elongatus of Fabricius, with the cleseription of which it appears to me wholly to agree?

"I send a specimen of Curabus purpuro-caruleus, which, from there being a local habitat to it in E. B., I conclude rare. I have found five or six specimens of it in a particular clayey bank.

"No. 6. is so much like what I call Carabus littoralis, except in wanting the maculæ at the base of the elytra, that it can hardly be considered other than a variety of that yet I never found it in company with $C$. littoralis, nor. indeed, anywhere but on the shore of the Humber, where it is not very common, and I never found a single specimen of $C$. littoralis near to this habitat.

"No. 7. is a small Caralus, which I also find on the banks of the Humber, and only there. . Its truncated and smooth, or most obsoletely striated elytra, so obviously characterise it, that I have little doubt of its being undescribed ill E. B.

"No. 8. is so exactly like Carabus marginatus, except in wanting its testaccous margin, that I imagine it is merely a varicty of that.

"No. 9. (1, 2, 3.), though differing considerably in colour, are, as you will at once perceive, the same insect, which is common under clods of earth on the shores of the Humber, in company with a species of Oniscus. Elsewhere I have not seen it. I at first imagined the testaceous specimens (No. 1.), which are most numcrous, had been but latcly disclosed from the chrysalis; and to determine this, I fed and kept alive orre of them for a month, but at the end of that period its colour was not altered. The punctulate pilose surface of these Carabi furnish characteristies not very common in this genus; yet I am uncertain whether any one of the varieties be described in E. B. No. 2. arrees, in colour and several other respects, with $C$. echinatus, but its elytra are not 'punctato-striate,' but striate, with puncta in the interstices. No. 3. would do pretty well for $C$. punctulatus; but its feet are not of the same colour as the abdomen, and no mention is made of any pubescerice on the surface of that. All the specimens of No. 9. which I have examined,-and I have observed many,-are furnished with a very good charactcristic, independent of colour. They have (like Carabus tibialis) no abbreviated strice next the suture at the base of the elytra. I send several specimens of this for examination: you wiil at once know whether it is new or not.

"No. 10. I have called Carabus foraminulosus, but with some hesitation, for neither does the colour altogether accord, nor can the strix be called 'subobsolete,' according to my idea of that term. In its punctulate and subpubescent surface, as well as colour, it agrees with the fuscous specimens of No. 9.; but its greater size, abbreviated strix next the suture (as is usual in this genus), and shorter impressed line on the thorax, afford sufficient discriminations. It inliabits a particular claycy bank, near us, on breaking lumps of which you may often find it in oval holes, in the inside of them, apparently just excluded from the chrysalis.

"Nos. 11. and 12., though extremely common, I am not able to refer satis. 
factorily to any in E. B, and I therefore send them, though $\mathrm{I}$ have no idea but that they are well known to you.

"My friend Mr. Watson informs me that you are writing a MIonograph of Staphylini, which I am extremely glad to hear, as my little experience has convinced me that there are many English ones yet undescribed; and, in a genus where so many species are of the same colour, long and full descriptions are peculiarly requisite. All the unnamed specimens I had of this genus I sent to Mr. Marsham; and if he finds any likely to be new to you, he will doubtless send them to you. I herewith enclose a few specimens. I shall be glad if any of them are new to you : if not, you will oblige me by returning them, named, by Mr. Rodwell, for my information.

"No. 13. I have called S. obscurus. It is common on the shore of the Humber.

"No. 14. must be S. cruentatus, not nncommon here. I send these two, because of their having local habitats given them in E. B.

"No. 17. is not uncommon here, but I can find no one in E. B. with which it accords well. The remaining Staphylini, chiefly minute oncs, I have not particularly examined, and probably many of them are described in E. B.

"No. 18. is a Cassida which I took some months ago, but I forget where. I am doubtful if it be described in E. B. With the specific character of C. similis it perfectly accords, but not with the size or the description, for neither is the thorax longitudinally elevated, nor are the feet paliid,- the thighs, except the apex, being wholly black. Can it be your $C$. liriophora? yet I see nothing of the macula and black puncta you mention. This I shall be able to determine shortly as I have at present by me two or three of the pupæ of, I expect, your C. liriophora, which I have found and fed, as you direct, on Carduus arvensis.

" Scarites thoracicus of “ Illiger's 'Käfer Prenssens,' I have found abundantly in the dried-up mouth of a pond, along with Heterocerus marginatus. Mr. Marsham tells me he has had it sent him, perhaps by yourself. I send, however, one or two specimens.

As Mir. Marshan mentions the place where, and person by whom, Coccinella 18-guttata was taken, I presume it is not found by every entomologist everywhere, and I therefore send a specimen. Its habitat is Pinus sylvestris, from different trees of which I shook, the other day, five or six specimens.

"This ends my list of duplicates of insects in my possession that there is a possibility of being new to you. I am sorry it is not in my power to send a greater number.

"Since I began my entomological career, which is within these six months, I have stumbled on a few insects to a certainty not described in E. B., viz. Donacia appendiculata and Carabus spinilabris of Panzer, 'Faun. Germ.', and Carabus dorsalis and C. discus of Fabricins, 'Ent. Syst.' Of these I have not duplicates, and I have sent them to Mr. Marsham. Since I wrote to him, I have found four or five specimens of Carabus elevatus of Fab. ' Ent. Syst.' No. 166. (not 33., which very absurdly has the same trivial name). One of these, No. 20., I enclose. Whether these have been found by any one else since the publication of E. B., I am ignorant. - But I hasten to conclude this long letter.

$$
\begin{aligned}
& \text { "I am, sir, respectfully, } \\
& \text { "Your most obedient servant, } \\
& \text { "WILliar SPENce." }
\end{aligned}
$$

To this letter I had the pleasure of receiving the following reply from Mr. Kirby :- 
"Barham, Nov. 30. IS05.

"Sir,- When your obliging letter and box of insects arrived here I was in London, and did not return till towards the middle of October, when Mr. George Rodwell had left Suffolk, or I would, if possible, have returned your box and an answer by him. Since that time I have been so busily engaged, principally in preparing my paper upon the genus Apion for the press, that $I$ have not had time to consider the contents of the little box you twere so good as to send. Huving now despatched that business, and besides having an opportunity by a private conveyance of getting this as far as Pocklington in Yorkshire, I shall at length endeavour to answer your queries as well as I am able. Your letters to my friend Marsham, of which he had indulged me with a sight, excited in my mind a strong inclination to correspond with a naturalist who, from his very outset, seemed to enter so deeply into the subject, - who, so far from falling into the errors ustual with beginners, determined his species with the judgment and precision of the most experienced naturalist. But I leave prefacing, as I have but little time allowed me to prepare my letter.

"1. Your Curculio No, 1. I have long been acquainted with, and have alWays taken it for the Curc. Quercus, Linn. The description in ' Faun. Suee.' mentions the triangle observable in certain lights at the base of the elytra. A correspondent of mine in Sreden, to whom I sent it, writes me word that it is certainly C. Viminalis of Fabr. and Paykull. I have not Panzer's 'Ent. Germ.,' only his 'Faun. Ins. Germ. Init.' ; therefore I cannot say whether the insect in question appears to me his $C$. Betuleti.

" 2. The specimen sent me is Curc. Avellanc, Marsh.: it has black antennæ. That taken upon the willow, which I once found here, is Curc. Saliceti of Fabricius, It is distinguished by a white scutellum, rufous stalk to the antennæ, and rufons tibix. In both these species the antennie are broken, though the first joint is not so long as is often the case ; but the insects being very minute, it is not easy to unfold the antennæ, and they usually are so closely folded as to look as if they were inserted at the base of the rostrum, and were unbroken ; but I have specimens of both, with the antennæ unfolded.

" 3. Curc. variabilis of Fabr., doubtless ; but I think Paykull right in giving it as a variety of $C$. nigrirostris. What hairs are left upon the elytra are green, and the colour of the substance of the elytra in nigrirostris is rufous. $C$. $v a-$ riabilis is probably a late-disclosed specimen. I have it from Sweden of all shades.

"4. It comes very near Dytissus lineatus of Marsham, but may be distinet, unless, as is probable, it is a sexual variety. My specimen of $D$. lineatus is a fimale, and No. 4. is a male. Neither of these is D. lineatus of Fabr. and Payk., which I have from Major Gyllenhal, my Swedish correspondent. I have only a single specimen of $D$. lineatus; one more I took and gave Mr. Marsham. No. 4. I never saw before; for the specimen you sent Mr. M., as this variety, was a black abdomened one.

" 5. D. flexuosus, E. B. ; D. pictus, Fabr. Payk. ; arcuatus, Panz. xxvi. 1.?

6. Carabus. I think, with you, that this is only a variety of $C$. litioralis. I had not seen it before. Observe, that most of these little Carabi, which we find in moist places, are of a different habit from the others. They come near to Elaphrus of Fabr., and are reckoned as such by some authors, but I think they would form a distinct genus. I had named it Ocys (Gr. ókìs, celer), but Latrcille has called it Bembidion ('Hist. des Crustac. et Ins.' vol. iii. p. 8., and vii. p. 232.). The exterior palpi are exactly those of Cicindela flavipes (Elaphrus), and so are their liabits. The last joint but one of the former is incrassate, and the last very minute and setiform. To this genus belong 51, 52, 53, 54. 56, 57. 73. 75. 77 ? 80, 81., of 'Ent. Brit.'

" 7. Carabus truncatellus, 'Ent. Brit.' 
" 8 . is, I think, distinct from C. marginatus. It is more shining ; proportionally shorter; the legs are entirely black, and the hind-legs not so long in proportion. I take it to be $C$. viduus, Panz., or very near it, or perhaps a variety of C. 8.punctatus, Marsh.

"9. (1.) C. punctulatus, E. B. I think, from a memoradum I made as to that insect, Corpus parum villosum. It is doubtless only a variety of $9 .(2,3$.

" 9. (2, 3.) C.echinatus, E. B. C. pubescens, Payk. I have fonnd it more than once near the salt-water rivers, sub alga.

" 10. is C. puncticollis of Paykull. It is certainly similar to C. foraminulosus, but it is smaller and blacker, the thorax something shorter in proportion ; perhaps it is the male ; in other respects they exactly resemble each other. Subobsolete may be rendered between strix that are of the usual depth and those that are but just visible : it is an indefinite term, and must be taken indefinitely. In my specimens of $C$. foraminulosus the strix are as deep as they commonly are in this genus.

"11. C. apricarius, Fabr.

"12. C. nigriceps, 'Ent. Brit.'

" 20. C. elevatus is C. unifasciatus, ' Ent. Brit.' It is scarcely C. elevatus of Fabricius, who says of his 'Statura et magnitudo omnino C. crux minor.' C. crux minor is of a different shape, and larer. 'This insect is very scarce.

" 13. is, I believe, Staph. punctulatus, 'Ent. Brit." It is not S. obscurus. The punctula upon the head and thorax of this latter are more numerous, and there is an impunetate line observable on the thorax. In punctulatus, too, the heal and thorax are nitida, but not so in obscurus.

" 14. St. cruentatus, 'Ent. Brit.; St. Glabratus, Gravenhor'st, 'Insect. Micropt Brunsvic,' p. 178. No. 38 .

"15. St. tricolor, Fabr. var.? not of Marsham. St. tricolor, 'Ent. Brit.' is Paderus melanocephalus of Fabr.

" 17. I have this for a variety of St. linearis, 'Ent. Brit.'; St. punctulatus, Gravenhorst, No. 37 .

"17. St. pyrrhopus, mihi.

"18. I think this is merely a small variety of Cassida similis, 'Ent. Brit.' (C. rubiginosa, Illig. Herbst.; C. viridis, Fabr. and Paykull, aecording to Major Gyllenhal). The base of the thighs is in all the specimens black. The thorax in this specimen is a little elevated longitudinally, at least anteriorly.

"Scarites thoracicus appears somewhat different from the species we find here, but I believe it to be the true one.

"Coccinella 18-guttata. Sinee that specimen was taken mentioned in 'Ent. Brit.' by my pupil Mr. Sheppard, I have found it plentifully myself.

"With respect to the other insects without a label. I find one new species of the Staphylinus tribe; but upon these I shall reserve myself till I return the box, into which I hope I shall have it in my power to put a few things that may not be unaceeptable to you, in return for your kindness ; but, having last year disposed of 1400 or 1500 specimens to various correspondents, my duplieate Irawer is rather poor at this time. I have received Donacia appendiculata from my Swedish friend, but lope you will find more, as I should be glad to possess a Britisl speeimen. It is $D$. Equiseti of Fabricius. There are a number of eurious things amongst those you sent to Mr. Marsham, but I had not time to examine them all. After you have supplied him, I shall feel much obliged if you oceasionally think of me, and I shall be happy to make such a return as I am able. Curabus spinilabris, Panz, is C. brunneus, Marsh., 'Ent. Brit.;' $C$. rufescens, Fabr., and $C$. ferrugineus of the Linnean Cabinet. With $C$. spiniburbis, and a non-descript I lave, it forms a distinct genus, but is not a Manticora. Latreille calls it Pogonophorus. Tom. 3., p. 88.

"I slould be much obliged to you to give my compliments to Mr. Watson, 
and thanks for his obliging letter, which I would have answered by this conveyauce, but $I$ had not time; but it shall not remain long unauswered. $\mathrm{My}$ best compliments and kind remembrances also to Mr George Rodwell. Should you ever by pleasure or business be induced to visit Suffolk, I should be extremely happy to have the pleasure of your company at Barham for a few days. $\mathrm{My}$ cabinet is tolerably rich both in indigenous and foreign insects.

"I have enclosed a list of my desiderata with respect to 'Ent. Brit.' that you may not have the trouble of sending me insects that I am already possessed of. If you could do the same with respect to your own insects, I should better know what to send. I have referred above to Gravenhorst's 'Insecta Microptera Brunsvicensia:' it is the most complete work upon Staphylinus, Linn. that has yet appeared. And now my paper admonishes me that it is time to assure you that $\mathrm{I}$ am, Sir,

"Your obliged and obedient, humble servant, "Wi. KirbY."

These two letters are given in full, as speeimens of the way in which our entomological correspondence was carried on, but from the remaining twenty-seven letters which passed between us up to October 22. 1808 (most of them very long, one of mine aecompanying 214 insects sent to Mr. Kirby, with remarks on them, filling sixteen ordinary folio pages, which received an answer oecupying almost as many). I shall give only extracts, as the letters themselves being purely scientific would liave no interest for the seneral reader, and not much for the entomologist, now that the points we so earnestly discussed as to identity of speeies, \&e., have been mostly long sinee settled:-

\section{"Barham, March 6th, 1806.}

"Dear Sir,-After thanking you, which I do very heartily for your kind and intelligent letter, I shill proceed immediately to business, lest I should not find this sheet long enough for what I have to say."

Then follow three elosely written pages of comments on my remarks and queries as to his observations on the insects I sent him, and the letter coneludes as below:-

"And now, my dear Sir, I think you will be almost inclined to say, Well here's a Rolaud for my Oliver. I fear you will not get through my dissertations with so little tedinm as I did yours. I beg you will never apologise to me for the queries you propose, for they lead to useful inquiries and the acquisition of knowledge, and mutually improve us in our farourite science. I shall be much disappointed, indeed, if, when you make your jonrney to London, you do not return viâ Barlam; it is only going two sides of an obtuse-angled triangle; if it was time of peace, vessels are often sailing from Ipswich to Hull. From London here, is about 72 miles, Cambridge 49 ; you know I imagine how far it is from thence to Hull,-Lynn, probably would be the shortest way. Pray remember me very kindly to Mr. George Rodwell, and tell him his brother and sister here are both well. I had a letter from Mr. Marsham the other day; he was well. I expect another to-morrow. I shall be glad to fill up any vacancies in your cabınet in my power, and, therefore, request your list of desiderata. I liave, I suppose, the best part of 1000 Coleoptera sent by my Swedish correspondent, Major Gyllenhal, by which $\mathbf{I}$ am enabled to ascertitin a large proportion of Paykull's insects, and I have many English you will not see elsewhere. If you collect foreign insects you will see here the best eollection of foreign IIymenoptera, I believe, now in England,- 
without Francillon's be excepted. You see I can't willingly quit the subject of your visiting Barham.

"Darkness is coming on, and admonishes me to conclude this long epistle. "I am, Dear Sir,

"Your obliged and sincere friend and servant, "WM. KinBY."

"P. S. - Do you see Sowerby's 'British Miscellany?' the Entomological part of it is now done by me. In No. 10. are figures of four very scarce British Coleoptera, viz. Staphylinus concolor, 'E. B.' (which is the true dilatatus of authors); Scarabaus pumilus to $\hat{\phi}$ do.; Cerambyx fulminans, Fabr., and Carabus chrysostomos, 'E. B.' which is Drypta emarginata, Fabr. 'Syst. Eleuth;' Cicindela emarginata, 'Ent. Syst.' and Panzer, \&c. The Lepidopterous part I have no concern in. There are several curious insects in the other numbers, and particularly my Stylops Melitta, with which my descriptions begin March 11."

In June 1806, I accepted Mr. Kirby's pressing invitation to visit him on my way from London to Hull, and spent ten delightful days with him at Barham. Five or six of these were devoted to a minute examinatirs together of his Coleoptera, species by species, and I need not say what a fund of knowledge I derived from this inspection, accompanied by his comments, nor what a large accession my collection received from his very liberal contribution of his duplicates. Three or four days were given to an entomological excursion in his gig, to visit the shores of the Orwell, where I found many insects new to me.

From the first letter I had from Mr. Kirby after my return to Hull copious extracts may be given, as they will be intelligible to entomologists without the letter to which it refers; and also from another containing the details of a pedestrian tour to which it alludes, which may interest non-entomological readers.

“Barham, August 11. 1806.

" Dear Sir,-Y Your kind letter was particularly acceptable, as I began to feel uneasy at not hearing from you, and was thinking of writing to you when it arrived. You will, perhaps, be disappointed at not receiving a folio sheet, but this is to go in a frank with other letters, and therefore I must content myself with the usual size. To make amends I will write as small and close as possible. And now to answer the entomological part of your letter. My larger Curculio rcsinosus stands in my catalogue under the name of Colon. Fabricius had a Curc. Colon, but it is now a Rhynchenus. Did you take many of Hister pygmaus? I have not an English specimen.

"...... Your frontispiece came safe: it lost not a joint either from antennæ or tarsi. I am speaking of your Carabus Bruntoni, under which name I have entered it in my catalogue. I feel much concern at the unexpected death of this gentleman, and regret your loss and that of natural history..... Of $\mathrm{Ca}$ rabus vivalis I should be glad of another specimen or two when you can spare them. .... I rejoice to find you have taken more of Donacia Zostera. Gyllenhal made Zosterce and Equiseti as varieties, but not as sexual..... . I have compared Dytiscus Frater with $D$. elegans, and believe you are right. There is also a pair of lines of points on the disk of the elytra, yet under three glasses I sometimes think I discover these points on Frater...... I have found no more specimens of Curculio globosus in our old favourite haunt, the chalk-pit. I have been there but twice since you left Barham. The first time I found a new 
Pselaphus like Anthicus Dresdensis (Panz, 98, i.), but with a narrower thorax, and palpi equally remarkable, and a very minute Cistela, nearly related to Cistela maritima, E. B., bnt much more diminutive, with the same characters exactly, except that the feet are red. This, with maritima, seem properly to forn a distinct genus, intermediate between Byrrhus and Cistela. I also found a nigro-æneous Omalium (once Acidota), of which I had never taken but one before in the same spot. The last time I took only a black Anisotoma, which $\Upsilon$ r had taken there once before ; nothing else of consequence has found its way into my phials. Sheppard's Tetratoma that he finds upon the fir, of which he gave you a pair, is Spharidium humerale, Fabr. 'Ent. Syst.' i. 79. 9. You remember my taking a small ferrngineous Nitidula upon the new pales as we went to the pit ; it turned out Spheridium Colon of Panzer, 84, i., but certainly not of Fabricius. Sheppard writes me word he has taken two more of Apion nigritarse upon Corylus, and above thirty Trox sabulosus, under the old ramis horn, where I took three. One of the Staphylini which you took at Levington you left here: it proved to be Staph. cephalotes of Gravenhorst, and looking at my MS., I find I had referred to your cabinet for it : therefore, concluding yon had a specimen, I put it in my own cabinet: if you find I am wrong, tell me, and I will send it with the rest. The Apion you found upon Lathyrus pratensis proves to be my Apion sabulatum; that upon Ononis, a variety of my Ervi. I found a nondescript one among Mr. Hooker's parcel, which I have called rotundicolle, from its globose thorax. There were forty insects in the two boxes [Mr. Hooker's] that were either new or very rare.

"I am going, if stout enough, - for I have been much troubled since you left Barham, with lumbago, - on Monday next, to take the tour of the Suffolk coast on foot, from Walton, where we slept, to Yarmouth, and hope I shall make some additions to the catalogue of British insects, and to the collections of myself and friends. I take a fortnight for the purpose; shall go to Sheppard's on Sunday evening, and then proeeed leisurely, and return home, I believe, inland. If the weather contimues as fair as it is now, the expedition will be delightful, and I shall only wish you were my comes in viû, but I must go solus cum solo Rangero.* Poor Sheppard can't foot it so far, and there is no other herus entomologicus in this neighbourhood. I wrote to Mr. MacLeay, but he can't get out for even a single day, he says. I had a letter from our good friend Marsham not long sinee; lie has been to visit the Dean of Rochester and Mr. Lambert (at least he was going when he wrote), but, I suppose, will soon return. I have been extremely busy upon the natural characters of Staphylinus, and have made drawings of the antennæ, palpi, \&c., of several of my families. I have not yet determined whether it is to be Callicerus Spencii or Aleochara Spencii, the palpi come so very near the latter genus. I often wish for you at my elbow to give me a lift, when occasionally I feel myself stupid. I find it difficult to get a clear idea of the interior palpi of Stenus. In this drawing, $a$, is the end of the tongue, and, $b$, the interior palpi as they appear from a specimen of mine. I think they are biarticulate, but cannot satisfy myself on this point. Be so good as to examine one of yours, and give me your ideas. When you go to Ripon I shall be glad to hear of your suecess, and shall detail to you the result of my expedition.

"Believe me, \&c."

"Barham, Sept. 24, 1806.

"Dear Sir, - I was gratified to find your tour was so pleasant and successful. Mine, unfortunately, terminated differently, and my entomological captures (of consequence) did not reach a Greek plural, being in number on!y

" His dog "Ranger." 
¿wo-one specimen of Tenebrio cadaverinus, Fabr., where Sheppard nsed to find it in tolerable plenty; and a new Carabus, connecting catenulatus of Marsham with violaceus of ditto. I take it to be catenatus of Panzer $(87,4$.$) ,$ but am not certain, as it does not quite agree with his description. An unhappy foot had trod upon my specimen, and very much injured it. I looked, as you may suppose, very earnestly for more, but could not find one. I showed it to an intelligent gentleman in the neighbourhood, who said, if he met with anything like it, he would take it.

"Now for my misfortunes. The first day of my travels proved exceedingly hot. I had at my back, under my coat, a pad called an 'Independent,' which was suspended from my shoulders and buttoned close to the small of my back. I found this friend, for a new aequaintance, much too warm in his attachment; he carried for me a double change of linen. I had, besides, ten pockets, disposed here and there about me, in which I carried, to little purpose as you find, all the needfuls for a Heros Entomologicns who would have a successful campaign. Hot as I was, I was so mnfortunate as to be disappointed in most of my efforts to procure refreshment; and at the public-honse where I proposed sleeping, the hostess could produce only a negative bill of fare, so that I was forced, after a long march, to eontent myseif with bread and butter and bad beer for my dinner. Indignant at this, and being resolved to taste flesh before I slept, I pushed forward to another village, and was hospitably received and entertained by a gentleman-farmer of whom I had some knowledge. I was, however, not a little fatigned; and to add to my disasters, the next day, when I proposed walking only four miles, and going by water the rest of my day's allotment, I unluckily missed my way, and was obliged to walk eleven miles, and great part through a very heavy sand. The fatigues of these two days, and the privations of the first, brought a nervous complaint upon me, attended by a most uncomfortable depression of spirits. However, between walking and riding, I managed to get as far as Lowestoft, from whence, at the end of the first week, I started with another gentleman in post-chaises for Barham, where I arrived on the Saturday morning. I was out of order for some time after my return home, but liave now recovered my usual health. I saw all the towns upon the coast I had not seen before, and every place that was worthy of notice. Thus mueh for my tour. I shall now begin my reply to your letter in order." [From the two closely-written pages that follow, snch short extracts only are given as are likely to interest the entomologist.]

"Staplyylinus caraboides was never before taken in England, that I know of, and I shall be thankful for British specimens. Carabus secalis, Payk., is eertainly synonymous with your C. Bruntoni... I suspect your Paderus, like orbiculatus, to be different from mine, on the head of which I can discover no impunctate line ... Your conjecture is right, that Curubus ochropus, E. B., is rotundutus, Payk. I have both an English and Swedish specimen . . . To your great satisfaction, I can assure you that your Dytiscus frater is not assimilis of Payk. . . . I have observed that the puncta upon the head and thorax of Staphylinus stercorarius are larger than in erythropterus and castanopterus; but with my triple glass I have not been able to see that they are ocellated : a hair arises from each, but that is also the case in erythroptcrus; so you see that the epithet lyncean belougs rather to your eyes than mine... I have the Hydrophilus like luridus you mention; but I have considered it only as a variety .... And now, I think, I have fusished my reply to all your queries, \&c. ; and must thank you both for the information you give me (always furnishing me with something valuable of which $I$ was before ignorant, and enabling me to attain by putting me upon research). I shall only farther observe upon this subject, that if yon do not furnish us with some ralnablo work upon some dspartment of our farourite science, you will be inexcusable. 
"Mr. Haworth spent a day with me about a month ago. He left me a specimen of what appears to be Dytiscus minimus of Schrank . . . . Hc left me likewise a Gyrinus very like natator, with rufous elytra ... . I don't recollect whether we made ont the Copris you took at Landguard-fort. I had receired one of the same species from Dillwyn, and named it reticulatus. I since find by comparing it with Gyllenhal's insects, that it is Scar. Xiphias of Paykull, Copris nuchicornis of Sturm, Illiger, and Panzer, but not of E. B. . . . I I have now given you all the entomological intelligence my budget contains. A later letter from my friend Marsham tclls me he had no success in that way in his late expedition. I shall hope to see something new in Norfolk, whither I am going for a month next Monday fortnight: I am sure I shall, at least, in Hooker's cabinet: so that if you write between the 20th of Scpt. and the 20th of Nov., your letter must be directed to me, Rev. Dr. Sutton's, Lower Close, Norwich. I shall not forget to inform you of what occurs in my way .... I hope you will do what you hint at - take a walk Barham-way next summer. I think I conld meet you on the road, at least as far as Cambridge, and accompany you here.

\section{"Believe me, \&c."}

"Barham, March 22, 1807.

"Dear Sir, - I don't wonder at your surprise at my long silenec; yet the reason of it is contained in your favour, for which I thank yon the more, because I do not deserve it. Yoll say - "The fact is, that for the two months succeeding my last I was so occupied with un-entomological affairs that I hat not leisure to look at an insect.' This bas been preciscly my ease .... I have boxes of insects both from Haworth and Hooker to name, which I am afraid the owners think I have cribbed; and when I shall have leisure to look them over and return them, I cannot tell : so I trust yon will accept of this my apology. In London, I went over Sir Joseph's Staphylini; but there was nothing very remarkable amongst them except $S$. aureus, which is of the same family with $S$. murinus, \&c. I found several non-clescript species in $\mathrm{Mr}$. M'Leay's cabinet, which he purchased from the Leverian Muscum, and one large and blue one from old Drury's eabinct. Another piece of entomological news I can tell you, - that $\mathrm{M} \cdot$ Leay has purchased all Donovan's foreign insects - a most valuable addition to his collection, which in value falls not very far short of Francillon's. I will now endeavour to answer your letter . . . ."

"Barham, April 1, 1807.

"Dear Sir, - Your box arrived lere safe last Thursday or Friday withont any damage of consequence .... I have looked over the contents of your box and Mr. Watson's, but have not yet had leisure to compare either with my own cabinet; but the following in your parecl at the first glance scem to me new :-No. 4, Carabus scitulus, No. 14, Dytiscus scitulus - a very pretty species. No. 19, Haliplus mucronatus? I have one very ncar it, I am sure. No. 20, Helophorus longipalpis, appears to me quite a new insect, and not Hyd. longipalpis of E. B. . . . No. 41, Catheretes Junci and nitidus, are both new to me, cxeept one be in Sheppard's cabinct. 44 is new to me. 76, Curculio Geranii, new to me as British. Apion, Nos. 81, 82. 93. 96, seem to me all new. 111, Mordella picea, new to me. 138, Staph. fulvipennis, new I think; 139 also, and 144. Aleochara, No. 160, is a very pretty species; the pile glitters like silver in certain lights. 194: I bulieve this may be distinet from lavior; 197, also, is new I think. I don't think what you have sent me as Anthopleagus caraboides is that insect; it secms to me to come nearer to Anth.alpinus. There are many others, concerning which I am clubions, but shall tell you more when I can compare them with my own insects . . . My entomological studies 
are pursued only between dinner and tea, so thiat sou may imagine they do not proeced very rapidly. I am now cngaged in making ont the synoilyms of Gravenhorst, whieh I find tedions enough. To save trouble, I mark in the margin of his family of Staphylinus the number of puncti in the thoracic series thus : . I find this save some tronble, and reconmend it to you ... I have the pleasure to tell you that I found, after you left me, the remains of Mordella fasciata, E. B, which you may recolleet I looked for in vain, and have put all together very adroitly." .... A A letter, dated July 7 , of ten pages, contained observations on the 214 insects sent in the box alluded to above.]

"Holme [Norfolk], July 31, 1807.

"My dear Sir, - Being so very near you as to discern, by the help of a glass, the Humber's mouth, it will not be so well if I do not speak a few words to you, and give you some aecount of what I have been doing sinee I left my own door." [After a deseription of his jonrney and of Holme, and of twelve insects he had taken, the letter continnes:] - But the pride and joy of my discoveries here is a new Apion, which I have found in tolerable numbers npon Statice Limonium. It is by far the most splendid and beantifui, and I think also the largest species of the genus that I yet am aequainted with. I have already taken fifty specimens, and shall endeavour to get more. I call it Apion Limonii, and it will form the coneluding species of my paper ; and so I may well say, Finis coronat opus." [Then follows a descrintion and referenee to a coloured figure on the blank page of the letter.] "The figure is tolerably correet, though I know not how to give the metallic liues of the original.

"I have no further communication now to make, except that we made some inquiry whether there were any vessel going from this neighbourhood to Hull; but we could not hear of any. If we had met with one with fair aecommodation, I don't know whether we shonld not have paid yon a flying visit. . . . ."

"Barham, Aug. 31, $180 \%$.

"My dear Friend,-At length I have gone through all the contents of your box, and that of Messrs. Watson and Simpson." ... [Then follow two pages of deseriptions of the new Staphylinida sent him.]

"In my last I detailed to yout many of my captures at Holme, ending with what I termed the pride and joy of my diseoveries, Apion Limonii; but sinec that capture I have taken two insects in the same village, which are still more valuable: they are both of the Staphylinida. One of these is a Tachinus, of which I took a pair in putrid wood. Its peeuliarity consists in its antennæ, which are uneommonly slender, with a knob at the end of each joint, and vertieils of hairs, thns, as in fig. 1. [Ilere follow two peneil sketches.] No. 2 represents the head and thorax of an Oxytelus, related to $O$. morsitans and cornutus, but with four long horns upon the head, the two anterior arising from the base of the maxillix and protruded before the head. It is, I think, a more curious inscet than even tricormis, of which, by the bye, I have also at last got a specimen: I took it one morning upon Mrs. Kirby's chemisette, as the ladies denominate their neck-handkerehiefs, as she was walking before breakfast in Dr. Sutton's garlen. In vain I laid traps of white linen for it; I conld not meet with a seeond, although $I$ also placed the same attraction in the same place. I found at Holnac, and in a neighbouring village, an abundant supply of Apion nigritarse upon the dock, the hazel, the hawthorn, the elm, \&.c.: so farewell my habitat, which seemed so remarkably eonfirmed by your talking it upon the same tree in the nortli.

" $\Lambda$ remarkable event befell me last week. I had beun much afflicted in the conrse of the week by the ear-ache (a disorder which. if you never knew, I hope you never will, and which, by the bye, must apologise for any mistakes 
you may find with respect to your inseets). Mrs. Kirby went to our party [a weekly erening one], when the mail-coach horn blew, and the coach stopped: my servant went to the gate. In the interim, a gentleman got ont, met the servant, left not his name but his compliments, and he would call the following day: then again mounted and disappeared. We were all puzzled who it should be; and I thought it must be Joseph Hooker (who is coming to-night), obliged by some eireumstance to ante-date his visit. I sent my man in the morning, thinking it possible the gentleman might have stopped at Claydon, to request his company at breakfast. When he came, instead of Hooker, I saw the countenance of a perfeet stranger, who said his name was Peek; that he was an American, and had been at Norwich with Dr. Smith, but that he had brought no letter of introcuetion, and that he eame on purpose to see me. Though he spoke English well, I thought his aecent rather French, and his having no vouchers were unpleasant cireumstanees; but I thought there eould be no harm in showing him my cabinet. His observations showed me that he understood the subject, and was a man of considerable information in Natural History. He promised to send me a publication of his upon Tenthredo Cerasi, seemed much gratified with what he saw, and professed himself greatly obliged. Upon the whole, I was mueh pleased with him, and it was doing some violenee to myself that I did not ask him to take a bed at my house; but his want of introduetory letters and vouchers of any kind would have made that an imprudent step...."

"Barham, Jan. 7, 1808.

" Barham ! ! ! So, then, the rector of Barham is not dead, as I imagined! This, my dear sir, would be a very natural exclamation upon seeing a letter from me. It is necessary, therefore, that I should make some apology for not sooner sending the boxes [of inseets] and for my long silence .... As to writing, I have been as deeply immersed in theology as yourself in political economy, so that I have not east my eye upon an insect for months; and having nothing to write about, I did not think a letter of common ehit-chat would pay the postage. ...."

We now come to the origin of the "Introduction to Entomology," the history of which will be best given by quoting the passages in our letters referring to it.

In the three or four letters I received from Mr. Kirby in the summer of 1808, nothing occurs generally interesting. In that of Oetober 12, after three folio pages of remarks on insects I had sent him, or in answer to queries as to tormer ones, he observes at its close : -

"I attend to what you say with respeet to pointing out the differences between allied speeies, and shall do my best in that way. I think it is now time to spare your eyes, which will have some difficulty in making out this scrawl. I have heard nothing lately either from Marsham or MI'Teay. 'Ent. Brit.' * I fear will never go on. A general English work on British Entomology I am sure would sell. Marsham could never have time to do it. You and $I$ in partnership might very well, if it conld be without hurting his feelings, and an English work properly would not interfere with his Latin one: let foreigners afterwards, if they liked, translate it. As your time is not taken up by secular business, you could oecasionally eome here for a few weeks, each having specified genera

" Marsham's "Entomologia Britannica."

P P 3 
and looking over each other's descriptions. I think we should show foreigners we are not so backward in this science as they imagine us to be.

"Farewell, and believe me to be,

" Yours very truly,

"IVAr. Titres."

The preceding letter was followed by another long one from Mr. Kirby, dated November 15th, wholly occupied by a synopsis of the families, and sections of his Monograph of the Staphylinida, on which he was then hard at work. My reply, dated Drypool, November 23rd, 1808 , to these two and a former letter was chiefly filled by remarks on this synopsis, and on his paper on Apion, in the Linnean "Transactions," and by giving an outline of my proposed Nonograph of the genus Choleva: after which it proceeded as follows:-

"I will not here attempt to reply to the whole of the three valuable letters for which I am indebted to you sinee my last ...... At present I must only advert to two of their topies, - your hint relative to a co-partnership English 'Entomologia Britannica,' and your remarks on the Linnean cabinet. The sormer seheme much pleased me, for, would you think it? the very same idea some time ago glanced across my mind. I have nothing more at heart than being able to contribute to the advance of our science in this country, and in 'thinking on an English description of our insects, the only mode of effecting. this, the thought has struck me, "could not my friend Kirby and I manage such a work?" I dismissed the idea as a mere pleasing fancy, partly from the reason you allude to, - the fear that our friend's feelings might suffer, and partly because I know yon are at present otherwise engaged. But really, on second thoughts, when confirmed by the similarity of yours, the plan does not want feasibility. As Mr. Marsham certainly cannot himself take any share in an English work, he could not be sorry that otlers undertook it, and so far from interfering with his Latin one, it would, indeed, greatly assist the sale. On the whole, I am inclined to think your scheme well worthy of further consideration, and I think we should not lose sight of it. I should, to be sure, be but a sorry partner in the concern, but my knowledge of German might be of some use, and greater dispatch might be made by two than one. My idea is, that such a work should be published in numbers or parts, montbly or quarterly. We should thus have more time; purchasers would more ensily be found ; and from these, which would rather be the materials of a more perfect work than a complete 'Entomologia Britannica,' eventually a regular work might be fabricated. The greatest obstacle with me is the risk of its not paying itself. Having tasted the sweets of literary profit (I got my bookseller's account a few weeks since: my six editions of 'Britain independent of Commerce,' leave about 230l. clear, - the first of the 'Radical Cause of the present Distresses of the West India Planters,' 30l, the second of this last, and my last pamphlets, are yet unsettled; my expense of advertising was about $80 l$., what a parenthesis ! pray don't hold your breath to the close of the sentence), I should not like to lose by such an undertaking, thongh I should not care if it only paid its way. But it is too bad to give one's labour, and lose money into the bargain. I confess $I$ am not so sanguine as you on this head. I fear we could not expect a greater sale than König and Sims had for their "Annals of Botany,' which did not answer. Aud yet, surely 250 English entomologists could be had for purchasers; and if so, by charging a goot price, I think it might be made to pay, if published in parts. The best plan to ensure success would be to have a respectable bookseller engaged with one. But to me there appears a desideratum whose acquisition would greatly contribute to the suc- 
cess of such a work-I mean a popular 'Introduction to Entomology:' and so long have I been convinced that this want is the greatest bar to the spread of the science amongst us, that in my solitary rambles I have sometimes occupied myself in sketching mentally the plan upon which I conceived it should be composed. If you give me encouragement I think I should be induced to give some form to my project. But it would be still better if you would become a partner in the speculation - and why not? I heartily wisl you would let our partnership begin here. I could give you a sketch of my scheme; you could correct, add to it, or propose another. Out of both one could be made, and we might then divide the several parts between us, and finally jointly amalgamate them into a whole. Pray think of this, and give me your opinion.*

"Believe me, my dear Sir,

"Ever yours,

"W. Spence."

Mr. Kirby's answer to the preceding remarks was dated Barham, Dec. 17, 1808. After referring to various entomological matters in my letter, he observes:-

"As our thoughts jumped, as they say, about a 'British Entomology,' so did they as to the preparatory step - an 'Introduction to Entomology,' - at least, I had such a work in my thoughts, and had gone so far as to draw up a list of

* It is proper to advert here to a discrepancy between my proposal in the above letter of a popular Introduction to Entomology when I first started the idea, and the short account of the origin of our book in my letter to the President of the Entomological Society, announcing the death of Mr. Kirby ("Transactions of the Entomological Society," Vol. i. New Series, Proceedings, p. 19.), in which the plan of giving it a popular form is spoken of as subsequent to a first idea I had mentioned to him, of making it scientific only. The fact is, that this was my impression both in writing our Preface (in which the plural number is necessarily used) and the letter to the President of the Entomological Society; and this impression remained until Mr. Freeman had sent me my letters to Mr. Kirby, and I had read the above extract. From it I now see, that though my first idea of an Introduction to Entomology was, as I well remember, that of making it scientific merely, but very soon changed jnto the conviction that a popular way of treating the subject was alone likely to fulfil my aim, that of making converts to a study which I found yield me so much delight,-I never mentioned the idea of a merely scientific Introduction to Mr. Kirby at all, but from the first proposed to him its being popular. This, in the many years which elapsed between the project of our book and the writing the Preface, as well as the letter to the President of the Eutomological Society, had wholly escaped my recollection, and gave rise to the discrepancy alluded to. In fact, from the moment Mr. Kirby had agreed to join me in carrying out my plan of an Introductory work, any reference to its precise origin vanished from my mind; all my thoughts for the many years the work occupied us, being devoted to executing and perfecting the design in conjunction with my illustrious frienil, without whose aid it could not have been satisfactorily realised. And that I should thus have proposed to him, and induced him to join me in carrying out my original idea, has always been to me a subject of self-gratulation; for not only did our work, in a great degree, dispel the prejudices which had inpeded the study of Entomology, and largely increase the number of its votaries, but it was of essential service to the science, by offering, under its various heads, fit opportunities for the reception from his note-book of the numerous detached observations collected by Mr. Kirby during many years, on the economy and habits of insects, which would otherwise, in all probability, have been lost to the world; and by placing him under the necessity of extending his former studies to a much wider and closer investigation of every department of Entomology, which led to a great accession to his previous knowledge, yielding a rich harvest to the science both in our work and his subsequent ones. 
parts, and of terms applied to those parts. In order to break the matter gradually to Marsham, I have told him of our plan of an 'Introduction to Entomology.' With MacLeay, upon whose secrecy and judgment I can rely, I have gone further, having opened to him our whole plan, and requested his sentiments, as we would both wish to do every thing as much as possible in a way not to hurt our friend Marsham's feelings. The former I expect to hear from daily; from the latter I bave heard, but he took no notice of what I said about our 'Introduction to Entomology:' And now let me reply to what you say about terms," \&c.

My reply to this letter is dated Drypool, Jan. 2, 1809, and six closelywritten pages are filled with further comments on his proposed monograph of Staphylinida. I then proceed towards the end as follows:-

"I am quite delighted that we have been so much in unison with regard to an 'Introduction to Entomology', and I am glad that you have broken our scheme to Marsham, and fully unfolded it to MacLeay. Yet I fear, from the former's silence, it is not quite what he approves, though I think it might be easily proved to him that nothing would be so likely to promote the sale of his work as an elementary work on the science. I shall be impatient for Mac Leay's opinion of the scheme."

In another letter to Mr. Kirby, dated January 25, 1809, principally devoted to giving my reasons for making as few changes as possible in old and generally-received entomological nomenclature, though it may not be strictly colrect, I observe towalds its close :-

"To turn to another subject, - our embryo 'Introdnction to Entomology,'I will here give you my idcas as to the plan of such a work, which I submit to your considcration. Tell me what you think of it, and propose any that you may deem better. The first requisite of such a work is, I think, that it should be popular, - that it be a book which might be read with pleasure and instruction even by those who have no intention of studying the technicals of the science. Entomology is at such a low ebb amongst us, and so many obstacles and prejudices are to be overcome in rendering its study general, that the first approach cannot be made tio attractive. In this view I would throw the work into Letters, - a form which admits of much latitude in amusing digressions, and for which Rousseau's 'Letters on Botany,' Sprengel's recent 'Letters on Cryptogamic Terminology, \&c. are sufficient precedents. From my own expericnee in studying the science of botany, I know how much more pleasant it is to have the at best rather dry materials of terminology conveyed in a familiar style, and made palatable by an attractive vehicle. Having fixed on the epistolary form, the first letter I would devote to refuting objections on the score of the trifling nature of the seience, - pointing out the advantages which man already derives from the insect world; - the probability of his greatly angmenting them; - the vast power of insects to injure.him;-the necessity, in warding otf this evil, of ascertaining them scientifically; - the pleasures to be derived from the study, Sc. \&c. Then I would proceed to the mode of collecting inscets, preserving them, \&c., which would fill three or four letters. Lastly, I would enter upon the terminology, - first giving a general idea of the system, and tiren teaching the terms by supposing the correspondent to have before him some very common Coleopterous speeics, the parts of which might be still further illustrated by a few good ontline figures. In this description of parts I would confine myself chieíy to the order Coleoptera, since that alone can at present be satisfactorily studied in this country. The peculiar terminology of 
the other orders, a synopsis and elucidation of all the British genera (a grand desideratum), various critieal remarks, \&c., would fully make up a second volume, if the first should be well received: and the interest of our pockets dissuades from risking too much at once. To the end of the rolume I would add a close-printed dietionary of terms, which would be useful for reference. The above outline, you perceive, wants a deal of filling up; but this sketch is sufficient to enable you to judge of the merits of the plan. I have thonght a good deal about it, and I am persnaded that some such plan, as far as making the worl: attractive is concerned, will be infinitely preferable to any dry chapter-andverse bare enumeration of the parts of insects, like Yeats's, or even Linné's and Fabricius's immortal 'Fundamenta' and 'Philosophia.' Every body reads with avidity aneclotes of the uses, injurions properties, habits, \&c., of insects ; and only admit your readers through such a vestibule, you will win numbers to the science, who would have been deterred at the very threshold of mere technical cliscussions. Indeed, I very much doubt whether fifty copies of a work of the latter deseription would be sold; of the former, I am sure, five hundred might. As I look upon our 'Introduction' scheme as determined on, ought we to lose much more time in setting about it ?"

Mr. Kirby's next letter to me is dated Feb. 13, 1809: and after three pages of remarks as to the expediency of retaining old and generally-used names, even though strictly not proper (as mandibula for maxillæ), which I had contended for, but to which he objected, he says towards the end of the letter -

"With respect to our copartnership, I do not think it is much concerned in this argument, for as our terms must be English we should do no more than mention the names of Latiu writers. The plan of the work which you have drawn up in your letter, upon the whole pleases me much. I see with yon the necessity of making it a popular work, and with a view to it, have been making extracts from Latreille, and have got so forward as to bave written a great part of the Introductory letter containing a defence of Entomology from all the objections that have bcen made to it. I think separate Letters should be allotted to the injuries and benefits of insects, another to the wonderful particnlars of their history, and then the mode of collecting and preserving them. But in my opinion the part that relates to terms shoild not be confined to Coleoptera, - it should take in all the orders, for which I have materials prepared from Latreille, whose Introduction will be a great help with respect to the Crustacea and Aptera, which you and I perhaps know at present little of. I want another term instead of terminology, which is a word of base origin, having: a Latin father and a Greek mother, Orismology, though ncw-born, is a legitimate word, and I think would soon be received into good company, since he deserves it as well as Orychtology, Ornithology, and many other children of his mother $\lambda o \gamma i a$.

"I have had a letter from my friend Marsham the other day, cortaining a long philippic against our innovations, and the multiplication of genera, in which he seems to say that he gives up all intention of going further in 'Entomologia Britanniea.' In my answer I gave him a fulther hint of our intention, by saying that besides our Introduction to Entomology, we had another plan in view, which we hoped would tend to promote the sale of 'E. B.' also, but that at present it was an unlicked cub, and therefore I should not say what it was at present. 'Tis best to break the ice gradnally; for though he ought not to be displeased at it, and our works do not interfere, yet I can plainly see there is a little jealousy hanging about him. I have a great regar' for him, and you may observe in my Apion how teuderly I have treated him 
when in error; and this I wish to do. In our 'Introduction' we should certainly recommend 'Ent. Brit.' to all Entomological students as the first systematical work that ever appeared in this eountry. I think it will be highly necessary that you and I should meet this year to settle termini. I hope you will be able to eome here for a month or two, and then all points could be much better settled and discussed than they could by lettcr. If you eould come bctween Easter and Midsummer I should be highly gratified."

Agreeably to Mr. Kirby's invitation I transferred myself to Barham in the sunmer of 1809 , and for several weeks we were hard at work laying the foundations of our book, which eonceiving to be the Letters on External Anatomy and Orismology, it was to these we first directed our attention, and before I left Barham we had drawn out a general sketch of the whole, founded on the examination of Mr. Kirby's insects, and diseussions, often very long, as to the propriety of various terms.

We had no leisure time for excursions, but as a short one we made one day led to a ludicrous adventure, which Mr. Kirby used often to refer to, and relate with great zest to his entomologieal visitors, its history may be here given. Mr. (now Sir William J.) Hooker was at that time staying at Barham, and being desirous to have pointed out to him, and to gather with his own hands, the rare Targionia hypophylla, from its habitat, first discovered by Mr. Kirby, near Nayland, some miles distant, it was agreed we three should walk thither, entomologising by the way, and after dinner proceed to the hedge-bank where it grew. Entering the head inn yard on foot, with dusty shoes, and without other baggage than our insect nets in our hands, we met with but a coot reception, which, however, visibly warmed as soon as we had desired to be shown into the best dining-room, and had ordered a good dinner and wine. We intended to walk back in the evening, but as the bank where the Targionia grew was a mile or two out of the direct road, and it came on to rain, we ordered out a post-chaise, merely saying we wanted to drive a short way on a road which Mr. Kirby indicated to the postilion.

When we arrived at the gate of the field where the bank was, the rain had become very heavy: so, calling to the postilion to stop and open the door, we scampered out of the ehaise, all laughing, and hastily telling him to wait there, without other explanation we elimbed over the gate, and not to be long in the rain, set off running as fast as we could along the field-side of the hedge, to the bank we were looking for. We saw amazement in the face of our postilion at what possible motive could have made three guests of his master elamber pell-mell over a gate into a field that led nowhere, in the midst of a heavy shower of rain, and then run away as if pursued: and it was the expression in his countenance which eaused our mirth, which was inereased to peals of merriment when we saw that instead of waiting for us at the gate, as we had directed, he mounted his horses with all speed, and pushed on in a gallop along the road on the other side of the hedge, evidently to eireumvent our nefarious plan (as he conceived) of bilking his master both of our dinners and the ehaise-hire. When the cessation of our uncontrollable mirth had allowed us to gather specimens of our plant, perceiving through the hedge whereabouts we stopped, he also halted to wateh our motions, and when he saw us run back, he obeyed our orders to return to the gate,--where we got 
into the chaise, still in a roar of laughter at the whole affair, and at his awkward attempt to explain away his not having waited for us there, as we had directed, and evident high satisfaction at bringing back in triumph to our inn the three cheats whose intended plans he had so cleverly frustrated, as lue no doubt told his master; to whom, being too much amused with the adventure, we did not make any explanation, but left it to form one of the traditions of the inn.

To return to our book: we had found the various investigations required, so much more numerous and difficult than we had calculated on, that at the time of our separation in consequence of other engagements, we had not done anything towards the preliminary and popular portion, rot having even definitely fixed what particular letters each should take; and though we had drawn up a provisional table of all the anatomical and orismological terms which the science seemed to demand, there were many of these still requiring further discussion before they could be finally adopted. To these discussions, the thirty-seven letters we exchanged during the years 1809 and 1810 were mainly devoted, and of these I shall give two of the earliest, to serve, as in the former instance of our first Entomological correspondence, as a specinen of our way of carrying on these investigations, and to show that we spared no labour either of mind or pen to attain accurate notions on the subject. Of the remaining letters (upwards of 100) which passed between us between 1809 and 1815 , when the first volume of the work appeared, a great portion of which was occupied with similar discussions, and with contributions by each to the "Letters" of the other, I shall as before quote only such detached passages, from a very few, as may be likely to interest the entomologist and general reader.

"Drypool, Nov. 20, 1809.

"My dear Sir,-I have been long very impatient for the pleasure of hearing from you, and but that for the last month we have been up to the cars in brick and mortar, during which my time was fully ocenpied with looking after the workmen, I shonld before now have beat up your quarters; for by this time you have doubtless ended your metropolitan campaign, and are safely seated in your Barhamian hybernacula, - rendered doubly agreeable by your long absence. It is only snch domesticated animals as you and $I$ that can feel all that is comprised in the word home,- - feelings unknown to the votaries of varicty and dissipation. I take it for granted you dnly received the last long letter which I sent you through MacLeay about six weeks ago, containing divers cogitations and snggestions relative to our work, on which I long for your opinion; for having made a collection of materials for the letters I am to undertake, I wish much to make a beginning upon them : but this I cannot satisfactorily do until I have your ideas as to the plan we are to follow.

"As I never lose sight of the importance of putting our terms (doubtless to be immortal!) to the ordeal of every possible objection, I have several additional doubts and difliculties to propose to your consideration : and, first, as to the Ilia and Ischia, about which latter term I believe I said something in my last. I am now fully convinecd that both terms are radically in1proper, both as being anatomically incorrect, and as being umiecessary. In the first place, Ilia employed in the plural number, as we must often employ it, is quite incorrect, for the Ilia in anatomy are the flanks or sides of the untilical region of the abdomen. Anatomists always say $O s$ ilium when they 
refer to the bone of the hip. Secondly, from a careful examination of son:e species of every order of inseets, I am now persuaded that both Illiger and we are wrong, also, in considering the Coxa as formed of two parts, and the Ischium as forming one of them. On the contrary, it is clearly a part of the thigh, to which it. is generally closely attached by a membrane admittiner only a very slight degree of motion, but perhaps never by a distinct joint. The joint is always between the Ilium and the Ischium, the latter serving as a sort of fulerum to the base of the thigh, often with a hole between them for the reception of the pivot of the Ilium. If you will dissect and examins a large foreign Geotrupes, you will see all this very clearly. You will find that even when the insect has had its joints made pliant by being immersed in hot water, there is little or no motion can be produced bctween the Ischinn and the thigh, which are attached to each other by that articulation callecl by anatomists amphiarthrosis; whereas there is a distinct ginylymus joint between the Ilium and the Ischium. It is true that in Hynenoptera, Diptera, and some Coleoptera, where the Ischia are not fixed obliquely to the base of the thigh, but transversely, the Ilium and Ischium do seem at first vierv like the two parts of one joint; but even then, as I have ascertained by examining living inseets, the Ischium is still fixed to the thigh by a menbrane and no joint, and the joint is still between the Iscliium and Ilium. Now, such being the facts, there cannot, I think, be a moment's hesitation in deciding that it can never be proper to consider a part as forming a portion of a limb with which it is connected by a true ginglymus joint; or not to consider it as portion of a limb with which in many cases it scems truly connate, and in all others closely connected by a membrane admitting of littlo or no motion. It appears to me, therefore, that our Ilium should be regarded as a peculiar and distinet joint, namely, the true hip-joint; and we cannot have a better name for it than $C_{0 x a}$, which Latreille also gives to it. Oul Ischium must be eonsidered part of the thigh, and cannot, I think, have a better name than Trochanter, which has the right of priority, and, though not strictly anatomically correct, is as near as in such cases we can expect to come : both are processes of the base of the thigh; only in man the trochanter is a mere projection of the base of the thigh; in insects a distinet part joined by a suture and membrane. Observe, some Ichneumons hare a double trochanter.

"I partieularly wish you would examine the elaw-joint of the tarsi of a large Cerambyx, Leptura, or Chrysomela, and I think you will agree with me that the small part of the base, thongh separated by a suture, is no distinct joint, but in fact a trochanter affixed to the claw-joint by the aurthrosis articnlation, and very closely analogous to the trochanters of the thighs. To me it seems that it wonld be quite as proper to consider this minute basal part a portion of the third joint (not of the claw-joint) of the tarsi as to call the trochanters parts of the Coxæ. Attention to the mode of articulation (evidently a material point) will lead to another good consequence - we can thus avoid regarding this supplementary part in the tarsi of Leptura, \&c. as a true joint, the reverse of which would sadly curtail our grand divisions founded on the tarsi ; and, by calling it a trochanter, we may possibly gain some good gencric charneters, if, as I suspect, the same eircumstance holds good in some other tribes.

"I have been puzzling myself a good deal to diseover what parts in the postpectus of Hymenoptera and Coleoptera are analogous to each other. I have not yet by any means satisfied myself on every point, but two or three fixed landinarks I think I have ascertained. One is, that your Collare ("Monograph. Apum Ang.') is not, as we liave supposed, analogous to the upper part of the thorax in Colcoptera. I was made pretty sure of this in the course of dissect- 
ing sevcral dried bees, ichneumons, \&cc., in which the collare always remained attached to the thorax, when the fore-feet were pulled off', and never came off along with them. But I was fully convinced from a large female ant which $I$ took a few days ago alive. In making efforts to release itself, the fore-feet were pulled to a considerable distance from the collare, to which they were attached above merely by a dilatable membrane; but the collare was immoveably fixed to the dorsum, and though there is a suture between them, it was with difficulty I conld separate them by dissection. Another observation which proves that the collare is no part of the thorax, is, that putting a pin under it, and enclearouring to push it off, the wings were strongly moved, so that their muscles must be attached to the uader side of it. Now we know that the wings in Coleoptera have no connection with the thorax. I am now persuaded that the upper side of that part in Hymenoptera analogous to the thorax in Coleoptera is rarely or never visible, the part itself being extremely thin, and wholly conccaled by the collare. The question then comes - 'What is the collare analogous to?' and here I confess that I have not altogether satisfied myself, but must apply to your more extensive acquaintance with the order. Illiger says your tuberculev are analogous to the scapularia of Coleoptera, and I am inclined to think rightly. If so, as the scapularia seem in general to be connate with the collare, or separated from it by an apparent suture, probably this part is analogous to a concealed vertical piece which I find at the base of the scutellum in a large foreign Geotrupes, and which you will easily see on dissection. Now, if this supposition be correct, then taking this Geotrupes for our Coleopterous instance, we shall see in it pretty clearly the parts to be seen in Hymenoptera (Vespa Crabro, for instance). Having separated the postpectus in the Geotrupes, we sce at the base of the scutellum, first a vertical part forming a right angle with it. This I conccive to answer to the collare, which in Vespa is deflexed nearly in the same manner. The tubercula in Vespa, or lateral triangular parts of the collare, I conceive to answer to the scapularia in Geotrupes. (I must here observe, in order to obviate the objection that the scapularia are not placed so high up, that the scapulare is not merely the triangular white part which I mentioned to you as being present in Coccinella 7 punctata, but includes also another part at the base of that, the base of the true scapulare, which is divided into two portions by an apparent, not real, suture, being in a line with the bass of the peristethium.) Next in the Geotrupes comes the concealed, horny, horizontal base of the scutellum; doubtless, as we have always considered it, equivalent to our dorsum in Hymenoptera, and the exposed or true scutellum is equivalent to your scutellum in Hymenoptera. Now comes in Vespa between the scutellum and your quondam metatlorax, another trans rerse piece, which, as you have not named in Apis, I suppese is not fourd in tinem. To what in Colcoptera is this analogons? Here, again, our Geotrupes comes into play. If you take off the scutellum, you will find concealed by it at the base of the channelled lumbi, with which it forms a right augle, it curious vertical, square, horny plate. This seems to me analogous to the above intermediate part in Vespa. Lastly, in Vespa comes your quondam metathorax, doubtless analogous to Illiger's interscapulium, or the channelled part in Coleoptera, covered by the base of the elytra. So much for the upper side. Next as to the under side of the postpectns in Vespa. The large clilated part between the fore and middle feet must be analogous to the peristetlium in beetles. The sides of this part seem to form your pleura. The scapularia I have mentioned before. The mesostcthium must be a very small yart between the four lind legs. and between the sides of this and the neristethium lie two smaller parts, which I conjecture to be our hypochondria. Thus I have made ont, in one way or othcr, all the same parts in Hymenoptsera which are found in Colcoptera; and vice versâ. You must decide 
whether rightly or not, and, as I have no hypothesis, I am perfectly open to conviction.

"I have now somewhat to observe respecting the names of these parts. First as to your collare. Though this is not the thorax, I think we should still call it collare. This term is not here absolutely improper, as it is like, though not in reality, a collar; it has been introduced by your ' Monog. Apum Ang., and adopted by Illiger, and we shall not easily find a better. In Coleoptera, of course, we shall very rarely have oceasion to make use of it, but in every other order it will be of constant oceurrence. Dorsum, I think as before, is very objectionable, from being a word of such general import, and so often improperly nsed for tergum. For this part I think we shonld have some word equivalent either to our good English term, after-corselct, or to ante-scutellum, the coining of which I give up to you, the master of our mint.

"I do not exactly recollect what parts we meant by lumbi, or interlumbium. If the former were intended for ycur quondam metathorax, I think it is objectionable, as being a plural name for one flat surface, and because in anatomy the terms apply only to the sides of the lumbar region; but I see no objection to interlumbium for this part. We still want a name for the transverse part between the sentellum and interlumbium. Might not this be the post-scutellum or something equivalent? Hypochondria.-In referring to a system of anatomy I fund that this term, as we use it, is anatomically ineorrect, the hypochoudria being, in fact, the sides of the epigastric region of the abdomen, but though in part covered by the false-ribs, forming no portion of the true pectus. As we apply the term epigastrium to the base of the abdomen, it will of course be highly improper to apply a term appropriated to the sides of the epigastrium to the pectus. On this account, and as Linue evidently in Cerambyy rubus applierl this term to the whole sides of the postpcetus (which was correct, according to his idea of regarding that part as the epigastrium - see Cantharis rufa) had not we better drop it, and adopt Knoch's parapleura, which seems unobjectionable?

"I camnot guess what we meant by Intercosta, Femoralia, and Costulc, though I very well remember giving those names to particular parts. But though I have since examined the postpectus of many Coleopterous insects, I see no parts but what may be referred to the peristethium, mesostethium, scapularia, and parapleura. These, indeed, are sometimes crossed by apparent sutnres, but $\mathbf{I}$ do not think this is a sufficient reason for dividing them into more distinct parts. Knoch's meriaex are clearly the hind coxx. Of course we have nothing to do with them.

"Squamula. - I stumbled lately upon an objection to the use of this term in the sense you have given to it in 'Mon. Apum Ang.,' viz., that Linné had applied it to the angular elevation of Formica. We shonld certainly, therefore, have a distinet name. Illiger's name, tegula, does not seem very much amiss, as in Ifymenoptera this part aptly enough may be compared to a little tile. Our English base-cover cannot be improved.

"So much for objections. Besides which I have to notice two or three things that we yet seem to want names for. 1 st. Should we not have a name for the upper wing-eases of Grylli, \&e., which being of so different a substance can searcely with propriety have the terms clytra and coleoptera applicd to then. Illiger uses tegmina, but perhaps a better term might be selected. I perceive in a large toreign Gryllus, which doubtless you possess, a curions concave shell-like process, between the claws of the tarsi, to which neither pulcillus nor onychium is applicable. What shall it be called? Would it not be very convenient to have a term signifying that the surface of any part of an inscet is fiee from all inequality, in opposition to foveola, strice, \&c.? Lavis is not sufficient, as properly it should be restricted to denote the absence of 
puncta, scabrities, \&c. only. Thus the thorax of an Apion might be foreolate, and yet lavis; and if it should chance to be neither, the absence of the former character conld not at present be expressed without a periphrasis. At present we are forced to say haud striatus, canaliculatus, \&c., which is contrary to the Linnean rule of not using negatives. Would aquatus, in English, even, do ?

$$
\begin{aligned}
& \text { "I am, \&c., } \\
& \text { "W. Spence." }
\end{aligned}
$$

The following is Mr. Kirby's answer to the preceding letter:-

"Barham, November 27th, 1809.

"My dear Sir,-I now mean to take my revenge, and show you that I also can write a long letter, a faculty which, from your late experience, you may begin to doubt my possessing. I shall not, however waste my time and yours in proliminary matters, but go directly to the unanswered parts of your letters. I shall begin with your last, by saying that I admit the validity of your reasoning with respect to Ilium and Ischium, and had on the last male a note in pencil, 'melius trochanter.' But if this is considered as part of the thigl, would not a term be necessary to distinguish what is commonly called the thigh? Perhaps it would be better to consider the trochanter as per se, and so arrange coxa, trochanter, femur, one under the other, as primary parts of the Pedes. I cannot look at your letters without wishing I had been with you during your examination and dissection of insects, to have taken some of your labour off your shoulders. Your success has been answerable to your pains, and no small degree of light will be thrown upon Entomology by your discoveries and observations. I must brush np my memory a little, for I seem to liave forgot the reference of many of our terms. As I go on with this letter, I propose to write the definitions of the terms of our anatomical table, which I shall then send to you for your obscrvations.

"I admit the jnstice of your observations, that the joint at the base of the claw-joint in Cerambyx, Scc., is perfectly analogous to that at the base of the thigh, but I think neither of them a true trochanter; which all the joints have independent of it. Is this an anomaly, or are we to look upon it (regarding the thigh as the tibia, with Dr. Wilmot), as analogous with the fibula? I strongly suspect he is correct in this opinion, for though the fibula in large animals is parallel with the tibial bone, it seems in other respects to answer to this, and in many insects it seems to run in that direction. I have no anatomical book, so I may speak rather ineorrectly, for I forget whether the name of the bone parallel with the fibula be called tibia or not. Observe - the insects that have this anarthrous joint at the base of the claw-joint have no onychium or pulvillus, or else an obsolete one. With respect to this term onychium, I must observe that it is by no means correct, for onychium signifies a little claw; now even in the Lucanides this little joint is terminated by bristles rather than claws, and I believe in the majority of genera it has nothing like claws. I an not wedded to pulvillus, which is certainly not generally proper, and yet one term ought to distinguish the same part in all cases. It seems to me more analogous to the ball of the foot than any other part, but planta wonld generate confusion; what think you of planiula, its riminutive? Now I am upon the subject of legs, I will observe that the part you notice in the anterior tibix of Lamprima (male) is one of the spinulce. I don't recollect whether in answer to your remarks upon antennx, and my terms radicle, scape, stalklet, and flagellum, I observed that these were not meant to be applied universally to the three first joints, and the whole of the rest, but only in cases where they are remarkable, which, I believe, are more numerous than you seem to think, for you will find in most of the 
Hemiptera, Neuroptera, and Diptera, that these parts are distinguishable from the rest. Take Tabanus, for example. How useful will the term flagellum be to describe the six last joints, together of so singular a shape, which cannot be described taking them joint by joint ; and in Gryllus the flagellum is often compressum, while the stalklet and scape are nearly globose. In Cimex and the Neuroptera, the scape, at least, is always remarkable. We want a fourth term for antennæ, viz., Capitulum, to be applied to Scarabceus, \&c. \&c. I observe in Geotrupes that the inner spinula is moveable, and the other fixed; but whether this is so in the other orders I cannot clearly determine, but I think in Vespa both are moveable. I observe in Gryllus the plantula you mention, but the same name may apply to it.

"Thorax or Collare. - I continue to think the parts that have been known by these names in Coleoptera and Hymenoptera are analogous to each other. The collare being connected by membrane, \&e., with the tubercula or scapularia, might on being taken off move them, and oecasion the motion of the wings you mention. I have taken off some this morning without producing this effect. If you take off the head of a Vespa, it will carry the forelegs with it, and leave the collar behind ; but $I$ have just taken off the heads of several Apes, Ichnenmons, Melitke, and other Hymenoptera, and they have more generally left the forelegs behind. The thoras in Coleoptera seems to me exactly in the place of the collare in Hymenoptera. I have taken to "pieces the Geotrupes you describe, and see the piece you think analogous to the collare; but this piece appears to me to belong to the interior anatomy, and to be part of the mediastinum, or of the strong membrane that separates this part from the pectus. Dytiscus, Mylabris, Buprestis, Curculio, all of which I have been examining, have nothing analogous to it, but mere membrane; in these large inseets I suppose it is of a more cartilaginous nature. In order to make it analogous to the collare, it ought to be universal. You seem to me to hare made out the analogous parts of Coleoptera and Iymenoptera extremely well; but what answers to the mesostethium appears to me not so very small, for it seems to me to extend more than half way towards the wings. The term dorsum might give place for post-collare, then we should have thorax and metathorax, collare and post-collare, and pectus and postpectus, which would give concinnity to our terms. The part you notice in Vespa, as succeding the scutellum, and to which your acenrate eye has discovered an analogous part under the scutellum of Geotrupes, might be called antelumbium, or postseutellum, as you suggest. This part seems not to be separated by a suture, but only by an impressed line in Vespa; but a suture distinguishes it in some genera : it is not very obvions in Apis. By the term lumbi we agreed to distinguish the parts that lie on each side of the channel that runs from the antelumbium to the abdomen. The channel itself, which in Coleopterous insects has often an elevated line ruming through it, or kind of vertebræ, we called interlumbium: this part exactly represents the loins with the back bone between them. We did wrong when we construeted our termini anatomici, in not making definitions when we named them, for I forget exactly now what we meant by femorale, unless we proposed to distinguish by it the dilated flat coxa of the posterior legs in Dytiscus and Buprestis. The intercosta was intended for a piece observable in Buprestis vittata, which is between the mesostethium and the posterior coxæ. 'The term costula was intended for a little piece which seemed inserted between the scapularia and the peristethium in the same Buprestis; but it is dubious whether they exist, and therefore I think with you we may strike out these terms. I see that it would be very convenient to have a term to distinguish sides from edge: in English we can say very well, sides deflexcd, edgre rounded. Perlaps, in Latin we might say, lateribus deflexis, acie rotundata; but even this might be liable to be misun- 
derstood, for a roundel cdge might be construed to mean, round instead of sharp, applying the term not to curvature of the sides. But on further consideration, it seems to me that the alverb utrinque, applied in this case, will do as well as coining a new word. Thorace utrinque deflexo luteribus rotundutis, or vice versâ, utrinque rotundato, lateribus deflexis, seems to me quite clear of objection. What do you think? I don't see that we have any term for the point of meeting of two joints. With respect to tibia and femur, geniculus will do very well; the other end of tibia and tarsus, if necessary to be noticel, would with equal propriety be denominated cals or heel. With respect to the point of meeting of two joints of antennæ or palpi, no term strikes me that would be proper: can you think of onc, or would one be necessary? You observe we have no term for ligula, Fabr. WVe agreed to call this part lingua. If a diminutive for lingua is to be used, it might as well be used for all tongues of insects that are properly such. I think the same name should be given to the same part in all orclers; in fact, in use the ligula comes nearer to the tongue of animals tlaw the sucker-tongues. Palpi. - I have no objection to employ this as Euglish instead of feelers.

"Ovate and obovate. - With respect to the abdomen of Coleoptera, I look upon tlicm to be ovate when broadest towards the thorax, and obovate when broadest towarls the ants; and so with respect to the whole insect. With respect to the thorax, Linné seems to revcrse this plan, calling the thorax in Carabus, obcordatus. His idea of ovatus is plain, from his calling Spharidium scarabcoides, ovatus. With respect to the head, Fabricius makes it ovate when it is broadest at the thorax in the Staplyylini of the family of lincaris. The thorax of Curculio Palmarum, Linné makes ovatus ; Cujculio Germanus is corpore orato. So that, as it should seem, the ovate body is broadest towards the head; the orate head is broadest towards the thorax; the ovate thorax is broadest towards the elytra ; but the ovate elytra or abdomen are broadest towards the thorax: the reason of this seems to be, that the apex of the elytra or abdomen must be reckoned at the anus; but one would think the apex of the whole body should not be reckoned as there.

"Hypochondria. - Having no anatomical books, I rely on the correctness of your statement with respect to its station. I thought the second eavity of the abdomen, which is analogous to our prospectus, was the region of the Hypochondria, in which case the term would be proper. I have no objection (stating our reasons for receding from Linné), to adopting Parapleura.

"Lcevis et cquatus, Syc.-TVe have a term (lcevigatus) which seems to answer for this purpose, 'very smooth without elevations or depressions,' but somelion or other we have not got lavis. I see in the book in which I ar'ranged Linné's terms alpliabctically, we have 'lavis, smooth, without elevations,' and 'lavigatus, smooth, without depressions.' I suppose we then thought one term sufficient. Linné uses the term aqualis for your aquatus, it should seen, under Tenebrio gigus and mortisagus. He appears to have wanted a term of this sort when he describes Teneb. lavigatus, and latipes, for he says, 'lavis, elytris lavibus,' to distinguish them from $T$. variabilis, which is lavis, elytris elevato-punctatis. If we use lavis and lavigatus, the former should signify the absence of stria, chan * nels, foveole, or fossula, and similar kinds of sculpture; and the latter, which implies a more intense degree, should denote the absence of points, granules, or any roughnesses of surface. It would sound well to say lavis, elyitri: lavigatis. But, perhaps, you will think three terms necessary, one for the absence of sinaller inequalities, another for the absence of larger, and a third for the absence of all inequalitics; then it would be aquatus or aqualis, without larger elevations or depressions; lavis, without smaller elevations or depres. sions; lavigatus, without any elevations or depressions. 
"Upper wings of Grylli, \&c. - The term elytrum is not improperly applied to these case-wings ; it means merely an integument, and I don't see that any confusion is generated by the use of it. Even amongst the Coleoptera, the elytra of some are scarcely more than coriaceons, while in others they are a very hard crnst. The term elytrum of itself does not properly convey the idea either of a corneous, coriaceous, or membraneous wing-cover, but merely of a wing-cover. The same observation holds good with respect to the Coleoptra, which is so convenient that it will not be easy to do without it, and it is used without impropriety, strictly considered, for when thus used it is merely saying wing-cases so and so. The term Hemelytrum is more applied to Cinices, I believe; elytrum would be proper for Cicada, but not for Chermes, Aphis, and Thrips. All that seems necessary is under each order or section to define the substance of the elytra. You seem not to have noticed the difference between the terms Coleoptera and Coleoptra. You will find, when it is applied to the elytra of individnals, it is always spelled in the latter way.

"Squamula. - Linné, indeed, in his generic character of Formica, uses the term squamula, but never once in his description of the species; here it is always squama. Fabricius and Latreille invariably have it squama. Linné's generic character will not be adopted, because it does not include all the species ; or if it should be adopted, squamula would properly be changed to squama. I therefore see no reason for giving $u p$ my own term, which I think every impartial person will prefer to Illiger's. A little scale is certainly much better than a little tile, for the part in question; indeed, the latter strikes me as bordering upon the ridiculous.

"I am sorry to find, that in my haste in putting up the insects, for Mr. Rodwell to take, I forgot the Scymnus I reserved for you, and also a little Aleochara (rufungula) which I hare of yours, taken when you were here, under some moss in Slirubland Park.

"Nov, 29. - I have carefully read over your excellent sketch for a plan of our work, and upon the whole very much approve of it. What we say in the first letter with respect to objections farther than glancing at them, should be to meet and refute the charge of cruelty, which is also one great objection with the fair sex from pursuing the study. The cui bono objections will be answered partly when we detail the general advantages, and more fully as you propose, and have done exccllently, in the 12th letter. I am not altogether of your opinion with respect io the mode of treating the Noxc Insectorum, for I think the general effect will be much the most striking and alluring, if we conclude with the ravages of the locusts. We are giving a general view of the subject. Our Introduction is a general Introduction to Entomology, and if we give a particular detail of the injuries our country receives, as we should of course do, this will be sufficient to interest the reader, and will remain longest upon his mind, because always under his eycs, thongh we leave off with cxotic depredations. Don't let us expose ourselves to the sneers of hypercritics, that we are proficients in the Bathos, or art of sinking. This is all matcrial that $I$ find to object to in your plan; the rest is admirable. I think the directions for taking insects, preserving, \&ce., should follow the technical part, for, as my friend Mac Leay observed, we should first tell our correspondent what an insect is, before we set him to cateh it. From your plan, which urges strongly the platcing Noxi before the Beneficia, yon seem to have imagined I had placed the latter first, but in this your memory failed you; it is always best to leave off with the fair side. . . . Pray tell me in your next what parts of the work, besides the History of Entomology, you would like best to do, as I shall soon set hard to work, and 'tis pity we should both gnaw the same bonc. When yon have gnawed your bones, send them to me, and I will do the same by minc; so they will stand a grood chance of being picked quite clean. I thall hope for nuch 
from you upon the miracula, as I have few authors to consult, and scarcely any travellers. I have never met with Barrow or Jackson. . . . .

"Yours very affectionately, "W. Kïırby.

“ Barham, January 23rd, 1810."

[In this letter, after mentioning the severe illnesses of two near relatives at Ipswich requiring his frequent visits, he proceeds :- ]

"To my great discomfort also, the business of settling the affairs of a man who has involved himself deeply in debt, has also unavoidably fallen upon me. I hope they will be settled in another fortnight. I mention all these circumstances, that you may see that it [the delay of writing] has not been for want of inclination, but of leisure. The misfortune is, I am fitted by nature for a contemplative rather than an active life; business, and the settlement of seeular affairs, makes my head wild, and I would gladly, if possible, disengage myself from it altogether; but this is at present out of my power, so you must not be surprised if $I$ am unable to do much for the present. This you may be surc of, when I am at leisure I will endeavour to make up for lost time." . . . .

The ahove extract is chiefly given for the sake of remarking, that though Mr. Kirby's natural dispositions were, as he states, more contemplative than active, yet no man ever less suffered his inclinations in this respect to encroach on or set aside his social duties. During the long course of our correspondence there is scarcely a letter without a reference to some executorship he had to carry out for a deceased relative or friend, to some secretaryship he had to fill for a charitable or other benevolent institution, or to some active services, like those referred to in the above letter, in arranging the affairs of persons often but distantly connected with him ; but all these duties, however contrary to his natural inclinations, he scrupulously fulfilled, in addition to those of his sacred office, before giving up any portion of his time to his scientific pursuits.

\section{"Barham, Feb. 17, 1810.}

"My Dear Sir,-Many thanks for your kind attention to my request to send the copy of the anatomical terms [to replace his, which he had mislaid]. I have already profited so far by it as to draw out the definitions, and have been for some days hard at work, one way or other, upon our work. . . . . I shall begin with sttending to your request with respect to what part of the work each should undertake. As I have made a pretty ample sketch for the three first letters,- -viz. the Introductory, Noxæ, and Beneficia, - if you approve it, I will fill up the outline I have drawn up for them. Then you may take the three next, - viz. Storgé, Food, and Ilabitations; then to my lot again might fall 7 , 8, 9, viz. - Societies, Defence, and Noises ; next to you, 10, 11, 12, Phosphorescence, \&c., Recapitulation, and Defence of Systematic Entomology; and likewise, if you please, the 13th, on the States of Insects, in return for my having done the 14th, General Exterior Anatomy. 15, 16, 17, and 19, Head and parts, Trunk and do., Abdomen and do., and Orismology, are already in great forwardness. 18, on the Interior Anatomy, you may take. 20, Class, Order, \&c., I will take. 21, Making out insects, let Spence take,-nobody makes out insects with more accuracy. 22, Seasons, Kirby had thought about, and will take ; and also 23, Haunts and Times of Flight. 24, Catching, Spence ; 25, Killing, Preserving, Cabinets, \&c., Spence; 26, Breeding, Kirby ; 27, Ilistory, Spence; 28, Conclusion and Dictionary, W. K. and W. S. conjointly, W. K.

Q Q 2 
giving terms from Linné, Fabricius's works (except 'Fundamenta Entomologia,' which $\mathrm{K}$. has not an opportunity of consulting), Latreille's 'Genera Ins.', Scopoli, Schrank, Walckenaer, De Geer, Reaumur; W. S. Illiger and the German cntomolugists, and 'Fundament. Entomolog.' Motions of Insects I forgot: Kirby will take. Short accounts of books, IV.S. The plan that strikes me as the best, with respect to the parts which each undertakes, is this - When yon or I have finished a letter, or (perhaps better) the whole of our parts, I to send mine to you, and you yours to me, that each may make his observations, and give his sanction to what the other has written, and add any particulars omitted by the other that may have occurred to him. If you wish any alteration made in the above apportionment of parts, you will state it in your next packet ....."*

* The above extract is mainly given for the purpose of adding to it some further explanation on the subject to which it refers.

In our Preface, p. xxi. [here, and thronghout this chapter, the 5th edition (1828) is referred to ] 1 , we have declined stating which letters were written by each; and in the thirty-seven years which have elapsed since we "excused ourselves from gratifying the curiosity" to ascertain this fact (if any such were ever felt), no clue to it has been given, except the disclaimer by Mr. Kirby, in the advertisement to our third and fourth rolumes, of agreeing with me in opinion on the theory of instinct in the letter on that subject, Vol. II., and the remarks, in Vol. IV. p. 19-33: both, as he wished it to be stated, written by me.

As this disclaimer, however, has broken the charm of secrecr, and as some future ingenions entomologist nuay think it worth his while to endeavour, from internal evidence, still further to solve the mystery, in attempting which he would be sure to fall into gross errors, it has seemed to me best (and Mr. Freeman coincides with me) to give here the entire list of the letters of our work which were ultimately agreed on, and which vary in some respects from that proposed above, with the name of the writer affixed to each, and such observations as are necessary to make the information correct and complete.

Preface.-Mr. Srexce.

\section{VoL. I.}

[The two paragraphs relative to the religious bearing of the work, pp. xiii. and xiv. [pp. xii. and xiii.]; the first half of one at p. xvi. [p. xiv.], beginning "The anthors," \&c., and one at p. xviii. [p. xv.], beginning "Besides these," \&c., were added by Mr. KIRBY.]

LETTERS.

I.-Introductory. MIr. KIRBY.

II.-Objections answered.

The first part, to p. 39. [20.] Mr. Kinis.

The second part, in defence of Systematic Entomology, pp. 40-53. [2027.7 Mr. SPEnce.

The concluding part as to cruelty. Mr. Kirer and Mr. Spexce.

III.-Metamorphoses. Mr. SPENCE.

From p. $72-77 .[37-40$.$] , by Mr. Kirbr.$

IV. to VIII.-Injuries caused by insects. Mr. KirbY.

IX. and X-Benefits derived from insects. Mr. KinBY.

[A large proportion of the facts, and several entire paragraphs and pages

in these seven letters, were furnished by Mr. SPENCE. ]

XI.-Affection of insects for their young. Mr. SPENCE.

XII. and XIII.-Food of insects. Mr. SPEACE.

XIV. and XV.-Habitations of insects. Mr. SPENCE.

\section{LETTERS.}

\section{VOL. II.}

XVI. to XX.-Societies of insects. Mr. KrnsY.

XXI.-Means by which insects defend themselves, Mr. KIrby.

XXII. and XXIII.-Motions of insects. Mr. KinBX.

XXIV,-Noises produced by insects, Mr. Kiriby.

i The pages 1eferred to in this 7 th Ed. follow between brackets. 
It will have been observed that, in our letters of Nov. 20 and 27, 1809, a discussion is begun as to what portions of the thorax (Linn.), in the

XXV.-Luminous insects. MIr. SPENCE.

XXVI.-Hybernation and torpidity of insects. Mr. SrExce.

XXVII.-Instinct of Insects. MIr. Spravce.

\section{VoL. III.}

LETTERS.

XXVIII.-Definition of the term insect. MIr. Kirby and Mr. SpExce. XXIX, to XXXII.-States of insects. "MIr. KIRHY and Mr. SPENCE.

[These four letters were originally assigned to MIr. Spence, and rough copies of them were prepared by him, extending to 120 pages of $\mathrm{MS}$. in large 4 to. ; but owing to his ill health (as explained in the advertisement to Vol. III.), the accumulation of new matter required the whole to be prepared for the press by Nr. KirisY.]

XXXIII. to XXXVI.-External anatomy of insects. Mr. Kirex and Mr. Spence.

[This department of the work, as has been previonsly here explained and in the advertisement to Vol. III., was that to which the authors, both during Mr. Spence's visits to Barham and in their long subsequent correspondence, mainly devoted their attention; and the tabular view of the parts of insects was the very first portion of the work drawn up by them as the result of their joint examination of a great number of insects of all orders, and of long discussions (both orally and by letter) as to their homological relations: but the more extended and connected survey of the whole subject contained in those letters was drawn up by Mr. KnnBx.]

Vox. IV.

LETTERS.

XXXVII. to XLIII.-Internal anatomy and physiology of insects. Mr. KrRsY and Mr. SPEXCE.

[The explanation given above as to the letters on the states of insects, applies equally to these seven letters on their internal anatomy and physiology. They were originally assigned to Mr. Spence, whose rongh draughts of the letters fill 125 MS. 4to. pages; but it was necessary, in consequence of his ill health, that the whole should be prepared for the press by Mr. Kirby, so as to incorporate the new facts with those which Mr. Spence had collected.]

XLIV.-Diseases of insects. Mr. KinBY.

XLV.-Senses of insects. MIr. Kirby.

XLVI.-Orismology, or explanation of terms. Mr. Kirby and Mr. SPENCE.

XLVII.-System of insects. Mr. Kirsy.

XLVIII.-History of Entomology. Mlr. Kirby and Mr. Spence.

XLIX.-Geographical distribution of insects, \&c.

[The first part, on general geographical distribution, by MIr.

KinBY; the remainder by MIr. KIRBY and MIr. SPENCE.]

L.-Entomological instruments, \&c. Mrr. KinbY and Mr. SPENCE.

LI.-Investigation of insects. Mr. Kırby and Mr. Spence.

Appendix.-Mr. KIReY.

[An enumeration of entomological works, and of papers in Transactions, Journals, \&c., drawn up by MIr. SPEAcE, and extending in MIS. to 126 pages large 4 to., was mavordably omitted, owing to the much greater bulk of the work than had been originally calculated on.]

$1 \mathrm{beg}$ to conclude this long note, which assigns to each, as far as practicable, his share in the work, with a repetition of our desire, expressed in the Preface, - and

$$
\text { Q Q } 3
$$


two orders Coleoptera and Hymenoptera, are really homologous. When at Barham, we had decided to regard Mr. Kirby's Collare of his "Monog. Apum Ang.", as he had then considered it, as the equivalent of the so-called thorax in Coleoptera; but on reaching home, and dissecting many insects of the two order's, I was led to suspect we had decided wrongly; and the anatomical facts on which my doubts rested, are detailed in the preceding letter of Nov. 20 (p. 588.). Mr. Kirby, it will have been seen, in his reply (p. 59\%.), adhered to his original opinion; and the discussion on this knotty point was contimued at great length, by reference to dissections we had made with this view, and arguments built on them, in the eight or ten letters which we exchanged in the spring of 1810 , without conviction on either side: but a letter from $\mathrm{Mr}$, Kirby, dated May 14, begins as follows, with an admission that he had seen reason to come over to my way of thinking on this subject, - an admission my candid friend could well afford to make, seeing how often he had convinced me of error, and brought me to adopt his views on points on which we had differed and as thoroughly discussed as this : -

"Barham, May 14, 1810.

"My Dear Sir, - I began a letter to you before breakfast this morning upon a conmon shect of paper, because I did not expect to have matter to fill a folio. I had not proceeded down one side before your letter arrived, the reply to which will, I think, enable me to eke out this $\mathbf{7 4}$, and therefore I shall begin anew. You probably got my letter the day after yours was despatched, which I hope set your mind at rest on that score. Ny object in writing again so soon was to express to you my full conviction that you are perfectly accurate

which I know was Mr. Kirby's as much as mine,-that in any reference to our work we may be always jointly referred to, with two exceptions: these are -1 st. The Letter on instinct (Vol. li.), and my farther remarks upon this subject (Vol. IV. pp. 19-33.), on which Mr. Kirby differed in opinion from me, as he has stated in the alvertisement to Vol. III., and for taking which different view from mine he has given his reasons at large in the Bridgewater Treatise (Vol. II. p. 222-280.); and 2nd. The Letter on hybernation (Vol. Il.), in which the denial of the possibility of satisfactorily explaining the retreat of insects to their winter quarters, and often the preparing of these previously, from the mere direct sensation of cold, I think it due to him to state (though he did not himself care to advert to it in the adrertisement above quoted) was in opposition to his opinions on the subject, and no portion of this Letter, nor of that on instinct, was written by him. With these slight exceptions, no reference to our book can ever be justly made except in our joint names; for the chances are, that even in the Letters here stated to have been written by one of the authors, the particular facts or observations referred to (often extending to whole paragraphs and several pages) may have been supplied by the other, as perpetually occurs. It was, indeed, next to that of criticising and perfecting our anatomicai and orismological terms, expressly for the purpose of thus adding to the stores of his coadjutor, that the greater part of the long letters that passed between us, during the extended period employed in the composition of the work, amounting in quantity of matter, if printel, to far more pages than its four volumes, were written by each. In fact, there probably never was a work, composed by two authors, more thoronghly" dove-tailed with the contributions of each, than ours. Our book was always in our thoughts; and our reading, even on dissimilar subjects, was constantly firnishing facts, or hints, or illustrations, bearing on the portions of each other, which were duly noted and transmitted, and most generally adopted: and, if it have merit, this is in a great degree owing to its being what it professes to be - a really joint production of two variously-instructed minds, anxions only to contribute to the perfection of their labour of love, - for such the work truly was to them, - during the many years it occupied them. 
in coneciving that the thorax, as it has been usually called, in Coleoptera is not analogous to the collare in Hymenoptera, and thus to do you ample justice for that penetration and discernment which enabled you so early to make this very importaut discovery. Truth seemed to me at first on the other side; but the observations I have made this spring, and another circumstance, which I shall presently explain to you, have made me a convert to your sentiments. If I know myself, I love truth better than opinion; and thongh I may be sometimes over warm, from the natural hastiness of my temper, in maintaining what appears to me so at the time, yet I an never baekward to own and embrace it, however contrary to my formier opinions, when, the clouds being removed, I see it in its native beauty. In my last letter you observed, I dare say, that I was beeome nearly of your opinion; I will now state what has made my eonviction complete. After I had finished the Orismology, I thonght to begin the Letter which treats of the body of an inseet eonsidered more at large. Beginning with the erust, or skeleton, I next turned my attention to its articulations, distinguishing those that have free motion, - I mean motion independent of that of the parts to which they are attached on any side. In this view, taking a coleopterous insect for my example, the borly to me appeared to eonsist of four, instead of three great joints - viz. the head, the thorax, the metathorax, and the abdomen. (With respect to the two last, - the metathorix and the abdomen, - they are much more closely connected in this order than the head and the thorax. I have not yet ascertained by observation whether they have free motion ; but as they certainly have in Hymenoptera, \&c., I for the present take it for granted.) Considering, then, that the upper part, or shield, of the thora: moves with the under part or breast, and together form the second joint, this convinced me that the collar in Hymenoptera, which has no free motion, and is therefore part of the metathorax, with which it moves, could not be regarded as analogous to the shield of the thorax, which moves with the breast, independently of the metathorax. The instances referred to in my last, - viz. Fonus and Xyphydria, in which the breast is evidently independent of the collar, - confirm this triumphantly. So in Hymenoptera, as well as Coleoptera, there are four free divisions; for I imagine that, although the head can move the thorax or breast, yet the breast ean move (as in Colenptera) independently of the head: but this, obscrvation must ascertain. This grand discovery of yours leads to some very important eonsequences, affording an admirable elue for a new order, and also for two great divisions of inseets viz. into Thoracici and Collares; the latter subdivisible into Collares, Collari distincto, and Collari evanescente. The Thoracici would include Coleoptera, Orthoptera, Hemiptera, and Neuroptera (excluding Phryganea and I'socus); and the Collares, Collari distincto, Hymenoptera, Trichoptera?, and Lepidoptera?; and the collares collari evanescente would eontain the Diptera. As to the Aptera, I eannot at present speak in this respect. With regard to my new order 'Trichoptera, every hour more convinces me of the propriety of it. In the Libellutida, Myrnelcon, Ascalaphus, Hemerobius, Semblis, Ephenera, Raphidia, \&c., the pectus is eovered by a thoracic shield; but in Phryganca and Psocus, and Panorpa? it is not. I have no speeimen of Termes to enable me to ascertain to which of these it belongs; but, from the veins of the wings, I should suspeet to the latter. Upon looking again at Panorpa, it seems to have a small thoracic shield; and as its wings have veins as well as nerves, it pro. bably belongs to the genuine Neuroptera: I wish much to lave your sentiments upon this idea. I use the term Trichoptera, because most of the insects (the genus Psocus exeepted) that belong to this order have hairs npon their wings, and it clistinguishes them, I think, well from their affinities, - the Lepidoptera. The next thing to be eonsidered is, by what name we shall denominate the shield of the thorax in the thoraeie insects: for eertainly the term Q Q 4 
collare should be restricted to the collar in the collaric tribe ; corselet and collar will do extremely well for English terms, but I don't know what to do for Latin. If we restrict Thorax to the shield, what term shall we use for the breast and shield together? Then, also, we must turn post-collare into metallorax, and have a new term for the after-breast and after-corselet taken together. Chest and after-chest would do in English, but I cannot at present find a good Latin term. Will not anatomy help us here? Having said my say upon this subject, I shall next turn to the queries of your letter received this morning. . . . . ."*

[Three folio pages of remarks follow on various matters I had adverted to.]

I am aware that, in giving this extract, I shall be liable to the imputation of vanity; but if laudari a laudato viro is allowed to excite a pleasurable feeling, which, being common to humanity, we mutually excuse, I shall scarcely be expected to form an exception to the general rule, by keeping back the expression of the good opinion of my friend, which gave me so much delight in my youthful days of entomological enthusiasm. But, in quoting this letter, I have another object in view, - that of presenting the remarkable example which it offers of Mr. Kirby's candour and love of truth. How few men in his position as one of the first of European entomologists, in which his "Monographia Apum Anglix" had placed him, would have had their minds open to the conviction of having been in error in one of its main anatomical details, and would have had the candour to admit that this error had been pointed out by a mere tyro in the science! For it must be observed that the question is not free from difficulties, but one on which much may be said on both sidest; and it would have been easy for one jealous of his authority, to have shut his eyes, and sheltered himself under this plea, and the weighty sanction of Illiger, who had adopted his views, from swerving from the decision he at first came to when I started my objections, that he continued of his former opinion as to the identity of the collare and thorax. But not so my excellent friend, who did not shrink from the closest contest of fact and argument, and frankly gave up his own opinions when convinced they were untenable. And so I ever found him during the course of our long friendship ; - tenacions of the opinions which careful examination of any question had led him to form, but quite willing to listen to any fair arguments bronght against them, and, when convinced, to admit their incorrectness.

* In a letter written two days after (May 16), Mr. Kirby has the following further remarks on collare and thorax:- "I find it necessary, before this sieve-like memory of mine loses all traces of them, to lay before you some further observations and concessions upon the subject of thorax, collar, \&s. I have been examining several thoracic insects this morning for something analogous to the Hymenoptera collar, and I find that what you took for the part in Coleoptera is certainly so. It exists in most Coleoptera, - perhaps in all, - in Hemiptera, and even in Lepidoptera, which have a true, though very slender thoracic shield. It is usually concealed under the membrane or ligament that unites the thorax to the metathorax, and its direction is downwards into the chest; so that in this order of insects it is a part of interior anatomy. The collar of Hymenoptera, in some instances at least (try Nomada, Apis, IIfelitta), is not merely a dorsal piece, but a belt which surrounds the whole metathorax, behind the pectus, though very slender at the breast. I have taken two, from a Nomade and Apis, off whole. This confirms beyond all doubt your discovery, and at the same time gives additional propriety to the term collare. ...."

† See "Int. to Ent." Vol. iii. p. 546-550. 
In May 1810, I received from Mr. Kirby four of his longest letters. There was then a pause of nearly three months; and his next letter, begun May 29th, was not finished and sent off till August 15. The beginning of this last portion is given, as it will interest Entomologists, and as furnishing some traits of my friend of his own sketching, but very similar, I fancy, to what we most of us experience in similar circunstances.

"Aug. 15, 1810.-Your reproof, my dear friend, was not unmerited; and what can I do but appeal to your good nature for forgiveness, after having stated circumstances which may a little extenuate, though not excuse, my indolence and procrastination? About the middle of June, I went to Livermere. near Bury, to visit a friend who was formerly entomologically inclined *: he lives in a spot very favourable to the entomologist. Here I picked up many good things, particularly Neuroptera, Hymenoptera, and Diptera; besides which, my friend permitted me to rummage over his collection and take what I liked, so that I carried home a large box full of insects. This set me, when returned to Barham, to looking over my collection in Orthoptera, Hemiptera, Neuroptera, Hymenoptera, and Diptera, a great many of which were scattered about in boxes, \&c., and which, upon inspecting them, I found were going fast to ruin; and I saw it was necessary, if I mcant to preserve the many good things I had collected, to put them in order, and in a place of security. This has employed all my leisure hours since my return from the above visit. I have now nearly finisled the Hymenoptera, which occasioned me infinite labour, and have then only the Diptera to put to rights. During this interval, also, my house has been full of guests. Yet with all this business I have been daily thinking of writing to you, but my employment kept seducing me ; so I said to myself, when I get through this genus I will write. Before your letter arrived, I had determined, as soon as I had done the Hymenoptera, to discharge the debt upon my conscience. It is too much my way, when I bave begun to delay writing to any friend, to procrastinate in this way ; and when I engage in any pursuit, it is with ardour; but if anything occurs to suspend my eareer, so that I lose the habit, I get a horror against it, which prevents my returning to it till after many efforts, - so that, as you justly say, sometimes I come down like a tropical torrent, and then follows a season of drought. You will see by this that I have not lately done much in our opus magnum. . . . . . With respect to your letters, I shall answer the last first. You say your letter on internal anatomy occupies fifty pages. Don't you think you can reduce it to smaller compass? for it strikes me that, considering the variety of matter we have to handle, that, unless we attend to brevity, we shall have our work extend to two or three volumes." [Then follow two folio pages of various remarks on the anatomy of insects, \&c.]

In the summer of 1812 , I spent four or five months in London, occupying the mornings chiefly in Sir Joseph Banks's rich library, which he threw open so liberally and unreservedly to the researches of naturalists, in collecting materials for our work; and about two months at Barham, where we jointly read and corrected the Letters that were to form the first volume of our work.

In the spring of 1814 I had the great delight to receive a long-promised visit from Mr. Kirby, but which, unfortunately, the delicate state of Mrs. Kirby's health obliged him to restrict to about ten days. These 
were chiefly spent in seeing the lions of Hull and the neighbourhood, and in visiting the many friends eager to pay their respects to him. We did little in insect collecting; but I had the great satisfaction of seeing him fish out with his own hands and secure a specimen of the then rare Donacia (Macroplea) Zostere, from the pond on the banks of the Humber, a quarter of a mile firom my house, where I first took it, and the source for a considerable period of the first British specimens.

He then returned home by York, Newark, Huntingdon, and Cambridge. From his letter of May 30, announcing his arrival at Barham, with a full account of his journey, a few passages may be extracted:-

"I arrived safe at Barham on Saturday night, and found my dear Mrs. K., though far from so well as I wished and expected, yet better than she had been the beginning of last week. ... I had a pleasant though a very cold ricle to York, especially upon the wolds. I saw Mrs. Sandwith and her solis at Beverley, and I took particular notice of your mative village, Bishop Burton, paid due respect to your old EIm, and assure you, without flattery, that l think it altogether the prettiest spot I saw in Yorkshire. We arrived at York about twelve, and after putting on clean linen, I marched to your friend Mr. H.'s, who received me very civilly. ... He would not be satisfied without my engaging to dine with lim, and then dismissed me, under the care of Mr. William H., to survey the Minster. I was much struck with this noble building, which exceeds everything of the kind I have ever seen; but I need not describe it to you. I then returned to dinner, and was sorry to find Mr. H. had decanted a bottle of fourteen-years old port for me, of which I could not partake. [Mr. Tirby at this time found his digestion improved by abstaining from wine.] After dinner be took me under his own care to show me the other York lions. ..."

In the remainder of the letter he adverts to the mode of burning lime at Brotherton; the very long and narrow canal barges he saw near Retford ; the gypsum pits near Newark; and to Southwell Minster, of which he describes the peculiar style of architecture, and sends a message respecting it to John .Crosse, Esq., of Hull, the eminent antiquary, with whom we had breakfasted.

At length, in the spring of 1815 , the first edition of 750 copies of Volume I. of our book appeared, - just in time to allow me to take one with me to show to our entomological friends on the Continent, where I made a four months' tour after the battle of Waterloo. A second edition was called for the next year, and a third in 1817 , when also was published Volume II., of which a second edition was required in 1818, and a third in 1822.

A sad interruption of our joint labours took piace in 1818, in consequence of my ill-health, caused by severe head-aches, gradually increasing, until at last they were excited by the slightest effort of attention in reading or writing. After struggling against them a year or more, and trying various rensedies recommended by my medical advisers, I was obliged to give in, and, adopting Dr. Baillie's prescription of being "for several years an idle man," to lock up my books and cabinets; to put in order and send to my coadjutor, whose grief and disappointment were equal to my own*, my large pile of unfinished MSS. for my share of the work;

* A letter from Mr. Kirby, dated Jan. 18, 1819, with an account of some experiments with acids, \&c., on the exterior crust of insects, concludes thus: - "Ton 
and to transfer myself and family fiom Yorkshire to the more genial climate of Exmouth, where we resided several years.

During this period, though I took no active share in the completion of our book, I gave suggestions on various points in the letters which we still regularly exchanged; and one summer Mr. Kirby, accompanied by Mrs. Kirby, made the journey from Barham to Exmouth, expressly to spend a few days with us, - I need not say low greatly to my delight.

In 1826, our concluding Volumes (Vols. III, and IVV.), appeared; and in this same year, as I found travelling always suit my health, which was still far from being re-established, I removed with iny family to the Continent, where we spent the next eight years, visiting in succession most of the European capitals, and residing four years in Italy, but migrating to Switzerland in summer. During the whole of this time, as well as on our return to England, my correspondence with my old friend was regularly kept up; and we frequently saw each other on the visits made by Mr. Kirby to London, and one winter at Leanington, where Mr. and Mirs. Kirby joined us, and we spent a month together. Space can be here afforded for extracts fron only two of Mr. Kirby's many letters during this period, - one addressed to Milan, and the other to Leamington.

"Barham, June 13, 1832.

" My Dear Friend, - I this morning received your kind and interesting letter from Pisa, and lose no time in setting an answer on the stocks, thongh it may be some days before I shall have leisure to finish it. I did not answer your last letters, because I was uneertain where to direct to you. I must begin by thanking you for the variety of new and interesting information your entertaining letters contain. They make my mouth water to be with you ; but, alas! it is not given to me to be partaker with you in your enjoyments. But I will not repine; I have too much to be thankful for, far beyond my merits, to feel any lasting emotions of envy; but when I read your letters the wish will rise in the heart. I have very little scientific intelligence to communieate, for I know very little what is going on in the scientific world, having had very little communication with it of late.

"June 15.-I very recently completed the fiftieth year of my residence at this place, and received some very gratifying marks of regard and attachment from my neighbours. The menbers of the Claydon Book Clnb had a julilee dimner on the oceasion, and, as a token of their regard, presented me with a very elerrant piece of plate; and yesterday evening they and their ladies, at least such as could come, were entertained here, about twenty-seven altogether; and a very happy and pleasant party we had. Bernard lBarton, the Quaker poet, a very friendly Friend, who before addressed some very pretty verses to me, inserted in our provineial paper a very beautiful address to me, but above my deserts, but which showed great liberality on his part to eulogise a receiver

cannot conceive how much I feel the loss of your assistance in the variety of subjects that come before me. I want your opinion upon so many points, that I sometimes feel half disposed to throw aside my pen. I have nobody upon whose judgment I can depend to consult, for MacLeay, who would on such occasions occur to me, is so extremely negligent as a correspondent (owing to his incessant official duties), that jf I asked him ten questions he would not give me an answer to five, and that in a hasty manner. I must do, however, as well as I can, but I shall hail with joy the day that restores you to the moderate use of your pen." 
of tithes, and to acknowledge him as a minister of the Gospel. They are too long to insert here, or I would send you a cony.

"You ask me to report progress with regard to my present undertaking. [The 'Bridgewater Treatise.'] It reguires more time than I calculated to bring it out in a satisfactory form. I have written nearly 200 pages, but I fear I shail not get all I have to say in a single volume; but this, time will show. I find my memory does not help me as it used to do. [A summary of his plan follows, and queries as to any observations made by my Italian friends on the animals of Aristotle or Pliny, especially the Polypus.] I forget whether I mentioned to you that the second rolume of Dr. Richardson's 'Fauna BorealiAmericana' is published. It is a most splendid volume, with coloured figures

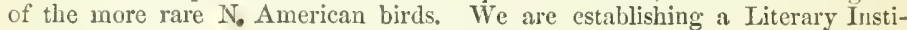
tution and Museum at Ipswich. I have promised them my herbarium, which is considerable, and shall also give them my fossils. . . . . We have escaped the cholera in this part of the kingdom, in spite of the communication between Ipswich and London, Newcastle, \&c. . . . I I have not taken an insect for ages. At seventy-three one cannot see.

$$
\begin{aligned}
& \text { "Yours, my Dear Friend, } \\
& \text { "Very affectionately, }
\end{aligned}
$$

"WM. KIRBY.

"Wm. Spence, Esq., Poste restante, Milan."

"Barham, January 11th, 1841.

"My Dear Friend,-I fear you have wondered and felt disappointed by the non-arrival of any letters from Barham since the rector and his lady reached that place. At first I was prevented from writing by an accumulation of lusiness which called for immediate attention; and since, with one thing or other, my time has been so fully occupied, that I have delayed from day to day beginning an epistle to the sojourners at Leamington. But though I have not written, we have daily thought of them, and spoke of them, and not seldom wished that we were again enjoying with them the murning rambles and social cvenings that were so pleasant to us. But I must tell you our history since we left Cambridge:-After spending a week at the latter place and Stretham very pleasantly, we packed ourselves into the Ipswich coach, and arrived at dear old Barham once more, on Friday, December 18th, which we left October 14th. We found all cur connections and friends well, and were received with hearty welcomes; and were thankful to see them again, and be settled down for the winter amongst them. And winter, indeed, it is, for the country has been covered with snow since the beginning of this month; but this morning a rapid thaw appears to hare commenced, so that I shall content myself with perambulating my passage instead of my parish. I wonder whether your Leamington meadows lave been covered with the above winter garment; this, I fear, would confine your rambles within a narrow space.

.... "Have you seen Ifenslow's paper on the diseases of wheat? I received it, not long since, from the author. It is printed in folio, and contains about seventeen pages. It was printed for private circulation, so I expect is not to be purchased. If you have not received a copy, I can send you minc. This is all the scientific news that I have to communicate. . . . ."

The first volume of a translation of the "Introduction" into Gernan by Professor Oken was published at Stuttgart in 1823; the second in 1824; the third in 1827; and the fourth in 1833.

A fifth edition of our book had been called for in 1828, and on its heing exhausted it was necessary to bring forward a sixth edition of Tols. I. and II., which it fell to my share to prepare, as my vencrable. 
friend's age precluded any attention to it on his part. This edition, which was brought up to the then state of the science by the addition of upwards of $100 \mathrm{MS}$. pages of new matter, appeared early in 1843.

On our return at the close of $18+3$ from a twelvemonth's visit to Italy, Mr. and Mrs. Kirby came to London for some weeks to meet us, and between this period and his death I visited him twice at Barham: when, though his memory and bodily strength had greatly failed, I found hini still the same kind-hearted friend, - still, as ever, happy and contented, ready to inform and be informed, to anuse and be amused, and takins. the same interest he always did in the progress of science generally, and especially of Entomology.

I give copies or extracts of a few of his last letters, which will show that though the lamp of life was beginning to fade, his friendliness of disposition and love of science suffered no abatement.

"Barham, November 23rd, 1843.

"My Dear Friend,-You will be pleased to learn that we arrived here salv: et sani, on Tuesday, in very good time to make up our dinner, which was not accomplished all at once. We travelled by railroad, accompanied by one of the officials of the concern, who appeared to be a very good specimen of a travelling companion. He quitted us, however, before we reached the Colchester Station. At Kelvedon we met our servant with a carriage and horses, which took ns home much more rapidly than I expected. We were very loth to leave yoir and your cara sposa bchind us, and talked often of you; but it is in vain to wish for what cannot be, so we must be contented with looking forward to onr next merry meeting; in the meantime often taking the pen to relate to each other our mutual adventures. We hope Mrs. Spence is now able to take the air, and look about her again, and see all the London sights that are worth looking at; and when she has run the round of sight-seeing, that she and you will come and renew your acquaintanee with the lions of Barham. Nothing is usually more strongly recommended to invalids that are convalescent than change of air.

"We are both, thank God, at this time very bonny, and I am resuming my old favourite pedestrian exercise.* How I should enjoy it with you ! Yet the great beauty of the country, the foliage of the trees, is fast departing. Yet those of the grove in my garden seem to hang on, while those of the vicinity are all fallen. . . . One thing I must not forget,- to return our best thanks to you and dear Mrs. Spence, for your great kindness and attention to us during: our stay in London. I don't know that I ever enjoyed a visit to the metropolis so much, and our enjoyment chiefly arose from your society and that of your better half. I shall leave the other side to Charlotte, who will address a line to her. $\dagger$

$$
\begin{aligned}
& \text { "I am, my Dear Friend, } \\
& \text { "Yours very affeetionately, • "Wa, Krrbr. }
\end{aligned}
$$

"W. Spence, Esq., 18, Lower Seymour Street, Portman Square, London."

* Mr. Kirby's love of walking exercise was remarkable. In one of his letters he says, "I never feel so happy as when on my ten toes."

† I had marked this complimentary paragrapl to be omitted; but, on second thoughts, it is given, as exemplifying that fine feature of Mr. Kirly's character which so much endeared him to all who had the happiness of knowing him, - his genuine friendliness of nature, which led him to over-estimate and gratefully acknowledge any attention his friends showed lim. 
"My Dear Friend,-I must begin by thanking you for another supply of excellent ginger, which arrived on Friday. I find it a very good stomachic; and I must likewise thank you for your interesting and amusing note.

"I should like to have been at your elbow at the meeting where Sir R. Peel was present. You made a handsome collection.

"I hope Mr. Patterson's work * will sueeed, as it was much wanted, and is well exeeuted. I have lent my copy to Sir W. Middleton, who will slow it to his friends. I was asked by a friend of his, if I was not going to publish a new edition of my Bridgewater Treatise, as he inquired for a eopy and could not procure one in town. I shall eonsult my friends abont it. What is your opinion?

"I was sorry Professor Owen has been suffering from dissecting poor Jack the elephant in the Zoological Gardens, of whose death I read this morning.

"My movements have not been far from my own house of late, but I do think I shall go with Miss Rodwell, her sister, and Mrs. Kedington, to the sca coast for a few nights ; we probably shall select Lowestoffe, or rather Felixstow, for our station, but we have not yet positively determined. I shall give you a line on our arrival at the coast; I dou't expeet our stay will exceed a few nights. I wish you and Mrs. S. could meet us there. I don't know whether you have any thoughts of attending the great mecting at Cambridge, for the elcetion of a Chancellor; had I a rote I should be happy to give it to Prince Albert.

"I heard you had been drinking tea lately with my poor dear Charlotte's brother, George Rodwell; when you see him again give my love to him. Pray remember me kindly to all my scientific friends who do me the honour to enquire for me. . . . . ."

\section{"Barham, October 4th, 1848.}

"My Dear Friend,-Thanks for your kind note, which arrived on my birthday, September 19th. Pray what is your birthday?

"I was amused with the portrait of Miss Silpha, and the verses that accompanied it. I have been much troubled by a painful attack of nenralgia in my left bicast, whiel must be my apology for this short note; when it has left me I will send you a longer. . . . ."

" Barham, Mareh 15, 1849.

"My Dear Friend,-I have received from Mr. Ransome the parcel contain. ing eopies of your address to the Entomologieal Society, and distributed them as directed. I heard it read, and liked it very much, and heartily wish your cfforts, and those of our friends, may be crowned with the suceess that they merit, and that our number of members may be inercased.

"I have been tronbled by an attack of $\mathbf{N e u r a l g i a}$ pectoris, which disables me from writing much, whieh must be my apology for my brevity.

"Miss Rodwell desires her kind reirards to yourself and Mrs. Spence, \&c. \&c.

$$
\text { "I am, ny Dear Friend, }
$$

"WM. KinBY."

One of the last notes I had from Mr. Kirby, of only a few liues, and written in a tremulous hand, was in answer to a letter enclosing the prospectus of the "Insecta Britannica," proposed to be published under the anspices of the Entomological Society, for which we were desirous of having his sanction as its venerated Honorary President. This he gare cmphatically, desiring that his name should be added to our list of subscribers, and expressing his strong wishes for the success of the plan,-

* "Introduction to Zoology, for tlie use of Schools." 
thus showing that, to the latest period of his life, the extension of his favourite science was one of the objects nearest his heart.

I will not encroach on the province of my friend Mr. Freeman, who is so well able to do justice to it, by expatiating more largely on the admirable traits which, in every point of view, distinguished the character of my dear old friend; but I will conclude this slight sketch of the history of our long friendship, which for forty-five years formed one of the great pleasures of our existence, - I know that I may truly say of his as of mine, - by pointing out to our brother entomologists, whom I have had chiefly in view in writing it, two circumstances in his study of insects by which I was always forcibly struck on my visits to him at Barhain.

The first was the little parade of apparatus with which his extensive and valuable acquisitions were made. If going to any distance, he would put into his pocket a forceps-net and small water-net, with which to catcl bees, flies, and aquatic insects; but, in general, I do not remember to have seen him use a net of any other description. His numerons captures of rare and new Coleoptera were mostly made by carefully searcli. ing for them in their haunts, from which, - if trees, slirubs, or long grass, \&c.,-he would beat them with his walking-stick into a newspaper; and, collected in this way, he would bring lome in a few small phials in his waistcoat pockets, and in a moderate-sized collecting-box, after an afternoon's excursion, a booty often much richer than his companions hat secured with their more elaborate apparatus.

The second circumstance in Mr. Kirby's study of insects to which I allude was the deliberate and careful way in which he investigated the nomenclature of his species. Every author likely to have described them was consulted, their descriptions duly estimated; and it was only after thus coning to the decision that the insect before him had not been previously described that he placed it in his cabinet under a new name. It was owing to this cautious mode of proceeding - which young entomologists would do well to follow - that he fell into so few errors, and rendered such solid service to the science; and a not less careful consideration was always exercised by him iu the forming of new genera and in his published descriptions of new species; as his admirable papers in the Linnean Transactions amply testify.

The above remarks are meant for entomologists ; but there is another moral to be derived from Mr. Kirby's life, to which, in concluding, I would fain draw the attention of all who, like him, have some leisure time to command, and reside in the country, - the great accession of happiness which he derived from his entomological pursuits, which not only supplied him with objects of interest for cvery walk, and for every spare moment within doors, but introduced him to a large circle of estimable naturalists at home and abroad, and thus virtually doubled the pleasures of his existence; and this without neglecting any one of his professional or social duties, with which, much as he did for Entomology, lie never allowed his study of it to interfere. 
LONDOX

PRINTED BY SPOTTISWOODE AND CO,

NEW-STREET SQU $\triangle$ BR 


\section{LIBRARY EDITIONS.}

\section{An INTRODUCTION to ENTOMOLOGY. By W. Kirby, M.A., F.R.S. and L.S., and W. Spence, Esq., F.R.S., and L. S. Sixth Edition. In 2 vols. 8 vo., with five coloured plates, price $31 s .6 d$.}

LIFE of the REV. W. KIRBY, M.A. By JoHN Freeman, M.A. In 1 vol. 8vo., with Portrait of W. Kirby, a View of Barham Parsonage, and an Autograph Letter, Price 15s. 



\section{MAUNDER'S}

\section{POPULAR TREASURIES.}

New and thoronghly revised Editions; each Treasury complete in One compact Volume, fcp. 8 vo. of about 900 pages, coinprising about 1,800 columns of sinall but very legible type.

\section{Maunder's \\ General Knowledge. \\ Treasury of Knowledge,}

and Library of Reference: A copious popular Compendium of Universal Know-

ledge : Including Grammar, Dictionary, Gazetteer, Mgthology, Chronology, Peerage, \&c......Price 10s.

Geography.

Maunder's Treasury of Geography,

Physical, Historical, Descriptive, and Political. (Completed by WiLliam

HuGHES, F.R.G.S.) With Maps aud Steel Plates.................. Price 10s.

Maunder's Historical Treasury: Com-

prising copious general introductory Outlines of Universal History, and separate Histories of every principal Nation................... Price 10s.

\section{Natural History. \\ Maunder's Treasury of Natural His-}

tory: A popular Dictionary of Animated Nature: Enlivened with Anecdotes of the Instiuct, \&c., of Animals; with 900 Woodcuts. ............. Price 10s.

\section{Science and Literature.}

\section{Maunder's Scientific and Literary}

Treasury: A neT and popular Encyclopadia of Science and the Belles-Lettres. Including every subject counected with Literature and Art........... Price 10 s.

\section{Blography. \\ Maunder's Biographical Treasury:}

Consisting of Memoirs, Sketches, and brief Notices of above 12,000 Eminent

Persons of all $\Lambda$ ges and Nations, extended to May $1859 . \ldots . \ldots \ldots . . .$. Price 108.

The SIX TREASURIES complete, price $\mathscr{\ell}$, cloth.

Each Treasury $\left\{\begin{array}{l}\text { price } 125.6 \mathrm{~d} \text {. neatly whole bound in calf, } \\ \text { price 12s. bound in roan, with gilt edges, or } \\ \text { price 10s. bound in cloth lettered, }\end{array}\right\}$ may be had separately

London: LONGMAN, GREEN, and CO. Paternoster Row. 


\section{LIST OF WORKS BY LORD MACAULAY.}

1.

The HISTORY of ENGLAND from the Accession of James the Second. By the Right Hon. Lord Macaulay. A New Edition of the first Four Volumes of the octavo edition, revised and corrected. In 7 vols. post 8 vo. price $42 \mathrm{~s}$. cloth.

II.

Lord MACAULAY'S HISTORY of ENGLAND from the Accession of James the Second. New Edition. Vols. 1. and 11. 8vo. price 32s.; Vous. III. and IV. 8 vo. price $36 \mathrm{~s}$.

III.

CRITICAL and HISTORICAL ESSAYS contributed to the Edinburgh Review. By the Right Hon. Lord Macaulay. Library Edition (the Ninth), 3 vols. 8 vo. price 36 s.

17.

Lord MACAULAY'S CRITICAL and HISTORICAL ESSAYS contributed to the Edinburgh Review. A New Edition, in Volumes for the Pocket. 3 vols. fcp. $8 \mathrm{vo}$. price $21 \mathrm{~s}$.

v.

Lord MACAULAY'S CRITICAL, and HISTORICAL, ESSAYS contributed to the Edinburgh Review. The Traveller's Edition, complete in One Volume, with Portrait and Vignette. Square crown 8vo. 21 s. cloth; calf, by HAYDAY, 30s.

VI.

Lord MACAULAY'S CRITICAL and HISTORICAL ESSAYS contributed to the Edinburgh Review. The People's Edition, complete in 2 vols. crown 8vo. price 8s. cloth; or in 7 Parts, 1s. each.

vi1.

List of Fourteen of ILord MACAULAY'S ESSAYS which may be had separately in $16 \mathrm{mo}$. in the Travellez's Libraky:-

WARREN HASTINGS.................... Is.

Lord CLIVE ................................ Is . WILLIAM PITT; and the Earl of

CHA THA M................................... Is. RANKE's History of the POPES; and Gladstunb on CHURCH and

STATE ..................................... $1 s$. Life and Writings of ADDISON; and HORACE WALPOLE
Lord BACON

Loid BYRON; and the COMIC DRA-

MATISTS of the Restoration ......... Is. FREDERIC the GREA T ................. Is. HALLAN'S CONSTITUTIONAL HISTORY of ENGLAND ................ Is

Crokea's Edition of Buswell's LIFE of JOHNSON ................................ Is.

ri11.

SPEECHES of the Right Hon. Lord MACAULAY, corrected by HIMSELF. 8 vo. 128 .

$1 \mathrm{x}$.

Lord MACAULAY'S SPEECHES on PARILAMENTARY REFOlRM in 1831 and 1832. Reprinted in the Travellek's Libraky. 16mo. price Is.

x.

LAYS of ANCIENT ROME. By the Right Hon. Lord MACAULAY. With lllustrations, original and from the Antique, by GEorge Scharf, jun., F.S.A., engraved on Wood by S. Willians. New Edition. Ficp. 4to. 21s, boards; morocco, by HAYDAY, $42 \mathrm{~s}$.

xi.

Lord MIACAULAY'S LAYS of ANCIENT ROME, with IVRY and the ARMADA. New Edition. 16mo. 4s. 6d. cloth; morocco, by HAYDay, 108. 6d.

London: LONGIAN, GREEN, and CO. Paternoster Row. 


\section{A. CAMAXQCUE}

OF

\section{NEW WORKS IN GEIERAL LITERATURE}

PUBLISHED BY

\section{LONGMAN, GREEN, LONGMAN, AND ROBERTS}

39 Paternoster Row, Lowdon.

\section{CLASSIFIED INDEX}

\section{Agriculture and Rural Affairs.}

Bayliton on Vahing Rents, \&ec. . . 6 C" on Rond Legislation • • 6 Circits Praire farming

Cecil's Stud Farm

Iloshyns"s Talpa

Iow's Elements of A riculture

Morton on Landed Estates : : it

Arts, Manufactures, and Architecture.

Brande's Dictionary of Science, \&c. $\quad$ - 6 Cresy's Civil Engineering

Fairbairn's Infolmation for Enciseers: Gwilt's Encyclopedia of A rehitucture :

llarford's Plates from $M$. Angelo.

Ilumphreys's Parables Slluminated

Jameson's sacred and Legendary Art : 13 "Commonplace-Burk * 13

Loudon's lineal A rchitecture 11

Mac Dougull's Campaigns of I lamibul. IJ

" Theory of War : 15

Moseley's Engincering . • : : 17

Piesse's Art of Perfumcry : 18

Richardson's Art of Horsemanship , 19

Sicottern on Projectiles, \&.c. . : 20

Steam Engine, by the Artisan tiub : 6
Ure's Dictionary of Art, \&c. . 23

\section{Biography.}

Arago's Lives of Scientific Mrn a $\quad 5$ Baillie's Memoir of Bate Mro 6 Brialmont's Wellington . . : 6 Bunarn's IIippolstus

l3ucting"a (1.r.) Life

Crosse's (Andrew) Nlemeriali":

$\cdot 8$

Green's Princerses of Friglini : : 10

Harford's Life of Michacl Angclo: : in

Lard ner's Cabinet Cycloperdid : : 13

Marahman's Life of Carey, Mlarshman,

and Ward. ? 15

Maunder"s Biographical Treniury ${ }^{\circ}$ : 15
Morris's Life of Becliet . • . 17

Mountain's (Col.) Memoirs : 17

Parry's (Admiral) Memoirs : • • 18

Russell's Mlemoirs of Mloore: : 17

"“ (Dr.) Life of Mezzofanti . : 20

Soutephen 21

Stephen's Ecclesiastical Biographs $\quad: 27$
Strichland's Queens of England

Srdney Smith's Memoirs

Symonds's (Admiral) Yemoirs :

Taylon's Loyola : : 22

"Wesley : W : 22

Uwins's Memoirs and Correspondence: 23 Walerton's Autobiograpliy and Essays: 24

\section{Books of Ceneral Utility.}

Acton's Drent-Book

Black's Treatise on Frewing . • . 6

Cabinet Gazetteer : • : : 8

Cust"s Invalid's Own Book : : : 7

Hints on Etiquette.

Hudson's Fxecutor's Guide:

" on Making Wills : : 12

Kestcren's Domestic Medicine : : 13

I.ardner's Cabinet Cyclopredia : : 13

Loudon's Lady's Country Companion . 1.1

Jaunder's 'Tiensurr of knowledre: If "A Biographical 'Treasury : 16

" Geograplical Treasury : 16

“ Scientific Trensury

"Trcisury of llistory : : 16

"Natural Historg : : 16

Piesse's Ait of Perfunery : : : 18

J'itt's How to Brew Good Bcer: : is

J'ocket and the Stur : : 11

pycroft's English Reading : 19

Rich's Compinion to Latın Dictionary: 19

Richardxon's Art of Horsemanship : 19

Kiddle's Latin Dic linnaries : : . 19

Roact's Englisli Thesaurus : 20

liowton's Debater: : : :

Short Whist : : : 21

simpson's Il andhook of Dinitg: : 21

Thounson's Inturest 'Tables : 22

Webster's Pomestic Economy : : 21

Willich's Populitr Tables : : 24

Wilmot's Blachstone : : : 24 


\section{Botany and Gardening.}

Hassall's British Freshwater Algre Hooker's British Flora Guide to Kew Gardens

Lindley's Introduction to Botany Srnopsis of the British

at 5 ith

Theory of Ilorticullure . . I

Loudon's lfortas Britannicus : 11 Amateur Girdener . . 11 Trers and Shrnbs. . 14 Gardening : . . 11 Plinta

Pereira's Materia Medica Rivers's Rose Amateur's Guide. Watson's Cyble Britannica : : 21 Wileon's British M

\section{Chronology.}

Brewer's Mistorical A tias

Bumsen's Ancient Eyrpt

Haydn's Beatson's Initex

Jaquenet's Tro Chronologies

\section{Commercs and Mercantile} Affairs.

Gilbart's Lozic of Banking

Treatise on Banking

Lorimer's Young Master Mariner.

I'Culloch's Commerce and Narigation'

Thomson's Intercst Tables

Tooke's History of Prices

\section{Criticism, History, and Iremoirs.}

Brewer's Historical Atlas

Bunsen's Ancient Egypt

" Hippolytus

Chapman's Gustarus Adolphus

Connolly's Sappers and Miners

Comybeare and Howson's St. Paul

Crowe's History of Erarce

Fischer's Francis Bacon.

Frazer's Letters during the Peninsular

and Waterloo Campaigns.

Gleir's Essay3. : 10

Gurney's Historical Sketches : . 10

Hayward'8 Essays. . . . . 11

Herschel's Essa ${ }^{\prime}$ s and Addresses . . 11

Jeffrey's (Lord) Contributions . . 13

Kemhle's anglo-Saxons . . . . 13

Lardner'\& Cabinet Cyclopedia : : 13

Macanlay's Critical and Hist. Essays - 14

"6 History of Engliand . . 14

"Specches - II

Nackintosh's Miscellaneous Works - 15

M 'Culloch's Geographical Dictionary : 15

Maunder's Treasury of History . . If

Nerivale's llistory of Rome . . . 16

" Roman Repablic . . : 16

$\begin{array}{ll}\text { Milner's Church History : } & 16 \\ \text { Moure's (Thomas) Memoirs, \&ic. : } \quad 17\end{array}$

Mure's Greck Literature . . . 17

Normanhy's Year of Revolution . . 18

Perry's Franks : - . 19

$\cdot 19$

Raddle's Iatin Dictionaries: : 19

Riddle's Latin Tictionaries. Revicw: 19

Rogers's (Sani.) Recollections . . 1 17

Roget's Engl sh Thesiurus :

SchimmelPenninck's Menoirs of Port 20
Royal. . . 20
SchimmelPenninck'sP1inciples of Bcauty' 20

Schmitz'g History of Greece. 20

Southey's Doctor 21

Stephen's Ecclesiastical Biogriphy - 22

" Lectures on French Ilistory - 21

Sydney Smith's Worke. . . . 21

"L Lectures : $: 21$

of Memoirs : . . 21

Taylor's Loyola : : : : : $: 22$

Thirlwall'g History of Greece . . . 23

Turner's Anglo-Sazons . . . . 23

Uwins's Memoirs and Letters : . 23

Vehse's Austrian Court . . . . 23

Wade's Enaland's Greatsess. . . 23

Young's Christ of Hislory . . . 24

\section{Geography and Atlases.}

Brever'a Historical Atlas

Butler's Geography ind Atlases . ?

Cahinet Gazetteer . \&

Johnston's General Gazetteer • : 13

M'Culloch's Geegraphical Dictionary : 15

Maunder's Treasury of Geography , i6

Murray's Encyclopadia of Geography . 17

Shurp's British Guzet:eer . 21

\section{Juvenile Bocks.}

Amy Herbert . . . . . 20

Cleve Hall * . . . 20

Earl's Daughter (The) . . . . 20

Experience of Lifo . . . . . 20

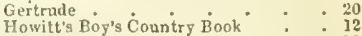

"6 (Mary) Children's Year . . 12

Ivors. .20

Katharine Ashton : . . . . 20

Ianeton Parsonage . . . . 20

Margaret Percival . . . . 20

Piesse'g Chymical, Natural, and Phy-

sical Magic. • . 19

Pycroft's Collegian's Guide : : : 19

\section{Medicine, Surgery, \&c.}

Brodie's Psychological Inquiries . . 6 Bull's Hints Lo Mothers , 7

or Management of Children : . 7

"Work on Blindness : : 7

Copland's Dictionary of Medicine . 8

Cust's Invalid's Own Book . 9

Holland's Mental Physiology: $:$. 11

"6 Medical Notes and Reflections 11

resteren's

Richarison's Coldwater Cure" : 19

Spencer's Principles of Psychology : 21

'Todd's Cyclopxedia of Anatomy and

Physiology?. . 22

\section{Miscellaneous Literature.}

Bacon's (Tord) Works . . . 5

Defence of Eclipse of Failh : : - 3

De Fonblanque on Army Adminislration 9

Greathed's Letters from Delhi : : 10

Greyson's Select Correspondence : 10

Gurney's Evening Recreations : . 10

Hassall's Adulterations Detected, \&c. : 11

Haydn's Book of Dignities . . . 11

Holland'g Mental Physiolngy . . 11 
Hooker's Kew Guide

Il “Visits to Remarkable Places: 1: Jameson's Conmonplace-Book : 13 Jeffrey's (Lord) Essays . : . . 13

Last of the Old Squires . . . 18

Letters of a Betrothed : "

Macauldy's Critical and Hist. Essays " 14

"Speeches : 14

Martineau's Miscellanies Works

Pycroft's English Reading : : $: 19$

Rioh s Companion to Latin Dictionary 10

Riddle's Latin Dictionaries. . . 19

Rowton's Debater $: 20$

Sir Roger De Coverley : : . 21

Smith's (Rev. Sydney) Works : 21

Southey's Doctor, \&c. : . : : 21

Spencer's Essays. . • : . 21

Stephen's Essays : . . . . 22

Stow's Training System . . . . 22

Thomson's Laws of 'hought -

Indii on the Native Languages of

Yonge's English-Greek Lexicon : . 24

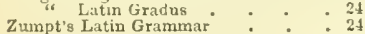

\section{Natural History in general.}

Agassiz on Classification

Catlow's Popular Conchology

Ephemera's Book of the salmon

Garratt's Martels of Instinct.

Gosse's Natural History of Jamaica

Kirby and Epence's Entomology.

Maunder's Natural History.

Morris's -

Quatrefages' Kambles of a Naturalist.

Stonehenge on the Dog. . . 22

Turton's Shells of the British islands : 23

Van der Hoeven's Handbook of Zoology 23

Waterton's Essays on Natural History. 24

Youatt's The Dog

$$
\text { "4 The Horse }
$$

\section{One-Volume Encyclopædias and Dictionaries.}

Blsine's Rural Sports

Brande's science, Literatnre, and Art." Copland's Dictionary of Mediciue : Cresy's Civil Engineering

Gwilt's Architecture

$\therefore 10$

Loudon"s Agriculture . . : 14 "Rural Architecture": : I4

"G Gardening

" Plants.:14

"Trees and Shrubs: : 1

M'Cullocli's Geographical Dictionary : 15 " Dictionary of Commerce : 15

Murray's Encyclopxdia of Geography : 17

Sharp's British Gazetteer . : 21

Ure's Uictionary of A rts, \&c. : : : 23

Webster's Domestic Economy : : 24

\section{Religious and Moral Works.}

Afternoon of Life

Amy Herbert : : : 20

Bunyan's Pilgrim's Progress
CaJvert's Wife's Manual.

Catz and Farlie's Moral Emblems

Cleve Hall.

Conyberre and Howson's St. Paul :

Cotton's Instructions in Christianity : 8

Dale's Domestrc Liturey . . ?

Defence of Eclipse of Faith : : : : 9

Earl's Daughter (The) : : : : 20

Fclipse of Fasth . . . 9

Englishman's Greek Concordance : 9

Experience (The) of L Chald. Concord. 9

Gritrude (The) of Life . . . 20

Harrison's Light of the Forge - - 20

Horne's lntrodnction to Scriptures

He scripturcs

Huc's Christianity in China : : : 11

Inmphress's Parables llluminated : 12

Ivors, by the A uthor of Amy Irerbere . 20

Jameson's Saints and Martyrs

"Monastic Legends : : 13

"Legends of the Madonni : 13

on Female Emplogment - 12

Jeremy T'uylor"s Works . 13

Katharine Ashton : : 20

König's Puctorial Life of Luther . : 10

Laneton Parsonage . $\quad 20$

Letlers tn my Unknown Friends . 13

Lyra Germanica : . . 7

Maguire's Rome : : : 15

Margaret Pelcival : : : 20

Marshm.n's Srrampore Mission: : 15

Martincau's Christian Life . . . 15

"Hymns : 15

Merivale's Christian Records : 15

Milner's Church of Clurst : 16

Moore on the Use of the Body : 17

" or Soul ani Body" : 16

"s Man and his Motives : $: 17$
Morning Clouds

Neale's Closing Scene $: 17$

Pattison's Earth and Word 18

l'owell's Christianity withou Judaism . 19

Readings for Lent

Readings for Lent. : * : : 20

Robinson's Lexicon to the Greek 'Tes-

tament. . . , 19

Selt-Examination for Confirmation : 20

Sewell's History of the Early Charch . 20

Sinclair's Jourvey of Life , 21

Smith's (Sydney) Moral Philosophy : 21

" (G.) Wesleyan Methodism : 21 (J.) Shipwreck of St. Paul :

Southey'B Life of Wesley . . . 21

stephen's Ecclesiastical Biography : 22

Taylor's Loyola : . . : 22

" Wesley : : : : 22

Theologia Germanica : . . 7

Thumb Bible (The). . , , 22

Young's (hrist of History : * 24 Mgstery : : : : 24

\section{Poetry and the Drama.}

Aikin's (Dr.) British ' 'oets.

Armold's Merope : : : : :

Baillie's (Joanna) Poetical Works : : 5

Calvert's W' ife's Mannal . . . 8

Goldsmith's Poems, illustrated . . 10

L. E. L.'s Poetical Works : : 14

Linwood's Anthologin Oxoniensis : 14 
Lyra Germanica

Macaulay's Lays of Ancient Finme MacDonald's Within and Withoul

Montgomery's l'aetical Yrorlis

Muore's Poictical Works.

"selections (illustrated

" Lalla hionkh

“ Irish Mclodies

c National Melodies

" Sarred Songs (with Mirsic)

c Sungs and Ballads

Shakspeare, bi Bowdler.

Sonthes's Poetical works

Thomsou's Seisons, illastrated

\section{The Sciences in general $2 x d$ Mathematics.}

Arago's Meteorological Essays Popular Astronnmy

Boume on the Steam Engine

" 's Catechism of Steam-Eugine

Boyd's Naval Cadet's Manual

Brande's Dictionary of Scienee, $R \cdot c$.

"Lectures on Organic Chemistry

Conington's Chemical Analysis

Cresy's Civil Fngineering

De la Rive's Electricity

Grore's Courelation of Physical Forees

Herschel's Outlines of Astronomy. II

Holland's Mental l'hysiology. . 1 !

Humboldt's A spects of Nature . . 12

Hunt on Light. $\quad$ : $\quad: \quad: \quad: 12$

Lardner's Cabinet Cyclopiedia : : 13

Marcet's (Mrs.) Conversations . . 1.5

Morcll's Elements of Psychnlogy . . 17

Moseley's Enginetring and A rchitectnı 17

Ogilvie's Master-Ruilfer's Plan . 18

Owen's Lectures on C'omn Anatomy: Is

Pereira on l'olarised Light . . . 18

Peschel's Ellements of Pliysics : 18

Phillips's Mineralogy : 18

"Guide to Geology : . : is

Powell's Lnity of Wo-lds: 19

“ Christianity w:thout Jndaism is

" Order of Nature 19

Smee's Electro-Metallurgy : 21

Steam-Engine, hy the Artisan Clnb : 6

Vebb's Celestial Objects for Conmon

Telescopis

\section{Rural Sports.}

Baher's Rifle and Hound in C'ylon

l3laine's Dictionary of syorts

Cecil's Stable l'ratice

if Stud Farm

Davy'g Fishing Kxeursions, 2 Selies

Ephemera on Angling

" Bank of the Salman

Freeman and Salrin's Fuleonry

Hawker's Young Sportsman.

The Hunting-Fied .

Idle's Hints on shooting

Pocket and the stud

Practical Horsemanuhip.

Pyeroft's Cricket-Field

Richardsnn's Hursemanchip.

Ronalde's Fly-Fincr's Entomology
Stable Talk and Tikle Tialk . . . In Stonehenge on the Dog : . 23

" " Greyliound - . 23

The Stu l, fer Practical Purposes . . Il

\section{Veterinary Medicine, \&c.}

Cecil's Stable Prictice.

"Stud Farm.

Hunt's Horse and his Master . 12

Hunting-Ficld (The) . 11

Miles's Ilorse-Shoping : $: 18$

"f on the Horse's Foot : : $\quad 15$

Porket and the stud . . . 11

l'ractical Horsemanship. . . . 11

Ricluadson's Horsemenship •. 19

stable Talk and Talto Talk : 10

Stonehenge on the Don. . . : 22

Stud (The) . . . . . I1

Yonatt's The Dng. . . . 24

"The Horse : : 21

\section{Voyages and Travels.}

Baker's Wanderings in Ceylon . . I

Marth's A frican Travels. . . is

Burton's East Afriea . - :

Domenech's Desert of Nortli Anerica

First Impressinrs of the New Wortd : 9

lorester's Sirrlinia and Corsica . 10

llin hliffs Travels in the Ains . . 11

Howitt"s Art-Student in Nunicls: . I\%

" (W.) Vietoria . : : 12

Huc's Clinese Empire : 12

Himboldt's Aspects of Nature . . 12

liutchinson's Western Africa . : 1:2

Kane's Wauderings of an A rtist : 13

I,ady's Tour round Monte Rosa . . 13

M'Clure's North West Passare - 18

Mac Dougall's Tovase of the Resnizie. 15

Minturn's New Yinh in I) llii . I6

Molllausen's Journes to the l'acific: 16

Osborn's Quedah . . . . . 18

Peaks, Paeses, and Glaciers... Is

Selerzer's Centril America . . . 20

Senior's Jnurnal in Turkey and Greece 20)

Snow's Trerra del Furgo. . . . 21

Tennent's C'eslom : :

Von Tempsk $y^{1} s$ Mrxico and Guatemala 23

Wanderings in the Innd of Itam. 2t

Weli's Yacations in Ireland. . 24

"r pyrences, West and East + : 21

“ United sitates and Conada. . :t

\section{Works of Fítion.}

Connoliy's Romance of tire Ranks . A Cruikhank's laktaff - * !) Howitt's Tallangettes . . . . 13

Moore's Enicurean : $: 17$

Sewell's Ursula : : : : : 20)

Sir Roger De Cosertey . - . 21

sketches (The), Three Tales : - 21

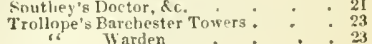




\title{
NEY WORKS and NEW EDITIONS
}

\author{
PUBLISHED EY
}

\section{LONGMAN, GREIN, LONGMAN, AND ROBERTS, PATERNOSTER ROW, LONDON.}

HTiss Acion's Modern Cookery for Private Families, rednced to a System of Eisy Practice in a Series of carefully-testerl Receipls, in which the Principles of Baron Liebig and other eminent writers have been as much as possible applied and explained. Newlyrevised and enlarged Edition; with 8 Plates, comprising 27 Figures, and 150 Woodeuts. Fed. Svo.7s. Gd.

Acton's English Eread-Book for Domestie Use, alauted to Families of every glade. Fip. svo, price $1 \mathrm{~s}$. Gl.

The Aftelnoon of Life. By the Anthor of Morning Clouds. New and cheaper Edition, thoronghly revised. Fep. $85^{\circ} 0,5 \mathrm{~s}$.

Agassiz. - An Essay on Classification. By Lours AG Assiz. 8ro. 12.

Aikin's Select Works of the British Poets from Ben Jonson to Beattie. Nesv Ladition; witls Biograplical and Critical Prefaces, and selections from recent Poets. Sro. I8s.

Arago (F.)-Biographies of Distinguished Scientific Hen. Translated by Admiral W. H1. SMrTI, I).C.L., 1.R.S., \&c, the ReV. BADEN POWELL, M.A.; and RobErt GraNt, M.A., F.R.A.S. 5 ro. $18 \mathrm{~s}$.

Arago's Meteorological Essays. With an introduetion by Baron II UMBOLDT. Translated under the superintendence of Lieut.-Col. E. SABINE, R.A., Treasurer and V.P.R.S. 8vo. 1ss.

\section{Arago's Popular Astronomy.} Trimslated and editer by Admirul W. H. SWY TIT D.C.L., F.R.S.; and loBERT GRANT, M.A., F.R.A.S. With 25 Plates and $35 \mathrm{~s}$ Woodents. 2 vols. 8\%o. price $22,5 \mathrm{~s}$
Arnold. - Iiteiope, a Tragedy. By Matrinew Arvold, With a Prefiee and an Historical Introduetion. Fev. 8vo. 5 s.

Arnold.- Foems. By Matthew ArNold, First Series, Third Edition, Fep. Svo, 5s. 6d. SECOND SERIES, price $5 \mathrm{~s}$.

Iord Bacon's Works. A NeW Edition, culleeted and edited by R. L. LuLtS, M.A., Fellow of Trinity College, Cambridge; J. SPEDDING, M.A. of Trinity College, Cambridge; and 1), D. Hедтн, Ls $q$., Barriste1-at-Law, and late Fellow of 'T' rinity College, Cambridge. Vous, 1. to V, comprising the Division of Philosophical Works; with a copiouts INDEX. 5 vols. 8ro. price \&. 6s. Vou. Vl. price 18s.

Yor VII., emmpleting the Division of Literary and Professional Works, is just ready.

\section{Joanna Baillie's Dramatic and}

Poetical Works: Comprising Plays of the Passions, Miscelianeous Dramas, Metrical Legends, Fugitive Pieces, and Ahalya Baee; with the Life of Joamna Daillie, Portrait and Vignette. Square crown bvo. 21s, cloth; or $42 \mathrm{~s}$. moroccu.

\section{Baker.-The Rifle and the Hound} in Ceylon. By S. W. BAKER, Esq. New Edition, with 13 lliustrations engraved ols Wood. F(p, 8ro, 4s, 6d.

Baker. -- Eight Year's' Wanderings in Ceylon. 13, S. W. BaKER, Esq. With 6 eoloured l'lates. Evo. 15s.

\section{Barth.-Travels and Discoveries} in North and Central Afriea: Being the Journal of an Expedition undertaken under the austyices of ller Britanuie Alajesty's Government in the Years 1819-1855. By Henry Barth, Ph.D. 1).C.L., \&c. With numerous Maps and Jilustrations. 5 vols. 8 vo. 25.5 s. elotl. 
Bate. - Memoir of Captain W. Thornton Bate, R.N. $13 \mathrm{y}$ the Rev. JOHN BAILLIE, Author of "Memoirs of Hewitson," "Memoir of Adelaide Newton," de. New Edition; with Portrait and 4 Illustrations, Fep. Svo. price 5s.

\section{Bayldon's Art of Valuing Rents} and Tillages, and Claims of Tenants upon Quitting Farms, at both Micliael. mas and Lady-day; as revised by MIr. Doxampson. Seventh Edition, enlarged and adapted to the Present Time. By RoBeft BAKER, LandAgent and Valuer, 8vo. price 10s, 6d.

Bayldon's (R.) Treatise on Road Legislation and Nanagement; with Remarks on Tolls, and on Repairing Turnpike-Roads and Highways. 8vo. price 3s. 6 d,

Blacl's Practical Treatise on Brewing, based on Chemical and Economical Principles: With formulie for Public Brewers, and lnstructions for Private Yamilies. Svo. I0s. Gu.

Blaine's Encyclopædia of Rural Sports; or, a complete Accomnt, II istorical, Practical, and Descriptive, of Hunting, Shooting, Fishing, Racing, \&c. Nevo Edition, revised and corrected to the Present Time; with above 600 Woodeut Illustrations, including 20 Subjects now added from Designs by ЈонN LE EсH. In One Volume, Svo. price $42 \mathrm{~s}$, half-bound.

Bloomfield... The Greek Testament: with copious English Notes, Critical, Plilological, and Explanatory. Especially adapted to the use of Theolomeal Students and Ministers. J3y the Rev. S. T. BLоOMFIBLD, D.D., F.S.A. Ninth Edition, revised.' 2 rols. 8 ro. with Map, E2. 8s.

Dr. Bloomfield's College \& School Edition of the Greek Testament: With brief English Notes, chiefly Philological and Explanatory. Seventh Edition; with May and Index. Fep. Sro. 7s, 6d,

Dr. Bloomfield's College \& Śchool Lexicon to the Greek Testament. New Edition, revised. Fcy. Svo. price 10s. 6d.

Boyd. $\rightarrow$ A Manual for Naval Cadets. Published with the sauction and approval of the Lords Commissioners of the Admiralty. By Jorn M'NeILl Bord, Captain, R.N. Witl Compass-Signals in Colours, and 236 Woodents. Fep. Svo. I0s. 6d.
Bourne. - A Treatise on the Steam Encine, in its Application to Mines, Mills, Steam Navigation, and Railways. By the Artisan Club. Edited by JoHn Bourne, C.E, New Edition. with 33 Steol Plates, and 319 Wood Engravings. 4 to. $27 \mathrm{~s}$.

Bonrne's Catechism of the Steam Engine in its various Applications to Mines, Mills, Steam Navigation, Railways, and Agriculture : With P'ractical Instructions for the Mantufacture and Manazement of Engines of every class. Fourth Edition, enlarged; with 89 Woodeuts. Fep, Svo. 6s.

\section{Brande's Dictionary of Science,} Literature, and Art; comprising the History, Description, and Scientific Principles of every Branch of Human Knowledge; with the Derivation and Definition of all the Terms in general use. Third Edition, revised and corrected; with numerous Woodents. Sro.60s.

\section{Professor Brande's Lectures on}

Organic Chomistry, as applied to Manufactures, including Dyeins, Bleacling, Calico Printing, Sugar Mianufactore, the Preservation of IVood, 'Tamning, die. Edited by J. SCOFrenN, M.B. Fep, Woodeuts, 7 s, 6 d.

\section{Erewer.-An Atlas of History} and Geograyhy, from the Commencement of the Christian Ela to the Present Time: Comprising a Series of Sixteen Coloured Maps, arranged in Chronological Order, with rllustrative Memoirs. By the Rex. J. S. Brewer, M.A. Second Edition, revised and corrected. Royal sro. 12s, 6d. half-bound.

\section{Brialmont. - The Life of the}

Duke of Wellington. From the French of AIEXIS BRIALMONT, Captain on the Staff of the Belgian Army : Witli Emendations and Ailditions. 13y the Rev. G. R, GLeIG, M.A. Chaplain-General to the Forces and Prebendary of St. Paul's. With Naps, Plans, and Portraits. Vous. I, and 11 . 8vo. price $30 \mathrm{~s}$,

The THInd and Fovrth Volomes (completion) are now in the press, and will tahe up the history of the Duke from the Battle of Waterloo, representing him as an Ambassador, as a Minister, and as a Citizen.

\section{Brodie.-Psychological Inqui-} ries, in a Series of Essays intended to illustrate the Influence of the Physical Orginisation on the Mentaf Faculties. By Sir Benjamin C. Bropiz, Bart. Third Edition, Fep, Sro, 5s. 
Dr. Bull on the Maternal 든 nasement of Children in Health and Disease, New Ldition. Fep. 8vo. 58 .

\section{Dr. Bull's Hints to Mothers on} the Nanagement of their Health during the Period of Pregnancy and in the Lying-in lRoom: With an Exposure of Popular Errors in connexion witli those stibjeets, \&c.; and Hints upon Nursing. New Edition. Fcp. 8 ro, 5s.

\section{Dr. Bull's Work on Blindness,} entitled the Sense of Vision Denied and Lost. Edited by the Rev. B. G. JöNs, Chaplain of the Blind school, St. George's Fields. With : brief introductory Memoir of the Author by Mrs, Bul, Fep, 8vo, 4s, 6d.

\section{Bunsen.-Christianity and Man-} kind, their Beginnings and Prospects. By Baron C. C. J. Bunsen, D.D., D.C.L., D.Ph. Being a New Edition, corrected, re-modelled, and extended, of Hippolytus and his Age. 7 vols. 8 vo. 25. 58.

" " This Edition is composed of three distinct works, as follows:-

1. Hippolytus and his Age; or, the Beginnings and Prospects of C'luristianity. 2 vols. 8 vo. $£ 1$, los

2. Ontline of the Philosophy of Universal History appliced to Language and Religion; containing in Account of the Alphabetical Conferences. 2 vols. 33 s.

3. Analecta Ante-Nic na. 3 vols.8vo, L2.2s.

\section{Eunsen. L Lyra Germanica.}

Translated from the German by CАTHE. RINE WINkWOETH, Fiflh Edition of the Frast Series, Hymus for the Sundays and Festivals of the Christian Year. New Eutition of the SECOND Series, the Christian Life. Fep. Svo. 5s. each Series.

HYMNS from Lyra Germanica, 18 mo. 18.

- These selections of German Hymns have been made from collections published in Germany by Baron BuNSEN ; and form companion volumes to

\section{Theologia Germanica:}

Which

setteth forth many fair lineaments of I ivine Truth, and saitl very lofty and lovely things touching a Perfect Life. Translated by SUSANNA WINISWORTH. With a l'reface by the Rev, Chardes KINGSLEY; and a Letter by Baron Bunstis. Third Edition. Fep. 8 vo. $5 \mathrm{~s}$.
Bunsen,-Egrpt's Place in Universal History: An Historical Investigation, in Five Books. t3y Baron C. C. I. BCNSEN, D.C.L., D.Pli. Transhated from the German by C. H. CotTreLL, Esq., M.A. With many tllustrations. VoL. I. Svo. 28s.; Vou. II. priee 30s.; and Vou. III. price $25 \mathrm{~s}$.

\section{Bunting, - The Life of Jabez}

Bunting, D.I.: With Notices of contemporary Persons and Events. 13y his Soln, Thomas Percival Bunting. VoL. I. with Two Portraits and a Vigrette, in post 8vo. 7s. 6d.: or (large paper and Proof Engravings) in square elown $8 \mathrm{vo}, 10 \mathrm{~s}, 6 \mathrm{l}$.

\section{Bunyau's Pilgrim's Progress:} With a Preface by the Rev. Crarles Kingstex, Rector of Eversley; and a Series of 120 Illustrations engravel on teel and on Woot from Original Designs by Chamles BenNetr. Frp. 4to, price 21s, cloth, silt edyes.

\section{Burton, - First Footsteps in East} Africa; or, an Exploration of Harar. By Richard i', juntor, Cantain, ISombay Army. With Hlaps and coloured Plitte. Svo, 1Ss.

\section{Burton.-Personal Narrative of} a Pilmrimage to El Medinah and Meecah. By Richard F. IBrtas, Captain, Bombay Arny. Second Edition, revised; with coloureal l'lates and W'ood cuts. 2 vols. crown 8 vo. $21 \mathrm{~s}$.

Bishop Eutler's Sketch of MIOdern and Ancient Geogranhy. New Edition, thorourhly revised, with sueh Alterations introduced as continually progressive Discoveries and the latest information have rendered necessary. I'ost 8vo, 7s, 6d.

\section{Bishop Butler's General Atlas} of Modern and Ancient Geography: comprising Fifty-two fult-coloured liaps; with complete Indices. New Edition enlarged, and greatly improved. Edited by the Author's Son, Royal 4to. 24 s.

\section{The Cabinet Lawyer: A Popular} Digest of the Laws of England, Civil and Criminal; with a Dietionary of Law Terms, Maxims Statules, and Judicial Antiquities; Correct Tables of Assessed Taxes, Stamp Dnties, Excise Lirenses, anil Post-HIorse Duties. PostOffice lesulations ; and Prison Discipline. 1sth Edition, eomprising the Publie Aets of the Sersion 1858. Fep. $8 v 0,10 \mathrm{~s}, 6 \mathrm{~d}$. 
The Cabinet Gazetteer: A Popular Exposition of All the Countries of the World. By the Author of The Cabinet Lawyer. Fep.8vo. 10s.6d.

\section{Caird. - Prairie Farwing in} Ameriea: With Notes by the way on Canada and the United States. By JAMEs CAIRD, M.P., Author of "Enelish Agrieulture," "High Farming," \&e. 16mo. 3 s. 6i.

\section{Calvert. - The Wife's Manual ;} or, Prayers, Thoughts, and Songs on Several Oecasions of a Matron's life. By the Rev. W. Calvent, M.A. Ormamented from Vesions by the Author in the style of Quecr Elizabeth's Prayer. Book. Crown 8vo. 10s, 6d.

\section{Catlow's Popular Conchology ;} or, the Sliell Cabinet arranged according to the Modern System: With a detailed Aceount of the Animals, sud a complete Descriptive List of the Families and fenera of Reeent and Fossil shells. Second Edition, improvel; with 105 Woodents. Post 8 vo.1Is.

\section{Catz and Farlie's Book of Em-}

blems.-Moral Emblems from JACOB CAtz and Robert Falire; with Aphorisms, Adages, and proverbs of all Nations. The Lllustrations frecly vendered from designs found in the works of Catz and Farlie, by JoIN LEIGETON, F S A and engraved under his superintendence. Imperial $8 \mathrm{vo}$ with Gi large Illustrations on Wood, andnumerous Vignettes and Tail Pieees.

\section{Cecil. - The Stud Farm; or,} Ilints on Breeding Horses for the Turf. the Chase, and the load. Adtressed to Breeters of IRace-IIorses and Hunters, Landed Proprietors, and Tewant Furmers. By Cecri. Fep. 8vo. 5̃s.

\section{Cecil's Stable Practice; or, Hints}

on 'Training for' the 'Turf, the Chase, and the load: with Obscrvations on Raeing anl Hunting, Wasting, Race-Riding, and IIandieaping : Aduressed to all who are eoncerned in Racing, SteepleClasing, and Fox-Hunting. Second Edition. Fep. Svo. with I'late, 5s.

\section{Chapman.--History of Gustavus}

Adolphus, and of the Thirty Years" War up to the King's Death: With some Account of its Conclusion by the Peace of Westphalia, in 16ts. By B. Cil para N, MI. Sro. Plans, iss. 60 .
Conington. - Hanabook of Chemieal Analysis, adapted to the Unitary System of Notation, By F, T. CosINGTON, M.A., F.C.S. Post 8vo.7s. 6u. Also, Tables of Quulitative Analy is. designed as a Companion to the Handbook. Price 2s.6d.

\section{Connolly.-The Romance of the}

Ranks; or, Anecdotes, Eybisodes, and Social Incidents of Military Lite. By T. W. J. Connolur, Quartermaster of the Royal Engineers. "2 vols. Svo. 2Is.

\section{Connolly:s History of the Royal} Sappers and Miners: Inchuling the Services of the Corps in the Crintea and at the siege of Sebastopol. Second Elition; with 17 coloured Plates. "2 vols, 8 vo. $30 \mathrm{~s}$.

Conybeare and Howson's Life and Epistles of Saint Panl : Comprising a complete Biograpliy of the Apostle, and a Translation of his Evistles inserted in Chronologieal Order. Third Edition, revised and corrected; with several Maps and Woodeuts, and Plates. 2vols. square erown 8 vo.31s.6d.

- Tise Original Edition, with more numerous 1 llustrations, in 2 vols. 4 to. price $4 s s$. - may also be had.

\section{Dr. Copland's Dictionary of}

Practical Medicine: Comprising feneral Pathology, the Nature and Treatunent of Diseases, Morbid structures, and the Disorders especially incidental to Climates, to Sex, and to the different Evoclys of Life; with numerous approved Formula of the Medicines recommended. Now complete in 3 vols. Sro. price $\{5$, iIs, elotlı.

Bishop Cotton's Instructions in the Doetrine and Practice of Christianily. Intended as an Introduction to Confirmation. Atli Edition. 1Smo. 2s. Get.

Cresy's Encyclopædia of Civil Fngineerins, llistorical, Theoretica1, and Practieal. Itlustrated by upwarcis of 3,000 Woodents. Seconil Edition. revised; and extended in a Supplement, comprising Hetrobolitan Water-sumbly, Drainaze of Towns, Railways, Cubical Jroportion, Brick and Irou Construction, Irons serew Piles, Tubular Bridges, \&c. Sro. 638 ,

Crosse. - Memorials, Scientific and Literary, of Andrew Crosse, the Electrician. Edited by Mrs. Crosse. Post 8vo.9s. 6d. 
Crowe.-The History of France. By Exre Evaxs Crowe. In Five Volumes. Vol.1.8vo.11s.

\section{Cruikshank. The Life of Sir} Jolnn Falstaif, illustrated in a Series of Twenty-four original Etelings by Georse Cruikshank. Accomnamied by an imaginary Biography of the kinight, Jy RoBETT B. Brovgr. Royal svo. price 12s, 6u. cloth.

Lady Cust's Invalid's Own Book : A Collection of Recipes from various Books and various Countries. Secoizl Edition. Fep. 8vo. 2s, Gu.

The Rev. Canon Dale's Domestic Liturgy and Family Chaptain, in Two Parts: PART 1. Church Services adlapted for Domestic Use, with Jrayers for Every Day of the Week, selected from the book of Common Prayer; PART 11. an appopriate Sermon for Every Sinday in the Year. Second Edition. Post 4to. 2ls, eloth; 31s. 6d. calf ; or \&2. 10 s, moroce.

THE FAMUI, CHAPLAin, $12 s$. Separately $\{$ The Dumestic Liturgy,

Davy (Dr. J.) - The Angler and his Friend; or, Piscatory Colloquies and Fishing Exeursions. By ЈоHN Davy, M1.D., F.1.S., se. Fcp. Svo. 6 .

\section{By the same Author,}

The Angler in the Lake District; or, Piscatory Colloquies and Fisling Fixeursions in Westmoreland and Cumsberlund. Fep. Svo. Gs. $6 \mathrm{~d}$.

\section{De Fonblanque.-The Admini-} stration and Ol'sanisation of the British Army, witl expecial refercnce to $\mathrm{Hi}$ natuce and supply. By EDWAPD B̉ARHTigTON DE FONBlaNeUR, Assistant Commissary-jeneral. svo. 12 s.

De la Rive's Treatise on Electricity in Theory and Practice. Translated for the Anthor by C. V. WALkLR, F.li.s. 3 vols. sro. Wookleuts, dis. 1.js.

Domenech.-_Seven Years' Residence in the Great Deserts of North America. Jiy the ABBE' DoMLNECur. With a Map, and ahout sixty Woodeut Illustrations. 2 vols. 8 vo, [just ready.

\section{Abbe' Domenech's Missionary}

Adventures in Texas and Mexico: A Per'sonal Narrative of Six Years' $\mathrm{So}$ journ in those Regions. $8 v 0.10 \mathrm{~s} .6 \mathrm{~d}$.
The Eclipse of Faith ; or, a Visit to a Religious Sceptic. 9th Edition. Fep. 8vo, 5 s.

Defence of The Eclipse of Faith, by its Author: Reing a Rejoinder to Professor Newman's Reply: Incluling a full Examination of that Writer's Criticism on the charaeter of Christ and a Chater on the Aspects and Pretensions of Modern Deism. Seeond Edition, revised. Post $8 v 0.5$ s. $6 \mathrm{~d}$.

\section{The Englishman's Greek Con.} cordance of the New Testament : Being an Attempt at a Verbal Connexiou between the Greek and the English Texts; including a Coucordance to the Proper Names, with Indexes, Greek. English and English-Greek. New Ldition, with a new Index. Royal 8vo.42s.

\section{The Englishman's Hebrew and}

Chaldee Concordance of the Old Testament: Being an Attempt at a Verbal Connexion between the Original and the English 'Translations; with Indexes, a List of the Proper Names and their Oceurrences, de. 2 vols. royal 8vo. $£ 3.13 \mathrm{~s}, 6 \mathrm{~d}$. ; large paper, $£ 1$. 14s. $6 \mathrm{~d}$.

\section{Ephemera's HandbookofAngling;} teaching Fly-fishing, Trolling, BottomFishing, Salmon-Hishing: ivith the Natural listory of River-Fish, and the best Mlodes of Catching them. 'Third Edition, corrected and improved; with Woodcuts. Fep. 8vo. 5s.

\section{Ephemera's Book of the Salmon :}

The Theory, Principles, and Practice of F'ly-Fishing for Salmon; Lists of good Salmon Flies for every good River in the Empire; the Natural History of the Salmon, its Habits described, and the best way of artificially Breeding it. Fcp. 8vo, with coloured Plates, 14s.

Fairbairn.-Useful Information for Engineers : Being a Series of Lectures delivered to the Working Eugineers of Yorkshire and Lancashire. By WrLLIAM FAtRBAIRN, F.R.S., F.G.S. Second Edition; with Plates and Woodcuts. Crown 8vo, 10s, 6d.

First Impressions of the New World on Two Travellers from the Old in the Autunn of $18 j 8$. With Map by Arrowsmith. I'ost 8vo, 8s, 6d.

Fischer. - Francis Bacon of Verulam: Realistic Philosophy and its Age. Iy Dr. K. Frscher. 'Translated by J. OXENFOzD. Post 8vo,9s, 6d. 
Forester. - Bambles in tha

Islands of Corsica ant Sardinia : With Notices of their IIistory, Antiquities, and present Condition. By Thoxas Forester. With coloured Map; and nnmerous Lithographic and Woodent Illustrations from Drawings made during the Tour by Lient.-Col. M. A. Bidduluh, R.A. Imperial $8 v 0.25 \mathrm{~s}$.

Frazer. - Letters of Sir A. S. Frazer, K.C.B. Commanding the Royal Horse Artillery muler the Duke of Wellington: Vritten during the Peninsular and Waterloo Campaigns. Edited ly MAJOR-GENERAL SABINE, R.A. With Portrait, 2 Ilans, and Plans. 8vo. I8s.

Freeman and Salvin...-Falconry: Its Claims, History, and Practice. By Gigr Earle Fregman, M.A. " Peregrine" of the Field newspaper"); and Cajtain F. H. SAlviN. Post Svo. with Woodcut lllustrations from Drawings by Wolf, price 10s. 6d. clotl.

Garratt. - II arvels and Mysteries of Instinct ; or, Curiosities of Animal Life. By George GarbatT. Second Edition, improved. Fep. 8vo.4s. Gd.

Gilbart. - A Practical Treatise on Banking. By James WrLluxi GiLbarT, F.R.S. Sixth Edition。 2 vols. $12 \mathrm{mo}$. 16s.

Gilbart's Logic of Banking: A Familiar Exyosition of the Principles of Reasoning, and their Apvlication to the Art and the Science of Banking. $12 m o$ with Portrait, 12s. 6 .

Gleig. Essays, Biographical, Historical, and Miscellaneous, contributed eliefly to the Ellinburgh and Quarterly Reviews. By the Rev, G. R. GLEIG, M.A. Chaplain-General to the Forees, and Prebendary of St. Paul's. 2 vols. 8 vo price $21 \mathrm{~s}$.

The Poetical Works of Olivor Goldsmith. Edited by BoLtoN CORNEY, Esq. Illustrated by Wood Engravings, from Designs by Hembers of the Eteling Club, Square crown 8vo. cloth, 21s.; moroceo, £1. 16s,

Gosse. $-A$ Naturalist's Sojourn in Jamaica, By P. H. Gosse, Esq. With Plates. Fost 8 vo. 14s.

Greathed.-Ietters from Delhi written during the Siege. By H. H. Greathen, late of the Bengal Civil Service. Edited by his Widow. Post 8 vo. 8s, 6d.
Green.-Lives of the Princesses of England. By Mrs, MART ANN EvERETT GreEN, Editor of the Letters of Royal and Illustrious Ladies. With numerous Portraits. Complete in 6 vols, post $8 \mathrm{ro}, 10 \mathrm{~s}, 6 \mathrm{~d}$. each.

Greyson.-Selections from the Correspondence of R. E. GrExsor, Esq. Edited by the Author of The Eclipse of Faith. New Edition. Crown Svo.7s,6d.

Grove - The Correlation of Physical Forces. By W. R. Grove, Q.C., I.A. Third Edition. 8ro, 7s.

\section{Gurney.-St. Louis and Henri}

IV.: Being a Second Series of Historical sketehes. By the Rev. JoHN H. GURNEX, M.A. Fep, 8vo, Gs,

EveningRecreations; or, Samples from the Lecture-Room. Edited by Rev, J. H. GURNEY. Crown 8vo. 5s.

Gwilt's Encyclopædia of Architecture, Historical, Theoretical, and Practical. By JosEPH Gwilt. With more than 1,600 Wood Engravings, from Designs by J. S. GwILT. 8vo. 42s.

Hare (Archdeacon). The Life of Luther, in Forty-eight Historical Engravings. 13y GUSTAV KöN1G. With Explanations by Arelideacon HARE and SUSANNAH WINEWORTH. Fep. 4to. 28s.

Farford,-Life of MichaelAngelo Buonarroti : With Translations of many of his Poems and Letters ; also Memoirs of Savonarola, Raphael, and Vittoria Colonna. By JonNS. HARFond, Esa., D.C.L., F.R.S. Second Edition, levised; with 20 Plates. "2 vols. 8 vo. 258 ,

Illustrations, Architectural and Pictorical, of the Genius of Michael Angelo Buonarroti. With Descriptions of the Plates, by the Commendatore CANINA; C. R. COCK ERELL, Esq., R.A.; andJ.S. HARFORD, Esq., D.C.L., F.R.S. Folio, 738.6d. half-bound.

Harrison. - The Light of the Forge: or, Counsels from the Sick-Bed ot E.M. By the Rev. IV. Harrison, M.A., Domestic Chaplain to the Duchess of Cambridge. Fep. 8 vo. $5 \mathrm{~s}$.

Harry Hieover's Stable Talk and Table Talk; or, Spectacles for Young Sportsmen. New Edition, 2 vols. 8vo. Portrait, 2ts. 
Harry Hieover.- The FuntiugField. By Harex Hicoter. With Two Plates. Fep. Svo. 5s, hali-bound.

Harry Hieover. - Practical Horsemanship. Second Edition; with 2 Plates. Fep. Svo. 5s. half-boumd.

Harry Hieover.-i'le Pocket and the Stud; or, Practical Ifints on the Mlanagement of the stable. By HARRY Hieover, Fep, Svo. Portrait, 5s.

Harry Hieover - The Stud, for Practical Purvoses and Practical Men: Being a Guide to the Choice of a Horse for use more than for show. Fep. 5s.

Hassall.u-A History of the British Freshwater Algx: Inciuding Descriptions of the Desmiclere and Diatomacer: By ARTHUR HiLl HASSALL, II.D, 2 vols, Svo, with 108 Plates, $21.15 \bar{s}$.

\section{Hassall. - AduIterations Detect-} ed ; or, Plain Instructions for the Dis. covery of Frauds in Food and Medicine. By Arthur HiLl Hassall, M.D. Lond., Anulyst of The Lancet sanitary Conumission, and Anthor of the IReport of that Commission published under the title of Food and its Actulterations (vhich may also be had, in S\%o, wice 2Ss.) With 225 Illustrations, engraved on Wood. Crown 8vo.17s.6u.

Col. Hawker's Instructions to Young Sportsmen in all that relates to Guns and Shooting. 11th Edition, revised by the Author's Son, Major 1'. IV. L. HAwk ER. With Portrait, l'ates, and Woodcuts. Sq. crown 8vo. 19g.

Haydn's Book of Dignities : Containing Rolls of the Official Personares of the British Empirc, Civil, Ecelesiastical, Judicial, Militury, Nuval, and Mlunicipal, from the Earliest 1'eriods to the Present Timc. Together with the Sovereigns of Europe, from the Foundation of their respcctive States: the Peerage and Nobility of Great 1'ritain, \&c. 8vo. 25s.

Hayward. - Biographical and Critical Essays, reyrinted from Rcvievs, with Additions and Corrections. By A. II TYW ARD, Esri, Q.C. 2 vols. 8 vo, 219 .

\section{Sir John Herschel's Outlines of} Astronouny. Fifth Elition, reviseck and corrected to the existing state of astronomical knowledge; with Plates and Woodcuts. 8vo, 18s.
Sir John Ferschel's Issays

from the Edinburgh and Quarterly Revieus, with Aduresses and other Pjeces. 8vo. $18 \mathrm{~s}$.

\section{Hinchlif. - Summer Months}

among the $\Lambda$ lys: With the $\Lambda$ scent of Monte Rosa. By Tros. W. HincyLIFT, Barister-at-Law. Post Svo. 10s. 6i.

Fints on Etiquette and the Usages of Society: With a Glance at Bal Habits. New Elition, revised (with Additions) by a Lady of Rank. Fcp. Svo. 2s. 6d.

Holland-Medical Itotes and Reflections, By Sir HENRYHoLtaND, M.D. F.1R.S., Xe. Physician in Ordinary to the Queen and Prince-Consort. Third Edition, Svo, 1ss.

\section{Sir F. Holland's Chapters on}

Mental Physiolory, founded chicfly on Chaters contained in Medical Notes and Reflections. Post 8vo,8s.6d.

Hooker.-Kew Gardens; or, a Popular Guicle to the Royal Botanic Gardelis of kew. By Sir WILLIAII JACKSON HoOKER, L.H. \&C. Direce tor. With many Woodeuts. 16mo, Gd,

\section{Yooker and Armott's British} Flora; comprising the Phrnogamous or Flowering Plants, and the lerns. Seventh Edition, with Additions and Corrections; and numerous Figures illustrative of the Umbelliferons Plants, the Composite Plants, the Grasses, and the Ferns. 12mo. with 12 Plates, 14s, with the Plates coloured, 21s.

Horne's Introduction to the Critical Study and linowledye of the Holy Scriptures, Tenth Elition, revised, corrected, and brought down to the present time. Edited by the Rev. T. Hartwell Horne, 13.1), (the Author); the Rev. SAMUEL DividSON D.D. of the University of Halle, an Li.D.; and S. PRIDEAUX'T'ReG ELLES LL.D.' With 1 Maps and 22 Vignettes and Facsimniles, 4 voIs, $8 v 0.23 .13 \mathrm{~s}, 6 \mathrm{~d}$.

\section{Horne.-A Compendious Intro.} duction to the study of the Bible. By the Rev. T. H ARTWELt HORNE, B. D. New Edition, with Aaps, dc. 12mo, 9s.

Hoskyns.-Talpa ; or, the Chronicles of a Clay Farnu : An $A$ gricultural Fragnent. liy CHANDOS WM:N Hosky Ys, Esq. Fourth Edition. With 21 Woodents from Designs by Givosg Cruikshay 
Howitt (A. M.) -An Art-Student in Iuniel. By ANNA MARY Howitr. 2 vols, post svo, 11s.

Howitt.-The Children's Year. By MARY Howitr. With Four Illustrations. Square $16 \mathrm{mo} .5 \mathrm{~s}$.

Howitt. - Tallangetta, the Squatter's Home : A story of Australian life. By Williak HowitT. 2 vols. post 8 vo. 18s.

Howitt. - Land, Labour, and Gold; or, Two Years in Victorin : With Visit to Sviney and Van Diemen's Land. By William Howitr. Second Edition. 2 vols, crown Sro. 10s,

W. Howitt'sVisits to Remarkable Places: Old Halls, Battle-Fields, and Scones illustrative of Striking Passages in English History and Poetry. Witl about 80 Wood Engravings, New Edition. 2 vols. square crown 8 vo. $25 \mathrm{~s}$.

\section{William Howitt's Boy's Coun.} try Book: Being the Real Life of a Country Boy, written by himself; exhilbiting all theAmusements, Pleasures, and Pursuits of Children in the Conntry. With 40 Woodeuts. Fep. Sro. 6s.

William Howitt's Rural Life of England. With Woodcuts by Bewick and Wiliams. Medium 8vo. 2ls.

\section{The Abbe' Huc's Work on the} Chinese Empire, founded on Founteen Years' Travel and Residence in China. People's Edition, with 2 Woodcut Illustrations. Crown Svo.5s.

Huc. - Christianity in China, Tartary, and Thibet. I3y M. l'Abbe Huc, formerly Missionary Apostolic in China, Vols. I. and II. Sro. 21s.; and YoL. IJI 10s, $6 \mathrm{~d}$.

\section{Hudson's Executor's Guide.}

New and improved Endition; with the Statutes enacted, and the Julicial Decisions pronounced since the last Edition incorporated. Fcp. 8 vo. 6s,

Iudson's Plain Directions for Mlaking Wills in conformity with the law. New Edition, corrected and re. vised by the Author; and practically illustrated by specimens of Wills containing many varieties of Requests, also Notes of Cases judicially decided since the Wills Act came into operation. Fep. Svo. 2s. $6 \mathrm{~d}$.
Hudson and Kennedy's Ascent of Mont Blanc by a New lioute and Without Guides, Second Edition, with Plate and Map. Post 8 vo. 5s, 6d.

Humboldt's Cosmos. Translated, witl the Author's authority, by Mrs. SABINE. Vols, I. and if. $16 \mathrm{mo}$ Half-a-Crown each, sewed; 3 s. Gd, each, cloth; or in post Sro. 12s. each, cloth. Vou, III post 8vo, igs, 6il cloth: or in $16 \mathrm{mo}$. Part I. 2s, 6d. sewed, 3s, $6 \mathrm{~d}$. cloth; and Part I1. \&s. sewed, 4 s. choth. Vol, IV. PART I. post 8 vo. 15s, eloth; $16 \mathrm{mo}, 7 \mathrm{~s}, 6 \mathrm{~d}$, cloth.

\section{Fumboldt's Aspects of Nature.} Translated, with the Anthor's authovity, by Mrs. SABINE. $16 \mathrm{mo}$, price $6 \mathrm{~s}$. or in 2 vols. $3 \mathrm{~s}, 6 \mathrm{~d}$. cach, cloth; 2s. $6 \mathrm{~d}$. each, sewed.

\section{Humphreys. - Parables of Our}

Lord, illuminated and ornamented in the style of the Missals of the Renais. sauce by 11 . N. HUMPHREYs. Square fev. 8vo 2 ? \& in massive carved covers or 30 s. bound in moroces, by Hayday.

Hunt (Capt.). - The Forse and his Master: With Hints on Breedine, Breaking, Stable-Management, Training, Elementary Horsenranship, Ridin to Hounds, ke. By VERE W. HuN'T, Fsq., late 109th Regt. Co. Dublin Milstia. Fep, 8vo. with Frontispiece, price 5 s.

Funt.-Researches on Light in its Chemical Relations; embraeing a Consideration of all the Photosraphic Processes. JH' RoBert HUNt, F.R.S. Second Edition, with Plate and Woodcuts. Svo, 10s, 6d.

Hutchinson. - Inipressions of Western Africa: With a Report on the Peculiarities of Trade up the livers in the Bight of Biafra. By.J.T. HeTcrisson, Esq., British Consul for the Bight of Biafra and the Island of Fernando Po. l'ost 8vo, 8s, 6u.

Idle-Fints on Shooting, Fishing, \&c., both on Sea and land, and in the Fresti-Water Lochs of Scotiand: Ieing the Experiences of C.IDLE, Esq. Fep. 3 ro. 5s.

Mrs. Jameson's Two Icctures on the Social Employments of Women, Sizter's of Charity and the Commenion of Labour. New Edition, with Prefatory Letter on the Present Condition and Requirements of the Women of England. Fep. 8vo. 2s. 
Mrs. Jameson's Legends of the Saints and Martyrs, as represented in Christian Art : Forming the FInst SERIES of Sacred and Legendary Art. Third Edition; with 17 Etehings and upwards of 150 Woodeuts. 2 rols. square erown 8vo. 31s, Gd.

Mrs. Jameson's Legends of the Monastic Orders, as represcnted in Christian Art. Forming the SEcond SERIEs of Sacred and Legendar"y Art. Second Edition, enlarged; with II Etchings by the $A$ uthor and 85 Woodcuts, square crown Svo. 268.

Mirs. Jameson's Legends of the Madonma, as remesented in Christian Art: Forming the THInd SERIES of Sacred and Legendary Art. Second Edition, corrected and enlarged; with 27 Litclings and $165_{0}^{-1}$ iVood Engravings, Square crown sro. 28 s.

Mrs. Jameson's CommonplaceBook of Thoughts, Memories, and Eancies, Origimal and Selected. Secont Eclition, revised and cormected; with Etchings and Woodcuts. Crown Svo. price $18 \mathrm{~s}$.

Jaquemet's Compendium of Chronology : Containing the most inportant l)ates of General History, Political, Ecelesiastical, and Literary, from the Creation of the World to the end of the lear 185t. Post 8vo.7s. Gd.

\section{saquemet's Chronology for} Schools: Containing the most important Dates of General History, Politieal, Ecelesiastieal, and Literiry, from the Creation of the World to the end of the Year 1857. Fep, 8vo.3s, 6il.

\section{Lord Jeffrey's Contributions to}

The Edinburgh Review. A New Edition, complete in One Volume, with Portrait and Vignette. Square crown 8vo. 218. eloth; or 30s, calt. $\rightarrow$ Or in 3 vols. 8 vo, price $42 \mathrm{~s}$.

\section{Bishop Jeremy Tayior's Entire} Works: With Life by.Bishop HEBER. Revised and corrected by the lRev. Charles Page Enen, Fellow of Oriel College, ")xford. Now complete in 10 vols. 8vo. 10s. Gd, each.

Kane.-Wanderings of an Artist among the Indians of North Ameriea; from Canada to Vaneorver's Island and Oregon, through the Hudson's Bay Company's Territory, anil back again. By PADL KANE. With Mal, Illistrations in Colours, and Wood Engravings. svo, $21 \mathrm{~s}$.
Kemble. - The Sazons in England: A History of the English Commonwealth till the Conquest. 13y J. JI. KEMBLE, M.A. 2 vols, $8 \mathrm{ro}, 28 \mathrm{~s}$.

\section{Keith Johnston's Dictionary of}

Geography, Descriptive, Physical, Statistical, and Historical: Forming a complete General Gazetteer of the wortd. Third Edition, reetified to May $1 \$ 59$. In 1 vol, of 1,360 pages, comprising about 50,000 Names of Places, 8 vo, $30 \mathrm{~s}$. eloth; or half-bound in russia, 35 s.

Kesteven. - A Manual of the Domestic Practice of Medicine. By W. 13. KesteVteN, F.R.C.S.E., de. Square post 8vo. 7s. Gd.

\section{Kirby and Spence's Introduction}

to Entomology; or, Elements of the Natural History of lnsects : Comprising an Account of Noxious and Tseful Inseets, of their Metamorphoses, Food, Stratasems, Habitations, Societies, Motions, Noises, Hybernation, Instinet, sc. Seventh Eation, with an Appendix rebtive to the Origin and Progress of the work. Crown 8vo, 5 s.

\section{A Lady's Tour round Monte} Rosa; with Visits to the Italian Valleys of Anzasea, Mastalone, Camasco, sesia, Lys, Challant, Aosta, and Cogne: In a Series of Exeursions in the Year's 1850, 1856, 15.5. With Map, 4 lllustrations in Colours from sketches by $\mathrm{Mr}$. (i. Baruard, and S Wood Eugravings. Post 8ro. 14s.

\section{Lardner's Cabinet Cyclopædia of} History, Biography, Literature, the Arts and sciences, Natural Ilistory, and Manufactures. A Series of Uriginal Works by EUINENT IVRITERS. (i)mplete in 132 vols. fep. 8 vo. with Vignette I'itles, price ti9. 19s. cloth lettered.

The Works separately, in single Volumes or Sets, price 3s. Gal. each Volume, elotil lettered.

Mrs. R. Lee's Elements of $\mathrm{Nam}$ tural History; or, First Prineiples of Zoology : Comprising the Principles of Classification, interspersecl with amusing and instructive Accounts of the most remarkable $\Lambda$ nimals. New Edition; Woodeuts, Fep. Svo.7s.Gd.

Tho Letters of a Betrothed. Fcp. 8vo. price 5s, cloth.

Letters to my Unknown Fiends. By a LADr, Author of Letters on IIappiness. Fourth Edition. Fep. 8vo. us. 
I.E.L. The Poetical Works of Letitia Elizabeth Landon; comprising the Improvisatrice, the Venetian Bracelet, the Golden Violet, the Troubadour, and Poetical Remains. 2 vols, $16 \mathrm{mo}$. Ios, clotli ; norocco, 2 is.

\section{Dr. John Lindley's Theory and}

Practice of Horticulture ; or, an Attempt to explain the principal operatious of Gardening upon Plyysiological Grounds: Being the Second Edition of the Theory of Horticulture, much eularged; with 98 Woodcuts. 8vo, 2ls.

\section{Dr. John Lindley's Introduction} to Botany. New Edition, with corrections and copions Additions. 2 vols. Svo. with Plates and Woodeuts, 2ls.

\section{Dr. John Lindley's Synopsis of} the British Flora arranged according to the Natural Orders; containing Vas. eulares or Flowering Plants. Third E'dition (reprinted). Fop. Svo, Gs.

Linwood. - Anthologia Oxoniensis, sive Florilegium e Lusibus poeticis diversorum Oxoniensium Greeis et Latinis decerptum. Curante GULIELXO LIN WOOD, M.A. Svo. Its.

\section{Lorimer's Letters to a Young} Master Mariner on some Subjects conneeted witl his Calling. Fep. Svo. price $5 \mathrm{~s}, 6 \mathrm{~d}$.

Loudon's Encyclopædia of Gardening: Comprising the Theory and Practice of Horticulture, Floriculture, Aboricultin'e, and Landscape-Gardening. With 1,000 Woodeuts, 8ro.31s.6ut.

Loudon's Encyclopæedia of Trees and Shruhs, or Arboretum et Fructicetum Britansicum abridsed: Containing the Hardy Trees and Shrubs of Great Britain, Natire and Foreign, Scienti-

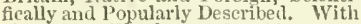
about 2,000 Woodcuts. Sro. 50s.

Loudon's Encyclopædia of Agriculture: Comprising the Theory and Practice of the Valuation, Transter, Laying-out, Improvement, and $\boldsymbol{H}_{\mathrm{a}}$ nasement of Ianied Prowerty, and of the Cultivation and Economy of the Animal-aled Vegetable Productions of Agriculture. With 1,100 Woodcuts. $8 \mathrm{Fo} .31 \mathrm{~s} .6 \mathrm{~d}$
Loudon's Encyclopædia of Plants: Comprising the Specific Character, Description, Culture, History, Applica: tiols in the Arts, and every otlier tesirable Particular lespecting all the Plants found in Great Britain. With upwards of 12,000 Woodeuts. 8ro. price £3. L's, 6 6 ?

Loudon's Encyclopædia of Cot. tage, Falm, and Villa Architecture and Furniture, New Edition, edited by: Mrs. LoudoN; with more than 2,000 IVoodeuts. 8vo. 63s.

Loudon's Hortus Britannicus ; or, Catalogue of all the Plants found in Great Britain. New Edition, corrected by Mrs. LOUDON. 8vo.31s. Gd.

\section{Mrs. Loudon's Lady's Country} Companiour : or, How to Enjoy a Country Life Rationally, Fourth Edition. Fep. 8vo.5s.

Mi's. Loudon's Amateur Gardener's Calendar, or Monthly Guide to what should be avoided and done in a Garden. Second Edition, revised. Crowu 8vo, with Woodeuts, 7s. 6d.

\section{Low's Elements of Practical} Agriculture; comprehending the Cultivation of Plants, the Husbandry of the Domestic Animals, and the Economy of the Farm. New Edition; with 200 Woodeuts. 8vo.2Is.

Macaulay. - Speeches of the Right Hon. LordMACAULAY. Corrected by HIMSELF. 8vo, 12s.

Macaulay, - The History of England from the Accession of James II. By the Right Hon. Lord MA CADLAS. Nery Edition. Tols, I. and 11. 8ro. 32s.; Vols, 111 and 1V. 36s.

\section{Lord Macaulay's History of Eng-} land from the Accession of James II. New Edition of the first Four Volumes of the Octavo Elition, revised and corrected. 7 vols, post 8 vo. 6 s, each.

Lord Macaulay's Critical and Historieal Essays contributed to 'The Edinburgh Review, Four Entitions:-

1. A Library Editron (the Eighth), in 3 vols. 8 vo, price $36 \mathrm{~s}$.

2. Complete in ONE Vorese, with Por trait and Vignette. Square crown 5ro. price $21 \mathrm{~s}$. cluth; or 30 s. calf.

3. Another NEw EDITIon, in 3 rols. fcp. 8vo. price 21s, cloth.

4. The PEOPLE's EDitiox, in 2 vols. crown 8vo. price 8s. cloth. 
Macaulay. - Lays of Ancient Rome, with Ivry and the Armaclu. By the Right Hon. Kord MACAULAY. New Edition. $16 \mathrm{mo}$, price 4s. 6d. eloth; or $10 \mathrm{~s}, 6 \mathrm{~d}$. bound in moroeco.

\section{Lord Macaulay's Lays of Ancient} Rome. With numerous Illustrations, Original and from the Antique, lrawn on Wood by George Seliarf, jum. Fep. 4to. 21s, boards; 01 $42 \mathrm{~s}$. bound in moroceo.

Mac Donald.-Poems. By George Mac DoNaLD, Author of Within and Without. Fep, sro, $7 \mathrm{~s}$.

Mac Donald. - Within and Without: A Dramatic Poem. By GEORGE Mac Doratid, Fep, Svo, is. 6u.

Mac Dougall. - The Theory of War illustrated by numerous Examples from History. By Lieutenant-Colonel MIAC Dougats, Commandant of the Staff College. Second Edition, revised. Post 8ro. with Plans, 10s, 6a.

\section{Mac Dougall. - The Campaigns} of Hannibal, arranged and critically considered, expressly for the use of Students of Military History. By Lieut.Col. P. L. M a c Douga LL, Commandant of the Stafi College. Pust Svo. 7s.6d.

M'Dougall. - The Eventful Voyage of I. M. Discovery Ship Resolute to the Arctic Regions in sear'ch of Sir John Franklise and the Missing Crews of H.M. Discovery Ships Erebus and Terror, 1852, 1553, 1851. l3y GEoraE F. M'Dovgat, Master. With a colonred Chart, llustrations in Lithography, and Woodeuts. 8vo. 21s.

Sir James Mackintosh's Miscellaneous Works : Ineluding his Contributions to The Edinburgh Review. Consplete in One Volume; witl P'ortrait and Vignette. Siquare erown svo. $21 \mathrm{~s}$, cloth ; or $30 \mathrm{~s}$, bound in call: or in 3 vols, fep. 8 vo. 21 s.

Sir James Mackintosh's History of England from the Earliest Times to the final Establishment of the Ireformation. 2 vols. 8 vo. $21 \mathrm{~s}$.

M'Culloch's Dictionary, Practical, Theoretical, and Historical, of Commerce, and Commereial Navigation. Illustraterl with Maps and Plans, New Edition, revised and adupted to the Present Time.

[Just ready.
M'Culloch's Dictionary, Geographical, Statistical, and Historieal, of the various Countries, Places, and principal Natural Objects in the World. Illustrated with Six large Maps. New Edition, revised. 2 vols. 8 vo. 63 s.

Magnire. - Rome; its Ruler and its Institutions. By JoH N Fancis MAGUIRE, MI.P. Second Edition, enlarged: with a new Portrait of Pope Pius LX. Post 8vo. 10s, 6 d.

Mi's. Marcet's Conversations on Natural Philosophy, in which the Elements of that Science are familiarly explained. Thirteenth Edition, enlarged and corrected; with 31 Plates, Fep. 8 vo. price 10s, $6 \mathrm{~d}$.

Mirs. Marcet's Couversations on Chemistry, in which the Elements of that Science are fiamiliarly explained and illustrated by Experiments. New Edition, improved, 2vols. ficp. 8vo.14s,

II arshman.-The Iife and Times of Carey, Marsinnan, and Ward: Embracing the History of the Serampore Mission. By JoHY CLARK MARSHMAN. 2 vols. 8vo. $25 \mathrm{~s}$.

Martineau. - Studies of Christianity: A Series of Original Pupers, now first collected, or New. By JAares MLATINEAU, Crown $8 v 0,7 \mathrm{~s}, 6 \mathrm{~d}$.

Martineau. - Endeavours aiter the Christian Lile: Discourses. By JAMIES MARTINEAU. 2 vols. post 8 vo. price $7 \mathrm{~s}, 6 \mathrm{~d}$, each.

Martineau. - Hymns for the Christian Church and Home: Colleeted and edited byJa mes Martineav. Eleventh Edition, 12mo. 3s. 6d, eloth, or 5s, calf; Fifth Edition, 32mo, 1s, 4d, eloth, or Is, Scl. roan.

Martineau,-Miscellanies: Comprising Essays eliefly religious and controversial. By JaMES MARTINEAU. Crown 8vo.9s,

Maunder's Scientific and Literary Treasury: A new and popular Fncyclopiedia of Science and the liellesLettres; including all Branclies of Science, and every subject connected with Literature and Art. Fep, 8vo,10s. 
Maunder's Biographical Treasury ; consisting of Mlemoirs, Sketclies, and brief Notices of above $12,000 \mathrm{Emi}$ nent Persons of All Ages and Nations, from the Earliest Period of History: Forning a complete Dictionary of Universal Biography. Eleventh Edition. corrected and extended in a supplenent to the Present Time. Fcp. 8 ro. 10s.

Maunder's Treasury of Knowledge, and Library of lieference; comprising an English Dictionary and Grammar, a Universal Giazetteer, a Classical Dietionary, a Chronology, a Law Dictionary, a synopsis of the Peerage, numerous useful T'ables, dc. New Edition, reconstructcd by B. B. WOODWARD, B.A.; assisted by J. Morris, solicitor, and W. HeGHEs, F.K.G.S. Fep. 8vo.10s.

\section{Maunder's Treasury of Natural} History; or, a Popular Dictionary of Animated Nature: In which the Zoological Characteristies that distingraish the different Classes, Genera, and Species, are combined with a variety of interesting Information illus. trative of the Habits, Instincts, and General Ecounomy of the Auimal Kingdom. With 900 Woodeuts. Fep. 10s.

\section{Maunder's Historical Treasury ;} comprising a Genesal Introductory Outline of Universal History, Ancient and Moderi, and a Serics of Separate Histories of every principal Nation that exists; their Rise, Progress, and Present Condition, the Mloral and Social Character of their respective luhabitisuts, their Religion, Nlanners, aud Custoins, de. Fep, 8vo.10s.

Maunder's Treasury of Geogra. pliy, Physical, Historical, Descriptive, and Political ; containing a suceinct $A \mathrm{c}$. count of Every Country in the World: l'receded by an Introductory Ontline of the History of Geography; a Faniliar Inquiry into the Varieties of Race and Language exhibited by different Nations; and a View of the Relations of Geography to Astronomy and the Physical seiences. Completed by IVILlias Hughes, F.k.tis.s. IVith 7 Maps and 16 steel Plates. Fep. Svo. 10s.

\section{Iferivale (Miss). - Christian} Records : A Short History of Apostolic Age. By L. A. Merivale. Fep. 8vo. price $7 \mathrm{~s}, 6 \mathrm{~d}$.

Merivale. - The Fall of the lioman Republic: A Short History of last Century of the Commouwealth. Jiy Rev, C. Mierivale. 12mo. 7s, 6d.
Merivale. - A History of the Romans under the Empire. By the Rev. Charles Mifrivale, B.D., late Fellow of St, John's College, Cambridge. 8 vo, with Maps.

Vous. I and II. comprising the History to the Fall of Julitus Cosar. Second Edition.28s.

Voc. III. to the Establishment of the Monarchy by Augustus. Second Edition.......1s.

VoL. IV and V. from Augustus to Claulius, B.C 27 to A.D.51 ......................... Voc. VI, from the Reign of Nero, A.D. 51 , to the Fall of Jerusalem, A.D, $70 \ldots \ldots . . . .$. l tis

Mildred Norman the Nazarene. By a IVonking Max. Crown Sro. $5 \mathrm{~s}$.

Miles.-The Horse's Foot and How to Keep it Sound. Eighth Edition; with an Appendix on Shoeing in seneral, and Hunters in varticular. 12 Plates and 12 Woodcuts, By W. Miles, Esq. Imperial 8vo. I2s. 6d.

Iriles's Plain Treatise on HorseShoeing. With Plates and Woodeuts. Second Edition. Post Sro. 28.

Milner's Fistory of the Church of Christ. With Additions by the late Rev, ISAAC MILNER, D.D., F.R.S. A New Edition, revised, witls additional Notes by the Rev. T. GraNtham, B.D. 4 vols. 8 vo. $52 \mathrm{~s}$.

Minturn. - From New York to Delhi by way of Rio de Janeiro, Australia, and China. By RoBERT B. IINTURN, Jun. With coloured RouteMay of India. Post 8vo. 7s, 6u.

Mollhausen.-Dial'y of a Journey from the Mississippi to the Coasts of the Pactic, with a United states Goverument Lxpedition. By B, BloL LHAUSEN, Topographieal Draughtsman and Naturalist to the Expedition. With an Introdnetion by Baron 11 U MBOLDT; Dlap, coloured Illustrations, and Woodcuts, 2 vols, 8 vo. $30 \mathrm{~s}$.

James Montgomery's Poetical Works: Collective Edition; with the Author's Autobiographical Prefaces, complete in One Volume; with Portrait and Vignette. square erown Svo. 10s. 6d. eloth; morocco, 21s,-0r, in 4 vols. fep. Svo. with Plates, 11 s.

Moore.-The Power of the Soul over the Body, considered in relation to Ilealth and Morals. By GEORGE MOORE, M.D. Fep. 8vo.6s. 
IIoore. - Man and his Motives. By Geore MIoone, M.D. Fep. Svo.6s.

Moore. The Use of the Body in relation to the Mind. By G. Moore, 11.D. Fep. Svo. 6s.

\section{Hoore-memoirs, Journal, and} Correspondenee of Thomas Moore. Fdited by the Right Hon. LORD JOHN RUSSELL, M.P. With Portraits and Vignettes. 8 vols, post 8 ro. 24. $4 \mathrm{~s}$.

Thomas IIoole's Foetical Works : Comprising the Author's Autobiogra phieal Prefaces, latest corrections, and Notes. Varions Euitions of the separate Poens and complete Poetical Works, as follows:LA Li ROOFH, 16 muby type .... d

LALLA ROOKH, square crown 8 \%o.

Plates ....................... 15

LALLA RUOKil, fep. ito. with wood-

cut Illnstrations by TEXNIEr., in the press.

IRISH MELODIES, 32mo ruby tyje.. I 0

IRISH MELODIES, 16 mo. VignetLe . 2

IRIS: ALLODIES, square crown 8 ro.

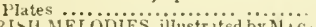

IRIMIL MELODIES, illustrated by MAC-

LISE, super-royalovo.... 6

SONGS, BALJADS, and SACRED

SONGS, 32mo. ruby type .......... 26

SONGS, BALLADS, and SÄCHED

SONGS, $16 \mathrm{mo}$. Vignette

POETICAL WORK', L'eople's Edition,

i1 Parts, each................... I 0

POETICAL WURKS, Cabinet Edition,

10 Vols. each $\ldots \ldots \ldots \ldots \ldots \ldots \ldots$

POETICAL WORES, Traveller's Edi-

tion, crown bro................. 12 6

PUE'ICAL W URKS, Library Edition, medium svo. .................... and PICTURES from THOMAS MOORE," fep. 4to, with Wood Engravings...................... 210

MOUIRE'S EPICUREAN, I6mo. Vig. nette..................... 5

\section{Editions mintal with the Ifusic.}

IRISH MELODIES, People's Edition, small t to

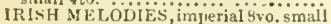
music size $\ldots \ldots \ldots \ldots \ldots \ldots \ldots \ldots \ldots . \ldots \ldots$. MELUDIES, imperial fro on 15

NatTlonal Alks, People's Ëdition,

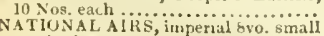
music size

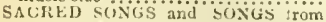
SCRIl'TURE, imperial 8vo. ........ If

No Edition of Thomas Moore's Poetical Works, or uny sepurate l'oem of Moore's, can be published complete except by Messrr. LongaAN and Co.
Morell. - Elements of Psychology : Pant I., containing the Analysis of the Intellectual Puwers. Ly J. 1). MokeLL, M.A., One of Her Majesty' Iuspectors of Schools. Post 8vo.7s.6d.

Morning Clouds. By the Author of The Aflemoon of Life. Seeond Edi. tion, levised thronghout. Fep. Svo. 5s.

Moris (F. O.) - Anecdotes in Natual Itistory. By the liev. F. 0. MORIIS, B.A., Reetor of Nunburnholme, Yorkshire, Author of "History of the Nests and Egys of British Binds," \&e. Fep. Sto. [Just recty.

\section{Morris (J.) - The Life and} Martyriom of St. Thomas Becket, Archbishop of Canterbury and leyate of the Holy See. By JoHx RJorris, Canon of Northampton. Post 8vo. 9s.

Morton.-The Resources of Estates: A Treatise on the Agricultural lumprovement and General Management of Landed Property. Ly Jour LOCKHART MORTON, Civil and Agricultural Engineer; Autlor of Thirteen Highland and Agrieultural Prize 1.ssays. With 25 Lithograplic Iliustra. tions. Royal Sro. $31 \mathrm{~s}, 6 \mathrm{u}$.

Moseley's Mechanical Principles of Engineering and Arehitecture. Second Eilition, enlarged; with numeruus Woodcuts, 8vo. 24 s.

Memoirs and Letters of the late Colonel Armins Mountain, Aidede-Camp to the Queen, and AdjutantGeneral of Her Nlajesty"s forees in India. Edited by Mls. Moentar. Second Eaition, Portrait. Fep. bvo. 6s.

Mure.A Critical History of the Language and Literature of Aneient Greece. By WILLIAII MUR, of Caldwell. Vous. 1. to $111.8 \% 0$. price

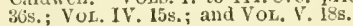

Miurray's Encyelopædia of Geography, comprising a complete Descri 1 tion of the karth : Exhibiting its Relation to the Heavenly Bodies, its Physical structure, the Natural ilistory of each Country, and the industry, Commerce, Political institutions, and Civil, and social state of All Nations. Secone? Edition; witl 82 Maps, and npwads ol 1,600 other Woodeuts. 8vo. 6us.

Neale.-The Closing Scene; or, Christiounity and Infidelity contristed in the Last Hours ol Remarkatile l'ersons, by the Rev. Mrskine Neali: M.A. 2 vols, fe'p. 8 vo, 6 s, ench. 
Normanby (Marquis of). - A

Year of Revolution. From a Journal kept in Paris in the Year 1813. By the MARQUIS OF NORMANBI, K.G. 2 vols. 8 vo. $24 \mathrm{~s}$.

\section{Ogilvie.-The Master-Builder"s}

Plan; or, the Principles of Orgavic A rehitecture as indicated in the Typical Iorms of Animals. BV GForge OGILVIE, H.D. Post 8vo. with 72 Woodcuts, price 6 s. 6 d.

Oldacre. - The Last of the old Squires. A Sketch. By CEDRIC OLDACRE, Esq., of Sax-Normanbury. Crown sro. 9s. 6u.

Osborn. Q Quedah; or, Stray Leaves from a Joumal in Malayan Waters. By Captain SH RRARD OSBOZN, R.N., C.B. With a coloured Chart and tinted Illustrations. Post 8vo. 10s. 6d.

Osborn. - The Discovery of the North-West Passage by H.M.S. Investigator, Captain R. M'CLURE, 1850-1851. Edited by Captain SHERARD OSBORN, C.B. Third Edition; with Portrait, Chart, and Illustrations. 8vo. 15s.

Professor 0 wen's Lectures on the Comparative Anatomy and Physiology of the Invertebrate Animals, delivered at the Royal College of Surgeons. Second Edition, with 235 Woodcuts. $8 \mathrm{vo}, 21 \mathrm{~s}$.

\section{Professor Owen's Lectures on} the Comparative Anatomy and Physiology of the Vertebrate Animals, delivered at the Royal College of Surgeons in 1814 and 1816. YoL. 1.8vo,14y.

Memoirs of Admiral Parry, the Aretic Navigator. By liis Son, the Rev. E. PARRY, DI.A., Domestic Chaplain to the Bishop of London. Sixth Edition; with a Portrait and coloured Clart of the North-West Passage. Fep. 8ro.5s,

\section{Pattison.- The Earth and the} Word; or, Geology for Bible Students. By S. R. P'ATTISoN, F.G.S. FCp. Svo. with coloured Map, 3s. 6d.

Peaks, Passes, and Glaciers: a Series of Excursions by Members of the Alpine Chub. Edited by Jonn BALL, M.R.I.A., F.L.S., President of the Alpine Club. Second Datition; with numerous Maps, coloured Illustrations, and Engravings on IVood. Square crown 8vo. 21s. - The EIGHT Swiss MAps, accompanicd by a Table of the HeIGHTS of MoUNTAINS, may be had separately, price 3s, 6 d.
Dr. Pereira's Elements of Mate. ria Medica and Therapeuties. Third Edition, enlarged aul improved from the Author's Materials by A. S. TAYLOR, M.D., and G. O. REES, M1.D. Vol, I. 8vo. 2Ss.; Vol. II. Part I. 21s, ; Vol. 11. Part 11.26s.

\section{Dr. Pereira's Lectures on Polar-} ised Light, together with a Lecture on the Mlicroseope. 2d Edition, enlarged from the Author's Materials by liev. B. PowELh, M.A. Fep. 8vo. Woodeuts, price 7 s.

Perry - The Franks, from their First Appearance in History to the Death of King Pepin. By WALTER C. PERRY, Barrister-at-Law. 8ro. 12s,6d.

\section{Peschel's Elements of Physics.}

Translated from the German, with Notes, by E. WEST. With Diagrams and Woodeuts. 3 vols, tep. 8 ro, 21 s.

Phillips's Elementary Introduction to Mineralogy. A New Edition, with extensive Alterations and Additions, by H.J. Brook E, F.R.S., F.G.S.; and IV. H. MILLER, MI.A., F.G.S. Witli uumerous Woodeuts. Post 8vo. 1Ss.

Phillips. $-A$ Guide to Geology. By Јон: PhILLIPS, M.A., F.R.S., F.G.S. de. Fourth Edition, corrected; with 4 Plates. Fep. 8vo. 5s.

Piesse's Chymical, Natural, and Physical Magie, for the Instruction and Entertainment of Juveniles during the Holiday Vacation: with 80 Woodcuts and an Invisible portrait of the Author, Fep. 8ro. 3s. 6d.

Piesse's Art of Perfumery, and IIcthods of Obtaining the odours of Plants; writh Instructions for the MIa. nufacture of Peifumes for the 1landkerchict, Scented Powders, Odorous Vinerars, Dentifrices, Pomatums, Cosmétiques, Perfumel soap, \&c.; and an Appendix on the Colours of Flowers, Artificial Fruit Essences, \&ic. Second Edition; Woodeuts. Crown 8vo. 8s, 6d.

\section{Pitt. - How to Brew Good Beer :}

A complete Guide to the $\Lambda \mathrm{rt}$ of Brewing Ale, Bitter Ale, Table Ale, Brown Stout, Porter, and Table Beer. To which are added Practical Instructions for Making Malt. By JOHN PITT, Butler to Sir William R, P. Geary, Bart. Fep. 8vo. 4s. 6d. 
Porter.-History of the Knights of Mtalta, or the Order of the Hospital of St. John of Jerusalen. IBy Major Whitwonth Porter, Royal Engineers. With 5 lllustrations. 2 vols. Svo. $21 \mathrm{~s}$.

\section{Powell-Essays on the Spirit of} the Inductive Philosophy, the Unity of Worlds, and the Philosophy of Creation. By the Rev. BADEN JowELL, M.A., de. Crown 8vo. Woodeuts, 12s, 6d.

Powell. - Christianity without Judaism: A Second Series of Essays on the Unity of IV orlds and of Nature. By the Rev. Baden PoweLL, Ml.A., \&c. Crown 8vo. 7s. 6d.

"T This rolume contrins the pith of Prcfessor Powell's argument urged often and nowerfully against the Judaic spirit among Christians. ....Upon the theological part of Professor Powell's a gument tve offer no opiuion; we simply desire to make known the nature of his book, and to secure for it the respe $t$ and attention it deserves." EXAMINER.

\section{Powcll.-The Order of Nature} considered in reference to the Claims of Revelation: A Third Series of Lssays on the Unity of Worlds and of Nature. By the Rev. BADEN POWELL, M.A. Crown $8 v 0.12 s$.

Pycroft. - The Collegian's Gide; or, Recollections of College Days : Setting forth the Advantages and Temptations of a University Education. by the Rev. J. Prcroft, B.A. Second Edition. Fep. 8 vo. $6 \mathrm{~s}$,

\section{Pycroft's Course of English} Realing; or, How and What to Read: Adapted to every taste and capacity. With Literary Anccuotes. F cp. 8vo, 5s.

Pycroft's Cricket-Field ; or, tho Science and History of the Game of Cricket. Third Edition; Plates and Woodeuts. F(p) 8vo.5s.

Quatrefages (A. De).-Rambles of a Naturalist on the Coasts of France, Spain, and Sieily, By A. DE QUATREFAoEs, Nemb. Inst. Translated by E. C. OTTE'. 2 vols, post 8 vo. $15 \mathrm{~s}$.

Raikes (T.) - Portion of the Journal kept by THomas RAmEs, Esq., from 1331 to 1817 : Comprising Reminiscenees of Social ant l'ulitieal Life in London and I'aris during that periou. New Edition, complete in 2 vols. crown $8 \mathrm{vo}$, price $12 \mathrm{~s}$.
Rich's Illustrated Companion to the Latin Dictionary and Greek Lexicon; Forming a Glossary of all the Words representing Visible Objects connected with the Arts, Manufactures, and Every-Day Life of the Aneients. With about 2,000 Wroodeuts from the Antique. Post 8vo.21s.

Richardson.-Fourteell Years' Experience of Cold Water: Its Uses and Abuses. By Captain MI. RICHAEDson. Post 8 vo. Woodeuts, 6 s.

Jorsemanship; or, the Art of Riding and Managing a Horse, adapted to the Guilance of Ladies and Gentle. men on the Road and in the Field: Vith Yustructions for Breaking-in Colts and Young llorses. By Captain RrchARDSON, late of the 4th Light Dragoons. Vith 5 Plates. Square crown Svo. 11s.

\section{Ridale's Completo Latin-English} and Enclish-Latin Dietionary, for the use of Colleges and Schiools. New Edition, revised and corrected, 8vo, $21 \mathrm{~s}$.

Riddle's Diamond Latin-English Dictionary. A Guicle to the Heaning, Quality, and right Aecentuation of Latin Classical Words, Royal 92mo.4s.

Riddle's Copious and Critical Latin-English Lexicon, founded on the German-Latin Dietionaries of Dr. William Freund. Post 4to. 31s, 6d.

Rivers's Rose-Amateur's Guide; containing ample Descriptions of all the fine leading variety of lioses, regularly classed in their respeetive Families; their History and Mode of Culture. Sixth Luition. Fep. Svo. 3s. 6il.

Dr. E. Robinson's Greek and English Lexicon to the Greek Testament. 4 New Elition, revised and in great part re-written. $8 v^{\circ} 0.18 \mathrm{~s}$.

Mr. Henry Rogers's Essays selected from Contributions to the Edinburgh Revieu. Sccond Edition, with Additions. 3 vols. fep. 8 vo. $21 \mathrm{~s}$.

Samuel Rogers's Recollections of Personal and Conversational Intercourse with Charles James liox, Edmund Burke, Henry Grattan, Richard Porsoll, Jolin Ilorne Tooke, Prince Talleyrand, Lord Jirskine, Sir Walter scott, Lord Grenville, axd the Duke of Wellington. Second Edition. Fep. 8 vo, 5s. 
Dr. Roget's Thesaurus of English Words and Plirases classified and arranged so as to facilitate the Expres: sion of Ideas and assist in Literary Composition. Eiglath Edition, revised and improved. Crown 8vo.10s. 6u.

\section{Ronalds's Fly-Fisher's Entomo-} lozy: With colotred Representation of the Natural and Artificial Insects, and a few Observations and Instructions on Tront and Grayling Fisluing. Fifth Eclition; with 20 new-coloured Plates. 8vo. $1 \mathrm{Hs}$.

\section{Fowton's Debater: A Series of} complete Debates, Outlines of Debates, and Questions for Discussion; with anple References to the best Sources of Information. Fep. 8 ro. $6 \mathrm{~s}$.

Dr. C. W. Russell's Life of Cardinal Mezzofinti: With an Introductory Memour of eminent Lincenists, Ancient and Motern. With Portrait and Facsimiles, Svo, 12s.

\section{Scherzer,-e'Travels in the Free}

States of Central America : Nicaragua, Honduras, and San Salvalor. By Dr. CARL SCMERZER. 2 rols, post Sro. $16 \mathrm{~s}$.

\section{SchimmelPenninck (Mrs.) -} Life of Mary Anne Schimmel Penninck. Fdited by her relation, CHRistrasa II $\mathrm{N}$ Kr. 'Third Edition, with Portrait. Post 8vo, 10s, 6d.

SchimmelPenniuck's (IIrs.) Select Memoirs of Port Royal. Fifth Edition, revised, de. ly the Anthor's relition, CIRISTIANA C, IlANKIN, : rols. post Sro. $21 \mathrm{~s}$.

SchimmelPenninck's (Mrs.) Principles of Beauty; witl an Essay on the Temperaments, and Thoughts on lirecian and Gothic Architecture. Edited hy the Author's relation, C. C. II AN KIN. Post Sro, with coloured llustrations, price $12 \mathrm{~s} .6 \mathrm{~d}$.

Di. L. Sclumitz's History of Greere, mainly based upon Bishop'Thirlwall's History. Fifth Edition, with Nine new supplementary Chapters on the Civilisation, Religion, Literature, and Arts of the Ancient Greeks, contributed by C. II. WATSON, M.A. Trin. Coll. Camb. also a Ilap of A thens and 137 Woodeuts designed by G. Schart, juı., F.S.A. 12mo.7S.6.l.
Scoffern (Dr.)-Projectile Weapous of War and Explosive Compounds. By J. ScofFerN, M.B. Lond., late Protessol of Chemistry in the Aldersgate Collere of Medicine, Fourth $E$ ii tion. Post 8ro. Woodeuts, 9s. 6d.

\section{Senior.-Journal kept in Turkey} and Greece in the Autumn of 1857 ari the berimning of 1858 . BY NASSAU WV. SENron, Esq. With 2 Haps and 2 Views. Post 8 ro, 12s.

Scwell (Miss). - New Edition of the Tales and Stories of the Author of Amy Herbert, in 9 vols. crown syo. irice $61.10 \mathrm{~s}$. cloth ; or each work comnplete in one volume, separatuly as follows :-

AMY HERBERT...........2s. $6 \mathrm{~d}$. GERTRUDE..............2s. $6 \mathrm{~d}$. 'The EARL'S DAUGHTER .. 2s. 6d. The EXPERIENCE of LIFE. . $2 \mathrm{~s}$, 61 . CLEVE HALL.............. 3s. 6d. IVORS, or the Two Cousixs 3s. 6ul. KATHARINE ASHTON .....3s. 6d. MARGARET PERCIVAL ...5s. 04. LANETON PARSONAGE .. 4s, 6d. Also by the Author of Amy llerbert.

Ursula : A Tale of Euglish Country Life. 2 vols. fep. 8vo. 12s.

History of the Early Church: from the First Preaching of the Gosnel to the Council of Nicea. 18mo. $4 s .6 \mathrm{~d}$.

Self-Ezamination before Confirmation: With Devotions and Directions for Confirmation-1Day, 32mo.1s.6d.

Readings for a Month preparatory to Confirmation: Compiled from the Works of Writers of the Early and of the English Church. Fep, Sro. is.

Readings for every Day in Lent : Compiled from the Writings of Bishop JEREAIY TAXIOR. Fen, SVO, 5s.

Bowdler's Family Shakspeare : In which nothing is added to the Original Text; but those words and exjressions are omitted which cannot with propriety be read alond. lllustrated with 36 Woodent Vigne'tes. The Libram Elition, in One Volume, medium svo. price 2 ]s.; a Pocket Edition, in 6 rols. fep. 5 ro. price 5 s. each. 
Sharp's New British Crazetteer, or Topographical Dictionary of the Britisly Jslands and narrow Seas: Comprising concise Deseriptions of about Gin, ocio Places, Scats, Natural Features, and Oljects of Note, foumded on the best autliorities, 2 fols, 8vo, 2.2. $16 \mathrm{~s}$.

Short Vhist ; its Rise, Frogress, and huvs: With Observations to make any one a Whist-l'layer. Containing also the laws of Piquel, Cassino, Ecarté, Cribbase, Backgammon, By Major A. New Edition: with Precepts for'Tyros, by Mrs. B, Fep. 8vo.3s.

Simpson.-m Handbook of Dining; or, How to Dine, theoretically, pliblosoplicaly, and historically considered: Based chiefly upon the Plizsiologie du Gont of Briljat-Sararin. BY LEONARD Fravers srmpsox, M.R.L.L. Fep. 8 ro. 5s.

Sinclair. - The Jouruey of Life. By CATHERINE Sincrain, Author of The Business of Life. Fep. 8 vo. 5 s.

\section{Sir Roger De Coverley. From} the Speetator. IVitl Notes and Hllustratiolis, by W. HENRT WrL.s ; and 1? Wook Engravings from Jesigus by $\mathbf{r}$. TAYr.BR. Crown 8vo. 1us, 6el.; or 21s. in moroceo by Haydity.

The Slietches: Three Tales. By the Authors of Amy Herbert, The Old Man's Home, and Inaclistoice. Fep. s:o. price $48,6 \mathrm{t}$.

Smee's Elements of Electro. Metalhurgy. Third Elition, revised; with Elect rotypes and numerous Woodclats. P'ost 8\%o, 10s, fid.

Smith (G.) - History of Wesleyan Methodism. Jy Guorgi SMITIT, F.A.S., Anthor of Sincred Annels, \&c. Vou. 1. Wesley and his T'imes; VoL. 11 . The Bridille Are of Melhodism, firom 1791 tu 1816. Crowm 8vo. 10s, 6cl, each.

Smith (J.) - Tho Voyage and Slipwreck of St. Paul: With Dissertations on the Life and irritings of St. Luke, and the Slips and Navioation of the Ancients. By JAMES SMITri, F.R.S. With Cliarts, Views, and Woodeuts. Crown 8ro, 8s, 6d.

A Memoir of the Rev. Syciney Smith. By his Daurhter, LADY IIOLLAND. With a selection from his Letters, edited by Mrs. A Cstrin. New Edition. 2 vols. 8 vo. 285.
The Rev. Sydney Smitl's Tiscellareous Works : Inehding his Contrilutions to The Edinburgh Review. Fou' Editions:-

1. A IsRriRy Eustix (the Fotrth), in 3 volu. 8vo. with Portriat, $36 \mathrm{~s}$.

2. Complete in Oxe Voud we, with Portruit and Vignette. Square crown, 8vo. 218 . cloth; or 30 s. Lound in calf.

2. Arother NEW EDIrIox, in 3 vols. fcp. Evo. 2 Is.

4. The Teople's Erlition, in 2 rols. crown svo. price $8 \mathrm{~s}$. cloth.

The Rev. Sydney Smith's Elementary Sketehes of Moral Philosophy, delivered at the Royal Institution in the Years 1801 to 1806 . Fep. 8vo. $7 \mathrm{~s}$.

Snow. - Twe Year's Cruise off Ticrra del Fuego, the Falkland Islands, Patagonia, and in the River Plate: A Narrative of Life in the Southern seas. BYW. PARK IR SNOW, late Commander of the lission Yacht Allen Gardiner. With Charts and lllustrations, 2 vols. post 8 vo. 2ls.

Robert Southey's Complete Poetinal Works: containing all the Author's last Introductions aukl Notes. The Iibiary Edition, eomplete in One Volime, with Portrats and Vionette. Medium $8 \% 0.21 \mathrm{~s}$. cloth ; 42s. bourid in moraceo. - Also, the First collected Edition, in 10 vols. fed. 8 ro, with Poltrait and 19 Vignettes, priee 358.

Southey's Doctor, complete in One volume. Edited by the Rer. J. W. WARTER, B.D. With Portrait, Vismette, Bust, and coloured Plate. squitre crown sio. 21s.

Scuthey's Life of Wesley; and Rise and Progress of Methodism. Founth Edition, edited by Rev. C. C. soctriex, M.A. 2 vols. crown 8vo. 12s.

Spencer.-Essays, Scientifie, Political, aul speenlative. By Herbert SPFACER, Author of Social Staties. Reprinted chicfiy from Quirterly lieviews, 8ro. 12s, cloth.

\section{Spencer. - The Principles of} Psychology. By lierbert SPENCER, Author of social Slatics. $8 \mathrm{ro} .16 \mathrm{~s}$.

Stephex. - Lectures on the History of France. By the Richlit Iforl. sir JaMis StepheN, K.C.B., LL.D. 'Third Edition. 2 vols, 8 vo. 24 's. 
Stephen. - Essays in Ecclesiastical Biograply ; from The Ediuburgh Review, By the Right Holl. Sir JAMES STEPHEN, K.C.B., LL.D. Third Editiost. 2 vols. 8 vo. 21 s.

\section{Stonehenge.-The Dog in Health} and Disease: Comprising the various Indes of Breaking and using him for Hunting, Coursing, shooting, \&c. ; and including the Points or Characteristics of Toy Dogs. By STONEHENGE, With about 70 Illustrations engraved on Wood. Square crows svo. price $15 \mathrm{~s}$. half-bound.

\section{Stonehenge's Work on the Grey-} hound: Being a Treatise on the Art of Breeting, Rearing, aud Training Greylounds for Pullie Running; their Diseases and riveatment: Coritaining also Rules for the Management of Coursing Meetings, and for the Decision of Courses. With Frontispiece and Woodents. square crown $8 v 0.21$ s.

\section{Stow's Training System, Moral}

Training scliool, and Normal Seminary for preparing schoolmasters and Governesses. Eleventh Edition: Plates aud Woodcuts. Post 8vo. 6s. 6d.

\section{Strickland_Lives of the Queens}

of England. By AGNes STrickLaNd. Dedicated, by express permíssion, to Her Majesty, Embellished with Portraits of $t v \geq 1$ y Queen, engraved from the most authentic sources. Complete in 8 vols, post $5 v 0.7 \mathrm{~s}, 6 \mathrm{~d}$. each.

Symonds.-Memoirs of the Life and Services of Kear-Admiral Sir Willian symonds, late surveyor of the Navy. Edited by J. A. SHARP. 8vo, witl Illustrations, pilee $21 \mathrm{~s}$.

Taylor.-Loyola : and Jesuitism in its Rudiments. Ry IsAaO TAYLOR. Post Svo. Medallion, i0s. 6u.

Taylor. - Wesley and Methodism. By IsaAC TAylor. Post Svo. Portrait, 10s, 6d.

Tenneut.-Ceylon: An Account of the Island, Physical, Historical, and Topographical: with Copions Notices of its Natural History, Antiquities, and Productions, Ilkustrated by 7 Maps, 17 Plans and Charts, and 101 Engravings on Wood. By sir J. EMERSON TENNENT, K.C.S., LL.D., \&c. 2 vols. 8 vo, price 50 s.
Bishop Thirlwall's History of Greece. Library Edition; with Mraps. 8 vols, 8 ro. $^{\circ} 3 .-$ An Edition in 8 rols. fep. 8vo, with Vignette Titles, 28s,

\section{Thomson's Seasons, Edited by} Bolton CorNex, Esq. Illustrated with 77 fine Wood Engravings from Designs by Nembers of the Etching Club. Square erown 8vo. 21s. eloth; or $36 \mathrm{~s}$, bound in noroceo.

Thomson (the Rev. Dr.) - An Outline of the necessary Laws of Thought: A Treatise on Pure and Applied Logic. By WiLrian THoyson, D.D. New Edition, Fcp. Sro, 7s. 6l.

Thomson's Tables of Interest, at Three, Four, Four-and-a-Half, and Five ver Cent, from One Pound to Ten Thousand, and from I to 365 Days, in a regular progression of single Days; with Interest at all the above Rates, from One to Twelve MIonths, and from Oue to Ten Years. Also, numerous other Tables of Exchange, Time, and Discounts. The Seventeentli Edition, thoroughly revised and stereotyped. $12 n 0.3 \mathrm{~s}, 6 \mathrm{~d}$.

The Thumb Bible; or, Verbum Sempiternum. By J.TAYZOR. Being an Enitome of the old and New Testaments in English Verse. Remrinted from the Edition of 1693. 6mmo. Is.6d.

Todd (Dr.) - The Cyclopædia of Anatomy and Physiology. Edited by ROBERT L. TODD, M.1., F.R.S., \&c., Physician to King's College Hospitai late Professor of General and Morbid Anatomy in King's College, London. Now complete in 5 rols. 8 vo. pp. 5,350 , illustrated with $2, \$ 53$ IVoodcuts, price \&6. 6s, eloth.

Tooke.-Yistory of Prices, and of the State of the Circulation, during the Nine Years from 1818 to 1856 inclusive. Forming Vols. V. and VI. of Tooke's History of Prices; and comprising a copious Index to the whole work. By Thomas TOOKE, F.R.S. and WilliaM NeWMARCH. 2 vols. 8vo. 52s. 6d.

Trevelyan (Sir C.) - Original Papers illustrating the History of the Application of the IRoman Alphabet to the Languages of India. Edited by Monier WILLiams, M.A., late Professol of Sanskrit in the East-India Collegc, Haileybury. Svo, with Map, price $12 \mathrm{~s}$. 
The Traveller's Library: A Collection of original Works well adajted for Travellers and Emigrants, for School-room Libraries, the Libraries of Ifechanics Institulions, Foung Mren's Libraries, the Libraries of Ships, and similar purposes. The separate volnmes are suited for School Prizes, Presents to Young People, and for general instruction and entertainment. The Series eomprises fourteen of the most popular of Lord Macizulay's Essays, and his $S_{i}$ reches on Parliamentary Reform. The department of Travels contains some acconnt of eight of the principal countries of Enrope, as well as trarels in four districts of Africa, in four of America, and in three of Asia. Miadame Pfeiffer's Furst Joume? rutul the World is included; and a general account of the Australian Culonies. In 13iography and History will be found Lord Macaulay's Biographical Sketches of Wraren Hastings, Clize, Pilt, Walyole, Bacon, and others; besides Memoirs of Wellington, Th renne, $F$. Arago, \&c. ; an Essay on the Life and Genins of Thomas Fuller, with Selections from his Writings, by $\mathrm{Mr}$. Henry Kogers; and a history of the Leipsic Cam. paign, by Mr. Gleig, - which is the only separate account of this remarkable-campaign. Worls of Fiction did not come within the plan of the TraveLLEIR's LiEaARY; bint the Confessions of $a W^{\prime}$ orking $M a n$, by Souvestre, which is indeed a fiction fonncted on fact, has been included, and has been read with unusnal interest by many of the work ing clisses, for whose use it is especially recommended. Dumas's story of the Mlaitre $d^{\prime}$ Armes, thounh in form a work of fiction, gives a strking picture of an episode in the history of Russia. Amongst the works on Science and Natural Philosophy, a general view of Creation is embodied in Dr. Kemp's Natural History of Creation; and in his Indications of lnstiuct remarkable facts in natnral history are collected. Ur. Wilson has contributed a popular account of the Eleclric Telegraph. In the volumes on the Caal-Fielels, and on the Tin and other Mining Districts of Cormwall, is given an account of the mineral wealth of England the habits and manners of the miners, an the seenery of the surrounding comntry. It only remains to add, that among the $M$ is cellaneons Works are is Selection of the best Writings of the Rev, Sydney Smith; Lord Carliste's Lertures and Addresses; an aeconnt of Mormonism, by the Rev. W. J. Conybeare; an exposition of Railway manazement and mismanagement by Mr. Herbert Spencer; an account of the Origin and Practice of Printing, by Mr. Stark; and an account of London, by Mr. M'Culloch - To be had, in complete Sets only, at $\mathcal{L} \overline{5}$. 5 s. Der Set, bound in cloth and lettered.

Tos The Traveller's Library may also be had as originally issued in 102 parts, 1s. each, forming 50 vols. $2 \mathrm{~s}$. $6 \mathrm{~d}$, each ; or any separate parts or volumes.
Trollope-The Warden, a Novel. By ANThoNy Trollope. New and cheaper Edition. Crown 8vo.3s.6d.

Trollope's Barchester Towers, a Sequel to The Warden. New and cheaper Fdition, complete in One Volume, Crown Sro. ป̀s.

Sharon Tuner's History of the Anglo-Saxons, froru the Earlicst Period to the Norman Conquest. 3 vols. 36 s.

Dr. Turton's Manual of the Land and Fresh-Wvater Shells of Great Britain: IVith Figures of each of the kinds. New Edition, with Additions by Dr. J. E. GR.tY, F.R.S., \&e., Kiveper of the Zoolocieal ('olleetion in the British Iuseum. Crown 8vo. with 12 coloured Plates, price $15 \mathrm{~s}$, cloth.

Dr. Ure's Dictionary of Arts, Manufactures, and Mines : Containing a clear Exposition of their Principles and Practice. New Edition, chiefly rewritten and greatly enlarged; with nearly 2,000 Woodeuts. Edited by RoB ERT IIUNT, F.R.S., F.s.S., Keeper of Mining Records. In course of publication in It Parts, price 5s. each, fortning \& vols. 8 vo.

Jwins. - Memoir and Correspondence of Thoxas Twins, R.A., late keener of the Royal Galleries and of the National Gallery, dic. Eulited by Mrs. UWINS. 2 vols, post Svo, 18s.

Van der Hoeven's Handbook of Zoology. Translated by the Rev. IVILhIAM Clark, M.D., F.R.S., Professor of Anatomy in the Unirersity of Cam. bridge. 2 vols. 8vo. with 21 Plates of Figures, price 60s. woth; or separately, VoL. I. Intertebrata, 30 s., and VoL. II. Vertebrata, sus.

Vehse.-Memoirs of the Court, Aristocracy, and Diplomacy of Austria. By Dr. E. VEHsE. Translated from the German by Franz Demmerr. 2 vols, post $85^{\circ} 0,2$ Is.

Von Tempsky.-Mitla ; or, Incidents and I'ersonal Adventures on a Journey in Mexico, Guatemala, and Salvador in the Years 185: to 1855 . By G. l. VoN TEMPSEx. With numerous Hilustrations. $8 v 0,18 \mathrm{~s}$.

Wade. - England's Greatness : its Rise and Progress in Government, Laws, Religion, and social life; Agriculture, Commerce, and Manufactures; Science, Literature and Arts, from the Earliest Period to the P'eace of Paris. By JoH N WADE, Author of the Calinet Luwyer, \&e. Post 8vo. I0s. 6d. 
Wanderings in the Land of Ham. By a DAUGHTER of JAFHET. Post 8vo. 8s. 6d.

Waterton.-Essays on Natural History, chietly Ornithology. By C. Watertor, Esq. With the Autobiograplyy of the Author, and Views of iValton Hall. 2 vols. fep. 8 vo, 5s, each.

Waterton's Essays on Natural IHistory. THIRD SinmIEs; with a Continuation of the Antobiography, and a Portrait of the Author. Fcp.Sro.69.

Watson. - Cybele Britannica ; or, Britisl Plunts and their Georrnphical Relations. Hy HEWRTt CoTTRELL WATEON. 4 vols. 8vo. 42s. cloth; or ench vol, separately, price 10s. $6 \mathrm{~d}$.

Webb. - Celestial Objects for Common Telescopes. 13y the Rev. T. WV. W EnB, H.A., F.R.A.S., Incnmbent of Hardwick, Herefordshire. With Vooleuts, and Ilay of the Moon 19 inches in liameter engraved on Steel, 10mo. $7 \mathrm{~s}$.

Webster and Parkes's Encycloparlia of Domestic Economy; comprising stich suhjects as are most immediately comnected with Housekceping : riz. The Constrution of Domestic Edifices, with theMlodes of WVarming, Veutilating, and Lighting them$\Lambda$ description of the various Articles of Furniture, with the Nature of their Materials - Duties of Servants - kc. With nearly 1,000 Woodeuts. $850.50 \mathrm{~s}$.

\section{Weld, - The Pyrenees, West} and East. By Charles Richarn IVFuD, Barrister-at-Law. With 8 llustrations in Chrome-xylograply from Ditawings by the $\Lambda$ uthor. J'ost 8 vo. 12s. $6 \mathrm{~d}$.

Weld's Vacation Tour in the United States and Canada. 109.6d.

Weld's Vacations in Ireland. Post 8vo. 10s. 6il.

Willich's Popular Tables for ascertaining the Talue of lifehold, Leasehoth, and Church Property, Renewal Fines, \&c. With numerous artditional Tables-Chemical, Ast ronomical, Trigonometrical, Common and Hyperbolic Losarithus; Constants, Squares, Cubes, Roots, Reciprocals, de. Fourth Edition. Post Svo. 10s.
Wilmot's Abridgment of Black-

stone's Commentaries on the Laws of Fngland, in a scries of Letters trom a Father to his Daughtcr. 12ıno. 6s. 64.

\section{Wilson's Bryologia Britamnica:}

Containing the Mosses of (ireat Britain and Ireland systematically arranger and described aecording to the Methoul of Bruch and Schimper; with 61 illustrative Plates. Being a New Edtition, enlarged and alterest, of the Muscologia Britannica of Mlessrs. Hooker and Taylor. 8vo. 42s.; or, with the Plites coloured, price $£ 4.4 \mathrm{~s}$.

\section{Yonge.-A New English-Greek} Lexicon: Containing all the Greek Worcls used by Writers of good autlority. By C. D. YoNGE, B.A. Second Edition, revised. Post 4to.21s.

\section{Yonge's New Latiu Gradus:} Containing Every Worl used by the Poets of good authority. For the use of Eton, Westminster, Winchester, Harrow, and Rugby Schools; King's College, London; and Marlborough College. Sixth Edition. Post Sro. 9s.; or, with APPENDIX of Epithets, 12s.

\section{Youatt's Work on the Horse:}

With a Treatise on Draught. New Edition, revised and cnlarged by E. $\mathrm{N}$. Gsmitu, M.R.C.S., C.V.S., secretary to the Rnyal College of Veterinary Surgeons. With numerous Woodent Illustrations, chiefly from designs by $W$. Harvey. Sro. vice 10s, 6d, cloth.

Youatt.-The Dog. By William Youatt. A New Elition; with mumerons Engravings, from Dcsigns by W. Harvey. 8vo. 6s.

Young.-The Christ of History : An Argument grounded in the Facts of His Life on Earth. By JOHN YOUNG, LL.D. Second Edition. Post 8vo.7s.6d.

Young.-The Mystery ; or, Evil and God. By JoHY Young, LL.J. Post 8vo. 7s. 6d.

Znmpt's Grammar of the Latin Language. Translated and adapted for the use of English Students by Dr. L. Sснмrтz, F.R.S.E.: With numerous Adutions and Corrections by the Author and Translat or. 8vo. 1fs.

[September 1559. 






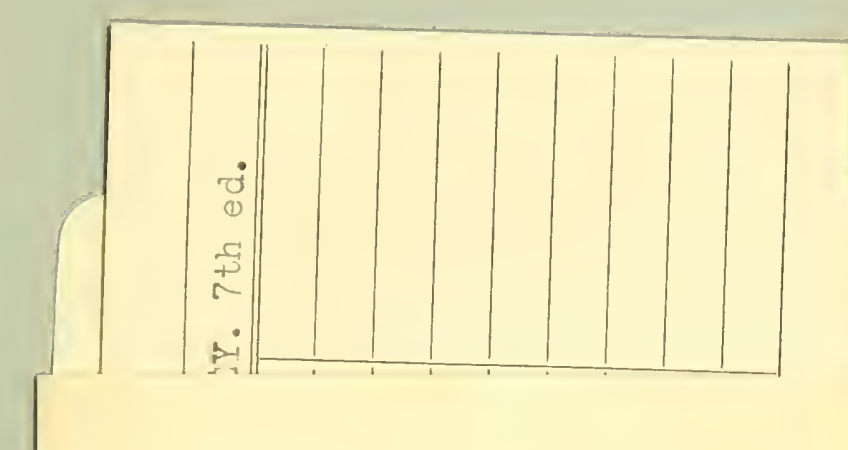


SMITHSONIAN INSTITUTION LIBRARIES

|

39088 003767558 nhent QL463.K58 1860

An introduction to entomology: or, Eleme 